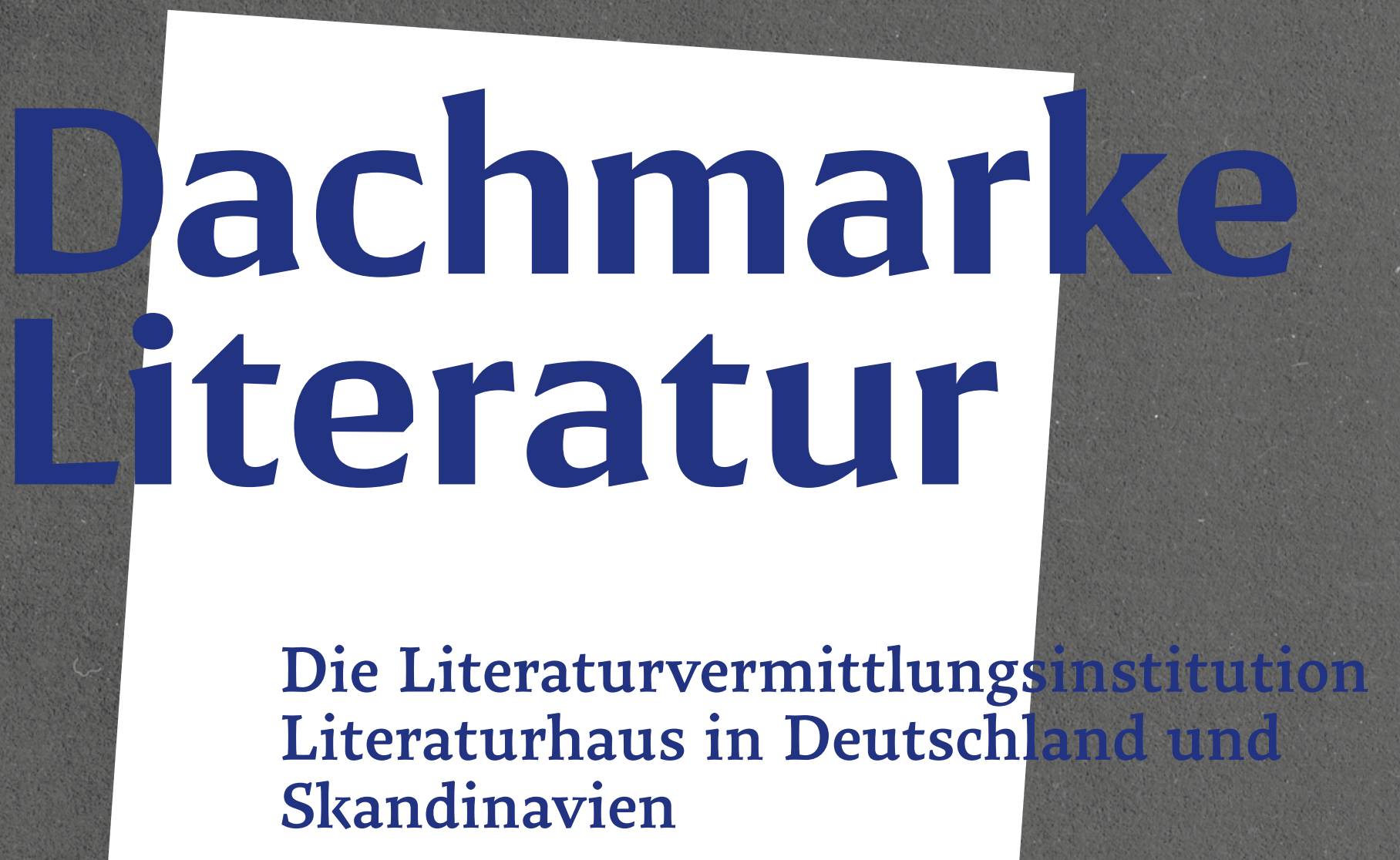

Carolin Löher 


\section{Dachmarke Literatur}

\section{Die Literaturvermittlungsinstitution Literaturhaus in Deutschland und Skandinavien}

Dissertation zur Erlangung des philosophischen Doktorgrades an der Philosophischen Fakultät der Georg-August-Universität Göttingen

vorgelegt von

Carolin Löher aus Werl

Göttingen 2018

$\Delta \Delta \Delta \Delta \Delta \Delta \Delta \Delta$ 

Dies ist die leicht überarbeitete Version der Dissertation, die ich im Oktober 2018 eingereicht und am 15. April 2019 verteidigt habe, inhaltlich wurden keine Aktualisierungen vorgenommen.

\section{Danke!}

Diese Arbeit entstand maßgeblich dank der großzügigen Förderung des DFGGraduiertenkollegs 1787 Literatur und Literaturvermittlung im Zeitalter der Digitalisierung an der Georg-August-Universität Göttingen. Allen Mitgliedern des Kollegs danke ich für gemeinsames Denken, organisatorische Kooperationen und die zusammen verbrachte Zeit; dem Forschungskolloquium des Skandinavischen Seminars für die skandinavi(sti)sche Komponente.

Neben den öffentlich verfügbaren Quellen bildeten die Programmhefte und Gespräche mit unterschiedlichen Literaturhaus-Akteur*innen eine Grundlage für diese Arbeit. Für die Unterstützung meines Projektes danke ich den Leiter*innen und Mitarbeiter*innen der untersuchten Literaturhäuser sehr - insbesondere aus dem Literaturhaus Berlin Ernest Wichner und Sabine Büdel, aus dem Literaturhaus Frankfurt Hauke Hückstädt und Kristina Köhler, aus dem Litteraturbuset in Oslo Andreas Liebe Delsett, Silje Riise Næss, Eline Skaar Kleven, aus dem Litteraturbuset i Bergen Anna Ofstad und Kristin Helle-Valle, aus Göteborgs Litteraturbus Sofia Gräsberg und Madeleine Bergmark, die Litteraturbuset Göteborg leitete, Ariane Veiergang aus dem LiteraturHaus in Kopenhagen und Claes Benthien aus dem dortigen Litteraturbuset. Das Literaturhaus Hamburg half zunächst während meines Forschungspraktikums im Herbst 2014 wie die anderen Einrichtungen. Seit ich dort angestellt bin, unterstützte mich das Team, Rainer Moritz, Isabell Köster, Tina Matthies und Saskia Seifert, dass ich die Dissertation „nebenbei“ wirklich fertigstellte.

Über ihre Arbeit in den Literaturhäusern gesprochen habe ich unter anderem mit den oben genannten Personen, länger mit Hauke Hückstädt, Andreas Liebe Delsett, Rainer Moritz und Anja Johannsen, außerdem mit den Kolleg*innen im Netzwerk der Literaturhäuser, vor allem Stefanie Stegmann und Florian Höllerer, sowie mit Helmut Böttiger (freier Schriftsteller und Kritiker), Martin Bruch (Literaturhaus Freiburg), Andrine Pollen (NORLA) und Stephan Samtleben (Buchbandlung Samtleben in Hamburg). Da diese Gespräche zum Teil in informellem Rahmen stattfanden, sind nicht alle dokumentiert. Sofern Gedanken direkt auf Gesprächspartner*innen zurückgehen, ist dies an der entsprechenden Stelle angegeben. Es war eine Freude, sich über Literaturvermittlung zu unterhalten. Setzen wir die Diskussion fort!

Anja Johannsen gab mir Einblicke in das Zentrum-Archiv und hat weit darüber hinaus diese Dissertation von Anfang an als Drittbetreuerin gefördert, sie war jederzeit eine konstruktiv-kritische Leserin und ist eine wichtige Gesprächspartnerin.

Sehr großer Dank gilt Prof. Dr. Karin Hoff und Prof. Dr. Simone Winko - meinen Betreuerinnen, die mich und meine Arbeit mit Elan begleiteten und immer genau die Unterstützung boten, die gerade gebraucht war.

Dank ihnen, dank meiner Freund*innen, ganz besonders dank meiner Eltern, meiner Schwestern und des geduldigsten Menschen meiner Welt ist sie so geworden, wie sie ist. Ihnen ist diese Arbeit gewidmet. 


\section{Inhaltsübersicht}

Einleitung

I Literaturhaus als Literaturvermittlungsinstitution .............................................21

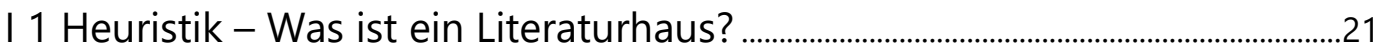

I 2 Forschungsumfeld und Methodendiskussion............................................................25

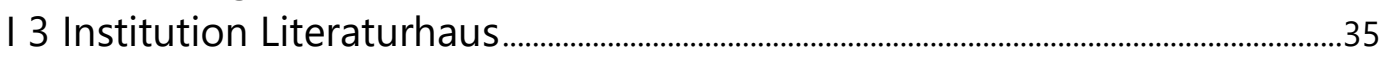

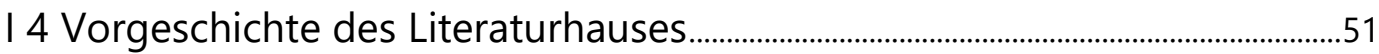

I 5 Akteur*innen und Funktionen des Literaturhauses .............................................65

II Literaturhäuser als Fallstudien ...............................................................................99

II 1 Literaturhaus Berlin - Das erste Literaturhaus........................................................ 101

II 2 Literaturhaus Hamburg - Das zweite Literaturhaus ......................................... 113

II 3 Literaturhaus Frankfurt - Ein Literaturhaus mit Standortwechsel ............. 127

II 4 Literarisches Zentrum Göttingen - Ein Literaturhaus?..................................... 143

II 5 LiteraturHaus und Litteraturhuset in Kopenhagen.............................................. 161

II 6 Litteraturhuset in Oslo - Das norwegische Modell ...............................................173

II 7 Litteraturhuset i Bergen - Ein Nachfolger in Norwegen.................................. 187

II 8 Göteborgs Litteraturhus - Ein Literaturhaus in Schweden .................................206

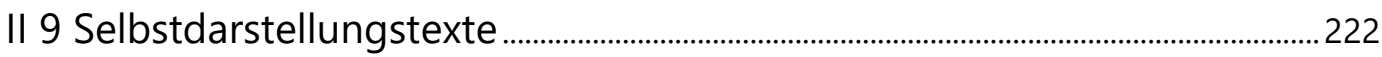

II 10 Programmheftpragmatik .......................................................................................... 239

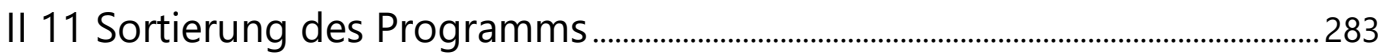

II 12 Das Literaturhaus im Zeitalter der Digitalisierung ............................................306

II 13 Programmanalyse - Formate und Inhalte ............................................................. 343

II 14 Programmanalyse - Autor*innen als Akteur*innen .........................................408

III Fazit - Individualität und Institution unter einem Dach.....................455

III 1 Zwischen Gesamtkonzept und Literaturveranstalter .......................................456

III 2 Kontextfaktoren................................................................................................................. 458

III 3 Literaturvermittlungsobjekte und -praktiken .....................................................467

III 4 Zwischen Einzelfall und Institution ..........................................................................4 477

IV Literaturverzeichnis ........................................................................................................... 481

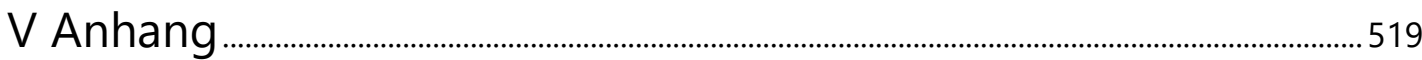




\section{Inhaltsverzeichnis}

Einleitung

I Literaturhaus als Literaturvermittlungsinstitution ..........................................21

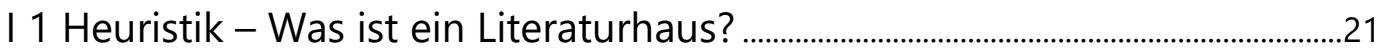

I 2 Forschungsumfeld und Methodendiskussion.....................................................25

I 2.1 Monografien und Einzelstudien über Literaturhäuser ....................................................25

I 2.2 Artikel zum Thema und Selbstreflexion.............................................................................2.

I 2.3 Literaturvermittlung und Literaturbetriebsforschung …................................................2.

I 2.4 Gegenwartsliteraturforschung und Praxeologie ................................................................31

I 2.5 Materiallage - Umgang mit den Archivbeständen ...............................................................34

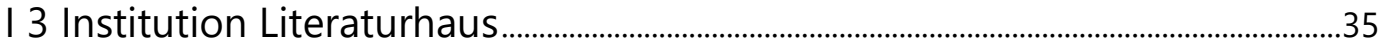

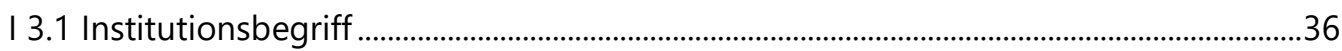

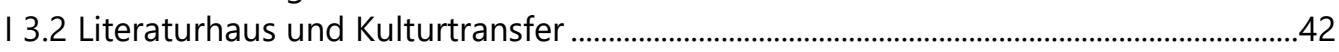

| 3.2.1 Vergleich als Methode.............................................................................................42

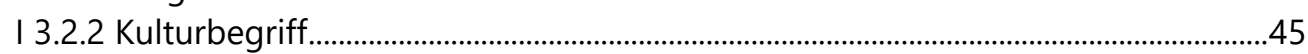

| 3.2.3 Transfer der Institution Literaturhaus .....................................................................45

| 3.2.4 Skandinavischer Einfluss auf das deutsche Literaturhaus.......................................48

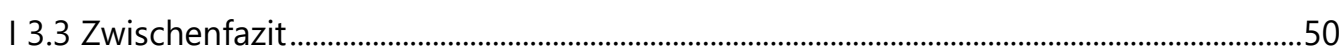

I 4 Vorgeschichte des Literaturhauses.....................................................................................51

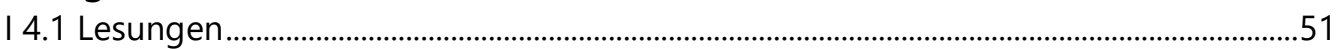

| 4.2 Professionalisierung des Literaturveranstaltungsbetriebs ............................................53

| 4.2.1 Literaturkritik vor Publikum - Gruppe 47 ............................................................53

| 4.2.2 Sprache im technischen Zeitalter - Walter Höllerer und das $L C B$.........................55

| 4.2.3 Rahmenbedingungen für Autor*innen ..................................................................5

| 4.2.4 1968er-Bewegung - Politisches Engagement..............................................................59

| 4.2.5 1980er-Jahre - Zurück zur Kunst...........................................................................59

| 4.2.6 ,Kultur für alle' - Kulturpolitik und Finanzierung ......................................................60

| 4.3 Zwischenfazit - Baugrund des Literaturhauses .....................................................................63

I 5 Akteur*innen und Funktionen des Literaturhauses ..............................................65

I 5.1 Trägerorganisationen......................................................................................................66

I 5.2 Kooperationspartner*innen und Konkurrent*innen ......................................................69

I 5.3 Leitungspersonen und Mitarbeiter*innen .............................................................................70

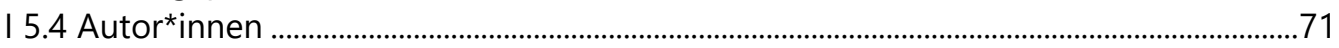

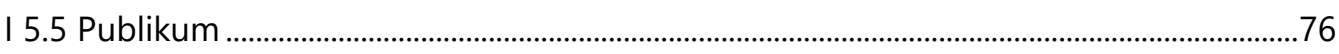

I 5.6 Wirkungen, Funktionen und Nutzen des Literaturhauses .............................................8

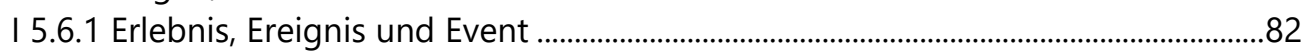

। 5.6.2 Selbstpräsentation und Gesehenwerden ...............................................................85

| 5.6.3 Authentizität und Präsenz ...................................................................................85

I 5.6.4 Orientierung und Reflexion ......................................................................................90

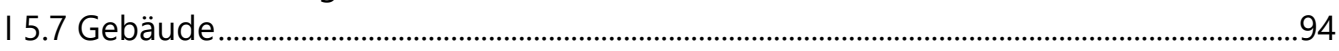

I 5.8 Zwischenfazit - Fundament des Literaturhauses ...........................................................96 
II 1 Literaturhaus Berlin - Das erste Literaturhaus..................................................... 101

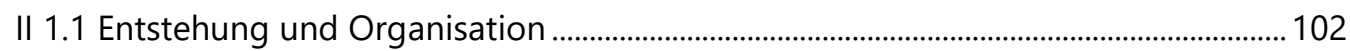

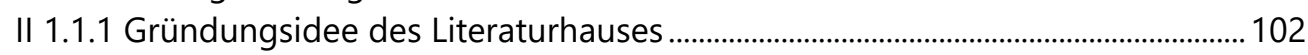

II 1.1.2 Weiterentwicklung der Literaturhaus-Idee durch den Verein .............................. 103

II 1.1.3 Ausgestaltung der Literaturhaus-Idee durch das Personal ................................105

II 1.1.4 Einfluss der Finanzierung auf das Literaturhaus .................................................. 106

II 1.2 Ein Name für eine Idee - Literaturhaus ......................................................................107

II 1.3 Soziogeografische Verortung in Berlin .......................................................................... 108

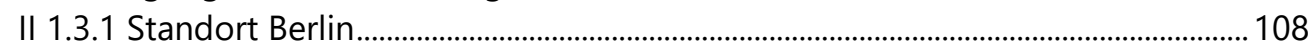

II 1.3.2 Literaturveranstaltungsbetrieb in Berlin - Vier weitere Literaturhäuser......... 109

II 1.4 Gestaltung und Außenwirkung des Literaturhauses Berlin ..........................................110

II 1.4.1 Räumlichkeiten ............................................................................................................ 110

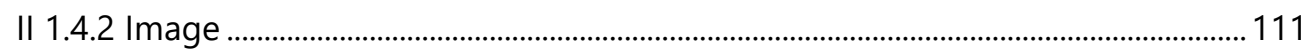

II 2 Literaturhaus Hamburg - Das zweite Literaturhaus .......................................... 113

II 2.1 Entstehung und Organisation ..................................................................................... 113

II 2.2 Soziogeografische Verortung in Hamburg .................................................................... 115

II 2.3 Gestaltung des Literaturhauses Hamburg..................................................................... 116

II 2.3.1 Weitere Einrichtungen im Literaturhaus .................................................................. 116

II 2.3.2 Veranstaltungsräume - Doppelnutzung als Café und Lesungssaal .................. 117

II 2.3.3 Setzungen durch den Ort....................................................................................... 118

II 2.4 Personalentwicklung und Programmatik............................................................................. 119

II 3 Literaturhaus Frankfurt - Ein Literaturhaus mit Standortwechsel ............ 127

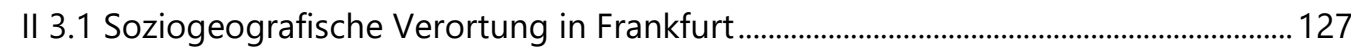

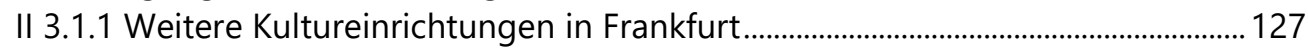

II 3.1.2 Exkurs - Offener Brief der Literaturhaus-Leitung 2015 ......................................... 130

II 3.2 Standort(e) - Vom Westend ins Ostend ............................................................................. 133

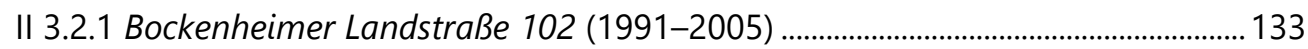

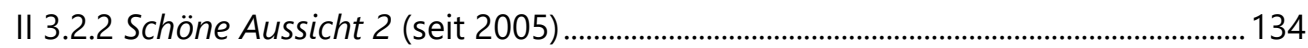

II 3.3 Personalentwicklung und Programmatik..................................................................... 138

II 3.4 Literaturhaus Frankfurt im Netzwerk der Literaturhäuser .............................................. 142

II 4 Literarisches Zentrum Göttingen - Ein Literaturhaus?....................................... 143

II 4.1 Literarisches Zentrum im Netzwerk der Literaturhäuser ................................................ 144

II 4.2 Entstehung und Organisation .......................................................................................... 145

II 4.2.1 Vorgeschichte und historisch gewachsener Name............................................... 146

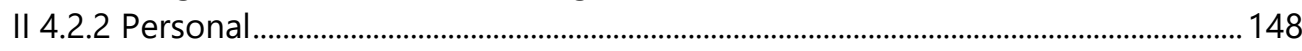

II 4.3 Gestaltung des Literarischen Zentrums Göttingen ........................................................ 149

II 4.4 Soziogeografische Verortung in Göttingen ..................................................................... 152

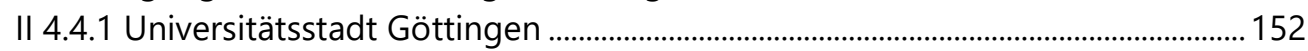

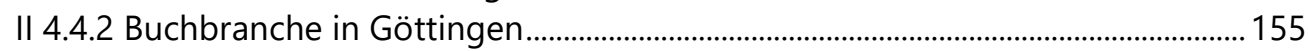

II 4.4.3 Literaturfestival Göttinger Literaturherbst ........................................................... 155

II 4.4.4 Weitere Kultureinrichtungen in Göttingen................................................................ 158

II 4.5 Literarisches Zentrum und die Institution Literaturhaus ................................................159 
II 5 LiteraturHaus und Litteraturhuset in Kopenhagen.............................................161

II 5.1 Gründungsidee für ein Literaturhaus in Kopenhagen ................................................. 161

II 5.2 LiteraturHaus als erstes Literaturhaus in Skandinavien ................................................... 163

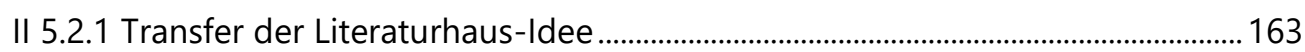

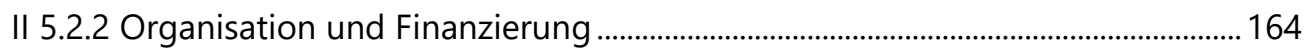

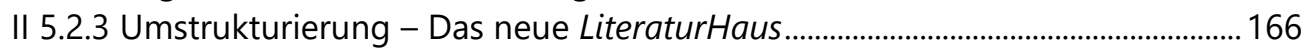

II 5.3 Weitere Literaturveranstalter*innen in Kopenhagen ..................................................... 168

II 5.4 Litteraturhuset als neue Umsetzung in Kopenhagen ...................................................170

II 5.5 Kopenhagen und die Institution Literaturhaus .............................................................. 172

II 6 Litteraturhuset in Oslo - Das norwegische Modell ............................................173

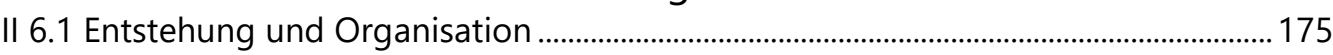

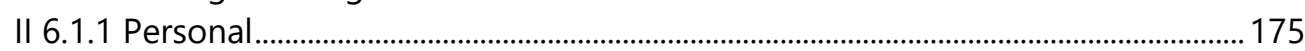

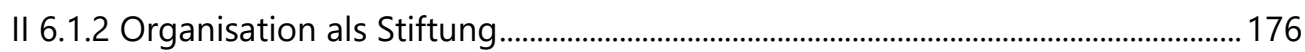

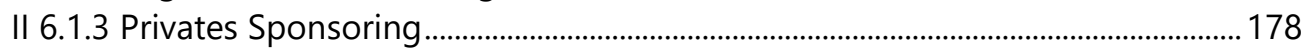

II 6.2 Soziogeografische Verortung in Norwegen und in Oslo ........................................... 179

II 6.2.1 Norwegens Zentrum ................................................................................................... 179

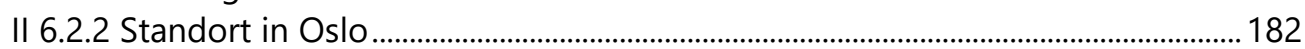

I| 6.3 Gestaltung von Litteraturhuset..................................................................................... 183

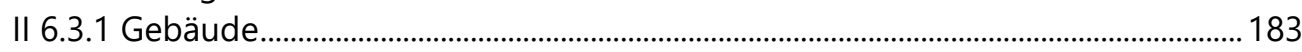

॥ 6.3.2 Veranstaltungsräume...................................................................................................... 184

II 7 Litteraturhuset i Bergen - Ein Nachfolger in Norwegen................................. 187

II 7.1 Entstehung und Organisation .................................................................................. 187

II 7.1.1 Entstehungsstrategie und Abgrenzung zum Litteraturhuset in Oslo................ 187

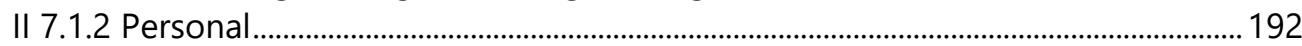

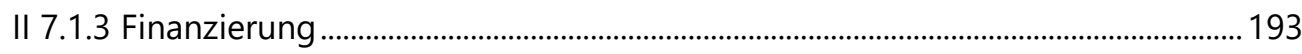

II 7.2 Soziogeografische Verortung in Bergen ....................................................................... 193

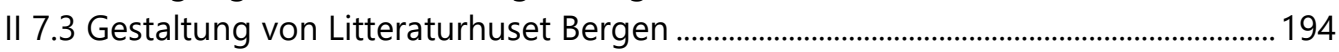

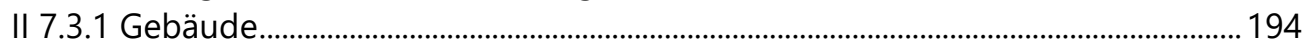

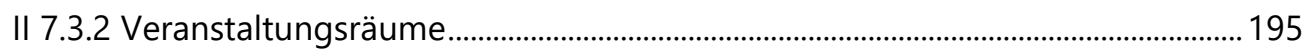

II 7.4 Litteraturhuset in Bergen als Transfer des Osloer Modells .......................................2200

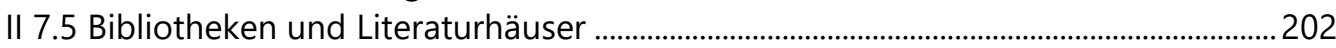

II 8 Göteborgs Litteraturhus - Ein Literaturhaus in Schweden ............................2206

II 8.1 Schweden und Literaturhäuser ....................................................................................2206

II 8.1.1 Schwedische Abgrenzung von Norwegen .............................................................206

II 8.1.2 Stockholm als Schwedens Zentrum ............................................................................207

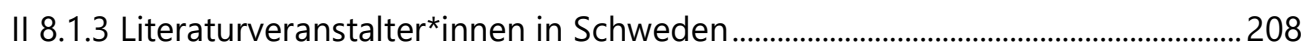

II 8.2 Aus Litteraturhuset Göteborg wird Göteborgs Litteraturhus..........................................2211

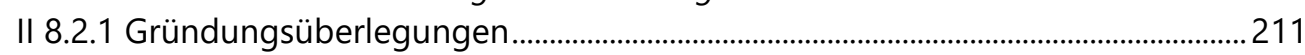

II 8.2.2 Litteraturhuset Göteborg - Organisation .................................................................2 214

II 8.2.3 Lagerhuset als Standort...........................................................................................2. 215

II 8.2.4 Göteborgs Litteraturhus - Weiterentwicklung und Organisation .......................217

II 8.2.5 Göteborgs Litteraturhus und die Institution Literaturhaus ..................................220

II 8.3 Zwischenfazit - Literaturhäuser in Deutschland, Norwegen, Dänemark und

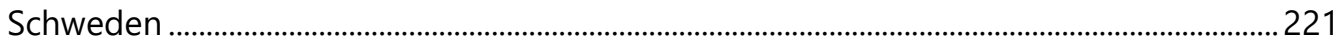




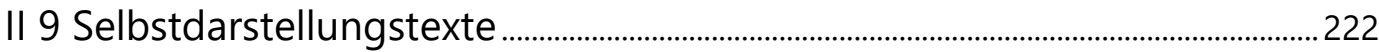

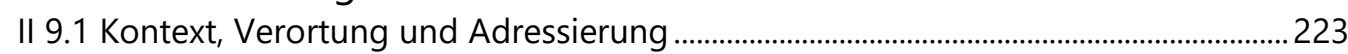

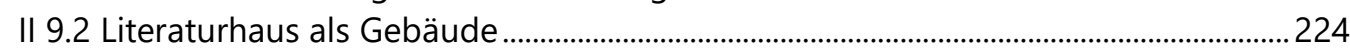

II 9.3 Treffpunkt als Begegnung - Debatte - Netzwerk .......................................................226

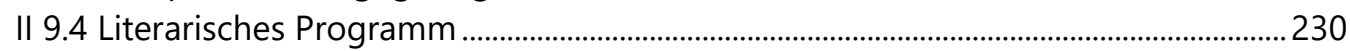

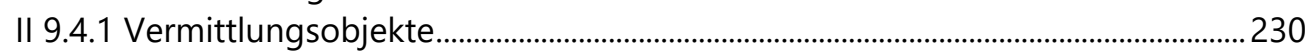

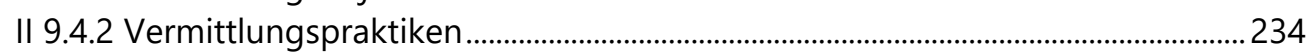

II 9.5 Zwischenfazit - Darstellung als, umfassendes Literaturhaus' .......................................2236

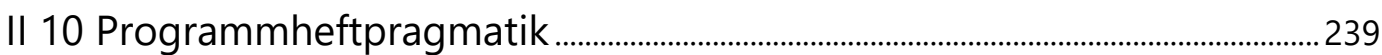

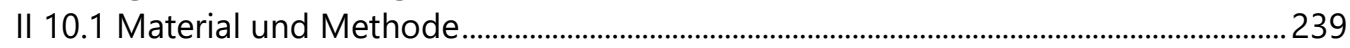

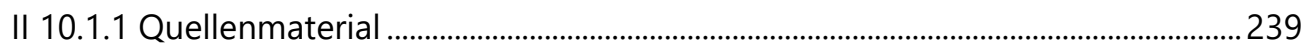

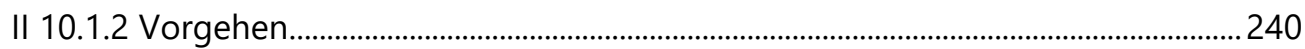

II 10.2 Funktionen der Programmhefte ....................................................................................... 244

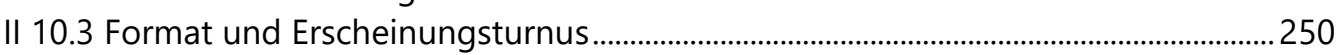

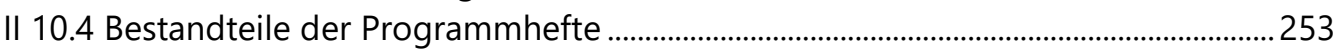

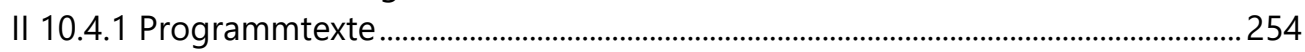

II 10.4.2 Rahmeninformationen - Zeiten, Orte und Preise .................................................269

II 10.4.3 Impressum und Editorial.............................................................................................2.

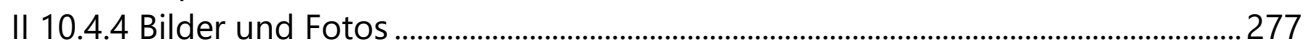

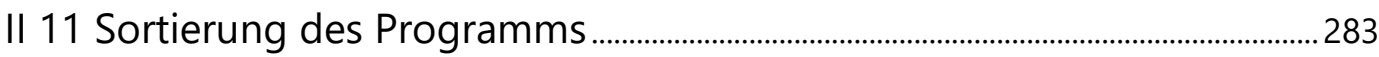

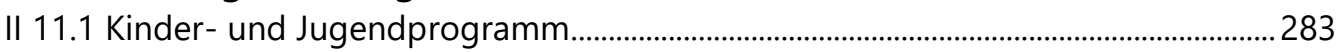

II 11.2 Gastveranstaltung und Veranstaltungskooperation ..................................................292

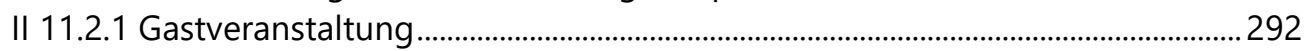

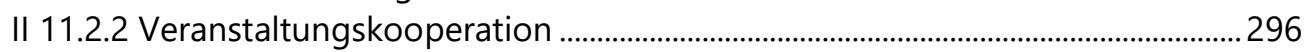

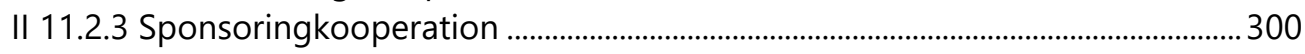

II 12 Das Literaturhaus im Zeitalter der Digitalisierung ..........................................306

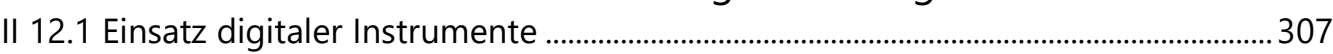

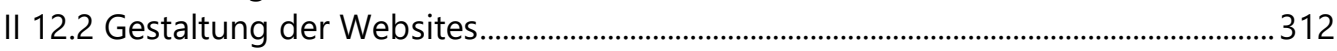

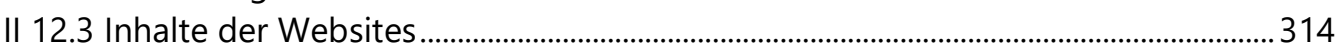

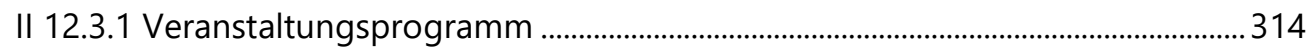

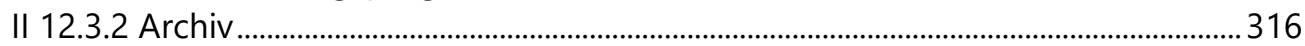

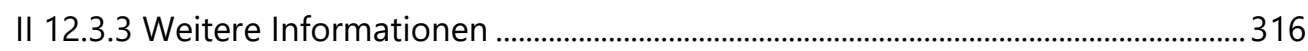

II 12.4 Digitaler Raum oder Ausweitung des, analogen' Raums? ...........................................318

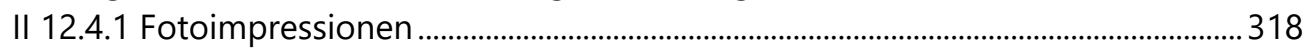

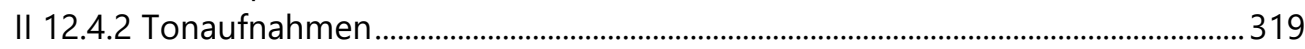

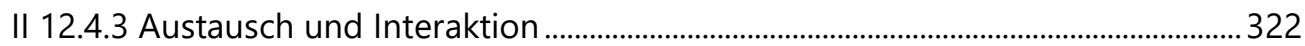

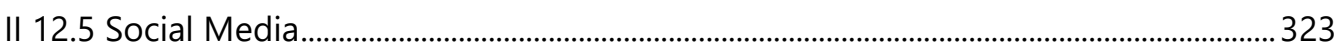

II 12.6 Literaturvermittlung jenseits von Vor-Ort-Veranstaltungen ......................................326

II 12.7 Zwischenfazit - Analog im Zeitalter der Digitalisierung ..............................................328

II 13 Programmanalyse - Formate und Inhalte ......................................................... 343

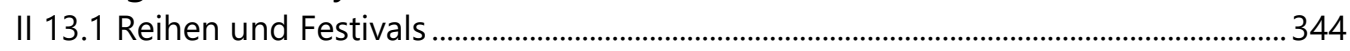

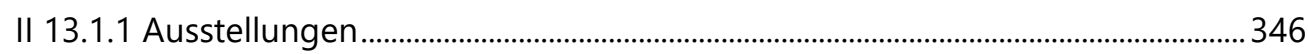

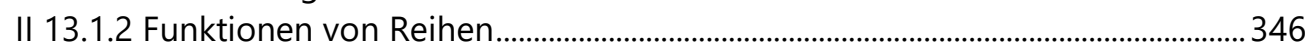

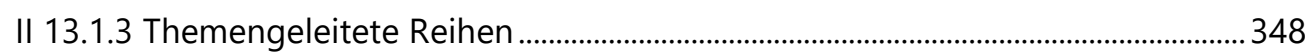

II 13.1.4 Reihen in Relation zu Symposien, Tagungen und Festivals.............................. 351

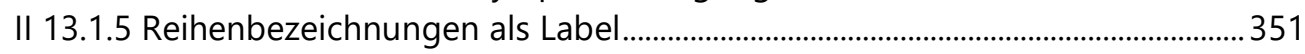

II 13.1.6 Format- und methodengeleitete Reihen................................................................353

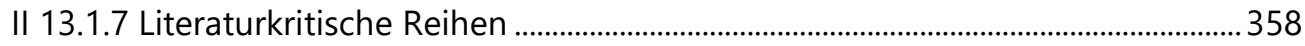




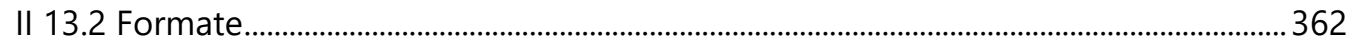

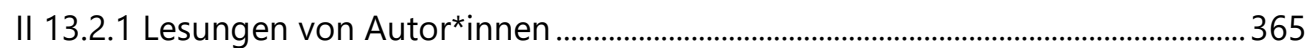

II 13.2.2 Lesungen von Texten nicht-anwesender Autor*innen..........................................371

II 13.2.3 Lesungen verschiedener Texte zu einem Thema .................................................. 373

II 13.2.4 Aktionen und Performances ...................................................................................... 374

II 13.2.5 Zwischenfazit - Veranstaltungen mit literaturinszenierendem Anteil ........... 384

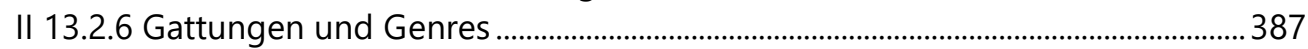

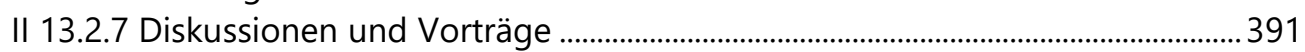

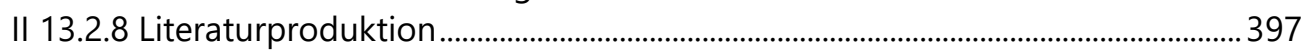

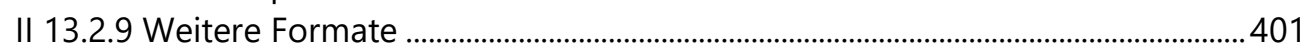

II 13.2.10 Intermedialität und Interdisziplinarität .................................................................... 403

Il 14 Programmanalyse - Autor*innen als Akteur*innen .........................................408

II 14.1 Autor*innen im Literaturhaus - Beruf und Funktion ......................................................409

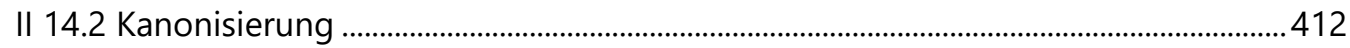

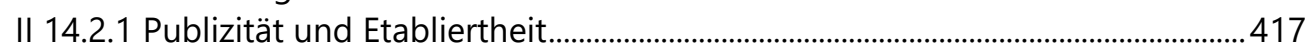

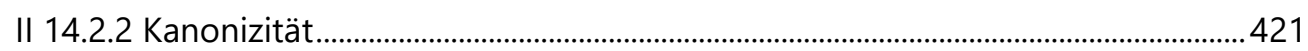

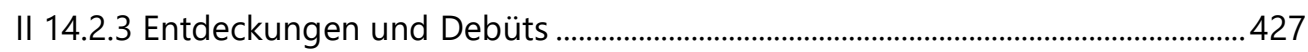

II 14.3 Nationale und internationale Ausrichtung ........................................................................430

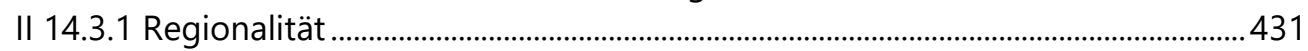

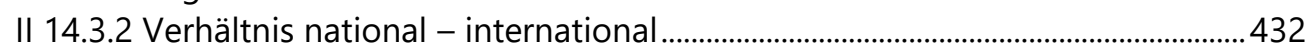

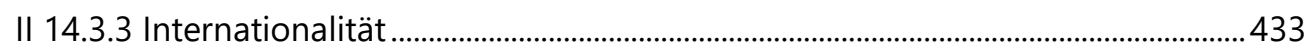

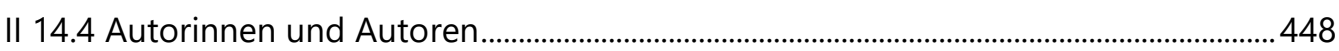

III Fazit - Individualität und Institution unter einem Dach.....................455

III 1 Zwischen Gesamtkonzept und Literaturveranstalter .........................................456

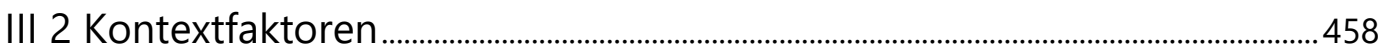

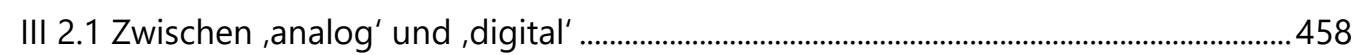

III 2.2 Zwischen Koalition und Konkurrenz .................................................................................. 460

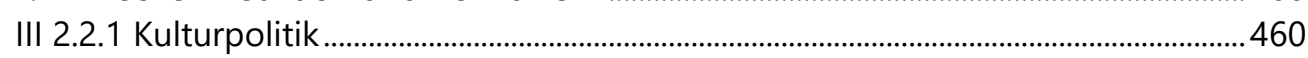

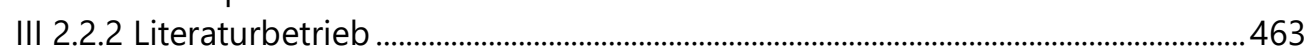

III 3 Literaturvermittlungsobjekte und -praktiken .......................................................467

III 3.1 Zwischen Einzelveranstaltung und Gesamtprogramm .................................................467

III 3.2 Zwischen engem Literaturverständnis und Interdisziplinarität ...................................469

III 3.3 Zwischen Literatur und Literaturvermittlung ................................................................... 470

III 3.4 Zwischen Kunst, Debatte und Ökonomie......................................................................... 472

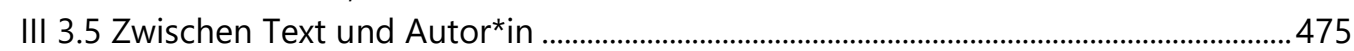

III 4 Zwischen Einzelfall und Institution ............................................................................477

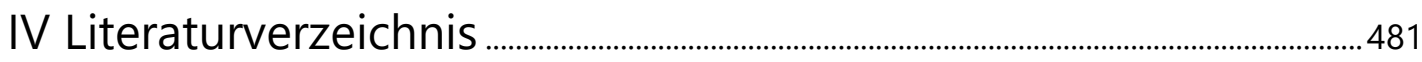

IV 1 Gedruckte Publikationen................................................................................................... 481

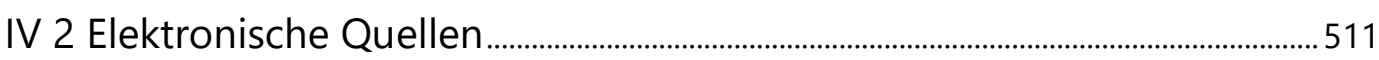

V Anhang ...............................................................................................................................

V 1 Selbstdarstellungstexte.......................................................................................................... 519

V 2 Abbildungen der Programmhefte (Auswahl)........................................................ 529

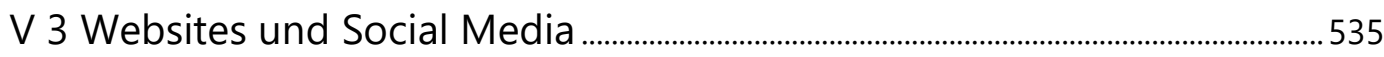

V 4 Register der erwähnten Autor ${ }^{\star}$ innen .................................................................... 538 



\section{Einleitung}

Auf die Gefahr hin, daß Sie mir Inkonsequenz vorwerfen, muß ich zugeben, daß ich in den traditionellen Lesungen, zu denen höchstens zweihundert oder dreihundert Menschen erscheinen, einen gewissen Sinn sehe. Und nicht nur deswegen, weil in dem viel kleineren Rahmen - ohne Scheinwerfer, ohne Mikrophone und Fernsehkameras - der Dilettantismus des Vortrages weniger auffällt. Im Grunde geht es bei solchen Veranstaltungen kaum um die Lesung. Sie ist meist nur Vorwand. Die Leute wollen mit dem Autor, für den sie sich interessieren, ein paar Worte sprechen, ihm einige Fragen stellen. Und mitunter kommt es bei einer solchen Gelegenheit, entschuldigen Sie das mißbrauchte Wort, zu einer ,Begegnung.'1

Inhaltlich direkt daran anschließen lässt sich das folgende Zitat, das die Besonderheit von Literaturveranstaltungen als Begegnung mit den Autor*innen² ebenfalls unterstreicht.

Nicht ausreichend hervorgehoben wird in der so notwendigen Diskussion und in den Abwärtsbeschreibungen bislang der Aufstieg der Literatur vor Publikum. Und das ist nicht mehr nur ein Phänomen, es ist wegweisend. Die Nachfrage auf die Begegnung mit Autoren, live oder virtuell, auf jeden Fall echt und authentisch, greifbar oder anklickbar, nimmt seit Jahren zu. Das Lesen, wie es allgemeiner Ansicht nach vor dreißig Jahren war, mag an Bedeutung verloren haben. Das Vorlesen, der kollektive Austausch, wird immer wichtiger. ${ }^{3}$

Zwischen diesen zwei Textauszügen liegen 56 Jahre. Im ersten hielt Marcel ReichRanicki bereits 1962 in einer Glosse fest, was den Literaturveranstaltungsbetrieb seitdem bedingt und umtreibt. Er bezog sich dabei abgrenzend auf die literarischen Großveranstaltungen, die Walter Höllerer in den 1960er-Jahren in Berlin initiierte und die als Vorläufer der heutigen moderierten Lesungen verstanden werden können. Im zweiten sprach Hauke Hückstädt sich im Jahr 2018 für die Bedeutung der Literaturveranstaltungen für Literatur im Allgemeinen und deren Zukunft aus. Bewährt haben sich über die Jahre die Literaturveranstaltungen ,in dem viel kleineren Rahmen“, die Begegnung zwischen Autor*innen und Leser*innen, zwischen Text und Körper.

Das, was 1962 noch mit kulturkritischem Unterton daherkam, wurde 2018 zur Hoffnung der Literatur ausgerufen. Passé ist inzwischen in den meisten Fällen der Dilettantismus der Autor*innen beim Vortrag. Autor*innen haben Lesungen, Auftritte und Diskussionen als Teil ihrer Rolle angenommen und treffen dabei direkt auf ihre Leser*innen. Homestories, Porträts und Autorenwebsites tragen zur Sicht-

\footnotetext{
${ }^{1}$ Reich-Ranicki 1962.

${ }^{2}$ Für den Umgang mit gendergerechter Sprache ist noch kein Konsens gefunden, deshalb wird hier eine Mischung aus Irritation und Lesbarkeit gewählt. Die Geschlechtszuschreibungen männlich, weiblich und inter sollen sprachlich abgebildet werden, allerdings nicht vom eigentlichen Inhalt des Textes zu sehr ablenken. Neben der*-Variante wird gelegentlich zugunsten des Textflusses auf die Betonung der Geschlechtervielfalt verzichtet, dennoch, wenn nicht anders angeben, sind unbedingt alle gemeint. ,Der Autor bezeichnet damit die Rolle von Autor*innen. Zugleich sei darauf hingewiesen, dass die Deklination zur jeweils letztgenannten Endung passt und,${ }^{*}$ innen` in der Regel an den Wortstamm angehängt wird, also beispielsweise ,Moderator*innen' genutzt wird.

${ }^{3}$ Hückstädt 2018.
} 
barkeit bei und fügen sich in die Alltagspraxis ein, obwohl es einigen Autor*innen bisweilen anzumerken ist, dass sie sich als Schriftsteller*innen verstehen und nicht als Vortragende, Sprechende und Debattierende. Die Auftrittshonorare helfen über geringe Einnahmen aus Buchverkäufen hinweg. Bei Lesungen kommen mittlerweile Scheinwerfer und Mikrofone zum Einsatz, denn es gibt Veranstalter*innen, die es als ihre Aufgabe ansehen, die Autor*innen auf der Bühne ins Rampenlicht zu rücken und ihnen Gehör zu verschaffen. Kurz: Der Literaturveranstaltungsbetrieb hat sich professionalisiert. Das schon 1962 „mißbrauchte“, überstrapazierte Wort „Begegnung' bildet dabei eine Konstante jenseits der strukturellen Veränderungen. An der Institutionalisierung der Literaturveranstaltung als Literaturvermittlungspraktik hatte und hat ein kollektiver Akteur entscheidend Anteil: Das Literaturhaus sorgt seit Mitte der 1980er-Jahre mit dafür, die Beschäftigung mit Literatur als soziales Freizeiterlebnis zu etablieren.

1986 startete in der Berliner Fasanenstraße die erste Einrichtung dieser Art, das Literaturbaus Berlin. Schon kurz vorher gründete sich in Hamburg ein Verein, der seit 1989 im Literaturhaus Hamburg Literaturveranstaltungen anbietet. Es folgten in einem „Gründungsboom“ und „Literaturhausfieber“4 weitere Literaturhäuser in Deutschland: Zum Beispiel gründete sich in Frankfurt der Trägerverein 1989, das Literaturhaus eröffnete 1991; das Literaturbaus München wurde 1997 eingeweiht, die Stiftung schon 1993 ins Leben gerufen; 1996 formierte sich das Literaturhaus Köln und machte ab 1999 Programm; das Literaturhaus Stuttgart begann 1997 als Verein und 2001 mit seinem Veranstaltungsangebot; schon 1989 gründete sich in Kiel ein Verein, der zunächst als Literaturbüro, seit 1998 als Literaturbaus Schleswig-Holstein Lesungen durchführt; seit 2001 gibt es in Wiesbaden ein Literaturhaus. Zeitgleich nahmen Initiativen in Österreich und der Schweiz den Grundgedanken auf. In Österreich traten zum Beispiel schon 1991 das Literaturhaus Salzburg und das Literaturhaus Wien auf den Plan. 2003 kam eine Einrichtung in Graz hinzu. In der Schweiz findet sich in den Städten Zürich seit 1999 und Basel seit 2000 jeweils ein Literaturhaus ebenso wie etwa das Aargauer Literaturbaus in Lenzburg, das seit 2004 tätig ist; die Liste lässt sich fortsetzen.

Mit dem LiteraturHaus in Kopenhagen eröffnete im Jahr 2005 eine Einrichtung auBerhalb des deutschsprachigen Raums. Mit der Verwendung des deutschen Namens bezog diese sich direkt auf die Institution. Ein Jahr später ergriffen Akteur*innen in Oslo die Initiative zum Litteraturhuset und gründen die gleichnamige Stiftung. 2007 wurde das Haus eingeweiht, das sich relativ schnell zu einem Erfolgsmodell entwickelte. Es etablierte außerdem die skandinavische Benennung. ${ }^{5}$ In seiner Nachfolge planten andere Städte in Skandinavien, insbesondere in Norwegen, den Aufbau von Literaturhäusern. In Fredrikstad und Bergen wurde diese Idee Anfang 2013 realisiert. In Göteborg richteten Stadt und Bibliothek im Herbst 2013 Litteraturbuset ein.

\footnotetext{
${ }^{4}$ Höllerer 2007, S. 215.

${ }^{5}$ Als Name verwenden die Einrichtungen meistens ,Litteraturhuset' mit dem Suffix -et, das die bestimmte Form des Substantives angibt und den Artikel enthält. Dieses Kompositum wird auf Dänisch, Norwegisch und Schwedisch gleich geschrieben. Bei skandinavischen Zitaten stammen die Übersetzungen in Klammern in der gesamten Arbeit von der Verfasserin.
} 
Im Herbst 2017 startete mit dem dänischen Namen Litteraturbuset ein weiteres in Kopenhagen.

Literaturhäuser finden sich also nicht mehr nur noch im deutschsprachigen Raum. Die Bezeichnung, die inzwischen als ,house of literature' - gelegentlich gar als Lehnübersetzung, literature house ${ }^{6}$ - sowie ,maison de la littérature ${ }^{6}$ und , litteraturhuset ${ }^{`}$ übersetzt wurde, macht es deutlich. Die Umsetzungen in den verschiedenen Ländern haben oft andere Zielsetzungen und Schwerpunkte, sind aber stets Orte, die Literatur via Veranstaltungen vermitteln. Das Literaturhaus Wien etwa ist auch Dokumentationsstelle für neuere österreichische Literatur. In London liegt mit dem 2009 eingerichteten Free Word Centre der Fokus viel stärker auf Fragen der Meinungs- und Pressefreiheit, es ist klar politisch positioniert. ${ }^{7}$ Das Prager Literaturhaus deutschsprachiger Autoren ist seit 2004 ein Ort für deutsche Literatur im Ausland und vermittelt vor allem deutsch-tschechische Literatur. Literaturhaus Europa dient als Titel für ein Kooperationsprojekt mehrerer europäischer Literaturveranstalter*innen, die sich zum Ziel setzten, europäische Gegenwartsliteratur an unterschiedlichen Orten zu vermitteln. Am weitesten verbreitet ist die Institution fortwährend im deutschsprachigen Kontext, gefolgt von Skandinavien, wo sich die engste Verbindung zum deutschen Modell feststellen lässt. Die ersten skandinavischen Literaturhäuser beriefen sich in ihrer Konzeption explizit auf die Tradition der freien Literaturhäuser in Deutschland, die folgenden auf skandinavische Vorbilder wie Litteraturbuset in Oslo. Besonders dieser Transfer der Literaturhaus-Idee ist Anlass, diese Arbeit als komparative Studie anzulegen, um darzustellen, wie die unterschiedlichen Einrichtungen zu verorten sind.

Die Institution ist auch in ihrem Ursprungskontext dynamisch. Neben Aktualisierungen in den bestehenden Literaturhäusern bilden sich im deutschsprachigen Raum nach wie vor Initiativen für Neugründungen. In den letzten Jahren sind zahlreiche weitere Literaturhäuser entstanden, fortgesetzt und professionalisiert worden. Es erscheint kaum möglich, alle Entwicklungen, die zum Teil nur lokal thematisiert werden, im Blick zu behalten. Seit 2009 beispielsweise existiert in der unterfränkischen Provinz das Literaturhaus Wipfeld; 2010 konnte ein neuer Verein das Literaturbaus Bonn konsolidieren, das seit 2011 Programm anbietet; in Hildesheim läuft seit 2014 das von einer Kirchengemeinde angestoßene Projekt Literaturhaus St. Jakobi Hildesheim in einer Kirche; in einer Buchhandlung in Herne lädt seit 2016 der 2015 eingetragene Verein Literaturbaus Herne Rubr zu Literaturveranstaltungen ein; in Freiburg eröffnete 2017 das Literaturbaus Freiburg, das auf einen 1988 gegründeten Trägerverein zurückgeht, der bereits seit 1992 das Literaturbüro Freiburg unterhielt; im Frühjahr 2018 öffnete das Literaturhaus Halle seine Türen. Diese Fälle illustrieren, dass sich das Spektrum des Literaturhauses erweitert. So lässt sich inzwischen eben-

\footnotetext{
${ }^{6}$ Vgl. European Literature House Meeting 2014.

7 Dies liegt auch daran, dass diese Einrichtung von der Organisation Free Word betrieben wird. Auf Free Word wird später bei der Beschreibung des Litteraturbuset in Oslo genauer eingegangen, weil die norwegische Stiftung Fritt Ord [Freies Wort] neben dem Osloer das Londoner Haus initiierte, vgl. „About Free“, Free Word Centre sowie „Langtidsprosjekter“, Fritt Ord. In den Fußnoten sind bei Internetquellen Kurztitel und Institution bzw. Veröffentlichungsplattform oder Autor*in und Kurztitel genannt, das Abrufdatum steht im Literaturverzeichnis. Ist eine Jahreszahl angegeben, handelt es sich um gedruckte Publikationen, vgl. z. B. FN 6. Internetquellen werden im Literaturverzeichnis getrennt von gedruckten Publikationen aufgeführt.
} 
falls das im Jahr 2000 initiierte Literarische Zentrum Göttingen als Literaturhaus begreifen.

Mit der Idee Herbert Wiesners, Begründer und bis 2003 Leiter des Literaturhauses Berlin, den konzipierten Ort für Literatur und Literaturvermittlung analog zu etwa Palmen- und Vogelhäusern schlicht ,Literaturhaus ${ }^{6}$ zu nennen, ${ }^{8}$ wurde ein Institutionalisierungsprozess in Gang gesetzt, dessen Weiterentwicklung nicht abgeschlossen ist. Das Konzept löst weiterhin Diskussionen über den Literaturveranstaltungsbetrieb und Vermittlungspraktiken aus. Deshalb lohnt es sich, bis zu den Anfängen zurückgehen und zu schauen, was es eigentlich mit dem Literaturhaus auf sich hat, um dann auch die Neugründungen und Veränderungen einordnen zu können.

\section{Anlass und Ziele dieser Studie}

Das Literaturhaus existiert wirklich erst seit Mitte der 1980er-Jahre und erlebte erst um die Jahrtausendwende einen markanten Bedeutungszuwachs. Diese Institution eignet sich in besonderem Maße dazu, zu erforschen, auf welche Weise im Zeitalter der Digitalisierung mit Literatur umgegangen und welche Rolle ihr zugeschrieben wird. Der Ausdruck ,Zeitalter der Digitalisierung' geht auf den Forschungskontext, in dem diese Arbeit entstand, zurück. ${ }^{9}$ Er stellt einen Versuch dar, einen Sammelbezeichnung für die gegenwärtige Periode ab den 1990er-Jahren zu finden, die ungefähr mit Etablierung des World Wide Webs beginnt und sich aufgrund erster Anzeichen in die Zeit der 1980er-Jahre ausdehnen lässt. Das Literaturhaus entsteht in dieser Zeit. ,Digitalisierung“ ist dabei „als eine Art ,Signatur der Zeit“"10 zu verstehen. ${ }^{11}$ „Wer über die Gegenwart redet, spricht immer auch über Digitalisierung." Diese „ändert nicht nur die Medien des Lesens, sondern auch die damit verbundenen Praktiken und Prozesse. "13 Dabei spielt sie für das Literaturhaus auf den ersten Blick nur eine untergeordnete Rolle. Schon allein, weil die ersten Einrichtungen bereits Ende der 1980er-Jahre eröffneten, kann kein direkter Zusammenhang zwischen der Gründung des Literaturhauses und dem Aufkommen der Digitalisierung bestehen. Trotzdem ist die erfolgreiche Durchsetzung des Literaturhaus-Konzeptes mit der fortschreitenden Mediennutzung in Verbindung zu bringen. Die „Eventisierung von Literatur als ein Effekt von Mediengesellschaften“"14 spielt eine entscheidende Rolle. So zeigt sich bei genauer Betrachtung, wie sehr das Literaturhaus ein Phänomen ist, das als Beispiel für „Lesen in der digitalen Gegenwart“"15 zu interpretieren ist, es bewegt sich innerhalb „eines Zusammenhangs, der sich grob gefasst vielleicht als ein Wiedererstarken der Sehnsucht nach den sozialen und sinnlich er-

\footnotetext{
${ }^{8}$ Vgl. Wiesner 2004.

${ }^{9}$ Das Graduiertenkolleg Literatur und Literaturvermittlung im Zeitalter der Digitalisierung nahm ausdrücklich nicht nur genuin digitale Phänomene in den Blick.

${ }^{10}$ Beilein und Stockinger 2017, S. 233.

${ }^{11}$ Heute ließe sich noch besser vom , digitalen Zeitalter' sprechen, weil ,Digitalisierung einen Prozess beschreibt: Bücher zu digitalisieren ist schließlich etwas anderes als Bücher mit digitalen Mitteln herzustellen und wieder etwas anderes als Bücher zur digitalen Rezeption zu publizieren. Da alles aber parallel stattfindet, halte ich mich hier an den Terminus ,Zeitalter der Digitalisierung', vgl. auch ebd.

12 Ebd.

${ }^{13}$ Böck et al. 2017, S. 16.

${ }^{14}$ Wegmann 2002, S. 133

15 Böck et al. 2017, S. 16.
} 
fahrbaren Dimensionen von Literatur bezeichnen ließe" $\mathrm{e}^{\text {"16. }}$. Das Digitale durchdringt unsere gesamte Lebenswirklichkeit. So spitz und pathetisch überzeichnet diese Formulierung anmuten mag, stellt sie sich doch klar gegen Beschwörungen, die die Einflüsse der Digitalisierung auf ,das Internet' reduzieren wollen.

Dass das Gedeihen des Literaturhauses im deutschsprachigen Raum nicht alleine auf spezifisch deutsche Voraussetzungen zurückzuführen ist, bestätigt der Transfer nach Norwegen. Die erst ab Mitte der Nullerjahre entstehenden Literaturhäuser im technikaffineren Skandinavien sprechen besonders dafür, die Institution von gegenwärtigen gesellschaftlichen Entwicklungen beeinflusst zu sehen. Das Literaturhaus wird in dieser Arbeit als Beispiel dafür interpretiert, dass parallel zur durch technische Veränderungen ermöglichten erhöhten Mobilität, ständigen Verfügbarkeit und Simultanität das Bedürfnis nach physischer Begegnung, Fokussierung und einmaligem Erleben nicht verschwindet, sondern sogar sichtbarer wird. Dies ist eine der Grundthesen der vorliegenden Arbeit.

Meinungen und Einschätzungen und allgemeine Urteile zu Literaturhäusern kursieren im Literaturbetrieb, doch noch mangelte es an einer wissenschaftlichen Untersuchung der sich erst herausbildenden Institution. Bislang existieren vor allem $\ddot{u}$ Berungen von direkt Beteiligten. Anja Johannsen, inzwischen selbst Leiterin des Literarischen Zentrums Göttingen, weist darauf hin, dass es sich dabei meist um „Dokumentationen institutionellen Selbstverständnisses“ handelt und es an „empirischen Studien, die die Arbeit der Literaturhäuser kritisch begleiten und dokumentieren “ ${ }^{\text {17 }}$ bisher fehlt. Einen Beitrag zur empirischen Analyse des Literaturhauses leistet die vorliegende Arbeit. Dabei wird vor allem unveröffentlichtes Archivmaterial ausgewertet. Auf breiter empirischer Basis können so exemplarische Programmanalysen der Literaturhäuser vorlegen werden.

Da zum Literaturhaus selbst bisher nur wenige Arbeiten vorliegen, ist es in einiger Hinsicht ergiebig, andere Kulturbetriebe ${ }^{18}$ als Vergleichsobjekte zurate zu ziehen. Theater- und Kunstbetriebe sind, besonders bezüglich Unternehmensstruktur und -zielen, den Literaturhäusern ähnlich. Verlage und Bibliotheken als Vergleichsobjekte bedenken stärker literaturspezifische Belange. Literaturhäuser entstehen selbstverständlich nicht in einem traditionslosen Raum, doch etablieren diese einen

${ }^{16}$ Johannsen 2012b, S. 184.

17 Ebd., S. 182.

${ }^{18}$ Es gilt zu unterscheiden zwischen dem Kultur- bzw. Literaturbetrieb als Gesamtheit und einzelnen Kulturbetrieben als Unternehmen. Werner Heinrichs formuliert dazu: „Der Begriff Kulturbetrieb wird in einem zweifachen Verständnis verwendet. Erstens gibt es den Kulturbetrieb als einzelne Institution wie beispielsweise ein bestimmtes Theater, Museum oder Orchester. Der Kulturbetrieb ist dann eine betriebliche Einheit, die ähnlich wie ein Wirtschaftsbetrieb singulär gesehen wird. [...] Zweitens versteht man unter Kulturbetrieb die Gesamtheit des institutionalisierten Rahmens zur Produktion und Vermittlung von Kultur, also beispielsweise auch Kulturvereine und Kulturverbände. In allen volkswirtschaftlichen Kontexten sowie in allgemeinen kulturpolitischen Aussagen ist immer der Kulturbetrieb im weiteren Sinne gemeint", Heinrichs 2011, S. 131. Bereits früher nimmt etwa François Colbert eine vergleichbare Unterscheidung zwischen ,Kulturbetrieb“ in einem engeren und in einem weiteren Sinne vor. Auch das Literaturhaus lässt sich als Kulturbetrieb klassifizieren. Eine Definition legt etwa Franz-Xaver Ohnesorg vor. Aus seinem Lexikonartikel geht hervor, dass bei einem Kulturbetrieb unterschiedliche kulturspezifische Faktoren berücksichtigt werden müssen, grundsätzliche Strukturen aber mit organisationsökonomischem Handwerkszeug bearbeitet werden können. Weder mit rein betriebswirtschaftlichen, soziologischen noch mit rein literaturwissenschaftlichen Verfahren kann man sich einem Kulturbetrieb angemessen annähern, vgl. Ohnesorg 1993. 
ganz neuen Namen und zeigen damit, dass es sich bei Literaturhäusern nicht um eine Weiterentwicklung eines bestehenden Konzeptes handelt, sondern sie zunächst als neue Institution in einem existierenden Raum interpretiert werden sollte.

Die vorliegende Arbeit ist bei der Aufarbeitung der Institutionsgeschichte zweierlei: Zum einem ist sie Ausdruck eines schon stattgefundenen Institutionalisierungsprozesses, denn wenn das Literaturhaus zum Thema einer Dissertation wird, muss es zu einem gewissen Grad etabliert sein. Zum anderen schreibt sie an der Institutionalisierung mit, weil sie dazu beiträgt, das Literaturhaus als Konzept zu präzisieren und so zu stabilisieren. Dabei stehen zunächst die vereinigenden Aspekte im Vordergrund, um das Phänomen Literaturhaus zu fassen. Dazu nutzen Fallbeispiele, deren sich herauskristallisierende Strukturen zu allgemeinen Erkenntnissen führen können.

Wie gestaltet sich die Institution Literaturhaus? Wie stellen sich die Literaturhäuser dar? Was vermitteln sie tatsächlich und auf welche Weise tun sie dies? Wie ist dies mit der generellen Entwicklung des Literaturbetriebs zusammenzubringen? Ein breit angelegter und verschiedene Aspekte einbeziehender Zugang zum Gegenstand ermöglicht es, die verknüpften Momente in ihrer Komplexität darzustellen.

\section{Vorgehen und Gliederung}

Die vorliegende Arbeit stellt auf breiter Materialbasis grundlegend dar, wie ausgewählte Literaturhäuser in Deutschland und Skandinavien im Literaturbetrieb agieren. Die heuristische Bestimmung zu Beginn des ersten Kapitels (I 1) bildet die Grundlage für die darauf aufbauende Studie. Sie intendiert „die konstituierenden Prinzipien und Strukturen" ${ }^{19}$ der Fallbeispiele zu extrahieren und so einen Diskussionsbeitrag zu einem sich weiterentwickelnden Forschungsgegenstand zu leisten. Dabei wird unter anderem der Frage nachgegangen, wie diese Literaturvermittlungsinstitution entsteht, sich entwickelt und sich verorten lässt. Neben sachgeschichtlichen Einblicken in konkrete Umsetzungen der Literaturhaus-Idee und ihre Umgebung präsentiert die Studie verallgemeinerbare Erkenntnisse zum gegenwärtigen Literaturbetrieb. So vollführt die Arbeit einen Balanceakt zwischen analytischer Abstraktion und genauen Einzelfallstudien und zwischen Fragestellungen infrastruktureller (etwa: Wie sind die Einrichtungen finanziert und organisatorisch aufgebaut), konzeptioneller (etwa: Wie vermitteln die Literaturhäuser Literatur? Was ist ihr Unternehmensziel?) und inhaltlich literarischer Art (etwa: Welche Texte und Autor*innen werden präsentiert?). Hier geht es nicht nur um die Darstellung des Literaturhauses, sondern implizit auch um die Frage, wie sich eine gegenwärtige, dynamische Institution untersuchen lässt.

Das erste Großkapitel (I) fundiert die Arbeit in ihren Forschungskontext (I 2), diskutiert methodische Fragestellungen zur ,Institution Literaturhaus' (I 3) und legt damit ihren Grundriss vor. Prämisse dieser Arbeit ist es, dass die Literaturhäuser, die unter diesem oder ähnlichem Namen wirken, Gemeinsamkeiten und Unter-

\footnotetext{
${ }^{19}$ Dürr 2009, S. 2.
} 
schiede aufweisen, die einen Vergleich der Einrichtungen rechtfertigen. Die Institution Literaturhaus wird verstanden als abstrakte Variante eines kollektiven Akteurs, eines aus Einzelakteuren verbundenen emergenten Akteurs. Aus den Einzelfällen der Literaturhäuser in Berlin, Hamburg, Frankfurt, Göttingen und theoretisch allen anderen deutschen Einrichtungen setzt sich die Institution des deutschen Literaturhauses zusammen, das unter den Bedingungen des deutschen Literaturbetriebes funktioniert. Die norwegische Variante besteht aus den Organisationen in Oslo, Bergen und den weiteren Exemplaren. Beide Abstrakta - das deutsche und das norwegische Literaturhaus - lassen sich unter den Begriff der transnationalen Institution subsummieren. Das Literaturhaus lässt sich außerdem als dynamisches Praxisgefüge modellieren, das von Konventionen und Praxiswissen ebenso wie von teilweise divergierenden Interessen bestimmt ist. Die Aktivitäten der beteiligten Einzelakteur*innen lassen den kollektiven Akteur entstehen. Theoretische Ausführungen zum Kulturtransfer helfen, die transnationale Institution Literaturhaus zu erfassen. Der Vergleich deutscher und skandinavischer Literaturhäuser ermöglicht, einerseits die Institution besser zu begreifen und andererseits Rückschlüsse auf die unterschiedlichen Kulturräume zu ziehen. Der ,Import ${ }^{\star}$ aus Deutschland ist vor allem deshalb interessant, weil sich daran erkennen lässt, wie das Konzept in anderen Kontexten aufgefasst und realisiert wird. Darüber zeigt sich unter anderem, was beispielsweise in Norwegen als für die deutschen Einrichtungen typisch erkannt wird. Die deutsch-skandinavistische Perspektive reflektiert dabei sowohl den deutschen als auch den skandinavischen Kontext. Pionierarbeit leistet diese Studie, weil sie sich eingehend mit dem Vergleich deutscher und skandinavischer Literaturhäuser befasst, denn bisherige Beiträge zu diesen Einrichtungen nehmen nur entweder die deutschen ${ }^{20}$ oder die norwegischen Literaturhäuser in den Blick.

Auf einen Abschnitt zur Vorgeschichte des deutschen Literaturhauses (I 4) folgen generelle Überlegungen zu den beteiligten Akteur*innen und den Funktionen des Literaturhauses (I 5). Antworten auf die Frage, warum es das Literaturhaus überhaupt gibt, liefert dieses Teilkapitel ebenfalls. Dabei wird herausgearbeitet, dass es in unterschiedlichen Handlungsbereichen agiert und dass die Arbeit von Literaturhäusern von möglichen Interessenkonflikten geprägt ist. Als Institution bewegt es sich beispielsweise zwischen Innovation und Tradition, zwischen Reagieren und Agieren, zwischen Koalition und Konkurrenz. Dass das Literaturhaus anstrebt, eine Balance innerhalb dieser Möglichkeitsspielräume zu finden, ist eine weitere Grundannahme der vorliegenden Arbeit, auf die immer wieder zurückgekommen wird.

Die Kombination aus unterschiedlichen Gesichtspunkten - etwa aus Zuhören als Lektüre, Diskussionsbereitschaft sowie sozialem Erlebnis - lässt sich als Movens für den Erfolg des Literaturhauses vermuten. Tätig ist die Institution Literaturhaus besonders im Bereich der Literaturvermittlung. Dabei lässt sich nach den Vermittlungsobjekten ebenso wie nach den Vermittlungspraktiken fragen, die kaum losgelöst voneinander untersucht werden können, wie das zweite Kapitel deutlich

\footnotetext{
${ }^{20}$ Dabei sind es vor allem deutschen Beiträger*innen, die sich mit Literaturhäusern auseinandersetzen und dann meist auf die bundesdeutschen fokussieren. Bei einer Betrachtung der deutschsprachigen Einrichtungen müssten die Eigenarten des deutschen, österreichischen und schweizerischen Kontextes berücksichtigt werden.
} 
herausarbeitet. Als Vermittlungspraktiken finden sich vor allem Literaturveranstaltungen.

Im zweiten Großkapitel (II) wird der im ersten Teil entworfene Grundriss noch plastischer. Erst aufgrund der Annahme des vereinigenden Schemas aus Kapitel I können die Beispiele überhaupt als exemplarisch für die Institution interpretiert werden. Sie besteht aus einer überschaubaren Anzahl von Einzeleinrichtungen, die als strukturierte Organisationen relativ stabil sind. Acht Einrichtungen bilden im Folgenden das konkrete Material: Literaturhaus Berlin, Literaturhaus Hamburg, Literaturhaus Frankfurt, Literarisches Zentrum Göttingen, LiteraturHaus in Kopenhagen, Litteraturbuset in Oslo, Litteraturbuset Bergen, Göteborgs Litteraturbus. Zunächst informieren chronologisch aneinandergereihte Präsentationen der Beispiele über ihre Strukturierung, ihre innere Organisation, ihre Finanzierung, ihre Entstehungserzählungen, die Akteur*innen und die physischen Orte (II 1 bis II 8). Dies geschieht mit Blick auf die übergeordneten Fragestellungen, sodass die Einrichtungen als exemplarisch für Aspekte dargestellt werden, die für die Instutition insgesamt relevant sind. Es folgt unter II 9 eine Untersuchung von Über-uns-Texten, die die Literaturhäuser auf ihren Websites veröffentlichten. Diese demonstrieren anschaulich, wie sich die Fallbeispiele nach außen präsentieren, und so lassen sich Erkenntnisse über das Selbstverständnis der Einrichtungen herausarbeiten. Die Auseinandersetzung mit dieser Textsorte ist in der Literaturwissenschaft bisher eher ungewöhnlich. Für die Literaturhäuser gehören derartige Texte hingegen zur Alltagspraxis. Wie wichtig sie sind, merkt auch Sonja Vandenrath an: „Eine solche Einrichtung zu leiten, ohne mit Nachdruck an ihrer Außenwirkung zu arbeiten, kann weder im Interesse des Publikums, noch der Förderer, geschweige denn der Autoren sein. " 21 Prononciert ergänzt werden muss, dass es vor allem im Interesse der Einrichtung selbst ist, ihre Außendarstellung ernst zu nehmen und sich konsistent zu präsentieren, denn das Literaturhaus ist zu großem Teil so, wie es sich - intentional oder unbewusst - darstellt. Dies machen neben den Selbstdarstellungstexten die Programmhefte deutlich, auf die sich diese Studie ab Kapitel II 10 konzentriert. Die Untersuchung dieser bisher von der Literaturwissenschaft vernachlässigten Textsorten erweist sich als sehr produktiv, um den Praktiken im Literaturhaus näher zu kommen. Die Akteur*innen im Literaturhaus rezipieren und produzieren diese Texte alltäglich - ohne ständig ihre sich darin äußernden Selbstverständnisse und Grundannahmen zu reflektieren. Dies macht sich die vorliegende Arbeit zur Aufgabe. Die Programmhefte der Literaturhäuser werden als repräsentativ für Programm und Programmatik der Fallbeispiele aufgefasst. In diesem Kontext lässt sich etwa darüber nachdenken, welche Programmprofile sich bei den einzelnen Literaturhäusern erkennen lassen, was etwa über die Betrachtung von Veranstaltungsreihen passiert. ${ }^{22}$

Aufgrund des Forschungsinteresses am Literaturhaus als Gesamtkonzept betrachtet die vorliegende Arbeit die Veranstaltungen nicht als Einzelinszenierungen und vor allem nicht in ihrem Vollzug. Hier stehen das Gesamtprogramm und seine Rahmung im Brennpunkt und das, was über die Literaturvermittlungspraktiken im Vorhinein kommuniziert wird. Kapitel II 10 und II 11 erläutern und interpretieren

${ }^{21}$ Vandenrath 2002, S. 188.

22 Vgl. Kapitel II 13.1. 
vor allem organisationale Aspekte des Literaturhauses, indem sie die Gestaltung und Struktur der Programme betrachten. Teil II 10 bezieht Textanalysen von Veranstaltungsankündigungstexten mit ein, die die literaturwissenschaftliche Ausrichtung dieser Arbeit unterstreichen.

Diese Kapitel dienen hier der Annäherung an das Literaturhaus, viele Aspekte sind jedoch auf andere Untersuchungsgegenstände übertragbar. Dies gilt ebenso für das dann Folgende. Bezugnehmend auf die Anfangsüberlegungen, dass das Literaturhaus eine Institution des Zeitalters der Digitalisierung ist, steht in Abschnitt II 12 seine Onlinenutzung und deren Verbindung zum physisch begehbaren Ort des Literaturhauses im Fokus. Dort zeigt sich unter anderem, dass die Einbeziehung des Digitalisierungsaspektes den Blick für das aktuell Charakteristische der Institution sowie für ihre Weiterentwicklung zu schärfen vermag. Es wird sichtbar, dass ,analoge Veranstaltungen im Zentrum der Vermittlungsarbeit stehen und weiterhin Autor*innen eine Bühne geboten wird. Kapitel II 13 und II 14 wenden sich noch stärker den Programminhalten zu und fragen, welches Verständnis von Literatur das Literaturhaus vertritt. Dabei bildet der Aspekt der Literaturvermittlung einen wichtigen Bestandteil, sodass nicht nur die vorgestellten Titel und Autor*innen, sondern ebenfalls die Veranstaltungsreihen und -formate betrachtet werden. Grundlegend für die Vermittlungsarbeit ist die Rezeptionstätigkeit des Literaturhauses, das durch seine Selektion literarisch wertet. ${ }^{23}$ Damit hat es ein literaturkritisches Moment inne, das sich überdies in entsprechenden Diskussionsformaten äußert. ${ }^{24}$ Die Auswahl der Autor*innen, die im Literaturhaus auftreten, leitet über zur Rolle des Literaturhauses in Kanonisierungsprozessen. ${ }^{25}$ Dadurch offenbart sich, dass diese Institution mitbestimmt, welcher Literatur Aufmerksamkeit geschenkt wird. Implizit entscheidet sie mit, was überhaupt als Literatur verstanden wird. Es lässt sich nämlich davon ausgehen, dass als Literatur dasjenige verstanden wird, das als Literatur vermittelt wird.

Die Fallstudienkapitel weisen zudem eine hohe Informationsdichte auf, da sie viele recherchierte Informationen mit referierten Debatten über die Einrichtungen sowie mit eigenen Programminterpretationen kombinieren. Gleichzeitig sind im Sinne der komparativen Arbeit stetig Vergleiche mit anderen Literaturhäusern und Querverweise der Kapitel untereinander eingebaut. Gerade die Verbindungen zwischen einzelnen Themenbereichen machen den Reiz der Analyse einer sich weiterhin bewegenden Institution aus. Die Unabgeschlossenheit des Untersuchungsobjektes erfordert eine Annäherung, die den Grundriss absteckt für anschließende Forschung und Diskussionen. Weitere Erläuterungen zum Vorgehen, Kontextualisierungen und Hypothesen ergeben sich im Verlauf der Studie. Die hier durchgeführten zum Teil kleinteiligen Textanalysen und exemplarischen Programmvorstellungen sind Mittel, sich dem Literaturhaus nicht nur abstrakt und diskursiv zu nähern, sondern mit einigen Tiefbohrungen zu prüfen, wie sich die Institution konkret untersuchen lässt.

${ }^{23}$ Vgl. z. B. Kapitel I 5.6.4, S. 92.

${ }^{24}$ Vgl. z. B. Kapitel II 13.1.7. Eine Bildungsfunktion lässt sich dem Literaturhaus vor allem im Kinderund Jugendbereich zuschreiben. Das ,Erwachsenenprogramm` enthält ebenfalls Punkte, die sich unter dem Stichwort Bildung subsummieren lassen. Information und literarästhetische wie literarhistorische Weiterbildung stehen dort genauso auf dem Programm wie die sogenannte Gesellschaftsbildung. 25 Vgl. Kapitel II 14.2. 
Das dritte Kapitel (III) resümiert und verortet die Literaturhäuser noch einmal explizit in einigen ihrer Spannungsverhältnisse. Es bezieht sich dabei auf die Frage, ob es angemessen ist, die verschiedenen Einrichtungen unter der Dachbezeichnung ,Literaturhaus` zu bündeln. Die Literaturhäuser werden untersucht als individuelle Einzeleinrichtungen mit spezifischen Profilen, die sich immer auch zum abstrakten Konzept der Institution, das sie gleichzeitig mitgestalten, verhalten müssen. Doch lässt sich von der ,Institution Literaturhaus' überhaupt sprechen? 


\section{Literaturhaus als Literaturvermittlungsinstitution}

\section{1 Heuristik - Was ist ein Literaturhaus?}

Mit ,Literaturhaus' werden literaturvermittelnde Einrichtungen bezeichnet, die an einem festen Ort in einer Stadt ganzjährig - mit Ausnahme von Sommerpausen öffentlich zugängliche Literaturveranstaltungen anbieten. Durch den Fokus auf Veranstaltungen für ein externes Publikum unterscheidet es sich von den älteren Literaturbüros, die vor allem als Einrichtungen zur Beratung und Förderung von Autor*innen tätig sind beziehungsweise waren. ${ }^{26}$ In der zeitlichen Kontinuität unterscheidet es sich markant von Literaturfestivals, die ebenfalls „ein sozialer Handlungs- und Kommunikationsraum“ ${ }^{27}$ sind, ihr Programm aber an einigen Tagen bis Wochen komprimiert präsentieren, was sich jeweils auf die Arbeitsstrukturen auswirkt. Von Dichterhäusern und Gedenkstätten, die ebenfalls einen konkreten Ort prägen, ist das Literaturhaus vor allem in Bezug auf seine Vermittlungsabsichten abzugrenzen. Während sich eine Personengedenkstätte einer Autorenfigur und der „Inszenierung einer Stätte (eines Hauses, einer Wohnung), an der eine Person verehrt wird" 28 , verschreibt, geht es im Literaturhaus um Vermittlung verschiedener Literaturen. Es ist in seinem Programm nicht auf einzelne Autor*innen, eine Region oder eine Zielgruppe festgelegt. Ein Schwerpunkt liegt auf gegenwärtiger nationaler wie internationaler Literatur, literaturhistorische sowie über Literatur hinausgehende Themen lassen sich ebenfalls verzeichnen. Autorenbesuche mit Lesung und Gespräch bilden einen Großteil der Veranstaltungen; Diskussionen, Vorträge und weitere Formate ergänzen diese. ${ }^{29}$ Dadurch, dass das Literaturhaus hauptsächlich Neuerscheinungen vorstellt, zeigt sich eine enge Orientierung am Buchmarkt des jeweiligen Landes. Neben Angeboten für Erwachsene organisieren viele Literaturhäuser außerdem Veranstaltungen für Kinder und Jugendliche. Einrichtungen, die sich ausschließlich der Kinder- und Jugendliteratur widmen, werden hier nicht berücksichtigt. ${ }^{30}$

Der Ort, häufig ein stattliches historisches Haus in zentraler Lage oder einer wohlhabenderen Gegend, wird oft als eine Stätte der Literaturvermittlung und -rezeption und gelegentlich -produktion inszeniert, indem ein gastronomischer Betrieb und eine Buchhandlung zusätzlich zu den Veranstaltungen zum alltäglichen literarischen

\footnotetext{
${ }^{26}$ Es handelt sich bei dieser Arbeit nicht um eine Bestandsaufnahme aller Literaturhäuser, -zentren und büros im weitesten Sinne, wie Kerstin Juchem sie bereits anstrebte, vgl. Juchem 2013. Selbst eine 2015 publizierte Liste ist nicht mehr aktuell, vgl. Uschtrin und Hinrichs (Hg.) 2015, S. 502-505. Deshalb verzichte ich in dieser Arbeit auf eine ähnliche Liste, die kaum vollständig sein kann. Die verschiedenen Funktionen und die Entwicklung der Literaturbüros ist aber für das Verständnis des Literaturhauses wichtig, weshalb dies weiter hinten vertieft wird, vgl. S. 79 sowie S. 149.

${ }^{27}$ Schaff 2013, S. 283.

${ }^{28}$ Kahl 2017, S. 337. Er unterscheidet dort zwischen ,Personengedenkstätte' und ,Personalmuseum‘, wobei letzteres ,,nicht der Musealisierung einer biografischen Stätte“ gewidmet sei, wenngleich es sich oft in der Nähe befinde.

${ }^{29}$ Vgl. Kapitel II 13.2.

${ }^{30}$ Die Aktivitäten der Fallstudien hinsichtlich eines Programms für Kinder und Jugendliche werden später dargestellt, vgl. Kapitel II 11.1.
} 
Austausch anregen sollen. Gedacht waren die ersten Literaturhäuser als literarische Begegnungsstätten.

Es handelt sich dabei in der Regel um gemeinnützige Organisationen, die zu Teilen öffentlich, zu Teilen privat, also nicht vollständig staatlich oder kommunal, finanziert sind. Dies grenzt sie strukturell von kommunalen Einrichtungen wie Stadttheatern, öffentlichen Museen oder Bibliotheken ab. Die Literaturhäuser als nichtkommerzielle Einrichtungen sind folglich in ihren Programmentscheidungen grundsätzlich unabhängig. Monetär-ökonomische Belange wirken dennoch auf die Programmplanung ein. ${ }^{31}$

Literaturhäuser weisen eine „professionelle Infrastruktur mit fest angestellten Mitarbeitern" 32 und häufig weiteren freien Projektbeteiligten auf, sie wirken entsprechend nicht nur auf ehrenamtlicher Basis. Meistens hat eine Person zugleich Geschäftsführung und Programmleitung inne, manchmal sind diese Funktionen aufgeteilt. Das Literaturhaus unterhält einen Geschäftsbetrieb und verantwortet ein selbst kuratiertes Veranstaltungsprogramm. Einige Einrichtungen ergänzen ihr Angebot durch Gastveranstaltungen. ${ }^{33}$

Diese Heuristik stimmt mit bereits existierenden Beschreibungen überein und geht über diese zunächst kaum hinaus. ${ }^{34}$ Hier steht sie jedoch nur am Anfang und macht deutlich, dass das Literaturhaus auf unterschiedlichen Ebenen untersucht werden muss. Dabei handelt es sich bei den genannten Punkten nicht um notwendige Kriterien, um eine Einrichtung kategorisch dem Begriff ,Literaturhaus' zuordnen zu können, vielmehr greift das Prinzip der Familienähnlichkeit. Begriffsgeschichtlich wichtig ist zudem festzuhalten, dass ,Literaturhaus' einerseits ein selbstgewählter Eigenname sein kann, andererseits als Funktionsbeschreibung zum Einsatz kommt.

\section{Eigenname und Funktionsbezeichnung}

Die Bezeichnung ,Literaturhaus', die mit der ersten Eröffnung in Berlin erfunden wurde, war zunächst ein Eigenname für einen neuen Ort der Literaturvermittlung. Geschützt ist dieser Name nicht, was ein Gerichtsurteil von 2004 zu einer Klage des Literaturhaus e. $V$. in Hamburg belegt, da dem Namen die originäre Unterscheidungskraft fehle. ${ }^{35}$ Die Einschätzung, „[d]ie für sich nicht unterscheidungskräftigen Wörter ,Literatur' und „Haus' seien in sprachunüblicher Weise zusammengeführt und in dieser Zusammensetzung einprägsam“, stand in den Gerichtsinstanzen des Verfahrens der Ansicht entgegen, dass es sich um die Beschreibung des Tätigkeitsbereichs handele, wie dies üblicherweise in anderen Kombinationen mit dem Wort „Haus`anzutreffen sei, etwa beim Möbelhaus, Autohaus oder Schuhhaus. ${ }^{36}$

\footnotetext{
${ }^{31} \mathrm{Zu}$ den Geldgeber*innen vgl. z. B. Kapitel I 5.1.

32 Vandenrath 2006, S. 169.

${ }^{33} \mathrm{Vgl}$. Kapitel II 11.2.1.

34 Thomas Böhm beispielsweise fasst in einem knappen Beitrag diese wichtigsten Punkte ebenfalls zusammen, vgl. Böhm 2005b.

${ }^{35}$ Vgl. „Fehlende Unterscheidungskraft““, Bundesgerichtshof 2004, S. 1504. Das Literaturbaus Hamburg klagte auch im Namen der anderen Literaturhäuser, die sich gemeinsam die Domains wmw.literaturhaus.de/org/net/com sichern wollten. Dass ein Unternehmen, mit dem das Literaturhaus Hamburg zunächst eine Zusammenarbeit plante, die Domains für sich beanspruchte, wollte der Verein unterbinden.

${ }^{36}$ Eine ähnliche Parallele zog Herbert Wiesner, der dem Literaturhaus Berlin seinen Namen gab, vgl. FN 473.
} 
,Literaturhaus' wurde als Name sowie als Konzept in anderen Städten übernommen. Das Literaturbaus Berlin ist dabei nicht der Prototyp, sondern eine Art Urtyp, von dem ausgehend, sich die Institution entwickelte. Der Individualname wurde nach und nach zu einer Begriffsbezeichnung. Dies beweist sich zum Beispiel dadurch, dass die Vokabel für den Transfer des Konzeptes nach Skandinavien dem Deutschen entlehnt wurde und selbst deutsche Einrichtungen, die zunächst unter einem anderen Namen firmieren, sich in ihrer Arbeit aber als ,Literaturhaus'verstehen, eine Umbenennung anstreben, um klar dem Begriff ,Literaturhaus' zugeordnet zu werden. Um dieser Annahme Rechnung zu tragen, wird eine Einrichtung in die Untersuchung einbezogen, die (noch) nicht Literaturhaus heißt: Das Literarische Zentrum Göttingen.

Die deutschen Einrichtungen, die ,Literaturhaus' im Namen tragen, folgen dem Bezeichnungsschema ,Literaturhaus Stadtname‘. Im Sprachgebrauch findet sich die Umstellung in beispielweise ,Frankfurter Literaturhaus'. Dies ist ein weiteres Argument dafür, ,Literaturhaus' als Begriffsbezeichnung zu verstehen, die unabhängig vom Eigennamen funktioniert. So wird vom Literarischen Zentrum Göttingen auch als dem ,Göttinger Literaturhaus' gesprochen. Die skandinavischen Einrichtungen nutzen bei ihrer Namensgebung unterschiedliche Varianten: In Kopenhagen begann LiteraturHaus - ohne Ergänzung des Stadtnamens; in Oslo nahm 2007 Litteraturbuset seinen Betrieb auf, ebenfalls ohne Attribut, gelegentlich ergänzt durch ,Oslo` oder ,i Oslo' [in Oslo]; noch inkonsequenter handhabt es Bergen mit Litteraturhuset [(i) Bergen]/Litthusbergen; in Göteborg agiert inzwischen Göteborgs Litteraturbus und in Kopenhagen zusätzlich Litteraturbuset ved V andkunsten. Die Zuordnung als Literaturhaus findet über die Bezeichnung eindeutig statt.

\section{Literatur und Haus}

Die literaturvermittelnde Einrichtung ist in der Regel in einem eigenen Gebäude situiert, sodass der Name ,Literaturhaus' wortgeschichtlich nachvollziehbar ist. ${ }^{37}$ Das Determinativkompositum ,Literaturhaus' enthält außerdem eine metaphorische Dimension, die sich für die Konzeption stark machen lässt. Als greifbares und unmissverständliches Bild kann das Literaturhaus der Literatur das symbolische ,Dach über dem Kopf' bieten. Semantisch ist dieser Metapher noch mehr zu entnehmen: Ein Haus bietet Schutz, Begegnung, Zugehörigkeit, Privatheit, als Heim ist es mit ,Heimat ${ }^{6}$ und ,Zuhause ${ }^{6}$ verknüpft. ${ }^{38}$ Nicht zufällig nutzt schon das skandinavische ,Volksheim' diese Bedeutungen. ${ }^{39}$ Sie lassen sich auf das Literaturhaus übertragen. All dies impliziert, dass diese Einrichtung ein Zuhause für die Literatur ist. Selbst ohne das Bild ausschweifend zu interpretieren, steckt darin die Vorstellung, dass das Literaturhaus ein Sammlungsort für Literatur und ihre Akteur*innen ist. Es ist nicht ausschließlich ein Ort für Autor*innen oder für Leser*innen, für Bücher oder für einen anderen Teilaspekt von Literatur, sondern für ihre Gesamtheit.

\footnotetext{
${ }^{37}$ Vgl. Kapitel I 5.7.

38 Thomas Wegmann legt eine Literaturgeschichte des Hauses vor, die für die vorliegende Arbeit im Detail zwar nicht relevant, für die Bedeutungsdimensionen von ,Haus' doch aufschlussreich ist, vgl. Wegmann 2016.

${ }^{39}$ Kritisch betrachtet Valeska Henze das schwedische Volksheim - Folkhemmet, vgl. Henze 1999, S. 6-25.
} 
Anders als bei Dichterhäusern spielt der Aspekt der Auratisierung beziehungsweise Re-Authentifizierung im Literaturhaus eine geringere Rolle. ${ }^{40}$ Das Literaturhaus wird nicht als sakraler Ort - als Tempel oder als Kirche - wahrgenommen. Auf der Handlungsebene weist das Literaturhaus vor allem in Skandinavien zwar Parallelen zur religiösen Praxis auf, da es als Ort gesellschaftlicher Debatten Funktionen, die vor allem in Skandinavien vormals von Gemeindezentren erfüllt wurden, übernimmt, doch lässt sich damit der Ort als solcher nicht als rituell überhöht interpretieren. Dass vor allem die älteren Literaturhäuser in Deutschland in Gründerzeitvillen und dadurch an historisch geprägten und prachtvollen Orten möglicherweise eine Schwelle für die Besucher*innen darstellen, trifft dennoch zu.

In der symbolischen Auslegung von ,Literaturhaus' ist zudem enthalten, dass es ,Hausherr*innen“ gibt. Als Gastgeberin fungiert die Organisationsstruktur, die den Ort als Veranstaltungsort gestaltet sowie Besucher*innen einlädt und empfängt. Die Gastlichkeit spielt in der Grundidee eine zentrale Rolle, wie die Integration eines Restaurants oder Cafés unterstreicht.

Mit der Eigenbenennung, Literaturhaus` markieren die Einrichtungen eine Zuordnung zu einem Begriff. Die weiteren geläufigen Bezeichnungen für familienähnliche literaturvermittelnde Einrichtungen setzen andere Akzente hinsichtlich ihrer Wirkungsabsicht. Beim ,Literaturbüro' schwingen Ordnung, Geschäft, Bürokratie, Verwaltung und Arbeit mit; ,Literarisches Zentrum' ist dagegen metaphorischer und nicht mit einem Bauwerk verknüpft, denn es impliziert eine Zusammenkunft, eine Bündelung, erinnert zum Beispiel an Forschungszentren, in denen vornehmlich Expert*innen konferieren. Außerdem bildeten sich ,Kulturzentren“ in Deutschland während kulturpolitischer Umbrüche der 1970er-/1980er-Jahre. Ein Kulturzentrum plädierte für Partizipation und Engagement der Bürger*innen. Bei Literaturvermittlungseinrichtungen, die sich ,Literaturbüro' oder ,Literarisches Zentrum‘/,Literaturzentrum' nennen, sind die Namen meistens mit der Genese der Einrichtungen begründbar, entweder, weil sie vor dem ersten Literaturhaus gegründet wurden oder weil sie zunächst in Abgrenzung zu den infrastrukturell breiter aufgestellten großstädtischen Literaturhäusern entstanden. ${ }^{41}$

Bemerkenswert ist in diesem Zusammenhang, dass sich in Skandinavien, nach dem Vorbild der ersten Einrichtung in Stockholm, bereits in den 1970er-Jahren kulturbus [Kulturhäuser] formierten. Inhaltlich entsprechen diese als schwellenlose Kulturorte gedachten Einrichtungen den deutschen Kulturzentren. Dies gilt es zu erinnern, wenn beobachtet wird, dass Anfang des 21. Jahrhunderts das ,Literaturhaus aus Deutschland importiert wird, denn mit dem kulturhus gibt es in den skandinavischen Ländern bereits eine kulturelle Institution, die sich als ,Haus' betitelt, die also unwillkürlich als Vergleichsobjekt herangezogen wird.

${ }^{40}$ Vgl. z. B. Autsch et al. 2005; Brenner-Wilczek und Singh (Hg.) 2008; Bohnenkamp und Vandenrath (Hg.) 2011.

${ }^{41}$ Vgl. Baumann 1995, S. 41. Die Ausführungen zum Literarischen Zentrum Göttingen veranschaulichen dies, vgl. Kapitel I 5.5, S. 79. 


\section{Ort und Akteur}

Wie im Bisherigen schon implizit enthalten, ist offensichtlich, dass mit ,Literaturhaus' sowohl das Gebäude beschildert wird, als auch der literaturvermittelnde Akteur bezeichnet wird und beides eng miteinander verknüpft ist. So erzählen beispielsweise Selbstdarstellungstexte die Geschichte des Literaturhauses anhand von Angaben zur historischen Nutzung des Gebäudes kombiniert mit Informationen zur Entstehung des Literaturvermittlers, an dessen Beginn meist eine Vereins- oder Stiftungsgründung steht. Die eigene Institutionsgeschichte vermengt sich oft mit einem Referat der historischen Bedeutung der Villa, der alten Schule oder der ehemaligen Kirche. ${ }^{42}$ Der polyvalente Gebrauch des Titels ,Literaturhaus', der gleichermaßen den Ort unter einer Adresse und den Literaturveranstalter mit regelmäßigem Programm benennt, kann zu Missverständnissen führen, wenn der Ort losgelöst von der Praxis betrachtet wird. Ein anschauliches Beispiel: Ein Gast kann im Literaturhaus Berlin gefrühstückt haben, ohne jemals etwas von einer Literaturveranstaltung gehört zu haben. ,Literaturhaus` kann also ein konkretes Gebäude, einen Raum mit Veranstaltungsangebot sowie einen Akteur der Literaturvermittlung benennen. Aus dem Kontext ergibt sich, welche Bedeutungsdimension jeweils gemeint ist.

\section{2 Forschungsumfeld und Methodendiskussion}

Das Literaturhaus vereint unterschiedliche Phänomene der Gegenwart unter einem Dach. Die Einbeziehung verschiedener Zugriffe ist der Überzeugung geschuldet, dass das Literaturhaus von unterschiedlichen Perspektiven aus betrachtet werden sollte. ${ }^{43}$ Im Folgenden werden einige Schwerpunktthemen und Forschungsrichtungen umrissen, die Einfluss auf die Konzeption der vorliegenden Arbeit haben.

\section{2.1 Monografien und Einzelstudien über Literaturhäuser}

Im deutschsprachigen Raum liegen neben einigen studentischen Abschlussarbeiten ${ }^{44}$ nur wenige ausführliche Analysen zum Literaturhaus vor. Herauszustellen sind vor allem drei Monografien, die jetzt lediglich kurz erwähnt werden, um sie später an geeigneter Stelle heranzuziehen.

Sonja Vandenrath fokussiert in ihrer Doktorarbeit über Private Förderung zeitgenössischer Literatur auf das Zusammenspiel von Finanzierung und Programmarbeit. Literaturhäuser untersucht sie exemplarisch für die Seite der Geförderten. Sie stellt die ökonomischen Zusammenhänge anschaulich und umfassend dar. Mit diesem

\footnotetext{
42 Vgl. Kapitel II 9.2.

43 Steffen Martus formuliert dies zu seinem Forschungsobjekt, Werkpolitik' auch explizit, vgl. Martus 2007b, S. 12.

${ }^{44}$ Online verfügbar oder von den Autor*innen erhalten lagen mir davon folgende Arbeiten vor: Kurzal 1997; Reuter 2000 sowie Martens 2005.
} 
Schwerpunkt leistet sie Grundlagenarbeit - auch für die vorliegende Arbeit, die diesen Bereich zwar berücksichtigt, jedoch nicht zum Hauptthema macht. ${ }^{45}$

Kerstin Juchem legt mit ihrer Dissertation im Bereich der Informationswissenschaften die erste Monografie vor, die Literaturhäuser schon im Titel explizit zum Schwerpunkt erklärt: Literaturbäuser, Literaturbüros und Literaturzentren im deutschsprachigen Raum. Eine Bestandsaufnabme. ${ }^{46}$ Aus der Überschrift geht ebenfalls hervor, dass die Autorin sich nicht auf Literaturhäuser beschränkt, sondern Literaturbüros und Literaturzentren integriert. Im Sinne der Zustandsbeschreibung ist das nachvollziehbar. Grundsätzlich interessant für die vorliegende Arbeit ist des Weiteren, dass sie unter anderem Webauftritte und -aktivitäten der Einrichtungen betrachtet. Die disziplinäre Verortung von Juchems Buch mag erklären, warum es sich hierbei jedoch in der Tat eher um eine statistische Bestandsaufnahme handelt und weniger um eine Interpretation und Kontextualisierung. Allerdings ist das Vorgehen in einigen Aspekten sehr fragwürdig. So erklärt sich beispielsweise nicht, inwiefern etwa die dortige Ermittlung des Mittelwerts der Gründungsjahre nützlich für die Analyse der Institution sein soll ${ }^{47}$ - wo es doch viel aussagekräftiger ist, in welcher Zeitspanne die Einrichtungen entstanden sind.

Susann Sophie Schmitt untersucht in ihrer Dissertation Nachwuchs für die Literatur informativ wie strukturiert Kinder- und Jugendprogramme ausgewählter Literaturbäuser Deutschlands, Österreichs und der Schweiz - so der Untertitel. ${ }^{48}$ Durch ihren Fokus auf die ,Jungen Literaturhäuser' trägt sie zu einem wichtigen Untersuchungsaspekt des Literaturhauses bei, der in der vorliegenden Arbeit nur marginal betrachtet bleibt. ${ }^{49}$

Ergänzend zu diesen drei aktuellen Studien ist für die historische Perspektive vor allem der 1988 erschienene Band Literaturwerkstätten und Literaturbüros in der Bundesrepublik - Ein Handbuch der Literaturförderung und der literarischen Einrichtungen der Bundesländer von Michael Basse und Eckard Pfeifer zu nennen. ${ }^{50}$ Darin zeichnen die Autoren die Geschichte der Einrichtungen nach, die aus heutiger Sicht durch die Literaturhäuser abgelöst wurden, die 1988 aber viel relevanter waren als das zu der Zeit einzige existente Literaturhaus Berlin. In dieser Richtung aufschlussreich ist zudem der Bericht Literaturförderung im kulturpolitischen Kontext Die Arbeit der Literaturbüros in Deutschland von Stefanie Baumann. ${ }^{51}$ Aus diesem geht besonders hervor, dass die Literaturbüros zunächst auf die Förderung von Autor*innen konzentriert waren, diese nach und nach in den Hintergrund geriet und „sich die Literaturbüros immer mehr zu einem modernen Dienstleistungsbetrieb für literarische Aktivitäten“"52 entwickelten und sich so funktionell den Literaturhäusern annäherten. ${ }^{53}$

\footnotetext{
45 Vgl. Vandenrath 2006.

46 Vgl. Juchem 2013.

47 Vgl. ebd., S. 42-43. Auch die Auswahl der Vergleichsobjekte - das Literaturhaus München und das Literaturbaus Nettersheim - ist aus wissenschaftlicher Sicht kaum gelungen, vgl. FN 436.

${ }^{48} \mathrm{Vgl}$. Schmitt 2016.

${ }^{49}$ Vgl. Kapitel II 11.1.

${ }^{50}$ Vgl. Basse und Pfeifer 1988.

51 Vgl. Baumann 1995.

52 Ebd., S. 7.

${ }^{53} \mathrm{Vgl}$. S. 79 sowie S. 149.
} 
Erwähnt sei außerdem die empirische Studie zur Literaturvermittlung in den fünf neuen Bundesländern zu Beginn des 21. Jabrbunderts von Stephan Porombka und Kai Splittgerber, die mit Interviews und Fragebögen arbeitete. Das Netəwerk der Literaturbäuser gab diese in Auftrag, um mehr über die Bedingungen für Literaturvermittlung und mögliche Literaturhäuser im Osten Deutschlands zu erfahren. Auf die Publikation folgte eine intensive, zum Teil kontroverse Diskussion der Ergebnisse, die ebenfalls dokumentiert ist. ${ }^{54}$

In Skandinavien, wo das Literaturhaus ein noch viel jüngeres Phänomen ist, setzt die Forschung zum Literaturhaus ebenfalls erst ein: Hier gibt es neben journalistischen Beiträgen bisher ebenfalls nur einige studentische Abschlussarbeiten. ${ }^{55}$

\section{2.2 Artikel zum Thema und Selbstreflexion}

Neben den genannten Arbeiten liegen vor allem Beiträge von Literaturhaus-Leiter*innen vor, die als „Dokumentationen institutionellen Selbstverständnisses“ “56 quellenkritisch behandelt werden müssen. „Den tatsächlichen Stellenwert der Einrichtung und deren Reichweite dokumentieren sie aber nur bedingt, da von den Institutionsleitern sicher nur eine beschränkt kritische Distanz zum eigenen Tun zu

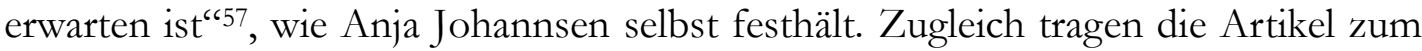
Beispiel von Herbert Wiesner ${ }^{58}$, Florian Höllerer ${ }^{59}$, Rainer Moritz ${ }^{60}$ und Anja Johannsen ${ }^{61}$, die alle ein Literaturhaus leiten beziehungsweise leiteten und Literaturwissenschaftler*innen sind - außer Wiesner alle sogar promovierte -, dazu bei, dass die Institution Literaturhaus zunächst in journalistischen Beiträgen, dann zudem im literaturwissenschaftlichen Diskurs vorkam und etwa schon relativ früh in Sammelbänden aufgenommen wurde. Sogar im Handbuch Kanon und Wertung ist das Literaturhaus mit einem Beitrag vertreten, was nicht nur seine Rolle in Kanonisierungs-

\footnotetext{
${ }^{54}$ Vgl. Porombka und Splittgerber 2010. Die erste Ausgabe erschien 2009. Im darauffolgenden Jahr kam eine um Stellungnahmen ergänzte Fassung heraus, denn einige von den in der Studie erwähnten oder direkt von ihr betroffenen Akteur*innen übten Widerspruch gegen die Ergebnisse der Studie, da sie sich falsch dargestellt fanden, und warfen ihr Ungenauigkeit vor.

55 Vgl. z. B. Gregersen 2014; Skaftnesmo 2014 sowie dieser Masterarbeit nachfolgend Skaftnesmo 2016; und eine Studie zu Literaturfestivals, die Nettverk for norske litteraturfestivaler [Netzwerk für norwegische Literaturfestivals] in Auftrag gegeben hat. Diese Studie fragt aber nach organisationalen Aspekten: „Samtidig som denne type formidling av litteratur øker, er det svært liten basiskunnskap om feltet, for eksempel hvor mange arrangementer som gjennomføres, hvor stor den samlede publikumsoppslutningen er, hvor mange forfattere som eksponeres, hvor store honorarene er, arbeidsinnsats knyttet til litteraturformidlingen, hvordan aktivitetene finansieres, osv.“, Ericsson und Rykkja 2015, S. 5. [Gleichzeitig mit dem Anstieg dieser Art von Vermittlung, findet sich relativ wenig Basiswissen über das Feld, zum Beispiel wie viele Veranstaltungen durchgeführt werden, wie groß der Publikumszuspruch insgesamt ist, wie viele Autor*innen präsentiert werden, wie hoch die Honorare sind, der mit der Literaturvermittlung verbundene Arbeitseinsatz, wie die Aktivitäten finanziert sind, u. s. w.]. Bei skandinavischen Zitaten stammen die Übersetzungen in Klammern in der gesamten Arbeit von der Verfasserin.

56 Johannsen 2012b, S. 182.

${ }^{57}$ Ebd.

58 Vgl. z. B. Wiesner 2000.

${ }^{59}$ Vgl. z. B. Höllerer 2007. Dieser Beitrag für die Publikation des Amtes für Auslandsbeziehungen wurde auf Englisch übersetzt, was die Rezeption über den deutschen Sprachraum hinaus ermöglichte.

${ }^{60}$ Vgl. z. B. Moritz 2009; Moritz 2013b; Moritz 2013 a.

${ }^{61}$ Vgl. z. B. Johannsen 2012b; Johannsen 2013a; Johannsen 2013b.
} 
prozessen beleuchtet, sondern für die eigene Etablierung spricht. ${ }^{62}$ Dass diese Akteur*innen den Gegenstand nicht grundsätzlich infrage stellen oder besonders kritisch beurteilen, um nicht gegen ihr eigenes Tätigkeitsfeld zu argumentieren, ist wenig überraschend. Ihr literaturwissenschaftlicher Hintergrund sorgt trotzdem dafür, dass das Literaturhaus sich als Forschungsgegenstand etablierte, denn die Verfasser*innen wissen ihren eigenen Arbeitsbereich wissenschaftlichen Ansprüchen folgend zu begutachten. Von diesen fundierten deskriptiven Artikeln profitiert die vorliegende Arbeit somit ebenfalls.

Die Literaturhaus-Verantwortlichen befassen sich zudem konkret mit ihrer Arbeitspraxis und reflektieren ihr Selbstverständnis und ihre eigene Rolle auf einer Metaebene. Dies geschieht vornehmlich auf internen Tagungen. ${ }^{63}$ Die dortigen Ergebnisse können fruchtbar sein für eine wissenschaftliche Untersuchung des Literaturhauses, zugleich mag eine beobachtende Perspektive von ,außen“ nützlich sein für die Praxis der Literaturhaus-Akteur*innen.

Als Beleg dafür, dass es den einzelnen Literaturhäusern nicht nur kurzfristig gesehen um den eigenen Erfolg geht, sondern ein Interesse an übergreifender Betrachtung besteht, dient, dass sie bestrebt sind, sich zu vernetzen und als LiteraturhausGruppe aufzutreten. Der Zusammenschluss von mehreren deutschen, österreichischen und schweizerischen Einrichtungen im Netzwerk der Literaturbäuser erhöht ihren potenziellen Einfluss, da sie gemeinsam sichtbarer sein und ihre Position in machtpolitischen Fragen stärken können. So unterstützt beispielsweise der Fernsehsender Arte den 2002 informell und 2008 als Verein gegründeten Zusammenschluss von Literaturhäusern. ${ }^{64}$ Neben dem erleichterten Austausch untereinander war dies ein zentraler Punkt bei der Vereinigung unter einem symbolischen Dach. ${ }^{65}$

\section{Selbstreflexion - Eigene Rolle}

Grundsätzlich gilt, Jürgen Joachimsthaler zufolge, für die Gegenwartsforschung, dass jede*r Beobachter*in dem Objektbereich ,Gegenwartsliteratur ${ }^{\star}$ angehört. Aus diesem Grund münde die Forschung wie die Literatur selbst häufig in Reflexionsschleifen. ${ }^{66}$ So ist die Literaturwissenschaft selbst, wie Anja Johannsen klarstellt, „als entscheidender, aber natürlich nicht unabhängiger Bestandteil eines dynamischen Geflechts" ${ }^{\text {667 }}$, das der Literaturbetrieb darstellt, zu verstehen. Allerdings wirken Literaturwissenschaftler*innen vor allem im universitären Bereich, in dem sie mit an-

\footnotetext{
${ }^{62} \mathrm{Vgl}$. FN 61.

${ }^{63}$ Beispielsweise fand im November 2014 im schweizerischen Lenzburg ein Zusammentreffen zur Zukunft des Literaturhauses statt, im Januar 2015 lud das Literaturhaus Frankfurt zu einem Kongress der Veranstalter ein. In Österreich konferierten Beteiligte im Herbst 2016, daraus entstand ein eher anwendungsorientierter Sammelband, der dennoch zum Verständnis des Literaturveranstaltungsbetriebs beiträgt, vgl. Bernhofer et al. (Hg.) 2016. Europäische Konferenzen fanden bereits etwa in Oslo und London statt. Das Netəwerk der Literaturbäuser plant für 2020 eine große internationale Tagung zu diesem Themenkomplex.

${ }^{64}$ Die Mitgliederzahl schwankt durch Erweiterung und Austritte manchmal, im Sommer 2018 waren diese Häuser vertreten: Jeweils das Literaturhaus in Basel, Berlin, Frankfurt, Hamburg, Köln, Leipzig, Rostock, Salzburg, Stuttgart, Wien, Wiesbaden, Zürich, Literarisches Colloquium Berlin und Literarisches Zentrum Göttingen.

${ }^{65}$ Zum Netzwerk der Literaturbäuser e. V. vgl. z. B. S. 146 sowie S. 300.

${ }^{66}$ Vgl. Joachimsthaler 2016, S. 273-274.

67 Johannsen 2010, S. 108.
} 
deren Codes und Herangehensweisen agieren als die Mitarbeiter*innen in einem Verlag, einer Buchhandlung oder einem Literaturhaus, die nicht einem Forschungsinteresse, sondern konkreten Unternehmenszielen folgen. Von Vorteil für die Untersuchung eines Literaturbetriebsakteurs ist es deshalb, sowohl in literaturwissenschaftlicher wie in davon abweichender literaturbetrieblicher Praxis versiert zu sein, damit der Gegenstand mit literaturwissenschaftlicher Brille zwar, doch vor literaturbetrieblichem Hintergrund betrachtet werden kann. Dazu ist Selbstreflexion nötig, die jedoch nicht in Endlosschleifen verweilen muss.

So muss ich als Verfasserin dieser Arbeit meine eigene Position reflektieren. Neben früheren Tätigkeiten im Bereich des Forschungsobjektes ist insbesondere zu erwähnen, dass ich im Juni 2016 eine Stelle im Literaturbaus Hamburg annahm und seitdem bis auf Weiteres dort für die Kommunikation zuständig bin. Von einem gewissen „institutionellen Selbstverständnis“ bin also auch ich nicht gänzlich frei. Doch obwohl ich in einer Rolle Literaturhaus-Mitarbeiterin bin, entstand diese Arbeit in der Funktion als Promovendin. ${ }^{68}$ Meine Analysen basieren auf empirischen Daten, die für andere nachvollziehbar sind. Außerdem war erstens das Forschungsdesign der vorliegenden Studie vor meinem Eintritt in die Literaturhaus-Praxis fixiert und zweitens endet der Hauptuntersuchungszeitraum Ende 2015, also deutlich bevor ich selbst dort aktiv wurde. Durch meine Teilnahme erfuhr ich von Zusammenhängen, die einer externen Kundschafterin verborgen bleiben würden. Dabei handelte es sich um eine offene Beobachtung. Gespräche mit LiteraturhausAkteur*innen brachten wertvolle Einsichten, ohne die Unabhängigkeit der Forschung infrage zu stellen.

\section{2.3 Literaturvermittlung und Literaturbetriebsforschung}

Literaturvermittlung ist, das wird schon im Titel deutlich, zentral für diese Untersuchung des Literaturhauses. Er legt keine besondere Forschungsperspektive nahe, sondern richtet den Blick auf die Aktivitäten und Akteur*innen, die mit Literatur etwas tun. ${ }^{69}$ Literaturvermittlung ${ }^{6}$ umfasse, Matthias Beilein zufolge, alle Prozesse, mit denen Literatur im weitesten Sinne vermittelt werde. Dabei stünden weniger Texte selbst im Vordergrund, sondern die Akteure und deren Handeln. ${ }^{70}$ Die Betonung der Handlungen lässt sich auf Siegfried J. Schmidt zurückführen, der in seiner

\footnotetext{
68 Außerdem sei daran erinnert, dass andere Wissenschaften ausgehend von der Anthropologie beziehungsweise Ethnologie sich schon lange innerhalb der empirischen Sozialforschung mit dem Dilemma des Going native und den Herausforderungen der teilnehmenden Beobachtung befassen, vgl. z. B. Wolff 2013, besonders S. 340-341.

${ }^{69}$ Diese Perspektive nimmt ebenfalls die Ende der 1980er-, Anfang der 1990er-Jahre aufkommende und Ende des 20. Jahrhunderts konsolidierte Kulturbetriebslehre ein, vgl. Klein 2011a, S. 1. Dies zeigt sich unter anderem daran, dass Kulturmanagement als Studienfach im deutschsprachigen Raum in dieser Zeit erstmals unterrichtet wurde, vgl. ebd., S. 2. Einen Überblick über einschlägige Bände zur Kulturbetriebslehre bietet Armin Klein in seiner Einleitung zu einem ebenfalls gut bündelnden Sammelband an, vgl. ebd., S. 5-6. Für die Analyse einer konkreten Einrichtung bietet dieser theoretische Vorstoß zwar keine Hilfsmittel, doch ist ihre Position als Interdisziplin ein Gewinn der Kulturbetriebslehre. Tasos Zembylas argumentiert in diesem Rahmen für eine Verknüpfung von ökonomischen, soziologischen und kulturwissenschaftlichen Ansätzen, vgl. Zembylas 2004. Auf den Literaturbetrieb bezogen hat dies Porombka 2006.

${ }^{70} \mathrm{Vgl}$. Beilein 2013, S. 585.
} 
Theorie der kommunikativen Handlungsrollen die Bereiche Produktion, Vermittlung, Rezeption und Verarbeitung differenziert. Er umfasst mit seiner „Theorie Literarischer Vermittlungshandlungen [...] alle diejenigen Handlungen (samt deren Kontexten), in deren Verlauf bzw. durch die Literarische Kommunikate Rezipienten und Kommunikationsverarbeitern zugänglich gemacht werden" ${ }^{\text {" } 71}$. Ohne sein analytisches Verfahren der empirischen Literaturwissenschaft detailliert auf das Literaturhaus anzuwenden, sei jedoch erwähnt, dass damit der Aspekt der Aktivitäten sichtbar wird, die für die Untersuchung ebenfalls zentral sind. Noch besser geeignet als die Bezeichnung ,Handlung` erscheint inzwischen ,Praktik zu sein, da diese verinnerlichte und unbewusster vollzogene Handlungen, jene hingegen intentionaler und einzelnstehender sind. ${ }^{72}$ Mit ,Praxis' sei ein Bündel von Praktiken bezeichnet, die inkorporierte Handlungen sind. Praktiken werden „überwiegend im Modus des Gewohnten und Selbstverständlichen" "73 vollzogen.

Unterschieden werden kann ferner innerhalb dieser Auslegung von ,Literaturvermittlung ' zwischen der stärker ökonomisch orientierten Distribution und der eher inhaltsfokussierten Mediation. Für die Untersuchung des Literaturhaus ist ,Literaturvermittlung in einem engeren Sinne als Mediation, als Verbindung von Inhalt und Konzept, nützlich, die insbesondere mittels Literaturveranstaltungen vollzogen wird.

,Literaturbetrieb“ bezeichnet ein dynamisches Gebilde mit „Wechselwirkungen

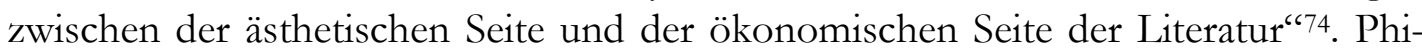
lipp Theisohn und Christine Weder stellen dieses in den Fokus ihres Sammelbandes:

Solche Reflexion zielt letztlich auf eine Poetologie des Betriebs, auf einen Versuch, das Verhältnis zwischen Poiesis und Warenform genauer zu bestimmen, es offensiv aufzunehmen und zu steuern. Weil es sich um ein Verhältnis handelt, wäre umgekehrt auch kurzschlüssig, Literatur in Zeiten des neuen oder neuesten Buchhandels einfach als Betrieb, als reinen Effekt des Betriebes zu beschreiben. Vielmehr ist zwischen der Literatur als Kunstform und ihrer betrieblichen Prozessualisierung ein komplexes Beziehungsgeflecht entstanden, das es verunmöglicht, die eine Seite von der anderen zu trennen oder die eine mit der anderen zu identifizieren. ${ }^{75}$

,Literarisches Leben' oder ,Literarisches Feld' werden häufig synonym für ,Literaturbetrieb، verwendet. Im Gegensatz zum durch Bourdieu theoretisch fundierten ,Literarischen Feld‘ bietet ,Literaturbetrieb‘ mehr Offenheit, da er nicht Teil eines größeren Bezugsmodells ist. ,Buchmarkt‘ wird in der vorliegenden Arbeit nicht völ-

\footnotetext{
${ }^{71}$ Schmidt 1980, S. 234. Vermittlung heißt bei Schmidt in diesem Zusammenhang eher Weiterleitung, da kein neues Produkt entsteht.

${ }^{72}$ Grage und Schröder fassen es beispielsweise so: „Als Handlung (skandinavisch: handling) wird der historisch singuläre, flüchtig-transitorische, prinzipiell kontingente performative Akt in seinem Ereignismodus bezeichnet“, Grage und Schröder 2012, S. 25, Hervorhebung im Original. Hillebrandt ergänzt dazu: „Praktiken sind also immer materiell, das heißt sie sind in ihrem Vollzug immer mit Körpern und Dingen verbunden. Sie sind zudem nur als Folgepraktiken vorstellbar. Sie können nicht voraussetzungslos, also quasi aus dem Nichts entstehen. Sie ereignen sich im Anschluss an bereits geschehene Praktiken und erzeugen nun gerade dadurch eine Praxis als Vollzugswirklichkeit, die sich aus der Verkettung von Einzelpraktiken als Ereignisse bildet", Hillebrandt 2014, S. 11.

73 Schmidt 2013, S. 14.

${ }^{74}$ Beilein 2013, S. 585.

75 Theisohn und Weder 2013, S. 10. In diesem Zitat deutet sich auch an, dass der Literaturbetrieb als Praxis der Autonomie im Zuge der Autonomisierung des Schriftstellers entstanden ist, vgl. z. B. Jürgensen und Kaiser 2011, S. 15.
} 
lig gleichbedeutend mit ,Literaturbetrieb“ eingesetzt. Der Buchmarkt ist als der auf ökonomische Aspekte fokussierte Teil des Literaturbetriebs zu verstehen. Beim Gebrauch von ,Buchmarkt' steht meist der Marktaspekt von Büchern im Fokus. Literaturveranstaltungen, die nicht vorrangig als Werbeveranstaltungen des Verlages zu interpretieren sind, gehören mehr zum Literaturbetrieb. Im Folgenden ist neben ,Literaturbetrieb“ von ,Literaturveranstaltungsbetrieb` die Rede.

Das Literaturhaus ist eine literaturvermittelnde Institution auf zwei Ebenen: Erstens präsentiert es konkrete einzelne literarische Texte und fungiert als Intermediär zwischen Autor*in, Verlag und Publikum. Über die Summe der Einzelveranstaltungen, die in den Programmen präsentiert wird, zeigt sich so, was Literatur ist beziehungsweise sein kann. Zweitens vermittelt es allgemeiner Literatur, denn die Bezeichnung ,Literaturhaus' impliziert, dass das, was dort geschieht, auf irgendeine Weise mit Literatur zu tun hat und Literatur ein Platz in der Stadt zuerkannt wird.

\section{2.4 Gegenwartsliteraturforschung und Praxeologie}

Bei der Untersuchung des Literaturhauses zu berücksichtigen ist, dass es sich um einen dynamischen Gegenstand handelt, wie die Arbeiten etwa von Vandenrath, Juchem und Schmitt belegen und die Erfahrung an der vorliegenden Arbeit zeigt. Vandenraths 2006 veröffentlichtes Buch und Schmitts 2016 publizierte Studie betrachten nur die dem Netzwerk der Literaturhäuser zugehörigen Einrichtungen und teilen ihnen eine „Sonderstellung“76 zu. Das Netzwerk ist jedoch in Bewegung und die Ausbreitung des Literaturhauses erreicht nicht - wie Schmitt annimmt - 2003 „vorerst ihren Endpunkt“"77, den schon Vandenrath mit der Eröffnung des Stuttgarter Hauses 2001 vermutet. $^{78}$ Ein weiteres Beispiel ist, dass Sonja Vandenrath erwähnt, dass die Überlegungen seitens der Städte Essen und Dortmund, „ein gemeinsames Literaturhaus für das Ruhrgebiet zu gründen, nach kurzer Zeit wieder versandeten"79 - was insofern nicht mehr stimmt, als die Stadt Dortmund inzwischen eine eigene Variante eines Literaturhauses eröffnet hat. Derartige stetig veraltende Informationen lassen sich bei einem tagesaktuellen Gegenstand wie dem Literaturhaus nicht vermeiden. Die vorliegende Studie, die sehr viele organisationale wie programmatische Aspekte integriert, riskiert, um umfassend auf das Forschungsobjekt einzugehen, somit Lücken und Überholungen. Zwar wurde der Untersuchungszeitraum vor allem für die im zweiten Kapitel durchgeführten Programmanalysen auf Ende 2015 eingegrenzt, doch fließen - sofern realisierbar - Aktualisierungen mit ein, um möglichst nah am aktuellen Stand zu bleiben. ,Der aktuelle Stand ${ }^{\text {' }}$ - das heißt in diesem Fall Sommer 2018.

Mit den methodischen Herausforderungen, sich einem dynamischen Forschungsobjekt zu nähern, befassen sich auch Arbeiten, die der Gegenwartsliteraturforschung zuzuordnen sind. ${ }^{80}$ Wie etwa Carlos Spoerhase darlegt, galt früher, Ge-

\footnotetext{
${ }^{76}$ Schmitt 2016, S. 28.

${ }^{77}$ Ebd.

78 Vgl. Vandenrath 2006, S. 197.

${ }^{79}$ Ebd.

${ }^{80}$ Vgl. z. B. Bierwirth et al. (Hg.) 2012; darin etwa die Beiträge von Beilein 2012; Dürr 2012 und Johannsen 2012a. Zur teilweise uneindeutigen Verwendung und unterschiedlichen Periodisierung von,Gegen-
} 
genwartsliteratur nicht als Sache der Literaturwissenschaft zu betrachten, sondern sie dem journalistischen literaturkritischen Bereich zuzuordnen. Dies habe sich in den letzten Jahren stark verändert, es sei in der Literaturwissenschaft eine zunehmende Beschäftigung mit Gegenwartsliteratur beobachtbar. ${ }^{81}$

Die Gegenwartsliteraturforschung ist für die vorliegende Untersuchung zudem in einer anderen Richtung relevant, nämlich hinsichtlich der „offensichtlichen Relevanz der Literaturwissenschaft als Umwelt der Literatur" ${ }^{\text {"82, }}$, wie Steffen Martus es formuliert. „Normalerweise ist die Selbstauslegung des Dichters eine kontrafaktische Imagination“"83, doch durch die Gegenwärtigkeit der Autor*innen komme es „zu einer Vermehrung des vom Autor verbürgten Wissens über sich und seine literarische Produktion." 84 Einrichtungen wie das Literaturhaus, wo Autor*innen und Rezipient*innen direkt aufeinandertreffen und über Literatur sprechen, fördern dies ausdrücklich. Auf diese Weise entstehen weitere Zugänge zu literarischen Werken. Teilweise produzieren die Literaturwissenschaftler*innen, beispielsweise, wenn sie selbst Literaturveranstaltungen moderieren, diese Quellen selbst. Dies könne, so Spoerhase, zu „einer prekären Verschränkung von Beobachtung und Teilnahme und $\mathrm{zu}$ einer unkontrollierten Aufwertung autorzentrierter Interpretationsverfahren" ${ }^{85}$ führen. Zu Recht plädiert etwa Norbert Otto Eke für eine Beschäftigung mit einer Literatur der Gegenwärtigkeit, die der „Selbstpositionierung der Autoren in

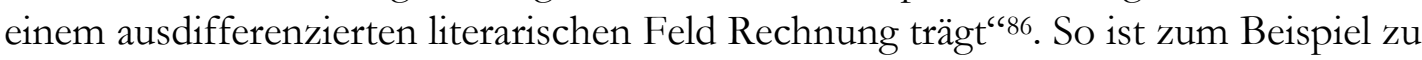
berücksichtigen, dass die eingeladenen Autor*innen häufig selbst Literaturwissenschaft studiert haben und somit der dortigen Praxis entsprechend über ihre Texte sprechen können. ${ }^{87}$

„Die Literatur der Gegenwart, die Literaturkritik sowie die Literaturwissenschaft stehen immer in einem sich reziprok beeinflussenden, dynamischen Verhältnis zueinander." 88 Die Tatsache, dass Einrichtungen wie Literaturhäuser personenfokussierte Zugänge zu Texten unterstützen, wirkt sich also einerseits auf die Literaturwissenschaft aus. Andererseits trägt eine sich intensiver mit Praktiken beschäftigende Literaturwissenschaft dazu bei, die Praktiken aufzudecken und ins Bewusstsein zu rufen.

\footnotetext{
wartsliteratur' vgl. Eke 2012, S. 29-33. In diesem Artikel macht er auch auf den Unterschied von,Gegenwartsliteratur' als Forschungsperspektive und als Forschungsgegenstand aufmerksam. Zum Verhältnis von Gegenwartsliteratur und Literaturwissenschaft vgl. Spoerhase 2014.

81 Vgl. Spoerhase 2014, S. 15.

82 Martus 2007a, S. 13. Dabei sollte allerdings nicht von „(Selbst-)kanonsierung“ die Rede sein, da Kanonisierungsprozesse als komplexe Prozesse erachtet werden sollten, die nicht auf diese Weise steuerbar sind, vgl. Kapitel II 14.2 .

83 Spoerhase 2014, S. 20.

${ }^{84}$ Ebd., S. 21.

85 Ebd., S. 22.

${ }^{86}$ Eke 2012, S. 37.

${ }^{87}$ Vgl. Spoerhase 2014, S. 22. Vgl. auch FN 304 und Kapitel II 14.1.

88 Johannsen 2010, S. 118.
} 


\section{Praxeologischer Blick}

Die vorliegende Arbeit versteht sich als Beitrag zu einer praxeologischen Literaturgeschichtsschreibung. ${ }^{89}$ Die Praxeologie „,bemüht sich um Empirisierung des theoretischen Blicks und setzt theoretische Konzepte fortlaufend empirischen Verunsicherungen aus. “90 Sie untersucht die „Praxis als Vollzugswirklichkeit ${ }^{\text {"911 }}$. Über die Situierung in diesen Forschungskontext wird deutlich, dass die Betrachtung von Organen der Literatur nicht nur mit den eigentlichen Objekten literaturwissenschaftlicher Forschung untrennbar verbunden ist, sondern auch, dass diese genauer untersucht werden müssen, um ihre Bedeutung nicht nur zu konstatieren, sondern um darüber zu weiterführenden Aussagen zu kommen. ${ }^{92}$ Zugrunde liegen diesen Überzeugungen Arbeiten wie die von Pierre Bourdieu, „eine der wichtigsten aktuellen Symbolfiguren einer am Praxisbegriff orientierten Soziologie“93. Darüber, dass seine Darstellungen „die wissenschaftliche Grundausstattung [...] liefern“"94 und für den konkreten Fall jeweils modifiziert werden müssen, besteht schon lange wissenschaftlicher Konsens. ${ }^{95}$ Die vorliegende Arbeit ist keine Theoriearbeit, sondern geht, fußend auf der mit dem unter anderem durch Bourdieus Arbeiten und deren Rezeption geschaffenen Verständnis soziologisch geprägter Literaturwissenschaft, den Forschungsgegenstand stärker induktiv an. Hier dienen vor allem die von den Einrichtungen selbst publizierten Texte dazu, interne Mechanismen sichtbar zu machen, und so auf die Praxis des Literaturhauses zu schließen. Diese Analyse trägt als ein Anwendungsbeispiel zur Frage literaturwissenschaftlicher Gegenwartsforschung bei, indem sie einen Vorschlag liefert, wie Praktiken untersucht werden können. Mittels der Programmhefte und Websites können unter anderem unterschiedliche Bestandteile einer Literaturveranstaltung - etwa der Lesungspart oder das Gespräch

${ }^{89} \mathrm{Vgl}$. Spoerhase und Martus 2009. Dabei ist die Praxeologie als Reflexionsangebot zu verstehen. Diese Gedanken sind maßgeblich auf ein Forschungsseminar mit Anja Johannsen und Steffen Martus in Göttingen am 07.03.2016 zurückzuführen, dafür sei den Leiter*innen gedankt. Erhellend in Bezug auf die Praxeologie waren auch die Gespräche mit Friederike Schruhl, auf deren entstehende Dissertation zu praxeologischen Perspektiven auf die Wissenschaftsgeschichte von Digital Humanities und Literaturwissenschaft hingewiesen sei, vgl. Schruhl 2020.

${ }^{90}$ Schmidt 2013, S. 16.

91 Hillebrandt 2014, S. 12.

92 Vgl. Beilein 2012, S. 45.

${ }^{93}$ Hillebrandt 2014, S. 10.

94 Wittmann 1983, S. 45. Reinhard Wittmann beispielsweise liefert bereits 1983 eine differenzierte Auseinandersetzung unter dem Titel Die Schriftsteller und das literarische Kräftefeld. Es bildet ein umfangreiches Kapitel in der gemeinsam mit Holger Funk veröffentlichten Untersuchung zu Literatur-Hauptstadt: Schriftsteller in Berlin beute, die eine empirische Arbeit darstellt. Dafür wurden Fragebögen mit ökonomischen, organisationalen und ästhetischen Kriterien, die von Berliner Autor*innen beantwortet wurden, ausgewertet, vgl. Funk und Wittmann (Hg.) 1983.

${ }^{95}$ Beispielsweise exemplifiziert Pierre Bourdieu seine Theorie des literarischen Feldes anhand der Situation in Frankreich im 19. Jahrhundert und unterteilt dieses in die Pole der reinen Produktion und der Massenproduktion. Um sein Modell zu nutzen, muss es entsprechend an die Gegebenheiten des untersuchten Feldes angepasst werden. Das Aufbrechen der klaren Trennung von Massenmarkt und avancierter Literatur ist für eine gegenwärtige Analyse zum Beispiel unabdingbar. Ebenso lässt sich das literarische Feld nicht mehr klar von anderen Feldern trennen, ökonomisch motivierte Handlungen finden parallel zu ästhetischen Entscheidungen statt. Ein Beispiel für eine gelungene Modifikation der Theorie unternimmt Nina Tessa Zahner in ihrer Dissertation über Andy Warhol und den Umbau des Kunstbetriebs im 20. Jahrhundert. Auch wenn es bei ihr um das künstlerische Feld der USA ab den 1960er-Jahren geht, so sind Übertragungen auf die Literaturhaus-Situation naheliegend. Sie beschreibt die Überschneidungszone der beiden bei Bourdieu dichotomischen Feldpole und erkennt darin das Subfeld der erweiterten Produktion, vgl. Zahner 2006, S. 241. 
über das Buch - beleuchtet werden. Details und Hintergründe lassen sich, wie sich zeigt, auf diese Weise allerdings nur bedingt erfahren, denn grundlegendes Praxiswissen, das die Akteur*innen sich mit der Zeit aneignen, wird in diesen Texten nicht dauernd erklärt. Für praxeologisch orientierte Arbeiten ist es folglich von Vorteil, wenn die Forschenden selbst teilnehmen und ihr implizites Wissen im Kontext reflektieren. Interviews und Beobachtungen können das dann gut ergänzen.

\section{2.5 Materiallage - Umgang mit den Archivbeständen}

Obwohl Einrichtungen wie das Literaturhaus von der Wissenschaft in eher literatursoziologischen Studien als entscheidender Faktor für die Gegenwartsliteratur durchaus erkannt werden, bilden sie noch relativ selten selbst den Forschungsgegenstand. Dass die ,literarischen Institutionen' bislang nur selten empirisch beforscht wurden, führt Jutta Ernst unter anderem darauf zurück, dass „die für konkrete Aussagen notwendigen Dokumente mitunter nicht zugänglich sind" ${ }^{\text {"96 }}$. In dieser Hinsicht bietet das Literaturhaus eine gute Chance, denn die Literaturhaus-Akteur*innen stehen wissenschaftlichen Annäherungen grundsätzlich aufgeschlossen gegenüberstehen und stellen Archivmaterial, sofern vorhanden, zur Verfügung. Es gilt trotzdem, dass für konkrete Aussagen notwendige Dokumente teilweise gar nicht archiviert sind.

Bei der Recherche in den Literaturhäusern wird schnell klar, dass diese keine Arbeit in gut organisierten Archiven ist, sondern, dass diese Materialsuche gleichsam daran mitwirkt, überhaupt erst die Zettelkästen zu öffnen und Programmrestbestände zu sortieren. Persönliche Briefe und alte Korrespondenzen, die für eine gröBere Objektivität durch Zeitgenossenschaft ausgewertet werden müssten, sind in der Regel nicht archiviert. Hinzu kommt, dass oft eine konsequent umgesetzte Systematik fehlt, weshalb das Material eine gewisse Willkür birgt. Analysen, die auf Archivmaterial beruhen, können selbstverständlich nur das abbilden, was tatsächlich zu finden ist. Fehlende Dokumente im Literaturhaus-Archiv müssen nicht unbedingt bedeuten, dass ihnen keine Relevanz zugeschrieben wurde oder dass sie absichtlich nicht aufbewahrt wurden. Die Anfangsjahre sind in der Regel für die Nachwelt nur nachvollziehbar, wenn die Beteiligten Geschichten, die aufbewahrte Schriftstücke erklären, erzählen. Sie kennen die persönlichen Verbindungen, die hinter Programm- und Personalentscheidungen steckten, und die Entstehungsgeschichten all das, was für Außenstehende anhand der Schriftstücke kaum nachvollziehbar ist.

Da die meisten Akteur*innen oft noch in den Literaturhäusern wirken oder zumindest noch nicht gestorben sind, waren Zeitzeugeninterviews für die vorliegende Arbeit denkbar. Da diese jedoch keine kleinteilige Genealogie der Einzeleinrichtungen nachzuzeichnen bestrebt ist, wird auf ausführliche Interviews verzichtet, zumal diese ebenfalls nur rekonstruierend stattfinden können. Die Geschichte der Literaturhäuser ist dennoch in hohem Maße eine Geschichte von Personen und deren Interessen, was stetig mitzudenken ist.

Einen großen Teil des Untersuchungsmaterials bilden die Programmhefte, die bisher noch nicht untersucht worden sind. Dazu waren zunächst eine Samlung und

${ }^{96}$ Ernst 2008, S. 321. 
ausgiebige Sichtung der Druckprodukte notwendig. Die Sortierung und Sondierung dieses umfänglichen Korpus ${ }^{97}$ ist nicht zu trennen von seiner Interpreation, da keine vorhergehende Studie auf diesen Anwendungsfall applizierbar war. Die Identifikation der für die übergeordnete Fragestellung relevanten Analyseaspekte bildete einen großen Teil der Arbeit an dieser Dissertation. ${ }^{98}$ Dass sich diese Arbeit vor allem in der Literaturwissenschaft verortet, zeigt sich bei der Wahl der Analysemomente und dem Zugang zum Material. ${ }^{99}$ Das zweite Kapitel ist Ergebnis einer intensiven Beschäftigung mit den Literaturhäusern generell, mit Forschungsarbeiten zum Thema und besonders mit konkretem Material aus der 30-jährigen Geschichte der Institution. Die Analyse liefert materialgestützte Bekräftigungen von Bekanntem, von Annahmen, die bisher nicht empirisch belegt wurden. Die Auseinandersetzung mit acht Fallbeispielen, ihren konkreten Publikationen und den Websiteauftritten ermöglicht, die Funktionen von Literaturhäusern in der Literaturvermittlung der Gegenwart zu rekonstruieren und kulturübergreifend zu vergleichen.

\section{3 Institution Literaturhaus}

Das Interessante an den Literaturhäusern ist, dass sie miteinander in einem Verweisgeflecht stehen. Aus diesem lässt sich ein Gesamtkonzept herausarbeiten. Diese von den Einzelfällen abstrahierende Form wird im Folgenden als ,Institution“ bezeichnet. Gewinn des damit verknüpften Konstrukts der Institution Literaturhaus ist es, (1.) dass der Professionalisierungsprozess und die Ausweitung nach Skandinavien beschreibbar sind; (2.) dass die Strukturierung des Literaturhauses als kollektiver Akteur und, (3.) als abstrakter kollektiver Akteur, der aus Einzeleinrichtungen besteht, sichtbar wird. Insbesondere die Betrachtung auf einer Mesoebene ist hilfreich für die Analyse des Literaturhauses als Einzelfall und als Teilhaber an gesamtgesellschaftlichen Prozessen. Über die Institution Literaturhaus können diese Prozesse gut sichtbar gemacht werden, weil sie ihrerseits einen Rahmen bietet und sich nicht nur nach privaten, sondern auch nach überindividuellen Handlungszielen richtet. Das ,Große' wird quasi im ,Kleineren“ abgebildet. (4.) Es ist hilfreich, dass sich so die für die Institution typischen Funktionen und die weiterführenden Aufgaben aufzeigen lassen. Konstitutiv für die Institution Literaturhaus ist, dass sie abstrakter kollektiver Akteur ist, der durch ein Zusammenspiel von Praktiken bestimmt ist. Es erscheint gerade fruchtbar, das Literaturhaus nicht nur als intentional handelnden Akteur zu begreifen, sondern die eigenen Regeln/Konventionen und die Infrastrukturen für das Vollziehen der ihm eigenen Praktiken zu integrieren. (5.) Darüber offenbart sich die notwendige Kontextualisierung von Prozessen. (6.) Die Bündelung dieser auf unterschiedlichen Analyseebenen angeordneten Aspekte unter ,Instituti-

\footnotetext{
${ }^{97}$ Vgl. FN 891.

${ }^{98}$ Die verschiedenen Untersuchungsdimensionen werden zusammen mit der Präsentation der Ergebnisse ausgeführt, um Wiederholungen zu reduzieren.

${ }^{99}$ Mehr zum Vorgehen und der Materialauswahl vgl. vor allem Kapitel II 10.1 und II 10.2. Mit vornehmlich literaturwissenschaftlichen Instrumenten, etwa Textanalysen mit Wortfeldanalysen, werden ebenfalls ausgewählte Selbstdarstellungstexte betrachtet, vgl. Kapitel II 9.
} 
on' illustriert gleichzeitig ihre Verflechtung, die sich in der Darstellung der vorliegenden Arbeit spiegelt und die sich als produktiv für die Erfassung des Gegenstandes erweist. (7.) Mit dem Ausdruck ,Institution` ist außerdem die teilöffentliche Finanzierung der Literaturhäuser angedeutet. All dies wird im Folgenden ausgeführt.

\section{| 3.1 Institutionsbegriff}

Das Literaturhaus Frankfurt bezeichnet sich auf seiner Internetseite kommentarlos als Institution. ${ }^{100}$ Als ,Institution' betitelt zu werden, kann im alltäglichen Gebrauch positiv konnotiert sein, aber auch - oft ideologiekritisch - Synonym für hegemoniale Machthaber beziehungsweise die Eindämmung innovativer Potentiale sein. ${ }^{101}$ „In Stein gefügte Einrichtungen" 102 nennen die Autoren der provozierenden Thesen zu Der Kulturinfarkt: Von allem zu viel und überall das Gleiche ${ }^{103}$ Institutionen - was zunächst einigermaßen neutral formuliert ist. Inkludiert in diese Begriffsauslegung ist die Annahme, dass Institutionen langsam entstehen und für Stabilität stehen. Diese Kontinuität wird von Kritiker*innen als ,Schwerfälligkeit', von Befürworter*innen als ,Zuverlässigkeit' ausgelegt. Sofern es nicht um dezidierte Kritik geht, zeugen die Beispiele von einer unreflektierten, weil verinnerlichten Benutzung der Bezeichnung. Deshalb lohnt es sich zu fragen, was eigentlich mit ,Institution“ gemeint ist.

Die alltagssprachliche Benutzung von ,Institution' wird abgeglichen mit wissenschaftlichen Verwendungen anderer Disziplinen, insbesondere der Sozialwissenschaften und Volkswirtschaftslehre, die sich, zwar nicht konsensuell, doch umfassend mit der Begriffsgeschichte und dem Begriff auseinandersetzen. Keinesfalls können oder sollen an dieser Stelle alle Ansätze dieser zentralen Vokabel der Gesellschafts- und Wirtschaftswissenschaften ausführlich diskutiert werden, sondern die für die vorliegende Arbeit nutzbaren Aspekte zielorientiert identifiziert werden.

Es lassen sich, verkürzt gesagt, zwei grundlegende Verständnisse erkennen, die sich im Alltagsgebrauch akkumulieren, wie der Duden bezeugt: „1. einem bestimmten Bereich zugeordnete gesellschaftliche, staatliche, kirchliche Einrichtung, die dem Wohl oder Nutzen des Einzelnen oder der Allgemeinheit dient; 2. (besonders Soziologie) bestimmten stabilen Mustern folgende Form menschlichen Zusammenle-

\footnotetext{
100 Vgl. II 9.2, S. 227.

${ }^{101} \mathrm{Zu}$ berücksichtigen ist in diesem Zusammenhang, dass Institutionen häufig öffentlich beziehungsweise teilöffentlich sind. Das ändert entscheidend etwas an den Aufgaben und Pflichten. Da die hier untersuchten Literaturhäuser jedoch offiziell alle unabhängig tätig sind, wird das Literaturhaus nicht ausführlich unter kulturpolitisch relevanten Fragen diskutiert, etwa welche Kultur förderungswürdig sei, die Kultur, die bewahrt oder die innovativ ist. Außerdem stehen die Kulturinstitutionen unter einem Wettbewerbsdruck: „Logikken er at konkurransen mellom institusjoner - og mellom kunstnere som ønsker å opptre eller stille ut $\mathrm{i}$ institusjonene - virker harmoniserende og innsnevrende på hva som til syvende og sist presenteres. Tendenser som dette forsterkes ved at institusjonene skjeler til hverandres publikumssuksesser når de setter opp sine programmer“, Bjørkås 2003, S. 442. [Die Logik ist, dass die Konkurrenz zwischen Institutionen - und zwischen Künstler*innen, die in Institution auftreten oder ausstellen möchten - harmonisierend und einengend auf das, was letzten Endes präsentiert wird, wirken. Derartige Tendenzen werden dadurch verstärkt, dass die Institutionen sich gegenseitig auf die Publikumserfolge schielen, wenn sie ihre Programme erstellen].

102 Haselbach et al. 2012b, S. 138. Sie setzen fort: „Deshalb strebt jede kulturelle Kraft hierzulande nach Institutionalisierung, nach Aufnahme in den Kanon des Kulturstaats.“

103 Vgl. Haselbach et al. 2012a.
} 
bens. "104 Die Soziologie versteht ,Institution' besonders als Wert, Konvention, Regel, Norm. Diese symbolische Verwendung ist für eine Institution wie das Literaturhaus ebenfalls nur symbolisch nutzbar. Fasst man soziale Institutionen als „relativ auf Dauer gestellte, durch Internalisierung verfestigte Verhaltensmuster und Sinngebilde mit regulierender und orientierender Funktion" "105, so lässt sich damit für die Nutzung in dieser Arbeit argumentieren, weil sich darin die Verbindung von Verinnerlichung der Verhaltensmuster mit regulierender und orientierender Funktion zeigt. Auch aus wirtschaftswissenschaftlicher Sicht heißt es: „Institutionen beeinflussen [...] als Restriktionen die Handlungen von Menschen. Zu den Institutionen zählen so unterschiedliche Dinge wie Märkte, Gesetze, Bräuche, Zahlungsmittel oder Standardverträge. "106 Es werden darunter also eher Regelwerke und Verträge respektive Vertragssysteme verstanden. Stabilisierung und Verfestigung sozialen Handelns geschieht in und durch Institutionen. Dies erfolgt vor allem durch Akzeptanz und Verinnerlichung. Die etymologische Bedeutung lateinisch ,institutio ${ }^{6}$ - Einrichtung - vergleiche das ,Institut ${ }^{6}$ - scheint vermengt zu sein mit der Auslegung als gesellschaftliche Normen und Konventionen, die das soziale Miteinander strukturieren. ,Institution“ ist dabei oft eine Zuschreibung, die auf mehr verweist als nur auf den Organisationscharakter des Betriebs.

Gottlieb Gaiser, der Anfang der 1990er-Jahre Literaturgeschichte und literarische Institutionen zum titelgebenden Thema seiner Monografie machte, zeigt die zweifache Benutzung auf, indem er bereits in der Kapitelbenennung zwischen ,Literatur als Institution' und ,literarischen Institutionen' unterscheidet und zu letzteren zum Beispiel das Theater ${ }^{107}$ und das Bibliothekswesen ${ }^{108}$ rechnet. Implizit versteht Gaiser damit die literarischen Institutionen in einem Sinn, der für das Literaturhaus weiterhilft, da er, ohne es ausdrücklich zu nennen, mit ,literarische Institution' nicht das einzelne Theater meint, sondern ein übergeordnetes Konzept von Theater. Den Institutionsbegriff nutzt er dabei unter anderem für die Beschreibung des jeweiligen Organisationsprinzips und der Funktionen. Die vorliegende Arbeit verfolgt diese Ansätze weiter. ${ }^{109}$

Obwohl es in der soziologisch ausgerichteten Literaturwissenschaft Bestrebungen zu einer Begriffsbestimmung gab ${ }^{110}$ und in den letzten Jahrzehnten das Interesse an der Beschäftigung mit Institutionen wächst, ${ }^{111}$ ist ,Institution“ für empirische Untersuchungen weitestgehend unreflektiert oder im Sinn von Gaisers, Literatur als Insti-

\footnotetext{
104 „Institution“, Duden online.

105 Göhler 1994, S. 22.

106 Sauerland: „Institution“.

107 Vgl. Gaiser 1993, S. 120-123.

${ }^{108}$ Vgl. ebd., S. 116-120.

109 Anja Johannsen hat in einem Aufsatz bereits Gaisers Studie mit dem Literaturhaus zusammengebracht, vgl. Johannsen 2012b, S. 179-180. Die vorliegende Arbeit führt diese Ansätze weiter. ${ }^{110}$ Vgl. z. B. Hohendahl 1985, S. 9; Barner 1990, S. 2; weitere Beiträge nennt Jutta Ernst in ihrem Lexikonartikel, vgl. Ernst 2008, S. 321.

${ }^{111}$ Dies sei auf die kommunikationsorientierten, systemtheoretischen und kulturwissenschaftlichen Ansätze zurückzuführen, wie Jutta Ernst darlegt, vgl. ebd.
} 
tution $^{\text {‘112 }}$ in Gebrauch. In Handbüchern und Sammelbänden zu den Bereichen Literaturvermittlung und Literaturbetrieb, die hier die erste Bezugsgröße sind, werden die ,Institutionen' immer thematisiert, begrifflich selten problematisiert. Stefan Neuhaus zum Beispiel schreibt ein Kapitel über „Literaturvermittlung in Bildungsinstitutionen" 113 und arbeitet mit anscheinend selbstverständlichen Beispielen wie Bibliotheken und Archiven. In der Einleitung zu seinem nächsten Band meinen er und sein Kollege Oliver Ruf mit „Kultur und Literatur vermittelnden Institutionen [...] etwa [die] Buchbranche“"114, ebenso sind dort Literaturpreise ${ }^{115}$ und Literaturunterricht ${ }^{116}$ Institutionen der Literaturvermittlung. Dies zeigt exemplarisch, wie intuitiv und gleichzeitig verschieden der Terminus ,Institution' verwendet wird. Etwas präziser fassen Matthias Beilein, Claudia Stockinger und Simone Winko den Fachausdruck und überschreiben ein Kapitel ihres Sammelbandes mit „Wertung und Kanon in Institutionen“117 und führen diese als „literaturvermittelnde Institutionen“118 ein. Diese ließen sich prinzipiell nach ihrer Zugehörigkeit zum literarischen Feld unterscheiden: Intraliterarische Institutionen (wie Autorengruppen, literarische Vereinigungen und Zirkel) gehörten ausschließlich dem literarischen Feld an, interliterarische Institutionen bewegten sich zwischen den Grenzen benachbarter Felder und Subfelder wie dem Feld der Ökonomie (Verlage, Agenturen), der Bildung (Schulen und Universitäten), der Publizistik (Zeitungen, Zeitschriften, Radio, Fernsehen und, so allgemein formuliert, das Internet) oder der Macht (staatliche und kommunale Einrichtungen). „Die Grenzen sind hier jedoch unscharf, da in vielen Fällen die Akteure der unterschiedlichen Felder in mehr als einem Feld agieren". ${ }^{119}$ Diese Auslegung von ,Institution' entspricht ungefähr dem, was der Buchwissenschaftler Günther Fetzer in einem Lexikonartikel als ,Organisationen“ bezeichnet. Diese möchte er aber von Institutionen abgegrenzt wissen: „Soziologisch zu unterscheiden sind Institutionen - wie das Bildungswesen (Literaturwissenschaften, Literaturunterricht, Erwachsenenbildung), die Massenmedien und die Literaturkritik einerseits von Organisationen andererseits, die teilweise im Rahmen dieser Institutionen agieren." ${ }^{120} \mathrm{Zu}$ diskutieren bleibt, wo die Trennlinie zwischen ,Institutionen" und ,Organisationen'verläuft, da die Differenzierung nur angedeutet ist. ${ }^{121}$ Bei Fetzer wird ,Institution“ tendenziell als das verstanden, was Beilein et aliae - in Anlehnung an Pierre Bourdieu - als Feld respektive Subfeld bezeichnen. Jutta Ernst weist darauf hin, dass der Fachausdruck ,Institution` bei Pierre Bourdieu nicht explizit

\footnotetext{
${ }^{112}$ Der Literaturwissenschaftler Hohendahl nutzt den Fachausdruck ebenfalls, um die aus seiner Sicht für die Literaturgeschichte notwendigen literatursoziologischen Untersuchungen der „Bedingungen, unter denen das Schreiben und Lesen stattfindet" einzuleiten, Hohendahl 1985, S. 45.

113 Neuhaus 2009, S. 234.

114 Neuhaus und Ruf 2011, S. 13.

115 Vgl. Klettenhammer und Wiesmüller 2011.

116 Vgl. Wrobel 2011.

117 Beilein et al. (Hg.) 2012, S. V.

118 Beilein et al. 2012, S. 7.

119 Ebd.

${ }^{120}$ Fetzer 2015, S. 267.

${ }^{121}$ Dabei vermischt Fetzer aber die Untersuchungsebenen, wenn „die Massenmedien“, ebd., der Literaturkritik gegenübergestellt und sie damit analytisch gleichgesetzt werden. Es sei jedoch angemerkt, dass es sich dabei um einen Lexikonartikel handelt, der gegebenenfalls ob seiner Kürze vereinfachen muss.
} 
vorkomme und er durch ,champ ${ }^{6}$ ersetzt worden sei. ${ }^{122}$ Bourdieu selbst fasst das Feld unter anderem so:

Die Grundlage der Wirksamkeit von Konsekrationsakten liegt im Feld selbst [...] in diesem sich schrittweise institutionalisierenden Spiel-Raum, das heißt in dem System der objektiven Beziehungen, aus denen er besteht, in den Auseinandersetzungen, deren Arena er darstellt, sowie in der besonderen Form von Glauben, der darin erzeugt wird. ${ }^{123}$

Dies entspricht folglich nicht dem von Beilein et aliae vertretenen Verständnis, welches Institutionen auf den verschiedenen Feldern positioniert, jene als Handelnde auf diesen begreift. ${ }^{124}$ Offensichtlich wird, dass die referierten Beiträge ,Institution“ unterschiedlich auslegen. In diesen Verwendungen ist das Literaturhaus einmal eine Institution, die in einem Feld agiert, und einmal eine Organisation, die im Rahmen von Institutionen agiert; sie beziehen sich also auf unterschiedliche theoretische Hintergründe. Es gibt zudem Beiträge, die ,Institution' als einen kollektiven Akteur und so wiederum als eigenes Feld verstehen, ${ }^{125}$ was von mir inhaltlich ebenfalls präferiert wird, obgleich ich nicht ,Feld‘ verwende. Dass die vorliegende Arbeit für das Literaturhaus den Terminus ,Institution“ dem des ,Feldes' vorzieht, liegt daran, dass damit die Akteursperspektive, die organisationale Strukturierung sowie die Praxiskomponente integriert werden können.

\section{Akteurs- und Handlungsebene}

Eine Variante des Begriffs aus literatursoziologischer Sicht stellt Jutta Ernst dar. Sie bezeichnet literarische Institutionen als „diejenigen Instanzen des Lit.systems, die an der Produktion [...], der Verbreitung [...] und der Rezeption und Verarbeitung [...] von Lit. beteiligt sind.“126 Hier geht es begrifflich um „Instanzen“, die sich über die aufgeführten Beispiele eher als Einrichtungen denn als Normen verstehen lassen. Sie zählt dazu genauso Autor*innen, Übersetzer*innen und Leser*innen wie das Druckgewerbe oder Bibliotheken und Bildungseinrichtungen wie Schulen und Universitäten. Der Lexikonartikel konstatiert, dass die literarischen Institutionen ein offenes, heterogenes Netzwerk mit vielfältigen Relationen und Abhängigkeiten darstellen, in denen die unterschiedlichsten gesellschaftlichen Prozesse zum Tragen kommen. ${ }^{127}$ Der unter anderem von Jutta Ernst erwähnte Netzwerkaspekt ist für das Literaturhaus zentral. Die literarischen Institutionen als Bestandteile eines uneinheitlichen Netzwerkes werden als Akteur*innen verstanden, die miteinander in Beziehung stehen.

Hinzu kommt, dass sich das Literaturhaus selbst aus einem Netzwerk aus Akteur*innen bildet. Folglich lässt es sich als kollektiver Akteur begreifen:

Organisierte Gruppen müssen als Akteure gelten, sofern ihre Handlungen erstens emergente Gesamtsystemleistungen sind, die zweitens im Organisationszusammenhang ihre Spezifität und Selektivität gewonnen haben. [...] Handlungsfähige

\footnotetext{
122 Vgl. Ernst 2008, S. 321.

123 Bourdieu 2001, S. 273.

${ }^{124} \mathrm{Vgl}$. Beilein et al. 2012, S. 7.

125 Vgl. Dederichs und Florian 2004.

${ }^{126}$ Ernst 2008, S. 320.

127 Vgl. ebd.
} 
Einheiten erfüllen die erste und die zweite Bedingung und sind somit kollektive Akteure, nicht im Sinne eines Kollektivs handelnder Individuen, sondern als handelnde Einheiten. ${ }^{128}$

Ein Literaturhaus ist eine handlungsfähige Einheit aus Einzelakteur*innen. Nennenswert ist zudem die Aussage Adloffs, dass kollektive Akteure auf einer emergenten Ebene angesiedelt seien. ${ }^{129}$ Das heißt für das Verständnis des Literaturhauses als kollektiven Akteur zum einen, dass sie mehr sind als die Summe der Handlungen der Einzelakteur*innen, und zum anderen, dass die Einzelakteur*innen, indem sie Teil der handelnden Einheit werden, ihre Eigeninteressen in den Dienst des Übergeordneten stellen. Hier taucht der Punkt der Organisation, des Organisierten auf, der in anderen Arbeiten zum Thema zentraler ist. „Zwischen institutionellen Regeln und dem Handeln kollektiver Akteure muss allerdings strikt unterschieden werden: Der institutionelle Rahmen prägt das Handeln, determiniert es aber nicht.“ “130

Eine Akteur- und Handlungsdimension in die Auseinandersetzung mit ,Institution' integriert der Soziologe Uwe Schimank, der in seinen Arbeiten die Systemtheorie mit der Akteursperspektive zusammenbringt: Dabei schlägt er den Bogen zum ebenso ausgiebig beforschten Begriff der, Organisation', der bei Fetzer bereits auftauchte: Schimank geht davon aus, dass alle Institutionen handlungsprägend sind. „Genauer: Eine Institution ist ein Zusammenhang wechselseitig aufeinander verweisender und einander wechselseitig tragender normativer, kognitiver und evaluativer Handlungsorientierungen. “131 Einige seien zusätzlich handlungsfähig und haben damit Akteursstatus. ${ }^{132}$ Als den wichtigsten Typus handlungsfähiger Institutionen in modernen Gesellschaften sieht er Organisationen an. ${ }^{133} \mathrm{Im}$ Literaturhaus entstehen ein Umgang mit Literatur (handlungsprägend), und dieser wird auch dort praktiziert (handlungsfähig). Wieder muss berücksichtigt werden, dass Schimank wie Adloff einen soziologischen Institutionsbegriff verwendet, der in der vorliegenden Arbeit so nicht benutzt wird. Hilfreich zur Beschreibung des Literaturhauses ist der Punkt, dass Schimank Organisationen als handlungsfähige Institutionen bezeichnet, die also Akteursstatus haben. Folglich schließt er nicht aus, dass Organisationen Institutionen sein können. Mit Organisationen befassen sich in der Regel vor allem die Wirtschaftswissenschaften in ihrer Unternehmenstheorie. In diesem Verständnis würden Literaturhäuser eher als Organisationen begriffen, die in Abgrenzung zu Institutionen „Personenkollektive [sind], deren Mitglieder sich organisiert haben, um ihre individuellen Ziele besser erreichen zu können (Kooperationsvorteile). “134 Dies trifft auf einer anderen Untersuchungsebene zu, denn als Einzelunternehmen sind Literaturhäuser durchaus Organisationen.

\footnotetext{
128 Adloff 2004, S. 318.

${ }^{129}$ Vgl. ebd., S. 309.

${ }^{130}$ Ebd., S. 319. Bei Adloff wird ,Institution` im soziologischen Sinne verstanden, für ihn handeln kollektive Akteure in einer institutionalisierten Umwelt, vgl. ebd. Institutionen sind bei ihm also keine Akteure. 131 Schimank 2004, S. 293.

132 Vgl. ebd.

133 Vgl. ebd., S. 300.

134 Sauerland: „Institution“. Dies ist in die sogenannte Transaktionskostentheorie einzuordnen. Auch wenn man es in der Literaturwissenschaft kaum ,Transaktionskosten' nennen würde, so wird damit etwas beschreibbar, das in der Nachfolge an Bourdieus Kapitalbegriff inzwischen selbstverständlich in geisteswissenschaftliche Disziplinen Einzug erhalten hat: Bei Kosten und Investitionen wird nicht mehr nur an Geld gedacht. Somit sind auch Transaktionskosten hinsichtlich symbolischen und sozialen Kapitals benennbar.
} 


\section{Abstraktum und Konkretum}

Die Definition der Soziologin Antje Gimmler zeigt einen weiteren wichtigen Aspekt von ,Institution' auf und legt Gründe für die verschiedenen Verwendungsweisen dar: „Die Bedeutungsvielfalt des Begriffes ,Institution“ hängt aber andererseits auch damit zusammen, daß Institutionen als Vermittlungselemente in sozialen, gesellschaftlichen und politischen Ordnungszusammenhängen eine intermediäre und vermittelnde Funktion zugewiesen wird. "135 Die intermediäre Rolle, auf die hin eine Institution untersucht werden sollte, steht in diesem Zitat im Fokus. Für die theoretische Beachtung des kollektiven Akteurs als Vermittlungsposition zwischen Makround Mikrosoziologie, zwischen der gesellschaftlichen und individuellen Ebene, argumentiert ebenfalls beispielsweise Frank Adloff. ${ }^{136}$ Es handelt sich dabei also um eine Instanz, die das Einzelne mit dem Allgemeinen verbindet. Dieser Begriffsinhalt ist sehr nützlich für Institution Literaturhaus.

Anschaulich macht dies ein in dieser Hinsicht vergleichbarer Fachausdruck aus der Literaturwissenschaft: die ,Gattung ${ }^{6}{ }^{67}$ Dieses Beispiel macht deutlich, dass derartige Sammelbezeichnungen notwendigerweise Abstraktionen von konkreten Beispielen sind und somit Vereinfachungen voraussetzen. Wie ein einzelner Text bei einer Beschreibung als ,Roman' nicht in allen seinen Eigenarten, sondern auf die charakteristischen Merkmale der Gattung hin betrachtet wird, so wird die einzelne Einrichtung bei der Subsummierung unter ,Institution' über allgemeinere, weniger spezifische Merkmale eingeordnet. Zugleich ordnet sich der Einzelfall in eine Gruppe ein und kann sich so in größerem Kontext untersuchen lassen. Mit ,Institution' ist hier nicht das eine konkrete Literaturhaus gemeint, sondern seine abstrahierte Form.

\section{Selbsterhaltung}

Die unterschiedlichen Institutionenbegriffe stimmen grundsätzlich darin überein, dass Institutionen einer Leitidee folgen und als etwas Stabiles, Kontinuierliches beschrieben werden. Durch den geschaffenen Rahmen bietet die Institution Orientierung und entlastet die Akteur*innen, weil sie eine Art Sicherheitshorizont für individuelle Entscheidungen darstellt. ${ }^{138}$ Es ist dadurch eine Erwartungssicherheit gegeben. ${ }^{139}$

Daraus ergeben sich wichtige Herausforderungen für die Institution. Als zentrale Ziele nennt Gottlieb Gaiser primär Bedürfnisbefriedigung und sekundär Selbsterhaltung. ${ }^{140}$ Besonders mit dem Moment des Selbsterhalts lässt sich das notwendige

\footnotetext{
135 Gimmler 1996, S. 9. Sie vergleicht in der Arbeit den Institutionsbegriff bei Weber und bei Habermas miteinander.

$136 \mathrm{Vgl}$. Adloff 2004.

137 ,Institution“ ist in der Literaturwissenschaft vor allem mit literatursoziologischem Blick ein Beschreibungsmittel. Selten wurde er auch für literaturwissenschaftliche Arbeiten im engeren/traditionelleren Sinne verwendet, doch für die Beschäftigung mit literarischen Texten bietet er keinen nennenswerten Mehrwert, weil er in der dortigen Verwendung am ehesten dem entspricht, was als ,Gattung' akzeptiert ist, vgl. z. B. Sanders 1981.

138 Vgl. z. B. Gimmler 1996, S. 11.

139 Arnold Gehlen stellte dies bereits 1976 als „Entlastung“ dar, wie Schimank referiert, vgl. Schimank 2004, S. 294.

140 Vgl. Gaiser 1993, S. 64.
} 
Austarieren von Tradition und Innovation fassen, das in der vorliegenden Arbeit als wichtig für das Handeln des Literaturhauses erkannt wird. Wie dargestellt, sind Institutionen als dynamische Komplexe zu verstehen, die zugleich stabil und flexibel sein müssen. Um fortzubestehen, muss eine Institution wiedererkennbar sein und gleichzeitig auf neue Bedürfnisse reagieren und sich der sich verändernden äußeren Bedingungen entsprechend wandeln.

Ebenfalls auf das Literaturhaus übertragbar ist die Annahme, dass neue Institutionen entstehen, wenn die existierenden die aktuellen Bedürfnisse nicht mehr befriedigen. Es entstehen neue Einrichtungen und/oder die bestehenden wandeln sich. Das Aufkommen neuer Institutionen kann Auswirkungen auf die alten haben. Und die neuen orientieren sich an den Bestehenden, kommen also keinesfalls aus dem ,Nichts'. Das Zusammenspiel der Literaturhäuser mit den Bibliotheken etwa ist vor allem in Skandinavien aufschlussreich, wie sich noch zeigen wird.

Wie deutlich geworden sein sollte, begreift diese Arbeit das Literaturhaus als Institution, weil darin unter anderem die Perspektiven auf das Abstraktum der Einzelbeispiele, auf den Akteur, die organisationale Struktur, das Praxisgefüge und die beteiligten Praktiken, beispielsweise die Veranstaltungen, sowie auf die umgebenden und grundlegenden Konventionen und Regeln kombiniert werden. Die beiden diskutierten Fachausdrücke ,Organisation“ und ,Institution' bezeichnen im Folgenden einen kollektiven Akteur und die emergente Verbindung aus Interaktionen von Einzelakteuren. ,Organisation“ wird verstanden als Synonym für ein Unternehmen, eine einzelne Einrichtung, zum Beispiel das Literaturhaus Berlin. ,Institution“ bezeichnet die abstrakte Variante, das Literaturhaus als Phänomen.

Das Literaturhaus bietet sich folglich auch deshalb zur Untersuchung im Institutionskontext an, weil die beteiligten Einzeleinrichtungen selbst von Beginn an einen Bezug zum übergeordneten Konzept suchten, was sich am offensichtlichsten an der gleichen Namensgebung zeigt.

\section{3.2 Literaturhaus und Kulturtransfer}

\section{3.2.1 Vergleich als Methode}

Für die Institution Literaturhauses ist die vergleichende Arbeit mit Fallbeispielen eine geeignete Methode. Es wird vergleichend gearbeitet und die Weiterentwicklung der Institution über den deutschsprachigen Bereich hinaus am Beispiel des Transfers nach Skandinavien analysiert. Es ist für die Untersuchung besonders aufschlussreich, Literaturhäuser nicht nur in ihrem Ursprungskontext, also Deutschland, sondern ihre Ausweitung über Grenzen hinweg zu studieren. ${ }^{141}$ So wird angenommen, dass es sich beim Literaturhaus um eine transnationale Literaturvermittlungsinstitution handelt. ${ }^{142}$ Damit sei nicht konstatiert, dass eine Institution im hier verwende-

\footnotetext{
${ }^{141}$ Das Hauptaugenmerk liegt hier auf dem Transfer, nicht auf der Betonung der Grenzen, die als Ausgangspunkt natürlich dennoch gebraucht werden. Zur Bedeutung der Grenze, Grenzziehung und ihrem Zusammenhang mit Exklusion und Inklusion vgl. z. B. Simanowski 1998.

142 Zur Entstehung und Entwicklung der Bezeichnung ,Transkulturalität', vgl. z. B. Ernst und Freitag 2015, S. 7-12. Mit den in den letzten Jahren vielfältig benutzten Termini Transkulturalität, Transnationalität, Transstaatlichkeit und Translokalität beschäftigen sich zum Beispiel Hühn und andere in ihrem
} 
ten Sinne per se transkulturell oder transnational sein muss, sondern dass die Perspektive auf die Institution in ihren verschiedenen Kontexten erhellend für das Verständnis des Gegenstandes sein kann. „Entscheidend ist also nicht die Phänomenkonstellation, sondern die Perspektive, aus der wir sie betrachten wollen." 143 Die Verwendung der Begriffsbezeichnung ,Kulturtransfer ${ }^{6}$ - dem ist zuzustimmen - ist Ausdruck des Analyseinteresses. Der Blick richtet sich in dieser Arbeit auf die dynamischen Prozesse und die Komplexität von Transfers:

In Transfers zeigt sich die Notwendigkeit, Einzelsysteme zu öffnen. [...] In Transfers kommt etwas Schöpferisches zum Zuge und schafft eine neue Ordnung. Transfers lösen Texte und Kontexte von ,Identität ${ }^{\star}$ schlechthin, schaffen aber Bindungen über Grenzen hinweg. Transferforschung deckt so einen zur vereinheitlichenden Globalisierung parallelen Vorgang auf: den Prozess des Komplexerwerdens. ${ }^{144}$

Die Ausführungen fassen Aspekte zum Kulturtransfer, den Michel Espagne und Michael Werner Mitte der 1980er-Jahre als Forschungsrichtung innerhalb der Komparatistik fundierten, bündig zusammen. ${ }^{145}$ Eine wichtige Unterscheidung betrifft die Differenzierung von ,Austausch' und ,Transfer', die Stamatios Gerogiorgakis et alii prägnant herausarbeiten: Während es sich beim ,Kulturaustausch“ um „Formen des Zufälligen, Wechselnden und Veränderlichen, die uns ständig umgeben - multidirektional, diffus, wiederkehrend, teils auch unverbindlich in ihrer Art" ${ }^{\text {"146 }}$ handelt, sind Kulturtransfers gewollt, gezielt, absichtsvoll. „Hierbei überschreiten offenbar nicht beliebige, sondern bestimmte Güter die Grenzen von Kulturarealen, nämlich solche, denen eine transkulturelle Bedeutung und eine zweckorientierte Nachfrage zukommt. "147 Zwischen Deutschland und Skandinavien findet Austausch statt. Der Transfer des Literaturhauses nach Skandinavien lässt sich als Transfer untersuchen.

In der komparatistischen Forschung gab es Diskussionen über die Stellung des Vergleichs, da einige Forscher*innen die Ansicht vertraten, dass es beim Vergleich um das Auffinden von Einflüssen und Abhängigkeiten gehe. ${ }^{148}$

Wenn das zu vergleichende Fremde im Grunde nur vor dem Hintergrund des Eigenen fassbar werden kann, besteht freilich die Gefahr, dass es dem Gegenstand, der den Ausgangspunkt des Vergleichs bildete, angeglichen wird oder aber

\footnotetext{
Sammelband, vgl. Hühn et al. (Hg.) 2010. Auf den darin enthaltenen Forschungsüberblick sei verwiesen. Begriffsbezeichnungen mit dieser Vorsilbe beinhalten „möglicherweise gleichzeitige Überwindung und Rückbindung an ihren Wortstamm. Dabei bleibe die Grenze gerade spürbar, aber es werde auch die Ambivalenz ausgedrückt, dass ,trans-' dem angehängten Konstrukt seine starre Begrenztheit nehme und dass es - im Gegenteil - Aspekte der Entwurzelung offenbare“, Hühn et al. 2010, S. 18. Dies wird von dem Geografen Peter Weichhart im gleichen Band noch stärker thematisiert, vgl. Weichhart 2010. Insbesondere das Moment der simultanen Überwindung und Rückbindung an das Nationale wird im Literaturhaus eingelöst. Dadurch, dass die Institution Grenzen durchquert, wird das Lokalspezifische zu einer relevanten Kategorie für die einzelne Einrichtung.

143 Ebd., S. 60.

144 Keller 2011, S. 117. Dieser Aufsatz gibt einen guten Überblick über die Forschung zum Thema. Thomas Keller betont dort unter anderem, dass diese Forschungsperspektive auch ältere Ansätze zu etwas Neuem integriert.

145 Vgl. Espagne und Werner 1988.

146 Gerogiorgakis et al. 2011, S. 395.

147 Ebd.

148 Vgl. Zelle 2013, S. 132.
} 
in eindeutiger Abgrenzung dazu erscheint, ohne dem Anderen wirklich gerecht zu werden. ${ }^{149}$

Die Kulturtransferforschung setzt diesem die Annahme entgegen, die beispielsweise Hartmut Kaelble formuliert, dass Vergleiche Transferuntersuchungen bräuchten und: „Umgekehrt brauchen Transferuntersuchungen den Vergleich, weil nur durch den Vergleich festgestellt werden kann, worin sich die Ausgangskultur und die Aufnahmekultur eines Transfers unterscheiden und worin der Wandel, also der Kern des Transfers, tatsächlich besteht. "150

Damit konkretisiert die Idee des Transfers den Vergleich als Methode. Grundsätzlich impliziert die hier relevante Bedeutung von ,Vergleich“ eine „Nebeneinanderstellung, aus welcher Ähnlichkeiten erkannt werden“"151. Ein Vergleich besteht somit aus mindestens zwei verglichenen Entitäten und einem Vergleichsbezug; ${ }^{152}$ beispielsweise wird das Literaturhaus Hamburg hinsichtlich seiner Personalstruktur mit dem Litteraturbuset in Oslo verglichen. In der vorliegenden Arbeit steht der äquivalente Vergleich im Zentrum, der über das Herausarbeiten von Gemeinsamkeiten die Institution Literaturhaus näher zu beschreiben versucht; dabei helfen kontrastive Vergleiche, die stärker die Unterschiede betonen, mit. ${ }^{153}$

Entscheidend ist dabei die Grundidee der Kulturtransferforschung, die Michel Espagne auf den Punkt bringt: „Transferieren bedeutet nicht transportieren, sondern eher modifizieren. “154 Dies ist ein Aspekt, der etwa in der Übersetzungstheorie, ausgehend von Friedrich Schleiermacher Anfang des 19. Jahrhunderts, mit den Strategien der Einbürgerung und der Verfremdung virulent ist. Espagne fährt fort: „Jeder Wechsel eines kulturellen Objekts von einem Kontext in einen anderen führt zwangsläufig zu einem Bedeutungswechsel, einer bedeutungsverändernden Dynamik, die man vollständig nur dann erfasst, wenn man die historischen Faktoren des Wechsels berücksichtigt.“155 Anna Veronica Wendland ergänzt dazu: „Finally, it holds that transferred objects or practices become part of their new contexts and are often used in different ways than in the former context." $" 156$

Anregungen aus Studien zum Kulturtransfer mit dem entwickelten Institutionsbegriff zu kombinieren ist produktiv, weil die Reflexion darüber, was das Vergleichsobjekt - in diesem Falle das Literaturhaus - überhaupt ist, notwendige Voraussetzung für den Vergleich ist. Über den Vergleich mit anderen Umsetzungen werden markante Charakteristika des Gegenstandes im ,Herkunftsland“ sichtbar. Ferner können anhand der Einrichtungen Eigenarten der jeweiligen kulturellen Umwelt

\footnotetext{
${ }^{149}$ Lüsebrink et al. 2013, S. 11.

${ }^{150}$ Kaelble 2005. Zur Auseinandersetzung mit „Vergleich, Transfer, Verflechtung“ sei auch der gleichnamige Artikel von Michael Werner und Bénédicte Zimmermann empfohlen, der wichtige Forschungsperspektiven erläutert und sinnig kritisiert, vgl. Werner und Zimmermann 2002. „Potenziale und Grenzen des Vergleichs“ stellt auch Christiane Solte-Gresser zusammen, vgl. Solte-Gresser 2013. „Der Vergleich ist zwar eigentlich noch keine Methode, sondern ein Grundelement kognitiver Prozesse. Gleichwohl hat er für die Kulturtransferforschung methodischen Status“, Lüsebrink et al. 2013, S. 15. 151 Schenk und Krause 2001, S. 676.

152 Vgl. ebd., S. 677.

153 Vgl. Zemanek 2012, S. 16.

154 Espagne 2016, S. 45.

155 Ebd.

156 Wendland 2012, S. 47.
} 
erkannt werden, sowohl an dem Ort, an dem es zuerst ein Literaturhaus gab, als auch dort, wo es später gegründet wurde. Demgemäß wird in dieser Arbeit der Hauptstrang - die Institution Literaturhaus - begleitet von dem auslandsskandinavistischen Interesse, welches per se komparativ angelegt ist, Diagnosen über den skandinavischen Kulturraum vorzulegen. ${ }^{157}$

\section{3.2.2 Kulturbegriff}

Auf den vorhergegangenen Seiten kam mehrfach der Ausdruck ,Kultur ${ }^{6}$ vor. Dieser bedarf einer Erläuterung, weil sie hier auf zwei unterschiedliche Weisen verwendet wird. ${ }^{158}$ Zum einen liegt im Zusammenhang mit ,Nation' und ,Kulturraum ein semiotischer Kulturbegriff zugrunde, der für die Kontextualisierung des Literaturhauses relevant ist. „Demzufolge wird Kultur als der von Menschen erzeugte Gesamtkomplex von Vorstellungen, Denkformen, Empfindungsweisen, Werten und Bedeutungen aufgefaßt, der sich in Symbolsystemen materialisiert. "159 Kultur ist somit ein Zeichensystem. ${ }^{160}$,Kultur ${ }^{6}$ ist eng verbunden mit einer Idee von Identität. „Kultur stützt sich deshalb auf Kommunikation, weil sie diese Regeln des Zusammenlebens durch Diskurse festlegt und das Verhalten der Menschen durch Diskurse steuert." "161 Zum anderen bezieht sich ,Kultur' vor allem auf Kunst, Theater, Musik und Literatur. Diese vor allem noch alltagssprachliche Verwendung geht auf eine historische Unterscheidung von Zivilisation und Kultur zurück. ${ }^{162}$ Die ursprünglich damit verbundene hierarchisierende Differenz von ,höherer oder ,hoher ${ }^{6}$ Kultur und ,Massenkultur', ,Unterhaltungskultur' oder ,niederer Kultur' lässt sich inzwischen ausklammern. Und so versteht auch die vorliegende Arbeit ,Kultur als einen neutralen und nicht normativen Fachausdruck zur gesammelten Bezeichnung von Literatur und vergleichbaren künstlerischen Ausdrucksformen, was sich beispielsweise im Terminus ,Kulturbetrieb“ spiegelt. Es ergibt sich hier jeweils aus dem Kontext, welche Dimension des Begriffs gerade entscheidend ist.

\section{3.2.3 Transfer der Institution Literaturhaus}

Da im westeuropäischen Literaturbetrieb schon lange Austausch und Transfers stattfindet, insbesondere zwischen Deutschland und Skandinavien, bleiben die skandinavischen Kulturentwicklungen und -einrichtungen gerade nicht unberührt

\footnotetext{
157 Die Ausführungen von Espagne zu diesem Aspekt lassen sich auf die deutsche Skandinavistik beziehen: „Die wechselseitige Wahrnehmung nationaler oder übergreifender literarischer Kulturen ist bestimmt durch die Wissenschaften, die sich mit den zugehörigen Kulturgebieten befassen [...] Diese Wissenschaften sind Ergebnis eines Kompromisses zwischen dem untersuchten literarischen Raum und dem Horizont desjenigen, der die Untersuchung durchführt", Espagne 2016, S. 51.

158 Einen hilfreichen Überblick zu Kulturbegriffen und Kulturtheorien liefert Ort 2003.

159 Nünning und Nünning 2003, S. 6.

160 Ausführlich zur Kultursemiotik vgl. Posner 2003, insbesondere S. 54.

${ }^{161}$ Hickethier 2003, S. 222.

162 Vgl. Hejl 2008, S. 392. Ein knapper Überblick zum engen und weiten Kulturbegriff findet sich bspw. bei Klein 2011c, S. 95-98. Er betont, dass auch Kulturpolitik abhängig sei vom jeweils angesetzten Kulturbegriff, vgl. ebd., S. 98.
} 
von den Ereignissen in Deutschland. ${ }^{163}$ Heute bieten die Institutionen dafür einen Rahmen, der die private, personengebundene Vermittlungsarbeit ablöst beziehungsweise ergänzt. ${ }^{164}$ Dabei ist es interessant, dass das Literaturhaus nicht intentionale Mittlerinstitution ist, sich also nicht explizit um den Transfer deutscher Kultur ins Ausland kümmert, wie zum Beispiel das Goethe-Institut und das Prager Literaturhaus es tun. Es geht nicht primär um die Einführung deutscher Kulturpraktiken oder güter in Skandinavien. Das deutsche Modell wird vielmehr ,benutzt ${ }^{6}$, weil es eine Struktur für die Befriedigung von Bedürfnissen bietet. Dies unterstreicht, dass ein Transfer wesentlich von der „Anerkennung eines relativen Vorteils durch die Aneignung von Kulturgütern" 165 bestimmt ist. Es ist bekannt, dass die Gründer*innen in Kopenhagen und Oslo sich eingehend mit deutschen Literaturhäusern beschäftigt haben, bevor sie ihre Vorstellungen realisierten. Skandinavische Akteur*innen übernahmen das Konzept, weil angenommen wurde, dass das Literaturhaus als Literaturvermittlungseinrichtung in Dänemark beziehungsweise Norwegen erfolgreich sein könnte. Dabei ist also weniger der nationalkulturelle Transfer beabsichtigt, sondern es steht die Bedürfnisbefriedigung im Fokus. Auch dies macht das Literaturhaus zu einem besonders interessanten Forschungsobjekt.

Die nationale Dimension bleibt für diese Untersuchung relevant, um die jeweiligen Modifikationen des Transferobjektes zu verstehen und dafür „die historischen Faktoren des Wechsels" "166 zu berücksichtigen. Literaturhäuser agieren in einem örtlich geprägten sozialen Zusammenhang. Für die Analyse ist der Fachausdruck ,national nützlich. Wird der Begriff des Nationalen nicht mehr an das historisch begrenzte Phänomen der Nation ${ }^{167}$ koppelt, wie Udo Schöning und Burkhard Pohl es vorschlagen, ${ }^{168}$ dann kann er auch das umfassen, was hier als ,Kulturraum Skandinavien' bezeichnet wird: „Wenn sich Internationalität von Literatur und Film durch Vernetzung konstituiert und Vernetzung durch Transfer entsteht, dann ist national, was des Transfers bedarf, um international zu werden."169 Skandinavien lässt sich mit diesem Verständnis des Nationalen als Eins verstehen. Diese Bezeichnung ,Skandinavien“ wird hier wie in den festlandskandinavischen Ländern selbst benutzt. Da das heutige Dänemark, Norwegen und Schweden keineswegs immer voneinander getrennt waren und es deshalb traditionell gesamtskandinavische Entwicklungen

\footnotetext{
${ }^{163}$ Dies ist in der deutschen Skandinavistik ein beforschtes Thema, als Beispiele können folgende Sammelbände dienen: Detering (Hg.) 1996; Detering et al. (Hg.) 2001; Fauth et al. (Hg.) 2014; Hoff et al. (Hg.) 2014.

164 Die Bedeutung der beteiligten Akteure für den Kulturtransfer benennt etwa Hans-Jürgen Lüsebrink, vgl. Lüsebrink 2012, S. 159. Auch Joachim Grage macht auf Institutionen als Vermittler literarischer Praktiken aufmerksam, vgl. Grage 2014, S. 112.

165 Gerogiorgakis et al. 2011, S. 448.

166 Espagne 2016, S. 45, vgl. FN 155.

167 Zur Diskussion des Begriffs ,Nation‘ vgl. z. B. Simanowski 1998, S. 34-35. Auf die Schwierigkeit einer Definition von ,Nation‘ weisen auch Udo Schöning und Burkhard Pohl hin. Sie betonen außerdem, dass die Verbindung mit Vorsilben wie ,inter oder ,trans` einen Begriff davon voraussetzen, vgl. Schöning und Pohl 2001, S. 9-10.

168 Vgl. ebd., S. 13.

${ }^{169}$ Ebd., S. 12-13.
} 
gab, kann es als ein Kulturraum betrachtet werden. Auch die enge Verwandtschaft der Sprachen spricht dafür. ${ }^{170}$

Skandinavien besteht dennoch aus Einzelstaaten. Zwischen ihnen ist ein Transfer von Ideen, Anschauungen und Gütern nicht immer notwendig, dennoch bleiben nationalstaatliche Gegebenheiten wichtig, wie am Beispiel des Literaturhauses sichtbar wird. Gleichzeitig gibt es Permeabilität, welche transnationale respektive skandinavische Überlegungen rechtfertigt. Dies ist gerade ein Argument für die Verwendung der Bezeichnung ,transnational' nach Frank Bösch und Hubertus Büschel. Für sie reflektiert ,transnational' die hartnäckige, langlebige, persistente Rolle von Nationen und nationaler Identität während der gegenwärtigen Globalisierung und der Schwierigkeiten, globale Strukturen genau zu erkennen und zu analysieren. ${ }^{171}$ Mit Verweis auf Anderson halten sie fest: „One can say that transnational perspectives mostly use ,imagined' nations or nationals only existing within political structures as the common basis of their analysis" 172 . Es handelt sich bei diesem Terminus von ,Nation' also um eine Hilfskonstruktion.

Die Beschäftigung mit Literaturhäusern macht deutlich, dass nationalstaatliche Vorgaben weiterhin zentral sind, weil kultur- und bildungspolitische Begrenzungen und doch eigene ,Traditionen` entscheidenden Einfluss auf die Literaturhaus-Ausgestaltungen haben. Politische Grenzen, die im vorliegenden Fall nicht zuletzt einen Sprachraum abstecken, prägen einen eigenen Literaturbetrieb. Obwohl wir übervernetzt sind, überschreiten literarische Texte nicht einfach nationale Grenzen, wie Alexander Starre es anmerkt. ${ }^{173}$ Der Beitrag von Schöning und Pohl ist folglich wichtig, denn

auch wenn Kunst sich dem Narrativ der Nation zunehmend widersetzt, weist die Analyse von Vermittlungsprozessen [...] die Interdependenz oder Simultanität von nationalen und internationalen Bezugnahmen im medialen Austausch nach, wobei ,Nation' allerdings weniger als historisch gewachsene Essenz denn als (politisch oder kulturell definierter) Wirtschaftsraum umrissen wird. ${ }^{174}$

Der Literaturbetrieb ist unter anderem ein Wirtschaftraum, der entscheidend von dem sprachlich fixierten Gebiet abhängt. Dies trifft auch auf die einzelnen skandinavischen Länder zu, die mentalitätsgeschichtlich große Gemeinsamkeiten aufweisen und kulturpolitisch eng zusammenarbeiten. ${ }^{175}$ Die Zuordnung des Literaturhauses zu Norwegen, Schweden oder Dänemark und gleichzeitig zu Skandinavien ist sehr nachvollziehbar.

\footnotetext{
170 Auf der anderen Seite wird in dieser Arbeit Deutschland und nicht etwa der deutschsprachige Raum in den Blick genommen. Da es hier um einen deutsch-skandinavischen Vergleich geht, werden Österreich und die Schweiz ausgeklammert.

${ }^{171} \mathrm{Vgl}$. Bösch und Büschel 2012, S. 372. Sie grenzen in ihrem Aufsatz, transnational ${ }^{`}$ von ,global ${ }^{`}$ ab und kommen zu diesem Resultat: „In fact, each concept focuses on a different subject. Transnational analyses are centered on interactions, connections and entanglement between persons, institutions or cultures across certain nations“, ebd. Vgl. dazu auch FN 142.

172 Ebd.

${ }^{173}$ Vgl. Starre 2015, S. 18. Bei Alexander Starre geht es im Zitat um das Produkt Buch, aber natürlich gilt das auch für den Literaturveranstaltungsbetrieb, obwohl dabei nicht ein fester Gegenstand transferiert wird, sondern ein in sich flexibles Objekt, das Literaturhaus-Konzept.

174 Schöning und Pohl 2001, S. 29.

175 Institutionalisiert ist diese Zusammenarbeit über den Nordisk Råd, vgl. dazu auch S. 388 sowie S. 448.
} 
Transferiert wird das Literaturhaus nicht nur bei der Übernahme in einem anderen Land. Mithilfe des Begriffes der Institution, die sich aus den vereinigenden Elementen verschiedener Einzeleinrichtungen konstituiert, wird offensichtlich, dass nicht erst der internationale Vergleich, die Gegenüberstellung unterschiedlicher größerer Kulturräume, hilfreich ist, sondern auch kleinere Radien die jeweiligen Literaturhäuser prägen. Deshalb geht es nicht nur darum, die Fallbeispiele nach nationaler Zugehörigkeit zu kontrastieren, sondern die einzelnen Häuser auch miteinander in Bezug zu setzen. Es lässt sich von „intrakulturellen Transfers“176 sprechen. In Skandinavien ist die entscheidende Bezugsgröße für die nachfolgenden Literaturhäuser - hier Bergen und Göteborg - dann Litteraturhuset in Oslo und nicht mehr die deutsche Idee.

Mit Blick auf das bisher Referierte ist die Doppelstellung des Literaturhauses zu beachten. Auf einer Analyseebene fungiert das Literaturhaus als Akteur der Literaturvermittlung. Auf einer anderen Untersuchungsebene kann es selbst als Kulturobjekt betrachtet werden, dessen Basiskonzept aus Deutschland ,importiert' wird. Die Institution ist dabei das Objekt der Vermittlung und Gegenstand der Rezeption und verändert sich gleichzeitig durch den Kontakt zu unterschiedlichen Umwelten. ${ }^{177}$ Das Literaturhaus ist also ein Literaturvermittler in dem Sinne, dass es Leser*innen und Autor*innen verbindet, dass es sich einsetzt für Literatur im Allgemeinen und ausgewählte Texte im Speziellen, dass es neue (internationale) Autor*innen der Öffentlichkeit vorstellt, bekannte Schriftsteller*innen einlädt und literarische Produktion ermöglicht. Es ist als Transferobjekt auch ein kultureller Transmitter in dem Sinne, dass es ortsspezifische Gewohnheiten und Praktiken reflektiert, dass es ein Verständnis von Literatur und literarischem Leben repräsentiert, das international wahrgenommen werden kann. Es macht ein literarisches Konzept des Landes für die Umgebung sichtbar. Kulturelle Eigenarten können nachverfolgt werden, wenn die Institution über Raum und Zeit analysiert wird.

\section{3.2.4 Skandinavischer Einfluss auf das deutsche Literaturhaus}

Das eindrucksvollste Literaturhaus, das ich kenne, steht in Oslo. Es hatte sich die deutschsprachigen Häuser zum Vorbild genommen, war aber noch einige Schritte vorangegangen. Der Besuch in Oslo war der Funke, um vor unseren Feiern des zehnjährigen Bestehens zu sagen: Wir müssen die ohnehin notwendigen Renovierungsmaßnahmen nutzen, das Haus weiterzudenken. ${ }^{178}$

Diese lobenden Worte über das Literaturhaus Oslo sprach Florian Höllerer zu seinem Abschied aus dem Literaturhaus Stuttgart, dessen Leitung er Ende 2013 für die Übernahme des Literarischen Colloquiums Berlin abgab. Höllerer hat nicht nur das Stuttgarter Haus aufgebaut, sondern war auch als Berater bei der Entwicklung des norwegischen Modells tätig. Bemerkenswert an dem Zitat und besonders auf-

\footnotetext{
${ }^{176}$ Lüsebrink 2012, S. 163, Hervorhebung im Original.

177 Auf „die komplizierte Lage, daß neben den inhaltlichen Transfers selbstverständlich auch auf der Ebene des Aufbaus der Institutionen Transfers stattfinden“, verweist Bernd Kortländer mit Blick auf die Transfers besonders von Universitätsmodellen, Kortländer 1995, S. 16.

178 Florian Höllerer zitiert nach: Friedl 2013.
} 
schlussreich für die Vergleichsperspektive ist es, dass der Blick der deutschen Literaturhäuser sich auch auf Oslo richtet. ${ }^{179}$ Dass sich die deutschen LiteraturhausAkteur*innen für die Osloer Variante interessieren, lässt erwarten, dass die modifizierte Ausgestaltung des deutschen Konzepts in Skandinavien auf die Programmatiken der deutschen Häuser zurückwirkt, wie das Zitat explizit vermittelt. Es liegt also keine monodirektionale Übernahme vor. Die Unterschiedlichkeit der Kulturräume kann besonders produktiv sein, wie Florian Höllerer zur Übertragung des Literaturhaus-Modells auf andere Länder, die auf den Ursprungskontext zurückwirken kann, sagt: „Allerdings kann gerade das Andere, das Nichtübertragbare, jenen zündenden Funken schlagen, der der eigenen Entwicklung eine unerwartete und neue Wendung gibt." "180

Diese Tatsache leistet einen empirischen Beitrag zur Weiterentwicklung des Kulturtransferansatzes, denn die Attribute ,Sender ${ }^{\varsigma}$ und ,Empfänger ${ }^{6}$ beziehungsweise Erst- und Zweitkontext lassen sich nicht nur jeweils auf einen Rezeptionskontext anwenden: Nicht nur der im ersten Schritt empfangende Akteur entwickelt das Objekt weiter, hingegen kann ebenso die Neuausrichtung des Konzeptes auf den ursprünglichen Sender zurückstrahlen, der dadurch selbst zum Empfänger wird. Dabei handelt es sich nicht um aufeinanderfolgende und abgeschlossene Sequenzen, sondern um parallele Entwicklungen, oft unreflektierte Einflüsse respektive unbewusste Adaptionen, komplexe Austauschprozesse „in einer Art Spiralbewegung““181. Für die Analyse bedeutet das, dass Veränderungen in den deutschen Programmen in der Regel nicht eindeutig auf die skandinavischen Einrichtungen zurückgeführt werden können. Wenn sich inhaltliche und konzeptuelle Annäherungen ergeben, müssen diese nicht auf einen direkten Einfluss zurückgehen. Der Nutzen des Vergleichs ist es schließlich nicht nur, zu erkennen, wo welche Idee entstand, sondern vor allem, Tendenzen der Literaturvermittlung herauszuarbeiten.

Dies korrespondiert methodisch mit dem Hinweis von Bernd Kortländer, dass es sein kann, dass „das Fremde“ häufig „bis zur Unkenntlichkeit“ in das Eigene eingearbeitet wird, sodass die Integration schwerlich wissenschaftlich gefasst werde kann. ${ }^{182}$ Dieser Aspekt kann für das Literaturhaus in Skandinavien ebenfalls diskutiert werden, weil zwar zunächst eine bewusste Integration des Konzeptes in das Eigene dokumentiert ist, doch im Verlauf die Referenz zum Ausgangsobjekt verschwimmt. ${ }^{183}$

\footnotetext{
${ }^{179}$ Gespräche mit deutschen Literaturhaus-Akteur*innen zeigen, dass Litteraturhuset in Oslo häufig als Idealtyp bezeichnet wird, was unter anderem an den Überlieferungen in dem relativ kleinen Literaturhaus-Netzwerk liegen kann.

${ }^{180}$ Höllerer 2007, S. 216.

${ }^{181}$ Espagne und Werner 1988, S. 34. Als ,nicht intentional' sind die Adaptionen hier bezeichnet, weil es wahrscheinlich ist, dass die Einrichtungen nicht nur beabsichtigt auf bestimmte Vorbilder zurückgreifen, sondern, dass viele Ideen Teil eines Diskurses sind, dass Aussagen unreflektiert reproduziert werden und nicht mehr klar auf einen Ursprung bezogen werden können.

182 Vgl. Kortländer 1995, S. 8. Das fehlende Bewusstsein ist sicherlich eine schwer untersuchbare Kategorie. Dies gilt auch für Formen ,der Verweigerung, der mentalen und kulturellen Resistenz, der NichtRezeption“, Lüsebrink 2012, S. 156. Dabei ist es, wie schon angedeutet, wenn nicht eindeutige Aussagen vorliegen, kaum prüfbar, ob absichtlich nicht transferiert wird oder ob es ganz andere Gründe für ein ,Fehlen von Etwas' gibt.

${ }^{183}$ So nannte zum Beispiel der Programmleiter des Osloer Literaturhauses Andreas Liebe Delsett im Gespräch im Dezember 2014 die Form der Literaturveranstaltung, die im Litteraturhuset den Hauptteil ausmacht, eine Osloer Besonderheit. Dabei ist die Parallele zur ,deutschen' moderierten Lesung offensichtlich. Dieses Beispiel veranschaulicht zum einen die Mobilität von literarischen Praktiken nach
} 


\section{3.3 Zwischenfazit}

Es liegt der vorliegenden Studie die Hypothese zugrunde, dass es zunächst Transferaber auch Austauschprozesse zwischen den Literaturhäusern gibt. Dass es sich dabei nicht respektive nicht immer um bewusste Entscheidungen der Akteur*innen handelt, schränkt die Anwendbarkeit der Forschungsbeiträge zum Kulturtransfer nicht ein - im Gegenteil unterstützt dies die Annahme, heuristisch hinsichtlich des konkreten Untersuchungsdesigns vorzugehen. ${ }^{184}$ Doch obwohl die Forschung zum Kulturtransfer eigentlich auf konkrete Beispiele anwendbar ist, lässt sich im vorliegenden Fall nur schwerlich empirisch rekonstruieren, wie sich die Literaturhäuser gegenseitig beeinflussen. Die Tatsache, dass die einzelnen Einrichtungen mehr oder weniger intensiv die Handlungen der anderen zur Kenntnis nehmen, findet selten direkten Niederschlag in der Hausgestaltung oder im Programm. Dies stellt jedoch kein Problem dar, denn die vorliegende Studie ist nicht primär bestrebt, Transferwege nachzuzeichnen, sondern baut auf der Annahme von Transferprozessen auf. Transfer und Austausch sind Bestandteil des Modells der Institution. Der Vergleich kommt dabei als „ein notwendiges Instrument der Transferforschung “185, der allerdings kein „genormtes Standardverfahren“ 186 darstellt, zum Einsatz.

Der komparative Ansatz, der offenlegt, welche Muster sich innerhalb der Institution Literaturhaus herauskristallisieren, findet auf unterschiedlichen Ebenen Anwendung: (1.) Jedes Fallbeispiel wird diachron über seine gesamte bisherige Existenzzeit bis einschließlich 2015 betrachtet. (2.) Alle exemplarischen Einrichtungen werden synchron untersucht und miteinander in Beziehung gesetzt. (3.) Die Literaturhäuser eines Kulturraumes werden denen eines zweiten gegenübergestellt. Dabei lassen sich die „Akteure, Gruppen und Objekte in ihren Beziehungsgeflechten mit ihren wechselnden Sinnzusammenhängen und sich wandelnden Identitäten“ 187 interpretieren. Primär geht es also um Erkenntnisse über die Institution Literaturhaus. (4.) Untrennbar damit verbunden, müssen ebenso die Kontexte, in denen dieser Gegenstand ,verwendet' wird, in die Analyse integriert werden. Das Literaturhaus stellt nämlich ebenso ein passendes Exempel für die Überlegungen zur Transformation innerhalb der Literaturvermittlung dar. Ändern sich Praktiken innerhalb des Literaturhauses, so wirken diese auf die Entwicklungen des Literaturbetriebes ein; gleichzeitig lassen sich Aktualisierungen innerhalb des Literaturhauses als Indizien

Joachim Grage, vgl. Grage 2014, S. 109. Zum anderen zeigen sich grundsätzliche Herausforderungen der empirischen Kulturtransferforschung.

184 Zur Überlegung, wie sich Transferprozesse nachweisen lassen, konstatiert Lüsebrink: „Fraglich ist außerdem, ob der Transfer-Begriff mehr als ein heuristisches Untersuchungsdesign sein kann, das bei der Anwendung jeweils der methodisch-sachlichen Präzisierung bedarf“, Lüsebrink et al. 2013, S. 17. Diese Ansicht teile ich grundsätzlich, doch ist der Transferbegriff als heuristisches Forschungsdesign nützlich das zeigt die vorliegende Arbeit.

185 Ebd.

186 Gerogiorgakis et al. 2011, S. 402. Sie sprechen mit ihrem Forschungshintergrund an, dass der Vergleich kein „genormtes Standardverfahren historiographischer Operationen schlechthin“ ist. Auch für literaturwissenschaftliche Studien bietet der Vergleich in Anlehnung daran kein Musterverfahren an.

187 Dücker und Müllerburg 2011, S. 571. Die Autor*innen beziehen diese Aussage zwar auf ihren Ansatz „Integration und Desintegration der Kulturen“, doch lässt sich diese Idee in diesem Falle aufgreifen. 
für eine sich wandelnde Umwelt interpretieren. Dies geschieht aus deutscher Perspektive mit Blick auf Skandinavien. ${ }^{188}$

\section{4 Vorgeschichte des Literaturhauses}

Bei der Frage nach den Ursprüngen und Traditionslinien des Literaturhauses sind zwei Momente zu berücksichtigen, die analytisch kaum voneinander zu trennen sind. Einerseits gilt es, die Praktik der Lesung respektive Literaturveranstaltung zu beleuchten, andererseits die Entstehung des Literaturveranstaltungsbetriebes. Das Literaturhaus stellt einen Raum und Akteur dar, der die Praktik der Lesung verstetigt und professionalisiert.

Die Literaturveranstaltungen im Literaturhaus sind gar nicht, wie die vorliegende Arbeit belegt, ausschließlich Lesungen in einem engeren Sinne. ${ }^{189}$ Hingegen gehört die Moderation zur ,klassischen' Literaturhaus-Lesung dazu. Dass dennoch häufig, auch in der vorliegenden Arbeit, von ,Lesung' die Rede ist, und damit eigentlich die moderierte Lesung gemeint ist, liegt daran, dass der Lesungsteil, zumindest in den deutschen Einrichtungen, weiterhin einen elementaren Bestandteil bildet, der historisch begründet ist.

\section{| 4.1 Lesungen}

Lesungen bilden einen wichtigen Teil der literarischen Kommunikation, jedoch tauchen sie beispielsweise in älteren Literaturgeschichten nur am Rande auf. Dies liegt, „so der Verdacht, in der Sache selbst, nicht in deren ignoranter Vernachlässi-

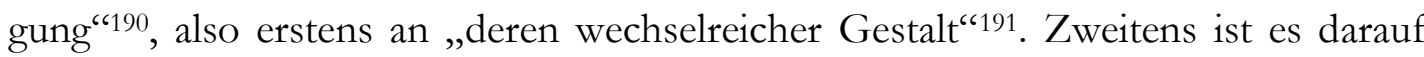
zurückzuführen, dass literatursoziologische Studien insgesamt erst in den letzten Jahren für die Literaturwissenschaft an Bedeutung gewonnen haben und drittens, dass die Arbeit von Autor*innen früher nicht so deutlich von Lesungen und öffentlichen Auftritten geprägt war wie heute - dies gilt zumindest bei Betrachtung der Rolle des Autors generell. Beiträge zu einzelnen Autor*innen, die einen bemerkenswerten Umgang mit ihrem Auftritt pflegten und/oder bei denen die Lesung Teil des Kunstkonzeptes war, liegen vor. Häufiger noch finden sich Äußerungen von Autor*innen, die sich über die meist ungeliebte Pflicht zur Lesereise äußern. Ein Lesebuch - keine Quellenedition - mit historischen Texten dieser Art legten Mitarbeiter*innen des Literaturarchivs Marbach vor, das einen Einblick in die Vielfalt von Lesungen bietet und die lange Tradition dieser Praktik bezeugt. ${ }^{192}$ Die Lesung als

\footnotetext{
${ }^{188}$ Für den Vergleich ist es wichtig, dies noch einmal zu betonen, weil ich als deutsche Skandinavistin auf den Gegenstand schaue. Einen Blick aus Norwegen auf den Literaturhaus-Vergleich wirft Gregersen 2014, S. 51-52.

189 Vgl. Kapitel II 13.2.

190 Berbig und Brandes 2013, S. 68.

191 Ebd., S. 68-69.

192 Erschienen sind drei Bände: Tgahrt (Hg.) 1984; Tgahrt (Hg.) 1989 sowie Tgahrt (Hg.) 1995.
} 
Kulturpraktik historisch und gegenwärtig aufzuarbeiten, setzte sich deshalb Thomas Böhm zum Ziel. Er hat unter anderem zwei Anthologien mit Texten von Autor*innen und Veranstalter*innen zum Thema herausgegeben. ${ }^{193} \mathrm{Im}$ Anschluss sind Lesungen zunehmend wissenschaftlich betrachtet worden. Nennenswert sind beispielsweise der vielzitierte Artikel von Gunter E. Grimm ${ }^{194}$ und ein Beitrag von Susan Esmann ${ }^{195}$. Beide nähern sich der Lesung unter anderem mit ästhetischen Fragestellungen an und begreifen sie als Paratext, worauf zurückzukommen sein wird. ${ }^{196}$ Grimm gibt darüber hinaus einen umfassenden Überblick über die historische Einordnung der heutigen Lesung, er konzentriert sich dabei auf die Lesung im engeren Sinne.

In der skandinavischen Forschung hat das Phänomen der Dichterlesung/Autorenlesung - ,forfatterlesning ${ }^{-}$- bisher kaum Beachtung gefunden. Dies liegt unter anderem schlicht daran, dass es Lesungen wie im deutschsprachigen Raum dort kaum gibt, Ausnahmen bilden Autor*innen, bei denen der Performance-Aspekt zum literarischen Konzept wird, wie in den 1960er-Jahren durch die Fluxus-Bewegung mit Autoren wie Bengt af Klingberg, Arthur Køpcke, Staffan Olzon oder Per Kirkeby. Katharina Müller nähert sich in ihrer Doktorarbeit der Autorenlesung um 1900 und stellt anhand von August Strindberg, Herman Bang und Selma Lagerlöf heraus, dass die Praktik der Dichterlesung zwar durchaus vorkam, jedoch kaum verallgemeinernd, sondern aufgrund der spezifischen Umsetzungen und Funktionalisierungen, die sie mit der Inszenierung der Autor*innen und ihres Werks verknüpft sieht, eher in Einzelfällen beschrieben werden kann. ${ }^{197}$ Auch bei den von ihr untersuchten ersten Lesetouren zeigt sich, dass die Autor*innen entweder gar nicht vorlasen, sondern Vorträge hielten (Strindberg), ihre Texte rezitierten (Bang) oder sich explizit als „Märchentante“ inszenierten (Lagerlöf), was in allen drei Fälle auf eine bewusste Inszenierung ihrer Autorschaft hinweise. ${ }^{198}$

\section{Lesungen im literarischen Salon}

Wie in anderen Beiträgen bereits ausführlich dargestellt, ${ }^{199}$ bildet der literarische Salon einen Referenzpunkt für das Literaturhaus. Dies ist vor allem der Fall, weil er

\footnotetext{
193 Böhm (Hg.) 2003 und Böhm (Hg.) 2006. Thomas Böhm war Programmleiter des Literaturhauses Köln und auch Initiator der Website wmw.lesungslabor.de, die Informationen zur Lesungspraxis, ihrer Geschichte und Kontextualisierung bieten wollte. Seit dem 07.02.2005 ist sie allerdings nicht mehr aktualisiert worden und es ist nur die Startseite noch erreichbar, auf die Unterseiten besteht von Außen kein Zugriff mehr (Stand: 30.08.2018). Daneben gibt es einige anwendungsorientierte Publikationen für Autor*innen und/oder Veranstalter*innen, vgl. z. B. Haag 2001, Moldenhauer und Bitter 2005, Reifsteck 2005 sowie Uschtrin 2015.

194 Vgl. Grimm 2008.

195 Vgl. Esmann 2007a.

196 Vgl. S. 100 sowie S. 369. Einzubeziehen ist in Lesungsanalysen folglich unbedingt die performative Dimension. Diese untersucht beispielsweise Lena Vöcklinghaus in ihrer an der Universität Frankfurt entstehenden Doktorarbeit. Ein Modell zur Lesungskritik schlägt beispielsweise Hanns-Josef Ortheil vor, vgl. Ortheil 2005. Auch Lena Dircks hat in ihrer Masterarbeit Lesungen im Horizont einer Ästhetik des Performativen betrachtet, vgl. Dircks 2016.

197 Vgl. Müller 2018, S. 149.

198 Vgl. ebd., S. 147-148.

${ }^{199}$ Susann Sophie Schmitt z. B. geht auf diese Vorläufer sehr ausführlich ein, vgl. Schmitt 2016, S. $37-59$. Auch etwa Sonja Vandenrath zieht diese Verbindungslinie, vgl. Vandenrath 2002, S. 173.
} 
ebenfalls einen sozialen Aspekt und die Beschäftigung mit gegenwärtiger Literatur kombiniert. Der literarische Salon stellt damit einen Vorläufer jeglicher mit Geselligkeit kombinierter Auseinandersetzung mit Literatur dar, „denn der Salon ist ein für Europa einzigartiger Raum kulturhistorischen Geschehens und sozialer Entgrenzung gewesen. Ausgehend von einem feudalen System, hat er die Öffnung zur intellektuellen bürgerlichen Gesellschaft vorweggenommen und teilweise eingeleitet." 200

Entscheidender Unterschied zwischen Literaturhaus und literarischem Salon ist die Tatsache, dass das Literaturhaus ein allen zugänglicher Ort ist in dem Sinne, dass der Zutritt nicht nur auf exklusive Einladung möglich ist, wie es für den literarischen Salon entscheidend ist. Gesagt ist mit dieser Bezugnahme vor allem, dass mit dem Literaturhaus nicht etwas gänzlich Neues erfunden wurde. Viel interessanter ist es, zu fragen, welche Entwicklungen dazu führten, dass seit 1986 eine Institution entstand, die die öffentliche literarische Auseinandersetzung und Kunstpräsentation zu ihrer Hauptaufgabe machte. Dazu reicht es nicht, nach Vorbildern für sozialgerahmte Auseinandersetzung mit Literatur zu suchen, sondern müssen die Entwicklungen des Literaturbetriebs und der Literatur insgesamt Berücksichtigung finden. Dabei spielen kulturpolitische Entwicklungen eine Rolle.

\section{4.2 Professionalisierung des Literaturveranstaltungsbetriebs}

Die Darstellung des deutschen Literaturbetriebs muss mit zwei zentralen Organen beginnen, die Helmut Böttiger als Erfinder des deutschen Literaturbetriebs vorstellt. ${ }^{201}$ Böttiger hat die Geschichte des Autors, Literaturwissenschaftlers und kritikers Walter Höllerer und der Gruppe $47^{202}$ untersucht und ihre Bedeutung herausgestellt. ${ }^{203}$ Auch die moderierte Lesung, bei der die Autor*innen nicht nur lesen, sondern über ihre Arbeit sprechen, findet hier ihren Ausgangspunkt.

\section{| 4.2.1 Literaturkritik vor Publikum - Gruppe 47}

Ein wichtiger Akteur, der das Interesse an Gegenwartsliteratur beförderte, ist für den Literaturbetrieb - in erster Linie für den deutschen Markt, aber im Transfer auch in anderen Regionen - die Gruppe 47.204 Bei den Jahrestagungen dieser nicht-

\footnotetext{
${ }^{200}$ Heyden-Rynsch 1995, S. 229. Vgl. auch Kapitel I 5.7.

${ }^{201} \mathrm{Da}$ es hier um die Gründungsbedingungen für die Idee eines Literaturhauses überhaupt geht, bleibt die skandinavische Situation an dieser Stelle größtenteils ausgeblendet, hin und wieder ergänzen Hinweise auf Parallelen oder Differenzen die Darstellung.

202 Zur Gruppe 47 vgl. auch Arnold 1987.

${ }^{203}$ Er betont zugleich, dass vor allem der Nachhall dieser Phänomene heute noch spürbar sei, und sie nicht direkt anschließbar an heutige literarische Praktiken seien, vgl. Böttiger 2012, S. 17.

${ }^{204}$ Eine Randbemerkung für die vorliegende komparative Arbeit: Es lässt sich in der Gruppe 47 auch ein Bestreben zum internationalen Austausch erkennen. In der Tagung 1963 im schwedischen Sigtuna, bei der vor allem Gustav Korlén als Vermittler aktiv war, habe, so Benzinger, der Beginn für Austausch von deutscher und schwedischer Gegenwartsliteratur gelegen. Die Wirkung der Gruppe 47strahlte also auch beispielsweise nach Schweden aus. „Unter dem Schlagwort, Weg von Provinzialismus“ wurden in Schweden gleichzeitig stärkere Bezüge zur deutschsprachigen Literatur gefordert und eine Internationalisierung des kulturellen Lebens angestrebt.“ Es sei um einen vertieften europäischen Kontakt gegangen. „In diese
} 
institutionalisierten literarischen Vereinigung haben sich erstmals nach dem Zweiten Weltkrieg neue literarische Stimmen vorgestellt, die ästhetische Diskussionen führten, die ein kulturgeschichtliches Zeugnis für die intellektuelle Entwicklung der Bundesrepublik darstellten, betont Böttiger. ${ }^{205}$ Erst dieser Kreis ermöglichte es, ihre Suche nach innovativen literarischen Ausdrucksformen für politische Themen offen auszuprobieren und zu problematisieren. Peter Gendolla zufolge stehe die Gruppe 47 für „eine Auflösung und eine Neukonstruktion zugleich“, denn mit ihr vollziehe sich einerseits „das „Ende“ der tradierten Formen der Literatur des Buchs“ und andererseits ,ihre Überführung, Integration (oder Dekonstruktion) in die Text-BildTon-Welten von Zeitung, Radio, Film und Fernsehen."206 Somit waren die Jahrestreffen wichtige Einrichtungen zur gegenwartsliterarischen Diskussion.

Die massenmediale Beeinflussung, die entscheidend zur Breitenwirkung der Gruppe beitrug, betraf nicht nur die Literaturproduktion, sondern auch ihre Präsentation, denn ,hier entwickelten sich die Mechanismen von Erfolg und Misserfolg, von öffentlicher Resonanz. "207 In der Folge wirkte die dort geäußerte Kritik als Auswahlinstrument des Marktes. „Durch diese Art der Vorkritik griff die Gruppe 47 in den Prozeß literarischer Meinungsbildung ein und wurde zunehmend als literarisch-kulturelles Legitimationsorgan der Öffentlichkeit“"208 aufgefasst. So hatten diese Zusammenkünfte den Charakter einer auch internationalen Literaturbörse und sorgten für eine Weiterentwicklung des Literaturmarktes, der Literaturkritik und des öffentlichen Auftritts von Autor*innen.

Gespräche über Literatur inklusive betrieblicher „Klatschgeschichten und Intrigen“ verdichteten sich in Deutschland bei den Jahrestagungen der Gruppe 47. Böttiger hält ferner fest, dass die Teilnahme die Voraussetzung für Autor*innen gewesen sei, „im Gespräch zu bleiben“209 - womit er beide Konnotationen des Ausdrucks meint, denn es bestand dort die Möglichkeit, sich erstens mit Kolleg*innen auszutauschen und zweitens als Schriftsteller*in medial und im Fachdiskurs wahrgenommen zu werden. Dabei war gerade der Doppelcharakter von Privatheit durch das Werkstattformat im Freundeskreis und Öffentlichkeit über die mediale Verbreitung für die Etablierung der Gruppe 47 leitend, ${ }^{210}$ der für heutige Literaturveranstaltungen insgesamt typisch ist und den Reiz für die beteiligten Akteur*innen ausmacht. ${ }^{211}$ Der Aspekt der expliziten Vernetzung, der für den Literaturbetrieb insgesamt und das Literaturhaus speziell ebenfalls zentral ist, fand folglich in dieser Autorengruppe seinen Anfang. So kommt Helmut Böttiger zu dem für die Untersuchung des Literaturhauses hilfreichen Fazit:

\footnotetext{
Richtung wirkten, neben den literarischen Interessen, auch akademische und wirtschaftliche Triebkräfte", Benzinger 1983, S. 41.

205 Vgl. Böttiger 2012, S. 12. Ihr gesellschaftskritisches Selbstverständnis und die im weitesten Sinne realistische Ästhetik konnten die politisch-publizistisch orientierten Autoren, die die Weimarer Republik als junge Männer noch erlebten, dort äußern, vgl. Hehl 2013, S. 179.

206 Gendolla 1997.

207 Böttiger 2012, S. 15.

208 Berg 1997, S. 91. Allerdings lässt sich nicht bestätigen, dass es je zu einer Monopolisierung des deutschen Buchmarktes durch die Gruppe 47 gekommen sei, obgleich sie Einfluss auf einzelne Verlage hatte, vgl. Meyer 2013, S. 172.

209 Böttiger 2012, S. 273.

${ }^{210}$ Vgl. Latsch 1997, S. 119.

211 Vgl. Kapitel I 5.6.3.
} 
Was von der Gruppe 47 geblieben ist, ist nicht ihre gesellschaftspolitische Stoßrichtung oder ihr Selbstverständnis von der Verantwortung des Schriftstellers. Es ist vielmehr die mit ihr einhergehende ,Eventisierung des literarischen Geschehens, es sind die unumgänglichen Marketingkonzepte für die Verbreitung von Literatur, für ihre Vermittlung und Rezeption. Außerliterarische Kriterien spielen bei den immer neu zu entwickelnden Formaten keine geringe Rolle. ${ }^{212}$

Allerdings sei betont, dass das Moment der Live-Kritik, das bei den Jahrestagungen entscheidend war, heute eher bei Literaturwettbewerben wie dem 1976 installierten Ingeborg-Bachmann-Preis oder dem seit 1993 vergebenen Open Mike noch eine Rolle spielt. Bei Literaturhaus-Lesungen setzen die Autor*innen ihre unveröffentlichte Texten nicht direkter Kritik aus, sondern stellen vornehmlich Publiziertes vor. Während die Gruppe 47 neben der Bühne für aufstrebende Autor*innen vor allem eine Präsentationsform und Professionalisierung der Literaturkritik voranbrachte, stehen im Literaturhaus die Autor*innen und ihre Text im Vordergrund.

\section{4.2.2 Sprache im technischen Zeitalter - Walter Höllerer und das $L C B$}

Einen Beitrag dazu, „der Literatur im Institutionengeflecht der sich rasant verändernden Gesellschaft der 1960er Jahre einen festen Platz zuzusichern“213, leistete maßgeblich der Schriftsteller, Literaturwissenschaftler, -kritiker und -organisator Walter Höllerer (1922-2003), der unter anderem der Gruppe 47 angehörte. Entsprechend lohnt sich ein kurzer Blick auf die von ihm angestoßenen Neuerungen.

\section{Literarisches Colloquium Berlin}

Walter Höllerer führte die literarische Großveranstaltung ein, nutze mediale Möglichkeiten und stellte sie in Verbindung zu ästhetischen Fragen. Darüber hinaus geht auf ihn die Gründung des Literarischen Colloquiums Berlin (LCB) zurück. Mit der Bezeichnung des $L C B$ als „[d]ie ,Urmutter“ all dieser Häuser“214 unterstreicht Anja Johannsen die Relevanz dieser Einrichtung am Wannsee für die folgenden Literaturhäuser. Allerdings ist das LCB dahingehend als Solitär einzuordnen, dass es aufgrund seiner geografischen Lage und seiner Residenzprogramme für Autor*innen und Übersetzer*innen von Beginn an nicht so sehr zentrales Publikumshaus war, sondern im Sinne eines Colloquiums immer auch ein überregionaler und doch interner Treffpunkt für Expert*innen. ${ }^{215}$ Die dahinterstehende Idee, Literatur, Literaturkritik und Literaturwissenschaft öffentlich zusammenzubringen und mittels Veranstaltungen zu präsentieren, ${ }^{216}$ findet sich im Literaturhaus jedenfalls fortgesetzt, sodass vieles dafür spricht, das LCB als das erste funktionale Literaturhaus zu ver-

\footnotetext{
212 Böttiger 2012, S. 436.

213 Geisenhanslüke und Hehl 2013, S. 13.

214 Johannsen 2013a, S. 63.

215 Der vom LCB zu seinem 50. Jubiläum herausgegebene kleine Band, gestaltet von der Buchkünstlerin Judith Schalansky, liefert mit Fotos der Hausfotografen Renate von Mangoldt und Tobias Bohm schöne Einblicke in die Atmosphäre in dieser Einrichtung am Wannsee. Die als Glossar angeordneten Beiträge von vielen Autor*innen illustrieren die Stimmung und Besonderheit des LCB und enthalten pointierte wie ironische Erläuterungen zum Literaturbetrieb, vgl. Schalansky (Hg.) 2013.

216 So sei es, initiiert durch die Person Walter Höllerer, im LCB geschehen, vgl. Böttiger 2005, S. 9.
} 
stehen. ${ }^{217}$ Durch die moderierte Lesung und die Schaffung eines öffentlichen Ortes des literarischen Austausches trug Walter Höllerer - der erste Literaturmanager ${ }^{218}$ und „aufgrund seiner polykontexturalen und mehrfachinkludierten Position im institutionellen und medialen Geflecht des literarischen Lebens seiner Zeit eine durch und durch exzeptionelle Erscheinung “'219 - zur Institutionalisierung der Literaturvermittlung durch Veranstaltungen bei.

\section{Ästhetisches Anknüpfen}

Neben diesen eher organisationalen und konzeptionellen Linien zeigt die vorliegende Arbeit, dass die Literaturhaus-Programme in den Anfangsjahren auch inhaltlich an Höllerers Projekte und seine literarästhetischen Vorstellungen anschlossen. Mit Höllerers öffentlichen Veranstaltungen „endete eine Ära deutscher Nachkriegsliteratur" ${ }^{\prime 20}$, wie Berbig und Brandes es darstellen. Auch Michael Peter Hehl zufolge stehen Walter Höllerer und Hans Werner Richter, der Initiator der Gruppe 47, für die Differenz innerhalb des literarischen Feldes der 1960er-Jahre. Während die Gruppe 47 unmittelbar nach Ende des Zweiten Weltkrieges vornehmlich realistische Schreibverfahren einsetzte, suchte Höllerer die Anknüpfung an die literarische Moderne, an die Neo-Avantgarde. ${ }^{221}$ „Höllerer fokussierte nicht auf den Klärungsbedarf jüngster deutscher Vergangenheit, sondern auf Anschluss an den Technikdiskurs.“222 Mit der durch seine Formulierung „Literatur und Sprache im technischen Zeitalter" proklamierten Ausweitung lenkte er den Fokus schon früh auf die technischen Neuerungen und vor allem auf ihren Einfluss auf die Sprache im Allgemeinen und die Literatur im Speziellen und interessierte sich, auch in seinem eigenen Schreiben, für die Avantgarde-Bewegungen der 1960er-Jahre, die Höllerer nicht gerne so, sondern lieber als Veränderungen bezeichnet habe. ${ }^{223}$ Walter Höllerer selbst stellte heraus, dass die ästhetische Beschäftigung mit der technisierten Gegenwart im Zentrum stehe: „Dieser Leseabend wird sich [...] nicht auf technische Motive beschränken. Das hieße den Ausdruck ,technisches Zeitalter' zu negativ auslegen. Er wird Ordnungsversuche zeigen in einer vor der Technik bewährten Wirklichkeit.“224 Dabei forderte er, wie es sich später im LCB noch deutlicher zeigte, keine Beschränkung auf Literatur, sondern bezog auch etwa Theater oder Film mit ein, was andeutete, dass im technischen Zeitalter die Grenzziehungen zwischen den künstlerischen Ausdrucksformen nicht streng gezogen werden sollten. Die Beschäftigung mit Fragen, wie Literatur Gegenwart fassen kann, findet später mit dem Literaturhaus eine Institution.

\footnotetext{
217 Vgl. dazu auch Kapitel II 4.1.

218 Vgl. Böttiger 2005, S. 8.

${ }^{219}$ Geisenhanslüke 2013, S. 8. Deutlich wird am LCB, an der Internationalen Lesereihe und Sprache im technischen Zeitalter ebenso, wie wichtig das Engagement einzelner Personen für die Entstehung und Ausgestaltung derartiger Unternehmungen ist - ein Aspekt, der für die Rekonstruktion der Institution Literaturhaus nicht zu unterschätzen ist.

220 Berbig und Brandes 2013, S. 82.

221 Vgl. Hehl 2013, S. 179-180.

222 Berbig und Brandes 2013, S. 80.

223 Vgl. Böttiger 2005, S. 145.

224 Walter Höllerer in seiner Eröffnungsrede der Lesereihe zitiert nach: ebd., S. 135.
} 
Literatur und Sprache im technischen Zeitalter

Das, was heute als ,Autorenlesungen' etwa im Literaturhaus typisch ist, ist geprägt von den Veranstaltungsreihen in Westberlin, die Höllerer ins Leben rief, die „Geschichte geschrieben haben, die nahezu mythisch geworden sind“225. Die offiziell im Januar 1960 gestartete Reihe, die sich zur literarischen Großveranstaltung entwickelte, ${ }^{226}$ lief zuerst unter dem Namen Literatur im technischen Zeitalter - angelehnt an das Institut Sprache im technischen Zeitalter, das Höllerer an der Technischen Universität Berlin gründete, und die 1961 gestartete Zeitschrift gleichen Namens, die bis heute vom Literarischen Colloquium Berlin herausgegeben wird - später unter dem Titel Internationale Lesereibe. Sie brachte jeden Montag im Semester Autor*innen vor ein stetig anwachsendes Publikum und, wie Helmut Böttiger darstellt,

zum ersten Mal unmittelbare Zeitgenossenschaft, brachte die Moderne nach Berlin. [...] Dabei handelte es sich um nichts weiter als Autorenlesungen - allerdings in einer Form, die sehr neu und ungewohnt war und heute selbstverständlich ist: Höllerer hatte wie nebenbei die ,moderierte Lesung' salonfähig gemacht, das öffentliche Gespräch mit dem Autor vor und nach seiner Lesung. ${ }^{227}$

Lesungen selbst sind keinesfalls eine Innovation dieser Zeit, Gespräche mit der Person des Autors passten aber nicht ins weihevolle Bild des Autors als Genie. Höllerer führte die Lesung als Event ein, das sei eine Neuerung gewesen, die vorher nicht bekannt gewesen sei, wie es Helmut Böttiger sieht, ${ }^{228}$ das Eventartige daran sei der Talkshowcharakter der Lesung: Ein Moderator spricht mit dem Autor und setzt damit dessen Person in den Mittelpunkt. Höllerer ,modifizierte‘ die übliche Präsentationsform, indem er die Lesungen massenmedial in Szene setzte und die Moderationsinstanz ergänzte. Das mediale Echo lässt sich als eine Kennzahl dafür auslegen, dass diese Art der Veranstaltung in breiter Öffentlichkeit auf Interesse stieß, dass also seitens des Publikums Neugier bestand, die Autor*innen live zu erleben.

$\mathrm{Zu}$ unterstreichen ist, dass diese Veranstaltungen aufgrund des großen Publikumsinteresses zum Teil im Fernsehen übertragen wurden. Aufgrund der Fokussierung auf das Podium, die schon bei den Jahrestagungen der Gruppe 47 durch die Kamera noch verstärkt wurde, sind auch Publikum und Podiumsgäste klar voneinander abgegrenzt. Gemeinsamkeiten mit einem literarischen Salon sind folglich nur noch rudimentär vorhanden. „Er [der Schriftsteller, Anmerkung C. L.] kann nicht angesprochen oder befragt, sondern nur noch angestarrt werden“"229, wie Marcel Reich-Ranicki schon 1962 in der eingangs zitierten Glosse zugespitzt formuliert, die „pure Sensationsgier“ führe das Publikum in den Hörsaal. Durch die mediale Inszenierung entstand eine Wahrnehmung des Autors als Mischung aus nicht mehr unantastbarem Autor als Größe über dem Text und massenmedialer Inszenierung der Figur als Star.

\footnotetext{
225 Böttiger 2005, S. 7. Diese Publikation ist das Begleitbuch zur Ausstellung über Walter Höllerer, die passenderweise im Literaturhaus Berlin stattfand.

${ }^{226}$ Im Herbst 1959 gab es die eher inoffizielle Eröffnung mit Günther Eich und Ilse Aichinger, vgl. ebd., S. 123-124. Zur auch thematischen Schärfung der Reihe vgl. Berbig und Brandes 2013. 227 Böttiger 2005, S. 7.

228 Zusätzlich zu den zitierten Publikationen gehen diese Informationen auf ein Gespräch mit Helmut Böttiger am 20.06.2014 in Berlin zurück.

${ }^{229}$ Reich-Ranicki 1962.
} 
Dabei habe Walter Höllerer jedoch nicht einer anspruchslosen Unterhaltungskultur gedient, sondern sei immer daran interessiert gewesen, literarische Talente zu befördern. „Er hatte ein untrügliches Gespür für das, was man damals ,Avantgarde nannte; er bemühte sich um die Autoren, um die es wirklich ging. Und er hatte großen Spaß daran, sie zu inszenieren. "230 Die Inszenierung der Autor*innen war dort also nicht Selbstzweck, sondern diente der Vorstellung neuer Literatur und vor allem ihrer anschließenden Diskussion - in massenmedialem Kontext ebenso wie im akademischen Umfeld.

\section{4.2.3 Rahmenbedingungen für Autor*innen}

Es lohnt sich für das Verständnis der Institution Literaturhaus außerdem, die Rahmenbedingungen, unter denen Autor*innen tätig sind, zu berücksichtigen: Die Professionalisierung des Autorenberufs fand entscheidend zu der Zeit statt, in der sich die ersten Literaturhäuser entwickelten. Die 1958 seitens des Vorgängers des heutigen Schriftstellerverbandes gegründete Verwertungsgesellschaft Wort und insbesondere die seit 1983 in Deutschland existierende Künstlersozialkasse sorgen seitdem für finanzielle und soziale Absicherung von Autor*innen. Außerdem organisierten sich die Schriftsteller*innen gewerkschaftlich, womit ihre Rechte gefestigt wurden. Dafür entscheidend ist die Gründung des Verbands deutscher Schriftstellerinnen und Schriftsteller 1969, der sich in der vereinten Dienstleistungsgewerkschaft (ver.di) zur stärksten Interessenvertretung für Autor*innen und Übersetzer*innen entwickelte. ${ }^{231}$ Damit wurde Schriftsteller*in als ausgeübter Beruf anerkannt. Diese Infrastruktur ermöglichte und erforderte gleichzeitig neue Erwerbsoptionen für Autor*innen. Sie generieren Einnahmen schon länger nicht nur über Buchverkäufe, sondern zum Beispiel über die multimediale Vermarktung ihrer Texte, also mit Honoraren aus Vorabdrucken und Hörfunksendungen, was besonders in der Nachkriegszeit in der Bundesrepublik eine übliche Einkommensquelle für Schriftsteller*innen darstellte. ${ }^{232}$ Mit Lesungen und Vorträgen ergaben sich weitere Verdienstoptionen, sie gehörten bald zum Berufsbild des Schriftstellers.

Dies geht einher mit der Vorhersage, die Funk und Wittmann bereits 1983 formulieren: Entgegen ökonomisch fundierter Prognosen, die den „,Medienautor ${ }^{6}$ als Überlebensstrategie für den ,freien Autor“" vermuteten, herrsche unter den Schriftsteller*innen nicht der ,Medienautor ${ }^{6}$ vor, sondern stünde gleichbedeutend neben ihm weiterhin der Schriftsteller, der sich auf ein einziges Medium beschränke. ${ }^{233}$ Mehr als dreißig Jahre und entscheidende mediale Umbrüche später lässt sich immer noch konstatieren, dass viele Autor*innen vornehmlich Verfasser*innen von Literatur sind und sie ihre Arbeiten mittels Büchern veröffentlichen, was auch die vorliegende Arbeit unterstützt. Der florierende Literaturveranstaltungsbetrieb ermöglicht es vielen finanziell, sich auf Literatur fokussieren zu können. Doch „der traditionelle

\footnotetext{
230 Böttiger 2005, S. 8.

${ }^{231}$ Vgl. Plinke 2005, S. 34-35. Er nimmt auch an, dass Agenturen dafür sorgen, dass heute die Verbände weniger wichtig seien, da die Agent*innen beispielsweise die Honorarverhandlungen für die Autor*innen führen.

${ }^{232}$ Vgl. Wagner 2007, S. 120.

233 Vgl. Funk und Wittmann 1983, S. 591-592.
} 
Konflikt zwischen ästhetischem Anspruch und ökonomischer Notwendigkeit" ${ }^{\text {‘234 }}$ bleibt trotzdem bestehen - für Autor*innen wie für Literaturvermittler*innen.

\section{| 4.2.4 1968er-Bewegung - Politisches Engagement}

Die Entwicklung der Literaturveranstaltungen von diesen Großveranstaltungen hin zu den ersten Literaturhäusern erfährt Ende der 1960er-Jahre eine Zäsur. Die Internationale Lesereibe endet, was abgesehen davon, dass das LCB sich zunehmend als literarischer Ort etablierte, mit Blick auf die Zeitgeschichte nachvollziehbar ist.

Bei Walter Höllerers Lesungsreihe wurden zwar die Autor*innen relevanter, doch weiterhin galt dort das bürgerliche Ideal, Literatur als Kunst zu begreifen. Die Lesungen fanden dabei im institutionalisierten Universitätskontext statt, der im Zuge der 68er-Bewegung infrage gestellt wurden. Der kunstfokussierte Blick bei den literarischen Großveranstaltungen wurde abgelehnt, die Zeit der Internationalen Lesereibe war Ende der 1960er-Jahre als eine Form des Bildungsbürgertums vorbei. Im Zuge dieser Politisierung des Kulturlebens gestalteten auch die Autor*innen ihre Rollen neu. Schriftsteller*innen waren nicht mehr verehrungswürdige, distanzierte Kunstgenies, sondern politisch engagierte Sprecher*innen. Die bürgerliche Lesung wurde damit abgelöst von basisdemokratischen Debatten. Nicht so sehr nach ästhetischen Wertmaßstäben, sondern nach gesellschaftspolitischer Aussagekraft wurden die Texte beurteilt. „Der politisch engagierte Autor, in Verbänden organisiert und in vielen Medien beheimatet war die Leit- und Zukunftsfigur der Literaturstrategen " 235 , wie Holger Funk und Reinhard Wittmann zeitgenössisch festhielten. Daneben wurde, wie erwähnt, ,Autor' für viele zur Berufsbezeichnung, nicht nur zur Berufung.

\section{| 4.2.5 1980er-Jahre - Zurück zur Kunst}

Die Vorstellung des politisch engagierten Autors habe sich, so Funk und Wittmann, in den 1980er-Jahren wieder geändert. Die jungen Schriftsteller*innen haben zusehends ein neues Selbstverständnis angenommen. Sie seien nur noch selten in Verbänden organisiert gewesen, „sie suchen sich ihre Öffentlichkeit unterhalb der staatlichen Einrichtungen; sie trennen politische Praxis und Schreiben oder setzten zumindest das Verhältnis beider nicht umstandslos ineins. "236 Literatur war nicht länger ein Instrument politischer Agitation, sondern wurde als Literatur selbst zurückerobert. ${ }^{237}$ Allerdings stellte sich damit, wie Renate von Heydebrand anmerkt, ein Zustand her, ,in dem Literatur mehr oder weniger auf ein privates Freizeitver-

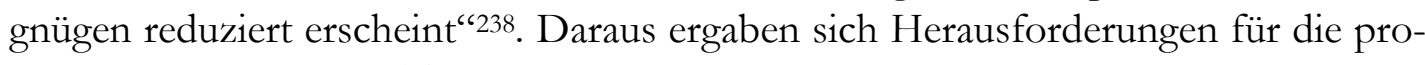
fessionell mit Literatur Tätigen. Neben den ökonomischen Aspekten, weil etwa Autor*innen und Buchhändler*innen auf Einnahmen angewiesen sind, fehlte es an einem öffentlichen Austausch über Literatur. Die Annahme sieht 1992 etwa

\footnotetext{
234 Wegmann 2005a, S. 30.

${ }^{235}$ Funk und Wittmann 1983, S. 591.

${ }^{236}$ Ebd., S. 591-592.

237 Vgl. Schnell 2013, S. 654.

${ }^{238}$ Heydebrand 1993, S. 12.
} 
Wilfried Weber, Hamburger Buchhändler und Mitgründer des LiteraturhausVereins, als Grund für die Entstehung der Literaturhäuser:

Den Mangel an Kommunikation auf dem Buchmarkt, den Ausfall des Dialogs zwischen Buchhändler und Leser können die Literaturhäuser kompensieren. In lockerer Atmosphäre, in der die Stimmung der legendären Kaffeehäuser lebendig wird, hat man, ohne einem Kaufzwang unterworfen zu sein, Anteil am literarischen Leben. ${ }^{239}$

Diese ideelle Motivation zur Einrichtung des Literaturhauses traf dabei auf eine kulturpolitische Situation, die die Umsetzung der Idee ermöglichte.

\section{| 4.2.6 ,Kultur für alle' - Kulturpolitik und Finanzierung}

Die sozialdemokratische Regierung unter Bundeskanzler Willy Brandt, die Anfang der 1970er-Jahre mit dem Slogan „Mehr Demokratie wagen“ agierte, förderte explizit auch eine demokratischere Kultur. Der damalige Frankfurter Kulturdezernent Hilmar Hoffmann prägte mit seinem Konzept „Kultur für alle“ jahrelang die deutsche Kulturpolitik, es wirkt bis heute fort. ${ }^{240}$ Zentral darin ist die Erweiterung des Gegenstandbereichs als „Ablösung der Tradition, die den Kulturbegriff ausschließlich an die Institutionen der Kultur bindet" ${ }^{\text {"241 }}$, der damit eine enge Verbindung zum alltäglichen praktischen Leben unterhalte. Damit verbunden war nicht in erster Linie eine Popularisierung der Programme, sondern der Versuch, allen Bürger*innen Zugang zu den gemeinhin als Hochkultur bezeichneten Künsten zu verschaffen, und zwar durch Vermittlung - „das neue Hauptwort der Kulturpolitik“242.

Da kulturpolitische Entscheidungen sich auf den gesamten Kulturbetrieb auswirken und nicht nur die öffentlichen Einrichtungen prägen, formen diese Ideen und ihre Umsetzungen auch das Literaturhaus mit. Auch erste Literaturfestivals entstanden in dieser Zeit. Das Literaturhaus konzipierten zwar nicht allein politische Akteur*innen, doch unterstützten diese es, weil darin eine Chance lag, Literatur basisdemokratisch zu vermitteln. Die Programmverantwortlichen der Literaturhäuser hingegen sahen darin zugleich die Möglichkeit, Platz in der Öffentlichkeit für Literatur als Kunst einzuräumen, wie das Zitat von Wilfried Weber oben bezeugt. Mit der Erweiterung des Kulturbegriffs etwa auf Stadtteilkultur oder Soziokultur verkleinerte sich dementsprechend das Budget für Kunst, also Kultur in einem engeren Sinne. Zugleich ergab sich im Zuge der zunehmend geforderten wie geförderten Vermittlung von ästhetischem Interesse an Literatur für die Literaturhaus-Begründer*innen die Option, von der neuen Ausrichtung der Kulturpolitik zu profitieren respektive überhaupt auf die Literaturhaus-Idee gebracht zu werden.

Die Bürger*innen, die diese Literaturhäuser tatsächlich initiierten, hielten aber durchaus ein bildungsbürgerliches Verständnis von Kultur hoch, wie sich am Literaturhaus Berlin zeigt, ${ }^{243}$ und nutzen dieses zur Distinktion. ${ }^{244}$ Als ab 1982, mit der Wahl Helmut Kohls zum Bundeskanzler, sich auch die Kulturpolitik wieder konser-

239 Weber 1992, S. 422. 
vativer ausrichtete, stieß diese literatursoziologisch gesehen bewahrende Position auf Zustimmung:

Dem konservativen Lebensgefühl, das sich nach Wiederherstellung der Wertorientierungen früherer Epochen sehnte, entsprach, neben Kohls Angebot einer geistig-moralischen Wende, auch eine Abneigung gegenüber den Resultaten kulturellen Experimentierens aus den 1960er Jahren.245

So konstatiert Hilmar Hoffmann der deutschen Kulturpolitik verstärkt für die Zeit nach der Wende eine „Fixierung auf repräsentative öffentliche Kultur“246. Und erst nach 1989 beginnen in Frankfurt, Köln und anderen Städten konkrete Überlegungen, Literaturhäuser aufzubauen. Die Entstehung dieser Einrichtungen ist folglich auch in diesem Kontext zu betrachten.

So ist die Blüte des kulturellen Lebens heute in der Bundesrepublik eine Folgeerscheinung des Siegeszugs der Instrumentalisierung. Der Anspruch der Künste, aktiver Bestandteil eines Prozesses von Emanzipation, von dauerhafter Entwicklung von Humanität zu sein, steht in Konkurrenz zum dekorativen Verbrauch der Künste. ${ }^{247}$

Obwohl Hoffmanns Aussage als Aussage eines damaligen sozialdemokratischen Kulturpolitikers eingeordnet werden muss, wird daraus deutlich, dass die Distinktion über und ,Dekoration“ mit Kultur in den 1980er-Jahren wieder relevanter wurden.

Wie sehr in dieser Zeit ein elitärer Literaturbegriff weiterhin virulent war, illustriert ein Beitrag von Ulrich Greiner in Die Zeit aus dem Jahr 1989. Der sieht darin, dass etwa Theater Inszenierungen mit „Champagner, Schafskäse“248 - so der Titel seines Artikels - Zuschauer*innen anlockten, ein „Behagen in der Kultur“, welches „das Schwierige, das unvermeidlich Anstrengende, das leidenschaftlich Erarbeitete, das glückhaft Gekonnte, kurz: die wirkliche Kunst" aus dem Blick verliere. Als Grund für die ,Bedrohung“ für die „wirkliche Kunst“ nennt er die von Hoffmann präsentierte Kulturpolitik. Allerdings verweist Greiner mit seiner Kritik stärker auf eine Tendenz des Kulturbetriebs, die später häufig mit dem Schlagwort ,Eventisierung' angegangen wurde, die jedoch, wie Hoffmann schon 1990 anmerkt, weniger auf die Linie von ,Kultur für alle` zurückzuführen sei, sondern auf eine zunehmende Ökonomisierung des Kulturbetriebs. ${ }^{249}$ Diese Ökonomisierung ist selbst nicht plötzlich aus dem Nichts aufgetaucht, sondern zeigt vor allem, dass sich jedes kulturpolitische Konzept ökonomisch nutzen lässt, sodass hier gar nicht beurteilt werden soll, ob nun Greiner oder Hoffmann mehr überzeugt. Das bisher Ausgeführte erklärt auch das Resümee zur Gründungsphase des Literaturhauses Hamburg, das zu dessen zehnjährigen Jubiläum in der taz erscheint:

\footnotetext{
240 Aktualisierungen liegen vor, vgl. z. B. Schneider (Hg.) 2010.

${ }^{241}$ Hoffmann 1981, S. 31.

242 Hoffmann 1990, S. 52.

243 Vgl. Kapitel II 1.1.2 und II 1.1.3.

${ }^{244}$ Die Bezeichnung ,Distinktion' geht in diesem Zusammenhang etwa auf Pierre Bourdieu zurück, vgl. bspw. Bourdieu 1982, S. 104-105.

${ }^{245}$ Hieber 2012, S. 362.

${ }^{246}$ Hoffmann 1990, S. 55.

247 Ebd., S. 55-56.

248 Greiner 1989.

${ }^{249}$ Vgl. Hoffmann 1990, S. 150.
} 
Viele hielten den Machern des Literaturhauses vor, es lieber als nobles Aushängeschild dieser Stadt etablieren zu wollen, als zu einer fördernden Begegnungsstätte der literarisch Produktiven werden zu lassen. Auch die Musealisierung bildungsbürgerlicher Literaturrezeption, die den Veranstaltungen in der Stadtvilla anhaftet, wirkte auf viele wie ein Affront, verfügten sie Ende der Achtziger doch selbst über keine literarische Struktur zum Kontern. ${ }^{250}$

Damit sind gleichzeitig drei wichtige Aspekte angesprochen, die das Literaturhaus entscheidend prägen, und die - hier nur auf Schlagworte reduziert - in der vorliegenden Institutionsgeschichte zentral sind: Literatur als Kunst - Literaturvermittlung $^{251}$ - Instrumentalisierung und Ökonomisierung des Kulturbetriebs. Das Literaturhaus ist ein gutes Beispiel, um zu illustrieren, inwiefern diese verschiedenen Handlungsmotivationen sich nicht unbedingt gegenseitig ausschließen, sondern ihr Zusammenwirken gerade typisch ist für eine Institution des gegenwärtigen Literaturbetriebs.

\section{Kulturpolitik in Skandinavien}

In Skandinavien lässt sich bereits seit Ende des Zweiten Weltkrieges eine Kulturpolitik ausmachen, die in Punkten der in Deutschland entwickelten Idee von ,Kultur für alle ähnlich war, die dort allerdings sehr viel ausgeprägter war beziehungsweise ist und durchaus als Vorbild für die deutsche Ausgestaltung Hilmar Hoffmanns gegolten haben mag. Zwei Hauptlinien, die weiterhin zentral seien, zeichnen die norwegische Kulturpolitik aus: „demokratisering av kulturen, og kulturelt demokrati“ ${ }^{\text {“252 }}$ [Demokratisierung der Kultur und kulturelle Demokratie]. Ersteres beziehe sich auf die Intention, Hochkultur in der breiten Bevölkerung zu streuen, zweiteres hebe darauf $a b$, die bereits in der Bevölkerung existierende Kultur zu betonen, wie Skaftnesmo zusammenfasst. Ohne hier einen genauen Vergleich beider Ansätze präsentieren zu können, zeigt sich ein markanter Unterschied darin, dass in Skandinavien der ,Volkskultur' eine grundlegende Akzeptanz zugeschrieben wird. Dies hängt auch damit zusammen, dass in Skandinavien eine relativ egalitäre Gesellschaftsstruktur vorliegt. ${ }^{253}$ Folglich ist ein Bildungsbürgertum, das wie in Deutschland die Hochkultur entscheidend prägte, gar nicht abzugrenzen. Olav Korsnes erläutert zusammenfassend, dass es in Medien und Fachliteratur üblich sei, Norwegen als eine besonders egalitäre Gesellschaft darzustellen, als Spezialfall hinsichtlich Klasse und Eliten. Dies werde damit erklärt, dass Norwegen als junger Staat keinen Landadel und kein starkes Industriebürgertum hatte. Außerdem sei im Verlauf des 20. Jahrhunderts ein Regierungsmodell entwickelt worden, das auf einem Gesellschaftsvertrag im Arbeitsleben zwischen Staat und mächtigen kollektiven Organisationen basierte und die Ungleichheiten beseitigte. Dem Aufbau eines starken und umverteilenden Wohlfahrtsstaates in der Periode nach dem letzten Weltkrieg werde der gleiche Effekt zugeschrieben, was sich im sogenannten ,norwegischen Modell

\footnotetext{
250 Pröhl 1999.

251 Die Autoren der Polemik Der Kulturinfarkt, die jenseits der Zuspitzung durchaus nutzbare Beobachtungen und Analysen enthält, sehen den Aufschwung der Vermittlung sogar erst in den ersten Jahren des 21. Jahrhunderts, vgl. Haselbach et al. 2012a, S. 111. Die Literaturhäuser sind also unbedingt in diesem Kontext zu verstehen.

252 Skaftnesmo 2016, S. 31.

253 Vgl. Fure 2001, S. 27.
} 
zeige. Und während die Entwicklung der modernen Gesellschaft in Europa an das dortige Bildungsbürgertum gekoppelt werde, das die Massen aufgeklärt habe, scheinen es in Norwegen das ,Volk' und die Volksbewegungen gewesen zu sein, die ,das Moderne'vorangebracht und die Eliten ,erzogen' haben. ${ }^{254}$

Allerdings finden sich in den vergangenen Jahren Stimmen, die auch in Norwegen eine Kulturelite entdecken. „Til tross for informantenes ,elitebevissthet' opplever de det likevel ikke som uproblematisk å være kulturelite i egalitære Norge“ "255 [Trotz ihres ,Elitebewusstseins' erleben es die Informant*innen dennoch nicht als unproblematisch, im egalitären Norwegen der Kulturelite anzugehören“, was unter anderem auf dem herrschenden ,antiintellektualisme“256 [Antiintellektualismus] beruhe. Dies spricht also weiterhin dafür, nicht davon auszugehen, dass Disktinktion via Kulturgeschmack offen kommuniziert wird, sondern im Gegenteil die Gleichheit betont wird. Diese Haltung trägt sich auch im Literaturhaus fort.

\section{4.3 Zwischenfazit - Baugrund des Literaturhauses}

Dieser Hintergrund ist wichtig für die Institution. Um die Entstehung des Literaturhauses und die Programme richtig zu kontextualisieren, bedarf es einer Erinnerung an diese kontextuelle Basis. Sie erklärt zum Beispiel, woher personelle Entscheidungen rühren, die einen Wechsel der programmatischen Ausrichtung hervorriefen. Die ,erste Generation“ von Literaturhaus-Leitungen ist stärker einer der Kunst verpflichteten Linie verbunden, während die ,zweite Generation“ offener unter anderem ökonomische Aspekte zum Auswahlkriterium für Veranstaltungen erhebt, was anhand der Programmuntersuchungen ausgeführt werden wird.

Mehrere Umstände und Motive unterschiedlicher Akteur*innen haben den Weg zur Einrichtung der deutschen Literaturhäuser geebnet. Für das Interesse an öffentlichkeitswirksamer Literaturkritik sorgte unter anderem die Gruppe 47 mit ihrer Inszenierung des literarischen Gesprächs, kombiniert mit einer Textpräsentation, die durch die Initiativen Walter Höllerers weitergeführt wurde. Die Literaturvermittlungsprojekte Höllerers mündeten in die Gründung des $L C B$ und nutzten der nach dem politischen Engagement der 1960er- und 1970er-Jahre erkennbaren Neuentdeckung von Literatur als künstlerischer Ausdrucksform. Dies spiegelt sich in den ersten Jahren der Literaturhäuser in den Programmen deutlich, denn eine Hinwendung zu einer von strukturalistischer und dekonstruktiver Theorie geprägten und entsprechend sprachfokussierten Literatur ist dort auffällig. ${ }^{257}$ Förderlich für die finanzielle Fundierung der Einrichtungen erwies sich die kulturpolitische Leitlinie, die der Vermittlung von Kunst eine zentrale Rolle zuschrieb. Genauso dienlich waren diese

\footnotetext{
${ }^{254}$ Vgl. Korsnes 2014, S. 12, er verweist dabei auch auf Danielsen (1998), Henningsen und Vike (1999), Rokkan (1987), Slagstad (1998), deren Positionen er wiedergibt.

255 Ljunggren 2014, S. 193. Jørn Ljunggren kommt nach Interviews mit 25 Personen mit viel kulturellem Kapital zur fachlich und öffentlich umstrittenen Frage, ob es eine Kulturelite in Norwegen gebe, zu dem Schluss, dass „kultureliten i Norge eksiterer“ [die Kulturelite in Norwegen existiert]. Seine Gesprächspartner*innen haben sich selbst als deren Mitglieder bezeichnet. Drei Kriterien machten die Mitgliedschaft aus: die richtige Arbeitsstelle, in der Öffentlichkeit sichtbar zu sein und eine Form von Macht innezuhaben.

256 Ebd., S. 207.

257 Vgl. Kapitel II 13.2.4.
} 
Häuser aus Sicht der Städte und privater Förderer zu repräsentativen Zwecken, denn sie konnten sich mit dieser Sichtbarmachung von Hochkultur dekorieren, zu einer Zeit, als relativ viel öffentliches Geld für Kulturprojekte ausgegeben wurde. ${ }^{258}$ Antrieb für den Aufbau derartiger öffentlicher Literaturorte waren aus Sicht der Literaturproduzent*innen und -vermittler*innen (aufmerksamkeits-)ökonomische Interessen. Das Literaturhaus als Ort der Begegnung mit Literatur zu etablieren, ist zugleich ein enthusiastisches Ziel von ,Literaturmenschen“.

„Es war eine Aufbruchsstimmung, als in den neunziger Jahren die Literaturhäuser gegründet wurden“259, schreibt die Literaturkritikerin Ina Hartwig rückblickend. Die ersten Literaturhäuser öffneten 1986, 1989 und 1991. Erst ab Mitte der 1990erJahre beziehungsweise um die Jahrtausendwende kamen in Deutschland deutlich mehr Einrichtungen hinzu. Deshalb ist es besonders interessant einzubeziehen, dass, wie zum Beispiel Volker Hage darlegt, die Aufmerksamkeit für zeitgenössische deutsche Literatur gegen Ende der 1990er-Jahre gestiegen sei. ${ }^{260}$ „Die Enkel der Nachkriegsliteratur treten an, befreit von mancher Beschwernis der vom Zweiten Weltkrieg geprägten Vorgänger-Generation,"261 konstatiert er schon im Oktober 1999 im Zusammenhang mit der Verleihung des Literaturnobelpreises an Günter Grass. Richard Kämmerlings setzt bereits das Jahr $1995^{262}$ als Moment eines „radikalen Umschwung[s] "263 an, als es aufgrund einschlägiger Publikationen, unter anderem Christian Krachts Roman Faserland, zu einer Umwertung der Gegenwartsliteratur gekommen sei. „War das bis dahin vornehmlich Literatur gegen die eigene Zeit gewesen, wurde sie zu einer Literatur für die eigene Zeit. Gegenwartsliteratur - das sind große Bücher vom Hier und Heute.“264 Diese Aussage ist aus zwei Gründen relevant: Zum einen markiert sie ab Mitte der 1990er-Jahre ein Interesse an der gegenwärtigen Belletristik, zum anderen belegt Richard Kämmerlings Annahme, dass Gegenwartsliteratur das „Hier und Heute“ thematisiere, das Verständnis von Literatur mit der Funktion der Gesellschaftsanalyse, „Gegenwartsliteratur als Erfahrungsdeutung “265 und nicht mehr nur als Erfahrungsersatz. In dieser Interpretation ist die Ausrichtung des heutigen Literaturhauses nachvollziehbar. Das Literaturhaus agiert an der Schnittstelle von Literaturvermittlung als Gegenwartsanalyse und Austausch und verhilft der Gegenwartsliteratur zu noch mehr Gegenwärtigkeit, indem die Autor*innen mit ihrem Text live zu erleben sind, und ermöglicht zugleich eine Diskussion darüber. ${ }^{266}$

\footnotetext{
258 Jürgen Kolbe sprach zur Eröffnung des Literaturhauses München polemisch davon, dass die Spartentrennung in einzelne Häuser in Deutschland „zu den Fundamentalismen einer Kulturpolitik gehörte, als die buchstäblich keine Fenster mehr fand, aus denen sie das Steuergeld werfen konnte“, Kolbe 1997. Herbert Wiesner wandte sich mit einer Replik gegen diese Absage an Literaturhäuser, vgl. Wiesner 1997. ${ }^{259}$ Hartwig 2009.

260 Vgl. Hage 2010, S. 15.

${ }^{261}$ Hage 1999a. Dieser Artikel hält das Wiedererstarken der deutschen Gegenwartsliteratur nach der Gruppe 47 fest.

2621995 wurde auch das Deutsche Literaturinstitut Leiprig gegründet, wie Volker Hage in diesem Zusammenhang erwähnt, vgl. Hage 2010, S. 16.

263 Kämmerlings 2011, S. 25.

264 Ebd., S. 28, Hervorhebungen im Original.

${ }^{265}$ Ebd., S. 18.

${ }^{266}$ Dass die zeitgenössische Literaturkritik kontrovers über diesen Gegenwartsbezug der Literatur und die Qualität der damaligen Gegenwartsliteratur diskutierte, dokumentiert z. B. ein Sammelband, der Zeitungs- und Originalessays vornehmlich von Literaturkritiker*innen vorstellt, vgl. Köhler und Moritz (Hg.) 1998.
} 
Wie dieser knappe Überblick zeigte, war es die richtige Zeit zur Umsetzung einer anscheinend guten Idee, die sich durchgesetzt hat. ${ }^{267}$ Neben den genannten Aspekten, die zur „Erfindung des modernen Literaturbetriebs“ beitrugen, lässt sich das Literaturhaus als Antrieb für den heutigen Literaturveranstaltungsbetrieb interpretieren. Mit seiner Verstetigung einer Infrastruktur für Literaturveranstaltungen entdeckten beispielsweise Verlage die Möglichkeiten, die diese Anordnung für ihre eigenen aufmerksamkeitsorientierten Zwecke bereithält. Zugleich konnte das Literaturhaus nur entstehen und wachsen, weil ein Bedarf für eine derartige Literaturvermittlungsinstitution gesehen wurde. Die ganze Zeit über bleibt eine finanzielle Abhängigkeit von Geldern bestehen, was dazu führt(e), dass die Literaturhäuser weder autark von kulturpolitischen Leitlinien noch frei von merkantilen Prinzipien Programm machen können und sich entsprechend nicht als elitäre Refugien stilisieren dürfen, sondern Ansätze zeigen, wie das Literaturhaus ,für alle zugänglich wird. Diese Einführung verdeutlichte zugleich, dass die Spannungen zwischen Instrumentalisierung und ästhetischer Innovation ermöglichten, dass die Institution Literaturhaus überhaupt entstand. Den Gründen, warum sie entstand und welche Bedürfnisse sie für welche Akteur*innen zu befriedigen in Aussicht stellte, widmet sich das folgende Kapitel.

\section{5 Akteur*innen und Funktionen des Literaturhauses}

Wie bereits eingeführt, geht es in dieser Arbeit um den abstrakten kollektiven Akteur Literaturhaus, der in einem bestimmten Bereich, der Literaturbetrieb genannt werden kann, seit Mitte der 1980er-Jahre agiert. Der Institution liegen konkrete kollektive Akteur*innene zugrunde, die sich wiederum emergent aus Einzelakteur*innen zusammensetzen, die in unterschiedlichen Rollen agieren. Die Beziehungen untereinander und $\mathrm{zu}$ anderen Akteur*innen im Literaturbetrieb sowie sich daraus ergebende Funktionen des Literaturhausese werden im Folgenden diskutiert. Wie herausgestellt, ist die primäre Funktion der Institution Bedürfnisbefriedigung unterschiedlicher Akteur*innen. Dabei lässt sich außerdem die Frage beantworten, warum das Literaturhaus überhaupt und noch dazu erfolgreich existiert. Sekundär prägt die Selbsterhaltungsfunktion die Aktivitäten des Literaturhauses. Mit zunehmender Institutionalisierung spielt diese eine größere Rolle, sodass sie eine übergeordnete Funktion einnimmt und stärkere Spannungen etwa zwischen Beständigkeit und Fortschritt auszutarieren sind. ${ }^{268}$

\footnotetext{
$267 \mathrm{Zu}$ diesem Schluss kommt auch Schmitt, wenngleich sie in ihrer Übersicht den Schwerpunkt vor allem auf die Verbindungen zum literarischen Salon legt und das Literaturhaus eindeutig als ein nichtkommerzielles Gegengewicht zum ökonomisierten Literaturbetrieb der Zeit sieht, was ich für nicht so eindeutig halte wie sie, vgl. Schmitt 2016, S. 81.

${ }^{268}$ Laut Anja Johannsen, die das Literaturhaus als Erste mit dem Institutionsbegriff zusammengebracht hat, ist nicht pauschal zu beantworten, in welchem „Verhältnis nun primäre und sekundäre Zielsetzung im Arbeitsalltag der Literaturhäuser stehen“, Johannsen 2012b, S. 189.
} 


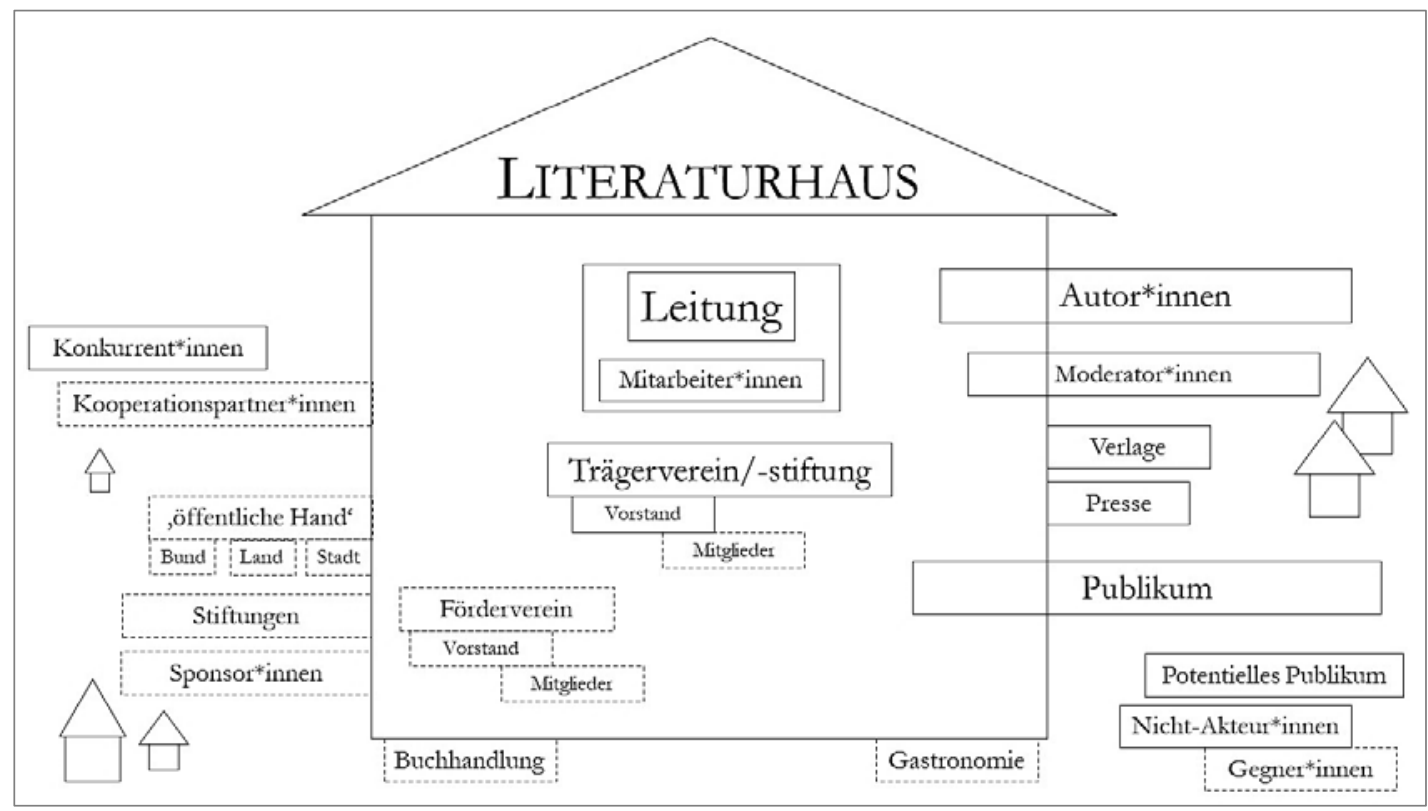

Abbildung 1: Schematische Darstellung des Literaturhauses (eigene Darstellung)

Das schematische Darstellung (Abbildung 1) veranschaulicht, wer am Literaturhaus beteiligt ist. Die gestrichelten Linien markieren optionale Bestandteile. Dabei lassen sich die innerhalb der skizzierten Wände positionierten Akteur*innen als das Literaturhaus im engeren Sinne bezeichnen, als den Literaturvermittler. Vergleichbare Institutionen im Umfeld sind durch ebenfalls abstrahierte Häuser integriert. Durch die Interaktion, die Handlungen, Praktiken und Bedürfnisse der Einbezogenen entsteht das Literaturhaus als kollektiver Akteur. Die Kontakte von Programmleitungen zu Verlagen, Autor*innen, Geldgeber*innen und Kooperationspartner*innen prägen ihre Tätigkeiten und folglich die Einrichtungen entscheidend mit. Die Qualität dieser Verbindungen wird bei der Beschreibung des Umfeldes teilweise mitberücksichtigt, steht jedoch nicht im Brennpunkt dieser Arbeit. ${ }^{269}$ Festzuhalten ist, dass das persönliche Netzwerk der Akteur*innen im Literaturhaus eine wichtige Rolle spielt. In dieser Arbeit liegt das Interesse nicht darin, bestimmte Personen und ihre (zwischenmenschlichen) Beziehungen zu analysieren, sondern die Institution als Zusammenspiel von Akteur*innen zu begründen.

\section{| 5.1 Trägerorganisationen}

Hinter dem ,Literaturhaus' steht meist ein Trägerverein oder eine Trägerstiftung gleichen Namens. Diese Körperschaft wird gebildet, um das Literaturhaus aufzubauen, zu unterhalten und aufrechtzuerhalten. Ein Vorstand vertritt diese nach auBen und entscheidet meistens, wer als hauptamtliche Geschäftsführung eingesetzt wird. Diese Struktur sorgt außerdem für mehr Kontinuität, weil die Entscheidungen final nicht nur von der Geschäftsführung abhängen, sondern vom Träger mitgetragen werden müssen. Diese Struktur legt zudem nahe, das Literaturhaus nicht nur als

${ }^{269}$ Auch um das Vertrauen, das mir meine Gesprächspartner*innen entgegengebracht haben und das ich als Mitarbeiterin im Literaturhaus Hamburg erfuhr, nicht auszunutzen, werde ich keine Aussagen über die tatsächlichen informellen Netzwerke der Akteur*innen treffen - zumal mein Wissen in dieser Hinsicht ebenfalls von meinen Kontakten abhängt. 
Anbieter singulärer Veranstaltungen zu verstehen, sondern das Literaturhaus als kontinuierliche Einrichtung zu begreifen.

In Deutschland ist von den größeren Einrichtungen nur das Literaturbaus München als Stiftung konzipiert, den anderen liegt jeweils ein eingetragener Verein zugrunde. Bei diesen Einrichtungen spielen entsprechend Vereinsmitglieder eine Rolle - als Zielpublikum sowie als finanzielle Unterstützer*innen. ${ }^{270}$ Die analysierten norwegischen Literaturhäuser werden jeweils von einer eigens gegründeten Stiftung getragen. Das erste Kopenhager Literaturhaus war zunächst nur ein loser Verbund, formalisierte sich dann 2016. Göteborgs Litteraturhus agiert seit 2015 in einer Vereinsstruktur, diese setzt sich aber nicht aus Privatpersonen, sondern nur aus korporativen Akteur*innen zusammen. ${ }^{271}$ Vereine, die aus Einzelpersonen bestehen, existieren im skandinavischen Literaturhaus-Kontext nicht. Dies beruht sicherlich auch darauf, dass Vereine heutzutage grundsätzlich einen schweren Stand haben, da sich kaum noch Personen an Einrichtungen binden möchten. ${ }^{272}$

Als Vereine oder Stiftungen unterliegen die Literaturhäuser einer Satzung, die ihren Zweck festlegt und den entsprechenden Betrieb erlaubt. Somit sind in der Regel Einnahmen über Eintritte erlaubt, da es keine ideellen Vereine sind, die eher eine Interessenvereinigung darstellen. Zugleich sind sie meist gemeinnützig, sodass sie keinen Gewinn erwirtschaften dürfen, was jedoch steuerliche Vorteile mit sich bringt und öffentliche strukturelle Förderung ermöglicht. Die meisten Literaturhäuser in Deutschland und in Skandinavien sind demnach keine rein ,öffentlichen " - im Sinne von ,kommunalen' beziehungsweise ,staatlichen' - Einrichtungen. Damit agieren sie unabhängig, sie müssen beispielsweise keinen Bildungsauftrag erfüllen oder Angebote für alle Bürger*innen anbieten. In ihrer Programmgestaltung sind sie grundsätzlich frei. Der private gemeinnützige Status hat Auswirkungen auf die Finanzierung, denn es handelt sich um Organisationsstrukturen, „die nicht durch eine öffentliche Trägerschaft eine Art Bestandsschutz genießen, sondern die ihre Ressourcen immer wieder neu akquirieren müssen. “273

Die meisten Einrichtungen werden allerdings von der ,öffentlichen Hand' unterstützt. Dies geschieht innerhalb der Kulturförderung, und sicherlich ebenfalls, weil das Literaturhaus als repräsentativer Veranstaltungsort der Städte kommuniziert werden kann. ${ }^{274}$ Die Gewichtung in den einzelnen Einrichtungen variiert dabei

\footnotetext{
${ }^{270}$ In München gibt es zusätzlich zur Stiftung den Förderverein Freunde und Förderer des Literaturhauses München e. $V$., in den private wie juristische Personen eintreten und das Literaturhaus mit einem Jahresbeitrag unterstützen können.

${ }^{271}$ Dies wird in Kapitel II ausgeführt.

${ }^{272}$ Vgl. Müller-Jentsch 2008, S. 497. Ältere Gesellschaften und Vereine wie Dichtergesellschaften haben in Skandinavien eine Bedeutung. Viele Personen sind Mitglied in einer literarischen Gesellschaft.

273 Vandenrath 2006, S. 175.

${ }^{274}$ Für die Städte bieten sich die Literaturhäuser zur Generierung symbolischen Kapitals an, das wiederum als ökonomischer Faktor eine Rolle spielt. Die Einrichtung wirkt nicht nur ein auf das literarische, sondern auch auf das kulturelle, politische, urbane, virtuelle Feld und andere. Derartige Machtfragen, die beim Literaturhaus definitiv eine Rolle spielen und mit Pierre Bourdieus Arbeiten untersucht werden können, beschäftigen auch Stadtsoziolog*innen und Stadtökonom*innen. Obwohl dies eine sehr interessante Herangehensweise an das Literaturhaus ist, so kann sich diese eher literaturwissenschaftlich orientierte Arbeit nur am Rande damit befassen. Dass das Literaturhaus einerseits den Kräften unter anderem der Politik und Wirtschaft ausgesetzt ist, und andererseits im Literaturbetrieb eine starke Position vertritt, ist eine Grundannahme.
} 
stark, wie Sonja Vandenrath in ihrem Vergleich der Berliner mit der Hamburger Finanzierung veranschaulicht. ${ }^{275}$ Dabei liegt eine wichtige Unterscheidung zwischen sogenannter, institutioneller' Strukturförderung und Projektförderung vor. Während die Strukturförderung den alltäglichen Betrieb finanziert, dienen projektbezogene Mittel zur Realisierung inhaltlich fixierter, meist temporärer Vorhaben. Gerade für ganzjährig tätige Einrichtungen ist eine regelmäßige Finanzierung des ,laufenden Betriebs' nötig, hingegen ist für Geldgeber*innen ein Beitrag zu sichtbaren einmaligen Projekten häufig attraktiver. Die finanzielle Stabilität der Institution schafft Planungssicherheit, was im Sinne des Selbsterhalts der Institution ein wichtiges Momentum ist. Projektabhängige Unterstützung fördert der Idee nach stärker die Innovationskraft der Institution, die ebenfalls notwendig ist. Dieser Interessenkonflikt ist ein großes Thema in Literaturhäusern wie in anderen Kultureinrichtungen, wie Publikationen zeigen. 276

Für die Erfassung der Einrichtung als Ganzes sind die Organisation und Finanzierung unabdingbar. ${ }^{277}$ Diese strukturellen Komponenten bilden nicht nur aus betriebswirtschaftlicher Sicht zentrale Punkte für die Exploration der Unternehmung. Für die Bestimmung der literarischen Ausrichtung spielen sie ebenfalls eine Rolle. Die Verbindung von finanziellen Bedürfnissen und Programmentscheidungen im Literaturhaus veranschaulicht Sonja Vandenrath. Dass dies nicht nur für das Literaturhaus gilt, sondern sich etwa auf Verlage beziehen lässt, die organisational in einigen Aspekten mit Literaturhäusern vergleichbar sind, stellt Elisabeth Kampmann heraus, denn dass „die pragmatischen Voraussetzungen und Rücksichten herstellerischer, rechtlicher, ökonomischer oder medialer Art eine größere Rolle für Programmentscheidungen “278 im Verlag spielen, sei bislang nicht ausreichend untersucht worden. Diese Aspekte steckten den Handlungsrahmen ab, innerhalb dessen das Programm entsteht. ${ }^{279}$ Angenommen wird hier, dass diese Aspekte zwar eng mit der tatsächlichen Spielplangestaltung verknüpft sind, doch dieser Konnex eher die ,Blackbox' vor dem Erscheinen des Programmes bildet, die sich nicht eindeutig beleuchten lässt.

Auch wenn es für die Handlungsfähigkeit des Literaturhauses entscheidend ist, wie es sich finanziert, so referiere ich im Folgenden nicht im Einzelnen die Budgets der Fallbeispiele und die Finanzierung durch unterschiedliche Posten. Nur dort, wo es für die Argumentation hilfreich erscheint, kommen Zahlen vor. Für eine stärker an organisationalen Fragen interessierte Arbeit und für die Literaturhäuser aus kulturpolitischer Sicht wäre es nützlich, die von Sonja Vandenrath referierten Zahlen zu aktualisieren und sie miteinander zu vergleichen sowie etwa die Budgetpläne von Kultureinrichtungen wie Theatern, Konzerthäusern oder Museen dazu in Beziehung zu setzen, auch um zu illustrieren, wie günstig das Literaturhaus in Relation ist. Vandenraths Aufstellung mit Zahlen von 2002 vermittelt weiterhin einen guten

\footnotetext{
275 Vgl. Vandenrath 2002, S. 180-182.

276 Vgl. z. B. bezogen auf das Literaturhaus Höllerer 2007, Porombka und Splittgerber 2010, S. 103-104 und Johannsen 2012b, besonders S. 190. Allgemeiner deutsche Kulturinstitutionen betreffend und als Streitschrift angelegt ist der Beitrag von Haselbach et al. 2012a.

277 Zum Einstieg sind Einführungen ins Kulturmanagement empfohlen, z. B. Klein (Hg.) 2011.

${ }^{278}$ Kampmann 2011, S. 411.

${ }^{279}$ Vgl. ebd., S. 402.
} 
Eindruck davon, wie unterschiedlich die Literaturhäuser finanziert sind. Dabei ist besonders der Aspekt der Mischfinanzierung hervorzuheben, der schon anklang. Die Trägerorganisationen arbeiten mit einer Kombination aus Eigenmitteln (Einnahmen des Vereins etwa über Mitgliedsbeiträge, aus Vermietungen oder durch Eintrittsgelder), aus öffentlichen Geldern (institutionelle und projektbezogene Förderung) und aus Drittmitteln (ebenfalls strukturell oder inhaltsbezogen von privaten Sponsor*innen, Stiftungen oder anderen Geldgeber*innen). Die beiden norwegischen Literaturhäuser sind maßgeblich durch die Stiftung Fritt Ord [Freies Wort] finanziert, hinzu kommen Projektförderungen etwa durch den staatlichen Kulturrat Kulturrådet, der vollständig vom Kulturministerium finanziert wird - dabei gilt armlengdesprinsippet [das Armlängenprinzip], das ausreichend Abstand zwischen Politik und Kunst fordert, also die Unabhängigkeit des künstlerischen Ausdrucks von politischen Entscheidungen garantieren soll. ${ }^{280}$ Die Zusammensetzung des Budgets aus den drei genannten Bereichen kann in den einzelnen Literaturhäusern sehr unterschiedlich ausfallen, immer hat sie entscheidenden Anteil an der inhaltlichen Arbeit.

\section{5.2 Kooperationspartner*innen und Konkurrent*innen}

Finanzielle Belange prägen letztlich das kooperative wie konkurrierende Verhältnis zu anderen (kollektiven) Akteur*innen im Kulturbetrieb, denn Kapital und Aufmerksamkeit sind innerhalb jeder Stadt begrenzt. Die verschiedenen Kultureinrichtungen buhlen gleichermaßen um Besucher*innen, um Fördermittel und um mediale Sichtbarkeit. Sie weisen in der Regel aber Alleinstellungsmerkmale auf, sodass sie koexistieren können. $\mathrm{Zu}$ nennen sind neben Literaturhäusern etwa Museen und Galerien, Dichterhäuser, Literarische Gesellschaften und Gedenkstätten, Bibliotheken, Bildungseinrichtungen und Kulturhäuser, Theater und Konzerthäuser, private Literaturveranstalter*innen und Literaturfestivals, Buchhandlungen und Verlage, Buchmessen, Onlineliteraturangebote wie Literaturplattformen und Literaturblogs.

Zugleich sind reziproke Synergieeffekte zu erwarten, wenn beispielsweise das Literaturhaus mit der örtlichen Universität kooperiert. Dagegen ist der Wirkungsspielraum des Literaturhauses eingeschränkt, wenn mehrere programmatisch ähnliche Literaturveranstaltungsorganisationen auf begrenztem Raum tätig sind. Allgemein lässt sich festhalten, dass einige Entscheidungen des Literaturhauses besser nachvollzogen werden können, wenn bekannt ist, in welcher Umwelt es agiert. Das Literaturhaus ist seinen nachbarschaftlichen Bedingungen folglich ausgesetzt und diese beeinflussen das Profil des Literaturhauses. Anhand von konkretem Material wird die Zusammenarbeit mit anderen Akteur*innen später ausgeführt. ${ }^{281}$

\footnotetext{
${ }^{280}$ Vgl. Mangset 2003, S. 9-10. In Deutschland existiere wegen der föderalistischen Struktur kein so wirkungsmächtiger nationaler Kulturrat, da dort von vornherein Kulturpolitik schwerpunktmäßig auf regionalem Niveau stattfinde.

${ }^{281}$ Vgl. Kapitel II 11.2.2.
} 


\section{5.3 Leitungspersonen und Mitarbeiter*innen}

Für die Mittelakquise und die Geschäftsführung wie für die Programmgestaltung sind die von den Trägerorganisationen hauptamtlich eingesetzten Leitungen verantwortlich. Inzwischen liegen beide Aufgabenbereiche häufig bei einer einzigen Person, während es in den Anfangsjahren oft getrennte Wirkungsfelder waren, „um ökonomische Fragen keinen direkten Einfluss auf die Programmgestaltung nehmen zu lassen“282. Dass inzwischen meist ein Intendanzprinzip gelte, wie Anja Johannsen ausführt, ${ }^{283}$ deutet auch innerhalb der Literaturhäuser auf die oben beschriebene Einsicht hin, dass Programmentscheidungen ohnehin nicht völlig losgelöst von finanziellen Belangen getroffen werden können. Damit einher geht für die Arbeitspraxis der Leiter*innen eine Kombination von Managementdiensten und künstlerisch-inhaltlichen Aufgaben. ${ }^{284}$

In Deutschland prägen vor allem die Programmleitungen das Literaturhaus. ${ }^{285}$ Dass die Programmleitung in der Außenwahrnehmung für das Programm steht, zeigt sich etwa daran, dass bei einem Personalwechsel meist nach der Neuausrichtung und der Beibehaltung gut eingeführter Programmpunkte des jeweiligen Literaturhauses gefragt wird. Obgleich die persönlichen Präferenzen nicht unbeachtet bleiben, handeln die Leitungen im Sinne der Institution und sind aufgefordert, ein Programm zusammenzustellen, dass zugleich den Erhalt der Einrichtung sichert und sie für die Zukunft stabilisiert. So interessiert unter anderem, in welchen unterschiedlichen Handlungsrollen die Leitungen agieren, denn viele Leiter*innen sind etwa auch als Literaturkritiker*innen, Autor*innen oder als Dozent*innen tätig, und welche ästhetischen wie thematischen Schwerpunkte sich daraus ergeben. Wichtig für die Verwendung der Bezeichnung ,Intendanz' ist es, dass in den untersuchten deutschen Literaturhäusern die Programmleitungen häufig nicht befristet eingestellt werden und sich nicht, wie im Theater, nach einigen Jahren um die Fortführung ihres Vertrags bemühen müssen. Dies sichert dem Literaturhaus Kontinuität, schränkt aber gegebenenfalls auch seine Beweglichkeit ein. Bei einem möglichen Intendanzwechsel im Theater werden „,regelmäßig Diskussionen in Gang gesetzt, bei denen man sich über das verständigt, was man überhaupt mit und von einem Theaterhaus will“'286, wie Kai Splittgerber und Stephan Porombka notieren.

Anzumerken ist für die untersuchten norwegischen Literaturhäuser, dass nach außen vor allem der daglig leder [Geschäftsführer*in] die Einrichtung vertritt. Sowohl in Oslo als auch in Bergen ist neben dieser Person noch eine Person als programsjef [Programmchef*in] beziehungsweise als programansvarlig [Programmverantwortliche*r] angestellt, die aber etwa bei Berichten über Litteraturbuset selten erwähnt sind. Dies ist ein Indiz dafür, dass die norwegischen Einrichtungen stärker als Gesamt-

\footnotetext{
282 Johannsen 2012b, S. 185.

283 Vgl. ebd.

${ }^{284}$ Diese Programmplanung solle aber anfangs möglichst getrennt gehalten werden vom Bereich der Geschäftsführung, meint Florian Höllerer zitiert nach: ebd., S. 186. Anja Johannsen ordnet diese Aussage ein und weist explizit auf den Konjunktiv in dieser Aussage hin, ist doch „die bewusste Prioritätensetzung $[. .$.$] je nach finanzieller Lage nicht immer leicht aufrecht zu erhalten“.$

285 Dieser Aspekt findet sich bei Johannsen schon erwähnt, vgl. ebd.

286 Porombka und Splittgerber 2010, S. 122.
} 
konzept wirken, während die deutschen sich über ihr Programm präsentieren. Diese Hypothese findet im Laufe der Arbeit in unterschiedlichen Hinsichten Bestätigung.

Neben den Leitungsfiguren wirken in der Regel weitere Mitarbeiter*innen am professionellen Gelingen des Literaturhauses mit. Dabei können Mitarbeiterzahl und Aufgabenverteilung ebenfalls nützliche Hinweise zur Arbeitsweise des Literaturhauses bieten. So stellt sich zum Beispiel heraus, dass es in den ersten Jahren keine Angestellten für die Öffentlichkeitsarbeit gab; dies ist eine Position, die sich in den Literaturhäusern zunehmend findet, was darauf hinweist, dass dieser Aufgabenbereich im Zeitalter der Digitalisierung an Relevanz und/oder an Umfang gewinnt. 287

Das Literaturhaus stellt zum einen Arbeitsmöglichkeiten im Literaturbetrieb beispielsweise für Geisteswissenschaftler*innen bereit, zum anderen bietet es Literaturvermittler*innen stabile Strukturen zur Realisierung ihrer Ideen.

\section{5.4 Autor*innen}

Die Fallstudien im zweiten Kapitel belegen, dass in den Veranstaltungsankündigungen selten eine besondere Ereignishaftigkeit und Exklusivität eines bestimmten Schriftstellerbesuchs direkt thematisiert wird; nur etwa dann, wenn Schreibende eingeladen sind, die nur in Ausnahmefällen öffentlich auftreten, zum Beispiel der US-amerikanische Romancier Don DeLillo (*1936) ${ }^{288}$ und seine „[s]eltene Lesung“ (HH 1992-10-29) oder der italienische Autor Antonio Tabucchi (1943-2012), denn: „Daß er kommt, ist ein Ereignis“ (HH 1997-10-20). Die Erwähnung der Besonderheit eines Auftritts trägt erstens zur Bewerbung dieser Veranstaltung bei und impliziert zweitens, dass öffentliche Auftritte von Autor*innen nicht grundsätzlich eine Seltenheit sind, sondern zur schriftstellerischen Praxis zu zählen sind. Es ist somit keine neue Erkenntnis, die Autorenpersona als eine für das Publikum und für den Markt stets beachtenswerte Größe anzusehen. Das Wachstum des Literaturveranstaltungsbetriebs ebenso wie mediale Inszenierungen bezeugen eine gestiegene Neugier beim Publikum auf die Menschen hinter den Büchern und ihre Auslegung des eigenen Textes, wie etwa Christoph Bartmann befindet:

So lebt die Institution der Lesung geradezu davon, dass sie die anderswo (in der Literaturwissenschaft) längst dekretierte Trennung von Autor und Werk, von empirischen und fiktionalen Ichs aufhebt und die planmäßige Verwechslung beider Sphären zur Grundlage eines spekulativen Spiels erhebt, das zumindest die eine der Parteien vergnüglicher findet als die Fiktion selbst. ${ }^{289}$

\footnotetext{
${ }^{287}$ Bei diesen Stellen machen Werbemaßnahmen einen zunehmenden Teil der Öffentlichkeitsarbeit aus, ,klassische Pressearbeit' wird dabei weniger. Was ein Indiz für die Hypothese sein mag, dass die ,traditionellen' Feuilletons von Zeitungen und Radiostationen Einfluss einbüßen und der Diversifizierung der medialen Aufmerksamkeit für Literatur Rechnung getragen wird. Dies führt auch Anke Vogel für den Buchmarkt insgesamt aus. Dennoch schreibt sie den, klassischen' Medien weiterhin eine große Bedeutung zu, vgl. Vogel 2011, S. 345. Litteraturbuset in Oslo jedoch benennt auf seiner Website bei den Arbeitsbereichen Presse- und Öffentlichkeitsarbeit nicht explizit.

${ }^{288}$ Die in Klammern angegebenen Lebensdaten der Autor*innen erlauben zumindest eine zeitliche Einordnung der Autorenpersona; ausführlicher ist das hier leider nicht für alle erwähnten Namen möglich, vgl. Anhang V 4.

289 Bartmann 2004, S. 126.
} 
Der Ausdruck vom ,Tod des Autors ${ }^{` 290}$ beziehungsweise seine Rückkehr ist sprichwörtlich für die akademische wie feuilletonistische Autorschaftsdebatte geworden. So findet der Ausdruck Verwendung, um aufgrund der gestiegenen Zahl etwa an Autorenlesungen, an publizierten Biografien ${ }^{291}$ oder journalistischen Autorenporträts auf die Relevanz des Autors hinzuweisen, wie es sich ebenfalls in obigem Zitat andeutet. Diese Konstatierung, dass die Formulierung zum ,Tod des Autors' zur Standardwendung geworden sei, ist inzwischen selbst eine literaturwissenschaftliche Sentenz. ${ }^{292}$ Die literatursoziologisch basierte Betrachtung, dass Autor*innen als Akteur*innen wahrgenommen werden, steht jedoch nicht, wie oft eher feuilletonistisch behauptet, im Widerspruch zur Debatte um den ,Tod des Autors', um die Theorie des ,Text-Autors'. Vielmehr sind beide Diskussionen auf verschiedenen Untersuchungsebenen anzusiedeln, wie Fotis Jannidis et alii anmerken. ${ }^{293}$ Beim ,Tod des Autors' und seiner Wiederkehr dreht es sich weniger um die Sichtbarkeit der Autorenpersona in der Öffentlichkeit, vielmehr beziehen sich die Beiträge auf literaturwissenschaftliche Theorie-Praxis-Debatten: Die Herausgeber*innen des Bandes Rückkehr des Autors haben vor allem auf eine Diskrepanz hinsichtlich theoretischer Autorschaftsmodelle und literaturwissenschaftlicher textanalytischer Praxis hingewiesen und diese zum Anlass genommen, den Autorbegriff zu revitalisieren. Die in der Literaturwissenschaft diskutierte Ersetzung des Autors durch eine Autorfunktion ${ }^{294}$ betrifft also stärker Momente der Textanalyse. So habe die von Michel Foucault in seinem Text „Was ist ein Autor?“ vorgeschlagene Autorfunktion, die für Textanalysen wichtig ist, den Blick vom Autor selbst weggeführt: „Der ,Autor als Ursprung aller Bedeutung aufgrund seiner Leidenschaften, Stimmungen und Gefühle sei abgelöst worden durch den ,Schreiber', der lediglich auf das Wörterbuch seiner Kultur zurückgreife. “295 Es wird dabei infrage gestellt, inwiefern der Autor als bedeutungskonstituierende Instanz des Textes zu interpretieren sei. Roland Barthes trug mit seinem einschlägigen Aufsatz „Der Tod des Autors“ - „,der radikalste Angriff gegen den Autor" ${ }^{\text {"296 }}$ - zu dieser Diskussion bei und sah im Verschwinden des Autors die Chance für die „Geburt des Lesers“ ${ }^{“ 297}$ als sinnstiftende Instanz. In der Interpretationspraxis der Literaturwissenschaft habe sich diese poststrukturalistische Ablehnung jedoch nicht niedergeschlagen, sondern werde der Autor in Textanalysen integriert. Die Herausgeber*innen stoßen mit ihrem Sammelband, der vor allem die kursierenden Autorbegriffe zu deuten und einzuordnen sucht, weitere Differen-

\footnotetext{
290 ,Autor' wird hier nicht gegendert, weil es sich um ein Abstraktum handelt.

291 Vgl. Forslid und Ohlsson 2013, S. 227.

${ }^{292}$ Mehrere Beiträge zum Thema merken berechtigterweise an, dass der ,Tod des Autors` sprichwörtlich geworden sei, vgl. z. B. Jannidis et al. 2000a, S. 22; Detering 2002, S. X. Dabei betonen zum Beispiel Jannidis et al., dass der damalige französische Kontext zu bedenken sei, um den Text in seiner Zuspitzung richtig einzuordnen, vgl. Jannidis et al. 2000b, S. 181. Beiträge zur Autorschaftsforschung, die nach diesen beiden wegweisenden Sammelbänden bis 2014 erschienen sind, liegen vor, vgl. Schaffrick und Willand 2014.

293 Vgl. Jannidis et al. 1999, S. 16. Vgl. dazu auch Grimm und Schärf 2008, S. 8.

294 Vgl. Detering (Hg.) 2002. Dieser im Zusammenhang mit dem gleichnamigen DFG-Symposium entstandene umfangreiche Sammelband veranschaulicht insbesondere die „Pluralität der theoretischen und methodischen Ausrichtungen ebenso [...] wie [...] kontroverstheologische Prämissen“, wie Detering in der Vorbemerkung formuliert, Detering 2002, S. X.

295 Jannidis et al. 2000a, S. 22.

296 Jannidis et al. 1999, S. 3.

297 Barthes 2000, S. 193.
} 
zierungen an. ${ }^{298}$ Eine kategorische Trennung zwischen Autor und Werk, die Bartmann der Literaturwissenschaft zuschreibt, gilt folglich nicht unbedingt. Weiter sei festgehalten, dass die literatursoziologische Forschung mit diesen Begriffsdiskussionen gar nicht beschäftigt ist, da sie von Beginn an, „den empirischen Autor immer schon als durch die Gesellschaft bedingt gesehen hat und damit die Kritik herausfordernde Überlastung des Begriffs vermieden wurde.“299

Für die literaturbetriebliche Praxis ist es somit irreführend, von der Rückkehr des Autors zu sprechen, denn aus ihr war er nie verschwunden 300 - anders als in der Literaturwissenschaft, die erst seit dem genannten Sammelband den Autor als Forschungsobjekt programmatisch wiederentdeckt hat. Mit der zunehmenden literaturwissenschaftlichen Beschäftigung mit dem Literaturbetrieb gewinnt jedoch auch der empirische Autor an Bedeutung in der Literaturwissenschaft, was beispielsweise die zahlreichen Untersuchungen zu schriftstellerischen Selbstinszenierungen belegen. Die literaturtheoretische Diskussion, die sich mit dem Autor im Text befasst, spielt bei der konkreten Untersuchung der Literaturhaus-Programme keine Rolle, denn relevant ist im Literaturvermittlungsbetrieb der historische, der empirische Autor. Im Literaturhaus treten die Autor*innen mit ihren Leidenschaften, Stimmungen und Gefühlen auf. Zu der von Bartmann genannten Vermengung von Autor und Werk kommt es dennoch. Dies muss jedoch nicht direkt mit der zunächst konstatierten literaturwissenschaftlichen Diskreditierung in Beziehung gesetzt werden, weil die Vermittlungspraxis im Literaturhaus eine andere ist als die der Literaturwissenschaft, obgleich es gewiss Überschneidungen gibt, da die Akteur*innen oft einen akademischen Hintergrund haben ${ }^{301}$ - wie Bartmanns Blick auf die Lesungen veranschaulicht.

„In der Tat erscheint die Trennung zwischen Autor und Werk aufgehoben zu sein, der Leser erfährt den Sprecher als den Verfasser des Werkes“302 - und zugleich den Verfasser als den Erzähler im Werk, wie der Satz von Gunter E. Grimm sich ergänzen lässt. Damit sind zwei unterschiedliche, aber verknüpfte Aspekte angesprochen: Zum einen ist es damit schlüssig, die Literaturveranstaltung als Paratext zu charakterisieren, wie etwa Susan Esmann darlegt:

Vorlesen ist damit ein Paratext, weil der Autor durch die Art des Vortrages andere Informationen zum Text liefert, als sie der Leser beim stillen Lesen abruft. [...] Die Loslösung vom Text und der Übergang zum Erzählen ist für mich der

\footnotetext{
${ }^{298}$ Dass es auch im Zeitalter der Digitalisierung nicht, wie auch vermutet wurde, zu einer Abschaffung des Autors kommen werde, stellt Florian Hartling heraus: „Bei aller Dissoziation von Autorfunktionen geht die Bedeutung und Wichtigkeit des Autors selbst keineswegs verloren; egal wie fremd und auf wie viele Akteure verteilt das Konzept auch zu sein scheint“, Hartling 2013, S. 92, denn selbst die tatsächliche Literaturproduktion im Internet sei weiterhin von ,starken Autoren mit einem sehr traditionellen Autorschaftsverständnis geprägt", ebd., S. 82.

${ }^{299}$ Jannidis et al. 1999, S. 33.

300 Dies steht in Anlehnung an Jeanine Tuschlings Äußerung, dass es irreführend sei, von einer Rückkehr des Autors als ordnendes Prinzip im Hypertext zu sprechen, ,ist er doch niemals daraus verschwunden“, Tuschling 2006, S. 102.

301 Vgl. Johannsen 2010, S. 107.

302 Grimm 2008, S. 162. Er weist auch auf das mögliche Scheitern hin: „Nicht immer wird die Erwartung eingelöst, es kann sich zuweilen auch eine Diskrepanz zwischen hochgespannter Erwartung und schlichter Realität einstellen - das Leseresultat kann peinlich werden“, ebd., 162.
} 
wichtigste und fruchtbarste Paratext, der zudem die Materialitäten am intensivsten gestaltet. 303

Gerade weil Werk und Urheber*in sich gemeinsam präsentieren, besteht eine Autorität des Autors als oberste Deutungsinstanz über den eigenen Text - was dann doch wieder an die oben genannte Autorbegriffsdiskussion anschließt. Die Verfasser*innen lesen aus ihren Werken, interpretieren diese durch die Textinszenierung und sprechen - häufig mit Literaturkritiker*innen oder Literaturwissenschaftler*innen und meist „alles andere als naiv“304 - über den Text. Dies ist als Beitrag zur Werkpolitik ${ }^{305}$ auslegbar. Zum anderen legt der Auftritt eine Ineinssetzung von Verfasser*in des Textes und dessen Erzähler*in nahe. Zwar müsse das nicht, wie Anja Johannsen darstellt, „zwangsläufig platt biografistischen Lesarten der präsentierten Texte Vorschub“306 leisten, doch lässt sich kaum vermeiden, zu fragen, in welchem Verhältnis Person und Text stehen und wie sehr die Erfahrungen der Person Einfluss auf den Text haben. ${ }^{307}$

Daneben lässt sich ein eher außerliterarisches Interesse am Autor bemerken, das auch dann besteht, wenn die Autor*innen „Texte schreiben, die jeglicher biografischer Bezüge entbehren“"308. Wie Ruth Nestvold urteilt, werde durch die Begegnung mit Autor*innen im Internet die unnahbare Größe des Autors relativiert, ${ }^{309}$ was sich ebenfalls für die Literaturhaus-Auftritte konstatieren lässt. Hier wie dort rückt die Person - „eller snarare hans eller hennes mediala persona“ 310 [oder eher seine oder ihre mediale Persona] - neben den Text in den Fokus und bekommt Gestalt. Dabei kann es aber - und das zeigt sich auf dem Literaturhaus-Podium ganz deutlich - für Besucher*innen gerade speziell sein, bei der direkten Begegnung während oder nach einer Lesung im Literaturhaus den Autor*innen, die beispielsweise im Internet über eine Website oder Social-Media-Accounts mit Leser*innen interagieren, ,live' gegenüberzustehen. Diese Besonderheit ist noch einmal größer, wenn die Autor*innen sich nicht online oder in anderen Medien zeigen. Barbara Schaff merkt an, dass sich „in der Interpretationspraxis der populären Medien schon immer ein oft voyeuristisches Interesse am Autor “ ${ }^{\text {"311 }}$ habe feststellen lassen, worin sie eine Parallele zur „Celebrity-Industrie“ sieht. Dies trifft tendenziell für die Autor*innen im Literaturhaus zu, denn dadurch, dass es diese Auftrittsgelegenheiten überhaupt gibt, sind viele Autor*innen als Personen und nicht nur als Autorennamen bekannt und damit kann einigen ein Celebrity-Status zugeschrieben werden.

\footnotetext{
${ }^{303}$ Esmann 2007a, S. 5. Präziser ist es, die Lesung als Epitext zu verstehen, vgl. FN 432.

304 Johannsen 2013a, S. 71.

305 Verbindungen zwischen kritischer Kommunikation und Werk stellt Steffen Martus mit ,Werkpolitik ${ }^{\star}$ her: „Bestimmte Leser handeln in einigen Lesesituationen so, als ob literarische Texte Anforderungen an sie stellten oder sogar Appelle an sie richteten. Als Werkpolitik im weiteren Sinn verstehe ich diese Zuschreibungen und die Arbeit vor allem von Autoren, Kritikern und Philologen, solche Zuschreibungen und Anforderungsprofile zu plausibilisieren und mit Wirksamkeit zu versehen“, Martus 2007b, S. 6.

306 Johannsen 2013a, S. 71.

${ }^{307}$ Dazu später mehr, vgl. Kapitel I 5.6.3.

308 Johannsen 2013a, S. 74.

309 Vgl. Nestvold 1998, S. 206.

${ }^{310}$ Forslid und Ohlsson 2013, S. 233.

311 Schaff 2013, S. 273.
} 
$\mathrm{Zu}$ fragen ist bei der Akteursgruppe der Autor*innen, ob sie ins Literaturhaus eingeladen werden oder nicht, denn auch die, die nicht dort auftreten, wirken dadurch, dass sie dort nicht sichtbar sind, auf das Literaturhaus ein. Alle sind zudem als Leser*innen zu verstehen, die zum potenziellen Literaturhaus-Publikum zu zählen sind. Ergänzt werden sollte, um an das Vorherige anzuschließen, dass erstens keineswegs alle Autor*innen, die bei Veranstaltungen zu erleben sind, erstens Celebrity-Status haben und weit bekannt sind, und zweitens nicht alle online als Autorpersona präsent sind. Für die eingeladenen Autor*innen dient das Literaturhaus vor allem zu ihrer Förderung - auf mindestens zwei Weisen: symbolisch und ökonomisch. Zum einen erfahren sie dort Anerkennung. Zum anderen bildet das Honorar für Lesungen inzwischen eine wichtige Einnahmequelle für Autor*innen, die in der Regel nicht allein von ihren Buchverkäufen leben können. ${ }^{312}$

Allein die Einladung ins Literaturhaus und die damit verbundene Bevorzugung vor allen anderen möglichen Gästen ist für die Autor*innen eine Anerkennung ihres Schaffens, „nämlich als Test, was sein Name in der Literaturwelt gilt und ob er als Kassenmagnet funktioniert" ${ }^{\text {313 }}$. Die Wertschätzung zeigt sich ihnen ferner darüber, dass sie als Gäste empfangen werden, ihnen die Reise und die Unterkunft finanziert wird und sie nach der Veranstaltung in der Regel zum Essen eingeladen werden. Der Restaurantbesuch nach der Lesung ist nicht Teil der öffentlichen Veranstaltung, gehört zur Praktik der Literaturhaus-Lesung aber dazu. ${ }^{314}$ Die Rolle des Literaturhaus-Teams als gute Gastgeber*innen ehrt zum einen die Autor*innen und ist zum anderen ein wichtiger Beitrag zum Gelingen einer Veranstaltung, denn wie schon Ernst Jandl (1925-2000) in seinen Hinweisen für Literaturveranstalter*innen erwähnt: „Ihr Gast wird die Sorgfalt, die Sie für seine Unterbringung aufbringen, dankbar bemerken. “315

Neben dem ökonomischen Gewinn erhalten die Gäste also symbolischen Zuspruch. Der Auftritt auf der Bühne ermöglicht es ihnen, sich dem Publikum vorzustellen. Aufgrund des direkten Kontaktes insbesondere im Anschluss an die Veranstaltung beim Signieren besteht so die Möglichkeit, mit Leser*innen zu sprechen, Lob zu erhalten, Fragen zu beantworten und Interesse seitens des Publikums unmittelbar zu erleben. Dass dies nicht allen Autor*innen ein Bedürfnis ist, sei zumindest angemerkt. Mit der Zusage zu einer Lesung lassen sich die Eingeladenen auf diese Praxiskonventionen ein - Ausnahmen gibt es natürlich - und akzeptieren dies als Bestandteil ihres Jobs als Autor*in, „dann kann es kaum ausbleiben, daß man zu sich selbst das Verhältnis eines Funktionärs entwickelt, also gewissermaßen die Inten-

\footnotetext{
312 Die Professionalisierung des Autorenberufs fand entscheidend zu der Zeit statt, in der sich die ersten Literaturhäuser entwickelten, vgl. Kapitel I 4.2.3. Dabei werden die Verträge meistens über die Verlage geschlossen sowie diese sich inzwischen oft um Einladung, Terminfindung und Reiseplanung kümmern, sodass die Autor*innen von diesen bisweilen zeitintensiven organisatorischen Fragen entlastet sind.

313 Grimm 2008, S. 166-167.

314 Wie auch Christoph Bartmann in seiner Darstellung der fünfgliedrigen Sequenz einer Autorenlesung festhält, vgl. Bartmann 2004, S. 125.

315 Jandl 2017, S. 12. Diesen Text hat der Lektor Klaus Siblewski im Nachlass des österreichischen Lyrikers Ernst Jandl entdeckt und ihn gemeinsam mit Hanns-Josef Ortheil zum Anlass für eine Anthologie mit Beiträgen von Gegenwartsautor*innen zur idealen Lesung genommen, vgl. Siblewski und Ortheil (Hg.) 2017.
} 
danz der eigenen schriftstellernden Person übernimmt" ${ }^{\text {"316, }}$, wie Thomas Steinfeld schon 1988 anmerkte und so auf die Selbstinszenierungsstrategien der Autor*innen hinwies. Anja Johannsen betont in diesem Zusammenhang für den Literaturveranstaltungsbetrieb, dass sein „einzig wahrhaft heikler Aspekt“ das „Kränkungspotential“" von Autor*innen ist, die zu Veranstaltungen eingeladen werden, obwohl sie diese „eigentlich verabscheuen“ und die Veranstalter*innen sie in „Rollen [...] drängen, die sie nur mehr spielen und nicht ausfüllen“317. Dass diese Befürchtung nicht ausgeräumt werden kann, zeigen die zahlreichen kritischen Äußerungen von Schriftsteller*innen zum Literaturveranstaltungsbetrieb. ${ }^{318}$ Gleichzeitig ist nicht zu unterschätzen, dass der symbolische Erfolg sich gegebenenfalls ebenfalls monetarisieren lässt, was in der Literaturwissenschaft seit Pierre Bourdieus Beschreibung des Kapitals eine akzeptierte Annahme ist. Die Anerkennung aufgrund der Einladung ins Literaturhaus kann sich positiv auf zukünftige Lesungsangebote auswirken, macht die Autor*innen beim Publikum bekannter und sorgt so generell für eine Verstärkung ihrer Sichtbarkeit und vielleicht dafür, dass mehr Bücher verkauft werden. So ist die Literaturveranstaltung wie das Buch mit einem Doppelcharakter aus Kunst und Kommerz ausgestattet.

Anzumerken ist, dass schon aufgrund dieser Organisationsstruktur nicht alle Autor*innen für das Literaturhaus gleichermaßen infrage kommen. Einige sind etwa wegen der Auflagenhöhen und Verkaufszahlen ihrer Bücher nicht auf den Zuspruch des Literaturhaus-Publikums, das in Relation ziemlich klein ist, angewiesen. Diese agieren vornehmlich in einem anderen Teilbereich des Literaturbetriebs, was wertfrei zu konstatieren ist: Sie begreifen ihre Rolle als Berufsautor*in maßgeblich durch das Geldverdienen und den Publikumszuspruch motiviert und weniger als, innere Erfüllung' oder Berufung mit dem Drang, etwas Schöpferisches mitteilen zu wollen oder zu müssen. ${ }^{319}$ Die Anerkennung als Belletristikautor*in durch die Literaturkritik und -wissenschaft spielt für sie eine geringere Rolle. Das Literaturhaus fordert damit einschlägig die Autor*innen, die dessen Praxis im Sprechen über und im Umgang mit Literatur teilen. An Fragen zu ihren unterschiedlichen Rollen und Funktionen wird bei den Fallstudien angeknüpft. 320

\section{5.5 Publikum}

Das skizzierte Schema vorne (Abbildung 1) zeigt deutlich, dass das Publikum als wichtiger Akteur des Literaturhauses zu verstehen ist. Es ist deshalb so relevant, weil die Zuhörerschaft natürlich das entscheidende Gegenüber bei öffentlichen

\footnotetext{
316 Steinfeld 1988, S. 985.

${ }^{317}$ Johannsen 2013a, S. 75.

318 Vgl. FN 315, 380.

319 Dies veranschaulicht z. B. die Biografie, die der Bestseller- und Thrillerautor Sebastian Fitzek auf seiner Website veröffentlicht. Der erste Impuls zum Schreiben wird dort als spontane Idee in einem Wartezimmer einer Arztpraxis inszeniert, vgl. Fitzek: „Meine Biographie“. Eine Abgrenzung von Autorenrolle und Privatperson durch ein Autorenpseudonym ist ebenfalls eher im Genrebereich zu sehen, z. B. der Schwede Jan Arnald, der als Arne Dahl Kriminalromane publiziert, oder die Pseudonyme der deutschsprachigen Thrillerautor*innen Zoë Beck und Marc Elsberg. Letzterer zählt z. B. auf seiner Website unter dem Reiter ,Erfolgsgeschichte ${ }^{6}$ Bestsellerlisten-Platzierungen statt Literaturpreise auf. 320 Vgl. Kapitel II 14.1.
} 
Veranstaltungen ausmacht und eine öffentliche Einrichtung ohne Gäste an ihrer Grundidee vorbei arbeitet. Das unabhängige Literaturhaus ist zugleich auf ein zahlendes Publikum angewiesen, weil Eintrittseinnahmen und private Spenden einen Teil seines Budgets ausmachen. Das Publikum des Literaturhauses besteht aus Zuhörer*innen, Zuschauer*innen und Leser*innen. In dieser Arbeit werden diese Substantive tendenziell austauschbar genutzt. Dabei sind ,Leser*innen“ Heinz Schlaffer zufolge von ,Lesenden“ dahingehend zu unterscheiden, dass ,Leser*innen“ „auf eine Vielzahl von Lektüren zurück- und vorausblick[en]"321 und die Bezeichnung sich nicht auf einen konkreten Leseakt beziehen muss. Dies kann für auf das Publikum des Literaturhauses zutreffend angenommen werden.

\section{Literaturbüros und Literaturhäuser}

Da seine Hauptaufgabe die Durchführung von Literaturveranstaltungen ist, ist das Literaturhaus ein Publikumsort. Das zeichnet sich erst mit der Zeit ab, denn die heutigen deutschen Literaturhäuser haben teilweise sehr unterschiedliche Ursprünge. Während zum Beispiel das Literaturhaus Freiburg, das sich aus dem Literaturbüro Freiburg entwickelte, auf Initiative einer Gruppe von Autor*innen und als Gegenkonzept zum städtisch organisierten, überregional orientierten Literaturgespräch gegründet wurde, entstanden die Literaturhäuser etwa in Berlin und Hamburg mit dem Ziel, einen Sammlungsort für Literaturveranstaltungen zu bieten und Literatur als Kunst in den Mittelpunkt zu rücken. Die Initiative ging dabei weniger von Selbstschreibenden als von Vermittelnden aus. Bei der historischen Betrachtung zeigen sich zwei Entwicklungslinien hin zum gegenwärtigen Konzept des Literaturhauses: Auf der einen Seite gibt es die Literaturbüros - das erste entstand 1980 in Düsseldorf ${ }^{322}$ - und auf der anderen Seite entwickeln sich die Literaturhäuser ab 1986.323 Die Literaturbüros stellen eher lokale Interessenvertretungen für Schriftsteller*innen dar, die diese in ihrer Arbeit unterstützen und für eine eher regionale Vernetzung sorgen. Nach dem ersten in Düsseldorf bildeten sich weitere vor allem in kleineren Städten. Literaturhäuser gründeten sich mit der Absicht, Literatur (der Gegenwart) überregional wirksam zu vermitteln. Die Literaturproduktion spielt dabei eine der Vermittlung untergeordnete Rolle. Zwar verstehen sich die Literaturhäuser konzeptionell als Ort des Austausches, auch unter Schriftstellerkolleg*innen, doch fungieren sie in erster Linie als Ort für ein Publikum. Im Literaturbüro liegt der Fokus auf der Beziehung von Autor*innen untereinander, während im Literaturhaus Leser*innen und Autor*innen zusammentreffen.

Für die Diskussion aufschlussreich ist eine akademische Arbeit, die sich schon 1993 mit dem Verhältnis von Literaturbüros und Literaturhäusern befasste. Stefanie Baumann legt darin dar, dass Literaturhäuser infrastrukturell nicht mit den Literaturbüros vergleichbar seien, und so blendet sie gerade die Literaturhäuser zugunsten der Literaturbüros als Untersuchungsgegenstand aus. ${ }^{324}$ Gleichzeitig kommt sie zu dem Schluss, dass die Literaturbüros sich nach und nach stärker der Organisation von Veranstaltungen zuwenden und ihre Informationsinstanz für Schriftstel-

\footnotetext{
321 Schlaffer 1999, S. 2.

322 Vgl. Baumann 1995, S. 44.

323 Vgl. z. B. Reuter 2000, S. 5.

324 Vgl. Baumann 1995, S. 10.
} 
ler*innen in den Hintergrund gerät, ${ }^{325}$ sodass ,,sich die Literaturbüros innerhalb der Literaturszene zu einem modernen Dienstleistungsbetrieb mit dem Schwerpunkt ,Literaturvermittlung' entwickelt haben. “" ${ }^{326}$ Es ist zu vermuten, dass die höhere Anzahl an Literaturagent*innen sowie die durch die Digitalisierung gesteigerten Möglichkeiten des Selfpublishings und des arbeitspraktischen Austausches diese Beratungsstellen zwar nicht unnötig, doch weniger notwendig machen. Öffentliche Literaturveranstaltungen werden hingegen vermehrt rezipiert und unterstützt. Diese Entwicklung unterstützt die Argumentation, ,Literaturhaus' auch als Funktionsbegriff zu verwenden, der die Literaturbüros, für die das Publikum ein wichtiger Bestandteil ist, einschließt.

\section{Publikumsanalysen}

Das Publikum des Literaturhauses teilt sich auf in Stammpublikum und Gelegenheitspublikum. Es gehört zum gesamten Akteurskomplex, der, wie oben angedeutet, über eine ähnliche literarische Praxis verbunden ist. ${ }^{327}$ In den deutschen Einrichtungen sind zusätzlich Vereinsmitglieder zu verzeichnen, die nicht unbedingt Stammgäste sein müssen, jedoch eine engere Verbindung zum Literaturhaus pflegen als Nicht-Vereinsmitglieder und sich über die Einzelveranstaltung hinaus mit der Institution identifizieren. Einmalige Besucher*innen kommen möglicherweise weniger wegen des Literaturhauses als Veranstalter und vielmehr allein anlässlich des einen bestimmten Bühnengastes zur Lesung und damit eher zufällig zum Literaturhaus als Ort. Es ist demnach bei Aussagen über das Literaturhaus-Publikum zu spezifizieren, ob von dem Publikum einer Veranstaltung oder dem generellen Publikum, das groBe Teile des Gesamtprogramms rezipiert, die Rede ist. Zu bedenken ist für den deutsch-skandinavischen Vergleich grundsätzlich, dass sich die traditionellen Publika dahingehend unterscheiden, dass es in Skandinavien kein klassisches Bildungsbürgertum gibt, das in Deutschland häufig mit dem Literaturhaus in Verbindung gebracht wird. Nur ausführliche empirische Publikumsstudien gestatten allerdings fundierte Einschätzungen. Zuschaueranalysen stehen jedoch nicht im Fokus der vorliegenden Arbeit. ${ }^{328}$ Dass sie in den letzten Jahren sowohl in der Forschung als auch in Kulturinstitutionen selbst an Bedeutung gewonnen haben, betonen die entsprechenden Publikationen. ${ }^{329}$

\footnotetext{
${ }^{325}$ Vgl. ebd., S. 78.

${ }^{326}$ Ebd., S. 79.

${ }^{327}$ Vgl. auch Björkman 2002, S. 108-109. Sie teilt darin Gruppen von Leser*innen ein, die etwas gemeinsam haben in ihrem Umgang mit Texten.

${ }^{328}$ Bspw. ließe sich das Publikum auf Basis von erhobenen Daten mit dem Ende der 1970er-Jahre entwickelten, später modifizierten und etablierten gesellschaftswissenschaftlichen Zielgruppenmodell des Markt- und Sozialforschungsunternehmens Sinus-Institut näher beschreiben. Zum Sinus-Modell vgl. Barth et al. (Hg.) 2018.

${ }^{329}$ Neben der grundständischen Leserforschung, vgl. z. B. Schneider 2004, und Untersuchungen etwa zur Kommunikation zwischen Leser*in und Autor*in, vgl. z. B. Christ 2017, gibt es empirisch interessierte Arbeiten zum Kulturpublikum, vgl. z. B. Klein 2003 und Glogner-Pilz und Föhl 2016, ein Handbuch, das auf einer Reihe früherer Beiträge fußt, vgl. z. B. im Sammelband Glogner-Pilz und Föhl (Hg.) 2011. Zu nennen ist außerdem der Bereich des Audience development, der in Deutschland vor allem durch Birgit Mandel etabliert wurde, die zahlreich zum Thema publiziert hat, vgl. z. B. Mandel (Hg.) 2005 oder Mandel (Hg.) 2013. In diesem Kontext entstehen auch Arbeiten zur Nicht-Besucher-Forschung, vgl. Renz 2016. Eine Übersicht zum Forschungsbereich ,Kulturvermittlung‘ bietet das Institut für Kulturpolitik der
} 
Aussagekräftige empirische Publikumsumfragen seitens der Literaturhäuser selbst liegen meines Wissens bisher nicht vor. Ertragreich für die Literaturhäuser wären diese, um besucherorientiert wirken zu können ${ }^{330}$ und um sich dabei auf die tatsächlichen und nicht nur die vermuteten Bedürfnisse der aktuellen, der potenziellen sowie der avisierten Besucher*innen einlassen zu können. Besonders in Anbetracht der Tatsache, dass nicht mehr von einer einheitlichen Kulturbesuchergruppe ausgegangen werden kann, ${ }^{331}$ könnten die Literaturhaus-Teams ihre Einschätzungen so präzisieren.

Verfahren zur Veränderung und Ausweitung der Publika kommen in den Einrichtungen demnach noch nicht zum Einsatz. Von einer intuitiven Auseinandersetzung mit diesem Thema ist hingegen auszugehen, denn es lassen sich in den Programmen durchaus Veranstaltungen identifizieren, die als Versuche, neue Zielgruppen anzusprechen, gedeutet werden können. Produktiv ist es folglich für die vorliegende Arbeit, das Zielpublikum bei den Fallstudien indirekt zu eruieren und so auf das implizite Selbstverständnis der Institution zu schließen. Wer wird vom Literaturhaus angesprochen? Über das Design der Programmhefte, die Textgestaltung und die Präsentation im Internet lässt sich beispielsweise sehen, dass sich vor allem die deutschen Einrichtungen an ein akademisch gebildetes Publikum richten. In direkten Äußerungen stellen sie sich hingegen niedrigschwelliger dar und betonen, dass ihr Publikum beispielsweise bezüglich der Kategorie Alter durchmischt sei.

Zugleich besteht diskursive Einigkeit darüber, dass, wie in anderen Kulturinstitutionen, der demografische Wandel plastisch wird, weil viele Ältere die Veranstaltungen besuchen. Mehr ältere Menschen sind nach Ende ihres Berufslebens agiler und haben mehr Freizeit. ${ }^{332}$ Zugleich sind es mehrheitlich Zuschauerinnen. ${ }^{333}$ Dies bestätigt Kari Hilde Skaftnesmo mit der Diskussion um die von Tomas Espedal geprägte Bezeichnung „kulturkjerring“ [altes Kulturweib] ebenso für Norwegen. ${ }^{334}$ Skaftnesmo hat die Leitungen in Oslo und Bergen dazu konkret befragt: Aslak Sira Myhre habe gesagt, dass die, die immer kämen, „den hvite og intellektuelle middelklassen“ [die weiße und intellektuelle Mittelklasse] bildeten, während Kristin HelleValle das Kernpublikum in Bergen als ,voksne mennesker med tilknytning til byens høyere utdanningsinstitusjoner“"335 [erwachsene Menschen mit Verbindung zu den höheren Bildungsinstitutionen der Stadt] bezeichnet habe. Ob sich dabei eher, wie Pierre Bourdieu es fasst, Intellektuelle, für die der Literaturhaus-Besuch „aufgrund seiner Häufigkeit und quasi professionellen Routinehaftigkeit nicht das geringste Außergewöhnliche“ darstellt, oder die Kulturbesucher*innen finden lassen, für die eine Veranstaltung „Anlaß zu aufwendigen Ausgaben wie zur Demonstration dieser

Universität Hildesheim online, vgl. „Kulturvermittlung online“, Institut für Kulturpolitik der Universität Hildesheim.

330 Vgl. Glogner-Pilz und Föhl 2016, S. 25.

331 Vgl. ebd.

332 Die Gründe dafür, dass vor allem Ältere ins Literaturhaus kommen, sind im Literaturhaus-Programm zu suchen, doch müssen ebenso die Alltagsabläufe der Menschen in unterschiedlichen Lebensphasen bedacht werden. Zu den Veranstaltungszeiten im Literaturhaus vgl. Kapitel II 10.4.2, S. 272.

333 Dies bestätigte unter anderem Kristin Helle-Valle in einem Mailwechsel mit mir, allerdings betonte sie, dass es Frauen unterschiedlicher Altersgruppen seien.

334 Vgl. Skaftnesmo 2014, S. 110-111.

335 Skaftnesmo 2016, S. 35. 
Ausgaben“336 ist, könnte über Befragungen beantwortet werden. Es liegt die Vermutung nahe, dass es sich eher um Ersteres handelt, weil beispielsweise die Codes die Kleidung betreffend im Literaturhaus anders sind als im Theater, im klassischen Konzert oder in der Oper. Wie sich andeutet, ist eine Fortsetzung dieser Diskussion zwar spannend, jedoch ohne empirische Grundlage zu spekulativ, um hier weitergeführt zu werden.

Ferner ist zu reflektieren, dass Publikumsanalysen in engem Zusammenhang stehen mit Überlegungen einerseits zur Finanzierung der Einrichtung, andererseits zum inhaltlichen Programm. Dass Finanzierung und Programmgestaltung ebenfalls miteinander verknüpft sind, wurde schon erwähnt. In Folge der oben angedeuteten „Stagnation oder gar des Rückgangs von Fördergeldern steigt gleichzeitig auch der Druck zur Erhöhung der Eigeneinnahmen über Eintrittsgelder, Gastronomie etc.“337. Daraus ergibt sich die Notwendigkeit, die Besucherzahlen zu erhöhen. „Die Umorientierung im Kulturbetrieb hin zu mehr Besucherorientierung hat sicherlich in gewisser Weise Auswirkungen auch auf das Produkt bzw. die Programmpolitik der Kultureinrichtungen."338 Andersherum wirkt sich das Veranstaltungsangebot darauf aus, welche Zuschauer*innen das Literaturhaus besuchen.

\section{5.6 Wirkungen, Funktionen und Nutzen des Literaturhauses}

Der Zuspruch des Publikums kann als Kriterium für den Erfolg der Einrichtung gelten. Dies betrifft einerseits den ökonomischen Erfolg durch viele zahlende Gäste, andererseits die Tatsache, dass sich offenbar überhaupt ein Publikum findet, das Veranstaltungen im Literaturhaus besucht. Die steigende Zahl an Literaturvermittlungsorganisationen spricht dafür, von einem vermehrten Interesse des Publikums auszugehen. Zu fragen ist deshalb prinzipiell - ausgehend vom Publikum -, welche Gründe für den Erfolg des Literaturhauses sprechen. Warum kommen Besucher*innen zu Lesungen? Was sorgt für die Attraktivität des Konzeptes? Dabei liegt im Folgenden der Fokus auf dem Besuch von Veranstaltungen, die den Angebotsschwerpunkt bilden. Beteiligt sind an einem Lesungsabend notwendigerweise ein*e Autor*in und ein Publikum; zu diesen gesellen sich im Literaturhaus meistens ein*e Moderator*in, die Veranstalter*innen (inklusive Organisations- und Technikpersonal sowie eventuell Kooperationspartner*innen), gelegentlich Vertreter*innen der Verlage und Journalist*innen. Der Büchertisch einer Buchhandlung und das gastronomische Angebot können die Veranstaltung rahmen.

Die Perspektiven der Autor*innen, Veranstalter*innen und der weiteren beteiligten Akteur*innen kommen ebenfalls vor, sie können sich von den Motivationen des Publikums natürlich unterscheiden, ${ }^{339}$ die beispielsweise die österreichische Autorin Teresa Präauer $(* 1979)$ veranschaulicht:

\footnotetext{
336 Bourdieu 1982, S. 420.

337 Glogner-Pilz und Föhl 2016, S. 21.

338 Klein 2003, S. 10.

${ }^{339}$ Dass dies keine neue Feststellung ist, zeigt beispielsweise Thomas Böhms Beitrag, vgl. Böhm 2005a, S. 204.
} 
Als akustisches Ereignis kann die Lesung begeistern für den Text, kann einen Zugang schaffen, kann aber auch das Nicht-Verstehen-Können zulassen, in Anerkennung der Schwierigkeit, die das Lesen von Literatur eben mit sich bringt. Während einer Lesung, einem Gespräch, einer Moderation, kann ich Menschen beim Laut-Denken zuhören. Ich kann mich als Autorin um Verständlichkeit, ich kann mich, im Publikum sitzend, um Verstehen bemühen. Und ich kann die offenen Fragen offen lassen. Ich kann aber auch nachfragen. Ich kann abdriften und kann auf Ideen kommen. Ich kann aufstehen und gehen, ich kann protestieren, ich kann erdulden, ich kann lachen oder weinen. Ich kann erschüttert werden, aufspringen, mein Leben in andere Bahnen lenken. ${ }^{340}$

Roger Willemsen prognostizierte bereits 2007: „Ich glaube fast mehr an die Zukunft der Lesung als an die Zukunft des Buches. In Zeiten der medialen Entwicklung ist das Bedürfnis nach Unmittelbarkeit größer denn je. “341 Die folgenden Überlegungen basieren auf Experteninterviews, Erfahrungen und Einschätzungen der Verfasserin und anderer Literaturbetriebsangehöriger und weiteren Diskursannahmen. An dieser Stelle geht es nicht darum, vollständig und detailliert die Funktionen und Wirkungen zu listen, sondern eine Diskussion über die Zusammenhänge von gesellschaftlichen Veränderungen und institutionellen Entwicklungen anzustoßen. Die Literaturveranstaltungen im Literaturhaus fungieren dabei als Beispiel.

Die Entstehung des Literaturhauses ist im Zusammenhang mit gesellschaftlichen Entwicklungen zu sehen, die sich im Zeitalter der Digitalisierung abzeichnen. Die verschiedenen Turns in den Geisteswissenschaften sind als Reaktionen auf einige davon zu verstehen. ${ }^{342}$ Dazu liegen unterschiedlich perspektivierte Beschreibungen der Gegenwart vor, die hier nicht im Einzelnen referiert werden. Die Beiträge der Raumtheorie oder die Ansätze, die Materialität und Körperhaftigkeit im Zuge des Performative Turns in die Literaturwissenschaft einbringen, sind einige Beispiele. Das Literaturhaus mit seinen Literaturveranstaltungen ist nicht nur unter literarischen Vorzeichen, sondern auch als soziale Praxis zu untersuchen.

Andreas Reckwitz zufolge charakterisiert die bisherige Vorstellung der Moderne, beginnend mit der Industrialisierung, diese durch Rationalisierung und zweckbezogene Standardisierung. Nicht gesehen werde dabei der Aspekt der Singularisierung, der ebenfalls eine immer wichtigere Rolle spiele. Angefangen in der Romantik, die das Individuelle in der Kunst vorzubringen versuchte, habe sich dieses Bedürfnis inzwischen über die Kunst hinaus verbreitet. Dass Andreas Reckwitz die Bezeichnung ,Singularität ${ }^{\star}$ statt ,Individualität ${ }^{\star}$ verwendet, verdeutlicht, dass sie nicht nur auf einzelne Individuen bezogen sein muss, sondern Kollektive ebenfalls nach Singularität streben können. ${ }^{343}$ Das Streben nach erfolgreicher Selbstverwirklichung führe zu einer Spannung zwischen Authentizität und Selbstinszenierung, die das heutige Leben der Menschen ausmache. ${ }^{344}$ Er betont damit, dass die Selbstverwirklichung und das persönliche Erleben häufig damit verbunden seien, gesehen zu wer-

\footnotetext{
340 Präauer 2016, S. 59.

341 Roger Willemsen zitiert nach: Esmann 2007b, S. 96.

342 Vgl. Bachmann-Medick 2009.

${ }^{343}$ Vgl. Reckwitz 2017, S. 10.

344 Reckwitz bezieht seine Beobachtungen auf die „,neue Mittelklasse“ im Westen, die Mittelklasse der Akademiker*innen, die seit den 1980er-Jahren gewachsen sei, sodass es immer weniger eine Elite gebe, vgl. ebd., S. 274-275. Das Publikum des Literaturhauses kann, auch ohne ausführliche Studien, größtenteils dieser Gruppe zugeordnet werden.
} 
den und so Prestige zu erlangen. Die innere Erfahrung werde erst erlebbar, indem sie durch die Zurschaustellung von außen sichtbar werde. Das Teilen privater Erlebnisse, die für die Anderen möglicherweise gar nicht bedeutend seien, in Sozialen Medien spreche ebenfalls für diese Einschätzung. So diene das Teilen auch der eigenen Selbstvergewisserung. Diese Entwicklungen sind im Zuge der Digitalisierung zu verstehen, die - verkürzt zusammengefasst - zu einer Ausweitung der Möglichkeiten, zu mehr, aber anonymerem Austausch und einer vernetzen Gesellschaft bei gleichzeitiger Enträumlichung geführt hat. Damit verbunden, wurde das Bedürfnis nach Konkretem, Materiellem, Evidentem wiederentdeckt, dieses scheint „doch möglicherweise eine tiefe Verunsicherung darüber zu artikulieren, was unter den gegenwärtigen Bedingungen noch als Wirklichkeit verstanden werden kann. “345 Die Gegenwart ist komplexer geworden und deshalb wird in der Gesellschaft der Wunsch nach Verlässlichkeit und direktem Kontakt ebenso wie nach intensiven, ,echten' Erlebnissen offensichtlicher. Marianne Streisand weist darauf hin, dass „die mit weltweiter Flexibilisierung und Dynamisierung verbundenen Symptome von Orientierungs- und Wertverlust für den Einzelnen und sein unmittelbares soziales Umfeld“346 ernst genommen werden, beispielsweise durch das wissenschaftliche Interesse an Phänomen der ,Intimität‘.

Ausgehend von diesen Überlegungen lassen sich unterschiedliche und miteinander verknüpfte, die Wirkungen und Funktionen des Literaturhauses betreffende Aspekte diskutieren. Zum einen sind dies für gegenwärtige westliche Gesellschaften generell geltende Momente, zum anderen konkret auf Literatur und Literaturveranstaltungen gemünzte Beobachtungen.

\section{5.6.1 Erlebnis, Ereignis und Event}

Vor einigen Jahren noch wurde der Begriff ,Event ${ }^{6}$ intensiv diskutiert, ${ }^{347}$ es war die Rede von Winfried Gebhardts viel zitiertem „Gespenst des Events“348. Der Terminus wird inzwischen seltener abwertend verwendet und kann als akzeptiert gelten, denn

[d]aß freizeitkulturelle Angebote aller Art erlebenswerte Ereignisse darstellen bzw. zumindest beinhalten müssen, wenn sie sich auf dem ,Markt' multipler Optionen in spät-, post- oder reflexivmodernen Gesellschaften überhaupt behaupten sollen, das ist - spätestens seit Gerhard Schulzes Deklaration der ,Erlebnisgesellschaft ${ }^{\circ}$ (1992) - eine sozialwissenschaftlich triviale Einsicht. ${ }^{349}$

Nützlich ist der Fachausdruck ,Event ${ }^{`}$ weiterhin, um die gegenwärtige Gesellschaft zu beschreiben, denn die Zunahme beispielsweise an Literaturfestivals und -projekten spricht dafür, von einem Interesse an vermeintlich einmaligen Veranstaltungen auszugehen. Zur Schilderung dieser Beobachtungen wird, wie das Zitat zeigt, in

\footnotetext{
345 Kajetzke und Schroer 2010, S. 202-203.

346 Streisand 2001, S. 35.

${ }^{347}$ Der Ausdruck ,Event ${ }^{6}$ war auch da nicht neu. Seine Ursprünge liegen in der Ethnologie und der Soziologie, in Verbindung mit dem Ritual. Aspekte des Rituals und der Ritualisierung finden sich auch im heutigen auf Kulturveranstaltungen bezogenen Event.

348 Gebhardt 2000, S. 17.

${ }^{349}$ Hitzler 2000, S. 405. Er setzt fort: „Erlebenswerte Ereignisse haben aber zwei Dimensionen: eine qualitative und eine quantitative bzw. eine der Intensivierung und eine der Extensivierung.“
} 
der Forschung vor allem auf Gerhard Schulzes Erlebnisgesellschaft zurückgegriffen, die zunächst eine Beschreibung der Gesellschaft ist, eine

[k]omparativ zu verstehende Bezeichnung für eine Gesellschaft, bei der im historischen und interkulturellen Vergleich innenorientierte Lebensauffassungen eine relativ große Rolle für den Aufbau der Sozialwelt spielen. Die Charakteristika der Erlebnisgesellschaft manifestieren sich unter anderem in folgenden Aspekten: soziale Milieus, Zeichensysteme, existentielle Anschauungsweisen, Erlebnismarkt, Rationalitätstypen, fundamentale Semantik. 350

Schulze prägte mit dem Terminus ,Erlebnis‘ einen Begriff, der eng mit dem des „Events' verknüpft ist, wie er später herausarbeitet: „Man kann das Eventphänomen als Radikalisierung der Erlebnisgesellschaft betrachten, in der sich bereits eine Wirtschafts- und Sozialwelt jenseits der Erlebnisgesellschaft ankündigt. “351 „Event` etab-

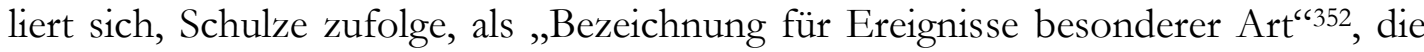
stark durch kommerzielle Beweggründe motiviert sind. ${ }^{353}$ Stephan Porombka betont ebenfalls die ökonomische Motivation von Events und legt den Ausdruck ,Eventisierung' entsprechend aus. Für ihn bedeutet ,Eventisierung“ „erst einmal und vor allem ,Professionalisierung““354.

Steckt diese Eventisierung - verstanden als Kommerzialisierung - also nicht in jeder Kulturveranstaltung? Die Ambivalenz von Literatur als Kunst und Ware, die für das Buch vorliegt, ist auch im Kontext der Literaturveranstaltung zentral. Kultur und Ökonomisierung seien inzwischen eine produktive Synthese eingegangen. ${ }^{355}$ Dennoch ist diese Art der Inszenierung nicht gleichzusetzen mit Events, die in erster Linie auf rein spektakuläre Aufmerksamkeitserregungen zur Verkaufssteigerung abzielen. Dass Events innerhalb von Marketingstrategien genutzt werden, um in einer Zeit, in der um Aufmerksamkeit konkurriert wird - was Georg Franck mit seiner Ökonomie der Aufmerksamkeit zitierfähig machte ${ }^{356}$-, Kund*innen zu erreichen, ist bekannt. Es beschreibt lediglich einen Teil der Literaturveranstaltung, die hier im Fokus steht. In den Literaturhaus-Programmen gibt es, dem Selbstverständnis der Einrichtungen und ihrer Struktur als gemeinnützige Organisationen folgend, keine Angebote, bei denen es vordergründig um den Verkauf oder das Spektakel als solches und nur sehr untergeordnet um die Literatur als Kunstform geht. Fälle, die ausschließlich auf das Buch als Produkt und vor allem auf dessen Verkaufserfolg zielen, interessieren deshalb hier nicht weiter. Fest steht dennoch, dass wirtschaftliche Interessen weder im privaten noch im gemeinnützigen Veranstaltungsbereich zu ignorieren sind. Interessant wird es an der Schnittstelle zwischen literarischem Anspruch und ökonomischer Begrenzung - denn, dass weniger große finanzielle Gewinne, vielmehr Kosteneinsparungen den Handlungsrahmen vieler Kulturakteur*innen abstecken, ist hinreichend bekannt.

\footnotetext{
350 Schulze 1993, S. 735.

351 Schulze 2007, S. 316.

352 Ebd., S. 310.

353 Vgl. ebd., S. 314.

354 Porombka 2003, S. 138.

355 Vgl. z. B. Reckwitz 2017, S. 111.

356 Vgl. Franck 1998. Franck zufolge gilt die Steigerungslogik wie beim Geld inzwischen ebenfalls für die Aufmerksamkeit, vgl. Franck 2007, S. 165.
} 
Unter dem Terminus ,Event ${ }^{\varsigma}$ verstehe ich also gerade nicht ,das Andere' von Literaturhaus-Lesungen, sondern Literaturveranstaltungen im weitesten Sinne, bei denen es immer auch um das Erlebnis (in Anlehnung an Schulze) geht. Sinnlich-Erlebbares im sozialen Rahmen mit kommerziellem Interesse kann „die beinahe schon klassisch zu nennende Verlaufsform ,Autorenlesung “"357 ebenso evozieren wie Poetry Slam im Stadion, Lesungen an ungewöhnlichen Orten oder andere Veranstaltungen, die unter ,Event-Verdacht ${ }^{\varsigma}$ stehen. „Und der Begriff ,Event ${ }^{`}$ bietet keine inhaltliche Bestimmung - auch wenn er so gebraucht wird, sobald man naiv und fahrlässig,

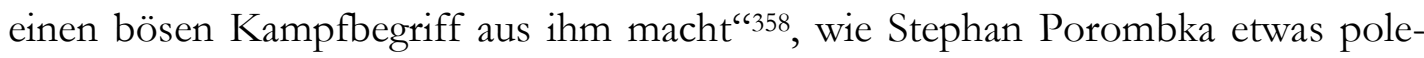
misch schreibt.

Dass einige Verfasser*innen ,Event ${ }^{6}$ und ,Ereignis' anders als Porombka auslegen und stärker auf inhaltlich-konzeptuelle Momente abheben, belegt beispielsweise diese Formulierung von Matthias Beilein und Claudia Stockinger: „Denn Literaturhäuser setzen gerade auf die Intimität der Begegnung von Autor und Publikum. Sie verzichten auf alles ereignishafte Beiwerk, bieten also ein Gegenmodell zu den Multimedia-Leseshows à la Frank Schätzing oder Sebastian Fitzek. "359 An diesem Zitat sind mindestens zwei Punkte zu diskutieren, obgleich die Grundaussage, dass die Veranstaltungen im Literaturhaus etwas anderes sein sollen als bombastische Spektakel sicherlich zutrifft. Erstens lässt sich die „Intimität der Begegnung“ genauso gut als Erlebnis bezeichnen. Zweitens konstruiert das Wort ,Gegenmodell' ein intendiertes Kontrastprogramm, das sich explizit vom Anderen abgrenzen will. Hilfreicher erscheint es in diesem Fall, von Parallelentwicklungen zu sprechen, zumal beide Lesungskonzepte so unterschiedlich letztlich gar nicht sind, wenn etwa die folgende Auslegung von Birgit Mandel zugrunde gelegt wird:

Im besten Sinne wirkt ein Event als eine Art Gesamtkunstwerk, durch eine Erlebnisdramaturgie, die unterschiedlichste ästhetische Mittel zusammenführt mit dem Ziel, Kunst optimal zur Wirkung zu bringen. Zugleich lassen gute Events den Teilnehmern bzw. Besuchern Raum für eigene Ideen, Aktivitäten und Kommunikation untereinander. ${ }^{360}$

Damit ist ein Aspekt angesprochen, den unter anderem Stephan Porombka aufdeckt, indem er darauf verweist, dass in den Literaturhäusern an einem „NonEvent-Markenimage“"361 gearbeitet werde. Und Sonja Vandenrath deutet eine historische Perspektive an und stellt heraus, dass die heutige ,Wasserglaslesung' selbst keine traditionelle Praktik ist, denn in „einer Zeit, in der die pure Lesung schwer an ihrem protestantischen Ruf trägt, mag man kaum glauben, dass sie vor nicht allzu ferner Zeit der Inbegriff der literarischen Eventkultur selbst war. “362 Das Medieninteresse und die Zuschauermassen, die die Gruppe 47 und Walter Höllerers Lesereihe aktivierten, hatten Eventcharakter, und gleichzeitig entsprachen die Lesungsformate dem, was heute tendenziell als ,traditionelle' Lesung, Autorenlesung und Moderatorengespräch, bezeichnet wird. Zur inhaltlichen Beschreibung von einzelnen Veranstaltungen nützt der Eventbegriff in diesem Kontext demnach wenig. Er verweist

\footnotetext{
357 Bartmann 2004, S. 124.

358 Porombka 2003, S. 134.

359 Beilein und Stockinger 2017, S. 236.

360 Mandel 2011, S. 54.

361 Porombka 2003, S. 138.

362 Vandenrath 2013, S. 124.
} 
jedoch auf den literaturbetrieblichen Zusammenhang, in dem auch das Literaturhaus zu positionieren ist. Peter Kemper fasst zusammen, dass unter Erlebnis ein inneres Ereignis zu verstehen ist, „[k]omplementär dazu ließe sich ein Event als Versuch verstehen, dieses innere Ereignis durch die äußere Inszenierung hervorzurufen“"363. Die Verbindung zum ,Ereignis‘, das unter anderem Erika Fischer-Lichte als Theaterwissenschaftlerin für die Performanzforschung genutzt hat, ist für das Verständnis der Lesung als körperlich-erfahrbares Phänomen ebenfalls zu berücksichtigen, wie beispielsweise Susan Esmann zeigt. ${ }^{364} \mathrm{Da}$ in dieser Arbeit jedoch keine Inszenierungsanalysen von Literaturveranstaltungen durchgeführt werden, wird im Folgenden auf die Benutzung der Bezeichnung ,Event ${ }^{\star}$ weitestgehend verzichtet und hauptsächlich von ,Veranstaltungen' gesprochen. Diese Vokabel ist allgemeiner, denn Veranstaltungen sind, nach Hubert Knoblauch, „anberaumte Zusammenkünfte einer größeren Zahl von Handelnden, die sich für eine bestimmte Zeit an einem bestimmten Schauplatz einfinden und bereit sind, einen oder mehrere gemeinsame Foci der Interaktion zu teilen. " ${ }^{365}$,Veranstaltung ist damit eine neutralere Begriffsbezeichnung.

\section{5.6.2 Selbstpräsentation und Gesehenwerden}

„Lesung. Literaturhaus. Wieder setzt sich kein Mensch in die erste Reihe. Ich schlage gleich vor, sie künftig gar nicht erst aufzustellen“, äußerte der Autor Thomas Kapielski (*1951) anlässlich der Verleihung des Preises der Literaturbäuser (BE 201005-27). Die Beobachtung im ersten Teil trifft auf die Veranstaltungen im Literaturhaus nicht (mehr) zu. Viele Zuschauer*innen suchen gerade die vorderen Plätze auf, sicherlich zum einen, um möglichst nah an den Gästen auf der Bühne zu sein, zum anderen um von ihnen und dem Rest des Publikums gesehen zu werden. Das Literaturhaus stellt einen Ort, an dem die Besucher*innen sich selbst als Leser*innen präsentieren können. Lesen ist eigentlich vor allem privat und singulär in der Ausübung, und so gibt es relativ wenige Orte, um sich einer Gruppe - ohne gerade zu lesen - als Leser*in zu zeigen und vor allem so wahrgenommen zu werden. Wie Heinz Schlaffer bemerkt: „Das eigentliche Vermögen eines Literaten besteht darin, daß er etwas über Literatur zu sagen weiß, nicht darin, daß er häufig über einem Buch angetroffen wird. "366 Mit dem Besuch des Literaturhauses markiert die Person ihre Zugehörigkeit zu einem Bereich, der Lesen als Kulturpraktik anerkennt und schätzt.

\section{5.6.3 Authentizität und Präsenz}

Der Aspekt der Authentizität ist einerseits für die Besucher*innen zu diskutieren, andererseits auf die Gäste der Literaturhaus-Podien zu beziehen. Im Literaturhaus finden Veranstaltungen mit unterschiedlichen Graden an Öffentlichkeit statt. Nicht

\footnotetext{
363 Kemper 2005, S. 119.

364 Vgl. Esmann 2007a, S. 2.

365 Knoblauch 2000, S. 36.

366 Schlaffer 1999, S. 23.
} 
alle Veranstaltungen im Literaturhaus sind für die Allgemeinheit bestimmt, zu einigen wird explizit eingeladen oder nur Angemeldeten Zutritt ermöglicht. Auch bei den eigentlich öffentlichen Veranstaltungen entsteht eine Spannung zwischen Öffentlichkeit und Intimität ${ }^{367}$, zwischen Bühnenperformance und Authentizität: Vor einem Publikum sollen die geladenen Autor*innen ein möglichst intimes oder zumindest authentisches Gespräch führen - „als Vertraulichkeit gegenüber einem ganz fremden Publikum“368. „[]t leaves room for surprises - positive or negative a reader may even read it in the paradoxical expectation of the unexpected." 369 Was Masschelein et aliae für das literarische Interview konstatieren, lässt sich auf die Literaturveranstaltung übertragen - die Erwartung des Unerwarteten ist dabei sogar noch stärker, weil diese live und ohne redaktionelle Bearbeitung gezeigt wird. Das Literaturhaus ist ein Raum, an dem die Auseinandersetzung mit Authentizität und Selbstinszenierung in der Öffentlichkeit von hoher Relevanz ist. Diese Verknüpfung findet sich in der Gegenwartsliteratur selbst wieder, denn autofiktionale Romanprojekte sind als Zeichen eines Zweifels an der Wahrnehmung der Wirklichkeit zu deuten und als „performativ biografisme“ ${ }^{370}$ [performativer Biografismus]. Die Frage nach ,authentischen' Darstellungsmöglichkeiten beispielsweise des eigenen Lebens und dessen zwangsläufiger Fiktionalisierung und Inszenierung durch das Aufschreiben und Erzählen bestimmt Projekte wie das wohl in Skandinavien wie in Deutschland bekannteste dieser Art, Min kamp $p^{371}$ des Norwegers Karl Ove Knausgård.

Relevant ist im Literaturhaus vor allem die ,personale Authentizität nach Sybille Krämer, die „nicht von der Echtheit von Dokumenten, vielmehr von der ,Echtheit und Glaubwürdigkeit einer Person“ ${ }^{\text {“72 }}$ handelt. „Was dabei erwartet wird, ist eine Übereinstimmung und Kohärenz zwischen dem, was diese Person ,äußerlich', also für andere wahrnehmbar, darstellt und ausdrückt und dem, was sie ,innerlich', also für sich selbst, ,tatsächlich“ ist. “" 373 Davon grenzt Krämer die ,materiale Authentizität ${ }^{\star} \mathrm{ab}$, die sie als Eigenschaft eines Produktes versteht, dessen Urheber sich ermitteln und identifizieren lässt. ${ }^{374}$ Obgleich sie am Beispiel von Zeugenschaft darlegt, dass die personale und die materiale Authentizität „nicht disjunkte Fassungen von Authentizität bilden“"375, sondern zusammenwirken, ist für die vorliegende Arbeit vor allem der Bedeutungskern von Authentizität als ,personale Authentizität ' hilfreich. Dieser bedeutet zugleich, dass die gesuchte Kohärenz von ,Innen“ und ,AuBen` empirisch nicht ermittelbar ist. So wie die Gerichtszeug*innen auf Glaubwürdigkeit geprüft werden, müssen beziehungsweise sollten im Literaturhaus die

\footnotetext{
${ }^{367}$ Marianne Streisand weist darauf hin, dass sich im Begriff ,Intimität' eine Vielzahl an Diskursen kreuzt. Er sei unter anderem ein relationaler Begriff, um soziale Beziehungen zu beschreiben. Seit den 1990erJahren erhalte er in der Wissenschaft einen Aufschwung, was mit dem oben beschriebenen beobachteten Orientierungsverlust einhergehe, vgl. FN 346. Zur Autorschaft insgesamt vgl. Kapitel I 5.4.

368 Steinfeld 1988, S. 978.

${ }^{369}$ Masschelein et al. 2014, S. 25.

370 Eglinger 2016, S. 397.

${ }^{371}$ In Norwegen wurden die sechs Bände von 2009 bis 2011 publiziert. Auf Deutsch sind sie in der Übersetzung von Paul Berf unter den Titeln Sterben, Lieben, Spielen, Leben, Träumen, Kämpfen von 2011 bis 2017 nacheinander erschienen.

372 Krämer 2012, S. 16.

${ }^{373}$ Ebd.

374 Vgl. ebd.

375 Ebd., S. 25.
} 
Autor*innen diese auf der Bühne vermitteln. Vertrauen bildet in diesem Zusammenhang eine wichtige Komponente. Den eigenen Text müssen die Autor*innen jedoch, anders als Gerichtszeug*innen, dem Publikum weniger als authentisch verbürgtes Dokument vorstellen, vielmehr müssen sie sich als authentische Urheber*innen des Werkes präsentieren. Das Paradigma des Authentischen liegt bei fiktionalen Texten zwar auch vor, doch muss der Text aufgrund seiner Konstruktion und Gestaltung dabei ,echt' im Sinne von ,überzeugend' sein. Bei Anwesenheit der Person des Autors wird die Frage nach der Glaubwürdigkeit wichtiger, weil die Leser*innen nach einem Abgleich zwischen Autorpersona und erzählter Welt suchen. Die Leser*innen müssen ihr die Geschichte glauben. Anschaulich wird dies zum Beispiel bei jungen Frauen, die über ältere Männer schreiben, oder bei Autor*innen, die über nicht selbst erlebte Kriegserfahrungen schreiben. Trauen die Rezipient*innen den Autor*innen die glaubhafte Erzählung zu?

Der Text wirkt ,echt', wenn der Autor ihn authentisch vermittelt. Das, was Michael Wetzel für Bilder festhält, lässt sich somit auf Texte anwenden: „Authentisch ist nicht das, was auf den Bildern dargestellt ist, sondern die Art und Weise der Darstellung [...] Authentisch ist das Künstlich-Künstlerische daran, nicht der nackte Bestand der Daten, sondern die gelungene, sprich: rettende Form ihrer Präsentation“376. Die Neugier des Publikums liegt unter anderem darin, zu sehen, ob der Autor glaubwürdig erscheint, denn - damit zurück zu Krämers Aufsatz - „[d]ie Reflexion über Authentizität eröffnet die Einsicht, dass unsere Sozialität tiefer auf Vertrauen und Glaubwürdigkeit angewiesen ist, als gemeinhin angenommen wird." ${ }^{377}$

In diesem Zusammenhang ist zu berücksichtigen, dass Autor*innen „ein bestimmtes Mischungsverhältnis zwischen Privatheit und Öffentlichkeit, zwischen Intimität und Distanz zu erzeugen“"378 versuchen. Dass bei dieser Suche nach Authentizität Autor*innen Inszenierungspraktiken nutzen, ist in der Forschung der letzten Jahre ausführlich diskutiert worden. ${ }^{379}$ Und Belletristikautor*innen selbst reflektieren ihre Position auf dem Podium. 380

Eine wichtige Ausdrucksform stellen Interviews dar, die mit den Rezipient*innen einen „pact of authenticity“381 eingehen. Torsten Hoffmann und Gerhard Kaiser verweisen in ihrem Sammelband Echt inszeniert auf verschiedene Funktionen des Autoreninterviews. ${ }^{382}$ Die Herausgeber fassen zusammen, dass Interviews nicht nur

\footnotetext{
376 Wetzel 2006, S. 54. Er führt als „Beispiel einer Darstellung von Unvorstellbaren“ Marguerites Duras’ Hiroshima mon amour an. Ähnlich beschreibt es Susanne Knaller mit der Bezeichnung ,Kunstauthentizität‘, die sie als besondere Form der, Objektauthentizität' begreift: „Als Authentizitätsgaranten dienen dabei im Kunstsystem der Autor/die Autorin bzw. die Kunstkritik“, Knaller 2006, S. 22.

377 Krämer 2012, S. 26.

${ }^{378}$ Knaller und Müller 2006, S. 7. Die Autor*innen beziehen sich dabei auf den Terminus ,Institutional Authenticity' nach Nikolas Coupland.

${ }^{379}$ Vgl. z. B. Künzel und Schönert (Hg.) 2007; Grimm und Schärf (Hg.) 2008; Jürgensen und Kaiser (Hg.) 2011; John-Wenndorf 2014 sowie die entstehende Doktorarbeit von Christian Dinger.

${ }^{380}$ Literarisch, unterhaltsam wie beobachtungsscharf, verarbeitet beispielsweise John von Düffel die Innenperspektive des Autors bei der Lesung, vgl. Düffel 2017. Verschiedene Anthologien präsentieren vergleichbare in Auftrag gegebene Kurztexte, vgl. z. B. Renz (Hg.) 1988; Böhm (Hg.) 2003 sowie mit internationaler Perspektive Böhm (Hg.) 2006. Erwähnt werden sollte unbedingt die Lesungsparodie in Loriots Film Pappa ante portas (1991), auf die auch Gunter E. Grimm hinweist, vgl. Grimm 2008, S. 154. 381 Masschelein et al. 2014, S. 37.

382 Der Band Echt inszeniert. Schriftstellerinterviews als Forschungsgegenstand ist im Anschluss an eine Tagung entstanden, die im Literaturbaus Frankfurt stattfand (FF 2012-09-26/28).
} 
der Informationsübermittlung dienen, sondern Schriftstellerinterviews vor allem diese Bedeutungen zukommen: (1.) eine „werkpolitische Funktion“, da die Aussagen die Interpretation der Texte beeinflussen, (2.) eine „kanonisierende Funktion“ als „Literaturgeschichtsschreibung in nuce“ und (3.) eine „ästhetische Funktion“, weil die Interviews bisweilen als eigenständige Texte rezipiert werden können. ${ }^{383}$ In der vorliegenden Arbeit steht nicht die Analyse der im Literaturhaus geführten Gespräche im Vordergrund, doch belegt die anhand der Fallstudien dargelegte Programmentwicklung im zweiten Kapitel die Annahme, dass Autoreninterviews als für den gegenwärtigen Literaturbetrieb typische Formate ernst genommen werden sollten. Sie entstehen in „the confusing simultaneous expose of scene and off-scene“ ${ }^{\text {“3 } 384}$, sie „suggerieren Intimität, sie inszenieren Authentizität“ 385 . In dieser ambivalenten Position zwischen Vertrauen, Glaubwürdigkeit und Inszenierung und Lenkung bilden sie einen zentralen Bestandteil des Erfolgs des Literaturhauses.

$\mathrm{Zu}$ integrieren sind in diesem Zusammenhang einige Beiträge von Hans Ulrich Gumbrecht, die unter anderem den Fachausdruck ,Präsenz' in der literaturwissenschaftlichen Debatte stark gemacht haben und in der Diskussion einen wichtigen Gesichtspunkt explizit herausstellen:

Vielleicht ist aber gerade ein Oszillieren zwischen Erfahren und Wahrnehmen jene lebhafte Existenzform und jene agile Form des Denkens, in deren Vollzug wir den Bannkreis des hermeneutischen Feldes und seines akademischen Nachlebens endlich verlassen können. ${ }^{386}$

Dabei reserviert Gumbrecht, Wahrnehmung“ für „die Seite der Sinnlichkeit“ und „Erfahrung“ „für die Seite der Begriffe und der Reflexion““387, die er später ,Präsenzkultur' und ,Sinnkultur' nennt. Ihm zufolge überlagert in der Literaturwissenschaft die Sinnkultur die Präsenzkultur und er plädiert für eine Stärkung der unmittelbaren Wahrnehmung. Es ist strittig und entsprechend kritisch diskutiert worden, ob dem von Gumbrecht beobachteten Zustand entgegengewirkt werden sollte, und ob es, wie Gumbrecht vorschlägt, eines „Diesseits der Hermeneutik“ in der Literaturwissenschaft bedarf, welches die Wahrnehmung zentral stellt und „dem Zeitalter des Zeichens ein Ende“"388 setzt. Ohne eine Absage an die Hermeneutik zu erteilen, kommt Niels Werber berechtigterweise zu diesem Schluss: „Es wäre zu wünschen, diese ,Präsenzdimension des ästhetischen Erlebens' zumindest nicht zu verleugnen.“389 Gumbrechts Ausführungen helfen für die Analyse des Literaturhauses dann weiter, wenn seine grundsätzlichen Beobachtungen, dass die Menschen sich nach Präsenz und Greifbarkeit sehnen, weil die Alltagswelt „beinahe unüberwindlich be-

\footnotetext{
383 Vgl. Hoffmann und Kaiser 2014, S. 11. Was nicht bedeuten darf, dass Schriftstellerinterviews unreflektiert als Sekundärliteratur rezipiert werden. Die Interviews sind unbedingt als Inszenierungspraktik einzuordnen und entsprechend quellenkritisch ist mit ihnen zu arbeiten.

384 Masschelein et al. 2014, S. 23.

${ }^{385}$ Hoffmann und Kaiser 2014, S. 19.

386 Gumbrecht 2012, S. 259-260. Dieser Artikel ist bereits 1997 erschienen und gilt als Vorarbeit für Diesseits der Hermeneutik. Dort wiederholt Gumbrecht dieses angenommene Oszillieren mehrfach, vgl. Gumbrecht 2004.

387 Gumbrecht 2012, S. 241.

388 Gumbrecht 2004, S. 70.

389 Werber 2004.
} 
wusstseinszentriert ist ${ }^{\text {"390 }}$, genutzt, seine Folgerungen für die Literaturwissenschaft jedoch ausgeblendet werden. Das vom oben stehenden Zitat Zusammengefasste lässt sich auf die Besucher*innen des Literaturhauses übertragen. Eine Literaturveranstaltung bietet idealiter eine Kombination aus Präsenz - als räumliches Verhältnis zur Welt, die greifbar wird ${ }^{391}$ - und Reflexion.

Das Moment der Reflexion wird im nächsten Kapitelabschnitt erläutert. Das Moment der Präsenz ist sowohl mit dem Ereignishaften einer Veranstaltung verbunden als auch mit der direkten Begegnung, die im Literaturhaus stattfindet. Leser*innen kommen unter anderem deshalb zu Lesungen, um den Podiumsgästen unmittelbar zu begegnen. „Die Leute wollen Autoren zum Anfassen“392, wie Tanja Graf, seit 2016 Leiterin des Literaturhauses München, es formuliert. Von „Schaulust“ und „Verlangen nach einer Intimität“ und „Suggestionen des Privaten“"393 spricht Christoph Bartmann. Dies kann unterschiedliche Gründe haben: Die Zuschauer*innen besuchen die Veranstaltungen, um die Autor*innen zu erleben, die sie vielleicht seit langem bewundern, deren Texte sie gelesen haben oder von denen sie möglicherweise noch nie gehört haben und von denen sie einen Eindruck erhalten möchten. Sie sind daran interessiert, deren eigene Interpretationen zu hören, also zu erkunden, wie die ,Autorität des Schreibers' über den Text spricht, welche Interpretationen sie nahelegt - ,Was will sie/er uns mit dem Text sagen?` Das Publikum ist neugierig, mehr über den Menschen ,hinter den Texten` zu erfahren, zum Beispiel wie dessen persönlicher Bezug zum Text ist, wie er sich literarisch einordnet, wie sein Alltag als Autor*in funktioniert oder wie er sich überhaupt mündlich auszudrücken weiß. Die Besucher*innen möchten einem moderierten Dialog mit den Podiumsgästen beiwohnen oder selbst mit ihnen ein Gespräch führen, die Autor*innen ,live ${ }^{6}$ erleben, von den Schriftsteller*innen persönlich vorgelesen oder vielleicht nur ein Autogramm im Buch oder ein Selfie bekommen. Denkbar ist des Weiteren, dass die Zuhörer*innen nur an der Veranstaltung teilnehmen, weil sie jemanden begleiten oder sie sich ,blicken lassen' wollen, sie also weniger literarische beziehungsweise literatursoziale, sondern soziale Beweggründe haben. Alle diese Optionen sind mit dem oben konstatierten Verlangen nach Selbstverwirklichung und Selbstrepräsentation sowie ästhetischem Erleben verbunden.

Dabei sollte die Lesung nicht als unmittelbarer Dialog zwischen Autor*in und Rezipient*in idealisiert werden. Tobias Christs Systematisierung von AutorRezipient-Kommunikation folgend, ${ }^{394}$ wäre die Literaturveranstaltung im Literaturhaus zunächst als symmetrische Face-to-face-Kommunikation als Gruppengespräch zu verstehen, gegebenenfalls als persönliches Einzelgespräch nach der eigentlichen Lesung. „Doch selbst bei mündlich-direkten Präsentationen handelt es sich trotz erhöhten Einbezugs des Publikums letztlich um weitgehend asymmetrische Kommunikationsformen, die den Rezipienten kaum mehr Raum einräumen als für Ap-

\footnotetext{
390 Gumbrecht 2004, S. 126.

391 Vgl. ebd., S. 11. Auf die Betonung der Präsenzkultur für den Literaturveranstaltungsbetrieb zielt auch Hückstädts eingangs zitierter Artikel, vgl. Hückstädt 2018.

392 Tanja Graf zitiert nach: Weiss: „Die Leute“.

393 Bartmann 2004, S. 125.

394 Vgl. Christ 2017, S. 255 bzw. 260.
} 
plaus und Zurufe. “395 Die Literaturhäuser und Moderator*innen handhaben es unterschiedlich, ob sie während der Veranstaltung ausdrücklich zu Fragen aus dem Publikum einladen, inwieweit also eine direkte Kommunikation ermöglicht wird. Gespräche von Angesicht zu Angesicht finden im Literaturhaus außerdem unter den Leser*innen statt.

\section{| 5.6.4 Orientierung und Reflexion}

Eine Literaturveranstaltung und das Literaturhaus sind, wie darlegt, stets auch unter ökonomischen Gesichtspunkten zu betrachten. Die Beschleunigung des Buchmarktes mit einer hohen Zahl an Neuerscheinungen einerseits und einer sinkenden Zahl an Käufer*innen andererseits fordert vor allem Verlage und Buchhandlungen heraus. ${ }^{396}$ Zugleich stieg mit der generellen Zunahme an Originalauflagen von deutschsprachigen Gegenwartsautor*innen die Konkurrenz auf dem Buchmarkt. Diese Veränderungen erhöhen in den Verlagen den Druck, wirtschaftlich erfolgreich zu sein. So ist aus Sicht der Verlage eine Literaturveranstaltung vor allem als Marketinginstrument zu bewerten. Dabei geht es nicht immer um Werbung nur für ein einzelnes Buch, vielmehr ist eine „Abgrenzung zwischen Verkaufsförderung und PR [...] bei Autorenlesungen nicht immer eindeutig möglich.“397 Dafür, dass sich die Bemühungen seitens der Verlage um Aufmerksamkeit für Titel, Autor*innen sowie das Lesen allgemein verstärkt haben, spricht beispielsweise, dass seit etwa Mitte der 1990er-Jahre eigene Veranstaltungsabteilungen in den Unternehmen installiert wurden. ${ }^{398}$ Der intern steigende Druck, Aufmerksamkeit und Absatz zu generieren, werde an die Literaturveranstalter*innen weitergegeben, die sich in ihrer Unabhängigkeit jedoch nicht durch finanzielle Lockangebote einschränken lassen sollten, wie Rainer Moritz äußert. ${ }^{399}$

\section{Selektion}

Eine Lesung im Literaturhaus jedoch als reine Marketingveranstaltung zu verstehen, greift zu kurz, wie das Ausgeführte ebenfalls belegt. Außerdem kosten die meisten Veranstaltungen Eintritt, sodass davon auszugehen ist, dass ihnen ein Wert an sich zugesprochen wird. Die immense Anzahl an Neuerscheinungen und überhaupt an verfügbaren Büchern stellt Leser*innen vor die sprichwörtliche,Qual der Wahl': ,Was soll ich davon lesen?‘ Diese Frage wird angesichts eines großen Angebotsspektrums und der begrenzten zur Verfügung stehenden Lesezeit drängender. Dies ist auch der Fall, weil im Zeitalter der Digitalisierung von einer „,Popularisie-

\footnotetext{
395 Ebd., S. 263.

${ }^{396}$ Die Zahlen, die der Börsenverein des Deutschen Buchbandels jährlich herausgibt, belegen für 2017 einen deutlichen Rückgang der Käuferzahlen. Neben tendenziell sinkenden Umsätzen ist also der Leserschwund ein akutes Problem - für Verlage, aber natürlich auch für Literaturhäuser, vgl. „Buchkäufer: Entwicklung“, Börsenverein des Deutschen Buchhandels.

397 Vogel 2011, S. 159.

398 Vgl. z. B. Johannsen 2013a, S. 68.

${ }^{399}$ Dies äußerte Rainer Moritz bei seinem Vortrag auf der Reflexionsveranstaltung im Aargauer Literaturbaus in Lenzburg am 23.11.2014. Der Vortrag ist nicht veröffentlicht worden, ich habe aber an der Tagung teilgenommen und die Kernthesen vom Vortragenden zur Verfügung gestellt bekommen. Zum entstehenden Druck seitens der Verlage vgl. Kapitel II 11.2.3.
} 
rung des Buchmarkts' die Rede sein [kann]: Jeder kann heute Autor werden. Nischen- und Special Interest-Titel, die auf dem angestammten Buchmarkt kaum rentabel gewesen sind, lassen sich digital rentabel vermarkten. Doch wer will das alles lesen?" "400 Gerhard Schulze konstatierte bei den Ausführungen zur Erlebnisgesellschaft: „Typische Begleitprobleme von Erlebnisorientierung sind Unsicherheit und Enttäuschung.“" ${ }^{01}$ Unsicherheit und Enttäuschung entgegenzuwirken versucht das Literaturhaus, indem es selektiert.

(1.) Es bietet eine Vorauswahl aus den Verlagsprogrammen an, die dem Anspruch nach unabhängiger und kritischer ist als die von direkten pekuniären Interessen motivierten Informationen seitens der Verlage und Buchhandlungen. Des Weiteren gilt für das Literaturhaus, dass es nicht nur einzelne Veranstaltungen durchführt, sondern als Institution die Chance bietet, ein kontinuierliches Programm zu gestalten, das gegebenenfalls als Gesamtes rezipiert wird: Auf diese Weise kann der institutionelle Rahmen eine Verlässlichkeit und Qualitätssicherung darstellen, der für Besucher*innen einen Ankereffekt haben kann. Dazu müssen die Leser*innen nicht einmal an allen Veranstaltungen teilnehmen, sondern können sich über die Monatsprogramme einen Überblick verschaffen. 402 (2.) Eine Veranstaltung lässt sich als Hilfe zur Leseentscheidung auffassen. Eine Veranstaltung kann zur weiteren Lektüre anregen, sodass am Ende des Abends der Buchkauf steht. (3.) Das Programm des Literaturhauses bietet den Leser*innen somit die Möglichkeit, mehrere Texte kennenzulernen, „ohne selbst sämtliche saisonale Höhepunkt lesen zu müssen“"403.

Bezogen auf das Literaturhaus, im engeren Sinne als Literaturvermittler, sind diese Selektionen als Handlungen literarischer Wertung einzuordnen, denn hier bilden „Werte die Motivationsgrundlage einer Handlung“"404. Renate von Heydebrand und Simone Winko unterscheiden zwei Arten des Selektierens als Typ literarischen Wertens. Die Literaturhäuser nutzen beide: Sie entscheiden zum einen, welche Texte überhaupt Öffentlichkeit erhalten, also ins Programm aufgenommen werden, zum anderen, wie diese präsentiert werden, womit sie eine Einordung nahelegen. „Die Werthaltungen, die den Entscheidungen zugrunde liegen, sind zum Teil von der jeweiligen Institution her vorgegeben und über Normen und Rollenerwartungen vermittelt." 405 Obgleich in diesem Zitat ein soziologischer Institutionsbegriff angesetzt wird, lassen sich diese Vorgaben und Rollenerwartungen ebenfalls dem einzelnen Literaturhaus zuschreiben, weil es einer Unternehmenstradition zu folgen hat.

\footnotetext{
400 Beilein 2013, S. 587. Er spricht sich so dafür aus, nicht von einer „Demokratisierung des Buchmarktes" zu auszugehen.

401 Schulze 1993, S. 736.

$402 \mathrm{Zu}$ den Funktionen der Programmhefte vgl. Kapitel II 10.2.

403 Wegmann 2002, S. 125.

404 Winko, S. 587-589. Vgl. auch II 13.1.7 und III 3.5.

405 Heydebrand und Winko 1996, S. 97. In diesem Zusammenhang sei verwiesen auf Diskussionen zum Problem der Gegenwartsliteraturwissenschaft, das in erster Linie eines der literarischen Wertung sei, vgl. z. B. Beilein 2012, S. 41 sowie Spoerhase 2014, S. 24. Die Gesprächsformate im Literaturhaus könnten als Beitrag zu einer auch literaturwissenschaftlichen Annäherung an Gegenwartsliteratur und ihre Wertung genutzt werden. Anja Johannsen plädiert bspw. für eine engere Verschränkung von Literaturwissenschaft und Literaturkritik, vgl. Johannsen 2010, S. 118.
} 


\section{Intensivierung und Extensivierung}

Eine Veranstaltung lässt nicht nur dann als gelungen für Zuschauer*innen und Veranstalter*innen einordnen, wenn die Zuhörer*innen den Titel letztlich erwerben. Neben den eben erwähnten sozialen Aspekten einer Literaturveranstaltung kann es sein, dass die Zuschauer*innen für ihr Interesse, genug gehört' haben und damit zufrieden sind. Sie haben sich 90 Minuten vor Ort auf einen Text eingelassen, indem sie anstatt das ganze Buch zu lesen - was in der Regel deutlich länger dauert -, eine Unterhaltung darüber verfolgt haben. Damit haben sie von vornherein einen Rezeptionsmodus gewählt, der aufgrund seiner zeitlichen Vorgabe und sozialen Rahmung dem von Kinofilmen, Theaterstücken oder Konzerten ähnlicher ist als der ,stillen Lektüre'. Dies ist als Ausdruck der Gleichzeitigkeit von Extensivierung und Intensivierung zu werten, die gegenwärtig zu beobachten ist. ${ }^{406}$ Thomas Wegmann nennt diese passend eine „Ästhetik des Verschwindens und Vergehens“407. Es ist, wie bereits angedeutet wurde, von einer gesteigerten Medienkonkurrenz auszugehen, denn nicht erst durch das Internet, sondern beispielsweise bereits durch das Kabelfernsehen und eigentlich ab der zweiten Hälfte des 20. Jahrhunderts, 408 bieten sich neben hunderttausenden neuen Büchern jedes Jahr zahlreiche andere Möglichkeiten der Freizeitgestaltung zur Konsumption an. Aufgrund einer Ausweitung der Optionen wird die Verfügbarkeit von Freizeit knapper, die Konkurrenz um Aufmerksamkeit größer. ${ }^{409}$ So gesehen stellt eine Literaturveranstaltung eine Art Kompromiss dar, sie verbindet Momente der Literaturrezeption mit sozialen Aspekten ${ }^{410}$ und ermöglicht es so, mehrere Bedürfnisse auf einmal zu befriedigen, wenngleich andere als die ,stille Lektüre'.

Mit der Extension der Gestaltungsoptionen des eigenen Lebens ${ }^{411}$ entsteht also nicht nur ein Nacheinander unterschiedlicher Angebote, sondern vor allem eine Gleichzeitigkeit, die zum sogenannten ,FOMO` - ,Fear of missing out ${ }^{\star}$ - führen, also die Sorge erzeugen kann, mit der Entscheidung für eine Aktivität etwas anderes $\mathrm{zu}$ verpassen. Dies ist auf unterschiedliche Weisen beschrieben worden, Douglas Rushkoff beispielsweise diagnostiziert einen ,Present shock', der dadurch zustande komme, dass Subjekte selten nur bei einer Sache und gedanklich an einem Ort, sondern ,always-on` seien und mehr Erlebnisse als verarbeitbar in einen gegenwärtigen

\footnotetext{
406 Vgl. FN 349.

407 Wegmann 2002, S. 123-124. Er bezieht sich dabei vornehmlich auf Literaturfestivals, seine Beschreibungen lassen sich aber auf das Literaturhaus übertragen. Diese Ästhetik stehe im Kontrast zum Buch, das auf Langfristigkeit angelegt sei.

408 Vgl. z. B. Rautenberg und Kuhn 2015, S. 260.

${ }^{409}$ Vgl. Franck 1998. Georg Franck habe die „Ökonomie der Aufmerksamkeit“ als Novum beschrieben und weitere Forschung ausgelöst, dabei habe es bereits vorher Studien gegeben, die sich dem Phänomen der Aufmerksamkeit widmeten, ohne diese Ausdrücke zu verwenden, wie Elisabeth Kampmann darlegt, vgl. Kampmann 2011, S. 29. Eine begriffliche Annäherung an ,Aufmerksamkeit‘ legt Bernhard Waldenfels vor, vgl. Waldenfels 2004.

${ }^{410}$ Die Möglichkeit, zugleich Content aufzunehmen und sozialen Bedürfnissen nachzukommen, wird beispielsweise häufig als Grund für den Erfolg von TV-Serien interpretiert, vgl. z. B. „Buchkäufer: Entwicklung“, Börsenverein des Deutschen Buchhandels, S. 27.

${ }^{411}$ Reckwitz spricht davon, dass das spätmoderne Subjekt sein Leben kuratiere, vgl. Reckwitz 2017, S. 295-298.
} 
Moment bündeln wollen. Selten seien sie dadurch wirklich gegenwärtig - präsent. ${ }^{412}$ In diesem Kontext ist eine Suche nach Intensivierung des Erlebens nachvollziehbar. In Zeiten, in denen Reiz- und Angebotsüberflutung, ständige Erreichbarkeit und Zeitmangel die Wahrnehmung in Anspruch nehmen, ${ }^{413}$ können Kontemplation und die Konzentration auf nur eine Sache Entspannung und Entschleunigung produzieren. Das performative Moment in Echtzeit einer Literaturveranstaltung stellt eine Möglichkeit dar, sich nur auf die Live-Situation einzulassen. Die Aufforderung vor der Veranstaltung, dass bitte die Mobiltelefone auszuschalten seien, fungiert somit als Symbol dieser Fokussierung auf das Bühnengeschehen.

\section{Geschmacksbildung und Urteilsfindung}

In einer sich diversifizierenden Gegenwart mit unterschiedlichsten Urteilen, Haltungen und zum Teil nur Meinungen bieten vorselektierte Angebote Orientierung, wie oben angesprochen. So ist im Literaturhaus, hierin vergleichbar mit dem literarischen Salon, mit der Lektüre und Diskussion von Literatur die Geschmacksbildung und Literaturkritik eng verbunden. ${ }^{414}$ Ebenso bedarf es der Einübung von Praktiken des Urteilens und Wertens, um literarische Entscheidungen treffen zu können. Das Interesse an Veranstaltungen im Literaturhaus liegt somit des Weiteren darin begründet, dass hier intendiert wird, fundierte Diskussionen anzubieten, die implizit vorführen, wie Gespräche über Literatur und darüber hinausgehende Themen geführt werden können. Daneben ergeben sich aufgrund der sozialen Situation Gespräche der Zuhörer*innen untereinander. Etwas Ähnliches beobachtet Anke Vogel darin, dass für Kund*innen das Gespräch mit Buchhändler*innen in den letzten Jahren an Bedeutung gewonnen habe. ${ }^{415}$

Reflexion als Sinnstiftung wird dementsprechend im Literaturhaus nicht völlig überlagert vom Wunsch nach Präsenz, vielmehr steht das Literaturhaus für eine Verbindung beider Modi. Es bietet in der aktuellen Literaturlandschaft Orientierung, sowohl über die Auswahl aus Neuerscheinungsmengen als auch über deren Präsentationsformen, die durch ästhetische Diskussion und zum Teil literaturhistorische Verortung Reflexionsangebote machen und Reflexionspraktiken vermitteln. Dies lässt sich als Indiz dafür deuten, dass in einer komplexer werdenden Gegenwart der Diskussionsbedarf insgesamt steigt. Diese Funktion des Literaturhauses spielt bei der Fallstudienanalyse eine maßgebliche Rolle.

\footnotetext{
412 Vgl. Rushkoff 2014. Er nennt viele Beispiele: In einer Bar sitzt etwa eine Person, die statt sich vor Ort zu unterhalten, ihr Smartphone benutzt, Nachrichten liest, sich informiert, was sonst noch los ist, ob vielleicht irgendwie eine zeitgleiche bessere Alternative als der aktuelle Besuch der Bar wartet. Damit ist diese Person weder richtig in der Bar noch auf einer der anderen sich via Smartphone anbietenden ,Partys'.

413 Angesichts der Ergebnisse, dass es immer weniger Buchkäufer*innen gibt, woraus geschlossen werden kann, dass auch die Leser*innen weniger werden, initiierte der Börsenverein des Deutschen Buchhandels eine kleine Studie, die sogenannte Abwanderer - Personen, die deutlich weniger Bücher lesen/kaufen als früher - zu ihren Motivationen und Bedürfnissen befragt hat. Das Ergebnis unterstützt die auch hier geäußerten Vermutungen, vgl. „Buchkäufer: Entwicklung“, Börsenverein des Deutschen Buchhandels. ${ }^{414}$ Zum literarischen Salon vgl. Simanowski 1999, S. 31 sowie Kapitel I 4.1.

415 Vgl. Vogel 2011, S. 150.
} 


\section{5.7 Gebäude}

Der soziale Aspekt des Literaturhauses bildet einen wichtigen Bestandteil seiner Konzeption. Dies geht aus Selbstbeschreibungen ebenso hervor wie aus der Konzentration auf öffentliche Veranstaltungen und aus der Einrichtung des Gebäudes als Treffpunkt. Mit professioneller Inneneinrichtung und Infrastruktur in repräsentabler Atmosphäre ist das Literaturhaus bemüht, ein einladendes Haus zu sein. So gehört zu guter Letzt das Gebäude selbst zum kollektiven Akteur Literaturhaus. Für den literarischen Salon nimmt Verena von der Heyden-Rynsch an, dass die Räumlichkeiten dabei stets sekundär waren. ${ }^{416}$ Anders spielt es im Literaturhaus - und spielte es gewiss schon im Salon - eine Rolle, ob die Veranstaltung „,in einem Palais oder in einer Dachstube “417 stattfindet. Literaturveranstaltungen lassen sich nicht ungeachtet ihrer Rahmungen betrachten. Dies gilt für jeden Rezeptionsakt, für die Literaturveranstaltung ebenso wie für die individuelle Lektüre, auf die sich Silvia Serena Tschopp bezieht:

Man wird in einem sakralen Raum ein und denselben Text vermutlich anders lesen, als wenn man denselben Text in einem völlig profanen Raum lesen würde. [...] Natürlich ist es schwierig, so etwas angemessen zu historisieren, aber ich glaube, dass man zumindest ein Bewusstsein dafür haben sollte, dass unterschiedliche Räume mit den ihnen inhärenten Bedeutungen und Wirkungen die Lesepraxis beeinflussen können. ${ }^{418}$

Die technische wie gestalterische Ausstattung der Veranstaltungsräume lässt somit Rückschlüsse auf die Inszenierungsabsichten der Veranstalter*innen zu. Eine professionelle Beleuchtung und die Ausrichtung hin zu einer Bühne setzen die Podiumsgäste anders in Szene als eine Wohnzimmerkulisse mit gedämpftem Licht und ohne Tonverstärkung. Zugleich bestimmen die Gegebenheiten der Literaturhäuser die Präsentationsmöglichkeiten mit, da die Gebäude nicht völlig umgestaltet werden können. Bisher wurde in Deutschland noch kein Haus eigens für die Nutzung als Literaturhaus neu gebaut; in Norwegen residiert auch nur Litteraturbuset $i$ Fredrikstad in einem Neubau. ${ }^{419}$ Es handelt sich um Umnutzungen und Umbauten bereits existierender Räume Dies grenzt die Gestaltungsmöglichkeiten - aus ästhetischen wie aus finanziellen Gründen - ein, was bei unter Denkmalschutz stehenden Häusern besonders eklatant ist. Die Gebäude der Literaturhäuser sind sehr verschieden. ${ }^{420}$ Gemein ist ihnen tendenziell, dass die Veranstaltungsräume häufig multifunktional nutzbar sind, weil sie gelegentlich vermietet werden und für unterschiedliche Formate und Publikumsgrößen bereitstehen müssen. Tonanlagen, Lichtversorgung und Bühnenelemente finden sich in allen untersuchten Literaturhäusern, was zeigt, dass die professionelle Präsentation des Podiums als grundlegend für ihre Arbeit gilt.

\footnotetext{
416 Vgl. Heyden-Rynsch 1995, S. 17.

417 „Die Räumlichkeiten sind dabei stets sekundär gewesen. Ob in einem Palais oder in einer Dachstube, wie es zunächst bei der berühmten jüdischen Salonière in Berlin, Rahel Levin-Varnhagen, der Fall war, entscheidend waren die Begegnungen im Gespräch und die uneingeschränkten zeitlichen Möglichkeiten, die dieses förderte - ein Kriterium, das für das Aussterben der Salons im 20. Jahrhundert mitverantwortlich ist", ebd.

418 Tschopp 2017, S. 287-288.

${ }^{419}$ Vgl. Skaftnesmo 2016, S. 33.

${ }^{420}$ Dies veranschaulichen die Einzeldarstellungen der Fallstudien.
} 
Jenseits der angebotenen Veranstaltungen versuchen die Literaturhäuser, Treffpunkt für Literaturinteressierte zu sein und Raum für private Begegnungen zu schaffen. Wenn Café, Buchhandlung oder andere Aufenthaltsgelegenheiten die Veranstaltungsräume, die meist nur zu den Veranstaltungen zugänglich sind, umgeben, was nicht in allen Einrichtungen der Fall ist, werden Besucher*innen zusätzlich außerhalb der Veranstaltungszeiten angelockt, ins Literaturhaus zu kommen und den Ort so noch auf eine andere Art zu beleben. Verbunden ist der Ort mindestens im Namen mit Literatur, denn das gesamte Haus wird in der Regel als ,Literaturhaus' bezeichnet. Dabei spielt die Literatur nicht unbedingt die ausschlaggebende Rolle, denn die Cafés stehen natürlich Personen ohne Literaturbezug gleichfalls offen. Die an Literaturhäuser angeschlossenen Cafés sind meist recht exquisit und höherpreisig und vermitteln damit einen genusswertschätzenden Lebensstil - was einerseits zu Kritik führen kann, weil sich viele Autor*innen diesen nicht leisten können, ${ }^{421}$ und andererseits zur Grundidee des Literaturhauses beiträgt, Literatur aus dem Keller in die Festsäle zu holen ${ }^{422}$ und in geselliger wie feierlicher Atmosphäre zu präsentieren.

Dieses Gesamtkonzept des Literaturhauses lässt sich in Zusammenhang mit der oben beschriebenen Suche der Akteur*innen nach unmittelbaren Begegnungen verstehen. Ähnlich kommen beispielsweise Museen kaum noch ohne ein angegliedertes Café aus. Buchhandlungen setzen ebenfalls zunehmend auf eine Kombination aus Buchgeschäft und Lesecafé, um „Fokuspunkte zum persönlichen Treffen anzubieten, an denen man sich wohlfühlt, weil man Gleichgesinnte trifft und immer etwas zu reden hat.“ ${ }^{\prime 23}$ Vergleichbar sind, zumindest in dieser Hinsicht, „Apple-Stores als analoge Erlebniswelten“424, die eine neue Sichtbarkeit von Produkten im digitalen Zeitalter ermöglichen und durch haptisches Ausprobieren und Anrühren sinnliche Erfahrungen mit den präsentierten technischen Geräten evozieren. Dahinter steht die Idee, das Einkaufen zum Erlebnis zu machen, was ein Werbeslogan für viele Verkaufsstandorte ist oder sein könnte. Diese Ladenlokale stellen ihre Alleinstellungsmerkmale im Zeitalter der Digitalisierung stärker heraus. Natürlich versuchen sie als Wirtschaftsunternehmen damit vor allem, ihr ökonomisches Überleben zu sichern. So ergibt sich beispielsweise mittels der Angebotserweiterung durch Kaffeeausschank für die Buchhandlung eine zusätzliche Einnahmequelle, die angesichts der Konkurrenz durch Onlineshops notwendig ist. ${ }^{425}$ Zugleich werden Kund*innen in den Laden gelockt.

Die Institution Literaturhaus hat sehr früh das Bedürfnis des Publikums zum persönlichen Erleben entdeckt und genutzt, das später durch die generelle Eventorientierung im Veranstaltungsbetrieb verbreitet und stärker monetarisiert wurde, ebenso wie etwa im gastronomischen und wirtschaftlichen Bereich beispielsweise durch Apple-Stores. Damit ist nicht gesagt, dass dieses Bedürfnis erst im Zuge der zunehmenden Digitalisierung der Lebenswelt entstanden wäre. Durch die Digitalisierung wurde es jedoch sichtbarer und wichtiger, was bei den Fallstudien aufgegrif-

\footnotetext{
${ }^{421}$ Dies wurde z. B. in Hamburg und Bergen diskutiert, vgl. Kapitel II 2.3.2 bzw. II 7.1.1.

422 Tilman Krause nutzte dieses Bild für das Literaturhaus Berlin, das die Literatur aus dem Souterrain in die Beletage befördert habe, vgl. Krause 1996.

423 Kappes 2013, S. 38.

424 Wilkens 2015, S. 100.

${ }^{425}$ Bei den Literaturhäusern trägt der Erlös durch das Café, sei es durch direkte Verkaufseinnahmen oder durch die Pacht, von Beginn an zur finanziellen Stabilisierung der Einrichtung bei.
} 
fen werden wird. ${ }^{426}$ „Wenn fast alles in die virtuelle Welt abgewandert ist und Digital der neue Standard ist, werden physische Orte besonders. “427 Die Formulierung von Andre Wilkens ist zwar etwas verkürzend und thesenhaft, doch benennt sie eine Beobachtung, die ebenso in der vorliegenden Arbeit gemacht wird. Die Wiedereröffnung von Videotheken, jetzt als Filmgalerien bezeichnet, steht bei ihm für eine ähnliche Rückeroberung des analogen Raumes wie die der Literaturhäuser als physische Orte der Literaturvermittlung hier.

Das Gebäude des Literaturhauses ist folglich ein sehr relevanter Faktor im Gesamtkonzept der Institution. Es bietet einen Rahmen, innerhalb dessen die Literaturhaus-Akteur*innen in ihrem Zusammenspiel einen Raum der Literaturvermittlung gestalten. Aus diesem Grund wird in der vorliegenden Arbeit neben der inhaltlichen Architektur der Literaturhäuser die Gestaltung des - physischen wie digitalen - (sozialen) Ortes in den Blick genommen. Wenn die Analyse des Programms beantwortet, was im Literaturhaus ausgestellt beziehungsweise dargeboten und wie dies umgesetzt wird, strebt die Einbeziehung des Ortes die Ermittlung des Rahmens der Inszenierung an. Das Gesamtkonzept unterstützt die Inszenierung als „kulturelle Oase, wo es leicht fällt, sich wohlzufühlen“428.

\section{5.8 Zwischenfazit - Fundament des Literaturhauses}

Das Literaturhaus als Institution des Literaturveranstaltungsbetriebs ist in unterschiedlichen Handlungs- und Wirkungsbereichen zu verorten, die seinen Grundriss abstecken. Ohne im Detail die einzelnen verknüpften Aspekte vorwegzunehmen und um Wiederholungen zu vermeiden, sind in Abbildung 2 einige für die Untersuchung wichtige sich gegenüberstehende Schlagwortpaare aufgelistet, auf die aus unterschiedlichen Richtungen zurückgekommen wird. Diese Paare stellen nicht zwangsläufig Polaritäten dar, sondern Kontinua und Möglichkeitsspielräume, die Interessenkonflikte auslösen können. Innerhalb dieser Spielräume gilt es, eine Balance zu finden. ${ }^{429}$ Die Aspekte betreffen zum Teil sehr unterschiedliche Betrachtungsebenen. An ihnen wird auf diese Weise anschaulich, welche verschiedenen Untersuchungsdimensionen bei einer Institution wie dem Literaturhaus Berücksichtigung finden müssen, um sie grundlegend zu erfassen.

\footnotetext{
${ }^{426}$ Dies wird in einem eigenen Kapitel ausgeführt, vgl. Kapitel II 12.7.

427 Wilkens 2015, S. 95.

${ }^{428}$ So präsentiert sich das Literaturhaus Hamburg, vgl. Anhang V 1.2.

${ }^{429}$ Dafür, die „Programmarbeit als einen permanenten Balanceakt“ anzusehen, plädiert auch Florian Höllerer zitiert nach: Johannsen 2012b, S. 186.
} 


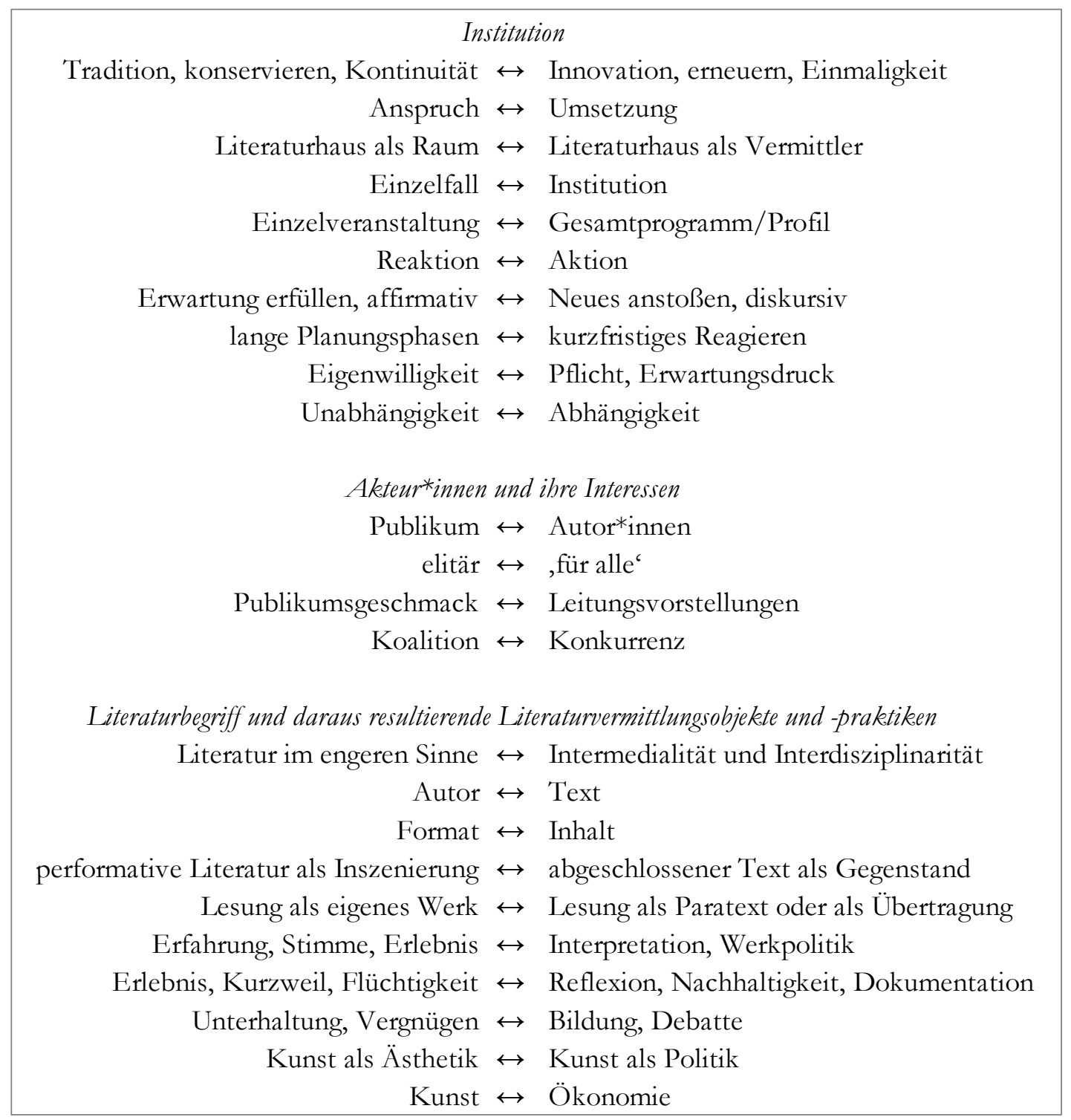

Abbildung 2: Komplex der möglichen Interessenkonflikte im Literaturhaus (eigene Darstellung)

Um die vorausgegangene Diskussion über die Gründe für die Existenz und den Erfolg des Literaturhauses aufzugreifen und daran Komplex der möglichen Interessenkonflikte zu veranschaulichen, lässt sich die Frage nach der Einordnung der moderierten Lesung herausgreifen: $\mathrm{Zu}$ überlegen ist, ob die Literatur erst durch die Inszenierung entsteht beziehungsweise der mündliche Vortrag ein neues Werk aus einem Text macht, oder ob die orale Präsentation eines als Buch abgeschlossenen Textes als Paratext behandelt werden sollte. Davon nicht zu trennen ist die Frage, ob das Hörerlebnis oder die Reflexion über den Text die größere Rolle spielt. Allerdings macht gerade die Verbindung beider Momente - Erlebnis und Reflexion - das Typische aus, denn allein durch die Verknüpfung von Stimme und Text kommt eine Gleichzeitigkeit von Erleben und Deutung zusammen. Die „Interpretation durch vokale Performanz" bildet, Meyer-Kalkus zufolge, eine wichtige Form der Interpretation und soll für Literatur- und Theaterwissenschaftler*innen eine selbstverständliche Fragestellung sein. ${ }^{430}$ Unweigerlich erhält der Text auf einer Bühne dadurch, dass der Autor ihn selbst vorliest, dessen eigene Intonation, also Interpretation.

${ }^{430}$ Vgl. Meyer-Kalkus 2001, S. 459. 
Ebenso vermischen sich auf der Rezeptionsebene Interesse am Text und Interesse an der Autorenpersona. Die authentifizierten Autor*innen geben ihrem Text eine Stimme, die bei der stillen Lektüre im Kopf der Leser*innen nachempfunden und ohne vorausgehendes Hören höchstens imaginiert werden kann.

Ein Vortrag eines eigens für die mündliche Präsentation verfassten Textes ist dabei zu unterscheiden von einer Lesung aus einem für die schriftliche Publikation erzeugten Text. Deshalb lassen sich beispielsweise Romanlesungen nicht besonders gut mit Poetry Slams vergleichen. Da es im Literaturhaus vor allem um Buchtexte geht, lässt sich die Frage, ob die Lesung ein eigenes Werk oder eine Interpretation eines Textes ist, sinnvoll stellen. Es spricht vieles für die Antwort, dass beides zutrifft. Die Lösung, eine Lesung als Paratext nach Gérard Genette aufzufassen, genauer als Epitext, ist hilfreich. ${ }^{431}$

Ein Epitext ist ein paratextuelles Element, das nicht materiell in ein und demselben Band als Anhang zum Text steht, sondern gewissermaßen im freien Raum zirkuliert, in einem virtuell unbegrenzten physikalischen oder sozialen Raum. Der Ort des Epitextes ist also anywhere out of the book, irgendwo außerhalb des Buches ${ }^{432}$.

Als Beitext zum Buch weist die Lesung als Vermittlungselement über sich selbst hinaus und zum Buch hin. Dies widerspricht zugleich nicht der Idee, die Literaturveranstaltung als eigene Realisierung aufzugreifen, die auch ohne Rückgriff auf das Buch funktioniert, und Thomas Böhms Forderung nach einem literarischen Verständnis von Lesungen nachzukommen. ${ }^{433}$ Heinz Schlaffer systematisiert unterschiedliche Formen des Umgangs mit Literatur und zeigt, dass die vollständige Lektüre eine Art neben beispielsweise aufgeschobener, vorgetäuschter oder partieller Lektüre sei. ${ }^{434}$ Mit der „Paralektüre“435 beschreibt er die Lektüre von Begleittexten und rückt damit die Perspektive stärker auf die Rezipient*innen. Unter der Annahme, dass eine Lesung einen Paratext darstellt, ist eine Literaturveranstaltung aus Sicht des Publikums in der literarischen Kommunikation des Lesens als Paralektüre zu verstehen. Mit Schlaffers Nebeneinanderstellung wird zudem deutlich, dass die Paralektüre etwa die vollständige Lektüre nicht grundsätzlich ersetzt, obwohl sie an ihre Stelle treten kann. Der Veranstaltungsbesuch muss die vollständige Lektüre nicht ausschließen, er kann es aber durchaus, denn manchmal ist die unvollständige oder die Paralektüre ausreichend, wie oben beschrieben.

\footnotetext{
431 Vgl. Grimm 2008, S. 149.

432 Genette 1989, S. 328, Hervorhebung im Original. „Der Paratext ist also jenes Beiwerk, durch das ein Text zum Buch wird und als solches vor die Leser und, allgemeiner, vor die Öffentlichkeit tritt“, ebd., S. 10. Texte innerhalb des Buches sind Peritexte und jene außerhalb Epitexte, so ,teilen Peritext und Epitext erschöpfend und restlos das räumliche Feld des Paratextes“, ebd., S. 12-13.

433 Vgl. Böhm 2003.

434 Vgl. Schlaffer 1999, S. 8-16.

435 Ebd., S. 5.
} 


\section{Literaturhäuser als Fallstudien - Zwischen Einzelfall und Institution}

Während sich das erste Hauptkapitel dem Gegenstand abstrahierender näherte, folgt das zweite den acht ausgewählten Literaturhäusern, die Institution ,Literaturhaus empirisch fundieren. Im Sinne der komparativen Anlage der Arbeit spielt hier die detaillierte Einzeldarstellung ebenso eine Rolle wie der davon abstrahierende Blick auf die Institution.

Für den Vergleich der Kulturräume bietet es sich an, zahlenmäßig ausgeglichen zu vergleichen. ${ }^{436} \mathrm{Um}$ ein einigermaßen breites Spektrum zu erfassen, wurden für Deutschland vier Häuser ausgewählt. Aus Skandinavien musste mindestens jeweils eins aus den drei Ländern einbezogen werden. Für Dänemark und Schweden fiel die Auswahl leicht: LiteraturHaus Kopenhagen und Göteborgs Litteraturbus waren zu Beginn der Studie die jeweils einzigen Literaturhäuser in ihrem Land. Beide unterscheiden sich hinsichtlich ihrer organisationalen Struktur von den deutschen und norwegischen Literaturhäusern. In Norwegen hingegen ist das Literaturhaus weiter als in den Nachbarländern verbreitet, deshalb werden zwei norwegische Einrichtungen genauer betrachtet. Litteraturhuset in Oslo ist das flächenmäßig größte Literaturhaus in Europa und erhält viel Aufmerksamkeit. Die Diskussionen um die Eröffnung des Bergener Literaturhauses ermöglichen es, für die Arbeit wichtige Rückschlüsse auf die norwegische Weiterentwicklung der Institution zu ziehen, denn Litteraturbuset $i$ Bergen kann exemplarisch gleichzeitig als Nachfolger und als Gegenspieler zum Osloer Konzept untersucht werden. Für Deutschland muss das erste Literaturhaus in Berlin betrachtet werden und die Einrichtung in Hamburg, die als Nachahmerin und als Innovatorin gedeutet werden kann. ,Gründungsmythen' der folgenden Literaturhäuser beziehen sich eher auf Hamburg als Vorbild, denn auf Berlin; beide sind die ältesten Vertreter der Institution. Das Literarische Zentrum Göttingen hat eine andere Vereinsgeschichte als Berlin und Hamburg und residiert nicht in einem eigenen Haus. Anhand dieses Beispiels lässt sich zudem diskutieren, inwiefern die Bezeichnung, Literaturhaus' nicht mehr nur noch Selbstzuschreibung ist, sondern auch als Funktionsbegriff dient. Der ehemalige Leiter des Literarischen Zentrums Göttingen Hauke Hückstädt hat 2010 die Leitung des Literaturhauses Frankfurt übernommen. Dies ist ein Grund für die Auswahl dieses Hauses als vierten deutschen Fall, denn vor allem für die Programmanalysen ist es interessant zu sehen, ob

\footnotetext{
${ }^{436}$ Es ist für diese Kontrastierung grundlegend, dass die Beispiele wirklich vergleichbar sind. So erweist es nicht als produktiv, etwa das Literaturhaus München mit einem Literaturhaus-Angebot einer Kleinstadt $\mathrm{zu}$ vergleichen, das an eine Bibliothek angegliedert ist und als lokaler Literaturveranstalter fungiert, wie Kerstin Juchem es macht, vgl. Juchem 2013. Keine Frage: Die Diversität der Literaturveranstaltungsorte ist bemerkenswert. Bei einer derartigen Analyse sind aber keine Ergebnisse zu erwarten, die über die Konstatierung der Vielfalt und der Nicht-Vergleichbarkeit hinausgehen. Als institutionsprägende Einrichtungen sind jene vergleichbar, die über ihre Region hinaus wahrgenommen werden und die sich in ihrer Arbeit selbst mit anderen Einrichtungen vergleichen - obwohl der Vergleich nicht kompetitiv sein muss. Diese wirken auf die übergeordnete Idee von ,Literaturhaus' maßgeblich ein. Ihre Voraussetzungen sind von Ort zu Ort zwar auch verschieden, doch nicht so diskrepant wie zwischen dem Literaturhaus München und dem Literaturhaus Nettersheim, die dennoch die Spannweite der Institution Literaturhaus illustrieren.
} 
sich die ,Handschrift ${ }^{`}$ der Leitung herausarbeiten lässt. ${ }^{437}$ Außerdem präsentiert sich Frankfurt unter anderem wegen der weltgrößten Buchmesse als Buchstadt. Dadurch wird Literatur in der Stadt eine besondere Stellung zugeschrieben, was sich auch unter kulturpolitischen Vorzeichen diskutieren lässt. Dies gilt ebenso für Leipzig und Göteborg, zwei weitere Städte, in denen es überregionale Buchmessen und Literaturhäuser gibt. ${ }^{438}$

Eine Auswahl ist eine Entscheidung für und damit implizit gegen einige Einrichtungen. Dass mit der hier getroffenen Auswahl etwa vier westdeutsche Literaturhäuser in den Blick genommen werden, sei angemerkt. ${ }^{439}$ Schwerpunktmäßig geht es also um diese acht Fallbeispiele Literaturhaus Berlin, Literaturhaus Hamburg, Literaturbaus Frankfurt, Literarisches Zentrum Göttingen, LiteraturHaus Kopenhagen, Litteraturbuset in Oslo, Litteraturbuset $i$ Bergen und Litteraturbuset Göteborg - flankiert von weiteren Beispielen an geeigneten Stellen.

Der erste Block (II 1-8) stellt die Fallbeispiele einzeln vor. Dabei werden Aspekte wie die Entstehung, Organisation und Finanzierung, die Hausgestaltung 440 und andere gesamtkonzeptionelle Gesichtspunkte der individuellen Literaturhäuser exemplarisch für die Institution diskutiert. Die Gliederungen der Unterkapitel variieren entsprechend der Fokusthemen. Mit diesem Aufbau wird gewährleistet, dass neben den übergeordneten Überlegungen zur Institution ortsspezifische Momente nicht zu kurz kommen. Die Unterkapitel sind chronologisch nach den Eröffnungsjahren sortiert, jedoch nicht zwingend in der dargestellten Reihenfolge zu lesen. Nach dem Überblick über die Fallbeispiele folgen Materialanalysen von Selbstdarstellungstexten, Programmheften und Websiteauftritten, die, um den komparativen Ansatz zu unterstreichen, aspektorientiert vorgehen. Die Untersuchungsparameter sind Ergebnisse einer induktiven Annäherung an die acht Einrichtungen und weitere Literaturhäuser.

\footnotetext{
${ }^{437}$ An dieser Stelle der Einschub, dass personeller Austausch keine Ungewöhnlichkeit mehr ist. Das Literaturhaus wird zunehmend als Arbeitsumfeld rezipiert, das für neue Akteur*innen attraktiv wird. Gleichzeitig steigen Leitungen aus kleineren Einrichtungen in die größeren Häuser auf; so geschehen in Frankfurt (Hauke Hückstädt vom Literarischen Zentrum Göttingen) und Stuttgart (Stefanie Stegmann aus dem Literaturbüro Freiburg, Florian Höllerer ans LCB in Berlin) und in gewissem Sinne auch in Berlin (Ernest Wichner stieg vom Stellvertreter zum Leiter auf).

438 Auf die Bedeutung der Buchmessen wird in den Kapiteln zum Literaturbaus Frankfurt, vgl. Kapitel II 3.1.1, und zum Göteborgs Litteraturbus, vgl. Kapitel II 8.2.4, ebenso wie im Abschnitt zur Internationalität der Literaturhäuser, vgl. Kapitel II 14.3.3, S. 441, und an anderen Stellen, vgl. z. B. FN 568, eingegangen. ${ }^{439}$ Für die Entwicklung des deutschen Literaturbetriebs wäre es aufschlussreich zu untersuchen, ob die Literaturvermittlungseinrichtungen in den ostdeutschen Städten beispielsweise Literatur der DDR und von Autor*innen, die im Osten aufgewachsen sind und leben, eine besondere Rolle spielen. Sicherlich lohnt sich außerdem ein erneuerter Blick auf die Literaturvermittlung in den neuen Bundesländern, die 2010 in einer Studie begutachtet wurde, vgl. FN 54. So ist seitdem etwa das Literaturhaus Halle eröffnet worden, vgl. S. 15. Dies böte allerdings Material für eine eigene Untersuchung. Hier wird flankierend etwa auf das Literaturhaus Leipzig eingegangen, vgl. z. B. S. 30, 150, 285, 348.

${ }^{440} \mathrm{Um}$ einen visuellen Eindruck der Literaturhäuser zu erhalten, lohnt sich eine Online-Bildersuche nach dem jeweiligen Literaturhaus und Schlagworten wie ,Saal` oder, Veranstaltung`. Die Bilder vermitteln dann auch einen guten Eindruck von verschiedenen Veranstaltungen und Bühnenaufbauten in den Literaturhäusern.
} 
Das folgende Großkapitel zeichnet sich durch einen hohen Informationscharakter aus, denn es integriert viele unterschiedlich gelagerte Tatsachen und Erläuterungen. Zugleich verbinden sich damit Interpretationen. ${ }^{441}$ So stehen Debattenbeiträge neben Fakten, Erfahrungswissen und hier vorgenommenen Deutungen, was sich als sehr produktiv erweist, weil so nicht zunächst referiert wird, sondern sich direkt und durchgängig Antworten zur übergeordneten Frage nach der Institution ergeben und der Gegenstand in seinen Verflechtungen dargestellt wird.

\section{1 Literaturhaus Berlin - Das erste Literaturhaus}

Das Literaturhaus Berlin war die erste Literaturvermittlungseinrichtung, die sich den Namen ,Literaturhaus' gab; „der Prototyp eines urbanen Ortes für Literatur, der über der Rezeption von Texten auch die schöne Geselligkeit nicht vernachlässigen will, ist und bleibt das Berliner Literaturhaus in der Fasanenstraße. [...] Das Beispiel hat schnell Schule gemacht." 442 Wie der Journalist Tilman Krause anlässlich des 30. Jubiläums des Literaturhauses Berlin von „Prototyp“ zu sprechen, entspricht der Anlage der vorliegenden Arbeit. Das Beispiel, das „,schnell Schule gemacht“ habe, ist der Initiator des Institutionalisierungsprozesses des Konzepts ,Literaturhaus' und so lässt sich daran die ursprüngliche Gründungsidee des ,Literaturhauses' gut nachzeichnen. Das Literaturhaus Berlin wurde erstens vom Senat genehmigt, aufwendig durch das Land Berlin renoviert, ${ }^{443}$ zweitens dem Trägerverein übergeben, drittens durch den hauptamtlichen Leiter Herbert Wiesner - „ein traditionsbewusster Bildungsbürger" ${ }^{\text {444 }}$ - tatsächlich umgesetzt. Auf einer Ambivalenz zwischen kulturpolitischer Gründungsidee und literatur-künstlerischer Gestaltung fußt das Literaturhaus folglich seit seinem Beginn. ${ }^{445}$ Außerdem zeigt das Berliner Beispiel, dass die Lage in Berlin und die ,Versorgung' der Gegend mit Literaturveranstaltungseinrichtungen Auswirkungen auf das Literaturhaus haben; zunächst vor allem auf das einzelne Literaturhaus, weil es durch die lokalen Mitstreiter eine klare eigene Position beziehen muss, und dann auf die Institution ,Literaturhaus', weil diese aus der Berliner Ursprungsidee erwächst und sich damit in einem bildungsbürgerlichen Milieu verorten lässt.

\footnotetext{
${ }^{441}$ Der Hauptuntersuchungszeitraum schließt Ende 2015 ab, an manchen Stellen finden Weiterentwicklungen bis zum Sommer 2018 Berücksichtigung. Die als Quellen angegebenen Links beziehen sich, wie die Datumshinweise in diesen Fällen zeigen, teilweise auf frühere Versionen der Websitetexte. Das genauer untersuchte Material ist aus diesem Grund im Anhang angefügt. Bei Ausführungen im Präsens gilt die Gegenwart im Sommer 2018. Die in dieser Arbeit durchgeführte Auswertung von umfangreichem Material birgt die Herausforderung, nicht alles immer lückenlos kontextualisieren zu können. Sollten Detailinformationen nicht ganz vollständig wiedergegeben sein, so ist dies auf die breite Anlage der Arbeit zurückzuführen.

442 Krause 2016.

${ }^{443}$ Die Einrichtung ist von Beginn an zum größten Teil öffentlich durch den Senat finanziert.

444 Krause 2017.

445 Zur literaturbetrieblichen und kulturpolitischen Situation in der Bundesrepublik Deutschland vor den Literaturhaus-Gründungen, vgl. Kapitel I 4.2.
} 


\section{1.1 Entstehung und Organisation}

\section{1.1.1 Gründungsidee des Literaturhauses}

Vom Senat als Zentrum der Literatur für die Stadt angebahnt, ${ }^{446}$ das zur Sichtbarmachung von West-Berlin als Kulturstadt dienen sollte - „Immer war auf eine glanzvolle Außenwirkung zu achten." 447 - wurde das Literaturhaus Berlin im Juni 1986 eröffnet. Anknüpfend an das frühere literarische Café wurde eine Möglichkeit gesucht, die zahlreichen Schriftsteller*innen in West-Berlin zusammenzubringen und dafür zu sorgen, dass „Künstler ein anregendes Umfeld in der Stadt vorfinden“448 _ „ein wenig wie eine Tagung der Gruppe 47 in Permanenz“449. Anfang der 1980er-Jahre habe es in Berlin keine öffentlichen Einrichtungen als Foren für den inhaltlichen Disput gegeben, wie damalige Autor*innen konstatieren, „als Reaktion darauf schätzen die Autoren Einrichtungen hoch ein, die einen unmittelbaren $\mathrm{Zu}$ gang zum Leser herstellen“450, und so sollte die ästhetische Diskussion wieder in den Mittelpunkt gerückt werden. 451

Geplante und schließlich umgesetzte Bestandteile sind Café, Buchhandlung, drei verschieden große Veranstaltungsräume, ein Kurt Tucholsky gewidmeter Raum, ${ }^{452}$ zwei Gästezimmer für Schriftsteller*innen und Künstler*innen anderer Sparten, ${ }^{453}$ drei Verwaltungsräume sowie eine Hausmeisterwohnung. ${ }^{454}$ Bei der Auswahl der Pächter der Buchhandlung und des Cafés sollte auf eine ,sachgerechte ${ }^{6}$ Vergabe geachtet werden, damit das Angebot zum erwarteten Publikum passe und das Gesamtkonzept aufgehen könne. Aus den ersten Konzeptdokumenten ist ablesbar, dass das Literaturhaus Berlin vor allem ,als organisatorisches Zentrum offen sein [solle] für vielfältige Aktivitäten, in denen das kulturelle, politische und soziale Selbstverständnis von Autoren und Literatur vermittelnder Personen zum Ausdruck“ ${ }^{* 455}$ kommt. Weiter sollten kontroverse Gespräche zur Gegenwartsliteratur angestoßen und dabei neue Vermittlungswege und -formen getestet werden. Doch auch literarischen Vereinigungen und Berufsorganisationen der Schriftsteller*innen sollten Räume zur Verfügung stehen. Dabei wurde neben Lesungen und Gesprächen an Beratungsgespräche für Berufsautor*innen, Kinderveranstaltungen tagsüber und eine Informationstheke zum literarischen Leben der Stadt gedacht. Im Konzept liegt damit der Schwerpunkt nicht allein auf der Vermittlung von Literatur durch

\footnotetext{
${ }^{446}$ Vgl. Senat von Berlin - Kultur: „Beschluss Literaturhaus“ 1983, S. 4.

${ }^{447}$ Rott 2009, S. 432. Wilfried Rott macht in diesem Buch sehr deutlich, dass gleich nach dem Mauerbau Pläne für eine Positionierung West-Berlins als Kulturstandort geschmiedet wurden, die Umsetzungsversuche seien zahlreich gewesen, vgl. ebd., S. 193.

${ }^{448}$ Ebd., S. 189. Obgleich diese Bestrebungen vor allem zu Anfang bestanden haben und sich später auf die Etablierung als Wissenschaftsstandort konzentriert worden sei, standen relativ viele Mittel für die Kultur zur Verfügung.

${ }^{449}$ Ebd., S. 204.

${ }^{450}$ Funk und Wittmann 1983, S. 592.

451 Vgl. ebd., S. 595.

452 Geplant war ein Haus, „das - auch diese Anregung kaum [sic] oft - den Namen Kurt Tucholsky tragen könnte“ Senat von Berlin - Kultur: „Beschluss Literaturhaus“ 1983, S. 4. Weiter hinten gehe ich darauf noch einmal ein.

${ }^{453}$ Diese Appartements werden heute für die Veranstaltungsgäste genutzt, oder sie werden an Künstler*innen vermietet.

${ }^{454}$ Vgl. ebd., S. 5.

455 „Vorläufige Konzeption“ o. J. [vermutlich 1983], S. 1.
} 
Veranstaltungen, sondern spielt die Vernetzung der literarischen Akteur*innen eine ebenso wichtige Rolle.

Hier sei unbedingt angemerkt, dass das erwähnte Konzeptpapier kein Vereinsdokument ist, sondern eine Senatsschrift. Darin enthalten sind also Aspekte, die kulturpolitisch wirksam, vom ausführenden Verein aber weniger gewünscht waren. Der Senat entwarf das Literaturhaus als Schaufenster für Literatur und Kulturpolitik. Aber die Menschen ,hinter dem Haus' haben sich nicht damit zufriedengeben wollen, Literatur vorzuführen, sie haben sich auch dazu verhalten wollen, wie Ernest Wichner in einem Zeitungsinterview bestätigt. ${ }^{456}$ Dennoch ist der Grundgedanke für diese Arbeit festzuhalten, dass das Literaturhaus als ein Ort gedacht wurde, der neben einem eigenen Programm auch literarische Akteur*innen zusammenbringen und ihnen auf unterschiedliche Weise Sichtbarkeit verschaffen solle. Dass dies so deutlich in den ersten Konzepten auftaucht, ist für diese vergleichende Studie vor allem deshalb interessant, weil - dies greift auf das nächste Kapitel vor - sich die deutschen Literaturhäuser später mehr auf das eigene Veranstaltungsprogramm konzentrieren, die Skandinavier hingegen andere Veranstalter deutlicher miteinbeziehen. Von den untersuchten deutschen Literaturhäusern kommuniziert das Literaturbaus Berlin die Veranstaltungen von externen Gastgebern am deutlichsten mit. Das lässt sich mit der größeren öffentlichen Verpflichtung erklären, die aus der anteiligen Finanzierung aus Landesmitteln resultiert, die relational deutlich höher ist als bei anderen Literaturhäusern. Letztlich legt dennoch der Verein die inhaltliche Ausgestaltung des Literaturhauses fest.

\section{1.1.2 Weiterentwicklung der Literaturhaus-Idee durch den Verein}

Wie die meisten der deutschen Literaturhäuser später, wird die Berliner Einrichtung von einem Verein betrieben. Aus den ersten Konzepten geht hervor, dass auch eine Gemeinschaft mit beschränkter Haftung $(\mathrm{GmbH})$ als Rechtsform vorstellbar war, klar war jedoch von Anfang an, dass das Literaturhaus einen privaten Träger haben sollte. Anders als zum Beispiel die entsprechenden Trägervereine in Frankfurt, Göttingen oder Hamburg besteht der Literaturbaus Berlin e. $V$. ausschließlich aus juristischen Personen: Körperschaften unterschiedlicher Bereiche des Literaturbetriebs. ${ }^{457}$ Zusätzlich zum Trägerverein gibt es seit 1999 den Verein der Freunde und Förderer des Literaturbauses Berlin e. V., dem Privatpersonen angehören können. Knapp 15 Jahre nach der Literaturhaus-Eröffnung werden Privatpersonen also stärker in die Einrichtung integriert. Diese Doppelvereinsstruktur ist nicht ungewöhnlich: Auch im Literaturhaus Stuttgart oder im Literaturhaus Freiburg gibt es zwei Vereine.

Im Literaturbaus Berlin e. $V$. besteht die Hauptversammlung aus Vertretern der Mitgliedsorganisationen, die sowohl einen Vorstand als auch die Leitungsperson

\footnotetext{
${ }^{456}$ Vgl. Ernest Wichner zitiert nach: Engberg 2007, S. 10. Dass es so in einer dänischen Zeitung steht, die sich mit den Literaturhaus-Planungen in Kopenhagen beschäftigt, ist für die vorliegende Arbeit auch dahingehend interessant, dass dort die literarische Aktivität des Literaturhauses betont wird. ${ }^{457} \mathrm{Im}$ Einzelnen waren dies Ende 2015: Alfred Döblin-Stiftung, Arbeitskreis Berliner Jungbuchbändler, Berliner Künstlerprogramm des DAAD, Berliner Kulturrat, VS-Berlin in der IG Medien, Literarisches Colloquium Berlin, Verband der Verlage und Buchbandlungen Berlin-Brandenburg e.V., Deutscher Bibliotheksverband e. V. - Landesverband Berlin und Haus der Kulturen der Welt.
} 
wählen. Dem Leiter obliegt die Programmverantwortung, der Verein hat also nur qua Wahl Einfluss auf die Inhalte des Literaturhauses. Als Kontrollgremium des Vereins ist ein Kuratorium eingesetzt, dem festgelegte Akteur*innen wie der jeweilige Kultursenator und der Vereinsvorsitzende sowie gewählte Mitglieder angehören. Es wacht darüber, dass „die dem Verein zur Verfügung gestellten Mittel ausschließlich zu gemeinnützigen, dem Betrieb und Programm eines öffentlichen Literaturhauses dienenden Zwecken verwendet werden. “458 Aus der Satzung des Literaturhaus Berlin e. $V$. geht der festgelegte Zweck hervor:

der Betrieb, die Programmkonzeption und die Verwaltung eines öffentlichen Literaturhauses in Berlin, das - literarischen Vereinigungen, Autoren und anderen Künstlern für ihre Arbeit und ihre Veranstaltungen zur Verfügung und - allen interessierten Berlinern und Gästen Berlins als zentrale Kommunikationsstätte offenstehen soll. 459

Dieser Satz widerspricht den vorne genannten behördlichen Ideen nicht: Gedacht wird an ein öffentliches Haus, das Berliner*innen und Gästen der Stadt zugänglich ist und in dem Autor*innen und Künstler*innen arbeiten können. Das Literaturhaus soll als „zentrale Kommunikationsstätte“ im Mittelpunkt des literarischen Austauschs stehen. Der Text setzt so fort:

Der Satzungszweck wird insbesondere verwirklicht durch Veranstaltungen zur Förderung der Literatur (Lesungen, Textinszenierungen, Diskussionen, Vorträge), Ausstellungen zu literarischen Themen bzw. Autoren/Künstlern, Autorenbegegnungen, Arbeitsforen, begleitende Tätigkeiten zur Förderung der Literatur. ${ }^{460}$

In dieser präzisierenden Zielformulierung des Vereins wird der Schwerpunkt mehr als im vorher erwähnten Konzeptpapier auf die Veranstaltungsaktivitäten des Literaturhauses gelegt. Die für die Vereinsbürokratie notwendigen Formulierungen werden den Vorstellungen der Behörde gerecht und sind doch breiter auslegbar. Schon der erste Teil des Zitierten offenbart, dass der Verein keine ganz Berlin ansprechenden und einbeziehenden Angebote plant: „interessierte Berliner und Gäste [Hervorhebung C. L.]" seien willkommen - ein bereits bestehendes Interesse wird also vorausgesetzt - und, salopp formuliert: Wen das Angebot nicht anspricht, der braucht auch nicht zu kommen. Spitzfindig lässt sich interpretieren, dass der Verein zwar dafür zu sorgen habe, dass das Literaturhaus als wichtiger Gesprächsort „offenstehen soll“", er sich jedoch nicht aktiv zu kümmern habe, dass Besucher*innen wirklich kommen.

Wie diese verkürzte Analyse zeigt, sind die in den Satzungstexten enthaltenen Zielsetzungen nicht sehr präzise. Die Satzungen der Trägervereine bilden in den meisten deutschen Literaturhäusern die rechtliche Handlungsgrundlage für die Literaturhaus-Mitarbeiter*innen, sie sind als Material für die vorliegende Studie meist

\footnotetext{
458 „Trägerverein Literaturhaus Berlin e. V.“, Literaturhaus Berlin. URL: www.literaturhausberlin.de/haus/traegerverein.html (Stand: 22.08.2016). Entgegen der in dieser Arbeit genutzen Zitierweise, mit Kurzbelegen zu arbeiten, werden bei Verweisen auf die Websites der acht Literaturhäuser die URLs und das Abrufdatum in den Fußnoten angegeben. Auf eine Auflistung aller zitierten URLs im Literaturverzeichnis wird dafür verzichtet. Eine Übersicht der Internetauftritte der Fallbeispiele findet sich im Anhang. Außerdem sei angemerkt, dass die Einrichtungen in den Belegen nicht kursiv gesetzt sind, um sie von selbstständigen Publikationen unterscheiden zu können.

459 „Satzung Literaturhaus“ o. J., S. 2.

${ }^{460}$ Ebd.
} 
aber wenig aufschlussreich, weil in ihnen möglichst breit gefasste Anliegen festgehalten sind, die den formalen Vorgaben genügen und den Akteur*innen Gestaltungsspielraum lassen.

\section{1.1.3 Ausgestaltung der Literaturhaus-Idee durch das Personal}

Der Verein stellt die Mitarbeiter*innen im Literaturbaus Berlin ein, 2016 waren sechs feste Stellen besetzt. Das Team sorgt für die tatsächliche Umsetzung des Vereinszweckes, die Programmleitung hat dabei Entscheidungshoheit. Die Aufgabenbereiche teilten sich in erstens Leitung, zweitens Organisation, Presse, Vermietung, drittens Ausstellungen, viertens Haustechnik, ebenfalls Presse, Projekte, fünftens Verwaltung/Finanzen und sechstens nochmals Haustechnik auf. Für die Abendveranstaltungen werden zusätzlich freie Mitarbeiter*innen beziehungsweise studentische Aushilfen engagiert, mit Praktikant*innen wurde bisher nicht gearbeitet. Das Literaturhaus Berlin war lange die einzige der untersuchten Einrichtungen in Deutschland, in der es noch keinen richtungsändernden Leitungswechsel gab. Der von 1985 bis 2003 amtierende Leiter des Hauses Herbert Wiesner (*1937) wurde von Ernest Wichner $\left({ }^{*} 1952\right)$ - „habituell exakt wie ein jüngerer Bruder des scheidenden Gentleman“ “461 - abgelöst. Seit 1988 war dieser als stellvertretender Direktor in der Nachfolge von Sissi Tax ${ }^{462}$ bereits ins Literaturhaus involviert und hat es auf diese Weise schon lange mitgeprägt. Zunächst war er für ein Jahr als Nachfolger seines ehemaligen Chefs vorgesehen, er blieb es schließlich bis zu seinem Ruhestand 2018.463 Beide Leiter sind Literaturwissenschaftler; Ernest Wichner, geboren in Guttenbrunn, Banat, Rumänien, ist außerdem als Lyriker und Übersetzer aus dem Rumänischen bekannt. Der Führungswechsel ging weitaus unauffälliger vonstatten als zum Beispiel in Hamburg oder Frankfurt. Im Literaturbaus Berlin gab es eine kleine Abschiedsfeier mit Reden, doch: „Komisch auch: Berliner Feuilletons nahmen nicht Kenntnis vom erlauchten Wechsel, weil, man mag's nicht glauben, die Presse nicht eingeladen war"“464, wie sich Claus Heinrich Meyer in der Süddeutschen Zeitung für die nicht eingeladenen Journalist*innen wundert. Auch im Programmheft wurde die Veränderung nur dadurch kommuniziert, dass auf der Impressumsseite hinter „im LH arbeiten“ von Februar auf März 2003 kommentarlos der Name ,Herbert Wiesner' durch ,Ernest Wichner' ersetzt wurde. Es scheint bezeichnend für die Haltung im Literaturhaus Berlin zu sein, nicht den Blick auf die Veranstalter, sondern allein auf Gäste und Literatur zu richten. ${ }^{465}$ Dies bewies sich schließlich auch beim Abschied Ernest Wichners im Dezember 2017, der leise und ohne viel Aufsehen vonstattenging. Dass sich mit der neuen Doppelspitze als Leitung von Janika Gelinek (*1979)

\footnotetext{
461 Meyer 2003.

462 Vgl. Michaelis 1986.

463 Anders als bei der Übertragung des Amtes auf den Stellvertreter oder der Benennung durch den Vorstand, wie im Falle Wiesners geschehen, wurde die Leitungsstelle in der Nachfolge des 2018 pensionierten Ernest Wichner bereits im August 2016 ausgeschrieben. Eine unabhängige Kommission führte das Bewerbungsverfahren durch.

464 Meyer 2003.

465 In einem informellen Gespräch im Literaturhaus Berlin am 03.11.2015 plädierte Ernest Wichner für mehr Bescheidenheit seitens der Literaturvermittler, nach dem Motto, dass die Autor*innen die ,Stars seien.
} 
und Dr. Sonja Longolius (*1978) ab Januar 2018 viel verändern wird, deutet sich schnell nach Amtseintritt an. Die Dokumentation und Untersuchung dazu bieten Material für eine an diese Arbeit anschließende Studie. Hier wird vor allem die Zeit davor thematisiert. ${ }^{466}$

Obwohl sich die Leiter als Personen nicht so sehr im Mittelpunkt sehen mochten, so war auch im Literaturbaus Berlin die Positionierung des Direktors eng verzahnt mit der Ausrichtung des Programms und mit der Außenwahrnehmung des Hauses. Und doch ist es bezeichnend, dass in diesem Absatz zum Personal nur auf die Leitungsfiguren eingegangen wird. In den relativ kleinen Arbeitsteams der Literaturhäuser gibt es in der Regel - wenn nicht Praktikant*innen beschäftigt sind - keine weiteren bedeutenden Hierarchieebenen, die Angestellten sind, wie oben erwähnt, für bestimmte Organisationsbereiche zuständig, das Programm liegt meist in der Verantwortung der Leitungsperson. Die Hypothese, dass Literaturhäuser (in Deutschland) nach dem Intendanzprinzip geführt werden, lässt sich anhand des Literaturhauses Berlin stützen. ${ }^{467}$ Für wesentliche Veränderungen habe Ernest Wichner, und das scheint zu seinem oben erwähnten Auftreten zu passen, keine Gründe gesehen. Er stellte sich jedoch vor, dass wieder mehr Besucher*innen kommen sollten, und auch der Vorsitzende des Vereins Detlef Bluhm wünschte sich eine deutlichere Öffnung zur Stadt hin. 468

\section{1.1.4 Einfluss der Finanzierung auf das Literaturhaus}

Es lasse sich, Helmut Böttiger zufolge, vermuten, dass sich das Literaturhaus Berlin Veranstaltungen mit nur 20 Besucher*innen ,erlauben' könne, weil es zum größten Teil aus öffentlichen Geldern finanziert werde. ${ }^{469}$ Das gilt, obwohl dieser Betrag Anfang der 1990er-Jahre gekürzt wurde ${ }^{470}$ und unter anderem die Stelle der stellvertretenden Leitung nicht nachbesetzt wurde, als Ernest Wichner zum Hauptleiter befördert wurde. Die Literaturhäuser in Hamburg oder Frankfurt sind stärker abhängig von Eintritts- und Spendeneinnahmen. ${ }^{471}$ Weitere Gelder kommen in Berlin aus Ticketverkäufen und Stiftungszuschüssen, meist aus Drittmitteln für die Ausstellungen im Haus. Mitgliedsbeiträge machen den geringsten Part aus. Außerdem stellen Mieteinnahmen einen Posten dar, im Vergleich zu Hamburg oder Frankfurt fällt dieser aber gering aus. ${ }^{472}$ Die Räume können zu privaten Zwecken oder für

\footnotetext{
466 Um diesen Umstand Rechnung zu tragen, wurden viele Beobachtungen in die Vergangenheitsform überführt.

${ }^{467}$ Vgl. Kapitel I 5.3.

468 Vgl. Plath 2003.

${ }^{469}$ Vgl. Böttiger 1995.

470 Zum Beispiel wurden 1992 im Vergleich zu 1986 die Mittel gekürzt, da im Zuge der Wiedervereinigung in Berlin das Geld knapper wurde. Weitaus stärker trafen die Kürzungen noch die ehemals ostdeutschen Einrichtungen wie die Literaturwerkstatt. Dokumentiert ist dies in Zeitungsartikeln, die im Archiv des Literaturhauses Berlin zu finden sind, hier aber nicht im Einzelnen interessieren. Später erhielt das Literaturhaus wieder eine Erhöhung.

471 Obgleich die Zahlen von Sonja Vandenrath von 2002 sind, reichen sie hier zur Veranschaulichung, vgl. Vandenrath 2006, S. 176.

472 Meistens finden die externen Veranstaltungen im Hochparterre im Kaminraum statt, da der große Saal für Literaturhaus-Veranstaltungen geblockt wird.
} 
Veranstaltungen gemietet werden. Diese Vermietungen machen einen Teil des Veranstaltungsangebots aus, sind dem Hauptprogramm aber untergeordnet. Auch aus seinen Buchverkäufen schöpft das Literaturhaus Berlin Kapital. Das Literaturhaus hat unter anderem 2008 den Vertrieb für die eingestellte Edition Mariannenpresse übernommen. Ferner verkauft es zahlreiche Begleitbücher zu den Ausstellungen und hat eine Festschrift im Angebot. Dieses Hausbuch enthält Beiträge über die Geschichte des Hauses Fasanenstraße 23, Vorschläge für literarische Spaziergänge sowie literarische Texte, in denen das Literaturhaus vorkommt. Anhand der Einnahmenliste kann man erkennen, dass Literaturhaus Berlin nicht nur als Veranstalter wirkt, sondern auch als Literaturproduzent in dem Sinne, dass es als Herausgeber und Distributor auftritt und als Kurator von Ausstellungen.

\section{1.2 Ein Name für eine Idee - Literaturhaus}

Die Verbindung zwischen Gesamtkonzept und räumlicher Ausgestaltung kommt, daran sei erinnert, durch das namensgebende Kompositum ,Literaturhaus' zustande. Das Literaturbaus Berlin prägte die Begriffsbezeichnung, wie im Folgenden nachvollzogen wird.

Palmenhäuser, Gewächshäuser, Freudenhäuser und Vogelhäuser sind Pflanz-, Brut- oder Heimstätten für das, was sie im Namen und im Schilde führen. Das Literaturhaus führt die Literatur im Schilde: Es ist ein Haus für die Literatur, für Autoren und ihre Leser, ein Haus aber auch für diejenigen, die glauben, auf die Phantasie der Dichtung, auf deren Entwürfe und Strukturen erinnerter Zukunft verzichten zu können. (BE 1986-06, siehe Anhang V 1.1)

Dies ist die erste veröffentlichte Darstellung eines Literaturhauses. Herbert Wiesner prägte sowohl den Namen als auch das damit verbundene Konzept: „Als das Berliner Haus eröffnet wurde, war das Wort Literaturhaus noch kein Begriff. Auf den Sinn von Vogel- und Palmenhäusern musste ich hinweisen, auch auf Freudenhäuser

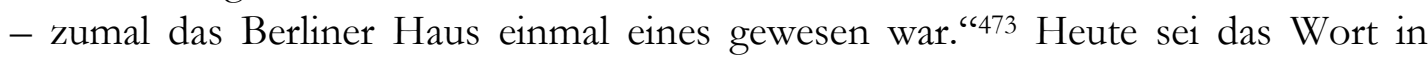
Verbindung mit dem jeweiligen Städtenamen „ein Markenzeichen für Literaturvermittlung geworden“" 474 . So bestätigt sich im Nachhinein, dass der Plan hinter dem nicht festlegenden, doch durch seinen, wenn auch weiten, Interpretationsrahmen beschränkten und daher präzisen Namen aufgegangen ist. Viel begrenzter wären die Handlungsmöglichkeiten der Akteur*innen, wenn der Ort nicht ,Literaturhaus' hieBe, sondern wenn die Einrichtung, wie überlegt wurde, nach Kurt Tucholsky benannt worden wäre. Das spätere Literaturhaus lehnte die personenehrende Bezeichnung von vorneherein ab: „Dieses Haus sollte keine Alibifunktion übernehmen, und es soll vor allem offen sein für gegenwärtige Literatur und für literarische Traditionen, die radikaler sind als der Stil des geschätzten Kurt Tucholsky. “475 Herbert Wiesner berief sich in diesem Leserbrief ebenfalls darauf, dass es keine westdeutsche Berliner Tradition gebe, Gedenkstätten für einzelne Autor*innen zu schaffen. ${ }^{476}$ Diese Offenheit den Inhalten gegenüber ist ein Novum des in Berlin etablier-

\footnotetext{
473 Wiesner 2004.

${ }^{474}$ Ebd.

475 Wiesner: „Leserbrief an“ 1995, S. 2.

476 Vgl. ebd.
} 
ten Literaturhauses. Schon länger existieren in Deutschland literarische Gesellschaften, die sich für das Werk eines, meist nicht mehr lebenden, Autors ${ }^{477}$ einsetzen und zum Teil Dichterhäuser beziehungsweise Gedenkstätten unterhalten, die vorrangig als Museum wirken. ${ }^{478}$ Auch in Skandinavien haben literarische Gesellschaften eine lange Tradition; dort konzentrierte sich die Literaturvermittlung noch länger auf die Bewahrung meist kanonisierter verstorbener Schriftsteller*innen, anstatt sich aktiv der Gegenwartsliteratur zuzuwenden. ${ }^{479}$ In Deutschland wurde der Dachverband Arbeitsgemeinschaft Literarischer Gesellschaften und Gedenkstätten (ALG) 1986 als Verein eingetragen. Während also in Berlin das erste Literaturhaus gegründet wurde, verbündeten sich die literarischen Gesellschaften. Mit dieser Erwähnung sei keinesfalls eine Korrelation behauptet, nur darauf hingewiesen, dass die literarischen Gesellschaften bereits ,Institution' waren, als es mit dem ,Literaturhaus' erst begann und noch nicht zu erahnen war, dass sich rund 15 Jahre später ein Netzwerk von Literaturhäusern zusammenfinden würde. Eine dezidierte Benennung nach einem Autor, in diesem Fall Kurt Tucholsky, schürt sonach berechtigte Erwartungen, dass es an diesem Ort, wenn nicht ausschließlich, so doch ausdrücklich um das literarische Erbe des einen Autors gehen soll. Dass damit zugleich Anhänger*innen dieses Autors befriedigt und befriedet werden, darauf weist Wiesner mit dem Ausdruck „Alibifunktion“ hin. Eine derartige Festlegung lehnte der Leiter explizit ab. Somit lässt der Name ,Literaturhaus' mehr zu und ist längerfristig angelegt, weil sich die Komponenten ,Literatur' und ,Haus' für jeden Ort und jede Zeit ausfüllen lassen. Es ist also nicht verwunderlich, dass der treffende Titel in anderen Städten übernommen wurde und sich außerdem zum Funktionsbegriff für Literaturvermittlungseinrichtungen fortentwickelte. Wichtig ist hier zu betonen, dass die Berliner Einrichtung sich engagiert für diesen Namen einsetzte und möglicherweise bereits über den Einzelfall hinausdachte. Ein Interesse an der Verbindung zu überregionalen ,Nachahmern' bezeugt zumindest das Mitwirken im Netzwerk der Literaturbäuser, dem das Literaturhaus Berlin seit Beginn angehört.

\section{1.3 Soziogeografische Verortung in Berlin}

\section{1.3.1 Standort Berlin}

In Berlin wurde ein Name für das sich dann verbreitende Konzept ,Literaturhaus gefunden. Der Fall des Literaturhauses Berlin offenbart zugleich, dass die lokale Verortung bei der Untersuchung von Literaturhäusern eine wichtige Rolle spielt. Besonders ist beim Standort Berlin, dass Berlin heute als Deutschlands Kreativhauptstadt gilt und es sich zugleich um eine Stadt handelt, die sich seit der Maueröffnung 1989 gravierend verändert hat und seit 1999 wieder Sitz von Deutschlands Parlament und Regierung ist. In einer ausgedehnten Stadt wie Berlin bedeutet ,Zentrum weniger ,Bündelung` als ,Vervielfältigung‘. Folglich kann ein Literaturhaus in urba-

\footnotetext{
477 Die weibliche Form ist hier in der Tat beinahe zu vernachlässigen.

478 Vgl. FN 28.

${ }^{479} \mathrm{Zu}$ literarischen Gesellschaften in Schweden vgl. Dahlström 1996.
} 
ner Umgebung kaum das eine Literaturhaus für eine ganæe Stadt sein - zumindest nicht mit den zur Verfügung stehenden finanziellen wie personellen Mitteln.

In den Anfangsjahren des 1986 eröffneten Literaturhauses ist vor allem die spezielle West-Berliner Position zu bedenken. West-Berlin sei während der deutschdeutschen Teilung ein „drittes Deutschland“ gewesen, stellt Wilfried Rott anschaulich wie umfassend dar, eine „Insel der Merkwürdigkeiten“. 480 Schon West-Berlin

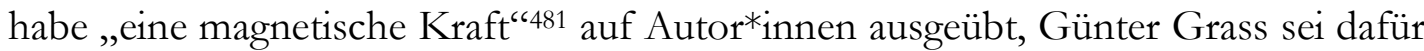
ein Beispiel. Es zieht weiterhin viele Schriftsteller*innen und jene, die es professionell werden wollen, an. Die Ansiedlung zahlreicher Verlage ist ein weiteres Indiz dafür, dass sich in dieser Stadt unterjährig ,der Literaturbetrieb“ versammelt; es sei etwa an den Rückzug des zwischenzeitlich Frankfurter Subrkamp Verlags nach Berlin zum Jahresbeginn 2010 erinnert. Dass sich Frankfurt mit seiner Buchmesse auch als Literaturstadt in Szene setzt, ändert wenig an der Attraktivität von Deutschlands einwohnerstärkster und sich weiterentwickelnder kreativer Stadt. ${ }^{482}$

Situiert in der Fasanenstraße 23 in Berlin-Charlottenburg-Wilmersdorf, wenige Meter von der Einkaufsstraße Kurfürstendamm - „die Großstadtstraße schlechthin“483 entfernt, lag das Literaturhaus bis 1989 im Kern West-Berlins. Nach der Ost-WestVereinigung bildeten sich nach und nach auch die städtischen Quartiere um. Mit dem Bedeutungszugewinn von Berlin-Mitte rückte die Fasanenstraße mehr in die Peripherie. Aufgrund des flächenmäßigen Ausmaßes von Berlin und der großen unterschiedlichen Bezirke ist der Standort der Einrichtung stärker noch als in Hamburg, München oder Frankfurt eine Aussage über die Verortung in einem Milieu: Charlottenburg gilt als bürgerlicher Bezirk, die Bevölkerung ist eher wohlhabend und alteingesessen. Entsprechend steht ein eher bildungsbürgerliches Publikum als Zielgruppe und ein korrespondierendes Programm zu erwarten. Die weiter hinten referierte Außenwahrnehmung des Literaturbauses Berlin passt zu diesen Vermutungen, die der städtische Standort weckt.

\section{1.3.2 Literaturveranstaltungsbetrieb in Berlin - Vier weitere Literaturhäuser}

Die Ausrichtung auf ein eher ,klassisches' Publikum hängt sicherlich neben der geografischen Lage damit zusammen, dass es in Berlin weitere einschlägige Literatureinrichtungen gibt, die andere Bereiche bedienen beziehungsweise in Konkurrenz zum Literaturhaus stehen. Vier davon werden ebenfalls institutionell vom Senat gefördert: ${ }^{484}$ Literarisches Colloquium Berlin, das, sicherlich auch aufgrund seiner randständigen Lage am Wannsee, mehr als Stipendiatenzentrum für Autor*innen und Über-

\footnotetext{
480 Rott 2009, S. 7.

481 Ebd., S. 203.

482 Ende Juni 2017 wurde eine Einwohnerzahl von rund 3,7 Millionen im Einwohnermelderegister erfassten Bewohner*innen verzeichnet. Die Bevölkerung wächst maßgeblich durch Zugezogene aus dem Ausland, vgl. Amt für Statistik Berlin-Brandenburg, Pressemitteilung 2017. Die Frage nach der Zentrumsposition wird anhand der norwegischen Beispiele für Skandinavien ausgeführt, vgl. Kapitel II 6.2.1. Richard Florida etwa spricht sich dafür aus, Kreativität als die Antriebskraft für Wachstum und Entwicklung von Städten, Regionen und Nationen zu erkennen, vgl. Florida 2005, S. 1.

${ }^{483}$ Rott 2009, S. 208.

${ }^{484}$ Vgl. „Literaturhäuser“, Senatsverwaltung für Kultur und Europa.
} 
setzer*innen und nicht so sehr als Publikumsort fungiert, ${ }^{485}$ Literaturwerkstatt Berlin, die 2016 bezeichnenderweise in Haus für Poesie - der Bezug zum ,Literaturhaus` im Namen ist eklatant - umbenannt wurde, Literaturforum im Brecht-Haus sowie LesArt Berliner Zentrum für Kinder- und Jugendliteratur, mit dem das Literaturhaus Berlin bei den Erlesenen Sonntagen, eine interaktive Literaturveranstaltung für die ganze Familie, zusammenarbeitet und was erklären mag, warum es zunächst kein weiteres Kinderund Jugendprogramm in der Fasanenstraße 23 gab. Daneben sei Lettrétage - das junge Literaturhaus als Beispiel für die sehr aktive freie Literaturszene aufgelistet. ${ }^{486}$ Ergänzend muss die hohe Anzahl an unabhängigen Lesereihen in Berlin genannt werden, die auf Lesebühnen und an wechselnden Orten stattfinden. ${ }^{487}$

Während Lettrétage die Bezeichnung, Literaturhaus' schon im Untertitel trägt, wird sie den anderen Einrichtungen nur zugeschrieben, und so heißt es, dass es eigentlich fünf Literaturhäuser in Berlin gibt. Das Literaturhaus Berlin wird deshalb oft, um Verwechslungen zu vermeiden, als ,Literaturhaus Fasanenstraße $e^{6}$ bezeichnet, obwohl, und dies betonte der frühere Leiter Herbert Wiesner ausdauernd, nur das hier untersuchte Literaturhaus Literaturhaus Berlin heißt. Erneut zeigt sich, dass ,Literaturhaus' mehr ist als nur ein Name, sondern der Terminus ebenso Literaturveranstaltungseinrichtungen unter einem Begriff zu bündeln vermag. In Berlin ist ,Literaturhaus' zu einer Dachmarke, zu einem Sammelbegriff geworden - ohne, dass es von den Initiatoren in der Fasanenstraße beabsichtigt gewesen wäre. Vielmehr lässt sich vermuten - dies bezeugt das Beharren Wiesners auf der Einzigartigkeit des Namens in Berlin -, dass das Literaturhaus Berlin alleinigen Anspruch auf den einprägsamen Titel haben und damit als der Ort für Literatur in Berlin wahrgenommen werden möchte. Dennoch ist der metonymische Gebrauch Tatsache. In Frankfurt gibt es zwar diese ,anderen' „Literaturhäuser' wie zum Beispiel die Romanfabrik, doch werden diese seltener direkt neben dem präsenteren Literaturhaus Frankfurt platziert. Dies ist nur in Berlin der Fall.

\section{1.4 Gestaltung und Außenwirkung des Literaturhauses Berlin}

\section{1.4.1 Räumlichkeiten}

Das Literaturhaus Berlin in Charlottenburg ist in einer herrschaftlichen Villa untergebracht, die 1889 von einem Korvettenkapitän, der die erste deutsche Expedition zum Nordpol unternahm, gebaut wurde. Danach war das Gebäude unter anderem im Ersten Weltkrieg ein Militärkrankenhaus; es diente als Volksküche, als Wohn-

\footnotetext{
${ }^{485}$ Dass auch das LCB mehr offene Veranstaltungen anbietet, deutet darauf hin, dass sich das Haus am Wannsee wandelt, sicherlich nicht zuletzt, weil es seit 2014 von Florian Höllerer geführt wird, der zuvor seit 2001 das Literaturbaus Stuttgart führte, und es seit 2015 Mitglied im Netzwerk, der Literaturbäuser ist, vgl. zum LCB Kapitel I 4.2.2 und zur Netzwerk-Mitgliedschaft Kapitel II 4.1.

486 Das Netzwerk, freie Literaturszene Berlin/NFLB ist eine Interessenvertretung freier Autor*innen, Übersetzer*innen, Literaturveranstalter*innen etc. aus Berlin gegenüber Politik und Öffentlichkeit, 2016 hat sie sich als eingetragener Verein formalisiert. Sie ist Teil der Koalition der freien Szene aller Künste, einem spartenübergreifenden Interessenverbund in Berlin.

${ }^{487}$ Monika Rinck fasst einige davon mit ihren jeweiligen Besonderheiten zusammen, vgl. Rinck 2003.
} 
haus für ausländische Studierende, war Kneipe, Bordell und Diskothek. ${ }^{488}$ Bürgerinitiativen verhinderten Mitte der 1980er-Jahre, dass es im Zuge städtebaulicher Umstrukturierungen abgerissen wurde, heute steht das Haus unter Denkmalschutz. ${ }^{489}$

Die meisten Veranstaltungen finden im Großen Saal im ersten Obergeschoss statt, das die Besucher*innen über eine Treppe gegenüber dem Café-Eingang erreichen. Der weiß gestrichene Saal hebt sich von den betuchten dunkelrot-bräunlichen Wänden der anderen Räume ab. Damit wirkt der Raum bei Eintritt aus dem Vorraum durchlässiger und frischer. Die Wände waren lange mit Ausstellungsplakaten der Autorengruppe OULIPO ${ }^{490}$ dekoriert. Die Bühne wird mit Strahlern beleuchtet, es ist keine spezielle Lichtanlage vorhanden. Der puristische Auftritt des Literaturveranstalters, der vorne erwähnt wurde, bestätigt sich im Hauptveranstaltungssaal. An den Saal schließt der kleinere Ausstellungsraum an, der selten für Veranstaltungen genutzt wird, höchstens, wenn mehr Platz benötigt wird oder Empfänge stattfinden. Im Vorraum, in dem sich die Abendkasse befindet, beginnen meist die Ausstelllungen. Der kleinere Kaminraum im Erdgeschoss, den oft Gastorganisationen nutzen, der aber auch für Eigenproduktionen geöffnet wird, vermittelt mit behaglichem Kamin, schweren Vorhängen und dunklerer Farbgestaltung eine gänzlich andere Atmosphäre als der helle, klare Saal im ersten Stock. Damit hat das Literaturhaus Berlin, anders als zum Beispiel das Literaturbaus Hamburg, zwei verschieden wirkende Räume zur Verfügung, um die Veranstaltungen auf gegensätzliche Weise zu rahmen: Herrschaftlich-Feudales trifft hier auf moderne Schlichtheit. ${ }^{491}$

\section{1.4.2 Image}

So unumwunden wie der damalige Leiter Herbert Wiesner es 1995 formulierte, finden sich selten Beschreibungen des Zielpublikums: „Wir sind nun mal kein Haus für literarische Anfänger, sondern wenden uns an ein bildungsbürgerliches Publikum, das regelmäßig das Feuilleton einer überregionalen Zeitung liest. “492 Es ist offensichtlich, dass er in seiner Rolle zwar Rechenschaft ablegen musste, dennoch frei war in seinen Entscheidungen. Das Literaturhaus habe oft gegen das Image des ,Elitären' anzukämpfen, man gehe bewusst das Risiko ein, dass zu Veranstaltungen nur 20 Interessierte kämen, bemerkt Helmut Böttiger 1995.493 „Elitär` zu sein, war für das Literaturhaus Berlin, wie die Aussage von Herrn Wiesner zeigt, nicht proble-

\footnotetext{
488 Führungen einmal im Monat, die das Literaturhaus anbietet, verorten das Haus, auch in seine unmittelbare Umgebung des Kurfürstendamms, historisch. Die Geschichte ist auch auf der Website präsentiert.

489 Die Decken im Hochparterre und Wandmalereien im Eingangsbereich wurden restauriert.

${ }^{490}$ Das Akronym OULIPO steht für L'Ouvroir de Littérature Potentielle [Werkstatt für Potentielle Literatur] und benennt einen Autorenkreis, der sich 1960 zusammengefunden hat. Zur Bedeutung dieser Gruppe für das Literaturhaus und sein Programm vgl. Kapitel II 13.2.4, S. 379.

${ }^{491}$ Dass die Ausstrahlung des Raumes im Literaturhaus Berlin in der Selbstdarstellung eine untergeordnete Rolle spielt, zeigen die Analysen der Selbstdarstellungstexte im nächsten Kapitel.

492 Herbert Wiesner zitiert nach: Zwoll 1995.

493 Vgl. Böttiger 1995.
} 
matisch. Urteile wie „im Literatenstadl in der Fasanenstraße“494 oder „das ansonsten eher verschnarchte Literaturhaus in der Fasanenstraße “495 offenbaren verschiedene Wertmaßstäbe und spielen objektiv-inhaltlich auf einen Punkt an, den die Leiter des Literaturhauses vermutlich nicht als Abwertung verstanden hätten: Der eher stille Auftritt des Literaturhauses bewirkte, wie auch im nächsten Kapitel bei der vertieften Analyse der Selbstdarstellungstexte ersichtlich wird, dass es im Literaturhaus Berlin mehr um den literarischen Text ging und nicht so sehr um das Literaturhaus als Akteur:

Doch geriet das Literaturhaus in den letzten Jahren in die Kritik. Seit Literatur zum Event geworden ist und Lesungen die Theater, Ländervertretungen, Botschaften, Kneipen, sogar das Kanzleramt erobern, erproben das Literarische Colloquium am Wannsee und die Literaturwerkstatt in der Kulturbrauerei neue Formen [...]. Das Literaturhaus setzt weiter vorwiegend auf die Einzellesung mit Wasserglas und Gespräch und sieht angesichts der Konkurrenz mit ihren flotten Titeln, Themen und Marketingmaßnahmen manchmal ein wenig alt aus - andere nennen es puristisch. ${ }^{496}$

Ernest Wichner erwiderte auf derartige Urteile, dass sein Literaturhaus nicht nur Kurzzeitphänomene betrachte, sondern sich zwischen aktuellem Feuilleton und Literaturwissenschaft sehe. Es bestehe dort eine Lücke, die das Literaturhaus mit einer Mischung aus Literaturkritik und Literaturgeschichte füllen solle. ${ }^{497}$ Die Selbstaussagen entsprechen also der Wahrnehmung von außen.

Von außen wird das Literaturhaus eindeutig auch als Ort wahrgenommen: „Einzigartig am Literaturhaus ist, daß es Literatur zu verknüpfen vermag mit einem gehobenen Lebensgefühl. 1986, als man in der Fasanenstraße anfing, zog die Literatur plötzlich aus dem ihr in Deutschland angestammten souterrain in die bel étage." "498 In diesem Zitat von Tilman Krause zum zehnten Geburtstag des Literaturhauses offenbart sich, dass der gehobene Anspruch im Literaturhaus nicht nur die vom Literaturhaus selbst erwähnte literarische Qualität betrifft, sondern in Krauses Verständnis auch die literarischen Akteur*innen gesellschaftlich aufgewertet wurden. Der Aufstieg aus der Kelleretage in die repräsentative Wohnung eines großbürgerlichen Hauses, die sich meist im ersten Stock befindet, steht nicht nur für einen faktischen Ortswechsel, sondern symbolisiert die gesellschaftliche Akzeptanz der Literaturschaffenden und deren Umgang mit Literatur. Sie ,verkehren in besseren Kreisen', Literatur ist (wieder) ,salonfähig' geworden - ein Adjektiv, das gleichermaBen mit Hilfe einer Raummetapher etwas als ,kultiviert', ,gesittet', ,wohlerzogen beschreibt. In dieser Bildsprache spiegelt sich die Differenzierung zwischen Kellersubkultur und vornehmer Hochkultur. Ideologiekritik ist nicht das Anliegen dieser Arbeit, dennoch kann beobachtet werden, dass im Literaturhaus Berlin die sogenannte Hochkultur positiv abgegrenzt wird von einem ,Anderen' - heute liegt die Vermutung nahe, in diesem Gegenstand das, was ich behelfsweise Unterhaltungs-

\footnotetext{
${ }^{494}$ So schreibt die taz in einem Artikel über Lesungen im Café Clara, das Literaturhaus wird nicht einmal erwähnt, allein diese spitze Bemerkung reicht offenbar als Verweis auf den bekannten Gegenentwurf aus, Klinggräff 1995.

495 Vogel 2005.

496 Plath 2003.

497 Vgl. Ernest Wichner zitiert nach: Engberg 2007, S. 10.

498 Krause 1996, Hervorhebungen im Original.
} 
kultur nenne, zu sehen; allerdings lässt sich der Umgang mit Literatur im Literaturhaus vor allem von der politisch engagierten Literatur der 1960er- und 1970er-Jahre abgrenzen, die eher in Kellerstuben und Studentenbuden zu verorten ist. ${ }^{499}$

Diese Darstellung zeigt, dass es unter anderem um die literarischen Praktiken gehen muss, die durch das Literaturhaus neu entwickelt wurden. Das Handeln mit und wegen Literatur verändert sich, Literatur wird ausgehend vom Literaturhaus Berlin feudaler zelebriert als zuvor. Der Ort trägt sonach dazu bei, dass für die Inhalte ein feierlicher Rahmen geschaffen wird. Die Beschäftigung mit Literatur wird verbunden mit herrschender sozialer Anerkennung, Genuss und gutem Geschmack'. Die Gegebenheiten und die Einrichtung des Hauses machen diesen Anspruch an die Art und Weise der Literaturvermittlung möglich. Diese Verbindung wird noch deutlicher beim Literaturbaus Hamburg, das im Fokus des folgenden Unterkapitels steht.

\section{2 Literaturhaus Hamburg - Das zweite Literaturhaus}

\section{2.1 Entstehung und Organisation}

In Hamburg gründete sich der Verein Literaturbaus e. $V$. schon 1985, er ist der älteste Literaturhaus-Verein und bis heute Träger der Einrichtung. ${ }^{500}$ Das Literaturhaus wurde im September 1989 eröffnet. Es kann diskutiert werden, ob das Haus in Hamburg oder das in Berlin als erstes Literaturhaus betitelt werden sollte. Es spricht vieles dafür, sich dem allgemeinen Verständnis anzuschließen, das Literaturhaus Berlin als Debüt zu betrachten, da es zuerst, und zwar deutliche drei Jahre vorher, seinen Betrieb aufnahm und die Dokumente belegen, dass bereits 1983 der Senat in Berlin die Einrichtung beschlossen hatte. Das Literaturhaus Berlin machte das Konzept publik, realisierte Ideen und testete die Anwendbarkeit. Es bot bereits Programm, als das Literaturhaus Hamburg eröffnete. Der Verein ist also mehr notwendige Körperschaft für das Literaturhaus, welches erst ab dem Einzug in ein Haus als solches öffentlich wahrgenommen wird.

Bevor das Literaturhaus im September 1989 als solches eingeweiht wurde, organisierte der Verein Veranstaltungen an unterschiedlichen Orten in der Stadt - wie zum Beispiel im benachbarten Stadtteil Winterhude auf Kampnagel, einem Veranstaltungsort, der weiterhin vor allem mit einem Tanz-, Musik- und Performanceangebot aufwartet - und bis zum Beginn der Umbauten in den schon ab August 1987 provisorisch eingerichteten Räumen des Literaturhauses. Zeitzeug*innen, die Lena Kovač für ihren Aufsatz zur Geschichte des Schwanenwik 38 interviewt hat, berichten davon, dass dieser improvisierte Veranstaltungsrahmen den „Geist der Zeit“"501 widerspiegelte und sich darin Hamburger Schlichtheit erkennen lasse, die für das Ham-

\footnotetext{
${ }^{499}$ Vgl. Kapitel I 4.2.4.

${ }^{500}$ Dieser Verein ist auch der einzige, der unter dem Namen ,Literaturhaus e. V. firmiert. Dass dieser

Name bereits gerichtlich verteidigt wurde, wurde bereits in Kapitel I 1 berichtet, vgl. S. 24.

${ }^{501}$ Kovač 2009, S. 16.
} 
burger Bildungsbürgertum charakteristisch sei. „Bis 1989 organisierte das Team rund 120 Lesungen, die an die 10.000 Teilnehmer zählten und kulinarisch von Schmalzbroten und Wein begleitet wurden“"502 im Erdgeschoss und im ersten Stock.

Der Einzug in das Literaturhaus vollzog sich in zwei Schritten: Zuerst wurde erreicht, dass der Literaturbaus e. $V$. das Haus Schwanenwik 38 direkt nutzen durfte. Dies geschah mit Einsatz des damaligen Literaturreferenten der Kulturbehörde Hamburg Reinhard Wittmann - der danach zunächst in gleicher Position nach München wechselte und 1996 die Leitung des neu gegründeten, 1997 eröffneten Literaturhauses München übernahm und bis Juni 2016 innehatte -, des Kultursenators Ingo von Münch sowie des Buchhändlers und Vereinsmitgründers Wilfried Weber. Daraufhin wurde der Hamburger Verleger Gerd Bucerius auf Anregung des Hamburger Oberbürgermeisters Klaus von Dohnany dafür gewonnen, dass die Zeit-Stiftung Ebelin und Gerd Bucerius das Haus 1987 kaufte, die Renovierungsarbeiten bezahlte und damit insgesamt drei Millionen Deutsche Mark spendete. Die Stadt Hamburg half mit weiteren 2,7 Millionen Mark aus; der bis 2009 anonyme Stifter Eddy Lübbert (1924 2016) spendete außerdem über eine eigens gegründete Stiftung eine Million Deutsche Mark, die für die laufenden Kosten des Literaturhauses aufgewendet werden sollten. Seitdem stellt die Zeit-Stiftung dem Literaturhaus-Verein das Gebäude mietfrei zur Verfügung, es bleibt im Besitz der Stiftung.

\section{Finanzierung}

Für Hamburg lässt sich festhalten, dass die Gründung des Literaturhauses auf die Initiative einiger Hamburger Bürger*innen zurückgeht, sie jedoch ohne öffentliche Unterstützung nicht realisierbar gewesen wäre. ${ }^{503}$ Privatpersonen bildeten den Verein, um neben Literaturveranstaltungen einen Ort der Zusammenkunft anbieten zu können. Einzelne Mäzene sorgen dabei auch über die Gründungszeit hinaus entscheidend für die Mitfinanzierung des Hauses. Die Unterstützung durch die ZeitStiftung und durch die Kulturbehörde tragen zur Aufrechterhaltung des Betriebs bei. Weiter finanziert sich das Literaturbaus Hamburg aus Eintrittseinnahmen, den Beiträgen der Mitglieder und Förderer des Vereins sowie Projektgeldern. ${ }^{504}$ Ohne selbst Mietkosten zahlen zu müssen, erhält der Verein Pacht von den anderen Einrichtungen im Schwanenwik. 38. Somit steht das Literaturhaus grundsätzlich auf einer soliden finanziellen Basis, zugleich ist das eigene Budget stark von Geldgebern wie unter anderem von den Mieteinnahmen abhängig.

\footnotetext{
502 Ebd.

503 Zeitdokumente und -berichte belegen, dass die Unterstützung seitens der Kulturbehörde entscheidend dazu beigetragen hat, dass die Idee ,Literaturhaus Hamburg' überhaupt realisiert werden konnte. Die Stadt Hamburg versprach sich dadurch Aufmerksamkeit für die Stadt, die auch als Kulturmetropole wahrgenommen werden sollte. Hamburg eröffnet sein Literaturhaus noch vor dem in München oder Frankfurt, die Konkurrenten in Deutschland um den Status als Kulturstadt nach Berlin. An Prestigeprojekte wie die im Januar 2017 eröffnete Elbphilharmonie war noch nicht zu denken.

5042015 konnte man in Hamburg für einen Jahresbetrag in Höhe von 85 Euro Mitglied im Verein Literaturhaus e. $V$. werden, für 500 Euro Förderer. In Hamburg gibt es, anders als beispielsweise in Stuttgart, München oder Freiburg nur einen Verein und nicht eine Doppelstruktur aus Träger- und Förderverein.
} 


\section{2.2 Soziogeografische Verortung in Hamburg}

Das Literaturhaus logiert in Hamburg am Schwanenwik 38 auf der Uhlenhorst, eine der teureren Wohngegenden Hamburgs und somit ein gehobenes Viertel, ${ }^{505}$ direkt an der östlichen Außenalster. Wie in den vergleichbaren Großstädten ${ }^{506}$ Berlin oder Oslo ist das Literaturhaus Hamburg im wohlhabenden Kontext situiert, dies wirkt sich entsprechend auf das Publikum aus. Obwohl nicht durch valide Zuschauerstatistiken gesichert, kann angenommen werden, dass die Verortung in der Stadt unmittelbar auf das Auftreten und die Wahrnehmung des Literaturhauses einwirkt. Das Literaturhaus ist mit öffentlichen Verkehrsmitteln nicht einfach zu erreichen und eigene Parkplätze stehen nicht zur Verfügung, sodass die Besucher*innen aus anderen Gebieten einen längeren Weg zum Literaturhaus Hamburg in Kauf nehmen müssen, respektive Menschen, die nicht in Uhlenhorster Kreisen unterwegs sind, gegebenenfalls seltener ins Literaturhaus kommen.

Für diese Hypothese sprechen überdies Elemente des Veranstaltungsprogramms wie beispielsweise die Reihe Schwanenwik goes Schulterblatt, die den Ortswechsel explizit mit einem Milieutausch verbindet: „Mehrmals im Jahr zieht das Junge Literaturhaus vom beschaulichen Schwanenwik ans trubelige Schulterblatt ins Kulturhaus III\&70, um Szeneluft zu schnuppern und fein ausgewählte Literatur ins Viertel zu bringen. Oft mit Musik, immer mit großartigen jungen Schriftstellern. “507 Das Schulterblatt ist eine Straße im Stadtviertel Sternschanze, die synonym für die alternative Szene in Hamburg steht. Der erwähnte Veranstaltungsort liegt direkt neben der Roten Flora, dem autonomen seit 1989 besetzten Kulturzentrum, das Symbolort für die linksradikale Bewegung in Hamburg ist. ${ }^{508}$ In diesem Quartier leben deutlich mehr jüngere Menschen als auf der Uhlenhorst. ${ }^{509}$ Hier wie dort stellt das Literaturhaus Hamburg „fein ausgewählte Literatur“ vor. An diesem Beispiel zeigt sich, dass bestimmte Angebote für einen anderen Ort besser geeignet sind, um die entsprechende Zielgruppe anzulocken beziehungsweise ,abzuholen‘. Die Programmgestaltung berücksichtigt dementsprechend die örtlichen Gegebenheiten.

\footnotetext{
505 Als Belege dafür dienen etwa die folgenden Daten: Es ließen sich 2015 überdurchschnittliche Preise für Immobilien und Grundstücke und keine Sozialwohnungen für dieses Viertel verzeichnen, außerdem ein unterdurchschnittlicher Anteil Leistungsempfänger nach SGB II (2,4\%, Hamburg gesamt 9,9\%); das durchschnittliche Einkommen je Steuerpflichtigem beträgt $2010 € 57.277$ (Hamburg: € 35.567), vgl. Statistisches Amt für Hamburg und Schleswig-Holstein 2015, S. 116-117.

${ }^{506}$ Hamburg ist die zweitgrößte Stadt in Deutschland. Die Einwohnerzahl lag in Hamburg Ende 2015 bei rund 1,79 Millionen, vgl. Statistisches Amt für Hamburg und Schleswig-Holstein, Pressemitteilung 2016. 507 „Reihen“, Literaturhaus Hamburg. URL: www.literaturhaus-hamburg.de/programm/reihen (Stand: 11.07.2016). Vgl. auch Kapitel II 10.4.2, S. 273.

${ }^{508}$ Dass diese Besetzung gerade 1989 begann, im Jahr der Eröffnung des Literaturhauses Hamburg, zeigt, welche unterschiedlichen kulturpolitischen Verhandlungen in dieser Zeit stattfanden. Die Rote Flora wurde besetzt, als es Pläne gab, dort ein repräsentatives Musicaltheater zu eröffnen, wogegen sich Protest erhob. Letztlich wurde die Neue Flora, unter anderem Aufführungsort des Musicals Phantom der Oper, ein paar Straßen weiter weg gebaut.

5092015 waren im Viertel Sternschanze 88,9\% der Bevölkerung unter 65 Jahren alt, also nur 11,1\% über 65. Auf der Uhlenhorst waren 20,4\% der Bewohner*innen über 65, der Vergleichswert für GesamtHamburg liegt bei 18,8\%. Unter 18-Jährige machten ,auf der Schanze`14,3\%, auf der Uhlenhorst 10,4\% und in Hamburg 15,7\% der Bevölkerung aus. Vgl. Statistisches Amt für Hamburg und SchleswigHolstein 2015, S. 58, 116.
} 


\section{2.3 Gestaltung des Literaturhauses Hamburg}

Die Gestaltung des Literaturhauses entspricht in Hamburg in etwa dem Ursprungszustand des Gebäudes, obwohl nur weniges original erhalten ist. Das Gebäude, das vorher unter anderem Tanzschule und Mädchenheim war, seit 1985 jedoch ungenutzt leer stand, 510 musste zur Eröffnung aufwendig renoviert werden. Besonders der heute eindrucksvolle Saal und die Deckengemälde mussten nach der seit 1939 jahrelangen Zwecknutzung als „Wohnheim für weibliche Lehrlinge, Durchgangsheim für gefährdete weibliche Jugendliche und Schutzhaftstelle für Aufgegriffene"511 massiv renoviert werden. Seitdem wurden nur notwendige Anpassungen an die aktuelle Nutzung, die im Prinzip seit 1989 gleichgeblieben ist, vorgenommen. Erweiterungen der Ausstattung, zum Beispiel die Kronleuchter im Großen Saal, kamen Mitte der 1990er-Jahre hinzu und im Sommer 2018 wurde ein Lift im Treppenhaus installiert. Seit 1990 steht das Literaturhaus Hamburg unter Denkmalschutz. Dies adelt das Haus als historisch bedeutsames Gebäude, erschwert unterdessen jedoch Umbauten.

\section{2.3.1 Weitere Einrichtungen im Literaturhaus}

Dem Literaturbaus e. $V$. obliegt die Vermietung des Hauses, die anderen Einrichtungen unter dieser Adresse sind folglich Mieter des Vereins. Dieser entscheidet hoheitlich, welche Organisationen im Hause vertreten sind und bleiben. Im Haus ansässig sind mit dem Literaturzentrum e.V.512, dem Börsenverein des Deutschen Buchhandels Landesverband Nord e.V. und der Buchbandlung Samtleben Einrichtungen des Literaturbetriebs und ein Café-Restaurant. Speziell die Buchhandlung, die schon seit 1989 im Literaturhaus geöffnet ist, und das Restaurant tragen dazu bei, das Literaturhaus als offenen Raum zu verstehen, den die Besucher*innen nicht nur zu Lesungen betreten, sondern zudem für private oder berufliche Begegnungen nutzen, wie es von Beginn an im Konzept intendiert war. ${ }^{513}$

Insbesondere die Kombination mit einem Restaurant findet sich in den meisten Literaturhäusern, wie in Berlin, Frankfurt oder Stuttgart, und kann als typisch für die ersten Vertreter der Institution Literaturhaus gesehen werden. Die Tatsache,

\footnotetext{
${ }^{510}$ Die Geschichte des Hauses ist in dem detaillierten vom Literaturbaus e. $V$. anlässlich des 20-jährigen Literaturhaus-Jubiläums in Auftrag gegebenen Aufsatz nachzulesen, vgl. Kovač 2009.

511 „Geschichte“, Literaturhaus Hamburg. URL: www.literaturhaus-hamburg.de/haus/geschichte (Stand: 30.09.2018).

512 „Um Literatur und ihre Verbreitung in der Öffentlichkeit zu fördern, wurde 1974 das Literaturzentrum von Hamburger Autorinnen und Autoren gegründet“, „Das Lit“, Literaturzentrum Hamburg. Dieser Verein bietet also schon deutlich länger als der Literaturhaus e. $V$. Literaturveranstaltungen an. Er kann zu den Vereinigungen gezählt werden, die bereits vor den publikumsorientierten Literaturhäusern auf starke Initiative von Autor*innen als, literarischer Verein' gegründet wurden und weiterhin in erster Linie von Selbstschreibenden geleitet werden, vgl. S. 79. Gelegentlich gibt es Verwechslungen zwischen dem Angebot des Literaturzentrums und des Literaturbauses Hamburg, weil beide im gleichen Haus als Veranstalter agieren. Das Literaturhaus Hamburg bildet z. B. auf einer Seite im Programmheft die Monatsübersicht des Literaturzentrums mit ab, markiert damit aber auch klar eine übergeordnete Position.

${ }^{513}$ Es gab offenbar die Idee, eine Autorenwohnung in der dritten Etage einzubetten, diese Idee stand jedoch der öffentlichen Nutzung des Gebäudes entgegen, vgl. Kovač 2009, S. 18.
} 
dass ebenfalls in Oslo und Bergen kontinuierliche Gastronomie angegliedert ist, unterstützt dies. Anhand des Hamburger Beispiels lassen sich Konfliktaspekte illustrieren, die diese Umsetzung als ,umfassendes Literaturhaus' mit sich bringt. ${ }^{514}$ In Hamburg wie in Berlin, Frankfurt, Oslo und anderen Literaturhäusern wird das Restaurant beziehungsweise Café nicht von dem jeweiligen Träger des Literaturhauses unterhalten. Gastronom und Veranstalter verfolgen jeweils andere Ziele und dennoch besteht ein berechtigtes Interesse zur Einigung. Beide Seiten möchten die Gäste mit ihrem Angebot überzeugen und dabei die Besucher*innen des anderen Akteurs im Idealfall für sich gewinnen und wenigstens nicht verschrecken. Sie sind schließlich finanziell aber auch konzeptuell aneinandergebunden: Bei einem Literaturhaus ohne gastronomischen Service würde ebenso ein zentraler Kommunikationspunkt fehlen wie bei einem Literaturhauscafé ohne Literaturveranstalter. ${ }^{515}$ In Hamburg betrieb ein Gaststättenbesitzer über 20 Jahre das Literaturbauscafé, bis er 2013 Insolvenz anmelden musste. ${ }^{516}$ Der nachfolgende Betreiber verzichtete unter anderem auf den spezifischen, ortstypischen Namen und veränderte sein Angebot durch angeblich exquisitere Speisen - wodurch auch die Preise stiegen. Aussagen des Literaturhaus-Personals und Lesungsbesucher*innen zufolge nahm das bisherige Publikum vor allem die Preiserhöhung unwillig zur Kenntnis. Die Fassadenbeschilderung mit dem Restaurantnamen sorgte zudem dafür, dass das Literaturhaus von außen nicht mehr eindeutig als solches gekennzeichnet war. Gastronomischer Betrieb und Literaturhaus harmonierten nicht besonders gut und in der Folge ergab sich für das Restaurant nicht der gewünschte Gewinn, sodass es bereits ein Jahr nach Eröffnung zahlungsunfähig war. Nach seinem Auszug konnte zügig ein Pächter gefunden werden. Seit August 2015 verantwortet ein neuer Inhaber das Literaturhauscafé - Restaurant und Events und an der Gebäudefront des Schwanenwiks 38 ist der Hausname ,Literaturhaus' wieder sichtbar.

\section{2.3.2 Veranstaltungsräume - Doppelnutzung als Café und Lesungssaal}

Das Literaturhaus Hamburg eignet sich nicht nur aufgrund der wechselnden Gastronomen als Beispiel für die Diskussion darüber, wie die unterschiedlichen Akteur*innen im Literaturhaus zusammenarbeiten, sondern auch, weil die besondere Raumsituation Interessenkonflikte offenkundiger macht. Denn dort wird der Veranstaltungssaal außerdem als Restaurantraum genutzt und infolgedessen müssen die Mitwirkenden Absprachen äußerst zuverlässig treffen. Bei Veranstaltungen des Vereins, die in der Regel im Großen Saal stattfinden, bietet das Café seinen Restaurantservice in der ersten Etage an und versorgt die Lesungsgäste an der Bar im Erdgeschoss. Tische, Stühle und die Bühne müssen jeweils umgestellt werden. Dieser organisatorische Aufwand betrifft nur die Beteiligten im Haus, für die Besu-

\footnotetext{
514 Vgl. auch S. 225.

515 Eine informative Übersicht über die Probleme verschiedener Literaturhäuser mit ihrer Gastronomie erstellt Julia Bähr 2006 anlässlich eines eskalierenden Streits im Literaturhaus München. In diesem Artikel wird das Literaturbaus Hamburg noch als Beispiel für eine problemlose Zusammenarbeit zwischen Literaturhaus und Gastronom aufgeführt, vgl. Bähr 2006.

516 Vgl. Hirschbiegel: „Vijay Sapre“.
} 
cher*innen des Literaturhauses sind diese Vereinbarungen normalerweise nicht einmal erkennbar.

Doch die Doppelnutzung des Ortes hat weitere Konsequenzen für die Ausgestaltung des Literaturhauses, die wiederum für die Wirkung auf das Publikum relevant sind. Bei den Veranstaltungen herrscht ,Caféhausatmosphäre‘, weil zugunsten der Stimmung, aber sicherlich ebenfalls aus organisationspraktischen Gründen die Restaurantmöblierung nicht ersetzt wird. Die Stühle werden nur eher auf das Podium ausgerichtet, das die Bühnengäste leicht erhöht platziert und zu jeder Veranstaltung aufgebaut werden muss. Dieses Ambiente entspricht der Idee des Literaturhauses Hamburg, es solle an die Caféhauskultur der Literaten in Wien oder Berlin zu Beginn des 20. Jahrhunderts erinnern. ${ }^{517}$ Es ergibt sich jedoch ebenso aus den baulichen Gegebenheiten und der Tatsache, dass beim Umbau vor 1989 die Örtlichkeiten weitgehend erhalten bleiben sollten. Beide Aspekte bedingen sich.

Der Raum im Literaturhaus ist dementsprechend für viele Besucher*innen mit zwei Funktionen besetzt: Lesungssaal und Restaurant. Dies führt verstärkt dazu, dass Literaturhaus-Verein und Gebäude beziehungsweise Café in eins gesetzt werden, was sich zum Beispiel daran zeigt, dass unter der Telefonnummer des Literaturhaus e. V. häufig Reservierungsanfragen für das Café eingehen. ${ }^{518}$ Dies mag Anekdotencharakter haben, dennoch ist die Beobachtung als vom Publikum empfangene Kommunikationsnachricht ernst zu nehmen. Erneut zeigt sich die ambivalente Wahrnehmung des Literaturhauses. Anhand des Fallbeispiels aus Hamburg lässt sich die Schwierigkeit, Literaturvermittler und Ort mit einem über Literatur hinausgehenden Angebot zu sein, zugespitzt illustrieren. Gleichzeitig ist hier augenfällig, wie eng die Verbindung von Literaturvermittlung und kultiviertem Alltag zum Konzept des Literaturhauses gehört, was sich ebenfalls am Literaturhaus Berlin offenbarte. Nachvollziehbar ist es somit, dass in der Außenwahrnehmung der Verein synonym mit dem Gebäude gesetzt wird, weil beide den Namen Literaturhaus führen.

\section{2.3.3 Setzungen durch den Ort}

Exemplifizieren lässt sich am Literaturbaus Hamburg ebenso, wie sehr die Gegebenheiten des Ortes seine Wirkung direkt beeinflussen. Die mit Putten, Stuckleisten und Deckengemälden verzierte Umgebung lässt eine feierliche Atmosphäre entstehen, die nahezu Ehrfurcht und Berührungsängste evoziert. Dies korrespondiert mit der Interpretation der Reihe Schwanenwik goes Schulterblatt, die einen Ort im Schanzenviertel präferiert und sich in die Ausgehpraxis anderer Literaturinteressierter einfügt. Da Raum- und Programmgestaltung miteinander verknüpft sind, gibt dort, wie in anderen Literaturhäusern in historischen Gebäuden, das Haus zum Teil vor, wie es bespielt werden kann - ,aber natürlich können Sie nicht in einer Gründerzeitvilla an der Außenalster so tun, als seien Sie ein hipper Club. “519 Möglicherweise ließen

\footnotetext{
${ }^{517}$ Vgl. z. B. Ursula Keller zitiert nach: Bollow und Kruse 1991, S. 10; Literaturhaus Hamburg: „Kurzbeschreibung Literaturhaus“ o. J. [vermutlich 1997], S. 2 sowie: „Ich möchte die Grenzen zwischen dem Tagesbetrieb und den Veranstaltungen aufheben“, Ursula Keller zitiert nach: Seegers 1991.

518 Das weiß ich aus eigener Erfahrung.

${ }^{519}$ Rainer Moritz zitiert nach: Twickel 2014.
} 
sich in einem denkmalgeschützten Gebäude Änderungen, die das Interieur betreffen, durchführen; doch ist anzunehmen, dass die Literaturhaus-Betreiber aus Kosten- und Präsentationsgründen wenig Interesse an einer kompletten Umgestaltung haben, zumal mit den Gegebenheiten gut gearbeitet werden kann. Die Frage nach der Wirkungsabsicht seitens des Literaturhauses steht in diesem Falle im Hintergrund, weil die aktiven Gestaltungsoptionen sehr eingeschränkt sind und der Verein in erster Linie auf die Zustände reagiert, die er allerdings mit dem Einzug in dieses bestimmte Haus gewählt hat. Das Selbstverständnis als beeindruckende weiße Villa am Schwanenwik ${ }^{520}$ ist aufgrund der zur Verfügung gestellten tatsächlich weißen Villa an der Alster entstanden. Dadurch steht die dortige Literaturvermittlung unweigerlich in der Tradition repräsentativer Geselligkeit, denn der heutige Saal wurde 1889, also genau hundert Jahre vor der Literaturhaus-Eröffnung, als privater Ballsaal in diesem bürgerlichen Wohnhaus ergänzt. Die Möglichkeiten zur Imageveränderung sind durch die örtliche Situation mitbestimmt respektive begrenzt.

Am Beispiel Hamburg wird anschaulich, dass die intendierte Verknüpfung von Ort und Raum, von Gebäude und Konzept auf der einen Seite gelingt und dass sie auf der anderen Seite die erwähnten Vermittlungskonfusionen, Gastronomie und Literaturhaus-Verein seien synonym gesetzt, steigert. Anhand des Literaturbauses Hamburg wird offenbar, dass die Vermischung von Veranstaltungssaal und Gastronomiefläche einerseits die Atmosphäre des Ortes prägt, andererseits von außen die Literaturveranstaltungen nicht klar als Hauptfunktion des Literaturhauses gesehen werden, was nicht im Interesse des Literaturhauses als Literaturveranstalter ist. Mit dem Wissen um die besondere Raumsituation im Literaturhaus Hamburg steht zu vermuten, dass diese bei der Selbstdarstellung Gewicht hat.

\section{2.4 Personalentwicklung und Programmatik}

Das Trägerorgan des Literaturhauses Hamburg ist der Verein Literaturhaus e. V. Dieser ernennt, vertreten durch den bei der Hauptversammlung gewählten Vorstand, die Leitung. In den Anfangsjahren war dies als Programmleiterin Dr. Christina Weiss (*1953) - inzwischen unter anderem Honorarprofessorin an der Universität des Saarlandes -, die das Literaturhaus verließ, weil sie zur Kultursenatorin in Hamburg ernannt und von 2002 bis 2005 Staatsministerin für Kultur und Medien wurde. ${ }^{521}$ Von 1992 bis 2005 war die Dramaturgin Dr. Ursula Keller (*1940) Programmleiterin. Damals wurde noch zwischen Programm- und Geschäftsleitung unterschieden. Es ist jedoch bezeichnend, dass vor allem über die künstlerischen Leiterinnen berichtet wird, denn für die Ausgestaltung des Literaturhauses ist die Programmverantwortliche zuständig. Die Geschäftsführung ist für das gesamte Fortbestehen der Einrichtung zwar ebenfalls sehr wichtig, agiert aber eher im Hintergrund. Später hatte im Literaturbaus Hamburg, wie in den meisten deutschen Literaturhäusern, eine Person Geschäftsführung und Programmleitung inne.

Seit Ende 2004 ist Dr. Rainer Moritz (*1958) - inzwischen vom Senat zum Ehrenprofessor der Stadt Hamburg ernannt, vorher Programmgeschäftsführer beim

\footnotetext{
${ }^{520}$ Dies wird bei der Analyse der Selbstdarstellungstexte sichtbar, vgl. Kapitel II 9.2.
}

${ }^{521}$ Die Geschäftsleitung hatte Jürgen Mackensen inne. 
Verlag Hoffmann und Campe - künstlerischer und kaufmännischer Leiter. Er hat vier feste Mitarbeiterinnen für diese Aufgabenbereiche: Kommunikation, Programmorganisation, Junges Literaturhaus und Verein sowie Koordination. Daneben gibt es Techniker, Praktikant*innen und projektbezogen freie Mitarbeiter*innen. ${ }^{52}$ Entscheidungen bezüglich des Hauptprogrammes obliegen - dem Intendanzprinzip folgend - gänzlich dem Leiter. Beim Angebot des Jungen Literaturbauses verfügen die Mitarbeiter*innen über Handlungsspielraum. Es wird offenbar, dass die Veranstaltungen am Abend als Hauptprogramm gewertet werden. Ähnlich wie im Literaturhaus Frankfurt, in Köln oder Kiel wird das Programm des Jungen Literaturhauses von anderen Personen erdacht, aber nicht losgelöst von der Leitung verantwortet.

\section{Leitungswechsel}

Führungswechsel stellen in den Literaturhäusern Schwellensituationen dar, die die Ausrichtung des Hauses justieren können, was auf die Institution ,Literaturhaus einwirkt, die ein Gesamtbild aus den einzelnen Fällen repräsentiert. Unabhängig von den Gründen für den Weggang der vorherigen Leitungsperson besteht ein gesteigertes Interesse der Öffentlichkeit am Literaturhaus, wenn eine neue Leitung sich ankündigt. Ähnlich wie bei Theatern oder anderen großen Kultureinrichtungen ist ein personeller Wechsel eine Möglichkeit, mediale Aufmerksamkeit zu erzeugen. Vor allem Zeitungen - dabei nicht nur die lokalen Kulturseiten, sondern selbst das überregionale Feuilleton - stellen die ,Neuen' in Porträts oder Interviews vor. Dies belegt, dass das Literaturhaus deutschlandweit rezipiert wird. Ein Interesse der Leser*innen an der jeweiligen Person kann ebenso angenommen werden wie eine Neugier auf die Autorenpersona auf der Bühne vermutet wird. In den Beiträgen zu Leitungswechseln wird explizit das jeweilige Programmkonzept und oft ex negativo das frühere Angebot thematisiert und mit der Person in Beziehung gesetzt.

Anhand des zweiten Leitungswechsels in Hamburg lässt sich exemplarisch vorführen, inwiefern Programmleitung und konzeptuelle Schwerpunktsetzungen des Literaturhauses verknüpft sind. Für diese beispielhafte Darstellung bieten sich das Literaturbaus Hamburg und das Literaturbaus Frankfurt an, weil es dort jeweils Konflikte gab, die für eine Studie produktiv sind, weil sie gegeneinanderstehende Positionen sichtbar machen. Im Folgenden gehe ich detaillierter auf die Aussagen über das Literaturbaus Hamburg zur Zeit Ursula Kellers und beim Wechsel zu Rainer Moritz ein, die hier als Typen, nicht als Privatpersonen behandelt werden. Dennoch sollte daran erinnert werden, dass in die analysierten Geschehnisse nicht nur Rollen, sondern auch Menschen involviert sind. ${ }^{523}$

\footnotetext{
522 Dies lässt sich auf der Website des Literaturhauses Hamburg nachlesen. Die Anzahl der Mitarbeiter*innen auf die Bereiche hat sich seit den Anfangsjahren, wie in den anderen Literaturhäusern, nicht bemerkenswert verändert. Gerade dies ist aber für alle Einrichtungen beachtenswert, schließlich ist das Arbeitspensum allein schon durch das quantitativ ausgebaute Veranstaltungsangebot gestiegen. Dies bestätigten mir Mitarbeiter*innen in unterschiedlichen Arbeitsbereichen von Literaturhäusern.

${ }^{523}$ Die Idee des Literaturhauses wird durch die Einrichtung selbst mitgesteuert, wenn sie anhand von Dokumenten analysiert wird. Die Selbstveröffentlichungen und besonders die Interviews der neuen Leiter*innen beinhalten Wunschdenken und Planungswillen und entsprechen nicht zwangsläufig den ,Tatsachen'. Sie sind als Teil einer Kommunikationsstrategie aber vor allem deshalb relevant, weil sie das Selbstverständnis der Einrichtung spiegeln, das so wichtig für die Außenwahrnehmung ist.
} 
Ursula Keller verließ bei Ende ihres Vertrags nach 13 Jahren Leitung das Literaturhaus. Damit stellte sie sich gegen die Vorstandsentscheidung, die eine Übergangsphase vorsah, in welcher Kellers Nachfolger Rainer Moritz eigentlich für ein Jahr neben ihr Geschäftsführer sein und nach Ablauf von Kellers Vertrag nach ihrem 65. Geburtstag Ende 2005 ihren Posten übernehmen sollte - ein Vorgehen, das hitzig diskutiert wurde.524 Diese Auseinandersetzungen zwischen Ursula Keller und dem Trägerverein des Literaturhauses sind nicht nur als persönlicher Zwist zu deuten, sondern geben Aufschluss über unterschiedliche Auslegungen des Literaturhauses, die mit der Neubesetzung verändert werden sollten. Zunächst einmal ist die Nachbesetzung einer Leitungsstelle immer Anlass, „die Programmleitung mit einer neuen, jüngeren Person zu besetzen, wie das bei Erreichen der Altersgrenze eigentlich ganz selbstverständlich ist" ${ }^{\text {". }} 25 \mathrm{Da}$ es Beschwerden unter anderem der Amtsinhaberin zum Prozedere gegeben habe, 526 entstanden „sachliche Konflikte, wie sie überall vorkommen, wo sich engagierte Individuen auf eine gemeinsame Linie einigen müssen“"527, wie Matthias Wegner für den Vorstand des Literaturhaus e.V. es formulierte und nicht weiter kommentierte. Wenngleich es nicht um „verschiedene ästhetische Standpunkte“ ${ }^{\text {"528 }}$ gegangen sei, so ist ob der Kürze dieser Aussagen zu vermuten, dass, wenn nicht im engeren Sinne ästhetische, so doch konzeptuelle Fragen die Meinungsverschiedenheiten verstärkten. Das literarische Profil sei ein wichtiger, aber eben nicht der einzige Faktor im Gesamtzusammenhang des Literaturhauses. Der Vorstand als Vertreter des Vereins sei dafür verantwortlich, das Ganze möglichst konfliktfrei zusammenzuhalten. Es ist davon auszugehen, dass Vereinsmitglieder mit der Bespielung des Literaturhauses durch Ursula Keller unzufrieden waren und sie im Wechsel eine Chance zur Justierung sahen. Dieser Streitfall soll hier nicht weiter nachgezeichnet und schon gar nicht kann an dieser Stelle beurteilt werden, wer im Recht gewesen sein und wer sich unangemessen verhalten haben könnte und: „Nüchtern betrachtet stellt sich der Vorgang weniger aufregend dar. “529 Doch lässt sich so zeigen, dass die Gründe für die Entscheidung gegen eine Verlängerung von Ursula Kellers Vertrag ${ }^{530}$ und ihr vermeintlich zu akademisches Programm mit Hypothesen der vorliegenden Arbeit zusammenhängen: mit den Annahmen, dass das Veranstaltungsangebot eines Hauses auf die Programmleiter*innen zurückführbar ist, und dass das konkrete Programm geprägt ist von dem konzeptuellen Selbstverständnis des Literaturhauses und andersherum, denn das Veranstaltungsangebot lässt indirekt Aussagen über das Selbstverständnis zu. Der Vereinsvorstand kann über Personalentscheidungen seinen Einfluss nutzen und letztlich die Programmrichtung des Hauses mitbestimmen. ${ }^{531}$ So kann die Neube-

\footnotetext{
524 Vgl. z. B. Schellen 2004.

525 Matthias Wegner zitiert nach: Seegers 2004. Es habe zudem einen offenen Brief gegeben, den Vereinsmitglieder, ,aber auch bundesweit in Sachen Literatur engagierte Personen“ unterschrieben haben. ${ }^{526}$ Diese wurden teilweise von Vereinsmitgliedern und Journalist*innen unterstützt, vgl. z. B. Greiner 2003.

527 Matthias Wegner zitiert nach: Seegers 2004.

528 Matthias Wegner zitiert nach: ebd.

${ }^{529}$ Briegleb 2003.

530 Wobei weiterhin zu bedenken ist, dass ihr Vertrag erst Ende 2005 auslief und sie selbst entschied, bereits 2004 auszutreten.

${ }^{531}$ Dass der Verein und dessen Vorstand in den meisten Fällen eine Leitungsperson einstellt und dieser dann Freiheit bei der Gestaltung des Angebots lässt, widerspricht dem nicht.
} 
setzung einer Leitungsstelle auch Anlass sein, die Programmatik und Linie der Einrichtung zu verschieben. Auch die Entscheidung Programm- und Geschäftsführung, nicht mehr zu trennen, kann als zentrale Neuerung gesehen werden. Während Ursula Keller die Trennung beider Bereiche für unerlässlich für eine „intensive,

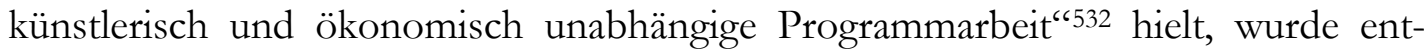
schieden, dass die inhaltliche Arbeit nicht mehr gesondert von finanziellen Belangen umgesetzt werden kann.

Zum Start von Ursula Keller im Januar 1992 wurde in Hamburger Tageszeitungen die neue Literaturhaus-Chefin vorgestellt, darin finden sich folglich Selbstaussagen Kellers zu ihrer Position. Sie kündigte darin an, „das nicht gerade flimmernde kulturelle Klima wenigstens an einer kleinen Stelle“ beleben zu wollen; die Autorenlesung als überwiegende Präsentationsform werde es mit ihr nicht geben. ${ }^{533}$ Der zweite Teilsatz verweist konkret auf die Programmarbeit und bietet einen Anhaltspunkt für die Untersuchung der Ankündigungstexte. Ursula Keller ließ erwarten, dass vor allem intermediale Vorführungen und interdisziplinäre Diskussionsformate im Literaturhaus umgesetzt werden sollten. Sie grenzte sich auf diese Weise nicht explizit vom bisherigen Programm des Literaturhauses ab - vielmehr lobte sie ihre Vorgängerin Christina Weiss, die ebenfalls keine „Einschaltquoten-Politik“"534 betrieben habe und für ein poststrukturalistisches Interesse am Text eingestanden sei. ${ }^{535}$

Ursula Keller stellt ihre hamburgweite Perspektive heraus. Gerade in Hamburg sei, wie oben zitiert, das Kulturleben wenig lebendig und die verschiedenen Kultursparten seien stark voneinander abgegrenzt. In diesen ersten Interviews vermittelte sie einen Veränderungswillen und schloss ein Scheitern nicht aus, denn sie wisse, dass die Zeit und die Stadt nicht für Debatten bereit seien, versuchen wolle sie aber dennoch, ihre Ideen zu realisieren. ${ }^{536}$ Dabei sei das alleinige Auswahlkriterium für Autor*innen und Veranstaltungsformen die Qualität, und sie wolle ein anderes Publikum als bisher ansprechen: ,jünger, neugieriger und kontroverser“ ${ }^{\star 537}$ oder ,jünger, gesprächiger und vielschichtiger [...] [n]icht so etabliert literarisch“"538 solle es sein. Ursula Kellers Konzept des Literaturhauses setzte darauf, ein Gesprächsforum für gesellschaftliche Debatten zu sein, darauf, die Kunstsparten zu verbinden und die Aufführungsformen zu variieren.

Sie wurde in Interviews noch direkter: Sie wetterte zum einen gegen „diesen ganzen abgefuckten literarischen Tourneebetrieb“539, gegen „diese[ ] rein passive[ ] Rezeptionshaltung “"540, argumentierte zum anderen für aktives Einmischen sogar des Publikums und schätzte das Literaturhaus als Geschenk für die Stadt ein. Es könne, so Keller, „für das kulturelle Leben der Stadt eine unglaublich integrative Funktion

\footnotetext{
532 Ursula Keller zitiert nach: Ustorf 2004, S. 59.

533 Ursula Keller zitiert nach: Helling 1991, S. 37.

534 Ursula Keller zitiert nach: Bollow und Kruse 1991, S. 1.

535 Dies wird später ausgeführt, vgl. Kapitel II 13.2.4.

536 Vgl. Ursula Keller zitiert nach: Helling 1991.

${ }^{537}$ Ursula Keller zitiert nach: ebd.

538 Ursula Keller zitiert nach: Bausch und Briegleb 1991.

539 Ursula Keller zitiert nach: Bollow und Kruse 1991, S. 1.

540 Ursula Keller zitiert nach: ebd.
} 
haben. Es könnte ein Ort übergreifender Reflexion sein, wo sich die unterschiedlichen Szenen - Film, Theater, Literatur, Uni - vermischen. “541

Korrespondierend mit den Analyseergebnissen der Programmankündigungstexte aus dem Literaturhaus Hamburg zur Zeit Ursula Kellers ${ }^{542}$ zeigt sich dieses Verständnis des Literaturhauses als „Refugium [...] für Kulturtechniken, die es schwer haben in der multimedialen Tralala-Kultur“ ${ }^{\star 543}$ dazu in anderen Aussagen der Leiterin. Diese fachsprachlichen Formulierungen mit hierarchisierendem respektive degradierendem Duktus passen inhaltlich und stilistisch zu den Worten Ursula Kellers, mit denen sie zu ihrem Auftakt Ende 1991 ihren Anspruch ausdrückte:

Ich halte es für ein utopisches Unterfangen, breite Bevölkerungsschichten für Literatur zu begeistern. Ich glaube nicht an das ,Kultur-für-alle-Konzept‘. Seit Jahren ist der Anteil an Lesern in der Bevölkerung konstant, und zwar bei etwa zehn Prozent. Und viel mehr bekommen Sie auch nicht zum Lesen, eine Animation dazu halte ich auch nicht für meine Aufgabe. Ich kann Kultur nur für die zugänglich machen, die sie wollen und nicht, für alle'. Das Literaturhaus hat in dieser Stadt nicht das Monopol auf literarische Aktivitäten. Auf vielen Ebenen kümmern sich Leute um Literatur. Das sollen sie auch um Himmels willen weiter tun. Das Literaturhaus darf diese Kräfte nicht absorbieren, zentralisieren und aussaugen. Das wäre eine fatale Wasserkopf-Funktion. ${ }^{544}$

Dieser exklusive Anspruch wird ebenfalls von den Rezipient*innen bemerkt. Das Hamburger Abendblatt formuliert zu Ursula Kellers zehnjährigem Jubiläum im Literaturhaus Folgendes: „Normalerweise steht Ursula Keller zu Beginn auf dem Podium und kündigt katzenhaft verführerisch etwas an, von dem kaum ein Gast so genau weiß, was ihn erwartet bei ,Alles Pop - oder was?‘ und Gesprächen über metropolitane Kultur.“545 Die Diskrepanz zwischen der Programmleiterin und dem Publikum wird in dieser Aussage sehr deutlich und sie habe „sich damit nicht nur Freunde gemacht“546, wie es die Süddeutsche Zeitung ausspricht: „Manchen gilt sie als elitär in ihrer Orientierung an internationalen Maßstäben, ihrer intellektuell anspruchsvollen Vermittlung, ihrer Neigung zum Diskurs, die manchmal einer Literatur wenig Raum lässt, die nicht ,auf Augenhöhe mit den Problemen ihrer Zeit' ist. "547 Heide Soltau fasst es im Norddeutschen Rundfunk so zusammen: „Gelegentlich wird darüber im Hamburger Literaturhaus gestritten, aber meistens doch eher gepflegt gefachsimpelt. Was die Schwellenängste mancher Besucher schürt. Nicht-Intellektuelle fühlen sich bisweilen unwohl in den heiligen Hallen der prunkvollen Villa." 548 Mit anderem Blickwinkel stellt es beispielsweise Sigrid Löffler dar: Für „eine solide Elite“ habe Ursula Keller Programm gemacht, „,dass die Funken nur so sprühten. “549

\footnotetext{
${ }^{541}$ Ursula Keller zitiert nach: ebd., S. 10.

542 Vgl. Kapitel II 10.4.1, S. 259.

${ }^{543}$ Literaturhaus Hamburg: „Kurzbeschreibung Literaturhaus“ o. J. [vermutlich 1997]. Dort wird das Selbstverständnis des Ortes in einer Aufzählung wie folgt beschrieben: „Das Literaturhaus definiert sich als Ort, - der der literarischen Sprache ebenso einen Raum gibt wie der Reflexion über sie. - der dem literarischen Text die vielfältigsten Formen von Auftritt verschafft. - der ein Refugium ist für Kulturtechniken, die es schwer haben in der multimedialen Tralala-Kultur. - an dem auch über kulturtheoretisch und zeitdiagnostisch relevante Themen nachgedacht und debattiert wird.“

544 Ursula Keller zitiert nach: Bollow und Kruse 1991, S. 10.

545 wend. 2002.

546 Schöne 2002.

547 Ebd.

548 Soltau 2002.

${ }^{549}$ Löffler 2002.
} 
Diese Äußerungen sowohl der Leiterin als auch der Journalist*innen erinnern an die Bemerkungen zum Literaturhaus Berlin aus dem vorausgegangenen Kapitel. Gerade kein Ort für „literarische Anfänger“ ${ }^{\text {“50 }}$ sein zu wollen, markierte Herbert Wiesner als Idee des Literaturhauses. Dies galt zunächst für das Literaturhaus Berlin, sollte aber, wie sich in Hamburg zeigt, weiter diskutiert werden. Obschon sich die Leiter in Berlin eher der klassischen Moderne verschrieben hatten, während die Anfangsjahre in Hamburg poststrukturalistisch geprägt waren, so ist den Leitungen gemein, dass sie es für unproblematisch, ja geradezu für attraktiv befanden, Programm für eine begrenzte, akademisch gebildete Gruppe anzubieten. Ihr eigenes literarisches Niveau war dabei maßgeblich, das Interesse an einem größeren Publikum erscheint diesem untergeordnet. Mit einer Orientierung an dem mit dem Literaturhaus in Verbindung gebrachten Konzept einer ,Kultur für alle' hat dies in der Tat recht wenig zu tun; Literatur wird nicht möglichst schwellenlos vermittelt, sondern unter bereits Interessierten verhandelt.

Mit dem Wechsel zu Rainer Moritz kündigte sich Berichten zufolge eine Veränderung an. Petra Schellen kommentierte die Vorstellung des neuen Leiters in Begleitung von Denis Scheck auf dem Podium mit „zelebrierte[r] Lausbubigkeit“, „Jovilität“" und „atemlose[r] Witzigkeit" heraus, der unter der neuen Leitung wichtiger werden soll: „Und gelacht werden soll künftig zünftig in den heiligen Hallen“552. Das Heraustreten „aus dem vielbeschrienen Elfenbeinturm“ 553 sei ebenfalls Programm; Petra Schellen vermutete, dass sich das Publikum jedoch nicht verjüngen werde und „vermutlich ein gut Teil Konventionalität einziehen wird“"554. Für das Programm unter Rainer Moritz wurde also eine größere Mischung erwartet, die nicht nur von einer kleinen ausgewählten Gruppe hochgeschätzt werde und die kurzweiligere humorvolle Unterhaltung in den Blickpunkt rücke. Dabei sei, Moritz zufolge, die ,allüberall geforderte Performancefähigkeit von Autor und Kritiker durchaus kritisierenswert ${ }^{\text {(555 }}$, es werde ein saisonales Gesamtkonzept zugunsten eines gemischten Angebots abgelehnt. Das Literaturhaus Hamburg unter Rainer Moritz widmet sein Programm nicht einem bestimmten Motto, es wird nicht in Spielzeitthemen wie beispielsweise in vielen großen Theatern gedacht. ${ }^{556}$ Weiter stellt Rainer Moritz zum Amtseintritt mehr literarhistorische Veranstaltungen in Aussicht und nicht nur die Präsentation von Neuerscheinungen. Außerdem sei eine Ausweitung des Kinder- und Jugendprogrammes geplant. Es wird aber auch ausgesprochen, dass viele bewährte Programmteile weitergeführt werden. Dies verwundert nicht, wurde doch bereits im Zusammenhang der Institution herausgestellt, dass eine neue Leitungspersönlichkeit sich an Traditionen respektive Vorgaben des Gegebenen halten und zugleich zur Fortentwicklung Neues erfinden muss. Die Ursprungsidee, das Literaturhaus als Forum für die Begegnung mit Literatur in jeder Form zu verstehen, hält Rainer Moritz weiterhin für gerecht-

\footnotetext{
${ }^{550}$ Herbert Wiesner zitiert nach: Zwoll 1995.

551 Schellen 2004.

${ }^{552}$ Ebd. Wieder ist die Rede von den „heiligen Hallen“ des Literaturhauses, vgl. FN 548.

553 Schellen 2004.

554 Ebd.

555 Ebd.

${ }^{556}$ Darauf werde ich bei den Programmanalysen zurückkommen, vgl. Kapitel II 13.1.2.
} 
fertigt. ${ }^{557}$ Diese bildet mitsamt ihren Interpretationsoptionen den Kern des Literaturbauses Hamburg - und der Institution Literaturhaus.

Spätere Äußerungen Moritz’ gehen in eine ähnliche Richtung. In seinen verschiedenen Rollen - als Literaturkritiker, Autor, promovierter Literaturwissenschaftler, als Leiter eines Hauses, seit 2010 als Sprecher des Netzwerks der Literaturhäuser und als Beobachter des Literaturbetriebs - äußert er sich auch zum Thema Literaturhaus. Während er in Sammelbandaufsätzen der Textsorte angemessen sachlich formuliert, spricht er in kolumnenlangen Beiträgen meinungsfokussierter und plakativer. Dabei kann unterstellt werden, dass seine Aussagen und Vorstellungen zum Literaturhaus allgemein ebenso für seine Arbeit als Literaturhaus-Geschäftsführer maßgeblich sind. Die Debatte, ja Polemik, zur sogenannten Wasserglaslesung558 soll an dieser Stelle als Selbstzeugnis für Rainer Moritz' Programmplanung im Literaturhaus Hamburg gelesen werden: Er plädiert für kontemplative Lesungen, bei denen „das Eigentliche, der Text [...] im Zentrum steht“559 und attestiert einen Fehlschluss, wenn davon ausgegangen werde, dass nur das sogenannte ,Event ${ }^{6}$ die Lesung am Leben erhalten könne - ,wie die Entwicklung zeigt, da das literaturaffine Publikum einer solchen Überinstrumentalisierung rasch überdrüssig wird“. .560 Dies heißt für ihn nicht, dass es nicht wichtig wäre, immer neue Verbreitungsformen für literarisch bedeutsame Bücher zu finden, wie er im Band Literaturbetrieb in Deutschland bemerkt. ${ }^{561}$ Dabei ist aber nicht von innovativen Formaten im Literaturhaus die Rede, hingegen wird das Literaturhaus selbst als neue Verbreitungsform für Literatur verstanden, gar als „Bastion des Widerstands“562; auch als Widerstand gegen eine grundsätzliche Ablehnung ökonomisch erfolgreicher Titel: Moritz betont, dass das Literaturhaus sich nicht nur Nischen oder Experimentellem widmen, sondern aus der Fülle des Angebots das literarisch Nennenswerte destillieren müsse. Die literarische Qualität sei hier oberstes Auswahlkriterium. Qualität nannte auch Ursula Keller als wichtigsten Faktor für die Programmauswahl. Unter qualitativ guter Literatur versteht die jeweilige Leitung also das, was sie im Literaturhaus-Programm unterbringt.

Direkt nach dem Wechsel von Ursula Keller zu Rainer Moritz wurde eine zusätzliche unterhaltungsorientierte Seite des Programms in Aussicht gestellt. In späteren Äußerungen, und mit einem anderen Gegenüber, überwog bei Moritz das konzentrierte Interesse am Text und am Gespräch, wobei ein größeres Publikum willkommen sei. In diesem Sinne repräsentiert Moritz ein stärker publikumsorientiertes Literaturhaus als seine Vorgängerin. Während ihm an einem heterogenen, viele Zielgruppen ansprechenden Programm liegt, vertrat sie ein stark inhaltlichkonzeptuell ausgerichtetes Haus. Rainer Moritz, selbst Literaturkritiker, betont mehr den Service des Literaturhauses, durch die Titelauswahl den Besucher*innen Orien-

\footnotetext{
557 Vgl. Rainer Moritz zitiert nach: Grund 2004.

558 Auf die dem kolumenhaften Erscheinungsformat des Branchenblatts angepasste Meinungsdiskussion von Stephan Porombka und Rainer Moritz gehe ich an dieser Stelle nicht weiter ein. Nachzulesen sind die drei Beiträge (und die begleitende Diskussion) online auf buchreport.de, vgl. in Erscheinungsreihenfolge Porombka: „Hat die“, Moritz: „Die Verteidigung“, Porombka: „Sturm aufs“.

559 Moritz: „Die Verteidigung“.

${ }^{560}$ Ebd.

${ }^{561}$ Vgl. Moritz 2009, S. 128.

562 Ebd., S. 127.
} 
tierung im Buchmarkt anzubieten. Ursula Keller mit ihrem Theaterhintergrund plädierte eher für die Verbindung der Kulturbereiche.

An dem Dargelegten lässt sich zum einen veranschaulichen, wie verschieden die Einzelpersonen das Literaturhaus zu führen beabsichtigen, dass die Gestaltung des Literaturhauses also entscheidend von der Leitung abhängt. Zum anderen demonstriert das Sprechen dieser beiden für Typen stehenden Literaturhaus-Beteiligten einen überindividuellen Wandel der Funktion und Position der Institution insgesamt. Gegen den Vorwurf, zu ,elitär ${ }^{\varsigma}$ zu agieren, hat es genauso zu kämpfen wie dagegen, zu ,kommerziell‘ zu sein. Diese Hypothese zur ,Mischkalkulation` wurde schon im vorherigen Großkapitel aufgestellt und nun mit ersten konkreten Aussagen gestützt. ${ }^{53}$ Die Absicht beziehungsweise Notwendigkeit, nicht nur ein Nischenprogramm zu kuratieren - wobei ,Nische` neutral, nicht despektierlich gemeint ist -, lässt sich unter anderem durch die Annahme begründen, dass das Literaturbaus Hamburg als literarische Einrichtung in der Stadt neben anderen Veranstaltern bestehen will. Dabei hat sich der Literaturveranstaltungsbetrieb als eigenständiger Bereich entwickelt, sodass es im Literaturhaus weniger um eine Durchmischung der Kunstausdrucksformen, sondern mehr um eine Konzentration auf den Buchbereich geht - was natürlich nicht bedeutet, dass es ausschließlich in einem engeren Sinne Literarisches gäbe.

Es lässt sich resümieren, dass die Positionierung des Literaturhauses von der jeweiligen Führung abhängt, was die Literaturhaus-Vereine bei Personalwechseln jedoch mitbestimmen können. Da diese nicht nur ein ästhetisches Interesse vertreten, sondern beabsichtigen, das Literaturhaus erfolgreich weiterzuführen, lassen sich die programmatischen Schwerpunktsetzungen auch als zeitverhaftet und gegenwartsreflektierend deuten. Die in Zeitungsartikeln widergespiegelten herrschenden Einschätzungen zeigen, dass Christina Weiss „dem literarischen Programm eine recht avantgardistische Farbe“ 564 gegeben hat, Ursula Keller mehr auf interdisziplinäre Symposien sowie themenfokussierte Diskussionsrunden setzte und Rainer Moritz unterhaltungs- und besucherinteressierter plante. Aus den vorgestellten Beschreibungen und Selbstaussagen der Leitungspersonen ergeben sich also Hypothesen für die weitere Analyse.

${ }^{563}$ Vgl. Kapitel I 5.8, Abbildung 2.

564 Pröhl 1999, S. 25. 


\section{3 Literaturhaus Frankfurt - Ein Literaturhaus mit Standortwechsel}

Das dritte Literaturhaus in Deutschland eröffnete Ende 1991 in Frankfurt. Die Idee kam 1989 auf, als auch über Frankfurts Position als Literaturstadt diskutiert wurde. ${ }^{565}$ Noch im selben Jahr gründete sich der Verein Literaturhaus Frankfurt, der ähnlich wie der Trägerverein des Literaturhauses Hamburg strukturiert ist. Er wird vom Vorstand und einem Kuratorium repräsentiert. Mit einem erhöhten Jahresbeitrag können Mitglieder zu Fördermitglieder werden, auch Mitgliedschaften für Firmen sind möglich. Der Verein besteht aber vor allem aus Privatpersonen. Auch in Frankfurt wurde das Projekt Literaturhaus mit städtischer Unterstützung realisiert. Insbesondere der damalige SPD-Kulturdezernent Hilmar Hoffmann, der in Deutschland die Idee der kulturellen Teilhabe prägte, ${ }^{566}$ setzte sich für das Literaturhaus ein.

\section{3.1 Soziogeografische Verortung in Frankfurt}

Frankfurt rangiert mit seinen rund 730.000 Bewohnern zwar hinter den vier deutschen Millionenstädten - Berlin, Hamburg, München und Köln -, gehört aber zu den größten Städten Deutschlands. ${ }^{567}$ Die Metropolregion Rhein-Main erweitert das direkte Einzugsgebiet außerdem um ein Vielfaches. Seine zentrale Lage unter anderem mit dem bedeutenden internationalen Flughafen macht die Stadt für Tourist*innen interessant. Besonders ist ihr Status als Messe- und Handelsstadt. Nachdem Bonn im Jahr 1949 die Wahl zum Regierungssitz der Bundesrepublik gegen Frankfurt gewonnen hatte, reifte Frankfurt mit dem Sitz der Börse und sich ansiedelnden Banken und Unternehmen zu Deutschlands Finanzzentrum heran. Dies bringt nicht nur mit sich, dass die Bewohner*innen aus unterschiedlichsten Regionen stammen, sondern auch, dass viele Menschen nur temporär in Frankfurt leben. Aufgrund der finanzstarken Firmen und Dienstleister finden sich in der Stadt private Förderer, die ihr Geld in den Kulturbetrieb investieren (können).

\section{3.1.1 Weitere Kultureinrichtungen in Frankfurt}

Im Literaturbetrieb ist Frankfurt insbesondere als Messestadt bekannt. Die Frankfurter Buchmesse ist das weltgrößte Branchentreffen. Sie versammelt dementsprechend einmal im Jahr verschiedenste Buchakteur*innen aus diversen Ländern der Welt. In Frankfurt werden im Oktober zahlreiche Lizenzen gehandelt und internationale Verträge geschlossen. Es geht bei der Messe nicht nur um eine Präsentation der Neuerscheinungen und darum, Kontakte zu knüpfen, sondern auch darum, Geschäfte zu machen. Wegen ihrer Größe und Wichtigkeit für den internationalen Markt ist die Buchmesse in Frankfurt kaum zum Beispiel mit der Leipziger Buch-

\footnotetext{
565 Vgl. z. B. sb. 1989.

566 Vgl. Kapitel I 4.2.6.

${ }^{567}$ Ende Juni 2016 war eine Einwohnerzahl von 727.232 verzeichnet, vgl. „Einwohnerinnen und“, Stadt Frankfurt, Bürgeramt, Statistik und Wahlen, S. 1.
} 
messe im Frühjahr oder der Göteborger Buchmesse im September zu vergleichen. Die Buchmesse in Leipzig richtet sich stärker direkt an Leser*innen, ${ }^{568}$ Bokmässan Göteborg wird vor allem zum skandinavischen Forum.

Die lokale Sichtbarkeit der, Welt des Lesens' in der umgebenden Stadt ist in Frankfurt gegeben. Da das Messegelände in Frankfurt nicht randstädtisch, sondern eine S-/U-Bahn-Station vom Hauptbahnhof entfernt liegt, wird das Ausmaß des Literaturbetriebs in der Stadt plastisch. Zahlreiche Veranstaltungen finden statt, sodass auch für die nicht-direkt Involvierten Literatur und Bücher nicht zu übersehen sind. Das Literaturhaus partizipiert an diesem literarischen Großereignis: ${ }^{569}$ Es präsentiert in seinem Programm Literatur des jeweiligen Buchmesse-Gastlandes und wird mit Verlagsempfängen und Partys an mehreren Messeabenden zum Treffpunkt für Verleger*innen, Autor*innen, Buchhändler*innen, Veranstalter*innen und Leser*innen. Im Vorfeld stellen dort ferner die Nominierten der Shortlist für den Deutschen Buchpreis ihre Bücher vor.

Bei der offiziellen Eröffnung der Buchmesse wird seit seiner ersten Verleihung 2005 der Deutsche Buchpreis überreicht sowie zu ihrem Ende seit 1951 der Friedenspreis des Deutschen Buchhandels in der Paulskirche vergeben wird. Verantwortet werden diese beiden auf unterschiedliche Weise wichtigen Literaturpreise vom ebenso in Frankfurt ansässigen Börsenverein des Deutschen Buchbandels e. V., dem Dachverband für Verlage, den Buchhandel und den Zwischenbuchhandel. Der Bundesverband sitzt im Haus des Buches im Frankfurter Zentrum. Wie im vorherigen Kapitel erwähnt, residiert einer seiner Regionalverbände im Literaturbaus Hamburg. An der Bezeichnung „Haus des Buches' lässt sich der klare Bezug zum Produkt Buch ablesen, während ,Literaturhaus' deutlicher auf die Texte abzielt.

Dass Frankfurt als Literaturstadt gilt, liegt zum Großteil an der Buchmesse, doch mit dem Börsenverein des Deutschen Buchhandels und der im gleichen Haus situierten Unternehmenstochter $M V B$ - Marketing- und Verlagsservice des Buchhandels GmbH, die die Messe organisiert, sind ganzjährig Buchmarktakteur*innen in der Stadt. Zu nennen sind außerdem mit der Frankfurter Allgemeinen Zeitung, der Frankfurter Allgemeinen Sonntagszeitung und der Frankfurter Rundschau Presseorgane mit überregionalen Feuilletons. Hinzu kommt, dass neben der Deutschen Nationalbibliothek renommierte literarische Verlage mit Frankfurt verbunden sind. Der Wegzug des Subrkamp Verlages ${ }^{570}$ nach Berlin ließ 2010 die Kulturverantwortlichen der Stadt fürchten, dass damit die literarische Bedeutung Frankfurts sinken würde, weil ein weiterer Akteur in die auf diese Weise nachweislich relevantere Kulturmetropole Berlin abgewandert sei. ${ }^{571}$

568 Die Leipriger Buchmesse setzt noch stärker als die business-fokussierte Frankfurter Version auf das Angebot für das Nicht-Fachpublikum und präsentiert mit Leipzig liest! - Werbeaussagen zufolge - Europas größtes Lesefest.

569 Auch Literaturhäuser in anderen Städten versuchen, von aufmerksamkeitsintensiven Ereignissen wie Literaturfestivals zu profitieren, indem sie kooperieren und sich gerade nicht verwehren, zum Beispiel das Literaturhaus Köln mit dem breitenwirksamen Festival lit.COLOGNE und das Literarische Zentrum Göttingen mit dem Göttinger Literaturherbst.

570 Der Verlag wurde 1950 von Peter Suhrkamp gegründet und entstand durch eine Abspaltung vom S. Fischer Verlag.

${ }^{571}$ Dies hat sich bisher nicht direkt bewiesen. Die Diskussion darüber bezeugt vielmehr die Bedeutung des Verlags für das Ansehen Frankfurts als Literaturstadt. Der Wegzug des berühmten Verlags könnte als Zeichen dafür gedeutet werden, dass die Stadt eben nicht (mehr) ein Zentrum für den Literaturbetrieb ist, sondern sich alles in Berlin bündelt. Am 14.02.2009 fand im Literaturhaus Frankfurt aus gegebenem Anlass eine Podiumsdiskussion zum Thema Frankfurt obne Subrkamp - na und? Frankfurter Reaktionen mit 
Nach dem Wegzug von Subrkamp sind noch der ebenfalls seit 1950 in Frankfurt sitzende Publikumsverlag S. Fischer Verlag ${ }^{572}$ und kleinere renommierte Verlage wie weiss.books und die Frankfurter Verlagsanstalt in der Stadt aktiv.

Wie in jeder deutschen Großstadt präsentieren in Frankfurt Buchhandlungen, die Zentralbibliothek, unabhängige Initiativen und Kultureinrichtungen nicht-verlagsgebundene Programme. Zu nennen sind außerdem vom Kulturamt der Stadt initiierte Literaturfestivals, die am Ende dieses Abschnitts Thema sind. Die großen Literaturveranstalter, die sich von der Bibliothek darin unterscheiden, dass es ihre vorrangige Aufgabe ist, ein Veranstaltungsangebot zu kuratieren, sind in Frankfurt neben dem Literaturbaus Frankfurt e. V. Romanfabrik e. V. und Hessisches Literaturforum im Mousonturm e. V. Die beiden letztgenannten Vereine wurden 1985 gegründet, „zu einer Zeit, als es für Literaten und Künstler noch keinen festen Ort in Frankfurt gab und noch niemand an ein Literaturhaus dachte“"573. Die Romanfabrik und das Hessische Literaturforum, das zunächst Hessisches Literaturbüro hieß, entstanden eher aus dem Kreis von Autor*innen und sind im Kontext der Literaturbüros der 1980er-Jahre zu verstehen, die zunächst vor allem regionale Literatur fokussierten. Dass auch sie sich als beachtete Vermittlungsorte profiliert haben, entspricht der im ersten Kapitel dargelegten Entwicklung der Literaturbüros, die sich zunächst besonders um die Belange von Schriftsteller*innen kümmerten, hin zu Publikumsorten. Wie in Berlin existieren in Frankfurt mehrere Organisationen nebeneinander, auf die sich der Funktionsbegriff ,Literaturhaus' anwenden ließe. Allerdings findet eine derartige Zuschreibung dort selten statt, was gegebenenfalls darauf zurückzuführen ist, dass das Literaturhaus Frankfurt stärker als das Literaturbaus Berlin den Anspruch erhebt, das Literaturhaus für die Stadt zu sein - was in Berlin angesichts der Größe und stärkeren Verteilung auf mehrere Stadtviertel weniger passt.

Die bisher genannten Einrichtungen kümmern sich in erster Linie um die Vermittlung von Gegenwartsliteratur. Daneben sei der Komplex aus Goethe-Haus, GoetheMuseum und vor allem dem neu entstehenden Deutschen Romantik-Museum zu nennen. Der Bau des „Erinnerungsort[es]“ für die „Romantik als Schlüsselepoche der deutschen und europäischen Geistesgeschichte" ${ }^{574}$ startete im Sommer 2016, die Eröffnung ist für 2020 avisiert. Die Planungen begannen 2011 nach dem Auszug des Börsenvereins des Deutschen Buchbandels aus dem an das Goethe-Haus angrenzenden Gebäude im Großen Hirschgraben. Schon das Goethe-Haus bietet Veranstaltungen an, im Deutschen Romantik-Museum wird die Zahl gewiss noch ansteigen und auch mit einer Ansprache eines nichtakademischen Publikums sollte bei der Größe des Projekts

dem Kulturdezernenten Frankfurts Felix Semmelroth, den Journalisten Hubert Spiegel und Arno Widmann sowie den Autor*innen Eva Demski, Wilhelm Genazino und Andreas Maier statt. Der Literaturkritiker Martin Lüdke moderierte. Die Veranstaltung erschien nicht im gedruckten Programmheft (FF 200901/02), sondern wurde mit einem einfachen Handzettel beworben (FF 2009-02-14-Suhrkamp); es ist also davon auszugehen, dass dieser Termin erst nach Drucklegung des Januar-Februar-Leporellos vereinbart wurde.

572 Der S. Fischer Verlag, gegründet 1886, machte sich einen Namen zum Beispiel mit der Publikation der Zeitschrift Neue Rundschau, des Werkes Thomas Manns oder der deutschen Übersetzungen Henrik Ibsens. Zur Geschichte des Verlags vgl. Stach 2003.

573 „Geschichte“, Romanfabrik.

574 „Das Projekt“, Deutsches Romantik-Museum. 
verstärkt zu rechnen sein. Der Schwerpunkt wird jedoch auf der Vermittlung romantischer Texte und Handschriften liegen, eine Konkurrenz für das Literaturhaus ist inhaltlich nicht zu erwarten. Dennoch entsteht mit dem umfassend angelegten und auch vom Bund mitfinanzierten Museum ein starker Akteur in Frankfurt, der die Aufmerksamkeit eines literaturgeschichtlich interessierten Publikums einfordert, das sich mit dem des Literaturhauses überschneidet.

Neben den dezidiert literarischen Einrichtungen sind in Frankfurt die fußläufig vom Hauptbahnhof erreichbaren Städtischen Bühnen mit Schauspiel Frankfurt und Oper Frankfurt ebenso wie Museen wichtige Akteur*innen. Am Museumsufer auf der anderen Seite des Mains finden sich unter anderen das bekannte Kunstmuseum Städel Museum, das Liebieghaus und das Deutsche Architekturmuseum. Direkt am Römerberg, auf dem das Rathaus steht, sind der Frankfurter Kunstverein und die Schirn Kunsthalle Frankfurt ansässig. Unweit entfernt steht ein Gebäude des $M M K-M u s e u m$ für Moderne Kunst. Der Vollständigkeit halber sei ebenso eines der größten Naturkundemuseen Europas erwähnt, das Senckenberg Naturmuseum Frankfurt im Stadtteil Bockenheim, in der Nähe des ehemaligen Universitätscampus und verbleibenden Standortes der Universitätsbibliothek Johann Christian Senckenberg - und unweit des ehemaligen Literaturbauses Frankfurt.

\section{3.1.2 Exkurs - Offener Brief der Literaturhaus-Leitung 2015}

Die drei genannten institutionell geförderten Literaturvermittlungseinrichtungen Literaturhaus Frankfurt e. V., Romanfabrik e. V. und Hessisches Literaturforum im Mousonturm e. $V$. bekamen 2015 zusammen etwa 435.000 Euro aus dem städtischen Etat, wobei das Literaturhaus den höchsten Betrag erhielt. ${ }^{575}$ Privates Mäzenatentum bleibt also für die Förderung zentral. Diese öffentliche Bezuschussung des Literaturhauses, die den meisten Literaturhäusern in Deutschland - wenn auch in unterschiedlichem Ausmaß - zugeführt wird, ist als ein Beleg für die kommunale Wertschätzung der Einrichtung einzuordnen. Dass es sich hier nicht um ein einseitiges Abhängigkeitsverhältnis handelt, sondern auch die Stadt nicht auf diese Literaturvermittlungseinrichtung verzichten will, demonstriert beispielsweise der offensive Vorstoß Hauke Hückstädts auf die Frankfurter Kulturpolitik in Gestalt eines offenen Briefes im Februar 2015. Dieser Einsatz wäre gar nicht möglich gewesen, wenn das Literaturhaus nicht ein gewisses Standing in der Stadt hätte, denn, dass dieser provozierende Schritt überhaupt angetreten - und ernst genommen - wurde, ist nur aufgrund der Reputation des Literaturbauses Frankfurt denkbar. Darin steckt die Selbstannahme, dass das Literaturhaus ein für das kulturelle Leben Frankfurts wichtiger Akteur ist und zum guten Ruf der Stadt insgesamt beiträgt. Die Diskussion wurde überregional geführt.

\footnotetext{
${ }^{575}$ Für eine gute Übersicht über die anderen Literaturvermittlungseinrichtungen in Frankfurt vgl. Balke 2015. Florian Balke stellt zudem heraus, dass auch auf Einladung der Universität in den letzten Jahren viele Schriftsteller*innen in Frankfurt aufgetreten seien, also weitere Gastgeber*innen zu Literaturveranstaltungen einladen.
} 
In diesem in der Frankfurter Allgemeinen Zeitung abgedruckten Schreiben an den Kulturdezernenten Felix Semmelroth ${ }^{576}$ kritisierte Hauke Hückstädt unter anderem, dass das Kulturamt der Stadt zunehmend selbst als Literaturveranstalter agiert. Es ist ein Spezifikum in Frankfurt, dass die Stadt selbst aktiv Veranstaltungen anbietet. Die Veranstaltungen der Stadt werden nicht aus dem gleichen Etat finanziert wie die geförderten Projekte. ${ }^{577}$ Doch ließen sich die Beträge aus diesem Zusatzbudget, das sich 2015 auf 131.000 Euro belief, ${ }^{578}$ so die Argumentation Hückstädts, ja auch zur Förderung von anderen Projekten nutzen. Als Hintergrund ist es wichtig zu wissen, dass Kulturämter in anderen Städten in erster Linie als Förderer fungieren und Projekte und Initiativen unterstützen, die an das Amt herangetragen werden, sodass sie selbst nicht mit einem konkurrierenden Angebot beitragen. „Im Normalfall sind Kulturreferenten Ermöglicher, nicht selbst Intendanten. "579

Als problematisch sieht Hauke Hückstädt in dem Brief vor allem, wie das Literaturreferat das zur Verfügung stehende Geld einsetzt. Insbesondere das Festival Open Books, das seit 2009 parallel zur Frankfurter Buchmesse stattfindet, „schadet dem Literaturhaus außerdem durch massive kostenlose Angebote“580, merkt Hückstädt an. In diesem Format werden, während die Aufmerksamkeit für Literatur in Frankfurt am größten sei, zahlreiche Neuerscheinungen mit Verlagsunterstützung präsentiert - ohne Eintrittsgelder zu erheben und ohne die Autor*innen finanziell zu honorieren. Er verweist auf weitere Aktivitäten des Kulturamtes, die hier kurz eingeführt werden sollen: Außer Open Books richtet das Kulturamt - ebenfalls zur Buchmesse Literatur im Römer sowie Frankfurter Premieren und im Wechsel stattfindend die Festivals literaTurm und Frankfurter Lyriktage aus. Das Literaturreferat übernimmt folglich Funktionen, für die es eigentlich die Literatureinrichtungen unterstützt. Für Hückstädt führt dies zu folgendem Schluss: „Das Literaturhaus stößt auf Konkurrenzverhalten und aktive Behinderung der eigenen Arbeit auf dem Markt der Neuerscheinungen und ihrer Autoren durch das Literaturreferat.“"581 Ferner versuche die Stadt, mit der Reihe Frankfurter Premieren, die zunächst nur Frankfurter Neuerscheinungen vorführte, die Historische Villa Metzler am Museumsufer als einen neuen Literaturvermittlungsort zu etablieren. Damit führe sie erneut weg von den bestehenden Orten wie Mousonturm, Romanfabrik oder Literaturbaus Frankfurt. Trotz Kooperation $^{582}$ torpediere dies die Arbeit der finanziell eingeschränkten Veranstalter*innen, bei der die Organisator*innen die Eintrittseinnahmen benötigten und auch für die auftretenden Gäste eine Entlohnung vorgesehen sei.

Hückstädts Ausführungen lassen sich wie folgt ausweiten: Die Stadt konkurriert mit anderen Veranstaltern damit nicht nur um Publikum und Schriftsteller*innen denn auch die Verlage möchten gegebenenfalls lieber die Einladung der Stadt nicht absagen als die einer anderen, minder mächtigen Einrichtung. Das Literaturhaus sieht sich dem offenen Brief zufolge durch Open Books auf zwei Weisen bedroht -

576 Der CDU-Politiker war seit 2006 im Amt und trat 2016 vorzeitig zurück; seitdem ist Ina Hartwig (SPD), vorher vor allem als Literaturkritikerin tätig, Kulturdezernentin der Stadt Frankfurt.

577 Vgl. „Literaturförderung“, Kulturamt Frankfurt am Main.

578 Vgl. Balke 2015.

${ }^{579}$ Hintermeier 2015.

${ }^{580}$ Hückstädt 2015.

581 Ebd.

582 Die Abschlussparty beispielsweise von Open Books findet seit 2010 am Buchmesse-Samstag im Literaturhaus statt. 
erstens könnte das Publikum abwandern, weil es mit den üblichen Konditionen, Eintritt für Lesungen zu zahlen, nicht mehr einverstanden sei. Zweitens kommt indirekt hinzu, dass das Literaturhaus Frankfurt finanziell ganz entscheidend mit den kommunalen Zuschüssen kalkuliert, es also an diese Einnahmen gebunden ist. Diese Dimension der Abhängigkeit liegt in anderen Literaturhaus-Städten auch vor. Speziell ist in Frankfurt, dass der Förderer, also das Literaturreferat der Stadt Frankfurt, mit eigenen, finanziell abgesicherten Veranstaltungen in direkte Konkurrenz zu den Literaturveranstaltern tritt und dabei privilegiert ist. ${ }^{583}$ Diese Konstellation enthält Konfliktpotential, wie Felicitas von Lovenberg schon 2009 in einem Zeitungsartikel anmerkt. Darin schreibt sie, dass man in der „Literaturreferentin mit eigenen Veranstaltungen durchaus eine Rivalin des Hauses sehen kann. “584

Der Brief löste Debatten zur Arbeit der Literaturveranstalter und ihrem Verhältnis zur Stadt aus, auch der Kulturdezernent reagierte auf die Anfrage nach der Zukunft des Literaturhauses in Frankfurt. An dieser Diskussion zeigt sich auf andere Weise der gestiegene Druck auf die Literaturhäuser, der oben schon im Zusammenhang mit den Leitungswechseln thematisiert wurde. „Wir sind auch durch den gesteigerten Output des Dezernats gezwungen, auf Auslastung und also Popularität zu setzen und verlieren dadurch an Profil “585, resümiert Hückstädt. Auslegen lassen sich diese Bemerkungen so: Die Konkurrenzsituation führt dazu, dass das Literaturhaus-Programm sich stärker daran orientieren muss, was viele Besucher*innen anlocken wird, was gegebenenfalls auf Kosten der individuellen Ausrichtung der Einrichtung gehe. Die finanzielle Ausstattung ist auf das Engste mit der Programmgestaltung gekoppelt. Im Zusammenhang mit der Verortung des Literaturhauses in der Stadt ist es wichtig, dies noch einmal zu betonen.

Aus Sicht der Stadt ist die Förderungspolitik und die Initiative zu eigenen Veranstaltungen nachvollziehbar, denn wie die Literaturreferentin Sonja Vandenrath in ihrer schon mehrfach zitierten Doktorarbeit festhält, sei zu beobachten,

daß auch bei öffentlichen Geldgebern die Neigung einer zu Unternehmen homologen Förderpolitik festzustellen ist und sie Förderung mehr und mehr als Medium der Selbstdarstellung verstehen. Dies führt zu einer Selektion nach Aufmerksamkeitseffekten und nicht nach Bedarfs- wie Qualitätskriterien. ${ }^{586}$

Allerdings wirken bei den vom Literaturreferat der Stadt Frankfurt initiierten Projekten Qualitätskriterien augenscheinlich mit.

Der offene Brief ist als Material für die wissenschaftliche Auseinandersetzung mit Praktiken ferner deshalb interessant, weil die Bemerkungen Hückstädts auch so zu interpretieren sind, dass das Kulturamt einen ,Verstoß' gegen die Literaturveranstaltungspraxis begehe, weil dort zentrale konventionalisierte Handlungen - kurz: Wer zahlt wem was? - verbalisiert werden. In der Regel wird selten ausgesprochen, wie und auf welcher Vereinbarungsgrundlage - ,das macht man so' - tatsächlich gehandelt wird. Hier war der Brief entsprechend Anlass, am konkreten Beispiel zu veran-

\footnotetext{
583 Die Vokabeln aus dem Wortfeld ,Macht‘, die in diesem Abschnitt verwendet werden mussten, zeigen, dass Theorien, die sich mit ,Macht ${ }^{`}$ auseinandersetzen, für das Verständnis der Institution ,Literaturhaus“ grundsätzlich sind. Sie sollen aber in dieser Arbeit nicht den Schwerpunkt bilden, deshalb wende ich an dieser Stelle nicht z. B. Bourdieus Vokabular an.

${ }^{584}$ Lovenberg 2009.

585 Hückstädt 2015.

586 Vandenrath 2006, S. 204.
} 
schaulichen, in welch angespanntem Verhältnis öffentliche Förderungseinrichtungen und private Veranstalter*innen stehen (können).

\section{3.2 Standort(e) - Vom Westend ins Ostend}

Das Literaturhaus Frankfurt war nicht schon immer am aktuellen Ort ansässig, sondern wechselte seinen Standort. Zunächst residierte das Literaturhaus im Stadtteil Westend. 2005 zog der Literaturhaus-Verein vom Westen in den Osten der Stadt. Aufgrund der in dieser Arbeit zentral gesetzten Verbindung von Gebäude, Standort und inhaltlicher Konzeption ist der Umzug besonders bemerkenswert. Der Name ,Literaturhaus', das wird deutlich, bezieht sich eben nicht nur auf das Gebäude, sondern auch auf die Raumnutzung - so kann ein anderer Bau zum ,Literaturhaus werden und das alte bleibt das ,ehemalige Literaturhaus'. Ein anderes Beispiel in Deutschland ist das Literaturbaus Köln, das bereits zweimal umzog und seit $2014 \mathrm{im}$ Haus Bachem im Stadtzentrum seinen Sitz hat. In Freiburg war der Übergang des Literaturbüros Freiburg in neue Räume in der Innenstadt mit einer finanziellen Aufstockung und einer Umbenennung in Literaturhaus Freiburg verbunden.

\section{3.2.1 Bockenheimer Landstraße 102 (1991-2005)}

1991 mietete die Stadt Frankfurt nach längerer Suche die leerstehende denkmalgeschützte neo-klassizistische Villa mit der Adresse Bockenheimer Landstraße $102 \mathrm{im}$ Westend, ${ }^{587}$ um dort das Literaturbaus Frankefurt zu eröffnen. ${ }^{588}$ In unmittelbarer Nähe befand sich bis zu dessen schrittweisem Umzug zum weiter nördlich liegenden Campus Westend das Zentrum der Goethe-Universität Frankfurt am Main. Diese Gegend lag im Kern des sogenannten ,Frankfurter Häuserkampfes' der späten 1960er- und 1970er-Jahre, bei dem die Besetzung von Wohnhäusern diese vor dem Abriss und der Umwandlung in Bürohochhäuser des Finanzsektors bewahren sollte. ${ }^{589}$ Vor allem der weitläufige „großbürgerliche Zuschnitt vieler Wohnungen“590, der der ehemaligen sozialen Struktur des Viertels entspricht, prädestinierte „das Westend seit den späten 1960er Jahren zum anti-bürgerlichen Experimentierfeld“591. Das Literaturhaus bezog in einem Haus Quartier, das nicht abgerissen wurde. Mit den Umbauten hat sich das Viertel seit den 1970er-Jahren deutlich gewandelt; es stehen dort moderne Hochhäuser neben alten Villen, die ehemalige Wohngegend ist zu einem Dienstleister- und Bankenzentrum geworden.

\footnotetext{
${ }^{587}$ Nach den Erbauern Anton und Ines Hoffmann, die 1912 einzogen, wird das Haus auch Villa Hoffmann und nach den späteren Besitzern (1918-1937) und Zwangsenteigneten Albert und Margarethe Sondheimer auch Villa Sondheimer genannt; 1950 erhielten die Töchter Sondheimer das Haus von der Stadt Frankfurt zurück, sie verkauften es 1952. In den 1980er-Jahren hatte eine Werbeagentur ihren Sitz in der Villa.

${ }^{588} \mathrm{Im}$ Gespräch war längere Zeit das Holz̧hausenschlösschen, für das es aber auch andere Interessent*innen gab und das die Frankefurter Bürgerstiftung letztlich übernahm, vgl. Zirlewagen 2014, S. 154-155.

${ }^{589}$ Ausführlich zum „Häuserkampf“ vgl. Führer 2016, S. 101-175.

${ }^{590}$ Ebd., S. 129.

${ }^{591}$ Ebd.
} 
Der Begutachtung wert ist neben dem neuen Standort des Literaturhauses die Entwicklung des Hauses in der Bockenheimer Landstraße nach dem Auszug des Literaturhaus-Vereins. ${ }^{592}$ In der Regel findet die Verwendung des Gebäudes vor dem Einzug des Literaturhauses Erwähnung, in diesem Fall wird das Literaturhaus aber zum historischen Beispiel. Das Gebäude in der Bockenheimer Landstraße 102 nutzten nach dem Auszug des Literaturhauses erst kleinere Kultureinrichtungen. Bemerkenswert ist, dass das Literaturbaus-Café zunächst am alten Standort erhalten blieb und versuchte, mit eigenem Angebot den Ort zu erhalten. Erst 2009 schloss das Café endgültig - vier Jahre nach dem Auszug des Literaturhaus-Vereins und dem damit verbundenen Verlust des Gebäudenamens Literaturbaus.

2012 kaufte letztlich die KfW Bankengruppe das Haus. Es soll als Kultur-, Veranstaltungs- und Schulungszentrum genutzt werden. Dabei wird direkt auf die Prägung durch das Literaturhaus verwiesen: Mit der notwendigen denkmalschutzgerechten Sanierung und Wiedereröffnung der Villa werde Frankfurter Bürger*innen „,ihre traditionsreiche Plattform für künstlerischen und kulturellen Dialog wieder zugänglich“"593 gemacht. Die Nutzung als Literaturhaus hat den Ort zu einem Ort der Kulturvermittlung gemacht, der für nachfolgende Organisationen Anknüpfungsmöglichkeiten bietet. Dies bezeugt ferner, dass das Literaturhaus Frankfurt in der Stadt so weit etabliert ist, dass auf der Website der $K f W$ der Verweis auf das Literaturhaus ohne weitere Erklärungen ausreicht, um zu vermitteln, dass es sich bei dem Haus um einen historisch für den Kulturbetrieb relevanten Ort handelt - obwohl die Geschichte des Literaturhaus-Vereins selbst noch nicht alt ist. Die Villa im Westend nutzt durch die Literaturhaus-Referenz dessen Renommee zur eigenen Erhöhung; diese Würdigung kommt wiederum dem aktiven Literaturhaus, jetzt im Ostend situiert, zugute.

\section{3.2.2 Schöne Aussicht 2 (seit 2005)}

Im Sommer 2005 zog das Literaturbaus Frankfurt in die wiedererrichtete Stadtbibliothek direkt am Main mit der Adresse Schöne Aussicht 2. Spenden der gemeinnützigen Hertie-Stiftung und der Landesbank. Hessen-Tbüringen ermöglichten der Stadt Frankfurt den Kauf der alten Stadtbibliothek, sodass sie dem Literaturbaus Frankfurt e. V. mietfrei zur Verfügung gestellt werden konnte. Damit wurde die Sichtbarkeit in repräsentativem Gebäude erhöht und die Miete, die in der Bockenheimer Landstraße sehr hoch war, 594 eingespart. Die Instandhaltung des größeren Gebäudes verursacht aber nicht unbedingt weniger Ausgaben als der erste Standort.

Das Literaturhaus Frankfurt liegt jetzt im östlichen Teil des Zentrums, eine Lage, die durch die Umgestaltung des Ostends an Osthafen und Großmarkthalle mehr frequen-

\footnotetext{
592 Diese ehemalige Literaturhaus-Stätte ist heute nicht mehr begehbar. Da ich bei den anderen Literaturhäusern ebenfalls den gegenwärtigen Zustand der Räume inspiziere, verzichte ich auf den Versuch einer ausführlichen Rekonstruktion des alten Literaturhauses in Frankfurt.

593 „Villa Bockenheimer“, KfW. „Das traditionsreiche Gebäude, in Frankfurt als ehemaliger Sitz des Literaturhauses bekannt, hat eine bewegte Geschichte. Nach langem Leerstand wird in der Villa 102 nach der Übernahme durch die KfW nun ein neues Zentrum für Kultur und Kreativität entstehen, das an den institutionellen Ruf des Gebäudes anknüpfen wird.“

${ }^{594} \mathrm{Vgl}$. Zirlewagen 2014, S. 159.
} 
tiert wird. Insbesondere durch die Errichtung des Hauptsitzes der Europäischen Zentralbank 2015 wurde das ehemalige Arbeiterviertel zu einem entsprechend hochpreisigen Wohnviertel umstrukturiert. Am Mainufer flanieren seitdem noch mehr Frankfurter*innen, aber auch Tourist*innen und andere temporäre Gäste. Das beim Einzug noch eher marginal gelegene Literaturhaus rückt damit weiter in den Stadtkern, der sich ausdehnt; möglicherweise entdecken also mehr Menschen ,zufällig das Literaturhaus.

Die historische Stadtbibliothek, gebaut von 1820 bis 1825 und 1892 deutlich erweitert, wurde durch Bombenangriffe 1943 und 1944 bis auf den markanten Portikus zerstört. ${ }^{595}$ Pläne, diesen zum Gefallenendenkmal umzugestalten, wurden nicht umgesetzt. Ab 1986 ergänzte die Staatliche Hochschule für Bildende Künste - Städelschule die Ruine mit einem provisorischen Anbau, den sie unter dem Namen Portikus als Ausstellungsraum bekannt machte. ${ }^{596} 2002$ beschloss die Stadt Frankfurt, das gesamte Gebäude originalgetreu zu rekonstruieren und es als Literaturbaus Frankfurt wiederzubeleben. ${ }^{597}$ Bei dem klassizistischen Bau an der Schönen Aussicht 2 handelt es sich also um einen Neubau aus den 2000er-Jahren, allein der Portikus besteht seit dem frühen 19. Jahrhundert. Nicht wiederherstellbar war die Umgebung des Literaturhauses, die sich natürlich weiterent-wickelt hatte: Direkt hinter dem prächtigen Literaturbaus Frankfurt ragt ein in den 1970er-Jahren zweckmäßig errichteter 19-geschössiger Waschbetonturm empor, das Personalwohnheim des Hospitals zum beiligen Geist.

\section{Gestaltung des Literaturhauses Frankfurt}

Im Zuge des Wiederaufbaus der Alten Stadtbibliothek wurden die Räume an die Bedürfnisse des Literaturhaus-Vereins angepasst. Das Gebäude des Frankfurter Literaturhauses konnte ab 2005 mit Erfahrungen nach 14 Jahren am anderen Standort nach und nach eingerichtet werden. Dass dies nicht reibungslos geschah, sei erwähnt: Zunächst sorgte die schlechte Akustik im neuen Saal für Tonprobleme und Beschwerden bei den Veranstaltungen, sodass unter anderem mit Vorhängen nachjustiert werden musste, um den Hall zu minimieren. 598

Der neue Lesesaal im Erdgeschoss links ist der Hauptraum für Veranstaltungen. Auf 180 Quadratmetern finden maximal 200 der schlichten dunkelbraunen Konferenzstühle Platz. Den Saal mit zwei langen und zugunsten der Akustik mit schweren Vorhängen bestückten Fensterseiten, eine davon Richtung Main, weißen Decken, grünlich-türkis gestrichenen Wänden und Holzparkett beleuchten große, modernklassische Kronleuchter und Wandlampen. In diesem schnörkellosen Design mit knalligen Wandfarben und dunklen Holztüren sind auch die anderen Räume gestaltet. Die Bühne besteht zur flexiblen Nutzung aus variablen Elementen. Meistens steht sie mittig an der Kopfseite, während in Reihe bestuhlt ist. Vor einer Umgestaltung 2014 bildete das schwarz-weiße Logo des Literaturhauses den Bühnenhinter-

\footnotetext{
595 Zur Geschichte der Alten Stadtbibliothek vgl. Allwörden 2006. Auch auf der Website des Literaturhauses findet sich ein historischer Abriss.

${ }^{596}$ Diese Ausstellungshalle für zeitgenössische Kunst besteht in einem Gebäude auf der anderen Seite des Mains mit dem Namen Portikus weiterhin.

${ }^{597}$ Der Name Alte Stadtbibliothek bleibt als Name für das Gebäude erhalten.

598 Vgl. des. 2005.
} 
grund; aktuell erinnern Regale mit Büchern und zwei Bildschirmen, die bei Lesungen Titel und Cover des vorgestellten Buches oder kleinere Präsentationen zeigen, an Bücherwände - vermutlich an jene, die bei vielen Besucher*innen in den Wohnzimmern respektive in Bibliotheken stehen. Diese Kulisse schafft eine etwas intimere Atmosphäre, zieht die Blicke der Zuschauer*innen aber auch auf sich und lenkt mehr vom eigentlichen Bühnengeschehen ab.

Dass die Autorenbesuche als Aufführungen verstanden werden, legt das Autorenzimmer nahe, das vom Lesesaal abzweigt und ins Foyer führt. Der kleine Raum mit Ledersesseln fungiert als Backstage-Bereich für den Saal. Abseits des Lesungspublikums und der Restaurantbesucher*innen finden dort die Podiumsbeteiligten einen Rückzugsort.

Aus dem weitläufigen weiß gestrichenen, mit hellem Marmor gefliesten und mit bläulicher Decke ausgestatteten Foyer führt eine mittige zweiläufige Treppe nach oben. Nach dem Mittelpodest, auch Vestibül genannt, führt die Treppe auf beiden Wandseiten weiter. Der Blick der Eintretenden fällt auf einen Bildschirm auf dem Mittelpodest, der Werbung für die nächste Veranstaltung oder das tagesaktuelle Programm zeigt. Auch im Erdgeschoss finden sich Bildschirme, die unterschiedlich genutzt werden. Anders als bei Plakatwänden ist so eine schnelle Änderung möglich. Die schlichte, geradlinige Gestaltung der Räume kombiniert mit den Bildschirmen ist vergleichbar mit modernen Kunstmuseen, an deren Ästhetik das Frankfurter Kulturpublikum durch die Kunsthalle Schirn oder das Museum für Moderne Kunst gewöhnt ist.

Im ersten Stock des Literaturhauses Frankfurt liegen die Büros des Teams, aber auch weitere Veranstaltungsräume. Der Konferenzraum Salon Schöne Aussicht, gelb gestrichen, ist über das Kleine Foyer mit dem Lesekabinett verbunden. In diesem fensterlosen hohen Raum mit einem Rundbalkon zieren Bücherregale und -vitrinen die kräftig roten Wände. Hier sind signierte Bücher von allen Autor*innen, die zu Gast waren, ausgestellt, sodass der Raum Funktionen eines Gästebuchs übernimmt und sichtbar macht, wer und vor allem wie viele Bücher im Literaturhaus Frankfurt Thema waren. Der Saal wird auch für Veranstaltungen genutzt und lässt bis zu 100 Besucher*innen zu.

Außerdem gibt es im Obergeschoss einen Raum, der mit einer orange gestrichenen Wand, runden pinken und violetten Teppichen, einer 70er-Jahre-Polstergarnitur, Sesseln, großem Arbeitstisch und tiefhängenden Glühbirnen ausgestattet ist. Dieser Stilwechsel ist auf Gesammelte Untertreibungen zurückzuführen: „Ein Raum unsentimentalen Erinnerns“"599, den Tobias Rehberger und Michael Callies 2006 in Gedenken an den Frankfurter Kabarettisten und Schriftsteller Matthias Beltz (19452002) als ständige Installation einrichteten (FF 2006-06-07). Wechselnde Ausstellungen fanden früher im Literaturbaus Frankfurt statt; sie sind heute aus organisatorischen Gründen nicht mehr umsetzbar. Versuche, das Literaturhaus auch untertags zu bespielen, sind die Kopf \& Hörer Hörstation - ein Sessel mit integrierter Anlage, wo über Kopfhörer die hr2-kultur Hörbuchbestenliste läuft, die eine Veranstaltungsreihe

\footnotetext{
599 „Rundgang“, Literaturhaus Frankfurt. URL: literaturhaus-frankfurt.de/haus/rundgang/ (Stand: 30.07.2018). Der Raum kann auf Anfrage besichtigt, aber nicht gemietet werden. Hauseigene, geschlossene Veranstaltungen finden gelegentlich dort statt.
} 
im Literaturhaus begleitet - und eine Fläche, die Gedichte zum Mitnehmen anbietet, indem dort Texte auf Abreißzetteln hängen.

Das Literaturhaus Frankfurt bietet viel Platz. Die unterschiedlichen Veranstaltungsräume und vor allem der weitflächige Eingangsbereich machen verschiedene Nutzungen möglich. Anders als in den relativ engen Literaturhäusern in Berlin und Hamburg, denen der alte Standort des Literaturbauses Frankfurt viel ähnlicher war, ist dort eine freizügigere Raumgestaltung umsetzbar. Weniger pompös und repräsentativ ist das Literaturhaus Frankfurt aber keinesfalls. Im Gegenteil: Der Portikus und die Freiflächen im Haus lassen noch mehr einen Eindruck von ,heiligen Hallen' entstehen, die eine Eintrittshürde darstellen können. Dennoch sind hier mehr Optionen denkbar, die feste Raumbesetzung zu durchbrechen. Die geradlinig-klassische, elegante Einrichtung des Gebäudes ähnelt Litteraturbuset in Oslo mehr als den älteren Literaturhäusern Berlin oder Hamburg. Mit dem Umzug in ein neues Gebäude hat sich das Literaturbaus Frankfurt räumlich stärker von seinen Vorbildern gelöst und eigene Vorstellungen realisiert.

Im Unterschied jedoch zu den meisten Literaturhäusern finden sich im Literaturhaus Frankfurt, abgesehen vom Restaurant, keine weiteren Organisationen - nicht einmal eine Buchhandlung. Die Räume stehen gänzlich dem Literaturveranstalter zur Verfügung. Externe Veranstalter*innen können die vorzeigbaren Räume zwar mieten, doch ein alltägliches Arbeitsleben findet nur in den Literaturhaus Frankfurt-Büros statt und im Restaurant. „Ein Restaurant ist für uns Bestandteil des Gesamtkonzepts und wird es selbstverständlich auch in der neuen Bleibe geben!“ (FF 200507/09/10) formuliert die Leiterin Maria Gazzetti 2005 im Programmheft. Das Bezugsmodell, dass ein Literaturhaus einen gastronomischen Bereich aufweisen müsse, lässt sich schon zu Beginn des Literaturhauses, noch in der ersten Unterkunft, erkennen: „Das Literaturhaus Frankfurt will nicht nur literarisches Programm (seit Januar 1991) anbieten, sondern auch ein Ort der Kommunikation sein. Hierfür braucht es dringend sein Café, wie es die Literaturhäuser Berlin und Hamburg haben“ (FF 1991-10, beigefügter Flyer). ${ }^{600}$ In diesem Zitat kommt ebenfalls heraus, dass sich die Häuser aufeinander beziehen und eine gewisse Konkurrenz besteht. Und auch ohne gleich von ,Konkurrenz' zu sprechen, lässt sich damit die Annahme belegen, dass es von Beginn an eine Vorstellung von der Institution ,Literaturhaus gab, die zur Orientierung diente.

Für den Standort in der Bockenheimer Landstraße fand sich schließlich der Betreiber Franz Zlunka, der das Café noch weiter nutzte, als das Literaturhaus schon an die Schöne Aussicht gezogen war, weil er selbst diesen Umzug nicht hätte bezahlen können. ${ }^{601}$ Der Literaturhaus-Verein verpachtet in der Alten Stadtbibliothek die Räume nicht selbst und die Restauranträume sind sehr groß. Die Komplikationen mit den Mietern der Gastronomieräume, die im vorherigen Kapitel zum Literaturhaus Hamburg ausgeführt wurden, tauchen auch im Literaturhaus Frankfurt auf. Inzwischen fin-

600 Zunächst fand sich keine Finanzierung für das Café, deshalb organisierten die Betreiber eine Art Crowdfunding: „Da öffentliche Gelder nicht zur Verfügung stehen, muß eine private Finanzierung gefunden werden. Mit der Aktion ,Café Imaginaire‘ wollen wir Ihre Neugier wecken, wobei alle Gäste eingeladen sind, mit viel Phantasie Möglichkeiten der Realisierung zu finden. Literarischer Schwerpunkt des ,Café Imaginaire“ ist Spanien.“

601 Vgl. Bähr 2006. 
det sich dort ein Restaurant unter dem Namen Goldmund im rechten Teil des Erdgeschosses, wo eine Sommerterrasse angeschlossen ist.

Ebenso wie ein Café wünschten sich die Literaturhaus-Initiator*innen eine Buchhandlung für das Literaturhaus, die sich aber weder im alten noch im neuen Gebäude tatsächlich realisieren ließ. Seit 1992 sorgt die Buchhandlung Land in Sicht dafür, dass das Publikum bei den Lesungen die Bücher der Gäste kaufen kann. Die auf Kinderbücher spezialisierte Buchhandlung Eselsohr bestückt bei den Veranstaltungen des seit 2010 aktiven Jungen Literaturhauses den Büchertisch. Obwohl es keine eigene Buchhandlung im Haus gibt, die zu üblichen Geschäftszeiten alle Bücher beschaffen und Buchkäufer*innen in das Literaturhaus locken könnte, stufen die Literaturhaus-Betreiber*innen den Buchverkauf entsprechend als wichtig ein. Ein Büchertisch gehört zu einer Literaturveranstaltung dazu.

\section{3.3 Personalentwicklung und Programmatik}

Seit der Eröffnung des Literaturbauses Frankfurt bis 1995 zeichnete Dr. Thomas Beckermann, vorher Lektor für deutsche Literatur beim Verlag S. Fischer, für die Programmarbeit verantwortlich. ${ }^{602} 1995$ kündigte dieser seinen Vertrag auf. In Zeitungsartikeln werden dafür vor allem organisationale Gründe angegeben, da Beckermann „einen großen Teil seiner Zeit habe dafür einsetzen müssen, seinem Haus das Überleben zu sichern." ${ }^{603}$ Noch während Beckermanns Amtszeit merkte Matthias Bischoff in der Frankfurter Allgemeinen Zeitung an, dass beim Literaturhaus Frankfurt von Beginn an ein Finanzierungsfehler vorgelegen habe, da zu viel Geld für die Miete im Westend und zu wenig für das Programm ausgeben wurde. ${ }^{604} \mathrm{Nach}$ den ersten Jahren kürzte zum Beispiel die Stadt ihren Zuschuss. Neben der Würdigung von Beckermanns „Pionierarbeit"“605 wurden zu seinem Abschied somit Wünsche formuliert, „daß ein neuer Leiter das Haus besser nach außen repräsentieren und auch dessen Interessen in der Stadt stärker vertreten solle, als Beckermann dies getan habe." 606 Nach den Anfangsjahren, in denen sich die Einrichtung etablieren und eine Basis für die weitere Arbeit sich bilden musste, kamen Forderungen auf, das Programm zur Besonderheit des Literaturhauses zu machen. Ähnlich wie im Literaturbaus Hamburg verabschiedete sich der erste Leiter nach fünf Jahren aus dem Literaturhaus, nachdem er das Fundament der Einrichtung gefestigt hatte.

Auf Thomas Beckermann folgte zur Herbstsaison 1995 Dr. Maria Gazzetti. Die gebürtige Italienerin und promovierte Romanistin (*1955) arbeitete unter anderem als Scout für italienische Verlage und als Übersetzerin in Hamburg und brachte Erfahrung im Veranstaltungsbetrieb mit nach Frankfurt. Dort war sie als Literaturhaus-Programmleiterin tätig, bis 2009 ihr Vertrag auslief und nicht verlängert wur-

\footnotetext{
602 Als Geschäftsführerin agierte von 1990 bis 1999 Karin Wittstock, die danach Leiterin der Kulturabteilung im Palmengarten Frankfurt war. Repräsentiert wurde das Literaturhaus von dem Programmchef. 603 Riebsamen 1995.

${ }^{604}$ Vgl. Bischoff 1993.

${ }^{605}$ Riebsamen 1995.

${ }^{606}$ Ebd.
} 
de. ${ }^{607}$ „Dass es sich bei dieser Nachricht um keine bloße Personalie, sondern um eine Hiobsbotschaft nicht nur für Frankfurt handelt, liegt am Rang der Institution, den die Leiterin entscheidend mitbegründet hat. “608 Es ist die Rede von „Abschied“, „Verlust“, von „traurige[r] Nachricht" ${ }^{\circ 09}$. Die Leiterin hat, diesen Fazits zufolge, das Literaturhaus einschlägig bereichert; so entstanden mit ihrem Weggang Bedenken um die Zukunft der Einrichtung.

Dass es hier, ähnlich wie im Literaturhaus Hamburg, nicht ohne Meinungsverschiedenheiten zu einem Leitungswechsel kam, bezeugen Zeitungsberichte. Im Zusammenhang mit dem Weggang Gazzettis ist einer der Vorstandsmitglieder ebenfalls zurückgetreten, „Differenzen“ seien der Grund gewesen, und „Empörung [...] über die Art und Weise, wie der Vorstand zuletzt mit Maria Gazzetti umgegangen sei.“610 Christoph Schröder fasst es in der Frankfurter Rundschau salopp zusammen:

Maria Gazzetti, die nie von ihrem klar umrissenen, anspruchsvollen Literaturbegriff abgewichen ist, wurde im vergangenen Jahr vom damaligen Vorstand zum 30. Juni 2010 der Stuhl vor die Tür gesetzt. Das Haus müsse brummen, so hieß es damals. Und sie sei kein Brummifahrer, konterte Gazzetti. ${ }^{611}$

Sie selbst sagte, dass fünfzehn Jahre genug gewesen seien, aber ebenso, „dass es schwieriger geworden sei, so radikal und intensiv zu arbeiten, wie es ihr vorschwebt. Der Druck, durch die Immobilie Geld zu verdienen, werde immer größer. “612 Dies impliziere, dass es im neuen Literaturhaus noch mehr Veranstaltungen geben müsse - jedoch ohne qualitative Einbußen in Kauf zu nehmen - und gleichzeitig mehr Geld durch die Vermietung der repräsentativen Räume erwirtschaftet werden müsse. Der Anspruch, auch ökonomisch erfolgreich zu arbeiten, wuchs insbesondere seit dem Umzug des Literaturhauses 2005. Die Forderung, nach Beckermann mehr eigene - eigenwillige - Veranstaltungen durchzuführen, setzte Maria Gazzetti, diesen Rückblicken zufolge, um. Adjektive wie „klar umrissen“, „,anspruchsvoll“, „radikal und intensiv" charakterisieren ihre Programmarbeit in den Artikeln; ökonomisch wurde von der Leitung des Literaturhauses Frankfurt jedoch wohl mehr verlangt. Wie ausgeführt, kursiert in Literaturhaus-Debatten die Annahme, dass der Druck auf die Literaturhäuser, finanziell wie inhaltlich ausgewogen zu wirtschaften, sich über die Jahre erhöht habe. Die Diskussionen bei personellen Veränderungen bestätigen dies: Es zeigt sich in Frankfurt wie in Hamburg, dass die Leitungen, die ein literarisch exklusives Programm anboten, ersetzt werden sollten von Programmleitungen, die eine Öffnung des Literaturhauses bewirken und mit einem breiter aufgestellten Programm auch neue Förderer gewinnen könnten. Diese Entscheidungen sind im Kontext der sich verändernden Bedingungen des Literaturveranstaltungsbetriebs zu sehen, an dessen Ausweitung die Institution Literaturhaus ihrerseits beteiligt ist. Die Erwartungen der verschiedenen Akteur*innen steigen mit dem Erfolg der Einrichtung; gleichzeitig nehmen die nutzbaren Mittel selten zu. Von dem Leitungswechsel 2010 versprach sich der Verein, dass das Literaturhaus Frank-

${ }^{607}$ Maria Gazzetti wechselte zunächst als Leiterin des Lyrik-Kabinetts nach München und 2013 nach Rom an die Casa di Goethe, ein Goethe und seiner italienischen Reise gewidmetes Museum.

${ }^{608}$ Lovenberg 2009.

${ }^{609}$ Hartwig 2009.

${ }^{610}$ Lovenberg 2009.

${ }^{611}$ Schröder 2010.

612 Lovenberg 2009. 
furt „,auf die Beine gestellt" ${ }^{\text {613 }}$, also öffentlichkeitswirksam und finanziell konsolidiert werde.

Als Gazzettis Nachfolger wählte der Vorstand im Jahr 2010 Hauke Hückstädt. Bei diesem Leitungswechsel wurde wie 2004 in Hamburg die Programmleitung zusätzlich mit der Budgetverantwortung beauftragt. Die bisherige Finanzchefin Maike Zeidler blieb innerhalb des Hauses zwar für die Finanzen zuständig, nach außen vertritt aber die Gesamtleitung fortan diesen Part. ${ }^{614}$ Diese funktionale Zusammenlegung lässt sich als Reaktion auf die Bedeutungszunahme der finanziellen Dimension interpretieren: Die Führungsperson muss verstärkt neue Förderer*innen und Sponsor*innen akquirieren. Die Programmarbeit und die Geschäftsführung sind eng miteinander verbunden und um dies zu unterstreichen, soll eine Person beide Bereiche kombinieren.

Hauke Hückstädt (*1969) wirkte schon als Student im Literarischen Salon mit, eine in Hannover an die dortige Universität angeschlossene Literaturvermittlungseinrichtung, die auch über Hannover hinaus für ihre Arbeit bekannt ist. Neben Herausgeberschaften veröffentlichte Hückstädt zwei Gedichtbände; ebenso wie zum Beispiel der ehemalige Berliner Literaturhaus-Direktor Ernest Wichner ist er nicht nur Literaturkritiker und -veranstalter, sondern selbst Lyriker, damit ein Akteur, der auch als Autor in ein Literaturhaus eingeladen werden könnte, zumindest die Belange von Autor*innen aus eigener Erfahrung kennt. 2001 baute er als Leiter das neugegründete Literarische Zentrum Göttingen auf. Nach zehn Jahren wechselte er an das Literaturbaus Frankfurt.

\section{Personeller Transfer}

Hückstädt war der erste Geschäftsführer eines der großstädtischen Literaturhäuser, der vorher schon eine vergleichbare, wenn auch kleinere Einrichtung geleitet hat. ${ }^{615}$ Ein Argument für die Auswahl des Literaturbauses Frankfurt als Fallbeispiel ist dieser personelle Transfer. Wie schon erkannt, ist eine Einrichtung direkt von den Vorstellungen der jeweiligen Leitung geprägt; ebenso ist anzunehmen, dass diese Person ihren Literaturhaus-Plan mitnimmt, wenn sie ein anderes Haus zu führen beginnt. So ist es Hückstädts Realisation des Literarischen Zentrums Göttingen, die ihn befähigte, das Literaturhaus in Frankfurt mit größerer Reichweite und Sichtbarkeit zu übernehmen. Der Ruf der Göttinger Einrichtung, der maßgeblich von Hauke Hückstädt etabliert worden war, sorgte dafür, dass er das Haus in Frankfurt übernehmen sollte. Gleichzeitig steigerte diese Personalentscheidung das Ansehen des Literarischen Zentrums Göttingen nach dem Weggang Hückstädts, da der Vorstand des Literaturhauses Frankfurt es anerkannte und es überregional Aufmerksamkeit erfuhr. So ist generell anzunehmen, dass die vorherige Arbeit der Programmverantwortlichen Einfluss auf den neuen Wirkungskreis ausübt. Wenn eine Literaturhaus-Leitung eine andere vergleichbare Einrichtung übernimmt, passiert dies schließlich auch deshalb, weil diese

${ }^{613}$ Joachim Unseld zitiert nach: Küveler 2010.

${ }^{614}$ Vgl. Balke 2010.

${ }^{615}$ Bereits 2000 wechselte Wolfgang Sandfuchs vom damals vor allem lokal wirkenden Literaturbüro Freiburg zum Literaturhaus Schleswig-Holstein in Kiel, das überregional weniger Aufmerksamkeit bekommt als das Frankfurter Haus. 
von der Erfahrung profitieren will. Weitere Beispiele sind Florian Höllerer, dessen Wechsel vom Literaturhaus Stuttgart zum Literarischen Colloquium Berlin das LCB mehr zum Literaturhaus machte. 2014 übernahm Stefanie Stegmann, die zehn Jahre lang das Literaturbüro Freiburg führte, Höllerers Nachfolge in Stuttgart. Auf die Position von Aslak Sira Myhre, der zunächst Litteraturbuset in Oslo leitete und 2014 die Direktion von Nasjonalbiblioteket übernahm, komme ich zurück. ${ }^{616}$

Von Hauke Hückstädt stammt die Idee, ein Literaturhaus als ,begehbares Feuilleton` $^{\prime} \mathrm{zu}$ gestalten. Die Formulierung übertrug er aber nicht wortwörtlich auf seine neue Wirkungsstätte, denn sie blieb für das Literarische Zentrum Göttingen erhalten. Der damit verbundene Grundsatz, die Diskussion zentral zu setzen und nicht nur Literatur in einem engeren Sinne zu vermitteln, sollte in Frankfurt jedoch weitergeführt werden. Wenn von der ,Handschrift' einer Leitungspersönlichkeit im Konzept und Programm eines Literaturhauses die Rede ist, geht es zunächst um diese prinzipielle Auffassung. Da Hückstädt in Hannover und Göttingen Erfahrung als Literaturvermittler gesammelt hatte, war er bereits mit Fragen der Programmplanung befasst, und so konnte er bei seiner ersten Pressekonferenz gelassen konstatieren - das geben Berichte einstimmig wieder -, dass er kein ausgearbeitetes Programm vorlege, sondern sich zunächst von der Stadt inspirieren lassen wolle. ${ }^{617}$ Dies lässt sich so interpretieren, dass mit dem Leitungswechsel ein Transfer eines LiteraturhausKonzeptes einhergeht, weil der Programmchef die ,alte` Umsetzung für den ,neuen Ort modifiziert: Aspekte, die in Göttingen gut funktioniert haben, werden möglicherweise auf Frankfurt übertragen. Diese Gesichtspunkte separat zu analysieren fällt aber deshalb schwer, weil sie in der Regel nicht extrahierbar sind. Nur selten lassen sich direkte ,Mitnahme-Produkte ${ }^{6}$ identifizieren wie Stefanie Stegmanns Transfer der Reihe zwischen/miete. Junge Literatur in WGs von Freiburg ins Literaturhaus Stuttgart. Es ist somit davon auszugehen, und Gegenteiliges legen die Programmanalysen nicht nahe, dass Hückstädt zwar mit den Erfahrungen aus dem Literarischen Zentrum Göttingen weiterarbeitet, doch keine Punkte direkt übernimmt - dies auch, weil das Literarische Zentrum weiteragiert und eben nicht identisch mit Hauke Hückstädt ist. Seine Bemerkung, sich von der Stadt inspirieren lassen zu wollen, spricht für die Hypothese dieser Arbeit, dass jedes Literaturhaus sich in seine Umgebung einfindet. Trotzdem bleibt es relevant, bei der Analyse der Programme zu bedenken, dass Hauke Hückstädt ab 2010 für das Frankfurter Programm zuständig ist und sich bis dahin für die Angebote im Göttinger Literaturhaus verantwortlich zeigte.

Stärker noch als beim ersten Leitungswechsel wurde diese personelle Veränderung im Literaturhaus Frankfurt nach außen kommuniziert. Während die Neubesetzung 1995 im hauseigenen Leporello nur impliziert erwähnt wurde, ${ }^{618}$ schrieb 2010 Maria Gazzetti Abschieds- und verfasste Hauke Hückstädt Begrüßungsworte im Sommer-

\footnotetext{
616 Vgl. Kapitel II 6.1.1 und II 7.5.

617 Vgl. ebd.

${ }^{618}$ Im Programmheft wird dieser Wechsel zunächst nicht deutlich markiert. Ebenso wie im Literaturhaus Berlin ändert sich nur die Zeile unter der Überschrift „Im Literaturhaus arbeiten“ mit dem Start der neuen Leiterin. Zum Jahresbeginn 1996 tritt das Literaturhaus aber mit einem umgestalteten Leporello in Erscheinung. Der Wechsel vom Hoch- zum Querformat stellt dabei die markanteste Änderung dar.
} 
beziehungsweise Herbstprogrammheft. ${ }^{619}$ Von der Präsentation in den Selbstdarstellungszeugnissen lässt sich darauf schließen, dass das Literaturhaus als Ganzes noch mehr mit der aktuellen Direktion verbunden gesehen wird. Die Ineinssetzung von Leitungsfigur und Literaturhaus wird offensiv kommuniziert, indem formuliert wird, dass der Leiter Hauke Hückstädt für das Literaturbaus Frankfurt stehe und unter seiner Führung Veränderungen zu erwarten seien. Dabei ist die Beobachtung, dass dies nach außen vermittelt wird, im Vergleich zur Antwort auf die Frage, ob denn tatsächlich vieles anders gemacht wird, nicht minder relevant.

\section{3.4 Literaturhaus Frankfurt im Netzwerk der Literaturhäuser}

Auch in diesem Teilkapitel wurden Informationen über das Literaturbaus Frankfurt kombiniert mit fall- sowie institutionsbezogenen Diskussionen. Die These, dass der Erfolgs- und Erwartungsdruck, dem das Literaturhaus ausgesetzt ist, über die Jahre gestiegen ist, ließ sich beispielsweise aus den Debatten bei Leitungswechseln herausarbeiten. Wie für die Fälle Literaturbaus Berlin und Literaturhaus Hamburg ebenfalls gezeigt, wird der Wunsch, breitenwirksamer zu agieren, von den Förderern und Finanzverantwortlichen regelmäßig an die Literaturhaus-Chefs herangetragen. In Frankfurt verstärkte sich diese Anforderung durch den Umzug in ein viel größeres Haus. Gleichzeitig bietet sich mit dem Umzug nach 14 Jahren, nachdem auch zahlreiche andere Literaturhäuser gegründet worden waren, die Möglichkeit zur Aktualisierung und Selbstbefragung.

Außerdem zeigte sich, dass sich das Literaturhaus Frankfurt der Institution ,Literaturhaus' zugehörig versteht. Es gehört zu den Gründern des LiteraturhausNetzwerkes. Schon früh engagierten sich Maria Gazzetti und ihr Team in der Interessengemeinschaft der Literaturhäuser, zunächst bestehend aus Berlin, Hamburg und Frankfurt. ${ }^{620}$ Auch europaweit nahm die Leiterin an Austauschtreffen von Literaturveranstaltern teil. ${ }^{621}$ Dass das Literaturbaus Frankfurt 2013 aus dem Netzwerk der

\footnotetext{
${ }^{619}$ Der Ton beider Texte ist grundverschieden. Während Maria Gazzettis Sätze in ihrer Formelhaftigkeit beinahe nüchtern-sachlich klingen, zeigt der Neukommende Elan und Wortgewandtheit. Gazzettis „Liebe Mitglieder, nach fünfzehn Jahren werde ich im Juni 2010 meine Arbeit im Literaturhaus Frankfurt beenden. Ich bedanke mich bei [...]“ (FF 2010-05/06/07) steht Hückstädts Anfang „Verehrte Besucher, liebe Freunde des Literaturhauses, jemand, der ein Gedicht oder einen guten Satz liest, erfährt eine geistige Beschleunigung. Alles ist dann möglich - Party auf dem Musikantenknochen des Unterbewusstseins“ (FF 2010-09/10) gegenüber. Selbst Gazzettis „Durch Ihre Teilnahme wurden unzählige Lesungen zu schönen, intensiven - ich möchte fast sagen unvergesslichen - Abenden“ wirkt eingeübt im Vergleich zu Hückstädts neuem Ton „Und das geht nicht ohne Sie. Denn was ist ein Haus ohne sein Publikum, ohne die ganze Aufregung der tadellosen Neugier, der gelungenen Empörung, der zuvorkommenden Aufgeschlossenheit." Dabei ist natürlich zu bedenken, dass die neue Leitung in der Regel engagierter und frischer auftritt als die abtretende Leitungsperson, die sich verabschiedet. Zur Illustration des Wechsels eignet sich diese Fußnote dennoch.

${ }^{620} \mathrm{Zu}$ deren erster gemeinsamer Veranstaltung war Édouard Glissant, ein Autor aus der französischsprachigen Karibik, im Mai 1999 eingeladen (FF 1999-05-11).

${ }^{621}$ Im Februar 2000 verkündete die Einrichtung im Monatsprogramm: „Mitteilung in eigener Sache: Auf Einladung der ,Maison des écrivains“ (Paris) und mit Unterstützung der Europäischen Kommission haben sich vom 2. bis 4. Dezember 1999 erstmals fünfzehn Repräsentanten europäischer Literaturhäuser und des Europäischen Schriftstellerverbandes (Ost und West) in Paris getroffen. Unter dem Thema ,Literatur und Austausch` erörterten die Teilnehmer verschiedene Aspekte der literarischen Arbeit und deren Vermittlung. Sie sprachen sich in einer Presseerklärung für eine konkretere Kooperation auf europäischer Ebene aus. Die ,Maison des écrivains‘ wird auf ihrer Homepage eine Übersicht über die literari-
} 
Literaturbäuser e.V. ausgetreten ist, wurde auf finanzielle Gründe zurückgeführt, zum Jahresbeginn 2018 erklärte es seinen Wiedereintritt in das Netzwerk. ${ }^{622}$ Dies ist letztlich vor allem ein Argument dafür, die Mitgliedschaft nicht als Definitionskriterium für ein ,Literaturhaus' zu benutzen, weil die Teilnahme freiwillig geschieht, obgleich das Netzwerk die Mitglieder einladen muss. Im Januar 2015 organisierte das Literaturbaus Frankfurt die Tagung Literatur 2020 - Kongress der Veranstalter. Standpunkte + Perspektiven. Damit machte der Leiter sein fortbestehendes Interesse an der Auseinandersetzung mit der eigenen Einrichtung und deren Verortung im Literaturveranstaltungsbetrieb deutlich. Eine angemessene Positionsbestimmung bezieht den Initiator*innen zufolge dann aber nicht nur die Literaturhäuser mit ein, sondern auch Literaturveranstalter*innen mit anderen Namen, die, wie sich gezeigt hat, auch in Frankfurt zu finden sind.

\section{4 Literarisches Zentrum Göttingen - Ein Literaturhaus?}

Das vorherige Unterkapitel schloss mit der Bemerkung, dass in eine dem Gegenstand angemessene Positionsbestimmung des Literaturveranstaltungsbetriebs nicht nur Literaturhäuser, sondern auch Veranstalter mit anderem Namen einbezogen werden müssten. Dass es neben den als ,Literaturhaus' benannten andere Einrichtungen gibt, die funktionell vergleichbar sind, ist mit der Konzentration auf die Institution ,Literaturhaus` keineswegs ausgeschlossen. Vielmehr gibt es Veranstalter wie das im Jahr 2000 gegründete Literarische Zentrum Göttingen, die sich ebenso als Vertreter dieser Institution verstehen lassen.

Die Zugehörigkeit oder Nichtteilhabe an einem Bereich erschließt sich mitunter in Relation zu einem Vergleichsobjekt. Das Literarische Zentrum Göttingen ist zum Beispiel aufgrund seiner Struktur und seiner Aufgaben eher als ,Literaturhaus' zu bezeichnen als es eine Stadtbibliothek ist, obwohl es in Bezug zu den anderen dargestellten Fallbeispielen, die sich explizit ,Literaturhaus' nennen, nicht so augenfällig dazugehört. Es geht in dieser Arbeit weniger darum, Literaturveranstaltungsorte eindeutig als ,Literaturhaus ${ }^{6} \mathrm{zu}$ kategorisieren, sondern unter ,Institution“ unterschiedliche Aspekte zu subsummieren und diskutieren zu können. Dazu gehört unter anderem, dass als ,Literaturhaus‘ Einrichtungen, die sich als solche bezeichnen, nennenswert sind, ebenso wie Veranstalter, die in ihren Funktionen einem Literaturhaus entsprechen.

schen Organisationen geben, die in Paris vertreten waren. Das Literaturhaus Frankfurt war seit Beginn (1998) Kooperationspartner des Projekts und wurde in Paris von Maria Gazzetti vertreten“ (FF 2000-02). Es gab also schon im Jahre 2000 eine Kooperation europäischer Literaturvermittler. Abgesehen von der Information, dass es diese Zusammenkunft überhaupt gegeben habe, ist für die Selbstdarstellung der Einrichtung aufschlussreich, dass sie dies als für die Leser*innen des Programmheftes wichtig erachtet. Das überregionale Wirken erhöht die wahrgenommene Relevanz des Literaturhauses Frankfurt.

${ }^{622}$ Vgl. Netzwerk der Literaturhäuser e. V., Pressemitteilung 2018. 
Diese eingangs erläuterten semantischen Dimensionen der Begriffsbezeichnung ,Literaturhaus' lassen sich anhand des Literarischen Zentrums Göttingen ${ }^{623}$ am konkreten Fall erörtern. Aufgrund der Selbstbezeichnung als Literarisches Zentrum Göttingen gilt es in einer strengen Definition nicht als ,Literaturhaus'. Die Einrichtung lässt sich dennoch als Literaturhaus verstehen, denn auf das Literarische Zentrum Göttingen trifft der Funktionsbegriff ,Literaturhaus` zu. Belegen lässt sich diese Hypothese mit den folgenden Ausführungen. Neben der Genese der Einrichtung und ihres Namens, der Kontextualisierung in der Stadt Göttingen sowie dem starken Austausch mit den lokalen Akteuren Universität und Literaturfestival Göttinger Literaturherbst dient die überregionale Vernetzung mit anderen Literaturvermittlungseinrichtungen als Begründung.

\section{4.1 Literarisches Zentrum im Netzwerk der Literaturhäuser}

Zentrales Argument für die Einordnung als ,Literaturhaus` ist die Tatsache, dass das Literarische Zentrum Göttingen innerhalb der Institution klar als ,Literaturhaus‘ akzeptiert ist. Seit 2015 ist es Mitglied des Netzwperks der Literaturbäuser. Die Aufnahme bringt ihm zum einen Anerkennung von anderen Literaturhäuser entgegen, zum anderen verstärkt diese seine überregionale Sichtbarkeit. Durch die Mitgliedschaft im Netzperk der Literaturbäuser, dessen Satzung früher nur Einrichtungen mit dem Namen ,Literaturhaus' zuließ, wird deutlich zugestanden, dass ,Literaturhaus' auch ein Funktionsbegriff ist. Genauso fand bei der Erweiterung des Verbunds 2015 das Literarische Colloquium Berlin (LCB) Einlass. ${ }^{624}$ Damit sind in diesem Netzwerk zwei Einrichtungen, die nicht ,Literaturhaus' heißen, gleichberechtigt mit den namentlichen Literaturhäusern vertreten. Das Netzwerk der Literaturbäuser trug schon durch seine Gründung zur Institutionalisierung des Literaturhauses bei, weil es mit dem Verbund der Einzeleinrichtungen davon ausging, dass die Beteiligten etwas gemein haben und ihr gemeinsamer Auftritt die Sichtbarkeit für diese übergeordnete Struktur erhöht. Mit der Zulassung des Literarischen Zentrums Göttingen und des LCB bestätigt diese Gemeinschaft, dass selbst diese beiden als ,Literaturhaus' bezeichnet werden können. Damit belegt die Öffnung des Netzwerkes die Annahme dieser Arbeit, dass die Einordnung als ,Literaturhaus' nicht mehr nur über den Eigennamen der Einrichtung funktioniert, sondern dass die Handlungen und Funktionen den Akteur zu einem Literaturhaus machen.

Die Erweiterung des Netzwerkes der Literaturbäuser um das LCB und das Literarische Zentrum Göttingen mag gleichfalls auf strategischen Gründen seitens des Vereins fuBen: Als eine Aufgabe des Verbundes sehen die Beteiligten, dass es unter anderem gelte, „die ,Marke“ Literaturhaus als Synonym für eine zeitgemäße, wandlungsfähige Förderung und Vermittlung von deutschsprachiger und internationaler Gegenwartsliteratur weiter zu verbreiten." 625 Es besteht somit ein Interesse daran, gerade die

\footnotetext{
${ }^{623} \mathrm{Im}$ Folgenden verwende ich in diesem Kapitel neben der Langversion des Namens die verkürzte Variante Literarisches Zentrum und das in Göttingen übliche Zentrum.

${ }^{624}$ Dessen Leiter Florian Höllerer führte lange das Literaturhaus Stuttgart und war in dieser Rolle im Netzwerk der Literaturbäuser tätig.

625 „Das Netzwerk“, Netzwerk der Literaturhäuser.
} 
Einrichtungen aufzunehmen, die zeitgemäße Literaturveranstaltungen anbieten. Das Netzwerk wählt seine Mitglieder folglich unter anderem danach aus, ob der Bewerber ein positives Beispiel für die Marke Literaturhaus darstellt. Einerseits werden die berufenen Mitglieder für ihre Arbeit, geadelt', andererseits garantieren die Mitglieder das Ansehen des Netzwerkes und somit implizit die Qualität der Marke Literaturhaus.

Das Netzwerk der Literaturbäuser entspricht nicht der abstrakten ,Institution Literaturhaus', denn in diesem Verein sind bei weitem nicht alle Literaturhäuser aus dem deutschsprachigen Raum oder alle Einrichtungen vertreten, die als solche bezeichnet werden können. Dennoch hat es, wie gerade beschrieben, Anteil daran, dass die Institutionalisierung wahrnehmbar wird. Es handelt sich dabei um einen Verein mit eigenen Interessen, der außerdem übergreifende Projekte durchführt. Um dabei konstruktiv zusammenarbeiten zu können, ist eine Beschränkung auf Teilnehmer, deren Gemeinsamkeiten überwiegen, nachvollziehbar. Alle Mitglieder in diesem Netzwerk lassen sich als ,Literaturhaus' interpretieren, wie das Beispiel des Literarischen Zentrums Göttingen zeigt, eine Mitgliedschaft ist aber nicht notwendig, um als Literaturhaus anerkannt zu sein, wie das Literaturhaus Freiburg oder Literaturhaus München beweisen. Im Falle Göttingens ist die Aufnahme in das Netzwyerk der Literaturbäuser ein wichtiges Signal, dass das Literarische Zentrum Göttingen nicht nur regional wirkt, sondern über Südniedersachen hinaus Beachtung findet.

\section{4.2 Entstehung und Organisation}

Wie bei den vorausgegangenen und noch folgenden Darstellungen der Fallstudien ersichtlich wird, ergreifen Einzelakteur*innen oder Gruppen die Initiative zu den jeweiligen Realisierungen eines Literaturhauses. Die Gründung ist dann ihrem Engagement und Verhandlungsgeschick zu verdanken. Wie abhängig der Erfolg eines solchen Projektes von den beteiligten Personen ist und wie die Entwicklung von ihnen geprägt ist, wird am Beispiel des 2000 gegründeten Literarischen Zentrums Göttingen anschaulich. Wie sehr es an den involvierten Menschen hängt, wer in welcher Position in welcher Einrichtung zu welchem Zeitpunkt arbeitet, spricht selten jemand so explizit aus, wie Heinz Ludwig Arnold es in einem Interview herausstellt, das im Buch Das begehbare Fenilleton. Gespräche und Berichte aus dem Kulturbetrieb abgedruckt ist. ${ }^{626}$ Offenbar wird in den Antworten von Heinz Ludwig Arnold (19402011) - unter anderem Begründer der edition text + kritik, Herausgeber von Kindlers Literatur Lexikon und des Bandes Literaturbetrieb in Deutschland -, dass die Gründung des Literarischen Zentrums entscheidend auf ihn selbst und seine vielseitigen Kontakte und Aktivitäten zurückzuführen ist. Die Gründungsgeschichte lässt sich verkürzt in Arnolds eigenen Worten wiedergeben:

Dann [Ende der 1990er-Jahre, Anmerkung C. L.] kamen irgendwann die Stadt und das Ministerium für Wissenschaft und Kultur auf mich zu und fragten, ob ich da etwas Neues aufbauen und entwickeln könnte. Ich habe mich bereit erklärt und mir überlegt, wie man so etwas aufziehen könnte. ${ }^{627}$

${ }^{626}$ Vgl. Blumenkamp und Hückstädt (Hg.) 2007.

${ }^{627}$ Heinz Ludwig Arnold zitiert nach: Blumenkamp 2007, S. 201. 
Wenig später ernannte die Georg-August-Universität Göttingen Arnold zum Honorarprofessor. In dieser Funktion setzte er Ideen um, ,wie man an der Universität das Fenster hin zur Praxis von Literatur aufstoßen könnte" "628. Diese Aussagen machen deutlich, wie quellenkritisch mit solchen retrospektiven Darstellungen von Beteiligten umgegangen werden muss - gleichzeitig sollte ernst genommen werden, dass Entscheidungen einiger Persönlichkeiten, deren persönliche Netzwerke sowie ,günstige Umstände' Konstellationen herstellen, die nicht im Einzelnen und nicht stringent zu rekapitulieren sind, wie es sich für die Institution Literaturhaus bestätigt.

\section{4.2.1 Vorgeschichte und historisch gewachsener Name}

Es stellt sich die Frage, warum das Literarische Zentrum Göttingen nicht ,Literaturhaus` heißt. Besonders interessant an den Gründen für den Namen ist die Tatsache, dass direkt Bezug genommen wurde auf die Ende der 1990er-Jahre virulenten Bezeichnungen ,Literaturbüro' und ,Literaturhaus' - und zwar in Form von Distanzierung.

Vor Gründung des Literarischen Zentrums gab es von 1986 bis Mitte der 1990erJahre den Verein Literaturbüro Südniedersachsen, der sich jedoch vornehmlich, wie ein Schriftstellerverein, um die Belange von Schreibenden kümmerte. Öffentliche Veranstaltungen waren die Ausnahme. ${ }^{629}$ Er stellte die Arbeit ein, als er nicht mehr öffentlich bezuschusst wurde. Diese Kürzung sei erfolgt, weil undurchsichtig gewesen sei, für welche Zwecke die Gelder genutzt worden seien, so Arnold. ${ }^{630} \mathrm{Um}$ Verwechslungen zu vermeiden, konnte die neue Einrichtung in Göttingen allein deshalb nicht ,Literaturbüro' heißen. Zudem betonen die Initiatoren des Zentrums, dass Literaturbüros für Literaturproduzenten geschaffen seien und bei „Büro' Verwaltungsarbeit anklinge, die mit Literatur wenig zu tun habe. ${ }^{631}$

Das Argument gegen die Bezeichnung als ,Literaturhaus' war nicht inhaltlichprogrammatischer Art, sondern verwendete die finanzielle Ausstattung als Unterscheidungsmerkmal: „Das Konzept von Literaturhäusern ist viel opulenter ausge-

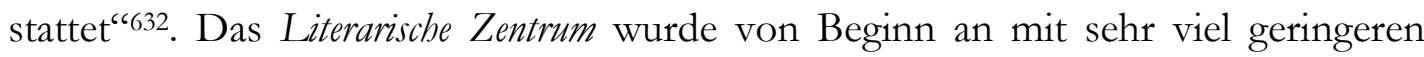
Mittel versehen als die ersten Literaturhäuser andernsorts. Finanziell sei dies der Fall gewesen, so Arnold, „weil wir eben zu einer Zeit angefangen haben, als die Kassen schon leer waren. “" 333 Seit Beginn im Jahr 2000 habe sich das finanzielle Gesamtvolumen nahezu verdreifacht, konstatierte Hauke Hückstädt 2010. ${ }^{634}$ Begonnen wurde zu einer Zeit, in der als ,Literaturhaus' in der Tat vor allem die prächtigen Literaturhäuser in Berlin, Hamburg, München und Frankfurt präsent waren, nicht einmal das Literaturhaus Stuttgart war eröffnet. 2000 hatte sich der Name noch nicht als Funkti-

\footnotetext{
${ }^{628}$ Heinz Ludwig Arnold zitiert nach: ebd.

${ }^{629} \mathrm{Vgl}$. Heinz Ludwig Arnold zitiert nach: ebd. Die Onlinechronik des Stadtarchives verzeichnet für Oktober 1988 die Internationalen Science Fiction Tage, für Mai 1990 den Dritten Göttinger Literaturfrübling, für April 1994 den siebten: Das Literaturbüro Südniedersachsen lud dabei ,alle Schriftsteller/Innen ein, aus noch unveröffentlichten Werken zu lesen“, „Chronik für“, Stadtarchiv Göttingen.

${ }^{630}$ Vgl. Heinz Ludwig Arnold zitiert nach: Blumenkamp 2007, S. 201.

${ }^{631}$ Vgl. Heinz Ludwig Arnold zitiert nach: ebd., S. 204. Vgl. auch Kapitel I 5.5.

${ }^{632}$ Heinz Ludwig Arnold zitiert nach: ebd., S. 203.

${ }^{633}$ Heinz Ludwig Arnold zitiert nach: ebd.

634 Vgl. Krüger-Lenz 2010.
} 
onsbegriff durchgesetzt und war eng mit den wirkungsvollen Literaturhäusern in den Metropolen verbunden.

Der Name Literarisches Zentrum sei zunächst nur ein Arbeitstitel gewesen, der sich aber durchgesetzt habe, erläutert Heinz Ludwig Arnold. ${ }^{635}$ Der Ausdruck ,Zentrum weist auf die bündelnde Aufgabe der Einrichtung hin; er steht dafür, dass das Bezeichnete den Mittelpunkt des Literarischen Lebens in der Stadt darstellt. 636 Älter als die Einrichtung in Göttingen sind zum Beispiel das Literaturzentrum Hamburg (seit 1974), oder das Literaturzentrum Neubrandenburg, das 1971 in der DDR entstand. Inzwischen existieren weitere Literaturveranstalter, die den gleichen Namen wie das Göttinger Modell tragen, unter anderem das Literarische Zentrum Gießen, das seit 2009 tätig ist, und eine enge Verbindung zur dortigen Universität pflegt.

Diese Benennung ist ebenso für sich verständlich, wie es ,Literaturhaus` ist. Etabliert waren um die Jahrtausendwende als Namen für Literaturveranstaltungseinrichtungen jedoch insbesondere ,Literaturhaus' und ,Literaturbüro' - von diesen grenzte sich das Literarische Zentrum Göttingen ab. Dadurch, dass es sich selbst nicht mit ,Literaturhaus' betitelt hat, nahm sich das Literarische Zentrum zunächst aus dem direkten Vergleich mit den Literaturhäusern der Großstädte heraus. Damit stand es nicht als ,kleines' Literaturhaus da, sondern konnte seine Individualität betonen und wurde gleichzeitig nicht mit der verwaltenden Funktion eines Literaturbüros in Zusammenhang gebracht. Zugunsten einer individuelleren Version fiel die Entscheidung gegen die pragmatische Zuordnung zu einer bereits existierenden Gruppe.

Das ist eher ungewöhnlich. Anzunehmen ist, dass um 2000 ,Literaturhaus“ und ,Literaturbüro' parallel genutzt wurden und die eingangs beschriebene historische Differenz noch galt. Deutlich jüngere Einrichtungen wählen in der Regel die Bezeichnung ,Literaturhaus` wie das in Bonn, eröffnet 2011, in Dortmund, gegründet 2013, oder die Initiative in Augsburg bezeugen. Sie wählen ihre Namen aus strategischen Gründen, weil sich die Bezeichnung so weit durchgesetzt hat, dass es naheliegt, sich unverkennbar dieser Institution anzuschließen. Das Literarische Zentrum Göttingen ist, darin liegt seine Besonderheit, eine in einer kleineren Großstadt neu entstandene Literaturvermittlungseinrichtung, die gerade nicht aus einem lokalen Schriftstellerverein entstanden ist, wie dies etwa in Freiburg der Fall ist. Im Jahr 2000 wäre es in Göttingen tatsächlich eines der ersten Literaturhäuser abseits der Metropolen gewesen. Weitere frühe kleinere Literaturhäuser sind etwa das Literaturhaus Darmstadt im John-F.-Kennedy-Haus, das die Stadt seit 1995 unterhält, oder das Literaturbaus Wiesbaden in der Villa Clementine, das seit 2001 existiert. Auffällig ist bei diesen Beispielen, dass das Gebäude nicht als Literaturhaus benannt ist, sondern andere historische Verweise liefert. Der Verein Literaturhaus Schleswig-Holstein existiert seit 1989, dessen Kieler Literaturhaus ist seit 1998 aktiv.

Mit der Ausweitung und Entwicklung der Institution Literaturhaus lässt sich der Funktionsbegriff Literaturhaus auf das Literarische Zentrum anwenden, wie ihn die aktuelle Leiterin Anja Johannsen selbst benutzt: „П]ch leite das Literarische Zentrum in Göttingen, das ist ein Literaturhaus, und dann wird natürlich nachgefragt, was ich da genau mache. Wenn ich dann sage, ich organisiere Veranstaltungen, dann

635 Vgl. Heinz Ludwig Arnold zitiert nach: Blumenkamp 2007, S. 201.

${ }^{636}$ Dies wurde bereits im ersten Kapitel ausgeführt, vgl. Kapitel I 1. 
hätte ich eigentlich gleich sagen können, das ist Kulturmanagement.“"637 Diese pragmatisch instrumentalisierte Verwendung der Begriffsbezeichnung zeigt, dass die anfängliche Abgrenzung von den großen Literaturhäusern nicht mehr notwendig ist und eher einer Anerkennung des Literarischen Zentrums außerhalb Göttingens eher entgegenwirkt.

Eine Umbenennung - ohne Umzug in ein eigenes Haus oder ohne Budgeterhöhung und ein damit ausgeweitetes Konzept, wie es in Freiburg geschehen ist - wäre in Göttingen schwer zu kommunizieren, zumal der Veranstaltungsort innerhalb Göttingens gut, sogar mit der Kurzform seines Namens, als Zentrum eingeführt ist. Nicht immer sind Name des Trägervereins und Literaturort identisch. In Rostock beispielsweise war 2011 die Umbenennung des Trägervereins von Literaturförderkreis Kubtor e. $V$. in Literaturbaus Rostock e. V. zugunsten einer Vereinheitlichung sinnvoll. Das sogenannte Kubtor war bis zum Umzug in das Peter-Weiss-Haus der Sitz des Literaturveranstalters. Obwohl das Gebäude selbst nicht ,Literaturhaus' heißt, gibt seit der Umbenennung des Trägervereins wenigstens der Vereinsname Aufschluss über die Arbeitsinhalte der Einrichtung, die seit 2008 Mitglied im Netzwerk der Literaturbäuser e. V. ist. Auch das Literaturbaus Nürnberg, das als solches 2003 eröffnete, hat eine Vorgeschichte als LiteraturClub Nürnberg e. V. Analog basiert das 2017 neu entstandene Literaturbaus Freiburg, erwachsen aus dem Literaturbüro Freiburg, auf dem Verein Literatur Forum Südwest. Das Kuratorium Haus des Buches e. V. - Literaturhaus Leipzig sitzt im Haus des Buches, welches auch als ,Literaturhaus' bekannt ist. ${ }^{638} \mathrm{Am}$ 1996 errichteten Haus des Buches in Leipzig ist der Börsenverein des Deutschen Buchbandels direkt beteiligt. Deshalb kam es bisher auch noch nicht zu einer formalen Umbenennung in den verwendeten Namen ,Literaturhaus‘. In Göttingen entspricht der Name des Vereins dem des Veranstaltungsortes - dies beugt Irritationen vor. AuBerhalb Göttingens trägt die erklärende Ergänzung des Signifikats - „das Literarische Zentrum in Göttingen, das ist ein Literaturhaus"“639 - zum Verständnis bei.

\section{4.2.2 Personal}

Im März 2000 gründete sich der Verein Literarisches Zentrum e. V. Die drei Vereinsgründer Heinz Ludwig Arnold, Verleger Thedel von Wallmoden und Hilmar Beck, damals wie heute Leiter des Fachbereichs Kultur der Stadt Göttingen, bildeten von Beginn an den Vorstand. Für Heinz Ludwig Arnold ergänzt Christiane Freudenstein-Arnold als Vorsitzende den Literarisches Zentrum Göttingen-Verein. 2017 hatte der Verein etwa 70 Mitglieder, die namentlich auf der Website des Literarischen Zentrums angeführt werden. Anders als bei den meisten Literaturhaus-Vereinen müssen neue Mitglieder von der Mitgliedsversammlung bestätigt werden. Die sozialen Aspekte einer Vereinsangehörigkeit werden damit herausgestellt, während es keine direkten Werbemaßnahmen für neue Mitglieder gibt. Akquiriert wird in erster Linie über persönliche Ansprachen. Die Nennung der Namen, unter denen sich viele Universitätsprofessor*innen finden, markiert die Anerkennung des Vereins.

\footnotetext{
${ }^{637}$ Anja Johannsen zitiert nach: Schuldt: „Irritationsmanagement“.

${ }^{638}$ Der Verein wurde 2019 schließlich in Literaturbaus Leipzig e. V. umbenannt.

${ }^{639}$ Anja Johannsen zitiert nach: ebd.
} 
Als erster Geschäftsführer wirkte Jan Strümpel mit einer 50-Prozent-Stelle, weitere Mitarbeiter*innen waren zunächst nicht finanzierbar. Bereits im November 2000 nahm der Leiter jedoch eine Stelle als Lektor beim Göttinger Steidl Verlag an. Als neuer Chef konnte Hauke Hückstädt gewonnen werden. Die Formulierung ,gewonnen werden' passt hier deshalb, weil er, den Aussagen Heinz Ludwig Arnolds zufolge, auf eine Empfehlung hin direkt eingeladen wurde, ${ }^{640}$ eine öffentliche Ausschreibung hat es nicht gegeben. Dies war anders bei dem Leitungswechsel 2010: Als Hauke Hückstädt zum Literaturhaus Frankfurt wechselte, setzte Dr. Anja Johannsen (*1974) sich gegen Mitbewerber*innen durch und übernahm zum Sommer 2010 die Führung des Literarischen Zentrums. Sie hatte vorher unter anderem im Literaturbaus Zürich mitgearbeitet und war über ihre Promotion hinaus noch an der Universität tätig. Anja Johannsen hatte sich schon früher wissenschaftlich mit dem Literaturbetrieb, unter anderem mit Literaturhäusern, beschäftigt. Die Nähe zur Universität bleibt mit ihr im Literarischen Zentrum folglich bestehen.

Festangestellt mit einer Vollzeitstelle war im Literarischen Zentrum vorerst nur die Leitungsperson. Eine zusätzliche Teilzeitstelle kam 2008 mit dem Projekt Literatur macht Schule hinzu. Dieses Bildungsprogramm wendet sich an Schüler*innen ebenso wie an Lehrer*innen; in der Regel finden Veranstaltungen mit Autor*innen in den Schulen der Umgebung statt. Es stellt also einen eigenen Arbeitsbereich dar. Unterschiedlichen Aufgaben zugeteilt waren lange Zeit jeweils vier Volontär*innen, die die Leitung mit jeweils etwa zehn Stunden pro Woche unterstützten. ${ }^{641} \mathrm{Da}$ sie für ein Jahr mitarbeiten, entsteht mehr Kontinuität als bei zwei- bis dreimonatlich wechselnden Vollzeitpraktikant*innen, die in vielen anderen Literaturhäusern tätig sind.

\section{4.3 Gestaltung des Literarischen Zentrums Göttingen}

Seine Auftaktveranstaltung feierte das Literarische Zentrum im Deutschen Theater im Mai 2000. Nach der Vorbereitung im ersten Jahr und dem Personalwechsel im November startete das Literarische Zentrum erst Anfang 2001 richtig: Eine Pressemeldung, die unter anderem als Notiz in der Frankfurter Allgemeinen Zeitung aufgenommen wurde, ${ }^{642}$ verkündete den Beginn der Literaturveranstaltungseinrichtung in Göttingen. Ab dann tritt es mit bis dato genutztem Logo in Erscheinung - ein markantes aus drei Balken in dunkelorange bestehendes , $Z^{\prime}$ umrundet von einem heller orangefarbenen Kreis. Im Jahr 2001 fanden die meisten Veranstaltungen im Künstlerhaus, auch Lichtenberghaus genannt, in der Gotmarstraße 1 statt, dem Sitz des Literarischen Zentrums bis 2002. Der Gewölbekeller im Künstlerhaus war der Hauptveranstaltungsraum. Mit nur 48 Quadratmeter im gemauerten Kellergewölbe standen maximal 70 Plätze zu Verfügung. Der fensterlose Raum, der eine düster-gemütliche Atmosphäre

${ }^{640}$ Vgl. Heinz Ludwig Arnold zitiert nach: Blumenkamp 2007, S. 202. Arnold betont die Spontanität und Zufälligkeit der Auswahl, indem er sagt, dass er „in Niedersachsen herumtelefoniert“ habe und ihm Hauke Hückstädt empfohlen worden sei. Dieser „,hat sich Bedenkzeit erbeten, aber ich glaube schon zwei Tage später haben wir ihn angerufen und er hat zugesagt. Damit war die Sache unter Dach und Fach.“ ${ }^{641}$ Auf dieses Volontariatsmodell komme ich bei der Darstellung der Beziehung zur Universität zurück. ${ }^{642}$ Vgl. dpa 2001. 
erzeugte, wurde, wie ein Foto im Programmleporello (GT 2001-09/12) zeigt, mit altmodischen Tischstehlampen mit rötlichen Lampenschirmen beleuchtet.

Gänzlich anders präsentierte das Literarische Zentrum die Bühne nach seinem Umzug 2002 in die heutigen Räume in der Düsteren Straße. Dem Literarischen Zentrum Göttingen steht dort kein ganzes Haus zur Verfügung, sondern die oberste Etage eines Fachwerkhauses, in der ehemals die Galerie Ablers ansässig war. Im Erdgeschoss und den anderen an den Innenhof angrenzenden Häusern befinden sich Restaurants, die mit Biergärten im Innenhof präsent sind, was vor allem im Sommer bei offenem Fenster zu Unstimmigkeiten hinsichtlich der Gesprächslautstärke führen kann. Das Gebäude ist also nicht allein der Literatur gewidmet, dennoch muss sich die Einrichtung hier nicht einer anderen kulturellen Organisation unterordnen, wie es vorher im Künstlerhaus der Fall war. Heute geht das Publikum ins Literarische Zentrum - und nicht in den Gewölbekeller im Künstlerhaus. Synergieeffekte mit anderen kulturellen Einrichtungen direkt vor Ort sind damit jedoch ausgeschlossen. Von außen weisen Leuchttafeln mit dem Logo den Weg zum etwas versteckt im Hinterhof liegenden Literarischen Zentrum. Diese Schilder wurden 2014 erneuert, um den Veranstaltungsort offensiver zu präsentieren.

Über eine schmale Treppe und ohne Foyer gelangen die Besucher*innen direkt in den einen Veranstaltungsraum im ersten Stock. Mit schweren Holzbalken, Fachwerkwänden, Dachschrägen, grauem Teppichboden und kleinen Sprossenfenstern korrespondiert die Grundeinrichtung mit der Außengestaltung des Hauses. Das Mobiliar, also die Bühnentischelemente und Stühle, sind in moderner Metalloptik schlicht und funktional gehalten und sorgen dafür, dass der Raum nicht nur wie ein dörfliches oder altstädtisches pittoreskes, gemütliches Fachwerkhäuschen daherkommt, sondern zeitgemäßer geprägt ist. An den Wänden hängen gerahmt die Halbjahresprogrammfolder - eine Ausstellung der eigenen Arbeit.

Es handelt sich um einen länglichen Raum, der durch eine kleine Treppe mit vier Stufen zweigeteilt wirkt. Am Ende liegen die Büroräume des Literarischen Zentrums. Besonders der hintere Teil des Raumes wird bei Veranstaltungen benutzt, bei Bedarf ist zusätzlich der vordere Teil bestuhlt. Das Podium, niedrige flexible Elemente, steht in der Regel rechts oberhalb der Stufen. Ausgerichtet ist es entweder zum hinteren Teil oder nach vorne, sodass die Zuhörer in beiden Raumhälften die Bühnengäste von der Seite sehen können.

Diese spezielle Raumsituation führte dazu, dass von Beginn an alle Veranstaltungen audiovisuell aufgezeichnet wurden und auf zwei Bildschirmen direkt übertragen wurden. So können auch die Zuschauer*innen, die keine gute Sicht auf das Podium haben, die Sprechenden sehen. Dies ist besonders hilfreich, wenn beide Seiten der Bühne vom Publikum besetzt sind und die Auftretenden statt zum Publikum auf die Kamera ausgerichtet sind. Die gute technische Ausstattung ist also den Räumlichkeiten geschuldet. Und so sind im Literarischen Zentrum alle dort abgehaltenen Veranstaltungen in Ton und Bild archiviert. Die meisten Literaturhäuser zeichnen ihre Veranstaltungen für interne Dokumentationszwecke auf Audiospeichermedien auf; Videoaufnahmen sind viel seltener. Diese Tonsammlungen, verschlossen in den 
Büros der Einrichtungen, bergen viel Material für Aufführungsanalysen oder für Untersuchungen zu einzelnen Autor*innen. ${ }^{643}$

Mittig des Veranstaltungsraumes biegt links der Barbereich mit Balkon zum Innenhof ab. Hierbei handelt es sich um einen Anbau, der das Gebäude mit dem Nachbarhaus verbindet. Unterhalb liegt der Durchgang vom Hof zum seitlich gelegenen Eingang des Literarischen Zentrums. Dieser Bereich ist also vom Biergarten aus sichtbar und wirkt einladend. Die Bar ist nur bei Veranstaltungen geöffnet, ausgeschenkt werden Getränke nur an Lesungsgäste. Ein öffentlich zugängliches Café gibt es im Literarischen Zentrum Göttingen entsprechend nicht. Weder direkt im Haus noch in unmittelbarer Nähe findet sich eine Buchhandlung. Zu den Veranstaltungen stellen wechselnde Buchläden den Büchertisch.

Da der Ort nur zu Veranstaltungen öffentlich zugänglich ist und nicht ein ganzes Haus der Literatur gewidmet ist oder zumindest ein Komplex aus Bühne, Café und zum Beispiel Buchhandlung existiert, ist der Name Literarisches Zentrum in dieser Hinsicht intuitiv angemessener als der Titel ,Literaturhaus'. Die Bemerkung von Heinz Ludwig Arnold aus dem Jahr 2007, dass Literaturhäuser „viel opulenter ausgestattet" ${ }^{644}$ seien als das Literarische Zentrum, ist aber nur noch bedingt richtig. Denn die Einrichtung lässt sich einfügen in eine Reihe neuerer, kleinerer Literaturhäuser, die in erster Linie als Veranstalter agieren und nicht das Konzept des ,umfassenden Literaturhauses' vertreten. Und wie gezeigt wurde, hat das große Literaturhaus Frankfurt ebenfalls keine eigene Buchhandlung. Genauso sorgen im Literaturbaus München, in Köln oder Wiesbaden ${ }^{645}$ externe Buchhändler*innen für den Buchverkauf bei den Veranstaltungen. Die enge Verbindung von Veranstaltungsort, Restaurant oder Café und Buchhandlung liegt nur in wenigen deutschen Literaturhäusern überhaupt vor, so in Berlin, Hamburg oder Stuttgart. Die Kombination mit einem gastronomischen Betrieb ist häufiger gegeben. Für den sozialen Aspekt des Treffpunktes ist ein Café zuträglicher als eine Buchhandlung, die zwar tagsüber, aber nicht mehr zu Lesungszeiten geöffnet hat. Ein Literaturhaus muss nicht Veranstaltungsort, Buchhandlung und Café in einem kombinieren.

Das Literarische Zentrum Göttingen ist nur als Veranstalter präsent und nicht als Ort, der mit Gastronomie oder anderem über die Veranstaltungen hinausgehenden Angebot stetig offensteht. Die Einrichtung ist ein Literaturhaus, das kein eigenes Gebäude prägt. Auch beim Literaturhaus in Freiburg wird als Kernaufgabe von Literaturhäusern die Organisation von Veranstaltungen verstanden. Vorerst ergänzen es weder ein festes Café noch eine Buchhandlung oder ein anderer tagsüber öffentlicher Ort zum ,umfassenden Literaturhaus' - und doch heißt es Literaturhaus Freiburg. Die Literaturveranstaltungseinrichtungen in Göttingen und Freiburg sind sich wegen des Veranstaltungsumfangs und der vergleichbaren Stadtstruktur sehr ähnlich obwohl die Vereinsgeschichten unterschiedlich sind. Das Literaturbüro Freiburg zog im Oktober 2017 in die Innenstadt um und heißt seitdem Literaturhaus Freiburg - das

${ }^{643}$ Vgl. Kapitel II 12.4.2.

${ }^{644}$ Heinz Ludwig Arnold zitiert nach: Blumenkamp 2007, S. 203.

${ }^{645}$ Das Literaturhaus Wiesbaden zum Beispiel hat eine Büchertauschstelle eingerichtet und setzt damit die Idee literarischen Austausches auf andere Art um. 
Literarische Zentrum Göttingen behält seinen Namen, hat weniger Personal und ist dennoch - anders als bisher Freiburg - im Netawerk der Literaturbäuser vertreten. Ein eigenes komplettes Gebäude muss für ein Literaturhaus also nicht notwendigerweise gegeben sein, für die Literatureinrichtung muss es aber einen festen Bezugsort geben, einen Ort, der für Lesungen und Literatur reserviert ist.

\section{4.4 Soziogeografische Verortung in Göttingen}

Göttingen ist mit seinen rund 130.000 Einwohner*innen eine kleinere Großstadt und keine Metropole mit Wirkung weit über die Region hinaus. Es liegt zwischen den größeren Städten Hannover im Norden und Kassel im Süden und ist umgeben von kleineren Orten. In der Region Südniedersachsen ist Göttingen aber die zentrale Stadt. Zur Zeit der DDR lag Göttingen im sogenannten Zonenrandgebiet, seit der Wiedervereinigung befindet sich die Stadt in der Mitte Deutschlands.

\section{4.4.1 Universitätsstadt Göttingen}

Göttingen, „Stadt, die Wissen schafft“ - so der Stadtmarketing-Slogan an den Fernverkehrsgleisen am Göttinger Bahnhof - ist eine Universitätsstadt. An der Universität und den Fachhochschulen sind mehr als 30.000 Menschen immatrikuliert, zwei Drittel davon wohnen in der Stadt. ${ }^{646}$ Damit bilden Studierende 15 Prozent der Gesamtbevölkerung, beziehungsweise sind knapp ein Viertel der in Göttingen Wirkenden Studierende. ${ }^{647}$ In diese Zahl sind noch nicht die Mitarbeiter*innen an den Hochschulen eingerechnet. Die Zahl derer, die direkt mit der Universität zu tun haben, ist entsprechend noch deutlich höher. In der Bahnhofsvorhalle liegen die Programme des Literarischen Zentrums aus, und es hängt am Informationsschalter ein Plakat, das die nächste Veranstaltung ankündigt. Wenn das Schild an den Gleisen zur Eigenbeschreibung der Stadt zu zählen ist, so lässt sich ferner die Präsentation der Literaturvermittlungseinrichtung dort als Teil des Selbstverständnisses als Wissenschaftsstadt begreifen. Das Literarische Zentrum steht in einer engen Beziehung zur durch die Hochschule geprägten Stadt und zur Universität selbst.

Die Nähe des Literarischen Zentrums Göttingen zur Universität ist darauf zurückzuführen, dass mit dem Gründer Heinz Ludwig Arnold eine Person die Einrichtung gründete, die für einen Austausch zwischen Literaturbetrieb und Universität plädierte; zudem ist eine enge Zusammenarbeit grundsätzlich sinnvoll in einer Stadt, in der das Publikum zu einem großen Teil aus Hochschulangehörigen bestehen wird. Die Verbindung ist historisch gewachsen und auf die Beteiligten zurückzuführen. Heinz Ludwig Arnold hat früh erkannt, dass eine Kooperation mit der Universität für beide Seiten sehr nützlich sein kann; er war sowohl in der Universität als auch im Literaturbetrieb tätig und wusste beide Sphären zu verknüpfen. Des Weiteren erklären

\footnotetext{
${ }^{646}$ Vgl. „Übersichtstabelle Studenten“, Göttinger Statistisches Informationssystem. Für 2015 waren 132.866 Einwohner gemeldet, 33.405 Personen sind an der Universität und den Hochschulen eingeschrieben. Von den Universitätsstudierenden wohnten rund 21.000 in Göttingen.

${ }^{647}$ Rechnet man die 10.000, die ihren Wohnsitz nicht in Göttingen gemeldet haben, zur Gesamtbevölkerungszahl, bilden die Studierenden 23,4\%.
} 
die Vorgeschichte des ersten prägenden Leiters Hauke Hückstädt im Literarischen Salon Hannover und die akademische Laufbahn seiner Nachfolgerin Anja Johannsen diese Orientierung. Möglicherweise entschied sich der Vereinsvorstand gerade aufgrund ihrer Nähe zur Universität für Johannsen - eine begründete Spekulation.

Es gehörte, wie oben andeutetet, von Beginn an zum Verständnis der Einrichtung, die Vermittlung von Literatur (und Literaturwissenschaft) und ihre Praktiken zum Thema des Literarischen Zentrums zu machen. 2000, als die theoretische Auseinandersetzung mit Autorschaft und Aufführungsaspekten in der Wissenschaft schon Konjunktur hatte und hochschulpolitisch zunehmend außeruniversitäre Kompetenzen und ,Praxiskomponenten“ für die Studierenden gefordert wurden, ist die Initiierung eines Literaturvermittlungsakteurs in Göttingen sinnvoll, denn so konnten die Studierenden als Besucher*innen an Lesungen teilnehmen und als Volontär*innen Arbeitserfahrungen sammeln. Zeitgleich mit der Akzeptanz und Steigerung von gegenwartsliterarischer Forschung gewinnen Begegnungen mit Autor*innen an Attraktivität. Dieser Prozess ist sicherlich kein Ursache-Folge-Phänomen, sondern eine sich gegenseitig beeinflussende Entwicklung.

Das Nebeneinander von Gegenwartsinteresse in der Wissenschaft und Stärkung literaturvermittelnder Instrumente und Akteur*innen lässt sich am Beispiel des Literarischen Zentrums Göttingen gut illustrieren. Öffentliche Veranstaltungen bei Tagungen oder Seminaren finden regelmäßig im Literarischen Zentrum statt. Beispielsweise finden seit 1999 jährlich - mit einer Pause von 2011 bis 2014 - die von ausgewählten Schriftsteller*innen gehaltene Lichtenberg-Poetikvorlesung und andere gemeinsame Veranstaltungen statt. Gelegentlich bieten die Mitarbeiter*innen des Zentrums Seminare an der Universität im Bereich Kulturmanagement und Veranstaltungsorganisation an. Die Nutzbarmachung der Praxiskompetenz bringt auch in anderen Städten Kooperationsmöglichkeiten jenseits von Veranstaltungen zwischen Universität und Literaturhaus hervor. Daneben sind in Göttingen das Kulturticket sowie das spezielle schon erwähnte Volontariatsmodell exemplarisch für die Partnerschaft von Literarischem Zentrum und Georg-August-Universität zu nennen. Das Kulturticket ist eine Initiative des allgemeinen Studierendenausschusses, bei der die Studierenden mit ihren Semestergebühren einen geringen Obolus zahlen, aus dem die mitwirkenden Kultur- und Freizeiteinrichtungen, wie Theater, Museen oder Sportstätten Anteile bekommen. Die Studierenden erhalten dafür an der Abendkasse freien Eintritt oder sehr große Vergünstigungen. Kulturpolitisch relevant ist dabei die Tatsache, dass der Zugang zu kulturellen Angeboten somit allen Studierenden unabhängig vom Einkommen offensteht. Das Literarische Zentrum profitiert davon, weil laut Aussagen des Teams mehr Studierende zu den Veranstaltungen kommen. Mit dem Kulturticket ist der Eintritt für Studierende zu Veranstaltungen des Literarischen Zentrums seit 2013 frei. Bekannt ist das Literarische Zentrum unter Göttinger Studierenden neben seinem Programm aufgrund der Volontariate, die es anbietet und die zunächst von den Seminaren der Deutschen, Skandinavischen, Slawischen, Englischen oder Romanischen Philologie sowie der Komparatistik finanziert wurden. Studierende dieser Fächer können sich bewerben und bis 2018 arbeiteten vier Volontär*innen über einen Zeitraum von einem Jahr offiziell je zehn Stunden pro Woche im Literarischen Zentrum mit. Die Volontär*innen sind mit Verträgen für studentische Hilfskräfte an 
der Universität beschäftigt. Es besteht hier eine enge gerade auch strukturelle Anbindung des Literarischen Zentrums an die Universität. Allerdings ist dies keine langfristig sichere Kooperation, seit 2018 sind beispielsweise nur noch zwei Stellen pro Jahr finanziert.

Diese Kooperation nutzt eigentlich beiden Seiten: Die Universität bietet ihren Studierenden die Möglichkeit, Praxiserfahrung zu sammeln, und die Literatureinrichtung bekommt qualifizierte Mitarbeiter*innen, für deren Bezahlung sie nicht aufkommen muss. Dieses Modell geht auf Heinz Ludwig Arnold zurück, der es gemeinsam mit Hauke Hückstädt schon früh anstieß. In Selbst- und Fremdbeschreibungen des Literarischen Zentrums spielt dieses Konzept eine wichtige Rolle, zumal es in dieser Regelmäßigkeit und Beständigkeit einzigartig in bundesdeutschen Kultureinrichtungen ist. Das Literaturbaus Freiburg hat das Modell übernommen, seit 2014 arbeitet dort jeweils ein Volontär aus dem Deutschen Seminar der Universität Freiburg mit. Dies unterstützt die Annahme, dass die Literaturhäuser stetig neue Möglichkeiten zur Finanzierung suchen und dass eine Einrichtung Anschluss an die lokalen Akteur*innen sucht, das Literaturhaus Freiburg somit ebenso einen engeren Kontakt zur örtlichen Universität anstrebt.

Zusätzlich zum geldwerten Vorteil des Literarischen Zentrums durch diese Kooperation ist dadurch die personelle Auswahl größer, denn die Universität motiviert die Studierenden zur Bewerbung. Die Kompetenzen der zahlreichen Hochschulangehörigen nutzen dem Literarischen Zentrum obendrein dabei, Moderator*innen für die Veranstaltungen zu finden. Oft leiten Literaturwissenschaftler*innen das Gespräch bei Lesungen, oder interviewen Akademiker*innen anderer Disziplinen die Gäste bei Sachbuchthemen. Dadurch ergeben sich seitens der Universität Möglichkeiten, ihre Stoffe für ein außeruniversitäres, breiteres Publikum aufzubereiten, was hochschulpolitisch zunehmend wichtiger wird.

Die Prägung des Literarischen Zentrums durch die Universität in der Stadt ist also vielseitig. Allerdings muss betont werden, dass abgesehen von den Volontariaten nur lose und projektbezogene Kooperationen bestehen und die Universität keinen direkten Einfluss auf die Literaturvermittlungseinrichtung hat. Anders ist dies in anderen Universitätsstädten beispielsweise beim Literarischen Zentrum Gießen, dem Literarischen Salon in Hannover oder dem Literaturbaus Graz in Österreich. Diese Literaturveranstaltungseinrichtungen agieren unter Trägerschaft der örtlichen Universität. Das Literaturhaus in Freiburg ist in den Räumen der Alten Universität angesiedelt, für die Umbaukosten für den ehemaligen Theatersaal kamen Universität, das Land Baden-Württemberg und die Stadt Freiburg auf. Der Trägerverein des Literaturhauses agiert jedoch inhaltlich völlig unabhängig von der Universität. Durch die räumliche Nähe und die Tatsache, dass der Saal des Literaturhauses weiterhin von den studentischen Theatergruppen, die schon vorher dort untergebracht waren, genutzt wird, entsteht eine organisatorische Pflicht zur Zusammenarbeit. Es zeigt sich an diesem Fall aber, wie brisant die Frage nach der Verbindung zur Universität bei gleichzeitiger Souveränität über das Programm und die Ortsgestaltung ist. Bei der Suche nach einem geeigneten Ort für das konzipierte Literaturhaus Freiburg standen unterschiedliche Möglichkeiten zur Diskussion. Überlegt wurde unter anderem, das Literaturhaus in Universitätsräume direkt neben der neuen Universitätsbiblio- 
thek zu platzieren. Dahinter stand die Idee, es so in das avisierte ,Geisteswissenschaftliche Zentrum` zu integrieren, was jedoch nicht verwirklicht wurde. Um öffentlichkeitswirksam zu agieren, hat die Universität ein berechtigtes Interesse an der Integration des Literaturhauses, allerdings versteht sich das Literaturhaus Freiburg, das in der Stadt schon lange unabhängig als Literaturbüro Freiburg tätig war, als autonome Einrichtung. Die Gefahr, von der Universität instrumentalisiert zu werden, ist bei einer hohen finanziellen wie infrastrukturellen Unterstützung zu groß. Dies betrifft natürlich nicht nur die Zusammenarbeit mit Universitäten, sondern jede Konstellation, wenn Förderer sehr großen Anteil an der Einrichtung haben. ${ }^{648}$

\section{4.4.2 Buchbranche in Göttingen}

Die Universitätsstadt Göttingen ist Standort einiger Fachverlage für wissenschaftliche Publikationen, wie der Psychologiefachverlag Hogrefe, der Verlag Cuvillier oder der Sierke Verlag. Besonders herauszustellen ist Vandenhoeck \& Ruprecht, ein Verlag, der bereits zu den Anfängen der Universität im 18. Jahrhundert in Göttingen akademische Schriften veröffentlichte. Neben diesen Wissenschaftsverlagen sitzen in der Stadt mit Steidl und Wallstein zwei renommierte, unabhängige Verlage, die neben Belletristiktiteln Kunst- und Sachbücher im Programm haben. Zu nennen ist ferner der Verlag Die Werkstatt, bekannt vor allem für Fußballbücher. Göttingen ist nicht nur historisch als Stadt der Göttinger Sieben mit den Brüdern Grimm oder als Gründungsort des PEN Zentrums Deutschland 1948 relevant, sondern ebenso heute beachtenswert für den Literaturbetrieb. Die genannten Einrichtungen sorgen dafür, dass der Wirkungskreis der Stadt abseits der Universitätssphäre nicht regional beschränkt ist.

Selbstverständlich sind in Göttingen ansonsten die Buchhandlungen als Literaturvermittler zu verstehen, die gelegentlich Autor*innen zu Lesungen einladen, ebenso wie die Theater oder die Universität. Außerdem finden in der Stadtbibliothek Göttingen Veranstaltungen statt, selten jedoch in Verbindung mit einem Schriftstellerbesuch.

\section{4.4.3 Literaturfestival Göttinger Literaturherbst}

Der größte Akteur des Literaturveranstaltungsbetriebs war in Göttingen anfangs das Literaturfestival Göttinger Literaturherbst. Seit 1992 treten im Oktober nationale und internationale Schriftsteller*innen an verschiedenen Orten in Göttingen auf. Als Veranstaltungsreihe über mehrere Monate angefangen, konzentriert sich der Göttinger Literaturherbst seit 1997 auf zehn Festivaltage, beginnend am Freitag der Frankfurter Buchmesse. Neben Belletristik wurde das Programm nach und nach mit Sachbüchern, zum Beispiel in einer Wissenschaftsreihe, ausgebaut. ${ }^{649}$ Die Fortentwicklung des Literaturherbstes ist unter anderem im Zusammenhang mit der in dieser Arbeit dargelegten allgemeinen Ausweitung des Literaturveranstaltungsbetriebs sowie kon-

${ }^{648}$ Vgl. Kapitel II 11.2.3.

${ }^{649}$ Vgl. ,Geschichte“, Göttinger Literaturherbst. 
kret mit dem Literarischen Zentrum zu sehen. Zum einen lässt sich insgesamt eine Zunahme an Literaturveranstaltungen und eine steigende Popularität von Literaturfestivals beobachten. Mächtige Festivals wie das internationale literaturfestival berlin oder die lit.COLOGNE feierten im Jahr 2001 ihre Premieren. Seit 2008 besteht in Hamburg das Harbour Front Literaturfestival. Doch auch länger bestehende Festivals wie das Erlanger Poetenfest (seit 1980) bauen ihre Positionen weiter aus. In München wurde das Konzept der Internationalen Frühjabrsbuchwoche (von 1990 bis 2008) überarbeitet und 2010 als Literaturfest München neu präsentiert. Der Göttinger Literaturherbst ist Selbstaussagen zufolge das älteste durchgehend veranstaltete Literaturfestival im deutschsprachigen Raum ${ }^{650}$ - das erwähnte Erlanger Poetenfest fiel 1992 einmal aus.

Literaturfestivals und Literaturhäuser sind keine sich ausschließenden Einrichtungen. Es lässt sich vermuten, dass sie sich gegenseitig anregen, was eine schwer nachweisbare, aber mit Indizien belegbare Hypothese ist. Der basale Unterschied liegt darin, dass Literaturhäuser kontinuierlich Veranstaltungen organisieren, während Festivals in der Regel nur einmal jährlich an wenigen Tagen oder einigen Wochen ein intensives Programm durchführen. Dies bezieht sich auf Unternehmen, deren Hauptaufgabe die Realisierung eines Festivals ist - wie die Göttinger Literaturherbst GmbH. Die Eindeutigkeit der Bezeichnungen verschwimmt, wenn in Literaturhäusern zusätzlich Festivals oder Symposien stattfinden, und Literaturfestivals außerdem unterjährig Lesungen anbieten. Das Verhältnis von Literaturhaus und Literaturfestival ist selten konfliktfrei, weil sie sich in einer Stadt als Konkurrenten gegenüberstehen können. Dies bedeutet nicht, dass beide nicht gleichzeitig zusammenarbeiten würden. Das Literaturhaus Köln beispielsweise kooperiert bei einigen Veranstaltungen mit der lit.COLOGNE und das Literaturbaus Berlin war sogar involviert in die Gründung des internationalen literaturfestivals berlin.

In Göttingen war die Beziehung zwischen Literaturberbst und Literarischem Zentrum lange Zeit sehr angespannt. Im ersten gemeinsamen Jahr 2001 wurde die Zusammenarbeit seitens des Festivals kurzfristig abgesagt. ${ }^{651}$ Die Sorge darum, dass die neue Einrichtung dem laufenden Festival öffentliche Gelder streitig mache, habe der Initiator des Literaturberbstes (Hans) Christoph Reisner (1965-2014) damals als Argument angebracht - was wiederum der Kulturamtsleiter Hilmar Beck negierte. ${ }^{652}$ Aussagen Hauke Hückstädts zufolge habe der Unmut seitens des Festivalschefs von Beginn an bestanden. Die Versuche, zu kooperieren, seien missglückt: „Und es ist doch rechtens zu sagen, das geht nicht zusammen - um es neutral auszudrücken." "653 Reisner sprach von „Abstimmungsproblemen“654. Es steht fest, dass der Göttinger Literaturherbst und das Literarische Zentrum anfangs keine gemeinsamen Veranstaltungen durchführten. Hauke Hückstädt antwortete auf die Frage zur Konkurrenz im Rückblick, dass der Göttinger Literaturberbst ihn bei seiner Arbeit in Göttingen „nie eingeschränkt"“655 habe. ,Konkurrenz' bedeutet aber nicht zwangsläufig, dass die

${ }^{650}$ Vgl. 25. Göttinger Literaturherbst 2016, S. 3.

${ }^{651}$ Vgl. Krüger-Lenz 2001.

${ }^{652}$ Vgl. Barke 2000.

${ }^{653}$ Hauke Hückstädt zitiert nach: Krüger-Lenz 2010.

${ }^{654}$ Christoph Reisner zitiert nach: Krüger-Lenz 2001.

${ }^{655}$ Hauke Hückstädt zitiert nach: Krüger-Lenz 2010. 
Beteiligten begrenzt werden, sondern dass sie in einem Wettbewerb stehen, sie in Relation zu einem Mitstreiter zu sehen sind und sie deshalb ihre Position präzisieren sollten, um allzu große Überschneidungen mit dem Gegenüber zu vermeiden. Für das Literaturhaus ist eine Mischung aus Eigenständigkeit und Zusammenarbeit wichtig - darauf läuft es in der vorliegenden Arbeit bei diversen Untersuchungsaspekten hinaus.

Als der Initiator des Literaturherbstes Christoph Reisner im Frühjahr 2014 verstarb und der vormalige technische Leiter Johannes-Peter Herberhold die Geschäftsführung übernahm, änderten sich die Verhältnisse. Die neue Führung ging davon aus, dass das Festival „nur ein wenig renoviert werden“656 müsste. Neben einer Erhöhung der Veranstaltungszahl formte sich vor allem die Organisationsstruktur um. Insbesondere für die Programmarbeit schloss Herberhold einen Kooperationsvertrag ausgerechnet mit dem Literarischen Zentrum. Gesa Husemann, die im Literarischen Zentrum mit einer 50-Prozent-Stelle das Bildungsprojekt Literatur macht Schule verantwortete, wurde mit einem zweiten Teilzeitvertrag dafür eingesetzt. Aus der personellen Verschwisterung ergeben sich weitreichende Konsequenzen; es tritt erneut die Simultanität von Konkurrenz und Koalition zutage.

Kommuniziert wird die geänderte Aufgabenverteilung im Impressum des Festival-Programmheftes in der Form, dass das Literarische Zentrum als einer der für die Veranstaltungskonzeption und Programmplanung verantwortlichen Akteure gelistet wird, der Name der Mitarbeiterin fällt ebenfalls. Doch offensiv betonen die Betreiber die gemeinschaftliche Arbeit nicht, alleiniger Festival-Veranstalter ist die Göttinger Literaturherbst GmbH. Das Literarische Zentrum wird bei dem aufmerksamkeitswirksamen Festival als Kooperationspartner präsentiert. Es ist für beide Parteien plausibel, auf diese Weise die gegenseitige Souveränität zu markieren. Zwischen ihnen besteht vor allem eine personelle Abhängigkeit. Anders verkündeten die Macher das Jubiläumswochenende Der Herbst im Frübling, das im April 2016 zum 25jährigen Bestehen des Literaturherbstes mit acht Veranstaltungen im Literarischen Zentrum stattfand. Hier luden beide zu einer Gemeinschaftspräsentation ein. Seit 2014 unterhält der Literaturberbst ein ganzjährig für Besucher*innen zugängliches Büro, unweit der Düsteren Straße. Der Literaturherbst nimmt buchstäblich einen Platz in der Stadt ein, was aus dessen Perspektive sinnvoll ist. Das Literarische Zentrum ist damit nicht mehr die einzige, dauerhaft auffindbare Einrichtung, die vorrangig Literaturveranstaltungen organisiert; es bleibt aber die einzige mit der vornehmlichen Funktion, das ganze Jahr über - abgesehen von den Pausen im Sommer und zum Jahreswechsel - Literaturveranstaltungen anzubieten.

Weiter ist anzunehmen, dass die zwei Einrichtungen um Gäste konkurrieren. Zum einen laden die großen Akteure Autor*innen, die mit ihren Neuerscheinungen im Herbst für Lesungen zur Verfügung stehen, in der Regel nur einmal in die Stadt ein; es gilt also, wer die ,Buchpremiere' in der Stadt ankündigen kann. Zum anderen bereitet die Personalunion möglicherweise Mühen, weil die Verantwortliche für zwei kooperierende und konkurrierende Unternehmen agiert: Wird die Autorin zum Literaturberbst eingeladen, oder möchte das Literarische Zentrum sie im Programm? Es gibt sicherlich Fälle, bei denen in dieser Hinsicht Kompromisse ausgehandelt werden

${ }^{656}$ Johannes-Peter Herberhold zitiert nach: Krüger-Lenz 2014. 
müssen, wie Gesa Husemann in einem informellen Gespräch bestätigte. Diese Diskussionen können allerdings bisher intern gelöst werden.

Da das Literarische Zentrum in der Regel nur etwa drei bis fünf Veranstaltungen pro Monat plant, im Oktober sogar meist weniger, gibt es selten Terminkollisionen mit dem Festival. Es ist aber nicht so, dass während des Göttinger Literaturherbstes gar keine Zentrums-Lesungen stattfänden. Der Veranstaltungszeitraum des Literaturherbstes kann aufgrund seiner Regelmäßigkeit vom Literarischen Zentrum langfristig einkalkuliert werden. Das Konfliktpotential, das ein konkurrierendes Angebot an einem konkreten Abend birgt, ist damit verringert. Anders war es etwa in Hamburg: Dort kam es 2015 wegen nicht geglückter Datumsabsprachen zwischen dem Harbour Front Literaturfestival und Literaturhaus Hamburg zum Eklat, denn Rainer Moritz kündigte vorerst die Zusammenarbeit der gewichtigen Literaturveranstalter auf. ${ }^{657} \mathrm{Ob}-$ wohl das Literaturhaus Hamburg weiterhin im Festivalprogramm vertreten ist, sich nach außen also keine konkreten Änderungen ergeben haben, machte die Nachricht darauf aufmerksam, dass die beiden Veranstalter ein Konkurrenzverhältnis hegen, wenn sie nicht in Austausch stehen, denn Absprachen sind für eine Koexistenz nützlich. Solche Zusammenstöße sind in Göttingen aufgrund der personellen Überschneidung absehbar nicht zu erwarten, die intensive Zusammenarbeit ist durch den Kooperationsvertrag geregelt. Außerdem haben sich Festival und ,Literaturhaus ' in Göttingen nach Jahren der Distanz angenähert, sodass die Beteiligten vermutlich keine öffentlichen Auseinandersetzungen provozieren werden. Trotz Koalition bleiben beide Literaturveranstalter aber weiterhin Konkurrenten.

\section{4.4.4 Weitere Kultureinrichtungen in Göttingen}

Über Veranstaltungen berichten in Göttingen als Feuilletonorgane, die in erster Linie regional rezipiert werden, vor allem die Lokalzeitung Göttinger Tageblatt und das seit 2010 am Seminar für Deutsche Philologie angesiedelte Litlog - Göttinger eMagazin für Literatur, Kultur und Wissenschaft. Litlog ist ein Beispiel für das Engagement der Universität, eine Verbindung zur ,Praxis' außerhalb der Wissenschaft zu schaffen, und es bezeugt das Göttinger Nebeneinander von Wissenschaft und Literaturbetrieb. Eine Verbindung zur Universität unterhalten weitere Kultureinrichtungen in Göttingen, wie das Deutsche Theater, das seit 1957 bestehende Junge Theater, das direkt in die universitäre Lehre integrierte Theater im OP, das Programmkino Lumière, das neben Filmvorführungen gelegentlich Lesungen oder Diskussionen anbietet, sowie das Kulturzentrum APEX, das vor allem Kleinkunst und Comedy im Programm hat. Als Veranstaltungsorte werden zusätzlich zu den genannten, die ein eigenes Programm anbieten, das Alte Rathaus, das bei größeren Lesungen vom Literarischen Zentrum genutzt wird, die Stadthalle und die Lokhalle bespielt. Die Stadthalle ist zum Beispiel der Saal des Göttinger Symphonieorchesters, die Lokhalle wird vor allem von Wirtschaftsunternehmen gemietet. Dort gastieren aber ebenso beispielsweise die jährlich stattfindenden Internationalen Händelfestspiele oder der genannte Göttinger Literaturherbst. Kunstmuseen gibt es in Göttingen nicht. Dafür muss das Göttinger Publikum in die gut erreichbaren Städte Kassel und Hannover reisen.

${ }^{657}$ Vgl. Andre 2015. 


\section{4.5 Literarisches Zentrum und die Institution Literaturhaus}

„Die Metropole ist im Kopf oder nirgends.“ Diesen Satz erklärte der Leiter des Literarischen Zentrums zum Motto der Einrichtung (GT 2001-01/04)658. Das Zitat spielt damit, dass der Terminus ,Metropole‘ nicht nur mit geografischen Kriterien klar zu beschreiben sei, sondern ebenso durch ein weltoffenes Programm der ansässigen Akteur*innen bestimmt werden könne. Dieses in Göttingen zum Leitspruch zu machen, ist eine ironische Auseinandersetzung mit dem eher provinziellen Charakter, der im Vergleich zu den Großstädten einer Stadt wie Göttingen anhaftet, die aber zu den sie umgebenden noch kleineren Städten als Oberzentrum fungiert.

Das Literarische Zentrum Göttingen wirkt durch seine Arbeit zunehmend über die Stadtgrenzen hinaus. Gemeinsam mit den erwähnten Kulturakteur*innen, wie Verlagen und dem Festival, prägt es Göttingen nicht nur als Universitätsstadt, sondern auch als Ort des Literaturbetriebs. Die Zusammenarbeit des Literarischen Zentrums mit überregionalen Organen unterstützt dies: Die Teilnahme am Netəwerk der Literaturbäuser ist zu nennen. Bereits seit 2005 besteht die Arbeitsgemeinschaft der sechs niedersächsischen Literaturhäuser Raabe-Haus: Literaturzentrum Braunschweig, Literaturhaus Hannover, Literaturbüro Lüneburg, Literaturbüro Oldenburg, Literaturbüro Westniedersachsen in Osnabrück und Literarisches Zentrum Göttingen. Bemerkenswert ist, dass sich diese Organisationen mit diversen Eigenbezeichnungen selbst unter dem Titel ,Literaturhaus' versammeln. Dieser Zusammenschluss stärkt die beteiligten Literaturveranstalter in Niedersachsen, denn ihr gemeinschaftlicher Auftritt erhöht die Sichtbarkeit der sechs eher kleinen Einrichtungen. Der Verbund präsentiert sich seit 2005 mit einem relativ großen Stand auf der Leipziger Buchmesse. Die Verlage stellen ihr kommendes Programm und die geplanten Lesereisen dann meistens allen Programmleitungen vor - Termine für alle sechs Einrichtungen einzeln könnten die Verlage vermutlich nicht realisieren. Solche Beobachtungen scheinen vermeintlich kleine Vorteile zu sein; doch da auf den Buchmessen respektive kurz danach die meisten Autorenreisetermine vereinbart werden, sind diese frühen Informationen und Kontakte ein wichtiger Aspekt für die Gestaltung eines aktuellen Veranstaltungsprogramms, wie es das Literarische Zentrum Göttingen - das geht aus der Programmanalyse hervor - durchführt.

Als Universitätsstadt hat Göttingen bei den Städten dieser Fallstudienanalyse Gemeinsamkeiten mit dem norwegischen Bergen. Doch es zeigt sich einmal mehr, wie wichtig es ist, die Städte und Literaturhäuser in ihrem Kontext zu verorten und bei Vergleichen verschiedene Aspekte zu berücksichtigen. Denn Bergen ist mit 250.000 Einwohner*innen die zweitgrößte Stadt Norwegens und neben der Hauptstadt die nächstgrößte Metropole und steht damit, wie in den folgenden Kapiteln ausgeführt wird, in einer anderen Beziehung zu den Großstädten ihres Landes als Göttingen. Anders als in Norwegen, wo Oslo dem übrigen Land und den anderen Orten gegenübergestellt ist, und alle Städte wie auch Bergen sich in Relation zu Oslo darstel-

${ }^{658}$ Paul Nizon veröffentlichte Anfang 2000 in der Frankfurter Rundschau einen Artikel mit dem Titel Metropole im Kopf. Die Weltstadt - ein Laboratorium der Zukunft, vgl. Nizon 2000. Auch der Historiker Heinz Schilling verwendete dieses Bild schon 1994 in einem Artikel. 
len, ist Deutschland weniger auf eine Stadt konzentriert: Die Bundeshauptstadt Berlin ist zwar ein wichtiges Zentrum, doch gibt es in Deutschland noch weitere Metropolstädte, die mit Berlin konkurrieren. Hinsichtlich ihrer Relation zur Metropole Oslo ist Bergen eher Hamburg, Köln oder Frankfurt ähnlich.

Als Stadt an sich ist Göttingen kaum mit Berlin, Hamburg oder Frankfurt zu vergleichen, doch das Literarische Zentrum Göttingen muss den Vergleich mit seinen großstädtischen Pendants nicht scheuen, wenn die lokalen Gegebenheiten Berücksichtigung finden. Es ist zum Beispiel einleuchtend, dass in Göttingen weniger Veranstaltungen pro Monat stattfinden als in den Literaturhäusern in den Großstädten, die finanziell üppiger ausgestattet sind und deren potenzielles Publikum aus einer höheren Anzahl von Menschen besteht. Am Beispiel Göttingen ist ersichtlich geworden, dass überregionales Wirken wichtig für die Wahrnehmung als Literaturhaus ist. Die Vergleichbarkeit begründet sich über das Programm. Ein Literaturhaus präsentiert nicht nur lokal wirkende Schriftsteller*innen, sondern bietet vornehmlich professionell Schreibenden eine Bühne und lässt nationale wie internationale $\mathrm{Au}$ tor*innen zu Wort kommen. Es ist eine Einrichtung mit festem Veranstaltungsort, die ganzjährig ein kuratiertes Programm vor allem mit Literaturveranstaltungen anbietet und dabei überregional wirksam ist. Unter Berufung auf diese Funktionsbeschreibung lässt sich das Literarische Zentrum Göttingen als Literaturhaus kategorisieren, denn das Programm des Literarischen Zentrums Göttingen folgte von Beginn an diesem Anspruch. Die finanzielle Ausstattung, die für Heinz Ludwig Arnold noch als Argument gegen die Bezeichnung als ,Literaturhaus' sprach, ist nicht prinzipiell ein Abgrenzungskriterium. Die zur Verfügung stehenden Mittel beschränken zwar den Umfang des Programmangebots, doch ein Literaturhaus muss nicht unbedingt jede Woche mehrere Veranstaltungen mit drei zu bezahlenden Akteur*innen anbieten, um als Literaturhaus zu gelten. Die Ambition, überregional und aktuell mitzumischen, spielt eine wichtigere Rolle.

In der Diskussion bewies sich, dass es produktiv für die Untersuchung der Institution ist, eine Einrichtung mit anderem Namen, der im Wissen um die Vereinsgeschichte verständlich ist, einzubeziehen. Die Darstellung des Literarischen Zentrums Göttingen macht deutlich, dass die Institution ,Literaturhaus' ebenfalls Veranstalter, die einen anderen Namen tragen, aber strukturell vergleichbar sind, umfasst.

Wie bei den anderen Einzeldarstellungen zeigte sich des Weiteren, dass jede Einrichtung ihr eigenes Profil aufweist. Die Charakteristika einer Kultureinrichtung ergeben sich aus den lokalen, finanziellen und personellen Gegebenheiten. Dies gilt sicherlich nicht nur für Literaturhäuser, sondern lässt sich auf Theater, Konzerthäuser oder Ausstellungsorte übertragen. Bei den Literaturhäusern mit relativ kurzer Historie und einer überschaubaren Anzahl an Beteiligten lassen sich diese Verstrickungen jedoch besser herausarbeiten als bei größeren älteren Einrichtungen.

Das Literarische Zentrum Göttingen passt sich an die Bedingungen der kleineren Großstadt an. Zudem ist es, wie oben dargelegt, insbesondere durch die hohe Affinität zur Universität geprägt, sowohl strukturell und personell als auch inhaltlich. Beim Selbstdarstellungstext, dessen Interpretation das nächste Kapitel bereithält, wird die Nähe zur Wissenschaft nicht besonders betont, dort erscheint das Eigenverständnis als „begehbares Feuilleton“ maßgeblich zu sein. Die Absicht, mit die- 
sem Programm nicht nur ein im engeren Sinne literaturinteressiertes und zwischen den Kunstarten differenzierendes Publikum anzusprechen, weist aber ebenfalls in Richtung Universität, die sich ja nicht ausschließlich mit Literaturwissenschaft befasst. Diese programmatische Ausweitung des Angebots über die Literatur hinaus ist außerdem mit Blick auf das ortsansässige, schon länger aktive Literaturfestival zu verstehen. Im Wettbewerb um Aufmerksamkeit stellt sich das Literarische Zentrum breiter auf, wenn es gleichermaßen Literat*innen und Nicht-Literat*innen einlädt. Derartige Wechselbeziehungen beeinflussen die Ausgestaltung einer Einrichtung entscheidend.

\section{5 LiteraturHaus und Litteraturhuset in Kopenhagen}

Das erste Literaturhaus in Skandinavien wurde 2005 in Kopenhagen eröffnet. Während der Arbeit an der vorliegenden Studie hat sich an der Situation in Kopenhagen einiges verändert, sodass diese Beschreibung einen Zwischenstand reflektiert. Abgeschlossen sind die Entwicklungen in den anderen Literaturhäusern ebenfalls nicht, doch beweist sich am Kopenhagener Beispiel, wie sehr die Institution in Bewegung ist: Zum einen ist LiteraturHaus strukturellen Veränderungen unterworfen, zum anderen entsteht mit Litteraturbuset ved Vandkunsten aktuell ein zweites Literaturhaus in der Stadt, das jedoch die dänische Variante des Namens trägt. Beide Aspekte sind für die Auseinandersetzung mit der Institution sehr interessant, wie im Folgenden ausgeführt wird. Ausgewählte Hintergrundinformationen zur Entstehung und Konzeption dienen wie in den vorherigen Unterkapiteln der Vorstellung und Einordnung der Fallbeispiele.

\section{5.1 Gründungsidee für ein Literaturhaus in Kopenhagen}

„Som turnerende lyriker har Pia Tafdrup set noget i udlandet, som vi ikke har herhjemme. Hun har set litteraturhuse. "659 [Als auf Tournee gehende Lyrikerin hat Pia Tafdrup etwas im Ausland gesehen, das wir hierzulande nicht haben. Sie hat Literaturhäuser gesehen.] Die dänische Lyrikerin Pia Tafdrup (*1952) stieß im Jahr 2000 die Diskusion zu einem Literaturhaus in Kopenhagen an. ${ }^{660}$ Als Reaktion führten das staatliche, dem Kulturministerium unterliegende Dansk Litteraturcenter [Dänisches Literaturzentrum (heute Teil des Dänischen Kulturfonds, Anmerkung C.L.)] in Zusammenarbeit mit dem Goethe-Institut im Mai 2001 eine Konferenz im Mostings Hus in Frederiksberg durch: Nach einem Wochenende mit öffentlichen Literaturveranstaltungen als „Litterær appetitvækker“661 [literarische Appetitanreger] stellte der klare Titel Litteraturhus Kobenhavn? die Ausgangsfrage für eine Diskussion, ob

\footnotetext{
${ }^{659}$ Lykkeberg 2001. Zur Erinnerung: Die in Klammern angegebenen Übersetzungen der skandinavischen Zitate stammen in der gesamten Arbeit von der Verfasserin.

${ }^{660} \mathrm{Vgl}$. Andersen 2000.

661 Andersen 2001a.
} 
und in welcher Ausführung ein Literaturhaus in der dänischen Hauptstadt sinnvoll und realisierbar sein könne. Eingeladen waren neben Kopenhagener Literaturbetriebsakteur*innen Vertreter*innen aus den Literaturhäusern in Berlin, Hamburg, Köln und Stuttgart, um von ihren Einrichtungen und Erfahrungen zu berichten. Dabei sei unter anderem die internationale Perspektive als wichtiges Charakteristikum für ein Literaturhaus identifiziert worden. Es habe also bei diesem Treffen viele Fürsprecher*innen, aber auch kritische Stimmen einem Kopenhagener Literaturhaus gegenüber gegeben. ${ }^{662}$ Nur ein Literaturhaus mit etablierten Autorennamen könne, wie etwa der Verleger von Dänemarks größtem Verlag Gyldendal anmerkte, „den rette gennemslagskraft" ${ }^{\text {"663 }}$ [die richtige Durchschlagskraft] erzeugen, die ein neu gegründetes Literaturhaus brauche, um sich zu konsolidieren. Auf der Konferenz bestand Einigkeit darüber, ,at det er for provinsielt og selvtilstrækkeligt, at vi ikke i København har et eneste forum for udenlandske forfattere“"664 [dass es zu provinziell und selbstgenügsam ist, dass wir in Kopenhagen nicht ein einziges Forum für ausländische Autor*innen haben].

Als Hauptstadt Dänemarks bildet Kopenhagen auch den kulturellen Mittelpunkt des Landes. ${ }^{665}$ Während die zweitgrößte Stadt Aarhus im Norden als Universitätsstadt sehr wichtig ist, lässt sich Kopenhagen, historisch gesehen unter anderem aufgrund der Personalunion mit Norwegen bis 1813 und wegen der geografischen Nähe etwa zum schwedischen Malmö, die durch die im Jahr 2000 eröffnete Øresundsbroen [Öresund-Brücke] noch betont wurde, als nordeuropäische Metropole beschreiben. Unter anderem aufgrund der 1479 gegründeten Kobenbavns Universitet und damit nach Uppsala der zweitältesten Universität in Skandinavien sowie natürlich aufgrund der Machtbündelung als Regierungssitz nimmt die Stadt schon früh eine zentrale Position in Dänemark und ganz Skandinavien ein. Dort haben zudem die beiden wichtigen Organe skandinavischer Zusammenarbeit Nordisk Ministerråd und Nordisk Råd ihren Sitz. Für die an der genannten Literaturhaus-Konferenz beteiligten Akteur*innen stellte ein Literaturhaus also auch die Chance dar, Kopenhagen als Kulturmetropole zu stärken und seine internationale Relevanz zu betonen. Die dort aufgeworfene Idee, ein Konzept für ein Literaturhaus in Kopenhagen zu entwickeln und zu prüfen, wurde allerdings im Anschluss nicht umgesetzt. Von Beginn an war deutlich, dass die Realisierung sehr teuer sein würde, „hvis man skal nå det ambitionsniveau, som eksisterer i de tyske litteraturhuse "666 [wenn man das Ambitionsniveau erreichen möchte, das ist den deutschen Literaturhäusern besteht]. So ist es vermutlich auf finanzielle Gründe zurückzuführen, dass die Überlegungen für ein Literaturhaus in Kopenhagen von öffentlicher Seite nicht weitergeführt wurden. Die kulturpolitischen Überlegungen, den Transfer des deutschen Literaturhaus-Modells zur Aufwertung der städtischen Positionierung im internationalen Kontext zu nutzen, spielten ebenfalls beim Litteraturbuset in Oslo eine Rolle, so werden sie im nachfolgenden Kapitel am Beispiel Norwegens ausgeführt.

662 Zur Zusammenfassung der Tagung vgl. Andersen $2001 \mathrm{~b}$.

${ }^{663}$ Johannes Riis zitiert nach: Thomsen und Starup 2006.

${ }^{664}$ Lykkeberg 2001.

${ }^{665}$ Die Einwohnerzahl von Kopenhagen betrug zum 1.1.2017 602.481, in Aarhus waren 335.728 Ein-

wohner*innen verzeichnet, vgl. „Statistikbanken“, Danmarks Statistik.

666 Andersen 2001b. 


\section{5.2 LiteraturHaus als erstes Literaturhaus in Skandinavien}

Paul Opstrup, der als Kulturvermittler an der Tagung im Mai 2001 teilnahm und die deutschen Literaturhäuser kannte, verfolgte das Vorhaben, in Kopenhagen ein Literaturhaus zu gründen, weiter. Neben einem konkretisierten Konzept galt es also, ein Haus für die Literatur zu finden. Die Suche nach einem geeigneten Ort endete, als Opstrup 2004 mit privaten Mitteln, ohne öffentliche Unterstützung das Gebäude in der Mollegade 7 im Stadtteil Nørrebro kaufte. Es handelt sich dabei um eine ehemalige Methodistenkirche der Bethania Kirke aus dem Jahr 1892, die seit 1995 leer stand, dann künstlerisch-experimentell zwischengenutzt und letztlich zwangsversteigert wurde. ${ }^{667}$ Aufwendige Renovierungen und Umgestaltungen, die in den deutschen Literaturhäusern durch öffentliche Mittel oder Stiftungsgelder ermöglicht wurden, ließen sich nach dem Kauf 2004 jedoch nicht realisieren. Das Gebäude wurde aber schallisoliert und für die Nutzung als Literaturhaus aufbereitet. Die langen schmalen Fenster und die Platzierung der Bühne im ehemaligen Altarbereich erhalten die Kirchenoptik weiterhin. Der Balkon im hinteren Teil des Saales wurde bis 2017 nur für die Lichtanalage genutzt, erst dann konkretisierten sich die Pläne, daraus einen stetigen Ausstellungsraum zu machen. Auch das Dachgeschoss ist nicht ausgebaut. Im Kellerraum richteten die Akteur*innen des LiteraturHauses ein mit verschiedenartigen gebrauchten Sesseln und Stühlen ausgestattetes Café ein. Es wird nicht extern, sondern ebenfalls vom Eigentümer betrieben, kann aus Geldmangel jedoch nicht tagtäglich geöffnet sein. Die Inneneinrichtung wirkt stellenweise etwas provisorisch, was dem Ort mit Graffitis an der Hausfassade ein alternativeres Ambiente verleiht, als es die hochwertig eingerichteten anderen Literaturhäuser aufweisen. Dies ist zwar unter anderem auf finanzielle Gründe zurückzuführen, passt aber in die Gegend: Nørrebro hat sich in den letzten Jahren zu einem vor allem für junge Menschen attraktiven Stadtteil mit Boutiquen, Galerien und Cafés entwickelt, der als gentrifizierter Stadtteil um „byens hipstertitel“"668 [Hipstertitel der Stadt] konkurriert, wie er für Tourist*innen beworben wird. In der Tat ist das Quartier eher mit Hamburgs Schanzenviertel oder Berlin-Neukölln zu vergleichen als mit den bürgerlich geprägten Standorten der Literaturhäuser in Hamburg, Berlin oder Oslo.

\section{5.2.1 Transfer der Literaturhaus-Idee}

Im April 2005 eröffnete LiteraturHaus in Kopenhagen. Wie der deutsche Name demonstriert, ist diese Einrichtung eindeutig an den deutschen Literaturhäusern orientiert. Dies illustriert auch die Auftaktveranstaltung, zu der Günter Grass eine Videobotschaft sendete und Ernest Wichner, der damalige Leiter des Literaturhauses Berlin, als Vertreter der deutschen Literaturhäuser sprach. ${ }^{669}$ Deutlicher als bei den anderen skandinavischen Literaturhäusern bestand in Kopenhagen mit dem Transfer des deutschen Modells eine direkte kulturelle Einordnung in den dortigen Kontext als Abgrenzung zu einer US-amerikanisch geprägten reinen Marktfokussierung. Als Teil

\footnotetext{
667 Vgl. Jensen 2006, S. 14.

668 „Københavns livlige“, Visit Copenhagen.

${ }^{669} \mathrm{Vgl}$. „Åbningen af“" LiteraturHaus via Wayback Machine.
} 
der Programmatik verstand Opstrup es, an die europäische Tradition anzuknüpfen, „hvor litteratur ikke kun styres af markedets kræfter"“670 [wo Literatur nicht nur von der Macht des Marktes geleitet wird]. Damit formulierte er anschaulich, was auch die theoretischen Ausführungen zum Kulturtransfer des ersten Kapitels zu fassen beabsichtigen. Das Literaturhaus-Konzept dient in diesem Fall zum einen als Anregung dafür, in Kopenhagen ebenfalls einen Ort als literarischen Treffpunkt und Veranstaltungsstätte aufzubauen, also dazu, ein Bedürfnis nach Austausch über Literatur zu stillen. Zum anderen betont Opstrup die Bezugnahme auf den deutschen Hintergrund deutlich: Das Transferobjekt, also das Literaturhaus-Konzept, ist somit auch Transfersubjekt und soll dazu dienen, ,deutsche Kultur 'beziehungsweise ,zentraleuropäische Kultur' im Sinne eines kulturkritischen Verständnisses nach Dänemark zu übertragen. Ihm ging es damit weniger um eine kultur- und städtepolitische internationale Verortung, sondern vielmehr um eine Zuordnung zu einem bestimmten Verständnis von Kultur. Dennoch unterstrich die Einrichtung vor allem in den Anfangsjahren ihr Interesse an europäischer Vernetzung. ${ }^{671}$

Opstrup griff auf die Grundidee des Literaturhauses zurück. Zwei offen auslegbare Kriterien habe er als entscheidend für den Erfolg eines Literaturhauses erkannt: ein gutes Programm und ein gutes Café. ${ }^{672}$ Obgleich LiteraturHaus nicht für ein regelmäßig geöffnetes Café Sorge tragen konnte, erscheint die dahinter liegende Absicht, den Ort als alltäglichen Treffpunkt zu etablieren, zumindest dadurch gelungen, dass das LiteraturHaus jahrelang mit ehrenamtlichem Einsatz Programm anbot und weiterhin anbietet. Inhaltlich markierte Paul Opstrup aber auch eine Abgrenzung von den deutschen Literaturhäusern. LiteraturHaus in der Mollegade sei aktivistischer, experimenteller und mehr „tværkunstnerisk“ [interdisziplinär, wörtlich: zwischenkünstlerisch] angelegt als die deutschen Literaturhäuser. ${ }^{673}$ Besonders die Einbindung anderer Kunstformen fällt im Kopenhagener Programm auf, denn Konzerte bildeten einen großen Anteil daran; so war das Haus etwa am jährlichen Kopenhagener Jazz-Festival beteiligt. Eine Affinität zu inszenatorisch bemerkenswerten Veranstaltungen weist auf das Interesse hin, das Literaturhaus als Erlebnisort zu begreifen, wo die Aufführung die Möglichkeiten des Raumes ausnutzt und nicht ,einfach nur vorgelesen wird. ${ }^{674}$ Wichtiger Programmpunkt war dementsprechend seit 2006 Kobenhavns Internationale Poesifestival.

\section{5.2.2 Organisation und Finanzierung}

Noch deutlicher als in den anderen Literaturhäusern geht das LiteraturHaus auf den Einsatz einer Privatperson zurück. Paul Opstrup (*1953) war vor dem Engagement für das Literaturhaus von 2001 bis 2003 Leiter von Huset, ein Kulturhaus, das sich in

\footnotetext{
${ }^{670}$ Paul Opstrup zitiert nach: Nielsen 2005.

671 Thomsen und Starup 2006. Thomas Bo Thomsen und Marie Starup waren ehrenamtlich im Literatur-

Haus tätig. Zum ersten Jubiläum der Einrichtung veröffentlichten sie die hier zitierte Chronik in der

Tagezeitung Information.

${ }^{672}$ Vgl. ebd.

${ }^{673}$ Vgl. ebd.

${ }^{674}$ Vgl. Jensen 2006, S. 15.
} 
einem in den 1970er-Jahren besetzten Haus entwickelt hatte. ${ }^{675}$ Ab 2004 investierte er nicht nur seine Arbeitszeit in den Aufbau und den Betrieb, sondern ermöglichte das Literaturhaus mit seinem Privatvermögen finanziell überhaupt erst. Mit einem öffentlichen Zuschuss von Kunststyrelsen [die Kulturverwaltung] in Höhe von 225.000 Dänischen Kronen [circa 30.000 Euro] für das erste Jahr, finanziert sich die Einrichtung vor allem über Eintrittsgelder, Mieteinnahmen und Projektmittel für einzelne Veranstaltungen. ${ }^{676}$

„En privat tænketank af ildsjæle indvier“ ${ }^{\prime 677}$ [Ein privater Thinktank enthusiastischer Individuen] und die Mithilfe von Praktikant*innen und weiteren Ehrenamtlichen führt seitdem die Veranstaltungen im LiteraturHaus durch. Paul Opstrup als Initiator und Hauseigentümer hatte bis 2016 auch die Programmleitung inne. Abweichend von den anderen untersuchten Literaturhäusern trat in Kopenhagen also nicht ein Verein oder eine Stiftung als Träger auf, sondern blieb das Unternehmen privat und auf eine Person konzentriert. Außerdem ist es das einzige der Fallbeispiele, das bisher keine strukturelle Förderung erhält, sodass für jede Veranstaltung eine eigene Finanzierung gefunden werden muss, „hvilket ikke giver os den offensive kraft, man har, når der er penge fra starten af" 678 [was uns nicht die offensive Kraft gibt, die man hat, wenn es von Beginn an Geld gibt], wie Opstrup konstatiert. Geplant war, dass die privaten Gelder für die ersten zwei Jahren ausreichen und dann öffentliche Förderung bewilligt werden würde, ${ }^{679}$ dies war jedoch nicht der Fall. Kritiker*innen der dänischen Kulturpolitik, wie der Autor Stig Dalager, bezeichneten es als typisch für Kopenhagen, dass die privaten Initiativen wie LiteraturHaus nicht unterstützt werden, obwohl ein Literaturhaus mit einem in Relation zu anderen Kunstsparten kleinem Budget arbeiten und das Kulturleben der Stadt davon profitierten könne, was sich wiederum positiv auf Kopenhagen insgesamt auswirken könne. ${ }^{680}$ Paul Opstrup selbst äußert in einem Interview, dass er nicht so gut darin gewesen sein, Geld zu akquirieren, dies jedoch der Schlüssel sei, denn es bedürfe „driftstøtte“681 [Betriebskostenzuschuss] zur langfristigen Planung.

Im Vergleich zu den anderen untersuchten Literaturhäusern fällt auf, dass der Auftritt der Kopenhagener Einrichtung weniger strukturiert und in diesem Sinne weniger professionell wirkt. LiteraturHaus in Kopenhagen arbeitete vor allem mit Freiwilligen und konnte somit keine solide Basis für das Gesamtprogramm aufbauen, weil es keine festen Mitarbeiter*innen gab, die sich hauptamtlich um die Konzeption und vor allem die finanzielle Absicherung kümmern konnten. Dies äußerte sich beispielsweise darin, dass die Website lange nicht modernisiert wurde, ${ }^{6} 82$ es kein regelmäßig erscheinendes Programmheft gab und LiteraturHaus immer mit dem Namen ,Paul Opstrup“ verbunden wurde, also kein ohne ihn stehendes Literaturhaus denkbar erschien.

$675 \mathrm{Zu}$ Huset vgl. „Om Huset“, Huset-KBH. Für weitere Informationen zu Opstrups dortigem Ausscheiden vgl. Westh: „Husets leder“.

${ }^{676}$ Vgl. Jensen 2006, S. 16.

677 Nielsen 2005.

${ }^{678}$ Paul Opstrup zitiert nach: Brandt 2017a.

${ }^{679}$ Vgl. Nielsen 2005.

${ }^{680}$ Vgl. Dalager 2012.

${ }^{681}$ Paul Opstrup zitiert nach: Brandt 2017a.

${ }^{682}$ Vgl. z. B. „Presseomtale“, LiteraturHaus via Wayback Machine. 


\section{5.2.3 Umstrukturierung - Das neue LiteraturHaus}

Im Jahr 2016 kam es im LiteraturHaus zu weitreichenden Umstrukturierungen, die zum Nye LiteraturHaus [Neues LiteraturHaus] führen sollten. Geplant war, dass die neu gegründete Trägerorganisation LiteraturHaus a.m.b.a. [Andelsselskab med begrænset ansvar, Gesellschaft mit beschränkter Haftung] Eigentümerin des Literaturhauses werden und damit die Aufgaben gemeinschaftlich verantworten sollte, die Paul Opstrup bisher allein innegehabt hatte. Das Haus wurde von Anfang an von Ehrenamtlichen unterstützt, diese Gemeinschaft sollte nun mit der neuen solidarischen Trägerschaft formalisiert und noch wichtiger werden. Paul Opstrup wollte sich auf diese Weise aus Altersgründen nach und nach aus dem Literaturhaus zurückziehen, aber für eine Fortführung seines „livsværk““683 [Lebenswerks] sorgen. Er trat dem Vorstand bei, was absichern sollte, dass die Umwandlung des LiteraturHauses im Sinne der alten und der neuen Leitung gelingen könne. ${ }^{684}$ Die LiteraturHausLeitung übernahmen im Herbst 2016 zunächst vier Akteurinnen, die zuvor ehrenamtlich im LiteraturHaus mitgearbeitet hatten, letztlich blieben Ariane Veiergang (*1989) und Henny Hagerup (*1988). Im Laufe des Jahres vom September 2016 bis November 2017 überarbeiteten sie die Website, die die „Fornyelse af LiteraturHaus"“685 [Erneuerung vom LiteraturHaus] verkündete, veröffentlichten Aufrufe zur aktiven Teilhabe an der Neuausrichtung, initiierten neue Veranstaltungen und brachten viele Ideen in das Haus. ${ }^{686}$

An diesem Fall werden die Herausforderungen von Gegenwartsforschung anschaulich: Innerhalb einer kurzen Periode - während der Arbeit an dieser Dissertation wurde LiteraturHaus umstrukturiert und es deutete sich an, dass das Kopenhagener Beispiel sich stabilisieren könnte. Dies ist für die vorliegende Studie unbedingt relevant. Doch es kam zu einem weiteren fundamentalen Einschnitt: Das Literaturhaus wurde letztlich nicht vollständig und nachhaltig umgewandelt, denn die Verhandlungen zwischen LiteraturHaus a.m.b.a., Paul Opstrup sowie Henny Hagerup und Ariane Veiergang mündeten nicht in einen Konsens. Nach etwas mehr als einem Jahr im November 2017 wurde die Gesellschaft niedergelegt und in der Folge gaben die Leiterinnen ihren Rücktritt bekannt. ${ }^{687}$ Diesen kommunizierte LiteraturHaus zunächst neutral und ohne Angabe von Gründen, was die Facebook-Meldung in Abbildung 3 belegt.

\footnotetext{
${ }^{683}$ Paul Opstrup zitiert nach: Almbjerg 2017.

${ }^{684}$ Vgl. Veiergang: „Om vores“.

${ }^{685}$ „Fornyelsen af“, LiteraturHaus via Wayback Machine.

${ }^{686}$ Vgl. z. B. Nielsen 2017.

687 Vgl. Brandt 2017b.
} 


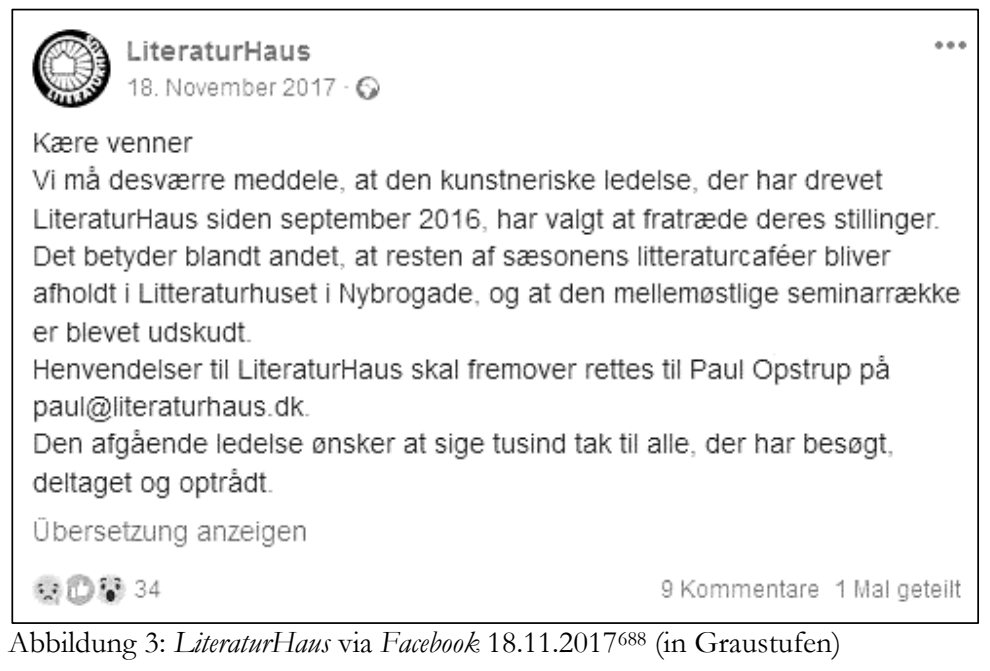

Die anschließende Berichterstattung stellt heraus, dass als Gründe für den Abschied seitens Opstrups finanzielle angegeben wurden, ${ }^{689}$ während Hagerup und Veiergang betonten, dass personale und strukturelle Differenzen zu ihrer Entscheidung geführt haben, wie sie es unter anderen in einer auf Facebook veröffentlichten Stellungnahme darlegten. ${ }^{690}$ Paul Opstrup als Eigentümer des Gebäudes übernahm somit LiteraturHaus wieder und suchte nach einer langfristigen Lösung:

Det er kun den binding, at det skal være et litteraturhus efter tysk forbillede, hvor der er tilbud til publikum. Derudover er der vide rammer. ${ }^{691}$

[Es gibt nur die Voraussetzung, dass es ein Literaturhaus nach deutschem Vorbild sein soll, wo es ein Angebot für ein Publikum gibt. Darüber hinaus sind die Rahmen weit.]

Eine solide Basis für das Literaturhaus in der Mollegade scheint sich bis zum Sommer 2018 noch nicht ergeben zu haben. Es finden dort Veranstaltungen statt, allerdings ist nicht klar, ob und in welcher Form diese Einrichtung eine Zukunft hat. „Og så har jeg tænkt mig at tinglyse en servitut på bygningen, som fastlægger, at det aldrig må være andet end litteraturhus. “692 [Und dann habe ich mir gedacht, ins Grundbuch als Auflage zum Gebäude eintragen zu lassen, dass es nie etwas anderes als ein Literaturhaus sein darf.] Mit der von der Stadt oder vom Land regelmäßig bewilligten Unterstützung einzelner Projekte des LiteraturHauses kann der Betrieb jedoch kaum aufrechterhalten werden. Mit dem auf strukturellen Gründen basierenden Weggang der beiden Leiterinnen verlor das LiteraturHaus zudem zwei wichtige Veranstaltungsreihen. Eine davon - Litteraturcafé - bildete eine wichtige Säule der inhaltlichen Programmatik des Literaturhauses. Dabei stellen in der Regel drei Au-

${ }^{688}$ LiteraturHaus via Facebook 18.11.2017. URL: www.facebook.com/literaturhauskbh/posts/10155 413999223978 (Stand: 30.08.2018) [Liebe Freund*innen / Wir müssen leider mitteilen, dass die künstlerische Leitung, die LiteraturHaus seit September 2016 führte, entschieden hat, von ihrer Position zurückzutreten. Das bedeutet unter anderem, dass für den Rest der Saison die Literaturcafés im Litteraturbuset in der Nybrogade stattfinden, und dass die mittelöstliche Seminarreihe verschoben wird. Anfragen an das LiteraturHaus sollten von nun an Paul Opstrup gerichtet werden unter paul@literaturhaus.dk. Die scheidende Leitung möchten allen, die zu Besuch waren, mitgemacht haben und aufgetreten sind, tausend Dank sagen].

${ }^{689}$ Vgl. Almbjerg 2017.

${ }^{690}$ Vgl. Veiergang: „Om vores“.

${ }^{691}$ Paul Opstrup zitiert nach: Almbjerg 2017.

${ }^{692}$ Paul Opstrup zitiert nach: Brandt 2017a. 
tor*innen, bekannte sowie noch unbekannte, ihre Texte vor. Begleitet werden diese Abende von einem günstigen gemeinsamen Essen. Der Austausch über die Lesung hinaus bildet also neben der Präsentation mehrerer Texte einen zentralen Aspekt der Reihe. Dieses von Beginn an regelmäßig in der Mollegade stattfindende Format wird jedoch seit Ende 2017 an einem anderen Ort angeboten: im Litteraturhuset in der Innenstadt Kopenhagens, das im übernächsten Abschnitt in den Blick genommen wird. Es bleibt also abzuwarten, wie sich die Situation von LiteraturHaus in Kopenhagen entwickeln wird, ob es ein Literaturhaus bleiben und wie sich dieses gestalten wird.

\section{5.3 Weitere Literaturveranstalter*innen in Kopenhagen}

Neben dem LiteraturHaus in der Mollegade und Litteraturbuset entstanden in Kopenhagen in den letzten Jahren weitere Literaturveranstaltungsorganisationen, von denen zwei beispielhaft genannt seien: International Forfatterscene und Poesiens Hus bieten Bühnen einmal für weltweit bedeutende Autor*innen und einmal für die Lyrikszene. Explizit auf Lyrik ausgerichtet ist Poesiens Hus [Haus der Poesie], das 2010 eröffnete. Aus finanziellen Gründen musste es 2012 zwischenzeitlich schließen und befindet sich seit 2014 an neuem Standort in Den Frie Udstillingsbygning [Das freie Ausstellungsgebäude] im Stadtteil Østerbro. ${ }^{693}$ Seit 2008 präsentiert International Forfatterscene [Internationale Autorenbühne] im 1999 fertiggestellten, architektonisch eindrucksvollen Gebäude der königlichen Bibliothek Den Sorte Diamant [der schwarze Diamant] anerkannte internationale Autor*innen mit dänischen Kolleg*innen. Diese Reihe ist von der gleichnamigen Veranstaltungsserie im Stockholmer Kulturbuset inspiriert. ${ }^{694}$ Die Gäste, die bisher bei International Forfatterscene in Kopenhagen auftraten, etwa Per Olov Enquist $(* 1934)$ aus Schweden, Juli Zeh $(* 1974)$ aus Deutschland, Delphine de Vigan (*1966) aus Frankreich, Jonathan Safran Foer (*1977), Paul Auster $(* 1947)$ und Siri Hustvedt $(* 1955)$ aus den USA, werden in Oslo, Hamburg oder München ins Literaturhaus eingeladen. In Kopenhagen selbst besteht also, seit Den Sorte Diamant diese Reihe durchführt, kein Bedarf für ein weiteres Podium für diese internationalen Autor*innen. ${ }^{695}$ Die Forderung, die bei der erwähnten Literaturhaus-Konferenz 2001 formuliert wurde, ein Literaturhaus zu nutzen, um große internationale Autorennamen zu präsentieren, erfüllen diese Veranstaltungen der Königlichen Bibliothek erfolgreich.

Hinzu kommt für Kopenhagen, dass seit 2010 das Festival Louisiana Literature an vier Tagen etwa 40 weltliterarisch relevante Gegenwartsautor*innen vorstellt. Zwar nicht direkt in Kopenhagen, sondern circa dreißig Minuten mit dem Zug entfernt gelegen gilt das Museum für Gegenwartskunst Lonisiana in Humlebæk, wo das Festival stattfindet, als wichtiger Kulturvermittler für ganz Dänemark, der unbedingt

\footnotetext{
${ }^{693}$ Vgl. „Om Huset“, Poesiens Hus. Als sich die Schließung ankündigte, gab es auch den Vorschlag, Poesiens Hus und LiteraturHaus zusammenzuführen und in zentraler Lage auszubauen, wie es etwa die Zeitung Politiken aufgriff, vgl. Bundegaard 2011. Eine Idee, die damals allerdings übergeordnet und kommunal hätte unterstützt werden müssen. Im September 2019 verkündeten beide Einrichtungen in der Tat, in Zukunft an gemeinsamen Standort in der Møllegade aufzutreten. ${ }^{694}$ Vgl. „Om International“, Det Kgl. Bibliotek; zum Kulturbuset vgl. Kapitel II 8.1.3, S. 211. 695 Ähnlich ist die Situation in Stockholm, wie weiter hinten ausgeführt wird, vgl. Kapitel II 8.1.
} 
mit der Hauptstadt verbunden wird. Das 1958 von Knud W. Jensen eröffnete Museum war von Anfang an nicht nur als Ausstellungsort konzipiert, sondern integrierte mit seinem Konzert- und Lesesaal größere Veranstaltungen in seine Arbeit und förderte so die breite gesellschaftliche Auseinandersetzung mit Kunst. ${ }^{696}$ Zugleich war und ist es ein Treffpunkt für internationale Künstler*innen. Das Literaturfestival im August integriert diese Aspekte anschaulich. Mit International Forfatterscene und Louisiana Literature bieten also zwei nicht nur in Dänemark, sondern auch in Skandinavien zentrale Kulturinstitutionen ein regelmäßiges Forum für international wahrgenommene Autor*innen. Sie übernehmen damit Funktionen, die einem Literaturhaus zugeschrieben werden können. Poesiens Hus hingegen ist deshalb mit dem Funktionsbegriff Literaturhaus zu beschreiben, weil es einen Treffpunkt für die Lyrikszene schafft und mit darauf spezialisierten Veranstaltungen die Vermittlung von Lyrik fokussiert, sodass sich ein Literaturhaus in Kopenhagen auch von dieser inhaltlichen Ausrichtung abgrenzen müsste.

Vor diesem Hintergrund ist es plausibel, dass LiteraturHaus mit der avisierten Aktualisierung das Programm stärker politisch ausrichtete ${ }^{697}$ und Wert darauf legte, internationale Literatur jenseits der großen westlichen Autorennamen zu präsentieren und etwa eine Reihe zur Literatur und Kultur des Mittleren Ostens anzustoßen. AuBerdem intensivierten die neuen Leiterinnen die Zusammenarbeit mit anderen literarischen Akteur*innen in der Mollegade, etwa den beiden nicht-gewinnorientierten Buchhandlungen Ark Books und Mollegades Boghandel, die zudem personell mit dem LiteraturHaus verbunden sind, indem sie mit dem Straßenliteraturfestival Lyse Natter [Helle Nächte] an mehreren Sommerabenden die Mollegade mit Literaturveranstaltungen bespielten. ${ }^{698}$ Diese Initiative weist darauf hin, in welchem Umfeld das LiteraturHaus situiert ist und inwiefern sich dieses auf seine Ausrichtung auswirkt. Sie zeigt aber zugleich, dass LiteraturHaus nicht so sehr bestrebt war und ist, breitenwirksam zu agieren, sondern in einer literarischen Nische Vernetzung von Leser*innen, Autor*innen und Vermittler*innen herzustellen. In dieser Fortentwicklung lassen sich eher Gemeinsamkeiten mit Göteborgs Litteraturhus als mit Litteraturbuset in Oslo und den Literaturhäusern in deutschen Großstädten erkennen. Dass dies eng mit dem finanziellen Spielraum der Einrichtung verknüpft ist, arbeitet dieses Unterkapitel heraus. Es stellt aber auch die Frage, die nicht pauschal, sondern für jeden Ort individuell beantwortet werden muss, ob ein Literaturhaus eher ein Treffpunkt für eine kleinere literaturbegeisterte Gruppe ist oder ob es das literarische Leben einer Stadt repräsentieren soll. Für Kopenhagen ist es durchaus nachvollziehbar, dass es keine öffentlichen Bestrebungen gibt, das mit diesem Namen bezeichnete Literaturhaus ausgiebig zu unterstützen, denn als vorzeigbarer Literaturort dient der Stadt mindestens Den Sorte Diamanten. Darüber hinaus findet seit 2008 das Literaturfestival KBH Laser [Kobenhagen liest] statt, das Ende Februar, Anfang März über einen Zeitraum von etwa zehn Tagen Literaturveranstaltungen im Stadtgebiet durchführt. Die Veranstalter*innen sind die öffentlichen Bibliotheken in Zusammenarbeit mit verschiedenen Kulturvermittler*innen wie Kulturinstituten, $\mathrm{Mu}$ -

\footnotetext{
${ }^{696} \mathrm{Vgl}$. ,Louisiana Historie“, Louisiana Museum of Modern Art.

697 Vgl. Almbjerg 2017.

${ }^{698}$ Vgl. „Lyse Nætter“, Ark Books; Møllegades Boghandel; LiteraturHaus.
} 
seen oder Buchhandlungen. Die Kulturverwaltung investiert also in dieses Angebot, das einen weiteren Versuch darstellt, die kulturpolitische Absicht ,Literatur für alle umzusetzen, ${ }^{699}$ für die die Volksbibliotheken seit ihren Anfängen stehen.

\section{5.4 Litteraturhuset als neue Umsetzung in Kopenhagen}

Kaum eine Woche nachdem die Tageszeitung Politiken eine Reportage über, det nye LiteraturHaus ${ }^{6}$ veröffentlichte, ${ }^{700}$ berichtete sie von den Plänen, in der Nybrogade ein ,Litteraturhuset ${ }^{6} \mathrm{zu}$ eröffnen. ${ }^{701}$ Das Besondere an dieser Einrichtung ist, dass sie von einem Verlag getragen wird. Im Verlag Vandkunsten, der seit 2003 internationale wie dänische Belletristik und Sachbücher publiziert, traten der Verleger Søren Møller Christensen und der Lektor Claes Benthien als Initiatoren auf. Der Verleger hatte bereits vorher die Idee gehabt, ein Literaturhaus in größerem Maßstab aufzubauen, dafür bekam auch er jedoch keine öffentliche Unterstützung. ${ }^{702}$ Mit dem Umzug des Verlages 2017 in die Nybrogade 28 ergab sich die Gelegenheit, dieses Literaturhaus aufzubauen. Der Verlag gibt dem Literaturhaus seinen Beinamen Litteraturbuset ved Vandkunsten, Vandkunsten heißt aber ebenfalls ein Platz in der Nähe von Litteraturbuset. Der Verlag V andkunsten finanziert das Projekt vollständig, sodass nicht ein Verein oder eine Stiftung es trägt. ${ }^{703}$ Auch diese Einrichtung ist also eine private Unternehmung. Allerdings steht der Verlag zwar hinter dem Projekt, doch habe er keinen Einfluss auf die Programmgestaltung. „Huset blir for alle“704 [Das Haus wird für alle sein], wie Claes Benthien in einem Interview erklärt. Als künstlerische Leitung von Litteraturbuset ist seit Sommer 2017 Anna Johansen (*1972) tätig, die zu diesem Zwecke eingestellt wurde und inhaltlich unabhängig vom Verlagsprogramm agiert. Dansk Forfatterforening [Dänische Autorenvereinigung] beispielsweise befürwortete die Initiative von Beginn an, da diese Autorenvereinigung selbst keine eigenen Mittel für die Gründung eines Literaturhauses habe. ${ }^{705}$

Die soziogeografische Position in der Stadt hat Einfluss auf die Ausrichtung des Literaturhauses. Dieser Aspekt ist bei den anderen Fallbeispielen ebenfalls relevant, doch macht der innerstädtische Vergleich sichtbar, wie die Programmatik des jeweiligen Literaturhauses mit der Umgebung korrespondiert. Während LiteraturHaus in Nørrebro in einer alternativeren, von unterschiedlichen Ethnien und inzwischen von Künstler*innen geprägten Gegend situiert ist, befindet sich Litteraturbuset zentral in Kopenhagens Innenstadt am Slotsholmskanal, nicht weit entfernt von Nationalmuseet, Den Kongelige Bibliotek, dem Rathaus und gegenüber von Christiansborg Slot. In der Nybrogade hat auch das dänische Kulturministerium seinen Sitz. Litteraturbuset liegt relativ nah an der Haupteinkaufsstraße Stroget und in einer Umgebung mit zahl-

\footnotetext{
${ }^{699}$ Vgl. „Om Kbh“, Kbh Læser, Københavns Biblioteker.

700 Vgl. Nielsen 2017.

701 Vgl. Nielsen und Wittrock 2017. Dieser längere Artikel erschien online, in der gedruckten Zeitung wurde eine kürzere Meldung platziert, wo nicht auf das LiteraturHaus Bezug genommen wurde.

702 Vgl. Steenberg: „København får““.

703 Vgl. ebd.

${ }^{704}$ Claes Benthien zitiert nach: ebd.

705 Vgl. Bangsgaard: „Boghandel, restaurant“.
} 
reichen Cafés. Vor dem Gebäude mit der Hausnummer 28 ist ein kleiner Platz, der als Freisitz benutzt werden kann. So wirkt Litteraturbuset für Passant*innen ebenfalls wie ein einladendes Café.

Auf ihrer Facebook-Seite, die statt einer eigenen Website zur Selbstpräsentation genutzt wird, beschreibt sich die Einrichtung als „et hus dedikeret til litteratur, bøger og god mad" ${ }^{\prime 706}$ [ein Haus der Literatur, Büchern und gutem Essen gewidmet]. In Abgrenzung zum LiteraturHaus solle Litteraturbuset von morgens bis abends und nicht nur zu Veranstaltungen geöffnet sein. Mit dem Verlagshintergrund der Einrichtung und mit der integrierten Buchhandlung, die vom Litteraturbuset geführt wird, ${ }^{707}$ besteht eine deutlichere Verbindung zum Buchmarkt als es im eher auf die Künstler*innen orientierten LiteraturHaus in der Mollegade der Fall ist. Die Litteraturbuset-Akteur*innen verstehen diesen neuen Ort als Kombination aus Restaurant, Buchhandel und Veranstaltungsort mit einem Raum für circa 50 Besucher*innen. Sie setzen den Aspekt der Begegnung zentral und berufen sich auf eine Tendenz, die sich an vielen Orten in Europa abzeichne:

At man prøver at skabe et miljø omkring noget, som går udover det, der er kernen i det. Det handler for os om at give en lidt større, samlet oplevelse af, hvad litteratur også er. ${ }^{708}$

[Dass man versucht, ein Milieu um etwas herum zu schaffen, das über dessen Kern hinausgeht. Es geht uns darum, ein etwas größeres, gebündeltes Erlebnis davon zu geben, was Literatur auch ist.]

Mit der Absicht, einen Raum um die Literatur herum zu kreieren, lehnt sich diese Einrichtung deutlich an die ursprüngliche Literaturhaus-Idee in Deutschland und seine Weiterführung in Oslo an, was auch in Presseberichten regelmäßig erwähnt wird. ${ }^{709}$ Die Eingliederung in einen über Kopenhagen und Dänemark hinaus weisenden Kontext spielt also eine wichtige Rolle. Vor allem wegen des Namens stellt die Einrichtung in der Nybrogade einen Bezug zur Institution Literaturhaus her. Für die Untersuchung der Institution ist dies sehr aufschlussreich, weil sich daran zeigt, dass die Literaturhaus-Idee, einen Ort zu schaffen für die öffentliche Auseinandersetzung mit Literatur, die auch in den älteren Literaturhäusern immer schon mit dem Buch als Ware verbunden war und ist, von Akteur*innen aufgegriffen wird, die Literatur stärker mit ökonomischen Interessen verbinden. Auch Verlage und Buchhandlungen versuchen, Leser*innen und Käufer*innen auf neuen Wegen zu erreichen. Dabei steht nur indirekt die Empfehlung der eigenen Produkte im Fokus, denn primär wird für Literatur, Lesen und Bücher generell geworben. Dies veranschaulicht Litteraturbuset in Kopenhagen sehr gut.

Anders als geplant konnte aufgrund baulicher Verzögerungen Litteraturbuset erst im Herbst 2017 eröffnen. Seitdem finden unterschiedliche Veranstaltungen statt, von Forfattersalon mit Gästen wie den etablierten dänischen Gegenwartsautor*innen Kim Leine (*1961), Helle Helle (*1965) oder Dorthe Nors (*1970), bis hin zu Dis-

\footnotetext{
706 „Info“, Litteraturhuset via Facebook. URL: www.facebook.com/pg/litteraturhusetkbh/about/?ref= page_internal (Stand: 30.08.2018).

707 Vgl. Andersen: „Hun vil“.

${ }^{708}$ Claes Benthien zitiert nach: Bangsgaard: „Boghandel, restaurant“.

${ }^{709}$ Vgl. z. B. Andersen: „Hun vil““.
} 
kussionen und Konzerten. Es bleibt also auch in diesem Fall abzuwarten, wie sich die Situation von Litteraturbuset in Kopenhagen entwickeln wird.

\section{5.5 Kopenhagen und die Institution Literaturhaus}

In Kopenhagen existieren also inzwischen zwei Literaturhäuser, die diese Begriffszuordnung in ihrem Namen tragen. Mit der Entscheidung für die Benennung LiteraturHaus suchte die erste der beiden Einrichtungen direkt Anschluss an die deutschen Literaturhäuser und deren Literaturverständnis. Litteraturbuset ved V andkunsten hingegen griff zurück auf die von der Osloer Einrichtung geprägte skandinavische Vokabel und damit auf das dort etablierte Modell. Die Bezeichnung ,Litteraturhuset' hat sich von der Gründung von LiteraturHaus 2005 in der Mollegade bis zur Eröffnung von Litteraturbuset 2017 in der Nybrogade in Skandinavien durchgesetzt, der Verweis auf die aus Deutschland stammende Institution findet sich darin nur noch implizit. Dennoch lässt sich beispielsweise an Zeitungsartikeln ablesen, dass die Referenz zum deutschen beziehungsweise europäischen Konzept Erwähnung findet, sie also relevant bleibt. Dass die Bezugnahme anderer skandinavischer Städte auf das Osloer Literaturhaus stärker ist als die auf deutsche Einrichtungen, liegt im kulturell eng verknüpften Skandinavien nahe. Ebenso nachvollziehbar ist es, dass eine dänische Organisation den dänischen Terminus verwendet. Die Institution Literaturhaus löst sich damit nach und nach von ihrem Erstkontext, weil die neueren Einrichtungen nicht mehr intentional das deutsche Modell, sondern eher das norwegische transferieren und weiter modifizieren. Dies unterstützt das im ersten Kapitel entworfene Modell, das die Institution Literaturhaus als einen dynamischen Zusammenhang versteht. Die beiden Kopenhagener Beispiele illustrieren das inzwischen ausgeweitete Spektrum der Institution.

Die Beobachtung, dass in Kopenhagen ein zweites namentliches Literaturhaus gegründet wurde, weist außerdem darauf, dass das erste, das lange Zeit das einzige seiner Art in Dänemark war, sich nicht in der Art etablieren konnte, dass innerhalb der Stadt eine Neugründung mit quasi gleichem Namen gar nicht erst infrage gekommen wäre und dass andere Städte im Land sich zur Nachahmung animiert gefühlt hätten. Als ein Grund dafür ist die Tatsache zu sehen, dass LiteraturHaus von Beginn an mit instabilem privatem Budget alternativer und ohne kommunale - monetäre wie symbolische - Unterstützung geführt wurde, sodass eine breitenwirksamere Aufmerksamkeit organisational nicht umsetzbar war. Der publike Zuspruch hat jedoch entscheidenden Einfluss darauf, ob sich ein Konzept längerfristig durchsetzt, wie das Literaturhaus in Oslo belegt, das seit seinem Start als Erfolgsmodell präsentiert wird. Ohne regelmäßige kommunale Förderung oder hohe private dauerhafte Investitionen lässt sich ein Literaturhaus mit ganzjährigem Programm nur schwer weiterentwickeln. Die angestoßene programmatische Fortentwicklung von LiteraturHaus mit veränderter Struktur bot die Chance einer Justierung, die möglicherweise - das lässt sich nur vermuten - neue Unterstützer*innen gefunden hätte. Auch die neue Einrichtung in Kopenhagen wird bisher nur von Eigenmitteln und Einnahmen aus dem Betrieb getragen. Der Interessenkonflikt zwischen ökono 
mischer Rentabilität und programminhaltlicher Marktunabhängigkeit ist in diesem privatwirtschaftlich finanzierten Unternehmen zwar augenscheinlicher als in den gemeinnützig organisierten Literaturhäusern, doch sind diese ja ebenfalls der Spannung ausgesetzt, pekuniär zuverlässig und zugleich in ihrer Literaturvermittlungsarbeit unabhängig zu bleiben.

Da die beiden sich ,Literaturhaus' nennenden Einrichtungen in Kopenhagen nicht öffentlich gefördert werden, entsteht keine direkte Konkurrenz zu den Bibliotheken. In Norwegen ist dies anders, denn dort spielen die öffentlichen Bibliotheken in der Literaturhaus-Diskussion eine weitaus größere Rolle. Aber auch in Dänemark wirkt sich die Grundidee des Literaturhauses, einen Ort für die Beschäftigung mit Literatur in sozialem Rahmen zu schaffen, auf die Bibliotheken aus. Dies beweist neben dem erwähnten stadtweiten Literaturfestival KBH Laser eine von der Kulturverwaltung in Auftrag gegebene Studie, die im Sommer 2018 veröffentlicht wurde: Die Frage nach der zukünftigen Kernaufgabe der Bibliothek wurde darin mit unterschiedlichen Szenarios beantwortet. Neben der Überlegung, die Bibliotheken zu nur noch digitalen und ohne physische Bücher organisierten Leihsystemen umzuwandeln, wurde eine Zukunft als ,Literathek' mit umfangreichem Veranstaltungsangebot und Begegnungsmöglichkeiten vorgeschlagen. ${ }^{710}$ Anders als bei der Aktualisierung des Bibliotheksgesetzes in Norwegen ${ }^{711}$ dient in Dänemark das Literaturhaus dabei jedoch nicht als direkte Referenz. Das Literaturhaus ist in Dänemark eine marginalere, privat organisierte Unternehmung geblieben. Der Literaturveranstaltungsbetrieb hat sich, wie am Beispiel Kopenhagens gezeigt, trotzdem fortentwickelt, denn öffentliche Literaturveranstaltungen finden an unterschiedlichen Orten statt und verschiedene Akteur*innen übernehmen unter anderem Literaturhaus-Aufgaben.

\section{6 Litteraturhuset in Oslo - Das norwegische Modell}

2005 ergriff die Organisation Fritt Ord [Freies Wort] mit ihrem damaligen Direktor Eric Rudeng die Initiative, ein Literaturhaus in Oslo aufzubauen. Im Dezember 2006 gründete Fritt Ord die unabhängige Stiftung Litteraturbuset. Fritt Ord übernahm die Bauherrschaft für das Gebäude im Wergelandsveien. In der Konzeptionsphase informierten sich die Beteiligten über die Arbeit anderer Literaturhäuser, um sich von diesen beraten und inspirieren zu lassen. Für das Publikum öffnete Litteraturbuset am 5. Oktober 2007 seine Türen.

Litteraturhuset wurde zum Vorbild für andere Literaturhäuser in Skandinavien, und selbst in Deutschland besteht Interesse an der modifizierten Variante des Modells. ${ }^{712}$ Aus diesem Grund lohnt es sich, zu überprüfen, wie es aufgebaut ist und sich etablierte, um dann zu eruieren, welche Position es in Norwegen und in Oslo

\footnotetext{
${ }^{710}$ Vgl. Kobenhavns Biblioteker 2018.

${ }^{711} \mathrm{Zu}$ dieser Diskussion in Norwegen vgl. Kapitel II 7.5.

712 Dies wurde im ersten Kapitel bereits ausführlicher dargelegt, vgl. Kapitel I 3.2.4.
} 
einnimmt. Die Diskussionen zur Literaturvermittlung, die das Osloers Haus in Norwegen auslöste, wirken sich unter anderem auf die Bibliotheken aus:

The term ,house of literature' has proven to provide us with a good tool. It has stimulated and challenged us internally, and it has had a positive effect on cooperation partners and owners, and not least in relation to the public. It has helped engender an increased understanding of how the social remit of the libraries is undergoing change - the libraries should undertake active dissemination. ${ }^{713}$

,Litteraturhuset' ist ebenfalls nicht mehr nur ein Name, sondern avancierte zum Funktionsbegriff, der insbesondere Einfluss auf die Bibliotheken hat, was später vertieft werden wird.

Litteraturbuset in Oslo kann allein deshalb als norwegisches Literaturhaus-Vorbild bezeichnet werden, weil es das erste seiner Art in Norwegen war. Trotz einer immer wieder etwas unsicheren Finanzlage stellt es sich seit seiner Eröffnung 2007 als Erfolgsmodell dar. Bei seinem Amtseintritt sagte der aktuelle Leiter Andreas Wiese, dass die Position des Geschäftsführers von Litteraturbuset eine der spannendsten und interessantesten im norwegischen Kulturleben sei. ${ }^{714}$ Er fährt fort mit einem Lob der kompetenten Mitarbeiter*innen, mit denen er gemeinsam das Haus weiterzuentwickeln plane. Abgesehen davon, dass es kommunikationsstrategisch klug ist, seine neue Stelle als ,Traumjob‘ zu bezeichnen und die Angestellten positiv hervorzuheben, zeigt sich daran die wahrgenommene Position von Litteraturbuset in Oslo. Wenn die Leitung der Einrichtung zu den attraktivsten Stellen im Osloer Kulturleben zählt, zählt die Anerkennung ebenso für das Haus als solches. Im Diskurs gilt es als Ort, der zur stetigen Weiterentwicklung bereit sei und der Einfluss auf die Kulturlandschaft Oslos habe. Dies bezeugt seine Auszeichnung 2013 mit dem Preis Gullegget, ein Preis der Buchbranche. Die Jury begründete ihre Entscheidung so:

Ved hjelp av dem har det blitt skapt en arena for meningsytringer, brytninger og dialog som kommer hele den norske offentligheiten til gode. De har gjort mer for litteraturens synlighet en noe annet tiltak på totusentallet, og hele det litterære feltet er dem en stor takk skyldig. ${ }^{715}$

[Mit ihrer Hilfe wurde eine Arena geschaffen für Meinungsäußerungen, Akzente und Dialog, die der gesamten norwegischen Öffentlichkeit zugutekommen. Sie haben mehr für die Sichtbarkeit der Literatur getan als jede andere Initiative im 21. Jahrhundert, und das ganze literarische Feld ist ihnen großen Dank schuldig.]

\footnotetext{
${ }^{713}$ Hortman 2013. Dieser Artikel bezieht sich auf das dreijährige Projekt der Bibliotheken in der Region Nord- Trøndelag, ein Literaturhaus aus der Bibliothek heraus aufzubauen. Zur Bibliothek in Norwegen vgl. Kapitel II 7.5.

${ }^{714} \mathrm{Im}$ norwegischen Wortlaut lautet das, was im Fließtext paraphrasiert auf Deutsch steht: „Stillingen som daglig leder av Litteraturhuset er en av de mest spennende og interessante i norsk kulturliv. Jeg kommer til et veldrevet hus med svært kompetente medarbeidere. Sammen med dem gleder jeg meg til å utvikle Litteraturhuset videre, sier Andreas Wiese“, Nipen 2014.

715 Der Preis wurde von der Norwegischen Verlegervereinigung und der Buchhändlervereinigung in dem Jahr erstmals verliehen. Im Programmheft, aus dem auch die zitierte Jurybegründung entnommen ist, kommentiert der damalige Leiter Aslak Sira Myhre die Begründung so: „Vi på Litteraturhuset er stolte og glade for å ha fått denne prisen og håper at flere enn bokbransjen opplever det slik“ (OL 2013-III, S. 3) [Wir im Litteraturhuset sind stolz und freuen uns, dass wir diesen Preis bekommen haben, und hoffen, dass mehrere als nur die Buchbranche es so erleben].
} 
Diese Jurybegründung fasst gut das Lob zusammen, das Litteraturbuset entgegengebracht wird. ${ }^{716}$ Und es ist nicht nur die öffentliche politische Debatte, für die das Literaturhaus steht, auch für kollegiale Treffen von Literat*innen eignet es sich. Die Autorin Vigdis Hjorth stellt heraus, dass es ein Ort sei, an dem man Literaturleute im Alltag treffe, angenehm und bequem. ${ }^{717}$

\section{6.1 Entstehung und Organisation}

\section{6.1.1 Personal}

Der vom Litteraturbuset-Stiftungsvorstand eingesetzte Geschäftsführer ist Chef für neun festangestellte Mitarbeiter*innen sowie weitere freiberuflich tätige Mitarbeiter*innen. Zu vermuten ist, dass weniger ein Intendanzmodell vorliegt, wie es die deutschen Literaturhäuser in der Regel nutzen, ${ }^{718}$ sondern ein Team mit flachen Hierarchien für die Programmentscheidungen steht. Argument dafür ist zum Beispiel die Aufgabenverteilung der Mitarbeiter*innen: Neben dem Daglig Leder [Geschäftsführung] gibt es eine Administrationschefin und einen Programmverantwortlichen. Die öffentliche Aufmerksamkeit beim Führungswechsel in Oslo zeigte jedoch, dass Litteraturbuset stark mit der Leitungsperson, id est Geschäftsführung, identifiziert wird. Von außen betrachtet lässt sich entsprechend zwischen den deutschen Literaturhäusern und Litteraturbuset kein signifikanter Unterschied hinsichtlich der deutlich höheren öffentlichen Präsenz der Leitungen im Vergleich zu den Mitarbeiter*innen ausmachen.

Im Literaturhaus Oslo waren bisher zwei Leiter im Amt. Aslak Sira Myhre (*1973) - Mitgründer und Geschäftsführer bis 2014 - hat entscheidend zur Positionierung der Einrichtung beigetragen. Er hat keinen literarischen Ausbildungshintergrund, sondern absolvierte ein Geschichtsstudium und war früher vor allem journalistisch und politisch tätig. Von 1997 bis 2003 war er Vorsitzender der Partei Rød Valgallianse/RV [Rote Wahlallianz], von 1999 bis 2003 im Kommunestyre [Gemeinderat] in Stavanger aktiv. Für die Partei, die sich aus RV 2007 zu Rodt entwickelte, ließ er sich bei den Wahlen zu Norwegens Nationalversammlung Storting 2009 und 2013 aufstellen. Dies ist relevant, weil Aslak Sira Myhres politische Position sich auf die Ausrichtung von Litteraturbuset auswirkte. Bis 2007 leitete er Foreningen !les [die Vereinigung Lies!], eine Non-Profit-Organisation, die Kinder und Erwachsene mit unterschiedlichen Projekten zum Lesen anzuregen versucht. ${ }^{719} 2014$ hat er Litteraturhuset verlassen, weil er zum Direktor von Nasjonalbiblioteket [die Nationalbibliothek] ernannt wurde, wo er eine neue Bibliotheksstrategie für Norwegen voranbrachte. ${ }^{720}$

\footnotetext{
${ }^{716}$ In Gesprächen, Diskussionen oder Artikeln zum Litteraturhuset sind es die genannten Aspekte, die immer wieder positiv hervorgehoben werden. Dass es daneben auch kritische Stimmen gibt - vor allem hinsichtlich der Gastauswahl, des vermeintlich elitären Ansinnens und der Sorge, dass den Bibliotheken Geld und Ansehen durch die Literaturhäuser genommen wird - sei angemerkt.

${ }^{717}$ Dies äußerte sie beim Seminar Trenger vi litteraturbus? [Brauchen wir Literaturhäuser?] am 31.10.2013 anlässlich des sechsten Jubiläums von Litteraturbuset in Oslo, vgl. FN 723.

718 Vgl. Kapitel I 5.3.

${ }^{719} \mathrm{Vgl}$. „Om oss“, Foreningen !les.

${ }^{720}$ Vgl. „Nasjonal bibliotekstrategi““, Kulturdepartementet und Kapitel II 7.5.
} 
Sein Nachfolger Andreas Wiese (*1958) kommt ebenfalls aus dem Arbeitsbereich des Journalismus. Seit 1993 schrieb er für die kulturfokussierte Tageszeitung Dagbladet und war so mit dem norwegischen beziehungsweise Osloer Kulturleben vertraut. Er ist wirtschaftswissenschaftlich ausgebildet, hat aber auch Literatur und Theaterregie studiert. Der Vorstand des Literaturhauses wählte also beim Leitungswechsel eine Person, die sich im Osloer Kulturbetrieb sowie mit ökonomischen Belangen auskennt. Der Leiter von Litteraturbuset muss sich intensiv auch mit finanziellen Fragen auseinandersetzen respektive viele Gelder erwirtschaften. Seit Mai 2019 leitet die Journalistin Susanne Kaluza das Literaturhaus.

\section{6.1.2 Organisation als Stiftung}

Die Leitung der Stiftung trägt die Finanz- und Planungsverantwortung des Hauses. Sie arbeitet unabhängig und nicht-kommerziell und hat zum Ziel, Literatur und Lesen zu vermitteln und Interesse daran zu wecken. Mit der Stiftung Fritt Ord als Initiatorin des Literaturhauses tritt ästhetisches Interesse an der Literatur hinter ein politisches; die Stiftung setzt sich, wie der Name ,Freies Wort' schon sagt, vor allem für die freie Meinungsäußerung ein. Lebendige Debatten sollen stimuliert werden. ${ }^{721}$

Litteraturhuset finanziert sich also über die Stiftung, über öffentliche Mittel und privatwirtschaftliche Investitionen. Hinzu kommen zum Beispiel Miet- und Ticketeinnahmen. Als Stiftung erhält die Einrichtung anders als die als Verein organisierten deutschen Literaturhäuser keinen regelmäßigen Betrag von Privatpersonen. Zunächst wurde das Literaturhaus vor allem aus Mitteln der Stiftung Fritt Ord finanziert. Diese Stiftung stellt ein jährliches Finanzvolumen bereit und ist für das Tagesgeschäft sowie Profilbildung und Programmangebot zuständig. Geplant war diese Hauptfinanzierung zunächst begrenzt auf fünf Jahre. Bis Ende 2013 sollte eine eigenständige Finanzierung gefunden werden über ein Modell, bei dem vier Organe beteiligt sind: Weiterhin Fritt Ord, jedoch mit einem geringeren Betrag, der Staat, die Kommune und ein oder mehrere private Sponsoren. Dabei sollte bei stabilem Etat keine Unterstützung höher sein als die Litteraturbuset-Eigenmittel, um Unabhängigkeit zu gewähren. Zunächst flossen keine öffentlichen Gelder in das Literaturhaus Oslo, doch Aslak Sira Myhre forderte öffentliche Mitfinanzierung:

Det er ikke bare å snu dette med et knips. Vi har ingen ambisjon eller ønske om å bli en offentlig institusjon, men vi ber om noe for å få langsiktighet i bunn. Vi trenger forutsigbarhet. ${ }^{722}$

\footnotetext{
${ }^{721}$ Die übergeordnete Stiftung Fritt Ord erklärt dies zu ihrem Stiftungsziel: „Stiftelsen Fritt Ords fremste formål er å verne om og styrke ytringsfriheten og dens vilkår i Norge, særlig ved å stimulere den levende debatt og den uredde bruk av det frie ord. Fritt Ord kan også støtte andre sider ved norsk kultur, i første rekke den del av kulturen som gjør bruk av ordet. I særlige tilfelle kan Fritt Ord bidra til å fremme ytringsfriheten i andre land“, „Om Fritt“, Fritt Ord [Das oberste Ziel der Stiftung Fritt Ord ist es, die Meinungsfreiheit und deren Bedingungen in Norwegen zu schützen und zu stärken, besonders indem die lebendige Debatte und der mutige Gebrauch des freien Wortes stimuliert werden. Fritt Ord kann auch andere Bereiche norwegischer Kultur fördern, in erster Linie den Teil der Kultur, der das Wort nutzt. In besonderen Fällen kann Fritt Ord dazu beitragen, die freie Meinungsäußerung in anderen Länder zu fördern].

722 Aslak Sira Myhre zitiert nach: Korsvold 2013.
} 
Es geht nicht nur darum, das mit einem Mal zu ändern. Wir haben weder die Ambition noch den Wunsch, eine öffentliche Institution zu werden, aber wir bitten um etwas, um grundsätzliche Langfristigkeit zu erhalten. Wir brauchen Planungssicherheit.]

Aufgrund der absehbar ungesicherten Finanzlage ab Januar 2014 haben sich unter anderem 20 namhafte norwegische Autor*innen für staatliche monetäre Unterstützung für das Literaturhaus eingesetzt. Die Frage, ob das Literaturhaus öffentlich bezuschusst werden solle, löste grundlegende Diskussionen über die Notwendigkeit, Funktionen und Erfolge des Literaturhauses aus, die sich unter anderem bei einem Symposium im Oktober 2013 zum sechsten Geburtstag des Literaturhauses fortsetzten. ${ }^{723}$ Schließlich hat der Staat drei Millionen norwegische Kronen [rund 330 Tausend Euro] zugesagt. Dabei seien für 2014 das Literaturhaus Oslo und jenes in Bergen ausnahmsweise priorisiert worden, dauerhafte staatliche Finanzierung sei jedoch nicht möglich und deshalb habe auch das Literaturhaus in Fredrikstad nicht mehr Geld bekommen. ${ }^{724}$

Diese Tatsache macht deutlich, dass die Literaturhäuser mit anderen kulturellen Institutionen, ebenso wie mit ihren ,Artgenossen“ konkurrieren. Wenn Oslo aufgrund des Finanzierungsausfalls durch die Stiftung und fehlender Privatinvestoren akut finanzielle Unterstützung braucht und das Literaturhaus in Bergen für das kommende Jahr entscheidende Neuerungen plant, bleibt kein Geld mehr für das Literaturhaus in Fredrikstad. Daran offenbart sich einmal mehr die Spannung zwischen Wettbewerb und Zusammenarbeit, zwischen Koalition und Konkurrenz der Einrichtungen und Institutionen untereinander. ${ }^{725}$ Die im ersten Kapitel angesprochene stetig unsichere Finanzlage betrifft also auch das zahlenmäßig für deutsche Verhältnisse sehr gut aufgestellte Litteraturhuset. 2012 beliefen sich die Gesamteinnahmen auf beinahe viereinhalb Millionen Euro. Dieses Gesamtvolumen übersteigt die Mittel der deutschen Literaturhäuser um ein Vielfaches; die Zahlen ähneln am ehesten denen des Literaturhauses München, dem in Deutschland das höchste Budget zur Verfügung steht. ${ }^{726}$

Vergleichbar ist Litteraturbuset in Oslo wie in Bergen auch deshalb mit dem Literaturhaus München, weil sie von einer Stiftung betrieben werden. Anders als die deutschen Einrichtungen können die norwegischen keine Einnahmen über Mitgliedsbeiträge aus Träger- und Förderverein generieren. Neben den finanziellen Konsequenzen hat dies Einfluss auf die Arbeit der Literaturhaus-Teams, weil sich somit die Mitarbeiter*innen nicht um die Vereinsverwaltung und die Akquise neuer Mitglieder kümmern müssen. Außerdem bestehen für Mitglieder keine Vorteile, die sie gegenüber anderen Besucher*innen bevorzugen - so existiert etwa für niemanden die Möglichkeit, die es in manchen deutschen Literaturhaus-Vereinen gibt, Veranstaltungstickets schon vor dem Vorverkaufsbeginn zu erwerben. Dies passt zum skandinavi-

\footnotetext{
${ }^{723}$ Eine Aufzeichnung der Diskussion wurde der Verfasserin als Audiodatei zur Verfügung gestellt.

724 Vgl. ebd.

${ }^{725}$ Vgl. Kapitel I 5.8, Abbildung 2.

${ }^{726}$ Die konkreten Zahlen für Oslo belaufen sich als Einnahmen auf 36.037.235 Norwegische Kronen (etwa 4.313.500 Euro) und als Überschuss auf 263.919 Norwegische Kronen (etwa 31.600 Euro), vgl. Arsberetning for Stiftelsen Litteraturbuset 2012 2013. Die Zahlen für München liefert Vandenrath, vgl. Vandenrath 2006, S. 186.
} 
schen Ethos der Gleichbehandlung und der Ablehnung von elitären Strukturen. Dieses demokratische Prinzip zeigt sich noch deutlicher beim Umgang mit Vermietungen und Kooperationen. ${ }^{727}$

Das Publikum fühlt sich durch die Organisationsstruktur jedoch gegebenenfalls weniger der Literaturvermittlungseinrichtung verbunden. Die Vereine der deutschen Literaturhäuser bieten zusätzlich eine organisierte ideologische Angliederung, die norwegischen setzen darauf, dass Ort und Konzept einen sozialen Raum entstehen lassen. Dabei spielt die Zusammensetzung unterschiedlicher Veranstalter*innen und Akteur*innen eine wichtige Rolle, nicht so sehr die Präsentationen des Literaturhauses im engeren Sinne als Veranstalter, wie auch die Untersuchung der Selbstdarstellungstexte ergibt.

\section{6.1.3 Privates Sponsoring}

Als Sponsor des Litteraturbuset konnte zum Beispiel 2014 Sparebankstiftelsen DNB [Sparkassenstiftung DNB] ${ }^{728}$ gewonnen wurden. Die Bank unterstützt Litteraturbusets Schwerpunkt Folkeopplysning [Volksaufklärung]. Unter diesem Schlagwort bündelte das Literaturhaus-Team damit die schon vorher existierenden Reihen Lordagsforedraget [der Samstagsvortrag] und Historisk sondag [Historischer Sonntag]. ${ }^{729}$ „Litteraturhusene må tenke helt annerledes om finansiering“730 [Die Literaturhäuser müssen ganz anders über Finanzierung nachdenken], weil Politik und Träger sich einig seien, dass Literaturhäuser eigenständige Einrichtungen seien und bleiben sollen. Dennoch seien sie auf die Mitfinanzierung durch öffentliche Gelder sowie durch Sponsoren, die ebenfalls eigene Konzerninteressen mit ihrer Geldspende vertreten, angewiesen. Was Knut Olav Åmås, von 2013 bis 2014 Staatssekretär im Kulturdepartementet [Kulturministerium] und seitdem Direktor von Fritt Ord, formuliert, wird hier plastisch. An diesem Beispiel offenbart sich, inwiefern die Literaturhäuser für Förderungszusagen Programmmodifikationen vornehmen. So ist anzunehmen, dass es unter anderem im Interesse der Bankstiftung lag, den volksaufklärerischen Aspekt der Veranstaltungen stärker betont zu wissen, als es vorher der Fall war. Mit der Subsummierung der beiden ähnlichen Formate am Samstag und Sonntag unter Folkeopplysning konnte die neue Finanzierung zudem gleich zwei Reihen absichern. Diese privatwirtschaftliche Stiftung unterstützt seit 2013 auch das Kinder- und Jugendprogramm. Sie fokussiert ihr Förderinteresse damit auf die Programmschwerpunkte, die sich der ,Demokratisierung von Kultur' widmen. Die ,Volksaufklärung ermöglicht Bildungsvorträge zu unterschiedlichsten Themen. Da sie ohne Eintrittsgebühr stattfinden, war die Idee, Bildung, für alle' anzubieten, offensichtlich Teil des Konzeptes. Bildungsarbeit, die die Beschäftigung mit Literatur immer auch ist, im

\footnotetext{
${ }^{727}$ Vgl. Kapitel II 11.2.

${ }^{728}$ DNB ist Norwegens größter Finanzkonzern. 2016 sagte die Stiftung einen Betrag in Höhe von

3,2 Millionen Norwegischen Kronen (rund 350 Tausend Euro) zu.

${ }^{729}$ Mehr zu den Reihen und ihrer Weiterentwicklung unten, vgl. Kapitel II 13.1.6.

${ }^{730}$ Knut Olav Åmås zitiert nach: Korsvold 2013. Die Sorge, Autonomie einzubüßen, wenn der Staat oder die Kommune finanziell stark beteiligt ist, zeigte sich schon bei der Entstehung der ersten Literaturvermittlungsinstitutionen in den 1980er-Jahren in Deutschland, wie Basse und Pfeifer 1988 dargelegten.
} 
Kinder- und Jugendbereich zu fördern, ist für private Stifter*innen aus Imagegründen ebenfalls sehr attraktiv. ${ }^{731}$

Die Zusammenarbeit mit Sponsor*innen oder die Trägerschaft durch eine politische auf den Schutz von Meinungsfreiheit fokussierte Stiftung veranschaulicht, dass die inhaltlichen Programme teils unmittelbar, teils indirekt mit der ökonomischen und organisationalen Struktur des Literaturhauses verbunden sind. Es deutet sich hier bereits an, dass Litteraturbuset in Oslo Literatur stark mit einem gesellschaftlich und politisch bildenden Auftrag verknüpft sieht.

\section{6.2 Soziogeografische Verortung in Norwegen und in Oslo}

\section{6.2.1 Norwegens Zentrum}

Die Einrichtung in Oslo bezeichnet sich als „Noregs fyrste Litteraturhus“732 [Norwegens erstes Literaturhaus]. Und die Tatsache, dass es ,Litteraturhuset' heißt, und nicht etwa ,Litteraturhuset Oslo', unterstreicht seine Vorrangstellung in Norwegen. Alle anderen norwegischen Literaturhäuser müssen sich im Anschluss zwangsläufig immer auch von dem einen Haus in der Hauptstadt abgrenzen. Dies markiert eine Vorreiterposition. Es findet seine Berechtigung zunächst darin, dass es in Oslo steht. Oslo bildet Norwegens Zentrum und ist nicht nur politische, sondern auch kulturelle Hauptstadt, kann sich als größte Stadt als Repräsentant des gesamten Landes darstellen. ${ }^{733}$ Zwar galt Bergen lange als intellektuelles Zentrums Norwegens, doch konzentriert sich beispielsweise der Buchmarkt heute eindeutig auf Oslo. So haben zum Beispiel die drei größten Verlage Cappelen Damm, Gyldendal Norsk Forlag und Aschehong sowie viele mittlere und kleine Verlage und die Verleger- und die Buchhändlervereinigung ihren Sitz in Oslo. Auch die Einrichtung für die Vermittlung norwegischer Literatur im Ausland NORLA (Norwegian Literature Abroad) ist in Oslo ansässig. Dort also kommen die norwegischen Literaturbetriebsakteur*innen alltäglich zusammen. Für den Empfang internationaler Gäste ist die geografische Lage und die infrastrukturelle Anbindung Oslos von Vorteil, um am „sich (auch) transnational organisierenden Kulturbetrieb" $" 734$ teilzunehmen.

Die Agglomeration des norwegischen Literaturbetriebs in Oslo findet jetzt ganzjährig im Litteraturbuset einen symbolischen Ort, da es sich als Sammlungsort für den Literaturbetrieb präsentiert, während andere Orte, wie Lillehammer mit Norsk Litteraturfestival - Sigrid Undset-dagene, nur zu Festivalzeiten zu einem Branchentreffpunkt werden. Dass sich das Literaturhaus in Oslo als Vertreter ganz Norwegens versteht, hat sicherlich zudem kulturpolitische Motive, die sowohl die innernorwegische als

\footnotetext{
731 Zum privaten Sponsoring von Kultur sei nochmals auf die grundlegende Studie von Sonja Vandenrath hingewiesen, vgl. Vandenrath 2006.

732 „Huset“, Litteraturhuset. URL: www.litteraturhuset.no/huset/ (Stand: 04.04.2016). Hierbei geht es mir vor allem um die Einordnung in den nationalen Kontext. Das Adjektiv ,erstes ' wird hier von den Schreibern sicherlich positiv wertend verstanden, auch wenn es sich eindeutig auf die zeitliche Dimension bezieht, so wird damit die Vorreiterposition unterstrichen. In Oslo wurde die Idee für Norwegen erfunden - daran soll kein Zweifel bestehen.

${ }^{733}$ Einwohnerzahl (Anfang 2017) etwa 666.700, vgl. „Folkemengde og“, Statistisk sentralbyrå.

734 Schöning und Pohl 2001, S. 28.
} 
auch die internationale Perspektive betreffen. Litteraturbuset in Oslo versteht sich als nationales Literaturhaus, was seine Wahrnehmung als transnationaler Akteur ermöglicht.

In Norwegen findet sich intranational eine viel stärkere Hierarchisierung zwischen Zentrum ${ }^{735}$ und Peripherie als in Deutschland. Der föderalistische Aufbau Deutschlands setzt anderes voraus als die, wenn auch erst relativ spät einsetzende, Konzentration auf die norwegische Hauptstadt, die als Kristiania lange nur im Schatten des dänischen Zentrums Kopenhagen stand. In Deutschland hingegen ist die Kulturlandschaft dezentraler organisiert, und Städte wie Hamburg, Frankfurt, Stuttgart oder München sind jeweils groß genug, um ein Gegengewicht zu Berlin zu bilden beziehungsweise, weil es ausreichend Publikum gibt, um mehrere Literaturhäuser auf gleichem Niveau, das heißt mit vergleichbarer Ausstattung und Betriebsamkeit, zu bewirtschaften. ${ }^{736}$ In Deutschland existiert zwar eine Unterscheidung zwischen den ,größeren' und den ,kleineren' Häusern, doch steht nicht ein Haus so einzeln vorne, wie es in Norwegen der Fall ist. Die Vergleichbarkeit zwischen den deutschen Literaturhäusern erscheint größer zu sein als zwischen Oslo und seinen Nachfolgern, was sich nicht zuletzt dadurch zeigt, dass deutsche Literaturhäuser sich in einem Netzwerk vereinigt haben, während Oslo sich von den anderen Einrichtungen in Norwegen abgrenzt. Diese Distanzierung lässt sich zwar ebenfalls als zugeschriebene ,Arroganz' der Oslo-,Städter' gegenüber dem ,Land' verstehen, doch sie unterstreicht gleichzeitig den Osloer Versuch, international ,mitzumischen`.

Grund für dieses internationale Ansinnen mag die Entwicklung Oslos der letzten Jahre hin zu einer Metropole sein. Der rasend schnelle Wandel von einem der ärmsten zu einem der reichsten Länder der Welt führte auch zu einschneidenden Veränderungen der Gesellschaft. ${ }^{737}$ „Aufgrund der wachsenden Kommerzialisierung der Kultur wird Urbanität ein Kennzeichen, das Konkurrenzfähigkeit innerhalb Euro-

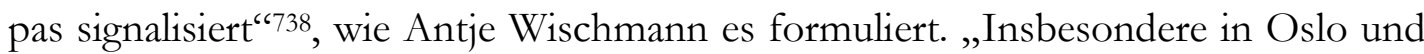
Helsinki hat von 1980 bis 2000 ein das Stadtbild verändernder Urbanisierungsschub stattgefunden, der im Vergleich zu anderen Städten durch seine zeitliche Raffung dramatisch wirkt. “739 Über das Literaturhaus, das sich als international ausgerichtet präsentiert, wird die Attraktivität Oslos als europäische Großstadt, die sich bewusst von der Provinz des Landes abgrenzt, unterstrichen. Litteraturbuset wird zu einem

\footnotetext{
735 Die Infragestellung des ,Zentrums‘ als Perspektivzentrum bildet ein Grundelement der Kulturtransferforschung, wie Michel Espagne ist seinem jüngsten Aufsatz zum Thema zusammenfasst, er nennt „,[d]ie radikale Relativität des Perspektivzentrums“, vgl. Espagne 2016, S. 54. Dieses Begriffsverständnis kollidiert jedoch nicht mit der hier verwendeten Auslegung im Sinne von ,Agglomeration` und ,Urbanität‘, da dieser eine andere Analysedimension betrifft.

${ }^{736}$ Dass Berlin dennoch die Kreativhauptstadt Deutschlands ist, wurde im Kapitel zum Literaturhaus Berlin erwähnt. Außerdem ist damit nicht geleugnet, dass es nicht eine Konkurrenz zwischen diesen Metropolen gibt, sodass auch sinngemäß Frankfurt auch ein Literaturhaus ,braucht', wenn Berlin und Hamburg eines haben.

${ }^{737}$ Dass Oslo sich seit den späten 1970er-Jahren baulich und vor allem gesellschaftlich stark verändert hat, beschreiben viele Studien unterschiedlicher Disziplinen, vgl. z. B. Andersen und Ljunggren 2014, S. 131.

${ }^{738}$ Wischmann 2006, S. 342.

${ }^{739}$ Ebd. Sie geht vorher darauf ein, dass Oslo den Status einer Metropole erst in den 1980er-Jahren erhielt, und eine Ursache für „das schwächer ausgeprägte norwegische Interesse an der Stadtkultur“ sein könnte, „dass Oslo aus historischen Gründen für eine nationalbewusste norwegische Identifikation wenig geeignet erscheint".
} 
Symbol von Urbanität. Die stärkere Angliederung an internationale respektive europäische Diskurse des Literaturhauses ist im Zusammenhang mit der von Antje Wischmann genannten Konkurrenzfähigkeit innerhalb Europas zu verstehen. Dazu passt es, dass Oslo eher Interesse an der Kooperation mit den europäischen Literaturhäusern als mit seinen nationalen Vergleichspartnern bekundet. ${ }^{740}$

Das Literaturhaus in Oslo bezieht sich explizit auf das Konzept der deutschen Literaturhäuser, versucht also, diesen Vermittlungsrahmen auf den norwegischen Kontext zu übertragen. Litteraturbuset ist also nicht etwa speziell an der Vermittlung deutscher Literatur interessiert. Dies unterstützt die dargelegte These, dass Litteraturbuset in Oslo zwei Motive für den Transfer hat: Erstens dient das Modell zur Verbesserung der eigenen Einrichtungen. Im deutschen Beispiel sahen die Initiator*innen eine Chance, den Literaturveranstaltungsbetrieb in Norwegen zu animieren. Literaturvermittlung über öffentliche Veranstaltungen war vorher in Norwegen weniger verbreitet. Die vom Transfer ausgelöste Diskussion belegt, dass beispielsweise die Bibliotheken diese Funktion zunächst nicht erfüllten. Zweitens ermöglicht der Transfer des Literaturhauses eine zunehmende Teilnahme am europäischen Betrieb, die vorher nicht auf diese Weise gegeben war, weil Oslo aus europäischer Sicht eher zur Peripherie gehörte, selbst aber an internationaler Zusammenarbeit interessiert ist. ${ }^{741}$ Dafür bedarf es aber der dezidierten Selbsteinordnungen in transnationale Kontexte. Dies erreichte Litteraturbuset dadurch, dass es sich in Oslo über seine Stadt- und Ländergrenzen hinausgehend präsentiert und sich seit Beginn auf deutsche Einrichtungen bezogen hat. Erst dann wird es von den deutschen Vorgängern, also im internationalen Kontext, wahrgenommen und als Vergleichsgröße akzeptiert. Wie gezeigt, macht erst die Anerkennung Oslos als international wahrnehmbare und vergleichbare Metropole eine Perspektivverschiebung auch im Ausland möglich. Dies trägt zur Erfüllung des Zwecks bei, eine innovative Position in den internationalen (Literaturvermittlungs-)Diskurs einbringen zu können. Zugleich erlangt Oslo damit eine Position der Urbanität, an der es, wie oben zitiert, seit den 1980er-Jahren arbeitet. Indem sich Oslo über das ,Norwegische Literaturhaus' im Ausland geradezu pars pro toto als Norwegen präsentiert, wird nicht nur Oslo, sondern Norwegen insgesamt diese Urbanität zugeschrieben. Auch in Deutschland ist im Literaturhaus-Diskurs in der Regel das Osloer Haus, viel seltener aber die anderen norwegischen Literaturhäuser und die dortigen Diskussionen bekannt, sodass meistens das Osloer Haus als einziges Litteraturbus aufgefasst wird. Dass dies konzeptuell durchaus seine Berechtigung hat, lassen die Ausführungen zum Bergener Literaturhaus erkennen. Und wie wichtig der Aspekt der Internationalisierung für Fritt Ord ist, manifestiert sich außerdem darin, dass diese Stiftung maßgeblich am Aufbau des Free Word Centers in London beteiligt war.

\footnotetext{
${ }^{740}$ Im Gespräch mit dem Programmleiter Andreas Liebe Delsett am 08.12.2015 im Literaturhaus Oslo wurde deutlich, dass kaum Interesse an einer Zusammenarbeit mit den anderen Literaturhäusern in Norwegen besteht, während es jedoch Austausch mit europäischen Einrichtungen gibt.

741 Dass dies schon 1994 der Fall war, zeigt Walter Rothholz, vgl. Rothholz 1994, S. 436. Bernd Henningsen stellt heraus: „Die gegenwärtige skandinavische Identitätssuche zeugt zunächst einmal von einer Krise des nationalen Selbstverständnisses in Skandinavien. Die Bemühungen, aufzuzeigen, wer man ist und wie man so geworden ist, wie man ist, sind in diesen Jahren so intensiv, wie dies zuvor im Norden noch nie der Fall gewesen war - vielleicht die nationalen Erschütterungen 1864 in Dänemark ausgenommen“, Henningsen 1994, S. 414.
} 


\section{6.2.2 Standort in Oslo}

Die Aussagen über die Verortung im Land liefern, wie gezeigt, Rückschlüsse auf die Position der gesamten Stadt und schließen an eine übergeordnete Diskussion von Stadt und Land, Zentrum und Peripherie sowie regional und international an. Doch Oslo ist natürlich keine homogene Stadt, und so spielt es eine Rolle, wo in der Stadt eine Einrichtung wie das Literaturhaus steht. In Oslo residiert Litteraturbuset im Wergelandsveien 29, in direkter Nähe zum Schloss, also im Zentrum der Stadt. Es befindet sich damit mitten in Oslo Vest und das ist für die Bewohner der Stadt ein Hinweis, wie es sozial und kulturell eigeordnet werden kann. Der schon lang bestehende Unterschied zwischen, verkürzt ausgedrückt, Oslo Vest - Wohlstand - und Oslo Ost weniger privilegiert - hält sich relativ stabil über die Zeit und wird in der Städtebauplanung sichtbar. Die Lage hat Einfluss auf die Positionierung der Einrichtung. ${ }^{72}$ Ohne gleich ideologisch von ,Kulturelite' sprechen zu wollen, ist es offenbar, dass Litteraturbuset dort steht, wo die Einkommensstarken und meist Hochgebildeten wohnen - und es damit eine ähnliche Lage wie das Literaturhaus in Berlin oder das in Hamburg hat.

Oslo als Hauptstadt und kultureller Ballungspunkt in Norwegen versammelt entsprechend den Regierungssitz, viele Museen und Kunstgalerien, eine große Universität und etwa die international bekannte Den Norske Operan an einem Ort. Somit wird an dieser Stelle auf eine genauere Einordnung des Literaturhauses in die Stadt verzichtet. Es sei aber angemerkt, dass städtische Projekte wie der Bau der neuen prestigeträchtigen Oper oder der Neubau der Hauptbibliothek Einfluss auf die Etablierung des Literaturhauses haben können. Audunson regt an, zu überlegen:

Omorganiseringer og det sterke fokuset på nytt hovedbibliotek kan nok også ha resultert i en innadvendthet og dermed et tomrom som litteraturhuset har fylt. ${ }^{743}$

[Die Umstrukturierungen und der starke Fokus auf die neue Hauptbibliothek kann gut ebenfalls zu einer Zurückgezogenheit und somit zu einem Leerraum geführt haben, den das Literaturhaus gefüllt hat.

Die Frage, die sich stellt, hier aber noch nicht beantwortet werden kann, ist, wie sich die Eröffnung der neuen Deichman Hovedbiblioteket in Oslo auf die Position von Litteraturhuset auswirken wird. Diese wird seit 2014 gebaut, die Eröffnung ist für 2020 geplant. ${ }^{744}$ Das Gebäude entsteht im Viertel Bjorvika, das als altes Containerviertel seit 2000 aufwendig zu einem modernen Kulturquartier entwickelt wird. Dass eine Institution entsteht, wenn ein Bedürfnis von dem Bestehenden nicht gestillt wird, ist dabei ein Aspekt, der sich für die Literaturhaus-Idee an ganz unterschiedlichen Stellen in dieser Arbeit zeigt.

\footnotetext{
${ }^{742}$ Dass Litteraturhuset nach eigenen Angaben diese Grenzen zu überwinden sucht, sei angemerkt. Dennoch steckt in der Lage in der Stadt eine historisch gewachsene Zuschreibung.

743 Audunson 2014, S. 22.

${ }^{744} \mathrm{Vgl}$. „Om biblioteket“, Deichman Hovedbiblioteket.
} 


\section{6.3 Gestaltung von Litteraturhuset}

\section{6.3.1 Gebäude}

Entworfen von dem Architekten Henry Fearnley Coll und 1932 für Oslo Larerskole [Oslos Lehrerschule] erbaut, wurde das Haus für den Einzug von Litteraturhuset umgebaut. ${ }^{745}$ Zunächst vom Eigentümer Entra gemietet, kaufte Fritt Ord 2017 das Haus selbst und überlässt es Litteraturbuset nun langfristig. Das prächtige Haus im Wergelandsveien 29 vereint mehrere Aspekte des norwegischen literarischen Lebens auf 3500 Quadratmetern unter einem Dach: Das Literaturhaus im engeren Sinne mit sechs unterschiedlich großen Veranstaltungsräumen, Büroräumen, einem Appartement für ausländische Autor*innen und Intellektuelle sowie offenen reservierbaren Arbeitsplätzen verteilt sich über das gesamte Haus. Auf der zweiten und dritten Etage haben zudem Norsk Forfattersentrum [Norwegisches Autorenzentrum], Norsk PEN., die Agentur Leser soker bok [Leser sucht Buch], die die Bedingungen für Menschen, die aus unterschiedlichen Gründen Schwierigkeiten mit der Lektüre gewöhnlicher Texte haben, zu verbessern versucht, ${ }^{746}$ tidsskriftforeningen [die Zeitschriftenvereinigung] und Norsk Shakespeare- og teatertidsskrift [Norwegische Shakespeare- und Theaterzeitschrift] ihre Büros. Nach außen präsenter und direkt im Eingang des Literaturhauses befinden sich eine Buchhandlung ${ }^{747}$ und Kafe Oslo, die ,gir viktige bidrag til helhetsinntrykket av huset ${ }^{6748}$ [einen wichtigen Beitrag zum Gesamteindruck des Hauses leisten]. „Kafe Oslo er husets avdeling for ikke-åndelig føde“"749 [Kafe Oslo ist die Abteilung für nicht-geistige Nahrung im Haus], dort finden zudem Literaturveranstaltungen statt und es stellt mit der LesBar eine Ecke zur Zeitschriftenlektüre bereit.

Besonders erwähnenswert ist, dass es im Literaturhaus Oslo Skriveloftet [das Schreibloft] gibt, eine Etage, die Arbeitsplätze für Verfasser*innen, Journalist*innen, Kritiker*innen und Dramatiker*innen beherbergt. ${ }^{750}$ Neben kollegialem Austausch und öffentlichen Veranstaltungen werden den Literat*innen praktische Bedürfnisse erfüllt, sodass diese konzentriert an ihren Texten arbeiten können. Eine Fläche zur kontemplativen Arbeit zu bieten, zeichnet ansonsten Bibliotheken aus, während das Literaturhaus eher als Ort des Austausches und des gesprochenen Wortes auftritt. Dennoch bildet die Produktion von Literatur einen festen Bestandteil. Alle drei genannten Aspekte - Austausch, Präsentation und Produktion - finden im Litteraturbuset Platz.

\footnotetext{
745 Zur Geschichte des Wergelandsveien und des Gebäudes vgl. Stenseth 2013.

746 Vgl. „Om oss“, Leser søker bok.

${ }^{747}$ Bis 2011 gab es im Literaturhaus eine Filiale der großen norwegischen Buchhandelskette Norli, seit 2010 dem fusionierten Konzern Norli Gruppen und Libris angehörig. Seitdem verkauft Tanum Litteraturbuset, ebenfalls Teil einer Buchhandelskette in Oslo, die dem Verlag Cappelen Damm angehört, Bücher im Literaturhaus.

748 Arsberetning for Stiftelsen Litteraturbuset 2012 2013, S. 4.

749 „Kafe Oslo“, Litteraturhuset. URL: litteraturhuset.no/kafeoslo/ (Stand: 30.08.2018).

${ }^{750}$ Vgl. Kapitel II 13.2.8, S. 400.
} 


\section{6.3.2 Veranstaltungsräume}

Im Litteraturbuset finden sich mehrere Räume, die für Vermietungen und eigene Veranstaltungen zur Verfügung stehen. ${ }^{751}$ Der größte Saal Wergeland mit 178 Quadratmetern bietet offiziell bis zu 200 Besucher*innen Platz. Ausgestattet mit Ton- und Lichtanlage sowie einer bewegbaren Bühne lässt sich der Raum für unterschiedliche Gelegenheiten nutzen. Er eignet sich somit nicht nur für Lesungen und Gespräche, sondern auch Filme können problemlos gezeigt, Konzerte durchgeführt oder Bild und Ton ohne extraordinären Aufwand aufgezeichnet werden. Schon bei der Einrichtung dachten die Verantwortlichen an plurimediale Verwendungszwecke des Literaturhauses. Diese konzeptuelle Entscheidung ließ sich 2007 selbstverständlicher umsetzen als in den Jahren, in denen die deutschen Literaturhäuser ihr technisches Inventar angeschafft haben. Ein Digitalprojektor beispielsweise ist im Osloer Saal selbstverständlich fest installiert. Variiert werden können die Podien der Hauptsäle in allen Literaturhäusern, mobile Bühnenelemente eignen sich, um den unterschiedlichen Formaten angemessen zu sein; die Bestuhlung beziehungsweise Raumwahl lässt sich der Anzahl der erwarteten Besucher*innen anpassen.

In Oslo kommt hinzu, dass die technische Ausstattung, die Beleuchtung beziehungsweise mögliche Abdunkelung des Zuschauerraumes, die Bühne mit Vorhang und nach hinten stufenweise erhobene Sitzreihen mit Sesseln eine Theaterraumkulisse erzeugen. Teppiche und weitere dekorative Elemente der Künstlerin May Bente Aronsen erzeugen „både intimitet og atmosfære“"752 [sowohl Intimität als auch Atmosphäre]. Die Agierenden auf dem Podium werden wörtlich ins Scheinwerferlicht gerückt. Diese Theateranalogie zu nutzen, ist in Oslo begründet, in den deutschen Literaturhäusern ist „Bühne', verstanden als deutlich erhöhter und vom Publikum distanzierter Schauplatz, hingegen oft gar nicht die treffende Bezeichnung. Passender und häufig verwendet ist der Terminus ,Podium', eine Erhöhung, die die Gäste für das Publikum sichtbar macht, aber nicht, in Szene' setzt. Während die Bühne einen zweiten Raum markiert, bleiben die Redner*innen auf dem Podium mit dem Publikum im gleichen Raum. Die Trennung von Zuschauerraum und Aufführungsort ist im Saal Wergeland in Oslo deutlicher markiert als im Großen Saal in Hamburg oder im Literarischen Zentrum Göttingen. So bildet sich ein völlig anderer Veranstaltungsrahmen. Wie im Abschnitt zum Literaturhaus Frankfurt dargestellt, setzt am ehesten der dortige Lesesaal die Autor*innen wie der Saal Wergeland in Oslo in Szene.

Besonders bemerkenswert ist die Bühnenkonzeption in Oslo deshalb, weil Litteraturhuset sich mittels seiner textlichen Äußerungen als Debattenarena darstellt, als Ort des Austausches und der Konfrontation. Von der Bühnengestaltung ausgehend, mutet das Haus eher wie ein Aufführungsort an, der es dem Publikum sogar ermög-

\footnotetext{
${ }^{751}$ Eine Beschreibung sowie fotografische Impressionen der Veranstaltungsräume und deren Ausstattung ist auch über die Website von Litteraturbuset abrufbar, damit sich potenzielle Mieter informieren können. Die Haupteinnahmequelle für Eigenmittel ist die Vermietung von Räumen für Einzelveranstaltungen. Es gibt inzwischen einige Veranstalter, die immer wieder das Literaturhaus für ihre Zwecke mieten. ${ }^{752}$ So beschreibt Litteraturbuset diese Dekoration auf seiner Website selbst, „Sal Wergeland“, Litteraturhuset. URL: litteraturhuset.no/sal/wergeland/ (Stand: 30.08.2018).
} 
licht, sich auf bequemen Stühlen einzurichten. ${ }^{753} \mathrm{Im}$ ersten Moment scheinen diese beiden Funktionen des Ortes - teilnehmende Auseinandersetzung und unterhaltsame Aufführung - sich zu widersprechen. Doch beanspruchen auch Drameninszenierungen im Theater für sich, Diskussionen anzustoßen.

In der Ausübung ähneln sich die Praktiken der Literaturveranstaltung in den untersuchten Literaturhäusern. Die Grundkonstellation ist, dass sich auf dem Podium Akteur*innen unterhalten, sie länger oder kürzer vorlesen und dass eine Zuhörerschaft diesem Geschehen beiwohnt und in unterschiedlichem Ausmaß partizipieren kann. Die Debatten finden zunächst auf der Bühne statt und nicht im direkten Gespräch mit den Zuschauer*innen; im Publikum werden sie im Anschluss, idealerweise, fortgesetzt. Dabei, das zeigt die Erfahrung, macht es, anders als meine Darstellung bis hierher erwarten ließ, für den Ablauf der Veranstaltung letztlich kaum einen Unterschied, ob die Bühne pompös ausgestattet ist oder ob die Gäste hinter schwachen Leselampen und auf Augenhöhe mit den Besucher*innen mehr kauern als sitzen. Die Gesprächsverläufe sind tendenziell unabhängig von der Rahmung. Die Rezeption des Gesagten jedoch ist verknüpft mit dem Umgebenden. Deshalb, so hier der Punkt, erzeugt die ausgeleuchtete Bühne eine Distanz zum Bühnengeschehen, aber auch eine öffentlichkeitswirksame Bedeutung. Die beschriebene Präsentation im Wergeland, die gar nicht nur aus dem Theater, sondern vor allem aus Talkformaten im Fernsehen bekannt ist, gibt dem Raum eine ,massenmediale Dimension', den Anschein, dass das, was auf der Bühne geschieht, im Fernsehen ausgestrahlt wird. Der Eindruck, sich in einem Fernsehstudio zu befinden, liegt auch deshalb nahe, weil bis 2014 der öffentlich-rechtliche Fernsehsender NRK (Norsk rikskeringkasting) [Norwegischer Reichsrundfunk] regelmäßig die Sendung Debatten live aus dem Litteraturbuset übertrug und damit dem Haus große Medienaufmerksamkeit bescherte. Die vermeintliche Intimität, die in der oben so genannten Caféhausatmosphäre im Literaturhaus Hamburg entsteht, beinhaltet hingegen eine Exklusivität und Verortung in diesem einen Raum.

Der größte Saal im Werglandsveien 29 mit seinem klar markierten Bühnenraum lässt die Zuschauer*innen demnach eher zum Beiwerk werden. Unmittelbarerer Kontakt zu den Zuhörer*innen bieten die weiteren Räumen an. Die kleineren Säle Amalie Skram - bis zu 120 Personen - und Kverneland - bis zu 30 Besucher*innen - liegen in der zweiten Etage, haben keine feste Bühne, nur einige Lichtspots, sowie Stromund Netzzugang. Die Atmosphäre erinnert eher an Seminarräume denn an Theatersäle. Im Untergeschoss befindet sich ein Raum, Kjelleren [der Keller] genannt, der mit Bücherregalen an der Wand und niedrigen Decken eine gemütliche Atmosphäre für bis zu 100 Zuhörer*innen schafft. Die dritte Etage ist mit den beiden Räumen Nedjma und Sjeherasad für Kinder reserviert.

\footnotetext{
${ }^{753}$ Nicht alle Literaturhäuser bieten Stühle, auf denen sich die Besucher*innen zurücklehnen können, worin sich Charakteristika dieser Institution verbildlichen: Flexible Raumgestaltung für unterschiedliche Veranstaltungen sowie Vermietungen und Teilnahme des Publikums statt bloßer Unterhaltung, so, als wollten die Stühle vermitteln: ,Hier darf es auch gelegentlich unbequem werden!‘
} 
Die Namen der Räume sind Programm:

Rommet har fått navnet Nedjma, som betyr Stjerne på arabisk. Nedjma er også den beintøffe jenta som alle kretser rundt i Kateb Yacines algeriske roman fra 1956.754

[Der Raum hat den Namen Nedjma bekommen, was Stern auf arabisch bedeutet. Nedjma ist auch das taffe Mädchen, das alle in Kateb Yacines algerischem Roman von 1956 umkreisen.]

,Scheherazade' verweist auf die persische Geschichtenerzählerin. Geheimnisvolles, Märchenhaftes und Internationales sollen die Kinder einführen in die Welt der Geschichten und der Literatur. Mit den Namen der Säle Wergeland und Amalie Skram positioniert sich das Literaturhaus in der norwegischen Literaturtradition - aber auch in der Stadt, schließlich steht das Literaturhaus am Wergelandsveien, da liegt es nah, den großen Saal dementsprechend zu benennen. Henrik Wergeland (18081845) war ein früher Verfechter der norwegischen Nation und kann aufgrund des öffentlich ausgetragenen Lyrikstreits mit Johan Sebastian Welhaven, der seinerseits für Skandinavismus und die dänisch-norwegische Literaturlinie focht, als Symbol für die eigenständige norwegische Nation gedeutet werden. Sein vielfältiges literarisches Werk umfasst neben Lyrik, Dramen und Romane und vor allem seine späten Texte „streifen die Grenzen zur Moderne“755. Er zählt nicht nur zu den bedeutendsten Dichter Norwegens, sondern setzte sich darüber hinaus stark für die Volksbildung ein, sich mit dem Judentum und Islam auseinander und nahm aktiv an (gesellschafts-)politischen Debatten teil. Diesen Impetus schreibt Litteraturbuset sich selbst auch zu, indem es sich in die Traditon dieses Dichters und Publizisten stellt. Amalie Skram (1846-1905) gilt als eine der bedeutendsten Vertreterinnen des sogenannten Modernen Durchbruchs und kämpfte schon früh für Frauenrechte und Gleichberechtigung. ${ }^{756}$ Mit der Ehrung dieser Autorin markiert auch das Literaturhaus seine Unterstützung der (literarischen) Emanzipationsbewegung und sieht darin einen wichtigen Bestandteil heutiger Gesellschaft und Literaturvermittlung. Das dritte Zimmer ist nach dem anerkannten norwegischen Comiczeichner und Illustrator Steffen Kverneland (*1963) benannt, der beispielsweise in seinen Bänden Amputerte klassikere [Amputierte Klassiker] literarisches Material verarbeitete und der für seine Comicbiografie Munch den Brageprisen, einen der wichtigsten norwegischen Literaturpreise, erhielt. In ,seinem' Raum im Litteraturbuset hat er in einer sieben Meter großen Wandmalerei 35 norwegische Gegenwartsautor*innen verewigt. Mit diesem in Auftrag gegebenen Kunstwerk bezieht sich die Einrichtung zum einen über die dargestellten Autor*innen auf die zeitgenössische Literatur, zum anderen über das Gemälde selbst auf das Literaturverständnis des Literaturhauses, das die Bildkunst des Comics neben der Wortkunst ebenfalls präsentiert. Die Auswahl der Autor*innen solle weniger einen Kanon vorgeben, sondern die Verschiedenartigkeit der vorgestellten Literaturgenres und -positionierungen symbolisieren. ${ }^{757}$ Anhand

\footnotetext{
754 „Barn og ungdom“, Litteraturhuset. URL: www.litteraturhuset.no/barnungdom/rommene.html (Stand: 11.07.2014).

${ }^{755}$ Hoff und Rühling 2016, S. 15.

${ }^{756} \mathrm{Im}$ Bergener Literaturhaus ist ebenfalls ein Raum dieser Autorin gewidmet, weshalb dort auf sie zurückgekommen wird, vgl. II 7.3.2, S. 198.

${ }^{757}$ Das zeigen die Diskussionen und wurde mir von Andreas Liebe Delsett im Gepräch ebenfalls vermittelt. Dieses Kunstwerk wirkt natürlich dennoch auf Kanonisierungsprozesse ein. Dass die Macher*innen
} 
der Gestaltung der Räume lässt sich also interpretieren, dass im Litteraturbuset traditionelle und zeitgenössische Literatur zugegen sind, Wort und Bild zu erwarten und andere mediale Umsetzungen möglich sind sowie eher die Autor*innen als die Texte allein präsentiert werden.

\section{7 Litteraturhuset i Bergen - Ein Nachfolger in Norwegen}

\section{7.1 Entstehung und Organisation}

\section{7.1.1 Entstehungsstrategie und Abgrenzung zum Litteraturhuset in Oslo}

Im Anschluss an Litteraturbuset in Oslo wurden in Norwegen weitere dieser Einrichtungen geplant und zum Teil umgesetzt. Neben Einrichtungen in Fredrikstad, Lillehammer und Trondheim ist Litthusbergen ${ }^{758}$ einer dieser Nachfolger. Dessen Trägerstiftung wurde 2009 gegründet, Litteraturbuset $i$ Bergen, auch Litteraturbuset Bergen, eröffnete offiziell im Februar 2013 mit dem Ziel,

å inspirere til lesing og leseglede, formidle kunnskap og sørge for engasjement rundt viktige debatt- og samfunnsspørsmål (BG 2015-I, S. 4)

[zum Lesen und zur Lesefreude zu inspirieren, Wissen zu vermitteln und für Engagement rund um wichtige Debatten- und Gesellschaftsfragen zu sorgen].

Aufgrund des Erfolges des Osloer Literaturhauses, das viele Akteur*innen des nationalen wie internationalen Literaturbetriebs zusammenbringt und damit weithin bekannter macht, wird das Konzept für andere Orte interessant. Ein Literaturhaus eröffnet die Chance, dass innerhalb von Norwegen Städte abseits des Zentrums alternative Kulturplätze werden und sich so unabhängiger von Oslo machen, weil dort ein mit dem Angebot in Oslo vergleichbares kulturelles Leben stattfindet. Wenn einer Stadt ein einladendes Literaturhaus zur Verfügung steht, finden zudem vermutlich mehr etablierte Literat*innen, Intellektuelle wie Künstler*innen den Weg in die vermeintliche Provinz, die dadurch eine Aufwertung erhält. Für die Verlage, Agenturen und Autor*innen kann dies attraktiv sein, weil sich die Auftrittsoptionen

\footnotetext{
die für das Wandgemälde ausgewählten Autor*innen nicht als alleinige Vertreter*innen eines materialen Kanons verstehen, müssen sie betonen. Dass die Autor*innen zum Teil symbolisch für einen Autorentyp oder eine Literaturrichtung ausgewählt seien, legt zumindest die Auswahlkriterien offen. Und eine Auswahl ist nötig, weil sie sich aus Platzgründen auf eine bestimmte Anzahl beschränken müssen. Über die Auswahl wurde bei der Eröffnung diskutiert, die Autorin Anne B. Ragde ist sogar ins Literaturhaus eingebrochen, um ihr eigenes Porträt hinzuzufügen, vgl. Gonsholt Ighanian: „Derfor er“. Abgebildet sind: Kyrre Andreassen, Hanne Ørstavik, Tone Hødnebø, Olaug Nilssen, Ragnar Hovland, Tor Åge Bringsværd, Jan Kjærstad, Erlend Loe, Gro Dahle, Tor Bomann-Larsen, Kjell Askildsen, Trude Marstein, Lars Saabye Christensen, Thomas Hylland Eriksen, Kjartan Fløgstad, Åsne Seierstad, Thorvald Steen, Eldrid Lunden, Dag Solstad, Jon Fosse, Herbjørg Wassmo, Thure Erik Lund, Ingvar Ambjørnsen, Per Petterson, Unni Lindell, Stein Mehren, Vigdis Hjorth, Margit Sandemo, Jostein Gaarder, Jon Bing, Jo Nesbø, Jan Erik Vold, Anne-Cath. Vestly, Walid al-Kubaisi und Karl Ove Knausgård, vgl. Aubert 2007. 758 Auf seiner Website nutzt Litteraturbuset in Bergen vor allem die Kurzversion Litthusbergen.
} 
erhöhen, denn möglicherweise schafft die Infrastruktur der Literaturhäuser Anreize, Lesereisen durch Norwegen zu organisieren. ${ }^{759}$

\section{Intranationaler Transfer des Literaturhauses}

Im vorherigen Kapitel wurde Oslos Zentrumsposition in Norwegen beschrieben und dabei besonders auf die internationale Wahrnehmung der Hauptstadt eingegangen: Im Ausland jenseits von Nordeuropa steht Oslo pars pro toto für Norwegen und nahm lange eine periphere Stellung im internationalen Kontext ein, die anderen Städte finden dort viel weniger Beachtung. National gesehen rangieren die anderen Städte im Land meist hinter Oslo, sind aber natürlich deutlich sichtbarer. Oslo liegt zwar meistens vorne, doch auch andere Städte versuchen, dem ein Gegengewicht entgegenzustellen; so bezeichnet sich das Literaturhaus in Fredrikstad als das zweitgrößte in Norwegen ${ }^{760}$ und Bergen ist die zweitgrößte Stadt. ${ }^{761}$ Bergen war zudem wegen seiner geografischen Lage lange Zeit der wichtigste Handelsplatz Norwegens. Durch die Universität - und Studierende machen heute zehn Prozent der Bevölkerung aus - entwickelte sich die Stadt zum akademisch-intellektuellen Sammlungsort. Es ließe sich also vermuten, dass auch Bergen im Literaturhaus-Kontext als norwegisches Zentrum gedeutet werden könnte. Doch vielmehr ist davon auszugehen, und das zeigt die vorliegende Arbeit an mehreren Stellen, dass sich das Literaturhaus nicht so sehr im akademisch-institutionellen Bereich verorten lässt, sondern stärker am Literaturbetrieb insgesamt teilhat. Akademiker*innen gehören zwar als Publikum, Bühnengäste und Mitarbeiter*innen zum kollektiven Akteur Literaturhaus und formen die dortige Praxis mit, doch spielt dort der publikumsvermittelnde und marktorientierte Bereich des Literaturbetriebs ebenfalls hinein. Die Universität ist als Akteur eher marginal am Literaturbetrieb beteiligt, denn Verlage oder Massenmedien beispielsweise gestalten diesen und prägen dessen Regeln stärker. Diese sitzen in Norwegen, wie erwähnt, vornehmlich in der Hauptstadt, weshalb Oslo als literaturveranstaltungsbetriebliches Zentrum anzunehmen ist.

Bei der Planung des Litteraturhuset in Bergen gab es die Idee, dass „et litteraturhus i Bergen kan styrke byens posisjon som motvekt til Oslo-dominansen"762 [ein Literaturhaus in Bergen die Position der Stadt als Gegengewicht zur Oslo-Dominanz stärken könne]. An dieser von den Bergener Literaturhaus-Initiatoren formulierten Wirkungsabsicht ist ablesbar, dass gewiss Interesse besteht, mit den Literaturhäusern den Kulturbetrieb national zu dezentralisieren. Es handelt sich dabei vorrangig um einen intranationalen Transfer des Literaturhauses. Dass damit nicht unbedingt beabsichtigt ist, Bergen als ein urbanes Gegengewicht zu Oslo zu etablieren, macht auch Hilde Kari Skaftnesmo deutlich, indem sie mindestens zwei Gründe für „bergenspatriotisme“ [Bergen-Patriotismus] nennt: Erstens sei Bergen die Hauptstadt des sogenannten Westlands und symbolisiere so den Zwist zwischen Østlandet,

\footnotetext{
${ }^{759}$ Dies ist gewiss auch dem Umstand geschuldet, dass Literaturveranstaltungen im Vergleich zu Theaterinszenierungen oder Musikaufführungen kostengünstig und mit wenig organisatorischem Aufwand umsetzbar sind.

${ }^{760}$ Vgl. „Huset og“, Litteraturhuset Fredrikstad.

${ }^{761}$ Einwohnerzahl (Anfang 2017) etwa 278.500, vgl. „Folkemengde og“, Statistisk sentralbyrå.

${ }^{762}$ Kristin Helle-Valle zitiert nach: „Heftig debatt“, Den norske Foratterforening.
} 
durch Oslo vertreten, und Vestlandet. Zweitens werde Bergen geschätzt, weil es gerade keine Metropole sei. Es werde so zum Repräsentanten für das gesamte Norwegen außerhalb der Oslo-Region, stehe damit für das ländliche, provinzielle Norwegen. ${ }^{763}$ In beiden Fällen geht es jedoch um den beschriebenen Versuch, Oslo mit dem Transfer des norwegischen Literaturhauses etwas entgegenzusetzen.

Svein Björkås konstatiert für das norwegische Kunstfeld - er beschränkt sich dabei nicht auf Literatur -, dass seit den 1990er-Jahren mehr als hundert neue Kunstfestivals in ganz Norwegen etabliert worden seien. Diese Prozesse seien in hohem Maße durch einen verstärkten internationalen Austausch bedingt, im Kunstbereich, aber auch in anderen gesellschaftlichen Zusammenhängen. ${ }^{764}$ Das Bestreben der Kunstvermittlung seit dem Zweiten Weltkrieg, die legitimierte Kunst aus dem Zentrum in die Regionen zu verbreiten, ${ }^{765}$ zeigt sich eingeschränkt gleichfalls am Literaturhaus. Die Regionen haben offenbar ein Interesse daran, der Hauptstadt nachzueifern und ihre eigenen Ausformungen des Literaturhauses zu etablieren.

Es ist keine bloß theoretische Konstruktion, die Entstehung des Literaturhauses in Bergen unmittelbar auf die Osloer Einrichtung zurückzuführen. Ausgesprochen deutlicher als auf die Tradition der deutschen Literaturhäuser bezieht sich die Initiatorin und Leiterin der Bergener Version Kristin Helle-Valle auf Litteraturbuset in Oslo: In ihrer vorherigen beruflichen Funktion arbeitete sie mit dem Literaturhaus Oslo zusammen und wünschte ein solches Haus für Bergen. Zum einen nimmt sie sich das Osloer Haus zum Vorbild und zum anderen sieht sie darin, wie oben zitiert, einen Weg, einen Gegenspieler zu Oslo zu etablieren und Bergen nicht weiterhin von der Hauptstadt ,kleinreden` zu lassen:

Etter 25 år i Bergen vet jeg noe om hvordan Oslo ser på oss. Jeg kjenner også betydningen av å ha en sterk opinion, en sterk kultur, og nødvendigheten av å få målbåret og konsolidert den. Et litteraturhus vil gi oss anledning til å få gjort nettopp det. ${ }^{766}$

[Nach 25 Jahren in Bergen weiß ich einiges darüber, wie Oslo auf uns blickt. Ich kenne ebenso die Bedeutung davon, eine starke Meinung zu haben, eine starke Kultur und die Notwendigkeit, diese zum Ziel zu bringen und zu konsolidieren. Ein Literaturhaus wird uns eine gute Möglichkeit geben, gerade dieses zu bewerkstelligen.]

Es fällt dabei auf, dass die Initialzündung von der Person ausging, die dann die Geschäftsführung übernahm, dass also die Person, die die Gründungsidee ersann, diese letztlich umsetzte. Es ist folglich ein auch persönliches Interesse an der Eröffnung der Einrichtung anzunehmen, weil sich Kristin Helle-Valle durch ihren Einsatz für das Literaturhaus eine Anstellung ermöglichte.

\footnotetext{
${ }^{763}$ Vgl. Skaftnesmo, S. 123-124. Diese regionalere Ausrichtung Bergens findet bei den Programmanalysen Unterstützung, denn ein deutlich geringerer Anteil der Podiumsgäste als in Oslo kommt in Bergen nicht aus Norwegen, vgl. Kapitel II 14.3.2. Mit dem geplanten Festival Littestbergen versucht die Einrichtung das sukzessive zu ändern, vgl. FN 791.

${ }^{764}$ Vgl. Bjørkås 2003, S. 440.

765 Vgl. ebd., S. 442.

${ }^{766}$ Kristin Helle-Valle zitiert nach: „Heftig debatt“, Den norske Foratterforening.
} 


\section{Debatten um die Eröffnung des Litteraturhuset in Bergen}

Zwei der erwähnten Aspekte - die Ideen der Leitungsperson sowie der Bezug auf Oslo - sorgten unter anderem dafür, dass das Haus schon vor seiner Eröffnung in die Kritik geriet und eine Diskussion über Chancen und Scheitern von Literaturhäusern entfachte. Insgesamt entstanden rund 500 Beiträge zum Thema, wie Hilde Kari Skaftnesmo in ihrer diskursanalytischen Magisterarbeit zur Debatte herausgefunden hat. ${ }^{767}$ Insbesondere die Frage nach der Finanzierbarkeit und Grundausrichtung des Projektes leitete die Verhandlungen an. Es wurde bemängelt, dass das Gebäude einem privaten Immobilienunternehmen gehöre, ,som ligger an til å bli litteraturhusprosjektets ubestridte seierherre“ ${ }^{\text {"7 } 68}$ [das wahrscheinlich der unbestrittene Sieger des Literaturhaus-Projektes werden wird], und dass dieses Literaturhaus wohl kein Haus für Literaturschaffende werden würde. Der Autor Tomas Espedal (*1961), der diese Debatte in der Tageszeitung Bergens Tidende anzettelte, führt dort aus, dass ,ein Haus für Literaturschaffende' unter anderem bedeute, dass es einen guten Vorleseplatz gäbe und weitere Infrastruktur wie Arbeitsplätze und ein Café, das - so ein zentraler Kritikpunkt - angemessen günstig sei, sodass Mitarbeiter*innen und Autor*innen dieses wirklich nutzen könnten. Er setzt fort:

Slik er det verken i Oslo eller Berlin. I begge husene er bokhandelen for dårlig, restauranten for dyr, klientellet for ensartet og kjedelig; her kommer de med penger, de som vil menge seg med kunstnere, kulturmenneskene. ${ }^{769}$

[So ist es weder in Oslo noch in Berlin. In beiden Häusern ist die Buchhandlung zu schlecht, das Restaurant zu teuer, das Klientel zu gleichartig und langweilig, hierher kommen die mit Geld, die, die sich unter die Künstler*innen mischen wollen, die Kulturmenschen.]

Espedal geht in dieser Debatte auch harsch gegen die Leiterin des Literaturhauses vor: Sie kenne die literarische, sehr rege Szene in Bergen nicht hinlänglich und er wirft ihr vor, dass sie in Bergen eine Kopie des Osloer Hauses umzusetzen plane, statt die Chance zu nutzen, in der unter anderem durch Studierende geprägten Stadt „noe helt annet" ${ }^{\text {"770 }}$ [etwas gänzlich anderes] aufzubauen. Vergleichbare Diskussionen um die Macht der Literaturhaus-Leitungen fanden sich, wie dargestellt, in Hamburg oder Frankfurt ebenfalls wieder. Die Person steht definitiv mit im Fokus.

Es wird deutlich, dass Espedal aus der Perspektive eines Autors spricht und Fürsprecher der Literat*innen ist, die sich in ihrem bisherigen aktiven Wirken in Bergen durch das neu entstehende Literaturhaus bedroht fühlen mögen. In seiner dezidierten Kritik an der personellen und finanziellen Ausstattung unterstützt ihn unter anderem Erling Gjelsvik. ${ }^{771}$ Als kollegialer Kontrahent Espedals und Gjelsviks in der Debatte kommentiert Ketil Bjørnstad (*1952) die Situation über Bergen hinausblickend und sieht vor allem die Vorteile, die ein Literaturhaus in Bergen birgt:

Opp gjennom tidene har mange av oss lagt merke til hvor lukket, arrogant og selvforherligende det litterære miljøet i Bergen kan være. Et litteraturhus etter

\footnotetext{
${ }^{767}$ Vgl. Skaftnesmo 2014, S. 11. Die Ergebnisse meiner verkürzten Darstellung anhand einiger Artikel finden in der Abschlussarbeit Unterstützung. Ihre ausführliche Diskursanalyse bestätigt, dass die zwei oben angeführten Positionen das Kontinuum der Standpunkte abstecken.

768 Gjelsvik 2011.

${ }^{769}$ Espedal 2011.

${ }^{770}$ Ebd.

${ }^{771}$ Vgl. Gjelsvik 2011.
} 
europeisk modell vil i beste fall kunne bli et levende og åpent kultursentrum der det litterære hierarkiet ikke kan fortsette å sementere fordommer eller fastlåste holdninger om hva litteratur er eller kan være. ${ }^{772}$

[Über die Zeit haben viele von uns bemerkt, wie abgeschlossen/verschlossen, arrogant und selbstverherrlichend das literarische Milieu in Bergen sein kann. Ein Literaturhaus nach europäischem Modell wird im besten Fall ein lebendiges und offenes Kulturzentrum werden können, wo die literarische Hierarchie nicht damit weitermachen kann, Vorurteile oder festgelegte Einstellungen darüber, was Literatur ist oder sein kann, zu zementieren.]

Einmal außer Acht gelassen, dass die Äußerungen von Individuen stammen und vermutlich persönliche Motive in die Urteile einfließen - obgleich dies nicht zu unterschätzen ist -, so können die beiden Positionen stellvertretend für die verschiedenen Standpunkte der Diskussion behandelt werden. ${ }^{773}$ Während Espedal im Literaturhaus als ideenlose Nachahmung, die das Bergener literarische Leben anzugreifen versuche, eher eine Beunruhigung von außen sieht, begreift Bjørnstad es als Konzept, das für den neuen Ort direkt förderlich sei. Er hält eine Veränderung von innen für möglich, gar für notwendig. An Bjørnstads Äußerung ist besonders interessant, dass er dem Literaturhaus zutraut, die Entscheidungsmacht der hegemonialen Kulturelite schmälern und dem akademisch geprägten Kulturleben in Bergen eine demokratischere Kraft hinzufügen zu können. Das Literaturhaus begegne den zementierenden Praktiken der literarischen Hierarchie mit einer durchlässigeren Vermittlungspraxis.

Der Norweger Ketil Bjørnstad - selbst viel in Europa unterwegs und, weil er sowohl Autor als auch Musiker ist, vertraut mit unterschiedlichen Kulturbereichen fügt eine für die komparative Perspektive der vorliegenden Arbeit aufschlussreiche Komponente hinzu. Er schreibt Deutschland literarische Vielfalt zu und nennt als Grund dafür, dass „litteraturen verdsettes så høyt i det landet ${ }^{\text {‘674 }}$ [die Literatur in diesem Land so hochgeschätzt wird]. Außerdem führe das Zusammenspiel der literarischen Institutionen, die Autor*innen und Leser*innen die Möglichkeit geben, sich in einem lebendigen, oft unvorhersehbaren Umfeld zu begegnen, zu literarischer Diversität. Diese Vorstellung veranschlagte auch Paul Opstrup für das LiteraturHaus in Kopenhagen.

Des Weiteren wird an der norwegischen Diskussion offenbar, dass von , deutscher ${ }^{6}$ Position aus anderes in Deutschland und Norwegen gesehen wird als aus einer norwegischen Perspektive. Dieser norwegische Blick auf die deutschen Literaturhäuser nimmt also weniger wahr, dass sie eine sogenannte Hochkultur bestätigen und verfestigte Formate nutzen, sondern erkennt darin eine Offenheit. Es ist zu berücksichtigen, dass der Artikel sich an ein norwegisches Publikum richtet. Das ,demokratische‘ Moment der Diskussion dient gegebenenfalls als ,Lockmittel' für

\footnotetext{
772 Bjørnstad 2011.

773 Die bereits erwähnte Magisterarbeit zum Thema stellt heraus, dass es bei der Diskussion um das zu eröffnende Literaturhaus in Bergen auch um die sich wiederholende Debatte um Schönliteratur versus Demokratisierung und Politisierung bzw. um Autoreninteresse versus Kulturpolitik gehe, die sie unter den Schlagworten ,Salong' [Salon] und ,Samfunnshus' [Gesellschaftshaus] zugespitzt sieht, vgl. auch Kapitel III 3.4. Skaftnesmo nennt noch weitere Diskurse, die anhand der öffentlichen Diskussion nachvollziehbar seien, vgl. Skaftnesmo 2014, S. 121.

${ }^{774}$ Vgl. Bjørnstad 2011.
} 
die Leserschaft. Der Autor leistet somit bereits innerhalb des Artikels einen Transfer, um das deutsche Modell für norwegische Rezipient*innen einzuordnen. Ketil Bjørnstad ist ein Beispiel für die Personen, die durch ihre professionellen Reisen Erfahrungen in ihr Ursprungsland bringen und so für personell vermittelten Kulturtransfer sorgen. Sein Standpunkt zum Literaturhaus Bergen verdeutlicht, dass er Aspekte aus Deutschland nach Norwegen übertragen möchte, die positiven Eindruck hinterlassen, um sie konstruktiv für den norwegischen Kontext zu nutzen.

Diese strategischen Überlegungen waren ein Gründungsimpuls für das Literaturhaus Bergen und verloren mit der Zeit an medialer Relevanz. ${ }^{775}$ Selbstredend verfolgten die Initiator*innen darüber hinaus die im ersten Abschnitt dieses Unterkapitels genannten Vorsätze zur Literaturvermittlung, die insbesondere organisationsextern kommuniziert werden. Diese auslegungsoffen formulierten Ziele, Lesefreude und Wissen zu vermitteln sowie sich für Debatten und Gesellschaftsfragen zu engagieren, bedürfen einer Umsetzung, die bezogen auf organisationale und raumgestalterische Aspekte hin auf den nächsten Seiten untersucht wird. Dass das Folgende Übereinstimmungen mit dem Litteraturbuset in Oslo herausarbeitet, trägt der eingeführten Hypothese Rechnung, dass spätere Einrichtungen Ideen von früheren transferieren und korrespondiert mit der dieser Arbeit zugrunde liegenden Auslegung von ,Institution'.

\section{7.1.2 Personal}

Wie erwähnt ergriff vor allem Kristin Helle-Valle (*1951) die Initiative für Litteraturhuset Bergen. Sie leitete von 2006 bis 2009 das norwegenweite Programm zum zweifachen 100-Jahre-Jubiläum 2008 von Olav H. Hauge - unter anderem daher mag seine weiter hinten beschriebene beständige Würdigung im Litteraturbuset kommen und dem Komponisten Geirr Tveitt. In dieser Funktion lernte sie das Literaturhaus in Oslo besser kennen und plädierte für eine vergleichbare Einrichtung in ihrer Stadt Bergen. Es waren dort wie in den anderen Literaturhäusern Einzelpersonen, die sich für die Neugründung stark machten. Seit der Eröffnung des Hauses Anfang 2013 gibt es in dem sechs Festangestellte umfassenden Team zusätzlich zur Geschäftsführerin unter anderem einen Programmverantwortlichen. Den Positionsbezeichnungen der Mitarbeiter*innen zufolge ist dort wie in Oslo die Leitung nicht ausdrücklich Hauptentscheidungsträger*in hinsichtlich des Programms. In den deutschen Literaturhäusern Berlin, Hamburg und Frankfurt wird deutlich markiert, dass neben der Leitungsperson Mitarbeiter*innen lediglich für die Programmorganisation, die Verwaltung oder Programmassistenzen angestellt sind. ${ }^{776}$ Beim Auftritt

\footnotetext{
775 Schlussendlich ist es sogar Tatsache, dass sich Tomas Espedal dem Literaturhaus nicht gänzlich verwehrt, sondern selbst öfter im Bergener Literaturhaus, auch im seitens des Litteraturbuset Bergen organisierten Programm, auftritt als zum Beispiel der klare Fürsprecher Ketil Bjørnstad.

776 In München beispielsweise wird bei allen inhaltlich involvierten Mitarbeiterinnen „Programm“ als Aufgabengebiet genannt, was aber nichts über die Verantwortlichkeiten aussagt. Beim Literarischen Zentrum Göttingen wird die Leitung spezifiziert: Anja Johannsen hat die Programmleitung und Geschäftsführung inne. Die meisten Literaturhäuser haben nur wenige Angestellte, sodass es meist neben der Leitung nur noch eine Programmassistenz gibt. Hauptverantwortlich für die Inhalte ist in den deutschen Häusern die Geschäftsleitung.
} 
nach außen lässt sich aber bei der Leitungsperson in Bergen eine ebenso hierarchische Präsentation erkennen wie in Deutschland, entsprechend gilt die Führungsperson als hausprägend.

Weil die Leitungsposition im Bergener Literaturhaus mit zeitlich begrenztem Vertrag besetzt wird, liegt die Parallele mit dem angesprochenen Intendanzmodell noch näher als in den deutschen Literaturhäusern, wo sich diese Vokabel vor allem auf die eigenständige Programmplanung der Leitungen, die in der Regel unbefristet angestellt sind, bezieht. Die Befristung stellt ein Moment der Qualitätssicherung dar und ermöglicht den Stiftungen in einem bestimmten Turnus automatisch eine Überprüfung und Justierung. Anfang 2016 überzeugte in Bergen die bisherige Leiterin den Stiftungsvorstand erneut, sodass es nicht zu einem Wechsel kam. Nach fünf Jahren wird die Stelle wieder ausgeschrieben werden. Kristin Helle-Valle könnte dann nicht wieder antreten, weil nur zwei ,Amtszeiten` zulässig sind. Außerdem ist davon auszugehen, dass sich die dann 70-Jährige beruflich zur Ruhe setzen wird.

\section{7.1.3 Finanzierung}

Im Jahr 2016 belief sich das Budget der Einrichtung auf ungefähr 13 Millionen norwegische Kronen [etwa eineinhalb Millionen Euro]. ${ }^{777}$ Ein Teil der Einnahmen stammt aus Veranstaltungen und Vermietungen, genauso wie aus öffentlichen Mitteln von Kulturdepartementet [Kulturministerium], der Kommune Bergen und der Fylkeskommune [Regierungsbezirk] Hordaland. Weiteres steuern private Geldgeber bei, darunter Fritt Ord, Sparebanken Vest, das Stromunternehmen BKK und der Mäzen Trond Mohn, einer der drei reichsten Unternehmer Norwegens und Unterstützer vieler Sport- und Kulturprojekte. Er sorgte 2011 nicht zuletzt mit einer großen Spende - für fünf Jahre per annum zwei Millionen Kronen - dafür, dass das Literaturhaus überhaupt realisiert werden konnte. Genauso wie die Initiative von Einzelpersonen für die Literaturhaus-Idee wichtig ist, bleibt Privatkapital für das Budget des Literaturhauses notwendig. Dies zeigte sich bereits am Hamburger Beispiel.

\section{7.2 Soziogeografische Verortung in Bergen}

Litteraturhuset Bergen befindet sich in der Østre Skostredet 5-7 im Kulturmiljoet Vågsbunnen, im alten Stadtkern, der restauriert und als kulturell-aktiver Zentrumsteil geplant wird - „en fremtidens bydel“"778 [ein Stadtteil der Zukunft] - unweit des Fisketorget

\footnotetext{
777 Diesen Betrag und die Förderer nannte mir die Leiterin Kristin Helle-Valle in einer E-Mail vom 25.10.2016.

778 Hevrøy: „Kulturmiljøet Vågsbunnen“. Dort wird dies noch ausgeführt: „Det foreligger en rekke planer og igangsatte opprustnings- og nybyggingsprosjekter i området, både i privat og offentlig regi. Østre Skostredet huser i dag Litteraturhuset og Lydgalleriet i nylig rehabiliterte bygninger. Kommunen har også igangsatt rehabilitering og oppussing av bydelens allmenninger og offentlige rom. Vågsbunnen betegnes som en ,skjult perle', og en fremtidens bydel i Bergen sentrum, med store muligheter og utviklingspotensial.“ [Es gibt einige Pläne und einige begonnene Renovierungs- und Neubauprojekte in der Umgebung, sowohl in privater als auch in öffentlicher Regie. Ostre Skostredet beherbergt heute Litteraturbuset und Lydgalleriet in neu renovierten Gebäuden. Die Kommune hat auch den Wiederaufbau und die Renovierung allgemeiner und öffentlicher Plätze des Stadtteils in Gang gesetzt. Vagssbunnen wird als ,ge-
} 
[Fischmarkt] und des alten Handelsviertels Bryggen, welches heute touristischer Anziehungspunkt ist. Die Hauptbibliothek Bergens Offentlige Bibliotek, das Theater Den Nationale Scene, die Universität und Litteraturbuset bilden geografisch ein Quadrat um $K O D E$, den Verbund mehrerer Museen zu einem Komplex für Kunst, Kunsthandwerk, Design und Musik. Das Literaturhaus ist zentral in der Stadt verortet und liegt auf dem Weg von Kulturinteressierten in Bergen. Zu erwähnen ist weiterhin, dass in der Stadt seit 1953 das im Norden größte Festival für Musik und Theater Festspillene $i$ Bergen - Bergen International Festival stattfindet. Zwei Wochen im Frühsommer ist Bergen damit Treffpunkt für die nordeuropäische Kunstszene. Bergen ist also wie die anderen untersuchten Städte von unterschiedlichen kulturellen Angeboten geprägt, Literatur wurde dort bisher vor allem durch die Bibliotheken vertreten.

Die universitätsgeprägte Stadt Bergen lässt sich in Deutschland besser mit Göttingen als mit den viel größeren Städten wie Berlin, Hamburg oder Frankfurt vergleichen. Für das Literarische Zentrum Göttingen spielt die Hochschule eine wichtige Rolle, was sich auf Bergen übertragen lässt. Die oben angerissene Diskussion um das literarische Leben in Bergen vor Eröffnung des Literaturhauses ließ eine hemmende Kluft zwischen universitärem inhaltsorientierten Habitus und soziokulturellem Verhalten der Literaturhaus-Nutzer*innen erwarten, die sich jedoch nicht als unüberwindbar bestätigt hat: Die Universität bietet selbst Veranstaltungen im Literaturhaus an. Die Anerkennung seitens der Universität belegt zum Beispiel die Vergabe des Christieprisen 2016 an das Literaturhaus Bergen. Die jährlich von der Universität Bergen vergebene Auszeichnung belohnt Vermittler*innen zwischen Forschung, Bildung und der umgebenden Gesellschaft. „Det er det lille trappetrinnet opp fra å være akseptert til å bli anerkjent." ${ }^{\text {"779 }}$ [Das ist die kleine Treppenstufe von der Stufe, akzeptiert zu sein, hinauf dahin, anerkannt zu werden.] Für das Literaturhaus bedeutet diese Auszeichnung die Anerkennung seitens der Universität, die, wie aus der Reaktion Kristin Helle-Valles auf den Preis hervorgeht, ein wichtiger Schritt für die Literaturvermittlungseinrichtung in dieser universitätsgeprägten Stadt ist.

\section{7.3 Gestaltung von Litteraturhuset Bergen}

\section{7.3.1 Gebäude}

Litteraturhuset in der Østre Skostredet ist ,skakt, skeivt og svært, og stammar tilbake frå 1700-talet“" (BG 2015-I, S. 4) [krumm, schief und außerordentlich, und stammt aus dem 18. Jahrhundert] - analog zu den anderen Fallbeispielen erklärt die Bergener Einrichtung die Geschichte des Gebäudes zu einem Bestandteil des Literaturhauses. Interessant an dieser Aussage aus dem hauseigenen Programm ist weniger, dass der Bau tatsächlich aus dem 18. Jahrhundert stammt, sondern, dass diese Information als nennenswert erachtet wird. Zum Konzept des Literaturhauses gehört es offen-

heime Perle، (Geheimtipp) bezeichnet, und als Stadtteil der Zukunft in Bergens Zentrum, mit großen Möglichkeiten und Entwicklungspotenzial.]

${ }^{779}$ Kristin Helle-Valle zitiert nach: Wehus: „Litteraturhuset i“. Die Vergabe dieses Preises ist zudem ein strategischer Zug der Universität, sich publikumsoffener zu präsentieren. 
bar, dass physische Haus miteinzubeziehen und damit das Literaturhaus als geschichtsträchtigen Ort attraktiv zu machen.

Im Erdgeschoss befindet sich das Restaurant Colonialen Kafé og Brasseri sowie der unabhängige Buchhandel Boksalongen [der Buchsalon]. Auch in Bergen bildet das Trio aus Gastronomie, Buchhandlung und Veranstalter das ,umfassende' Literaturhaus. In der zweiten Etage liegen Büros. Dort arbeiten Norsk Forfattarsentrum Vestlandet [Norwegisches Autorenzentrum Westland], Den Norske Forfattarforening [Die norwegische Autorenvereinigung], Norsk Faglittercer Forfattar- og Oversetterforening [Norwegische Fachliterarische Autoren- und Übersetzervereinigung], die Kunsttriennale Bergen Assembly und die Kulturveranstaltungsagentur Unison. Wie in vielen anderen Literaturhäusern haben literaturaffine Organisationen ihren Sitz im Haus, in Bergen Schriftstellervereinigungen wie Kulturveranstalter. In der obersten, dritten Etage gibt es wie in Oslo mit Skriveloftet [das Schreibloft] kostenlose Arbeitsplätze, die Autor*innen nutzen können.

\section{7.3.2 Veranstaltungsräume}

\section{Gestaltung der Veranstaltungsräume}

Die sechs unterschiedlich großen Veranstaltungsräume sind im Erdgeschoss und im ersten Stock eingerichtet. Boksalongen fungiert ergänzend als Veranstaltungsraum, vor den Bücherwänden finden sogar recht viele Abendveranstaltungen statt. Litteraturhuset Bergen nutzt diese Bücherkulisse als passendes und angenehmes Setting für Literaturveranstaltungen. Vergleichbar ist dieses mit dem Lesekabinett im Literaturhaus Frankfurt, ein Bibliothekssaal, in dem jedoch keine Bücher verliehen oder verkauft werden, sondern vor allem die Bücher der bisherigen Gäste des Literaturhauses ausgestellt sind und der nur bei einigen Veranstaltungen überhaupt zugänglich ist. Die Bibliotheksatmosphäre erscheint eine angemessene Kulisse für Lesungen zu sein, denn offenbar umgeben sich Leser*innen auch im Zeitalter der Digitalisierung gerne mit Büchern, die ein Gefühl von Gemütlichkeit und ,Wohnzimmerstimmung evozieren. Dass der dekorative Aspekt von Bücherwänden bestehen bleibt, veranschaulichen diese Räumlichkeiten sehr gut.

Bei den Veranstaltungen sind die Bücher in Boksalongen mehr Kulisse als Gebrauchsgegenstände, doch sind sie tagsüber im Buchhandelsbetrieb natürlich nutzbar und verkäuflich. Im kleineren Raum nebenan finden sich ebenfalls Bücher: Fosse-Stova [Fosse-Salon] beinhaltet dank seines Verlags Samlaget alle Publikationen Jon Fosses, die norwegischen wie internationalen Ausgaben sind in Regalen aufgereiht. In diesem Raum legen die Bücher eine Verwendung als Bibliothek ebenso wie als unberührtes Prestigeobjekt nahe.

In der ersten Etage liegt Auditoriet. Der große Saal mit gleichem Namen wie sein Osloer Pendant birgt neben der im vorherigen Unterkapitel beschriebenen Theateratmosphäre den Hörsaalcharakter eines Auditoriums, der die Nähe zur Universität unterstreicht. Hier finden maximal 162 Personen Platz und wie in Oslo besteht die Möglichkeit, das Bühnengeschehen in andere Räume zu übertragen, sodass es noch mehr Personen verfolgen könnten. 
Der zweitgrößte Raum Olav H. Hauge, in dem knapp 150 Menschen sitzen können, ist ein Beispiel für flexible Raumnutzungen im Literaturhaus. Dieser längliche Raum lässt sich mit einer mobilen Wand zweiteilen und somit verkleinern. Die Fensterseite als Tageslichtquelle ist in Weiß gehalten, die gegenüberliegende und die Kopfseite sind unverputzte, rot geklinkerte Ziegelwände. An der Decke sind große, freiliegende metallene Lüftungsrohre angebracht. Mit den kaum verkleideten Deckenträgern entsteht in dem Raum so ein moderner Industriestil. Auf diese Weise wird die Historie des Gebäudes aufgegriffen, zudem ist es Anfang des 21. Jahrhunderts in Mode, Fabrikcharme zu evozieren. Das zeigt „die Abneigung gegen übertriebene Prachtentfaltung und zieht schlichte Bequemlichkeit ${ }^{\text {" } 780}$ vor, wie es sich für skandinavisches Design insgesamt festhalten lässt. Die ästhetische Gestaltung öffentlicher Räume steht in Skandinavien in der Tradition des Wohlfahrtsstaates und folgt der Vorstellung des Volksheims.

Alver ist ein mittelgroßer, breiter Raum, der ohne Podium die Zuschauer*innen nah zu den Redner*innen bringt. Er ist farblich licht und mit Holzboden, wie er in allen Räumen liegt, ausgestattet, sowie mit hellhölzernen einfachen, doch zum Sitzen angenehmen Stühlen und schlichten Lampen ausgestattet - in typischer formaler Schönheit und praktischer Schlichtheit. ${ }^{781}$ Durch diese reduzierte Innengestaltung kommt ein gezeichnetes künstlerisches Porträt in der vorderen linken Ecke gut zur Geltung: Hier wird Amalie Skram abgebildet.

\section{Namen der Räume mit Literaturbezug: Alver, Zinken Hopp, Olav H. Hauge und Jon Fosse}

Wie die Räume in Oslo lassen im Litteraturbuset Bergen die Räume abgesehen vom Auditoriet durch ihre Namen eine literarische Bezugnahme erkennen: Olav H. Hauge, Jon Fosse, Zinken Hopp und eben Amalie Skram, deren Geburtsname Alver den zuletzt beschriebenen Raum benennt.

1846 in Bergen geboren, erlangte Berthe Amalie Alver durch ihre Hochzeit mit dem Schriftsteller Erik Skram den Namen Amalie Skram, unter dem sie heute bekannt ist. Die Frauenrechtlerin setzte sich schon früh mit ihren ersten Eheromanen für weibliche Belange ein, ließ sich dabei aber nicht allein auf eine rationale Diskussion ein, sondern bezog den Körper explizit mit ein. ${ }^{782}$ Ihr Naturalismus machte sie zu einer radikalen Stimme der Emanzipationsbewegung. Dass beide untersuchten norwegischen Literaturhäuser dieser Autorin einen Raum widmen, bezeugt ihre $\mathrm{Ka}$ nonisierung - und macht einmal mehr deutlich, dass Kanones nicht statisch und festgelegt, sondern dynamisch sind. Die Wahl von Amalie Skrams Namen für die Räume zeigt, dass mindestens ein gewisses Maß an Publizität und Etabliertheit der Person vorausgesetzt wird, und sie verstärkt sogleich die Aufmerksamkeit für die Schriftstellerin. Mit dieser Bezugnahme setzen die Literaturhäuser zugleich ein emanzipatorisches Zeichen. Bergen unterstreicht damit Amalie Skrams Zugehörigkeit in diese Region, denn nicht der Nachname des dänischen Ehemanns, sondern ihr Bergener Geburtsname findet Beachtung.

\footnotetext{
${ }^{780}$ Fiell und Fiell 2015, S. 17.

${ }^{781}$ Vgl. ebd., S. 16.

782 Vgl. Heitmann 2006, S. 203.
} 
Die anderen Raumwidmungen tragen analog zur Kanonisierung dieser Autorenfiguren bei und markieren gleichzeitig die Relevanz der Region um Bergen. Zinken Hopp, der Künstlername von Signe Marie Hopp (1905-1987 in Bergen), steht Patin für den Kinderraum, in dem maximal 50 Menschen Platz finden. Sie schrieb zunächst Lyrik und wechselte dann zu Kinderbüchern, die heute als Klassiker gelten. Außerdem war sie als Übersetzerin etwa von Lewis Carrolls Alice's Adventures in Wonderland tätig, ein Text, der ihr berühmtes Werk Trollkrittet beeinflusste, in das sie Volkssagen und Mythen einarbeitete. Norsk biografisk leksikon beschreibt sie folgendermaßen:

Zinken Hopp var historisk og kulturhistorisk interessert med eit særleg blikk på folks daglegliv. Ho hadde ei enorm kunnskapsglede og eit suverent minne og kunne delta i samtalar om svært mange emne, anten samtalepartnarane var kunstnarar, lærde akademikarar eller uskulerte arbeidsfolk. ${ }^{783}$

[Zinken Hopp war historisch und kunstgeschichtlich interessiert mit einem besonderen Blick für das Alltagsleben der Menschen. Sie hatte eine enorme Freude an Wissen und ein souveränes Gedächtnis und konnte an Gesprächen zu sehr vielen Themen teilnehmen, ob die Gesprächspartner auch Künstler, gelehrte Akademiker oder Arbeiter ohne Schulbildung waren.]

Sprachspielerei und Weltwissen prägen ihre Arbeiten, im Auftreten war sie selbstbewusst emanzipiert. Im Litteraturbuset $i$ Bergen wird sie zur Vorbildperson, indem ihr der Raum gewidmet ist, in dem in erster Linie die Kinderveranstaltungen wie Lesestunden oder Werkstätten stattfinden. Auch Zinken Hopp lebte lange Zeit in Bergen und der Bezug auf sie unterstützt das Anliegen von Litteraturbuset, sich auf die ,eigenen'Autor*innen zu besinnen.

Der Bezug auf Olav H. Hauge (1908-1994) 784 mag ein Verständnis des Litteraturbuset als international ausgerichtete und lokal verwurzelte Einrichtung widerspiegeln. Der Autor Olav H. Hauge lebte Zeit seines Lebens als Obstbauer in Ulvik, einem kleinen Ort im fylke [Regierungsbezirk] Hordaland, dessen Hauptstadt Bergen ist. In seiner auf Nynorsk [Neunorwegisch] verfassten, reduzierten Lyrik wird die Natur des Westlands zum Motiv. „Metaphern und Bilder werden zurückgedrängt zugunsten eines direkten Kontakts mit den Gegenständen, einer Poetik des Alltäglichen und des Konkreten." 785 Sein als poetischer Minimalismus bezeichnetes Schreiben findet beispielsweise Ausdruck in den sogenannten Dinggedichten der 1960er-Jahre. Seine weltoffene Perspektive erklärt sich durch die intensive Lektüre und zahlreiche Übersetzungen deutscher, englischer und französischer Lyrik. Später schrieb er zusammen mit seiner Frau Bodil Cappelen $A B C$, ein Bilderbuch mit einem Reim zu jedem Buchstaben des Alphabets. Nach Hauges Tod wurden im Jahr 2000 seine Tagebücher, die er seit 1924 schrieb, veröffentlicht - das umfangreichste literarische Tagebuchwerk auf Norwegisch. Die Aufmerksamkeit wurde insbesondere 2008 bei der Inszenierung seines 100. Geburtstags auf den belesenen Schriftsteller gerichtet - ein literarisches Ereignis in Bergen vor Gründung des Literaturhauses.

Jon Fosse $\left(*^{* 1959}\right)^{786}$ ist, wie erwähnt, ebenfalls ein Raum gewidmet. Darüber hinaus präsentiert Litteraturbuset alle Publikationen des Autors von Lyrik, Prosa,

\footnotetext{
783 Økland: „Zinken Hopp“.

${ }^{784} \mathrm{Zu}$ Olav H. Hauge vgl. z. B. Stegane: „Olav H“ sowie Seiler 2006, S. 296.

${ }^{785}$ Ebd.

${ }^{786} \mathrm{Zu}$ Jon Fosse vgl. Rottem: ,Jon Fosse“.
} 
Kinderliteratur und Dramen. Fosses Schreiben, das seine Anfänge in der Postmoderne der 1980er-Jahre nahm, gilt als minimalistisch. Seine Theaterstücke werden weltweit aufgeführt und seine Bücher in viele Sprachen übertragen. Die Liste der Auszeichnungen sowohl für sein Prosa- als auch sein Dramenwerk ist lang, unter anderem erhielt er Nordisk Råds litteraturpris 2015 und Den internasjonale Ibsenprisen 2010. Mit seiner internationalen Bekanntheit schmückt sich so auch das Literaturhaus in seiner Geburtsstadt. Jon Fosse schreibt wie Olav H. Hauge vorwiegend auf Nynorsk. Diese Schriftsprache, die eher aus den westnorwegischen Dialekten entwickelt wurde, unterstreicht das typisch Regionale und eine Abgrenzung vom vornehmlich Bokmål nutzenden Osten des Landes mit der Hauptstadt Oslo. In der Referenz auf die aus der Gegend stammenden Autor*innen von internationalem Rang liegt der Versuch, das Bergen-Eigene aufzuwerten. Hierbei präsentiert Litteraturhuset Bergen nicht explizit urbane Bergener Autor*innen, sondern beruft sich auf die Tradition des Ländlichen. Mit der Benennung der Räume offenbart sich, wie Bergen sich als eigenständiger, Eigenes produzierender Ort in der Provinz inszeniert. Auf diese Weise stellt sich wieder ein Bezug zur eingangs dargelegten ,Rivalität ${ }^{6}$ zwischen Oslo und Bergen her. Amalie Skram beansprucht das Bergener Literaturhaus gar für sich, indem es mit der Nennung ihres Geburtsnamens markiert, woher die für Norwegen bedeutende Autorin ursprünglich kommt.

Veranstaltungen zu Amalie Skram, Olav H. Hauge, Jon Fosse

Abgeleitet von dieser Präsenz der genannten vier Autorinnen und Autoren im Litthusbergen steht zu erwarten, dass das Veranstaltungsprogramm sie extra berücksichtigt, dass inhaltlich ein besonderes Vermittlungsinteresse an ihnen besteht. Doch diese Hypothese lässt sich aufgrund der hier durchgeführten intensiven Auseinandersetzung mit den Programmbroschüren nicht festigen: Amalie Skram war zwar Sujet eines Vortrags - unter dem Titel Amalie for hun ble Skram [Amalie bevor sie Skram wurde] rekurriert dieser auf Amalie Alver, bevor sie bekannte Schriftstellerin wurde, und stellt damit nochmals einen Bezug zu ihrer Geburtsstadt Bergen her (BG 2013-02-02). Dieser Vortrag war Bestandteil der Eröffnungstage, an denen die thematische Ausrichtung des Literaturhauses gesetzt wird, weil die (mediale) Öffentlichkeit sehr aufmerksam auf das schaut, was die neue Einrichtung anbietet, und dies als Indikator für das Kommende gedeutet wird. Doch im darauffolgenden Programm ${ }^{787}$ taucht Amalie Skram nur noch einmal auf: In der Reihe Dramatiske Samtaler [Dramatische Gespräche] beschäftigten sich die Gäste mit der Inszenierung ihres Romanzyklus Hellemyrsfolket als Theaterstück und Musical (BG 2014-09-24). Und diese Kooperationsveranstaltung mit dem Theater Den Nationale Scene wurde noch dazu mehr vom Theaterspielplan angestoßen als vom Literaturhaus.

Ebenfalls zur Eröffnung brachte Henrik Mestad, musikalisch unterstützt von dem Komponisten und Saxophonisten Trygve Seim, das auf Olav H. Hauges Tagebuchtexten basierende, als Hörspiel umgesetzte Einmannstück Ein tanke slo meg her om dagen [Ein Gedanke kam mir dieser Tage] auf die Bühne (BG 2013-02-03). Henrik Mestad war als Schauspieler ferner beteiligt an dem zweiten von drei Olav H. Hauge-Abenden im Bergener Literaturhaus: Bei der Vorpremiere des NRK-Films

${ }^{787}$ Das hier bis einschließlich 2015 untersucht wurde. 
Den andre mannen $i$ meg [Der andere Mann in mir] wurde aus dem bereits erwähnten Tagebuch Hauges gelesen (BG 2014-10-18). Es liegt nahe, dass der Film mit Literaturbezug zuerst im Litteraturbuset lief. An diesem Beispiel wird außerdem deutlich, dass das Programm eines Literaturhauses großenteils eine Reaktion auf Angebotenes ist. Die Kooperation zur Filmpremiere passte einfach gut ins Programm. Olav H. Hauges Tagebücher - wieder nicht seine Gedichte - waren ein drittes Mal Thema, als sich Lektor*innen und Kulturredakteur*innen in der Reihe Dypdykk $i$ klassikerne [wörtlich: tiefgetaucht in die Klassiker] intensiv mit diesen Texten befassten (BG 2014-12-04). Im Fokus standen bei allen Terminen also die Tagebücher. Dies spricht zum einen für die regionale Vereinnahmung des Lyrikers und zum anderen für das generelle Interesse an Autorenfiguren, das, wie die vorliegende Arbeit mit unterschiedlichen Argumenten herausstellt, ein wichtiges Motiv für den Erfolg der Institution Literaturhaus überhaupt darstellt.

Obwohl noch lebend, ist Jon Fosse während des Untersuchungszeitraums nicht persönlich im Litteraturbuset-eigenen Programm vertreten. Nur einmal ist sein Nattsalme [Nachtpsalm] Interpretationsobjekt in der Reihe Sondagsskulen [die Sonntagsschule] ${ }^{788}$ (BG 2013-10-06). Jon Fosse tritt jedoch allgemein nicht gerne auf, sodass nicht unterstellt werden kann, dass er nur Litthusbergen meiden würde oder dass das Literaturhaus keine Veranstaltungen mit diesem Schriftsteller machen möchte. Vielmehr ist davon auszugehen, dass das Literaturhaus begründetes Interesse an öffentlichen Besuchen Fosses hat, dies allerdings nicht realisierbar ist respektive andere Organisationen ihn zu Auftritten ins Literaturhaus einladen. Die Einrichtung einer Fosse-Bibliothek und die entsprechende Raumbenennung ist seitens Litteraturbuset eine Huldigung, die das Werk vor die Person des Autors stellt. Eine eigene Bibliothek nur mit Fosses Texten veranschaulicht die Breite seines Schaffens wie die Vielzahl seiner Bücher in Übersetzungen und würdigt den aus dem Vestlandet stammenden Schriftsteller schon zu Lebzeiten als überdauernden Literaten; sie ehrt zusätzlich den Verlag Den Norske Smalaget, der Fosse seit seinem Debüt 1983 begleitet. Jon Fosse wird als Bergener Autor mit Weltstarstatus im Litteraturbuset geehrt.

Da die Programminhalte für Kinder- und Jugendliche nicht im Fokus dieser Untersuchung stehen, lässt sich an dieser Stelle nicht belegen, dass es keinen Schwerpunkt auf die Texte Zinken Hopps gibt. Anhand der anderen drei Beispiele zeigt sich aber, dass im Programm keine Konzentration auf die Namensgeber*innen der Veranstaltungsräume feststellbar ist. Die Raumtitel als solche können aber durchaus als Teil eines Kanonisierungsprozesses verstanden werden, weil die Namen auf diese Weise ständig präsent sind und damit ausdrücken, dass diese Personen seitens des Literaturhauses geschätzt werden. Die aktive Beschäftigung damit liegt dann bei den Rezipient*innen.

Wie bereits bei der Analyse des Literaturhauses Berlin herausgestellt, stellen sich die Literaturhäuser absichtlich thematisch flexibel auf. Die Besonderheit ist gerade, dass sie nicht auf die umfassende Beschäftigung mit bestimmten Autor*innen festgelegt sind. Wie erwähnt pflegt das Literaturhaus Berlin zwar einen Kurt Tucholsky-Raum, doch herrscht dabei vertragliche Pflicht vor überzeugter Intention. Das Literaturhaus München kann mit seinen benannten „Hausgöttern“ Oskar Maria Graf und Thomas

${ }^{788}$ Vgl. Kapitel II 13.1.6. 
Mann ${ }^{789}$ als Ausnahme unter den deutschen Literaturhäusern eingeordnet werden. Es konzentriert sich aber ebenfalls nicht wie etwa eine literarische Gesellschaft auf die Vermittlung der Werke dieser beiden Autoren. Diese inhaltliche Offenheit gilt genauso für die beiden untersuchten norwegischen Einrichtungen. Trotz der expliziten Bezugnahmen auf konkrete Verfasser*innen wird in Bergen und Oslo, wie veranschaulicht, die jeweilige Autorfigur und ihr Werk bei den Veranstaltungen nicht bevorzugt beziehungsweise nicht auffallend häufig in den Fokus gerückt. Die Nennung bestimmter Namen dient vielmehr zur Orientierung hinsichtlich der literarischen Richtung und nicht so sehr zur Erhöhung einer einzelnen Autorenfigur. Indem das Literaturhaus etwa Amalie Skram würdigt, vermittelt es, dass es sich selbst als liberale, gleichberechtigende und gesellschaftskritische Einrichtung verstanden wissen will. Die Referenz auf die genannten ursprünglich aus dem Vestlandet kommenden Autor*innen in Bergen präsentiert zudem die Gegend als künstlerisch relevante ,Kinderstube', wie oben ausgeführt wurde.

\section{7.4 Litteraturhuset in Bergen als Transfer des Osloer Modells}

Die in diesem Unterkapitel gezogenen Vergleiche vom Bergener zum Osloer Litteraturbuset verdeutlichen, dass es viele konzeptuelle Gemeinsamkeiten zwischen beiden Einrichtungen gibt, und im Verlauf dieser Arbeit finden sich weitere Belege für die Hypothese, dass das Bergener Haus sich das Osloer zum Vorbild genommen hat. Die Gestaltung der Räume in Bergen ist also ein Beispiel, denn sie erinnert sehr an die in Oslo: Die ähnliche Namensgebung der einzelnen Räume, die Aufteilung auf unterschiedlich nutzbare Räume sowie die Existenz eines für Kinder reservierten Veranstaltungsraumes, ähnlich modern-schlicht designte und funktionale Inneneinrichtungen, die zudem als typisch für Skandinavien identifiziert wurden. Überdies lassen sich in den folgenden Kapiteln etwa beim Webauftritt und insbesondere bei den Programmbroschüren deutliche Übereinstimmungen mit dem Literaturhaus in Norwegens Hauptstadt entdecken. Außerdem wurde diese Bezugnahme in der Diskussion um die Gründung deutlich.

Zusammenfassend aus den Kapiteln über Oslo und über Bergen lässt sich festhalten, dass die Initiator*innen in Bergen das Osloer Modells transferierten. Die Beobachtung, dass sie das Osloer Literaturhaus als Erfolgsgeschichte rezipierten, unterstützt Joachim Grages Bemerkung:

Vergleichbare Milieus scheinen ebenfalls eine Voraussetzung dafür zu sein, dass eine Praktik ihren Ort wechseln kann. [...] Damit hängt zusammen, dass der ursprüngliche kulturelle Kontext, aus dem eine Praktik übernommen wird, eine Vorbildfunktion oder zumindest ein gewisses Renommee für das Milieu haben muss, in das hinein die Migrationsbewegung führt. ${ }^{790}$

Viele Aspekte, die in Oslo erfolgreich wirkten, übernahm die Einrichtung in Bergen. Die mit dem Transfer ebenfalls verbundene Modifikation ist in diesem Fall eher

\footnotetext{
${ }^{789}$ Vgl. „Die Hausgötter“, Literaturhaus München. Oskar Maria Graf, der im Selbstinszenierungskontext als ,lederhosentragender Anti-Intellektueller bei öffentlichen Lesungen“, Jürgensen und Kaiser 2011, S. 14, beschrieben wird, was sich ebenfalls ausführlicher auf das Literaturhaus bezogen interpretieren ließe. 790 Grage 2014, S. 114.
} 
eine sich von Oslo abgrenzende Anpassung. Die Betonung von bergenspezifischen Autor*innen und die formulierte Absicht, Litteraturhuset als Gegengewicht zu Oslo zu etablieren, sprechen dafür. Deutlich wird anhand der Diskussionen rund um die Eröffnung des Literaturhauses in Bergen und der Überlegungen zur Verortung des Osloer Hauses, dass beim intentionalen Transfer von Objekten respektive Konzepten am Standort ein Mangel konstatiert wird, der mit dem ,Neuen' verringert werden könnte. Zugleich kann die Existenz eines ,Anderen', zum Beispiel ein Literaturhaus in Oslo, ein bisher nicht bewusstes Bedürfnis aufdecken, etwa eine fehlende Literaturvermittlungseinrichtung in Bergen.

Auf kulturpolitischer Ebene dreht es sich dabei nicht nur um die konkrete Literaturvermittlungspraxis, sondern um übergeordnete Positionierungsfragen: Während Oslo sich, um transnational und über Norwegen hinausgehend wirken zu können, eher von den anderen norwegischen ,provinziellen' Literaturhaus-Umsetzungen abgrenzt, suchen die kleineren Städte mit Hilfe des Literaturhauses den Anschluss an Oslo. Bergen ist bemüht, sich mit Litteraturbuset geradezu als Hauptstadt der Provinz zu präsentieren. Dies unterstützt auch die weitere Entwicklung: Im Frühjahr 2019 fand das erste Littfestbergen statt, ein vom Literaturhaus in Bergen ausgerichtetes Literaturfestival für Belletristik und Sachbücher mit nationalen und internationalen Gästen - und mit geplant großer öffentlicher Aufmerksamkeit. ${ }^{791}$

Der Transfer nach Norwegen lief über das Osloer Literaturhaus, das das Modell für Norwegen modifizierte. Das Litteraturbuset Bergen übernahm diese Version für die eigene regionale Umsetzung. Die Literaturhäuser in Deutschland stoßen damit nicht-intendiert in Norwegen eine Art der literarischen respektive literaturbetrieblichen Diskussion an, die in Norwegen vorher nicht in dieser Weise geführt wurde. Die norwegischen Initiator*innen greifen intentional auf das deutsche Modell zurück, um ihr neu entdecktes Bedürfnis zu stillen. Dabei entsteht ,Litteraturhuset", das die Institution um spezifisch skandinavische Aspekte erweitert. Dieses regt wiederum die Überlegungen in anderen Städten der Region an, ob nicht auch dort eigene Literaturhäuser möglich oder gar nötig sind, oder ob sich andere Umsetzungen realisieren ließen respektive bestehende Strukturen wie die Bibliotheken transformiert werden könnten. Die gefürchtete Prognose, die viele 2011 ausdrückten, dass es einen „byggeboom“ [Bauboom] für Literaturhäuser in Norwegen geben könnte, nach dem die meisten der Häuser als Leerstand enden würden und für andere Aktivitäten genutzt würden, bewahrheitete sich nicht. ${ }^{792}$ Beispiele für umgesetzte Projekte sind Litteraturbuset Fredrikstad, das zur Eröffnung 2013 ganz neu gebaut wurde, ${ }^{793}$ sowie Litteraturhus Lillehammer, das eine seit 2012 bestehende Zusammenarbeit zwischen Lillehammer bibliotek, Nansenskolen, Hoyskolen i Lillehammer und Norsk Litteraturfestival-Sigrid Undsetdagene ist. Die Hauptverantwortung liegt dort bei der Bibliothek, wo auch die Veranstaltungen stattfinden. ${ }^{794}$ In Skien, der Geburtsstadt von Henrik Ibsen (1828-1906), zog eine seit 2009 existierende Initiative unter dem Namen Litteraturhuset i Skien in das Gebäude von Ibsenhuset ein, das ebenfalls Veranstaltungen

\footnotetext{
${ }^{791}$ Vgl. Nielsen: „Stor litteraturfestival“.

792 Vgl. Skaftnesmo 2016, S. 33.

${ }^{793}$ Vgl. „Huset og““, Litteraturhuset Fredrikstad.

794 Vgl. „Huset“, Litteraturhus Lillehammer.
} 
anbietet, allerdings weder auf Ibsen noch auf Literatur beziehungsweise Dramatik begrenzt ist. ${ }^{795}$ Litteraturbuset $i$ Trondheim, seit Oktober 2016 aktiv, ist im Vergleich zu den anderen Einrichtungen „nedskalert“ [verkleinert, kleiner im Maßstab] und „langt rimeligere“ [viel kostengünstiger]. Nach langer Planungsphase stehen ihm jetzt nur kleine eigene Räume zur Verfügung, für Veranstaltungen nutzt es andere Lokalitäten im umgebenden Kulturkvartalet [das Kulturviertel], sodass Kooperationen mit anderen Akteuren grundlegend zum Konzept gehören. ${ }^{796}$ Anhand dieser Beispiele zeigt sich, dass, litteraturhus ${ }^{6}$ - mit kleinem Anfangsbuchstaben geschrieben - in Norwegen inzwischen zu einer Dachmarke für öffentliche Literaturvermittlungsorte geworden ist, und in diesem Bereich noch sehr vieles in Bewegung ist, verschiedene Umsetzungen entstehen und sich noch kein abschließendes Resümee ziehen lässt. Als institutionsprägend wird der Aspekt aufgefasst, dass ein Literaturhaus ein öffentlicher Ort zum Austausch und zur Debatte sowie als Kontaktfläche für und mit Literatur gestaltet sein soll.

\section{7.5 Bibliotheken und Literaturhäuser}

In Zusammenhang mit der Annahme, dass ein Transfer intendiert ist, um einen Mangel der existierenden Institutionen zu beheben, ist die Tatsache höchst spannend, dass 2013 das norwegische Bibliotheksgesetz dahingehend geändert wurde, dass es „reflekterer bibliotekenes møteplassfunksjon og ansvar for aktiv formidling av kunnskap og kultur'"797 [die Treffpunktfunktion und Verantwortung der Bibliotheken zur aktiven Vermittlung von Wissen und Kultur reflektiert]. Außerdem wurde gesetzlich verankert, die öffentlichkeitswirksame Arbeit dieser Bibliotheken steigern zu müssen. ${ }^{798}$

Das Gründungsteam des Litteraturbuset in Oslo hat mit seiner Ausrichtung des Literaturhauses zu einer starken Entwicklung des Literaturveranstaltungsbetriebs und insbesondere der Bibliotheken in Norwegen beigetragen. Mit dieser Erkenntnis erscheint es folgerichtig, dass Nasjonalbiblioteket [die Nationalbibliothek] Aslak Sira Myhre, den ersten Litteraturbuset-Leiter, 2014 zu ihrem neuen Chef ernannte. Dieser trug sogleich zur Formulierung einer Nasjonal bibliotekstrategi [Nationale Bibliotheksstrategie] vom Kulturministerium bei, die die Gesetzesänderung aus dem Vorjahr umsetzen sollte. Dieser Bericht leistet eine Übersicht über die staatliche Verantwortung und die Aufgabe, folkebibliotekene [die Volksbibliotheken] ausgehend von der Nationalbibliothek weiterzuentwickeln. Neben einer intensivierten und gemeinsa-

\footnotetext{
795 Vgl. „Om LiS“, Litteraturhuset i Skien.

796 Vgl. „Om oss“, Litteraturhuset i Trondheim. Dort lässt sich auch die etwas komplizierte Entstehungsgeschichte nachlesen. Die Suche nach einem geeigneten Gebäude gestaltete sich dort ebenso schwierig wie bspw. in Freiburg. Es zeigt sich außerdem, dass auch das Trondheimer Literaturhaus sich als offenen, gleichberechtigenden Ort versteht: „Har du et forslag til arrangement, en idé, eller et ønske om å bidra så er vi alltid mottakelige for det!“" [Hast du einen Vorschlag für eine Veranstaltung, oder eine Idee oder den Wunsch, beizutragen - dafür sind wir jederzeit ansprechbar!]

797 Prop. 135 L (2012-2013) Proposisjon til Stortinget (forslag til lovvedtak) 2013, S. 18.

$798 \mathrm{Zu}$ den Ähnlichkeiten und Unterschieden von Literaturhaus und Bibliothek vgl. auch Kapitel II 13.2.8, S. 401.
} 
men Arbeit an der digitalen Infrastruktur ${ }^{799}$ steht der Ausbau der kommunalen Bibliotheken zu - wörtlich - Literaturhäusern auf dem staatlichen Finanzierungsprogramm:

En nyinnretting av midlene som varsles i denne planen bidrar til at landets folkeog fylkesbibliotek vil kunne skape en bølge av arrangement som skal styrke bibliotekene som de lokale litteraturhusene landet rundt. 800

[Eine Neueinrichtung von Mitteln, die in diesem Plan angekündigt sind, tragen dazu bei, dass die Stadt- und Regionalbibliotheken eine Reihe von Veranstaltungen organisieren können, die die Bibliotheken im ganzen Land als die lokalen Literaturhäuser stärken sollen.]

Die Kleinschreibung des Substantives betont, dass ,litteraturhus' in Norwegen zum Funktionsbegriff geworden ist, der sich vom Namen der Einrichtung in Oslo, die sich mit großem Anfangsbuchstaben schreibt, gelöst hat. Der Wortlaut „,bibliotekene som debatt- og litteraturhus“ findet sich nicht nur in der Einleitung des Direktors Myhre, der diese Formulierung für Litteraturbuset kontinuierlich benutzte, sondern ebenfalls im Bericht selbst sowie auf der Website zur Bibliotheksentwicklung. ${ }^{801}$ Dieser Gesichtspunkt wird dementsprechend zentral gestellt und er trägt der erwähnten Gesetzesänderung Rechnung.

In dieser landesweit gültigen Gesetzesaktualisierung offenbart sich der Einfluss, den die Neueinführung einer Institution - angestoßen durch Litteraturbuset in Oslo auf bestehende Einrichtungskomplexe - die Bibliotheken - hat. Hinzu kommt der personale Transfer, denn Aslak Sira Myhre soll seine im Litteraturbuset in Oslo ausgebildeten Kompetenzen nicht nur in der Hauptstadt, sondern auch in der Provinz einsetzen, indem Nasjonalbiblioteket übergeordnete Entwicklungsaufgaben erhält und das Ressourcenzentrum darstellt. ${ }^{802}$ Zunächst war Myhres Einsatz entscheidend für die Etablierung von Litteraturbuset, denn ein Grund für das Erfolgsmodell sei „en drivende dyktig leder som har makten å plassere litteraturhuset i sentrum for offentlighetens oppmerksomhet ${ }^{\text {"803 }}$ [ein engagierter geschickter Leiter, der die Macht hat, Litteraturhuset im Zentrum der öffentlichen Aufmerksamkeit zu platzieren]. Dann bekam er den Auftrag, dieses Konzept für die Bibliotheken zu modifizieren. Das eine hängt unmittelbar mit dem anderen zusammen.

Die Analyse dieses intranationalen und interinstitutionellen Transfers ist auch für das Verständnis der transnationalen Institution ,Literaturhaus' hilfreich. Es sei nicht schwierig zu verstehen, warum eine Praxis, die erfolgreich Verwendung findet, von anderen imitiert werde, die einen ähnlichen Erfolg erreichen wollen, oder warum ein Vorschlag, der das Versprechen in sich trägt, Probleme zu lösen, global verbreitet

\footnotetext{
${ }^{799}$ Diese führt unter anderem zur fortgesetzten Arbeit an Bokhylla.no. Das Projekt Bokbylla.no [Bücherregale.no] wurde 2009 zunächst als Experiment gestartet, inszwischen sind alle Bücher bis einschließlich 2000 dort online und kostenfrei für norwegische Bürger*innen sowie ausländische Forschende zugänglich.

800 Myrhe 2014, S. 6.

${ }^{801}$ Vgl. „Nasjonal bibliotekstrategi“, Kulturdepartementet, S. 7, 17-18 sowie Bibliotekutvikling.no 2014. Dieser Internetauftritt dokumentiert zudem, wie die Strategie realisiert wird, und stellt viele Informationen und Dokumente zum norwegischen Bibliothekswesen bereit.

${ }^{802}$ Vgl. „Nasjonal bibliotekstrategi“, Kulturdepartementet, S. 13-14.

803 Audunson 2014, S. 23.
} 
werde, wie Ragnar Audunson bemerkt. ${ }^{804}$ Die Weiterentwicklung der Institution (in anderen Ländern) bildet ein empirisches Beispiel für die Reaktionen des Literaturbetriebs und seiner Akteur*innen auf sich ändernde Bedingungen der Umgebung. So wurde Göteborgs Litteraturbus gegründet, als die Stadtbibliothek wegen Umbauten einen alternativen Veranstaltungsort benötigte. Die erste Initiative für das Literaturhaus erfolgte in diesem Fall also aus der Bibliothek heraus, die dann von einer Interessenvertretung literaturvermittelnder Akteur*innen abgelöst wurde. ${ }^{805}$ Gleichzeitig sind es die Innovationen, die eine neue Institution versprechen, die eine Veränderung der Umgebung anregen. Es heißt beispielsweise, dass seit der Eröffnung von Litteraturbuset in Oslo viel mehr Literaturveranstaltungen stattfinden, dass das öffentliche Interesse an Literatur und öffentlicher Diskussion gestiegen sei. ${ }^{806}$

Als konkretes Beispiel referiert der Bericht zur Nasjonal bibliotekstrategi das Projekt Folkebibliotek som litteraturbus, das Troms fylkesbibliotek zum litteraturbus umgestalten sollte. Inbegriffen waren beispielsweise Seminare für Bibliotheksmitarbeiter*innen zur Veranstaltungsplanung. ${ }^{807}$ In anderen Regionen liefen vergleichbare Projekte. In der Gegend Nord-Trøndelag wird der Name Litteraturbus Nord-Trondelag zukünftig als Dachmarke für die Vermittlungsaktivitäten aller Bibliotheken der Region verwendet. Diese durch die Literaturhaus-Idee angestoßenen Projekte führten somit auch dazu, dass die einzelnen kleineren Bibliotheken stärker zusammenarbeiten, wobei die fylkesbibliotek die Rolle des Koordinators gemeinsamer Aktivitäten wie der Planung von Lesereisen innehat, womit sich diese überhaupt erst realisieren lassen. ${ }^{808}$

Ein weiterer Beleg für die Anregung von bestehenden Einrichtungen durch das Literaturhaus in Norwegen ist die Tatsache, dass auch in den Literaturhaus-Städten die Literaturhaus-Idee in den Bibliotheken diskutiert und weitergetragen wird. In Bergen eröffnete 2011 die neue Hauptbibliothek, die im Zuge der Gründungsdebatten zum Litteraturbuset eine wichtige Rolle spielte. ${ }^{809}$ In Oslo erwägt die Universität, bei der Neueinrichtung der Juridisk bibliotek im Osloer Stadtkern einen ,akademisk møteplass og debattarena i sentrum“ [akademischen Treffpunkt und Debattenarena im Zentrum] zu etablieren, denn aktuell finden viele Vermittlungsaktivitäten von Universitetet $i$ Oslo $(\mathrm{UiO})$ im Litteraturhuset statt. ${ }^{810}$ Und wie sich die Neueröffnung von Deichman Hovedbiblioteket auf Litteraturbuset am Wergelandsveien auswirken wird, ist bisher nicht zu beantworten. Das Literaturhaus schlägt in Norwegen zumindest weitere Wellen.

\footnotetext{
804 Vgl. ebd., S. 22.

805 Vgl. Kapitel II 8.2.4.

${ }^{806}$ Dies habe ich unter anderem aus Gesprächen mit dem Programmleiter des Hauses Andreas Liebe Delsett erfahren, und auch von nicht direkt Beteiligten wie der NORLA-Mitarbeiterin Andrine Pollen. 807 Vgl. „Nasjonal bibliotekstrategi“, Kulturdepartementet, S. 21. Dieses Literaturhaus-Projekt ist inzwischen abgeschlossen, der Abschlussbericht steht online zur Verfügung, vgl. „Litteraturhus 2017“, Troms fylkeskommune. Fylkesbibliotek ist eine übergeordnete Stelle, die unter sich die einzelnen Folkebibliotek der Region bündelt. Troms ist eine Provinz [fylke] im Norden Norwegens mit Tromsø als Verwaltungszentrum.

${ }^{808}$ Vgl. „Fylkesbiblioteket“, Trøndelag fylkeskommune.

${ }^{809}$ Vgl. Skaftnesmo 2016.

810 Vgl. Loge: „Domus Bibliotheca“.
} 


\section{Eine Frage der Perspektive}

Anhand der Diskussion um die Stellung von Bibliotheken, die in Norwegen und, wie sich im nächsten Kapitel zeigt, auch in Schweden im Kontext der Literaturhäuser oft stattfindet, wird augenfällig, dass bei der Betrachtung des Literaturhauses zum Beispiel in Skandinavien andere Faktoren berücksichtigt werden müssen als in Deutschland. Gerade die Beziehungen und Aufgaben von Literaturhaus und Bibliothek spielen in Skandinavien eine Rolle, besonders in Zusammenhang mit der oben erwähnten Parzellierung auf Stadt und Provinz. Als Wettbewerber der Literaturhäuser um städtische und staatliche Gelder gelten somit dort insbesondere die Bibliotheken, die als öffentliche Einrichtungen vollkommen mit Steuergeldern versorgt werden. Auch diese ringen um ihre finanzielle Absicherung und sahen in der Ausweitung des Literaturhauses im Land ein Risiko, weil sie befürchteten, dass diese neuen Einrichtungen aus dem Bibliotheksetat versorgt werden könnten. Volksbibliotheken haben aus Literaturhaus-Sicht in Deutschland eine ganz andere Position, sodass sie die deutschen Literaturhaus-Debatten selten tangieren. Wenn Audunson, norwegischer Professor für Soziologie mit einem Forschungsschwerpunkt auf Informationspolitik, vermutet, dass die Literaturhäuser in Deutschland eine Angebotslücke der Bibliotheken füllten, 811 wird vor allem seine skandinavische Perspektive auf den Gegenstand deutlich. Wie der zitierte Artikel herausgestellt, sei der Hauptunterschied zwischen Literaturhaus und Folkebiblioteket respektive Stadtbücherei das Zielpublikum: Während sich das Literaturhaus an literarisch Interessierte wende, richte sich die Volksbibliothek an das allgemeine Publikum. ${ }^{812}$ Bibliotheken fungieren eher als Serviceeinrichtungen für alle Bürger*innen, während sich die Literaturhäuser in einem Diskurs bewegen, der Literatur als Kunst interpretiert und Literatur dort in gehobener Atmosphäre darbietet. Das mag stimmen. Trotzdem ist es sehr interessant, dass in Deutschland dieser Vergleich so selten gezogen wird, obwohl die Angebote gar nicht so anders sind. ${ }^{813}$ In deutschen Diskussionen taucht ein Vergleich von Literaturhäusern und Bibliotheken selten auf, sie werden nicht als direkte Konkurrenten betrachtet. Allenfalls im Kinder- und Jugendbereich, bei dem es um Leseförderung und die Einübung literarischer Praktiken geht, erscheint bisher in Deutschland ein Vergleich berechtigt. Dabei müsste untersucht werden, ob nicht die deutschen Stadtbibliotheken ebenfalls häufiger Literaturhaus-Funktionen übernehmen respektive übernehmen sollten. Bisher wurde darüber, da das Literaturhaus in Deutschland nicht so neu ist wie in Skandinavien und sich deshalb traditionell in einem anderen Bereich des Literaturbetriebs verortet, selten explizit nachgedacht. Erst die komparative Perspektive der vorliegenden Arbeit stellt diese Differenz zwischen der deutschen und skandinavischen Diskussion heraus, der mit einer verstärkten Beschäftigung in Deutschland mit Stadtbibliothek als/und Literaturhaus begegnet werden könnte.

\footnotetext{
811 Vgl. Audunson 2014, S. 23.

812 Vgl. ebd. Hier sind in Deutschland vor allem die öffentlichen Stadtbibliotheken gemeint, die anders als zum Beispiel Universitätsbibliotheken vor allem zur Freizeitbeschäftigung dienen.

${ }^{813}$ In Bezug auf die Institution Literaturhaus in den neuen deutschen Bundesländern weisen darauf Porombka und Splittgerber hin, vgl. Porombka und Splittgerber 2010, S. 26-28.
} 


\section{8 Göteborgs Litteraturhus - Ein Literaturhaus in Schweden}

Während in den drei anderen untersuchten Ländern das erste Literaturhaus jeweils in der Hauptstadt eröffnete, befindet es sich in Schweden seit Oktober 2013 in der zweitgrößten Stadt des Landes - in Göteborg. ${ }^{814}$ Dieser Gründung ging eine landesweite (Feuilleton-)Diskussion voraus, denn, wie Zeitungsartikel belegen, wurde bereits im Jahr 2008 in Schweden wahrgenommen, dass Literaturhäuser dort grundsätzlich möglich seien, doch: „Än har inte litteraturhustrenden nått Sverige på all-

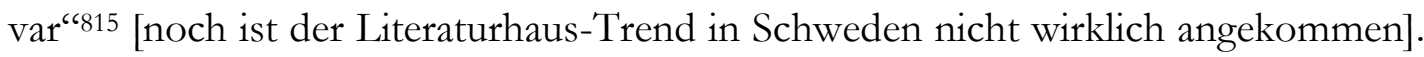
Aspekte dieser Debatte, die für das Verständnis der Institution ,Literaturhaus ‘ in Schweden relevant sind, werden im Folgenden herausgearbeitet, um dann die Entstehung des Literaturhauses in Göteborg genauer zu studieren. Dies mündet in der Konklusion, dass die ,Literaturhaus-Welle' Schweden nicht mit gleicher Kraft erfasste wie Norwegen. Die Institution führte dort vielmehr zu einer Reflexion und Aktualisierung bestehender Einrichtungen.

\section{8.1 Schweden und Literaturhäuser}

\section{8.1.1 Schwedische Abgrenzung von Norwegen}

Ähnlich wie in den vorherigen Kapiteln für Norwegen konstatiert, interessierten sich auch in Schweden Akteur*innen des Literaturbetriebs für die Entwicklung des ,Literaturhauses'. Selbst als es noch keine konkreten Ideen für ein Literaturhaus in Schweden gab, wurde dabei auf Norwegen als Vorbild und Konkurrent verwiesen. In einem Zeitungsartikel mit dem bezeichnenden Titel „Norge har allt som vi i Sverige saknar" ${ }^{\prime 816}$ [Norwegen hat alles, was uns in Schweden fehlt], nennt die schwedische Kulturjournalistin und Autorin Åsa Linderborg ${ }^{817}$ zentrale Unterschiede zwischen Norwegen und Schweden, zum Beispiel die norwegischen festen Buchpreise, die ein variierendes Angebot in diversen Buchhandlungen ermöglichten. Zudem betont sie, dass Norwegen ein Prozent seines aufgrund der immensen Einnahmen der Ölindustrie üppigen Bruttosozialproduktes für Kultur ausgebe. In der Diskussion um Literaturhäuser in Schweden gibt sie Folgendes zu bedenken:

Jag förstår de som nu ropar efter ett Litteraturhus i Stockholm, men vi har trots allt Kulturhuset. Och ABF på Sveavägen - men dit hittar ju inga liberaler. Som Madelaine Levy påpekade här $\mathrm{i}$ torsdags, måste vi först rädda biblioteken - $\mathrm{i}$ hela landet. En femtedel av folkbiblioteken lever under akut hot. Det är lätt att

\footnotetext{
${ }^{814}$ Ende 2017 wurden für Göteborgs Kommune 564.039 Einwohner*innen verzeichnet, für Stockholm 949.761, Schweden insgesamt wies eine Bevölkerungszahl von rund 10,12 Millionen auf, vgl. „Kommuner i“", Statistiska centralbyrån.

815 Pettersson 2008.

${ }^{816}$ Linderborg 2012.

817 Åsa Linderborg (*1968) war für Vänsterpartiet [Die Linkspartei] aktiv und ist seit 2009 Leiterin des Ressorts Kultur der schwedischen Tageszeitung Aftonbladet. 2007 erschien ihr Belletristikdebüt Mig äger igen [auf Deutsch 2010 unter dem Titel Ich gehöre keinem erschienen; Übersetzung: Paul Berf]. Ihre politisch deutlich linke Orientierung ist bei der Einschätzung ihrer Aussagen zu bedenken. Zu Linderborg vgl. auch Kapitel II 14.3.3, S. 447.
} 
omfamna idéer om man inte bekymrar sig om verkligheten. Litteraturhuset i Oslo är en stiftelse, grundad av pressbyrån Narvesens ägare. Tio miljoner om året baxar han in. Borgerliga mecenater. Det är nåt vi heller inte har. ${ }^{818}$

Ich verstehe die, die nun nach einem Literaturhaus in Stockholm rufen, aber wir haben immerhin Kulturbuset. Und ABF (Arbetarnas bildningsförbund, der Bildungsverbund der Arbeiter, Anmerkung C. L.) am Sveavägen (eine der Hauptverkehrsstraßen im Zentrum Stockholms, Anmerkung C. L.) - aber dorthin finden ja keine Liberalen. Wie Madeleine Levy hier am Donnerstag gezeigt hat, müssen wir erst die Bibliotheken retten - im ganzen Land. Ein Fünftel der Volksbibliotheken lebt unter akuter Bedrohung. Es ist leicht, Ideen zu begrüßen [wörtlich: zu umarmen], wenn man sich nicht um die Wirklichkeit kümmert. Litteraturbuset in Oslo ist eine Stiftung, gegründet vom Eigentümer des Zeitungskiosk Narvesen ${ }^{819}$. Zehn Millionen Kronen im Jahr schleppt er hinein. Bürgerliche Mäzene. Das ist etwas, was wir auch nicht haben.]

Ausgehend von diesem stichwortreichen Beitrag lassen sich Aspekte des Diskurses um Literaturhäuser in Schweden ausführen, weshalb er recht lang direkt zitiert wurde. Die schwedische Perspektive des Textes ist für die vorliegende komparative Studie aufschlussreich, denn es wird deutlich, dass Überlegungen zum Transfer des ,Literaturhauses' nach Schweden maßgeblich von der Bezugnahme auf Norwegen beeinflusst sind. Die deutschen Literaturhäuser oder die Kopenhagener Einrichtung kommen darin kaum noch vor, was die Argumentation der vorherigen Kapitel unterstützt, dass Litteraturhuset in Oslo eine skandinavische Ausführung prägte und diese zum Vorbild innerhalb von Norwegen, aber auch in Schweden wird.

Am augenfälligsten ist im zitierten Artikel die Betonung von Norwegens finanziellem Vorteil. Es bleibt zwar unerwähnt, dass das Literaturhaus in Oslo zunächst gar keine öffentlichen Gelder erhielt, doch ist der durch die Ölindustrie ermöglichte staatliche Beitrag zur Kultur insgesamt sehr hoch - was die grundsätzliche staatliche Bereitschaft zur Finanzierung von Kulturprojekten demonstriert. Ebenso gebe es Linderborg zufolge in Schweden keine bürgerlichen Mäzene. Diese sind aber, wie in den vorherigen Kapiteln herausgestellt, für den Betrieb eines Literaturhauses unabdingbar. Es ist also auch in Schweden von Anfang an klar, dass die Diskussion um Literaturhäuser immer auch eine Frage des Geldes ist.

\section{8.1.2 Stockholm als Schwedens Zentrum}

Weiter ist Åsa Linderborgs Stockholm-Perspektive bemerkenswert. Die ZentrumPeripherie-Diskussion, die am Beispiel Norwegens vorne geführt wurde, lässt sich auf Schweden übertragen. Mit Blick auf das tatsächlich existierende schwedische Literaturhaus in Göteborg wird hier das Verhältnis von Stockholm und Göteborg kommentiert: Zwischen Göteborg und Stockholm herrscht ,Rivalität'. Vor allem Göteborg in Westschweden schaut mit Argwohn auf Stockholm; Stockholm, die viel größere Metropole, die Hauptstadt, die internationalere und reichere Stadt, das Machtzentrum. Göteborg hingegen ist traditionell eine Industrie- und Handelsstadt - unter anderem Sitz der Unternehmensgruppe Volvo. Später siedelten sich im Zu-

\footnotetext{
${ }^{818}$ Ebd.

${ }^{819}$ Die Stiftung Fritt Ord wurde, wie im Kapitel zum Litteraturbuset in Oslo beschrieben, von Narvesen, Norwegens größter Zeitungskioskkette gegründet.
} 
ge des notwendigen Strukturwandels mehr Medien- und Kommunikationsunternehmen an. Jetzt gilt Göteborg, das zudem wichtiger Universitätsstandort ist, als moderne und kreative Stadt. ${ }^{820}$ Doch, wie von Åsa Linderborg angedeutet, ist Stockholm die finanzstärkere Stadt. Zentrum ist es auch für den Buchmarkt: Die dominierenden Verlage in Schweden, erstens Bonnier Förlagsgrupp, zweitens Norstedts Förlagsgrupp (KF Media), zu der unter anderem Rabén \& Sjögren zählt, und drittens Natur \& Kultur haben ihren Sitz in Stockholm. ${ }^{821}$ Nach Göteborg kommen die Akteur*innen des skandinavischen Literaturbetriebs - zumindest oder nur - einmal jährlich zur Buchmesse. Auch geografisch ist Göteborg mit Norwegen und Dänemark eng verbunden: Es liegt näher an Oslo und Kopenhagen als an Stockholm. Göteborg orientiert sich also nicht nur an der schwedischen Hauptstadt, sondern auch an den westlichen Nachbarmetropolen - in denen es ebenfalls Literaturhäuser gibt. Ein Literaturhaus in Göteborg könnte diese Nähe intensivieren.

\section{8.1.3 Literaturveranstalter*innen in Schweden}

Der Fokus auf Stockholm ist in Linderborgs Artikel ferner deshalb nachvollziehbar, weil die ersten Überlegungen zu einem Literaturhaus in Schweden es in Stockholm platzierten. Dort ist allerdings bis dato keines realisiert. 2012 wurde zwar auf Initiative von Författarförbundet [die Autorenvereinigung] und Svenska förläggareföreningen [die schwedische Verlegervereinigung] in Kooperation mit dem schwedischen PEN die Stiftung Stockholms internationella Litteraturhus [Stockholms internationales Literaturhaus] gegründet.822 Doch inzwischen ist die Website des Projektes nicht einmal mehr online verfügbar. So ist davon auszugehen, dass es ad acta gelegt wurde. Als Grund dafür sind - neben den fehlenden Geldern - die in Stockholm etablierten Organisationen zu nennen, auf die Åsa Linderborg hinweist: Kulturbuset, ABF-buset und die Bibliotheken. Diese Akteur*innen erfüllen unter anderem Funktionen, die mit denen eines ,Literaturhauses ' übereinstimmen. Es ist deshalb anzunehmen, dass der Bedarf für ein zusätzliches Literaturhaus in Stockholm nicht besonders groß ist.

Das Verhältnis des Literaturhauses zur Bibliothek steht wie in Norwegen in Schweden zur Diskussion. Dies verwundert nicht, wurde doch bereits erläutert, wie wichtig Bibliotheken, insbesondere Folkbibliotek, in Skandinavien sind. Was jedoch für Norwegen in diesen Ausmaßen nicht galt, ist die große Bedeutung von Kulturbuset und $A B F /$ Arbetarnas bildningsförbund [der Bildungsverbund der Arbeiter], die als Institutionen der Volksbildung verstanden werden können, weil sie dieses in Schweden aus den folkrörelser [Volksbewegungen] entstandene alternative Bildungsmoment verkörpern. $A B F-1912$ aus der Arbeiterbewegung heraus gegründet eröffnete auch erst 1961 am Sveavägen - zeitlich kurz vor dem und örtlich in unmittelbarer Nähe zum Kulturbuset - ABF-buset, wo mit Vorträgen und Studienkreisen ein

\footnotetext{
${ }^{820}$ Vgl. Metcalf: „Sweden Unzipped“. Der Artikel, erschienen in der New York Times, stellt Göteborg aus ausländischer Sicht dar, er macht deutlich: „There is no exaggerating the centrality of the concept ,underground' to Goteborg's self-image."

${ }^{821}$ Diese größten Verlagshäuser sind auch Buchhandelsketten, was bedingt, dass es, wie Linderborg schreibt, keine vielfältige Buchhandelskultur in Schweden gebe, vgl. „Informationen zum“, Frankfurter Buchmesse.

822 Vgl. Söderling 2012.
} 
Ort der gesellschaftsbildenden Debatte entstand. Christian Berrenberg betont, dass Belletristik für die schwedische Arbeiterbewegung immer eine wichtigere Rolle spielte als für die norwegische. ${ }^{823} A B F$ ist also unter anderem im Bereich der Literaturvermittlung tätig, stärker als die vergleichbaren Einrichtungen in Norwegen. Kulturbuset sollte in den 1960er-Jahren am Sergels torg mitten in Stockholm der Kommerzialisierung der Stadt entgegenwirken und „ett slags kulturens vardagsrum“824 [eine Art Wohnzimmer der Kultur] darstellen. 1974 wurde das Gebäude schließlich vollständig eröffnet. Während sich in Deutschland zum Beispiel das Literarische Colloquium Berlin formierte, entstand so ohne ein eindeutiges Vorbild, aber in einer Zeit, in der sich an vielen Orten ähnliche Zentren bildeten, Kulturbuset. Es fand seinerseits Nachahmer. Gedacht als niederschwellige Einrichtung, die unterschiedliche Kulturbereiche zu verknüpfen versuchte und allen Bürger*innen innovative Kunst näherbringen wollte, galt es als Inbegriff des Folkhem-[Volksheim-]Gedankens und einer ,Kultur für alle'. 825

Seit Juni 2013 agiert Kulturhuset in Fusion mit Stadsteatern als mächtige, öffentlich finanzierte Kulturinstitution in Schweden. ${ }^{826}$ Kulturbuset Stadsteatern wird seitdem als Mehrspartenhaus betrieben und einen der sieben Bereiche bildet Literatur. ${ }^{827}$ Dort findet unter anderem die Reihe Release me statt, die literarische Debüts vorstellt. Im Kulturbuset entstand außerdem bereits 1998 die Reihe Internationell författarscen [Internationale Autorenbühne], die internationale Autor*innen zum Gespräch einlädt. Kulturbuset in Stockholm vertritt folglich einen überregionalen, internationalen Anspruch. ${ }^{828}$ Kulturbuset Stadsteatern, ABF und die öffentlichen Bibliotheken machen deutlich, dass es in Stockholm nicht an der Literatur gewidmeten und ständig zugänglichen Publikumsorten fehlt. Ein extra ,Literaturhaus‘ in Stockholm hätte damit schwierige Startbedingungen, weil es der Präsenz dieser existierenden Kulturinstitutionen, die quasi so etwas wie ein Literaturhaus in sich tragen, erst einmal etwas entgegenstellen und eine Abgrenzung durchsetzen müsste. Um zu reüssieren, bedürfte es vermutlich einer Zusammenarbeit mit dem Bestehenden sowie eines klaren Neuigkeitswertes.

Unter Verwendung des Funktionsbegriffs, Literaturhaus' lässt sich sagen, dass Stockholm längst ein Literaturhaus hat. Dass es dennoch eine Diskussion über die Gründung eines so benannten Litteraturbuset gab, unterstützt die Argumentation, zwischen Einrichtungen, die sich explizit als Literaturhaus bezeichnen - die Ausnahmen wurde am Beispiel Göttingen ausgiebig dargelegt - und denen, die auch Literaturhaus-Funktionen übernehmen, aber in der Regel einen anderen Schwerpunkt setzen - etwa Bibliotheken - oder in der Ausrichtung breiter aufgestellt sind

\footnotetext{
823 Vgl. Berrenberg 2014, S. 269.

${ }^{824}$ So soll es der Architekt Peter Celsing, der das Gebäude erdachte, formuliert haben, vgl. „Husets Historia“, Kulturhuset Stadsteatern.

825 Von Beginn an waren die angegliederten Spezialbibliotheken ein wichtiger Aspekt des Aktivitätskomplexes. Früh angegliedert wurde auch ein Kinder- und Jugendtheater. Dennoch wurde es eher zum Spielraum für innovative junge Künstler*innen und die kulturelle Elite, vgl. Löfgren (Hg.) 2004 sowie FN 824. 826 Obacht: Die Domain wmw.kulturbuset.se wird inzwischen nicht mehr von diesem unterhalten, Kulturbuset Stadsteatern präsentiert sich unter der Domain www.kulturbusetstadsteatern.se.

${ }^{827}$ Neben Literatur stehen Theater, Tanz, Kunst/Design, Musik, Film und Forum/Debatte auf dem Programm.

${ }^{828}$ Die Kulturhäuser abseits von Stockholm fördern hingegen vor allem lokale Kultur und Debatte.
} 
- siehe Kulturbuset -, zu differenzieren. Ein Literaturhaus zu eröffnen ist aber vor allem dann sinnvoll, wenn es Bedürfnisse erfüllt, die in der Stadt bisher noch nicht befriedigt werden.

Die von Åsa Linderborg erwähnten Einrichtungen sind nicht nur stockholmspezifisch. Auf unterschiedliche Weise transferierten andere Städte diese Konzepte. Kulturhäuser und $A B F-Z e n t r e n$ beispielsweise gibt es in den meisten schwedischen Regionen. Internationell författarscen fand Nachahmer in der Stadtbibliothek in Malmö, in Göteborg und sogar in Kopenhagen ${ }^{829}$. Die Internationalität wird dabei besonders unterstrichen. Die veranstaltende Bibliothek respektive das Kulturhaus erfüllt damit längst eine Literaturhaus-Funktion - nicht nur in der Hauptstadt, sondern besonders in mit Stockholm verglichen kleineren Städten. Dies wird aber erst durch die mögliche Einführung des Literaturhauses reflektiert.

Neben den örtlich fixierten Einrichtungen sind im schwedischen Literaturbereich gerade was die breitenwirksame Aufmerksamkeit für Literatur anbetrifft - Literaturfestivals nicht zu vernachlässigen: Direkt in Stockholm veranstaltet Moderna Museet seit 2013 ein eigenes Literaturfestival unter dem prägnanten Namen Stockholm Literature. ${ }^{830}$ Littfest - Umea Internationell Litteraturfestival ist seit 2007 aktiv und betont die internationale Ausrichtung des Festivals in der nordschwedischen Stadt Umeå schon im Namen. Geografisch zwischen Stockholm und Uppsala findet seit 2011 Sigtuna Litteraturfestival statt. Im März 2017 feierte Malmö Litteraturfestival seine Premiere. ${ }^{831}$ Literaturfestivals sind kein Novum in Skandinavien, es fällt jedoch auf, dass in Schweden parallel zu den Diskussionen um Literaturhäuser Festivals neu entstehen. Ebenso wie die Beobachtungen, dass in diesem Kontext die Lage der Bibliotheken diskutiert wird oder in Stockholm Kulturbuset sich mit dem großen Kulturakteur Stadsteatern verbindet, ist dies Zeichen für eine Veränderung: Ohne damit eine Ursache-Wirkung-Beziehung behaupten zu wollen, lässt sich dennoch annehmen, dass der Anstoß durch die Institution ,Literaturhaus' und die Eröffnung von Literaturhäusern in Norwegen und anderen Ländern eine Diskussion in Schweden hervorbrachte, die sonst wahrscheinlich nicht auf diese Weise geführt worden wäre. Der Artikel von Åsa Linderborg ist ein anschauliches Beispiel dafür. Der denkbare Transfer des Konzeptes nach Schweden führte zu einer Reflexion über den ,eigenen', national organisierten Veranstaltungsbetrieb. Das ,Literaturhaus' richtet dabei den Fokus aber auf die Literatur.

Ähnlich wie am Beispiel Oslos und Bergens gezeigt, spielt in diesem Kontext der Vergleich mit anderen Ländern eine wichtige Rolle. Die Akteur*innen beobachten, wie andere handeln, was an anderen Orten entsteht und daraus folgt. Dabei liegt kein unmittelbar auf die Einzeleinrichtungen bezogenes Konkurrenzverhältnis vor. Vielmehr werden der Vergleich und der grundsätzliche Wettbewerb der Staaten

\footnotetext{
${ }^{829} \mathrm{Vgl}$. Kapitel II 5.3.

${ }^{830} 2018$ allerdings musste dieses Festival aus finanziellen Gründen vorerst ein Jahr aussetzen. Wie es mit diesem Festival weitergeht, bleibt abzuwarten, vgl. Modig und Nasiell, Pressemitteilung 2018.

${ }^{831}$ Dieses Festival verstand sich aber als ,en organisk stadsfestival“ [ein organisches Stadtfestival], bei dem alle, die wollten, Veranstaltungen anbieten konnten. Es nähert sich also eher dem Konzept von Göteborgs Litteraturbus, vgl. „Malmö Litteraturfestival“, Malmö Litteraturfestival.
} 
genutzt, um die eigenen Ideen zu realisieren und um mögliche Koalitionspartner für die eigenen Interessen zu finden. ,Norwegen hat alles, was in Schweden fehlt', ist dabei einerseits eine Annahme, für die sich Belege finden, andererseits - neben einem Ausdruck von Neid - provokativer Aufruf, daran etwas zu ändern. Allein dies kann nennenswerter Gewinn für den schwedischen Kulturbetrieb sein, weil die eigene Situation reflektiert wird. So entwickelt sich zugleich die Institution weiter selbst als noch kein Literaturhaus in Schweden eröffnet war und nicht einmal absehbar war, ob dies jemals geschehen würde.

Aus den Debatten um die Institution ,Literaturhaus' erwachsen in Schweden schließlich einige konkrete Aktivitäten: Litteraturbuset Trampolin setzt sich als Teil von Sandvikens Kulturcentrum seit Sommer 2013 für die Lese- und Sprachförderung von Kindern und Jugendlichen ein. ${ }^{832}$ Nordiska litteraturbuset in Åmål fällt als Formulierung in Zusammenhang mit Bokdagar $i$ Dalsland - ett nordiskt centum för litterära upplevelser [Buchtage im Dalsland - ein nordisches Zentrum für literarische Erlebnisse]. ${ }^{833}$ Det fria ordets hus [Das Haus des freien Wortes] in Växjö, seit 2014 tätig, ließe sich als ,Literaturhaus' bezeichnen. ${ }^{834}$ Außerdem sind zum Beispiel in Lund, Uppsala und in der Region Dalarna Vereinigungen oder Gruppierungen aktiv, die sich für ein Literaturhaus in ihrer Stadt beziehungsweise Region einsetzen. Abgesehen von den Einrichtungen, die sich nur der Kinder- und Jugendliteratur beziehungsweise dem Werk einzelner Autor*innen widmen oder strukturell einer Bibliothek unterstehen, gibt es bis dato nur ein Literaturhaus in Schweden, das mit festem Ort bereits Programm anbietet: 2013 als Litteraturbuset Göteborg eingeweiht, wechselte es 2014 seinen Namen zu Göteborgs Litteraturbus. Das damit verbundene Gründungsund Umstrukturierungsprozedere wird im Folgenden genauer betrachtet. Darin setzt sich die Diskussion um den Transfer der Institution nach Schweden am anschaulichen Fall fort.

\section{8.2 Aus Litteraturhuset Göteborg wird Göteborgs Litteraturhus}

\section{8.2.1 Gründungsüberlegungen}

Im August 2011 beauftragte die Kulturverwaltung der Stadt Göteborg die Literaturwissenschaftlerin und -kritikerin Ingrid Elam $(* 1951)^{835}$, einen Entwurf für ein Literaturhaus in Göteborg zu entwickeln. Dieses Grundlagenpapier für die Einrichtung von Litteraturbuset Göteborg kumuliert Aspekte unterschiedlicher Diskussionen zum ,Literaturhaus'. Es thematisiert denkbare Erfordernisse, die ein Literaturhaus erfüllen sollte und schlägt Realisierungskonzepte vor. ${ }^{836}$ Während in den vorherigen Kapiteln vor allem Zeitungsberichte verwendet wurden, kommen hier Konzept-

\footnotetext{
832 Vgl. „Litteraturhuset Trampolin“, Sandvikens Kommun.

833 Vgl. „Bokdagar i“, Bokdagar i Dalsland.

834 Und es wäre dem Namen nach vor allem denen vergleichbar, die von der Stiftung Fritt Ord subventioniert werden, vgl. „Om Det“, Växjö Kommun.

835 Zu der Zeit war Ingrid Elam Dozentin an Malmö Högskola, seit 2012 ist sie Dekanin der künstlerischen Fakultät von Göteborgs Universitet, seit 2014 Professorin für Litterär gestaltning.

836 Vgl. Elam 2011.
} 
und Behördenpapiere vor. Die hier folgenden Stichworte entstammen diesem Dokument; weiterführende Informationen und Interpretationen ergänzen Elams Ausführungen.

Die erste Idee für die Gründung in Göteborg folgte der zunächst simplen Feststellung, dass andere Orte erfolgreich Literaturhäuser unterhalten, wie am Anfang dieses Kapitels vermutet. Es entstammt folglich der Motivation, ,mitmachen' und die Chancen, die ein Literaturhaus bieten kann, nutzen zu wollen. In dem Text wird das relativ neu aufkommende Interesse in Schweden am ,Literaturhaus' interpretiert als „om inte ett krisfenomen så i alla fall ett tecken på förändring “637 [wenn nicht ein Krisenphänomen, so immerhin ein Zeichen von Veränderung]. Es werde zwar in Schweden sehr viel gelesen, doch sei die literarische Vielfalt vom Markt bedroht. In dieser Hinsicht könne ein Literaturhaus Abhilfe schaffen.

\section{Transfer der Literaturhaus-Idee}

Der Bezug von jüngeren auf frühere Literaturhäuser ist Teil des Modells der Institution Literaturhaus. Auch das betrachtete Dokument aus Göteborg umreißt die europäische Geschichte des Literaturhauses. Ingrid Elam interpretiert darin das Literaturhaus als Ergebnis der Kulturpolitik der Nachkriegszeit beziehungsweise des Wirtschaftswunders der 1970er-Jahre, in der nach dem Motto „Kultur für alle‘ Kultur nicht mehr nur als Vergnügen für eine kleine Gruppe dienen, sondern allen zugänglich sein sollte. Starke Kulturinstitutionen seien in der Zeit entstanden, neben Bibliotheken, Museen und Staatstheatern eben Literaturhäuser. ${ }^{838}$ Ohne diesen halbseitigen Absatz des Dokuments überzubewerten, ist doch bemerkenswert, dass dort die deutschen Literaturhäuser als Zeichen der Demokratisierung von Kultur verstanden werden. Die stärkere Kunstfokussierung mit einer Kombination aus Literaturkritik und Genuss, die das Literaturhaus ebenfalls verkörpert, wird doch nicht gesehen oder zumindest ausgeblendet. Für den schwedischen Kontext ist es nachvollziehbar, dass die gesellschaftliche Bedeutung des Literaturhauses unterstrichen wird und die kulturpolitische basisdemokratische Motivation herausgestellt wird. Mit der Verortung in den 1970er-Jahren wird das Literaturhaus etwas zu früh situiert, was durch die Einordnung in eine ,Kultur für alle' verständlich ist, die zu dieser Zeit auch in Deutschland relevanter wurde. Als Vorbilder für Literaturhäuser stellt der Text nicht nur die deutschen, und dort die Berliner Einrichtungen - das Literarische Colloquium Berlin versteht sie dabei als eines der ältesten -, und die skandinavischen Fälle Litteraturbuset in Oslo und LiteraturHaus in Kopenhagen ${ }^{839}$ heraus, sondern auch das auf Poesie spezialisierte Maison de la Poésie in Paris und Passa Porta in Brüssel. Diese Einrichtung wurde 2003 eröffnet und ist funktional ein Literaturhaus. Zusätzlich zu diesen „publiktillvända“"840 [publikumsorientierten] Häusern gebe es viele Übersetzer- und Autorenzentren. Die Referentin bezieht sich nicht vorrangig auf die in Deutschland situierten, sondern sichtet zudem Einrichtungen in anderen Teilen Europas. Mit diesen Beispielen wird implizit betont, dass in anderen europäi-

837 Ebd., S. 7.

${ }^{838}$ Vgl. ebd., S. 2-3.

${ }^{839}$ Dieses wird - wie sich im ersten Teil dieses Unterkapitel schon angedeutete - vor allem deshalb nicht als direktes Vorbild identifiziert, weil das Literaturhaus in Oslo finanziell weitaus stärker aufgestellt ist.

840 Ebd., S. 5. 
schen Ländern schon Literaturhäuser existierten - in Schweden noch nicht. Nebenbei wird ersichtlich, dass bei der Recherche der funktionale Literaturhaus-Begriff genutzt wurde.

\section{Göteborg als Kontext}

Die Initiator*innen ließen sich von den existierenden Literaturhäusern inspirieren, konzentrierten sich jedoch darauf, was speziell für Göteborg gilt. ${ }^{841}$ In Göteborg, das sich als Literaturstadt aufzustellen versucht, ist unter anderem die in Schweden älteste an eine Universität angegliederte Schreibschule ansässig. Seit 1996 wird Litterär gestaltning an Göteborgs Universitet unterrichtet. Diese institutionalisierte Form von Creative-Writing-Kursen, die in Schweden seit den 1980er-Jahren angeboten werden, bildet Autor*innen aus. Entsprechend leben in der Stadt relativ viele Nachwuchsschriftsteller*innen, die ihre Arbeiten vorstellen möchten. Für die Präsentation neu entstehender und eher experimenteller Texte findet seit 2007 das Literaturfestival Textival - för litteraturen utanför mittfäran [für Literatur abseits der Mitte] statt und bereits seit 1980 Göteborgs poesifestival, Schwedens ältestes Poesifestival. ${ }^{842}$

Neben weiteren kleineren Literaturveranstaltern wirken drei große literarische Einrichtungen in Göteborg. Zum einen ist die Buchmesse Bok \& Bibliotek [Buch \& Bibliothek] zu nennen, die jährlich im September stattfindet und sich seit ihrer Gründung 1985 zum zentralen Buchbranchentreffen in Nordeuropa entwickelt hat. Göteborg ist damit Knotenpunkt für den skandinavischen Buchmarkt. Eine weitere Einrichtung ist das Kulturangebot des $A B F$. Mit der Einbeziehung dieser Organisation wird „Folkrörelsetraditionen“ [die Volksbewegungstradition] als für den literarischen Betrieb prägend identifiziert. ${ }^{843}$ Als dritte mächtige literaturvermittelnde Akteurin und öffentliche Einrichtung wirkt Stadsbiblioteket Göteborg. Sie organisiert unter anderem seit 2010 Internationell författarscen Göteborg nach dem Vorbild der Reihe in Stockholm.

Das Grundlagenpapier des Literaturhauses in Göteborg nimmt besonders auf die Bibliothek und deren moderne Entwicklung hin zum Treffpunkt und Veranstaltungsort Bezug. Obwohl für beide Einrichtungen Übereinstimmungen konstatiert werden, erfülle ein Literaturhaus doch eine andere Funktion als eine Bibliothek: ${ }^{844}$ Die Bibliothek wird verstanden als Platz für Leser*innen respektive Bürger*innen, hingegen mangele es an Förderung für Autor*innen. Ein Literaturhaus müsse das Hauptaugenmerk auf den Produktionsaspekt von Literatur richten, Distributionsund Rezeptionsmaßnahmen tauchen in der Darstellung untergeordnet auf. Damit ist ein wegweisender Wunsch an das Literaturhaus formuliert: Mit dem Literaturhaus solle Göteborg sich weiter als Literaturstadt etablieren und Ort nicht nur der Repräsentation von Literatur, sondern vor allem ihrer Produktion sein. Dies bedeutet, dass unter anderem Schreibkurse angeboten und auch Amateurautor*innen Möglichkeiten zur Präsentation und Unterstützung erhalten sollen.

841 Vgl. Ingrid Elam zitiert nach: Clausson 2011.

842 Seit der Eröffnung des Literaturhauses finden diese beiden Festivals dort statt, sie sind Mitglieder des Literaturhaus-Vereins.

843 Vgl. Elam 2011, S. 6.

844 Vgl. ebd., S. 2. 
Auf Basis der in dem Grundlagenpapier nachvollziehbaren Abwägungen wurden zunächst vier mögliche Umsetzungen eines Literaturhauses für Göteborg erarbeitet. Diese illustrieren einige unterschiedliche Realisierungsmöglichkeiten für Literaturhäuser generell: Erstens ein Literaturhaus, das die bestehenden Bühnen an einem Ort bündelt und mit dem Namen das Bestehende unter einem Markenlabel vereint; zweitens ein Literaturhaus für das freie und alternative Literaturleben, am besten im Lagerhuset, drittens ,Litteraturhuset Göteborg' ohne dabei ein eigenes Gebäude zu betreiben und nur als Stempel für die Angebote in der Stadt, die bereits als ,Litteraturhuset bezeichnet werden könnten; viertens ein Literaturhaus in der Stadt als etwas gänzlich Neues, ein Haus, das die Autor*innen ins Zentrum stelle und Literatur als Kunstform fokussiere. Ein Literaturhaus verhalte sich dabei zu einer Bibliothek wie eine Kunsthalle zu einem Kunstmuseum, das eine widme sich der Produktion, das andere vor allem der Bewahrung und Verwaltung. ${ }^{845}$

Parallel zur Entstehung des Literaturhauses wurde eine Kulturstrategie vorgelegt, die Göteborg als eine führende Kultur- und Veranstaltungsstadt sah. ${ }^{846}$ Im Zuge des Aufbaus des Literaturhauses schrieb die Behörde außerdem einen Literaturpreis aus, ${ }^{847}$ um Autor*innen zu fördern, deren Arbeit sichtbarer zu machen, dem Literaturhaus eine prestigevolle Aufgabe zu geben und es in der schwedischen Literaturszene zu positionieren. ${ }^{848}$ Dies sind weitere Anzeichen dafür, dass kultur- und stadtpolitische Argumente die Errichtung des Literaturhauses von Anfang an steuern sollten und zugleich eine passende Umgebung für das Literaturhaus geschaffen werden sollte.

Schließlich entschied sich die Kulturverwaltung im Mai 2012 für die sogenannte Lagerhuset-Variante, oben als zweite genannt. In der offiziellen Begründung klingt dies nach einem durchdachten Kompromiss. ${ }^{849}$ Björn Sandmark, als Chef der Kulturverwaltung in Göteborg von 2008 bis 2014 einer der Initiatoren des Literaturhauses, nannte diese Wahl in einer Rückschau 2016 die kleinste der Optionen. ${ }^{850}$ Am 2. Oktober 2013 eröffnete Litteraturbuset Göteborg.

\section{8.2.2 Litteraturhuset Göteborg - Organisation}

Angesetzt auf zwei Jahre lag die Projektleitung und die Finanzierung zum größten Teil in öffentlicher Hand. Die Kommune stellte dafür jährlich je eine Millionen

\footnotetext{
845 Vgl. ebd., S. 17.

846 Vgl. Kulturstrategi för Göteborgs Stad 2012.

847 Vgl. Sandmark und Frizell 2013b, S. 2.

${ }^{848}$ Vgl. Sandmark und Frizell 2013a, S. 1. Göteborgs Stads litteraturpris wurde jedoch 2016 eingestellt. Kritik daran war unter anderem, dass die Preisträger*innen nicht unbedingt einen Göteborg-Bezug haben mussten, sondern es ein nationaler Preis war, und dass der Preis nicht einmal im Literaturhaus vergeben wurde, vgl. Norrmann 2016.

849 Vgl. Sandmark und Frizell 2012.

850 Vgl. Sandmark 2016. Ähnlich wie Åsa Linderborg weist er außerdem darauf hin, dass die finanzielle Ausstattung eines Literaturhauses zentral sei. So plädiert er dafür, ,att det är bra att med en gång skrota de allra största planerna när det gäller planering av nya kulturhus“" [dass es gut ist, sofort die allergrößten Pläne zu verschrotten, was die Planung neuer Kulturhäuser betrifft] - zu bedenken ist, dass der Artikel in einer Tageszeitung stand, die in Mittelschweden, also abseits der Metropolregionen Stockholm, Göteborg und Malmö, erscheint. Björn Sandmark, inzwischen Theaterchef von Göteborgs Stadsteater, spricht sich auf diese Weise besonders in der Provinz dafür aus, eher kleine Kulturhaus-Projekte anzustreben.
} 
Schwedische Kronen [circa 100.000 Euro] bereit. Diese Konstellation war befristet und die Trägerschaft wurde danach wie geplant weitergegeben. Für die Realisierung und Evaluation dieser ersten Variante wurde eine Projektleitung eingesetzt und eine Referenzgruppe mit Beratungsfunktion. ${ }^{851}$

Stadsbiblioteket hatte als städtische Einrichtung in der Gründungsphase direkten Einfluss auf das Literaturhaus, denn die eingesetzte Projektleiterin Madeleine Bergmark war schon damals Mitarbeiterin von Stadsbiblioteket und übernahm in dieser Funktion diese Aufgabe. Dazu muss gesagt werden, dass das StadsbiblioteketGebäude von 2012 bis 2014 umgebaut und vergrößert wurde. Während der Renovierung musste das Hauptgebäude am Götaplatsen ${ }^{852}$ schließen. Die Projektleiterin des Literaturhauses war die Leiterin der Stadsbiblioteket 300 m2, die ab 2012 als Ausweichfiliale während der Umbauarbeiten bereitstand. Ins Litteraturbuset Göteborg wurde ein Teil der Veranstaltungsaktivitäten der Bibliothek verlagert. In der Diskussion um die Aufgabe des Literaturhauses und der Bibliotheken ist diese Tatsache höchst interessant, denn es ist offensichtlich, dass die Unterschiede in der Aufgabenverteilung beider Einrichtungen verschwimmen. Das Literaturhaus wird direkt von der Bibliothek bespielt. Nach der Wiedereröffnung von Stadsbiblioteket wurde das Literaturprogramm für Erwachsene, wie es im und für das Litteraturbuset entwickelt wurde, dort weitergeführt. Die Projektleiter*innen sollten also im neuen Bibliotheksgebäude das Programm aktiv mitgestalten. 853 Die Kompetenzen, die sie in den ersten zwei Jahren im Literaturhaus sammelten, fließen damit zurück in die Bibliothek. Somit kann das erste Litteraturbuset Göteborg als Ersatzfiliale für die Bibliothek interpretiert werden. Letztlich verstärkte dieses Projekt also die Literaturveranstaltungsaktivität der Bibliothek. Synchron konnte sich die Erfahrung der Bibliotheksmitarbeiter*innen und die stadtweite Präsenz der Stadsbiblioteket positiv auf das Literaturhaus auswirken und es als Ort der Literaturvermittlung etablieren. Der Grundstein für eine weitergeführte, langfristige literarische Vermittlungsarbeit im Lagerhuset war damit gesetzt. Für die Bibliothek war dies eine gute Gelegenheit, die Umbauphase des Hauptgebäudes zu überbrücken und Litteraturbuset konnte in vivo getestet werden.

\section{8.2.3 Lagerhuset als Standort}

Göteborgs Litteraturhus befindet sich im Lagerbuset, was wie erwähnt zum Konzept gehört. Früher fungierte das Gebäude am Rosenlundkanal als Hafenlager. Es stand leer, als die kommunale Immobiliengesellschaft Higab es 1996 kaufte; seit 1999 arbeiten Verlage, Zeitschriften und andere Kultureinrichtungen dort, zum Beispiel die Vereinigung Förlagshuset, ein Zusammenschluss kleinerer Verlage, oder Nätverkstan, die dort ein digitales Medialab unterhalten. Bereits 2009 wurde entschieden, das Haus umzubauen und das Erdgeschoss als zugängliches kulturelles Zentrum zu etablieren. ${ }^{854}$ Seit 2012 residiert unter dieser Adresse außerdem das junge Kulturhaus Frilagret, wo Menschen zwischen 13 und 30 Jahren beispielsweise kostenlos Veranstal-

${ }^{851}$ Vgl. Sandmark und Frizell 2013b, S. 2.

852 Am Götaplatsen sitzen die etablierten Kulturinstitutionen der Stadt: Göteborgs Stadsbiblioteket, Göteborgs

Stadsteater, Konserthus und Göteborgs Konstmuseum. In der Nähe befindet sich die Universität.

${ }^{853}$ Vgl. Sandmark und Magnusson 2014, S. 2.

854 Vgl. Lekvall: „Transformation: From“. 
tungen anbieten können. Außerdem findet sich dort das Restaurant mit dem Namen Lagerbuset. Der Ort war also bereits vor dem Einzug des Litteraturhuset ein Platz der alternativen Literaturszene mit kleinen unabhängigen Verlagen und Kulturvermittlern. Die Verortung im Lagerhuset folgt der Idee, nicht eine neue literarische Bühne zu eröffnen, sondern das literarische Milieu, das mit dem Lagerbuset verbunden wird, sichtbarer zu machen und zu stärken. Vermisst worden sei, den Gründungserklärungen des Literaturhauses zufolge, bisher eine breite Öffentlichkeit für die Arbeit im Lagerhuset. Die Einrichtung des Literaturhauses dort versprach Aufmerksamkeit für die alternative Literaturszene. Es sollen nicht nur die Akteur*innen, die im Haus ansässig sind, dort auftreten, sondern der gesamten Literaturszene Göteborgs Präsentationsmöglichkeiten gegeben werden.

Lagerhuset steht am Heurlins Plats 1 im Bezirk Masthugget im Stadtteil MajornaLinné855. Unweit entfernt ist die Zentrale des ABF am Olof Palme Plats, direkt bei Järntorget, ein Viertel, das zunächst Arbeiterzentrum war und sich zum Treffpunkt mit vielen Lokalen und Kulturangeboten entwickelt hat. Diese ,neue' Gegend entstand, weil seit 2000 ein Tunnel gebaut wurde, sodass der Straßenverkehr unter die Erde verschoben und Platz gewonnen wurde. Das Umfeld des Lagerhuset wandelt sich besonders seit dieser Zeit - gekoppelt damit ist jedoch, dass es lange eine Großbaustelle war. Die Ansiedlung kultureller kollektiver Akteur*innen kann als Versuch interpretiert werden, das Quartier neu zu beleben.

Faktisch bezeichnet Göteborgs Litteraturhus nicht das ganze Gebäude, sondern den rund 170 Quadratmeter großen Raum im Erdgeschoss, der vorher als Buchlager eingesetzt war. Im offiziellen Protokoll der Kulturverwaltung ist zu lesen, dass vorgeschlagen wurde, das Projekt „Rum för litteratur“856 [Raum für Literatur] zu nennen. In Anbetracht der Tatsache, dass es sich wirklich nur um einen Raum des Gebäudes handelt, wäre die Entscheidung nachvollziehbar gewesen. Für die Einordung in einen größeren literaturbetrieblichen Kontext ist es hingegen klug gewählt, die Einrichtung als ,Litteraturhus' zu betiteln, wie das Departement kurz später selbst erklärt, ${ }^{857}$ weil der Funktionsbegriff sich in Fachkreisen bereits durchgesetzt hat.

Zur Nutzung als Litteraturbuset wurden Anpassungen an die Bedürfnisse des Literaturveranstalters vorgenommen, die Bühne wurde Ende 2016 noch einmal erneuert. Stühle gibt es für maximal 120 Personen. Es handelt sich dabei um einen offenen, recht schlicht gestalteten Raum, in dem Gebäude entsprechendem modernem Factory-Stil mit Sofa und breitem Arbeitstisch. Der Raum kann, ähnlich wie ein großflächiges Loft, flexibel genutzt werden. Tagsüber fungiert er auch als Arbeitsund Aufenthaltsraum. Zunächst war er gleichzeitig das Büro der Angestellten - seit 2016 nutzen sie andere Räume im Lagerbuset. Offener Arbeitsraum bleibt das Literaturhaus wegen des Projekts Ett (inte helt) enkelt rum [Ein (nicht ganz) eigenes Zimmer], das - referierend auf Virginia Woolfs Essay A Room of One's Own - Schreibende einlädt, im Litteraturbuset zu arbeiten - nach dem Prinzip eines Coworking Space, in

\footnotetext{
${ }^{855}$ Das Durchschnittseinkommen liegt dort über dem Göteborger Durchschnitt, vgl. „Göteborgsbladet 2015“, Samhällsanalys och Statistik, Göteborgs stadsledningskontor, S. 13-14.

${ }^{856}$ Sandmark und Frizell 2012, S. 3. Damit wurde von städtischer Seite auch beabsichtigt, diesen „Raum für Literatur“ als ein Zimmer der gesamtem Literaturstadt Göteborg zu verstehen.

${ }^{857}$ Vgl. Sandmark und Frizell 2013b, S. 1.
} 
dem Kolleg*innen in Kontakt kommen und sich in angenehmer Atmosphäre über Literatur und ihre literarische Arbeit austauschen sollen.

Die Gestaltung der Räumlichkeiten steht im Gegensatz vor allem zu den ,altehrwürdigen' Interieurs der Literaturhäuser in Hamburg und Berlin. Zwar gilt, wie bereits erläutert, dass die Orte aufgrund baulicher Vorgaben nicht jede Umgestaltung zulassen, doch platziert sich Göteborgs Litteraturbus designmäßig in einer anderen Szene als die ersten Literaturhäuser. Die Ausstattung verspricht Modernität und ,Coolness', während sich das Literaturbaus Hamburg als extremstes Gegenbeispiel in einer puttenverzierten Villa herrschaftlich gebärdet. Für die Analyse der Weiterentwicklung der Institution ist dieser Aspekt sehr interessant: Die Hinwendung zu gegenwärtig kreativen Produzierenden bricht die typische (Selbst-)Präsentation als Ort des ,kultivierten“ Umgangs mit hochbedeutender Literatur. Dort wird im Austausch gearbeitet, nicht nur ehrfürchtig gelauscht. Allerdings spiegelt sich darin vor allem die notwendige Kontextualisierung in verschiedenen Traditionslinien: ${ }^{858} \mathrm{Wäh}$ rend diese ,Industriearchitektur ${ }^{6}$ in Deutschland einer alternativeren, nichtbürgerlichen Szenen zugerechnet wird, fruchtet eine solche Unterscheidung in Schweden nicht. In skandinavischen Zusammenhängen verblüfft die Gestaltung des Literaturhauses in Göteborg nicht, auch Kulturbuset zum Beispiel ist in dieser modernen Industrieoptik gehalten. ${ }^{859}$ Bürgerliche Präsentationsräume, die die älteren deutschen Literaturhäuser nutzen, gibt es in Schweden nicht. An der Einrichtung wird also nicht so sehr ein Spezifikum von Göteborgs Litteraturbus ersichtlich, vielmehr offenbart sie im Kontrast zu den deutschen Einrichtungen einen Unterschied des deutschen zum schwedischen Kulturbereich. Dies wird durch die komparative Perspektive ersichtlich.

Ein regelmäßig geöffnetes Café, das ohne literarische Ambitionen besucht werden könnte, gibt es im Göteborger Literaturhaus nicht - das Restaurant Lagerbuset ist zwar nebenan, arbeitet aber nicht direkt mit dem Literaturhaus zusammen. Bei Veranstaltungen werden - ähnlich wie im Literarischen Zentrum Göttingen - Getränke ausgeschenkt, beim Besuch von Ett (inte helt) enkelt rum stehen Kaffeeküche und WLAN zur Verfügung. Göteborgs Litteraturhus lädt also im Unterschied zu vielen anderen Literaturhäusern nur zu fika [Kaffeepause] ein, wenn es Literatur einbezieht.

\section{8.2.4 Göteborgs Litteraturhus - Weiterentwicklung und Organisation}

Wie geplant fand nach ungefähr einem Jahr eine Evaluation statt und daraufhin ergab sich tatsächlich eine Veränderung: Seit Oktober 2014 wirkt die zweite Version der Literaturhaus-Organisation: Göteborgs Litteraturbus. Die Umbenennung ist begründet, weil sich nun hinter dieser Bezeichnung ein neuer Verein verbirgt. Während die erste Version die typische Reihenfolge von Literaturhaus und dem Stadtnamen innehatte, findet die zweite Variante eine neue Kombination, indem es die

\footnotetext{
858 Außerdem darf bei diesen Überlegungen nicht vergessen werden, dass die deutschen Literaturhäuser im Durchschnitt 20 Jahre vor dem Göteborger Literaturhaus eröffneten; die Entstehungszeit hinterlässt langfristig ihre Spuren in den Einrichtungen. Vielleicht wäre das Literaturbaus Hamburg auch der Designmode der 2010er-Jahre gefolgt, wenn es erst dann gegründet worden wäre.

${ }^{859}$ Schon für die norwegischen Literaturhäuser wurde hier auf das skandinavische funktionale Design mit hochwertigen Materialien verwiesen, vgl. FN 780.
} 
Stadt voranstellt. Weiterhin vorerst kommunal mitfinanziert, betreibt es die ideelle Vereinigung Göteborgs Litteraturbus. Zunächst erhielt diese noch die für das Litteraturbuset Göteborg in den Stadthaushalt eingestellten Mittel, für die Folgezeit beantragte sie als Einrichtung des freien Kulturlebens erfolgreich verksambetsstöd [institutionelle Förderung]. Es wird somit in Vereinsträgerschaft nicht gänzlich kommunal fortgeführt. ${ }^{860}$

Im Vergleich zu den anderen Literaturhäusern ist das Besondere an diesem Verein, dass die Mitglieder andere kollektive Akteur*innen des Literaturbetriebs sind, die schon vorher Literaturveranstaltungen organisierten beziehungsweise Interesse haben, dies zu tun. Werden sie aufgenommen, zahlen sie einen Jahresbeitrag in Höhe von 1.000 Schwedischen Kronen [circa 100 Euro] und können dafür unter anderem die Räume und die Bühne im Lagerhuset kostenlos nutzen; Ende 2017 waren es 51 Mitgliedsorganisationen. ${ }^{861}$ Die Vereinsmitglieder tragen in Göteborg aktiv zur inhaltlichen Mitgestaltung des Literaturhauses bei. Diese Konstellation ist eine Weiterführung der ersten Literaturhaus-Umsetzung in Göteborg; stärker noch als mit der Beteiligung der Stadsbiblioteket werden auf diese Weise die bereits literarisch produktiven Akteur*innen präsentiert. Durch die Vorteile für Mitglieder stellt sich Göteborgs Litteraturbus zudem als Anlaufstelle für Literaturschaffende respektive Literaturvermittler dar, die Beratungen anbietet und gegebenenfalls Projekte der Mitglieder finanziell unterstützt. Und die Mitgliedsorganisationen gestalten mit ihren Veranstaltungen das Programm des Literaturhauses aktiv mit. Den anderen Hauptteil des Veranstaltungsangebots machen Kooperationen von Göteborgs Litteraturbus mit anderen Organisationen aus, bei denen der Verein vor allem die Infrastruktur beisteuert.

Die Mehrheit der Veranstaltungen wird von den Mitarbeitern des Literaturhauses nicht inhaltlich verantwortet. ${ }^{862}$ Die Auswahl des Programms entscheidet sich stark über die Aufnahme von Mitgliedern, deren Veranstaltungen - Selbstaussagen zufolge - das Fundament der Arbeit des Literaturhauses bilden. Die Veranstaltungen des künstlerischen Leiters sind nur ein Teil des Ganzen und werden nicht gesondert herausgestellt. Dies markiert Offenheit anderen Ideen gegenüber. Außerdem ist dadurch mehr Aktivität im Literaturhaus gewährleistet, weil zwei Angestellte - noch dazu in Teilzeit wirkende - nicht so ein umfassendes Programm umsetzen könnten. Dieses Literaturhaus entwickelt zu den bisher kennengelernten Optionen für die Durchführung von Veranstaltungen - erstens eigenes Programm der Leitung, zweitens Kooperationen und drittens externe Veranstaltungen - eine vierte: von Mitgliedern organisierte Angebote.

$860 \mathrm{Vgl}$. Rosengren und Ulin 2015.

861 Vgl. Verksambetsberättelse 2017 2018, S. 3.

862 Der Jahresbericht des Vereins vermeldet für 2015206 Veranstaltungen, davon 116 von den Mitgliedern organisiert, 41 von Kooperationspartnern, 36 von externen Mietern und nur 13, das heißt 6\% von Göteborgs Litteraturbus allein angebotene, vgl. Gräsberg und Ljusberg 2016, S. 8. Dies war auch schon bei der ersten Version in Göteborg der Fall, dort wurden alle Veranstaltungen lediglich im Einvernehmen mit Litteraturhuset Göteborg organisiert. Auch bei der ersten Variante trat Litteraturbuset Göteborg bei den im Betriebsjahr insgesamt 120 Angeboten in den seltensten Fällen als Hauptveranstalter auf. Die erste Version bot genau ein Jahr Programm an, von Oktober 2013 bis Ende September 2014. Die Veranstaltungen wurden auf dem Blog der Stadsbiblioteket angekündigt, ein eigenes Programmheft gab es nicht, vgl. Sandell: „Litteraturhuset våren“. 
In der gleichberechtigen Positionierung des Programms unterschiedlicher Veranstalter manifestiert sich ein markanter Unterschied insbesondere zu den deutschen Literaturhäusern. Die direkte Integration von verschiedenen Literaturveranstaltern im Göteborger Modell stellt eine Weiterführung der skandinavischen LiteraturhausIdee dar, als Träger des Literaturhauses nicht so sehr selbst Programmarbeit zu leisten, sondern vielfältige Angebote diverser Anbieter zuzulassen. In Göteborgs Litteraturbus zahlt die Mehrzahl der Veranstalter einen jährlichen Beitrag, nicht aber explizit Miete für die Nutzung der Räume, und wird als Bestandteil der Einrichtung verstanden.

Der Verein hat zwei in Teilzeit Angestellte: Die Geschäftsführerin Sofia Gräsberg (*1979) ist neben ihrer Arbeit im Literaturhaus Institutschefin von Litterär gestaltning, sie hat bei Internationell författarscen Göteborg und Göteborgs Poesifestival mitgearbeitet. Seit 2015 gibt es außerdem einen künstlerischen Leiter. Von 2015 bis 2018 hatte der Däne Jesper Brygger (*1974) diese Position inne, vorher war er vor allem als Autor und Übersetzer tätig. Er hat in Göteborg Litterär gestaltning studiert und publiziert auf Dänisch Lyrik und Prosa. Ab August 2018 übernahm Olav Fumarola Unsgaard, vorher vor allem als Journalist tätig, die Rolle. Nach der Bibliotheksvariante übernahmen also zwei Personen die Leitung des Literaturhauses, die aus der literarischen Szene Göteborgs kommen. Die Geschäftsführerin ist im Veranstaltungsbetrieb erfahren. Der erste künstlerische Leiter kannte sich insbesondere in der gegenwärtigen dänischen und schwedischen Literatur sehr gut aus, der zweite kam über das politische Engagement des Literaturhauses zu Göteborgs Litteraturbus. Ob dieser Leitungswechsel mit einer Neuausrichtung des Literaturhauses einhergeht, ist zu vermuten, weil er andeutet, dass das Literaturhaus sich in Zukunft noch stärker für die demokratische Kraft von Literatur einsetzen wird.

Die erste Version des Literaturhauses bot keine eigenen Veranstaltungen an - abgesehen von einer offenen Bühne, die sich als hierarchielose Literaturförderung in der Stadt verstehen lässt. ${ }^{863}$ Göteborgs Litteraturbus wartet, seit es einen künstlerischen Leiter hat, mit einem eigenen Programm auf, im eigentlichen Untersuchungszeitraum dieser Arbeit finden noch nicht viele eigene Litteraturbus-Veranstaltungen statt. Für die inhaltliche Ausrichtung von Göteborgs Litteraturhus bemerkenswert ist etwa HÄR, NU - nedslag i svensk samtidspoesi [HIER, JETZT - Aufschläge in schwedischer Gegenwartspoesie] ${ }^{864}$. Diese Reihe, die schwedische Poesie vorstellte, spiegelte Jesper Bryggers Interesse an gegenwärtiger Lyrik. Anfang 2016 begann das Literaturhaus die Reihe Klubb Söndag, die neue Stimmen der Göteborger Literaturszene präsentiert und die Begegnung von „etablerade och icke-etablerade litterära utövare och arrangörer" (GB 2016-01-10) [etablierten und nicht-etablierten literarischen Praktizierenden und Veranstaltern] fördern solle.

Auch gegenwärtige Literaturbetriebsdiskussionen werden kurzfristig aufgegriffen: Mit Vi måste tala om Bokmässan [Wir müssen über die Buchmesse reden] reagierten

\footnotetext{
${ }^{863}$ Die Informationen zu den Veranstaltungen sind den Texten des Blogs der Stadsbiblioteket entnommen, vgl. ebd. Auf der Website wmw.goteborgslitteraturbus.se finden sich im Programmarchiv die Hinweise zu den Veranstaltungen von Götebogs Litteraturhus ab Herbst 2014. Gedruckte Programmhefte liegen nicht vor. ${ }^{864}$,Nedslag' bedeutet auch ,Anschlag einer Schreibmaschine', Aufprall, Einschlag.
} 
die Verantwortlichen zügig auf die Debatten um die Teilnahme antidemokratischer und rassistischer Aussteller*innen auf der Buchmesse 2016 (GB 2016-10-19). Im Jahr darauf engagierte sich die Einrichtung für eine Alternative zur Buchmesse und initiierte zusammen mit Världskulturmuseet die Idee zu Scener \& Samtal [Bühnen/Szenen \& Gespräche], das an zwei Tagen parallel zur Buchmesse im September stattfand: Das Motto „Litteraturen är på samma gång stark \& sårbar. [...] Vilken roll kan litteraturen spela här \& nu? “865 [Die Literatur ist zugleich stark und verletzbar. [...] Welche Rolle kann die Literatur hier und jetzt spielen?] war der Ausgangspunkt 2017. Die Fortsetzung fand im September 2018 statt. Es bleibt also zu beobachten, in welche Richtung sich das Programm entwickelt.

\section{8.2.5 Göteborgs Litteraturhus und die Institution Literaturhaus}

Das Projekt ,Litteraturhuset' in Göteborg war zu Beginn in kommunaler Verwaltung und musste dementsprechend einen öffentlichen Auftrag erfüllen. Mit der Entscheidung für die Positionierung im Lagerhuset markierten die Initiator*innen gerade eine Unterstützung der freien Literaturszene, der Literatur als Kunstform, der Neuproduktion von Literatur. Dabei wurde Wert daraufgelegt, kein völlig neues Konzept zu etablieren und somit keine zusätzliche Konkurrenz für das Bestehende anzudrohen. Kulturpolitisch gesehen ist dies eine vernünftige Entscheidung, denn damit sieht es so aus, als ob niemandem Mittel, weder Geld noch Aufmerksamkeit, entzogen werden und parallel kann das Label ,Literaturhaus‘ ein wichtiges Instrument für die Vermarktung als Literaturstadt sein. An Göteborgs Litteraturbus ist momentan die tatsächliche Programmarbeit für einen wissenschaftlichen Überblick weniger produktiv als die hier analysierten Absichtserklärungen. Zu diesem relativ frühen Zeitpunkt, speziell aufgrund der Umstrukturierung, sind besonders die Pläne zum Literaturhaus aufschlussreich, die aus diesem Grund in diesem Kapitel hauptsächlich verwendet wurden. Die strategischen Überlegungen zur Initiierung oder Neuordnung eines Literaturhauses spiegeln zentrale Punkte, die der Institution von den Literaturhaus-Akteur*innen zugerechnet werden. Wie anhand der acht Teilkapitel zu den Beispielen deutlich wurde, sind die verschiedenen Debatten, die über das jeweilige Literaturhaus geführt werden, für das Verständnis des Einzelfalls - und im abstrahierenden Schritt für die Institution - von großer Bedeutung. Das Literaturhaus ist nicht losgelöst von kulturpolitischen Überlegungen, kultursozialen Befindlichkeiten, finanziellen Belangen oder personalen Entscheidungen zu betrachten. Die Falldiskussionen haben bis hierher auch offenbart, dass das Literaturhaus an unterschiedlichen Debatten teilnimmt, die ihrerseits die Wahrnehmung der Einrichtungen von außen prägen.

Es zeigt sich am Beispiel Göteborgs, wie der Transfer des Konzeptes dafür sorgen kann, dass sich die späteren Ausführungen weiter von der Ursprungsinstitution entfernen. Auf diese Weise wird die Bandbreite der Dachmarke ,Literaturhaus' ersichtlich. Das Literaturhaus wird in der vorliegenden Arbeit ausgehend von den deut-

865 „Scener och samtal 2017. Program“, Göteborgs Litteraturhus. URL: goteborgslitteraturhus.se/scenerochsamtal/\#program (Stand: 30.08.2018). 
schen Literaturhäusern als Gefüge gedeutet, bei dem das Kuratieren eines bestimmten literarischen Programms die Hauptarbeit ausmacht. Der Vergleich des Göteborgers insbesondere mit den deutschen und den norwegischen Literaturhäusern ist damit nicht so sehr im inhaltlichen als mehr im strukturellen Detail lohnend.

\section{8.3 Zwischenfazit - Literaturhäuser in Deutschland, Norwegen, Dänemark und Schweden}

Die Beschäftigung mit dem Literaturhaus in Göteborg zeigt, dass es nicht so eine sofortig durchschlagende Kraft hatte wie Litteraturbuset in Oslo. Aufgrund der Ausstattung war dies für Litteraturbuset Göteborg/Göteborgs Litteraturbus von Anfang an vorhergesagt worden: ,[D]et tar tid att ta språnget från kvalitet till volym. Bäst, alltså att börja i mindre skala. "866 [Es braucht Zeit, den Sprung von Qualität zu Volumen zu schaffen. Das Beste ist also, kleiner zu beginnen.] Es gab folglich gar nicht den Anspruch, das Literaturhaus für Schweden zu sein - es ist noch in der Entwicklung. Wie bereits zu Beginn des Kapitels eingeführt, setzte sich das Literaturhaus in Schweden insgesamt nicht in gleicher Weise als Dachmarke durch wie in Norwegen.

Det kan være vanskeligere å forstå hvorfor noe griper om seg og blir populært i noen land, for eksempel Norge og Tyskland, men ikke slår særlig an i land vi ellers har det aller meste til felles med, for eksempel Sverige og Danmark. Littersturhusbølgen som vi de siste årene har opplevd i Norge, er et slikt fenomen. ${ }^{867}$

[Es kann schwieriger sein zu verstehen, warum etwas um sich greift und in einem Land populär wird, zum Beispiel in Norwegen und Deutschland, aber nicht so gut ankommt in Ländern, mit denen wir sonst das Allermeiste gemein haben, zum Beispiel Schweden und Dänemark. Die Literaturhaus-Welle, die wir in den letzten Jahren in Norwegen erlebt haben, ist ein derartige Phänomen.]

Neben personenabhängigem individuellem Engagement und einer üppigen Finanzierung sorgte die solide Unterstützung durch Fritt Ord dafür, dass Litteraturbuset in Oslo von Beginn an als Erfolgsgeschichte präsentiert werden konnte. Da es seit der Eröffnung professionell strukturiert und öffentlichkeitswirksam arbeitete, konnte es leichter als Vorbild gedeutet werden als das auf Initiative und mit dem Engagement einer Einzelperson betriebene LiteraturHaus in Kopenhagen. Aufmerksamkeitswirksames Auftreten und ein solides Budget tragen entscheidend zum Gelingen eines Unternehmens bei, doch bedarf es auch - um im ökonomischen Vokabular zu bleiben - eines Produktes, das eine Marktlücke füllt, respektive ein Bedürfnis befriedigt, von dem die Konsument*innen möglicherweise noch nicht wussten, dass sie es überhaupt haben. Anschließend an Ragnar Audunson ist zu vermuten, dass die Idee des Literaturhauses in Oslo sich unter anderem deshalb durchsetzen konnte, weil das Angebot im Literaturveranstaltungsbetrieb bisher noch nicht ausreichte. Finanzielle Hürden und vor allem starke andere Kulturinstitutionen in Schweden sorgen dafür, dass das Literaturhaus dort ein marginales Phänomen bleibt. Auch Audunson sieht die Stellung der Bibliotheken als einen triftigen Grund dafür, dass sich das Literaturhaus in den skandinavischen Ländern unterschiedlich durchgesetzt hat. Ihm

866 Elam 2011, S. 16.

867 Audunson 2014, S. 22. 
zufolge haben die Bibliotheken in Schweden und Dänemark eine höhere Präsenz als in Norwegen. Die enge Verbindung zur Bibliothek veranschaulicht das Göteborger Beispiel ebenfalls.

Bisher wurde verallgemeinernd von ,Skandinavien' gesprochen, doch strebt diese auslandsskandinavistische Arbeit eine angemessen differenzierte Betrachtung Skandinaviens an. Lässt sich hinsichtlich des Literaturhauses von einem homogenen skandinavischen Konzept sprechen oder müssen nationale Differenzen doch stärker gemacht werden? Allein die Zahlen sprechen dafür: Während in Kopenhagen neue Einrichtungen das Literaturhaus-Modell auf den Prüfstand stellen, und in Schweden vor allem in Göteborg die kleine Variante aktiv ist, hat Litteraturhuset in Oslo sich so durchgesetzt, dass es mehrere Nachahmer gefunden hat. So zeigt sich, dass es im Detail zu verallgemeinernd ist, alle drei Länder gleichzusetzen, weil die Voraussetzungen doch andere sind. Dies hat für die vorliegende Arbeit methodische Konsequenzen: Es führt dazu, dass das Hauptaugenmerk vor allem bei der Programmanalyse auf den norwegischen Literaturhäusern als skandinavisches Beispiel liegt. Die Konzentration auf Oslo und Bergen ist eine pragmatische Entscheidung, weil diese Einrichtungen schon im Untersuchungszeitraum bis einschließlich 2015 so weit gefestigt waren und weiterhin etabliert sind, dass sie hier analysierbar sind. Die Berücksichtigung der Literaturhäuser in Dänemark und Schweden in dieser Studie fungiert mehr als Einordnung der norwegischen Einrichtungen in den nationalen, den skandinavischen und den internationalen Gesamtkontext - mit notwendiger Sensibilität für norwegische respektive Osloer und Bergener Besonderheiten.

Die norwegische ,Literaturhaus-Welle‘ ebbt ab. Dies bezeugte bereits die im vorherigen Kapitel dargestellte Entwicklung in Norwegen, wo beispielsweise die Bibliotheken stärker Funktionen einnehmen, die einem Literaturhaus zugeschrieben werden. So gesehen bringt das Literaturhaus andere Institutionen in Bewegung und der Literaturveranstaltungsbetrieb in Schweden ist wie in den anderen untersuchten Ländern in den letzten Jahren vitaler geworden.

\section{9 Selbstdarstellungstexte}

Die Selbstpräsentationen der Literaturhäuser spielen für die Konstruktion der Institution eine wichtige Rolle, weil der kommunizierte Anspruch zum Gesamteindruck beiträgt. In Gesprächen nennen die Literaturhäuser Charakteristika wie Ungefälligkeit, Unvorhersehbarkeit, Kreativität, Kritik, Offenheit (für alle), Bildung, Austausch, Begegnung, Relevanz, Sprache und Ästhetik, also vor allem kulturpolitischstrategische, legitimierende oder als von ihnen erwartet angenommene Aspekte. ${ }^{868}$ Derartige Antworten sind von Experteninterviews mit der jeweiligen Programmleitung zu erwarten. Doch wie stellen sie sich der Öffentlichkeit tatsächlich dar? Im Folgenden stehen exemplarisch die Eigendarstellungen auf der Website im Fokus. Sie werden der hier gewählten Textsortenbezeichnung ,Selbstdarstellungstexte ent-

868 Aus zum Teil informellen Gesprächen mit Akteur*innen des Literaturhauses. 
sprchend untersucht und sie kommunizieren explizit und implizit das Selbstverständnis der Einrichtungen. Auf allen Websites der ausgewählten Literaturhäuser finden sich, zunächst mit Ausnahme von Litteraturbuset Bergen, Texte über die jeweilige Einrichtung. ${ }^{869}$ Diese bilden das überschaubare Korpus (Stand Winter 2015/2016) für die folgende Dokumentenanalyse. ${ }^{870}$ Sie unterstützt die Annahme, das Literaturhaus in einem weiteren Sinne als Ort, als ,umfassendes Literaturhaus‘, und in einem engeren Sinne als Literaturvermittler zu verstehen.

\section{9.1 Kontext, Verortung und Adressierung}

Der Kontext, in dem die Selbstdarstellungstexte erscheinen, muss berücksichtigt werden. Sie richten sich in erster Linie an Veranstaltungsbesucher*innen, aber auch an Interessierte, die sich allgemein über die Einrichtung informieren wollen - beispielsweise potenzielle Mitarbeiter*innen - an Kooperationspartner*innen oder Förder*innen, an Autor*innen oder Verlage. Sie fungieren als Informationstexte und erfüllen ebenso eine werbende Funktion. Das Literaturhaus wird darin zum Objekt, über das meist in der dritten Person Singular gesprochen wird. Einzig im Literaturbaus Berlin steht zweimal „uns“ und einmal „wir“", im Litteraturbuset in Oslo und in Göteborgs Litteraturbus findet sich je an einer Stelle das Personalpronomen „vi“ [wir] und in Göteborg richten sich die erwähnten Aufnahmebedingungen direkt an interessierte Neumitglieder. Besonders beim Literaturhaus in Göteborg fällt für den restlichen Text ein unpersönlicher Stil mit vielen Passivkonstruktionen auf. Anders ist dies bei den Fällen, in denen auf der Startseite zusätzlich eine Kurzbeschreibung steht, beim Beispiel aus Göttingen, Kopenhagen und Frankfurt. Dort laden die Texte aus Göttingen und Kopenhagen die Besucher*innen konkret ein, weil sie die Adressat*innen direkt mit „Sie“ oder „du“ sprechen und mit „Seien Sie unsre Gäste wir freuen uns auf Sie!“ (GT1) und „God fornøjelse!“ (KH1) [Viel Vergnügen!] willkommen heißen. In Frankfurt macht der kurze Text deutlich, dass die Zuschauer*innen ein notwendiger Bestandteil des Hauses sind und dass Literaturhaus und Publikum sind ,wie die Bücher selbst: vielschichtig und vielseitig“. Dieser Text richtet sich eher wie die ,Begrüßungstexte ${ }^{`}$ an potenzielle Besucher*innen der Veranstaltungen (FF1). Schon die Einleitung des Textes „Wer Bücher liebt, weiß, dass alles an ihnen interessant ist" (FF1) bezieht die Leser*innen indirekt in diese Zuschauergruppe ein. Sie suggeriert, dass die Leser*innen des Textes eben Bücherliebhaber*innen sind und dementsprechend die nachfolgende Aufzählung der an Büchern interessanten Aspekte nachvollziehen können. Willkommen geheißen werden die Gäste tendenziell in allen untersuchten Texten. Trotz der beschriebenen sachlichen Hinwendung an die Leser*innen präsentieren sich die Literaturhäuser als offene

\footnotetext{
${ }^{869}$ Zur Dokumentation der Bezugstexte sind diese im Anhang mit den hier verwendeten Siglen aufgeführt, vgl. Anhang V 1.2. Zu den Internetauftritten der Literaturhäuser vgl. Kapitel II 12.

${ }^{870}$ Die Bedeutung dieser Über-uns-Texte auf den Websites zeigt sich auch daran, dass das Literaturhaus in Bergen im Januar 2016 keinen publizierte, inzwischen findet sich jedoch unter ,Kontakt ${ }^{`}$ ein kurzer informativer Absatz. Da die anderen Texte aber mit dem ursprünglichen Stand untersucht werden, findet dieser neuere Text keinen direkten Eingang in dieses Kapitel, der damalige Vorstellungssatz auf Facebook ist stattdessen einbezogen. Das Problem ist andernfalls, dass die anderen Beispieltexte ebenfalls in aktualisierten, sich hin und wieder ändernden Fassungen betrachtet werden müssten. Ihr Tenor bleibt allerdings gleich, sodass die Ergebnisse der Momentaufnahme aus dem Winter 2016 nicht überholt sind.
} 
Orte der Literaturvermittlung - mit graduellen Unterschieden hinsichtlich der Emotionalität des Geschriebenen.

Das Literaturhaus Berlin macht auf die Entwicklung des Literaturhauses aufmerksam: „Damals [in den Gründungsjahren des Literaturhauses; Anmerkung C. L.] galt der Name des Hauses als erklärungsbedürftig, inzwischen ist er zum Begriff geworden“ (BE). Die Literaturhäuser Hamburg und Frankfurt reihen sich in ihren Texten nicht in eine Literaturhaus-,Tradition' ein, sondern betonen ihre Besonderheit; die Einrichtung in Hamburg wurde „[e]rdacht im Jahre 1985 von literaturbegeisterten Hanseaten“ (HH), und die in Frankfurt „war für eine Gruppe engagierter Frankfurter Bürger 1989 ein Projekt mit Zukunft" (FF2). Das Literarische Zentrum Göttingen bezieht sich im Text auf die Zugehörigkeit zum Netzwerk der Literaturbäuser. Es platziert sich damit in den Literaturhaus-Kontext; ein Bestreben, das für diese Einrichtung aufgrund des Namens eine andere Notwendigkeit hat als für die explizit ,Literaturhaus' genannten Organisationen.

Für die Transferperspektive ist wichtig anzumerken, dass die Literaturhäuser Kopenhagen und Oslo in diesen relativ kurzen Texten ihren Anschluss an die deutsche Institution anführen. Oslo erwähnt, dass das Haus von einer deutschen Tradition der freien Literaturhäuser inspiriert sei (OL2) und Kopenhagen schreibt, dass die Literaturhaus-Idee ihre Wurzeln in Deutschland habe, wo es heute rund zwanzig gut etablierte Einrichtungen gebe (KH2). Kopenhagen und Oslo waren die ersten Versionen eines Literaturhauses in Skandinavien. Der Bezug zum deutschen ,Modell' stellt ein Mittel zur Legitimation dar und ermöglicht eine dezidierte Einordnung in einen übernationalen Kontext. ${ }^{871}$ Litthusbergen stellt keine textliche Verbindung zum Osloer Konterpart her und auch Göteborg erwähnt keine Vorbilder. Es ist $\mathrm{zu}$ vermuten, dass die nachfolgenden Einrichtungen diese Einreihung in eine Tradition nicht mehr benötigen, weil bekannt ist, was ein Literaturhaus ist beziehungsweise sein kann.

\section{9.2 Literaturhaus als Gebäude}

Anhand der untersuchten Texte lässt sich belegen, dass die Literaturhäuser sich einerseits als Literaturvermittlungseinrichtung darstellen und andererseits das Gebäude als Ganzes in den Blick gerät. Die Fälle, die das ,Haus' im Namen tragen, also alle außer dem Literarischen Zentrum Göttingen, gehen in ihren Darstellungen auf das Gebäude ein. Das Bild des Hauses wird in den Texten unterschiedlich ausgespielt. Im Literaturhaus Hamburg ist gar von „Heimat“ die Rede. Auch das LiteraturHaus in Kopenhagen ist bezeichnet als „litteraturens tiltrængte hjemsted“ [der passende Heimatort der Literatur].

Die Relevanz des Gebäudes für das Literaturhaus zeigt sich schon bei der Textaufteilung auf den Websites: Während in Berlin und Kopenhagen unter dem Reiter ,Haus', der Unterpunkt ,Geschichte' beziehungsweise ,Om LiteraturHaus Auskunft über Träger und Gebäude gibt, unterscheidet das Literaturhaus Hamburg unter dem Reiter ,Haus` die Subpunkte ,Das Literaturhaus', was die Präsenz des

${ }^{871}$ Vgl. Kapitel II 6.2. 
Ortes einbezieht und hier die Textgrundlage bildet, und ,Geschichte', was sich auf die Geschichte des Gebäudes bezieht. Das Literaturbaus Frankfurt trennt zwar noch einmal strikter zwischen der Geschichte der Alten Stadtbibliothek und dem Literaturhaus-Verein, doch unter ,Haus' gibt es mit dem als ,pro domo' betitelten Text eine Zusammenfassung beider Aspekte, die das Motto „Eine Institution wie ein Buch. Das Literaturhaus hat viele Seiten und befindet sich seit 2005 in dem neu errichteten Gebäude der Alten Stadtbibliothek" ${ }^{872}$ vertieft. Auch in Kopenhagen findet die ehemalige Bestimmung des Literaturhauses explizit Erwähnung: Die frühere Methodistenkirche im Stadtteil Nørrebro kommt sowohl im Begrüßungstext als auch in der ausführlicheren Version der Selbstdarstellung vor. Hier wird eine direkte Einflussnahme des physischen Raumes - „[d]e fysiske rammer med den højloftede sal i kirkerummet“ (KH2) [die physischen Rahmen mit den hohen Decken im Saal des Kirchenraumes] - auf die Atmosphäre des Literaturortes gesehen - „er med til at skabe en god og anderledes atmosfære til husets mange arrangementer" (KH2) [wirken mit, eine gute und andere Atmosphäre für die vielen Veranstaltungen des Hauses zu schaffen]. Neben dem ehemals sakralen Raum trägt das intime Café im Keller zu diesem Eindruck bei. Beim Litteraturhuset in Oslo verweist der kurze Text auf der Startseite zumindest darauf, dass es in „Oslos gamle lærerskole“ (OL1) [in Oslos alter Lehrerschule] situiert ist. Klar wird bereits in diesem Zweizeiler, dass das gesamte Haus im Wergelandsveien 29 vom Keller zum Dachgeschoss der Literatur im weitesten Sinne gewidmet sei. Damit steht die Adresse synonym für das Literaturhaus der Stadt, was auch in den anderen Einrichtungen vorkommt. In Göteborg wird nicht so sehr auf die längere Historie des Lagerbuset hingewiesen, sondern darauf, dass dieser Bau schon seit den 1990er-Jahren als Arbeitsplatz rund um die Literatur genutzt wird. Es geht also nicht so sehr darum, den Ort in seiner historisch vielseitigen Nutzung zu präsentieren, wie in Berlin, nicht darum, sein repräsentatives und ,prächtiges' Gewicht zu betonen, wie in Frankfurt, oder den Bruch zwischen ehemaliger und heutiger Nutzung herauszustellen, wie in Kopenhagen, sondern zu verdeutlichen, dass die Göteborger Auslegung des Konzepts ,Literaturhaus‘ als Netzwerk und Plattform für die literarische Landschaft der Stadt an diesem Ort seinen berechtigten, gar ,logischen' Platz hat.

Die Literaturhäuser verstehen sich in den untersuchten Texten nicht als ,heilige Hallen'. Bei den Selbstbeschreibungen des Ortes kann für die untersuchten Literaturhäuser kein Vergleich mit einer Kirche oder einem Tempel herausgestellt werden, den die gewünschte konzentrierte Atmosphäre, die Begegnung mit Gleichgesinnten oder die durchdachte Gestaltung des Raumes als Indikatoren für eine kirchenhafte Semantisierung nahelegen. ${ }^{873}$ LiteraturHaus bildet keine Ausnahme, denn dort ist der erwähnte Kirchenverweis kein Vergleich, sondern eine Referenz zur tatsächlichen früheren Nutzung des Ortes.

Es ist festzuhalten, dass die untersuchten Literaturhäuser ihrer oft historisch aufgeladenen Bauwerke als Räume mitprägen und die Ort-Raum-Besetzung unmittelbar an ihrem Selbstverständnis mitwirkt. Auf die eigene Geschichte gehen alle Literaturhäuser zumindest in der Form ein, dass das Gründungsjahr genannt wird.

872 „Haus“, Literaturhaus Frankfurt. URL: literaturhaus-frankfurt.de/haus/ (Stand: 30.08.2018).

${ }^{873}$ Vgl. Kapitel I 1, S. 25. 


\section{9.3 Treffpunkt als Begegnung - Debatte - Netzwerk}

Das Literarische Zentrum Göttingen bildet eine Ausnahme, indem es nicht auf die Geschichte des Gebäudes verweist. Dies verwundert nicht, weil es mit seinem Namen einen anderen Schwerpunkt legt. In seinen Texten argumentiert es dennoch deutlich für den Ort als „Schnittstelle“, als „Treffpunkt“ und insbesondere als „begehbares Feuilleton“ (GT2). Schon in der Überschrift „Literatur braucht Orte!“ (GT1) offenbart sich, dass hier zwar nicht von einem physischen Haus, so doch von einem Konzept als Begegnungsort die Rede ist. Abgesehen davon also, dass nicht explizit auf die tatsächliche Lage in der Stadt und auf das Haus als Gebäude eingegangen wird, deutet der Text das Zentrum trotzdem eindeutig als Ort, der in diesem Sinne ein ,Literaturhaus' ist. In dieser Hinsicht ist es nicht mehr Exzeption, sondern Regelfall: In allen untersuchten Literaturhaus-Texten spielt die Wirkung des Ortes und ihr Einfluss auf das, was als Literaturhaus bezeichnet wird, eine zentrale Rolle. Einerseits wird die Atmosphäre stark betont, andrerseits die Interpretation als Stätte der Begegnung, des Austausches, des Netzwerks - drei Dimensionen, die gleich mit unterschiedlichen Schwerpunkten näher beleuchtet werden. Oft werden diese Aspekte zusammengefasst, indem das Literaturhaus als angenehmer, offener Begegnungsort für kulturellen Austausch in der Stadt bezeichnet wird, wie für Göttingen schon gezeigt. Das Literaturhaus Berlin ist „zusammen mit der Buchhandlung und dem Café-Restaurant ein lebendiges, urbanes Zentrum literarischen Lebens“, das Literaturhaus Hamburg „Mittelpunkt des literarischen Lebens in der Hansestadt“ mit überregionaler Relevanz.

In allen Fällen wird das Literaturhaus als Zentrale, als Ort des Austausches verstanden. Eine Auslegung, die das Literarische Zentrum Göttingen im Namen trägt und die anderen im Text vermitteln. Dieses Verständnis als Mittelpunkt manifestiert eine angenommene Vorrangstellung, die unterstützt wird durch Superlative und Worte, die Einzigartigkeit ausdrücken, zum Beispiel stellt sich hier das Kopenhagener Haus als „Danmarks eneste litteraturhus“ (KH1) [Dänemarks einziges Literaturhaus] vor, das Literaturhaus Frankfurt veranstaltet „das bundesweit einzige kritische Diskussionspodium zum Hörbuch“ und Litteraturbuset in Oslo ist „Europas største litteraturhus“ (OL2) [Europas größtes Literaturhaus]. Diese Relevanz der Einrichtung wird zusätzlich betont durch Konsekrationsmarker, zum Beispiel anerkannte Mitgliedschaften wie die Erwähnung, dass das Literarische Zentrum seit 2015 Mitglied im Netzwerk der Literaturbäuser ist (GT1), Preise wie „2005 erhielt das Literaturhaus Frankfurt den ,Binding-Kulturpreis‘ für seine Aktivitäten und seine Bedeutung für das kulturelle Leben in der Stadt Frankfurt" (FF2) sowie hohe Mitgliederziffern und Besucherzahlen wie „årleg vitjar meir enn 250.000 huset“ (OL2) [jährlich besuchen mehr als 250.000 das Haus].

\section{Begegnung als Erleben}

Der Satz oder gar Slogan „Wer still liest, folgt einem Autor. Wer ins Literaturhaus geht, trifft ihn auch.“ (FF1) fasst eine wichtige Eigenart des Literaturhauses zusammen, die in den untersuchten Texten vorhanden ist, aber - anders als erwartet - 
nicht so deutlich herausgestellt wird wie in dem Zitat aus Frankfurt. Das glaubwürdige Aufeinandertreffen mit Autor*innen bildet einen wichtigen Faktor für den Erfolg des Literaturhauses, doch in der Selbstdarstellung der ausgewählten Literaturhäuser ist diese Bedeutung so nicht zu erkennen. In Göteborg und Oslo spielt diese physische Präsenz einer Autorpersona keinerlei Rolle im Text. Auch in Kopenhagen wird eher ein Aufeinandertreffen auf Augenhöhe, wird der Dialog zwischen Rezipient*innen und Produzent*innen angebracht. Fan- beziehungsweise Starallüren finden somit, den Selbstpräsentationen zufolge, im Literaturhaus wenig Platz. Der Gast „trifft“ (FF1) Schreibende und Lesende, was recht neutral formuliert ist.

Damit verbunden ist die Beobachtung, dass wenige Vokabeln die tatsächlichen räumlichen Bedingungen für Inszenierungen kommunizieren. Ausnahme bilden Oslo, das von „hovudscena“ [Hauptbühne] und „fem scener“ (OL2) [fünf Bühnen] schreibt, und Göteborg, das kurz die von Göteborgs Stadsblibliotek benötigte externe Bühne nennt, die ein Anlass für die Umsetzung der Litteraturbus-Idee in der Stadt war. In Frankfurt wird zumindest auf „,vielfältigere und größere Veranstaltungsräume“ (FF2) des neuen Standorts verwiesen. Dass es eine Bühne gibt, wird eher implizit durch die Auflistung von Veranstaltungsformaten vermittelt, bei denen es sich um „öffentliche“ (BE) Veranstaltungen handelt. Es scheint keine Notwendigkeit gesehen zu werden, in diesen Darstellungstexten auf die Abläufe im Literaturhaus einzugehen. Es bleibt offen, ob Leser*innen, die noch nie dort waren, sich anhand dieser Texte eine Vorstellung von den Veranstaltungen machen können. Doch natürlich muss der Text in seinem Publikationskontext betrachtet werden, denn die Websites stellen noch weitere Informationen und Wirkungen dar.

Bei der Inspektion der Texte auf Formulierungen, die die performative Dimension des Literaturhauses unterstreichen, sind Worte zu erwarten, die das Erleben, die Erfahrung, das Emphatische ausdrücken, welche die Rezeption von Literatur im Literaturhaus von der stillen, solitären Lektüre unterscheiden. In Formatbenennungen wie ,Lesung، oder ,Performance' ist der Aufführungsaspekt von Literatur zwar inbegriffen, doch erstaunlicherweise wird das (Zu-)Hören auf Seite der Rezipient*innen respektive das (Vor-)Lesen auf Seite der Produzent*innen in keinen Text nachdrücklich einbezogen: ,Stimme ${ }^{6}$ und ,Klang ${ }^{6}$ kommen nicht vor. ${ }^{874}$

In Berlin wird am deutlichsten konstatiert, dass im Literaturhaus vor allem eine Begegnung mit Text stattfindet, dass die Akteur*innen dabei nur Mittler*innen sind. Vielmehr als den Texten Gehör zu verschaffen, produzieren die ausgewählten Literaturhäuser Öffentlichkeit (GT2), stellen Autor*innen, Bücher und Ideen vor (FF1), lassen ihre Neugier gelten (BE), bieten anregendes Klima $(\mathrm{HH})$ und eine Reihe Veranstaltungen (KH2), vermitteln Literatur und wecken Interesse für das Lesen (OL2), kooperieren und verbinden literarische Akteur*innen (GB). Literatur als Hörerlebnis ist nicht Teil der Selbstdarstellung, es geht um den Austausch, das Gespräch.

Damit, dass kein Hörerlebnis erwähnt ist, soll nicht gesagt sein, dass ein Erlebnisaspekt nicht vorkäme. Im Gegenteil: Die Antonomasie des Literaturhauses als „kulturelle Oase, wo es leicht fällt, sich wohlzufühlen“, denn „das Publikum liebt die gastfreundliche Atmosphäre, das anregende Klima und das anspruchsvolle literarische Programm“ (HH), die „lebendige Vermittlung“ (FF2), „kulturopplevelser“ (BG) [Kulturerlebnisse] und „oplevelser“ (KH2) [Erlebnisse] und die dänische Auf-

${ }^{874}$ Auch bei den Veranstaltungstexten ist dies nicht der Fall, vgl. Kapitel II 10.4.1. 
forderung „Kom tæt på litteraturen og oplev også musik, film og kunst etc. i litteraturens eget hus“ (KH1) [Kommen Sie der Literatur nah und erleben Sie auch Musik, Film und Kunst etc. im eigenen Haus der Literatur] bezeugen diese Erlebnisdimension. Es gilt auf Basis des Untersuchten nur Abstand zu nehmen von der Annahme, dass dieses Erleben in erster Linie mit einer Literatur-als-Kunst-Erfahrung zusammenhinge. Literatur ist im Literaturhaus geknüpft an eine ästhetische oder gesellschaftspolitische Auseinandersetzung, sie steht nicht für sich.

\section{Austausch zwischen Personen und über Themen}

Wie angedeutet lässt sich der Terminus, Austausch` in zwei Hinsichten anwenden.

(1.) Austausch als Begegnung: Es geht um den eher privaten zwischenmenschlichen Kontakt, der enger mit der oben genannten Begegnung verbunden ist. Der soziale Aspekt des Beisammenseins und die Verbindung von Freizeitbeschäftigung und literarischem Angebot werden dadurch betont, dass die Infrastruktur des Ortes mitkommuniziert wird. Das Literaturhaus wird, obwohl die Betreiber selten eins sind, auch verstanden als Hausgemeinschaft, die Café und Buchhandlung selbstverständlich integriert. Das Literarische Zentrum Göttingen erfüllt diese Idee, indem es sich als Ort versteht, „,der das Bedürfnis nach Austausch, nach Anregung zum Nachdenken ebenso erfüllen will wie jenes nach einem unterhaltsamen, an der Bar anklingenden Abend" (GT1). Diese sozialen Aspekte werden gestützt durch bestimmte Wortfelder: Die Wortfamilie um ,Leben' wird oft bedient - das Literaturhaus Berlin als „lebendiges [...] Zentrum literarischen Lebens“"875. In eine leicht andere Richtung weist das semantische Feld um das Substantiv „Gast". Das Literaturhaus versteht sich als freundlicher Gastgeber. Außerdem soll es offenstehen für private, kollegiale Treffen von Literat*innen, was besonders Litteraturbuset in Oslo starkmacht, indem es die Etage mit Arbeitsplätzen für Schreibende erwähnt.

(2.) Austausch als Debatte: Explizite öffentliche Debatten zu politischen Themen und insbesondere eine literarische Auseinandersetzung spielen als Konnotation von ,Austausch“ ebenfalls eine Rolle in den untersuchten Texten. Diese Diskursfunktion wird dabei spezifiziert, indem das Literaturhaus periphrasiert wird als „Ort der Diskussion über ästhetische und literaturpolitische Probleme“ (BE), „Ort [...], an dem öffentliche Diskussionen über Literatur stattfinden, immer eingebettet in größere kulturelle, soziale und politische Zusammenhänge“ (GT1), „et åbent forum for alle litteraturinteresserede" (KH2) [ein offenes Forum für alle Literaturinteressierten], „scener og rom for samtale, debatt og formidling“ (OL2) [Bühnen und Räume für Gespräche, Debatte und Vermittlung], „arena for litteratur, debatt og kulturopple-

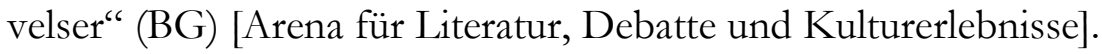

Die Verbindung von Begegnung und Debatte wird noch deutlicher in der Präsentation als „mødested“ (KH2) [Treffpunkt], für „dei som vil halde sitt eige møte“ (OL2) [die, die ihr eigenes Treffen abhalten wollen]. Das dänische/norwegische Wort ,møde /,møte als Übersetzung des deutschen ,Treffen', aber auch, und darin stärker als im Deutschen, ,Versammlung', Zusammenkunft‘, ist aufgeladen mit As-

875 Angemerkt sei, dass dort der Ausdruck ,literarisches Leben` genutzt wird, der den Begriff ,Literaturbetrieb` bezeichnet und so ein eingeführter Terminus ist. 
soziationen an politische Treffen, die sich in Skandinavien wiederum an die Tradition kirchlicher Zusammenkünfte anlehnen, bei denen gesellschaftsbildende Debatten ebenfalls ein zentraler Aspekt sind. Der strikte Moralglaube der protestantischen Kultur, die Skandinavien eindeutig prägt, schwingt dabei mit. Und auch wenn der Bezug nicht propagiert wird, so wird offenbar, dass im Litteraturhuset als ,debattarena' Fragen diskutiert werden, die traditionell an anderer Stelle, zum Beispiel bei religiösen oder volksbildungsorientierten Treffen, aufgeworfen wurden. Die Betonung des Diskussionsaspekts wird also besonders durch den skandinavischen Kontext nachvollziehbar. Und dies zeigt sich dort noch stärker, wo nicht eine Privatperson mit künstlerischem Anspruch die Einrichtung gestaltet wie in Kopenhagen, sondern wo eine Stiftung mit dem Auftrag, die Meinungsfreiheit zu stärken und zu schützen, der Träger ist wie Fritt Ord in Oslo.

\section{Netzwerk}

Die Literaturhäuser stellen sich auch so dar, dass sie im Sinne der ,Institution“ als kollektiver Akteur auftreten und literarische Akteur*innen miteinander verbinden wollen. Letzteres betrifft insbesondere Göteborgs Litteraturbus, das dies zu seinem Hauptziel erklärt. Die Absicht, „,[att] verka för litterär bildning i Göteborg“ (GB) [sich für literarische Bildung in Göteborg einzusetzen], realisiert es, indem es mehr als Vermittler zwischen literarischen Organisationen und Veranstalter*innen und weniger mit einem eigenen Programm hervortritt. Es positioniert sich weniger inhaltlich, sondern schafft eher die Struktur für andere Akteur*innen, Veranstaltungen durchzuführen.

In allen Texten der untersuchten Literaturhäuser werden unterschiedliche Akteur*innen des Literaturhauses benannt: die Autor*innen und die meist unter dem Kollektivum ,Publikum` vereinigten Zuhörer*innen. Bei der Hälfte der Fälle finden innerorganisatorische Akteur*innen, wie der offizielle Träger (Verein beziehungsweise Stiftung), die Vereinsführung (GB), oder (ehemalige) Leiter*innen (BE, FF2, GT2, KH2) Erwähnung, in Göteborg sogar alle Mitglieder der ideellen Vereinigung. In Hamburg, Frankfurt, Kopenhagen, Oslo und Göteborg werden zudem die Initiator*innen des Literaturhauses als Gruppe aktiver Menschen vorgestellt, in Berlin und Göttingen ist die Gründung mit Passivkonstruktionen ohne Objekt formuliert. ${ }^{876}$

Wie schon gesagt kommen, wenn vorhanden, Gastronomiebetrieb und Buchhandlung vor. Mit Veranstaltungskooperationspartner*innen wird unterschiedlich verfahren: In Berlin, Hamburg und Göttingen lässt sich nur herauslesen, dass mit anderen Einrichtungen zusammengearbeitet wird, Frankfurt nennt exemplarisch kooperierende Veranstalter und Kopenhagen beschreibt, dass sein Grundprinzip auf Zusammenarbeit beruht - es „har allieret sig med en litterær tænketank og en række frivillige" (KH2) [hat sich mit einem literarischen Thinktank und einer Reihe freiwilliger zusammengetan].

\footnotetext{
${ }^{876}$ Beispiele für derartige Formulierungen sind: „,von literaturbegeisterten Hanseaten“ (HH); ,eine Gruppe engagierter Frankfurter Bürger“ (FF2); „Initiativtageren og ejeren af LiteraturHaus Paul Opstrup“ (KH2) [der Initiator und Besitzer des LiteraturHauses]; „Göteborgs Stadsbibliotek [...] och aktörerna i Lagerhuset“ (GB) [Göteborgs Staatsbibliothek und die Akteur*innen im Lagerhaus] (GB).
} 
Dass Göteborg die Zusammenarbeit der beteiligten Akteur*innen zum erklärten Ziel macht, wurde bereits erläutert. Noch klarer als im hier vorrangig analysierten Text ,Om oss ' [Über uns] wird in der dort verlinkten Zielsetzung, dass sich das Literaturhaus als Arrangeur versteht, der den Rahmen für (literarische) Bildung schafft. 877 Oslo, Berlin und Bergen nehmen nicht auf Kooperationen bei ihren Veranstaltungen Bezug, sondern auf die Gastveranstaltungen, die in den Literaturhäusern stattfinden, und sie machen implizit oder explizit auf die Möglichkeit aufmerksam, die Räume für andere Zwecke zu mieten. ${ }^{878}$

\section{9.4 Literarisches Programm}

Die Selbstdarstellungstexte geben außerdem Auskunft über das literarisch-inhaltliche Programm der Literaturhäuser. So ist zu fragen, ob es konkrete Äußerungen zum Literaturverständnis gibt oder ob einzelne Autor*innen als Beispiele dienen. Wer und was ist Objekt der Literaturvermittlung? Zusätzlich ist zu prüfen, ob Hinweise auf die Literaturvermittlungspraktiken vorkommen. Wie wird Literatur im Literaturhaus vermittelt?

\section{9.4.1 Vermittlungsobjekte}

\section{Erwähnte Literatur}

Auf identifizierbare literarische Texte, zum Beispiel bestimmte Buchtitel, rekurrieren die untersuchten Selbstdarstellungen nicht. Allein das Literaturbaus Frankfurt lässt im Text einen Schriftsteller zu Wort kommen. ${ }^{879}$ Mit dem indirekten Zitat Elias Canettis (1905-1994), der als Nobelpreisträger und Aphoristiker sowie etwa für seinen Roman Die Blendung (1931) und seine Studie Masse und Macht (1960) bekannt ist, markiert die Einrichtung ihren literarischen Horizont. Gleichzeitig nimmt sie sich mit dem Zitat hinter die Formulierungsgabe von ,großen' Dichter*innen zurück, die „damit gültig aus[sprechen], worum es nach wie vor geht“ (FF1). Damit verschreibt sich das Literaturhaus der respektive einer literarischen Historie. Ebenso verweist das Zitat auf die übliche Praxis, in Vorträgen, Festreden oder Werbetexten ,Klassiker ${ }^{6}$ anzuführen und dabei nicht nur zu beabsichtigen, auf den konkreten Autor, hier Canetti, zu verweisen, sondern das Zitierte zu nutzen, weil es treffend aus-

877 Z. B. „,som ger möjligheter för möten mellan alla som intresserar sig för läsning och litteratur. [...] som möjliggör olika sorters läsningar och framträdanden. [...] ska dessutom erbjuda olika kontexter [...] ska erbjuda möjlighet för unga människor att möta litteratur [...] ska knyter kontakter [...] ska vara en mötesplats“, „Ideella föreningen Göteborgs Litteraturhus programförklaring“, Göteborgs Litteraturhus. URL: goteborgslitteraturhus.se/wp-content/uploads/2015/05/goteborgslitteraturhusprogramforklaring.pdf (Stand: 30.08.2018) [das die Möglichkeit bietet für Treffen von allen, die sich für Lesen und Literatur interessieren (...) das unterschiedliche Arten von Lesungen und Auftritte ermöglicht (...) es soll außerdem unterschiedliche Kontexte ermöglichen (...) soll jungen Menschen die Möglichkeit bietet, Literatur zu begegnen (...) soll Kontakte knüpfen (...) soll ein Treffpunkt sein].

${ }^{878}$ Vgl. Kapitel II 11.2.

879 „Wer Bücher liebt, weiß, dass alles an ihnen interessant ist: Der materielle Prozess ihrer Entstehung, ihre Vermittlung, ihre Verbreitung, ihr Preis, die Kreise von Menschen, die sich um ihretwillen allein bilden, ihre Aufnahme, das Auf und Ab ihrer Geltung, ihre Verdrängung, ihr Verschwinden, aber auch das Rätsel ihres Bestandes, “ so habe es dem Literaturbaus Franfurt-Text zufolge Canetti formuliert (FF2). 
drückt, was gesagt werden soll. Die Nennung des Autorennamens zeigt dann eigentlich nur an, von wem dieser Satz stammt; allerdings lässt sich dieser Fall nicht losgelöst vom Autorennamen betrachten, der vielen vertraut sein wird. Diese Erwähnung markiert in beiden Fällen indirekt, in welchen literarischen Bereich sich das Literaturhaus bewegt.

Die intendierte literarische Verortung präzisiert allein das Literaturhaus Berlin in seinem Text, es habe Interesse „auch an der Geschichte der literarischen Moderne und ihren Konflikten mit der Politik“ (BE). Die Formulierung „Projekt Moderne“ (BE) pointiert das Programm dieses Literaturhauses. Obgleich nicht eindeutig erklärt wird und bestimmt ist, was sich hinter diesem ,Projekt' verbirgt, so erhalten die entsprechend gebildeten Leser*innen eine Vorstellung vom literarischen Anspruch: Erwartet wird die Beschäftigung mit Literatur der Jahrhundertwende ebenso wie Nachkriegstexte und Veröffentlichungen der Gegenwart. Darüber hinaus erwähnt der Text das mit Literatur verbundene politische Interesse ausdrücklich.

Des Weiteren liege im Literaturhaus Berlin der Blick auf „der gegenwärtigen deutschsprachigen und internationalen Literatur“" (BE). Dies gilt ausnahmslos für die untersuchten Literaturhäuser, obwohl es nicht in jedem Fall so unmissverständlich verbalisiert wird - und in den skandinavischen Einrichtungen ,deutschsprachig ${ }^{6}$ natürlich durch die jeweilige Nationalsprache ersetzt werden muss. Die internationale Ausrichtung kommt explizit in allen Texten vor, kann dementsprechend als zur Institution gehörend markiert werden. Dabei teilen die Texte nicht nur mit, dass die Literaturhäuser internationale Literatur vermitteln, sondern dass auch die Gäste aus dem In- und Ausland kommen, sowie dass sie Vernetzung beziehungsweise Sichtbarkeit über die städtischen und sogar nationalen Grenzen hinweg anstreben. ${ }^{880}$

Der lokale Verweis bezieht sich dabei nicht auf die vorgestellte Literatur, sondern auf das Literaturhaus als Vermittlungseinrichtung in der Stadt. Bereits im allerersten Selbstdarstellungstext der Institution unterstreicht der damalige Leiter des Literaturhauses Berlin die Relation von Lokalität und Internationalität: „Literatur in diesem Haus ist Berliner Literatur und Literatur für Berlin, aber vor allem eben Literatur also überregional und international." ${ }^{881}$ Dadurch, dass die Literaturhäuser ihre Internationalität hervorheben, treffen sie zugleich Aussagen über ihre literaturästhetische Verortung: Kriterium für die Qualität von Literatur ist für die Literaturhäuser nicht die regionale Wirksamkeit von Literatur, sondern ihre ortsunabhängige Gültigkeit.

Es widerspricht nicht der angekündigten Konzentration auf Gegenwartsliteratur, dass, wie oben ausgeführt, die Selbstdarstellungstexte nicht so sehr auf die physische Anwesenheit der Literat*innen abheben. Vielmehr ist im Gegenwartsbezug ein Ver-

\footnotetext{
880 Z. B.: Mit einigen Ausstellungen „hat das Literaturhaus weit über Berlin hinaus gewirkt.“ (BE); Das Literaturhaus Hamburg „,sorgt mit seinem Renommee für Aufmerksamkeit über die Grenzen Hamburgs hinaus.“ (HH); Das Literaturhaus Frankfurt ,,ist eines der prächtigsten Gebäude für die lebendige Vermittlung der Literatur in Europa.“ (FF2). Allerdings ist es hier nicht eindeutig, ob sich „Europa“ auf die „Literatur“ oder das „Gebäude für [...] Vermittlung der Literatur“ bezieht. Gleichzeitig ist es interessant, dass von „der Literatur“ mit bestimmtem Artikel die Rede ist und es nicht offener mit, Vermittlung von Literatur" formuliert wurde.

${ }^{881}$ Folder zur Eröffnung vom Literaturhaus Berlin. Der Text findet sich im Anhang, vgl. Anhang V 1.1.
} 
such zu erkennen, die Zeitgenossenschaft des Vorgestellten als Möglichkeit zum Gespräch zu nutzen, zum Gespräch über Literatur „,immer eingebettet in größere kulturelle, soziale und politische Zusammenhänge“ (GT1). Dabei beschränken sich die Literaturhäuser nicht expressiv verbis auf neu erschienene Texte. Vielmehr fällt auf unterschiedlichen Ebenen auf, dass Vielseitigkeit herausgestellt wird. So machen sie zum Beispiel nicht nur strikt literarische Angebote, sondern legen überdies die Vermischungen mit anderen Künsten als programmatisch dar.

\section{Qualitativer Anspruch}

„Das Literaturhaus [...] liebt gute Bücher.“ (FF1) - darin sind sich die Texte aus Deutschland weitestgehend einig. Wie genau diese literarische Qualität bestimmt ist, wird in der Regel nicht direkt spezifiziert. Vermeintlich eindeutige, tatsächlich eher evasive Adjektive wie „anspruchsvoll“ ( $\mathrm{HH})$ geben eine Einordnung des Programmes vor. Die Verwendung des Attributs ,anspruchsvoll' sagt insbesondere auf einer Metaebene etwas aus über das Selbstverständnis des Literaturhauses und über die adressierten Zuhörer*innen. Es ist ein sehr gutes Beispiel für die Kommunikationskonventionen zwischen Sender*innen und (idealen) Empfänger*innen. ,Anspruchsvoll ${ }^{`}$ setzt mindestens zwei Dinge voraus; erstens, dass die Empfänger*innen verstehen, was die Sender*innen mit diesem ,Anspruch ‘ meinen; zweitens, dass beide Seiten es als attraktiv ansehen, wenn dieser Anspruch vorhanden ist. Das Adjektiv suggeriert eine Erwartungshaltung an das Programm ebenso wie an das Publikum, das als gebildet und weiterbildungsinteressiert einzuschätzen ist.

Tatsächlich benutzt wird das Wort ,Anspruch“ nur im Text des Literaturhauses Hamburg. Unter diesem Terminus fassbar sind aber auch andere Formulierungen. Das Literaturhaus Frankfurt begnügt sich mit „Büchern von guten Bekannten wie guten Unbekannten“ (FF1). Auch diese Qualität wird nicht näher präzisiert, doch scheint das Werturteil gut' nicht einem hohen Bekanntheitsgrad der Verfasser*innen vorbehalten zu sein. In Literaturhaus-Kreisen Arrivierte wie (noch) Unentdeckte werden als gute Bücherschreiber*innen deklariert. Dabei besteht offenbar Einigkeit darüber, was als ,bekannt ${ }^{\varsigma}$ vorausgesetzt wird. Hier stehen die Autorennamen metonymisch für ihre Produkte, denn natürlich müsste es präzisierend lauten, dass die Texte der „Bekannten“ wie „Unbekannten“ gut seien. Dieses Beispiel veranschaulicht sowohl die Bedeutung einer Autorfunktion als Marke für das gegenwärtige Sprechen über Literatur als auch die Relevanz der Autorenpersona im Literaturhaus.

\section{Autor*innen}

Die Bedeutung der Autorenpersona im Literaturhaus unterstützt zudem die Tatsache, dass allenthalben aufgezählt wird, welche Akteur*innen anzutreffen sind dann, anders als oben am Falle Canettis gezeigt, ohne konkrete Referenz auf einen literarischen Text. Dies geschieht entweder über die Nennung von konkreten Autorennamen - diese lassen sich einteilen in erstens als kanonisch beziehungsweise als in Feuilleton und jüngerer Literaturwissenschaft etabliert geltende Autor*innen, und zweitens in andere Künstler*innen, die eher ein nicht-hochkulturelles, medial vielfältiges Programm bezeugen - oder über eine Auflistung von verallgemeinerten Zu- 
schreibungen (FF2). ${ }^{882}$ Dabei wird meist die Mischung aus arrivierten und noch unbekannten Künstler*innen betont, zum Beispiel „Nobelpreisträger und Nachwuchsautoren, für Künstler und Theaterleute, für Philosophen und Diskutierfreudige“ $(\mathrm{HH})$, „Übersetzer, Schauspieler und Sprecher, Wissenschaftler und Kritiker, selten auch Musiker und bildende Künstler sind neben den Schriftstellern unsere Mittler- und unsere Gesprächspartner“ (BE), „etablerede og spirende forfattere, kunstnere og litterært interesserede" (KH2) [etablierte und aufkommende $\mathrm{Au}$ tor*innen, Künstler*innen und literarisch Interessierte]. Diese Nennungen bieten eine Orientierung für potenzielle und dabei literarisch versierte Zuhörer*innen und fungieren als Belege dafür, dass die Literaturhäuser ,an der gegenwärtigen deutschsprachigen und internationalen Literatur interessiert sind“ (BE), wie oben erwähnt.

Die Litteraturbus in Oslo, Bergen und Göteborg listen anders als die untersuchten deutschen Literaturhäuser und das erste Kopenhagener nicht auf, welche Künstler*innen anzutreffen sind. 883 Oslo versteht sich vielmehr als ein Platz für nicht weiter spezifiziert „litteraturinteresserte“ (OL1) [Literaturinteressierte] und offeriert den Besucher*innen vor allem Handlungsoptionen - „mange typer aktivitetar“ (OL2) [viele verschiedene Aktivitäten]. Das literarische Programm wird nicht auf andere Weise weiter ausbuchstabiert, ${ }^{884}$ eher richtet sich der Blick auf den Rahmen und die unterstützende Infrastruktur für Vermittlung als Weiterbildung. Damit rückt das Literaturhaus als Haus für und mit Literatur ins Zentrum, es wird Etage für Etage mit Aktivitäten besetzt: Im Erdgeschoss Buchhandel, Café und Hauptbühne (in dieser Reihenfolge), in der zweiten Etage weitere Räume, eine eigene Abteilung für Kinder und Jugendliche. Und das Dachgeschoss ist reserviert für Verfasser*innen. Außerdem wird die Autorenwohnung für „utanlandske forfattarar og intellektuelle“ (OL2) [ausländische Autoren und Intellektuelle] vorgebracht. Der Text spricht sowohl Besucher*innen als auch Autor*innen, Cafégäste, Buchkäufer*innen wie Kinder an.

\footnotetext{
${ }^{882}$ Ein Zufallsfund: In einer vorherigen Version tauchten in Göttingen auch solche Namen auf. Ein Grund, warum diese im neuen Text nicht mehr auftauchen, könnte sein, dass vermieden werden soll, einzelne Namen paradigmatisch für das eigene Programm zu setzen. Auch wenn ich sie im Fließtext deute als Marker für ein individuelles, offenes Programm, so sind diese Namen auch unter dem Stichwort Kanon zu diskutieren: Diese Namen sind vielleicht nicht Teil eines bildungsbürgerlichen Literaturkanons, sind aber durchaus in anderen Szenen kanonisiert und sprechen damit eine andere Publikumsgruppe an. Die Erwähnung in den untersuchten Texten festigt ihre Position bzw. baut sie aus.

${ }^{883}$ Wobei anzumerken ist, dass im Litteraturbuset in Oslo im Foyer Jahrestafeln hängen, auf denen alle Gäste jedes Jahres aufgereiht stehen, ohne jegliche Hierarchisierung.

${ }^{884}$ Die Formulierung „litteratur i den romslegaste tydinga av ordet“ (OL2) [Literatur im weitesten Sinne des Wortes] lässt offen, was genau darunter verstanden wird, das kann auch dahingehend beurteilt werden, dass das Literaturhaus jegliche Programmidee offenhält, und es nicht für nötig erachtet, konkreter zu sein. Es ist also nicht so sehr dieser Ausdruck allein, der mich zu der Deutung führt, dass das literarische Programm nicht kommuniziert wird, sondern vielmehr die Abwesenheit weiterer Ausführungen zu den Veranstaltungen des Literaturhauses. Auf der Website findet sich neben dem aktuellen Programm aber auch eine Übersicht über die Reihen des Literaturhauses. Hier wird erneut deutlich, dass die hier ausgewertete Textauswahl nur einen Teil des Ganzen abbilden kann. Dennoch steht im Text „Om Litteraturhuset" nicht, welches Angebot das Literaturhaus als Veranstalter offeriert.
} 


\section{9.4.2 Vermittlungspraktiken}

Veranstaltungsformate und -reihen

In den Texten stellen die Literaturhäuser selten konkrete Inhalte vor, sondern berufen sich eher auf die exemplarische Nennung von Veranstaltungsformaten, also auf die dort auffindbaren Praktiken, die allgemeiner und damit vielfältiger zutreffend beschreiben, womit sich die Literaturhäuser beschäftigen. Da Veranstaltungsformate aus diesem Grund in der vorliegenden Arbeit Untersuchungsobjekt sind und sie als unmittelbar mit den Inhalten verknüpft gelten können, ${ }^{885}$ lohnt sich ein Blick auf die Benennungen, die die Literaturhäuser selbst für die unterschiedlichen Angebote wählen. Diese Ausdrücke sind dort keine Neukreationen, sondern Diskurszeugnisse, was sie für die Analyse interessant macht.

Es lässt sich grundsätzlich differenzieren zwischen Termini, die die organisatorische Rahmung fassen, und solchen, die enger mit der Aufführung zusammenhängen - obgleich diese Unterscheidung nicht trennscharf ist. Keine speziell diversifizierenden Vokabeln für die Formate spricht das Literarischen Zentrum Göttingen an. Dort liegt der Schwerpunkt allgemein formuliert auf Diskussionen und der intermedialen Vermittlung, die Formen der Übertragung werden nicht spezifiziert (GT1). Auch Oslo (und Bergen) zählen keine Formate auf, die Programminhalte sind dort, wie schon ausgeführt, nicht Teil der untersuchten Selbstdarstellungstexte. Das Literaturhaus Göteborg kann gemietet werden für „,kulturella arrangemang, konferenser, årsmöten, kurser m.m.“ (GB) [kulturelle Veranstaltungen, Konferenzen, Jahrestreffen, Kurse, und viele mehr] - diese Termini beziehen sich auf infrastrukturelle Kriterien. Aus den Texten aus Berlin, Hamburg, Frankfurt und Kopenhagen lassen sich für beide Bereiche Exempel extrahieren.

Beispiele für organisatorisch-rahmende Bezeichnungen sind: Literarische Veranstaltungen, Symposien, Ausstellungen (BE), Festivals ( $\mathrm{HH})$, literarische Veranstaltungen, Symposien und Tagungen (FF2), „festivaler“ (KH1). Symposien beispielsweise nutzen Diskussion und Vorträge.

Beispiele für format-inhaltliche Bezeichnungen sind: Autorenlesungen, Vorträge, szenische Lesungen, Diskussionen (BE), Lesungen, Podiumsdiskussionen, Gesprächsrunden, literarische Abende $(\mathrm{HH})$, Lesungen, Diskussionen, Partys, Performances (FF1), Autorenlesung, Lesungskonzerte, Ausstellungen (FF2), „tværkunstneriske arrangementer med litteratur, musik, film, billed- og videokunst" (KH2) [kunstdialogische Veranstaltungen mit Literatur, Musik, Film, Bild- und Videokunst], Festivals, Debattier- und Leseclubs, Konzerte, Literaturcafés, literarische Gesellschaften, Vorträge, Filmabende (KH1). Bei diesen Typen wird deutlich, dass die Literaturhäuser, die auf Formate eingehen, betonen, dass es nicht nur Lesungen gibt, sondern gleichfalls andere Umsetzungen.

Neben den erwähnten Veranstaltungsformaten geben Veranstaltungsreihen Auskunft über das regelmäßige Angebot. Die Literaturhäuser vermitteln so eher Kontinuität, statt sich nur mit einzelnen hervorstechenden Veranstaltungen zu präsentieren. Das Literarische Zentrum Göttingen spricht im untersuchten Text direkt aus, dass

${ }^{885}$ Vgl. Kapitel II 13.2. 
seine Veranstaltungsreihen am besten über sein Profil Auskunft geben (GT1). Während es an dieser Stelle nicht einzelne Beispiele aufnimmt und trotzdem die unmissverständliche Bedeutung der Reihen für das „Profil“ (GT1) unterstreicht, wählen das Literaturhaus Hamburg und das Literaturhaus Frankfurt Exempel für Reihen aus, die vor allem einen Eindruck von Vielseitigkeit unterstützen. Dies stützt die Annahme, dass die Literaturhäuser sich stark über ihre Reihen identifizieren. Die Selbstdarstellungstexte suggerieren beispielsweise, dass im Literaturbaus Berlin Ausstellungen einen großen Teil einnehmen; dass in Hamburg die Reihen Philosophisches Café, März \& Moritz \& 1 Gast, Irgendwie komisch, Gemischtes Doppel und die Festivals Nordische Literaturtage und Hamburger Graphic Novel Tage - nicht etwa das Hamburger Krimifestival - bedeutend sind (HH); und dass in Frankfurt gerade die wiederkehrenden Angebote wie Streiffall, Schöne Aussichten oder Kopf \& Hörer oder die gemeinsame Lesung der sechs Autoren der Shortlist des Deutschen Buchpreises und besonders genannte Veranstaltungen wie „Lesungskonzerte“, „große Partys“ oder „Lesungen in Privatwohnungen“" (FF2) das Profil prägen. In der Tat bieten die Reihen einen guten Anhaltspunkt zum Programm der Literaturhäuser, obgleich sie in den einzelnen Einrichtungen von unterschiedlicher Relevanz sind. ${ }^{886}$

Die in den kommenden Kapiteln folgenden Programmanalysen stellen heraus, dass die skandinavischen Vertreter ihr Programm gar stärker als die deutschen über Reihen strukturieren. Dies stellen die gerade untersuchten Texte allerdings nicht heraus, weil das eigene Veranstaltungsprogramm dort insgesamt kaum Erwähnung findet.

Produktion

In den Texten offenbart sich, dass die Literaturhäuser sich nicht nur als Orte mit Reproduktions- beziehungsweise Rezeptions- oder Distributionsaufgaben verstehen, sondern die Produktion von Literatur integrieren. Dies ist in den skandinavischen Einrichtungen deutlicher der Fall als in den deutschen Einrichtungen: Litteraturbuset in Oslo versteht sich, wie oben beschrieben, ausdrücklich als Ort der Literaturproduktion. Ähnlich werden im LiteraturHaus in Kopenhagen die Möglichkeiten für künstlerisch Tätige betont: Sie begegnen einem „deltagende publikum“ (KH2) [teilnehmenden Publikum], die Zuschauer können in einen Dialog mit der Literatur und den ausübenden Künstler*innen gehen (KH2). Dennoch steht genauso dort das Gespräch über Literatur im Vordergrund vor der tatsächlichen Produktion. Im Göteborgs Litteraturbus wird im Haupttext nicht auf diese Aspekte eingegangen, in der Programmerklärung tritt dann deutlich hervor, dass der Schwerpunkt auf literarischer Bildung und auf der Schreib- und Leseförderung der Gäste liegt. Es ist dabei nur nachrangig die Rede von Literaturveranstaltungen, bei denen Autor*innen auf einer Bühne einer Zuhörerschaft ihre Werke präsentieren.

Das Literaturhaus Berlin spricht direkt aus, dass es die Produktion gelegentlich der „Reproduktion [Vorstellung vorhandener Bücher]“ (BE) ${ }^{887}$ vorziehe und bezieht sich dabei auf sein eigenes Wirken: Es initiiert literarische Auftragsarbeiten, publiziert Buchreihen und kuratiert Literaturausstellungen - „Eigenproduktionen wie

${ }^{886}$ Ausführlicher zu Reihen in den Literaturhäusern vgl. Kapitel II 13.1.
887 Ergänzung in Klammern im Original. 
Übernahmen“ (BE). Mit diesem Fokus ist das Literaturbaus Berlin die einzige der untersuchten Einrichtungen, die in ihrer Selbstpräsentation herausstellt, dass sie auch als Produzent im Literaturbetrieb agiert. Nennenswert ist hier der Fachausdruck ,Reproduktion‘ als Terminus für die Vermittlungshandlung seitens des Literaturhauses. ,Reproduktion“ verweist darauf, dass es um die erneute Präsentation eines bereits vorgestellten Produktes geht, das heißt ein publiziertes Buch wird im Rahmen einer Veranstaltung aufgeführt, also erneut produziert. Die Rezeption findet dann seitens des Publikums statt. Anhand der Vokabel ,Reproduktion“ wird besonders die Vermittlerposition des Literaturhauses deutlich. In diesem Kontext ist es höchst interessant, dass der Text des Literaturbauses Berlin die Zusammenstellung von Ausstellungen als ,Produktion' begreift, die Veranstaltungen als ,Reproduktion'. 888 Es scheint nicht nur einen quantitativen Unterschied zu geben zwischen der Organisation eines Lesungs- oder Diskussionsabends und der Gestaltung einer Ausstellung, sondern auch eine qualitative Differenz. Dies konkretisiert der Text zwar nicht weiter, doch deutet er eine akademische Kontextualisierung an, schließlich taucht auch in der vorliegenden Arbeit die Frage nach dem hybriden Status einer Literaturveranstaltung als Produktion und Reproduktion mehrfach auf. 889

\section{9.5 Zwischenfazit - Darstellung als, umfassendes Literaturhaus'}

Die Analyse der Selbstdarstellungstexte auf den Websites zeigt, dass die selektierten Literaturhäuser in Norwegen, Dänemark und Schweden nicht genauer das von ihnen angebotene literarische Programm akzentuieren. In den deutschen Beispielen hingegen wird die Kuratorenleistung des Akteurs Literaturhaus markiert. Dies passt mit der Interpretation zusammen, dass die Literaturhäuser in Skandinavien sich stärker als Orte begreifen; als Räume, die der Literatur generell Aufmerksamkeit zuteilen. Sie verstehen sich eher als Plattform, die einen Rahmen schafft: „Idéen med LiteraturHaus er at bringe litteraturen i spil og skabe rammerne for et åbent forum for alle litteraturinteresserede“" (KH2) [Die Idee des Literaturhauses ist es, Literatur ins Spiel zu bringen und die Bedingungen für ein offenes Forum für alle Literaturinteressierten zu schaffen].

Der Begegnungsaspekt ist, wie gezeigt, in den deutschen Literaturhäusern ebenfalls virulent, doch vermitteln deren Texte stärker eine literarische Programmatik. Die Literaturhäuser fungieren als Mediatoren für von ihnen ausgewählte Literatur. Das LiteraturHaus ist ihnen in diesem ästhetischen Anspruch ähnlich, und so lässt sich dem ersten Kopenhagener Literaturhaus eine Zwischenstellung zuschreiben, weil es das literarische Programm im Vergleich zu den anderen Skandinaviern noch eher zum Thema macht. Die neueren Einrichtungen legen besonderen Wert auf die Handlungen der Akteur*innen, die im Literaturhaus wirken, während die deutschen

\footnotetext{
888 Ausstellungen finden in den ausgewählten Literaturhäusern ausschließlich in Berlin statt, Frankfurt, so ist nachlesbar, ,zeigte in der Vergangenheit Ausstellungen zu literarischen Themen“ (FF2). Obwohl heute keine Ausstellungen mehr angeboten werden, wird diesen ein Absatz gewidmet, der näher auf die stattgefundenen Ausstellungen eingeht. Es scheint also ein nicht zu vernachlässigender Aspekt des Literaturbauses Frankfurt zu sein. Dass aus eher organisatorischen Gründen zurzeit keine Ausstellungen angeboten werden, steht jedoch nicht im Text. Zu den Austellungen vgl. Kapitel II 13.1.1.

889 Vgl. z. B. S. 100 und S. 369
} 
Häuser mehr um eine inhaltliche Ausgestaltung des Hauses bemüht sind. In Skandinavien geht es, den Texten zufolge, mehr darum, ein Forum zu bieten, Austausch und die Beschäftigung mit Literatur zu ermöglichen. Die deutschen Häuser integrieren diese Vermittlungsarbeit in ein formuliertes literarisches Programm, das zur Selbstdarstellung eindeutig dazugehört, ohne es im Detail darzulegen, also ohne sich zu sehr festzulegen. Dies stützt die These, dass es bei den neueren Einrichtungen viel stärker um den Ort als Literaturnetzwerk und die Präsenz von Literatur als Anregung zur Debatte geht als um die Selektionsfunktion des Literaturhauses als Literaturvermittlungsverein. Die jüngste Umsetzung, Litteraturhuset in Göteborg, macht dies besonders klar. Der Verein ist eine Bündelung literarischer Akteur*innen, die das Literaturhaus als Bühne nutzen können. Vom eigenen Veranstaltungsprogramm seitens des vom Verein gesetzten Mitarbeiterkreises ist in dem Text keine Rede. Im Text aus dem Litteraturbuset Bergen und in Oslo deutet sich zumindest an, dass die Trägerstiftung eigene Veranstaltungen anbietet.

In den deutschen Literaturhäusern spielt folglich das dezidierte Veranstaltungsangebot eine größere Rolle, während in Norwegen das Literaturhaus als Präsentationsfläche für Literatur und Diskussion betrachtet wird, in Kopenhagen der kreative Dialog auf dem Programm steht und in Göteborg vor allem die schon aktiven Literaturvermittler vereinigt werden sollen. Es lässt sich also nur eingeschränkt von einer typisch skandinavischen Linie sprechen; vielmehr sind mit Blick auf die Eigenpräsentationen graduelle Weiterentwicklungen im Selbstverständnis der Literaturhäuser erkennbar. LiteraturHaus in Kopenhagen hat mit seinem künstlerischen Anspruch mehr gemein mit den Eigenbeschreibungen der deutschen Literaturhäuser. Bergen orientiert sich in dem knappen Text klar an der Osloer Version. Göteborg geht noch einen Schritt weiter, indem es sich vor allem als Netzwerkort präsentiert.

Diese hier analysierten prägnanten Texte machen deutlich, dass sich die Literaturhäuser in ihrem Selbstverständnis unterscheiden. Diese Divergenz lässt sich unter anderem auf die verschiedenen Kontexte, Traditionen und Entstehungszeitpunkte zurückführen, in denen sich die Einrichtungen mit diesen untersuchten Selbstdarstellungstexten positionieren. Gemein ist den Literaturhäusern den Texten zufolge, dass sie sich als Orte der Literatur präsentieren und unterschiedliche Akteur*innen in Gesprächen zusammenbringen wollen und sie sich als soziale Orte verstehen.

Alle Einrichtungen möchten also zur Debatte anregen. Dabei verlegen sich die skandinavischen Literaturhäuser eher darauf, Raum für Debatten zur Verfügung zu stellen, in dem Diskussionen demokratisch stattfinden können, während in den deutschen Einrichtungen die inhaltliche Einflussnahme seitens des LiteraturhausVereins relevanter ist. Damit nehmen sich in den untersuchten skandinavischen Literaturhäusern die Leitungen mehr hinter einem Programm zurück, das grundsätzlich ,alle' demokratisch gestalten. ${ }^{890}$ In den Texten aus Berlin, Hamburg, Frankfurt und Göttingen wird offenbar, dass es dort jeweils eine Instanz gibt, die über die Inhalte entscheidet - das Literaturhaus als Literaturvermittler. Das LiteraturHaus in Kopenhagen bildet in dieser Hinsicht eine Ausnahme. Allerdings konnte sich diese Struktur so bisher nicht in der Stadt durchsetzen. Das ,neue' Literaturhaus in der

890 Zur ,demokratischen` Programmgestaltung vgl. auch Kapitel II 11.2 und Kapitel III 3.4. 
Nybrogade 28 verortet sich eher in einer Linie mit dem norwegischen Litteraturbuset, was sich allerdings nur vorsichtig abzeichnet.

Die Institution Literaturhaus präsentiert sich über die Fallbeispiele weniger als Bühne, sondern als Gesprächsort. Der soziale Aspekt der Beschäftigung mit Literatur überragt dabei die Begegnung mit einem auratisch-überhöhten Autor. Die Institution widmet sich damit der Literatur, und sie meint damit nicht in erster Linie das gesprochene Wort, denn Literatur selbst hat dort eher eine schriftlich gebundene, abgeschlossene Form, die zur Debatte anregt, sie ist Diskussionsgegenstand und weniger klangliches Ereignis.

Außerdem spielt die Idee, Autor*innen dort in einer Star-Fan-Beziehung live erleben zu können, keine ausdrückliche Rolle. In diesem Zusammenhang sei jedoch noch einmal an den Publikationskontext dieser Selbstdarstellungstexte erinnert, denn als teilöffentliche Einrichtungen betonen die Literaturhäuser ihre gesellschaftliche und kulturelle Relevanz. Die Texte haben nämlich nicht nur eine werbende Funktion, sondern dienen auch der Legitimation. Der oft kulturpessimistisch abgelehnte ,Personenkult' um ,Autor*innen zum Anfassen“ und ihre Homestories wird hier ausgeblendet. Wie diese Arbeit herausstellt, sind die Literaturhäuser mit dieser Live-Begegnung im Zeitalter der Digitalisierung höchst aktuell, sodass gerade dies sie als bedeutsame Institution der Gegenwart legitimieren könnte - der inhaltliche Anspruch muss darunter schließlich nicht leiden - und sie dies in ihren Selbstdarstellungstexten deutlicher herausstellen könnten.

Ganz im Sinne der vorliegenden Arbeit zur Institution standen bisher vor allem die vergleichbaren Elemente der deutschen und skandinavischen Einrichtungen im Fokus. Um die Eigenarten und verschiedenen Gewichtungen zu beleuchten, werden zum Abschluss dieses Kapitels die Einzeleinrichtung komprimiert beschrieben. Das Literaturbaus Berlin stellt sich dar als Literaturstätte mitten in Berlin, die inhaltsfokussiert, fundiert, gleichzeitig rezipierend wie produzierend arbeitet. Das Literaturhaus Hamburg erscheint als vorzeigbare Villa, in der den Gästen sowohl Unterhaltung in angenehmer Atmosphäre als auch Anregung zur literarästhetischen Auseinandersetzung geboten wird. Das Literaturhaus Frankfurt in der repräsentativen Alten Stadtbibliothek setzt auf Vielseitigkeit, empfängt ein variierendes Publikum und unterschiedlichste Podiumsgäste zu Veranstaltungen zwischen bewährten Texten und innovativen Formaten. Das Literarische Zentrum Göttingen konzentriert sich in der Darstellung auf das begehbare Feuilleton, indem es sich als intermedialer Vermittler vor Ort zeigt. LiteraturHaus in Kopenhagen versteht sich als Treffpunkt aktiver künstlerischer Auseinandersetzung, bei dem der Kontakt und das Erleben zentral sind. Litteraturbuset in Oslo wirkt in erster Linie als Gebäude, in dem für Literatur im weitesten Sinne Raum geschaffen wird, Literatur im engeren Sinne wird nicht zum Programm ernannt. Göteborgs Litteraturhus stellt sich dar als „Netzwerker', der das vorhandene Engagement zur literarischen Bildung der Stadt bündeln möchte. Zum Litteraturhuset $i$ Bergen lässt sich keine andere Zusammenfassung finden als die selbstformulierte: Eine Arena für Literatur, Debatte und Kulturerlebnisse. Dies ist auBerdem eine Periphrase des Literaturhauses, die alle obengenannten Schwerpunkte zusammenfasst und in ihrer Allgemeingültigkeit zu allen untersuchten Literaturhäusern und damit zur Institution Literaturhaus passt. 


\section{10 Programmheftpragmatik}

\section{10.1 Material und Methode}

\section{10.1.1 Quellenmaterial}

Die gedruckten Programmhefte bilden das Hauptuntersuchungs- und Quellenmaterial der folgenden umfassenden Auseinandersetzung mit den Literaturhaus-Programmen. Es mag überraschen, dass in einer Studie, die sich mit einer Institution der Literaturvermittlung im Zeitalter der Digitalisierung befasst, insbesondere die gedruckten Programmhefte zentral sind. ,Spielt sich das alles nicht inzwischen sowieso nur noch online ab? Nein, denn die untersuchten deutschen und norwegischen Literaturhäuser verwenden weiterhin Druckprodukte. Diese erweisen sich als gut nutzbares Material, um über unterschiedliche Aspekte des Literaturhauses zu sprechen. Die Programmhefte ermöglichen eine parallele Untersuchung von kommunikationsstrategischen Elementen und Informationen zu den Programminhalten. Sie demonstrieren einerseits, wie die Literaturhäuser sich präsentieren, und entscheidend für die Institution erwies sich schon im Vorausgegangenen, wie sich die Einrichtungen nach außen darstellen. Andererseits halten sie Informationen zu Veranstaltungen, denn sie präsentieren chronologisch und übersichtlich gebündelt die Veranstaltungen, und organisationalen Entwicklungen nachvollziehbar fest, da sie nicht wie Websitetexte überschrieben werden können.

Als Begleitkommunikation werden sie von den Literaturhäusern von Anfang an herausgegeben. Es handelt sich dabei um öffentlich verwendetes Material. Aufgrund ihrer zeitlich begrenzten Gültigkeit sind die Programmhefte jedoch nicht mehr öffentlich verfügbar, sodass die Archivbestände der einzelnen Literaturhäuser eine wichtige Rolle für die Arbeit spielen.

Aufgrund der zugewandten Unterstützung seitens der Mitarbeiter*innen in den Fallbeispiel-Literaturhäusern, denen ich dafür ausdrücklich danke, hatte ich Zugang zu den Programmarchiven der Einrichtungen beziehungsweise erhielt das Material aus Bergen als PDF-Datei. Die Druckdaten der genuin digital erstellten Programmhefte sind nicht immer elektronisch aufbewahrt, sodass, vor allem in den deutschen Literaturhäusern, auf die Papierprodukte zurückgegriffen werden musste. Zum Teil erhielt ich die Erlaubnis, sofern mehrere Exemplare vorhanden waren, jeweils eines mitzunehmen, in anderen Fällen wurde mir die Leihgabe zugestanden, oder die Möglichkeit angeboten, die Dokumente vor Ort zu kopieren respektive zu scannen. So liegt mir ein einzigartiges partiell analoges, partiell digitales - entweder PDFs der Druckdateien oder PDFs des gescannten Materials - Literaturhaus-Programmarchiv vor, das sich aus den Programmheften der deutschen und norwegischen Fallstudien konstituiert. Dies ermöglicht eine intensive Auseinandersetzung mit dem Material, ohne von Archivbesuchen abhängig zu sein. ${ }^{891}$

891 Allerdings wurde auf die Digitalisierung der gesamten Programmhefte verzichtet. Dies hat aber nicht nur zeitökonomische Gründe, sondern liegt mit daran, dass die Scanner der Literaturhäuser keine professionellen Digitalisierungsgeräte sind, sondern nur für den Bürogebrauch taugen. Die automatische Texterkennung funktioniert außerdem bei den Scans nur sehr eingeschränkt. Für die zahlreichen Papierexemplare wären viele Scanvorgänge und diverse Korrekturdurchläufe notwendig, deren Aufwand dem Erkenntnisinteresse der vorliegenden Arbeit nicht angemessen wäre. Die Scans, die ich von den Pro- 


\section{10.1.2 Vorgehen}

Auf Forschung, die sich direkt mit Programmheften von Literaturhäusern auseinandersetzt, kann, da bis dato insgesamt wenige Studien zu dieser Institution vorliegen, nicht zurückgegriffen werden. Beschreibungen des Programms und der Arbeit der Literaturhäuser basieren bisher ausschließlich auf qualitativen Interviews, halbstandardisierten Fragebögen und Erfahrungswissen von Beteiligten. ${ }^{892}$ In ihrer bereits erwähnten Dissertation untersucht Susann Sophie Schmitt die Programme der ,Jungen Literaturhäuser' und sie verwendet als Material vor allem qualitative Interviews und zieht Programminformationsmaterial nur ergänzend hinzu. Trotz sehr langer Methodenbeschreibungen finden sich dort keine Ausführungen zur Untersuchung von Programmheften. Hilfreich sind hier Beiträge aus anderen Disziplinen, die sich mit Theaterzetteln und Weiterbildungsprogrammen befassen. $\mathrm{Zu}$ Theaterzetteln liegen ältere Forschungsarbeiten vor und neuere, die sich in erster Linie mit deren Funktionen beschäftigt haben. ${ }^{893}$ Dabei gilt es zu unterscheiden zwischen dem oft kurzfristig erstellten Theaterzettel, der im Theater ,Programmheft ${ }^{`}$ genannten Broschüre und dem Literaturhaus-Programmheft. Im Theater bekommt jede Inszenierung ein eigenes Heft, das an mehreren Abenden genutzt werden kann. Im Literturhaus besteht das Programm aus einer Aneinanderreihung von Einzelveranstaltungen - und darin illustriert sich ein elementarer Unterschied beider Institutionen. Im Theaterspielplan findet sich eine Aneinanderreihung von seriell aufgeführten Stücken. In einem Spielplan, der im Theater eine Übersicht über das Angebot eines Monats beziehungsweise einer Spielzeit bereithält, sind Inszenierungen versammelt, die mehrmals auf der Bühne gezeigt werden. Das LiteraturhausProgrammheft ist analog dazu Monatsspielplan und Programmheft der Einzelaufführungen in einem. Die Forschung zum Theaterzettel, der in der Regel Rahmeninformationen enthält, ist also vor allem für die Überlegungen zu den Funktionen der

grammen zum Beispiel im Literaturhaus Hamburg gemacht habe, sind meines Wissens die ersten digitalen Kopien dieser Papierdokumente überhaupt. Es würde sich für eine Verbindung von Digital Humanities und praxeologisch ausgerichteten Kulturbetriebsstudien sicherlich lohnen, die Archive umfassend zu digitalisieren, zu sortieren und katalogisieren, um weiter mit dem Material arbeiten zu können. Für diese einzelne Dissertation ist es nicht umsetzbar, eine Datenbank mit allen Veranstaltungen in den sechs beziehungsweise acht Literaturhäusern zu erstellen, die nur den für diese Arbeit ausgewählten Fallbeispielen gelten und die anderen Literaturhäuser von vornherein ausblenden würde. Einige Literaturhäuser, wie das Literarische Zentrum Göttingen, bieten inzwischen auf ihren Websites Listen mit allen bisherigen Podiumsgästen an, die sogar durchsuchbar sind. Auch das Literaturhaus Stuttgart oder das Literaturbaus Zürich stellen diese Übersichten bereit. Bei den anderen Einrichtungen lässt sich teilweise über die Archivfunktion gezielt suchen, allerdings sind nicht immer alle Veranstaltungen online archiviert. Obwohl in Zeiten der Digitalisierung Möglichkeiten gegeben sind, große Datenmengen zu bewältigen, wird an diesem Beispiel offensichtlich, wie zeitintensiv digitale Verfahren sind, die auf analoge Quellen angewendet werden. Und nicht nur unter dem Zeitaspekt erweist es sich als sinnvoller, sich dem Material mit Detailuntersuchungen zu nähern statt mit in erster Linie computergestützten Verfahren - darauf wird zurückzukommen sein.

892 Vgl. Kapitel I 2.

${ }^{893}$ Ein DFG- Forschungsprojekt an der Universität Düsseldorf „,Theaterzettel als Textsorte, Indikatoren kultureller Selbstpositionierung und Parameter kulturwissenschaftlicher Forschung “ (2005-2008) hat sich mit der Erschließung des Bestandes von Theaterzetteln auseinandergesetzt hat. Im Anschluss an das Kolloquium „Vom Einblatt zum Programmheft - Theaterzettel“ im April 2007 ist statt eines Tagungsbandes ein Bericht erschienen, der über die wesentlichen Thesen der Vortragenden informiert. Ziel des Projektes war es, „den Diskurs über die bisher kaum ausreichende Erforschung einer seit Jahrhunderten bekannten, kontinuierlich als Medium genutzten und in einer Fülle von Archiven in teils umfangreichen Sammlungen vorhandenen Archivalie [zu] intensivieren“, Cepl-Kaufmann: „Vom Einblatt", S. 1. 
Hefte hilfreich. Ebenso sind Überlegungen zu Verlagsvorschauen einzubeziehen, die inhaltlich Überschneidungen mit den Literaturhaus-Programmheften aufweisen, die sich allerdings vornehmlich an den verbreitenden Sortimentsbuchhandel richten. ${ }^{894}$ Methodische Ansätze zu Programmanalysen leistet die Forschung zur Erwachsenenbildung in Weiterbildungsorganisationen. ${ }^{895}$ In den Beiträgen zeigt sich zwar, dass sie einer anderen Disziplin als der Literaturwissenschaft entstammen und das Erkenntnisinteresse von meinem abweicht, weil dort vor allem Instrumente zur Evaluation des Bildungsangebotes gesucht werden. Doch können sie die vorliegende Untersuchung unterstützten, weil Programmanalysen dort schon ausgiebiger diskutiert wurden. Sigrid Nolda betont etwa, dass Programmanalysen anfällig seien für Instrumentalisierungen. 896

Für die praxeologische Literaturwissenschaft sind diese Texte und die Untersuchung des ,Werbematerials' ergiebig; zwar sind die keine Textsorte, mit der sich die Literaturwissenschaft üblicherweise befasst, doch erweist es sich als produktiv sie hier mit literaturwissenschaftlichem Blick zu untersuchen. Da diese Arbeit Grundlagenarbeit bei der Analyse sowohl der Institution Literaturhaus generell als auch der Programme speziell leistet, lassen sich noch sehr viele Fragen an das Material stellen. Die Vielschichtigkeit des Gegenstandes erfordert es, sowohl die zugrunde liegenden Praktiken herauszufiltern als auch die Verflechtungen der unterschiedlichen Untersuchungsebenen zu rekonstruieren, literarische Einordnungen vorzunehmen und damit eine literaturgeschichtswissenschaftliche Retrospektive anzubieten sowie dafür jeweils Kriterien zur Operationalisierung zu bestimmen. Dieses Kapitel ist eine Auseinandersetzung mit dem konkreten Material und zugleich eine Reflexion über die Methoden zur Programmanalyse. Gleichzeitig lassen diese Methodendiskussionen erkennen, auf welche Weise welche Untersuchungsaspekte relevant sind und bieten Anschlussmöglichkeiten für andere Studien zu Institutionen und deren Programmen sowie zu Fragestellungen hinsichtlich des gegenwärtigen Literaturbetriebs.

Die Daten werden auf Basis der gedruckten beziehungsweise online zugänglichen Programmankündigungen gesammelt. ${ }^{897}$ Wie die untersuchten Selbstbeschreibungs-

${ }^{894}$ Vgl. Luft 2004, S. 41. In ihrer veröffentlichten Magisterarbeit stellt Sabine Luft die Bedeutung der Verlagsvorschauen für die Arbeit des Verlages heraus. Es finden sich einige Gedanken, die in der vorliegenden Arbeit auf ähnliche Weise herausgearbeitet wurden, Lufts Arbeit jedoch ist eindeutig in der Buchwissenschaft zu verorten und beschränkt sich an vielen Stellen auf die Untersuchung der Werbestrategien der Verlage, statt beispielsweise die generelle Zunahme von Bildern und Fotos - Stichwort Iconic Turn - zu reflektieren.

${ }^{895}$ Vgl. z. B. Beiträge der Sektion „Programmforschung“ im Sammelband von Gieseke (Hg.) 2003.

${ }^{896}$ Vgl. Nolda 2003, S. 223-224. Es müsse folglich sorgfältig gearbeitet und das Vorgehen möglichst offengelegt werden. Diese Aussage sollten Wissenschaftler*innen als selbstverständlich ansehen.

${ }^{897}$ Die Belege aus den Programmheften werden in Klammern im Text angegeben. Dabei folgt die Angabe diesem Schema: Die Abkürzung steht für das jeweilige Literaturhaus. Das folgende Datum im Format ,Jahr-Monat-Tag' benennt den Veranstaltungstag und bezieht sich auf die Angabe im jeweiligen mir vorliegenden Programmheft. Die Programmhefte aus Oslo und Bergen sind mit Seitenzahlen versehen, sodass die Abgabe ,OL-2015-I, S. 3' beispielsweise die dritte Seite des Programmheftes des ersten Quartals 2015 aus dem Literaturhaus in Oslo meint. Die Programmpublikationen aus den untersuchten deutschen Einrichtungen haben keine Seitenzahlen; die Angabe ,BE 2015-01/02‘ weist auf das Berliner Programmheft von Januar/Februar 2015 hin. Der Schrägstrich trennt Anfangs- und Enddatum voneinander. Direkte, nicht extra gekennzeichnete Zitate beziehen sich auf den am Ende des Satzes oder Absatzes angegebenen Veranstaltungstext. 
texte auf den Websites obliegen die verwendeten Formulierungen und Schwerpunktsetzungen den Mitarbeiter*innen der Literaturhäuser, sie müssen also quellenkritisch betrachtet werden. Dies eröffnet gleichzeitig die Chance, Rückschlüsse auf den Adressatenkreis und das Selbstverständnis der Einrichtung zu ziehen. „Der Textproduzent wählt ein Handlungsziel [...], plant und verwirklicht die Texterzeugung; er setzt dazu gesellschaftliche(s)/individuelle(s) Erfahrungen und Wissen ein. Der Textempfänger aktiviert ein sozial, situativ, enzyklopädisch und sprachlich determiniertes Rezeptionsverhalten." ${ }^{898}$ Dabei antizipieren die Absender*innen ein Rezeptionsverhalten bei den Leser*innen, auf das die Texte zugeschnitten werden. Die Texte und Kommunikationsmittel werden entsprechend ihrer jeweiligen Zielgruppe gestaltet, schließlich fungieren sie unter anderem als Werbemittel.

\section{Programme als Absichtsbekundungen}

Es gilt zu betonen, dass die Literaturhaus-Programmhefte lediglich über geplante Veranstaltungen Auskunft geben, und die Texte zeitlich vor der eigentlichen Veranstaltung erstellt wurden. Sigrid Noldas Ausführungen zu der Hypothese „Programme sind ein Weg zur Erschließung von Erwachsenenbildungsrealität [respektive Literaturhaus-Realität, Anmerkung C. L.] - Programme sind nicht identisch mit der Veranstaltungsrealität und dokumentieren Konstruktionen" 899 beziehen sich bei ihr zwar auf ihren Untersuchungsgegenstand, doch sie treffen ebenso auf LiteraturhausProgrammhefte zu. Diese sind mehr Absichtserklärungen als Aufführungsberichte und als solche zu analysieren. Mithin sagen die gedruckten Programmhefte nichts über mögliche kurzfristige Umstellungen bei der Bühnenbesetzung oder über Veranstaltungsausfälle aus. Früher finden sich hin und wieder manuelle Korrekturen oder Ergänzungen mit Aufklebern, heutzutage nutzen die Akteur*innen für spontane Aktualisierungen nach Drucklegung das Internet als Kommunikationsorgan. Da derartige Änderungen erfahrungsgemäß relativ selten vorkommen und sie nicht als programmatische Modifikationen verstanden werden, wirken sie sich auf diese Studie nicht entscheidend aus. Außerdem und weitaus wichtiger zu bedenken ist, dass die Ankündigungen einen geplanten Ablauf der Veranstaltung versprechen, für das tatsächliche Geschehen auf der Bühne sind sie keine Gewähr. Dieser Gedanke ist relevant, wenn später gezeigt wird, dass sich die norwegischen Texte dahingehend von den deutschen unterscheiden, dass sie viel expliziter auf den Fortgang beziehungsweise auf avisierte Gesprächsthemen der organisierten Abende eingehen.

Auf die Möglichkeit eines Unterschieds zwischen Ankündigung und tatsächlicher Durchführung sei ausdrücklich hingewiesen, wenngleich bei der vorliegenden Programmanalyse nicht beabsichtigt ist, besonders ,die Diskrepanz zwischen Selbstdarstellung der Institutionen und Realität der Angebote ${ }^{\text {" } 900}$ aufzuzeigen, wozu es eingehender Aufführungsuntersuchungen bedürfte. Da das Literaturhaus regelmäßig Veranstaltungen durchführt und somit Interesse besteht, die Zuhörer*innen wiederholt zu gewinnen, ist anzunehmen, dass im Programmheft nur angekündigt und damit zugesichert wird, was tatsächlich passiert oder zumindest angestrebt ist. Dies

\footnotetext{
898 Thiele 2008, S. 706.

${ }^{899}$ Nolda 2003, S. 213.

900 Cepl-Kaufmann: „Vom Einblatt“, S. 1.
} 
ist eine intuitive Form von Erwartungsmanagement, denn Zuschauer*innen, die mit durch Werbung evozierten unangemessenen Aussichten das Literaturhaus besuchen, werden vermutlich enttäuscht und eher unzufrieden nach Hause gehen.

\section{Vergleichende Darstellung}

Neben der Verknüpfung von Methodenreflexion und Interpretation akzentuiert die Darstellung die Ergebnisse der vergleichenden Analyse. Deshalb werden die einzelnen Literaturhäuser wie im vorherigen Unterkapitel gleich kontrastiert - zugunsten der komparativen Arbeit, zulasten der Präsentation der einzelnen Literaturhäuser. Dennoch muss beispielsweise Berücksichtigung finden, wer zu welcher Zeit für das Programm verantwortlich ist, sodass auffällige Änderungen in einem LiteraturhausProgramm gegebenenfalls auf einen Leitungswechsel zurückzuführen sind. Um einordnen zu können, wie sich ein einzelnes Literaturhaus zur Gesamtinstitution verhält, gilt zu klären, wie sich das jeweilige Programm in die Tradition des Hauses einfügt, ob es sich um Alleinstellungsmerkmale oder institutionstypische Charakteristika handelt.

\section{Eingrenzung des Materials}

Ein weiterer wichtiger Unterschied der hier durchgeführten Analyse etwa zu Schmitts Studie ist, dass Schmitts Untersuchungsperiode der Begutachtung der erst später aufkommenden ,Jungen Literaturhäuser' deutlich kürzer ist. Neben einem überschaubareren Materialkorpus bedeutet dies, dass statt einer Entwicklung ein Zustand beschrieben wird. Die historische Dimension ist für die Erfassung der Institution Literaturhaus aber sehr relevant, sodass hier die frühen Programme einbezogen werden. Vorgestellt werden schwerpunktmäßig die Programme der Einrichtungen in Berlin, Hamburg, Frankfurt, Göttingen, Oslo und Bergen. Die Literaturhäuser in Kopenhagen und Göteborg sind anders organisiert als die untersuchten deutschen und norwegischen, sodass auf ein regelmäßiges Druckprodukt auch aus Kostengründen - verzichtet wird. Da, wie bei den Einzelvorstellungen herausgearbeitet, ${ }^{901}$ es sich als sinnvoller erweist, klarer zwischen den norwegischen, schwedischen und dänischen Literaturhäusern zu differenzieren, werden das dänische und das schwedische Literaturhaus vor allem zur Illustration der Spannweite der Institution hinzugezogen, sie sind nicht in deren Zentrum anzusiedeln, werden im Folgenden weiterhin für Ausblicke hinzugezogen.

Eine weitere Eingrenzung des Materials ergibt sich durch die Konzentration auf das sogenannte Hauptprogramm. Das Kinder- und Jugendprogramm sowie das Angebot von externen Veranstalter*innen werden zwar als strukturell wichtige Bestandteile der Institution identifiziert und entsprechend mit eigenen Abschnitten berücksichtigt, doch lässt sich ihre inhaltliche Ausgestaltung innerhalb dieser Arbeit nicht in notwendiger Ausführlichkeit darlegen.

${ }^{901}$ Vgl. Kapitel II 8.3. 


\section{Drei Perspektiven auf die Programme}

In den folgenden Kapiteln (bis II 14) sind drei Perspektiven auf die Programmhefte von Interesse. Erstens richtet sich der Blick auf die Publikationsweise und Gestaltung der Programme sowie auf die vermittelten Auskünfte über organisatorische Rahmenbedingungen des Angebots. Zweitens werden die Veranstaltungsankündigungstexte als Texte analysiert. Und drittens stellen die Informationen, die aus den Heften hinsichtlich der inhaltlichen Ausgestaltung des Programmes extrahierbar sind, das Material für eine Beschreibung und Interpretation des Angebots dar. Ein Exkurs scheint das Unterkapitel zu den Onlineaktivitäten der Literaturhäuser zu sein. Es schafft jedoch eine wichtige Verbindung zum größeren zeithistorischen und gesellschaftlichen Kontext des Zeitalters der Digitalisierung und steht gleichzeitig in direktem Zusammenhang sowohl mit den gedruckten Programmheften, den Werbemaßnahmen, den Vermittlungsformaten als auch dem (Selbst-)Verständnis des Literaturhauses.

Zunächst werden die Funktionen der Programmhefte erläutert, um deren Bedeutung für die Institution herauszuarbeiten und damit die Untersuchungsmomente deutlicher zu strukturieren und die Argumentation für das weitere Vorgehen zu fundieren. Im Anschluss steht die Vorstellung der Programmhefte, um dann ausgehend vom Material verschiedene Aspekte herauszuarbeiten, die nicht thematisch, sondern nach dem jeweiligen Untersuchungsgegenstand sortiert sind. Es zeigt sich, dass das Selbstverständnis der Einrichtungen, die Adressierung des Programmes und die Absichtserklärungen seitens der Literaturhaus-Organisationen für das Verständnis der Institution mindestens ebenso wichtig sind wie die tatsächliche Ausgestaltung des Programmes.

\section{10.2 Funktionen der Programmhefte}

Die Programme erfüllen mehrere Funktionen. (1.) Die Literaturhaus-Programmhefte vermitteln Informationen zu den Veranstaltungen. (2.) Damit werben sie für das Angebot des Literaturhauses. (3.) Die Ankündigungs- und Einleitungstexte haben feuilletonistischen Charakter und machen die Hefte zu kleinen Magazinen, die auch (4.) Aufschluss über die Kulturlandschaft der jeweiligen Zeit bieten, darüber, was in den jeweiligen Jahren diskursrelevant war. (5) Die Druckwerke erfüllen eine Erinnerungsfunktion, denn hier sind alle bisherigen Angebote archiviert. (6.) Sie fungieren als eine Art, Visitenkarte' des Literaturhauses, indem sie auf mehreren Ebenen wichtige Beiträge zur Markenbildung der Einrichtung leisten. ${ }^{902}$ Adressat*innen der Programmhefte sind das potenzielle Publikum und andere Akteur*innen, die sich für das Literaturhaus insgesamt interessieren, wie Kooperationspartner*innen oder Konkurrent*innen. Die Annahme, dass die Programmhefte nicht nur Einzelveranstaltungen ankündigen, sondern ebenso, vorausschauend und im Blick zurück, ein Bild des Literaturhauses vermitteln, findet damit Unterstützung. Die folgenden Ausführungen unterstreichen das methodische Vorgehen, in-

902 Dass diese Magisterarbeit über Verlagsvorschauen, Visitenkarte des Verlags` im Titel trägt, beweist, wie anschaulich das Bild der Visitenkarte ist, das auch in der vorliegenden Arbeit schon intuitiv verwendet wurde, vgl. FN 894. 
dem sie erläutern, in welcher Hinsicht die Programmhefte als Material produktiv für die Analyse der Institution Literaturhaus sind.

\section{(1.) Informationen zu den Veranstaltungen}

Die Programmhefte beinhalten in erster Linie textlich vermittelte Informationen, diese finden sich in Veranstaltungsankündigungstexten, die den größten Anteil der Broschüren ausmachen, sowie in den begleitenden Auskünften. Die Informationsfunktion ist zentral, denn die Hefte können als „ereigniszentrierte intentionale Informationsträger “903 beschrieben werden. In dieser Formulierung steckt zum einen der Gebrauchstextcharakter, zum anderen der von einer speziellen Veranstaltung abhängige Bedarf für den jeweiligen Einladungstext. Das Literaturhaus-Programm liefert mit den Detailtexten zur einzelnen Veranstaltung eine Kurzeinleitung in die jeweilige Aufführung. Sie enthalten dabei gerade die Informationen, die die Rezipient*innen überzeugen sollen, zur vorgestellten Veranstaltung zu kommen und/oder das Gesamtprogramm als attraktiv einzuschätzen. Die Aufgabe der Informationsvermittlung ist also kaum trennbar von den nachfolgend erwähnten Funktionen der Werbung und der Repräsentation der Literaturhaus-Arbeit.

Da die Programmtexte Angaben zu den Veranstaltungen enthalten, können sie außerdem verwendet werden, um Aussagen zu den geladenen Gästen, den Themen und Formaten zu treffen, was später in dieser Arbeit geschieht. Sie geben zudem indirekt Hinweise auf die antizipierte Zielgruppe und etwa das Literaturverständnis der Akteur*innen, denn die Auswahl der Informationen und ihre sprachliche und gestalterische Präsentation lassen derartige Rückschlüsse zu. Dies wird ebenso vertieft werden.

\section{(2.) Werbende Funktion}

Wie erwähnt dienen die Programmhefte der Veranstaltungsankündigung und damit gleichsam der Werbung. ${ }^{904}$ Bereits 1983 plädierte Florian Tielebier-Langenscheidt in seiner Dissertationsschrift Werbung für deutsche Gegenwartsliteratur für eine Berücksichtigung von Werbung in der literaturwissenschaftlichen Praxis, was damals ein Novum war. ${ }^{905}$ Die vorliegende Arbeit beweist mehr als 35 Jahre später, dass Werbematerial in literaturwissenschaftliche Forschung selbstverständlicher einbezogen wird und so gilt es möglicherweise heute besonders, an den werblichen Charakter zu erinnern und das Material einer notwendigen quellenkritischen Betrachtung zu unterziehen. Aufschlussreich ist es für diese Studie zur Literaturvermittlung, zu reflektieren, wie sich der Umgang mit den Programmheften als Werbemitteln entwickelt.

\footnotetext{
903 Helmut Schanze zitiert nach: Cepl-Kaufmann: „Vom Einblatt“, S. 1.

${ }^{904}$ Da unter ,Marketing in der Wissenschaft jedoch nicht nur explizite Werbemaßnahmen verstanden werden, sondern dazu die Bereiche Produkt-, Preis-, Distributions- sowie Kommunikationspolitik zählen, und das, was in dieser Arbeit als, Werbung' bezeichnet wird, nur einen Teil der Kommunikationspolitik ausmacht, verzichte ich in dieser primär literaturwissenschaftlich angelegten Arbeit weitestgehend auf den Terminus ,Marketing', um ihn gerade nicht durch die alltagssprachliche Verwendung zu verwässern. Gleichzeitig gründen die hier vorgestellten Überlegungen auf Vorgehensweisen, die mit Begriffen der Marketingforschung unterstützt werden könnten. Zugeschnitten auf den Kulturbetrieb führt Armin Klein die Grundlagen des Marketings gut zusammengefasst aus, vgl. Klein 2011b.

905 Vgl. Tielebier-Langenscheidt 1983. Eine aufschlussreiche Studie, die in vielen Aspekten weiterhin hilfreich ist.
} 
Die weiter unten ausgeführten Textanalysen belegen, dass diese Funktion im Zeitverlauf expliziter wird. Das lässt sich nicht nur an der Machart der Texte belegen, sondern ebenfalls daran, dass eigene Werbeanzeigen für die Vereinsmitgliedschaft oder für den Vorverkauf regelmäßiger in die Broschüren integriert werden.

Die Marketingaktivitäten und Öffentlichkeitsarbeit der Literaturhäuser nehmen seit den Anfangsjahren zu, was in Zusammenhang mit der steigenden ökonomischen Abhängigkeit von einem Publikum zu deuten ist. Dabei ist zu beachten, dass das Literaturhaus als teils öffentlich finanzierte und häufig gemeinnützig wirkende und damit nicht gewinnorientierte Einrichtung vor allem zwei Marketingziele avisiert - wie schon Armin Klein ausführt: „Zum einen sind die vorgegebenen bzw. selbst gesetzten inhaltlichen Zielsetzungen so gut wie möglich zu realisieren und dabei andererseits der anvisierte Interessentenkreis so weit wie möglich zu erreichen. "906 Die Kommunikationspolitik der Einrichtungen ist entsprechend auf diese Ziele zugeschnitten.

\section{(3.) Feuilletonistische Kommentarfunktion}

Literaturhäuser kommentieren und reflektieren unter anderem das aktuelle Literaturbetriebsgeschehen und sind Teilnehmer am gegenwärtigen literarischen Diskurs. Dies lässt sich anhand der Programmhefte respektive der Ankündigungstexte belegen. Die Texte sind als Organe sekundärer literarischer Kommunikation zu deuten, denn sie sind, wie später ausgeführt wird, als Kurzrezensionen zu Büchern oder als Artikel über Autor*innen zu interpretieren. Außerdem greifen sie generelle literarische oder zeitlich gebundene Themen auf, indem sie etwa auf die Bedeutung eines bestimmten Genres oder auf zeitgenössisch aktuell geführte Diskussionen etwa im Feuilleton oder in der Wissenschaft referieren, sodass sie sogar ohne direkten Bezug zur verknüpften Veranstaltung gelesen werden können. Dies lässt sich als feuilletonistische Kommentarfunktion benennen.

Zudem deuten Äußerungen seitens der Literaturhäuser in den Medien, inzwischen vor allem über Onlineplattformen, auf diese Teilnahme am Literaturbetrieb hin: Zum Beispiel posteten die meisten deutschen Einrichtungen am Tag der Veröffentlichung der Longlist zum Deutschen Buchpreis 2015 - am 20. August 2015 - einen Beitrag auf Facebook, meist mit dem Verweis darauf, welche der nominierten Autor*innen bei ihnen im Literaturhaus zu Gast waren und/oder noch sein werden. Dies markiert vor allem die breite Wahrnehmung und Marketingkraft des Deutschen Buchpreises, doch offenbart diese Seitenbemerkung ebenso die Verankerung der Literaturhäuser im aktuellen Literaturbetrieb. ${ }^{907}$ Die Tatsache, dass das Literaturhaus Berlin zunächst in keinem sozialen Netzwerk präsent war, lässt somit ersichtlich werden, dass die Nichtteilnahme am Austausch im Internet auch damit einhergeht, dass diese Einrichtung sich nicht öffentlich zu Geschehnissen des Literaturbetriebes äuBerte - was dem Selbstverständnis des Literaturhauses Berlin unter der Leitung von Ernest Wichner entsprach. ${ }^{908}$ Dass die Literaturhaus-Leiter*innen gelegentlich von der Presse zu allgemeinen literarischen Themen befragt werden, sei hier ebenfalls

\footnotetext{
906 Klein 2011b, S. 543, Hervorhebungen im Original.

${ }_{907}$ Hier deutet sich an, dass die Onlineaktivitäten die Programmhefte ergänzen, was hinten vertieft wird. 908 Vgl. z. B. FN 465.
} 
erwähnt. Daran lässt sich noch besser festmachen, dass das Literaturhaus als Beiträger zum literaturbetrieblichen Diskurs anerkannt ist.

\section{(4.) Zeitdokumente}

Die Programmhefte sind weiterhin ertragreiche Zeitdokumente, die bisher von der Forschung nicht weiter beachtet wurden. Vorteil dieser Archivalien ist, dass sie sich nicht wie der Onlineauftritt ständig verändern können. Und im Gegensatz zu Interviews, die auch deshalb nicht die Hauptquellen dieser Untersuchung darstellen, behalten die Programmhefte ihre jeweils zeitgenössische Perspektive. Rekonstruierende Rückblicke geschehen erst innerhalb dieser Arbeit, persönliche Erinnerungen von Beteiligten bleiben so weitgehend außen vor. Die Dokumente bewahren damit

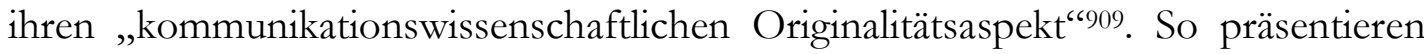
sie einen unvermittelten Blick auf die historischen Inhalte, Formulierungen und Gestaltungselemente und lassen Aussagen über ihre jeweilige Gegenwart zu. „Programmanalysen belegen die Abhängigkeit des Angebots vom Zeitgeist “910, wie Sigrid Nolda es sieht. Gleichzeitig ist anzunehmen, dass die Programminhalte nicht nur abhängig sind von Denkmoden, sondern entscheidend auf diese einwirken und diese mitprägen. Deshalb sollte eher von einer gegenseitigen Einflussnahme von ,Zeitgeist ${ }^{`}$ - ob der fehlenden Begriffsschärfe in Anführungszeichen geschrieben und Programmangeboten - hinsichtlich ihrer Inhalte sowie ihrer Kommunikation gesprochen werden. Chance und Manko zugleich gegenüber Interviews ist, dass das Material ohne Vorsortierung und Strukturierung durch die Interviewpartner*innen untersucht werden muss, wodurch keine Schwerpunktsetzung vorgegeben ist.

\section{(5.) Erinnerungs- und Archivfunktion}

In den gedruckten Heften sind alle Informationen zu den Veranstaltungen, die nach außen kommuniziert wurden, konserviert. Dieses Archiv bietet unter anderem für die Arbeit der Literaturhäuser eine wichtige Quelle, um, zum Beispiel, zu recherchieren, wann ein Autor/eine Autorin zuletzt zu Gast war, welche Kooperationspartner daran beteiligt waren oder wer die Lesung moderiert hat. Seit der Nutzung etwa von elektronischen Datenbanken und den Websites finden sich diese Informationen auf anderem Wege. Alles davor ist in der Regel nicht digital archiviert.

Wie beim Programmheft im Theater ist folglich für das Literaturhaus-Heft „die polyvalente Fähigkeit des Mediums, Informationsträgerschaft und Memorialfunktion zu übernehmen“911 explizit zu nennen, denn eng mit der Nutzbarkeit der Programmhefte als Zeitdokumente ist die Archivfunktion verbunden. Klaus Gerlach geht sogar noch weiter, wenn er für Theaterzettel konstatiert, dass diese anstatt des theatralen Ereignisses wirkten, dass sie „Repräsentanten“"912 seien. Sie dienen damit ebenso Gästen als Erinnerungsmomente wie Wissenschaftler*innen als Archivmaterial, um das Angebot aus zeitlicher Distanz nachvollziehen zu können. Die Ankündigungen fungieren als Stellvertreter der tatsächlich durchgeführten Veranstaltun-

\footnotetext{
${ }^{909}$ Helmut Schanze zitiert nach: Cepl-Kaufmann: „Vom Einblatt“, S. 2.

${ }_{910}$ Nolda 2003, S. 218.

${ }^{911}$ Klaus Gerlach zitiert nach: Cepl-Kaufmann: „Vom Einblatt“, S. 4.

912 Klaus Gerlach zitiert nach: ebd.
} 
gen. Damit gehen insbesondere die im Vorhinein verbreiteten Texte in die Archive ein, was Gerlachs Argumentation stützt, diese Ankündigungen als Repräsentanten zu begreifen. Die Kommunikation seitens der Literaturhäuser ist zum Großteil auf die kommenden Angebote ausgerichtet. Die tatsächliche Veranstaltung ist damit für das persönliche Erleben der Teilnehmenden reserviert. Nachberichte sind selten. ${ }^{913}$

Während die Programmzettel aus den Anfangsjahren der frühen Literaturhäuser Berlin, Hamburg und Frankfurt nur spärlich vorhanden sind, gibt es später in der Regel deutlich mehr Exemplare jeder Ausgabe. Dies hängt damit zusammen, dass gelegentlich Exemplare herausgegeben werden und es sich nicht um professionelle Archive handelt, was darauf hindeutet, dass die Literaturhäuser erst nach und nach stärker darauf setzen, die Geschichte ihrer Einrichtung zu dokumentieren und sich ihrer eigenen Historizität bewusst werden. Es lässt sich annehmen, dass sich der Gedanke, dieses Material aufzubereiten und somit nachhaltig auch außerhalb der Einrichtung nutzbar zu machen, erst durch die Möglichkeit der langfristigen öffentlichen Verfügbarkeit von Programmen online festigt. Dies gilt insbesondere für die Tonarchive, die viele Einrichtungen besitzen und die nur sukzessive aufbereitet werden, worin viele hochwertige Fundstücke für die Forschung lagern. Die Archive der Literaturhäuser sind nicht nur Archive der einzelnen Häuser, sondern symptomatisch für den zeitgenössischen Literaturbetrieb als ,Zeitdokumente“ untersuchbar: Für die Forschung zu einzelnen Autor*innen und beispielsweise zur Entwicklung von deren Rezeption können diese Hefte Aufschluss über Kanonisierungsprozesse geben. Die vorliegende Arbeit stellt unterschiedliche Perspektiven auf dieses Material auszugsweise vor.

\section{(6.) ,Kurzprofil' des Literaturhauses/Markenbildung/selbstidentifikatorische Funktion}

Die Tatsache, dass alle Literaturhäuser ihre Programmhefte archivieren, bildet ein Argument für die sechste und jetzt letztgenannte Funktion. Die Programmhefte stellen ein wichtiges Instrument zur Markenbildung und Selbstdarstellung dar, da sie als Bestandteil der Corporate Identity, „die strategisch geplante und operativ eingesetzte Selbstdarstellung und Verhaltensweise eines Unternehmens nach innen und außen“9914, gelten. Sie können als ein ,Kurzprofil' des Literaturhauses interpretiert werden.

Auf zwei Ebenen präsentieren die Programmhefte das Profil des jeweiligen Literaturhauses: Erstens geschieht dies durch die vermittelte Kontinuität durch ein wiedererkennbares Design. Ebenso ist dabei die textliche Gestaltung zu berücksichtigen, die Aufschluss über den implizierten Leser respektive das angesprochene Publikum gibt. Exemplarische Textanalysen im übernächsten Kapitel vertiefen diesen Aspekt hinsichtlich der Gattung des Ankündigungstextes, der als Gebrauchstext zwischen Werbung und literaturkritischer Äußerung changiert. Zweitens trägt die Präsentation des Veranstaltungsangebots auf inhaltlich-programmatischer Ebene zur Profilbildung des Literaturhauses bei; diese Untersuchungsdimension macht einen weiteren Teil der folgenden Analyse aus.

913 Vgl. z. B. Kapitel II 12.3.

${ }^{914}$ Schnell 2005, S. 95. 
Als selbstidentifikatorisches Mittel sind die Programmhefte zusätzlich ein Arbeitsprodukt des Teams. Die Arbeitsprozesse sind an den Drucktermin des neuen Programmheftes gebunden, dies ist der Zeitpunkt, an dem möglichst alle Informationen zur Veranstaltung stehen müssen, sodass sie in Druckerschwärze fixiert werden können. Die Bedeutung des Drucktermins der Hefte bestätigt zum Beispiel Litteraturbuset in Oslo damit, das in der Regel alle eigenen Veranstaltungen gedruckt einsehbar sind. Bei den externen Veranstaltern kommen nach Druckschluss gelegentlich Angebote hinzu, die dann nur online auftauchen.

Damit ist eine Gleichsetzung der Vokabeln ,Programmheft' und ,Programm` in dieser Hinsicht nachvollziehbar. Die gedruckten Programme stellen die Spielpläne der Literaturhäuser dar. Dabei macht es einen Unterschied, ob sie monatlich, zweimonatlich, quartalsweise oder semesterweise erscheinen. Das Literarische Zentrum Göttingen gab bis Anfang 2018 ein Halbjahresprogramm heraus, welches etwa sechs Monate präsent war, während die Monatsprogramme des Literaturhauses Hamburg nach vier bis sechs Wochen, vergessen' sind. Die Veranstaltungen des Literarischen Zentrums Göttingen, die in der Zahl geringer sind, wirken damit möglicherweise nachhaltiger auf die Einrichtung als die vielen Veranstaltungen des Literaturbauses Hamburg. Doch gehört es wohl zum Profil des Literaturbauses Hamburg, zahlreiche Angebote innerhalb eines Monats zu präsentieren, die jeweils kompakt beworben werden.

In jedem Fall halten die Programmhefte trotz Flüchtigkeit und Einmaligkeit jede einzelne Veranstaltung fest, die in einem Monats- oder Halbjahresspielplan kontextualisiert ist. Aus diesem Grund lassen sich die Veranstaltungsankündigungen als ein Gesamttext rezipieren, der programmatisch für das Image eines jeden Literaturhauses steht und mittels des Vergleichs ein Bild der Institution zeigt. Die einzelne Veranstaltung gilt es deshalb im Zusammenhang der Gesamtheit aller Veranstaltungen zu interpretieren. Zu sehen ist dann, ob die Einrichtungen stärker an einer Gesamtlinie arbeiten, oder ob sie sich über einzelne ,Schlaglichter' positionieren. So wie es in dieser Arbeit nicht um den Einzelfall, sondern um das Gesamtkonstrukt ,Literaturhaus' geht, dienen bei der Analyse einzelne Veranstaltungen als Exempel für das Komplettprogramm.

Zusammenfassend lässt sich sagen, dass die markante Präsenz der Ankündigungen offenbart, wie bedeutend es für die Selbstidentifikation der Literaturhäuser ist, was geplant und angeboten wird. Erst auf einer nachgelagerten Ebene geht es darum, wie die Einrichtungen die Angebote tatsächlich realisieren. Für die Analyse des Literaturhauses ist es dementsprechend sinnvoll, den Einladungstexten als Selbstpräsentations-, Werbe- und Informationsorgan viel Platz einzuräumen.

Dabei ist zu diskutieren, dass gerade im Zusammenhang mit der Forderung nach politischer und gesellschaftlicher Debatte im Literaturhaus diese Flüchtigkeit der Veranstaltungen gewissermaßen paradox erscheint, denn es lässt sich ein grundsätzliches Dilemma des Literaturhauses vermuten: Die programmatische gesellschaftliche und literaturkritische Bedeutung des Literaturhauses kollidiert mit dem Erlebnischarakter und der flüchtigen Unmittelbarkeit des Live-Events. Selbst wenn angenommen wird, dass die Zuschauenden aus der Veranstaltungserfahrung weitergebildet werden, so ist das Konstrukt, relativ teure Einzelveranstaltungen für ein 
zahlenmäßig stark begrenztes Publikum anzubieten, exklusiv. Werden die Ebenen von nachhaltiger Programmarbeit und individuellem Live-Erleben jedoch getrennt voneinander betrachtet, so lassen sich gerade diese beiden Momente als für das Literaturhaus gleichermaßen zentrale, nicht dichotomische Funktionsaspekte destillieren. In Bezug auf die einzelne Veranstaltung steht das persönliche Erlebnis für die Besucher*innen im Vordergrund. Hinsichtlich des Gesamtprogramms interessiert die generelle Ausrichtung des Literaturhauses als Literaturbetriebsakteur. Die Programmhefte zeigen nämlich außerdem, dass den Literaturhäusern daran gelegen ist, über die Ganzheit ihrer Angebote und damit als kontinuierliche Literaturvermittlungseinrichtungen wahrgenommen zu werden. Die Programmhefte lassen sich gar als eigentliche Ausstellungsstücke des Literaturhauses begreifen.

Die Literaturhaus-Programmhefte erfüllen ihren primären Zweck, die Veranstaltungsankündigung; sie sind jedoch nicht nur temporär gültige Kommunikationsmittel, sondern im Gesamtzusammenhang wichtige Instrumente zur Institutionsbildung. So lässt sich beispielsweise anhand der ersten Programme der frühen Literaturhäuser erkennen, dass sich zunächst eine Ankündigungspraktik herausbilden muss, die dann recht zügig konventionalisiert und damit professionalisiert wird. Nach anfänglichem Ausprobieren mit Textlängen und Informationsgehalt hin zu einheitlicheren Präsentationen gleichen sich die Programmfolder einander relativ schnell an. In Aufbau und Struktur ähneln die heutigen Produkte den älteren noch sehr. Ein aufwendig und gut recherchiertes Programmheft gehört auch im Zeitalter der Digitalisierung zum Selbstverständnis des Literaturhauses. ${ }^{915}$ Neben den norwegischen Literaturhäusern räumt beispielsweise das neukonzipierte Literaturhaus Freiburg der gedruckten Publikation eine hohe Relevanz ein, indem es mit einem aufwendig gestalteten Heft startete.

Unter Berücksichtigung der individuellen Ausgestaltung, die das Profil der einzelnen Literaturhäuser herausstellt, kann für die Institution Literaturhaus konstatiert werden, dass eine grundlegende Programmheftpragmatik erkennbar ist. Diese wird im Folgenden näher beleuchtet und bildet gleichzeitig das Fundament für die Programminterpretation der Fallbeispiele.

\section{10.3 Format und Erscheinungsturnus}

Formate und Gestaltung

Mit den hier relevanten sechs Fallstudien, vier deutschen und zwei norwegischen Literaturhäusern, entstand ein Korpus aus sondierten Programmheften, die insgesamt rund 1.100 Literaturhaus-Monate umfassen. ${ }^{916}$ Die Bilder im Anhang illustrie-

\footnotetext{
915 Der fortwährenden Bedeutung des gedruckten Programmheftes im Zeitalter der Digitalisierung widmet sich das Unterkapitel zu den Onlineaktivitäten, vgl. Kapitel II 12.7.

916 Die Schätzung kommt unter der Annahme zustande, dass in jedem Jahr 11 Monate Veranstaltungen stattfinden. Im Gründungsjahr ist der Zeitpunkt der Eröffnung berücksichtigt worden. Bei den sechs Literaturhäusern ergibt sich dann eine Summe von 1.111 Monaten. Mit der Schätzung der jährlich durchschnittlichen Zahl der Veranstaltungen ergibt sich für diese Literaturhäuser eine Veranstaltungszahl, die zwischen 9.000 und 10.000 steht. Es ist also klar, dass nicht alle Veranstaltungen in dieser Arbeit Berücksichtigung finden können.
} 
ren die gestalterische Entwicklung der Programme. ${ }^{917}$ Bisher war verallgemeinernd von ,Programmheften“ die Rede. Tatsächlich kommen in der Geschichte der gedruckten Literaturhaus-Programme jedoch Faltblätter/Folder, Leporellos, Flyer und Broschüren vor. Es gibt gefalzte und geheftete beziehungsweise geklebte Ausführungen. Die meisten Einrichtungen der Fallstudien arbeiten inzwischen mit Heftvarianten. Die deutschen verwenden Hefte, die norwegischen für die umfangreichen Quartalsprogramme zunächst ebenfalls, wechselten 2011 aber zu Klebebindungen mit einem Buchrücken. Ausnahme bildet das Literarische Zentrum Göttingen, das die Anzahl ihrer Semesterveranstaltungen gut auf zwei Folderseiten abbilden kann. ${ }^{918}$ Auch das Literaturhaus Stuttgart etwa nutzt für das Monatsprogramm eine Falzausgabe. Das Endformat vieler deutscher Programmhefte ist DIN lang, das Format von Standardbriefumschlägen, in die zweifach quer gefaltete DIN A4-Seiten passen, was eine übliche Größe für derartige Druckprodukte ist. Es eignet sich für den Postversand und entspricht den Vorgaben für Flyer-Auslagestellen. Das Literaturhaus Berlin wechselte 2009 von diesem Format zu einer DIN A6-Variante. Davon abweichende Maße weisen die Produkte der Einrichtungen in Oslo und Bergen auf, die Differenz von Höhe zu Breite ist dabei geringer, sodass sie eher Broschüren sind. Da derartige gestalterische Details für die weitere Untersuchung nicht relevant sind, wird im Folgenden verallgemeinernd von ,Programmheft ${ }^{6}$ - respektive zur sprachlichen Variation von Leporellos, Foldern, Flyern oder ähnlichem - gesprochen.

Bemerkenswert ist an dieser Stelle noch die Tatsache, dass das Literaturhaus Oslo das erste war, das kein Leporello, sondern ein Heft einsetzte. Die Transferprozesse innerhalb der Institution Literaturhaus lassen sich anhand der Gestaltung der Programmhefte herausarbeiten, da hier sehr deutlich wird, dass die neueren deutschen Broschüren von der norwegischen Variante, die zumindest in Oslo bereits seit 2007 gedruckt wird, inspiriert wirken. Die Austauschbewegungen sind reziprok, denn Litteraturhuset begutachtete die deutschen Druckprodukte, entwickelte seine eigene Version, die wiederum die aktualisierten Designs in Berlin, Hamburg, Frankfurt und Göttingen beeinflusst zu haben scheint, da die neueren deutschen Hefte in der Grundstruktur dem Osloer sehr ähnlich sind.

\section{Erscheinungsturnus}

,Monatsprogramm` bezeichnet im Folgenden - sofern nicht explizit auf die monatliche Erscheinungsweise hingewiesen wird - generalisierend regelmäßige zeitlich begrenzte Druckprodukte zur Ankündigung mehrerer Veranstaltungen. Faktisch unterscheiden sich die Hefte hinsichtlich ihres Erscheinungsturnus. Das Literaturbaus Hamburg ist das einzige der Fallbeispiele, jedoch nicht das einzige Literaturhaus überhaupt, das seit Beginn jeden Monat ein neues Programm veröffentlicht, mit Ausnahme von Doppelheften für den Jahreswechsel und die Sommermonate. Auf

\footnotetext{
917 Vgl. Anhang V 2.

918 Im Literaturhaus Berlin entsteht mit dem Leitungswechsel Anfang 2018 ein neues CI mit überarbeiteter Website und passendem Programmfolder. Diese Neupräsentation kann in der vorliegenden Arbeit jedoch nur am Rande betrachtet werden, erstens, weil der Hauptuntersuchungszeitraum sowieso nur bis 2015 geht, zweitens, weil es sich aus arbeitspragmatischen Gründen nicht umsetzen lässt, alle Neuerungen gleich zu reflektieren und, drittens, weil sich die endgültige neue Variante im Literaturbaus Berlin selbst noch nicht herauskristallisiert hat.
} 
gleiche Weise verkünden die Einrichtungen in Stuttgart und München ihr umfangreiches Veranstaltungsangebot. Das Literaturbaus Berlin und das Literaturbaus Frankfurt begannen mit Zweimonatsflyern. Während in Berlin der Rhythmus beibehalten wurde, weitete die Einrichtung in Frankfurt die Gültigkeitszeiten aus. Seit Herbst 2010 - zum Auftakt des neuen Leiters - erschienen die Hefte jeweils für drei Monate, seit 2016 sogar für noch längere Zeiträume. Quartalsweise bilden die Broschüren der beiden norwegischen Literaturhäuser das Programm ab, zuzüglich entsteht jeweils ein Sommerheft. Diese neueren Literaturhäuser haben sich also von der in Deutschland üblichen Praxis der kurzfristigeren Veröffentlichungen abgewendet. $\mathrm{Ob}$ das zeitlich nach dem Osloer Litteraturbuset eingeführte länger gültige Programmheft in Frankfurt von der norwegischen Variante inspiriert wurde, lässt sich nur vermuten. Gleichfalls lässt sich annehmen, dass die Erfahrung von Hauke Hückstädt in Göttingen mit einem temporal ausgedehnt nutzbaren Druckprodukt zu dieser Umstellung führte. Das Programm des Literarischen Zentrums Göttingen nämlich erschien zweimal im Jahr, im Frühjahr und im Herbst, angepasst an die akademischen Semesterzeiten der Universität. Diese Angleichung belegt die beschriebene enge Verbindung dieser Einrichtung zur Universität.

Während monatlich erscheinende Hefte spontanere Planungen und Änderungen zulassen, eine geringere Anzahl von Veranstaltungen abbilden und diese damit exklusiver bewerben, ermöglichen seltener erneuerte Programme längerfristige Planungen - sowohl für die Literaturhaus-Teams als auch für die Besucher*innen. Die länger gültigen Programme zeigen, dass in den Literaturhäusern nicht nur monatsweise, sondern weiter im Voraus geplant wird. Außerdem stellen die gedruckten Hefte nicht mehr das einzige Ankündigungsorgan dar und so kann die Außenkommunikation über die Onlinekanäle nachjustiert werden, sollten sich spontane Änderungen ergeben.

Bemerkenswert ist dann, dass im Zeitalter der Digitalisierung die Planungsperioden nicht kürzer werden, ganz im Gegenteil: Die Vorlaufzeiten dehnen sich aus. Dass, wie Literaturhaus-Mitarbeiterin*innen bestätigen, viel weiter in die Zukunft geplant wird als anfangs, parallel aber, wie später ausführlicher dargelegt, zunehmend Neuerscheinungen bei den Veranstaltungen thematisiert werden, illustriert die Beschleunigung des Literaturbetriebes. Es ist sogar so, dass sich auf den Buchmessen die Literaturhaus-Leitungen nicht mehr über die eigentlich derzeitig aktuell erscheinenden Bücher informieren, sondern sogenannte Vorvorschauen erhalten, die - der Name verrät es schon - jeweils das für die übernächste Saison geplante Angebot präsentieren. Auf der Frankfurter Buchmesse im Oktober erfahren sie also, welche Titel auf der Leipziger Buchmesse im März den Leser*innen vorgestellt werden. Diese längerfristigen Planungen können mitunter dazu führen, dass Veranstaltungen zu Büchern angekündigt werden, die bei Drucklegung des Programmes selbst noch nicht gedruckt vorliegen.

Alle untersuchten deutschen Programmhefte wurden im Laufe der Zeit mindestens einem Designwandel unterzogen. Feststellbar sind gestalterische Veränderungen, die nicht immer mit einer Erneuerung der gesamten Corporate Identity einhergehen, wenn eine neue Person die Leitung übernimmt oder bei Vereins- und Eröffnungsjubiläen. Manchmal lassen sich jedoch keine äußeren Gründe für die Veränderung 
attestieren, wie bei der grafischen Reorganisation im Literaturhaus Hamburg 2013. Diese kann allerdings im weiteren Kontext des 25-jährigen Jubiläums 2014 verortet werden. Vorher wurde dort die Gestaltung zum Beispiel im Dezember 1993 verändert, ein Jahr nachdem Ursula Keller die Programmleitung übernommen hatte. Sofort mit Antritt der neuen Führungspersonen 2010 präsentieren sich das Literarische Zentrum Göttingen und das Literaturbaus Frankfurt über ihre Folder in gewandelter Form. Das erneuerte Heft visualisiert eindeutig den avisierten programmatischen Umschwung, was ein Argument für die Annahme ist, das Programmheft als ein wichtiges Repräsentationsinstrument des Literaturhauses zu verstehen.

Die norwegischen Literaturhäuser arbeiten seit Beginn mit professionell gestalteten Quartalsprogrammen. Anders als bei den älteren deutschen Literaturhäusern bedurfte es hier keiner nach außen sichtbaren Experimente, sondern wurde die gesamte gestalterische Identität des Litteraturbuset vor der Eröffnung konzipiert und umgesetzt. Diese Publikationen haben sich seitdem nicht grundlegend verändert, dennoch sehen sie mit jeder Ausgabe etwas anders aus, weil verschiedene Farbkombinationen und Grafikelemente zum Einsatz kommen. Im Litteraturbuset in Oslo ließen sich weder beim Führungswechsel 2014919 noch zum zehnjährigen Geburtstag 2017 Neuerungen im Design erkennen, was die Absicht, das Literaturhaus weiterzuentwickeln, aber nicht grundlegend zu verändern, ausdrückt.

Die Leporellos waren in den Anfangsjahren das einzige Organ, das aus dem Literaturhaus heraus Informationen zu den Veranstaltungen vermittelte. Trotz der Erweiterung der Kommunikationskanäle durch das Internet bleibt dieses Instrument weiterhin zentral. Es mag zunächst überraschen, dass fortwährend so sehr auf die gedruckte Präsenz gesetzt wird, denn neben den Arbeitsveränderungen durch den Digitaldruck und durch weitere elektronische Instrumente liegt der offensichtlich größte Wandel der Kommunikation in der Nutzung des Internets. Am Beispiel der Institution Literaturhaus zeigt sich, dass die Kommunikations- und Informationswege sich gerade nicht vollständig, ins Internet ${ }^{`}$ verlagern, sondern weiterhin ,analoge ' Mittel zum Einsatz kommen, was im Unterkapitel zur Onlineaktivität vertieft wird.

\section{10.4 Bestandteile der Programmhefte}

Während sich die Programmpublikationen gestalterisch über die Jahre verändert haben, bleiben sie in der Struktur nahezu identisch. Alle untersuchten Hefte bilden die Veranstaltungen chronologisch ab. Bei einigen Heften unterstützt eine Übersichtsseite diese kalendarische Darstellung. Die Ankündigungstexte zu den einzelnen Veranstaltungen, das Kernstück der Hefte, machen den größten Teil aus. Ergänzt werden sie von Rahmeninformationen zu den einzelnen Veranstaltungen. Als

\footnotetext{
919 Beim Führungswechsel verabschiedete sich der scheidende Leiter im Vorwort der Broschüre (OL 2014-IV, S. 3) und dort dankte der neue Direktor Andreas Wiese seinem Vorgänger und gab keine Neuausrichtung des Programms oder vergleichbare Änderungen bekannt, nahm sich also ebenfalls hinter die bisherige Arbeit des Teams zurück (OL 2015-I, S. 3).
} 
weitere Bestandteile sind Coverseiten, Bilder, Anzeigen, allgemeine Informationen/Impressum/Kontakt und gelegentlich eingesetzte Vorworte im Folgenden näher zu beleuchten. Anhand der Rahmeninformationen tritt zutage, dass sich die organisationale Basis des Literaturhauses kleineren Veränderungen angepasst hat, grundsätzlich jedoch gleichgeblieben ist. Historische Veränderungen ergeben sich in der Textgestaltung und bei der Verwendung von Bildmaterial, was in den Kontext des sich insgesamt verändernden Literaturbetriebs und der zunehmenden Nutzung von Bildern gesetzt wird. Auch mittels dieser Untersuchungsparameter bestätigt sich die Annahme, dass das Literaturhaus als Institution in seiner eigenen Tradition steht und doch immer wieder Versuche zur Selbsterneuerung unternimmt und zum Beispiel in der Ansprache nach und nach weniger exklusiv, sondern werbender auftritt.

\section{10.4.1 Programmtexte}

Hauptbestandteil der Programmhefte sind die Veranstaltungstexte, die eine eigene Pragmatik erkennen lassen. Die Programmtexte enthalten meist ähnlich gelagerte Informationen: Ein Abschnitt geht bei Lesungen auf das Buch ein, bei Diskussionen oder Themenabenden liefert ein Teil einen Überblick über das Thema oder informiert über den Anlass respektive aktuellen Kontext. Eine weitere Passage enthält eine Kurzbiografie der Gäste. Diese erläutert mehr oder weniger ausführlich biografische Angaben und bei Autor*innen Hinweise zu früheren Veröffentlichungen. Manchmal folgt ein Abschnitt zur Moderation oder zum Ablauf des Abends. Gelegentlich sind Zitate integriert - selbstverständlich als solche markiert. Stammen diese vom Gast der angekündigten Veranstaltung selbst, erhalten die Rezipient*innen einen direkten Eindruck von dem Text oder der Position des Autors. Nicht weniger häufig werden andere anerkannte Autor*innen oder Kritikermedien wie überregionale Zeitungen zitiert. Diese Konsekrationsinstanzen unterstreichen die Relevanz des beworbenen Buches oder Schriftstellers.

Die Veranstaltungstexte beziehen sich in den Beschreibungen der erwähnten Bücher entweder auf deren Machart oder auf deren Themen. Neben ästhetischen Momenten sind es also inhaltliche Aspekte. Dabei werden vor allem gesamtgesellschaftliche Fragen und überindividuelle Relevanz betont - „als eine spannende terra incognita der menschlichen Seele“ (FF 2001-11-05)920. Familiengeschichten sind dann ebenfalls Chroniken von Regionen oder historischen Zeitabschnitten - „Die großen ethischen Fragen unserer Zeit sind in diesem Buch ebenso präsent wie ein halbes Jahrhundert russischer Geschichte“ (FF 2001-03-12) ${ }^{921}$. Die geschichtliche und politische Tragkraft von Texten wird herausgestellt und wenn es um Einzelschicksale geht, wird der größere Zusammenhang, die Überzeitlichkeit, die Welthaltigkeit der Texte hervorgehoben - „Ein Sittenbild voller Formeln und Codes“ (GT 2010-03-19) ${ }^{922}$. Für einladungswürdig werden Texte erklärt, an die Gespräche über Überindividuelles angeknüpft werden können. Entweder sind es allgemein mensch-

\footnotetext{
${ }^{920}$ Bei dieser Veranstaltung war Martin Mosebach mit seinem Roman Der Nebelfürst (2001) zu Gast.

921 Über Ljudmila Ulitzkaja und ihren Roman Reise in den siebenten Himmel (2001).

922 Über den Roman Kürzere Tage von Anna Katharina Hahn (2009).
} 
liche Aspekte oder zeithistorische Ereignisse, die wiederum Analysen der Vergangenheit oder der Gegenwart sind, die über das im Buch Erzählte hinausgehen und den Blick der Leser*innen weiten. Viel seltener geht es allein um ,eine gute Geschichte ${ }^{6}$ um ihrer selbst willen, der reine Unterhaltungswert eines Textes wird damit tendenziell ausgeblendet. Der Unterhaltungsfaktor kommt vor allem durch die Veranstaltungsformate zustande und ließe sich über Dokumentationen von Einzelveranstaltungen rekapitulieren.

Im Folgenden steht vor allem die textliche Gestaltung der Ankündigungstexte im Fokus; Beispiele für Veranstaltungen kommen ebenfalls vor, um einen Eindruck von den Programminhalten zu vermitteln. In der Regel ist die Perspektive der Verfasser*innen nicht erkennbar, die Texte stellen, wie Werbetexte, eine vermeintlich objektive Position dar. Die Texte geben Aufschluss über ihre impliziten Leser*innen, die als Zielgruppe des Literaturhauses verstanden werden können, ebenso wie über den Bildungshorizont, vor dem sich das Literaturhaus selbst positioniert. Stilistisch ändern sie sich über die Zeit, weil sie insgesamt werbender werden und weniger nur eine eingeschränkte Gruppe ansprechen. Dennoch verwenden sie keine ,leichte' Sprache und richten sich an ein akademisch gebildetes Publikum. Die Texte sind sorgfältig konzipiert und elaboriert verfasst, dabei informativ und inhaltlich so gehaltvoll, dass sie den Leser*innen meist etwas Neues näherbringen. Zu den Wechselbeziehungen der Sprache der Feuilletons und der Klappentexte von Büchern stellte Heinz Gollhardt bereits 1966 fest, dass sich die „Sprache der Reklame [...] im kritischen Feuilleton niedergelassen“ hat und „die Sprache der Kritik [...] ihrerseits auf den Werbestil der Klappentexte“923 wirkt. Dies lässt sich anhand der Programmtexte unterstützen, die sich sowieso als Hybrid aus Werbe- und Feuilletontext beschreiben lassen, wie oben ausgeführt.

Für die hermeneutische Betrachtung der Ankündigungstexte ist aufgrund der Materialfülle eine Stichprobenauswahl notwendig. Für einen überschaubaren, aber doch die gesamte Literaturhaus-Zeit überspannenden Querschnitt liegen hier beginnend mit dem Jahr 1992 in Zehnjahresschritten bis 2012 die Texte des Erwachsenenprogramms aus dem Monat März zugrunde. 1992 war das Literaturhaus Frankfurt bereits ein Jahr tätig, 2002 gilt dies für das Literarische Zentrum Göttingen; das erst 2014 eröffnete Litteraturhuset $i$ Bergen fällt auf diese Weise zwar aus der Auswahl, doch lassen sich deutliche Parallelen zur Osloer Einrichtung entdecken. Der März kann grundsätzlich als repräsentativ für das Programmjahr gelten, denn in diesem Monat bieten alle Einrichtungen Programm an. Obwohl es der Monat der Leipziger Buchmesse ist, ändert sich das reguläre Monatsgeschehen nicht einschlägig. Somit besteht das Textkorpus aus zwölf Monatsprogrammen - jeweils 1992, 2002 und 2012 aus den Literaturhäusern in Berlin, Hamburg und Frankfurt, sowie 2002 und 2012 des Literarischen Zentrums Göttingen und der Teil für März 2012 im Litteraturbuset in Oslo. Durch diese Beschränkung verbleiben immer noch 95 Texte für die genaue Analyse. Zunächst folgt eine detaillierte chronologische Auseinandersetzung mit den deutschen Texten, die Betrachtung der norwegischen schließt sich daran an.

923 Gollhardt 1966, S. 2115 zitiert nach: Kampmann 2011, S. 6. 
Exemplarische Analysen $1992-2002-2012$

1992

Die Programmtexte des Jahres 1992 aus dem Literaturhaus Berlin sind gleich aufgebaut: Zu Beginn steht ein Zitat des jeweiligen Gastes oder aus dem vorgestellten Buch, das einen Eindruck vom im Zentrum der Veranstaltung Stehenden gibt. Die folgende vier- bis sechszeilige parataktische Passage zum Gast ist nüchtern-informativ ohne ergänzende Wertungen. Auf diese Weise spricht das obige Zitat für sich und so nehmen sich die Verfasser*innen des Ankündigungstextes hinter Autor*in, Buch oder Thema gänzlich zurück. Das Zitat kann allerdings nur von erfahrenen Leser*innen eingeordnet werden. Es wird deutlich: Wer zum zitierten Absatz keinen Zugang findet, wird sich vermutlich bei der Veranstaltung ausgeschlossen fühlen.

Ebenso wie in Berlin geht aus dem Faltblatt des Literaturhauses Hamburg nicht hervor, wer diese Texte geschrieben hat - nicht einmal, wer im Literaturhaus arbeitet, findet sich in dem Papier abgebildet. Da fällt es besonders auf, dass einige Texte in gesamter Länge als Zitate gekennzeichnet sind und die Schreiber in Parenthese angegeben werden: Renate Reimers, Gerda Zeltner und Bazon Brock. ${ }^{924}$ Nicht erwähnt ist, wo der Text zuvor erschienen ist oder ob er nur für das Programmheft formuliert wurde. Es lässt sich jedoch recherchieren, dass Gerda Zeltners Passage aus einem Artikel der Neuen Zürcher Zeitung kommt. Allein die Nennung dieser drei Namen antizipiert im zeitgenössischen Kulturbetrieb versierte Rezipient*innen, die die Namen einordnen konnten und als Konsekrationsinstanzen zur Kenntnis nahmen. Diese drei Texte eignen sich an dieser Stelle weniger für die genaue Lektüre als die direkt vom Literaturhaus verfassten Beiträge. Diese unterstützen gleichermaßen die These, dass sich die Texte an eine kulturell gelehrte Leserschaft wenden. Formulierungen wie „mit einem akribisch recherchierten Psychogramm“; „Das Movens der Autorin ist die Faszination, die von der dunklen Abseite des literarischen Ruhms ausgeht" (HH 1992-03-03); ,,ist zugleich auch clownesker Inszenator seiner Texte“ (HH 1992-03-24) oder: „Eine Fülle von Lebensentwürfen so kunstvoll verschränkt, daß die komplexe Bewußtseinstopograhie einer Generation sichtbar wird" ( $\mathrm{HH}$ 1992-03-31) entstammen einer Fachsprache, die ein akademisch gebildetes Publikum auch außerhalb wissenschaftlicher Publikationen verwendet. Die Hinwendung zu dieser Klientel drückt sich in der Wortwahl aus sowie in der Diskursivierung des Vorgestellten, die sich wie Ankündigungen für wissenschaftliche Tagungen lesen und zwar nicht für Studienanfänger*innen. ${ }^{925}$

\footnotetext{
924 Gerda Zeltner-Neukomm (1915-2012) lässt sich als Schweizer Romanistin und Literaturkritikerin einordnen, Bazon Brock (*1936) ist Künstler und hatte bis zu seiner Emeritierung den Lehrstuhl für Ästhetik und Kulturvermittlung in Wuppertal inne, Renate Reimers' Position im Kulturbetrieb lässt sich heute nicht klar rekonstruieren.

925 Z. B. der Text für einen Abend mit Marianne Krüll zu ihrer Monografie Im Netz der Zauberer. Eine andere Geschichte der Familie Mann (1992): „Sie war schon so gut wie verschwunden aus den literarischen Debatten der letzten Jahre: die gute alte, unerschöpfliche Frage nach der Moral der Kunst. Jetzt ist sie, hochgespült von den Turbulenzen der neuesten Geschichte, wieder da und rüttelt an den gutbefestigten Elfenbeintürmen einer ästhetischen Autonomie. Längst vergessene Begriffspaare wie ,Kunst und Charakter', ,Leben und Werk', ,Talent und Gesinnung' erleben eine verblüffende Auferstehung. Grund genug, die diversen Formen der Remoralisierung von Literatur genauer zu untersuchen“ (HH 1992-03-03).
} 
Hinsichtlich der Öffentlichkeitsarbeit erscheint das Literaturhaus Frankfurt in seinem zweiten Jahr mit den monatlich unterschiedlich farbigen Foldern zunächst bereits professioneller als das Hamburger Pendant, doch ein Impressum findet sich hier ebenso wenig und die Texte unterscheiden sich innerhalb des einen Monats in ihrer Komposition sehr. Dies kann darauf hindeuten, dass sie von verschiedenen Personen beigetragen wurden. Einige Texte sind den kurzen Berliner Ankündigungen sehr ähnlich: So stehen für die Lyriklesung von Andreas Koziol (*1957) und Ulrich Zieger (1961-2015) von den Künstlern selbst verfasste literarische, mit Symbolen und Metaphern versehene, ironische Arten- und Lebenswegbeschreibungen am Anfang (FF 1992-03-13). Nur auf die Biografie und das Werk eingegangen wird hingegen im Text zur Lesung mit Hans Sahl (1902-1993) (FF 1992-03-16): ,Und doch steht zwar im Titel, allerdings geht aus dem Text nicht hervor, dass es sich dabei um eine Sammlung mit „Essays und Kritiken aus zwei Kontinenten“, so der Untertitel des 1991 erschienenen Bandes, handelt. Wie eine Kurzrezension wirkt der Hinweis auf den Termin von Ingrid Puganigg (*1947), der mit Neue Literatur (FF 1992-03-18) überschrieben ist. Da wird mit eingefügten Zitaten aus dem Primärtext nicht nur die Handlung, sondern das Thema des Romans interpretiert. Dieser längste - mit etwa 1200 Zeichen immer noch weniger umfangreich als die beschriebenen Hamburger Texte - zu einer „Comiclesung, Diashow, Musak, Video“ (HH 1992-03-27) ${ }^{926}$ führt etwas weiter in das Werk der Künstlerin Mariola Brillowska (*1961) ein. Mit Formulierungen wie „die Ästhetik des Comics“ nähern sich die Texte der für das Literaturbaus Hamburg im Jahr 1992 als charakteristisch beschriebenen Fachsprache, sie sind in ihren inhaltlichen Verweisen aber nicht so explizit wissenschaftlich orientiert. Die Eindeutigkeit der Ansprache des Programms 1992 aus Hamburg steht somit einer etwas unklareren Adressierung seitens der Literaturhäuser in Berlin und Frankfurt gegenüber. In allen drei Heften gibt es keine unvermittelte Publikumsansprache oder indirekte Aufforderung zur Teilnahme an den Veranstaltungen.

\section{2}

Zehn Jahre später hat sich an den Programmleporellos einiges verändert: In Frankfurt war der 1996 komplett neugestaltete Folder, eingeführt von der im Jahr 1995 gestarteten Programmleiterin Maria Gazzetti, bis zum Umzug des Literaturhauses im Herbst 2005 in Verwendung. Ebenso sind Änderungen inhaltlich erkennbar, die auf eine Vereinheitlichung und zunehmende Professionalisierung hindeuten. Offensichtlich fest integriert ist die Nennung der Personen, die moderieren oder bei nichtdeutschsprachigen Autor*innen aus den Übersetzungen vorlesen. Die Texte sind überschrieben mit dem Namen des Gastes, dem Buch, aus dem gelesen wird, und verbindendem Verb, liest aus' oder, spricht über' und besagten weiteren Akteur*innen im Untertitel. Hinsichtlich der Textlänge und der Struktur sind die Beiträge weiterhin unterschiedlich. Das Design des Folders gibt keine feste Zeichenzahl vor und richtet sich nach der Textlänge; dies ist nicht bei allen Programmheften so und wirkt sich auf das Verfassen aus: Entweder gibt das Format die ungefähre Länge vor oder es bestimmen die Texte, zumindest bis zu einer maximalen Zeichenzahl,

\footnotetext{
926 ,Musak' meint Hintergrundmusik, auch als ,Fahrstuhlmusik' bezeichnet und häufiger ,Muzak' ge-
} schrieben. 
das Aussehen des Programms. Im vorliegenden Frankfurter März-Programm füllen die Bilder entstandene Freiflächen. Nachvollziehbar ist es, dass etwa die Veranstaltung Jour Fixe pour Proust (FF 2002-03-15), die achtzigste Fortsetzung der Lesung aus Auf der Suche nach der verlorenen Zeit, nur mit einem kurzen Proust-Zitat und organisatorischen Details angekündigt wird, denn die regelmäßigen Leser*innen benötigen nicht erneut eine lange Projektbeschreibung, und Menschen, die das Programm zum ersten Mal ansehen, verstehen dennoch, was es damit auf sich hat. ${ }^{927}$ Bei Autorenlesungen steht jeweils ein Einführungsblock mit Hinweisen zum aktuellen Buch des Gastes und eine Einordnung in das Werk. Bei Susan Sontag (1933-2004) wird vor einigen Sätzen zum vorgestellten Roman In Amerika darauf hingewiesen, dass die New Yorker Autorin und Essayistin „kürzlich mit ihrer unkonventionellen Interpretation der Terroranschläge vom 11. September [...] ins Kreuzfeuer der Kritik“ (FF 2002-03-20) geriet. Das Adjektiv ,unkonventionell‘ lässt sich als Wertung verstehen - wobei nicht eindeutig zu klären ist, ob es im Text positiv oder abwertend urteilend verwendet wird. In jedem Fall wird damit betont, dass es sich bei der Autorin um eine nicht unumstrittene Intellektuelle handelt, und an eine Diskussion erinnert, die den Rezipient*innen des Programmheftes - so ist anzunehmen - bekannt ist. Die deutlichste Wertung findet sich bei einer Lesung aus einer Novelle, deren Form „der geglückte Versuch“ und die selbst „,bewunderungswürdige Literatur“ (FF 2002-03-18) sei. Insgesamt sind die Texte mit Wertungen zurückhaltend.

Treu in der Außenpräsentation blieb sich von 1992 bis 2002 das Literaturhaus Berlin, dort wirkte im März 2002 weiterhin der erste Leiter Herbert Wiesner. Der 1996 aktualisierte Programmfolder, benutzt bis zum Herbst 2004 - auch dort gab es ein Jahr nach dem Leitungswechsel eine neue Gestaltung -, bietet für die Termine bei gleicher monatlicher Veranstaltungszahl mehr Platz. In der Regel beginnt die Ankündigung immer noch wie 1992 mit einem Zitat. Die dann folgenden Ausführungen unterrichten wertneutral über den Gast oder das Thema. Allein Günter Brus (*1938) wird als „einer der bedeutendsten österreichischen Künstler nach 1945“ (BE 2002-03-05) beschrieben, es folgen sogleich Argumente, indem einige seiner Ausstellungen - Documenta, Tate Gallery, Centre Pompidou und weitere - aufgezählt werden, die kulturell gebildete Leser*innen als bedeutend einzuschätzen wissen. Dass er „schreiben und erzählen kann, hat er [...] hinlänglich bewiesen“ und dies unterstreiche die literarische Qualität dieses Autors. Derartige explizit positive Beurteilungen stehen recht selten im Programmheft dieses Literaturhauses. In diesen Texten werden ganz selbstverständlich Fachausdrücke wie ,Edition`verwendet; statt ,veröffentlichen' fällt oft ,publizieren'; ,analysieren' oder ,erläutern' präzisieren die sonst in den Programmtexten benutzten Verben wie ,sprechen über' oder ,vorstellen‘. Ein Satzteil wie „Komik, die gelegentlich aus der Diskrepanz zwischen Etymologie und Wortgebrauch entsteht“ (BE 2002-03-07) ist Beleg dafür, dass bei den Adressat*innen literarische Kenntnisse vorausgesetzt werden. Abgesehen von einem Verständnis der Fachtermini wie ,Etymologie ${ }^{6}$ und der Fremdworte wie ,Diskrepanz' bedarf es bei den Leser*innen eines Wissens darüber, welcher Witz aus der Unstimmigkeit zwischen der ursprünglichen Bedeutung eines Wortes und seiner tatsächlichen Verwendung entstehen kann. Es wird also mit sprachlich versierten

927 Zu dieser Veranstaltungsreihe vgl. auch S. 347 und S. 374. 
Rezipient*innen gerechnet, die einen ästhetisch bedachten Umgang mit Worten pflegen und zu schätzen wissen.

Voraussetzungsreich sind ebenfalls die Ankündigungstexte von Ursula Keller im Literaturhaus Hamburg. In diesem Fall lässt sich belegen, dass die Leitung für die Texte und die Redaktion des Heftes zuständig zeichnet - mit Ausnahme der Programme 2000 und 2001 ist im Impressum seit 1996 „Programmtexte und -redaktion: Dr. Ursula Keller" vermerkt. Es fügt sich die Programmleiterin nicht in ein Team ein, sondern bleibt als Hauptverantwortliche präsent. Sie steht damit mit ihrem Namen für die Qualität. Gleichzeitig wird deutlich, dass die Texte für so wichtig erachtet werden, dass die Intendantin sie selbst verfasst. Sie sind mit etwa 1.800 Zeichen deutlich länger als die anderen Texte, die Zeichenzahl entspricht einer vollgeschriebenen Normseite (30 Zeilen mit maximal 60 Anschlägen). Nicht nur aufgrund der Länge sind sie umfassende Einführungen in die Veranstaltungen. Bei den Lesungsankündigungen referieren sie etwa andere Texte der Autor*innen, ordnen das neue Buch ins bisherige Werk ein und umreißen die Inhalte des Romans. Im hier näher untersuchten Monat März 2002 sind es wirklich nur männliche Autoren, die ihre Romane, ja, nur Romane, bei Lesungen präsentieren. Diese Konzentration auf Prosa, insbesondere auf Romane, legt nahe, davon auszugehen, dass diese im Literaturhaus besonders häufig vertreten sind und ihnen damit eine besondere Relevanz zugemessen wird. Dies bestätigen die Programmanalysen. ${ }^{928}$

Ursula Keller skizziert nicht nur den Inhalt der Bücher, sondern spart nicht mit Lob: Joachim Helfers Roman Nicht Himmel, nicht Meer (2002) sei „ein äußerst intelligenter, vergnüglicher“ Text, und „[z]ur Freude des Lesers [...] mit hintergründigem Witz und unwiderstehlichem Charme“ (HH 2002-03-04) versehen; Steffen Kopetzkys Roman Grand Tour oder die Nacht der Großen Complication (2002) erzähle mit „fulminanter Sprachkraft“, sei „ein meisterlich konstruierter Krimi“ und, das wird nochmal betont, ein „kunstvoll komponierte[r] Roman“ (HH 2002-03-07); Ulrich Peltzer zählt sie „zu den wichtigsten Autoren seiner Generation“, der Roman Byrant Park (2002) sei „ein literarisches Wagnis, das inmitten der ästhetisch unreflektiert dahinplätschernden neuen deutschen Debütantenliteratur die größte Aufmerksamkeit verdient" (HH 2002-03-12). Im letzten Zitat urteilt sie gleich doppelt: Zum einen wertet sie Peltzers Schreiben ausgesprochen positiv, dies noch mehr, da sie es im Kontext der anderen zeitgenössischen neuen Literatur verortet. Indem sie die Literatur von Debütant*innen abwertet, erhebt sie den vorgestellten Roman noch deutlicher aus dem Gros der Literatur hervor. In diesem Kommentar steckt ferner, dass Ulrich Peltzer gewichtigere Texte schreibe als die zu der Zeit in hoher Zahl erschienenen Debüts. Dieser Stich gegen die anderen Texte müsste an dieser Stelle gar nicht sein - es sei denn, die Verfasserin möchte ihr Urteil zur aktuellen Literatur abgeben. Die oben genannte feuilletonistische Kommentarfunktion der Programmhefte wird so anschaulich. Diese Hamburger Texte könnten ebenso mit anderer Rahmung im Kulturteil einer Zeitung abgedruckt gewesen sein. Dies trifft auch deshalb zu, weil sie nicht verwissenschaftlicht, sondern im Stil des Feuilletons geschrieben sind. Im Feuilleton als „ein literarisch-publizistisches Textgenre“929 wird geist-

928 Vgl. Kapitel II 13.2.6.

${ }^{929}$ Kauffmann 2000, S. 12. 
reich-unterhaltsam formuliert, emphatisch und polemisch bisweilen. Die zitierten positiv wertenden Adjektive belegen dies ebenso wie Formulierungen wie ,abenteuerlicher Bildungsroman“ (HH 2002-03-07) oder ,als der Hazardeur unten den jungen deutschen Autoren ausgewiesen“ (HH 2002-03-04) - Worte aus der Wissenschaftssprache, die aber nicht nüchtern beschreibend, sondern wertend und emphatisch, manchmal gar polemisch verwendet werden. Die Literarizität der Sprache beweist sich ebenfalls durch Metaphern wie die „Erzählschienen dieses [...] Romans“, auf denen der Leser „reist“ (HH 2002-03-07) oder „die ein wenig verloren zwischen allen ideologischen Stühlen platzierte Generation der Nach-68er" $(\mathrm{HH}$ 2002-03-12).

Besonders deutlich wird der Unterschied zwischen den Berliner und den Hamburger Texten im direkten Vergleich: Im März 2002 ist der Ungar László Darvasi (*1962) im Literaturbaus Hamburg (HH 2002-03-14) und am Tag darauf in Berlin (BE 2002-03-15) zu Gast - im Herbst 2001 übrigens bereits im Literaturbaus Frank-furt (FF 2001-10-25). Es moderiert jeweils, der üblichen Praktik des Literaturhauses entsprechend, eine andere Person. Im Hamburger Text finden sich Variationen der Standardsätze in Autorenbiografien, die in diesem Fall im Berliner Beispiel zu finden sind. Statt der Formulierung „International bekannt wurde er mit dem 1995 in deutscher Übersetzung publizierten Erzählungsband ,Das traurigste Orchester der Welt“ heißt es dort: „Mit seinen Erzählungen ,Das traurigste Orchester der Welt hatte der junge ungarische Autor die Aufmerksamkeit der deutschen Leser auf sich gezogen." Beide Sätze zielen darauf ab, über die internationale Anerkennung des Autors zu berichten. In Hamburg liegt der Schwerpunkt auf dem ,junge[n]“ Autor und seiner Aktivität: Er zog die Aufmerksamkeit auf sich. In Berlin werden die bibliografischen Angaben referiert und die Rezeption hervorgehoben - in einer Passivkonstruktion. Hinzu kommt, dass dieser Satz in Hamburg zu Beginn steht, er also das Interesse der Leser*innen für den Gesamttext hervorrufen soll. In Berlin hingegen beginnt der Absatz mit biografischen Hinweisen und fügt mittendrin die zitierte Information ein. Mit dem Erfolg beginnend, beabsichtigt der Hamburger Text stärker als das sachlich-informative Berliner Pendant, zu werben. Die Notiz aus Berlin, der Autor „entwirft ein mitteleuropäisches Welttheater, das sich von Polen bis Siebenbürgen, von Belgrad bis Venedig, Wien bis Szeged erstreckt ${ }^{“ 6930}$, steht dann der lobenden Formulierung aus Hamburg gegenüber, die lautet: So „setzt es [das Buch Die Legende von den Tränengauklern, Anmerkung C. L.] sich über alle Grenzen von Zeit und Raum hinweg, durchquert Epochen und die Länder Europas, [...] László Darvasis grandiose[] apokalyptische[] Legende von den wahren Schrecken der europäischen Geschichte“.

Die Texte des Literaturhauses Hamburg sind 2002 nicht nur feuilletonistischkritisch geschrieben, sondern, wie erwähnt, voraussetzungsreich. Die Einleitung zum Termin der Reihe Lesarten des Terrors im hier vorgestellten Monatsprogramm „Was für eine Hiobsbotschaft verkündet der Terror? Keine, außer sich selbst. Genauer: eine Steigerung seiner selbst, eine himmelwärts gerichtete Parabel, die zwangsläufig auf Ästhetisierung hinauslaufen muss. Das Porträt des Täters als junger Mann.“ (HH 2002-03-05) - lässt sich nicht bei einem flüchtigen Lesen durch-

\footnotetext{
${ }^{930}$ Der Berliner Text übernimmt leicht abgewandelt Formulierungen des Klappentextes des Subrkamp-
} Bandes. 
dringen. Kompliziert macht es erstens der Satzbau mit verschachtelten Ellipsen, deren Bezugsobjekt in der Ausgangsfrage beim Lesen erneut gesucht wird, zweitens die komplexe semantische Struktur, dass der Terror sich selbst verkünde, und drittens die Vokabeln ,Parabel' und ,Ästhetisierung', die als bekannt vorausgesetzt werden. Der letzte Kurzsatz steht ohne klare Verbindung zum vorherigen, der Anschluss ergibt sich erst aus dem folgenden Absatz. Es scheint bei der angekündigten Veranstaltung um den Zusammenhang von Katastrophenfilmen und den Bildern des 11. Septembers 2001 gegangen zu sein. Die Texte zu diesen medienkritischen Auseinandersetzungen bilden schon in den Ankündigungstexten ab, dass an den Abenden wissenschaftlich anspruchsvolle Theoretiker sprechen. Im Monat zuvor war der französische Soziologe und Philosoph Jean Baudrillard (1929-2007) in der Reihe zu Gast. Während es diesen thematischen Schwerpunkt zu Lesarten des Terrors gab, wurden in zwei anderen Texten, die nicht in direktem Zusammenhang mit der Reihe stehen, Verweise auf den 11. September 2001 gesetzt (HH 2002-03-26 und HH 2002-03-12). Damit entsteht ein klarer Bezug zur aktuellen Zeitgeschichte und zum thematischen Fokus des Literaturhaues. Das Literaturhaus Hamburg beschäftigte sich im März 2002 intensiv mit dem Sujet ,Terror ${ }^{6}$ und richtete selbst bei Veranstaltungen, die nicht unmittelbar mit diesem Stoff verbunden waren, den Blick auf Aspekte, die zum aktuellen Hauptthema beitrugen. ${ }^{931}$ Im Programmheft lässt sich entsprechend neben der textgestalterischen eine inhaltliche Linie erkennen, die verborgen bliebe, wenn jede Veranstaltung alleine angekündigt würde. Dies bestätigt das hier angesetzte Vorgehen, die Programmbroschüren in ihrer Komposition zu betrachten.

Weder emphatisch-lobend noch schlicht-ernst wirken die Texte aus dem im Jahr 2000 gegründeten Literarischen Zentrum Göttingen. Die Einrichtung formuliert bescheiden, aber entschieden etwa 1.100 Zeichen lange, sprachlich komponierte Texte. Ähnlich wie im zitierten Hamburger Beispiel kommen im Literarischen Zentrum Göttingen selten die erwähnten ,Standardsätze“ vor. „Ihr Romandebüt war in Polen innerhalb weniger Tage ausverkauft" (GT 2002-03-21, Malgorzata Saramonowicz) ist sprachlich kein besonders feinsilbiger Satz, doch alterniert er übliche Aussagen und drückt nunmehr indirekt aus, dass das Buch ein Verkaufserfolg war. Der Text lobt nicht nur den positiven ökonomischen Effekt, sondern vertieft sich ebenso in eine Interpretation des Buches: Eine Formulierung wie „Ein Augenöffner am Abgrund des scheinbar Übersehenden und sorgfältig Vergessenen. Die Schwester (1996) - ein Sog, ein Strudel aus drei Stimmen“ enthält weitere Belege für die literarische Verwendung von Sprache. Alliterationen und Metaphern bezeugen, dass es hier nicht nur um Werbung für die Veranstaltung geht, sondern dass der Text selbst als literarisch verstanden werden soll. Das Literarische Zentrum Göttingen präsentierte sich so auf andere Art als Mittler der Literatur. Das Sprachinteresse der Einrichtung spiegelt sich gewissermaßen in seinen Ankündigungstexten. Dabei deuten die Texte den ,Ton' der angekündigten Veranstaltung beziehungsweise des Buches oder Themas an. So leitete das Attribut „Des grimmen Friedrich Nietzsches Erweckungserlebnis“ in eher altertümlicher Sprache eine Auseinandersetzung mit Friedrich Nietzsches musikalischen Kompositionen ein.

${ }_{931} \mathrm{Zu}$ Reihen und Themenschwerpunkten im Literaturhaus vgl. Kapitel II 13.1. 
Gelegentlich verwendete das Literarische Zentrum Göttingen in diesem exemplarischen Programmheft umgangssprachliche Konstruktionen, wie etwa der Abschnitt „Das Jahrbuch [der Lyrik, Anmerkung C. L.] kann man immer kaufen, schon deshalb, weil es sich kompromisslos auf die Stärke seines Genres verlässt. Da stehen halt Gedichte drin, ziemlich gute und Jahr für Jahr liest man ein paar neue Namen." (GT 2002-03-26) bezeugt. Modalpartikel wie ,halt` oder ,ziemlich‘, Verkürzungen wie ,drinstehen' und die Nutzung des unbestimmten Pronomens ,man' sorgen dafür, dass der Ton ungezwungen und mündlich wirkt. Die Ansprache richtet sich an jüngere, nicht nur der sogenannten Hochkultur anhängende Kulturintressierte, die ein wenig sprachliche ,Lockerheit' unproblematisch finden.

Dafür argumentiert gleichermaßen der Abend, der schon rein thematisch ungewöhnlich für die Institution Literaturhaus ist - erst recht kurz nach der Jahrtausendwende - und sich „Neues aus Konsolistan“ (GT 2002-03-28) nennt. Wie eine Abenteuergeschichte mit Hinweisen auf mythenumwobene Welten - Diamantenminen, Planeten, Dschungel - erzählt der Text von Erlebnissen mit dem Heimcomputer C-64, der den Leser*innen zumindest ansatzweise bekannt sein muss, um den Text zu verstehen. Referiert wird auf bestimmte Spiele, die die Leser*innen selbst entschlüsseln müssen. Dieser Text spricht Menschen an, die mit diesem Computer der 1980er-Jahre aufgewachsen sind und eine leicht überspitze Prognose wie „die erste deutsche Kulturgeschichte eines Mediums [...], von dem in einigen Jahrzehnten vielleicht mit derselben Hochachtung gesprochen wird wie heute von einem Roman oder Spielfilm“ nicht grundsätzlich ablehnen. Der Computer, der Roman und der Spielfilm werden nebeneinandergestellt. Dies passiert auf textlicher Ebene ebenso wie im Programmkonzept des Literarischen Zentrums Göttingen.

2012

Die beschriebene Literarizität findet sich auch in einigen Texten des Frankfurter Programms 2012. Im Satz „In Geisterbahnen irisieren Geister, dunkle Mächte und Spinnwebnetze.“ (FF 2012-03-05) folgt der Rhythmus einer Regelmäßigkeit, die für einen reinen Gebrauchstext nicht nötig wäre. Derartige Aufzählungen von Worten, die mehr assoziativ zusammenpassen, fallen auf und finden sich ebenso in den erwähnten Göttinger Texten aus dem Jahr 2002. Ausdrücke, die als einprägsame Werbeslogans funktionieren, wie „,[d] as literarische Quartett ohne Quotendruck und Fernbedienung“ (FF 2012-03-06), bestimmen ebenfalls einige Texte. Das Faktum, dass Hauke Hückstädt von Göttingen nach Frankfurt wechselte, lässt sich also in den Programmtexten erkennen. In der Tat ändert sich die Art zu texten im Literaturhaus Frankfurt mit dem Leitungswechsel im Jahr 2010.

Insgesamt variieren 2012 die Texte stilistisch mehr, sie wirken nicht so sehr ,aus einer Hand' zu stammen wie im Literarischen Zentrum Göttingen oder dem Literaturhaus Frankfurt 2002. Im näher untersuchten Monat März 2012 finden sich unter den Frankfurter Texten ebenso Beiträge, die mit Schlagworten wie „der große spanische Romancier“ (FF 2012-03-21) oder „packend und fesselnd“ (FF 2012-03-21) in Verlags- und Presseankündigungstexten übliche Formulierungen benutzen. Doch auch dieses Beispiel ist keine Kopie eines Buchumschlagtextes und benutzt ebenso etwa ein metaphorisch verwendetes Adjektiv - „die menschengroße Frage“. Dass die 
Texte heterogener erscheinen, hängt vermutlich damit zusammen, dass nicht nur eine Person alle schreibt, sondern Mitarbeiter*innen und Kooperationspartner*innen Texte beisteuern. Aufgrund der gestiegenen Veranstaltungs- und damit Textanzahl ist diese Arbeitsteilung wahrscheinlich und lässt sich bei den Programmtexten der anderen Literaturhäuser aus dieser Zeit ebenso sehen.

In den drei Beiträgen des Literarischen Zentrums Göttingen aus dem März 2012, dessen Texte mit etwa 700 Zeichen zu den knappsten zählen, sprechen beispielsweise die Veranstaltungstitel, die oft gerade nicht nur die Titel der vorgestellten Bücher umfassen, die Leser*innen an: Der Abend mit Steven Uhly (*1964) ist unter Identitäten auf Speed (GT 2012-03-08) und der Besuch von Mark Z. Danielewski (*1966) unter Die Revolution der Revolutionen (GT 2012-03-23) zu fassen. Die Veranstaltung zu einer Ausgabe von Tondokumenten Heiner Müllers (1929-1995) heißt wie der griffige Titel der Dateiensammlung selbst MÜLLER MP3 (GT 2012-03-13). Werturteile finden sich in diesen Texten selten in Form von emphatischen Adjektiven, sondern eher subtil: Es ist die Rede von einem Buch, „das absichtslos vorwegnahm, was seit letztem Winter die Republik beschäftigt“ (GT 2012-03-08), oder - „Erneut führt der Autor von Das Haus [...] das Medium Buch an seine Grenzen und reizt alle Potentiale des Romans bis zum Letztmöglichen aus" (GT 2012-03-23). Dass diese Bemerkungen in die Ankündigungstexte einbezogen sind, dass sie als positive Wertungen einzuordnen sind, das ergibt sich aus dem Publikationskontext. An diesen zwei Beispielen lassen sich so Beurteilungskriterien für Literatur seitens der Literaturhäuser erkennen: Gute Literatur nimmt gesellschaftliche Themen der Zeit auf, oder gar vorweg, und sie lotet die existierenden Begrenzungen aus, um durch das Überschreiten der Grenze ästhetisch Neues zu erschaffen. ${ }^{932}$

Außerdem sind mit diesen Formulierungen als Adressat*innen (literatur-)wissenschaftlich gebildete Leser*innen avisiert, die diese zitierten Aussagen einzuordnen vermögen. Flüssig lesbar sind die Sätze, doch ganz selbstverständlich hantieren sie mit fachsprachlichen Ausdrücken wie „Präsenz“, „Aphoristiker“, „Utopisten“ (GT 2012-03-13), „Potenziale des Romans“ oder „Kulturgeschichte des Landes“ (GT 2012-03-23). Da schreibt jemand, der firm in literaturwissenschaftlichen Diskursen ist. Diese werden so eingeflochten, dass die Ankündigungen gerade nicht auf gleiche Weise in einer wissenschaftlichen Publikation zu finden sein würden, sondern eindeutig Veranstaltungshinweise außerhalb der Universität sind; ein Beispiel ist: „Da palavern die Germanisten seit Jahr und Tag über das komplizierte Verhältnis von Fakten und Fiktion - und was macht Felicitas Hoppe? Sie erfindet sich einfach eine Traumbiografie!“" (GT 2012-04-20) Dieses Zitat veranschaulicht die beschriebene von der wissenschaftlichen Praxis abweichende Art zu formulieren, die mit inhaltlichen Verweisen auf die literaturwissenschaftliche Forschung der letzten Jahre kombiniert wird. Das Literarische Zentrum in der Universitätsstadt Göttingen steht der Wissenschaft recht nah, wie in der Vorstellung der Einrichtung ausgeführt wurde; die Ankündigungstexte spiegeln diese Verwandtschaft. Von den untersuchten deutschen Literaturhäusern ist das Literarische Zentrum Göttingen das einzige, das Buchtitel kursiv und nicht in Anführungszeichen markiert - also so, wie es literaturwissenschaftliche Praxis ist.

932 Vgl. Kapitel III 3.2. 
Im Literaturhaus Hamburg fällt 2012 besonders auf, dass Leser*innen direkt adressiert werden. Mit (rhetorischen) Fragen oder Mitteln, die einen Dialog fingieren, ziehen die Texte die Aufmerksamkeit der Rezipient*innen auf sich. Am Ende steht oft eine direkte Ansprache, wie „Doch bitte, liebes Publikum, beweisen Sie es dem Dichter [...]“ (HH 2012-03-13) und „Hierzulande sind wir toleranter, oder?“ (HH 2012-0315). Außerdem künden die Texte davon, dass bei der Veranstaltung etwas zu entdecken sei, was die werbende Funktion betont. Auf die Frage etwa „Wer ist Jochen Schmidt?“ folgt die Antwort, dass es „,im Internet [...] viele Vertreter dieses $\mathrm{Na}$ mens“ gebe. „Der beste Jochen Schmidt von allen“ sei aber der Autor, zu dem einige bio-bibliografische Punkte genannt werden, um auf den Abend neugierig zu machen, denn: „Wer er wirklich ist, erfährt, wer am 1. März in den ,Toten Salon“ ins Hamburger Literaturhaus kommt.“ (HH 2012-03-01)933 Unterhaltsam-provokante Thesen motivieren ebenso zum Lesen der Texte. Karl May sei „vielleicht der einzige Star, den die deutsche Literatur besitzt, und seine Figuren gehören vielleicht zum Kernbestand deutscher Kultur“ (HH 2012-03-08). Solche Mutmaßungen brechen augenzwinkernd mit dem unterstellten bildungsbürgerlichen Kulturverständnis des Literaturhaus-Publikums. Hyperbolisch verwendete Adjektiv - so wird etwa „eine hartgesottene Moderatorin“ (HH 2012-03-27) angekündigt, die es mit dem Kolumnisten Harald Martenstein aufnehmen könne - und Verweise zum Beispiel auf „die gute, alte Jane Austen“ (HH 2012-03-15) zeigen, dass im Literaturhaus Hamburg Unterhaltung durchaus erwünscht ist. Die Texte lassen keine fromme Andacht bei den Veranstaltungen erwarten. Eine ehrfürchtige Zurücknahme des LiteraturhausTeams vor dem ,Dichter ${ }^{6}$ findet sich höchstens noch andeutungsweise in den Berliner Texten von 2012, wie die folgende Gegenüberstellung illustriert: Im März 2012 fand als Teil des Projektes literatour.cz des Netzwerkes der Literaturbäuser sowohl in Hamburg als auch in Berlin ein Abend zu tschechischer Gegenwartsliteratur statt. Der Vergleich dieses inhaltlich identischen Veranstaltungsabends exemplifiziert, dass das Literaturbaus Hamburg deutlicher publikumsbezogen kommuniziert. Zum Projekt selbst wird im Hamburger Beispiel weniger ausgeführt, dennoch erhalten die Leser*innen genügend Informationen, um die Idee der Lesereise, in Deutschland noch unbekannte tschechische Gegenwartsliteratur vorzustellen, zu verstehen. Beide Texte beginnen mit einer Aufzählung von „hierzulande“ (HH 2012-03-05) beziehungsweise „in Deutschland“ (BE 2012-03-07) bekannten tschechischen Autor*innen. Wieder mit einer rhetorischen Frage - „Aber sind das wirklich die Autoren, mit denen sich auch junge Tschechen identifizieren?“ - fingiert der Hamburger Text eine direkte Publikumsansprache. In Berlin heißt es sachlicher: „Ein unscharfes Bild, denn [...] [davon] gibt es noch einige zu entdecken.“ Der Stil in Hamburg nähert sich dabei einem eher mündlichen an, weil Satzkonstruktionen nicht verkompliziert, sondern abgekürzt werden; Formulierungen wie „das zu entdecken, hat sich das Netzwerk der Literaturhäuser vorgenommen" machen den Text gut lesbar. Der Berliner Text ist eher zurückhaltend und vornehmlich deskriptiv. Im zweiten biografischen Teil vermischt der Hamburger Text die Informationen zu beiden Vorgestellten Tomás Zmeškal (*1966) und Markéta Pilátová (*1973) und versucht so, die auf der Bühne sich begegnenden Gäste schon im Text zueinander

933 Der Tote Salon war eine Veranstaltungsreihe und bezeichnet nicht etwa einen Raum im Literaturhaus Hamburg. 
in Beziehung zu setzen. In Berlin bleibt dies den Leser*innen überlassen, der Text lässt die Viten aufeinanderfolgen.

2012 - Oslo

Die Programmtexte des Litteraturbuset in Oslo, exemplarisch im März 2012, unterscheiden sich im Aufbau je nach Veranstaltung, die sie ankündigen. Einen großen Teil bilden Vorträge der Reihen Lordagsforedraget [Samstagsvortrag] und Historisk sondag [Historischer Sonntag]. Eine kurze, leicht verständliche Zusammenfassung des Themas lässt erwarten, dass der Vortrag sich populärwissenschaftlich mit dem jeweiligen Sujet auseinandersetzt. Die Vortragenden ,sprechen nicht über' oder ,erörtern“, sondern sie „forteller“ (OL 2012-03-04) [erzählen], entsprechend sind die Ankündigungen informativ und erzählen zugleich Geschichten. Es wird nicht davon ausgegangen, dass die Leser*innen schon Details über zum Beispiel Alv Erlingsson (OL 2012-03-18), Magnus den Guten (OL 2012-03-04) oder die Expeditionen der Wikinger in Afrika (OL 2012-03-11) kennen. So holen diese Texte die Leser*innen $\mathrm{ab}$, indem sie kurz referieren, etwa dass der deutsche Philosoph Immanuel Kant 1724 geboren wurde, dass sein Hauptwerk Kritik der reinen Vernunft 1781 erschien und wie seine Hauptthesen lauten (OL 2012-03-24). Wie auch die heftinterne Beschreibung der Reihe darlegt, ist bei diesen Veranstaltungen kein großes Vorwissen nötig (OL 2012-I, S. 4). Dass das Publikum jedoch Interesse an historischer und philosophischer Auseinandersetzung haben sollte, machen die Programmtexte deutlich. Dies entspricht der Absicht der Vorträge, die als „Litteraturhusets åpne universitet" (OL 2012-I, S. 4) [die offene Universität des Litteraturbuset] angelegt sind, niederschwellig über wissenschaftliche und historische Themen zu informieren. Die Vortragenden selbst finden in diesen Ankündigungen nur kurz Erwähnung. Dort steht klar das Thema im Mittelpunkt. Fragen oder Hinweise darauf, worum es in dem Vortrag konkret gehen wird, zeigen, dass diese Texte Abstracts darstellen, die bereits für sich stehend Wissen vermitteln. Wenn nur eine Person auf dem Podium einen vorbereiteten Vortrag präsentiert, kann im Vorhinein relativ genau formuliert werden, was die Veranstaltung beinhalten wird. Bei Vorträgen unterscheiden sich die Programmtexte des Litteraturhuset in Oslo nicht einschlägig von den untersuchten deutschen Texten.

Ähnlich beworben wie die Vorträge werden im Litteraturbuset Veranstaltungen wie Narlesning, am besten übersetzbar mit dem englischen close reading. ${ }^{934}$ Im März 2012 setzten sich innerhalb dieser Reihe zwei Universitätslehrende mit dem „blikk på den politiske tilskueren“ [Blick auf den politischen Zuschauer], den der französische Philosoph Jacques Rancière in Den emansiperte tilskuer [im französischen Original Le spectateur émancipé] beschrieben hat, auseinander, denn: „De senere årene har han [Jaques Rancière, Anmerkung C. L.] vært et hett navn i norske kunst- und litteraturkretser" (OL 2012-03-28) [In den letzten Jahren war er ein heißer Name in norwegischen Kunst- und Literaturkreisen]. Mit dieser Bemerkung spricht der Text Zuhörer*innen aus dem Kunst- und Literaturbetrieb sowie aus der Universität an, eben jene, die sich für derartige Debatten interessieren und sich näher und intensi-

934 Vgl. Kapitel II 13.1.6, S. 357. 
ver auf den Referenztext einlassen möchten, und er positioniert das Literaturhaus im kunsttheoretischen Diskurs. ${ }^{935}$

Ausdrücklich hingegen an alle - „Alle kann være med“ (OL 2012-03-09) [Alle können dabei sein] - richtet sich die Veranstaltung Apen mikrofon [Offenes Mikrofon]. Dabei sind ,alle ${ }^{6}$ nicht nur zur Rezeption eingeladen, sondern dazu, auf der Bühne ihre eigenen Texte zu präsentieren. Die Aufforderung „Velkommen til litterært påfyll“" spielt dabei mit dem norwegischen Wort ,påfyll', das im Alltagsgebrauch für das kostenlose Nachgießen beim Kaffee steht und in diesem Fall in metaphorischer Verwendung mit Literatur kombiniert wird. Dieser ,literarische Nachschub“ illustriert somit ebenfalls, dass auch die Programmtexte des Litteraturhuset sprachlich über eine rein informierende Weise hinausgehend gestaltet sind.

Deutliche strukturelle Unterschiede zu den deutschen Literaturhaus-Programmtexten lassen sich bei den Veranstaltungen mit Belletristikautor*innen feststellen, die in Oslo vor allem unter dem Label Onsdagskvelder [Mittwochabende] präsentiert werden.936 Die norwegischen Texte nehmen stärker Bezug auf die Veranstaltungskonzeption und erklären implizit die norwegische Lesungspraxis, die von der in Deutschland gängigen abweicht. In den deutschen Ankündigungen wird selten konkret darauf eingegangen, worüber bei den Lesungen gesprochen wird. Hinweise auf die Einladungsmotivation finden sich selten, bloß gelegentlich wird etwa an vorherige Besuche der Autor*innen erinnert. In den norwegischen Texten hingegen werden in der Regel mindestens zwei Bühnenakteur*innen vorgestellt und ihre Gemeinsamkeiten respektive Anknüpfungspunkte herausgearbeitet, sie begegnen sich ,i samtale [im Gespräch]. Die Publikationen der Gäste stellen einen Aufhänger für eine Unterhaltung über Themen, die Werk und Biografie des Gastes nahelegen, dar. Diese Verbindung entsteht schon über die Programmtexte, die meistens nicht so eindeutig zwischen Autor*in und Moderator*in differenzieren. Die Programmtexte geben einen Ausblick darauf, welche Themen zur Sprache kommen werden. Ausführungen zu den Gästen oder Büchern werden kurzgehalten. Im März 2012 trifft das auf folgende Beispiele zu: Mit Marguerite Abouet, Graphic-Novel-Autorin der Elfenbeinküste (*1971), und Alain Mabanckou, Schriftsteller aus der Republik Kongo (*1966), kommen zwei afrikanische, frankophone Autor*innen mit ihren Adoleszenzbüchern der 1970er-Jahre unter dem Titelthema „Barnets blikk“ [Blick des Kindes] zusammen (OL 2012-03-21). Ihre vorgestellten Bücher werden im Text verglichen; so sei Mabanckous I morgon blir jeg tjue ${ }^{937}$ wie Abouets Aya ${ }^{938}$ mit Humor geschrieben, aber härter im Ton und ironischer. Ebenso verknüpft die Ankündigung zu einem Krimiabend mit dem schwedischen Autor Johan Theorin (*1963) und der Norwegerin Karin Fossum (*1954) die aktuellen Bücher inhaltlich und bietet Gesprächsthemen an, sie sprechen „om lik i kjelleren, mørke sykehuskorridorer

\footnotetext{
935 Ähnlich spezifische Metathemen respektive selbstreflexive Veranstaltungen lassen sich auch in den deutschen Literaturhäusern finden, vgl. Kapitel II 13.2.7.

936 Vgl. Kapitel II 13.1.5.

937 Auf Norwegisch erst im März 2013 erschienen, im Original als Demain j'aurai vingt ans 2010, auf Deutsch mit dem Titel Morgen werde ich zwanzig 2015 veröffentlicht.

${ }^{938}$ Kurz vor der Veranstaltung auf Norwegisch als Aya fra Yopougon erschienen, das französische Original kam 2006 heraus, auf Deutsch kam der erste Teil ebenso 2006 heraus, seit 2014 sind mehrere Teile gebündelt erhältlich.
} 
og hva som egentlig foregår inne i hodet på en forfatter som skriver psykologisk krim“ (OL 2012-03-28) [über Leichen im Keller, dunkle Krankenhausflure und über das, was eigentlich im Kopf eines Autors, der psychologische Krimis schreibt, vorgeht]. Durch derartige Vorausschauen auf die zu erwartenden Gesprächsthemen werben die Texte direkter für den einen speziellen Abend als dies in vielen Texten der deutschen Literaturhäuser der Fall ist.

Dass in den Ankündigungen der deutschen Lesungen relativ wenig darüber gesagt wird, wie der Abend verlaufen wird, könnte folgende Gründe haben: Zunächst lässt sich über einen vorliegenden Text leichter schreiben als über das Gespräch, das von einer Moderationsperson geleitet werden wird. Es lässt sich also nicht vorwegnehmen, worüber gesprochen wird, weil auf die Spontanität der Unterhaltung gesetzt wird, beziehungsweise würden so gegebenenfalls bei den Besucher*innen Erwartungen geschürt, die der Abend dann nicht einlöst: Das Publikum könnte enttäuscht werden. Dies funktioniert nur, weil der literarische Text selbst eine so große Bedeutung für die Veranstaltung einnimmt. In Norwegen liegt der Blick nicht so deutlich auf den einzelnen Publikationen, sondern es geht dort stärker um ein themenfokussiertes Gespräch. Aus diesem Grund steht in Norwegen die Überlegung, worüber die Podiumsgäste sprechen könnten, am Anfang der Veranstaltungsplanung. So ist zu vermuten, dass die Literaturhaus-Mitarbeiter*innen in Norwegen die Veranstaltung stärker inhaltlich mitvorbereiten, während in Deutschland die Gestaltung des Abends maßgeblich bei den Bühnengästen liegt. Dies hängt vermutlich unter anderem damit zusammen, dass sich in den deutschen Literaturhäusern die Tradition der ,Dichterlesung deutlicher fortsetzt und somit die Autor*innen und die Moderator*innen als Autoritäten auf der Bühne die inhaltliche Ausgestaltung dominieren, während sich das Literaturhaus-Team dahinter zurücknimmt. Und in arbeitspraktischer Hinsicht ist zu bedenken, dass die Veranstaltungen relativ kurz vor der Programmdrucklegung vereinbart werden, sodass dann noch gar nicht unbedingt klar ist, wie der Abend genau verlaufen wird. Stärker auf die einzelnen Veranstaltungen wirken die norwegischen Literaturhaus-Teams mit ihren Texten ein.

Die Tradition der Dichterlesung begründet außerdem die noch grundsätzlichere Beobachtung, dass in den deutschen Programmtexten der lange Lesungsteil nicht ausdrücklich aufgeführt, sondern maximal mit der Verbkonstruktion ,aus dem Buch lesen' beziehungsweise ,das Buch vorstellen' verkürzt kommuniziert wird. ${ }^{939}$ Es liegt die Vermutung nahe, dass das Format als bekannt vorausgesetzt wird: Regelmäßige Literaturhaus-Besucher*innen haben die Praxis der Literaturveranstaltung inkorporiert, es ist klar, dass es eine kurze Begrüßung gibt, dass der Moderator den Gast dann vorstellt und erste Fragen an den Autor richtet, dass bald - ,Aber nun hören wir erst einmal etwas aus dem Text ${ }^{6}$ - der Autor oder bei nichtdeutschsprachigen Gästen ein Sprecher 30, eher 45 Minuten vorliest, dass anschließend die Podiumsgäste miteinander ins Gespräch kommen und dass eventuell das Publikum noch Fragen stellen kann. Die Annahme, dass der Hergang einer Veranstaltung bekannt ist, liefert indirekt Aufschluss über die implizierten Adressat*innen des Literaturhaus-Programms: jene, die wie die Literaturhaus-Teams selbst mit der Praktik der

939 Vgl. Kapitel II 13.2.1. 
,klassischen Lesung' vertraut sind; Personen, die an einer solchen noch nicht teilgenommen haben, erfahren durch die Programme nicht mehr über die Praktik, denn es steht nirgends, dass sie circa 45 Minuten Lesung und circa 45 Minuten Gespräch erwarten können.

Entsprechend der Beobachtung, dass die norwegischen Ankündigungstexte sich auf die thematische Ausrichtung der Veranstaltungen konzentrieren, finden ästhetische Kriterien selten Erwähnung. Wertungen kommen in den Texten gelegentlich vor, zum Beispiel sei der finnische Autor Juha Itkonen (*1975) „et av finlandslitteraturens nye stjerneskudd“ (OL 2012-03-14) [eine der neuen Sternstunden (wörtlich: Sternschnuppen) der finnischen Literatur] und Alain Mabanckou „en av de viktigste stemmene i fransk samtidslitteratur" (OL 2012-03-21) [eine der wichtigsten Stimme in der französischen Gegenwartsliteratur]. Insgesamt ist der freundliche, aber nicht distanzlose Ton der Texte ähnlich wie in den untersuchten Literaturhäusern im Jahr 2012. Weder bedienen sich die Texte einer Umgangssprache, noch sind sie mit wissenschaftlichen Vokabeln gefüllt oder kompliziert formuliert wie die deutschen Texte manchmal. Dabei gilt es zu bedenken, dass das beschriebene Egalitätsprinzip damit zu tun hat, dass die norwegische Wissenschaftssprache, ähnlich wie im Englischen, sehr auf Verständlichkeit ausgelegt ist.

Eine Besonderheit der Sprache muss bei den norwegischen Texten unbedingt berücksichtigt werden: Die Texte aus dem Litteraturbuset in Oslo sind alternierend in beiden Schriftsprachen des Norwegischen verfasst, in Bokmal [Buchsprache] und in Nynorsk [Neunorwegisch]. Die zwei Varianten ähneln sich, sodass sie für alle des Norwegischen Mächtigen lesbar sind. Im Gebrauch dominiert Bokmål, im Landesdurchschnitt wird sein Anteil auf 85\% geschätzt; Nynorsk ist als Minderheitensprache interpretierbar. ${ }^{940}$ Die relativ ausgeglichene Verwendung im Programmheft widersetzt sich der durchschnittlichen Bevorzugung des Bokmål und sorgt ausdrücklich für Gleichberechtigung: ${ }^{941}$ „Dette er unikt for ikke-nynorske kulturinstitusjoner i Oslo. “942 [Das ist einzigartig für nicht-neunorwegische Kulturinstitutionen in Oslo.] Die Editorials des ersten Leiters Aslak Sira Myhre demonstrieren, dass er selbst auf Nynorsk schreibt; dies lässt vermuten, dass unter anderem durch ihn eine Sensibilität für die sprachliche Ausgeglichenheit besteht und dass sie nebenbei auf pragmatische Gründe zurückzuführen ist, weil er die ihm vertraute Sprache benutzt. Myhres Nachfolger Andreas Wiese formuliert auf Bokmål.

Die Programmhefte aus dem Litteraturbuset Bergen sind den Osloern insgesamt sehr ähnlich; so lassen sich die Beobachtungen zu den Ankündigungstexten aus dem Osloer Litteraturbuset auf diese Einrichtung übertragen. Auch im westnorwegischen Bergen, wo Nynorsk weitverbreitet ist, stehen die Texte auf Bokmål und Nynorsk, wobei sogar seltener Nynorsk zu lesen ist. Dass die spezielle Sprachsituation Norwe-

\footnotetext{
940 Vgl. Braunmüller 1999, S. 138, 185-186. In dieser Einführung zu den skandinavischen Sprachen lässt sich auch die historische Entstehung der beiden Schriftsprachen des Norwegischen nachvollziehen. ${ }^{941}$ Samisch zum Beispiel ist ebenfalls anerkannte Minderheitensprache in Norwegen, Regionen im Norden sind zweisprachig. Abgesehen von einzelnen Veranstaltungen, die sich mit der samischen Kultur und Literatur auseinandersetzen (z. B. OL 2009-02-12), gibt es im südlichen Oslo keine direkte Beschäftigung mit dem Samischen.

942 Arsberetning for Stiftelsen Litteraturbuset 2012 2013, S. 6.
} 
gens in Diskussionen regelmäßig Thema ist, spiegelt sich im Programm des Literaturhauses wider. Die Reihe Ut med Språket [Raus mit der Sprache] widmet sich diesem Thema regelmäßig, die Programmtexte sind durchgängig auf Nynorsk formuliert (erstmals BG 2013-04-30). Dies markiert eine deutliche Verortung in Westnorwegen und unterstützt die bei der Einzeldarstellung angeführte Annahme, dass dieses Literaturhaus eine besondere Verbindung zu seiner Region betont. Zur Stellung von Bokmål in der Gesellschaft fand in Bergen eine zweitägige Veranstaltung mit Beteiligten aus unterschiedlichen Bereichen statt (BG 2015-04-22/23), diese Ankündigung ist natürlich auf Bokmål verfasst. Auch im Literaturhaus in Bergen wird, was das Norwegische angeht, auf sprachliche Gleichberechtigung geachtet.

\section{Zwischenfazit}

Es hat sich gezeigt, dass inhaltsorientierte Aspekte bei dieser textfokussierten Analyse nicht völlig außen vor zu lassen sind. Tendenziell ließ sich eine Entwicklung von nüchtern-informierenden beziehungsweise akademisch-interessierten Darstellungen hin zu werbenden und im Vergleich emphatischeren Beiträgen erkennen. Dies ist als Marketingstrategie im Kontext der auch ökonomischen Abhängigkeit vom Publikum, das möglichst umfassend und breit angesprochen werden soll, zu sehen. Früher lag das Sich-Einfühlen, ob es sich um eine lohnende Veranstaltung handelt, eher bei den Rezipient*innen selbst, die Texte boten dazu Hinweise. Mit der späteren, verhältnismäßig lockereren Ansprache liegt die Betonung dann zusätzlich auf der Unterhaltung und der Begeisterung für Literatur - ohne dabei weniger Informationen zu liefern.

Die Programmtexte zeigen darüber hinaus, dass die Rezipient*innen sich intellektuell herausgefordert fühlen sollen und dass dort der Auseinandersetzung mit Literatur eine tendenziell wissenschaftliche Denkweise zugrunde liegt. Damit gilt die Ansprache gerade nicht der ,breiten Masse', sondern adressiert explizit ein höher gebildetes Publikum. Obwohl die Texte mit der Zeit leichter zugänglich werden, bleiben sie in einigen Aspekten voraussetzungsreich: Anspielungen auf andere Schriftsteller*innen, auf literaturbetriebliche Diskurse oder kulturpolitische Annahmen fallen auf und stecken das Beschäftigungsfeld der Einrichtungen ab.

Anhand des Vergleichs der deutschen und norwegischen Texte haben sich vor allem im Aufbau Unterschiede ergeben. Die Erkenntnis, dass die norwegischen Texte expliziter den Gesprächscharakter von Veranstaltungen betonen, während bei den deutschen Einrichtungen der literarische Text zentral ist, wird bei den inhaltlichen Programmanalysen aufgegriffen.

\section{10.4.2 Rahmeninformationen - Zeiten, Orte und Preise}

Prägnante Rahmeninformationen ergänzen die längeren Fließtexte. Sie geben Auskunft zum Beispiel über die Veranstaltungszeiten, -orte und Eintrittspreise. Hinzu zählen hier des Weiteren die Hinweise zu Kooperationspartnern oder Festival- und Reihenzugehörigkeit. Im folgenden Abschnitt steht also weniger die Darstellungsweise der Informationen im Vordergrund, sondern vielmehr die vermittelten Informationen selbst. Auch die Veranstaltungstage und -zeiten, die Veranstaltungsorte 
sowie Eintrittspreise beleuchten die Praxis der Institution Literaturhaus näher, die häufig als bekannt vorausgesetzt wird.

\section{Veranstaltungstage und -zeiten}

Eigene Veranstaltungen finden im Literaturhaus vornehmlich unter der Woche statt. Die Hauptveranstaltungstage sind Dienstag bis Donnerstag. Dass dies als typisch für das Literaturhaus gelten kann, beweist etwa die Entscheidung des Litteraturhuset in Oslo für Mittwoch als seinen ,egen arrangementsdag“" (OL 2011-II, S. 5) [eigenen Veranstaltungstag]. Üblicherweise beginnen die Lesungen zwischen 19 und $20 \mathrm{Uhr}$ und sind für 90 Minuten, in Bergen häufig nur für 60 Minuten angesetzt. Es gibt Veranstaltungen, die begründet zu einer späteren Uhrzeit starten, zum Beispiel die Reihe Nachtcafé im Literaturbaus Hamburg (z. B. HH 1992-09-25) oder das freitags datierte Apen mikrofon in Oslo (z. B. OL 2014-09-12), oder am Wochenende stattfinden, wie die Reihe Literaten im Hotel, organisiert vom Literaturhaus Hamburg in einem nahegelegenen Hotel, die etwa viermal im Jahr sonntags um 17 Uhr läuft. In Oslo gibt es häufiger durchgeführte Reihentermine, die explizit am Samstag oder Sonntag, dann tagsüber, stattfinden. Zu diesen Zeiten wird dort auch ein Kinderprogramm angeboten, sodass Eltern und Kinder ihre Freizeit am Wochenende im Literaturhaus verbringen können. Unter der Woche bleibt neben der Schule keine Zeit für derartige Unternehmungen und aus diesem Grund richtet sich an Werktagen das Kinder- und Jugendprogramm in den Literaturhäusern oft an Schulklassen und Kindergartengruppen. ${ }^{943}$

Schon zu Beginn konzentrierten sich die Angebote der Literaturhäuser für Erwachsene auf die Arbeitswoche. Das mag daran liegen, dass somit die relativ geringe Anzahl an Mitarbeiter*innen nicht zusätzlich am Wochenende im Einsatz sein muss, denn wenn das Literaturhaus-Team als Gastgeber auftritt, so sind in der Regel mindestens die Leitungspersonen persönlich zugegen. Außerdem kann es andere organisatorische Motive geben, etwa die Doppelnutzung des Saals im Literaturbaus Hamburg, der besonders samstags und sonntags für das Restaurant wichtiger Cafébereich und oftmals vermietet ist. Ein weiterer und entscheidender Grund mag sein, dass am Wochenende die Konkurrenz zu Theater, Konzert sowie Feiern, Reisen und Familienleben zu beträchtlich ist, da das Literaturhaus mit anderen Kultureinrichtungen und Freizeitbeschäftigungen um die begrenzte Zeit und Aufmerksamkeit - „die Währung des immateriellen Einkommens“944 - des Publikums buhlt. Doch dies gilt für jegliche Freizeitaktivitäten und folglich auch für die Veranstaltungszeiten an Abenden der Werkwoche. Allerdings ist der Literaturhaus-Besuch damit stärker in den Alltag integriert und stellt für einige Besucher*innen nicht so sehr etwas Außergewöhnliches dar. Damit einhergeht, dass im Literaturhaus beispielsweise keine aufwendige Abendgarderobe Konvention ist wie im Konzertsaal oder Theater. Dies hängt historisch vermutlich damit zusammen, dass Literatur in der öffentlichen Aufführung früher keine repräsentative Funktion hatte, sondern vornehmlich in Lesegesellschaften und Salons genutzt wurde - also nicht in feudalen Gebäuden stattfand und nicht sosehr zur Demonstration von Macht genutzt

${ }_{943}$ Zum Kinder- und Jugendprogramm vgl. Kapitel II 11.1.

${ }_{944}$ Franck 2007, S. 164. Vgl. dazu auch Franck 1998. 
wurde. Der Literaturbetrieb verlangt keine festliche Abendbekleidung. Erfahrungsgemäß tragen die Besucher*innen eher Alltagskleidung beziehungsweise Bürokleidung. Dies ist als ein Argument dafür zu vermuten, dass sich der Besuch im Literaturhaus eher zur Distinktion als Intellektuelle, wie sie Pierre Bourdieu vorschlägt, nutzen lässt. ${ }^{945}$

Die Terminierung der Veranstaltungen auf werktägliche Abendstunden hat Konsequenzen hinsichtlich der Zuschauer*innen. Es ist kaum verwunderlich, dass tendenziell vornehmlich Rentner*innen oder Studierende das Publikum bilden, denn bei Berufstätigen stehen in der Freizeit nach Dienstschluss außerdem Familie, Freund*innen, Sport und weitere Alltagsarbeit auf dem Aktionsplan. Zudem benötigt es Muße, sich um 19.30 Uhr nach einem Arbeitstag 90 Minuten auf eine Lesung einzulassen. Diese Art der Beschäftigung kann aber gleichfalls Ruhe bringen und ist mit einer eingeübten durchschnittlichen Dauer eine zeitlich gut kalkulierbare Aktivität, die unter der Woche genutzt wird. Und letztlich sind auf diese Weise nicht nur die Mitarbeiter*innen und das Publikum, sondern auch die Gäste auf der Bühne von Wochenendterminen entlastet, sodass diese meist als freie Autor*innen oder Journalist*innen Tätigen ihre Veranstaltungsaufträge, die Teil ihrer Erwerbsarbeit sind, ebenso unter der Werkwoche erledigen können.

\section{Veranstaltungsorte}

Die deutschen Literaturhäuser führen die deutliche Mehrzahl ihrer Termine in den eigenen Räumlichkeiten durch. Von Anfang an finden Veranstaltungen ergänzend ,außer Haus' an anderen Orten statt. Lokalitäten außerhalb des Literaturhauses werden aufgesucht, wenn die hiesigen Raumkapazitäten nicht ausreichen, etwa bei der erfolgreichen chilenischen Romanautorin Isabel Allende (*1942) (FF 2015-10-14). Zudem handelt es sich oft um Kooperationsveranstaltungen, die in den Räumen der Partnerorganisation abgehalten werden, zum Beispiel mit dem Amerikahaus (HH 1997-06-09, Lesung mit dem US-amerikanischen Autor Stewart O’Nan). Es gibt außerdem Außer-Haus-Veranstaltungen, die nicht aus organisatorischen, sondern aus konzeptionellen Gründen an einem anderen Ort stattfinden. Das Literaturhaus Hamburg versucht seit 2012 regelmäßig mit der Reihe Schwanenwik goes Schulterblatt durch einen Stadtteilwechsel ein neues Publikum zu erreichen (erstmals HH 2012 06-07): Das Literaturhaus „wagt sich [...] vom pittoresken Schwanenwik“ (HH 2012-06-07) ins „Szenegetümmel auf dem Schulterblatt“ (HH 2013-02-26).946 Das Literaturhaus Frankfurt zog schon im Jahr 2000 in die U Bar in der Innenstadt - in Frankfurt damals bis zur Schließung 2002 vor allem als Technodiskothek U 60311 berühmt - und präsentierte „,[n]euste deutsche Literatur“ (FF 2000-09-27). Für einige Abende wechselte ebenso das Literarische Zentrum Göttingen in den Kellerclub electroOsho, um etwa den Autor und DJ Thomas Meinecke - im Gespräch mit der damaligen Literaturredakteurin der Zeitung Frankfurter Rundschau Ina Hartwig - zu empfangen (GT 2001-10-01). Mit diesen Ausflügen in die Ausgehszene versuchten die Literaturhäuser andere Adressat*innen anzusprechen, sich dementsprechend ,ässig und jung` darzustellen, wie auch die Ankündigungstexte belegen. Im Litera-

945 Vgl. Bourdieu 1982, S. 420. Vgl. auch Kapitel I 5.6.2.

946 Diese Reihe kam schon im Kapitel zum Literaturhaus Hamburg vor, vgl. S. 117 und S. 120. 
turhaus selbst fiele die Umsetzung dieser Absicht noch schwerer. „Was dagegen nur mit dem Risiko harter Reibungseffekte und arger Verrenkungen für alle Beteiligten funktioniert, ist der Versuch, das Literaturhaus subkulturell zu auratisieren. " 947 Dazu sollten, Sonja Vandenraths These folgend, alternative Orte zum Literaturhaus gewählt werden, obgleich sich diese „,bei der Wahl von Clubs als Austragungsorte literarischer Performances [...] durchaus mit Kritik konfrontiert" ${ }^{\text {"9 }}$ "48 sehen, was zum weiten Themenfeld von Publika, literarischer Szene und freier versus institutionalisierter Literaturvermittlung weist.

Andere konzeptbedingte Ortswechsel sind zum Beispiel Reihen, die in privaten Wohnungen stattfinden: in Frankfurt Hütten, Paläste (erstmals FF 2010-12-04; Folgetermin FF 2011-05-10) und die Variante allein für Vereinsmitglieder Mitglieds Heim (erstmals FF 2010-10-30; Folgetermin FF 2011-04-09) sowie in Göttingen Hausbesuch (erstmals GT 2006-03-10; Folgetermin GT 2006-10-14). Diese drei Reihen sind überdies ein Beleg für den Transfer von Programmideen durch die Leitungsperson, denn der ehemalige Chef des Literarischen Zentrums überträgt ein in Göttingen etabliertes Format auf das Literaturhaus Frankfurt und modifiziert es etwa durch die besondere Variante nur für Mitglieder. Die exklusive und dadurch intime Atmosphäre, die sich bei dieser Art Lesung bildet, erinnert noch stärker an literarische Salons als die übliche Veranstaltung im Literaturhaus. Am eigentlich privaten Ort entsteht eine engere Verbindung zu den Podiumsgästen sowie den Zuschauer*innen untereinander, die teilnehmen an diesem pseudo-privaten Erlebnis. Die Konzeption derartiger Reihen unterstreicht die Absicht seitens des Literaturhauses, Räume der Begegnung entstehen zu lassen, und den exklusiven Eintritt in eine unbekannte privat genutzte Wohnung interpretieren die Besucher*innen, so ist anzunehmen, als Mehrwert.

Die Tendenz, Literaturveranstaltungen an ungewöhnlichen Orten durchzuführen, die in mehreren Artikeln von Autor*innen selbst eher ironisiert wurde, ${ }^{949}$ lässt sich im Kontext der Entwicklung betrachten, in der nicht nur dem Inhalt im engeren Sinne Bedeutung zugeschrieben wird, sondern die Veranstaltungsorte und rahmungen als elementarer Bestandteil begriffen werden, wie eingangs erläutert. ${ }^{950}$ Dies findet des Weiteren Bestätigung in der Beobachtung, dass beim Göttinger Hausbesuch nicht mehr nur Privatwohnungen, sondern ebenso Geschäftsräume (GT 2014-05-10) oder Museumssäle (GT 2014-12-04) genutzt wurden. Ähnlich sind Sonderaktionen wie Lesungen im Freien einzuordnen, zum Beispiel die vom Literaturhaus Berlin stetig angebotenen literarischen Spaziergänge außerhalb - wenngleich im Umkreis - der Fasanenstraße 23.

Hauptsächlich werden somit von den Literaturhaus-Organisationen die eigenen, namensgebenden Räume für Veranstaltungen genutzt, doch der Wechsel an andere Orte jenseits des Literaturhauses spielte in Deutschland immer schon eine Rolle und scheint mit der Zeit wichtiger geworden zu sein. Für das Literaturhaus Frankfurt lässt sich mit Stichproben belegen, dass die Zahl der Außer-Haus-Veranstaltungen leicht gestiegen ist. Während 1995 bei insgesamt 94 Literaturhaus-Veranstaltungen nur

\footnotetext{
947 Vandenrath 2013, S. 128.

948 Schmitt 2016, S. 324.

949 Anja Johannsen gibt bspw. wieder, wie der Autor Klaus Modick erzählte, dass er eine Veranstaltung abgesagt habe, bei der die lesenden Autor*innen auf Bäumen sitzen sollten, vgl. Johannsen 2013a, S. 64 950 Vgl. z. B. S. 98. Vgl. auch Vandenrath 2013, S. 128.
} 
eine nicht in der Bockenheimer Landstraße 102, sondern im Frankfurter Opernfoyer stattfand, bewegten sich 2005 von 93 Angeboten sechs außerhalb des Literaturhauses - in diesem Jahr ist zu bedenken, dass einige der Außer-Haus-Veranstaltungen literarische Spaziergänge im Zuge des Umzugs des Literaturhauses darstellten - und im Jahr 2015 liefen neun von insgesamt 89 Veranstaltungen nicht im Literaturhaus ab, sondern bei einer Kooperation in der Alten Oper, während der Buchmesse mit bekannten internationalen Autor*innen im Schauspiel Frankfurt, für eine Projektpräsentation im Museum für Moderne Kunst, im Deutschen Filmmuseum sowie in Privatwohnungen. 2005 und 2015 fanden also rund 90 Prozent der Veranstaltungen im Literaturhaus Frankfurt statt, 1995 sogar 99 Prozent. Im Literaturhaus Hamburg verhält es sich im Trend ähnlich: Während im Jahr 1995 (2005) sechs (acht) von insgesamt 81 (107) Veranstaltungen außer Haus erfolgten, was etwa siebeneinhalb Prozent der Gesamtanzahl darstellt, lässt sich 2015 eine Steigerung auf rund 22 Prozent verzeichnen, da 31 von 143 Veranstaltungen außerhalb des Literaturhauses durchgeführt wurden.

In den vergangenen Jahren bildeten öfter die begrenzten Raumkapazitäten im Literaturhaus den Grund für eine andere Location, wie sich an den Stichproben zeigt. Die Zahl der Autor*innen, die viel Publikum anziehen, in den LiteraturhausProgrammen ist, so lässt sich spekulieren, gestiegen. In Göttingen beispielsweise kommen Wechsel zum größeren Alten Rathaus aufgrund tatsächlich hoher Publikumsnachfrage gelegentlich vor, wenn der Vorverkauf längst läuft. Derartige kurzfristige Änderungen werden über die Website, Newsletter und Presse kommuniziert, sind folglich im gedruckten Programmfolder nicht nachvollziehbar. So ließe sich der Bekanntheitsgrad von Autor*innen oder das temporäre Interesse eines breiten Publikums an diesen Figuren und deren Schaffen an den vom Literaturhaus ausgewählten respektive wirklich genutzten Veranstaltungsorten und deren Fassungsvermögen ablesen. Diese spontanen Ortswechsel gäben darüber noch besser Auskunft, weil sie mit einer realen Publikumsnachfrage korrelieren, nicht mit einer hypothetischen. Das Interesse an einer Lesung mit Mario Vargas Llosa (*1936), Literaturnobelpreisträger seit 2010, war im Literaturhaus Hamburg schon 1998 so groß, dass es zwar keinen anderen Ort wählte, aber eine Live-Übertragung in den ersten Stock organisierte (HH 1998-03-03).

An den gerade genannten Zahlen für das Literaturhaus Hamburg wird zudem offensichtlich, dass die Veranstaltungszahl von 2005 zu 2015 gestiegen ist. Dies untermauert die These, dass die Literaturhäuser aufgerufen waren, mehr Veranstaltungen pro Jahr zu organisieren, wie bereits bei den Einzeldarstellungen in Verbindung mit den Leitungswechseln in Hamburg und Frankfurt diskutiert wurde. Doch ist durch den erhöhten Anteil an Außer-Haus-Veranstaltungen die Anzahl der im Literaturhaus durchgeführten Veranstaltungen nur unwesentlich gestiegen. Die Veranstaltungsmenge im Literaturhaus selbst hat sich über die hier stichprobenhaft ausgewählte Zeitspanne nicht markant verändert, schon für die Anfangsjahre sind im Durchschnitt zwei Veranstaltungen pro Woche zu verzeichnen. Die vermehrte Veranstaltungszahl ist somit auch auf Kooperationen zurückzuführen, die nicht allein vom Literaturhaus ausgerichtet werden.

Trotzdem lässt sich konstatieren, dass die Organisationen in Frankfurt, Hamburg und Göttingen für eigene Veranstaltungen zuweilen Orte abseits des Literaturhauses 
ansteuern, was wichtig für die Untersuchung der Institution Literaturhaus ist, denn ,Literaturhaus' fungiert damit gleichzeitig als Marke für den Literaturveranstalter nicht nur am festen Ort. Das Gesamtprogramm am eigenen Standort bildet die Grundlage für diese Markenbildung, und die ,Ausflüge‘ können ihrerseits zurückwirken auf die Wahrnehmung des Literaturhauses als Veranstaltungsort. Die Ortswechsel lassen sich damit zusätzlich als Maßnahmen der Öffentlichkeitsarbeit deuten. Um den Namen und das umfassende Konzept des Literaturhauses zu prägen, ist es jedoch zweckdienlich, hauptsächlich am angestammten Platz Lesungen durchzuführen.

Das Literaturhaus Berlin wechselt bisher mit seinen Veranstaltungen kaum den Ort, eigentlich nie. Da dieses Literaturhaus weniger Autor*innen, die von einem großen Publikum nachgefragt sind, im Programm hat, ist davon auszugehen, dass die Platzgrenzen des Saals seltener überstrapaziert sind. Außerdem ist es aufgrund der anderen mit der Funktionsbezeichnung, Literaturhaus' beschreibbaren Einrichtungen in Berlin nicht der einzige feste Ort für Literaturveranstaltungen in der Stadt, sodass es seinen abgesteckten Platz behaupten muss. Zudem entwickelte dieses erste Literaturhaus das Konzept des umfassenden Literaturhauses, bei dem das Gebäude als dauerhafter Literaturvermittlungsort zentrales Charakteristikum ist. Da es bis Ende 2017 in einer geradlinigen Leitungstradition geführt wurde, ist davon auszugehen, dass dieser Grundsatz von 1986 über die 31 Jahre vertreten wurde. Dieses Literaturhaus definiert sich vor allem als Ort für Literatur, während bei den anderen untersuchten deutschen Einrichtungen die Marke ,Literaturhaus' respektive ,Literarisches Zentrum` auch jenseits des einen Veranstaltungsortes verwendet wird.

Bei den untersuchten norwegischen Literaturhäusern fällt auf, dass sie gar keine Veranstaltungen außerhalb des Litteraturbuset durchführen, womit sie dem Berliner ähnlich sind. Die Ausnahme bilden in Oslo die Skolebesøk, bei denen Autor*innen Schulen im gesamten Stadtgebiet besuchen, oder Schüler*innen ins Literaturhaus kommen. Diese Veranstaltungen laufen als gesondertes Projekt und tauchen im Hauptheft zunächst nicht auf, sodass sie nicht Maßstab für das gesamte Litteraturbuset sind. Das norwegische Literaturhaus versteht sich vor allem als Stätte für Literatur und erst nachgelagert als Literaturveranstalter, der auch außerhalb des Literaturhauses Programm anbietet. Als charakteristisch für die Institution Literaturhaus wird in Norwegen somit die Idee des ,umfassenden Literaturhauses' verstanden.

Ob sich die Marke ,Literaturhaus' in Norwegen zukünftig gleichfalls für das Haus und den ortsungebundenen Literaturveranstalter durchsetzen wird, bleibt vorerst offen. Da dem Litteraturbuset in Oslo im größten Saal mehr Sitzplätze zur Verfügung stehen als den untersuchten deutschen Einrichtungen, ist kaum zu erwarten, dass aus Platzgründen auswärtige Anmietungen avisiert werden müssen. Zudem hat sich das Literaturhaus in Oslo als bekannter Veranstaltungsort etabliert, der über seine vielfältigen Veranstaltungsakteur*innen unterschiedliche Publikumsgruppen attrahiert. Somit finden sich mehr Indizien für die Hypothese, dass Litteraturbuset, die norwegische Version des Literaturhauses, auf die Konzeption als Ort für Literaturveranstaltungen und Diskussionen setzt und eher dritten Organisationen zu Sichtbarkeit verhilft, als die Präsenz der eigenen Literaturveranstaltungen durch Außer- 
Haus-Veranstaltungen zu erhöhen versucht. Diese Einrichtung wirkt damit eher an der Vermittlung von Literatur generell mit, indem sie für Literatur einen Raum bereitstellt, als selbst durch konkrete Angebote Literatur zu selektieren und als Gatekeeper hervorzutreten. Diese Auswahl- und Orientierungskompetenz rechnen sich die deutschen Literaturhäuser mit ihren Veranstaltungen auch außerhalb des Literaturhauses höher an. In Norwegen herrscht eher ein Gleichheitsprinzip, bei dem kein Akteur sich allein über andere stellt. ${ }^{951}$ Unterstützt wird diese Argumentation von den Ausführungen zum Gastprogramm und zu Kooperationen.

\section{Eintrittspreise und Vorverkauf}

Der Großteil der Veranstaltungen in den Literaturhäusern kostet Eintritt für die Besucher*innen. In den Literaturhäusern Frankfurt und Hamburg lag der Betrag in den Anfangsjahren bei fünf bis zehn Deutschen Mark. Das Literaturbaus Berlin bot Veranstaltungen zunächst entgeltlos an - „Der Eintritt zu Veranstaltungen ist noch frei“ (BE 1998-01/02, Hervorhebung im Original in rot) -, im Jahr 1998 kosteten aber auch dort die Lesungen Eintritt, später meistens sieben Euro. Aktuell bewegen sich die Preise zwischen sechs und zwölf Euro beziehungsweise zwischen 75 bis 90 Norwegischen Kronen, womit die Preise in Norwegen etwa so hoch sind wie in Deutschland. In den Literaturhäusern Frankfurt und Hamburg sind die Preise gerade bei Außer-Haus-Veranstaltungen gelegentlich höher, hier ist von zusätzlichen organisatorischen Kosten auszugehen. Ebenso lässt sich vermuten, dass sich bei diesen meist größeren Veranstaltungen eine Möglichkeit für Einnahmenüberschüsse bietet, was für die Einrichtungen relativ selten der Fall ist.

Hin und wieder ist der Eintritt frei. In diesen Fällen handelt es sich meist um Kooperationen oder subventionierte Veranstaltungen. In Oslo finden so zum Beispiel die Reihen Lordagsforedraget und Historisk sondag statt, die von der der größten Bank Norwegens mitfinanziert werden. Diese Angebote stellen die schwellenlose Vermittlung von Kultur und Bildung deutlich heraus. ${ }^{952}$ Neben diesen Ausnahmen zahlen die Besucher*innen für die Veranstaltungen im Literaturhaus Eintritt, denn die Einnahmen sind Bestandteil der Finanzierung der Einrichtungen.

Alle untersuchten Literaturhäuser gewähren etwa Studierenden, Schüler*innen, Schwerbehinderten und Arbeitssuchenden reduzierten Eintritt. In den deutschen Einrichtungen erhalten außerdem Vereinsmitglieder Ermäßigung, was als Vorteil der Mitgliedschaft kommuniziert wird. Da in Oslo und Bergen kein Verein angegliedert ist, gibt es dort dieses spezielle Angebot nicht. Um trotz der sinkenden Bereitschaft, sich langfristig für einen Verein, eine Organisation oder Stiftung zu verpflichten, ${ }^{953}$ ein Stammpublikum zu etablieren, ist in Oslo seit 2009 Litteraturbuskortet [die Literaturhaus-Karte] in Gebrauch, mit der die Besucher*innen zehn Prozent Rabatt auf Tickets für vom Litteraturbuset-Team organisierte Veranstaltungen erhalten. Damit fördern die Karteninhaber*innen das Literaturhaus aber nicht ideell wie mit einer Vereinsmitgliedschaft, bei der regelmäßige Beiträge nicht ausschließlich Geldvorteile bringen, sondern indirekt die Arbeit des Vereins insgesamt hono-

\footnotetext{
951 Vgl. Bjørkås 2003, S. 452.

952 Vgl. Kapitel II 6.1.3.

953 Vgl. Bjørkås 2003, S. 445-446.
} 
rieren. Dieses Mittel zur Besucherbindung ohne Vereinsmitgliedschaft ähnelt der bereits seit 1996 erhältlichen Zehnerkarte im Literaturhaus Hamburg (HH 1996-02).

Hinsichtlich des Kartenverkaufs lassen sich unterschiedliche Modelle identifizieren. Während im Literaturhaus Berlin nur Reservierung per Telefon oder E-Mail möglich sind, bevorzugen die anderen Einrichtungen feste Buchungen. Auch telefonische Bestellungen über das Büro des Literaturhauses sind sonst nur noch selten möglich: Das Literaturhaus Hamburg bietet die Option als Service für seine Vereinsmitglieder an, der allgemeine Vorverkauf ist ab Januar 1998 möglich. Auch im Literaturhaus Frankfurt gab es zunächst ausschließlich die Möglichkeiten, Karten zu reservieren, ab 2003 konnten mit einem Zuschlag von zehn Prozent Tickets im Literaturhaus vorher erworben werden, jetzt kosten die Karten an der Abendkasse sogar etwas mehr als im Vorverkauf. Die meisten Einrichtungen, auch die norwegischen, kooperieren mit Ticketdienstleistern und lagern damit diese Arbeit aus. Die verbindlichen Vorabbuchungen gewinnen an Bedeutung, denn sie befreien den Veranstalter von der Unsicherheit, wie viele Zuschauer*innen bei der Lesung tatsächlich zu erwarten sind, denn läuft der Vorverkauf nicht gut, besteht die Möglichkeit, noch Werbung für diese Veranstaltungen zu machen - um den Saal zu füllen und so die Bilanz auszugleichen. Und sie gewährleisten Ticketeinnahmen. Dies beweist, dass die Reservierung nicht mehr nur eine Dienstleistung für das Publikum ist, sondern die Eintrittsgelder den Literaturhäusern Einkünfte garantieren, mit denen sie kalkulieren.

\section{10.4.3 Impressum und Editorial}

Rahmende Texte, die das Literaturhaus als Literaturveranstalter einzuordnen ermöglichen, sind neben praktischen Informationen Einleitungen oder Editorials. Ein Impressum mit Kontaktdaten und Hinweisen etwa zum Vorverkauf und oft zu Förderern und Sponsoren findet sich in allen untersuchten Literaturhaus-Programmen. Nur das Litteraturbuset in Oslo erwähnt dort seine Mitarbeiter*innen und deren Funktionen nicht. So ,verschwindet ${ }^{6}$ das Personal hinter der Idee des Literaturhauses $^{954}$ und das Literaturhaus im engeren Sinne hinter dem umfassenden Literaturhaus. Allerdings stammt das Vorwort jeder Programmbroschüre dort von dem Literaturhaus-Leiter, was sich als Zeichen dafür auslegen lässt, dass die Konzentration auf die Leitungsperson in Norwegen, dies gilt nämlich ebenso für Bergen, in der Außenwahrnehmung doch nicht markant von der in den deutschen Literaturhäusern abweicht. Als Repräsentant des Literaturhauses lässt sich die Person verstehen, die das Editorial unterzeichnet. Für die Analyse der Institution ist dieser Programmheftbestandteil - „die von Primäradressaten gewöhnlich überlesenen Texte wie Vor- und Grußworte ${ }^{6955}$ - nutzbringend, weil er die einzelnen Veranstaltungen textlich verbindet, einen Bogen spannt und so den Magazincharakter unterstreicht

954 Der Vollständigkeit halber sei erwähnt, dass auf der Website hingegen die Namen aufgeführt sind - in alphabetischer Reihenfolge, nicht hierarchisch sortiert, dies spricht für die Hypothese, dass ein Literaturhaus in Norwegen ausdrücklicher von einem Team und nicht so markant von einer Leitungsperson geführt wird wie dies in Deutschland der Fall ist, da in Norwegen insgesamt in flacheren Hierarchien agiert wird.

955 Nolda 2003, S. 222. 
und weil er weitere Hinweise zur jeweiligen Einrichtung gibt, die zur Organisationsbildung beitragen. Obligatorische Komponente ist das Editorial jedoch in den Literaturhaus-Programmen nicht. Ebenso wie Litteraturbuset in Oslo reserviert das Literaturbaus Hamburg seit 2013 in jedem Monatsprogramm eine Einleitungsseite. Dort unterschreiben wie im Literaturbaus Köln namentlich die Mitarbeiter*innen des Literaturhauses das Vorwort, wodurch an dieser Stelle nicht so sehr die Programm- und Einrichtungsleitung von Rainer Moritz betont wird, sondern das Team die Besucher*innen willkommen heißt. Die Nennung der Teamangehörigen fällt vor allem deshalb auf, weil in den anderen Fällen meist die Leiter*innen als Sender*innen auftreten. Im Literaturhaus Frankfurt wird zunächst ein Vorwort nur dann eingesetzt, wenn ein konkreter Anlass für die Ansprache durch die Leitungsperson gegeben ist (z. B. FF 2011-09/10), so wie früher in Hamburg (HH 2005-02). Seit Herbst 2017 begrüßen „Hauke Hückstädt und das Team des Literaturhauses“ die Leser*innen in jedem Quartalsheft mit einem Einleitungstext (FF 2017-08/12). Nach den bisherigen Ausführungen zum Literaturhaus Berlin überrascht es nicht, dass sich das Personal dort nur über die Ankündigungstexte zu Wort meldet; im Fokus steht das Gesamtangebot, sodass die Rezipient*innen auf Seite drei zuerst die Programmübersicht des nächsten Monats aufschlagen. Die Gesamtschau ist auch für das Literarische Zentrum Göttingen wichtig, denn das dortige Leporello präsentiert die Veranstaltungen nicht auf einzelnen Seiten, sondern untereinander.

Ebenso nur gelegentlich verzeichnen die Literaturhäuser grundsätzliche Informationen zur Einrichtung. Von den untersuchten notieren nur die Programmhefte aus Oslo und Bergen generelle Auskünfte über das Literaturhaus (z. B. OL 2014-IV, S. 108). Dass in den deutschen Heften, anders als in Norwegen, nicht mehr erklärt wird, was ein Literaturhaus ist, lässt sich zum einen darauf zurückführen, dass die deutschen Einrichtungen älter und damit gefestigter sind und sich die Begriffsbezeichnung ,Literaturhaus' etabliert hat, zum anderen lässt sich diese Beobachtung so interpretieren, dass die Literaturhäuser sich in erster Linie über ihr Programm definieren. Dies bestätigt die Analyse der Onlineaktivitäten. ${ }^{956}$

\section{10.4.4 Bilder und Fotos}

\section{Fotos und Autorenporträts}

Die Literaturhaus-Programme verwenden nicht ausschließlich Schrift zur Vermittlung. Während einige Hefte auf der Frontseite nur mit Farbflächen und andere mit markanten Bildelementen arbeiten, enthalten alle heutigen Programme im Innenteil Bilder. Dies lässt sich interpretieren im Kontext der technischen Voraussetzungen, der zunehmenden Bedeutung der Autorpersona sowie des gesteigerten Werbeinteresses der Literaturhäuser.

Theoretisch betrachten die Wissenschaften einen Signifikanzgewinn von Bildern gegenüber Schrift bereits seit Anfang/Mitte der 1990er-Jahre - gebündelt unter dem Schlagwort Iconic beziehungsweise Visual Turn. ${ }^{957}$ Es lässt sich ebenso seit dieser Zeit eine gestiegene Relevanz des Visuellen in der Medienkommunikation konstatie-

\footnotetext{
${ }^{956}$ Vgl. Kapitel II 12.3.1.

${ }^{957}$ Vgl. Bachmann-Medick 2008, S. 300.
} 
ren. ${ }^{958}$ Diese Wendung erkennt Matthias Beilein etwa auf den Feuilletonseiten der überregionalen Zeitungen, denn „die elitären feuilletonistischen ,Bleiwüsten“ mussten einem gefälligen, bunten Layout weichen." "959 Dabei spielen Porträts von Autor*innen eine große Rolle, denn die ,professionelle Ausgestaltung von Autorenfotos ist das wohl sichtbarste Zeichen für die zunehmende Inszenierung visueller Paratexte in der öffentlichen Kommunikation über Literatur" "960, wie Marc Reichwein anmerkt. Insgesamt lasse sich für den Literaturbetrieb der 1990er- und 2000erJahre als wesentliche Tendenz konstatieren, dass die mediale und öffentliche Aufmerksamkeit für Bücher und ihre Autor*innen eine veränderte Berichterstattung über Literaturpreise und -wettbewerbe befördert habe und neben Interviews Porträts an Bedeutung gewonnen haben. ${ }^{961}$ Dies ist eine Diskussion, in die sich die Literaturhäuser außerdem inhaltlich einbrachten: Zum Beispiel präsentierte Wilhelm Genazino im Literaturbaus Frankfurt einen Essay über Autorenfotos, der später unter dem Titel Das Bild des Autors ist der Roman des Lesers (1994) erschien (HH 1992-0522). Im Literaturbaus Berlin beantwortete 1995 Klaus Wyborg in einem Vortrag mit Videoperformance die Frage W as erwarten wir von Bildern (BE 1995-05-04). Dieser Vortrag geht vermutlich zurück auf die im Vorjahr im Literaturhaus Hamburg durchgeführte Vortragsreihe mit gleichem Titel (HH 1994-12-01). ${ }^{962}$

Die Literaturhaus-Programmhefte liefern also für die Bedeutungszunahme von Autorenporträts selbst empirische Belege. Während in den ersten Jahren im Hamburger Programmheft nur Text gedruckt war, wird seit Oktober $2001 \mathrm{zu}$ fast jeder Veranstaltung mindestens ein illustrierendes Bild eingefügt. Der Konnex von technischen Errungenschaften und geänderten Wahrnehmungsweisen aktualisiert die Praktiken der Programmhefterstellung, denn dass in den ersten Jahren selten Autorenporträts eingebunden waren, liegt mitunter an den Publikationsvoraussetzungen der jeweiligen Zeit. Mit Aufkommen des Desktop-Publishings ist die Arbeit mit Fotos unkomplizierter geworden, weil Bilder als digitale Dateien und in hoher Auflösung vorliegen sowie mittels Speichermedien oder webbasiert versendet und am Personal Computer in die Druckvorlage eingebaut werden können. Der Zeitpunkt, ab dem das Literaturhaus Hamburg regelmäßig Fotos ins Heft einfügte, lag drei Jahre nach der Einrichtung einer Website mit eigener Domain. ${ }^{963}$ Dies kann als Indiz dafür gedeutet werden, dass unter anderem die Nutzung des Internets zu einer steigenden Bedeutung von Bildern für die Weltwahrnehmung beiträgt. Dabei wird keine Ursache-Wirkung-Beziehung von technischen Entwicklungen und geänderten Weisen der Bild-Text-Wahrnehmung angenommen, sondern von ineinandergreifenden Prozessen ausgegangen.

In jedem Fall ist die häufigere Verwendung von Autorenfotos in Zusammenhang mit dem gesteigerten Interesse an Autorenpersonen zu verstehen, ${ }^{964}$ in den das Lite-

\footnotetext{
958 Vgl. Reichwein 2007, S. 93.

${ }_{959}$ Beilein 2013, S. 596.

960 Reichwein 2007, S. 93-94.

961 Vgl. Birnstiel 2014, S. 70.

962 Dies ist ein weiteres Beispiel für den Transfer von Veranstaltungen von Literaturhaus zu Literaturhaus, denn die längere Reihe wurde in komprimierter Form nach Berlin übertragen.

963 Vgl. Kapitel II 12.1.

964 Zur Entwicklung und Bedeutung von Autorenfotos vgl. z. B. die Beiträge von Reichwein 2007 und Oster 2014 sowie den entsprechenden Absatz bei John-Wenndorf 2014, S. 335. Zur mediengeschichtlichen Etablierung und Entwicklung der Gattung des Autorenfotos vgl. Bickenbach 2010.
} 
raturhaus insgesamt zu setzen ist, in einen „übergreifenden kulturellen Wandel [...] zu einer Präsenzkultur, welche sich [...] auch für das Reale kultureller Artefakte interessiert: Gestaltung und Platzierung eines Buchs, Stimme und Gesicht des Autors, Lebensgeschichte und Bühnen-Performance. “965 Anhand der LiteraturhausBroschüren wird deutlich, wie die zur Verfügung stehenden technischen Mittel eine solche Entwicklung befördern können. Die Präsentation von Porträts in den Programmheften ist zugleich Ursache und Symptom der Diagnose, dass in der Literaturvermittlung die Schriftsteller*innen selbst zunehmend von öffentlichem Interesse sind, schließlich tragen die Literaturhaus-Programme dazu bei, den Blick auf die Personen ,hinter den Büchern` zu richten.

Dass der technische Fortschritt und die sich generell wandelnde Literaturvermittlungspraxis jedoch nicht zwangsläufig zu einer sofortigen Entwicklung hin zu mehr Bildern führten, zeigen die Literaturhäuser zugleich: Das Literarische Zentrum Göttingen beschränkte sich bei der ersten Version des Faltblattes auf Text. Platz für Fotos der Gäste wurde erst mit der Umgestaltung 2010 eingeräumt - das Produkt wird damit teurer als ohne Farbbilder. Nachdem im Programm des Literaturhauses Frankfurt im November 1992 zunächst eine Seite mit fotografischen Porträts eingesetzt worden war, verzichtete das von der seit 1995 neuen Leiterin Maria Gazzetti verantwortete Leporello auf Abbildungen von den Gästen, nur gelegentlich ergänzen Illustrationen oder Fotos von bereits verstorbenen kanonisierten Schriftsteller*innen die Texte. Erst mit der erneuten Umgestaltung im Herbst 2005 kamen aktuelle Fotos der eingeladenen Autor*innen zum Einsatz. Die Ausrichtung der Leiter*innen ist somit bei der Einschätzung der Kommunikationsmittel zu berücksichtigen, denn das Literaturhaus-Team unter Maria Gazzetti hat sich 1995 bewusst gegen die Integration von Autorenfotos in das Printprodukt entschieden. Denkbar sind organisationspraktische Gründe, da die Arbeit mit Fotomaterial zusätzlichen Arbeitsaufwand bedeutet. 2005 dann - so ist folglich anzunehmen - ist die fotografische Sichtbarkeit von Schriftsteller*innen, sowohl technisch als auch die kulturelle Praxis betreffend, derart alltäglich geworden, dass sie ins Literaturhaus-Programmheft aufgenommen wird. Die Konzentration auf Text mag auch an einer absichtlichen Abwendung von der Relevanz des Visuellen und an einem intendierten Fokus auf Schriftsprache liegen, sodass sich das Literaturhaus auf diese Weise kunstästhetisch positionieren würde, indem ein Literaturbegriff angelegt war, der ausschließlich Worte als zur Literatur zugehörig versteht. Eher als von derartigen literaturästhetischen Gründen ist hingegen davon auszugehen, dass auf diese Weise eine Kritik an Marketingstrategien markiert wurde. Die textliche Veranstaltungsinformation sollte nicht mit von der Literatur wegführenden Bildern angereichert werden, Literatur wurde nicht als Verkaufsobjekt, sondern als Kunstwerk verstanden. Dies gibt zwar ebenfalls Hinweise auf das vertretene Literaturverständnis, jedoch in einer anderen Hinsicht. Diese Ebene betrifft den Literaturbetrieb beziehungsweise den Buchmarkt und nicht zuvorderst literaturästhetische Kriterien.

Im Sommer 2018 werden Autorenfotos - zunächst mit Ausnahme des Literaturhauses Berlin - regelmäßig in die Programme aufgenommen. Die zur Veranschaulichung hier ausgewählten 2015er-Programme der Fallstudien unterscheiden sich je-

965 Birnstiel 2014, S. 71 mit Verweis auf Gumbrecht 2012. 
doch in ihrem Text-Bild-Verhältnis ebenso wie in der Farbigkeit der Bilder. Im zu der Zeit quartalsweise erscheinenden Frankfurter Heft sind die Bilder quantitativ sehr reduziert, auf den Veranstaltungsseiten wirken vor allem die Textinhalte und die farbig unterlegten und damit hervorgehobenen Namen und Titel. In der Heftmitte finden sich auf der Übersichtsseite schwerpunktmäßig Fotos in schwarz-weiß. Wenn Bilder auf den einzelnen Veranstaltungsseiten eingefügt sind, so sind diese ganzseitig und damit sehr präsent gesetzt und überlagern anteilsmäßig den Text. Viele Seiten sind hingegen gänzlich auf den Text konzentriert. Beim Literaturhaus Hamburg illustrieren meist farbige Fotos immer das obere Viertel der Veranstaltungsseite; die Broschüren wirken also textlastiger, die Fotos zurückhaltender. Die Fotos ergänzen damit den Text, ohne ihn zu überlagern. Darin vergleichbar ist das Programm des Literarischen Zentrums Göttingen, ein Leporello mit Textfokus und kleineren Autorenporträts. Diese Fotos bilden in der Regel die Autor*innen ab, manchmal auch weitere Akteur*innen wie die Moderator*innen, Sprecher*innen des deutschen Textes oder Dolmetscher*innen.

Das Berliner Programm, mit dem seit 2010 genutzten Design, ist zwar bebildert, doch handelt es sich dabei nicht um Autorenporträts oder Bilder zu den Veranstaltungen, sondern um eine Gesamtillustrierung des Heftes. Typografische Hervorhebungen zierten bis einschließlich 2012 die Komposition. Danach, ab 2013, treten Bilder an diese Stelle. Diese sind meist keine zeitgenössischen Abbildungen, sondern zeigen lesende Figuren aus unterschiedlichen historischen Perioden, etwa Buchläden aus den 1950er-Jahren (BE 2015-01/02), eine „Lesende Geisha“ (BE 2015-03/04) oder Ausschnitte aus dem Comic Superman (BE 2015-05/07). Insgesamt ergibt sich dadurch eine Ästhetik, die an die Klassische Moderne erinnert und damit auf das Selbstverständnis dieses Literaturhauses als Vertreter des „Projekts Moderne" referiert. ${ }^{966}$ Das Literaturbaus Berlin präsentiert sich gleichermaßen in den Selbstdarstellungstexten, in der Programmtextgestaltung wie in Gesprächen mit einem besonderen Interesse an Literatur als Kunst, die einzelnen Autor*innen als ,Privatpersonen' treten hinter die Texte zurück - wie sich im Design des Programmheftes zeigt.

Das Programmheft des Literaturhauses Oslo ist ebenfalls durchgestaltet: Bei einigen Ankündigungen finden sich Autorenfotos. Bei den Hinweisen zur zentralen Reihe Onsdagskvelder werden Porträts der Gäste mit Bildbearbeitungsprogrammen verändert, sodass die Farbgebung der jeweiligen Broschüre entspricht, und das Ergebnis an Pop Art-Kunst wie Andy Warhols berühmte Siebdrucke erinnert. ${ }^{967}$ Die Bilder wirken dadurch leicht verfremdet, fügen sich als Illustrationen mit dem Text verbunden gleichwohl besser ins Gesamtkonzept ein. Mit der Entscheidung gegen eine fotorealistische Abbildung wird der Schwerpunkt dieser Veranstaltungen auf die literarischen Themen, auf Literatur als Kunstwerk und nicht so sehr auf die Autor*innen als Personen unterstrichen. Ebenfalls mit hervorstechenden Bildern sind die Veranstaltungen für Kinder angekündigt, bei denen Bilderbücher und illustrierte Kinderbücher und damit Zeichnungen eine wichtige Rolle spielen. Grafische Muster tauchen in der Publikation immer wieder auf. Außerdem sind Zitate aus einem literarischen Text, der in der jeweiligen Programmperiode Thema ist, im Heft verteilt.

966 Vgl. Selbstdarstellungstext BE im Anhang V 1.2 sowie S. 233.

967 Vgl. Abbildung im Anhang V 2. 
Der Bezug zur Literatur stellt sich somit subtil her, indem Worte, Sätze, Verse als Element in das Designkonzept integriert werden. Die Aufmachung der Broschüre des Litteraturbuset Bergen erinnert sehr an die regelmäßige Veröffentlichung des Osloer Literaturhauses. Gerahmt wird dieses Dreimonatsprogramm beispielsweise ebenso von Autorenzitaten - eines am Anfang und eines markant auf einer der letzten Heftseiten gedruckt. Außerdem illustriert jeden Eintrag mindestens ein buntes Autorenfoto. Bei diesen norwegischen Programmheften lässt sich eine Mischung der ,deutschen' Konzepte bemerken: Als ,roter Faden'verbinden die Zitate und die Art der Fotobearbeitung die einzelnen Veranstaltungen ganz deutlich zu einem Ganzen, dabei wird aber nicht, wie in Berlin, von Abbildungen der Autor*innen abgesehen. 968

Mit Ausnahme des Berliner Programmheftes verwenden Broschüren von 2015 Fotos von den Autor*innen, reine Textprodukte publiziert keines der untersuchten Literaturhäuser. Grafische Elemente lockern die Darstellung auf und ziehen eher die Blicke des Rezipienten auf sich. Eine gesteigerte Werbefunktion der Hefte konnte schon die Analyse der Ankündigungstexte bestätigen. Bemerkenswert ist dabei, gerade aufgrund der konstatierten engen Zusammenarbeit mit Verlagen und Buchhandlungen, dass in der Regel keine Umschlagsabbildungen der thematisierten Bücher abgedruckt werden. Das Interesse liegt somit stärker auf den Autor*innen, weniger auf dem Verkauf der Bücher. Zum einen ist dies eine wichtige Beobachtung für die Grundausrichtung der Institution Literaturhaus, die ab den 2000er-Jahren als ihre Besonderheit stärker die Begegnung mit Schriftsteller*innen kommuniziert, obgleich zunehmend Novitäten das Programm bestimmen. Gleichzeitig lassen sich die Autorenfotos als hilfreiche Werbemittel interpretieren, denn schließlich gewinnen diese nicht nur in den Literaturhaus-Programmheften an Gewicht, sondern werden ebenso von den Verlagen umfassender eingesetzt und bekommen, wie oben zitiert, in den klassischen Literaturmedien mehr Sichtbarkeit. Die Nutzung von Autorenfotos ist subtilere, emotionalere Werbung als das Zeigen des Buchcovers. Die Werbewirkung der inszenierten Fotos kann als eine Reaktion darauf gedeutet werden, dass die Menschen für visuelle Botschaften empfänglicher geworden sind, was wiederum eine Reaktion auf die sich ändernde visuell geprägte Gegenwart ist. Obgleich Literaturveranstaltungen auch Anteil am Marketing für Bücher haben, ${ }^{969}$ setzen die Literaturhäuser, die kein unmittelbares Interesse an einer Verkaufssteigerung der vorgestellten Bücher haben, auf das Live-Erlebnis mit den Autor*innen. Somit ist es im Sinne der Institution nachvollziehbar, dass Fotos der Gäste die Programmhefte bebildern.

\section{Anzeigen}

Ökonomische Aspekte beschäftigen die Literaturhaus-Teams daneben in anderer Hinsicht. So finden sich seit Beginn in ihren Programmheften Anzeigen, die neben den Veranstaltungsfotos Bildelemente darstellen. Die Annoncen können interne

\footnotetext{
968 Dabei ist anzumerken, dass sich das neue Design des Literaturbauses Berlin dahingehend entwickelt, dass flächige farbige Beabeitungen von Autorenporträts die Programme schmücken - gerade so, als würde die Gestaltung nun die Osloer Grafikidee weiterführen, vgl. Anhang V 2.

969 Vgl. Vogel 2011, S. 159.
} 
Inserate des Literaturhaues selbst, wie Hinweise auf Mitgliedschaften und den Vorverkauf oder für besondere Angebote, wie Führungen durch das Literaturhaus ( $\mathrm{HH}$ 1998-02) oder Merchandise-Produkte - das Literaturhaus Hamburg verkaufte 1999 beispielsweise T-Shirts (HH 1999-01) -, sowie Werbeanzeigen von Drittanbietern sein. Bis heute findet sich Werbung von Verlagen, Theatern, Veranstaltern, Buchläden, gelegentlich auch von Brauereien und Hotels in den Leporellos. Von den Fallstudien druckt nur das Literaturbaus Berlin keine Fremdanzeigen ab - mit Ausnahme einer Bildseite des Fernsehsenders Arte, die jedoch aufgrund der Medienpartnerschaft mit dem Netzwerk der Literaturbäuser nicht als bezahlte Anzeige gewertet werden kann. Es handelt sich um Anzeigen von Verlagen zu konkreten Büchern, um Veranstaltungshinweise, Imagepflege von anderen Kultureinrichtungen oder Werbung von Unternehmen, die nicht mit dem Kulturbetrieb verbunden sind. Dabei unterscheiden sich die Programme dahingehend, ob es einen Anzeigenblock am Ende gibt oder ob die Anzeigen zwischen den Veranstaltungsankündigungen zu finden sind. Im Hamburger Heft wie im Göttinger Leporello erscheinen Inserate en bloc am Ende der Veranstaltungshinweise. Im Heft verteilt gibt es in den Broschüren der norwegischen Literaturhäuser Annoncen. Beim Literaturbaus Frankfurt fällt auf, dass Verlagsanzeigen häufig direkt neben der Veranstaltungsankündigung platziert sind, was eine engere Verbindung zu den Verlagen vermuten lässt, worauf später beim Thema ,Zusammenarbeit mit Verlagen` zurückzukommen ist. ${ }^{970}$
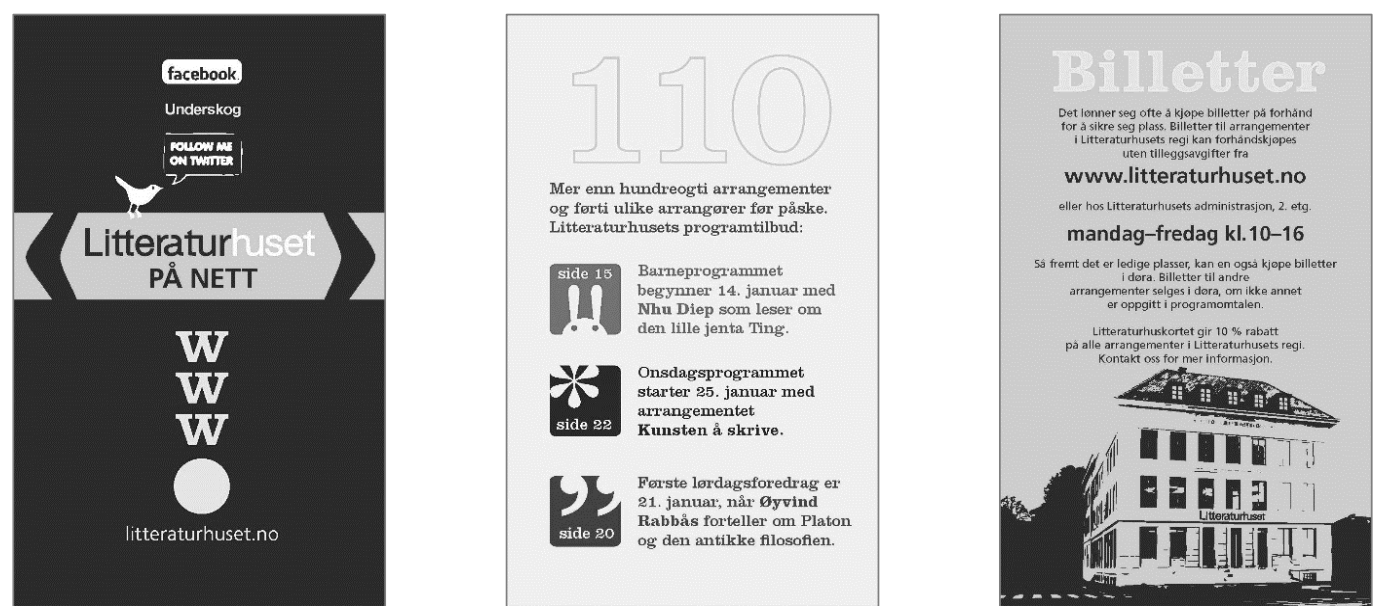

Abbildung 4: Anzeigen Programmheft Litteraturbuset in Oslo (OL 2012-I, S. 11, 13, 91) (in Graustufen, Original in rot-rosa Farben - das für das Literaturhaus in Oslo typische Farbspektrum).

Derartige Bildseiten sind also regelmäßig in den Programmen zu finden, in den sehr umfangreichen norwegischen Quartalsbroschüren häufiger als in den deutschen Heften - Abbildung 4 illustriert Beispiele aus dem Litteraturbuset in Oslo. Sie unterbrechen die textlastigen Veranstaltungsseiten. Sie füllen außerdem Seiten, um bei gehefteten oder fadengebundenen Broschüren eine durch vier dividierbare und bei Klebebindung eine den Druckbogen ausfüllende Seitenzahl zu erreichen. Trotzdem richten sie die Aufmerksamkeit dezidiert auf einzelne Elemente. Die Seite zu Billetter [Eintrittskarten] etwa bringt wichtige Serviceinformationen für die Besucher*innen zur Geltung und promotet gleichzeitig den Vorverkauf. Externe Anzeigen generieren Einnahmen.

970 Vgl. Kapitel II 11.2.3. 


\section{11 Sortierung des Programms}

Die Literaturhaus-Veranstaltungen sind, wie erwähnt, in den Programmheften chronologisch abgebildet. Neben den bereits betrachteten organisatorischen Rahmeninformationen enthalten die Veranstaltungsankündigungen weitere Markierungen, die noch andere Sortierungen nahelegen. Diese Einteilungen rekurrieren stärker auf die inhaltlich-konzeptuelle Arbeit des Literaturhauses. Besonders ergiebig für das Verständnis der Institution im deutsch-norwegischen Vergleich sind die Abgrenzung beziehungsweise Integration des Kinder- und Jugendprogramms, der Umgang mit Gastveranstaltungen und Kooperationen sowie die Einordnung der Veranstaltungsangebote in Reihen, Festivals oder Einzelveranstaltungen. Letzteres bildet den Auftakt zur stärker inhaltlichen Analyse des Literaturhaus-Programms im übernächsten Kapitel, die ersten beiden Punkte werden im Folgenden ausgeführt.

Darüber hinaus finden sich speziell markierte Angebote innerhalb des Erwachsenenprogramms mit einer exklusiven Zielgruppe - etwa für Vereinsmitglieder, die es aufgrund der Organisationsstruktur nur in den deutschen Literaturhäusern gibt. Diese Unternehmungen verdeutlichen, dass das Literaturhaus von einem Verein getragen ist und das Gruppenerleben eine Rolle spielt. An diesen Abenden sind „Mitglieder und solche, die es werden wollen“ (HH 1995-11-17, Fest zum zehnten Geburtstag des Literaturhaus-Vereins) eingeladen. Erwähnt seien außerdem die hauseigenen Feste wie Saisoneröffnungen (z. B. HH 1994-09). Ebenfalls feiern die Literaturhäuser ihre Einrichtungsjubiläen, etwa das Literaturbaus Hamburg zum fünften (HH 1994-09) und zum 25. Jahrestag (HH 2014-09) sowie das Literaturbaus Frank-furt zum 20. Geburtstag (FF 2011-04-30). Bei dieser Feier legten 20 nichtprofessionelle DJs - Akteur*innen aus dem Literaturbetrieb - Musik auf. Dieses Format findet, seit Hauke Hückstädt das Literaturbaus Frankfurt leitet, jährlich zum Tanz in den Mai statt. Auch ein Sommerfest wurde im 20. Literaturhaus-Jahr gefeiert (FF 2011-05-04) - eine Idee, die bereits im Literarischen Zentrum Göttingen regelmäßig realisiert wurde (z. B. GT 2007-06-30). Das Litteraturbuset in Oslo beging im Oktober 2017 seinen zehnten Geburtstag in großem Stil mit einer Jubiläumswoche, Litteraturbuset Bergen feierte 2018 seinen fünften Geburtstag. Derartige Feste unterstützen den sozialen Aspekt des gemeinschaftlichen Zelebrierens (von Literatur) und stärken die Marke ,Literaturhaus', indem sie die eigene Literaturhaus-Historie thematisieren. Dadurch, dass die Einrichtungen dabei ihre Traditionslinien und Zukunftsansprüche formulieren, werden die Besucher*innen in diese Geschichte einbezogen und damit zum Teil des Literaturhauses erklärt.

\section{11.1 Kinder- und Jugendprogramm}

Inzwischen ergänzt in vielen Literaturhäusern ein Kinder- und Jugendprogramm das Repertoire des ,alten' Literaturhauses. Ihr Angebot für Kinder und Jugendliche, insbesondere Literaturveranstaltungen für Schulkinder, etikettieren beispielsweise die Literaturhäuser in Hamburg, Frankfurt, Köln, Leipzig und Kiel seit einigen Jahren mit dem Label Junges Literaturhaus - eine Untermarke des Literaturhauses. Dieser Bereich entwickelt wie ein Imprint im Verlagswesen zwar ein eigenes Programm mit 
spezieller Ausrichtung, behält aber eine enge Verbindung zur übergeordneten Organisation bei. Die Benennung als Junges Literaturhaus ist nachvollziehbar, weil damit die Präsenz neben dem ,Hauptprogramm' markiert ist. Die Sichtbarkeit dieser Marke ist unter anderem aus kulturpolitischen Gründen sinnvoll, weil die zunehmende Einbeziehung von Kindern ins Literaturhaus im Bildungsdiskurs anzusiedeln ist. Ebenso wie der demografische Wandel dazu führt, dass viele Senior*innen Kultureinrichtungen besuchen, finden sich mehr Angebote, um dem Nachwuchs die Kulturtechnik des Lesens näherzubringen.

Eine umfassende Darstellung des Kinder- und Jugendangebots und dessen Einordung in den kulturpolitischen und -pädagogischen Diskurs unternimmt Susann Sophie Schmitt in ihrer Doktorarbeit. ${ }^{971}$ Ihre und die vorliegende, zeitlich deutlich vor Erscheinen von Schmitts Buch begonnene Arbeit ergänzen sich gut, wie schon im ersten Kapitel offengelegt. Schmitt setzt ihre Untersuchungsperiode vor allem mit Benennung des ersten Jungen Literaturbauses 2007 in Köln an, ${ }^{972}$ konzentriert sich damit auf die aktuelle Situation (2009 bis 2012). ${ }^{973}$ Sie berücksichtigt nur die damaligen Mitglieder des Netzwerkes der Literaturbäuser. Das Literarische Zentrum Göttingen und die skandinavischen Einrichtungen bezieht sie nicht ein. Die hier vorgenommene Durchsicht der Programme seit 1986 ergibt, dass Veranstaltungen für Kinder und Jugendliche, zunächst speziell für kleinere Kinder, fast seit Beginn in den Literaturhäusern vorkommen. Die Sichtbarkeit im Hauptprogramm und die Anzahl der Veranstaltungen für diese Zielgruppe haben sich über die Jahre deutlich erhöht und die Selbstdarstellungstexte heben das Kinderprogramm ebenfalls hervor. Das Kinderund Jugendprogramm spielt ergo für die Gesamtkonzeption des Literaturhauses eine zunehmend wichtigere Rolle.

Diese Entwicklung wird anhand der Untersuchung der Programmhefte plastisch. Bei den Fallstudien sind die Veranstaltungen für Kinder und Jugendliche heute meist in den allgemeinen Programmheften mit abgebildet. So lässt sich festhalten, dass in der Außenkommunikation das junge Programm mit der Zeit durch die Hervorhebung der Zielgruppe sichtbarer in das ,Hauptangebot ${ }^{6}$ integriert wird, obgleich, wie die von Schmitt geführten Interviews ${ }^{974}$ und meine Erfahrungen beweisen, das Programm für Erwachsene das für Kinder und Jugendliche hinsichtlich finanzieller Mittel und interner Priorisierung dominant überragt. Dass das kinderund jugendliterarische Angebot in der Regel nicht von der Leitung des Literaturhauses kuratiert wird, lässt sich somit in den Programmbroschüren nicht offensichtlich erkennen. Das Literaturbaus Frankfurt, Litteraturbuset in Oslo und zeitweise das Literarische Zentrum Göttingen präsentieren, wie das Literaturhaus Kiel, diesen Programmbereich zusätzlich auf einem gesonderten Flyer und geben ihm damit eher den Status einer eigenständigen Abteilung. Dennoch verzichten sie nicht auf die Abbildung im Gesamtprogramm, womit die Hypothese Unterstützung findet, dass ein Kinderund Jugendprogramm sich inzwischen als Bestandteil der Institution Literaturhaus etabliert hat.

971 Vgl. Schmitt 2016.

972 Vgl. ebd., S. 115.

973 Ausführlich zu den Programmschwerpunkten für Kinder und Jugendliche in den auch hier relevanten Literaturhäusern Berlin, Hamburg und Frankfurt, vgl. ebd., S. 203-211.

${ }^{974}$ Vgl. ebd., S. 265-266. 
Junges Literaturhaus Hamburg und Junges Literaturhaus Frankfurt

Programm für Kinder- und Jugendliche gab es schon früh im Literaturhaus Hamburg. Die Reihe Spaß mit Büchern, die im April 1990 ins Haus geholt wurde, besteht bis heute in Kooperation mit dem Jugendinformationszentrum fort. Interessant ist dabei jedoch die Einbindung der Reihe ins Gesamtprogramm: Zum Start wurde die Reihe einfach ins Literaturhaus-Programm integriert, ab 1996 gab es dann zunächst eine deutlichere Markierung (HH 1996-04-04)

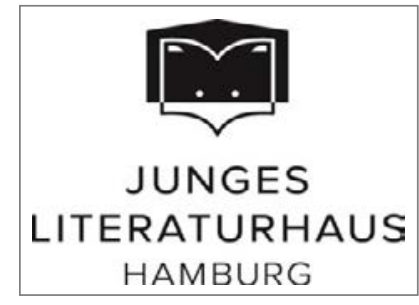

Abbildung 5: Logo Junges Literaturhaus Hamburg und ab 2000 wurde die Ankündigung unter die Überschrift ,Gastprogramm`geschoben (HH 1998-01-15), womit eine Distanzierung vom Hauptprogramm stattfand. In den Heften aus dem Jahr 2005 wird Spaß mit Büchern wieder mit den anderen Angeboten gemischt kommuniziert. Viele Jahre war die Reihe Spaß mit Büchern der einzige Termin für Kinder ab circa sechs Jahren - die Altersangaben wechseln je nach Veranstaltung. 1999 etablierte sich eine weitere Reihe: Schüler treffen Autoren, die später $S T A^{*}$-Club heißt. Schriftsteller*innen, nicht ausschließlich Kinder- und Jugendbuchautor*innen, stellen exklusiv für Schüler*innen ihre Texte vor. Dabei wird betont, dass die Veranstaltung eher Workshop- denn Lesungscharakter habe (erstmals HH 1999-05-05). Die Partizipation der Jugendlichen ist also direkter gefordert als bei Auftritten für Erwachsene, die Vermittlung ist ausdrücklich Teil der Reihe. Ebenso wird Wert gelegt auf die Vitalität der Begegnung; „Lebendige Literatur“ heißt es im Text. Daneben gibt es weitere Reihen, etwa Gedankenflieger-Philosophieren mit Kindern oder Supernova, und Projekte wie Schulbausroman oder Schreiblabor - die Prosawerkstatt für Jugendliche. Mit der namentlichen Etablierung des Jungen Literaturhauses im Zuge der Umgestaltung der Corporate Identity 2013 setzt es sich programmatisch zwar vom Hauptprogramm ab, legt aber dennoch kein eigenes gedrucktes Programm vor. Einige Zeit unterhielt das Junge Literaturbaus Hamburg eine eigene Website, die inzwischen jedoch als Unterseite des Literaturhaus-Auftritts reintegriert wurde. Damit stehen die Kinder- und Jugendveranstaltungen gleichberechtigt mit den Abendterminen im Programm - abgesetzt durch die Fuchsaugen im Logo (vgl. Abbildung 5) -, obwohl sie nicht federführend von der Literaturhaus-Leitung kuratiert werden.

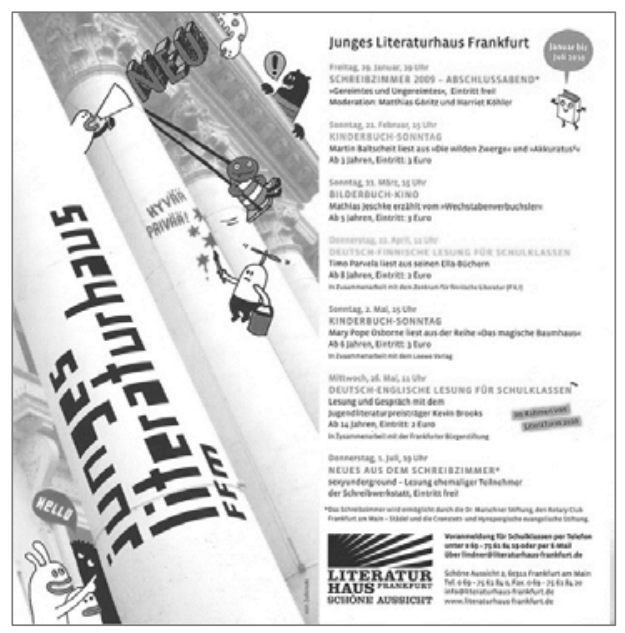

Abbildung 6: Programmflyer Junges Literaturbaus Frankfurt (in Graustufen)
Sehr ähnlich verhält es sich mit dem Programm für Kinder und Jugendliche im Literaturbaus Frankfurt, das mit dem Leitungs- und Designwechsel seit Herbst 2010 (FF 2010-0929, vgl. Abbildung 6) ebenso subsummierend als Junges Literaturhaus betitelt ist. Es besteht aber aus mehr Einzelterminen und ist weniger in Reihen strukturiert als das Hamburger Pendant. Schon von Beginn des Literaturhauses an war diese Zielgruppe zu Veranstaltungen eingeladen, wie die ersten Folder belegen, etwa Lyrik für Kinder ab 8 Jahren mit dem Grafiker und Autor Jürgen Spohn (1934-1992) 
(FF 1991-03-09) oder Lesereisen mit Lesungen etwa aus Carlo Collodis Klassiker Pinocchio (FF 1991-09-05) sowie die immer noch durchgeführten Kinderbuch-Sonntage (z. B. FF 1994-11-20). Neben Autorenlesungen finden regelmäßig Termine des Schreibzimmers statt, eine Prosa- und eine Lyrikwerkstatt für 14- bis 18-Jährige. Das Format existiert seit 2005, der Name seit 2007. In dem Jahr hat sich daran anschlieBend ferner sexyunderground entwickelt, ein Textkollektiv, das für Absolvent*innen der Schreibkurse offensteht, folglich eine etwas ältere Altersgruppe anspricht. Ebenso wie in Hamburg zeichnen in Frankfurt Mitarbeiter*innen, die nicht die Leitung der Gesamteinrichtung innehaben, verantwortlich für das Programm des Jungen Literaturhauses. Lesungen und Schreibwerkstätten machen dabei den größten Teil aus.

\section{Literatur macht Schule des Literarischen Zentrums Göttingen}

Das Projekt Literatur macht Schule begründet die besondere Konstellation hinsichtlich des Kinder- und Jugendprogramms im Literarischen Zentrum Göttingen: Es organisiert seit 2008 Schullesungen in Göttingen und im Umland. Von 2012 bis 2018 bündelte es all diese Veranstaltungen, deren Zahl stieg, in einem eigenen Programmfolder. ${ }^{975}$ $\mathrm{Da}$ es als eigenes Projekt betrachtet wurde, grenzte es sich auf diese Weise stärker vom ,Hauptprogramm a ab. Nur manchmal finden Veranstaltungen zusätzlich abends im Literarischen Zentrum statt. Als Bildungsprogramm unterstützen maßgeblich Förderer das Projekt. Ein ebenfalls umfassendes und drittmittelbasiertes Projekt in Zusammenarbeit mit Schulen führt das Literaturbaus Stuttgart durch, wo sich aus Schreibwerkstätten für Jugendliche 2012 das Literaturpädagogische Zentrum entwickelte, das nicht nur Veranstaltungen anbietet, sondern insbesondere Lehrer*innen in der Vermittlung von Literatur fortbildet. Dies ist sicherlich ebenso wie in Göttingen ein Grund dafür, weshalb es kein weiteres öffentliches Angebot für Kinder gibt. Die direkte Verbindung zu den Schulen erweist sich als besonders sinnvoll, seit Ganztagsschulen den Schulalltag vom Vormittag auf den Nachmittag ausdehnen, und vor allem seit außerschulische kulturelle Bildung an Bedeutung gewonnen hat.

\section{Kulturelle Bildung}

Dass die deutschen Literaturhäuser, die dezidiert mit einem Erwachsenenprogramm starteten und das Kinderprogramm nur marginal berücksichtigten, zunehmend Angebote für Jugendliche integrieren, ist für die Beschreibung der Institution relevant und liefert gleichzeitig Belege für die Annahme, dass ein bildungspädagogischer wie empathischer Zugang zu Kultur/Literatur an Bedeutung gewinnt - nicht zuletzt aufgrund der sogenannten ,PISA-Debatte, wie Susann Sophie Schmitt die Argumentation ergänzt ${ }^{976}$. Laut Stiftung Lesen lasen Jugendliche zwischen 14 und 19 Jahren in Deutschland 2000 im Vergleich zu 1992 weniger, statt 81 Prozent griffen nur noch 71 Prozent mindestens einmal pro Woche zu einem Buch; bei den ohnehin weniger lesenden 20- bis 29-Jährigen sank der Anteil von 58 auf 41 Prozent. ${ }^{977} \mathrm{Zu}$ -

\footnotetext{
975 Ab Februar 2018 erscheinen die öffentlichen Veranstaltungen wieder gebündelt in einem Folder. Die Schullesungen werden in direktem Kontakt zu Lehrerinnen und Lehrern vermittelt. Deutlich wird, dass die Hauptfunktion des Programmfolders Werbung ist und erst untergeordnet zur Selbstdarstellung dient. 976 Vgl. ebd., S. 32.

977 Vgl. Leseverhalten in Deutschland im neuen Jahrtausend 2000, S. 9.
} 
rückzuführen ist dies unter anderem auf die veränderte Lesesozialisation, die im familiären wie schulischen Umfeld an Bedeutung verloren hat, wie die Stiftung Lesen für 2008 bestätigt, ${ }^{978}$ die aber entscheidenden Einfluss auf die Lesepraxis im Jugendalter hat. Daneben ist die Aufwertung von Kinder- und Jugendliteratur in der Literaturwissenschaft um die Jahrtausendwende zu bedenken. ${ }^{979}$ Die Hinwendung von Literaturvermittler*innen zum Nachwuchs ab dem Grundschulalter und eine Begleitung die gesamte Schulzeit über ist eine Investition in die eigene Zukunft. Einerseits kommen Kinder sowohl mit dem Lesen im Sinne der ,Leseförderung ${ }^{6}$ als auch mit Genusslesen und dem Unterhaltungspotential einer Literaturveranstaltung in Berührung, was diese zu Literaturhaus-Rezipient*innen prädestiniert. Andererseits gilt dies als Legitimationsstrategie für Geldzuwendungen, denn für Projekte unter dem Stichwort ,kulturelle Bildung erhalten öffentliche und gemeinnützige Einrichtungen wie Museen, Theater, Bibliotheken oder Literaturveranstalter eher finanzielle Unterstützung. Diese beschränkt sich allerdings in der Regel auf Projektförderung und umfasst damit keine grundständige strukturelle Förderung. Die Finanzierung des jungen Programms speist sich meist nicht aus dem Hauptbudget der Literaturhaus-Organisation, was Susann Sophie Schmitt für die Jungen Literaturhäuser schlüssig zusammenfasst und mit ihren Interviews belegen kann, ${ }^{980}$ zusätzliche Finanzierung ist also wichtig. Während die Kinderveranstaltungen zunächst nachrangig kommuniziert wurden, findet heute eine klare Integration ins Gesamtprogramm statt, sodass auch für die erwachsenen Rezipient*innen - unter anderem potenzielle Förderer - ersichtlich wird, dass das Kinderprogramm zum Gesamtkonzept des Literaturhauses gehört. Wie unterschiedlich intensiv dies der Fall ist, offenbaren die folgenden Ausführungen zum jungen Angebot des Literaturhauses Berlin und des Litteraturbuset, exemplarisch anhand von Oslo und Bergen.

\section{Tendenz zu weiteren Kinder- und Jugendprogrammen}

Kein eigenes regelmäßiges Programm für Kinder und Jugendliche entwarf lange das Literaturhaus Berlin und schien damit weniger Offenheit dieser Zielgruppe gegenüber zu zeigen. Dennoch wurden Kinder beziehungsweise Familien hin und wieder eingeladen, denn in Kooperation mit LesArt, dem selbstbenannten Kinder-Literaturhaus in der Stadt, spielten sich seit Ende 2002 regelmäßig Erlesene Sonntage im Literaturhaus Berlin ab (erstmals BE 2002-12-01). Die zu Beginn dieses Fallstudienkapitels beschriebene Aufteilung der Kompetenzen und Schwerpunkte auf mehrere ,Literaturhäuser' in Berlin wird hier anschaulich. Durch diese Zusammenarbeit entsteht keine Konkurrenz, sondern ein für beide Seiten nützliches Arrangement: Das Literaturhaus Berlin kann auf diese Weise, ohne eigenen Aufwand, diese Zielgruppe erreichen und LesArt findet einen weiteren Veranstaltungsort für seine stadtweiten Veranstaltungen. Dass die Initiation dieser Kooperation auf den ab Februar 2003 amtierenden Leiter Ernest Wichner zurückgeht, ist zu vermuten. Wie der damals neue Chef zur Leitungsübernahme konstatierte und der Vereinsvorstand sich vom personellen Wechsel wünschte, sollte sich das Literaturhaus zur Stadt hin öffnen,

\footnotetext{
978 Vgl. Lesen in Deutschland 2008 2008, S. 32.

979 Vgl. z. B. Ewers 2000, S. 9-13.

980 Vgl. Schmitt 2016, S. 356.
} 
die Einbeziehung dieser Familienmatinee kann als ein Schritt in diese Richtung interpretiert werden. Außerdem findet seit 2004 jährlich das Literarische Kinderquartett als Kooperationsprojekt in der Fasanenstraße 23 statt, wo Kinder nach einer längeren gemeinsamen Vorbereitungszeit in Anlehnung an die formatprägende Kritikerrunde im Fernsehen Das Literarische Quartett ein Streitgespräch über vorgestellte Bücher führen (BE 2004-09-19). Das Literaturhaus München bietet ebenso vorerst keinen selbst kuratierten kinder- und jugendliterarischen Veranstaltungsplan an, sodass ein hauseigenes Programm für ein junges Publikum kein notwendiges Charakteristikum für die Institution Literaturhaus darstellt. Hin und wieder aber kommen in allen untersuchten Literaturhäusern eigene Kinderveranstaltungen vor; so las schon 1990 im Literaturhaus Berlin Günter Grass ,für Kinder und deren erwachsene Begleiter aus seinem Gedichtband ,Tierschutz"“ (BE 1990-06-17). Und tendenziell weiten die Einrichtungen ihr Angebot für Kinder und Jugendliche aus, sodass zu erwarten ist, dass zukünftig noch mehr Orgnanisationen sich zusätzlich an Heranwachsende wenden. Der Aufbau eines Jungen Literaturbauses Berlin Mitte 2018 unterstützt diese Prognose.

\section{Kinder im Litteraturhuset in Oslo und in Bergen}

In Bezug auf das Programm für Kinder und Jugendliche ist der Vergleich mit den norwegischen Literaturhäusern besonders aufschlussreich, weil diese noch stärker von den Angeboten für diese Zielgruppe geprägt sind. Dabei ist zu erwähnen, dass die Literaturhäuser in Göteborg und Kopenhagen sich hingegen auf das Erwachsenenprogramm konzentrieren

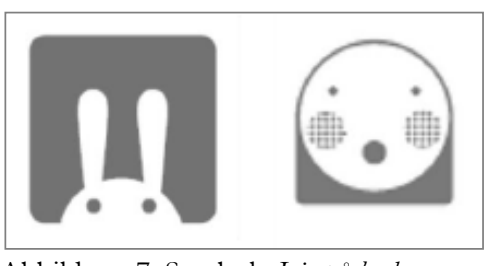

Abbildung 7: Symbole Liv på lordag, Oslo (links, rot) und Lillelordag, Bergen (rechts, blau), in Graustufen und bisher kein Angebot für Kinder und Jugendliche haben. Litteraturbuset in Oslo widmet sich dezidiert dem Nachwuchs und involviert dabei Klassiker in der Reihe Lordagsklassikeren [der Samstagsklassiker] wie Neuerscheinungen, Literatur wie andere Medien ins Programm. Ohne ins Detail zu gehen, lässt sich sagen, dass das Angebot für Kinder in Norwegen ebenso wie in den deutschen Literaturhäusern vielfältig ist und es dabei den Bezug zur Literatur, zum Zuhören und Selberlesen stetig in den Mittelpunkt stellt. So regen in Oslo unterschiedliche Kurse den Nachwuchs zur literarischen Produktion an, zum Beispiel ein Fortellekurs for barn [Erzählkurs für Kinder] (OL 2008-05-07). Die Ausweitung des Kinder- und Jugendprogrammes in Deutschland geschieht zeitlich parallel mit der Konzeption des Osloer und später des Bergener Literaturhauses, die beide den Nachwuchs von Anfang an integrieren. Schon im ersten Programmheft betonte das Team in Oslo, dass , [e]i av hovudsmålsetningane til litteraturhuset er å vere ein attraktiv møteplass for barn og unge" (OL 2007-III, S. 6) [eine der Hauptzielsetzungen des Literaturhauses ist es, ein attraktiver Treffpunkt für Kinder und Jugendliche zu sein]. Aus diesem Grund bedarf es keiner abgrenzenden Markendifferenzierung durch ein zusätzliches Wortlabel für den gesamten jungen Veranstaltungsbereich. Die Angebote werden lediglich durch das jeweilige Reihensymbol markiert (vgl. Abbildung 7), die in den Programmheften ebenfalls für die verschiedenen Serien des Hauptprogrammes genutzt werden. Es 
bedarf keiner Betonung, dass es nun zusätzlich ein Kinder-Literaturhaus gibt, weil es seit Beginn als Baustein des Litteraturbuset zu begreifen ist.

Das regelmäßige Programm in den beiden norwegischen Literaturhäusern findet nicht nur für Schulklassen und Kindergartengruppen statt, sondern auch für Individualbesucher*innen am Wochenende - wie ebenso zum Beispiel beim KinderbuchSonntag des Literaturhauses Frankfurt. Und abgesehen von den konkreten Veranstaltungen öffnet das Literaturhaus in Oslo unter der Woche sein Apent barnerom [Offenes Kinderzimmer] mit Büchern und Vorlesen im eigens für Kinder reservierten Raum Sjeherasad. ${ }^{981}$ In der Anfangszeit wurde samstags Foreldrefri [Elternfrei] angeboten - Kinderbetreuung, während die Eltern am Mittag einen Vortrag besuchen konnten (erstmals OL 2007-IV, S. 7). Später finden parallel zu diesen Erwachsenenangeboten Lesungen und Spielrunden für Kinder statt, sodass die Kinderversorgung in eine feste Veranstaltung umgewandelt wurde und als Liv på lordag [Leben am Samstag] Schule gemacht hat, denn das Literaturhaus Bergen adaptierte das Format und nannte es Lillelordag [kleiner Samstag]. Der Lillelordag in Bergen lädt ein zu „Grøt, saft og høytlesning til folket!“ [Haferbrei, Saft und Vorlesen für das Volk!] und ist ein „drop-in-tilbud for alle barnefamilier i byen“" [Drop-in-Angebot für alle Familien mit Kindern in der Stadt] (z. B. BG 2014-04-05). Der Name wirkte zurück auf das Osloer Pendant, denn Liv på lordag heißt nun Minilordag [Minisamstag] (erstmals OL 2016-I, S. 8). Auf die Integration des Litteraturbuset-Besuchs in den Familienalltag zielte in Oslo ebenfalls Tirsdagsbarn [Dienstagskinder] ab: Jeden dritten Dienstagnachmittag im Monat sorgte das Kafe Oslo für kindergeeignetes Essen und das Litteraturbuset für „Bokbesøk“ (OL 2014-I, S. 9) [Buchbesuch], die Reihe wurde später komplett dem Café zugerechnet.

In Skandinavien spielen Kinder eine zentrale Rolle und sind als prägender Teil der Gesellschaft akzeptiert. ${ }^{982}$ „Sie sind überall dabei, werden nach ihrer Meinung gefragt und in Entscheidungen eingebunden." $" 983$ Dementsprechend sind öffentliche Räume kinderfreundlich ausgestattet und so beleben Kinder tagsüber auch Litteraturbuset in Oslo. Die Bedeutung der Familie und Einbeziehung von Kindern in die Konzeption des Litteraturbuset ist folglich für Skandinavien als typisch zu interpretieren. Aus deutscher Perspektive überrascht dieses selbstverständliche Nebeneinander von Kinderangeboten und Erwachsenenprogramm eher, da, wie die deutschen Literaturhäuser belegen, eine Trennung zwischen den Veranstaltungen für Kinder tagsüber und dem Abendprogramm gezogen wird.

Es ließe sich außerdem vermuten, dass dieses Nicht-Exkludieren von Kindern in den norwegischen Literaturhäusern darauf zurückzuführen ist, dass in Skandinavien Comics von allen Altersgruppen gelesen werden ${ }^{984}$ und vor allem, dass viele $\mathrm{Au}-$ tor*innen für Erwachsene sowie für Kinder und Jugendliche schreiben ${ }^{985}$ - angefangen bei der Nobelpreisträgerin Selma Lagerlöf (1858-1940) mit ihrem bekanntesten, 1906-1907 veröffentlichten Kinderbuch Nils Holgerssons underbara resa genom Sverige [auf Deutsch unter dem Titel Die wunderbare Reise des kleinen Nils Holgersson mit

981 Zur Raumgestaltung im Litteraturbuset vgl. Kapitel II 6.3.2.

982 Vgl. Leira 2003.

983 Hegenscheidt: „An Regeln“.

984 Vgl. Eglinger 2016, S. 390.

985 Vgl. Heitmann 2006, S. 213. 
den Wildgänsen erschienen, wörtliche Übersetzung: Nils Holgerssons wunderbare Reise durch Schweden], bis hin zu norwegischen Gegenwartsautor*innen wie Ingvar Ambjørnsen (*1956), Vigdis Hjorth (*1959), Jo Nesbø (*1960) und natürlich Jostein Gaarder (*1952), der mit Sofies verden/Sofies Welt - ein ,adaptierter Bildungsroman, der bewährte pädagogische Leitbilder stabilisiert" $" 986$ - einen Weltbestseller schrieb, der die „Auflösung der Grenzen zwischen Jugend- und Erwachsenenliteratur vo-

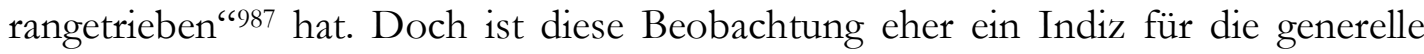
gesellschaftliche Positionierung von Kindern und der für sie geeigneten Literatur und nicht für die Konzeption des Literaturhauses, denn im Litteraturhuset sind wie in Deutschland zu den Abendveranstaltungen in erster Linie Erwachsene angesprochen. Die Vermischung der Generationen gelingt eher dadurch, dass es für Kinder explizit Platz - und sogar einen eigenen Raum - und ein eindeutig auf sie zugeschnittenes Programm gibt. Das Kinderprogramm kann gleichfalls als Beitrag zur Kinderversorgung gedeutet werden, was unter anderem die kommunale Förderung von Apent barnerom beweist.

In der inhaltlichen Ausrichtung der jungen Literaturhaus-Programme gibt es im deutsch-norwegischen Vergleich viele Überschneidungen; markante Unterschiede liegen besonders in der Struktur, da vor allem Litteraturbuset in Oslo sich tagtäglich als ein belebter Literaturort präsentiert, der damit zur Leseförderung beiträgt, weil sich ein alltäglicher Kontakt zur Literatur festigt. Das Angebot für Kinder unterstreicht diese Konzeption als ,umfassendes Literaturhaus', das von allen Altersgruppen frequentiert wird.

\section{Jugendbildung im Litteraturhuset in Oslo}

Nachdem bei den norwegischen Fallbeispielen gerade vor allem das Angebot für Kinder Thema war, lohnt sich ein zusätzlicher Blick auf die Ansprache junger Erwachsener. Wie oben herausgestellt, richteten sich die jungen Programme in den deutschen Literaturhäusern zunächst vor allem an kleinere Kinder, doch nach und nach weitete sich das Angebot auf ältere Kinder und Jugendliche aus, was, wie erwähnt, unter anderem im Kontext von Bildungspolitik und Leseförderung zu sehen ist. Noch stärker ist diese Verbindung zur Gesellschaftsbildung im Litteraturbuset in Oslo. So erinnern die als Skolebesök [Schulbesuch] betitelten, zunächst nicht im öffentlichen Quartalsprogramm beworbenen, Besuche von Schüler*innen zu speziellen Lesungen im Literaturhaus beziehungsweise Besuche von Autor*innen in Schulen in ganz Oslo an das Projekt Literatur macht Schule in Göttingen. Diese Formate verdeutlichen die angestrebte Bildungsvermittlung ebenso wie Aspekte der Integrationspolitik, was im Litteraturhuset gleichfalls auf die kostenfreien Ferienworkshops für Teenager mit dem Titel Hostungdom [Herbstjugend] zutrifft, die ebenso „[g]jennom bevisst rekruttering blant østkantskoler og ungdomsklubber" 988 [durch

\footnotetext{
986 Wischmann 2006, S. 339.

987 Ebd.

988 Arsberetning for Stiftelsen Litteraturbuset 2012 2013, S. 4. Es gilt zu bedenken, dass dieser Jahresbericht ein möglichst positives Bild der Einrichtung zu vermitteln versucht. Die Integration von Minderheiten gilt, besonders im Kinder- und Jugendbereich, als wichtig, sodass dieser Aspekt herausgestellt wird. Die Jugendclubs sind in der Regel kommunal gefördert und verfolgen gemeinschaftsbildende Ziele. Oslo-Vest
} 
bewusstes Rekrutieren in Schulen in Ost-Oslo und Jugendclubs] erwirkt haben, dass die Mehrzahl der Teilnehmenden multikulturellen Hintergrund gehabt habe. Einen ähnlichen Zweck hatte die angebotene Lesegruppe, die sich mit Themen der sogenannten Migrationsliteratur auseinandersetzte (z. B. OL 2008-I, S. 7). Die in Norwegen vertretene Bildungsabsicht, mit der Literatur stark verbunden wird, manifestiert sich im Litteraturbuset in Oslo außerdem darin, dass es kein öffentliches Format für Literatur im engeren Sinne ausdrücklich für Jugendliche gibt. Hingegen führt die Reihe Ny debatt [Neue Debatte] ${ }^{989}$ (erstmals OL 2011-01-27, Folgetermin OL 2011-02-17) Jugendliche zwischen 16 und 25 Jahren an eine Diskussionskultur heran und lässt sie diese Praktik einüben. Gleichzeitig nimmt dieses Forum, das eine Zusammenarbeit mit je nach Sujet wechselnden Jugendorganisationen ist, die Fragen junger Erwachsener ernst und markiert damit Interesse an deren thematischen Bedürfnissen. Schon im Jugendbereich zeigt sich so, was sich später für das Erwachsenenprogramm bestätigt: Debatten sind in Norwegen fest ins Kulturleben integriert. Die Jugendlichen sollen entsprechend vorbereitet werden und kritisches Denken und Argumentieren erlernen, ganz im Sinne der Trägerstiftung Fritt Ord. Obwohl die Reihe in der heutigen Form erst 2011 begann, gab es schon im ersten Litteraturbuset-Jahr einen Versuch, ein derartiges Debattenformat zu etablieren: Sofasnakk [Sofagespräch] fand jedoch nur einmalig statt (OL 2008-04-23). Die spätere Kooperation mit den Jugendorganisationen und der prägnantere Name verbesserten offenbar das Konzept, sodass die Reihe sich konsolidieren konnte.

,Junges' Programm in den Literaturhäusern

Neben den Veranstaltungen dezidiert für Kinder und Jugendliche versuchen die deutschen Literaturhäuser zunehmend, auch etwas ältere junge Menschen zu attrahieren, mit Poetry Slams, Club- oder Barlesungen, verbunden mit Szenewechseln, ${ }^{990}$ oder von Studierenden selbst organisierten Projekten. So gestaltet beispielsweise im Literaturhaus Hamburg seit Sommer 2014 jedes Semester ein Kurs des Universitätsseminars Buch braucht Bübne - Projektmanagement im Literaturbetrieb einen Abend (erstmals HH 2014-07-09). Zu nennen ist ferner die Lesereihe zwischen/miete - Junge Literatur in WGs, vom Literaturbüro Freiburg 2010 initiiert und inzwischen unter anderem vom Literaturhaus Stuttgart und Literaturhaus Köln adaptiert. Diese Formate sind als Versuche zu bewerten, eine andere Zielgruppe zu erreichen, die altersmäßig oberhalb der meisten Jungen Literaturbäuser zu verorten ist, aber nicht den üblichen Generationen des Literaturhaus-Publikums entspricht. Diese Angebote werden unterschiedlich zugeordnet, entweder wie etwa in Köln als Teil des Jungen Literaturhauses begriffen oder dem Hauptprogramm zugerechnet, womit sich zeigt, dass derartige Veranstaltungen am ehesten eine Brücke zwischen den beiden nach Altersgruppen sortierten Programmbereichen schlagen. Das Literaturbaus Stuttgart etwa unterstreicht diese Zwischenstellung mit dem Label U35 für die entsprechende Programmlinie. In den norwegischen Literaturhäusern findet sich insgesamt eine stärke-

und Oslo-Ost wurden im Einzelkapitel zu Oslo schon hinsichtlich des Bildungsstandes und Einkommens der Einwohner*innen unterschieden, Litteraturbuset befindet sich in Oslo-Vest.

${ }^{989}$ In Anlehnung an die früher regelmäßig gesendete NRK-Sendung Debatten, vgl. S. 187 und S. 298.

990 Vgl. Kapitel II 10.4.2, S. 273. 
re Durchmischung von Themen und Altersgruppen, sodass explizite Ansprachen jüngerer Erwachsenenzielgruppen nicht so markant auffallen.

In diesem Abschnitt klangen die nachfolgend dargelegten Gliederungsaspekte bereits an: Die Bemerkung zur anfänglichen Einsortierung der Kinderveranstaltungen im Literaturhaus Hamburg etwa wies auf das sogenannte Gastprogramm hin; zudem deutete sich die Kooperationsoption mit anderen Organisationen an; implizit vermittelt der Abschnitt außerdem, dass der Programmbereich für Kinder und Jugendliche vorrangig in Reihen strukturiert ist, ${ }^{991}$ was aufgrund der unterschiedlichen angesprochenen Altersgruppen als besonders sinnvoll einzuschätzen ist.

\section{11.2 Gastveranstaltung und Veranstaltungskooperation}

\section{11.2.1 Gastveranstaltung}

Die Analyse der Programmhefte liefert Material für eine Auseinandersetzung mit extern oder kooperativ organisierten Veranstaltungen im Literaturhaus, die hier mit den Bezeichnungen ,Gastveranstaltung' und ,Veranstaltungskooperation' auseinandergehalten werden sollen. Beide werden von den untersuchten deutschen und norwegischen Literaturhäusern aus konzeptionellen Gründen unterschiedlich kommuniziert. Dies stützt die leitende Hypothese, dass die norwegischen Einrichtungen sich stärker als demokratische Orte der Literatur verstehen und die deutschen sich zunehmend als Literaturveranstalter präsentieren.

Die ökonomische Abhängigkeit von Mieteinnahmen ebenso wie von Kooperationen hat Sonja Vandenrath ausführlich dargestellt, denn Literaturhäuser „operieren an der Grenze zwischen Ausgabendeckung und Profitabilität, was von ihnen unternehmerische Arbeitsweisen abverlangt, die sowohl mit ihrem Gemeinnützigkeitsstatus als auch mit ihrem Bildungs- und Kulturauftrag in Einklang zu bringen sind. " Die nicht täglich vom Literaturhaus-Veranstalter selbst beanspruchten Räumlichkeiten stehen folglich gegen eine Gebühr zur Nutzung bereit und werden somit häufig von externen Organisationen bespielt - ohne inhaltliche Einflussnahme des Vermieters. Diese Veranstaltungen heißen ,Gastprogramm' respektive ,Gastveranstaltungen'. Der deutsch-norwegische Vergleich veranschaulicht, dass diese Vermietungen nicht allein auf finanzielle Ursachen zurückzuführen sind, sondern ebenso auf die Konzeption des Literaturhauses als Raum öffentlicher Debatte rekurrieren. Denn während die deutschen Literaturhäuser die zusätzlichen Veranstaltungen im Haus nur marginal oder gar nicht mitbewerben, stehen in den norwegischen Programmen alle Veranstaltungen gleichberechtigt nebeneinander.

In den norwegischen Programmheften fügen sich alle Terminankündigungen in die kalendarische Sortierung ein. Es ist zu vermuten, dass die meisten Leser*innen sich nicht unbedingt dafür interessieren, wer für das Angebot, das sie besuchen, verantwortlich zeigt. Im Werbematerial wird eine Separation zwischen den Auftritten, die von der Literaturhaus-Stiftung, und denjenigen, die von externen Veranstaltern or-

991 Zur Übersicht über die Reihen auch anderer junger Literaturhäuser vgl. Schmitt 2016, S. 227.

992 Vandenrath 2006, S. 172. 
ganisiert werden, jedenfalls nicht forciert. Bei den Rahmeninformationen ist im Litteraturhuset in Bergen und in Oslo zu jeder Veranstaltung der jeweilige ,Arrangør angegeben, sodass das Gastprogramm nicht gesondert markiert ist. Im gedruckten Programm tauchen jene Termine auf, die zur Drucklegung bereits feststehen, online erscheinen alle Publikumsangebote. Der Osloer Stiftungsjahresbericht dokumentiert für das Jahr 2012 insgesamt 1473 Veranstaltungen, davon seien 875 öffentliche Veranstaltungen für Erwachsene gewesen, von denen die Stiftung 151 inhaltlich verantwortete. ${ }^{993}$ In den Programmheften lassen sich weniger Gastveranstaltungen verzeichnen, was zeigt, dass die Hefte nur einen kleinen Einblick ins Gastprogramm geben, das vom Litteraturbuset kuratierte hingegen nahezu vollständig abbilden.

Den Veranstaltungen des Osloer Litteraturbuset im engeren Sinne wird subtil meist doch etwas mehr Platz eingeräumt, unter anderem durch größere Fotos oder leicht variierende Grafikgestaltung. Das Editorial bezieht sich in der Regel ausschließlich auf das hauseigene Programm und manchmal weisen Anzeigen dezidiert auf dieses hin, wie Abbildung 4 (S. 282) veranschaulicht. Diese Hervorhebung lässt sich in letzter Zeit außerhalb des gedruckten Programmes noch deutlicher beobachten: Im E-Mail-Newsletter stehen die Termine in Litteraturbuset-Regie bebildert im oberen Teil und die weiteren Veranstaltungen als Texttabelle weiter unten. Auf der im Herbst 2017 relaunchten Website findet sich neben dem Kalender eine explizite Differenzierung nach eigenen und externen Arrangements. Anders als das gedruckt fixierte Programmheft lässt der Onlineauftritt zu, nach verschiedenen Kriterien zu sortieren. Durch diesen Umgang mit Gastveranstaltungen kann das Team markieren, welche Inhalte es verantwortet, womit es sich von Veranstaltungen ausdrücklich abgrenzen und zugleich das von ihm erdachte Programm der eigenen Arbeitsleistung zuweisen kann. Darin kommt es der in den deutschen Literaturhäusern üblichen Praxis näher. Das Literaturhaus in Bergen bindet das vom Team organisierte Programm weiterhin eindeutig ins Gesamtangebot ein. Es bleibt also zu beobachten, wie sich Litteraturbuset in Oslo in dieser Hinsicht entwickelt.

Das Literaturbaus Berlin war hinsichtlich der Einbindung des Gastprogrammes den norwegischen Einrichtungen am ähnlichsten. Wie bei der Einzeldarstellung herausgearbeitet, ist diese in erster Linie vom Berliner Senat finanzierte Einrichtung stärker einem öffentlichen Auftrag verpflichtet. Der Trägerverein besteht aus korporativen Akteur*innen, nicht aus Privatpersonen. In den Gründungsstatuten ist die Idee, ein Zentrum für Literatur in Berlin zu sein, expliziter verankert als in den aus Bürgerinitiativen entwickelten anderen deutschen Literaturhäusern. Dies beweist sich anhand des Programmheftes, das in den ersten Jahren ein farblich unterscheidbares Zusatzprodukt für die „Veranstaltungen der Mitglieder des Trägervereins und Gastveranstaltungen“ ergänzte und welches viele Gastveranstaltungen, seit 2003 deutlich als solche markiert, nach den Angeboten des Literaturhaus-Vereins auflistete. Auch dort bleibt abzuwarten, wie sich dies nach dem Leitungswechsel 2018 fortführt.

Die Literaturhäuser in Hamburg und Berlin integrierten anfangs gelegentlich ebenso mit deutlicher Abgrenzung - Gastangebote. Dies ist sicherlich unter anderem darauf zurückzuführen, dass sich die Häuser zunächst noch nicht als Veranstal-

993 Vgl. Arsberetning for Stiftelsen Litteraturbuset 2012 2013, S. 1-2. 
tungsorte etabliert hatten. Dies hat sich im Laufe der Zeit gewandelt, sodass nun vornehmlich die hauseigenen Termine präsentiert werden. Für das Literaturhaus Hamburg ist außerdem zu berücksichtigen, dass inzwischen das Literaturhauscafé die Räume vermietet, sodass der Verein keinen Einfluss auf die Mietnehmer hat respektive nicht in die Planung involviert ist. Aktuell sind in den Programmheften aus Frankfurt, Göttingen und Hamburg Gastveranstaltungen nur erwähnt, wenn es einen erkennbaren Mehrwert für die Präsentation gibt, wenn etwa das Renommee der Gastveranstaltung auf das Literaturhaus abstrahlen könnte. Dann ist meist für die Rezipient*innen nicht ersichtlich, dass es keine genuine Literaturhaus-Veranstaltung ist, zum Beispiel bei Preisverleihungen: Im Literaturbaus Frankfurt wird beispielsweise der Literaturpreis der Jürgen-Ponto-Stiftung verliehen (z. B. FF 2015-11-26), im Literaturhaus Hamburg schon seit Beginn die Förderpreise der Kulturbebörde Hamburg (z. B. HH 2012-12-03) sowie alle vier Jahre der Hubert-Fichte-Preis (z. B. HH 2013-01-30).

Das benannte Ziel des Literaturhauses Oslo, als Arena für Debatten heterogene Zielgruppen anzusprechen und über Literatur hinausgehend Diskussionen anzuregen, verwirklicht es somit dadurch, dass das Angebot keinesfalls ausschließlich vom Literaturhaus-Team kuratiert wird, sondern unterschiedliche Akteur*innen die Räume für ihre eigenen Arrangements nutzen. Diese Veranstalter*innen müssen keine speziellen Kriterien erfüllen, solange sie nicht gegen norwegisches Recht verstoßen. Damit wird jeder, der die Miete bezahlt, aufgenommen. So handhabt es auch das Litteraturbuset in Bergen, wo, wie die hier durchgeführten Zählungen ergeben, von 2013 bis 2015 insgesamt 845 Termine einschließlich Kinderprogramm in den Heften verzeichnet sind. 305 davon waren vom Litteraturbuset in Eigenregie vorbereitet, mehr als die Hälfte (115) davon Kinderveranstaltungen, 101 als Kooperationen und mit 439 die knappe Mehrzahl von anderen Unternehmen. Das Gastprogramm stellt also einen großen Anteil am Gesamtprogramm dar. Neben den öffentlichen Publikumsangeboten mieten Organisationen Räume für geschlossene Veranstaltungen. Obgleich selbst die nicht-öffentlichen Veranstaltungen das Haus beleben, ist bei diesen die Miete höher, was zeigt, dass Veranstaltungen, die ein ,allgemeines‘ Interesse ansprechen, bevorzugt stattfinden sollen. Zwei Tendenzen lassen sich im Gastprogramm ausmachen, die das Litteraturbuset-Programm ergänzen und zur Zielsetzung beitragen, ein Treffpunkt „for et litteratur- og debattinteressert publikum ${ }^{\text {‘994 }}$ [für ein literatur- und debatteninteressiertes Publikum] zu sein: Neben eindeutig auf Literatur bezogenen Angeboten, zum Beispiel Buchpräsentationen, Schreibseminaren oder Lesungen, durchgeführt von Verlagen, Zeitschriften oder Verbänden wie Norsk Forfattersentrum, bilden generellere gesellschaftsrelevante Themen in diversen Richtungen, organisiert etwa von Polyteknisk Forening [Polytechnische Vereinigung], Nettverk for menneskerettigheter $i$ Kina [Netzwerk für Menschenrechte in China] oder Det Norske Studentersamfund [Die norwegische Studentengemeinschaft] ${ }^{995}$ einen Großteil des Veranstaltungsangebots.

Im Vergleich ist es besonders auffällig, dass das Literaturhaus in Oslo, welches als Veranstalter zunächst relativ häufig kooperierte, inzwischen nur noch sehr selten

\footnotetext{
994 Ebd., S. 1.

${ }_{995}$ Hierbei handelt es sich um eine Zufallsauswahl, um die Unterschiedlichkeit der Organisatoren zu illustrieren.
} 
Lesungen und Diskussionen mit anderen Organisationen abwickelt, ${ }^{996}$ Ausnahmen bilden die im Haus ansässige Buchhandlung Tanum Litteraturbuset oder die bereits erwähnten Jugendorganisationen bei Ny Debatt. In den Anfangsjahren führte die Einrichtung zum Beispiel Kinderstunden gemeinsam mit der Stadtbibliothek Deichmanske Bibliotek durch, die mit ihren Filialen auch in Stadtvierteln vertreten ist, deren Publikum Litteraturbuset sonst vermutlich nicht ansteuern würde (OL 2008-04-12). Ebenso organisierte das Team Lesungen gemeinsam mit zum Beispiel dem GoetheInstitut. Bei den Hauptveranstaltungen unter der Sammelbezeichnung Onsdagskvelder [Mittwochabende] ${ }^{997}$ bestand die Osloer Einrichtung von Beginn an auf der alleinigen Programmhoheit, die es mit der jetzt geltenden Absage an externe Kooperationspartner noch verstärkt. Die Absage liegt einerseits daran, dass ihre eigenen Programmkapazitäten beschränkt sind und andererseits daran, dass sie mögliche (empfundene) Ungerechtigkeiten ausschließen möchte.998 Dieses Prinzip der Gleichbehandlung kann als Ausdruck des skandinavischen Ethos gedeutet werden, ${ }^{999}$ sodass nicht ein einzelner - die Literaturhaus-Stiftung - als Vermieter sein Revier markiert, sondern alle Veranstalter*innen - unabhängig von der Programmausrichtung, solange sie mit der norwegischen Verfassung vereinbar ist und sofern sie für die Mietkosten aufkommen können - im Haus Platz bekommen. Prinzipiell kann dort also jede ${ }^{*}$ geschlossene oder öffentliche Veranstaltungen durchführen. ${ }^{1000}$ Die impliziten Grenzen dieser Maxime der Gleichbehandlung werden ersichtlich: Im Literaturhaus Veranstaltungen anbieten können die Organisationen, die sich die Miete leisten können.

Die faire Behandlung aller potenziellen Partnerorganisationen ist nachvollziehbar, da die Mieteinnahmen Teil des Finanzierungsplans sind. Kooperationsanfragen können damit außerdem kategorisch abgelehnt werden, Mietminderung erhält niemand. Das Litteraturhuset kann also monetär und inhaltlich von den externen Veranstaltungen profitieren, da es auf diese Weise, um mit Bourdieu zu sprechen, öko-

\footnotetext{
996 Dies betonte auch der Programmleiter Andreas Liebe Delsett im Gespräch im Litteraturhuset in Oslo am 08.12.2015.

$997 \mathrm{Zu}$ dieser Reihe vgl. Kapitel II 13.1.5.

${ }_{998}$ Dies bestätigte mir die Mitarbeiterin Eline Skaar Kleven per E-Mail am 12.02.2014.

${ }^{999}$ Symbolisch und zugespitzt gefasst wird dies mit dem sogenannten Jantelovet/Jantelaget [Jante-Gesetz]. Basierend auf dem Roman En flyktning krysser sitt spor [Ein Flüchtling kreuzt seine Spur] des dänischnorwegischen Autors Aksel Sandemose (1899-1965) aus dem Jahr 1933 wurde Jante-Gesetz zu ,so etwas wie einem gemeinnordischen Murphy's Gesetz“, Henningsen 1994, S. 413. Gedacht als Angriff auf SpieBer*innen und Kleinbürger*innen habe es sich als zentral für die Analyse der nordischen Mentalität und ihrer Skepsis Eliten gegenüber erwiesen.

1000 Auf seiner Website expliziert Litteraturbuset dies unter dem Menüpunkt „Utleie“ [Vermietung]: „Litteraturhuset er primært en utleiearena. Vi får mange henvendelser om hvorvidt Litteraturhuset kan samarbeide om programidéer og arrangementer, eller stille rabatterte eller gratis lokaler til rådighet. Det kan vi dessverre ikke, grunnet både kapasitetshensyn og et likebehandlingsprinsipp vi har god erfaring med. Litteraturhusets mål er å tilrettelegge for at så mange aktører som mulig skal kunne avholde møter, seminarer, debatter og kulturproduksjoner i egen regi, på like økonomiske vilkår“", „Utleie“, Litteraturhuset. URL: www.litteraturhuset.no/utleie/ (Stand: 15.10.2016) [Litteraturhuset ist in erster Linie ein Vermietungsort. Wir bekommen viele Anfragen, ob Litteraturhuset bei Programmideen oder Veranstaltungen zusammenarbeiten oder vergünstigte oder kotenlose Räume zur Verfügung stellen kann. Das können wir leider nicht, sowohl aufgrund der Kapazität als auch aufgrund des Gleichbehandlungsprinzips, mit dem wir gute Erfahrungen haben. Ziel von Litteraturhuset ist es, zu gewährleisten, dass so viele Veranstalter*innen wie möglich Treffen, Seminare, Debatten und Kulturproduktionen in eigener Regie abhalten können, zu gleichen ökonomischen Konditionen].
} 
nomisches und symbolisches Kapital erwirtschaftet. Dies bejaht das LitteraturbusetTeam:

Vi følger så klart nøye med på de eksterne arrangementene, og jobber også aktivt for å få inn aktører som har gode arrangementer å tilby et publikum. ${ }^{1001}$

[Wir begleiten die externen Veranstaltungen natürlich genau, und arbeiten aktiv daran, Akteur*innen hereinzubekommen, die einem Publikum gute Veranstaltungen anzubieten haben.]

Mit dem Gebäudekonzept ist es dem Litteraturbuset ermöglicht, jegliche Veranstaltung unter seiner Adresse zu offerieren, ohne inhaltlich selbst verantwortlich zu sein. Damit gewährleistet die Trägerstiftung Litteraturbuset zum einen Vielfalt hinsichtlich sowohl des Themenspektrums als auch der vermittelnden Organisationen im Gesamtangebot. Dies entspricht dem politischen Grundverständnis der Stiftung Fritt Ord und des ersten Leiters Aslak Sira Myrhe: „Det er gjennom dette mangfaldet Litteraturhuset gir meining“ (OL 2007-IV, S. 4) [Durch diese Vielfalt ergibt das Literaturhaus Sinn]. Zum anderen erlaubt es ein eigenes klares Programmprofil, das sich zwar auch multiperspektivisch darstellt, aber doch auf die Arbeit nur eines festen Teams zurückführbar ist.

Teil seines Konzeptes ist es, Kulturveranstalter*innen Infrastrukturen für deren Ideenverwirklichung bereitzustellen. Diese Organisationen sind nicht als Konkurrenz für das Literaturhaus als Veranstalter zu verstehen, vielmehr zeigt sich, dass die grundsätzlich hierarchieloseren Verbindungen des Akteurs zu anderen die Anerkennung des Literaturhauses im kulturellen Oslo erhöhen und gleichzeitig das Ansehen der Kultur in Oslo zunimmt. Wenn beispielsweise das norwegische öffentlich-rechtliche Fernsehen NRK oder die überregionale Tageszeitung Aftenposten im Litteraturbuset ihre Debattenforen veranstalten, steigert dies die Medienaufmerksamkeit, die dem weiteren Programm zugutekommen mag. Dies gilt auf ähnliche Weise für die Kooperationen der anderen Literaturhäuser. Litteraturbuset $i$ Bergen bietet im Programm gleichberechtigt sowohl ihre vollständig eigenen, ihre Kooperationen und die Gastveranstaltungen an.

\section{11.2.2 Veranstaltungskooperation}

An die Gedanken zum Gastprogramm schließt ein Überblick über die Zusammenarbeitskonstellationen an. Hinweise auf Kooperationsaktivitäten kamen in dieser Arbeit schon an diversen Stellen vor, hier sollen besonders Veranstaltungskooperationen - nicht administrative Arbeitspartnerschaften, die etwa mit Buchhandlungen, Druckereien oder Hotels bestehen - anhand von Beispielen der Fallstudien systematisiert werden. ,Kooperation“ ist als „Zusammenarbeit zwischen meist wenigen, rechtlich und wirtschaftlich selbstständigen Unternehmungen zur Steigerung der gemeinsamen Wettbewerbsfähigkeit " ${ }^{\text {11002 }}$ zu verstehen. Die Programmheftpräsentation dieser institutionstypischen Praktik bildet dabei wieder den Ausgangspunkt, denn die Veranstaltungsankündigungen erwähnen die Partnerakteur*innen in der Regel entweder im Fließtext oder darunter, manchmal mit Logoabdruck, da diese

${ }^{1001}$ E-Mail der Mitarbeiterin Eline Skaar Kleven vom 12.02.2014 an die Verfasserin.

1002 Weerth und Mecke: „Kooperation“. 
ihre Beteiligung abgebildet sehen möchten. Mittels der Programmhefte lässt sich valide rekonstruieren, bei welchen Veranstaltungen weitere Organisationen beteiligt waren und wann es sich um eine Realisierung des Literaturhauses allein handelte. ${ }^{1003}$ Es lässt sich ablesen, dass es in den Literaturhäusern Kooperationen seit ihrem Beginn gab und weiterhin gibt, und diese damit eine wichtige Rolle für den kollektiven Akteur Literaturhaus spielen.

Kooperationen sind aus unterschiedlichen Gründen für die Einrichtungen nützlich, vor allem bieten sie ökonomische Synergieeffekte. Sofern die Absprachen gut getroffen sind, entstehen dadurch Arbeitsvereinfachungen für die Organisationen. ${ }^{1004}$ Neben finanziellen Erleichterungen lassen sie einen Gewinn an Aufmerksamkeit und Zuspruch erwarten, weil sich durch unterschiedliche Veranstalter mehr potenzielle Besucher*innen angesprochen fühlen und diese verstärkte Sichtbarkeit positiv auf das Literaturhaus insgesamt zurückwirken kann. Außerdem ergeben sich so Möglichkeiten, weitere Veranstaltungen ins Programm aufzunehmen - ohne diese komplett eigenständig planen und realisieren zu müssen -, die vielleicht jenseits des eigenen Kompetenzbereichs liegen, etwa bei internationalen Autor*innen, die auf Einladung, die gemeinsam mit dem jeweiligen Kulturinstitut der Stadt ausgesprochen wird, anreisen. ${ }^{1005}$ Zusätzlich zu finanziellen Vorteilen und zur Erweiterung des Programmes dienen Kooperationsveranstaltungen dem kollegialen Austausch. Zum einen sind einige Kooperationen sicherlich auf das persönliche Netzwerk der Leitungsperson zurückzuführen, wenn zum Beispiel Maria Gazzetti im Literaturhaus Frank.furt regelmäßig mit dem Istituto Italiano di Cultura in Frankfurt zusammenarbeitete, und diese Organisationsbeziehung nach dem Leitungswechsel aufrechterhalten wurde, etwa dann, wenn der Autor des Romans La solitudine dei numeri primi [Die Einsamkeit der Primzahlen] Paolo Giordamo (*1982) las (FF 201403-21). Zum anderen symbolisieren gemeinsame Veranstaltungen, dass die Partnerorganisationen sich tendenziell wohlmeinend gegenüberstehen, statt in einem strengen Konkurrenzverhältnis zu agieren. Wie bei der Darstellung der Beziehung zu den großen für sich stehenden Literaturfestivals in Göttingen, Hamburg, Frankfurt und Berlin unterstrichen, wird eine Balance zwischen Kooperation und Konkurrenz angestrebt. 1006

Die Literaturfestivals in Oslo und Bergen, wie De Litterare Festspill in Bergen, Oslo internasjonale poesifestival oder Oslo Bokfestival, nutzen ebenfalls das jeweilige Literaturhaus als Bühne, was in diesem Fall weniger Aufschluss über die Kooperationsbereitschaft gibt als vielmehr über Akzeptanz und Ansehen des Litteraturbuset als Vermittlungsorte in der Stadt. Das Verhältnis zu anderen Akteur*innen entsteht hier einschlägig dadurch, dass diese Litteraturbuset vor allem als nutzbaren Veranstaltungsort rezipieren, wie der Umgang mit dem Gastprogramm verdeutlicht.

\footnotetext{
${ }^{1003}$ Dies gilt unter der Annahme, dass alle derartigen Informationen im Programmheft vermerkt sind. Es besteht schließlich die Möglichkeit, dass vergessen wird, Kooperationspartner*innen zu nennen oder explizit kein Interesse daran besteht. Dies kann hier ob der Menge vernachlässigt werden. 1004 Angedeutet findet sich dies auch bei Vandenrath, vgl. Vandenrath 2002, S. 184.

1005 Dass das Literaturhaus deshalb aber nicht zu einem „Gemischtwarenladen“ werden muss, betont etwa Florian Höllerer, vgl. Höllerer 2007, S. 219. 1006 Vgl. Kapitel II 4.4.3.
} 
Insgesamt verstärken die Kooperationen also die professionelle Vernetzung innerhalb des Kulturbetriebes. Das Kapitel mit den Einzelvorstellungen der Literaturhäuser ging auf diese Verortung innerhalb der kulturellen Umgebung der Stadt mit konkreten Beispielen ein. Zu betonen ist, dass die Zusammenarbeit nicht nur zwischen Organisationen des Literaturbetriebs, sondern gerade spartenübergreifend im Kulturumfeld stattfindet. Gleichartige Kooperationspartner*innen sind dabei Kultureinrichtungen und -veranstalter*innen wie Museen, Kunstakademien, operativ tätige Stiftungen oder Theater. Außerdem lassen sich stadtübergreifende Initiativen nennen, an denen das Literaturhaus partizipiert, beispielsweise die Teilnahme des Literaturhauses Frankfurt am Projekt Frankfurt liest ein Buch (z. B. FF 2014-04-01) oder der Beitrag des Literaturhauses Hamburg zu Die Tage des Exils (HH 2016-06-02). Natürlich arbeiten sie auch innerhalb des Literaturbereichs zusammen. So stellte das Literaturhaus Berlin gemeinsam mit dem Literarischen Colloquium Berlin vor allem in den Anfangsjahren Stipendiat*innen der Autorenförderung des LCB vor (z. B. BE 1995 11-02) und 2001 luden die fünf großen Literatureinrichtungen in Berlin zur Reihe ortsversetzt ein (BE 2001-10-20/2001-11-30).

Außerdem entstand das seit 2008 einer Satzung unterliegende Netzwerk der Literaturbäuser nicht aus der Absicht, sich über arbeitspraktische Fragen auszutauschen, sondern gemeinsame Projekte zu gestalten. Die Literaturhäuser aus Hamburg, Frankfurt und Berlin luden schon 1993 gemeinsam zur Diskussion Hereinbrechende Ränder in ihre Häuser ein, die sich mit der Literatur Mitteleuropas und den Auswirkungen der Kriege befasste, jeweils mit zum Teil unterschiedlichen Gästen - kroatische, serbische, slowenische, ungarische Autor*innen - und Themenschwerpunkten (HH 1993-02-11/12; FF 1993-02-18). Die ersten gemeinsamen Veranstaltungen der „Interessengemeinschaft der Literaturhäuser Berlin, Frankfurt und Hamburg“ fanden 1998 mit dem karibisch-französischen Autor Édouard Glissant (1928-2011) statt (FF 1998-05-11; BE 1998-05-12; HH 1998-05-14), im folgenden Jahr widmeten sich die Einrichtungen Vladimir Nabokov zu dessen 100. Geburtstag (HH 1999-0228/29). Erst 2002 stießen weitere Literaturhäuser zu diesem zunächst losen Verbund hinzu und verliehen erstmals den Preis der Literaturhäuser. ${ }^{1007}$ Innerhalb des Netzwerkes besteht außerdem eine Medienpartnerschaft mit dem deutsch-französischen Kulturfernsehsender Arte, die vor allem bei Großprojekten zum Tragen kommt. Die deutschen Literaturhäuser kooperieren gelegentlich direkt vor allem mit den lokalen öffentlich-rechtlichen Rundfunkstationen, wie in Frankfurt hr2(-Kultur), in Hamburg insbesondere NDR Kultur, Berlin mit dem RBB und bei der Präsentation der SWR Bestenliste, die alle als Radiosender ein besonderes Interesse an Lesungen haben, da dort im Gegensatz zu anderen Aufführungsformen Bilder problemlos vernachlässigt werden können.

Daneben kommen Kooperationen seitens der Literaturhäuser mit Forschungseinrichtungen regelmäßig vor. Das Literaturhaus Berlin hielt etwa mit dem Zentrum für Antisemitismusforschung und dem Institut für Literaturwissenschaft der Technischen Universi-

\footnotetext{
1007 Die gemeinsamen Projekte des Netzwerkes sind auf dessen Website nachlesbar. Passend zu den Programmheften sind die Informationstexte dort Vorankündigungen und keine Dokumentationen des tatsächlichen Geschehens.
} 
tät Berlin die Tagung Verbergen, überschreiben, zerreißen: Die Schicksale der Bücher (BE 2005-01-12/15.) ab. Seit 2003 finden dort wiederkehrend die Literaturtage des Zentrums für Literatur- und Kulturforschung (ZfL) statt, so 2015 zum Thema Feste Feiern. Exzess und Ritual in der Gegenwartsliteratur (BE 2015-11-20/21). ${ }^{1008}$ Die Literaturhäuser bieten den Universitäten ein Forum für die Präsentation ihres Schaffens - eine Verbindung, die unter Berücksichtigung des Gastprogramms in Oslo und Bergen noch stärker ist. Für die deutschen Literaturhäuser lässt sich seit den Anfangsjahren in dieser Hinsicht eine Zunahme bemerken, was im Zusammenhang mit den veränderten öffentlichkeitswirksamen Vermittlungsabsichten seitens der Universitäten zu sehen ist. ${ }^{1009}$ Die Literaturhäuser stehen der Wissenschaft insgesamt offen gegenüber, nicht zuletzt sind die Bühnengäste häufig Akademiker*innen, und viele Belletristikautor*innen schreiben mit literaturwissenschaftlichem Bildungshintergrund. ${ }^{1010}$

Aus den Programmheften und damit von außen nicht zu erkennen ist bei Kooperationen, welche Vereinbarungen diesen genau zugrunde liegen. Somit kann nicht ergründet werden, welche Intention die Beteiligten zur Gemeinschaftsproduktion motivierte. Die standardmäßig genutzten Formulierungen ,in Zusammenarbeit/Kooperation mit', ,eine gemeinsame Veranstaltung von' beziehungsweise bei den norwegischen Literaturhäusern die Nennung des ,Arrangør' bei jedem Termin lassen nicht eindeutig erkennen, was dahintersteht. Es lässt sich nur spekulieren, dass die Erstnennung des Partners eine Hierarchisierung bedeutet, dass beispielsweise der Ausdruck ,eine Veranstaltung von hr2-kultur in Zusammenarbeit mit dem Literaturhaus Frankfurt“ (z. B. FF 2015-01-09) heißt, dass der Radiosender den Hauptpart - kuratorisch, organisatorisch und/oder finanziell - übernimmt. Genauso ist es möglich, dass das Literaturhaus Frankfurt als gleichberechtigter Partner sich aus Höflichkeit an zweiter Stelle nennt. Grundsätzlich lässt sich sagen, dass Kooperationen Folgendes beinhalten können: Erstens, dass einer der Akteur*innen die Programmhoheit innehat und der Partner oder die weiteren Partner*innen sich nur in der Ausübung anschließen. Dabei kann das Literaturhaus ebenso den anführenden Beitrag wie den mitfolgenden erbringen oder sich gar als ,Trittbrettfahrer' verhalten. Zweitens ist es möglich, dass die Akteur*innen den gleichen Einsatz für die Veranstaltung leisten. In diesem Falle konzipieren die Beteiligten das Angebot von Anfang an zusammen. Drittens besteht die Möglichkeit, dass die Kooperation dem entspricht, was meist mit Ausdrücken wie ,mit (freundlicher) Unterstützung von oder ,gefördert durch' benannt ist. Selbst damit ist nicht zwangsläufig direkte finanzielle Hilfe bezeichnet, genauso sind geldwerte Leistungen wie die Mitbewerbung der Veranstaltung möglich. Diese Formulierungen tauchen in der Regel aber bei Organisationen auf, die selbst keine Veranstaltungen durchführen und nur als Förderer erwähnt werden möchten, also öffentliche Einrichtungen, Stiftungen oder privatwirtschaftliche Sponsor*innen. Bei als ,Kooperation' gekennzeichneten Veranstaltungen lässt sich folglich nicht erkennen, wie sehr eine Veranstaltung genuin dem Literaturhaus zuzuschreiben ist. Da jedoch generell gilt, dass die Gründe für die Durchführung einer jeden Veranstaltung nur intern bekannt und extern nur zu

\footnotetext{
${ }^{1008}$ Das Wort „Feiern“ ist im Original in der Tat großgeschrieben. ${ }^{1009}$ Vgl. Kapitel II 4.4.1.

1010 Vgl. Johannsen 2013a, S. XX.
} 
vermuten sind, kann diesen Überlegungen bei der Programmanalyse nur Rechnung getragen werden mit der Erwähnung, dass unterschiedliche Grade der Kooperation vorliegen können. Anhand der Programmanalysen lässt sich so empirisch fundieren, dass die Literaturhäuser sich aus unterschiedlichen Quellen finanzieren.

\section{11.2.3 Sponsoringkooperation}

Neben den erwähnten Unterstützungsleistungen von Geldgeber*innen - wie Stiftungen, öffentlichen Einrichtungen wie Kulturämtern oder privatwirtschaftlichen Sponsor*innen - bilden die Beiträge von Verlagen eine spezielle Art der Zusammenarbeit respektive Mithilfe. Vandenrath nimmt in ihrer Übersicht Verlage und Buchhandel als gesonderte Akteursgruppe zusätzlich zu Kooperationspartner*innen auf, ${ }^{1011}$ wie in der vorliegenden Arbeit in der schematischen Darstellung der Literaturhaus-Akteur*innen befürwortet wird. ${ }^{1012}$ Dennoch treten Verlage manchmal als Kooperationspartner bei einzelnen Veranstaltungen auf. Im Folgenden wird anhand der besonderen Beziehung zu Buchverlagen, die sich unter anderem an den Programmheften illustrieren lässt, dargelegt, inwiefern eine strikte Trennung zwischen Veranstaltungskooperationen, ,gekauften“ Lesungen und institutioneller Unterstützung mitunter schwierig ist. Anhand der genannten Verlage kann zusätzlich die literarische Verortung der Literaturhäuser reflektiert werden. Die enge Zusammenarbeit mit den Buchverlagen ist dabei möglichst getrennt zu betrachten von einem direkten oder indirekten finanziellen Sponsoring.

Das Interesse der Verlage, für ihre Autor*innen Veranstaltungen zu vereinbaren, ist, wie zum Beispiel Anja Johannsen festhält, seit den 1990er-Jahren stark gestiegen. ${ }^{1013}$ Dabei kann nicht oft genug betont werden, dass hier unterschiedliche Interessen zusammenstoßen: Während die Verlage als Wirtschaftsunternehmen klar merkantile Belange vertreten, arbeiten die häufig gemeinnützig organisierten Literaturhäuser unabhängig und nicht gewinnorientiert. Formulierungen in den frühen Programmheften wie „Andrea De Carlo [...] gewinnt keine literarischen Preise mehr, ist jedoch zuverlässig auf den italienischen Bestsellerlisten zu finden“ (HH 1994-03-30) offenbaren, dass die Einrichtungen zunächst noch deutlicher zwischen wirtschaftlichem Erfolg und literarischer Qualität trennten, während sich heute die Leiter*innen einig sind, dass Bestseller nicht per se von minderer literarischer Güte sind, wie Programme ebenso zeigen.

Nur in Ausnahmen wird in den Programmbroschüren verbalisiert, wenn eine Veranstaltung zusammen mit einem Verlag geplant wurde, etwa als im Literaturbaus Berlin die Premiere des neuen Buches vom deutschen Autor Friedrich Christian Delius (*1943) stattfand, ,die das Literaturhaus zusammen mit dem Rowoblt Verlag veranstaltet" (BE 1995-08-11). Höchst selten ist einem Verlag gar ein Abend gewidmet, ohne dass explizit die Unterstützung seitens des Verlags genannt wird, wie das Ver-

1011 Vgl. Vandenrath 2006, S. 171.

1012 Vgl. Kapitel I 5, Abbildung 1.

1013 Vgl. Johannsen 2013a, S. 68. 
lagsjubiläum von Das Wunderhorn im Literaturhaus Berlin (BE 2008-12-04) oder im Literaturhaus Hamburg, als im September 1998 DuMont mit seinem ersten literarischen Programm an den Start ging (HH 1998-09-22). Dies kann als Exzeption und als Kommentar zum literaturbetrieblichen Geschehen gelten.

In Frankfurt hingegen fanden im Jahr 2011 die S. Fischer lectures statt, bei denen zum Beispiel der Soziologe und natürlich S. Fischer-Autor Harald Welzer (*1958) zum Thema Die Rechte der Menschen sprach (FF 2011-06-15): ein Beispiel für direktes Zusammenwirken von Verlag und Literaturhaus. Die Literaturhäuser in den Städten, die Sitz größerer Verlage sind - und das sind in Deutschland neben Berlin, Hamburg und Frankfurt die weiteren Orte mit den überregional relevanten Literaturhäusern wie München und Stuttgart -, interagieren mit den Verlagen. Da bietet es sich an, Premieren von Büchern in den Literaturhäusern zu feiern, etwa in Frankfurt zum neuen Roman Rücken an Rücken (S. Fischer) der Autorin Julia Franck (*1970) (FF 2011-10-25). Die Verlage führen diese Veranstaltungen gerne in den Großstädten durch, weil diese medienwirksamer stattfinden können. Dies ist nicht immer Ausdruck von Verlagsdruck und -unterstützung, sondern für das jeweilige Literaturhaus aus eigenen Marketinggründen interessant, weil Premierenlesungen den Aspekt der Einmaligkeit erhöhen.

Eine enge Kooperation und ein stetiger Austausch zwischen Literaturhaus und Verlagen ist ohnehin gegeben: Neben der Bereitstellung von Vorschauen, Werbematerialien, Autorenfotos oder Leseexemplaren führen die Verlagsmitarbeiter*innen oftmals stellvertretend für die Autor*innen die vertraglichen Absprachen. Terminanfragen und Einladungen richten die Veranstalter*innen damit selten an die Gäste direkt, sondern korrespondieren mit den Verlagen beziehungsweise Agenturen. Obgleich die Literaturhäuser in der Regel für die Honorare und Reise- wie Übernachtungskosten ihrer Gäste aufkommen, bedarf es gelegentlich der Zuschüsse von Verlagen, gerade bei Lesereisen internationaler Autor*innen. So sprechen selbst die Literaturhaus-Leitungen inzwischen offen aus, dass eine „enge Kooperation mit den Verlagen, um handlungsfähig zu bleiben“" notwendig ist, denn dies zu verneinen sei „unredlich“1014. Dieses allgemeine Zugeständnis findet sich in den Programmheften jedoch nicht so klar kommuniziert, wie gezeigt wurde. Aus nachvollziehbaren Gründen offenbaren die Literaturhaus-Teams nicht, welche Lesungen in welchem Ausmaß der Verlag anteilig bezahlt. Diese auf Vertrauen basierenden Absprachen schützen Verlage ebenso wie die Literaturhäuser, denn die Veranstalter*innen setzen damit nicht ihr Image als unabhängige Einrichtungen aufs Spiel. Beide geraten zudem nicht in die Verlegenheit, den Autor*innen erklären zu müssen, dass das Literaturhaus sie nicht unbedingt einladen wollte. Dennoch ist es für die immer knapp finanzierten Literaturveranstalter*innen verlockend, wenn eine Veranstaltung durch Zuschüsse relativ günstig oder gar kostenneutral wird. Doch „die Verlage nötigen einem ja ohnehin nicht wirklich irgendwas auf“"1015, betont Anja Johannsen für das Literarische Zentrum Göttingen in einem Interview. Es gehört zur Aufgabe der Literaturhaus-Leitung, im Sinne der Institution zu handeln, also die Finanzierung zu sichern und gleichzeitig die Qualität des unabhängigen Programmes zu wahren.

1014 Moritz 2013a, S. 134.

1015 Anja Johannsen zitiert nach: Schuldt: „Irritationsmanagement“. 
Neben expliziter Bezuschussung einzelner Veranstaltungen durch Verlage gibt es Formen der indirekten Zusammenarbeit, die ebenfalls darauf beruhen, dass die Mitarbeiter*innen beider kollektiven Akteure in kollegialem Austausch stehen. Manche Verlage zahlen in Deutschland als korporative Literaturhaus-Vereinsmitglieder einen jährlichen Beitrag und markieren damit Interesse am Fortbestand des Literaturhauses. Verlage in Norwegen wählen das Litteraturbuset als Ort für ihre eigenen Veranstaltungen und zahlen Miete. Ebenso ist auf die bereits erwähnten Anzeigen in den Programmheften hinzuweisen. So nutzten bereits 1990 Verlage die Möglichkeit, im Literaturhaus Hamburg-Folder Werbung zu schalten. Dass oft Anzeigen zu Büchern, zu denen eine Veranstaltung stattfindet, abgedruckt werden, manchmal direkt neben der Lesungsankündigung platziert, wie im Kulturteil von Zeitungen die Anzeige oft neben einer Buchbesprechung auftaucht, muss nicht unbedingt heißen, dass der redaktionelle Anteil respektive die Autoreneinladung erkauft wurde, was bei Journalisten gegen den Pressekodex und bei Literaturhäusern gegen ihren Unabhängigkeitsanspruch verstoßen würde; dennoch ist von einem Zusammenhang auszugehen. Es ist schließlich attraktiv, eine Anzeige zu schalten, wenn die Rezipient*innen schon, neutral' auf den jeweiligen Titel aufmerksam gemacht wurde. Ähnlich verhält es sich im Literaturhaus Hamburg, das monatlich eine Ausstellungsvitrine im Veranstaltungssaal vermietet und so zusätzliche Einnahmen generiert. Es liegt nahe, die Verlage anzusprechen, deren Autor*in im jeweiligen Monat bei einer Veranstaltung zu Gast ist. Die Verlage sehen sich jedoch gelegentlich in der ,Ehrenpflicht', Anzeigen zu schalten oder die Präsentationsvitrine zu mieten, um damit das Literaturhaus zu subventionieren. Andersherum funktioniert es jedoch nicht: Nicht, wer die Anzeige schaltet, bekommt einen Veranstaltungsplatz. Es kann an dieser Stelle nicht abschließend beurteilt werden, wie unabhängig beziehungsweise abhängig die Literaturhäuser von den Verlagen sind, und andersherum - darüber lässt sich kontrovers diskutieren. Festgehalten werden kann, dass eine enge Zusammenarbeit zwischen Literaturhäusern und Verlagen besteht.

Die Unterstützung funktioniert bisweilen reziprok, denn die Literaturhaus-Teams bewerben indirekt die Verlage mit. In den deutschen Ankündigungstexten steht in den letzten Jahren meist ein bestimmtes Buch im Zentrum und dabei ist in der Regel der jeweilige Verlag mitgenannt, was vor allem deshalb auffällt, weil es früher nicht so gehandhabt wurde. In Kombination mit der später ausgeführten Wahrnehmung, dass die Anzahl an Neuerscheinungslesungen anteilig zunimmt, stützt diese Beobachtung die Hypothese, dass das Buch - die materialisierte Version des geistigen Erzeugnisses ${ }^{1016}$ - auch im Literaturhaus nicht $\mathrm{zu}$ trennen ist von seiner Produkthaftigkeit, seiner Funktion als Handelsware. Dies ist wiederum ein entscheidendes Argument für die kursierende Annahme, dass die Literaturhäuser zunehmend zu ,Abspielstätten'1017 für Verlagsnovitäten geworden seien und dass sie der Beschleunigung des Literaturbetriebs insgesamt ausgesetzt seien. Der werbende

\footnotetext{
1016 Vgl. Rautenberg 2015, S. 66-67.

1017 Woher diese Bezeichnung ursprünglich kommt, ließ sich nicht valide rekonstruieren, Anja Johannsen verweist dabei auf Sigrid Löffler, vgl. Johannsen 2013b, S. 213 sowie in dieser Arbeit ausführlicher in Kapitel III 2.2.2.
} 
Anteil durch die Mitnennung ist für die Verlage, die ein beständiges ökonomisches Interesse an der Aufführung im Literaturhaus haben, vorteilhaft.

Umkehrt lässt sich vermuten, dass Literaturhäuser Verlage in die Ankündigungstexte einfügen, um die Buchauswahl zu legitimieren. Durch die Erwähnung der Publikationshäuser machen sie zum einen deutlich, dass sie sich auf die Vorauswahl der Verlage als Gatekeeper berufen, aus der sie wiederum vermeintlich das Beste herausfiltern; zum anderen bietet die Verlagsangabe für Rezipient*innen eine Orientierung im Programm. Aus diesem Grund ist es spannend zu eruieren, aus welchen Verlagen die vorgestellten Titel stammen respektive welche Verlage in den Programmheften auftauchen.

Zur Veranschaulichung dient eine Stichprobenauswahl: Erhoben wurden alle Verlage, die in den Programmheften des Literaturhauses Hamburg aus dem Jahr 2015 vorkommen. Werden Unternehmensnamen in einem Text mehrfach aufgeführt, so wurden sie nur dann häufiger aufgenommen, wenn sie auf diverse Buchtitel rekurrieren. Die Anzahl der Nennungen jedes Verlags entspricht damit der Menge der Verlagstitel im Literaturhaus-Programm der untersuchten Periode. Dass diese Datenauswahl nicht unbedingt repräsentativ ist, sei angemerkt; sie illustriert jedoch eine Tendenz. Darüber hinaus entspräche mit diesem Vorgehen auch eine Vollerhebung nur unter Vorbehalt der realen Verteilung, weil nur die Angaben aus den Heften einfließen und unter anderem die Einschränkung gilt, dass früher oft Verlage nicht ausdrücklich im Text zu finden waren.

In den Literaturhaus Hamburg-Programmheften werden im ausgewählten Zeitraum 122 Mal Bücher mit Verlagsangabe erwähnt, 58 unterschiedliche Verlage sind dabei zu verzeichnen. 27 Nennungen von 14 Verlagen beziehen sich explizit auf das Kinder- und Jugendbuchsegment, ${ }^{1018}$ sodass 95 Erwähnungen von 44 Unternehmen zum Hauptprogramm zu zählen sind. Bemerkenswert ist zunächst, dass alle Bücher überhaupt in klassischen Verlagen veröffentlicht wurden und nicht im Selbstverlag oder über andere Publikationsorgane. Dies ist besonders deshalb interessant, weil im Zuge der „Popularisierung des Buchmarktes“1019 zu vermuten wäre, dass zunehmend Texte in den Programmen auftauchen, die nicht von der klassischen Verlags-Buchhandels-Kette distribuiert werden. Dies ist, wie dieses Exemplum empirisch zeigt, nicht der Fall.

Die Häufigkeiten bestätigen die Vermutung, dass vor allem die großen Publikumsverlage, ${ }^{1020}$ die für ihr literarisches Programm anerkannt sind, präsent sind: Rowoblt (11) und Rowohlt Berlin (1), Hanser (10) und Hanser Berlin (2), Subrkamp (7), Hoffmann und Campe (6), Kiepenheuer \& Witsch (5), S. Fischer (4) und Fischer Taschenbuch (1), btb (3), dtv (3), Wallstein (3). ${ }^{1021}$ Die Annahme, dass das Literaturhaus ein literarisch anspruchsvolles Angebot bietet, lässt sich somit dahingehend präzisieren, dass

\footnotetext{
1018 Im Einzelnen sind das: Beltz \& Gelberg (5), Carlsen (3), Sauerländer (3), Tulipan (3), mixtvision (2), Nilpferd in Residen₹ (2), NordSüd (2), Aracari (2), Audoba (Hörbuchverlag, 1), Carlsen Comics (1), Klett Kinderbuch (1), Lektora (1), Oetinger (1), Terzio (1).

1019 Beilein 2013, S. 587. Vgl. dazu auch FN 400.

1020 Als Publikumsverlage sind Belletristik- und Sachbuchverlage von den Fachverlagen abzugrenzen.

${ }^{1021}$ Die weiteren Verlage sind avant-Verlag, Droschl, DuMont, Klett-Cotta, Luchterhand, Metrolit, Residenz (jeweils 2), Antje Kunstmann, Aufbau, Der gesunde Menschenverstand, Dölling \& Galitə, Dörlemann, Edition Hochparterre, Edition Moderne, Goldmann, Hamburger Edition, Herder, Klöpfer + Meyer, Knaus, Limmat, Mairisch, Manesse, Matthes \& Seitr, Osburg, Pattloch, Reprodukt, Transit, Ullstein, Unionsverlag, Voland \& Quist, Wagenbach und zu Klampen (jeweils 1).
} 
dafür die Qualitätskriterien der klassischen Literaturverlage gelten, die das traditionelle Feuilleton ebenfalls rezipiert.

In die Auswertung einzubeziehen ist jedoch, dass die zahlreichen vertretenen Verlage jede Saison mehr Titel anbieten als kleinere Verlage wie Droschl oder Luchterhand und ein vielfältigeres Titelspektrum vorweisen als spezialisierte Verlage wie Reprodukt für Comics oder Matthes \& Seit: Zu bedenken ist ferner, dass mit Rowohlt und Hoffmann und Campe zwei Hamburger Unternehmen sehr präsent sind, was wieder dafür spricht, dass enge Verbindungen zu den ortsansässigen Verlagen bestehen. Außerdem lässt sich - unter der Prämisse, dass Programmentscheidungen unter anderem von Kooperationen mit Verlagen geprägt sind und auf das individuelle Urteil der Leiter*innen zurückgehen - das persönliche Netzwerk des LiteraturhausLeiters, der im Hamburger Fall vorher Programmgeschäftsführer bei Hoffmann und Campe war, einrechnen, obgleich damit keine ,Seilschaften“ unterstellt sein sollen.

In Kontrast zu diesen Bemerkungen über die untersuchten deutschen Literaturhäuser und ihre Verortung im deutschsprachigen Buchmarkt stellen die Organisationen in Oslo und Bergen die Verbindung zu den norwegischen Verlagen nicht prinzipiell explizit heraus. Dennoch ist auch dort eine enge Zusammenarbeit mit den Verlagen anzunehmen, weil der Literaturbetrieb noch überschaubarer ist als der deutsche und damit Kontakte zwischen den einzelnen Akteur*innen wahrscheinlich sind. Wenn Verlage genannt werden, sind es norwegische Publikationshäuser.

Mit einer Selbstverständlichkeit war bisher jeweils von den Unternehmen, die Bücher auf Deutsch beziehungsweise auf Norwegisch herausbringen, die Rede. Ausschließlich diese erscheinen in den Programmbroschüren. Es bestätigt sich damit die nationale Funktionsweise der Buchmärkte, was grundsätzlich darauf zurückführen ist, dass Literatur eine von Sprache abhängende Kunstsparte ist. Obwohl internationale Autor*innen regelmäßig in den Literaturhäusern zu Gast sind, steht vor allem bei Neuerscheinungen die Übersetzung des Titels im Fokus. Dies geht einher mit der Beobachtung, dass in den Ankündigungstexten nur implizit kommuniziert wird, dass die Veranstaltungen auf Deutsch beziehungsweise auf Norwegisch stattfinden, in Deutschland etwa durch Nennung einer Person, die den deutschen Text liest. Die Moderator*innen fungieren, wenn nicht zusätzlich Dolmetscher*innen vorkommen, als Vermittler*innen zwischen den Sprachen. Häufiger in Norwegen als in Deutschland sind Veranstaltungen in englischer Sprache angekündigt, was an dieser Stelle aber wegführt von der eigentlichen Beobachtung, dass die Verlage abgesehen von Lizenztransfers - nicht international tätig sind, sondern die Auftrittschancen für Autor*innen in einem Land erhöht sind, wenn ihre Bücher in entsprechender Übersetzung vorliegen und ein Verlag sie bereits als vermittlungswürdig beurteilt hat. Die Lesereisen sind meist von den deutschen beziehungsweise norwegischen Verlagen der Schriftsteller*innen geplant, sodass nur in wenigen Fällen internationale Autor*innen durch die beiden Länder touren. Dies hängt unter anderem damit zusammen, wann die jeweiligen Übersetzungen erscheinen.

Die Verlage der Originalausgaben kommen praktisch nicht vor. Die hier konstatierte Zusammenarbeit bezieht sich also auf die national tätigen Buchunternehmen, was sich nachvollziehen lässt, weil auch in den Buchhandlungen in der Regel hauptsächlich Übersetzungen zu erwerben sind. Die Veranstaltungsbesucher*innen sollen 
im Literaturhaus somit mit Büchern in Berührung kommen, die sie nach der Veranstaltung selbst komplett lesen können. Dies spricht wiederum dafür, Lesungen im Literaturhaus unbedingt auch als Werbeveranstaltungen für das jeweilige Buch zu verstehen. Dies allerdings muss weder heißen, dass es eine allein lobende, nicht interpretative Auseinandersetzung gibt, noch, dass die Verlage die Veranstaltungen erkauft haben, noch, dass dies die einzige Funktion einer Lesung ist.

Aufgrund der unterschiedlichen Kooperationspartner*innen und Sponsor*innen, die in diesem Kapitel dargelegt wurden, lässt sich schließen, dass den Literaturhäusern daran liegt, möglichst unabhängig von einzelnen Geldgeber*innen zu bleiben. „[D]ie relativ breite Streuung an Ressourcen garantiert den Häusern ihre Unabhängigkeit, die sich nicht zuletzt darin manifestiert, daß sie Veranstaltungsvorschläge und Kooperationsangebote ablehnen können." ${ }^{1022}$ Die überlegte Auswahl im Austarieren zwischen ökonomischer Absicherung und inhaltlicher Qualitätskontrolle ist für die Institution Literaturhaus notwendig, um den Ruf als Literaturvermittler mit autonomer Programmgestaltung aufrechtzuerhalten. Das Image als Literaturveranstalter mit erlesenem Angebot spielt in den deutschen Literaturhäusern eine größere Rolle, wie sich auch daran gezeigt hat, dass die Einrichtungen gelegentlich außerhalb des Literaturhaus-Gebäudes Veranstaltungen durchführen. Doch ob es den Literaturhäusern möglich ist, eine allzu große Abhängigkeit von Verlagsprogrammen zu vermeiden, „oder ob sie, wie rein kommerzielle Anbieter, allein dasjenige katalysatorengleich noch befördern, das ohnehin erfolgreich ist, hängt maßgeblich von ihren

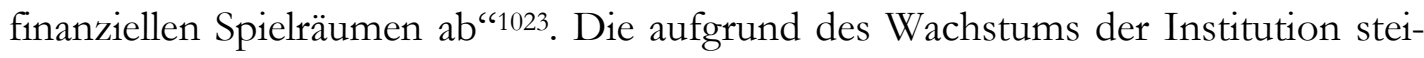
genden Kosten halten die Kritik, die bereits 1996 geäußert wurde, jedoch aktuell: „Eine feine Sache und stets einen Versuch wert ist es für Verlage, den höchst repräsentativen Ort Literaturhaus gewissermaßen als verlängerten Arm ihrer PRAbteilung zu instrumentalisieren. Es gibt subtile und unverdächtige Methoden dafür." ${ }^{1024}$ Diesen subtilen und verdächtigen Methoden mit Belegen beizukommen, bleibt schwierig.

Vielleicht bauen die Skandinavier ihr selbst kuratiertes Programm zukünftig aus. Doch was für Göteborg noch vermutet werden kann, hat sich für Oslo schon manifestiert: Das Gastprogramm bildet einen zentralen Punkt der Institution Litteraturbuset, womit unterschieden werden muss zwischen der skandinavischen und der deutschen Ausprägung der Institution. Die Gastveranstaltungen tragen zum Gesamtkonzept des Litteraturbuset bei, sind jedoch für die inhaltliche Arbeit des Literaturhauses im engeren Sinne als Veranstalter nicht prägend. Da in dieser Arbeit aus deutscher Perspektive vergleichend auf das Literaturhaus geblickt wird, finden nur Veranstaltungen, bei denen das Literaturhaus als Mitarrangeur auftritt, Beachtung bei der inhaltlichen Analyse. Die finanzielle Abhängigkeit von dritten Veranstalter*innen ist bei den norwegischen Literaturhäusern offensichtlicher ablesbar. Gleichzeitig trägt die präsentierte Vielzahl an Veranstalter*innen im Litteraturbuset zur Realisierung der Idee des umfassenden Literaturhauses als demokratischer Ort

\footnotetext{
1022 Vandenrath 2006, S. 198.

1023 Johannsen 2013b, S. 213.

1024 Huttenlocher 1996.
} 
der Literatur und Literaturvermittlung bei. Seine Rolle als kompetenter Literaturvermittler geht dabei tendenziell leicht unter. Jedoch ist zu berücksichtigen, dass die kommunikationspraktische Entwicklung im Osloer Litteraturbuset eher in die Richtung der deutschen Literaturhäuser deutet, die mit ihrem Hausnamen synonym für das ausgewählte Programm stehen und damit ihre Position stärker wollen. Dies zeigte sich bei den Einzeldarstellungen, bei den Selbstdarstellungstexten auf den Websites und nun ebenfalls beim Umgang mit Gast- und Kooperationsveranstaltungen. Gemein ist den Akteuren der Institution, dass sie versuchen, ihr inhaltliches Programm „med en tydelig armlengdes avstand“1025 [mit einer deutlichen Armlänge Abstand] zu Geldgeber*innen und Abhängigkeiten zu halten. Dies gilt es für die folgenden Programmanalysen im Hinterkopf zu behalten, obgleich nicht eindeutig empirisch belegbar ist, dass diese Programmfreiheit jederzeit gewährt ist.

\section{12 Das Literaturhaus im Zeitalter der Digitalisierung}

Wie schon im vorherigen Kapitel erwähnt, unterhalten alle Fallbeispiele eine eigene Website ${ }^{1026}$, was in den 2010er-Jahren als so selbstverständlich betrachtet werden kann wie Geschäftskorrespondenz via E-Mail. Darüber hinaus verschicken die meisten einen regelmäßigen Newsletter und sind auf verschiedenen Social-MediaPlattformen aktiv. Neben den gedruckten und darin statischen Programmheften stehen damit weitere Sendungsinstrumente zur Verfügung, die alle untersuchten Literaturhäuser, obgleich unterschiedlich intensiv, anwenden. Im Folgenden wird dargestellt, auf welche Weise die Literaturhäuser sich online als Literaturvermittler präsentieren. ${ }^{1027}$

Wie sich bei der vorhergehenden Einzelpräsentation der Literaturhäuser gezeigt hat, sind die Räume durch die örtlichen Gegebenheiten determiniert, denn ein neoklassizistischer Saal mit täglichem Restaurantbetrieb ermöglicht andere Gestaltungen als ein extra zum Zwecke des Literaturhauses eingerichtetes Auditorium. Bei der Begutachtung ist entsprechend von Interesse, inwiefern die Webaktivitäten und das dortige Design auf den Raum des Literaturhauses - als physischer Ort und/oder als Veranstalter - rekurrieren. Da hier außerdem die historische Entwicklung betrachtet wird, lässt sich das Folgende als Beispiel dafür verwenden, am konkreten Fall nachzuvollziehen, wann sich das Internet ,durchgesetzt ${ }^{\star}$ hat. Es sollen also nicht anwenderorientiert die Instrumente des Internetmarketings für das Literaturhaus vorge-

\footnotetext{
1025 Skaftnesmo 2016, S. 33.

1026 ,Website‘ wird hier synonym mit ,Webaufritt', ,Internetpräsenz ${ }^{6}$ verwendet. Eine ,Webseite entspricht einer ,Unterseite‘ auf einer Website. ,Homepage‘ wird gleich verwendet wie ,Startseite‘. ,Online‘, ,Web` und ,Internet ${ }^{\star}$ werden in Wortkombinationen ebenfalls gleichbedeutend benutzt. Und da es im Folgenden nicht um eine technische Annäherung an das World Wide Web (WWW) geht, wird der Ausdruck synonym mit ,Internet' verwendet, obgleich die Ineinssetzung streng genommen nicht korrekt ist. Das WWW ist eine Anwendung des Netzes aus Computernetzwerken, das als ,Internet' bezeichnet wird. 1027 Der Stand dieses Kapitels ist Sommer 2017, ergänzende Aktualisierungen werden markiert. In diesem Kapitel wird besonders offensichtlich, dass es sich um einen dynamischen Forschungsgegenstand handelt, denn die hier gegebenen Informationen und Quellen könnten bei der jetztigen Lektüre nicht mehr aktuell sein, dies macht sehr sichtbar, dass diese Arbeit einen historischen Zwischenstand darstellt.
} 
stellt werden, ${ }^{1028}$ sondern diese Aktivitäten mit der übergeordneten Frage, wie sich die Literaturvermittlungsinstitution Literaturhaus zu neu aufkommenden Vermittlungsmöglichkeiten verhält, in Bezug gesetzt werden.

Bei der nun folgenden Untersuchung der Internetnutzung kommt heraus, dass die älteren Literaturhäuser schon zeitig online vertreten waren, sie jedoch nicht besonders experimentell mit den neuen Möglichkeiten umgingen und umgehen. Vielmehr lässt sich konstatieren, dass das Literaturhaus als analoges Phänomen in der sogenannten Erlebnisgesellschaft das Moment des Live-Erlebnisses weiterhin oder gar verstärkt in den Mittelpunkt seines Selbstverständnisses stellt und sich dabei der Blick auf die Bühnengäste richtet. Obgleich Aspekte des Austausches, auch mit dem Publikum, wichtig sind, konzentriert sich das Interesse der Besucher*innen auf die Sprechenden auf der Bühne. Es ist so, dass im Zeitalter der Digitalisierung direkte Vermittlungsangebote bedeutender werden, und dass die Autor*innen als Sprechende im öffentlichen Diskurs keinesfalls irrelevant werden würden. Das Folgende setzt somit wieder an den konkreten Beispielen an, um dann allgemeiner zu interpretieren und die im ersten Kapitel dargestellten Überlegungen zur Wirkung und Funktion des Literaturhauses zu vertiefen.

\section{12.1 Einsatz digitaler Instrumente}

\section{Gegenseitige Verweise zwischen offline und online}

Einzugehen ist vorab auf die im Folgenden verwendeten Ausdrücke ,analog ${ }^{6}$ und ,digital'. Sehr einleuchtend führen Kathrin Passig und Aleks Scholz aus, welche Bedenken bei der oft unkritischen Verwendung der Termini herrschen sollten. ${ }^{1029}$ Sie explizieren darin den technischen Unterschied zwischen ,analog' und ,digital'. Schon 1985 erklärte auch Petru Dumitriu: Bei analoger Übertragung bleiben die Signale vergleichbar, sie erfordert Geräte, die genau dieses eine Signal verarbeiten oder übertragen können; digitale Signale sind nur mit zusätzlichen Instrumenten, die den digitalen Code übertragen und übersetzen können, lesbar. ${ }^{1030}$ Wissend um diese Unterscheidung und doch die Begriffsbezeichnungen der alltagssprachlichen Nutzung angepasst, wird im Weiteren ,analog` im Sinne von ,ohne zusätzliche Geräte rezipierbar' verwendet, während , digital' wie, virtuell' im Folgenden meistens Internetanwendungen betrifft. Für die hier avisierte Betrachtung ist zudem das Nebeneinander von ,offline' und ,online' relevant.

Zunächst ist zu beantworten, ob die seitens des Literaturhauses online und offline genutzten Kommunikationsinstrumente aufeinander verweisen. Auf den hauseige-

\footnotetext{
1028 Zur praxisorientierten Vorstellung des klassischen Internetmarketings vgl. Frank 2011, S. 562-580. ${ }^{1029}$ Vgl. Passig und Scholz 2015.

1030 Vgl. Dumitriu 1985, S. 46-50. Bei diesem älteren Beitrag von Dumitriu ist weiterhin nennenswert, dass er aus einer Zeit stammt, bevor das WWW bei der „kommunikationstechnischen Revolution“ überhaupt eine Rolle spielte, sondern Video- und Telekommunikationsgeräte zentral stehen, wie sich auch bei den weiteren Programmanalysen im Literaturhaus zeigen wird. Bei der nun folgenden Untersuchung der Internetnutzung zeigt sich, dass die älteren Literaturhäuser zeitig online vertreten waren, jedoch nicht besonders experimentell mit den neuen Möglichkeiten umgegangen wurde und wird.
} 
nen Websites und Social-Media-Seiten stehen nur sporadisch Hinweise auf die Existenz eines gedruckten Programmheftes. Implizit findet sich ein Verweis, wenn etwa das Literaturhaus Frankfurt mit dem Vorteil „Programmheft und Newsletter frei Haus"1031 Menschen von einer Vereinsmitgliedschaft überzeugen möchte. Ebenso vorausgesetzt ist dies in Bergen, wo auf der Website für Anzeigen in der Broschüre geworben wird. ${ }^{1032}$ Über die Social-Media-Kanäle taucht gelegentlich auf, dass es das Programm auch gedruckt gebe, zum Beispiel in einem Tweet von@ @itthusbergen ${ }^{1033}$ :

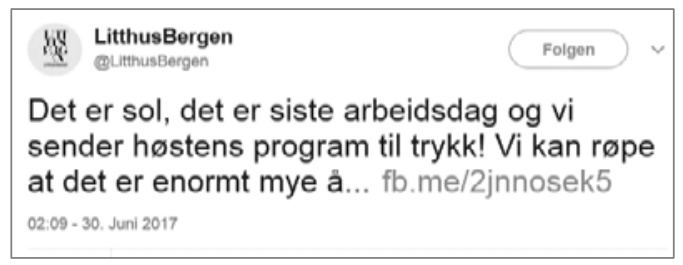

Abbildung 8: Litthusbergen via Twitter zur Sommer-

pause, 30.06.2017 (in Graustufen)

Derartige Beiträge klären nicht explizit über das zugrundeliegende Produkt auf, sondern gehen davon aus, dass der Bezug bekannt ist. Die Rezipient*innen müssen wissen, dass ein gedrucktes Programmheft existiert, und dass dieses synonym für das kommende Quartalsprogramm steht, das in der Regel gebündelt veröffentlicht wird, um im zitierten Tweet zu verstehen, warum es etwas Besonderes ist, dass die Mitarbeiter*innen eine Veranstaltungsankündigung schon vorab veröffentlichen.

Andersherum versucht das Druckprodukt die Rezipient*innen zum Onlineauftritt des jeweiligen Literaturhauses zu lenken. Darin manifestiert sich, dass davon ausgegangen wird, dass ,Analogleser*innen` sich dem Onlineauftritt zuwenden, während weniger erwartet wird, dass Besucher*innen der digitalen Präsenz sich dem papierenen Produkt zuneigen. Außerdem ist das Interesse seitens der Einrichtungen größer, neue Onlinerezipient*innen zu gewinnen, die sich regelmäßig auf der Website, über den Newsletter oder die Social-Media-Accounts über das Programm informieren, als den Adressatenstamm des regelmäßig postalisch verschickten Heftes zu erhöhen. Wie weiter hinten ausgeführt wird, erfüllen die Druckwerke zudem teilweise etwas andere Funktionen als die Programmwerbung per Internet.

Eine ungewöhnliche Verbindung von Druckprodukt und Internetpraxis erzeugte in den ersten Jahren das Literarische Zentrum Göttingen: Im Folder fand sich unter jeder Veranstaltung ein „Link“ (GT 2001-01 bis GT 2004-12). Dies konnten weiterführende Informationen, Hinweise auf andere Texte, auf Radiosendungen oder Filme sein. Dieser analoge Link führt über den abgedruckten Text hinaus und lädt zur weiteren Beschäftigung mit dem Thema ein. Er war ein Spiel mit der neu aufgekommenen Praktik des Verlinkens, das nach 2006 nicht weitergeführt wurde - mög-

\footnotetext{
1031 „Verein, Mitgliedschaft“, Literaturhaus Frankfurt. URL: literaturhausfrankfurt.de/verein/mitgliedschaft/ (Stand: 30.08.2018).

1032 Vgl. „Kontakt“, Litteraturhuset Bergen. URL: www.litthusbergen.no/kontakt/ (Stand: 30.08.2018).

1033 Litthusbergen via Facebook, 30.07.2017. URL: www.facebook.com/litthusbergen/posts/ 1389383584432457 (Stand: 30.08.2018) [Die Sonne scheint, es ist der letzte Arbeitstag und wir schicken das Herbstprogramm in den Druck! Wir können verraten, dass es enorm viel gibt, worauf es sich zu freuen gilt, und das feiern wir damit, dass wir die erste Veranstaltung schon jetzt veröffentlichen. Wir sehen uns auf dem Slippfest (Fest zur Veröffentlichung des Programmes, Anmerkung C. L.)!] sowie Litthusbergen via Twitter 30.07.2017. URL: twitter.com/LitthusBergen/status/880715020656660480 (Stand: 30.08.2018). Der Link zum Facebook-Posting setzt fort mit: ,å glede seg til, og feirer med å slippe første arrangement allerede nå. Sees på slippfest i Boksalongen 15. august!“‘
} 
licherweise, weil Linksetzungen so gewöhnlich waren, dass ,der Witz' daran nicht mehr funktionierte, oder weil die Leser*innen weiterführende Lektüre sowieso online suchten, oder, auch das ist bei der Untersuchung einer Einrichtung stets zu bedenken, aus arbeitspraktischen Gründen.

Die Onlineadresse des Literaturhauses sind heute in den Druckprodukten immer erwähnt. Es kann davon ausgegangen werden, dass gegenwärtige Leser*innen selbstständig den Schritt vom gedruckten Programmheft zur Website wählen, wenn an dem auf Papier Rezipierten weiteres Interesse besteht. Früher war mit der Angabe der Internetadresse, der Domain, oft ein Aufruf zum Besuch der (neuen) Website verbunden. Die Website des Netzpverks der Literaturbäuser etwa wurde im Frankfurter Programmheft Anfang 2003 damit beworben, dass deren erste fünf Besucher*innen, die ihre Meinung dazu äußerten, Eintrittskarten gewännen (FF 2003-01). Beim Literaturhaus Hamburg galt die Aufforderung, die neben der Hauptseite anderen aktiven Onlinepräsenzen, die Webseite des Jungen Literaturhauses und die Facebook-Seite, zu besuchen, noch 2016: „Besuchen Sie uns auch hier im Internet“ (z. B. HH 201605). Mit dem gegenseitigen Verweis verbinden Programmheft und Website folglich ,analogen' und ,digitalen' Auftritt miteinander.

\section{Adressen der Literaturhäuser im Internet, Domains}

Die folgenden Ausführungen konzentrieren sich auf die noch heute aktiven Literaturhaus-Domains, zumal die älteren meist nicht mehr aufrufbar sind. Die Internetadressen der deutschsprachigen Literaturhäuser sind in der Regel, vergleichbar mit denen von Universitäten, nach identischem Muster aufgebaut: www.literaturbausberlin.de, www.literaturbaus-hamburg.de, www.literaturbaus-frankfurt.de sind die in dieser Arbeit genauer inspizierten. Ausnahme bildet in dieser Studie aus dem einfachen Grund, dass der Name ein anderer ist, das Literarische Zentrum Göttingen, das über wmw.literarisches-zentrum-goettingen.de erreichbar ist. Bei den norwegischen Einrichtungen gestaltet sich die Adressierung etwas anders. Bergen residiert unter wmm.litthusbergen.no und hat dieses Silbenkurzwort ferner zum Social-MediaBenutzernamen erkoren. Diese Abkürzungsvariante verwendet ebenfalls zum Beispiel Litteraturbuset Fredrikstad als @Litthusfred. Mit der Wahl der Domain wmw.litteraturbuset.no markiert Litteraturbuset in Oslo den in der Einzeldarstellung ausgeführten Anspruch, das eine Literaturhaus für ganz Norwegen zu sein. ${ }^{1034}$ Außerdem war es der erste Akteur, der sich diese Domain gesichert hat. Gleiches gilt für: wnw.literaturhaus.at, vom Literaturhaus der österreichischen Hauptstadt genutzt, wnw.literaturhaus.ch, vom Literaturhaus Zürich verwendet, sowie wnw.LiteraturHaus.dk, zur Website des ersten dänischen Literaturhauses führend. Die naheliegenden URLs wnw.litteraturbuset.dk und www.literaturhaus.de sind nicht von Literaturhäusern in Benutzung. Dass beide Domains jedoch vergeben sind, bestätigt die Attraktivität dieser Adressen, was wiederum für den Institutionscharakter von ,Literaturhaus' beziehungsweise ,Litteraturhuset` spricht. ${ }^{1035}$ Das Netzwerk der Literaturbäuser ist über

\footnotetext{
1034 Vgl. Kapitel II 6.2.

1035 Die Seite wmw.literaturhaus.de führt zu einer Startseite, die meldet: „Das Literaturhaus im Internet wird zum Forum und Netzwerk für Literatur. Bitte etwas Geduld! Bald geht es los!“ Da jedoch kein Impressum oder Kontakt angegeben ist, lässt sich nicht erschließen, wer diese Seite reserviert hat und zu welchem Zweck genau. Die inhaltliche Nähe zu den existierenden Literaturhäusern ist aber schon in der
} 
wnw. literaturhaus.net erreichbar. Darin spiegelt sich zum einen der Name des Vereins, zum anderen markiert die Domainendung ,net' keine landesbezogene Bindung; die österreichischen und schweizerischen Literaturhäuser sind damit gleichermaßen abgebildet. ${ }^{1036}$

\section{Zeitpunkt der Einrichtung der Internetauftritte}

Wann die Literaturhäuser Berlin, Hamburg und Frankfurt ihre Internetseiten initiierten und wie sie diese kommunizierten, lässt sich durch die Nennungen der Domain im Programmheft nachvollziehen. Neben den angeführten schriftlichen Hinweisen in den historischen Dokumenten nutzen als Quelle Auskünfte von den Literaturhaus-Mitarbeiter*innen sowie das Internetarchiv Wayback Machine, das in unterschiedlichen Abständen Captures von Websites durchführt und speichert. ${ }^{1037}$ Damit wird an Beispielen rekonstruierbar, wann die Nutzung von Websites und Geschäfts-E-Mail-Adressen gängige Praxis wurde und ebenfalls, ob und wie diese zeitgenössisch in der Ausführung reflektiert wurde.

Das Literaturhaus Hamburg war die erste der untersuchten Einrichtungen mit einer Internetpräsenz. Im April 1996 stand im Programmheft, dass das Literaturhaus „ab sofort“ online zu finden sei. Zunächst wurde noch keine eigene Domain verwendet, sondern ein lokaler Onlineservice genutzt (vgl. Abbildung 9). Ein Jahr später war die Internetadresse wmw.t-online.de/ home/literaturhaus in Verwendung ( $\mathrm{HH}$ 1997-10). Im Mai 1998 gab das Literaturbaus Frankfurt bekannt: „Ab sofort ist das Literaturhaus auch über Internet erreichbar unter: www.f-r.de/literaturhaus. Dorthin können Sie auch eine E-Mail schreiben!" (FF 1998-05). Nach dieser Meldung wurde die Onlinepräsenz jedoch zunächst nicht mehr im Pro-

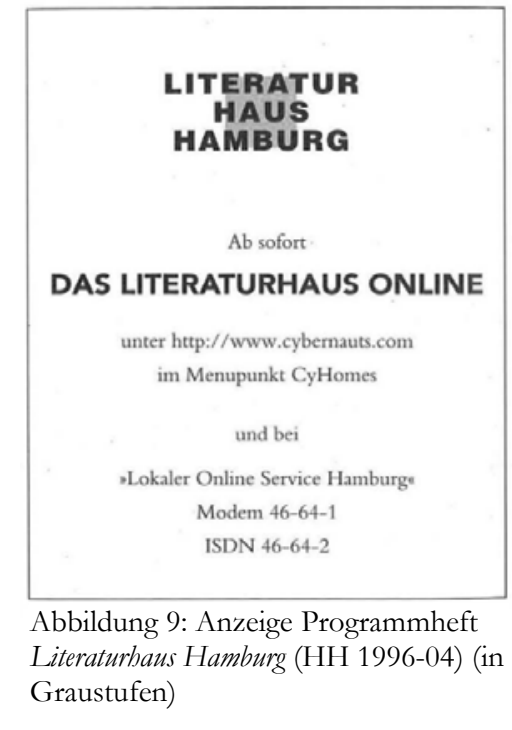
grammheft erwähnt. Die Nennung der heutigen Homepage-URLs bei den Kontaktinformationen - was ein zeitlicher Beleg für den Gebrauch ist - erstreckt sich für die drei älteren Literaturhäuser über vier Jahre, die E-Mail-Adressen wurden jeweils etwa ein Jahr vorher benutzt. ${ }^{1038}$ Schon 1998 richtete das Literaturhaus Hamburg eine Website unter der heutigen Domain ein (HH 1998-10). Das Literaturbaus Berlin folgte Ende 2001 - war allerdings, den Programmfoldern zufolge, vorher gar nicht onli-

kurzen Ankündigung gegeben (Stand: 30.08.2018). Ein indirekter Bezug zur Institution stellt sich ebenso auf der dänischen Seite www.litteraturbuset.dk her. Hier bloggt eine dänische, junge (2018 29-jährige) Psychologin: „Litteraturhuset er mit forsøg på at få min kærlighed til skønlitteraturen ud i verden. Ønsket er at skabe et sted, hvor vi kan samles om litteraturen og også se den fra et psykologisk perspektiv“" [Litteraturhuset ist mein Versuch, meine Liebe zur Belletristik in die Welt zu tragen. Der Wunsch ist es, einen Ort zu schaffen, an dem wir uns um die Literatur herum versammeln und sie auch aus einer psychologischen Perspektive betrachten können] (Stand: 30.08.2018).

1036 Zu berücksichtigen ist auch das Urteil zur Domain wmw.literaturbaus.de 2004, vgl. FN 35.

${ }^{1037}$ Erreichbar über die Domain www.web.archiv.org. Die Informationen zu den älteren Websiteversionen entstammen diesem Webarchiv, dort wurde jeweils nach den bis heute verwendeten Domains der Einrichtungen gesucht (Stand: 26.07.2017).

1038 Vgl. z. B. BE 2000-01. 
ne präsent (BE 2001-11). Das Literaturbaus Frankfurt zog zur Herbstsaison 2002 nach (FF 2002-09). ${ }^{1039}$

Das Literaturhaus Berlin behielt dieses erste Design am längsten bei, bis Anfang April 2014. Das Literaturbaus Berlin hatte zwar keinen ausgesprochen späten Onlinestart, es schien jedoch nicht besonders interessiert daran, ,auf der Höhe der Zeit ${ }^{6} \mathrm{zu}$ bleiben, und sich den technischen Moden eindeutig anzupassen, was die Beobachtung, dass 13 Jahre lang das Aussehen des Webauftrittes nicht einschlägig aktualisiert wurde, stützt. Vielmehr erscheint die Aktivität auf ein angenommenes Mindestmaß reduziert gewesen zu sein. So richtete dieses Literaturhaus etwa als letzte der Fallstudien eine Facebook-Seite ein. Das Literaturhaus Hamburg hingegen, das anfangs auch im Programm Interesse an neuen Technologien und medial bedingten Veränderungen demonstrierte, ${ }^{1040}$ experimentierte schon relativ früh auf dem noch ungewohnten Kommunikationskanal.

Göttingen ist das deutsche Beispiel, das seit der Gründung 2000 eine eigene Website hat. Zu dieser Zeit, so ist anzunehmen, ist es ein üblicher Schritt, bei einer Neueröffnung die Einrichtung sogleich online zu präsentieren, obwohl in diesem Fall zunächst nur ein kurzer Text darüber erschien, was das Literarische Zentrum Göttingen sei. Anfang 2001, als Hauke Hückstädt die Leitung übernommen hatte, kündete die Seite von „Umbauten“, um im Herbst mit vollständiger Website online zu sein. Eine erste Überarbeitung fand im Herbst 2004 statt, Ende 2010/Anfang 2011 wurde im Zuge der Aktualisierung des Programmleporellos durch die Leiterin Anja Johannsen eine erneute Anpassung vorgenommen.

Die deutlich jüngeren Literaturhäuser in Kopenhagen, Oslo, Bergen und Göteborg veröffentlichen zeitgleich mit der Eröffnung des Hauses eine Website. Beide Sphären, analog und digital, gehören mindestens seit dem Jahr 2005 - das Eröffnungsjahr der Kopenhagener Einrichtung - unmissverständlich zusammen. mmm.litthusbergen.no berichtete sogar schon vor der Einweihung im Januar 2013 von den Fortschritten der Planung und der Baustelle. ${ }^{1041}$

\footnotetext{
${ }^{1039}$ Visuelle Eindrücke der Website-Startseiten finden sich im Anhang V 3.1, Abbildung 25. Die erste Website des Literaturhauses Frankfurt ging 2001 online, Inhalte wurden zwischen Mai und August 2002 auf die Seite gestellt. Bis dahin war nur ein Bild des Gebäudes dargestellt, die Adresse und Telefonnummer sowie der Verweis „In Kuerze finden Sie hier unsere Internetpräsenz.“ Erneute Änderung der Seite dann im Frühjahr 2013, vgl. URL: web.archive.org/web/20010925142619/http://www.literaturhausfrankfurt.de/ (Stand: 03.04.2017). Laut Wikipedia wurde 1985 die erste Domain überhaupt registriert, vgl. „Domain-Registrierung“, Wikipedia. Diese Domain nordu.net war der Auftritt desgleichnamigen nordeuropäischen Netzwerkprojektes und stellt ein Beispiel für die Fortschrittlichkeit der nordischen Länder hinsichtlich der Vernetzung über das WWW dar. 1040 Vgl. z. B. Kapitel II 12.7, S. 343.

1041 Vgl. Litthusbergen via Wayback Machine 29.07.2012. URL: web.archive.org/web/2012090100000 0*/www.litthusbergen.no (Stand: 24.07.2017).
} 


\section{12.2 Gestaltung der Websites}

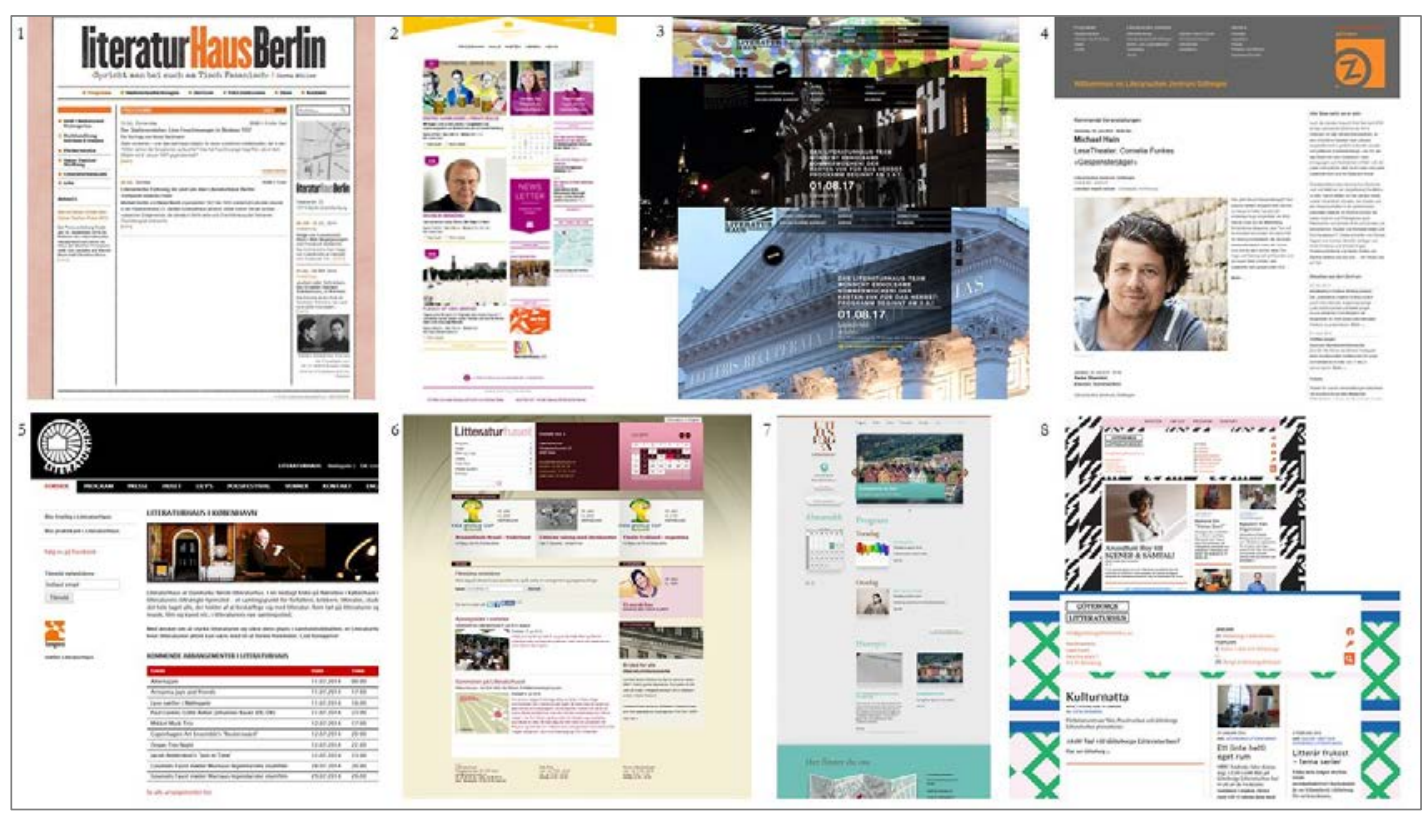

Abbildung 10: Screenshots der Website-Startseiten (2014): 1 Literaturbaus Berlin, 2 Literaturhaus Hamburg,

3 Literaturbaus Frankfurt (2017), 4 Literarisches Zentrum Göttingen, 5 LiteraturHaus Kopenhagen, 6 Litteraturbuset in Oslo,

7 Litteraturbuset in Bergen, 8 Göteborgs Litteraturbus (2016)

Dass dieser Abschnitt mit einer Abbildung beginnt, markiert, dass sich ein Eindruck der Websites der untersuchten Literaturhäuser am besten über Bilder vermitteln lässt. Die eingefügten Screenshots der Startseiten dienen der Vorstellung der 2014 aktuellen Websites. Dabei ist beabsichtigt, dass Details nicht unbedingt erkennbar sind und die Ausschnitte nicht immer gleich gewählt wurden. Die Abbildungen wurden zum Großteil im Frühjahr 2014 erstellt. Allein bei Göteborgs Litteraturhus vergleiche ich die erst 2015 initiierte Website des umstrukturierten Literaturhauses mit den früheren Versionen der anderen Häuser. Da die Websites sich ohnehin stetig wandeln und sie inzwischen nicht mehr garantiert den hier zugrunde gelegten Präsentationen entsprechen, ist es zu vernachlässigen, dass die Seiten hier nicht exakt dem gleichen Datum entstammen.

Im Design passten die Seiten sich den mit der Zeit geänderten Gepflogenheiten an, obwohl deutlich wird, dass nicht alle Websites hinsichtlich dieses Aspektes immer auf dem neuesten Stand sind. Jedoch sind Relaunches nicht in gleichen kurzen Zeitintervallen realisierbar wie sich ,Internetmoden' wandeln. Dabei offenbart sich die Zeitgebundenheit von Websites, denn die ersten Internetauftritte der älteren Literaturhäuser entsprechen den damaligen technischen Möglichkeiten. Damit ist gar „nicht das direkte Design der Seiten gemeint, sondern die Art und Weise, wie die Räume auf der Seite verteilt sind, wo die Navigation und wo der eigentliche Inhalt der Seite untergebracht ist." 1043 Dass der Auftritt des Literaturhauses in Oslo zu seinem Beginn aus heutiger Warte mehr der damaligen Mode entsprach als die Websites der deutschen Literaturhäuser, liegt mit daran, dass diese Einrichtung 2007 die Seite ganz neu entwickelte, während die der deutschen Literaturhäuser bereits

1042 Die Webadressen der Fallbeispiele finden sich aufgelistet am Ende des Literaturverzeichnisses. Die Screenshots bilden, bis auf das Göteborger Beispiel, den Stand Juli 2014 ab.

1043 Neutzling 2002, S. 139. Diese Webdesigngrundlagen von 2002 gelten weiterhin. 
online waren. Über zehn Jahre hinweg wurde die Litteraturbuset-Seite im Frontend nicht verändert, sodass sie dann ebenfalls nicht mehr ganz zeitgemäß wirkte. Zum Jubiläum in Oslo im Herbst 2017 modernisierte die Einrichtung seine Website jedoch, von der Farb- und grafischen Gestaltung her ähnelt sie aber der vorherigen Version, sodass sie wiedererkennbar ist.

Die deutschen Literaturhaus-Internetpräsenzen haben sich über die Jahre gewandelt: Einschlägige Erneuerungen der Websites führte das Literaturhaus Hamburg 2006 und erneut 2013 bei Veränderung des Corporate Designs durch. Sie ist in den ,Hausfarben' gehalten und wechselt, passend zur aktuellen Monatsfarbe - in Abbildung 10 gelb -, zum Beispiel im Header die Farbe. Zusammen mit Farbfotos und grafischen Elementen wirkt die Seite dadurch recht bunt. Ihr liegt die Idee zugrunde, dass möglichst viele Informationen in Sidebars, Bannern und mit viel Text auf der Startseite zu finden sein sollten; das Netzwerk pinterest, eine Art virtuelle Pinnwand, prägte diesen Gestaltungsgedanken, der schon nicht mehr den modischen Designprinzipien entspricht. ${ }^{1044}$ Das Literarische Zentrum Göttingen pflegt die 2018 älteste Seite (seit 2010), die mit ihrem weißen Hintergrund und ruhiger Übersichtlichkeit der bis Anfang 2018 aktuellen des Literaturhauses Berlin ähnlich ist, die erst 2014 aktualisiert wurde. ${ }^{1045}$ Beide Homepages sind textfokussiert und nehmen Elemente des Logos und der Hausfarben - beide arbeiten mit Orange, Schwarz und Weiß - auf. Diese Seiten können als klassisch gestaltete Websites kategorisiert werden. ${ }^{1046}$ Durch die Kombination von großen, flächigen Bildern als Hintergrund und wenig Text verwendet die zuletzt 2013 relaunchte Website des Literaturhauses Frankfurt eine freiere Formensprache. Die textliche Reduktion und die raumgreifenden Fotoimpressionen korrespondieren deutlich mit der in Kapitel II 3.2.2 eruierten Wirkung des Gebäudes des Literaturhauses Frankfurt. Die konstatierte Kombination aus Opulenz und Schlichtheit spiegelt sich im Webauftritt wider. Bemerkenswert ist hier zudem, dass die 2016 durchgeführte Überarbeitung des Programmheftes sich der Websitegestaltung anpasst, in diesem Fall also zunächst die Website anders aussah und die Druckprodukte sich dieser nachfolgend angeglichen. Der Auftritt wnw.litteraturbuset.no ähnelt in der Informationsfülle auf der Startseite dem des Literaturbauses Hamburg. Das Literaturhaus in Bergen präsentiert sich online schlicht und klar gestaltet, sodass die Versuchung naheliegt, von ,zeitloser' Aufmachung zu sprechen. Doch beweisen schon die oben vorgenommenen Beschreibungen der 2014 beziehungsweise 2016 aktuellen Websites, die jeweils zu unterschiedlichen Terminen in den letzten zehn Jahren designt wurden, dass ,zeitlose 'Webgestaltung kaum möglich ist und sich die Seh- und Lesegewohnheiten der User sukzessiv verändern. Da sich die Gewohnheiten bei Internetauftritten relativ schnell wandeln, könnte jede Website nach einigen Jahren generalüberholt werden, dafür stehen meistens keine Ressourcen zur Verfügung.

Die Seite des Litteraturbuset Bergen wirkt deshalb am aktuellsten, weil sie tendenziell vertikal und nicht auf die Breite des Desktopbildschirmformats ausgerichtet ist. Bei der Erstellung 2013 waren mobile Endgeräte schon so weit verbreitet, dass die

\footnotetext{
1044 Diesen Gedanken, darin eine Verbindung zu pinterest zu sehen, verdanke ich einem Gespräch mit Martin Bruch.

1045 Im Sommer 2018 wurde diese Website vollständig relauncht, vgl. FN 918.

1046 Vgl. ebd., S. 139-140.
} 
Seite derart gestaltet wurde, dass beim Umstellen auf die mobile Ansicht nur wenige Elemente verschoben werden müssen. Diese Website ist responsiv, sie passt sich also dem Gerät beziehungsweise dem Browserfenster an, über das sie aufgerufen wird. Ebenso funktionieren, obwohl es ihnen nicht in der Grundgestaltung auf dem Desktopbildschirm anzusehen ist, die Internetseiten der Literaturhäuser Berlin und Hamburg, ebenso wie etwa die des Literaturhauses Köln und die neuere Seite des Litteraturbuset in Oslo. Andere Einrichtungen machen von der Option einer zusätzlichen mobilen Version Gebrauch, bei der Nutzer*innen zwischen zwei Templates auswählen können, meist unterschieden als ,mobile und ,klassische“ Ansicht. Solche Lösungen verwendeten das Literaturhaus Oslo in der alten Version und zum Beispiel das Literaturhaus München. Keine Anpassung für Smartphones und Tablets bieten das Literaturbaus Frank.furt und das Literarische Zentrum Göttingen an. Anhand des Erscheinungsbildes lässt sich also nicht auf die technische zeitgemäße Umsetzung schließen und vice versa.

Abgesehen vom etwas herausstechenden Webauftritt des Literaturbauses Frankfurt, der wiederum auf das aktuelle Corporate Design der Einrichtung abgestimmt ist, vertreten alle untersuchten Literaturhäuser tendenziell klassische, einfach handhabbare Umsetzungen des Onlineauftritts. Sie stimmen mit der Gestaltung der Druckprodukte überein. Es findet also keine Unterscheidung zwischen einer Online- und Offlinezielgruppe statt. Und die Literaturhäuser ,prunken' nicht mit neuester Technik, sondern wählen die Formate, die eine hohe Praktikabilität erwarten lassen. Dies ist, so ist anzunehmen, an die Lesegewohnheiten der Literaturhaus-User*innen angepasst.

Das Literaturhaus Frankfurt schafft mit seiner Website eine gestalterische Übertragung der Raumwirkung des Literaturhaus-Gebäudes. Ähnlich reflektieren in ihrer Farbigkeit und Geradlinigkeit die skandinavischen Einrichtungen ihren physischen Ort im Onlineauftritt. Der stärkste Bruch zwischen Literaturhaus-Gebäude und Websitedesign lässt sich in Hamburg erkennen. Die kräftigen Farben und die grafische ,Schnörkellosigkeit erinnern nicht an die spätklassizistische Villa und ihre eindrucksvolle Wirkung. Dafür setzt die Seite den Gedanken, dass bei einem Literaturhaus ,alles unter einem Dach' geschieht, um.

\section{12.3 Inhalte der Websites}

\section{12.3.1 Veranstaltungsprogramm}

Auf den Websites der untersuchten Literaturhäuser ist wie in den Programmheften die wichtigste Komponente das Veranstaltungsprogramm. Alle präsentieren die nächsten Veranstaltungen auf der Startseite, das Frankfurter setzt zumindest einen Link zur Programmseite. Das Programm bildet damit den wichtigsten Aspekt der Einrichtung, der den Website-Besucher*innen als erstes angeboten wird. Dies unterstreicht etwa die aktuelle Website des Literaturbauses Freiburg, die das Veranstaltungsangebot so zentral setzt und andere Informationen versteckter präsentiert. 
Die Ankündigungstexte auf den Websites und, wenn dort Veranstaltungsseiten angelegt sind, ebenso auf Facebook entsprechen denen in den gedruckten Heften. Die Zeichenzahl, die wegen des begrenzten Platzes auf den Druckbögen beschränkt ist, wird online selten erhöht. Die Texte werden also für das Heft wie für die Website als gleichermaßen geeignet erachtet. Webmarketingexpert*innen empfehlen dies aufgrund unterschiedlicher Rezeptionsweisen von Print- und Onlinetexten nicht, ${ }^{1047}$ allerdings kommen auf diese Weise die Texte mehrfach zum Einsatz und so sind beide Auftritte hinsichtlich der Einzelankündigungen grundsätzlich identisch - Korrekturen oder kurzfristige Änderungen lassen sich online natürlich vornehmen. Diese Beobachtung stützt die Hypothese, dass die Programmhefte eine tragende Rolle bei der Selbstdarstellung der Einrichtungen spielen und sie mit der gleichen Textpraxis auf die Onlineaktivitäten übertragen werden. Die Literaturhaus-Teams wenden somit keine marketingspezifischen Praxistipps an, sie führen hingegen einen am Text, nicht am Medium orientierten Umgang mit Texten fort.

Weder die gestalterische noch die textliche Ansprache über die Website unterscheidet sich in der Adressierung vom Programmheft. Denkbar wäre ja, besonders in den Jahren, in denen das Internet sich noch nicht gesamtgesellschaftlich durchgesetzt hatte, dass die Einrichtungen ,online' eine andere Zielgruppe als ,offline' ansprechen würden, eher technikaffine, tendenziell jüngere Menschen, die vielleicht weniger zum typischen Literaturhaus-Publikum gezählt werden. Doch tatsächlich ist es so, dass es den einen formulierten Ankündigungstext gibt, der an mehreren Stellen vorkommt. ${ }^{1048}$ Ergänzt werden diese erst, seit über Social-Media-Postings und Newsletter auf weiteren Kanälen Endkund*innen erreicht werden können. Wie Susann Sophie Schmitt herausstellt, gibt es für Kinder und Jugendliche ebenfalls keine den neuen Kommunikationsformen angepassten Onlinepraktiken. ${ }^{1049}$

Wenn im Programmheft Fotos von Autor*innen abgedruckt sind, tauchen diese gleichfalls auf der Website auf. Und das Literaturbaus Frankfurt, das in seinem 2017er-Design des Programmheftes im Vergleich zum früheren die Bilder sehr reduziert hat, bildet die Gäste online stets fotografisch ab. Das Literaturhaus Berlin ergänzte die nicht-illustrierten gedruckten Texte online gelegentlich mit Coverabbildungen oder Porträts. Auf den Websites finden sich folglich mehr Bilder als in den begrenzten Druckprodukten. In den Programmarchiven auf den Websites der deutschen Literaturhäuser kommen kaum noch Autorenfotos vor, was unter anderem rechtliche Gründe hat, da die Lizenzen für die Porträts von den Fotograf*innen oder Verlagen in der Regel nur zum Zwecke der Terminankündigung freigegeben sind. Das Literarische Zentrum Göttingen bebildert das Archiv nachträglich mit Fotos, die am Lesungsabend entstanden sind.

\footnotetext{
1047 Vgl. Frank 2011, S. 564. Aus Sicht des Webmarketings sind suchmaschinenoptimierte Texte empfohlen, die mit zahlreichen Schlagworten die jeweiligen Webseiten als relevanter einstufen, sie in der Suchliste entsprechend höher ranken und auf diese Weise die Sichtbarkeit der Veranstaltungen erhöhen. 1048 Vgl. Kapitel II 10.4.1.

1049 Vgl. Schmitt 2016, S. 345-346.
} 


\section{12.3.2 Archiv}

Mit dem Archiv ist ein wichtiger Aspekt des Webauftritts angesprochen, der bereits bei den Funktionen der Programmhefte Erwähnung fand: Die Webpräsenzen fungieren als öffentliche Archive der Literaturhaus-Programme. Die Veranstaltungsmitteilungen der letzten Monate und oftmals Jahre sind dort nachlesbar. Seit die Literaturhäuser ihre Veranstaltungen online ankündigen, verlagern sie diese Texte nach der Durchführung der Veranstaltung in dieses Archiv, das entweder als ,Archiv gekennzeichnet ist, wie in Frankfurt, Göttingen und Berlin, oder das über das Zurückklicken im auf der Seite integrierten Kalender zugänglich ist, wie in Oslo oder Hamburg. Allein in Bergen verschwinden die sich ereigneten Veranstaltungen nach dem jeweiligen Kalendertag von der Website. ${ }^{1050}$ Darin manifestiert sich zweierlei: Erstens mag es an der allgemeinen Nutzung des Internets liegen, dass die Veranstaltungen sichtbar bleiben. Nur nach und nach bildete sich die Praxis heraus, anstatt alles einmal Veröffentlichte online zu halten, lieber auf Aktualität bedacht nur die heute und künftig relevanten Informationen anzubieten, also Beiträge wieder zu entfernen, wie es im Litteraturhuset $i$ Bergen geschieht. Dies ließe vermuten, dass es keine weiter reflektierte Handlung der Literaturhäuser ist, sondern die eingeübte Praxis des Speicherns auf das Internet übertragen wurde. Mercedes Bunz führt jedoch aus, dass das Internet „von Beginn an kein Speichermedium gewesen“1051 ist, sondern auf der Idee des Teilens beruht. Zweitens mag das Veranstaltungsarchiv der bewussten Entscheidung entstammen, die jeweilige Literaturhaus-Identität zu präsentieren. Schließlich ist das Programm das, was die Einrichtung ausmacht. So kann sie als Veranstalter eines Gesamtangebots wahrgenommen werden, bei dem es auf die Summe der einzelnen Teile ankommt. Ob dieser Effektwunsch erfüllt wird, ließe sich über eine Userstatistik oder Leserbefragung abklären. Es ist schwer einschätzbar, ob Nutzer*innen sich tatsächlich über das vergangene Programm informieren. Für die vorliegende Arbeit ist die Tatsache interessant, dass die Ankündigungstexte zu gewesenen Veranstaltungen verfügbar bleiben.

Ein digitales Archiv zu Presseartikeln über das jeweilige Literaturhaus ist online selten zu finden. Anders als bei Theatern ist nicht davon auszugehen, dass positive journalistische Besprechungen von Veranstaltungen einen direkten Werbeeffekt haben, ${ }^{1052}$ weil, wie schon betont, das Literaturhaus-Programm eine Aneinanderreihung von Premieren ohne Wiederholung anbietet.

\section{12.3.3 Weitere Informationen}

Die Websites der Literaturhäuser bilden nicht nur das Veranstaltungsprogramm ab. Schon auf der Startseite informieren einige, längst nicht alle, ausdrücklich über ihr Selbstverständnis. Von den Fallbeispielen geben nur die Einrichtungen in Oslo und Göttingen dort explizit an, als was die Einrichtung zu verstehen sei. Bei den anderen Literaturhäusern gilt die Annahme, dass die Seitenbesucher*innen wissen, was ein

\footnotetext{
1050 Auch das Literaturhaus Köln hält die vergangenen Veranstaltungsankündigungen nicht einsehbar. 1051 Bunz 2009, S. 18.

1052 Ausnahmen bilden Ausstellungen, zu denen etwa das Literaturhaus Frankfurt 2006 Pressestimmen zur Werbung nutzte (FF 2006-05).
} 
beziehungsweise was dieses Literaturhaus ist, besonders deutlich wird das beim Litteraturbuset $i$ Bergen, das gar keinen Über-uns-Text bereitstellt. Dies legt zwei Interpretationen nahe: Zum einen lässt es sich so einschätzen, dass seitens des Literaturhauses kein Interesse daran besteht, als verantwortliche Organisation wahrgenommen zu werden. Zum anderen kann es bedeuten, dass als bekannt vorausgesetzt wird, was ein Literaturhaus ist und/oder die Erklärung auf einer Unterseite ausreicht. Die Selbstbeschreibung erfolgt indirekt über das Programmangebot, das die Einrichtung als Literaturvermittlungsort auszeichnen. Das Programm repräsentiert das Literaturhaus.

Doch ob nun markant auf der Startseite oder über einen Klick anwählbar, in der Regel finden sich auf den Websites weitere Informationen zur Geschichte und Struktur der Einrichtung. Meistens sind neben den im vorherigen Kapitel untersuchten Selbstdarstellungstexten Übersichten über regelmäßige Reihen, Festivals oder Kooperationen erwähnt. Bei den deutschen Literaturhäusern gibt es einen Bereich, der über den Verein und die Mitgliedschaft informiert. Einrichtungen, deren Räumlichkeiten für Vermietungen zur Verfügung stehen, stellen auf einer Unterseite die Räume, die Konditionen und gelegentlich einen Saalplan vor. Dies geschieht auf den Websites der Literaturhäuser in Berlin, Hamburg, Frankfurt, Oslo und Bergen.

Hin und wieder wird die Seite für weiterführende Informationen genutzt, die über die Einrichtung selbst hinausweisen, indem etwa auf Literaturagenturen (Hamburg) oder andere Literatureinrichtungen in der Stadt (Göttingen) aufmerksam gemacht wird. Außerdem führen Links direkt zu den jeweiligen Ticketingdienstleistern, die den Literaturhäusern, die Onlinetickets anbieten, die Infrastruktur dafür bereitstellen. Abgesehen vom Literaturhaus Berlin bieten alle begutachteten Literaturhäuser Onlinetickets an. Die Berliner Einrichtung bildete damit, dass es bis 2018 noch keinen Onlinevorverkauf anbot, eine Ausnahme im deutschsprachigen Bereich. In Hamburg sind Karten seit 2013 online zu erwerben, in Frankfurt seit dem Leitungswechsel im Herbst 2010 und in Göttingen seit Herbst 2006. Die Literaturhäuser in Oslo und Bergen verkaufen seit Beginn Tickets im Internet.

Hinsichtlich des weiter oben extrahierten Selbstverständnisses als internationale Einrichtung ist relevant, ob für nicht-deutsch- beziehungsweise nicht-norwegischsprachige Site-Nutzer*innen Informationen in Erfahrung zu bringen sind. Da die Veranstaltungen größtenteils in der jeweiligen Landessprache stattfinden, ist nicht zu erwarten, dass die Ankündigungstexte übersetzt vorliegen; dies ist tatsächlich in keinem Literaturhaus der Fall. Eine kurze Beschreibung des Literaturhauses inklusive Kontaktinformationen auf Englisch steht auf den Websites der Literaturhäuser in Berlin, Frankfurt und Oslo. ${ }^{1053}$ Es überrascht zunächst, dass Litteraturbuset in Bergen keine englische Ansprache anbietet, denn in Skandinavien ist Englisch aktiver in das Alltagsleben integriert als dies für Deutschland anzunehmen ist. Bei der Analyse des Programmes zeigt sich für dieses Literaturhaus jedoch eine relativ geringe Anzahl

\footnotetext{
1053 Nennenswert ist außerdem die organisationale Entscheidung des Litteraturbuset in Oslo, mit Umgestaltung der Website 2017 einen Unterpunkt mit englischsprachigen Veranstaltungen einzufügen, und einen englischen Podcast anzubieten, vgl. S. 321.
} 
ausländischer Gäste, sodass der Internationalitätsanspruch dort möglicherweise nicht gilt und der Fokus auf dem Norwegischen liegt.

Die beschriebene Basisstruktur hat sich von den frühen Websites bis heute nicht einschlägig verändert, weil dort alle als relevant erachteten Informationen vorkommen, die sich seit Beginn nicht grundlegend verändert haben. Die Internetauftritte ergänzen folglich die gedruckten Programmhefte. Sie erfüllen ebenso die Funktion der Information und Werbung und geben zudem nicht nur monatsprogrammabhängige Informationen, sondern vermitteln allgemeine Auskünfte über die jeweilige Einrichtung. Sie sind Spielplan und Imagebroschüre in einem, eine Dauerpräsenz des Literaturhauses. In diesem Sinne entsprechen sie den Anforderungen, die Besucher*innen der Website an diese stellen werden. Auf der Website finden sich in der Regel mehr Informationen als in dem gedruckten Material. Damit ist der erwähnte Verweis vom Druckprodukt zum Internetauftritt wichtiger als die Weiterleitung von der Webseite zum Programmheft. Dies macht gleichzeitig deutlich, dass ,analog und ,digital' sich nicht ausschließen, sondern aufeinander verweisen.

\section{12.4 Digitaler Raum oder Ausweitung des, analogen' Raums?}

Die Frage, in welchem Verhältnis analoger Raum und virtuelle Präsenz der Literaturvermittlungseinrichtungen zueinanderstehen, bedarf noch einer anderen Antwort als allein der Beschreibung der Integration der grafischen und informativen Elemente in analog und digital verfügbaren Materialien. Der Aspekt ist zwar wichtig, doch soll ein zusätzlicher Punkt ergänzt werden. Erweitert der Internetauftritt den Raum des Literaturhauses oder entsteht ein eigener Raum? Werden atmosphärische Übertragungen versucht? Gibt es Überschneidungen von Literaturvermittlungsarbeit und Onlineaktivität? Finden literaturvermittelnde Angebote genuin onlinebasiert statt?

\section{12.4.1 Fotoimpressionen}

Hinsichtlich der Atmosphäre lässt sich prüfen, ob Charakteristika des Ortes in den Internetauftritt integriert werden. Festzuhalten ist, dass alle untersuchten Literaturhäuser Fotos des Gebäudes und manchmal zudem des belebten Veranstaltungssaales auf ihrer Website zur Schau tragen. Auf der Website lädt etwa das Literaturhaus Frankfurt zu einem ,Rundgang' durch die Alte Stadtbibliothek ein und stellt die einzelnen Säle mit Fotos vor. Bereits auf der Startseite prangt jeweils ein großflächiges Bild des Literaturhauses.

Das Literarische Zentrum Göttingen ersetzt, wie erwähnt, die allgemeinen Autorenporträts nach der Veranstaltung durch Fotos, die bei der Lesung entstanden sind. Somit enthält das Archiv neben den gespeicherten Ankündigungstexten zumindest ein Erinnerungsbild an die jeweilige Veranstaltung. Das Literaturhaus Frankfurt präsentiert unter dem Titel ,Bildband' ebenfalls Fotoimpressionen von einigen Veranstaltungen. Auf diese Weise entsteht eine bildliche Verbindung von Internetauftritt und Literaturhaus-Ort. Eine Abbildung des physischen Literaturhauses im Digitalen 
ist also beabsichtigt. Dies ergibt Sinn, weil das Gebäude einen Wiedererkennungswert hat und bildlich vermittelt wird, wie sich das Literaturhaus gestaltet.

\section{12.4.2 Tonaufnahmen}

Seheindrücke allein sind nicht das, was ein Literaturhaus ausmacht. Es geht ums Hören. Wie erwähnt, zeichnen die Literaturhäuser in Hamburg, Frankfurt und Göttingen ihre Veranstaltungen auditiv auf. Nur im Literaturhaus Berlin blieben die Lesungen bisher flüchtig und sind nicht gespeichert. Das Literarische Zentrum Göttingen verfügt sogar über audiovisuelle Mitschnitte. Auf den Websites sind jedoch keine Audiodateien abrufbar. Einige Literaturvermittlungseinrichtungen wie das Literaturhaus Stuttgart bieten seit 2017 Mitschnitte ausgewählter Veranstaltungen an. Das Literaturbaus Zürich etwa kooperiert seit 2016 mit dem Start-up Voice Republic, streamt einige Lesungen live und stellt die Aufnahme außerdem zum Nachhören zur Verfügung. ${ }^{1054}$ Mit kostenlosen Audioaufzeichnungen von Veranstaltungen warten außerdem die beiden norwegischen Literaturhäuser auf: Mit LittPod ist der Podcast des Literaturhauses Bergen seit Beginn der Einrichtung auf iTunes verfügbar. ${ }^{1055}$ Litteraturbuset in Oslo bietet seit Herbst 2016 Podcasts an, einen norwegischen Litteraturbusets podkast ${ }^{1056}$ und, weil es gelegentlich Veranstaltungen gibt, die auf Englisch stattfinden und in Oslo nicht übersetzt werden, einen englischsprachigen LitHouse Podcast ${ }^{1057}$. Ebenso wie beim Literaturhaus Zürich liegen die Daten nicht auf den Servern der Literaturhäuser selbst und leiten die Besucher*innen weg von der eigenen Website. Dort werden aber alle Beiträge des jeweiligen Literaturhauses übersichtlich präsentiert und sind zu abonnieren. Auf diese Weise erhalten die Dateien eine Rahmung, die sie aufgrund ihrer Metadaten gut auffindbar machen. Allerdings ist zu bedenken, dass so Abhängigkeit von den Dienstleistern herrscht, die keine unbefristete Archivierung versprechen können. Doch ist das Podcast-Angebot nicht zwangsläufig als langfristig angelegtes Archiv gedacht, sondern soll Zuhörer*innen möglichst einfach zugänglich sein. „Von sicher zu flüchtig - Speichern im WWW dient hier nicht mehr der sicheren Aufbewahrung, sondern der vorübergehenden Darstellung von Daten.“1058

Schon aus den Anfangsjahren der Literaturhäuser existieren Tonaufnahmen, die erst seit circa 2001 genuin digital aufgezeichnet wurden. ${ }^{1059}$ Außerdem liegen die analogen und einige digital erstellte Aufnahmen zum Teil auf Medienträgern wie MiniDiscs vor, die heute kaum noch abspielbar sind, weil die Lesegeräte fehlen. Aufgrund der zunehmend vereinfachten Distribution von digital erstellten Dateien mit tech-

\footnotetext{
1054 Auf der Website des Literaturhauses findet sich der Link zum Dienstleister, vgl. „Podcasts“, Literaturhaus Zürich. Voice Republic speichert die Daten auf seinem Server.

1055 Verfügbar über: „LittPod“, Litteraturhuset i Bergen via iTunes.

1056 Verfügbar über: „Litteraturhusets podkast“, Litteraturhuset via iTunes.

1057 Verfügbar bei Soundcloud und über den Podcast-Dienstleister libsyn: „LitHouse podcast“, Litteraturhuset via Liberated Syndication. Der englischsprachige Podcast vergrößert das potenzielle Publikum. Es ist sinnvoll, die beiden unterschiedliche Sprachen nutzenden Podcasts getrennt voneinander zu präsentieren. 1058 Bunz 2009, S. 17.

1059 Dies gilt für das Literaturhaus Hamburg, in den anderen Einrichtungen wird es ähnlich sein. Dort wurden die Mitschnitte erst auf Kassetten und bis 2008 auf MiniDiscs gespeichert, danach auf einer Festplatte.
} 
nisch leicht bedienbaren Instrumenten, die vor allem in der Nutzung kostengünstig sind, kam dann die Idee überhaupt erst auf, die flüchtigen Veranstaltungen nicht nur für interne Zwecke zu dokumentieren, sondern gegebenenfalls zu verbreiten. Vorher lagerten die Aufnahmen jahrzehntelang ungenutzt in Kisten in den Literaturhäusern.

Die historische und wissenschaftliche Bedeutung der Mitschnitte ist unumstritten, wie das Projekt dichterlesen.net bestätigt, das sich aus der 2011 begonnenen Idee Lesungen.net fortentwickelt hat. Initiiert vom Literarischen Colloquium Berlin ist seit 2015 ein frei zugängliches Onlinetonarchiv von literarischen Veranstaltungen der beteiligten Akteur*innen im Aufbau. Die Absichtserklärung reflektiert die langfristige Planung und die explizit auf wissenschaftliche Zwecke abgestimmte Intention des Projektes: „Gemeinsam haben es sich die kooperierenden Einrichtungen zum Ziel gesetzt, ihre Veranstaltungsmitschnitte, die bis zu einem halben Jahrhundert deutscher und internationaler Literaturgeschichte abbilden, der Öffentlichkeit zugänglich zu machen." ${ }^{1060}$ Dafür werden archivierte Audiodokumente digital aufbereitet sowie gegenwärtig abgehaltene Veranstaltungen mitgeschnitten und für die Veröffentlichung bearbeitet.

Es handelt sich um ein Archiv, bei dem die Bezugsquellen der Archivalien zum Teil direkten Einfluss auf die Zusammensetzung der Sammlung haben. Die Initiator*innen behalten sich die Auswahl und die Speicherung vor. Anders als von Mercedes Bunz veranschlagt, werden die Daten nicht nur flüchtig aufbewahrt und durch Verbreitung gespeichert. ${ }^{1061} \mathrm{Im}$ Gegenteil funktioniert diese Sammlung wie ein analoges Archiv, nur, dass es online und kostenfrei zur Verfügung steht. Die kooperierenden Einrichtungen entscheiden selbst, welche ihrer Veranstaltungen eingepflegt werden und bestimmen damit, welche Lesungen einfließen sollen und damit sichtbar werden beziehungsweise welche nicht aufgezeichnet und damit der Öffentlichkeit vorenthalten werden. Für heutige Lesungen bedeutet dies zudem, dass die Autor*innen sowie weitere Bühnenbeteiligte vor der Veranstaltung ihr Einverständnis geben, dass der Mitschnitt vollständig oder in Auszügen auf der Seite dichterlesen.net hochgeladen wird. Sie können sich fortan entscheiden, ob sie vermerkter Teil von einem „halben Jahrhundert deutscher und internationaler Literaturgeschichte“ werden möchten oder nicht. Obgleich Autor*innen sich nicht selbst kanonisieren können, sondern viele Instanzen zu einem Kanonisierungsprozess beitragen, erhöht sich auf diese Weise ihr Kanonisierungspotential. ${ }^{1062}$ Bei den erwähnten Podcasts wird die längerfristige Archivierungsfunktion von den Literaturhäusern nicht so explizit kommuniziert, doch sind sie ebenfalls Bestandteil von Kanonisierungsprozessen. Möglicherweise ändert sich durch das Wissen um die Aufzeichnung gar die Art des Sprechens der Podiumsgäste, vielleicht werden sie zurückhaltender oder sie versuchen, besonders gewichtige, später zitierbare Aussagen zu formulieren, wenn ihnen bewusst ist, dass ihre Worte für die Literaturgeschichtsschreibung verwendet

\footnotetext{
1060 „Über das“, dichterlesen.net, Literarisches Colloquium Berlin. Die Initiative geht zurück auf das Literarische Colloquium Berlin, Kooperationspartner sind das Deutsche Literaturarchiv Marbach, das Literaturhaus Basel und das Literaturbaus Stuttgart, mitfinanziert wurde das Projekt von der Beauftragten der Bundesregierung für Kultur und Medien, der Kulturstiftung des Bundes und der S. Fischer Stiftung. 1061 Vgl. Bunz 2009, S. 17. 1062 Vgl. Winko 2002, S. 11 sowie Kapitel II 14.2.
} 
werden. ${ }^{1063}$ Öffentliche Aussagen seitens der Autor*innen und die Herausgabe von Informationen, die das Werk und/oder die Person betreffen, wirken immer schon auf ihre publike Wahrnehmung und Anerkennung ein, doch war den Veranstaltungen im Literaturhaus bisher nicht so ausdrücklich ihre langfristige, gerade nicht flüchtige Relevanz eingeschrieben, wie sie dichterlesen.net formuliert.

Dies könnte Auswirkungen auf die Entwicklung der Institution Literaturhaus haben, weil damit möglicherweise ihr Anspruch, ein Ort des offenen Denkens zu sein, eingeschränkt wird. Das ist jedoch längst noch nicht überprüfbar. In jedem Fall ändert sich der mediale Status der Veranstaltung von einem einmaligen, nur live an dem einen Ort erlebbaren Gespräch zu einem wiederholbar abrufbaren Dokument. Dies hat Auswirkungen auf den Aspekt der Performanz: Es konserviert sich im Archiv und im Podcast ,nur die Tonspur des Geschehens. Dies ist der entscheidende Unterschied zur Ursprungsveranstaltung. Die im ersten Kapitel angeführte für das Gesamtkonzept des Literaturhauses und für jede Veranstaltung bedeutende Rahmung, die eine Literaturveranstaltung unter anderem als soziale Praktik begreifbar machen, wird in dieser Form abgeschnitten. ${ }^{1064}$ Entfernt werden in manchen Fällen außerdem die Momente, die die Veranstaltungen als Live-Geschehen identifizierbar machen: Versprecher, Räuspern, Husten, Störungen des Ablaufs oder Pausen werden manchmal getilgt. Das macht deutlich, dass es für die Organisator*innen zu überlegen gilt, ob möglichst die Ereignishaftigkeit der Veranstaltung oder der Inhalt des Gesprächs verbreitet werden soll, ob also der Verweis auf die LiteraturhausVeranstaltung beibehalten oder eine Art Radiosendung entstehen soll.

Mit der Nutzbarmachung von Literaturhaus-Veranstaltungen wird sich erst über die Zeit zeigen lassen können, ob der Rahmen, der eine Lesung unter anderem zu einer zwischenmenschlichen Begegnung formiert, die Bedeutung behalten wird, die ihm heute zugeschrieben wird, oder ob neue Formen der Einbettung eingeübt werden. Prognostiziert werden soll und kann an dieser Stelle nichts und kulturkritisches Lamentieren ist nicht angebracht. Dennoch ist es denkbar, dass kommende Zuschauer*innen und Zuhörer*innen die aktuellen Kulturtechniken transferieren, sodass diese sich eines Tages von den heute gängigen entfernt haben werden. Dass zum Beispiel Literaturveranstaltungen statt in voller 90-minütiger Länge vor Ort konsumiert zu werden per Live-Stream oder Podcast beim Joggen gehört werden, ist ja keine Zukunftsvision, sondern passiert bereits. Die Verstetigung von zunächst flüchtigen, performativen Aufführungen lässt sich nicht nur im Literaturhaus nach und nach beobachten, sondern findet vielerorts statt. Auch etwa im Theater werden Erlebnisse zu konservieren versucht, indem Inszenierungen oder Ausschnitte davon aufgezeichnet und verbreitet werden. Somit vermehrt sich mit diesen Lesungsaufzeichnungen das Repertoire dessen, was als Literatur bezeichnet werden kann. Diese Dokumente werden mit der Veröffentlichung rezipierbarer Teil des Literaturbetriebes und damit der Literatur selbst. Sie weisen auf einen erweiterten Literaturbegriff

\footnotetext{
1063 Dank an Stefanie Stegmann für das Gespräch zu diesen Überlegungen.

1064 Dies bestätigt Renate Giacomuzzi, die für Autorenlesungen im Internet konstatiert, dass es sich dabei um eine De- beziehungsweise Rekontextualisierung einer Reallife-Lesung im Internet handelt, die mit einem Verlust der Performanz einhergeht, da die Interaktion mit dem Publikum wegfällt, vgl. Giacomuzzi 2014, S. 27.
} 
hin, der für die Literatur im Zeitalter der Digitalisierung bereits mehrfach konstatiert wurde.

Mit der entgeltfreien Bereitstellung von Tondokumenten im Internet stellen sich zugleich unter anderem rechtliche Fragen, die heute noch nicht abschließend geklärt werden können, weil nicht kalkulierbar ist, wie sich die bereitstellenden Plattformen entwickeln und weil aktuell die Rechte an dem Material bedenkenlos an Dritte weitergegeben werden. Zwar stimmen die Beteiligten zu, doch ist dies ein Beispiel dafür, dass Handlungen einer juristischen Versicherung vorausgehen, wie dies etwa bei den E-Book-Verkaufsrechten in Autorenverträgen, die vor der Produktion von digitalen Medien abgeschlossen wurden, der Fall war. Intern diskutieren die Teams der Literaturhäuser die Chancen und Risiken dieser Serviceleistungen und erhoffter Erhöhung der Reichweite. Es ist zu erwarten, dass in Zukunft weitere Literaturhäuser Mitschnitte hochladen. Damit passt sich das Literaturhaus an einen gesellschaftlichen Fortschritt an und bleibt zeitgemäß. Parallel verstärkt das Literaturhaus diese Progression durch seine Teilnahme daran, obwohl es sich dabei möglicherweise um eine dem Literaturhaus traditionell grundsätzlich widerstrebende Entwicklung handelt. Es gilt auch in diesem Fall, eine Balance zwischen Erneuerung und Selbsterhalt der Institution zu erlangen.

Fakt ist, um zurück zur Vorstellung der Webauftritte zu kommen, dass sich vor allem bei den skandinavischen Literaturhäusern eine Entwicklung hin zur zusätzlichen inhaltlichen Abbildung der vor Ort durchgeführten Angebote abzeichnet. Diese, so die Absicht seitens der Einrichtungen, locken zum einen Besucher*innen zum analogen Ort des Literaturhauses und steigern zum anderen ihr Ansehen als Literaturraum, an dem relevante Diskussionen passieren, die sogar nachgehört werden können. Die Integration vom physisch erlebbaren Raum in die digitale Sphäre geschieht also über einen Transfer der Inhalte. Bei dieser Übertragung geht der atmosphärische und soziale Aspekt verloren, denn es handelt sich um Aufnahmen, die bei dem Wechsel der Darstellungsform ihre Rahmung verändern. In der neuen Umgebung funktionieren sie anders und sind mit aufgezeichneten Radiosendungen oder anderen abgeschlossenen Formaten vergleichbar, auf deren Verlauf die Rezipient*innen nicht mehr einwirken können.

\section{12.4.3 Austausch und Interaktion}

Der Aspekt des Austausches, den die Literaturhäuser in ihren Selbstbeschreibungstexten stark machen, spiegelt sich auf den Websites nicht wider. ,News', ,Aktuelles', ,Nyheter ${ }^{6}$ [Neuigkeiten] oder ,Husnytt' [Neues aus dem Haus] teilen die Literaturhaus-Teams regelmäßig mit, dies sind beispielsweise organisatorische Hinweise zu einzelnen Veranstaltungen, Pressemitteilungen, die seitens der Literaturhäuser veröffentlicht wurden, oder Meldungen aus dem Literaturhaus, etwa über Sommerpausen oder eingeschränkte Erreichbarkeit des Büros. Einige Literaturhäuser verkünden des Weiteren Nachrichten, die das Literaturhaus nur indirekt betreffen, zum Beispiel über die Vergabe von Literaturpreisen an Autor*innen, die bereits zu Gast im Literaturhaus waren oder es bald sein werden. Diese Neuigkeiten weisen zwar über die 
Programmhefte hinaus und zeugen davon, dass die Seiten regelmäßig aktualisiert werden, doch handelt es sich um monodirektionale Kommunikation.

Kommentarfunktion oder ,Gästebuch', obwohl sich dieses - bei der Metapher bleibend - bei einem Literaturhaus anbieten würde, liegen auf den Websites nicht vor. Das ,Gästebuch`ist eine Vorlage, die Besucher*innen einer Website befähigt, Nachrichten zu hinterlassen. Dieses Feature hat sich jedoch insgesamt nicht längerfristig durchgesetzt, zumal die sozialen Medien direkteres Feedback erlauben. Einzige Reaktionsfunktion ist bei einigen Einrichtungen das Kontaktformular, das wiederum zum Mailprogramm weiterleitet und in einen privaten Austausch zwischen Sender*in und Empfänger*in, das heißt Literaturhaus-Mitarbeiter*in, mündet. Dies trifft ebenfalls auf den Newsletter zu, der an viele Empfänger*innen gleichzeitig verschickt wird und zwar die Möglichkeit bietet, direkt auf ihn zu antworten, doch läuft der Austausch nicht öffentlich, sondern zwischen zwei Akteur*innen ab. Der Newsletter ist weniger als Instrument des Austausches, sondern als zusätzliches Marketingmittel einzuordnen. Außerdem ist es gerade bei kurzfristigen Programmänderungen hilfreich, dass Kund*innen direkt erreicht werden können. Außerdem lassen sich über Newsletter, die über externe Anbieter verschickt werden, Reaktionsverhalten wie Öffnungsraten oder Klicks nachvollziehen. Dies sind digitale Werbeinstrumente, die heute von vielen Organisationen verwendet werden. Die Websites der Literaturhäuser sind folglich Organe von One-to-Many-Kommunikation und erfüllen in erster Linie Servicefunktionen.

\section{12.5 Social Media}

Die auf den Websites nicht gegebenen Interaktionsmöglichkeiten bestehen auf den Social-Media-Kanälen, die die Literaturhäuser unterschiedlich ausgiebig unterhalten. Zielgerichtete Links zu den Facebook-Auftritten oder anderen verwendeten sozialen Medien sind auf den Websites integriert, sodass eine Verbindung geschaffen wird. Auf Twitter sind von den Fallstudien bis Sommer 2017 die Nutzer@LitZentrumGoe, @Litteraturbuset,@LitthusBergen und @literaturbausdk, seit Juli 2017 @LiteraturbausB (Berlin) zu finden. Den bildbasierten Onlinedienst Instagram verwendeten bis dahin die Literaturhäuser Oslo, Bergen, Kopenhagen und das Literarische Zentrum Göttingen. 1065 Über Facebook-Seiten verfügen alle untersuchten Literaturhäuser, diese dienen nun als Beispiel für ein soziales Medium, in dem das Literaturhaus aktiv ist.

1065 Seit Frühjahr 2018 ist auch das Literaturbaus Frankfurt dort aktiv, seit 2019 außerdem das Literaturhaus Hamburg und das Junge Literaturbaus Berlin. 


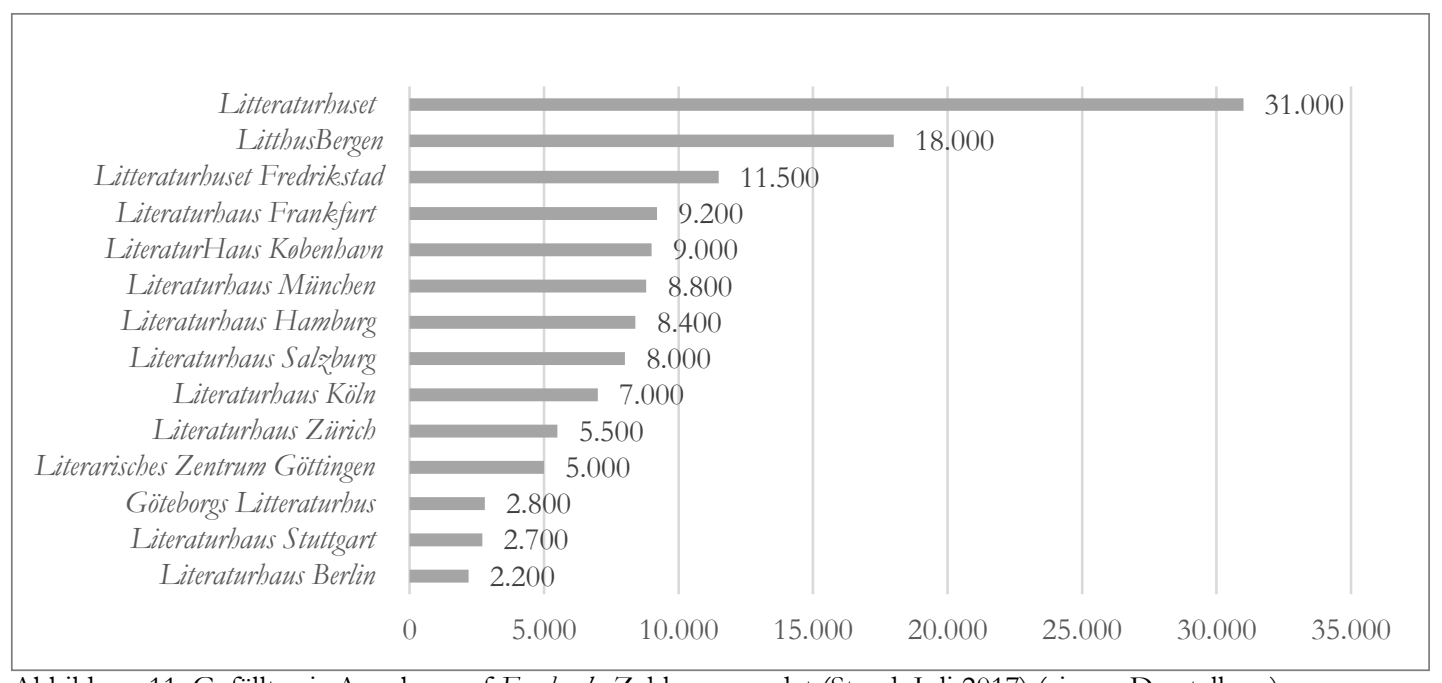

Abbildung 11: Gefällt-mir-Angaben auf Facebook, Zahlen gerundet (Stand: Juli 2017) (eigene Darstellung)

Extrem unterscheiden sich die Fallbeispiele hinsichtlich ihrer Reichweite auf Facebook. 1066 Wie aus Abbildung 11 hervorgeht, folgten dem Litteraturbuset in Oslo im Juli 2017 rund 31.000 Facebook-Nutzer*innen. Das sind im Vergleich zu den anderen Literaturhäusern sehr viele, die Zahl ist mehr als dreimal so hoch wie die des Literaturhauses Frankfurt, die Follower-stärkste deutsche Einrichtung. Auch Litteraturbuset $i$ Bergen legte mit 18.000 eine große Anzahl an Fans vor, immer noch doppelt so viele wie Frankfurt. Um die Zahlen der Fallbeispiele noch besser einschätzen zu können, wurden weitere Literaturhäuser aus Deutschland, Norwegen, Österreich und der Schweiz hinzugezogen. Dabei zeigt sich an den 11.500 Follower*innen von Litteraturbuset Fredrikstad, dass die norwegischen Organisationen insgesamt deutlich höhere Nutzerzahlen haben. Dass den meisten User*innen das hauptstädtische, national und international rezipierte Litteraturbuset, gefällt', ist nicht überraschend. 9.000 Follower*innen des Literaturhauses in Kopenhagen sind ebenfalls viel, wenn bedacht wird, dass die Einrichtung im Vergleich etwa zur Osloer eine relativ geringe Reichweite hat. Die 2.800 Anhänger*innen von Göteborgs Litteraturbus entsprechen der Disposition als kleinere Einrichtung, die nicht so sehr über Göteborg hinaus wahrgenommen wird. Außerdem ist es deutlich jünger als die anderen Beispiele und entsprechend weniger bekannt; die Zahlen reflektieren diese Tatsache. ${ }^{1067}$

Spannender ist der deutsch-skandinavische Vergleich, bei dem die markante Differenz zwischen Norwegen und Deutschland auffällt. Unterschiedliche Erklärungen liegen nahe: Der Rezeptionsradius des Literaturhauses hat Einfluss auf die Anzahl der Gefällt-mir-Angaben. Dafür spricht die Seite des Literarischen Zentrums Göttingen, das ,nur 5.000 Fans hat - was für die Größe der Stadt wiederum keine niedrige

\footnotetext{
1066 Screenshots dieser Seiten finden sich im Anhang unter V 3.2. Als Follower*in, die Bezeichnung, der vom Nachrichtendienst Twitter stammt, sich für andere soziale Medien jedoch ebenfalls durchgesetzt hat, werden hier die Profile bezeichnet, welche die Seite mit,Gefällt mir' markiert haben, alternativ verwende ich ,Fans‘. Das können neben Einzelpersonen Facebook-Auftritte von kollektiven Akteur*innen wie Verlagen oder anderen Kulturvermittlern sein. Es ist automatisch eingestellt, dass diese Profile die Seiten, die ihnen gefallen, auch abonnieren, deren Beiträge also in ihrem eigenen News Feed angezeigt werden, vgl. „Was bedeutet“, Facebook. Nur ein verschwindend geringer Anteil derer abonniert bei ,Gefallen“ diese Seite nicht, so kann sich im Folgenden mit den Vokabeln ,Follower*in' und ,Fan' auf die „Gefällt-mir“Angaben bezogen werden - dies gilt jedenfalls bei den untersuchten Literaturhäusern. Es besteht seitens der Besucher demnach Interesse, über deren Postings und Veranstaltungen informiert zu werden.

1067 Das Entstehungsjahr der Facebook-Seite spielt ebenfalls in die Zahlen herein, wie zusätzlich das Literaturhaus Berlin belegt, das dort erst seit Juli 2017 vertreten ist.
} 
Zahl ist. ${ }^{1068}$ Es ließe sich also interpretieren, dass die Literaturhäuser in Deutschland eine kleinere Anhängerschaft haben. Dies könnte daran liegen, dass sie stärker als einzelner Literaturveranstalter auftreten und sich nicht so deutlich wie die norwegischen Literaturhäuser als Arena verstehen, in der diverse Akteur*innen ihre Veranstaltungen durchführen. Das größere Spektrum an Themen, Disziplinen und Organisator*innen im Litteraturbuset lässt ein umfangreicheres Publikum erwarten. Auf die Literaturhäuser bezogen erscheint die Hypothese wahrscheinlich, da sich in Deutschland die Institution Literaturhaus mehr innerhalb eines kleiner abgesteckten Literaturbetriebs positioniert als in einem umfassenderen Gesellschaftskontext. ${ }^{1069}$

Möglich ist des Weiteren, dass die norwegischen Einrichtungen sich mehr um die Pflege der Seite kümmern, suchmaschinenoptimiert arbeiten oder Beiträge als Werbeanzeige bezahlen und somit ihre Reichweite erhöhen. Auf den Facebook-Seiten selbst ist inhaltlich jedoch kein grundsätzlicher Unterschied zu den deutschen Seiten zu erkennen. Ebenso wenig ist in den Literaturhäusern in Skandinavien deutlich mehr Personal angestellt, keine Mitarbeiter*innen sind ausgewiesen für die Internetkommunikation zuständig. Denkbar ist zusätzlich, dass bei einer Neugründung das öffentliche Interesse höher ist und sich dieses unter anderem über die FollowerZahlen ablesen lässt. Über Facebook kann die Neugier auf die Einrichtung markiert werden, sodass Nutzer*innen sofort erfahren, wenn es Meldungen dazu gibt. Die Facebook-Seite einer bereits aktiven Einrichtung büßt diesen Neuigkeitswert ein. Es ist zugleich nicht ausgeschlossen, dass die Literaturhäuser in Deutschland weniger Engagement für die Facebook-Aktivitäten aufbringen als in Norwegen, weil die Social-Media-Accounts nicht als zentrale Kommunikationsorgane aufgefasst werden. ${ }^{1070}$

Diese Vermutungen münden in die Feststellung, die sich mit den dargelegten Zahlen belegen lässt: In Skandinavien ist die Nutzung des Internets generell und von Social Media speziell weiter verbreitet als in Deutschland. ${ }^{1071}$ Dies gilt - sich gegenseitig bedingend - sowohl für Unternehmen als auch für User*innen. Dafür argumentiert zudem, dass die norwegischen Literaturhäuser Twitter-Konten pflegen und dort für Oslo sowie für Bergen den Facebook-Zahlen ähnelnde Follower-Ziffern auftauchen. Neben Facebook werden Twitter und Instagram stärker frequentiert.

Die Facebook-Seiten werden vor allem für die Bewerbung von Veranstaltungen genutzt, die von User*innen gelikt, geteilt oder kommentiert werden können. Außerdem geben die Mitarbeiter*innen dort Neuigkeiten kund, die oft parallel auf die Website gestellt werden. Allgemeine Nachrichten des Literaturbetriebes oder All-

1068 Zum Vergleich: Die Facebook-Seite des örtlichen Theaters Deutsches Theater Göttingen hatte am 27.07.2017 4.600 Gefällt-mir-Angaben, vgl. „Deutsches Theater“, Deutsches Theater Göttingen via Facebook.

${ }^{1069}$ Dafür spricht ferner, dass etwa die Frankfurter Buchmesse als Organisation des größten Buchbranchentreffens der Welt am 27.07.2017 ,nur' knapp 55.000 Gefällt-mir-Angaben vorweisen konnte, vgl. „Frankfurter Buchmesse“, Frankfurter Buchmesse via Facebook. Das Literaturhaus als Kultureinrichtung macht in der gesamten Buchbranche sogar nur einen kleinen Teil aus.

1070 Das dies in Skandinavien anders ist, belegt darüber hinaus das neue Litteraturbuset ved Vandkunsten in Kopenhagen. Dieses beschränkt sich vorerst ganz auf die Facebook-Seite und hat keine eigene Website. Diese Einrichtung kann hier aus arbeitspraktischen Gründen aber nur marginal einbezogen werden. Das dänische und das schwedische Literaturhaus werden ebenfalls nur flankierend hinzugezogen, vgl. Kapitel II 8.3.

${ }^{1071}$ Øyvind Prytz erwähnt mit Verweis auf Rüdiger Wischenbart, dass die skandinavischen Länder insgesamt einen hohen Anteil an Internetuser*innen aufweisen, vgl. Prytz 2013, S. 22. 
tagsgeschichten aus den Büros ergänzen diese Ankündigungen. Das Literarische Zentrum Göttingen tritt außerdem durch Rückblicke in Erscheinung. ${ }^{1072}$ Literaturkritische Diskussionen beispielsweise finden jedoch selten Platz. Die Seiten dienen vor allem zur impliziten und expliziten Bewerbung des eigenen Programms, und somit fällt die Auswahl auf das Teilen von lobenden Rezensionen oder Verkündungen von Literaturpreisen.

Auf ähnliche Weise nutzen die Literaturhäuser, die auf anderen Plattformen präsent sind, ihre dortigen Möglichkeiten: Das Literaturhaus München schreibt seit Dezember 2015 einen Blog, der Veranstaltungsnachberichte oder Vorabinterviews abbildet. Es bespielt außerdem einen Youtube-Kanal. Dies tun ferner das Literaturbaus Stuttgart, vor allem mit kurzen Clips, Programmvorschauen oder Zusammenschnitten von Veranstaltungen, und das Literaturbaus Sal々burg, ausschließlich mit Lesungsvideos. Besonders die letztgenannten Kanäle haben noch Experimentstatus und könnten ihre Auffindbarkeit und Filmprofessionalität noch verbessern. Dies belegen unter anderem die geringen Klickzahlen, die sich zwischen neun und 100 bewegen.

\section{12.6 Literaturvermittlung jenseits von Vor-Ort-Veranstaltungen}

Neben der Bereitstellung von Informationen nutzen die Literaturhäuser ihre Onlinepräsenzen nur sehr eingeschränkt als Orte der Literaturvermittlung, eher als „Komplementärmedien“1073. Zwar ergeben sich mit den Tonaufnahmen und zum Teil Videoaufnahmen Optionen, Veranstaltungen über den Saal des Literaturhauses hinaus zu verbreiten, doch werden bisher selten genuin digitale Wege der Vermittlung genutzt.

Es ließe sich mutmaßen, dass sich auf den Websites von Häusern der Literatur zumindest direkte literarische Bezüge, Zitate oder Derartiges finden. Abgesehen von den Programmtexten selbst ist dies selten der Fall. Das Literaturbaus Hamburg ist mit der aktuellen Website die einzige Einrichtung, die unter der Überschrift „Schöne Sätze“ und „Notizen aus dem Exil“" Zitate von Autor*innen am unteren Rand der Seite einblendet. Das Literaturbaus Frankfurt integriert in seine Newsletter oder in Facebook-Postings oft lyrische Texte. Gedichte, die zum Thema des Beitrages passen und die nicht nur von Autor*innen stammen, die im Literaturhaus zu Gast waren oder sein werden. Auf diese Weise erhalten die Abonnent*innen insgesamt literarischen Input.

Meinen Recherchen zufolge gab es bisher kaum spezielle digitale Formate, keine digital-only-Angebote in den Literaturhäusern. Ausnahme ist etwa die in Abbildung 12 illustrierte Twitter-Aktion des Literarischen Zentrums Göttingen. Es twitterte im Herbst 2014 Märchen und rief zur Teilnahme auf. Aufgabe war es, Märchen in 140

\footnotetext{
1072 Diese kommen auch im Literaturhaus Hamburg regelmäßig vor. Hier sei aber ausdrücklich daran erinnert, dass die Verfasserin dieser Arbeit seit Mitte 2016 auch den Facebook-Account des Literaturhauses Hamburg verantwortet. Die Aktivitäten auf der Seite nach Mai 2016 sind eine Folge der Beschäftigung mit den anderen Literaturhaus-Seiten. Das ist auch im Literaturhaus selbst übliche Praxis und nicht nur auf die Arbeit an dieser Dissertation zurückzuführen. Durch die vorliegende Arbeit wird dieser Umgang jedoch reflektiert und hier nachlesbar.

1073 Hickethier 2003, S. 325.
} 
Zeichen nachzuerzählen beziehungsweise zusammenzufassen. Die Aktion lief in Kooperation mit der Göttinger Stadtbibliothek. ${ }^{1074}$

(2) LiterarischesZentrum
Und wenn sie nicht gestorben sind, dann
twittern sie noch heute...
\#poetweet \#thehappyend
08.13 - 21. Nov. 2014

Abbildung 12: Tweet zum Projekt Märchen twittern, 21.11.2014

(in Gaustufen)

Damit gibt es kaum Experimente der Literaturhäuser, die elektronische Mittel zu einer anderen Art der Literaturvermittlung zu nutzen, als - zugespitzt formuliert kommentarlos Tonaufnahmen von vergangenen Veranstaltungen hochzuladen.

Vor Ort schaffen die Literaturhäuser ebenfalls selten eine Verbindung beider Sphären. Obgleich außerhalb von Literaturhäusern schon häufig etwa via Twitter oder per Webkonferenz Gäste eingezogen werden, finden derartige Nutzungen noch selten im Literaturhaus statt. Auch das Literarische Zentrum Göttingen führte in Zusammenarbeit mit dem DFG-Graduiertenkolleg Literatur und Literaturvermittlung im Zeitalter der Digitalisierung ein derartiges Experiment durch:1075 Der deutsche Autor Tilman Rammstedt (*1975) präsentierte sein aktuelles Buch Morgen mehr (2016), das selbst Ergebnis eines Social-Reading-Versuches war. Parallel zur Moderation konnte sich das Publikum per Handzeichen oder Tweet, übertragen auf die auf einer Leinwand im Raum projizierte Twitter-Wall, einbringen. Die Veranstaltung wurde von Lovelybooks livegestreamt und ist weiterhin online verfügbar'1076 (GT 2016-09-29).

Es lassen sich in den Programmen wenige Autor*innen verzeichnen, die Netzliteratur herstellen und „Texte für die Rezeption am Computer verfassen“"1077. Derartige Veranstaltungen und Gäste kommen folglich nicht oft im Literaturhaus vor. ${ }^{1078}$ Eher finden sich gelegentlich innovative Konzepte zur Stärkung des Analogen. Zum Beispiel führt das Literaturbaus Frankfurt seit März 2017 Shared Reading durch, „eine neue Art, Literatur gemeinschaftlich zu erleben. [...] Es entsteht ein Raum für Begegnungen, neue Lesarten, spontane Gefühle, ausgelöst durch die Kraft der Litera-

\footnotetext{
1074 Literarisches Zentrum Göttingen via Twitter 21.11.2014. URL: twitter.com/LitZentrumGoe/status /535828303987638272 (Stand: 30.08.2018). Diese Aktion war verbunden mit einer Veranstaltung in Kooperation mit der Stadtbibliothek Göttingen, sie integrierte Twitter mit einer analogen Veranstaltung (GT 2014-11.21).

1075 Die Veranstaltung war integriert in die Tagung \#Lesen. Transformationen traditioneller Rezeptionskonzepte im digitalen Zeitalter (29.09.-01.10.2016). Da die Verfasserin der vorliegenden Arbeit und Kollegiatin jedoch in die Planung eingebunden war, kann dieses Projekt als eine Auswirkung der Ideen und Forschungen des Graduiertenkollegs gewertet werden. Dies liefert ein weiteres Argument dafür, keine Veranstaltungszeiträume zu analysieren, in denen ich selbst oder Akteur*innen des Graduiertenkollegs in den Literaturhäusern aktiv war/waren beziehungsweise aufmerksam zu reflektieren, wenn dies doch der Fall war. 1076 Vgl. „Das Social-Reading-Experiment“, Lovely Books.

1077 Paulsen 2007, S. 258. Kerstin Paulsen kategorisiert Autorschaft im Internet und benennt die zitierte als zweite Grundform.

1078 Vgl. Kapitel II 11.2.3, S. 305.
} 
tur“ (FF 2017-03/04). Die Shared Reading-Gruppe trifft sich zum gemeinsamen Lesen. ${ }^{1079}$

Angemerkt sei an dieser Stelle, dass die Literaturhäuser sich in Diskussionsveranstaltungen durchaus mit den medialen Veränderungen der Gegenwart auseinandersetzen. Zwei Beispiele aus den frühen Jahren der Institution sind: Buchmaschinen. Alte Erinnerungen und ibre neuen Speicher, ein von einer Ausstellung begleitetes und von dem Autor Thomas Hettche (*1964) kuratiertes Symposium, an dem unter anderem Friedrich Kittler und Rainald Goetz teilnahmen (FF 2000-11-03/05). ${ }^{1080}$ Und das Literaturbaus Hamburg widmete sich schon früh den neuen Entwicklungen, nicht nur hinsichtlich der organisationalen Praxis der Einrichtung, wie oben gezeigt, sondern auch mittels kulturtheoretischer Reflexionen im Programm zur „,neuen elektronischen Kultur“ und den „,neuen virtuellen Welten“. Etwa innerhalb der Reihe Vom Verschwinden der Wirklichkeiten:

Was ist Wirklichkeit, und wozu brauchen wir sie? Sie [die Vortragenden der Reihe, Anmerkung C. L.] setzen sich mit der ebenso rasanten wie epochalen, aber so gut wie kaum öffentlich reflektierten Veränderung der Wirklichkeit und ihres Aggregatzustands unter der Herrschaft der neuen Medien auseinander und mit ihren absehbar unabsehbaren Folgekosten für unsere Sinne, Seelen und Körper, für unser Zusammenleben und unsere Erfahrungsformen, für die Kunst und die Imagination. (HH 1996-01-09) 1081

Hier offenbart sich, inwiefern diese Einrichtung bestrebt war, darüber nachzudenken, wie der „Übergang von der Gutenberg-Galaxie zu der Galaxie der neuen Medien [...] ganz neue Anforderungen an unser Hirn" stelle (HH 1996-05-21). Nicht nur der Aspekt, dass von „,neuen Medien“ die Rede ist, sondern auch der Einfluss auf die Art des Denkens und Wahrnehmens war 1996 im Literaturhaus Hamburg schon Thema. Dies wird in dieser Intensität später nicht fortgesetzt.

\section{12.7 Zwischenfazit - Analog im Zeitalter der Digitalisierung}

Wie sich in der vorliegenden Arbeit bestätigt, entstand und institutionalisierte sich das Literaturhaus im Zeitalter der Digitalisierung, in der sowohl die Verbreitung des Internets als auch die Verfügbarkeit enormer Datenspeicherungsoptionen stetig fortschreitend direkten Einfluss auf die Arbeit und Entscheidungen des Literaturhauses haben. Um nachzuspüren, wie die Literaturhäuser sich in ihrer Gegenwart verorten, hat es sich als ergiebig erwiesen, die expliziten Praktiken im Internet zu

\footnotetext{
${ }^{1079}$ Vgl. „Shared Reading“, Literaturhaus Frankfurt. URL: literaturhaus-frankfurt.de/programm/sharedreading/ (Stand: 30.08.2018).

1080 Das Programm ist auf dem Blog von Thomas Hettche www.hettche.de einsehbar. Dort sind seine Aktivitäten gesammelt und dort können die genannten Veranstaltungen zum Teil angehört werden. 1999 initiierte Hettche mit NULL eine der ersten Onlineanthologien deutschsprachiger Gegenwartsliteratur im Internet, das später als gedrucktes Buch erschien. Zu bedenken ist für die korrekte Einordnung, dass Rainald Goetz' Netztagebuch Abfall für Alle bereits 1998 als Buch erschien, er also sehr früh den Blog literarisch nutzte.

${ }^{1081} \mathrm{Zu}$ Gast waren unter anderem der Philosoph Peter Sloterdijk (*1947), der Hirnforscher Detlef B. Linke (1945-2005) sowie der Literaturwissenschaftler und Medientheoretiker Friedrich Kittler (1943-2011). Dass Kittler sowohl bei Buchmaschinen in Frankfurt als auch in dieser Reihe sprach, unterstreicht seine zentrale Rolle in der deutschen medientheoretischen Auseinandersetzung.
} 
begutachten. Der professionelle Werktag ist geprägt von digitalen Mitteln und Methoden, diese sind jedoch so integriert, dass sie nicht mehr als etwas Besonderes auffallen. Allen Beteiligten ist geläufig, dass es - natürlich - einen Internetauftritt gibt und ein Großteil der Kommunikation über E-Mail läuft. In den 1990er- und frühen 2000er-Jahren wurden diese Praktiken im Alltag noch stärker reflektiert. Dieser Exkurs zur Webpräsenz der untersuchten Literaturhäuser arbeitete heraus, dass die Institution Literaturhaus seit etwa 2000 online vertreten ist. Die danach gegründeten Literaturhäuser nutzen seit ihrer Eröffnung eine Website und nach und nach eigneten sich die Einrichtungen zudem Social-Media-Praktiken an. Insgesamt verhalten sie sich nicht besonders innovativ hinsichtlich der Darstellungsformen, doch sie stellen durchdachte Internetauftritte bereit, obgleich sich hinsichtlich des spezifischen Onlinemarketings vieles optimieren ließe. ${ }^{1082}$ Es lässt sich folglich nicht feststellen, dass die Literaturhäuser den sich während ihrer eigenen Genese entwickelnden neuen Arbeitsinstrumenten ablehnend oder besonders kritisch gegenüberstehen würden.

\section{Sichtbarkeit durch Programmheft und Onlineauftritt}

Die skandinavischen Literaturhäuser, insbesondere Oslo und Bergen, nutzen die Website nicht grundlegend anders als die deutschen Einrichtungen, doch zeigte sich, dass sie mit ihrem Start (2007 beziehungsweise 2013) Webauftritt und Druckprodukte bereits besser aufeinander abstimmen konnten und sie zu ihrer Anfangszeit modisch aktuellere Internetseiten unterhielten als die anderen Fallbeispiele. Die Webnutzung ist dort zu dieser Zeit bereits alltäglicher als in Deutschland. Es ist jedoch zu bedenken, dass die beiden norwegischen Einrichtungen erst mit ihrer Arbeit begannen, als die deutschen Fallbeispiele schon lange - auch online - präsent waren. Das digitale Konzept erscheint dort von Anfang an stärker ausgearbeitet gewesen zu sein, wie zum Beispiel die Podcasts vorführen oder die Planung, dass beide ihre Newsletter mit einem Überblick über die Veranstaltungen der Woche jeden Montagvormittag um zehn Uhr verschicken, womit für die Abonnent*innen eine Verlässlichkeit entsteht. Vieles spricht dafür, dass das Bergener Literaturhaus sich dabei an dem Osloer orientierte. Die anderen Literaturhäuser versenden ihre elektronischen Rundschreiben zwar ebenfalls in ungefähr gleichen Abständen, hingegen nicht so exakt regelmäßig. Außerdem nutzen die Literaturhäuser Oslo und Bergen die Social-Media-Kanäle intensiver, was sich vor allem an den hohen Follower-Zahlen gezeigt hat. Die Technikaffinität ist in Skandinavien tendenziell höher als in Deutschland, die gesellschaftliche digitale Praxis zeigt sich etwa anhand der weiten Verbreitung immer neuer technischer Geräte. ${ }^{1083}$ So ist es nicht verwunder-

\footnotetext{
1082 Optimieren ließen sich die Sites etwa hinsichtlich der Textgestaltung und der Integration von multimedialen Beiträgen, die z. B. Simon A. Frank beschreibt, vgl. Frank 2011, S. 564.

1083 Vgl. z. B. Fiell und Fiell 2015, S. 464. Die skandinavischen Länder habe ab 1981 das erste gemeinsame Mobilnetz der Welt, das Nordic Mobile Telephone verbunden. Das finnische Unternehmen Nokia habe lange Zeit für die Verbindung von skandinavischem Design und technischer Innovation gestanden. Unter anderem daraus erklärt sich die fortbestehende Affinität für neue technische Devices in Skandinavien. Das schwedische Unternehmen Ericsson ist ebenfalls weltweiter Akteur der Kommunikationsbranche. Es war auch ein schwedisches Start-up, das 2006 den inzwischen global agierende Streamingdienst Spotify gründete.
} 
lich, dass mehr Skandinavier die dortigen Kultureinrichtungen mit ,Gefällt mir markieren.

„Internet-Marketing ist gerade bei Kultureinrichtungen nicht als losgelöste Aufgabe oder Funktion zu sehen, sondern muss als ein Instrument innerhalb des MarketingManagement-Prozesses [...] und der Öffentlichkeitsarbeit [...] verstanden wer-

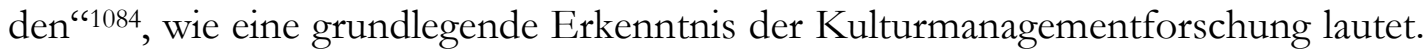
Für die Analyse des Literaturhauses in dieser speziellen Medienumbruchszeit ist es dabei besonders aufschlussreich, dass die Literaturhäuser ihre Programmhefte nicht zugunsten des Onlineauftrittes verwerfen. Das Gegenteil ist der Fall: Wie die Neugestaltung im Literaturhaus Berlin sowie der Transfer des Literaturhaus-Konzeptes nach Norwegen zeigen, ist das Programmheft als wichtiges Element der Institution aufzufassen. In Norwegen schreiben die Einrichtungen der gedruckten Broschüre eher noch eine höhere Bedeutung zu. Die Synonymsetzung von Druckprodukt und Veranstaltungsprogramm offenbart sich etwa daran, dass Litteraturbuset $i$ Bergen zum Erscheinen des neuen Quartalsprogrammes ein Slippfest [Veröffentlichungsfest] veranstaltet, bei dem das Publikum eingeladen ist, mitzufeiern und sich über die nächsten Monate im Literaturhaus zu informieren. Damit geht einher, dass die Ankündigungen zeitgleich als Heft und online erscheinen, die Termine also nicht deutlich früher online sind, sondern gebündelt präsentiert werden.

Litteraturbuset in Oslo behandelt die Programmhefte geradezu wie eigene Bücher. Erstens haben die Produkte eine Klebebindung und deshalb einen Buchrücken, was realisierbar ist, weil das Programm so umfangreich ist. Zweitens begreift Litteraturhuset seine Broschüren nicht nur als Werbeprodukte mit begrenzter Geltungsdauer, sondern der erste Leiter Aslak Syra Myhre betonte, dass das Programmheft - „som du sjølvsagt samlar på“ (OL 2008-08, S. 10) [das du natürlich sammelst] - einen breiten Überblick über die norwegische Literaturlandschaft biete. Er legt nahe, die Hefte zu sammeln und damit ein Stück norwegischer Literaturgeschichte zu archivieren. Dies verweist zudem zurück auf die vorher beschriebenen Funktionen der Programmhefte als zeitgeschichtliche Dokumente. Und es bestätigt die Annahme, das Literaturhaus als zentrale Einrichtung der Vermittlung und Speicherung von Gegenwartsliteratur zu verstehen. Darin steckt aber auch, dass das Literaturhaus annimmt, dass Leser*innen Bücher sammeln. Aus diesem Grund lässt sich vermuten, dass sie der technischen Beschaffenheit des Produktes Buch Wert beimessen. Drittens verbreitet das Team das Heft nicht nur analog, sondern als PDF-Version über die Veröffentlichungsplattform issun ${ }^{1085}$ ergänzend digital. Auf dieser Seite können Publikationen hochgeladen und von Leser*innen kostenlos und ohne Anmeldung ,durchblättert' ${ }^{\varsigma}$ und bei Registrierung heruntergeladen und abonniert werden. Einige Verlage verwenden diesen Dienst ebenfalls, um Leseproben aus Büchern anzubieten. Diese Internetdistribution des norwegischen Literaturhauses ist gleichermaßen ein Argument für seine intensive Nutzung von Onlinewegen wie für die Bedeutung des zugrunde liegenden Printproduktes. Wie bei E-Books, die neben gedruckten Ausgaben erscheinen, wählen die Leser*innen das Publikationsformat

${ }^{1084}$ Frank 2011, S. 560-561.

1085 Vgl. „Publications“, Litteraturhuset via Issuu. 
aus, das am besten zu ihren Lesegewohnheiten und Rezeptionsbedürfnissen passt. Das E-Programmheft ist außerdem weltweit verfügbar, sodass auch eine Leserin in Deutschland die Broschüren jederzeit ansehen kann, was etwa für die vorliegende Arbeit eine Erleichterung darstellte. Trotzdem existiert dieses digitale Produkt nur, weil es auf Druckdaten basiert und diese als Datei transferiert werden. Die Veranstaltungsinformationen des norwegischen Literaturhauses sind als gedrucktes Heft, als online blätterbares PDF, integriert in die Website und auf der Facebook-Seite erhältlich.

Früher war das Programmheft in seiner physischen Distribution das einzige Werbemittel der Literaturhäuser, jetzt koexistiert es neben den im Internet verbreiteten Möglichkeiten. Der Onlineauftritt ist notwendiges Instrument, aber ersetzt die gedruckten Produkte nicht, sondern erweitert den Kommunikationsraum. Für den Zeitraum seit 1986 müssen zugleich die Auswirkungen der Digitalisierung auf Druckverfahren und Informationswege generell Berücksichtigung finden. Das lässt sich anhand der Druckprodukte der Literaturhäuser veranschaulichen. Matthias Beilein beispielsweise hat darauf hingewiesen, dass Druckvorlagen und Druckvorgänge „heute fast ausschließlich in einem überwiegend digitalen Arbeitsablauf“1086 abgewickelt werden. Ab 1992 setzt sich das sogenannte Desktop-Publishing nach und nach durch:1087 Mit Software zum Setzen von Text mit grafischen Funktionen wie Quark.XPress (Quark Inc., seit 1987) und das heute meist genutzte Adobe InDesign (Apple, seit 1999) können Druckdaten digital erstellt werden. Diese werden direkt an die Druckereien weitergegeben. Obgleich weiterhin meist im Offsetdruckverfahren und nicht im Digitaldruck gedruckt wird, erfolgt die Belichtung der Druckplatten zunehmend digital. Vor allem bei den Druckvorstufen hat die Digitalisierung Publikationsvorgänge zum einen vereinfacht und beschleunigt, zum anderen vergünstigt. Die in diesem Zuge entstehenden Onlinedruckereien ermöglichen außerdem zusätzliche Druckprodukte zu einem relativ niedrigen Preis. Die technischen Fortschritte hinsichtlich der Druckverfahren ließen die Hefte farbiger und aufwendiger werden.

Das Programmheft lässt sich verstehen ,als Endprodukt einer Vielzahl von Entscheidungen“"1088, als Arbeitsprodukt der Einrichtung. An ihm lässt sich grundsätzlich erkennen, dass die langfristige Planung erst durch Akzeleration aufgrund schneller E-Mail-Korrespondenz und zum Beispiel wegen des Versandes von Druckfahnen und Vorab-Leseexemplaren als PDF per E-Mail und größerer Datenmengen etwa Autorenfotos per Transfersoftware realisierbar ist. Vergleichbares gilt etwa für Verlagsvorschauen, die umfangreich und aufwendig gestaltet versendet werden und damit zur Steigerung der Marketingaktivitäten der Verlage beitragen.

Es ist folglich nicht zu unterschätzen, dass die Druckprodukte erst durch digitale Fertigungsmechanismen in der Aufmachung aufwendiger und gleichzeitig relativ kostengünstig hergestellt werden können. Es entstehen dadurch selbstverständlich dennoch Kosten. Obwohl Produktions- und Distributionskosten bei Verzicht auf Papierprodukte folglich drastisch reduziert werden könnten - und das Thema Fi-

\footnotetext{
1086 Beilein 2013, S. 585.

1087 Vgl. „Desktop-Publishing“, Wikipedia.

1088 Nolda 2003, S. 212.
} 
nanzierbarkeit ist, wie betont, in der Institution virulent -, halten die Einrichtungen an gedruckten Programmheften fest. Ebenso spielt der Aspekt ökologischer Nachhaltigkeit dabei offenbar eine untergeordnete Rolle, denn die Herstellung dieser aufwendigen Hefte verbraucht Papier und - wie jede Industrie - Energie. ${ }^{1089}$ Programmhefte sind, trotz der anderen dauerhaft wirksamen Funktionen, eindeutig Wegwerfprodukte. Ohne an dieser Stelle weiter auf die Frage nach umweltbewussten Aspekten einzugehen, ist dies ein empirischer Beleg für die These, dass ,digital ,analog' nicht verdrängt, und sich sogenannte materielle und immaterielle Räume überlagern. ${ }^{1090}$ „Die virtuellen und realen Kommunikationsräume konkurrieren nicht miteinander, sondern scheinen sich produktiv zu ergänzen." ${ }^{1091}$ Es lässt sich interpretieren als ein Beispiel für das Nebeneinander von gedrucktem und elektronisch verfügbarem Programmheft, also von im Endprodukt einmal analogem und einmal digitalem Produkt, das sich auf das Produkt Buch übertragen lässt und somit die Hypothese, dass E-Books gedruckte Bücher nicht verdrängen, unterstützt. Daraus lässt sich schließen, dass mit zunehmender Digitalisierung - verstanden als Agglomerat verschiedener Gesichtspunkte, darunter die Ausweitung des Internets, dessen Nutzung durch Vertreter*innen aller Altersgruppen sowie die zugänglicher und günstiger werdenden Druck- und Herstellungsverfahren - das ,Analoge ${ }^{6}$ und „Haptische ${ }^{6}$ besondere Bedeutung erlangt und deshalb nicht einfach ersetzt wird.

Zahlreiche gegenwärtige kulturwissenschaftliche Forschungsarbeiten stellen heraus, dass die Materialität von Kunstwerken bei Rezipient*innen an Bedeutung gewonnen habe. So zeigt zum Beispiel Alexander Starre, dass in der amerikanischen Gegenwartsliteratur Autor*innen sich nicht nur theoretisch-diskursiv, sondern mit „material interventions“1092 mit Materialitätsfragen auseinandersetzten: Mark Z. Danielewskis House of Leaves oder Jonathan Safran Foers Tree of Codes beziehen die Materialität des Mediums in ihre Erzählweise mit ein. Es seien Bücher, die extra für das Medium des gedruckten Buches gemacht seien. ${ }^{1093}$ Die Tendenz, die sich in der Musikindustrie mit einer Verdrängung der CD zugunsten digitaler Formate auf der einen Seite und einer Zunahme aufwendiger Vinylausgaben auf der anderen Seite abzeichnet, wurde für den Buchmarkt ebenfalls schon vermutet: E-Books konkurrieren mit günstig produzierten Taschenbüchern neben opulent gestalteten Druckausgaben. ${ }^{1094}$ Zugleich unterstützt dies die These von Passig und Scholz: „Unsere Umgebung ist weder digital noch analog. [...] Analoges und Digitales existiert in Menschen und Geräten gleichzeitig, je nachdem, wie genau man auf welcher Ebene hinschaut.“"1095 Da fügt sich die Beobachtung von Andre Wilkens ein, dass besonders durch die Produkte des Herstellers Apple „Digital auch zum Anfassen schön“"1096 wurde, dass also die Haptik und das Design von digitalen Medienträgern sich ästhetischen Maßstäben anglich.

\footnotetext{
${ }^{1089}$ Fraglich bleibt gleichzeitig, ob eine verstärkte Nutzung digitaler Mittel langfristig nachhaltiger ist als Druckdistribution, denn der Energieverbrauch von Servern ist immens.

1090 Vgl. z. B. Dander et al. 2013, S. 10, 13.

1091 Schaff 2013, S. 284.

1092 Starre 2015, S. 24.

1093 Vgl. ebd., S. 23-24.

1094 Vgl. z. B. Tschopp 2017, S. 290.

1095 Passig und Scholz 2015, S. 80.

1096 Wilkens 2015, S. 15. Vgl. auch Kapitel I 5.7.
} 
Für den Nicht-Verzicht auf die routinierten Wege der Offlineausteilung der Literaturhaus-Programme sind weitere damit verknüpfte Motive denkbar: Eines ist die Annahme, dass das Literaturhaus-Publikum tendenziell ,papieraffin' ist und dementsprechend ein Programm als Printprodukt schätzt. Die Beobachtung, dass bei den Veranstaltungen die Buchhändler*innen eigentlich nur gedruckte Bücher anbieten, spricht beispielsweise dafür. ${ }^{1097}$ Außerdem sind die Hefte in den deutschen Einrichtungen als Kommunikationsorgan etabliert. So lassen sich die Druckprodukte als Instrument der Besucherbindung interpretieren. ${ }^{1098}$

Dies erklärt aber noch nicht, warum auch von den jüngeren norwegischen Literaturhäusern Programme gedruckt distribuiert werden. Ein Grund dafür kann neben der erwähnten Sammlungsidee die generelle Notwendigkeit sein, online und offline sichtbar zu sein. In Cafés oder Kultureinrichtungen sowie im Literaturhaus selbst dienen die Hefte der Präsentation des Veranstalters. Damit sind sie an der Seite von Programmwerbung beispielsweise von Theatern, Museen oder anderen Literaturvermittlern auffindbar. Dazu gehört, dass gedruckte Programme, die an unterschiedlichen Orten ausliegen, gegebenenfalls neue Kund*innen ansprechen. Ein Druckprodukt kann einer Person buchstäblich ,in die Hände geraten'. Ebenso wie Plakate in der Stadt Passant*innen zufällig ins Auge fallen, entdecken sie das Programm der Literaturhäuser - sofern sie es als ansprechend einordnen. Der Besuch der Website hingegen kann zwar über Suchmaschinenergebnisse ebenso zufällig geschehen, doch steuern die User*innen in der Regel den Onlineauftritt absichtlich an - es besteht also bereits ein erster Zugang zur jeweiligen Einrichtung. Die Internetaktivitäten müssten deshalb so konzipiert sein, dass Zuschauer*innen eventuell zunächst ,versehentlich ${ }^{`} \mathrm{zu}$ den Webpräsenzen gelangen. Online befindet sich das einzelne Literaturhaus nicht grundsätzlich in kultureller Umgebung, das Nebeneinander in einem Prospektständer markiert die kulturelle Zugehörigkeit deutlicher. Außerdem kann das Programmheft einer Person, in die Hand gegeben', also im persönlichen Kontakt als Gabe überreicht werden. Das ist ein Akt, der eindrücklicher wirkt als ein Link oder ein verbaler Verweis auf den Webauftritt. Vor Ort ist es schlicht die naheliegendste Werbeaktion. Ohne die Präsenz online und offline gegeneinander abwägen zu wollen, ist festzuhalten, dass es für die Literaturhäuser wichtig ist, sowohl im Internet als auch in der kulturellen Landschaft der eigenen Stadt verortet zu sein. Es ist also bedeutend, für Veranstaltungen mit physisch anwesenden Bühnenakteur*innen und Publikumsgästen nicht nur online, sondern weiterhin analog, also stufenlos, face-to-face, präsent zu sein. Ein Flyer in der Tasche oder auf dem Küchentisch ruft die angekündigte Veranstaltung direkt in Erinnerung. ${ }^{1099}$ Eine ,analoge' Veranstaltung wird auch ,analog' beworben. Doch gleichzeitig ist es wichtig, anderen Rezeptionsweisen und Alltagspraktiken Rechnung zu tragen und etwa anzubieten, die Veranstaltungsagenda online in den elektronischen Kalender übertragen zu können.

\footnotetext{
1097 Hier knüpfen Überlegungen zur Sichtbarkeit von E-Books in Verkaufssituationen an. Ein E-Book lässt sich außerdem nur schwerlich von Autor*innen signieren, was jedoch ein ebenfalls wichtiges Moment des Live-Erlebnisses ist.

1098 Zur Besucherorientierung und -bindung im Kulturbetrieb vgl. Klein 2003.

1099 Ebenso wie etwa ein SuB - Stapel ungelesener Bücher, ein Ausdruck, der vor allem in Literaturforen und auf Buchblogs verwendet wird - als Metapher verbildlicht, dass die aufgetürmten Bücher die Leser*innen an Lektüreabsichten gemahnen.
} 
Die Distribution der Programmhefte hat natürlich entscheidende Auswirkungen auf die Sichtbarkeit des Literaturhauses in der Stadt. Ohne im Detail diese Aussendungsstrukturen zu untersuchen, lassen sich allein beim Vergleich der Berliner und der Hamburger Einrichtung große Unterschiede notieren. Während das Literaturhaus Berlin sein Programm nur postalisch an circa 1.000 Adressen verschickt und im Haus auslegt, 1100 verteilt das Literaturbaus Hamburg seines mit einer Auflage von 20.000 nicht nur an Vereinsmitglieder, sondern gibt es über Flyer-Auslagestellen in der Stadt heraus und erreicht damit potenziell eine größere Menschenmenge. Die Osloer Broschüren liegen in den Tanum Buchhandlungen in der Stadt, in den Filialen der Stadtbibliothek sowie natürlich im Litteraturhuset selbst aus. Neben den regelmäßigen Monats- beziehungsweise Quartalsprogrammbroschüren geben alle untersuchten Literaturhäuser gelegentlich zusätzliche Drucksachen heraus. Bei größeren Veranstaltungen, Reihen oder Festivals lohnt es sich für die Literaturhäuser manchmal, Extraplakate und Flyer zu designen, zu drucken und zu verteilen. Aus Kostengründen und weil es sich bei der monatlichen Veranstaltungszahl anbietet, das vollständige Angebot anzukündigen, verzichten sie in der Regel auf die zusätzliche Bewerbung mit Flyern oder Plakaten von Einzelveranstaltungen, die schon im Gesamtprogramm erwähnt sind. Da im Literaturhaus die meisten Veranstaltungen einmalig sind, liegt es nahe, dass eher das Gesamtprogramm als die einzelne Veranstaltung, die, anders als im Theater, tatsächlich nur einmal stattfindet, beworben wird. ${ }^{1101}$ In Hamburg finden sich an einigen Stellen in der Stadt monatliche Übersichtsplakate, die mit den Broschüren verteilt werden. Lediglich in Göttingen hängen DIN A3-Plakate zur nächsten Veranstaltung in der Stadt, wie erwähnt etwa in der Bahnhofsvorhalle und an einigen Litfaßsäulen. Zudem lassen sich die Göttinger Leporellos so aufhängen, dass eine Hälfte des Angebots sichtbar ist. Das Literarische Zentrum Göttingen führt aber im Vergleich zu den anderen deutschen Literaturhäusern im Schnitt weniger Veranstaltungen durch.

Zur Ausgangsfrage, wie sich die Herstellung von virtuellem und analogem Raum unterscheidet und ob eine Verbindung zwischen den ,beiden Sphären` entsteht, lässt sich demnach sagen, dass die Onlinepräsentation bisher vorrangig der Informationsvermittlung respektive Werbung dient. Der virtuelle Raum präsentiert - im Sinne von vorführen - hier eher das Programm des physischen Ortes, als dass sich dort ein eigener Literaturvermittlungsraum bildet. Eine visuelle Identifikation von Webauftritt und Literaturhaus-Gebäude ist, wie dargelegt, am ehesten im Literaturhaus Frankfurt gegeben. Die anderen Einrichtungen binden das Design stärker an die Optik der Programmbroschüren zurück. Dies ist ein weiteres Argument dafür, dass sich das Literaturhaus als Raum vor allem über sein Programmangebot definiert und erst nachgelagert über die Wirkung des Gebäudes. Die Websites haben somit den Programmheften vergleichbare Funktionen. Dies erklärt die ähnliche Gestaltung dieser Publikationsmittel.

\footnotetext{
1100 Diese Information hat mir die Mitarbeiterin Sabine Büdel im Gespräch im Literaturbaus Berlin am 01.11.2014 gegeben. Ob es mit den neuen Leiterinnen weiterhin so ist, wäre zu prüfen. ${ }^{1101}$ Die Abgrenzung zu den Aufführungen im Theater gilt natürlich nur, wenn ausnahmsweise Aufführungs- und Inszenierungsforschung unter dem Stichwort ,Performanz ${ }^{\prime}$ ausgeblendet werden. Für die Ansprache des Publikums betont das Theater die Einmaligkeit jeder Aufführung schließlich auch nicht und allein darum geht es mir hier.
} 


\section{Live-Veranstaltungen vor Ort}

Ein Basisinteresse der vorliegenden Arbeit ist es, zu klären, wie sich das Literaturhaus im Zeitalter der Digitalisierung entwickelt. Es ist ein Beispiel dafür, dass Analoges, id est haptisch Erfassbares, Bedeutung behält. Innerhalb der Institution zeigt dies sich etwa daran, dass die Druckprodukte eben nicht ersetzt werden, sondern ein zentrales Instrument der Einrichtungen sind und bleiben. Des Weiteren sind die Existenz von Literaturhäusern mit ihrer aktuellen Hauptfunktion - Literaturveranstaltungen vor Ort - und ihr Boom grundlegende Argumente dafür, dass die neuen Möglichkeiten der Literaturvermittlung nicht zwangsläufig in ein nur digital rezipierbares Produkt münden. Wie oben gezeigt, gibt es bis dato kaum Angebote zur Literaturvermittlung exklusiv auf den Websites oder anderen internetbasierten Strukturen. Die Vermittlungsarbeit konzentriert sich also auf zeitlich und örtlich verankerte Angebote. Ausnahmen liegen vor und werden mit der Zeit vermutlich zahlreicher werden. Zwar sind die Angebote der Literaturhäuser durch elektronisch transportierende Instrumente leichter umzusetzen - und sie ermöglichen beispielsweise Übertragungen in einen zweiten Raum im Haus, wenn der Veranstaltungssaal ausverkauft ist, wie es im Litteraturhuset in Oslo regelmäßig geschieht -, doch sind sie im Endeffekt nur unmittelbar und live konsumierbar. Und genau dies macht ihren Erfolg aus, denn sie sind ein Beleg dafür, dass seitens des Publikums ein Interesse an lokal fixierten Veranstaltungen besteht. ${ }^{1102}$ Christina Weiss äußerte in ihrer Funktion als Kultursenatorin in Hamburg bereits 1999 diese Vermutung: „Das Bedürfnis nach der leibhaftigen Auseinandersetzung eigener Verhaltens-, Präsentations- und Denkformen im realen Raum der Städte könnte durch die Virtualität der Begegnungen im Internet eher wachsen. “1103 Sie sah darin eine Chance und Notwendigkeit für die kulturpolitische Richtung, wie der Titel ihres Buches Stadt ist Bühne illustriert. Das Literaturhaus ist exemplarisch dafür, dass das präsente Erleben im Zeitalter der Digitalisierung zu einer wichtigen gesellschaftlichen Komponente wird - gerade im Kontrast zur gleichzeitigen Verlagerung vieler Alltagspraktiken ins Digitale.

Es bleibt abzuwarten, ob sich zum Beispiel mit einem vermehrten Upload von Audiodateien die Funktion des Literaturhauses hin zu einer Art Radiostation, zu einer Tonbibliothek verschiebt. Gegebenenfalls eröffnet sich mit der Bereitstellung eine erweiterte Zuhörerschaft, weil etwa diejenigen angesprochen werden, die den heutigen festen Rahmen ablehnen, aber an den Inhalten interessiert sind; die Rentabilität müsste dabei überprüft werden. ${ }^{1104}$ Doch selbst die Podcasts gehen von den LiveErlebnissen vor Ort aus, archivieren diese und machen sie in alternativem Kontext

\footnotetext{
1102 Dieser Aspekt wurde in den Kapiteln I 5.6 und I 5.7 bereits ausführlich behandelt.

1103 Weiss 1999, S. 17.

$1104 \mathrm{Zu}$ bedenken ist in diesem Kontext, dass bisher die Podcasts kostenlos zur Verfügung gestellt werden. Kostenlos ist das Hochladen im Internet jedoch für die Einrichtungen nicht. Abgesehen von Personalkosten muss für den ebenso nicht unbegrenzt zur Verfügung stehenden Speicherplatz aufgekommen werden. Außerdem ignoriert dies die grundsätzliche Debatte, ob der Wert kultureller Güter sinkt, wenn sie kostenfrei angeboten werden, die Verlage und Musikverwerter*innen sowie Zeitungen, also die Akteur*innen, die genuin Inhalte auf analogen Medienträgern gegen Bezahlung anbieten und seit ihrer digitalen Teilhabe um ihre Einnahmen bangen, stetig beschäftigt. Wie schon im ersten Kapitel beschrieben, sind die Literaturhäuser das Kapital betreffend auf Publikum vor Ort angewiesen, aus finanziellen Gründen auf die Eintrittseinnahmen, sowie hinsichtlich des kulturellen, sozialen und symbolischen Kapitals auf die Anerkennung als Institution.
} 
wiederabrufbar. Voraussetzung bleibt die einzelne Veranstaltung. Diese Zweitverwertung ist also eine andere Art der Literaturmediation als genuin digitale Literaturvermittlung wie Chatrooms mit Autor*innen und originär für die Internetverbreitung hergestellte Erzeugnisse; dazu zählt das erwähnte Experiment des Literarischen Zentrums Göttingen, Märchen zu twittern.

Es ist denkbar, dass die Literaturhäuser einen digitalen Raum für Literaturvermittlung jenseits der Veranstaltungen, die im Literaturhaus stattfinden, entwickeln. Ein weiterer Ansatz in dieser Richtung war beispielsweise das Projekt des Netzwerkes der Literaturbäuser 2016/2017 Fragile - Europäische Korrespondenz̨en, bei dem 28 europäische Autor*innen sich jeweils in Paaren zum Thema Europa austauschten und die Projektleitung diese Texte zunächst auf dem Blog fragil-europe.net veröffentlichte. Erstaunlich wirkt es jedoch in diesem Kontext, dass das Projekt vorsah, dass sich die Teilnehmenden Briefe, ausdrücklich Papierbriefe, schreiben sollten, die erst digital online und später auszugsweise als Buch erschienen. Die Blogpublikation macht die komplette Korrespondenz öffentlich, das Buch selektiert, bildet aber eine weiterhin wichtige Veröffentlichungsform.

Solche Ansätze finden sich in den Literaturhäusern relativ wenig. Hauptaufgabe bleiben die ,typischen' Veranstaltungen vor Ort. Durch Tonaufnahmen oder fotografische Dokumentationen von Veranstaltungen werden Aspekte in den Onlineauftritt integriert, die für das Literaturhaus neu, insgesamt aber wenig innovativ sind. Die Institution nimmt ebenso wie mit ihren Social-Media-Aktivitäten teil an den medialen Entwicklungen, prägt diese aber nicht entscheidend mit. Das Literaturhaus setzt sich dem ,digitalen Fortschritt' nicht entgegen. Dies ist, um nicht zu veralten, im Sinne der Institution zum Selbsterhalt ebenso wichtig wie das Festhalten an seinen genuinen Funktionen. Weil das Literaturhaus als Institution in Wandlungsprozessen tendenziell träge ist, ist es nicht verwunderlich, dass in diesem Bereich bisher wenig ausprobiert wurde. $\mathrm{Ob}$ dies mit absichtlicher Absage passierte oder es den Teams bisher nicht in den Sinn kam, lässt sich aus der Beobachterperspektive nicht abschließend beantworten. Bis dato wurde dafür offenbar kein dringender Bedarf gesehen, was wiederum sehr dafür spricht, dass die momentanen Funktionen des Literaturhauses nicht grundsätzlich infrage stehen, sondern gerade ein entscheidendes Charakteristikum der Institution sind.

\section{Direkte Begegnung und Partizipation}

Durch Audiomitschnitte wäre eine Verknüpfung zwischen Vor-Ort-Geschehen und Onlinepräsentation herstellbar, doch ist bei den Literaturhäusern bisher online die Möglichkeit zur Interaktion, zur Einflussnahme auf den Verlauf der Veranstaltung, ausgespart. Die Teilhabe ist aktuell auf den Veranstaltungsort des Literaturhauses beschränkt, Partizipation ist nur für Anwesende beim ,Event erreichbar. Unter Berücksichtigung der von Henry Jenkins beschriebenen „Participatory Culture“ ${ }^{\text {"1105, }}$, in der - inzwischen maßgeblich durch Mittel, die das Internet ermöglicht - Leser*innen zu produktiven Beiträger*innen werden, mit Gleichgesinnten diskutieren und in direkten Kontakt mit Autor*innen und deren Texten treten können, wirkt dies zu-

1105 Jenkins 2006b. 
nächst paradox. So ist für das Publikum im Literaturhaus die Option auf ein Gespräch mit den Bühnengästen zwar gegeben - allerdings gerade nur im unvermittelten Aufeinandertreffen, nicht online. Geteilt wird das Gehörte in erster Linie mit den ebenfalls Anwesenden, aber nicht in einem aktiven Prozess, sondern durch die gleichzeitige Erfahrung im Raum.

Diese Fokussierung auf die ,analoge‘ Begegnung lässt sich ihrerseits sehr wohl als Teil der Participatory Culture auffassen. Vermutlich beeinflusst die durch die digitalen Kommunikationswege angeregte Neugier auf die ,Autor*innen hinter den Büchern' das Gefallen daran, die Autorenpersona leibhaftig erleben und sich ganz auf dieses eine Gespräch fokussieren zu können. Auf Websites, über Social-MediaProfile und in Leserunden - etwa auf der Plattform lovelybooks - entstehen Möglichkeiten für Leser*innen, persönlich Kontakt zu Autor*innen aufzunehmen. Diese vermeintliche Nahbarkeit des Autors, korrekt der Autorenfigur, führt mit dazu, dass verstärktes Interesse an den schreibenden Personen und nicht nur an ihren literarischen Produkten besteht. Für die Autor*innen wird die Selbstdarstellung als Person durch „unterschiedliche Realisierungen der Autorinszenierung im Internet “1106 noch stärker zum Bestandteil ihrer schriftstellerischen Arbeit, „[d]enn Schriftsteller, und das gilt vor allem für jene mit Kanonanspruch, wollen nicht nur Werke in die Welt setzen, die vom Publikum gelesen werden, sie wollen vielmehr als Person dauerhaft in der Vorstellung ihrer Leser gegenwärtig sein. “1107 Analog dazu gewinnt die Inszenierung auf Veranstaltungsbühnen an Relevanz.

Gleichzeitig lässt sich überlegen, ob die existierende Zuschreibung, dass die Literaturvermittlung im Literaturhaus nicht innovativ sei, ${ }^{1108}$ daher rührt, dass die Veranstaltungen zu wenig Teil der Participatory Culture sind; zu allererst, weil das Geschehen auf den Ort des Literaturhauses beschränkt ist; und zusätzlich, da die Scheinwerfer auf die Sprechenden auf der Bühne gerichtet sind. Die Literaturveranstaltung kann eher als eine vom Publikum abgegrenzte Darbietung aufgefasst werden, bei der erst danach Raum für Diskussion besteht. Die LiteraturhausVeranstaltungen sind also eine Mischung aus Aufführung für ein Publikum und Debatte mit einem Publikum.

Hinzu kommt, dass die Zuschauer*innen ihre Zugehörigkeit mit ihrer sichtbaren, nicht-anonymen Teilnahme vor Ort deutlicher markieren können als in einer Onlinecommunity. Der Aspekt der Exklusivität spielt im Literaturhaus allein deshalb eine Rolle, weil die Plätze im Saal de facto begrenzt sind. ${ }^{1109}$ Außerdem liegt es für

\footnotetext{
1106 Paulsen 2007, S. 258.

1107 Schöttker 2002, S. 277. Dies gilt bereits seit Autor und Werk überhaupt miteinander verbunden sind, also etwa seit der Genieästhetik aus dem Sturm und Drang.

1108 Vgl. z. B. die sogenannte Wasserglasdebatte, vgl. FN 558.

1109 Tobias Christ äußert sich zum Thema Exklusivität in Zeiten von Massenkommunikation: „Konnte um 1800 noch ein vergleichsweise großer Teil des kleinen, sozial relativ homogenen Publikums im Rahmen einer bürgerlichen Öffentlichkeit und Geselligkeitskultur in Zirkeln und Salons oder über Briefkorrespondenzen und Zeitschriften an symmetrischen Formen der Autor-Rezipient-Kommunikation teilnehmen, so kommt in unserer Zeit nur ein verschwindend geringer Teil des sozial sehr heterogenen Massenpublikums überhaupt in den Genuss des Austausches mit Autoren“, Christ 2017, S. 259. Obwohl, worauf Tobias Christ hinweist, vor allem Berufsleser*innen direkt mit den Autor*innen in Kontakt treten, ist die Chance, persönlich mit den Autor*innen sprechen zu können, bei einer Veranstaltung in relativ kleinem Rahmen im Literaturhaus tendenziell groß. Die These von Andre Wilkens - „Analog wird
} 
Publikumsgäste nahe, die Lesung als soziales Ereignis - jenseits der eigentlichen Literaturveranstaltung - zu feiern, beispielsweise als Anlass für ein Wiedersehen mit Bekannten. Diese soziale Funktion, die bereits auftauchte, als von der Gesamtkonzeption, der Ortsgestaltung und Selbstbeschreibung des Literaturhauses die Rede war, findet also ferner dadurch Begründung, dass die Literaturhäuser eindeutig auf die Veranstaltung vor Ort setzen und sie die Onlineauftritte selten als Organe zur Literaturvermittlung nutzen. Die gesellschaftlichen Veränderungen durch die digitalbasierten Medien prägen die Arbeit des Literaturhauses folglich stärker als deren konkrete Nutzung als Literaturvermittlungsinstrument.

\section{Autor*innen als Wortführer*innen und als Prominente}

Die in diesem Absatz geführte Diskussion über die Onlineaktivitäten und das Verhältnis zu gegenwärtigen gesellschaftlichen Rezeptionspraktiken leitet zurück zur Grundmotivation des Literaturhauses hinsichtlich der dortigen Akteur*innen. In der Gegenwart, in der es zunehmend schwieriger wird, eindeutig Position zu beziehen, ${ }^{1110}$ bietet das kuratierte Literaturhaus-Programm Orientierung an, wie diese Arbeit schon an mehreren Stellen zeigte. Seitens des Publikums besteht Interesse daran, zu erfahren, wie die Bühnengäste ihre eigenen Texten einschätzen, wie sie sich zur Literatur insgesamt verorten, wie sie ihre Text mit ihrer eigenen Lebensrealität verknüpft sehen, aber ebenso, wie sie sich hinsichtlich anderer sozial relevanter Themen positionieren, denn, wie später ausgeführt, finden sich diese Bereiche in den Programmen wieder. Die Autor*innen sollen unter anderem zur Urteilsfindung und Gegenwartseinordnung beitragen.

In diesem Kontext offenbart sich zudem, dass weniger der sogenannte Prosumer, die Verschmelzung von Produzent*in und Konsument*in, im Literaturhaus relevant ist, sondern weiterhin ein komplementäres Verständnis von Autor*in und Leser*in vorherrscht, das zwischen beiden trennt und dem Autor weiterhin Autorität beimisst. ${ }^{1111}$ Dieser Schluss schränkt somit die These ein, die Geert Lovink 1997 formulierte: „In fact, the intellectual as opinion leader is slowly losing ground“1112. Mit dem Literaturhaus etabliert sich ein Raum, in dem unter anderem Autor*innen sich zu ihrer Arbeit und daran anschließenden Themen äußern. Dies ist allerdings eine zweischneidige Diskussion: Einerseits herrscht in Deutschland die Annahme, dass

tendenziell teurer sein als digitale Massenproduktion“, Wilkens 2015, S. 125 - bezieht sich eigentlich auf die kostengünstigeren digitalen Produktionsprozesse, trotzdem lässt sie sich hier ebenfalls anbringen, denn die Organisation von Literaturveranstaltungen mit Kosten etwa für Reisen und Infrastruktur sind im Durchschnitt gewiss teurer als die Nutzung von Chatrooms.

${ }^{1110}$ Vgl. Lovink: „Portrait of“. Diese Beobachtung führt bei Lovink zu der Schlussfolgerung: „This again is drawing us deeper into a status of passive consumers, bored by the overkill of undistinguishable strains of infotainment.“ Sie führt aber, wie sich 20 Jahre später zeigt, zu dem Bedürfnis, an Sprecherrollen, ,the intellectual that is still living in the paper world", wie Lovink formuliert, festzuhalten.

1111 Für das Internet wurde eher eine Differenzierung dieser Autoritäten angenommen: „Ob der ,NetzIntellektuelle‘ eine gesamtgesellschaftliche Sprecherrolle, die über die Partialöffentlichkeiten von Diskussionsrunden auf dem Netz hinausgeht, überhaupt noch beansprucht und wie er sie wahrnehmen könnte, steht dahin. Das Projekt des Virtuellen Intellektuellen weist jedenfalls auf die mediengeschichtlichen Bedingungen und Wandlungen der Intellektuellenrolle“, Jäger: „Der Schriftsteller“, S. 26 mit Bezug auf Geert Lovink.

1112 Lovink: „Portrait of“. Auch wenn Aspekte seines Vortrags zu relativieren sind, fasst der Medienwissenschaftler Lovink darin Beobachtungen der Gegenwart des Jahres 1997 pointiert zusammen. 
es nach den in den 1960er- und 1970er-Jahren wichtigen Autoren wie Heinrich Böll, Günter Grass oder Martin Walser, die noch „wichtige Personen des öffentlichen Lebens, ja geradezu Wegweiser ethischen und politischen Verhaltens" ${ }^{\text {"1113 }}$ gewesen seien, kaum noch derartig wirkende Autor*innen gebe - „Wer erwartet heute noch ernsthaft von unseren Gegenwartsautoren Antwort auf drängende gesellschaftliche Fragen?“"1114 Andererseits lässt sich festhalten: „Autoren aber, deren Meinung kaum noch jemanden interessiert, muss man natürlich auch nicht bei einer Lesung persönlich erleben. "1115 Der Erfolg der Literaturhäuser zeigt somit, dass es Interesse geben muss, zu hören, was Autor*innen und Literaturexpert*innen zu sagen haben, schließlich baut darauf die Idee dieser Institution auf. Die angenommene Achtung der Äußerungen der geladenen Gäste lässt sich außerdem darin erkennen, dass die Literaturhäuser die Podiumsgespräche selten öffentlich nachbereiten, fortsetzen oder kritisch reflektieren, sondern diese im Moment der 90 Veranstaltungsminuten verweilen. ${ }^{1116}$ Somit steht die Veranstaltung und das Gesagte für sich. Dabei konzentriert sich die Aufmerksamkeit jedoch nicht auf wenige große Namen, sondern reflektiert eine Diversifizierung, die schon allein durch die relativ hohe Anzahl an Veranstaltungen zustande kommt. Der oder die eine Intellektuelle als „opinion leader“ mag darin wirklich an Boden verlieren, der Intellektuelle als Abstraktum erhält im Literaturhaus eine Bühne.

Diese suggerierte Abgeschlossenheit lässt sich ebenfalls hinsichtlich der vermittelten Literatur, die meist aus fertigen Büchern stammt, feststellen. Dies unterscheidet sich deutlich von dem, was Geert Lovink als ,virtuell‘ bezeichnet - „open, ever changing, in constant contact with other e-writers (and readers), no longer focussed on the closed, hermetic Magnus Opus that defined the ,Age of the Author"“1117. Wie deutlich geworden ist, behauptet die vorliegende Arbeit keine dichotomische Zuordnung $\mathrm{zu}$ entweder einem, virtuellen/digitalen' Bereich oder einem , analogen'. Somit ist nicht alles, was online passiert, per se fluide und nicht mehr am einzelnen Werk weder als einzigartiges Original noch als reproduzierbares Objekt - interessiert, ${ }^{1118}$ und im Literaturhaus kommt es im Kontrast dazu nicht nur auf das originäre Kunstwerk an. Es kommt zu Vermischungen. Durch die Literaturveranstaltungen im Literaturhaus fügen die Autor*innen ihren Werken hingegen stetig Epitexte hinzu, was zumindest diese als Werk erweitert und deren Rezeption zu lenken versucht. Die Autor*innen bleiben aufs Engste mit ihren Texten verbunden und ihr Auftritt inklusive ihrer Äußerungen zu Literatur und anderem erhält eine zentrale Bedeutung in der Außenwahrnehmung. Leser*innen fragen sich somit nicht mehr nur noch, ob sie diese Autorin oder jenen Autor schon gelesen haben, sie fragen sich auch, ob sie diese oder jenen bereits gesehen, gehört, erlebt haben. Autor*innen können Fans haben und als Personen verehrt werden, gleichzeitig können sie als Intellektuelle Wertschätzung und für ihre Arbeit Bewunderung erfahren. Die Status Celebrity und

\footnotetext{
1113 Reifsteck 2005, S. 9.

1114 Ebd.

1115 Ebd.

1116 Reihen und Festivals geben den Themenschwerpunkten zwar mehr Platz, finden jedoch maximal in Buchpublikationen oder anderen Aufzeichnungen ihren Nachhall.

1117 Lovink: „Portrait of“"

1118 Vgl. Gehlen 2013, S. 21.
} 
Intellectual bilden dabei Orientierungspunkte auf einem Kontinuum, keine Polaritäten.

\section{Literaturhaus als "begehbares Feuilleton"1119}

Es lässt sich hier zwar nicht empirisch belegen, dass ein gestiegenes Interesse des Publikums vorliegt, in direkten Kontakt mit den Künstler*innen zu treten, oder ein ₹unehmendes Bedürfnis besteht, das Erlebnis als Erinnerung festzuhalten, sich deshalb Bücher signieren zu lassen, Selfies mit dem Bühnengast zu erbitten oder das Programmheft mit nach Hause zu nehmen. Doch lässt sich konstatieren, dass es diese Nachfrage gibt - „der Autor/die Autorin (wieder einmal) als reiner Medieneffekt inszeniert"1120 reicht somit nicht aus. Die boomende Literaturveranstaltungspraxis bedient ein Verlangen, dass mit der Option auf Befriedigung erst zutage tritt. Es gilt somit gerade nicht das, was Harro Segeberg 2007 annimmt, dass sich „eine Welt der Telepräsenz [bildet], in der die ,alte ${ }^{6}$ physische Real-Präsenz des an einen leiblichen Körper, einen unverwechselbaren topographischen Raum sowie an eine bestimmte Zeit gebundenen Menschen außer Kraft gesetzt wird“"1121. Der konstatierte Mehrwert der Vor-Ort-Begegnung ist hingegen weiterhin so attraktiv, dass das Publikum seinen Weg in die Fasanenstraße 23, den Schwanenwik 38, zur Schönen Aussicbt 2, in die Düstere Straße 20, Østre Skostredet 5-7 sowie in den Wergelandsveien 29 antritt, ${ }^{1122}$ um Autor*innen in unmittelbarem Zusammentreffen zu erleben. Auch für die Künstler*innen ergibt sich dadurch eine Möglichkeit zur „Erzeugung von öffentlicher Aufmerksamkeit durch das spektakuläre Ereignis“"1123, das Detlev Schöttker als zentral für die Herstellung von „Autorpräsenz als Voraussetzung von Kanonpräsenz “1124 erkennt. Die Etablierung des Literaturhauses und vergleichbarer Lesungsarrangements erst im Zeitalter in der Digitalisierung - und nicht etwa Jahrzehnte oder Jahrhunderte früher - sprechen dafür, dass die Nachfrage bleiben wird. Sie ist schließlich - langfristig gesehen - erst vor Kurzem entstanden; und zwar geradezu gleichzeitig mit den ,neuen' technischen Entwicklungen. Das Literaturhaus als Stellvertreter für den Literaturveranstaltungsbetrieb ist ebenso ein als ,neu' zu bezeichnendes Phänomen, das unbedingt im Kontext des Zeitalters der Digitalisierung interpretiert werden muss.

Der Raum ,Literaturhaus' konstituiert sich aus dem Zusammenspiel eines Veranstaltungsprogrammes und unvermittelter sozialer Interaktion. Der Onlineauftritt berichtet von diesem Raum, trägt aber nur sehr eingeschränkt zu dessen digitaler Ausdehnung bei. Das Literaturhaus ist jedoch von seiner Umgebung beeinflusst.

1119 Der Ausdruck, begehbares Feuilleton` geht auf Hauke Hückstädt zurück, vgl. Hückstädt 2003, was auch in dieser Arbeit schon erwähnt wurde, vgl. S. 143, S. 162 und S. 228, und auch im Folgenden relevant bleiben wird, vgl. S. 359 und S. 472. Das begehbare Feuilleton - diese Selbstzuschreibung des Literarischen Zentrums ist auch der Name für einen Band, der „Gespräche und Berichte aus dem Kulturbetrieb“, so der Untertitel, versammelt, der ebenfalls bereits erwähhnt wurde, vgl. Blumenkamp und Hückstädt

(Hg.) 2007.

1120 Künzel 2007, S. 22.

1121 Segeberg 2007, S. 248.

1122 Zur Erinnerung: Dies sind die Adressen der näher untersuchten Literaturhäuser in Deutschland und Norwegen.

1123 Schöttker 2002, S. 284.

${ }^{1124}$ So der Untertitel und die Quintessenz seines Aufsatzes, vgl. ebd., S. 277. Vgl. auch Kapitel II 14.2. 
Obwohl es nicht als Vorreiter der digitalen Literaturvermittlung gesehen werden kann, so steht es in einer Gesellschaft und Gegenwart, die zunächst als „Erlebnisgesellschaft“"1125, von der „Ökonomie der Aufmerksamkeit“1126 und „Eventisierung“"1127 geprägt, dann stärker vom WWW beeinflusst als „Participatory Culture“1128 und „Convergence Culture“1129 oder etwa als Zeit der „Umstellung vom Speichern zum Verteilen“1130 bezeichnet wurde. Wenngleich diese beispielhaft ausgewählten Termini verschiedene Phänomene fokussieren, so treffen die durch sie umrissenen Beobachtungen auf das Literaturhaus einschlägig zu. Wie bereits im ersten Kapitel dargelegt, ist es sinnvoll, sich bei der Untersuchung des Literaturhauses nicht auf eine dieser Ausrichtungen festzulegen, sondern es aus verschiedenen Perspektiven zu betrachten, um sondieren zu können, wie es mit aktuellen medientheoretischen Auseinandersetzungen, die insbesondere das Internet einbeziehen, in Beziehung zu setzen ist.

Das Literaturhaus ist kein Beispiel für eine Einrichtung, die technische Veränderungen schnell adaptiert. Im Sinne der Institution wandelt es sich langsamer als mediale Umbrüche neue Realitäten schaffen. Das Literaturhaus ist hingegen ein Beispiel für eine Einrichtung, die den Literaturveranstaltungsbetrieb als Reaktion auf und Symptom für gesellschaftliche Wandlungsprozesse im Zuge der sogenannten Digitalisierung einzuordnen ermöglicht. Weniger produktiv für das Verständnis des gegenwärtigen Literaturbetriebs ist also eine dichotomische Gegenüberstellung von Internet und Literaturhaus, ${ }^{1131}$ vielmehr ist von Parallelprinzipen auszugehen, die sich beispielsweise hinsichtlich der Lust am inhaltlichen Austausch sehr ähneln und sich insgesamt gegenseitig verstärken. Die Frage, ob Literatur einen Ort zur Vermittlung wie das Literaturhaus braucht, ist also zu bejahen, denn ein fester Platz in der Stadt garantiert dieser Ausdrucksform Sichtbarkeit und Präsenz - und das ist im Zeitalter der Digitalisierung umso wichtiger.

\section{Medienumbruch im Blick zurück}

Als Überleitung von diesen eher institutionspraktischen Beschreibungen und Deutungen zum stärker auf Programminhalte fokussierenden nächsten Baustein folgt nun ein kurzer Blick darauf, wie sich die Literaturhäuser diskursiv mit dem Zeitalter der Digitalisierung befassten. Dieser lohnt sich vor allem deshalb, weil die Veranstaltungsankündigungen einen Aspekt illustrieren, der aus heutiger Perspektive in Debatten zur digitalisierten Gegenwart beinahe in Vergessenheit gerät. Nicht erst das für alle verfügbare Internet sorgte für einen gesellschaftlichen Wandel rund um die Jahrtausendwende, sondern bereits in den 1980er-Jahren habe das private kom-

\footnotetext{
1125 Schulze 1993.

1126 Franck 1998.

1127 Hitzler 2011.

1128 Jenkins 2006b.

1129 Jenkins 2006a. Der Terminus ,Konvergenz' hat sich für die Beschreibung der medialen Vermischungen etabliert, vgl. z. B. Hadenius und Weibull 2003, S. 255.

1130 Bunz 2009.

1131 Wie sie beispielsweise Andreas Kurzal in seiner Diplomarbeit von 1997 noch annimmt: „So gesehen kann der Grundgedanke des Internets als das Gegenprinzip des Literaturhauses gelten: von Raum unabhängige Dezentralisierung (Internet) versus räumliche Zentralisierung (Literaturhaus), wobei beide durch Merkmale wie den Austausch von Kommunikation und Informationen definiert werden können“, Kurzal 1997, S. 32.
} 
merzielle Kabelfernsehen einen markanten Umbruch ausgelöst, der bis heute anhalte, so Harro Segeberg. ${ }^{1132}$ Die Literaturhaus-Programme als Zeitdokumente unterstützen diese Hypothese, weil sie in Erinnerung rufen und untersuchbar machen, dass in der Tat das Fernsehen in den 1980er- und frühen 1990er-Jahren als zentrale Konkurrenz für das Lesen galt.

Unter dem Titel Lesen, Zappen, Cyper-Space. Auf dem Weg in eine leselose Zukunft? diskutierten so 1993 Verleger Vito von Eichborn, Autor Wilhelm Genazino, Demoskopin Renate Köcher, Computerexperte Theo Lutz und Fernsehredakteur Wilhelm von Sternburg mit dem Moderator Wilfried F. Schoeller unter der Annahme, dass Leser*innen multimediale Persönlichkeiten seien.

Dennoch wurden den neuen Medien Opfer gebracht. [...] Die Konkurrenz für das Buch wird härter, wenn bald 50 und mehr Satellitenprogramme die Wohnstuben erreichen und Computer-Animationen am Großbildschirm oder im Hosentaschenformat faszinieren. (FF 1993-10-10)

Anfang der 1990er-Jahre referierten die Diskutant*innen demzufolge vor allem auf die zahlreichen TV-Programme, obwohl die „Computer-Animationen [...] im Hosentaschenformat" bereits mitgedacht waren. Ähnliches zeigt im gleichen Jahr etwa das Symposium Literatur im Fernsehen, wo im Literaturhaus Hamburg „Autoren, Literatur- und Medienwissenschaftler, Fernsehredakteure und Werbeexperten die Möglichkeiten einer anderen, innovativen Fernsehästhetik für Literatursendungen entwickeln." Dieser Ankündigungstext weist darauf hin, dass der damaligen Präsentation von Literatur im Fernsehen vor allem Unbehagen und Kritik entgegenschlage, die aber weitestgehend folgenlos bliebe. Damit illustriert er, wie derartige kulturpessimistische Positionen bereits vor mehr als 25 Jahren als solche erkannt wurden. In „mäkeligem Kulturpessimismus“ werden sowohl die „Vermassung, die Popularisierung des traditionell gehobenen Kulturgutes Literatur [...] v. a. aber die ,Personalisierung': zuviel Aufmerksamkeit für den Autor, zu wenig für den literarischen Text“ moniert. Von „Show-how prominenter Meinungsmacher“ und „Illustrationsjournalismus“ sei die Rede, obwohl es statt dieser Kritik „eine fernsehgerechte, innovative Form der Präsentation“ bedürfe (HH 1993-03-22). ${ }^{1133}$ Auch das Literaturhaus Frankfurt fragte noch Ende des Jahrtausends: Wie spricht das Fernsehen über Literatur? (FF 1999-06-24). Zeitgleich finden sich Veranstaltungen, bei denen die gemeinsame TVRezeption zum Konzept gehörte: So lud das Literaturhaus Hamburg unter anderem 1991 ein zur TV-Live-Übertragung der Tage der deutschsprachigen Literatur in Klagenfurt, bei denen unter anderem der Ingeborg-Bachmann-Preis verliehen wird ( $\mathrm{HH}$ 1990-06). Oder im März 1994 konnten die Besucher*innen sechs Stunden am Stück die Dokumentation Deutsche Literatur seit 1945 schauen, die unmittelbar vorher im Fernsehen lief, und über die anschließend diskutiert wurde (HH 1994-03). Das Literaturhaus bot dies sozusagen als Public Viewing im geselligen Kontext an und

\footnotetext{
1132 Vgl. Segeberg 2007, S. 246. „Fortgeführt und radikalisiert“ werden die Angebote des Kabelfernsehens durch die neuen Anwendungsoptionen des Computers, der sich ,in eine Bild, Schrift und Ton integrierende Medien- und Kommunikationsmaschine verwandelt“, ebd., S. 247.

${ }^{1133}$ Dies fand als Programmpunkt der Mediale statt, ein Symposium, an dem unter anderem der Norddeutsche Rundfunk beteiligt war. Es diskutierten, der Ankündigung zufolge, diese Männer: WDR-Kulturredakteur Christhardt Burgmann, Medienwissenschaftler Klaus-Peter Dencker, Literatur- und Medienwissenschaftler Lutz Kramaschki, Autor Bodo Hell, Filmproduzent Charly Leske, hr-Kulturredakteur Wilfried F. Schoeller. Es moderierte Literatur- und Medienwissenschaftler Siegfried J. Schmidt.
} 
sprach gleichzeitig das literaturhistorische Interesse der Zuschauer*innen an. Damit rahmte es die Fernsehsendung neu und fügte ihr ein soziales Moment hinzu. Selbst das „Fernsehereignis des Jahres“ 2000 ließ die Literaturhaus-Programme nicht unberührt: „Big Brother" oder wer sind die Anderen bildete im Literaturhaus Berlin einen Themenabend. Zur Ausstrahlung der ersten Staffel förderte gar der private Fernsehsender RTL 2 die Veranstaltung (BE 2000-06-14). Dieser Programmeinblick soll hier vor allem veranschaulichen, dass es wichtig ist, die Literaturhäuser in ihrem jeweiligen Kontext zu untersuchen und nicht anachronistisch vorzugehen. Diese Gefahr ist im Zeitalter der Digitalisierung deshalb so groß, weil sich relativ schnell ziemlich eklatante Veränderungen ergeben. Zugleich bietet das Literaturhaus die Chance, diese möglichst direkt anzugehen, weil es, anders als beispielsweise eine Forschungseinrichtung, im Programm eine Mischung aus akademischer tiefgehender Herangehensweise und feuilletonistischer spontanerer Gegenwartsbeobachtung erlaubt.

\section{13 Programmanalyse - Formate und Inhalte}

$[\ldots]$ wird lesen und $[\ldots]$ ein Gespräch führen, das, so haben wir uns vorgenommen, bei Literatur beginnt. Aber wohin das führt, wo wir da rauskommen, das weiß natürlich niemand.

Dieses Zitat aus dem Text, mit dem das Literarische Zentrum Göttingen eine Veranstaltung ankündigte, bei der Alexander Kluge, „einer der letzten Universalgelehrten“ (GT 2004-03-06), mit dem Filmkritiker Volker Lilienthal sprach (GT 2002-05-10), lässt sich zum Geleit über die kommende inhaltliche Programmanalyse stellen. Während die vorausgehenden Kapitel sich schwerpunktmäßig mit den Kommunikationspraktiken des Literaturhaus-Programmes befassten, steht im Folgenden die Frage im Zentrum, was die Literaturhäuser vermitteln und auf welche Weise sie dies tun. Es zeigt sich unter anderem, dass die Fallbeispiele sich - in unterschiedlicher Intensität zwar, aber doch - inhaltlich mit Literatur im engeren Sinne befassen, gleichzeitig andere Kunstsparten in ihr Programm einbeziehen und außerdem Themen angehen, die auf den ersten Blick nur entfernt mit Literatur zu tun haben, was wiederum für einen erweiterten Begriff von Literatur spricht. Vielseitigkeit ist dort, wie die Selbstdarstellungstexte nahelegten, in der Tat Programm. Deshalb ist es eine Herausforderung, diese Spannbreite so zu untersuchen, dass am Ende nicht allein die Konstatierung von Vielfalt steht. Um dem entgegenzuwirken, stellt das Folgende den Versuch dar, die Vermutung zu untermauern, dass im Literaturhaus auf den einzelnen Text bezogen ein eher enges Verständnis von Literatur herrscht, während sich die Programmarbeit insgesamt keinesfalls auf Literatur beschränkt, sondern von Anfang an andere Disziplinen einbezieht.

Die Antwort auf die Frage, ob das Literaturhaus Autor*innen oder Texte präsentiert, kann ebenfalls nur ,sowohl als auch' lauten, denn, wie sich bereits abzeichnete, kommt den Autor*innen als Urheber*innen der präsentierten Texte eine entscheidende Rolle zu. So ergibt sich in Unterkapitel II 14.2 die Gelegenheit, ausführlicher 
über die Rolle des Literaturhauses in Kanonisierungsprozessen zu sprechen. Die enge Verzahnung von Autorenpersona und literarischer Einordung veranschaulicht ferner der spätere Abschnitt zur Internationalität.

Ausgehend von der Strukturierung der Literaturhaus-Programme in Reihen und von den Veranstaltungsformaten setzt dieses Kapitel das Vorgehen fort, die Ausrichtung und Praxis des Literaturhauses als Institution des Literaturbetriebes darzulegen. Zu interpretieren sind dabei einerseits implizite Annahmen der Programmmacher*innen, die ihren stärksten Ausdruck in der grundsätzlichen Programmzusammenstellung finden, andererseits explizite Äußerungen zur eigenen Haltung und Positionierung im gesamtgesellschaftlichen sowie engeren kulturellen Kontext, die in den Programmtexten gelegentlich auftauchen. Dabei begrenzte sich die Recherche in der Regel auf die Informationen, die sich in den Heften selbst finden lassen.

Das zur Verfügung stehende Material lässt sich aufgrund seiner immensen Fülle in einer einzelnen Doktorarbeit nicht erschöpfend systematisieren und nicht immer lückenlos ausdeuten. Und so erscheint sich selbst nach der hier vorgenommenen intensiven Auseinandersetzung mit den Veranstaltungsprogrammen eine Zufälligkeit in den Beispielen zu ergeben. Doch die Beispiele sind natürlich nicht willkürlich ausgewählt, sondern ermöglichen qualitative Detailstudien, die Tendenzen exemplifizieren, die aus der durchgeführten umfassenden Materialauswertung stammen. Die Vielzahl der Beispiele illustriert die Vielfältigkeit der Angebote.

\section{13.1 Reihen und Festivals}

Die Veranstaltungen, die von den Literaturhäusern verantwortet werden, können danach sortiert werden, ob sie als Bestandteil einer Reihe oder als einzeln stehende Angebote präsentiert werden. Obwohl die Gesamtheit aller Termine hier als profilbildend verstanden wird, weil die Programmhefte eine sortierende Rahmung bieten, ist die von den Literaturhäusern selbst vorgenommene Zuordnung in Themen- oder Formatkomplexe hilfreich für die weitere Untersuchung, denn Reihen erfordern und fördern konzeptuelles Arbeiten.

Mit dem Fachausdruck ,Reihe ${ }^{6}$ - alternativ ,Serie ${ }^{6}$ - sind inhaltlich und thematisch verbundene Folgen von Veranstaltungen, die in meist regelmäßigen Abständen stattfinden, gemeint. ${ }^{1134}$ Ähnlich den einzelnen Büchern einer Buchreihe lassen sich die zugeordneten Termine auch für sich stehend rezipieren. Es handelt sich dabei nicht um chronologische Gliederungen, die wie Vorlesungen, viele Fernsehserien oder literarische Mehrteiler aufeinander aufbauen. In der Literaturwissenschaft wurde der Aspekt der Serialität zuletzt vor allem für Formen von Narration in Kunstwerken diskutiert und ausgeführt, dass Teile einer Serie nicht als Einzeltexte rezipiert werden sollten, da sie dann ,in ihren elementaren Praxen unverständlich“"1135 bleiben. Frank Kelleter macht zugleich auf den Unterschied zwischen Serialität als Zweckstruktur, etwa bei einem Konzertabonnement, und Serialität als künstlerische

\footnotetext{
1134 Vgl. „Serie“, Duden online.
}

1135 Kelleter 2012, S. 15. 
Verfahrensweise aufmerksam. ${ }^{1136}$ Veranstaltungsreihen im Literaturhaus, die ausschließlich in der Gesamtschau funktionieren und als „periodische Weitererzählung einer Geschichte“1137 angelegt sind, kommen insgesamt selten vor - Ausnahme bildet die fortgesetzte Proust-Lesung im Literaturhaus Frankfurt, ${ }^{1138}$ die als serielle Verarbeitung eines zusammenhängenden Romans gedeutet werden kann. Als Reihen im Literaturhaus lassen sich eher lose verbundene Veranstaltungen oder wiederkehrende Formate bezeichnen, die über einen übergeordneten Titel verknüpft sind, die aber nicht unbedingt aufeinander aufbauen, sodass zwar ein Zusammenhang hergestellt ist, sie „als Folge einer periodischen Konstruktion“1139 und prozessual entwickelt werden, jedoch nicht alle vorherigen Termine besucht werden müssen, um einer zeitlich nachgelagerten Veranstaltung folgen zu können.

Alle untersuchten Literaturhäuser bieten Veranstaltungen in Reihenstruktur an, was belegt, dass die Literaturhäuser grundsätzlich nicht nur als Stätten zur Präsentation von Einzelveranstaltungen verstehen. Am deutlichsten zeigt sich diese Konzeption am norwegischen Litteraturbuset, dessen zwei Fallbeispiele Oslo und Bergen ihr Programm klar in Serien unterteilen. Auf einer Doppelseite in der Quartalsbroschüre erläutern sie die Bestandteile vom „fast programm“ (OL 2009-II, S. 4) [festen Programm] und markieren die entsprechenden Termine im kalendarischen Programm mit einem reihenspezifischen Symbol oder zumindest dem Reihentitel. ${ }^{1140}$ In den Programmheften der deutschen Literaturhäuser finden sich derartige Einbettungen nicht so präsent. Das Literarische Zentrum Göttingen arbeitet am markantesten von den deutschen Fallbeispielen mit thematischen Veranstaltungsserien und ordnet Termine in der Randspalte dem jeweiligen Reihennamen zu. Das Literaturbaus Frankfurt nutzte eine Zeit lang ein Symbol, das eine Reihenzugehörigkeit markierte, schaffte es jedoch mit der Umstellung des Heftes 2016 wieder ab. Im Literaturhaus Hamburg-Heft lautet entweder der Veranstaltungstitel wie die übergeordnete Reihe, oder es gibt mindestens im jeweiligen Ankündigungstext einen Verweis auf die Serie. Auf den Websites hingegen führen diese drei Einrichtungen ihre Reihen unter einem eigenen Reiter gesondert auf. Das Literaturbaus Berlin kommunizierte online keine klare Reihenzuteilung, sie erschloss sich allein aus den Ankündigungstexten. Dieses Literaturhaus ist von den untersuchten jedoch das einzige, das wechselnde Ausstellungen kuratiert und mit diesem umfangreichen Ausstellungsangebot bis dato gezielte Schwerpunkte setzt.

\footnotetext{
1136 Vgl. ebd., S. 14. Insgesamt macht diese Einleitung zum Sammelband deutlich, dass der Begriff, der mit ,Serialität' bezeichnet wird, für ein fundiertes Verständnis von ,Populärkultur' hilfreich ist.

${ }^{1137}$ Hickethier 2003, S. 147.

${ }_{1138} \mathrm{Zu}$ diesem Veranstaltungskonzept vgl. S. 260 und S. 374.

1139 Hickethier 2003, S. 146.

1140 Litteraturbuset $i$ Bergen verwendet die anfangs eingesetzten grafischen Reihensymbole nur bis Oktober 2014 (BG 2014-III), die verbalen Bezeichnungen und damit die Strukturierungen bleiben aber. Die Zuordnung zu diesen Reihensymbolen ist im Programmheft also nicht konsequent durchgesetzt. Dies erschwert die Untersuchung des Programmes dieses Literaturhauses dahingehend, dass nicht eindeutig zu erkennen ist, welche Reihen in welchem Rhythmus stattfinden. Zudem unterliegt die dortige Präsentation einer Vermischung von eigenen mit Gastreihen. Dies bestätigt weiterhin, dass das Literaturhaus in der kleineren Stadt Bergen noch stärker von den externen Veranstaltern geprägt ist als das Osloer, vgl. Kapitel II 11.2.1.
} 


\section{13.1.1 Ausstellungen}

Ausstellungen kommt ein besonderer Status zu, denn sie schaffen einen konzeptuellen Rahmen für weitere Veranstaltungen, sind aber nicht nur als Rahmen zu verstehen, sondern auch für sich genommen als Literaturvermittlungshandlung zu interpretieren. ${ }^{1141}$ In den Literaturhäusern spielen Ausstellungen unterschiedliche Rollen. Das Literaturbaus Frankfurt führte bis vor einigen Jahren regelmäßig literaturbezogene Ausstellungen durch, etwa über den österreichischen Dichter Ernst Jandl (19252000) kurz nach seinem Tod (FF 2000-11-09) oder über den russischen Autor Vladimir Nabokov (1899-1977) und sein Schaffen in den 1960er- und 1970er-Jahren (FF 2003-01-22). Aus organisatorischen Gründen finden im Literaturbaus Frankfurt keine wechselnden Ausstellungen mehr statt. ${ }^{1142}$ Bis zum letzten Leitungswechsel 2004 stellten im Literaturbaus Hamburg unterschiedliche Künstler*innen nacheinander ihre im weitesten Sinne literarischen Schauen aus. Jetzt findet sich dort nur noch eine permanente Präsentation von fotografischen Autorenporträts im öffentlich zugänglichen Treppenhaus. Diese ist mit den Wandgemälden in den Literaturhäusern Oslo und Bergen vergleichbar. Aktuell bilden ferner in Stuttgart, Leipzig oder München Ausstellungen einen Teil des Literaturhaus-Angebots. Im Literaturbaus Berlin prägen maßgeblich geschichtsbildende Ausstellungen das Programm, die unter den neuen Leiterinnen weitergeführt werden sollen. Einige bedeutende literarhistorisch relevante Ausstellungen fanden dort statt, etwa Zensur in der DDR (BE 199103-17/05-01), die im Anschluss im Literaturbaus Frankfurt gezeigt wurde (FF 199105-15/06-20), oder Elefantenrunden (2005-10-26), eine Beschäftigung mit Walter Höllerer, kuratiert von Helmut Böttiger, dessen Begleitbuch für die vorliegende Arbeit hilfreiche Informationen lieferte. ${ }^{1143}$ Korrespondierende Veranstaltungen vertiefen die Auseinandersetzung mit dem Ausstellungsstoff auf ähnliche Weise wie einige Reihen Themen eingehend betrachten.

\section{13.1.2 Funktionen von Reihen}

(1.) In Reihen zusammengefügte Veranstaltungen geben den Besucher*innen Orientierungshilfen im Programm. Im Kinderprogramm deuten sie etwa auf die vorgesehene Altersgruppe, oder sie weisen schon mit dem verbindenden Titel auf das übergeordnete Thema hin, zum Beispiel neu_übersetz̨ (erstmals GT 2011-03-07 mit Rosemarie Tietze). Diese Voreinordnung leistet das Literaturhaus-Team also selbst, und so ist diese mit dem nach außen kommunizierten Selbstverständnis der Einrichtung verbandelt, sodass in der Begutachtung der Reihen Rückschlusse auf die inhaltliche Programmatik gezogen werden können. (2.) Reihenangebote laden die Zuhörer*innen zum regelmäßigen Besuch ein, fungieren damit als Mittel zur Publikumsbindung. (3.) Programmreihen beeinflussen die Arbeit der LiteraturhausTeams, da die ,Vorgaben' einer Reihe auf die Planungen und Auswahl von Au-

\footnotetext{
1141 Zur Ausstellung von Literatur in Museen und Dichterhäusern vgl. z. B. Autsch et al. (Hg.) 2005; Hügel 2005; Schneider-Kempf et al. (Hg.) 2005; Brenner-Wilczek und Singh (Hg.) 2008; Bohnenkamp und Vandenrath (Hg.) 2011; Plachta 2011 und Kroucheva und Schaff (Hg.) 2013.

1142 Dies bestätigte mir Hauke Hückstädt im Gespräch am 20.04.2015 im Literaturbaus Frankfurt.

1143 Vgl. Kapitel I 4.2.
} 
tor*innen einwirken, weil sie Selektionskriterien vorgeben. Sollen Serien bestehen bleiben, bedarf es immer wieder passender Sujets und Gäste. Die Fortführung von Reihen schränkt damit die Programmmacher*innen auch ein; und die hohe Zahl an Neuerscheinungen in jeder Saison erschwert die Vergabe der begrenzten Programmplätze ohnehin. (4.) Eine weitere Motivation für Reihenveranstaltungen ist, dass sie sich zuweilen als Projekte propagieren lassen, was vor allem andere Finanzierungsmodelle zulässt. ${ }^{1144}$ (5.) Einige Reihen ermöglichen es, Gedanken und Gegenstände umfassender, weil inhaltlich vielfältiger und zeitlich ausgedehnter, aufzubereiten. (6.) Reihen geben damit Auskunft über das Profil des jeweiligen Literaturhauses. ${ }^{1145}$ Es lässt sich sogar weitergehend annehmen, dass diese konzeptuelle, über einen Abend hinausgehende, längerfristige Arbeit das Literaturhaus gerade von anderen Lesungsanbietern wie Buchhandlungen abgrenzt. Thomas Böhm sieht in der „Etablierung langfristiger Veranstaltungsformate, die die Bedürfnisse des Publikums und der Öffentlichkeit verlässlicher befriedigen als einmalige Events während eines Festivals“1146 ein Alleinstellungsmerkmal des Literaturhauses und dessen Chance im Konkurrenzkampf mit literarischen Großveranstaltungen. Und dadurch, dass es neben Reihen Einzelveranstaltungen anbietet, unterscheidet sich das Literaturhaus von Veranstaltern, die ausschließlich für ein bestimmtes Reihenformat stehen. Besonders in der jüngeren unabhängigen Szene vor allem in den größeren oder von Studierenden geprägten Städten im deutschsprachigen Raum formieren sich Kollektive, die regelmäßig zu konzeptuell ähnlichen Abenden einladen, etwa Meine drei lyrischen Ichs in München. ${ }^{1147}$ Reihenformate unterstützen damit die längerfristige Planung des Literaturhauses und tragen zur Kontinuität bei. Und zugleich können derartige Vorhaben meist nicht unaufhörlich weitergeführt werden, da viele eher thematisch orientierte Reihen nach einiger Zeit ausgereizt und ,abgenutzt ${ }^{6}$ sind. Veranstaltungsreihen sind also exemplarisch sowohl für Beständigkeit als auch für Veränderlichkeit, die in Kombination als Grundprinzip der Institution gelten. Ihre unterschiedlichen Ausgestaltungen lassen Rückschlüsse auf die Vermittlungspraxis und die Vermittlungsobjekte der Literaturhäuser zu, was im Folgenden ausgeführt wird.

Die Reihen lassen sich zunächst hinsichtlich ihrer Frequenz differenzieren: Während einige Angebote sich über einen langen, grundsätzlich unbegrenzten Zeitraum erstrecken, sind andere von vornherein temporär befristet und finden eher komprimiert innerhalb weniger Tage, Wochen oder Monate statt. So strukturieren außerdem jährlich wiederkehrende Veranstaltungen das Literaturhaus-Jahr, wie sie das Literaturbaus Frankfurt unter der Überschrift „In steter Folge“ auf seiner Website vorstellt. Neben Preisverleihungen, in Berlin zum Beispiel des Walter Serner-Preises im Dezember, sind das etwa in Frankfurt die Shortlist-Lesung zum Deutschen Buchpreis ${ }^{1148}$,

\footnotetext{
${ }^{1144}$ Da Drittmittel oft projektgebundene Finanzierung geben, sind die Literaturhäuser, wie andere Kultureinrichtungen, oft ,gezwungen', Projekte durchzuführen, vgl. Kapitel I 5.1.

1145 Dies betont auch Anja Johannsen. Bisher hat sie dies nur in Vorträgen ohne anschließende Publikation geäußert. 1146 Böhm 2005b, S. 230.

1147 Dies zeigt zum Beispiel die Initiative Unabhängige Lesereihen, die sich 2015 gründete, um den Austausch der jungen Literaturvermittler*innen zu stärken - und damit deren Sichtbarkeit zu erhöhen, vgl. „Wir“, Unabhängige Lesereihen.

1148 Diese Lesung fand erstmals am 27.09.2008 statt. Der Termin ist allerdings nicht im Programmheft abgedruckt, im Veranstaltungsarchiv auf der Website jedoch eingefügt.
} 
in Berlin Die Gedichtbände des Jahres als „Finissage und Ermunterung zum Weiterlesen“ zum Programmabschluss (erstmals BE 2001-12-06/08), in Göttingen bis 2011 das Sommerfest zum Saisonausklang und in Oslo Den store debutantdagene [Die großen Debütantentage] (erstmals OL 2007-12-05/06), Äntligen! [Endlich!], ein Gespräch über den jeweiligen Literaturnobelpreisgewinner (erstmals OL 2008-10-30) und das Literaturquiz zum Juleavslutning [Weihnachtsabschluss/Weihnachtsfeier] als letzte Veranstaltung des Jahres im Litteraturbuset (erstmals OL 2007-12-20).

Ferner lassen sich Reihen nach ihrer charakteristischen Konstante systematisieren: Sie können eine thematische Ausrichtung haben, sich explizit einer Epoche oder Gattung widmen oder Veranstaltungen sein, die ihr organisatorischer oder konzeptueller Rahmen eint. Die erkennbare Aufteilung in themengeleitete versus formatgeprägte Reihen unterstützt die Hypothese, dass für die inhaltliche Programmanalyse gleichermaßen Fragen des Veranstaltungsaufbaus wie der Themen- und Gastauswahl relevant sind. ${ }^{1149}$ Die diachrone Begutachtung des Umganges mit Reihen in den Literaturhäusern beleuchtet die Veränderungen des Literaturveranstaltungsbetriebes insgesamt. Der synchrone Vergleich lässt Rückschlüsse auf die Struktur und Konzeption der Institution Literaturhaus zu und legt markante Unterschiede frei zwischen der in Deutschland umgesetzten Ausgestaltung des, Literaturhauses', die deutlicher auf Literatur fokussiert ist, und der in Norwegen realisierten Idee, wo der politisch-diskursive Ansatz zentraler ist.

\section{13.1.3 Themengeleitete Reihen}

Im Literaturbaus Hamburg lässt sich ein besonders starker Wandel im Umgang mit Reihen feststellen. Während früher, insbesondere unter Ursula Keller, die das Literaturhaus von 1992 bis 2005 leitete und einem tendenziell universitären sowie theaternahen Umfeld entstammte, häufig thematische Reihen im Programm Schwerpunkte setzten, nahm diese Art der inhaltlichen Strukturierung ab, als vermehrt Buchneuerscheinungen präsentiert wurden. Unterschiedliche singuläre Veranstaltungen bilden seitdem stärker Vielfalt als Spezialisierung ab, und das Literaturbaus Hamburg übernahm, ausgelöst durch den Leitungswechsel zu Rainer Moritz, der aus dem Verlagswesen kam und als Literaturkritiker tätig ist, vor allem eine Orientierungsfunktion im Literaturbetrieb.

In den thematischen Reihen im Literaturhaus Hamburg, in denen Literatur und Theorie aufeinandertrafen, wurde oft Aktuelles aus dem akademischen Diskurs aufgegriffen, zum Beispiel vertieften im Sommer 1997 Vorträge und Lesungen das Motto des Monats Orte. Nicht-Orte (HH 1997-06-09). Dort trat unter anderem der französische Anthropologe Marc Augé (*1935) auf, der mit seinen Überlegungen zu „NichtOrten“ diskursprägende Beiträge zum sogenannten Spatial Turn der Geisteswissenschaften verfasst hat. Dabei sprachen dezidiert nicht nur literarische Intellektuelle

\footnotetext{
${ }^{1149}$ Weitere Beispiele für in den Literaturhäusern durchgeführte Serienveranstaltungen und Schwerpunktsetzungen folgen dementsprechend in den nächsten Abschnitten, wo sie außerhalb des Reihenkontextes zur Analyse der Programmprofile hinzugezogen werden.
} 
miteinander, sondern Wissenschaftler*innen unterschiedlicher Fachbereiche. Diese interdisziplinären Darbietungen gingen über ein streng literarisch verstandenes Literaturhaus hinaus. Theoretische, politische und zeitdiagnostische Auseinandersetzungen standen dabei neben sprachfokussierten Literaturveranstaltungen, die alle von der Intention, keinesfalls nur kurzweilig zu unterhalten, geprägt waren. Die Annahme eines auf diese Weise erweiterten Literaturbegriffes trifft auf alle untersuchten Literaturhäuser zu, doch lassen die großangelegten Projekte des Literaturhauses Hamburg um die Jahrtausendwende auf ein Bestreben dieser Einrichtung schließen, eine konfrontierende Debatte initiieren zu wollen, die über das Literaturhaus hinaus wirkte. Die Diskussionsreihe Perspektiven metropolitaner Kultur (erstmals HH 1994 05/06) zum Beispiel, die im Kontext des Hamburger Architektur Sommers - in der Tat nur männliche - Autoren, Philosophen und Kulturtheoretiker einlud, sich mit der Frage zu beschäftigen, ,was es bedeutet, wenn die Stadtkultur verfällt und das urbane Leben aus den Städten verschwindet" (HH 1994-06). Neben dem französischen Philosophen Jean-François Lyotard (1924-1998) und dem amerikanischen Kultursoziologen Richard Sennett $(* 1943)^{1150}$ - „einer der bedeutendsten Theoretiker unserer Zeit“ (BE 1995-08-14) - war der Stadtplaner Georg Franck (*1946) zu Gast, dessen Vortrag mit dem Titel „Prominenz als Statussymbol. Zu einer Ökonomie der Aufmerksamkeit" (HH 1994-05-25) eine wichtige Vorarbeit zu seinem bekannten Buch Ökonomie der Aufmerksamkeit1151, 1998 erschienen, war. Die Vorträge dieser Reihe sind gesammelt in der Edition Subrkamp erschienen. ${ }^{1152}$ Ähnliche Schwerpunkte, die „das Thema [...] literarisch philosophisch und theoretisch“ (HH 1997-11) umkreisten, waren 1997 die Reihe Das Böse unter anderem mit dem französischen Soziologen und Medientheoretiker Jean Baudrillard (HH 1997-04-29), die Serie Das Neue (HH 1999-01-28), Fakten, Fakes und Fiktionen (erstmals HH 2001-05-18) - lange bevor heute von Fake News gesprochen wurde und sogar vor 9/11 -, sowie ein Symposium zum Thema Zeit, bei dem die Teilnehmenden sich damit befassten, wie „die neuen Technologien und die Medien die Zeiterfahrungen strukturieren. Und was machen die Künste?" (HH 1997-04-23/25). An diesen Exempeln manifestiert sich zum einen die Verortung des früheren Literaturhauses im wissenschaftlichen Kontext und zum anderen der Wunsch, dass es substanziell zum akademischen Diskurs beiträgt und produzierend tätig ist, statt nur zu rezipieren und vermitteln. Diese Art der Produktion bezieht sich auf die Kulturwissenschaften und nicht auf die Erzeugung belletristischer Literatur. Dies ist ein Aspekt, der in Relation zu den norwegischen Literaturhäusern später noch sichtbarer wird.

Dass diese im Literaturhaus Hamburg angestoßenen Diskussionen an akademische Diskurse andockten und damit an ein Publikum gerichtet waren, das intellektuellen Zirkeln angehörte, mag Grund für die Zuschreibung gewesen sein, dass sich das Literaturhaus Hamburg unter Ursula Keller an eine kleine Elite richtete und dass dort anders als heute vielfach vertreten - dies auch mit Blick auf die (teils) öffentliche

1150 Die Veranstaltung mit Richard Sennett, angekündigt für November 1995, musste, wie ein Einlegezettel im Archivmaterial verkündet, ausfallen (HH 1995-11-08, Einleger).

1151 Vgl. Franck 1998.

1152 Vgl. Keller (Hg.) 2000. Die Auseinandersetzung mit städtebaulichen Fragen war um die Jahrtausendwende virulent, auch das Literaturhaus Berlin lud in vier Folgen Architekten und Schriftsteller zum Gespräch unter dem Titel Stadt - Raum - Text ein (BE 2000-10). 
Finanzierung der Institution - keine Öffnung zur breiteren Gesellschaft stattfand, sondern eine abgeschlossene akademisch ausgebildete Klientel bedient wurde. Diese programmatische Ausrichtung lässt sich zwar auf Ursula Keller zurückführen, doch zumindest die personelle Entscheidung für sie als Programmchefin beweist ja, dass sie ein Literaturverständnis und eine Idee für das Literaturhaus vertrat, die den Vorstellungen der Vereinsvorstandsmitglieder entsprachen. Mit dem Personalwechsel wurde ein Programmwandel gefordert, der für die Institution symptomatisch ist und in einer umfassenden Veränderung des Literaturveranstaltungsbetriebs kontextualisiert werden kann. So lassen sich ebenfalls im Literaturbaus Frankfurt unter Maria Gazzetti häufiger universitätsspezifische Praktiken wie Tagungen verzeichnen. Dort fand beispielsweise das erste internationale Rainald-Goetz-Symposium Goetz, 50 Theorie + Praxis statt (FF 2004-05-24/25), oder es wurde ein Veranstaltungsmonat dem die sogenannte Frankfurter Schule prägenden Theodor W. Adorno (1903-1969) zu dessen 100. Geburtstag gewidmet (FF 2003-11). Bereits beim Abschnitt zum Thema ,Kooperationen“ zeigte sich, dass das Literaturhaus Berlin ebenso regelmäßig bei Symposien mit Forschungseinrichtungen kooperiert und es eigenständig Tagungen organisierte, zum Beispiel ein Symposium zum Problem der ,Unspielbarkeit', das vor allem Bezüge zum Theater herstellte (BE 1991-01-17/19). Gleichfalls spricht die beständige Integration von Begleitveranstaltungen zu Ausstellungen ins Programm dafür, dieses Literaturhaus, mindestens bis zum Programmleiterwechsel Anfang 2018, als weniger von literarischen Neuerscheinungen abhängig zu charakterisieren. Das Literarische Zentrum Göttingen stellt einige seiner Veranstaltungen unter übergeordnete Themenkomplexe; so befasst sich eine Reihe unter dem Titel Der Geist weht (erstmals GT 2012-07-10) mit der Verbindung von Literatur und Religion respektive Glauben, eine andere, 2015 abgeschlossene Reihe begutachtete Das Alter in der Literatur (erstmals GT 2011-03-11). Derartige thematische Sortierungen kommen in den anderen untersuchten Literaturhäusern nur noch selten vor. Allenfalls über Kooperationen legen sich die Programmleiter im Literaturbaus Hamburg und Literaturbaus Frankfurt inhaltlich fest. Die Beobachtung, dass inzwischen weder in Hamburg noch in Frankfurt wechselnde Ausstellungen erfolgen, lässt sich in Zusammenhang mit der früher zeitlich ausgedehnteren tiefergehenden Auseinandersetzung mit Themen und Figuren verstehen. Die kürzeren, meist nur einen Abend dauernden Veranstaltungen lassen sich mit dem stärkeren Einfluss des Buchmarktes auf die Arbeit des Literaturhauses verketten. Die Absicht, möglichst mehrere unterschiedliche Bücher und Autor*innen vorzustellen, liegt unter anderem an dem gestiegenen Angebot von Schreibenden, die für Lesungen zur Verfügung stehen. Gleichzeitig erhöht sich diese Zahl sicherlich angesichts der gesteigerten Auftrittsmöglichkeiten. Die Literaturhaus-Programme versuchen die größere Menge an Neuerscheinungen abzubilden, die konzeptuell-konzentrierte Ausrichtung sinkt damit zwangsläufig, was sich also daran zeigt, dass weniger Themenreihen und seltener langfristigere Schwerpunktmottos zu finden sind. Unter Einbeziehung anderer bundesdeutscher Literaturhäuser lässt sich in jüngerer Zeit allerdings beobachten, dass wieder häufiger Veranstaltungen stattfinden, die themenfokussiert in Reihen oder in anderen mehr auf Langfristigkeit angelegten Formaten organisiert sind, was die Hypothese nahelegt, dass nach dem Untersuchungszeitraum dieser Arbeit gesellschaftsbildende und auf Kontinuität ausgerichtete Angebote wieder an Bedeutung gewinnen. 


\section{13.1.4 Reihen in Relation zu Symposien, Tagungen und Festivals}

Insgesamt lässt sich feststellen, dass umfangreiche Projekte in der Regel entweder über einen längeren Zeitraum hinweg als ,Reihe' oder komprimiert an einigen Tagen als ,Symposium' bezeichnet wurden. Symposien in Literaturhäusern lassen sich heutzutage zum Teil mit dem Terminus ,Festival' gleichsetzen, der sich jedoch vor allem für die jährlich wiederkehrenden Großveranstaltungen wie die lit.Cologne oder den Göttinger Literaturherbst durchgesetzt hat, die ab Anfang des 21. Jahrhunderts den Begriff prägten, ${ }^{1153}$ und deren Anzahl in Deutschland weiterhin wächst, obgleich sie nicht so präsent sind wie beispielsweise in Großbritannien. ${ }^{1154}$ Für Drittmittelgeber*innen und insbesondere für Sponsor*innen sind diese oftmals von der breiteren Öffentlichkeit wahrgenommenen Angebote ergiebiger. Im Fahrwasser dieser kurzzeitig viel Aufmerksamkeit akkumulierenden Veranstaltungen kündigen auch die Literaturhäuser ,Festivals' an. So ließe sich zum Beispiel das Symposium Europa schreibt (HH 2003-01-26/31), bei dem mehr als 30 Autor*innen sich an fünf Tagen und Abenden ${ }^{1155}$ öffentlich über die Frage „Was ist das Europäische an den Literaturen Europas?" austauschten, heute als Festival bezeichnen - obgleich die Zuordnung als Symposium eine hilfreiche Abgrenzung von den erwähnten Literaturfestivals und mehr Nähe zu wissenschaftlichen Tagungen und Konferenzen, ebenfalls ,Symposien“ genannt, ermöglicht. ${ }^{1156}$ Das ,Festival', das implizit ökonomische Aspekte stärker betont, stellte damit eine Abkehr von exklusiven Fachgesprächen dar. Konzeptionell stehen Veranstaltungen wie das im Frühjahr 2015 vom Literaturhaus Stuttgart durchgeführte Scheitern. Ein Festival des Misserfolgs, das „Strategien aus Literatur, Kunst, Politik und Wissenschaft" ${ }^{\text {" } 1157}$ auslotete, eher in der Tradition der bereits in den Anfangsjahren in den Literaturhäusern organisierten Symposien. Derartige tagungsähnliche Formate weisen gerade nicht die „Episodenhaftigkeit“ und die „Serialisierung des Einmaligen" 1158 auf, die Thomas Wegmann Literaturfestivals zuschreibt, und sie gehorchen damit weniger einer Steigerungslogik, sondern versuchen sich konzentriert und multiperspektivisch einem Gegenstand zu nähern.

\section{13.1.5 Reihenbezeichnungen als Label}

Da die Literaturhäuser mit ihrem selbstauferlegten Auftrag, vor allem neue Literatur zu präsentieren, auf die Verlagsprogramme angewiesen sind, schränkt eine thematische Folie die Auswahl ein. Gleichzeitig ergibt sich durch Reihen die Möglichkeit beziehungsweise die Selbstverpflichtung, bestimmten Genres oder Buchgruppen Platz einzuräumen. Das Literarische Zentrum Göttingen lud regelmäßig Autor*innen von Kriminalliteratur ein (Krimi, erstmals GT 2013-03-19) und widmete sich mit

\footnotetext{
1153 Vgl. Wegmann 2005b, S. 223.

1154 Vgl. Schaff 2013, S. 280. Dies ist vermutlich unter anderem auf die Existenz von Literaturhäusern zurückzuführen.

1155 Von Montag bis Freitag ab 10.30 Uhr, ein Zeitfenster, das deutlicher an eine Fachtagung erinnert als an Freizeitbeschäftigungen.

1156 Nenes aus Europa präsentierte auch das Literaturbaus Frankfurt anlässlich der EU-Osterweiterung (FF 2003-09-04/06; FF 2004-05-05).

1157 „Scheitern. Ein“, Literaturhaus Stuttgart.

1158 Wegmann 2005b, S. 224.
} 
neu_übersetət Übersetzer*innen und ihren Arbeiten (erstmals GT 2011-03-07). Bei diesen Reihen gestalten sich die einzelnen Veranstaltungen mitunter recht unterschiedlich.

Sehr offen für unterschiedliche Realisierungen sind die Vorgaben jener Reihenbezeichnungen, die eher wie ein Etikett funktionieren. Das Literaturhaus Hamburg führte auf seiner Website, nicht im Programmheft, bei den Reihen des Jungen Literaturhauses eine Zeit lang die Kategorie Junge Literatur auf, der nicht mit eindeutigen Kriterien Veranstaltungen zugeschrieben wurden. Diese zusätzliche Markierung stellte für die Rezipient*innen eine Orientierung im Programm dar und vor allem für jüngere Leser*innen heraus, dass diese Veranstaltungen insbesondere für sie gedacht sind. Zugleich präsentierte das Literaturhaus damit unmissverständlich, dass es ,junge Literatur' ins Programm aufnimmt und demonstriert so Aufgeschlossenheit gegenüber verschiedenen Altersgruppen, es implizierte damit allerdings unbewusst, dass der Rest des Programms gerade nicht jung sei.

Eine ähnliche Vorsortierung der Veranstaltungsangebote mittels Reihenbezeichnungen unternimmt Litteraturbuset in Oslo, das Veranstaltungen vor allem über deren Format oder das grobe Überthema zu Reihen verknüpft. Am deutlichsten wird diese Einordnungsfunktion an den Onsdagskvelder. Einen Abend in der Woche, seit 2011 Mittwoch, ${ }^{1159}$ reserviert Litteraturbuset für die eigenen Veranstaltungen, zu denen, laut Eigendarstellung, norwegische und ausländische Autor*innen zu Lesung und Gespräch eingeladen und Themenabende organisiert werden. Diese setzen sich in den Programmbroschüren gestalterisch von den anderen Terminhinweisen ab und ihnen wird in der Regel eine Doppelseite Platz zugestanden. Auf diese Weise fallen diese Ankündigungen in den Heften besonders ins Auge, was ihre große Bedeutung für die Programmatik dieses Literaturhauses unterstreicht.

Der feste Wochentag für diese Literaturveranstaltungen, der gleichfalls für die so bezeichneten Samstagsvorträge gesetzt ist, ist eine konzeptionelle Modifizierung des auf unterschiedliche Werktage verteilten Angebotes der deutschen Literaturhäuser. Dies ist verständlich unter Berücksichtigung der speziellen norwegischen respektive skandinavischen Litteraturhuset-Struktur: Mit den reservierten Tagen grenzt das Literaturhaus-Team die selbst kuratierten Angebote von den ,Gastveranstaltungen' ab und schafft eine Kontinuität für die Besucher*innen, die sich einprägen können, dass in der Regel mittwochs Literaturveranstaltungen im Litteraturhuset stattfinden.

Für die dargelegte Interpretation des Bergener Literaturhauses als Adaption des Osloer Modells spricht bezogen auf die Reihenstruktur ferner, dass dort ebenfalls angestoßen wurde, bestimmte eigene Formate an einem Wochentag zu fixieren und sie mit einem Titel als fortgesetzte Programmstruktur zu markieren: Skjerpet tirsdag „Tirsdag er dagen for hjernetrim og faglig føde med ulike innganger og utganger" (BG 2013-II bis BG 2014-II, S. 4) [Geschärfter Dienstag: Dienstag ist der Tag für Gehirntraining und fachliche Nahrung mit unterschiedlichen Ein- und Ausgängen]. Diese Festlegung auf ein Format an einem Wochentag wurde im Litteraturbuset Bergen nur im ersten Jahr durchgeführt, was die These zum Transfer noch unterstreicht, da

1159 Bis 2011 war der Hauptveranstaltungstag noch der Donnerstag, sodass das Label entsprechend torsdagskvelder [Donnerstagabende] hieß. 
offenbar zunächst das Prinzip übernommen wurde, es im Verlauf getestet, letztlich aber wieder abgesetzt wurde.

Die Onsdagskvelder in Oslo demonstrieren, dass die Reihen dort einerseits sehr offen in der Zielsetzung, andererseits strukturbildend für das Programm sind. Sie zeigen Vermittlungsabsichten des Litteraturbuset. Neben den dezidiert literarisch ausgerichteten Veranstaltungen mittwochs prägen weitere Reihenzuordnungen das Angebot dieses Literaturhauses. Dabei fällt auf, dass bei diesen das Format beziehungsweise die Herangehensweise an Themen oder an Texte das vereinigende Element der jeweils unter einer Reihenbezeichnung subsummierten Veranstaltungen ist.

\section{13.1.6 Format- und methodengeleitete Reihen}

Unter dem Titel Lordagsforedraget wurden im Litteraturbuset in Oslo an einigen Samstagnachmittagen Themen aus verschiedenen Wissenschaften populärwissenschaftlich und essayistisch referiert. Meist gab es innerhalb der Reihe Subthemen, denen mehrere Vorträge gewidmet wurden. Die Themen erstreckten sich weit, Theatergeschichte neben Architektur, Religion, Philosophie, Literaturwissenschaft oder politisch-sozialen Gegenständen etwa eine Auseinandersetzung mit dem nordeuropäischen Gesellschaftsmodell (OL 2009-01-31). Historische Sujets wurden bei Historisk Sondag vorgestellt. Sonntagmittags um 13 Uhr hielten meist Wissenschaftler*innen oder Journalist*innen, in einigen Fällen Verfasser*innen fiktionaler, intensiv recherchierter Texte, die Expert*innen für das Thema sind, einen halbstündigen Bildungsvortrag. Oft basierte die Präsentation auf einem Fach- oder Sachbuch, das nicht unbedingt eine Neuerscheinung sein musste, sodass das Interesse am Thema in diesem Fall eindeutig ausschlaggebend für die Auswahl der Redner*innen war. Bei Historisk Sondag bildeten sich wie bei den Samstagsvorträgen gelegentlich Themenblöcke, sodass hier thematische Schwerpunkte identifiziert werden können. Beispielsweise befassten sich mehrere Samstagsvorträge mit den Weltreligionen (Auftakt zum Thema: Hinduismus, OL 2013-01-19). ${ }^{1160}$ Seit 2014 wurden Lordagsforedraget und Historisk sondag unter dem Label Folkeopplysning gebündelt. Der Bildungsaspekt steht dort im Zentrum, der sich beim Literaturhaus im norwegischen beziehungsweise skandinavischen Kontext deutlicher zeigt als in den deutschen Einrichtungen. ,Literarisch' ist dies für Litteraturbuset in dem Sinne, dass gesellschaftlich relevante Themen durch die Lektüre der Sachbücher der Redner*innen vertiefend diskutiert werden können - für Litteraturbuset beinhaltet ,Literatur' somit eine politische wie bildende Dimension. Die Wissensvermittlung steht bei diesen Vorträgen noch vor der Diskussionsabsicht im Vordergrund, was durch die Ankündigung betont wird, dass diese Reihen „Litteraturhusets universitet, gymnas og ungdomsskole på en gang“" (OL 2014-I, S. 6) [zugleich Universität, Gymnasium und Mittelstufe (oberste Klasse der zehnjährigen Grundschule, Anmerkung C. L.) ${ }^{1161}$ des Literaturhauses] seien. Die Ähnlichkeit der beiden vorgestellten Vortragsserien führte 2016 zu einer

\footnotetext{
1160 Auch der Katholizismus, über den im protestantischen Norwegen ebenfalls wenig als bekannt angenommen werden kann, war Thema dieser aufklärenden Vortragsreihe (OL 2009-11-22).

${ }^{1161}$ Vgl. „Ungdomsskole“, Store norske leksikon.
} 
gemeinsamen Umwandlung zu Saklig Sondag [Sachlicher Sonntag]. Derartige Vorträge, die an Vorlesungen erinnern, sind in den deutschen Literaturhäusern seltener.

Eine ähnlich angelegte Reihe im Literaturhaus Bergen unterstreicht den Ursprung dieser Bildungsformate am Sonntag noch deutlicher: Sondagskulen [Die Sonntagsschule] (erstmals BG 2013-02-10). In der protestantischen Kirche kommen dabei Kinder und Jugendliche zur Katechese zusammen. Bürgerliche Sonntagsschulen vermittelten im 19. Jahrhundert über die Schulen hinausgehend Wissen und trugen neben der kirchlich-institutionalisierten Erziehung zur Allgemeinbildung von Heranwachsenden bei. ${ }^{1162}$ Der Ankündigungstext der Litteraturbuset-Reihe stellt den Bezug zur protestantischen Sonntagsschule deutlich heraus und betont zugleich, dass sie sich an Erwachsene richte und es im Literaturhaus nicht um den Transfer religiöser Praktiken gehe:

Søndagsskulen - for vaksne! Gjer søndagen høg, gjer ånden vid! Søndagsskulen byttar ut hellige skrifter med åndeleg føde, og dyrker det som gikk i glemmeboka. (BG 2013-I, S. 5)

[Die Sonntagsschule - für Erwachsene! Macht den Sonntag groß, macht den Geist weit! Die Sonntagschule tauscht heilige Schriften gegen geistige Nahrung, und preist, was in Vergessenheit geraten ist.]

Diese volksaufklärende Absicht realisiert sich in Bergen außerdem über die Einbeziehung von konkret politischen Fragestellungen in das Programm und beispielsweise die Serie Bok \& Storting (erstmals 2013-02-13). Dabei waren jeweils Politiker*innen eingeladen, sich Autor*innen als Gesprächspartner*innen auszusuchen. Die Themen drehten sich nicht unbedingt um Realpolitik oder Parteipositionen, sondern konnten je nach Gast Literatur oder künstlerisches Arbeiten betreffen. Auf diese Weise werden die Politikerpersonen für das Publikum persönlich nahbarer und die politische und literarische Sphäre ausdrücklich verknüpft. ${ }^{1163}$

Bei vielen Reihen bildet also die vorgegebene Rahmung die stetige Komponente. Dazu können ebenfalls die Serien gezählt werden, die mit ,Gastgeber', der meist die Reihe kuratiert, und einem relativ klar umrissenen Oberthema Akteur*innen einladen. Die Literatursoiree in Hamburg schenkt Einblicke in das bisherige Werk und die schriftstellerische Praxis des jeweiligen Gastes (erstmals HH 2009-11-30), ein vertiefendes Format, bei dem derselbe Moderator, zunächst der Literaturkritiker Andreas Isenschmid, später Lothar Müller, mit Autor*innen spricht. Beim Göttinger Liederabend unterhält sich der Literaturwissenschaftler Gerhard Kaiser mit jeweils einem Gast über Musikthemen, zum Auftakt - in der vernetzen Universitätsstadt kaum überraschend - mit dem Professor für Literaturwissenschaft Heinrich Detering, denn: „Nobody talks about Dylan like Detering“ (GT 2013-06-10). Im Literaturhaus Berlin wies das zwar nicht genuin für diese Einrichtung entwickelte und vielerorts angebotene Format Suchers Leidenschaften in eine ähnliche Richtung, obwohl dabei ausdrücklicher literarische Texte im Fokus standen. Der Theaterwissenschaftler und -kritiker C. Bernd Sucher stellte jeweils einen Autor und das Werk vor (z. B. BE

1162 Vgl. „Søndagsskoler, borgerlige“, Store norske leksikon.

1163 Vgl. auch die Reihe Partilederforedrag in Oslo, erläutert auf S. 407. 
2010-01-22). ${ }^{1164}$ Stark vom Gastgeber Reinhard Kahl bestimmt ist das in Hamburg seit 1999 angebotene Philosophische Café, dessen erster Gast Odo Marquardt war (erstmals HH 1999-01-14). Dadurch, dass jedes Mal dieselbe Person diese Reihentermine moderiert, ähneln sich diese Abende in der Durchführung, was bei der Literatursoiree zum Beispiel schon aus den Ankündigungstexten hervorgeht, die kontinuierlich einen Absatz zur Idee der Reihen enthalten. Die verschiedenen Themen und Gesprächspartner*innen sorgen dafür, dass die Abende inhaltlich immer anders gestaltet sind. Dies ist zudem der Fall bei den Reihen, die einen bestimmten Ort außerhalb des Literaturhauses zum charakteristischen verbindenden Moment erklären. ${ }^{1165}$

Die beiden programmatischen Ausrichtungen, einerseits gesellschaftspolitisch, andererseits literarisch-kunstästhetisch, finden ebenfalls in den norwegischen Literaturhäusern Beachtung. Deutlich auf einen aktiven Umgang mit konkreten literarischen Texten ausgerichtet ist im Osloer Literaturhaus die Reihe Narlesning [nicht direkt ins Deutsche übersetzbar, wörtlich ,Nahlesen', beziehungsweise ,close reading' auf Englisch], zu der seit 2012 in Kjelleren [der Keller] eingeladen wird. Eine oder mehrere Personen nähern sich einem Text und dessen Sprache, indem sie ihn einem close reading unterziehen. Als Vorgänger der Reihe kann die Einzelveranstaltung Kva er det med Moby Dick? [Was hat es mit Moby Dick auf sich?] gedeutet werden, die sich anlässlich der Neuübersetzung eingehend mit dem Klassiker von Herman Melville beschäftigte (OL 2009-12-10). In diesem Format stehen nicht nur ältere bekannte Texte, klassische wie Shakespeares Sonette (OL 2014-05-30) und gegenwärtigere wie der Gedichtzyklus Alfabet der Dänin Inger Christensen (19352009) zur Diskussion (OL 2014-01-21), sondern setzten sich Expert*innen mit aktueller Literatur, wie Den nye norske poesien [Die neue norwegische Poesie] mit den Lyriker*innen Anja Høvik Strømsted (*1986), Aina Villanger (*1979) und Erlend Nødtvedt (*1984) (OL 2013-03-15), ebenso wie mit Kulturtheorien, Filmen oder Fernsehserien, etwa mit der US-amerikanischen Serie Homeland und ihrem israelischen Vorgänger Hatufilm (OL 2014-01-24), genau auseinander. Nicht ein enges, auf kanonisierte Werke begrenztes literarisches Verständnis ist entscheidend für das Prädikat ncerlesningsverd [ncrlesnings-wert], sondern das breite Interesse an unterschiedlichen Textsorten und künstlerischen Ausdrucksformen.

Ähnlich wie Narlesning sei für Oslo Nachspielforedrag [Nachspielvortrag] genannt, ein Reihenformat, welches sich einem Sujet auf andere Weise vertiefend widmet: Ein bekannter Gast ist dabei eingeladen, über Musiker*innen, Künstler*innen oder Kulturpersönlichkeiten zu sprechen, die für ihn/sie eine besondere künstlerische Bedeutung haben. Dabei rücken Sportidole - den Auftakt bildete eine Veranstaltung über den Boxer Mike Tyson (OL 2014-03-21) - sowie Musikbands oder Schauspieler*innen in den Mittelpunkt und selbst die Vortragenden kommen aus unterschied-

\footnotetext{
${ }^{1164}$ Diese Serie entwickelte Sucher selbst und reist damit durch mehrere deutsche Städte, es handelt sich dabei also nicht um ein vom Literaturhaus entwickeltes Format, sondern um eine gekaufte ${ }^{6}$ Veranstaltung, die im Literaturhaus-Programm sogar zunächst unter, Gastveranstaltung' präsentiert wurde (z. B. BE Gastveranstaltung 2009-02-20). Aus dem Programmheft geht diese Zusatzinformation nicht hervor; das Literaturbaus Berlin integriert Suchers Leidenschaften ohne Hinweis auf diese anderen Veranstaltungen in sein Programm.

1165 Dies wurde beim Absatz zu den Veranstaltungsorten vertieft, vgl. Kapitel II 10.4.2, S. 273.
} 
lichen Bereichen. Das erinnert an das erwähnte Bok \& Storting und dessen als solche interpretierbare Weiterentwicklung Professorens valg [des Professors Wahl] (erstmals BG 2015-01-21), wo Professor*innen über ein von ihnen favorisiertes Sujet redeten, das nicht unbedingt ihr Forschungsgebiet sein musste. Das Interesse daran, zu hören, was diese Personen außerhalb ihrer öffentlichen Rolle beschäftigt, ist Anlass für diese Reihen. Die vielfältigen, gar überraschenden Themen sprechen dafür, diese Angebote als Bildungs- und Unterhaltungsformate zu deuten.

Diese Beispiele veranschaulichen zudem die Spannweite des Literaturbegriffes, denn ,Klassiker‘ finden neben tendenziell der Populären Kultur zuordenbaren Werken Platz. Die Gegenstände eines Literaturhauses lassen sich also nicht immer klar von denen des schon dem Namen nach breiter ausgerichteten Kulturhus abgrenzen. Litteraturbuset $i$ Bergen gab beispielsweise mit der Reihe Synopsis Einblicke „i de kreative prosessene bak store film- og TV-produksjoner" [in die kreativen Prozesse hinter großen Film- und TV-Produktionen] (erstmals BG 2015-01-14). Von einer wie im deutschen Kulturraum traditionell stärker verfestigten Hierarchisierung oder zumindest einer Differenzierung - von ,Hochkultur' und dem als Trivial- oder Populärkultur bezeichneten ,Anderen' kann in Skandinavien nicht ausgegangen werden. „Die Kluft zwischen Hoch- und Unterhaltungskultur, die in Skandinavien ebenso wie in den angelsächsischen Ländern weniger ausgeprägt erscheint als etwa in Deutschland, wird seit den 1980er Jahren noch geringer." 1166 Darum überrascht es nicht, dass nicht nur Literatur in einem engen Sinne dort im Literaturhaus präsentiert wird. Die Integration von Film, Musik, bildender Kunst ebenso wie die von Alltagsphänomenen in das Programm belegt zusätzlich die Hypothese von Thomas Steinfeld, dass Philologie sich nicht nur der Literatur zuwendet und „eher, als daß sie sich einem bestimmten Korpus verpflichtete, [...] sie ein bestimmter Typus von Wissen - und eine intellektuelle Technik“1167 ist. Die Reihe Narlesning des Litteraturbuset veranschaulicht dieses zeitgenössische Verfahren literaturwissenschaftlicher und literaturkritischer Praxis innerhalb der Literaturvermittlung. Es zeigt sich, dass selbstverständlich, ohne dies zu problematisieren - dort nicht nur Buchtexte Objekte literarischer Auseinandersetzung darstellen, sondern Einflüsse anderer Kunstsparten in den Gegenstandsbereich integriert werden.

Dieser Befund, dass von den norwegischen Literaturhäusern Literatur selbstverständlich in einem weiten Kulturverständnis verortet wird, während die deutschen Einrichtungen in ihren Programmen stärker hierarchisieren, ist hilfreich für die Untersuchung kultureller Transfers. Er verdeutlicht, inwiefern das kulturelle Umfeld das Programm der Literaturhäuser prägt, und er illustriert parallel, dass das Veranstaltungsangebot im Literaturhaus Ausdruck für diese kulturellen Voraussetzungen ist. Durch den Vergleich der norwegischen mit den deutschen Literaturhäusern zeigt sich zudem, dass sich das traditionelle Literatur- und Kulturverständnis auch in Deutschland gewandelt hat: Die vorgestellten Reihenbeispiele aus Deutschland und Norwegen signalisieren, dass das Literaturhaus nicht nur auf die Vermittlung von Literatur setzt, sondern literaturkritische Verfahren auf andere Kulturprodukte anwendet.

1166 Hoff und Rühling 2017, S. 27.

1167 Steinfeld 2004, S. 229. 
Die deutschen Literaturhaus-Programme unterscheiden sich folglich nicht grundsätzlich inhaltlich markant von den norwegischen, die Differenz liegt eher darin, wie die Inhalte kommuniziert werden: Die beschriebenen Serien des Litteraturbuset in Oslo illustrieren das uneingeschränkte Nebeneinander von kanonischen Texte der Literaturgeschichte, modernen ,Klassikern', Gegenwartslyrik und -prosa sowie anderen eher populären künstlerischen Ausdrucksformen wie TV-Serien - von Shakespeare-Sonetten, Inger Christensens Lyrik und Homeland. Durch die Verbindung über den Reihenkontext wird jegliche Hierarchisierung ausgeblendet. Ein derartig abgrenzungsloser Umgang mit anderen Bereichen neben der Literatur lässt sich bei den Reihen in den untersuchten deutschen Literaturhäusern nicht feststellen. Das Literarische Zentrum Göttingen demonstriert mit dem Liederabend definitiv sein offenes Verständnis dessen, was in einem Literaturhaus Beachtung finden sollte, doch führt die Einordnung unter einen Reihennamen zu einem expliziten Herausheben der Musikthemen aus dem Gesamtprogramm. Dies führt zwar zu einer Stärkung der intermedialen Komponente, doch gleichzeitig zu einer Abgrenzung von im engeren Sinne literarischen Sujets. Mit dem Selbstverständnis als „begehbares Feuilleton“1168 aber ähnelt diese Einrichtung aufgrund seines expliziten Einbezugs eher populärer Formen den norwegischen gegenwärtig stärker als die anderen Fallstudien. Dies gilt so ausdrücklich besonders im Hinblick auf die angebotenen Reihen, die hier als Hinweise auf die programmatische Ausrichtung gedeutet werden. Die in den letzten Jahren fortgeführten Serien in den Literaturhäusern in Berlin, Hamburg und Frankfurt unterstreichen, dass diese Einrichtungen weiterhin in erster Linie literarische Gegenstände behandeln. Bei den Einzelveranstaltungen zeigt sich ein differenziertes Bild, denn Film oder Musik und regelmäßig Sport sind auch dort in die Programme integriert.

Diese Reihenformate demonstrieren außerdem, dass die Veranstaltungen nicht nur lehrreich, sondern auch persönlich und unterhaltsam sein sollen. Eine Beeinflussung durch Unterhaltungsshows im Fernsehen, Late-Night-Gesprächsformaten und kontroversen Diskussionsrunden lässt sich bei diesen Veranstaltungen feststellen. ${ }^{1169}$ Deutlich wird, dass die Reihenformate auch in den deutschen Literaturhäusern einen gewandelten Umgang mit Literatur offenbaren, der einen Einfluss von Fernsehformaten nahelegt. Unterhaltung spielt dabei ebenso wie die kritische Auseinandersetzung mit Texten eine Rolle.

\footnotetext{
1168 Auf die Konzeption als ,begehbares Feuilleton“ wurde schon hingewiesen, vgl. FN 1119.

${ }^{1169}$ Noch deutlicher wird in Norwegen der Einfluss von TV-Formaten auf Literaturveranstaltungen dadurch markiert, dass als Bokbad inzwischen generell Buchpräsentationen mit Interview des Autors bezeichnet werden, obwohl die Bezeichnung mit bestimmtem Artikel - Bokbadet - ursprünglich einem Fernsehformat galt, bei dem jeweils ein Autor zu seinem Werk oder noch häufiger zu einer Neuerscheinung interviewt wurde und das von 1996 bis 2004 in der Regie von De Norske Bokkelubbene aus dem ehemaligen Torgata bad in Oslo - daher der Name - gesendet wurde, vgl. „Bokbad“, Det Norske Akademis ordbok. Ein Format, für das es auf Deutsch keine eindeutige Übersetzung gibt, wie die folgenden Ausführungen implizit veranschaulichen. Zu übersetzen wäre die Vokabel mit Buchvorstellung/Buchpräsentation. Allerdings zeigen Aufzeichnungen von den Sendungen im norwegischen Fernsehen, dass diese ausdrücklich unterhaltungsorientiert sind, da Live-Musik und ein großes Studiopublikum an eine Unterhaltungsshow zur ,Primetime‘ erinnern. Sendungen von Bokbadet sind online bei NRK ansehbar.
} 


\section{13.1.7 Literaturkritische Reihen}

Ein eingeübter Ablauf ist die verbindende Komponente bei den Reihenveranstaltungen, die auf einer „konstanten Präsentationsform“1170 beruhen und stark an Fernsehformate erinnern. Als bestes Beispiel dienen literaturkritische Diskussionsformate: Fast alle untersuchten Literaturhäuser bringen Kritikerrunden respektive Buchempfehlungsveranstaltungen auf die Bühne, bei denen es um belletristische Titel und um Sachbücher geht. Die stetige Wiederholung der Abfolge mit zum Teil festem Personal wird bei einigen Reihen betont durch die fortlaufende Zählung der einzelnen Termine, beispielsweise bei Streitfall-Autoren in der Kontroverse (Frankfurt) oder März \& Moritz \& 1 Gast (Hamburg). Gleiche oder sich stark ähnelnde Ankündigungstexte unterstreichen die Beständigkeit des Formats. Diesen Formaten lässt sich gar ein alltagssprachliches Verständnis von ,Ritual' beziehungsweise ,Ritualisierung' zuschreiben, der von der fachbegrifflichen Verwendung durch „die Isolierung des Segments der Repetition vom normativen Anspruchsbezug “"1171 abzugrenzen ist. Bei diesen Reihen wird ebenfalls vor allem auf die Wiederholung gesetzt, die zwar mit einem Moment der Gemeinschaftsbildung, nicht jedoch mit einem normbildenden Übergang einhergeht. Mehrmals im Jahr diskutieren in der Regel professionelle Literaturkritiker*innen über meist vier bis fünf Bücher und mit zwei oder drei gesetzten Akteur*innen und einem wechselnden Gast gibt es dafür ein relativ abgestecktes Verfahren. Dieser Ablauf ist eindeutig angelehnt an das erfolgreiche Literarische Quartett im ZDF (1988-20011172, Neuauflage 2015), das 1990 das Schweizer Fernsehen als Literaturclub adaptierte. Das Literarische Quartett, dessen Idee und Struktur so naheliegend und einfach wie nachahmenswert sind, lässt sich als maßgeblich für die literaturkritischen Diskussionsformate in den Literaturhäusern interpretieren. Das Fernsehformat, das zunächst in einer Studiosituation begann, wechselte nach sechs Folgen in Räume mit Publikum, dessen Funktion darin bestand, „die LiveAtmosphäre zu sichern“1173, wie Petra Kirchner schon 1994 konstatierte. Dreimal sendete das ZDF die Sendung sogar live aus den Literaturhäusern in Frankfurt und Hamburg, ${ }^{1174}$ sodass die Vergleichbarkeit beider Auftrittssituationen noch offensichtlicher wurde. Doch tatsächlich integrierten die untersuchten Literaturhäuser dieses Format nicht sofort in ihr Programm.

Das Literaturhaus Frankfurt richtete von den Fallstudien als erstes ein Kritikerformat ein, zunächst jedoch, um sich Sachbüchern zu widmen: Streitfall. Autoren in der Kontroverse (erstmals FF 2000-02-18 bis FF 2015-10-09) - initiiert vom Hessischen Rundfunk zusammen mit dem Forum für Philosophie, seit dem dritten Mal gemeinschaftlich im Literaturbaus Frankfurt durchgeführt - beschäftigte sich vor allem mit politischen und philosophischen Sachbüchern. Um diese Einschränkung zu umgehen und die

\footnotetext{
1170 Hickethier 2003, S. 148.

1171 Dücker 2008, S. 631.

1172 Eine vollständige Transkription aller Sendungen vom 25.03.1988 bis 14.12.2011 ist nachlesbar in: Directmedia Publishing (Hg.) 2005.

1173 Kirchner 1994, S. 275.

1174 Sendung vom 19.10.1995 im Literaturhaus Frankfurt. Die auf Youtube gestellten Aufnahmen vermitteln außerdem einen Einblick in das alte Gebäude des Literaturhauses. Die Sendungen im Literaturbaus Hamburg vom 28.02.1997 und 04.05.2001 sind ebenfalls auf Youtube verfügbar.
} 
„Vielfalt des Sachbuchs“ zu würdigen, ergänzte zunächst und ersetzte später Zur Sache! Das Frankfurter Sachbuchquartett die ursprüngliche Reihe (erstmals FF 2013-0528). In dieser Tradition ist etwa $W$ as ist denn hier passiert? im Literaturhaus Berlin zu sehen, wo genauso die Sortierung von „Neuerscheinungen zur Geschichte, Politik und Literatur" auf dem Programm stand (erstmals BE 2009-12-10). Die dortigen Gesprächsleiter Jörg Baberowski (*1961), Professor für Geschichte Osteuropas an der Humboldt-Universität Berlin, und Michael Jeismann (*1958), Historiker und Journalist, bis 2012 Leiter des Hauptstadtbüros des Goethe-Instituts Berlin - also keine Literaturkritiker im engeren Sinne -, debattierten mit einem Gast Sachbuchtitel und lockten so nicht nur Literaturinteressierte an, sondern schlugen eine Verbindung zum universitären Milieu Berlins.

Eine Kritikerrunde für belletristische Literatur kam ebenfalls als erstes im Literaturbaus Frankfurt im Mai 2003 hinzu. Bei Bockenheim 102 diskutierten die Literaturkritikerin Verena Auffermann und der Literaturkritiker Burkhard Spinnen, Literaturhaus-Leiterin Maria Gazzetti und der als Moderator eingesetzte Hans-Joachim Neubauer über neue Bücher: „Lassen Sie sich überraschen von einer leidenschaftlichen, oft auch kontroversen Debatte um literaturästhetische Fragen!““ (erstmals FF 2003-05-09). Dass diese Veranstaltung insgesamt nur dreimal stattfand, hängt sicherlich mit dem Umzug des Literaturhauses Frankfurt 2005 zusammen, womit mindestens der Name veraltet war. Erst 2008 greift die Einrichtung das Format unter dem Titel Schöne Aussicbten. Das Frankfurter Literaturgespräch auf, es besteht bis heute fort (erstmals FF 2008-12-08). Das Literaturhaus Berlin hatte im Untersuchungszeitraum bis 2015 kein eigenes Kritikerformat für Belletristik, es wurde dort jedoch regelmäßig die Besprechungsrunde der $S W R$ Bestenliste aufgezeichnet, eine Bücherliste, die bereits seit 1975 von Literaturjournalist*innen als Antipode zu den verkaufszahlbasierten Aufzählungen ausgewählt wird (z. B. BE 2010-04-29). Im Literaturbaus Hamburg debattieren seit 2011 unter dem Titel März \& Moritz \& 1 Gast Ursula März, Rainer Moritz und jeweils ein Gast regelmäßig Novitäten. Der Ankündigungstext zur Premiere dieses Formats gibt Aufschluss über die Absicht der Reihe und einen Anhaltspunkt für die literaturbetriebsgeschichtliche Einordnung der Beobachtung, dass derartige Formate in den Literaturhäusern zunehmen. Diagnostiziert wird eine Bedeutungsminderung der Literaturkritik: Es „droht die Literaturkritik ihre Funktion zu verlieren und als Steigbügelhalter der Buchpromoter zu agieren“ (HH 2011-09-29). Der Tendenz versuchten diese Formate entgegenzuwirken. In der zitierten Formulierung spiegelt sich ferner die thematisierte Beziehung zu den Verlagen - insbesondere die Unterstellung, dass Literaturhaus-Veranstaltungen vornehmlich als Marketingmaßnahmen einzuschätzen seien. Diese Reihe stellt sich diesem Vorwurf entschieden entgegen.

Daran, dass diese literaturkritischen Reihen nicht schon seit Beginn in den Literaturhäusern vorkommen, lässt sich eine generelle Zunahme dieser Kritikerformate konstatieren. Da außerdem die Annahme gilt, dass die Literaturhaus-Programmmacher*innen nicht mehr völlig unabhängig von der Besucherresonanz agieren (können) und damit Reihen nicht weiterlaufen lassen würden, wenn es nicht guten Zuschauerzuspruch gäbe, lässt sich weiter bestätigen, dass diese Gesprächsformate auf veritables Interesse beim Publikum stoßen. Andersfalls liegt der Leitungsperson 
programmatisch besonders viel an der Reihe, um eine eher schlecht frequentierte stetig fortzuführen.

Ähnlich wie das Literarische Quartett, dem unter anderem ein Unterhaltungswert zugesprochen wird, ${ }^{1175}$ verbinden diese Literaturhaus-Veranstaltungen Literaturkritik mit Showcharakter. Für die TV-Kritikerrunde konstatiert Heinz Schlaffer: „Am Erfolg des ,Literarischen Quartetts' zeigt sich das anhaltende Bedürfnis nach einer literarischen Geselligkeit, die jedoch außerhalb inszenierter und honorierter Veranstaltungen kaum noch zu finden ist."1176 Diese Literaturhaus-Reihen lassen sich als Reaktion auf ebendiese Beobachtung interpretieren - dort sind sie wiederzufinden.

Diese Kritikerrunden machen eine Funktionsverschiebung des Literaturhauses sichtbar. Das Literaturhaus fungiert zunehmend als literaturkritische Instanz, indem es zum einen Praktiken der Literaturkritik für die Bühne modifiziert und zum anderen Orientierung im aktuellen Literaturbetriebsgeschehen bietet, da die ausgewählten Titel in der Regel Bücher sind, die zur selben Zeit in den Feuilletons, also von überregionalen Zeitungen und Kultursendern besprochen werden. ${ }^{1177}$ Anhand der drei älteren untersuchten Literaturhäuser lässt sich diese dezidiert literaturkritische Funktion seit frühestens Mitte der 2000er-Jahre empirisch fundieren. Statt einer Abnahme der Literaturkritik im Literaturhaus lässt sich eher eine Verstetigung innerhalb der Institution protokollieren. Dies wird unterstützt von der Tatsache, dass das jüngere Literarische Zentrum Göttingen im Hauptuntersuchungszeitraum dieser Arbeit kein literarkritisches Debattenformat anbot, im Frühjahr 2017 fand dann zum ersten Mal im Anschluss an die Leipziger Buchmesse eine Kritikerdiskussion mit dem Titel Leipziger Allerlei statt, die weitere Fortsetzungen findet (erstmals GT 2017-0410) - ein Indiz dafür, dass aus Programmmachersicht ein derartiges Format in einem Literaturhaus vertreten sein sollte.

Für diese Hypothese finden sich zudem Argumente, wenn der Blick auf Norwegen geht. Bereits in seinem ersten Programmheft kündigte Litteraturhuset $i$ Bergen Kritisk Kvartett [Kritisches Quartett] an (erstmals BG 2013-02-19). Ein Transfer des richtungsweisenden Konzeptes von Das Literarische Quartett kann dort ebenso wie beim Frank-furter Sachbuchquartett nur vermutet werden. Die Namenskongruenz fällt aber auf und genauso stimmen die Konzepte überein. Das norwegische Kritikerquartett in Bergen - bestehend aus Morgenbladet-Literaturkritikerin Carina Elisabeth Beddari, Eirik Vassenden, Professor für Literaturwissenschaft an der Universität Bergen mit Publikationen zu Gegenwartsliteratur ${ }^{1178}$ und einem Forschungsprojekt zur Geschichte der zeitgenössischen Literaturkritik, Frode Helmich Pedersen, Postdoc am gleichen Institut und Literaturkritiker bei Bergens Tidende, und jeweils einem Gast hat sich als festes Format im Litteraturhuset $i$ Bergen bewährt und 2016 wurde es sogar zum Norsk Sakprosafestival im Litteraturbuset in Oslo und 2017 zum großen Norsk Litteraturfestival in Lillehammer eingeladen. Auch für Norwegen kann damit ein Publikums- und Veranstalterinteresse an einer literarkritischen Gesprächsrunde belegt

\footnotetext{
1175 Vgl. Blumenkamp 2011, S. 173.

1176 Schlaffer 1999, S. 24.

1177 Vgl. Kapitel I 5.6.4.

1178 Vgl. z. B. Vassenden 2004.
} 
werden. Im Programm des Litteraturhuset-Teams in Oslo hat noch keine vergleichbare Variante Einzug erhalten - ob intentional oder zufällig, bleibt offen. Göteborgs Litteraturhus bietet seit 2016 ebenfalls Kritikersalongen [der Kritikersalon] an, bei dem die Literaturkritikerin Jenny Högström mit jeweils zwei jedes Mal wechselnden Kolleg*innen über ein aktuelles Buch spricht (erstmals GB 2016-02-25). ${ }^{1179}$

Als Einsatz für insgesamt von der feuilletonistischen Literaturkritik vernachlässigte Bereiche der Literaturproduktion stellen sich weitere Buchdiskussionen dar, die einen differenzierten Schwerpunkt haben, zum Beispiel die beiden 2012 initiierten Reihen Auf dem Prüfstand im Literaturbaus Hamburg speziell für Kinder- und Jugendliteratur (erstmals HH 2012-12-05) und Kopf \& Hörer - Die Frankfurter Hörbuchkritik im Literaturhaus Frankfurt (erstmals FF 2012-02-06) zu aktuellen Hörbüchern, die sich, passend zur Aufführungssituation im Literaturhaus, mit der klanglichen Umsetzung von Literatur auseinandersetzt. Durch die kritische Beschäftigung mit diesen literarischen Spezialgebieten streben die Veranstalter*innen deren Aufwertung in der öffentlichen wie literaturkritischen und literaturwissenschaftlichen Wahrnehmung an. Dies passierte zeitlich nach Belletristik- und Sachbuchreihen, weil sich diese Formate etabliert hatten und dann weiterentwickelt und ausgeweitet wurden.

In diesem Zusammenhang von den genannten kritischen Beurteilungsformaten abzugrenzen ist zum Beispiel das im Literaturhaus Hamburg seit 2005, kurz nach Moritz' Amtseintritt, abgehaltene Gemischte Doppel, bei dem NDR Kultur-Redakteurin Annemarie Stoltenberg und Rainer Moritz Buchempfehlungen aussprechen (erstmals HH 2005-04-13). Da seit dem ersten Ankündigungstext explizit auf die Möglichkeit hingewiesen wird, die vorgestellten Titel am Veranstaltungsabend zu erwerben, liegt dort der Fokus noch stärker auf merkantilen Interessen. Gleichzeitig unterstützt die Reihe die Servicefunktion des Literaturhauses, im gegenwärtigen Buchmarkt Orientierung durch eine erprobte und für lesenswert befundene Auswahl zu offerieren. Die literaturkritische Dimension findet sich darin, Werturteile implizit über die Selektion der Titel zu treffen und auf der Bühne dann vor allem die positiven Werturteile zur Sprache kommen zu lassen - genauso wie es für die Einladung von Autor*innen bei den anderen Veranstaltungen gilt. Zweifelsohne bewerben die beiden Literaturkritiker damit die vorgestellten Bücher, wobei sie mit ihrer eigenen Reputation für die Auswahl haften, weshalb davon auszugehen ist, dass die angepriesenen Titel das Gemischte Doppel tatsächlich überzeugen - mindestens ebenso sehr, wie es für alle bei Lesungen vorgestellten Texte gilt.

Die in diesem Abschnitt beschriebenen Formate betonen die gegenwartsliteraturkritische Funktion des Literaturhauses gerade deshalb so sehr, weil bei den üblichen Veranstaltungen, bei denen die Autor*innen anwesend sind, der Text nicht vorbehaltslos kritisch reflektiert wird, um allein aus Gastfreundschaft und Respekt für die Künstler*innen negative Werturteile zu vermeiden. Die literaturkritische Komponente des Literaturhauses liegt in diesen Fällen im Ablauf zeitlich früher - bei der

${ }^{1179}$ Kritikersalongen wird unterstützt von Statens Kulturråd und wird in Kooperation mit Folkuniversitetet, Institut för litteratur, idébistoria och religion på Göteborgs Universitet, Kultur $i$ Väst och bokcirklar.se durchgeführt. Diese Zusammenarbeit bestätigt ein breiteres Interesse an derartigen Formaten. 
Erstellung des Programmes. Auch bei den Moderator*innen, meist in der professionellen Literaturkritik tätig, gehört es zum guten Ton sowie zum Selbstschutz, keine Bücher öffentlich zu diskreditieren, mit deren Verfasser*innen sie in absehbarer Zeit auf der Bühne zusammentreffen.

Der große Unterschied dieser Diskussionsrunden zu Lesungsveranstaltungen ist so offensichtlich wie einschlägig: Einmal stehen die Bücher im Fokus, einmal sind die Autor*innen leibhaftig zu Gast. Das Gespräch über einen Text verläuft unter jeweils anderen Vorzeichen, wenn Literaturkritiker*innen ihrer Berufspraxis gemäß sprechen oder wenn die Verfasser*innen selbst zugegen sind. Diese vermeintlich banale Erkenntnis, die sich anhand der Beobachtung, dass literaturkritische Reihen an Relevanz gewinnen, illustrieren ließ, ist entscheidend für das Verständnis der Institution Literaturhaus, die den eingeladenen Gästen grundsätzlich wohlmeinend begegnet.

Ferner zeigte sich, wie wichtig es ist, sowohl thematisch-inhaltliche als auch formatbezogene, konzeptionelle Fragen an die Literaturhaus-Programme zu stellen. Als Einstieg in die inhaltliche Auseinandersetzung mit den Literaturhaus-Programmen dienten diese Ausführungen zu den Reihen, die einen Überblick über die jeweiligen Schwerpunkte der Literaturhäuser vermittelten. Veranstaltungsreihen wurden hier als maßgeblich für die konzeptuelle Arbeit der Einrichtungen interpretiert. Findet die Strukturierung in erster Linie über Einzelveranstaltungen statt, kann dies für das einzelne Literaturhaus ebenfalls profilbildend sein. Die Grundzüge, die durch die Analyse der Reihen herausgearbeitet wurden, reflektieren die Gesamtrichtung der Programme, wie sich im Folgenden erweist.

\section{13.2 Formate}

Lesungen machen nur einen Teil der Programme des Literaturhauses aus. So konstatiert unter anderem Sonja Vandenrath, „dass sich um die Autorenlesung ein immer ziselierteres Angebot an Meta- und Paraveranstaltungen entwickelt, seien es Kritikergespräche, Poetikdozenturen, Varianten des Erzählens über Genregrenzen hinweg und Crossover-Projekte aller Güte." 1180 Die hier vorgelegte Darstellung der Veranstaltungsreihen untermauert diese Annahme empirisch. Und die Bedeutung dieser Formatvielfalt für die Institution Literaturhaus selbst stellt die Analyse der Selbstdarstellungstexte heraus, die ausdrücklich auf die unterschiedlichen Veranstaltungsarten eingehen. ${ }^{1181}$ Grund genug, die verschiedenen Formate zu systematisieren, um dadurch das Bild der Institution Literaturhaus zu präzisieren.

,Format' sei hier schlicht verstanden als Formatierung, als Aufbau der einzelnen Veranstaltung. Die umfassende Rahmung in einem Raum beziehungsweise Kontext bleibt an dieser Stelle ausgeklammert, weil die Veranstaltungsräume vorne beschrieben wurden. Ebenso wenig ist mit ,Format' „ein medienindustriell optimiertes Gen-

${ }^{1180}$ Vandenrath 2013, S. 123

${ }^{1181}$ Vgl. Kapitel II 9.4.2. 
re“1182 gemeint, das von einem inkludierten ökonomischen Interesse ausgeht, wie die medienwissenschaftliche Verwendung der Begriffsbezeichnung bezüglich Fernsehformaten nahelegt. Es wird damit ebenso wenig eine „strikte Einhaltung des vorgegebenen und vertraglich festgeschriebenen Konzepts"1183 als notwendig angenommen. Auf Basis der untersuchten Programme ergeben sich hinsichtlich der Veranstaltungsformate folgende Rubriken:

- Lesung (und Gespräch) zu einem meist neu erschienenen Titel eines anwesenden Autors, wobei es sich häufig um belletristische Titel handelt, aber auch Sachbücher vorkommen;

- Lesung und Gespräch zum Gesamtwerk beziehungsweise zu verschiedenen Texten eines anwesenden Autors;

- Lesung, Gespräch oder Vortrag zu einem Text oder Gesamtwerk eines verstorbenen/nicht anwesenden Autors, oft anlässlich von Jubiläen oder Neuausgaben;

- Lesung aus verschiedenen literarischen Texten zu einem Thema nach dem Anthologieprinzip, zum Beispiel ,Literatur und Frühling;;

- Performances oder Aktionen mit theatralem Element, bei denen der Aufführungsaspekt im Zentrum steht;

- Vorträge und Diskussionen, entweder zu literaturbezogenen Themen (Literaturgeschichte, Literatur und bestimmtes Thema, Metaebene) oder nicht explizit literarischen Sujets, beispielsweise gesellschaftspolitischer Art;

- Formate der Literaturproduktion, wie Werkstätten;

- andere Formate, die sich aufgrund von Alleinstellungsmerkmalen nicht einer der oben genannten Kategorien zuordnen lassen. Darunter sind auch Formate zu fassen, bei denen Literatur nur ,Beiwerk ${ }^{6}$ ist und etwas anderes wichtiger erscheint, literarische Spaziergänge, kulinarische Lesungen etc.

Einzelne konkrete Veranstaltungen lassen sich nicht immer kategorisch, sondern je nach Perspektive mehrfach zuordnen, weil die hier aufgeführten Formatarten Ergebnis abstrahierender Deskription sind und sich zum Teil auf unterschiedliche Untersuchungsebenen beziehen. Nützlich ist diese Sortierung vor allem, um verschiedene Absichten und Wirkungen der Literaturhaus-Veranstaltungen zu illustrieren und auf die Arbeit der Institution insgesamt zu schließen. Die fünf ersten Typen fokussieren stärker auf literarische Texte. Vereinfacht dargestellt, lassen sich den einzelnen Rubriken folgende unterschiedliche Funktionen zuteilen: Bei Gespräch und Diskussion steht der Austausch im Zentrum, bei der Lesung der Text und bei den weiteren Formaten geht es vordergründig um einen ansprechenden Zugang zu Text und Diskussion, der vor allem Teilnahme und Teilhabe fokussiert. Formate der Textproduktion sind gesondert von Veranstaltungen mit direkter Literaturvermittlung zu behandeln. Zwischen den acht Bereichen lassen sich graduelle Nuancen setzen. Abbildung 13 setzt die Beziehungen der verschiedenen Formate schematisch

1182 Hickethier 2003, S. 152.

1183 Ebd., S. 153. 
um. Die folgenden Ausführungen zu den Formatkategorien leiten jeweils weitere Themenbereiche ein, die die Entwicklung der Programme nachzuzeichnen ermöglichen.

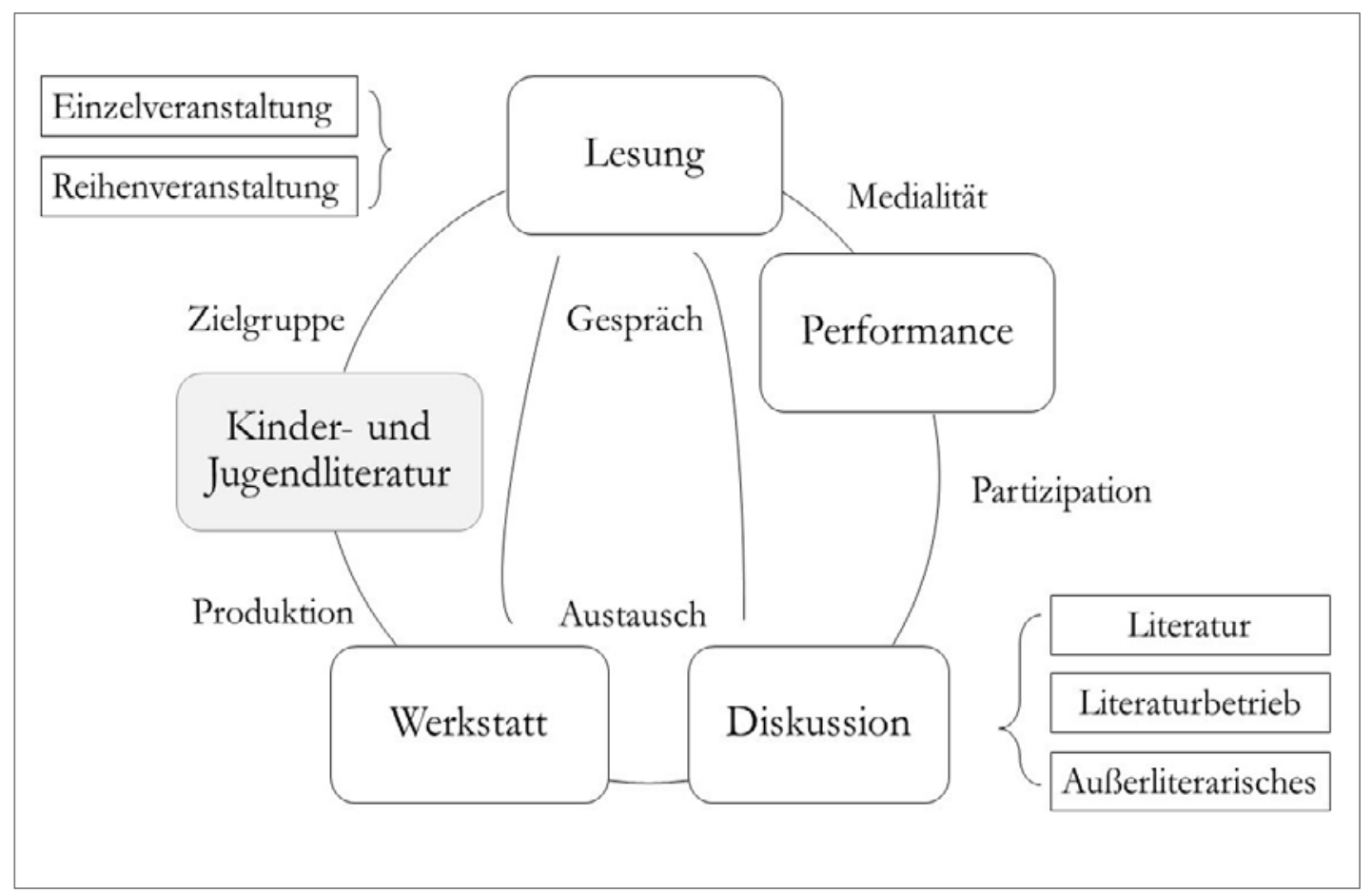

Abbildung 13: Übersicht Formate (eigene Darstellung)

Ein Spannungsverhältnis bei Veranstaltungskonzeptionen besteht generell zwischen stilistischen Beurteilungsmerkmalen und Formatkriterien. ${ }^{1184}$ Prüfsteine für die Qualität eines literarischen Textes sind nicht per se identisch mit Gütekriterien für eine gelungene Veranstaltung - und dabei sind die Wertmaßstäbe nicht festgelegt, obgleich sich je nach Umfeld konventionalisierte Bestimmungen herausfiltern lassen können. Das Literaturhaus muss dazwischen Kompromisse finden beziehungsweise entscheiden, welche Attribute wichtiger sein sollen. Sicherlich werden von den Programmleiter*innen einige Texte als literarisch relevant eingeschätzt, die sich jedoch nach Aufführungskriterien für eine Lesung kaum eignen, weil sie beispielsweise zu komplex konstruiert sind, um verstanden zu werden, wenn nur Auszüge vorgelesen werden. Andersherum gibt es Texte, bei denen die Beurteilungsinstanzen des Literaturhauses eine geringere literarische Bedeutung attestieren, die sich indessen gut für eine Veranstaltung eignen. Dieser Überlegung ließe sich anhand von exemplarischen Aufführungsanalysen nachgehen. Die Literaturhaus-Leitungen agieren zwischen ihrem Verständnis von ,guter ${ }^{6}$ Literatur und ,guter ${ }^{6}$ Literaturveranstaltung. ${ }^{1185}$ Das Literaturhaus vermittelt Literatur und da es dies in erster Linie mittels Veranstaltungen tut, sind Fragen der Komposition der einzelnen Veranstaltung ein wichtiger Aspekt der Programme, der jedoch von den Veranstaltern nach außen selten explizit thematisiert, hingegen als implizite Praktik vollzogen wird.

${ }^{1184}$ Dank an Helmut Böttiger, der in einem Gespräch diese Spannung begrifflich fasste.

$1185 \mathrm{Zu}$ den Bedingungen und Mechanismen der Wertung von Literatur vgl. Heydebrand und Winko 1996. 


\section{13.2.1 Lesungen von Autor*innen}

Als klassisches Veranstaltungsformat im Literaturhaus gilt die Autorenlesung, bei der die Verfasser*innen der vorgestellten Texte anwesend sind und ein moderiertes Gespräch führen. In den meisten Fällen präsentieren die Gäste belletristische Bücher, ${ }^{1186}$ regelmäßig aber auch Sachbücher. Dabei lässt sich differenzieren zwischen Abenden, die sich auf einen, meist neu erschienenen, Titel konzentrieren, und Abenden, die ein Gesamtwerk beziehungsweise mehrere Publikationen in den Blick nehmen. Insgesamt handelt es sich dabei nur um eine theoretische Einordnung, die verdeutlichen soll, dass es Fälle gibt, in denen explizit zwischen beiden Varianten unterschieden wird. Um über mehrere Titel eines Autors zu sprechen, nutz(t)en die Literaturhäuser Frankfurt und Hamburg eigene Reihen, in Frankfurt gab es WerkTag. Ein Opus in 90 Minuten (z. B. FF 2011-06-27) und in Hamburg gibt es die bereits erwähnte Literatursoiree ${ }^{1187}$. In der Regel referieren die deutschen Veranstaltungsankündigungen auf ein einzelnes Buch, das in vielen Fällen relativ neu erschienen ist. Die norwegischen Programmtexte beziehen sich nicht so signifikant auf die jeweils aktuelle Publikation, obgleich häufig ebenfalls eine kürzlich erschienene zugrunde liegt. Daher fallen im Osloer Programm Veranstaltungen auf, die, wie Forfatterparade [Autorenparade] (OL 2007-11-29), explizit literarische Neuerscheinungen vorstellen und damit einen Überblick über die Novitäten der Saison geben.

Als Hauptaufgabe des Literaturhauses ist in Deutschland die Präsentation von Neuerscheinungen zu nennen. In der Tat lässt sich in den Programmtexten bemerken, dass etwa seit der Jahrtausendwende häufiger Novitäten kommuniziert werden und große Anteile am Gesamtprogramm darstellen. Dies ist in Zusammenhang mit der generellen Beschleunigung des Kulturbetriebs und der Konzentration auf Neues zu sehen. So kommt in dieser Zeit an den deutschsprachigen Theatern Uraufführungen vergleichbar hohe Aufmerksamkeit zu, womit parallele Entwicklungen in unterschiedlichen Kultursparten beobachtbar sind. Auf dem Buchmarkt ist der Anteil an Backlist-Titeln - Publikationen aus früheren Verlagsprogrammen - in Deutschland rückläufig. ${ }^{1188}$ Dafür, dass viele dieser Titel lieferbar gehalten werden können, sorgt die gesetzliche Buchpreisbindung, ${ }^{1189}$ dennoch ist die Aufmerksamkeit und der Werbeeinsatz für diese Titel gering. ${ }^{1190}$ Noch stärker auf Neuerscheinungen konzentriert ist der norwegische Buchmarkt, der quantitativ deutlich begrenzter ist als der deutschsprachige. Titel erscheinen deshalb in niedrigeren Auflagen und die Optionen, ältere Titel am Markt zu halten, sind geringer, weil das Marktvolumen insgesamt kleiner ist. ${ }^{1191}$ Litteraturbuset versucht entsprechend, nicht nur auf Einzeltitel konzentrierte Veranstaltungen anzubieten. In den deutschen Literaturhäusern lassen sich immer wieder Versuche verzeichnen, Backlist-Titel unterzubringen, etwa bei

1186 ,Belletristik“ sei hier verstanden als „ordnende Kategorie im Sortimentsbuchhandel“, Dotzauer 2005, S. 43, also als Abgrenzung zum Bereich des Sachbuches.

1187 Vgl. Kapitel II 13.1.6.

1188 Vgl. Vaihinger 2005, S. 39. Wieder erweist sich Das BuchMarktBuch als hilfreiches Nachschlagewerk.

${ }^{1189}$ Vgl. Schenkel 2005, S. 89-90.

1190 Vgl. Vaihinger 2005, S. 40.

1191 Mit dem erwähnten Digitalisierungsprojekt Bokhylla.no ändert sich dies zukünftig insofern, dass zumindest alle Leser*innen in Norwegen Zugang zu den publizierten Büchern bis zum Jahr 2000 haben, vgl. FN 799. 
den erwähnten Werkschauen. Im Literaturhaus Frankfurt bot die Reihe Backlist ausdrücklich diesen Büchern eine Bühne (z. B. FF 2011-10-05, in Kooperation mit dem ZVAB - Zentrales Verzeichnis Antiquarischer Bücher). Allein die Initiierung dieser Serie belegt, dass diese Titel sonst selbst im Literaturhaus kaum zur Sprache kommen. Allerdings fand Backlist keine Fortsetzung, was im Umkehrschluss die mangelnde Aufmerksamkeit für diese ,alten`Bücher bestätigt.

Ob nun Neuerscheinung oder Backlist-Titel, die Mehrzahl der literarischen Veranstaltungen in den untersuchten Literaturhäusern in Deutschland und Norwegen bezieht sich auf in Verlagen publizierte Bücher. Diese Beobachtung ist relevant erstens - für die dargestellte Zusammenarbeit der Einrichtungen mit anderen Akteur*innen des kommerziellen Buchmarktes und - zweitens - für die historische Verortung der Institution in der Lesungskultur. Dadurch, dass nur sehr selten Literaturveranstaltungen als Lesungen aus Entwürfen und Skizzen, von noch Unbekanntem und noch Ungehörtem, vielmehr aus bereits verfügbaren Büchern präsentiert werden, ist ein inhaltlich konzeptioneller Unterschied zum literarischen Salon fassbar. Drittens zeigt sich auf diese Weise, dass die Literaturhäuser sich vorrangig als Einrichtungen für das Publikum präsentieren, dem die Autor*innen ihre fertigen, abgeschlossenen Texte vorstellen, und sich nicht so sehr als Versuchsräume für die Schreibenden verstehen, die ihre entstehenden Texte öffentlich ausprobieren könnten. Dieser Aspekt ist keineswegs nur wichtig für die geschichtliche Einordnung, hingegen positioniert er die Literaturvermittlungseinrichtung im gegenwärtigen Diskurs um Autor*in-Leser*in-Kollaborationen im Schreibprozess. Er plädiert dabei implizit für eine klare Trennung von Autor*in als Kunstschaffendem und Leser*in als Kunstrezipient*in.

Eine Ausnahme hinsichtlich der Abgeschlossenheit des Präsentierten bildet etwa die Reihe Snikkikk im Literaturhaus Oslo (erstmals OL 2007-10-11). Dort lesen Autor*innen aus ihren Manuskripten beziehungsweise noch unveröffentlichten Büchern. Der Name setzt sich aus ,snik' und ,kikk' zusammen, was etwa ,heimlicher Blick $^{`}$ oder ,verstohlenes Hereinblicken' bedeutet. Zunächst fanden Termine über das Jahr verteilt statt, inzwischen werden die Sommermonate für kostenlose Lesungen vor dem Literaturhaus genutzt. Dabei zeichnet sich ab, dass die Texte häufig bereits für die Veröffentlichung überarbeitet sind und es sich dabei eher um eine Vorabschau auf Bücher der neuen Saison denn um eine Teilhabe am Schreibfortgang handelt - eine Möglichkeit für die Leser*innen, schon vor Veröffentlichung einen Eindruck von neuen Texten bereits etablierter Schriftsteller*innen zu erhaschen. ${ }^{1192}$ Das Besondere an diesem Format ist zudem, dass hier das Vorlesen im Mittelpunkt steht, was sonst in Oslo nachrangig ist. Aus einem noch nicht verfügbaren Text vorzulesen, erscheint dort als interessanter eingeschätzt zu werden als das Vorlesen eines bereits erschienenen.

\footnotetext{
1192 Erster Gast war die 2018 mit dem Leipziger Buchpreis zur Europäischen Verständigung ausgezeichnete Journalistin und Autorin Åsne Seierstad (*1970) mit ihrem dann im November 2007 erschienenen Buch De krenkede [wörtlich: Die Gekränkten, auf Deutsch publiziert unter dem Titel Der Engel von Grosny. Tschet schenien und seine Kinder].
} 


\section{Lesungspart}

Es ist der deutschen Perspektive geschuldet, dass hier so häufig von ,Lesung' die Rede ist, und damit meist die Kombination von Lesung und Gespräch gemeint ist. Bei den Veranstaltungen in Oslo beziehungsweise im gesamtskandinavischen Raum handelt es sich eher um Gesprächsformate als um moderierte Lesungen mit langen Leseblöcken, wie sie in Deutschland üblich sind. Die Tatsache, dass in den skandinavischen Sprachen keine klare Bezeichnung für ,Lesung ${ }^{6}$ vorliegt, zeigt diese Differenz ebenfalls. ${ }^{1193}$ Obwohl die Analysen der Programmtexte zeigten, dass in den deutschen Literaturhäusern selten auf den Verlauf der Veranstaltung eingegangen wird, bleibt die Lesung zentrales Moment des Autorenbesuchs im Literaturhaus. Der Lesungspart müsste eigentlich als einzelner Veranstaltungsbaustein gesondert untersucht werden, weil die Frage nach der Funktion - Paratext oder Kunstwerk aufkommt. Durch den langen Lesungsteil in den deutschen Literaturhäusern bleibt ein auratisierendes Moment bestehen. In dieser Hinsicht ist das Plädoyer Thomas Böhms „für ein literarisches Verständnis von Lesungen“"1194 durchaus berechtigt, denn um diese „Frontalanimation“ gelingen zu lassen, bedürfe es passender Textstellen und eines guten Vortrags, um „[i]nnere Musik“ bei den Zuhörer*innen zu erzeugen und so zu einer Auseinandersetzung mit dem vorgestellten Buch zu animieren. ${ }^{1195}$ Die durch die Autor*innen selbst oder durch die Agenturen und Verlage getroffene Auswahl der vorgelesenen Textpassagen müsste also bei einer Lesungsanalyse einbezogen werden. In Böhms Forderung zeigt sich zugleich, dass gelingender Vortrag und glückende Literaturvermittlung eng zusammengehören, denn Thomas Böhm argumentiert letztlich implizit dafür, dass die Lesung ein Akt der Literaturvermittlung sei, der das Interesse am Buch wecken solle.

Zugleich ist die Lesung eine Interpretation des Textes. Reinhart Meyer-Kalkus konstatiert, dass die Lesung als „Verkörperung von Texten [...] in der Tat eine Art von Sinn-Festlegung" 1196 sei. Er verdeutlicht noch einen anderen wichtigen Aspekt der Lesung, indem er in seine umfassende Monografie Stimme und Sprechkünste im 20. Jahrbundert die Physiognomik einbezieht und annimmt: „Stimmen können nicht auf ihre Funktion als Informationsträger reduziert werden [...] In der Stimme findet sich die ganze Person verkörpert. "“1197 Die Lesung trägt also nicht nur zur Vermittlung des literarischen Textes bei, sondern verbindet diesen mit der Persona des Autors. Die Lesung eines Textes durch den Autor vermittelt dabei einerseits Authentizität als glaubwürdige Textinterpretation durch seinen Urheber, andererseits rückt damit die Persönlichkeit des Autors in den Fokus. ${ }^{1198}$

Für diese Linie spricht ferner, dass die Lesung zu einer „von der Lese-Anstrengung entlastenden, re-auratisierenden Praxis“1199 erhoben wird. Doch wenn „[d]urch die Lesung [...] die sinnliche Erfahrbarkeit der Literatur eingeholt [wird], die ihr durch

\footnotetext{
1193 Vgl. Kapitel I 4.1, S. 54 sowie Kapitel II 10.4.1, S. 267. Die Vokabel ,bokbad‘ findet deshalb hin und wieder Verwendung, sie ist im Literaturhaus-Kontext kaum in Gebrauch, vgl. FN 1169.

1194 Böhm 2003, S. 173. Vgl. dazu auch Kapitel I 5.8.

1195 Ebd., S. 178.

1196 Meyer-Kalkus 2001, S. 461.

1197 Ebd., S. 449.

1198 Vgl. Novak 2012, S. 365 sowie Kapitel I 5.6.3.

1199 Porombka 2005, S. 210.
} 
den Druck verloren geht" ${ }^{\text {"1200, }}$, wenn es damit im Literaturhaus um die Textinszenierung vom Verfasser persönlich und den Klang geht, so wäre zu erwarten, dass darauf in den Programmtexten eingegangen wird. Hinweise auf die Lese- und Aufführungsqualität des Gastes finden sich jedoch erstaunlich selten. Es sind wenige Fälle, in denen genau dieses Moment betont wird; dann treten meist bekannte Textinszenierungskünstler*innen auf wie der österreichische Schriftsteller und Maler Anselm Glück (*1950) („leibhaftiges Inszenieren“, HH 1996-06-11), „das Klangwunder“1201 Harry Rowohlt (1945-2015), der in einigen Ankündigungstexten als Übersetzer und Lesestimme ausnahmsweise gar vor dem ebenfalls anwesenden Autor genannt wird, was unüblich ist (HH 2000-01-25), ${ }^{1202}$ oder der „Künstler des Erzählens“, der syrisch-deutsche Autor Rafik Schami (*1946) (FF 1993-04-30). Der bekannte Synchronsprecher Christian Brückner (*1943) sprach, eingeladen von Literarischen Zentrum Göttingen und Deutschen Theater Göttingen, über seine Arbeit und sollte „live synchronisieren (absolute Premiere!)“ (GT 2001-10-18). Die Bühnenpräsenz steht ebenfalls im Zentrum bei Veranstaltungen mit dem australischen Autor Les Murray (*1938): „Wer den Dichter im Literaturhaus Frankfurt schon mehrmals hat lesen hören, weiß, wie faszinierend der Poet in Cordhose, Wollhemd und mit einer Schirmmütze seine Gedichte vorträgt. Man sollte Les Murray nicht verpassen!“ (FF 2006-05-16). Eine ähnliche Formulierung wurde übrigens beim Besuch des „Poet[en] in Cordhose“ zwei Jahre vorher benutzt (FF 2004-03-29).

Die Lesungen im Literaturhaus werden in der Regel weder als für sich allein stehende Kunstwerke betrachtet noch als kontemplative ,Gottesdienste', bei denen die Sprechenden monologisieren und ihre Kunst vortragen. Im Gegenteil wird etwa durch die Moderationsinstanz angestrebt, die Distanz zwischen Autor*in, Text und Publikum zu verringern und die Aufnahme des Textes bei den Zuhörer*innen zu lenken - bei den erwähnten Lesekünstlern funktioniert die Vermittlung schon über die Rezitation. Der Vermittlungsaspekt gewinnt durch die Kombination von Lesung und Gespräch an Bedeutung. Die Lesung fungiert dabei als „Kostprobe“ des Werkes. Dies unterstützt auch die Tatsache, dass Schauspieler*innen aus den deutschen Übertragungen lesen, wenn fremdsprachige Autor*innen zu Gast sind.

Es spricht folglich einiges dafür, den Lesungspart einer Veranstaltung als Leseprobe und Höreindruck zugleich zu deuten, denn Bücher sind Erfahrungsgüter, „deren Qualität der Nutzer erst durch ihren Konsum überprüfen kann“1203. Im Kontext eines beschleunigten Literaturbetriebes beziehungsweise der beschleunigten Gegenwart insgesamt, wo die Zeit zum Lesen knapper wird, ist dies ein Serviceaspekt. Doch die Lesung stellt im deutschen Kontext noch etwas anderes dar und ist historisch einzuordnen. Bei einer Buchveranstaltung in deutschen Literaturhäusern ist der Vorleseanteil in der Regel relativ hoch, gelesen wird meist 30 bis $45 \mathrm{Mi}$ nuten, trotzdem ist die Vortragsfähigkeit des Autors nicht unbedingt der Grund für die Einladung ins Literaturhaus. Die oben genannten sich unterscheidenden Wertungskriterien für den Text einerseits und für die Veranstaltung andererseits werden

\footnotetext{
$1200 \mathrm{Ebd}$

${ }^{1201}$ Cammann 2017.

1202 Dies verwundert bei der allgemeinen Anerkennung Harry Rowohlts heute wiederum nicht.

1203 Huse 2015, S. 92.
} 
folglich nicht immer bewusst angewendet. Vielmehr betont Rainer Moritz die notwendige Anstrengung, die der Lesepart gelegentlich erfordere:

Sich eine Stunde auf die Lesung eines Romans einzulassen ist eine Herausforderung. Die simple Grundsituation - Autor auf der Bühne, lesend und gelegentlich am Wasserglas nippend, Publikum still zuhörend - ist auch eine $\mathrm{Zu}$ mutung, zumal wenn es sich um komplexe ästhetische Gebilde handelt, die da zu Gehör gebracht werden. Doch wann war große, bedeutende Literatur jemals leicht zu konsumieren? Wenn man daran festhält, dass Literatur als sprachliches Kunstwerk sich kategoriell von anderen Formen der Rede unterscheidet, dann gehört dieses Fremdartige und Unerhörte zum Wesen von Literatur und zum Wesen von Lesungen. ${ }^{1204}$

Buchstäblich anspruchsvolle Lektüre - mit unmittelbarem, leichtem Lesegenuss hat diese Beschreibung wenig zu tun. Gerade auch Literatur, die für eine Lesung eigentlich zu komplex sei, werde von den Programmmacher*innen zur Präsentation ausgewählt. Eine leichte Überforderung des Publikums während der Veranstaltung werde damit zum Qualitätsmerkmal für die vorgestellte Literatur, weil sich darin ihre Vielschichtigkeit erahnen lasse. An diesem Beispiel wird sehr deutlich, dass es im Literaturhaus nicht so sehr um die mündliche Aufführung von Literatur geht, sondern der gedruckte Text zentral bleibt. Die Lesung erfordert es, sich einige Zeit auf einen Text als Text zu konzentrieren. Dabei steht in diesem Moment der Text für sich, der zwar durch den Vorlesenden eine Interpretation erhält, jedoch direkter wirkt als ein Gespräch über den Text. In dieser Zeit ist der Vermittlungsaspekt zurückgestellt hinter unmittelbare Rezeption. Damit markiert das Literaturhaus sein ästhetisches Interesse an Literatur, das eine unbequeme Annäherung enthalten kann. An dieser Stelle offenbart sich eindrücklich die zu Anfang dargelegte Überlegung der Initiator*innen, das Literaturhaus als Reaktion auf die Kulturpolitik der 1980er-Jahre als Ort der Kunsterfahrung zu konzipieren und dort den ,Anspruch an Literatur zu bewahren, wenn die Umgebung zunehmend für eine Gleichsetzung der Literatur etwa mit Soziokultur plädiert. ${ }^{1205}$ Heute in einer sich verändernden schnelllebigeren Gegenwart lässt sich die Lesung als kontemplatives Moment der Ruhe und Fokussierung einordnen. ${ }^{206}$

\section{Lesung und Gespräch}

Es liegen meines Wissens keine aussagekräftigen Publikumsbefragungen dazu vor, weshalb Zuschauer*innen zu moderierten Lesungen ins Literaturhaus gehen. Anzunehmen ist, dass die Kombination aus Textlesung und Konversation den Reiz ausmacht. Wie selbstverständlich finden im Literaturhaus hauptsächlich moderierte Lesungen in Anlehnung an das von Walter Höllerer, erfundene' Format statt, für deren Etablierung die Institution Literaturhaus maßgeblich sorgte. ${ }^{1207}$ Durch den Vergleich mit den norwegischen Literaturhäusern, die den Gesprächsanteil lebhaft herausstellen, wird dieses Spezifikum der klassischen Literaturhaus-Veranstaltung erheblich sichtbarer.

\footnotetext{
1204 Moritz 2013b, S. 294. Er setzt damit fort, dass die Lesung ein Bollwerk gegen die Verdummungskultur sei, was den leicht polemischen Ton unterstreicht.

1205 Vgl. Kapitel I 4.2.6.

1206 Dies veranschaulicht die sogenannte Wasserglasdebatte sehr gut, vgl. FN 558.

1207 Vgl. Kapitel I 4.2.2.
} 
Daran anschließend lässt sich die Frage zum Status von Literaturveranstaltungen aufgreifen. Es spricht vieles dafür, anzunehmen, dass jede Literaturveranstaltung eine Ablösungsbewegung vom Buch vollzieht, ${ }^{1208}$ und zwar einerseits dadurch, dass das Gespräch sich nicht auf das Buch allein beschränkt, andererseits dadurch, dass die Lesung zu einer eigenen Ausdrucksform des Textes wird, ebenso wie das Gespräch. ${ }^{1209}$ Zugleich kann eine Literaturveranstaltung die Rezeption und Interpretation des Werkes massiv beeinflussen, ${ }^{1210}$ weshalb sie gleichzeitig eine Rückbewegung zum Buch darstellt. Somit lässt sich eine Literaturveranstaltung verstehen als Paratext zum Buch ${ }^{1211}$, als „by-product"1212 beziehungsweise als Anschlusskommunikation vergleichbar mit einer Buchrezension oder einer anderen literaturkritischen Äußerung oder als intermediale Inszenierungsform respektive als selbstständiges Kunstwerk. ${ }^{1213}$ Anhand der Untersuchung der Veranstaltungsformate mittels der Ankündigungstexte wird ersichtlich, dass es darauf keine eindeutige Antwort gibt. Meine Literaturveranstaltungserfahrung unterstützt diese Einschätzung, denn die Veranstaltungen im Literaturhaus liefern auf unterschiedliche Weise Argumente für beide Einordnungen. Durch die Kombination mit einer Unterhaltung ist die Aufführung des Textes - Auszüge eines längeren Textes, kürzere Prosastücke oder Lyrik - meistens nicht als allein stehende Kunstform, sondern als Teil der Gesamtveranstaltung zu deuten. Dies korrespondiert mit der bei der exemplarischen Analyse der Ankündigungstexte herausgearbeiteten Erkenntnis, dass inszenatorische Qualitäten der Gäste und die Aufführungssituation seltener kommuniziert werden, sondern vom gedruckten Text ausgegangen wird. Die konstatierte ,Renaissance des Hörens' bezieht sich damit weniger auf den Rezeptionsprozess von Kunst und vielmehr auf die Unterhaltung über Literatur, auf mündliche Literaturvermittlung. Literatur wird zum Gesprächsanlass.

Im Litteraturbuset in Oslo und Bergen lassen sich seltener ,klassische Lesungen“ verzeichnen, was mit einer anderen Bildungstradition zusammenhängt. Die Literaturveranstaltung entstammt der dortigen Tradition von Vortragsabenden wie etwa författarbesök [Autorenbesuche] und ähnlichen gesellschaftsbildenden Formaten; für die Arbeiterbewegung in Norwegen hält Christian Berrenberg fest, dass Literatur in nahezu jeder Bildungseinrichtung relevant gewesen sei. „Auffällig ist jedoch, dass Literatur zwar ,stattfand', jedoch nur selten als spezifisch literarisch akzentuiert wurde." ${ }^{1214}$ Literaturvermittlung ist eng verbunden mit einer Bildungsabsicht, die zurückzuführen ist auf einen Hintergrund, der ,Bildung' nicht als autoritäre Wissensübertragung, sondern als gemeinsame Diskussion versteht. Moderierte Buch-

\footnotetext{
1208 Vgl. Johannsen 2013a, S. 67.

1209 Vgl. Hoffmann und Kaiser 2014, S. 11. Interview und Gespräch sind hier weitestgehend synonym zu verwenden. Dabei sei angemerkt, dass die Forschung zum literarischen Interview/Autoreninterview sich häufig auf gedruckt veröffentlichte Interviews beziehen, die durch die Möglichkeit des Redigierens anders zu untersuchen sind als Live-Interviews.

1210 Vgl. Masschelein et al. 2014, S. 18.

1211 Vgl. Esmann 2007a, S. 5.

1212 Johannsen 2013b, S. 212, Hervorhebung im Original.

1213 Vgl. Böhm 2003, S. 173.

1214 Berrenberg 2014, S. 269. Anders als in Schweden, wo Belletristik eine wichtige Rolle in der Arbeiterbewegung gespielt habe, sei für die norwegische Arbeiterbewegung ein Literaturideal erkennbar, welches aus literaturwissenschaftlicher Perspektive als Sachprosa bezeichnet werden könne, die sich kaum durch ihre stilistische, sondern durch ihre funktionale Qualität auszeichnete.
} 
vorstellungen sind dennoch eine übliche Veranstaltungsform, wenn etwa in der Bergener Reihe Nye Stemmer [Neue Stimmen] Autor*innen zu ihren Titeln interviewt werden. Die dortigen Literaturhäuser entwickeln außerdem eigene Formate zur Vermittlung von Literatur, zum Beispiel Utvekslingsstudier [Austauschstudien] in Bergen. Zwei Autor*innen tauschen sich über ihre aktuellen Titel aus - „et møte med sanntidkritikk og spontan respons" [ein Treffen mit Echtzeitkritik und spontaner Reaktion] unter Kolleg*innen (BG 2015-II, S. 7). Den Auftakt machten der schwedische Autor und Regisseur Stig Larsson $(* 1955)^{1215}$ und der norwegische Lyriker und Prosaautor Ole Robert Sunde (*1952), die über ihre autobiografisch geprägten Romanprojekte sprachen (BG 2013-10-20). Dort treten oft Autorenkolleg*innen auf der Bühne in einen Dialog.

\section{13.2.2 Lesungen von Texten nicht-anwesender Autorinnen}

Seit Beginn präsentieren die Literaturhäuser neben zeitgenössischen Texten literarische Werke, deren Autor*innen bereits verstorben sind. Dabei finden sowohl konsekrierte als auch wiederzuentdeckende Texte Eingang ins Programm. ${ }^{1216}$ Beispielsweise wurde im Literaturhaus Berlin im Zuge des internationalen literaturfestivals berlin unter dem Titel Erinnerung, sprich! „[i]m Rückblick auf deutsche und internationale Literatur vergangener Jahrzehnte und Jahrhunderte in einer Kombination aus Lesung und Vortrag an Autoren erinnert - an bekannte, verkannte und vergessene.“ (BE 2005-09-13/16) In dem Jahr waren das Herman Melville (1819-1891), Alberto Savinio (1891-1952), Eugen Gottlob Winkler (1912-1936) und Ambrose Bierce (1842-1914) - ausschließlich männliche Autoren. Im Literaturbaus Frankfurt war Herman Melvilles Moby Dick schon 1994 Thema (FF 1994-07-13). Weiteres Beispiel ist dort der Vortrag von Gedichten der deutsch-schweizerischen Lyrikerin Meret Oppenheim (1913-1985) (FF 2003-02-18). Die Kombination von Lesung und Gespräch ist neben den Vorträgen bei diesem Gegenstandsbereich ein beständig realisiertes Format. Auffällig ist, dass bei den deutschen Fallbeispielen zu kanonisierten Texten reine Lesungsveranstaltungen ohne Kommentar früher häufiger vorkamen. Eine derartige Präsentation ist, wie die Lesung Michaela Ehringers Aus Anna Livias Monolog von James Joyce, eine Veranstaltung, „die die Sprache in den Mittelpunkt stellt“ (FF 1994-01-28). In Hamburg und Frankfurt gab es darüber hinaus Projekte, Bücher vollständig vorzulesen, die diesen Aspekt noch stärken. Im Literaturhaus Hamburg lasen Robert Gernhardt, Harry Rowohlt und Josef Bilous in angekündigten circa sieben Stunden den gesamten „Säuferroman“ Die Reise nach Petuschki des russischen Autors Wenedikt Jerofejew (1938-1990) und verschafften dem recht unbekannten Text damit Aufmerksamkeit (HH 1998-01-27). ${ }^{1217}$ Im gleichen Jahr fand eine „Dauerlesung“ von Virginia Woolfs spätem Roman Die Wellen (1931) statt (HH

\footnotetext{
${ }^{1215}$ Nicht zu verwechseln mit dem Verfasser der ,Millenniumtrilogie‘ Stieg Larsson (1954-2004).

1216 Ausführlicher zu ,Kanon‘ und Kanonisierungsprozessen später, vgl. Kapitel II 14.2.

1217 Und sie setzten den „Säuferroman“ auch im eigenen Alkoholkonsum auf der Bühne um, wie der Buchhändler des Literaturhauses Hamburg Stephan Samtleben mir erzählte. Ihm sei für diese speziellen und allgemeinere Zeitzeugeneinblicke gedankt.
} 
1998-09-05). Im Literaturbaus Frankfurt las, wie bereits erwähnt, ${ }^{1218}$ der Rundfunkautor und Hörspiel- und Synchronsprecher Peter Heusch (1938-2014) Marcel Prousts Werk Auf der Suche nach der verlorenen Zeit (1. Band 1913) aus der Übersetzung von Eva Rechel-Mertens. Bei diesem Jour Fixe pour Proust führte er die Lesung jeden dritten Freitag im Monat über 13 Jahre hinweg fort. Mit der Ungewissheit zu Beginn, wann dieses Projekt zu Ende sein würde, behielt der Sprecher „diese Kontinuität, die er unserem event-angefixten ,Literaturbetrieb“ schenkt“ (FF 2004-03-19), bis zum Abschlussfest bei (FF 1994-03-18 bis FF 2007-03-16). Die Klassikerlesungen von Peter Heusch setzten Anfang 2008 bis 2010 beim Tristram-Day mit Laurence Sternes Leben und Ansichten von Tristram Shandy, Gentleman (1. Band 1759) fort (FF 2008-02-25 bis FF 2010-04-19). Daran lässt sich Folgendes erkennen:

(1.) Diese über einen längeren Zeitraum realisierten und vollständigen Aufführungen eines Buchtextes ohne ausdrücklich erwähnte Kommentierung stellten das Kunstwerk, das für sich stehend präsentiert wird, in den Mittelpunkt. Dass vergleichbare Formate nur noch selten vorkommen, liegt unter anderem daran, dass das Literaturhaus weitere Informationen und Analysen zu den Texten sowie zu den Autor*innen vermittelt, anstatt davon auszugehen, dass das Publikum sich bereits mit dem Gegenstand auskennt. Der Vermittlungsaspekt wird wichtiger.

(2.) Die Lesungen, die das Vorlesen als für sich stehende Kunstform verstehen und sich nicht auf 90 Minuten komprimieren lassen, sind als ,Live-Hörbücher ${ }^{6} \mathrm{zu}$ interpretieren. In der beschriebenen schnelllebigen Gegenwart sind diese zeitlich zunächst offenen Veranstaltungen schlechter unterzubringen. Es lässt sich durch diese Beobachtungen festhalten, dass die polemisch als „Häppchenkultur“"1219 bezeichnete Tendenz, zum Beispiel epische Romane nicht mehr vollständig zu lesen, sondern sich auf Ausschnitte zu beschränken, sich im Literaturhaus widerspiegelt. Diese Veranstaltungsform, bei der der Gegenstand die Länge vorgibt, war selbst im Literaturhaus nicht die übliche, hingegen machten von Beginn an Abende, die sich in Lesung und Gespräch einem Thema, einem Schreibenden, einem Text widmeten, den Großteil der Programme aus. Die gerade genannten Beispiele aus den deutschen Literaturhäusern in den 1990er-Jahren können als Versuche gelten, dieser „event-angefixten“ Entwicklung etwas entgegenzuhalten, womit die Verantwortlichen in den Literaturhäusern aktiv einen anderen Schwerpunkt in der Vermittlungsarbeit anstrebten, um das Sicheinlassen auf einen Text bei den Zuhörer*innen anzustoßen.

(3.) Diese Veranstaltungen nehmen die konstatierte ,Renaissance des Hörens', den ,acoustic turn“ ${ }^{\prime 220}$ auf beziehungsweise begründen diese mit. In dieser Zeit hat-

\footnotetext{
1218 Diese Reihe wurde hier bereits in anderen Zusammenhängen als Beispiel hinzugezogen, vgl. S. 260 und S. 347.

1219 Vgl. z. B. Moritz 2013a, S. 137. Doch diese Bezeichnung ist nicht neu. Bereits 1991 sieht HansChristian Schmidt für die klassische Musik im Radio eine Gefahr, da dieses die Musik zu „Verzehrhäppchen miniaturisiert. Es entwertet die ,schönen Stellen' dadurch, daß man sie sich nicht mehr, verdienen muß im Kontext ihres kompletten Gefüges“, Schmidt 1991. Auch der Literaturkritiker Fritz J. Raddatz umschreibt mit „Häppchenkultur` - vielleicht als Erster - eine kulturkritische Perspektive, die sich, wie das Zitat von Moritz beweist, auch mehr als zwanzig Jahre später nicht verflüchtigt hat. Mit ,Häppchenkultur' meint er ,nicht die Häppchen, die man auf feineren Cocktails bekommt, ich meine damit, daß wir seit langem (und im Moment in einer akuten Phase) dabei sind, Kultur und kulturelle Information zu zerhacken zu einem leicht verdaubaren Informationsbreit“, Raddatz 1983, S. 130.

1220 Petra Maria Meyer widmet dem ,Acoustic Turn` einen Sammelband, kommt jedoch zu dem Schluss, dass mit dem visuellen und performativen Turn immer auch die Rückkehr des Auditiven verbunden
} 
ten Hörbücher, die um die Jahrtausendwende „aus der Nische“1221 herausdrängten, bereits den Markt erobert, es lässt sich gar von einem „Boom“ sprechen. ${ }^{1222}$ „Das Hörbuch kommt einer gewissen Bequemlichkeit unserer Zeitgenossen entgegen [...,] Lektüre nicht als Arbeit, sondern als passives Vergnügen“"1223 zu begreifen. Die Leser*innen gewöhnen sich so daran, Lektüre auditiv zu erfahren, was ermögliche, nebenbei etwas anderes zu tun, Autofahren, Joggen oder die Augen schließen, ${ }^{1224}$ was hier im Kontext der Literaturhaus-Podcasts diskutiert wurde. ${ }^{1225}$ Argument für die Relevanz des Zuhörens ist außerdem, dass 2008 das Literaturhaus Frankfurt zur ersten „Konzeptlesung“ einlud, bei der „ein lebender Autor sein eigenes, soeben erschienenes Buch vollständig vorliest“" (FF 2007-03-12), es war der deutsche Schriftsteller Ulf Erdmann Ziegler (*1959), der an acht Abenden seinen Debütroman Hamburger Hochbahn komplett vorlas. Dies war allerdings der einzige verzeichnete Fall einer Autorenlesung eines gesamten Buches. Vermutlich gerade aufgrund von problemlos erhältlichen Hörbüchern konnte sich diese Vermittlungsform im Literaturhaus nicht durchsetzen.

\section{13.2.3 Lesungen verschiedener Texte zu einem Thema}

Eine andere Form, Texte von nicht-anwesenden Autor*innen vorzustellen, ist das Vorlesen verschiedener Beiträge einer historischen Periode, eines bestimmten Genres oder zu einem Thema. Allerdings lassen sich vergleichbare Formate nur vereinzelt in den untersuchten Literaturhaus-Programmen aufspüren, etwa ein „,zwölftägiges Text-Panorama von Berlin, erarbeitet und aufgeführt von Studenten der Hochschule für Schauspielkunst „Ernst Busch“" unter dem Titel Ich suche allenthalben eine Stadt, wo „Urberliner Texte“ vorgestellt wurden (BE 2005-06-27/07-08). Dieses Beispiel führt vor, dass derartige Veranstaltungen einen hohen Vorbereitungsaufwand verlangen, weil die Texte ausgewählt und für die Präsentation aufbereitet werden müssen. Vielleicht ist dies ein Grund, warum Formate nach dem Anthologieprinzip nicht häufiger in den Programmen zu finden sind. Ein geringes Interesse des Publikums an derartigen Zusammenstellungen kann nur vermutet werden; im Buchhandel verkaufen sich Themenanthologien selten gut.

gewesen sei, weshalb sie nicht von einem ,Acoustic Turn'sprechen möchte, gleichzeitig den Relevanzgewinn des Auditiven aber unterstreicht, vgl. Meyer 2008, S. 12.

1221 Wie Dorothee Meyer-Kahrweg schon im Titel ihres den Hörbuchmarkt 2003 gut zusammenfassenden Artikels festhält, vgl. Meyer-Kahrweg 2003, S. 241.

1222 Vgl. Sarkowicz 2003, S. 245. Dieser Beitrag stellt heraus, dass die Kooperation zwischen öffentlichrechtlichen Rundfunkanstalten und Verlagen seit den 1990er-Jahren aufgrund organisatorischer Synergieeffekte entscheidend zum Erfolg des Hörbuchs beigetragen haben.

1223 Lilienthal 2003, S. 254.

1224 Vgl. ebd., S. 255.

1225 Vgl. Kapitel II 12.4.2. 


\section{13.2.4 Aktionen und Performances}

Der Dichter liest und alle hören zu. Dieses Grundmuster ist allen Darbietungen der Kategorie Lesung gemein, selbst wenn es sich wie im Falle des Literaten und Lautpoeten Michael Lentz um in vieler Hinsicht ungewöhnliche Sprech-Performances handelt. Aber seit Neustem wird bei Lentz zurückgesprochen. (FF 200602-13)

Der Künstler Michael Lentz (*1964) trat während der Lesetour zum Preis der Literaturbäuser in Frankfurt mit einer Combo von Knetfiguren auf. Dies ist ein Beispiel für Aktionen mit theatralem Element, bei denen der Inszenierungsaspekt im Zentrum steht. Hierunter lassen sich Veranstaltungen einordnen, die sich in der Aufführung stark von der schriftlich fixierten Vorlage lösen oder eigenständige Texte auf die Bühne bringen, sodass sie von der ,einfachen' Lesung aus einem Buch abzugrenzen sind. Die Veranstaltung bezieht sich nicht unmittelbar auf ein Buch oder eine andere medial-fixierte Grundlage, sondern erklärt das Vor-Ort-Erleben zum Kunstwerk.

Außerdem sind besondere Veranstaltungen zu nennen wie die im Literaturhaus Berlin durchgeführte 100 Jahre DADA - Rekonstruktion einer Gedächtnisfeier (BE 201510-09). ${ }^{1226}$ Daran zeigt sich zum einen das Programminteresse dieser Einrichtung an der Literarischen Moderne, zum anderen stellt diese Veranstaltung die Frage, wie Formate archivierbar sind beziehungsweise erinnerbar sein können. Durch den Versuch der originalgetreuen Re-Inszenierung mit anderen Akteur*innen an einem anderen Ort zu einer anderen Zeit entsteht diese Reflexion implizit und wird jetzt, in dieser Arbeit, zum Anlass, den Aspekt des Performativen aufzugreifen.

Grundsätzlich werden insbesondere die Einmaligkeit und Nicht-Wiederholbarkeit einer jeden Literaturhaus-Veranstaltung dadurch offenbar, dass sie dezidiert nur einmal stattfindet. Ausnahmen sind selten, etwa als das Literaturhaus Frankfurt im Jahr 1993 eine szenische Lesung im Kontext des russischen absurden Theaters mit dem Titel Fehler des Todes „wegen großer Nachfrage“ (FF 1993-04-23) wiederholte. Diese Sonderfälle betreffen Vorstellungen mit festem Skript, die sonst im Literaturhaus kaum vorkommen. Weitere Beispiele mit einer höheren repetitiven Komponente für die Bühnenakteur*innen sind Lesereisen, bei denen Autor*in und Moderator*in gemeinsam in mehreren Städten auftreten. Dann ist ein Grad an Routine enthalten, denn, das ist zu vermuten, die Abende werden nicht jedes Mal von neuen Fragen geleitet. ${ }^{1227}$ Generell ist anzunehmen, dass Autor*innen, die mit einem neuen

\footnotetext{
${ }^{1226}$ Rekonstruiert werden sollte die damals von Hugo Ball und Richard Huelsenbeck organisierte Gedächtnisfeier für gefallene Dichter vom 12.02.1915. Schon früher versuchte sich das Literaturhaus Hamburg an einer „Rekonstruktion des STURM-Kunstabends vom 15. 2. 1918“ mit dem Titel Sturm Dir Sturm/allen Sturm. Expressionisten in Hamburg, der fast komplett rekonstruierte Abend bringe unter anderem Texte von Hermann Essig, August Stramm, Saul Friedländer (Mynona) und Kompositionen von Herwarth Walden zur Aufführung (HH 1989-12-08). Den Rahmen bildete die expressionistische Zeitung Der Sturm (19101932).

${ }^{1227}$ Höchst selten erwähnen die Texte, dass der Auftritt im Literaturhaus Station einer Lesereise ist. Von dieser Information kann nicht im Einzelfall erkannt werden, ob die Programmleitung sich von bestehenden Angeboten und Lesererwartungen antreiben lässt; Tendenzen lassen sich jedoch ausmachen. Es ist interpretationswürdig, wenn ein Literaturhaus vornehmlich Autor*innen einlädt, die sowieso gerade mit einem neuen Buch auf Lesereise sind und medial präsent sind. Dazu wäre es sehr aufschlussreich, wenn die Gäste aller Literaturhäuser untersucht würden. Dann würde sich zeigen, ob es Autor*innen gibt, die durch die Literaturhäuser touren oder ob es tatsächlich Einzelveranstaltungen sind, die auf eine eigene Programmgestaltung des Literaturhauses hinweisen. Vermutet wird auch hier die viel beschworene
} 
Buch auf Tournee gehen, sich mit der Zeit bestimmte Antworten auf wiederkehrende Fragen angewöhnen, was Aufführungsanalysen empirisch bestätigen könnten. Das lokale Publikum nimmt diese Geübtheit vermutlich nicht wahr, wodurch die Einmaligkeit des Angebots an diesem einen Veranstaltungsort bleibt. Gerade bei Lesung und Gespräch besteht Interesse an Unkalkulierbarkeit, an Überraschungsmomenten, wenn das Publikum den Bühnenakteur*innen beim spontanen Reden und Lautdenken zuhört. Insgesamt enthält jede Literaturveranstaltung performative Elemente, dennoch finden sich in den Literaturhaus-Programmen Hinweise auf Abende, die besonders die inszenatorische Ausgestaltung fokussieren, indem sie dies in den Ankündigungstexten stark machen, etwa las im Literaturhaus Berlin die niederländische Autorin Margriet de Moor (*1941) aus ihrem neuen Roman, während bei der gleichen Veranstaltung der flämische Performer Tom Lanoye (*1958) die deutsche Übersetzung seines Romans spielte (BE 1993-10-19). Die Betonung derartiger Performances und Verbindungen von Text und Klang stehen in den ersten Jahren häufiger in den Programmheften, was für eine höhere Bedeutung inszenatorischer Aspekte der Veranstaltungen spricht.

Die Veranstaltungsformate stehen in Zusammenhang mit der Entwicklung des jeweiligen Literaturverständnisses. Während der Anfangsjahre, in denen einzelne Bücher in den Programmheften weniger sichtbar waren, lassen sich viele Abende mit Performance-Experiment-Charakter verzeichnen. 1991 beispielsweise ging es unter dem Titel To do a public poem um die als Aktionskunst abseits des Happenings sich verstehende Poesie, die einer ihrer Mitbegründer, der Belgier Alain Arias-Misson $\left({ }^{*} 1936\right)^{1228}$ in einer Performance vorstellte - ein Künstler, über den heute relativ wenige Informationen zu finden sind, sodass sich die Funktion des LiteraturhausProgrammheftes als historische Quelle erweist (HH 1991-06-04 und BE 1991-0607). ${ }^{1229}$ Dies knüpfte an die avantgardistische Kunst der 1960er-/1970er-Jahre an. Nachdem in den 1960ern in der Literatur generell ein „Aufstand gegen das Erzählen" ${ }^{\prime 230}$ wirksam gewesen sei, habe sich dies im folgenden Jahrzehnt in einer Produktion gattungsloser experimentierender Texte geäußert, die mit einem „Überdruss am eigenen Metier“"1231 einhergegangen sei. „Die Beobachtung, dass sich im Übergang zu den 80er Jahren eine Rück- und Neubesinnung auf die ,Eigenart des Ästhe-

Mischkalkulation. Für das lokale Publikum ist es jedoch nicht unbedingt relevant, dass der Gast auch in anderen Städten liest und das einzelne Literaturhaus hat insgesamt wenig Interesse daran, auf diese anderen Termine hinzuweisen.

1228 „Alain Arias-Misson, der in Belgien geborene, in den USA lebende Mitbegründer einer sich als Aktionskunst verstehenden visuellen Poesie zeigt sein BERLIN PUBLIC POEM. Das von ihm initiierte Public Poem bezieht die Ereignisse und Zeichen der Stadt in den Text mit ein. Die Veranstaltung beginnt vor dem Literaturhaus und setzt sich auf den Straßen der Stadt fort“ (BE 1991-06-07).

${ }^{1229}$ Ein anderer Zugang, sich mit Lyrik öffentlichen Raum anzueignen, war die Aktion Poesie in die Stadt, bei der aber nicht der Entstehungsprozess publik war, sondern die Ausstellung von existenter Literatur öffentlich zugänglich war. 1999 initiierte das Netzwerk der Literaturbäuser das Projekt (z. B. HH 1999-06), das an öffentlichen Orten wie Plakatwänden Gedichte anbrachte und damit Literatur in den öffentlichen Raum transportierte und sich als Institution Sichtbarkeit verschaffte. Diese Aktion fand in den Sommermonaten bis 2009, zunächst jährlich, dann alle zwei Jahre Wiederholung. Dass die Durchführung von der Drittmittelfinanzierung abhing, stellt der Text im Programm des Literaturhauses Frankfurt heraus: „Vorbehaltlich der Finanzierungszusagen, die zum Zeitpunkt der Drucklegung unseres Programms noch nicht vorlagen“, sollte im Sommer 2003 wieder Poesie in die Stadt kommen (FF 2003-07-04).

${ }^{1230}$ Hage 2010, S. 17.

${ }^{1231}$ Ebd., S. 18. 
tischen' (Lukács) vollzieht, dass verstärkt sogar auf die Widerstandskraft der Poesie gesetzt wird“1232, lässt sich anhand der Aufführungssituationen in den Literaturhäusern erkennen.

Tritt während der 70er Jahre unverkennbar eine Rückbesinnung auf Individualität und Subjektivität in die Literatur der Bundesrepublik, so zu Beginn der 80er Jahre eine Rückeroberung der Literatur selber [...] Die Rückeroberung der Literatur im Übergang zu den 80er Jahren antwortet ihrerseits auf das ästhetische Defizit der ,neuen Subjektivität', indem sie versucht, die Umgrenzungen und Beschränkungen dieses egozentrierten Wahrnehmungshorizonts mit seinen Beschädigungen und Leid-Erfahrungen poetisch zu entgrenzen. In diesem Versuch äußert sich zugleich das Bemühen, einem literarischen Dilettantismus entgegenzuwirken. ${ }^{1233}$

Dies demonstrieren die sprachkritischen und klangkonzentrierten Veranstaltungen in den einzelnen Literaturhäusern, die besonders in den 1980er- und frühen 1990erJahren auffallen. Zu dieser Zeit erfuhren stilistische Kriterien und das Verständnis von Literatur als Kunst eine erneute Aufwertung, weshalb ein Schwerpunkt auf sprachexperimentellen Texten lag, die eine besondere Art der Präsentation erforderten. Zum Beispiel lud die Hamburger Programmleiterin Christina Weiss, die mit einer Arbeit über Seb-Texte. Zur Erweiterung des Textbegriffs in konkreten und nachkonkreten visuellen Texten ${ }^{1234}$ promoviert worden war, mit dem auf Konkrete Poesie und Hörspiel spezialisierten Professor für Literatur und Mitbegründer des Bielefelder Colloquiums Neue Poesie Klaus Ramm und den Performancekünstlern und Schriftstellern Franz Mon, Oskar Pastior und Hartmut Geerken zu einem Abend phonetischer Poesie, der mit einem Vortrag begann und damit endete, dass einige Zuhörer*innen „ein virtuoses Sprechstück, dessen Partitur der Dichter, Jazzmusiker und Schauspie-

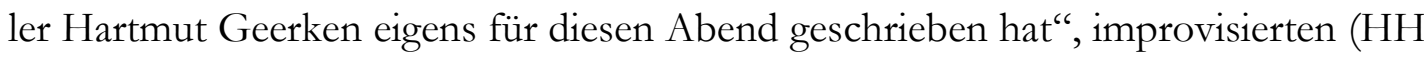
1990-01-25). ${ }^{1235}$ Eine vergleichbare Veranstaltung führte das Literaturbaus Frankfurt 1992 durch (FF 1992-05-08) und es widmete sich ebenfalls 1994 der Nenen Poesie (FF 1994-05-04). Noch 2004 besuchte das Bielefelder Colloquium mit einer begleitenden Ausstellung Frankfurt (FF 2004-04-04). Diese kunstästhetische Verortung beweist sich nicht nur an den Formaten, sondern gleichfalls an den geladenen Gästen, für die neben den genannten etwa Helmut Heißenbüttel (1921-1996) exemplarisch ist, dessen Werk „den Weg der selbstkritischen künstlerischen Avantgarde in Deutschland entscheidend geprägt“ habe, und der „eine spielerisch-witzige sprachliche Bestandsaufnahme der Wirklichkeit" lieferte (HH 1989-12-15). ${ }^{1236}$ Auch der

\footnotetext{
1232 Schnell 2013, S. 662-663.

1233 Ebd., S. 654.

1234 Vgl. Weiss 1984.

1235 Das von 1978 bis 2002 jährlich durchgeführte Bielefelder Colloquium Neue Poesie verstand sich als Forum für avancierte Literatur, dessen Konzept die Kombination aus internem Arbeitstreffen und öffentlicher Literaturveranstaltung war. Einen Eindruck vom letzten Colloquium im Mai 2002 vermittelt ein Artikel in der Tageszeitung NZZ, vgl. Lange 2002. Einen auditiven Eindruck bietet eine Zusammenstellung auf zwei CDs, vgl. Schmidt und Vogt 2002. Im Studienzentrum für Künstlerpublikationen in der Weserburg ist der audiovisuelle Teil des offiziellen Archivmaterials des Bielefelder Colloquiums aufbewahrt. Neben den Filmund Tonmitschnitten der Lesungen sind dies Plakate, Fotografien, Flyer und Programmzettel, die einen umfassenden Einblick in die Arbeit und die Struktur des Colloquiums geben. Weiterhin sind Kataloge und Dokumentationen vorhanden.

${ }^{1236}$ Neben Ernst Jandl ist Helmut Heißenbüttel - dessen Ansehen sich zum Beispiel daran beweist, dass er 1969 den Georg-Büchner-Preis erhielt - einer der Begründer des erwähnten Bielefelder Colloquiums Neue Poesie. Er schrieb in Die Zeit einen ersten Artikel zu diesem damals noch nicht etablierten Tagungsformat
} 
erwähnte Oskar Pastior (1927-2006) war als erstes deutschsprachiges Mitglied des 1960 in Frankreich gegründeten Kollektivs OULIPO (Owroir de littérature potentielle) [Werkstatt für potentielle Literatur] regelmäßiger Gast in den drei untersuchten älteren deutschen Literaturhäusern. Mit unter anderem Klaus Ramm, Elke Erb oder Schuldt trat er bei der Eröffnung des ersten Literaturhauses auf (BE 1986-0630/07-01). Seit 1991 fand im Literaturbaus Berlin alle drei Jahre das OULIPO-Treffen statt, das aus Arbeitstagung und öffentlicher Vorstellung bestand, „womit Sie die Gelegenheit haben, alles über OULIPO zu erfahren, was Sie immer schon wissen wollten“ (BE 2015-11-26/28). In diesem Literaturhaus ist außerdem die 2008 gegründete Oskar Pastior-Stiftung ansässig, die den Oskar Pastior-Preis vergibt an „Autoren, deren Werk in der Tradition der Wiener Gruppe, des Bielefelder Colloquiums Neue Poesie und von OULIPO (der Werkstatt für potentielle Literatur) steht"1237. Es manifestiert sich folglich im Literaturhaus Berlin eine besondere Bindung zu dem in Siebenbürgen geborenen Autor und seiner ästhetischen Orientierung hin zur Konkreten Poesie, welche die drei als Referenz für die Preiskriterien genannten Gruppierungen teilen.

Eine Beziehung zu dieser Literaturrichtung blieb ebenfalls in den anderen älteren Literaturhäusern jahrelang bestehen, wobei in den Ankündigungstexten keine Hinweise darauf gegeben werden, dass OULIPO-Veranstaltungen sich zu dieser Zeit auch an anderen Orten Erfolg und Beliebtheit erfreuten. Selbst im ersten Jahr des Literarischen Zentrums Göttingen trat Oskar Pastior auf, als Übersetzer und Vorleser italienischer Lyrik, unter anderem von Giacomo Leopardi (GT 2001-02-18). Pastior präsentierte ferner seine Texte im Jahr 2000 und 2003 im Literaturhaus Frankfurt (FF 2000-11-14 und FF 2003-01-29) und 1993 lud dieses zu einem OULIPO-Spieleabend (FF 1993-06-24) ein. Das Literaturhaus Hamburg stellte 1991 in sieben Veranstaltungen diese Literatur vor (erstmals HH 1991-03-01) und widmete sich drei Jahre später der Theorie und Praxis von OULIPO, wobei der Ankündigungstext eine Beschreibung des poetischen Programmes der Künstlergruppe liefert, das zugleich auf die damaligen literarischen Grundfesten der Literaturhäuser bezogen werden kann:

Bescheidener, realistischer auch als die Frühromantiker und die Surrealisten visieren die Oulipisten nicht die Versöhnung von Kunst und Leben an. Es geht um die ,Literarisierung der Literatur' und nicht des Lebens. Auch fehlt es völlig am elitären Getue, das dort gern aufkommt, wo der Dichter als inspirierter Seher und Künder verehrt wird. Hier geht es um literarisches Handwerkszeug, um Verfahren und Methoden, die zur Benutzung und Verwandlung explizit freigegeben sind (HH 1994-01-13).

Sie strebten keine Verknüpfung von Kunst und Alltagsleben an. Zugleich wurden Autor*innen nicht als Genies verehrt, sondern als Akteur*innen gesehen, die es ausgehend von ihren handwerklichen Fertigkeiten verstanden, Text zusammenzustellen. Literatur galt als Ausdrucksform, die vom spielerischen und experimentellen Umgang geprägt sein sollte. Dies zeigt sich außerdem im Selbstverständnis des Literaturbauses Hamburg, formuliert in einer Broschüre aus dem Eröffnungsjahr:

und nahm darin explizit Bezug auf die Gruppe 47 und ihre Art der literaturkritischen Auseinandersetzung, die hier in Bezug zum Literaturhaus gesetzt wird, vgl. Heißenbüttel 1978 sowie Kapitel I 4.2.

1237 „Oskar Pastior-Stiftung“" Literaturhaus Berlin. URL: www.literaturhaus-berlin.de/oskar-pastiorstiftung.html (Stand: 09.02.2018). 
Treffpunkt für alle, die Texte lesen, schreiben, collagieren, montieren, filmen, sprechen, drucken, verkaufen oder vertreiben, für alle, die neugierig auf die Sprache sind, über ihre Winkelzüge staunen können, sich von ihren Labyrinthen und Mehrdeutigkeiten, von ihren Krassheiten und Kessheiten provozieren lassen wollen. [...] Eine Sprachkunst, die ihre eigenen Maßstäbe setzt. ${ }^{1238}$

In diesem insgesamt circa 300 Worte umfassenden Text werden zudem Roland Barthes und Ludwig Wittgenstein zitiert, die trotz ihrer unterschiedlichen sprachphilosophischen Perspektiven eine inhaltliche Hinwendung zur sprachkritischen Theorie bezeugen. Der Text wendet sich an Akademiker*innen und Sprachinteressierte, die wissen, dass das Zitat „Lust am Text“ für eine poststrukturalistische Anschauung steht - vor allem, wenn in Klammern Roland Barthes als Urheber angegeben ist, denn die Formulierung weckt ja schon ohne Theorieanbindung vielfältige Assoziationen. Es bleibt in der Broschüre nicht bei einem Verweis auf Roland Barthes: Auf der nächsten Seite findet sich sogar ein Absatz aus „Die Lust am Text" ${ }^{“ 1239}$ abgedruckt. Für das Literaturbaus Hamburg ist es in den Anfangsjahren programmatisch, dass Roland Barthes' Explikation des Begriffes ,Text', der vor allem auf die Prozesshaftigkeit von Text abhebt, in dieser Broschüre auftaucht. Höchst interessant daran ist zudem, dass in der Forschung der sich entwickelnde Veranstaltungsbetrieb geradezu im Gegensatz zu den Theoriediskussionen um den „Tod des Autors“ ebenfalls von Roland Barthes - gesehen wird ${ }^{1240}$ und die Zunahme an Lesungen ein Zeichen dafür sei, dass der Autor keineswegs eine zu vernachlässigende Größe sei, sondern als Person die Leser*innen interessiere und dass die sogenannte ,Praxis ${ }^{6}$ konträr zur literaturwissenschaftlichen Theoriebildung handele. Anhand des genannten Beispiels offenbart sich Folgendes:

(1.) Eine strikte Trennung von sogenannter ,Praxis', also dem anwendungsorientierten Teil des Literaturbetriebs, und ,Theorie', ergo der Wissenschaft, kann in diesem Fall nicht aufrechterhalten werden, denn die Akteur*innen agieren mit ihrer Lebensform ${ }^{1241}$ in beiden Bereichen, da akademische Bezugstexte anstandslos in eine Selbstdarstellungsbroschüre des Literaturhauses einfließen. Die LiteraturhausAkteur*innen argumentieren auf Basis der Theoriedebatte.

(2.) Daran ist bemerkenswert, dass es in diesem Text zur LiteraturhausEröffnung gerade nicht um den Autor, sondern um den Text geht. Dies ist angesichts der späteren Diskussion über die „Rückkehr des Autors“1242 überraschend. Festgehalten werden kann, dass in den Literaturhäusern zu Anfang das Interesse an Sprache und Text maßgeblich war. Der zitierte Einleitungstext macht deutlich, dass der Fokus nicht auf den unterschiedlichen Akteur*innen lag, sondern auf deren Umgang mit Text.

Außerdem ist in der erwähnten Broschüre zur Eröffnung des Literaturbauses Hamburg ein Auszug von „Die Literatur als Lüge“ des italienischen Schriftstellers Giorgio Manganelli (1922-1990) abgedruckt, der darin für eine eindeutige Trennung

\footnotetext{
1238 Weiss 1989.

1239 Erschienen in: Barthes 1974.

${ }^{1240}$ Vgl. Jannidis et al. 2000a, S. 22. In diesem Band erschien Barthes' Text erstmals in deutscher Übersetzung: Barthes 2000. Ausführlicher wurde dies schon im ersten Hauptkapitel dargestellt, vgl. Kapitel I 5.4.

1241 Verwendung der Begriffsbezeichnung, Lebensform‘ nach Jaeggi 2014.

1242 Vgl. Jannidis et al. (Hg.) 1999.
} 
von Literatur und politischem Leben plädiert, ${ }^{1243}$ was sich ebenfalls als programmatische Ansage einordnen lässt. Für die literarische Entwicklung der 1980er-Jahre in der Bundesrepublik Deutschland sei „Widerstand der Ästhetik“ - der Titel des Romans von Peter Weiss (1916-1982) - zur Formel geworden, wie Ralf Schnell schreibt. ${ }^{1244}$ „Zugleich lässt sich zu Beginn der 80er Jahre ein verstärktes politisches, zumindest gesellschaftliches Engagement der Schriftsteller in der Bundesrepublik beobachten" 1245 , was sich ebenfalls anhand der Literaturhäuser belegen lässt. Die Literaturhäuser setzen stark auf thematische Diskussionen und brachten gesellschaftliche ebenso wie kunstästhetische Debatten in ihr Programm ein. ${ }^{1246}$ Anfang der 1990er haben sich Literaturstreits ob der Trennung von Politik und Literatur beziehungsweise von politisch engagierter Literatur und autonomer Kunst entsponnen. ${ }^{1247}$ In dieser Spannung positionierte sich folglich das Literaturhaus, indem es Literatur als Kunst inszenierte und gesellschaftspolitische Diskussionen anstieß, die unabhängig von konkreten literarischen Texten entstanden.

Mit der Zeit wurden die Veranstaltungen zu Sprachexperimenten im Literaturhaus seltener zugunsten einer stärkeren Inhalts- und Themenorientierung. Schon 1994 stand im Literaturbaus Frankfurt zur Debatte, ob der Gegensatz von ,engagierter Literatur' und ,reiner Literatur' für Schriftsteller*innen noch von Bedeutung sei (FF 1994-06-24). ${ }^{1248}$ Gar provozierte die Überlegung „Wozu Literatur, wir haben doch Politik“ (HH 1992-10-18). ${ }^{1249}$ Diese Beispiele beinhalten kritische Selbstbefragungen und Legitimierungsstrategien für die Literatur der Gegenwart und der Zukunft, wofür sich weitere Exempel nennen lassen: Diskussionen über Einstiege - Abschiede - die Literatur der 80er Jahre (HH 1992-09-22), über Aspekte der deutschen Nachkriegsliteratur und die Gäste „reflektieren und diskutieren über ihre mögliche Neubewertung“ (HH 1993-02-16) sowie über Addio - Abschied von der Literatur (BE 1995-11-18; HH 1996-01-26). ${ }^{1250}$

Diese Debatte zur Aufgabe von Literatur prägte die Programme der Literaturhäuser in den Anfangsjahren. Einflüsse der Konkreten Poesie, die auf auditiv inszenierte und visuell gestaltete Texte setzten, und eine Literaturauffassung, die die Aufführung als Teil ihrer Poetik begreift, spielte in den älteren Literaturhäusern eine große Rolle. ,Orale‘ Formen, verstanden als Formate, bei denen kein gedruckter Text zugrunde liegt, sondern Texte entweder für die Aufführung verfasst werden

\footnotetext{
1243 Vgl. Manganelli 1989. Der gesamte Text ist nachlesbar in: Manganelli 1987, S. 136. „Es sind also nicht die historischen Ereignisse und nicht der Leitfaden der Literaturgeschichten, die uns einen Zugang zur Literatur verschaffen, sondern die Definition der Sprache, die in ihnen Struktur gewinnt“, ebd., S. 139.

1244 Vgl. Schnell 2013, S. 668.

1245 Ebd., S. 654.

1246 Vgl. Kapitel II 13.1.3.

1247 Vgl. Opitz und Opitz-Wiemers 2013, S. 675.

1248 Der Text setzt folgendermaßen fort: „Welche Vorstellungen verbindet man mit diesem Begriffspaar in Frankreich bzw. Deutschland? Hat die Ablösung des Ost-West-Antagonismus durch eine Vielzahl unübersichtliche Konflikte das Bewußtsein von der Verantwortung der Literatur verändert? Fühlen sich die Schriftsteller durch den Zerfall des Blockdenkens eher befreit oder anderen Zwängen ausgesetzt?"“ ${ }^{1249}$ Diese Diskussion fand jedoch in der Literaturkantine statt, die nur eine von Literaturbaus Hamburg unterstützte Reihe war. Dies belegt zugleich, dass es sich bei diesen Diskussionen nicht um auf eine allein vom Literaturhaus geführte Debatte beschränkt, sondern das Thema insgesamt im Literaturbetrieb virulent war.

${ }^{1250}$ Der Gast Reinhard Baumgart hat einen Essay mit diesem Titel geschrieben, der an diesen beiden Abenden diskutiert wurde.
} 
oder in der Inszenierung stark von der fixierten Vorlage abweichen, bilden seit Beginn einen Teil der Programme. Zugleich finden sich thematische Diskussionen, die neben der Beschäftigung mit Literatur ablaufen.

Eine Wiederkehr der Oralität in der Literatur manifestiert sich in der Expansion des Literaturveranstaltungsbetriebs und begründet die Existenz der Literaturhäuser ganz grundsätzlich. Das Literaturhaus ist „primär ein Ort des Zuhörens. Und also auch ein kleines Bollwerk gegen den Niedergang des Hörens“, wie 1993 im Literaturhaus Hamburg zur Veranstaltung Die Kunst des Hörens formuliert wurde (HH 1993-1101/02). In eine ähnliche Richtung zielte ein viertägiger Workshop 1996 in Hamburg: Bei Klang - Ton - Kunst kamen auch Musikwissenschaftler*innen ins Haus (HH 1996-01-20). Daher liegt die Vermutung nahe, dass diese Strömung ebenso wie die Verwendung multi- beziehungsweise intermedialer Inszenierungsformen über die Zeit noch ansteigt. Doch dieser Annahme stehen die Programmanalysen entgegen. Im Literaturhaus Berlin kam zum Beispiel 1991 „die Ouvertüre zu einem multimedialen Lesetheater von ,Finnegans Wake““ (BE 1991-06-15) zur Aufführung und es lassen sich etwa bis zur Jahrtausendwende noch häufiger Kombinationen von Lesung und musikalischer Begleitung, beispielsweise vertonte Lyrikarrangements, verzeichnen. Tendenziell ist in den untersuchten deutschen Literaturhäusern dann ein Rückgang von Veranstaltungen mit literarischem Performancecharakter festzustellen.

Die heuristische Annahme, dass Literaturhaus-Veranstaltungen zurückgreifen auf Vorlesesituationen im Sinne des literarischen Salons, wo der Vortrag von Texten zentral war, und vor allem im Sinne moderierter Lesungen, die die Autor*innen über die eigenen Texte ins Gespräch bringen, wie sie im Kontext des Literarischen Colloquiums Berlin etabliert wurden, muss also erweitert werden. Die vorliegende Arbeit bestätigt zwar, dass die moderierte Autorenlesung das zentrale Veranstaltungsformat im Literaturhaus ist, doch gleichzeitig präzisiert die hier vorgenommene intensive Auseinandersetzung mit den historischen Programmen die Aussagen über Traditionen respektive Referenzpunkte des Literaturhauses. Das sprachkritische, avantgardistische Erbe wurde in dieser Deutlichkeit bisher nicht herausgestellt. Aus heutiger Sicht allein war es nicht zu vermuten, da es in den gegenwärtigen Programmen nicht so markant hervortritt wie in den früheren Veranstaltungshinweisen. Einschlägig ist die Feststellung, dass die Institution sich nicht bin zu einer von mündlicher Literatur geprägten Literaturvermittlungsakteurin entwickelt hat, sondern seit Beginn stark von der in den 1980er-Jahren vitalen, für die öffentliche Inszenierung produzierten Literatur bestimmt war. Darin offenbart sich nicht so sehr ein vermittelnder - im Sinne von erklärender - Zugang zur Literatur, sondern deutlicher eine gerade unmittelbare Kunsterfahrung. Die hier durchgeführten Programmheftlektüren eruieren damit ein Moment, das den Literaturhaus-Programmen und -Selbstverständnissen zwar zugrunde liegt, gegenwärtig jedoch nicht mehr kommuniziert wird. 
Für die spätere Zeit konstatiert zum Beispiel Helmut Böttiger, dass es Anfang des neuen Jahrtausends tatsächlich so geschienen habe,

dass man von zwei literarischen Parallelgesellschaften sprechen konnte: der traditionelle Literaturbetrieb auf der einen Seite, über den in den Feuilletons verhandelt und der in den betreffenden Institutionen gepflegt wird, und eine vor allem der Mündlichkeit verpflichtete Szene auf der anderen Seite, mit HiphopTexten und Rap-Lyrik, mit Slam-Poetry und Elementen des Varieté. ${ }^{251}$

Mündliche Präsentationsformen von Literatur, die aus avantgardistischer Ästhetik erwachsen, kommen in dieser Gegenüberstellung gar nicht mehr explizit vor. $\mathrm{Zu}$ dieser Zeit waren sie in den Programmen schon seltener. Für die Weiterentwicklung seit 2000 könne hingegen beobachtet werden, dass die Literaturhäuser, die nach Böttigers Auslegung zum traditionellen Literaturbetrieb zu zählen sind, verstärkt orale literarische Formen in ihr Programm integrierten und somit der Poetry-Slam und andere weniger, verkopfte' Formate Einzug ins Literaturhaus gefunden haben. ${ }^{1252}$ Die Trennung zwischen den Formaten, die sich auf schriftlich publizierte Texte beziehen, und jenen, die genuin mündliche Literatur hervorbringen, beinhaltet bei Böttiger eine Differenzierung zwischen literarischen ,Szenen“ - „literarische Gesellschaften“ bei Böttiger -, die sich dann annäherten und vermischten. Diese Unterscheidung bezieht sich also weniger auf die Art und Weise der literarischen Produktion und die Frage, ob das Präsentierte ,der Mündlichkeit verpflichtet' ist oder im Umkehrschluss der Schrift folgt, sondern verweist vielmehr auf die Annahme, dass Ende der 1990er-Jahre der Pop Einzug in die Feuilletons erhalten und so die Grenze zwischen E und U aufgeweicht habe. ${ }^{1253}$ „Die Unterhaltung ist endgültig in der Hochkultur angekommen“, wie Matthias Beilein ob der Tatsache konstatiert, dass Verlage wie Subrkamp ,neben dem anspruchsvollen literarischen und wissenschaftlichen Programm auch eine eigene Krimi-Reihe verlegen"1254. Das Literaturhaus Hamburg bot ebenfalls schon 1991 eine Veranstaltung zum Sänger der Band the doors Jim Morrison an (HH 1991-10-28). Die Tatsache, dass der Abend angekündigt wird ohne einen expliziten Verweis darauf, dass es sich um eine für das Literaturhaus sehr ungewöhnliche Vorführung handele, zeugt davon, dass die Grenzen zwischen Pop, Rock und Hochkultur damals fließend waren, womit deutlich eine inhaltliche Beeinflussung von postmodernen Literatureinflüssen erkennbar wird und die sprachkritische Linie an Relevanz verliert und sie somit heute kaum noch erkennbar ist.

\section{Unterhaltung}

Dass die zitierte Aussage Böttigers eine stärkere Einbeziehung von Unterhaltungsformaten diagnostiziert, unterstützen die Literaturhaus-Programme, für die hier schon eine nach und nach zunehmende Beeinflussung von Fernsehshows konstatiert wurde. ${ }^{1255}$ Dafür finden sich in den untersuchten deutschen Literaturhäusern

\footnotetext{
1251 Böttiger 2007, S. 9.

1252 Allerdings fand im Literaturhaus Hamburg bei der Reihe Literaturkantine des Verbands der Schriftsteller „mit freundlicher Unterstützung des Literaturhaus e. V.“ schon 1996 Poetry Slam statt (HH 1996-01-25).

1253 Vgl. Kämmerlings 2011, S. 57.

1254 Beilein 2013, S. 593.

1255 Vgl. Kapitel II 13.1.7.
} 
weitere Belege. So trat im Literaturbaus Hamburg erstmals 1999 Die Liv Ullmann Show auf - eine Veranstaltungsreihe, die üblicherweise im Club Molotow auf der Reeperbahn im Stadtteil St. Pauli stattfand - dieses Mal mit der Andy Warhol Show, initiiert unter anderem von den Hamburger Autoren und Literaturveranstaltern Alexander Posch (*1968) und Michael Weins (*1971), die bereits 1996 mit dem Laola-Club „einen Austragungsort für Literaturperformances und eine Brutstätte neuer Sprech- und Darbietungsweisen“"1256 gegründet hatten:

Das schräge Spektakel, eine sehr bunte Mixtur aus Texten, Musik, Performance und Filmen, die sich brennenden Themen wie Apokalypse, Mutter, Armut, Musik, Heimat, Haare, Orient-Express oder Seemann 2000 widmet und abwechselnd von einem der Künstler konzipiert und moderiert wird, liegt diesmal in den Händen der polnischen Diva, Trickfilmerin, Poetin und Prosaistin Mariola Brillowska. Die factory samt der Ikone Andy Warhol auf der Bühne aufleben zu lassen, ist ein alter Traum der Brillowska. (HH 1999-04-13)

Die Liv Ullmann Show im Literaturhaus ist ein passendes Exempel für die Vermischung von Pop und Hochkultur, zum einen auf organisationaler Ebene, denn die Künstler*innen, die sonst ihre Vorstellungen in einem Indie-Club darboten, wechselten für einige Abende ins Literaturhaus. Zum anderen ist Andy Warhol als Wegbereiter der Pop-Art selbst Inbild dieser Verschränkung von Massentauglichkeit und exklusiver Kunstrezeption. Die inszenatorischen Vermittlungsabsichten hinter diesen performativen Veranstaltungen sind auf einer anderen Ebene anzusiedeln als die vorne beschriebene Bezugnahme auf sprach- und kunstfokussierte Darbietungen, weil der Aspekt der Unterhaltung bei dieser Veranstaltung deutlich hervortritt. Dieser ist nicht allein auf die Popularisierungsversuche der theateraffinen Programmleiterin Ursula Keller zurückzuführen, denn Die Liv Ullmann Show wurde nach Kellers Weggang fortgesetzt und im Anschluss boten Alexander Posch und Michael Weins sowie Sven Amtsberg (*1972) „Literatur Entertainment“ unter dem Titel Shishisho (erstmals HH 2006-02-21, letztmals HH 2007-05-31). Rainer Moritz veranlasste zudem bald nach seinem Amtseintritt die Serie Irgendwie komisch, die mit dem vielseitigen Hamburger Autor, der sich Heinz Strunk (*1962) nennt, begann (erstmals HH 2005-05-26, letztmals HH 2011-06-06). Diese Reihe unterstrich den Spaßfaktor von Veranstaltungen, den der neue Leiter bei seiner ersten Vorstellung angekündigt hatte. ${ }^{1257}$ Dessen Absicht, „ohne intellektuelle Scheuklappen“ (HH 2004-12-07) Programm zu machen, lässt sich ab dieser Zeit auch für die anderen Literaturhäuser konstatieren. Das Literaturhaus Hamburg eignet sich jedoch sehr gut, diese generelle Tendenz empirisch zu fassen: Der markante Leitungswechsel Ende 2004 wurde zu einer Zeit vollzogen, in der sich dieses spezielle Literaturhaus ebenso wie der Buchmarkt beziehungsweise Literaturveranstaltungsbetrieb insgesamt im Wandel befand. Um die Jahrtausendwende gab es etwa in den Literaturhäusern in Hamburg und Frankfurt Versuche, sich einer jüngeren Szene zu öffnen, was mitunter im Kontext der gegen Ende der 1990er-Jahre wichtigen Popliteratur und des großen Interesses an literarischen Debüts zu sehen ist. Diese Veranstaltungen behielten aber Experimentcharakter und setzen sich nicht entschieden durch.

\footnotetext{
1256 Schoon 2005, S. 194.

1257 Vgl. Schellen 2004 sowie Kapitel II 2.4, S. 126.
} 
Grund für die Initiierung und gleichfalls für die Beendigung vergleichbarer unterhaltungsbasierter Reihen mag die Ausweitung des Lesungsbetriebs sein, sodass beispielsweise die Reihe Shishisho nur im Literaturhaus Hamburg aufgegeben wurde und an anderen Stellen fortbesteht. Zudem existieren seitdem beispielsweise Lesebühnen in den Städten als Orte mündlicher Literatur. ${ }^{1258}$ Ab 1989 gründeten sich diese Vortragsbühnen vor allem in Berlin, doch erst im Jahr 2000 brachte Der Spiegel einen ausführlichen Bericht über diese Lesebühnen heraus, der das Phänomen weiter bekannt machte. ${ }^{1259}$ Diese starke Präsenz von Lesebühnen in der deutschen Hauptstadt ist mit dem Programm des Literaturhauses Berlin zusammenzubringen: Einerseits lässt sich die Entstehung dieser finanziell unabhängigen Orte für Live-Literatur als Gegenbewegung zum institutionalisierten Programm des Literaturhauses interpretieren, andererseits lässt die Streuung der Literaturformate auf mehrere verschiedentlich ausgerichtete Veranstalter*innen in der seit den 1990er-Jahren kulturell stark wachsenden Metropole eine Spezialisierung einzelner Einrichtungen zu, sodass das Literaturbaus Berlin eine Nische neben den Lesebühnen besetzen konnte und es so nicht zu Überschneidungen kam. ${ }^{120}$ Die Entstehung dieser neuen Literaturveranstaltungsakteur*innen belegen ein Interesse für ,Literatur-Entertainment und die Literaturhäuser starteten Versuche, daran teilzuhaben und damit ein anderes Publikum zu erreichen.

Beleg dafür sind ferner sogenannte offene Bühnen, die zu den mündlich geprägten Auftritten zu zählen sind und sich nicht eindeutig einer der vorne aufgestellten Formatrubriken zuordnen lassen. An diesen Abenden sind im Literaturhaus alle eingeladen, literarisch produktiv zu werden und ihre Texte öffentlich vorzulesen: ein Zeichen dafür, dass nicht nur professionelle Autor*innen, sondern auch Hobbyschriftsteller*innen und Nachwuchsschreibende Raum finden. Gleichzeitig handelt es sich dabei um Präsentationen, die sich entweder als Lesung eigener Texte oder Auftritt mit Performancecharakter systematisieren lassen. Bemerkenswert ist, dass derartige Formate in den deutschen Literaturhäusern nicht mehr vorkommen, obgleich es sie vor einigen Jahren gab: Das Literarische Zentrum Göttingen etwa lud zu Open Microphone (erstmals GT 2001-07-06, letztmals GT 2004-06-29) ein und das Literaturbaus Hamburg warf Perlen vor die Säue - Literaturhaus-Premiere für unentdeckte Talente (erstmals HH 2008-04-28, letztmals HH 2010-09-15). Diese Reihen versuchten, sich einem anderen Bereich literarischer Praxis anzunähern, der nicht an den Buchmarkt gekoppelt ist. Das Aufgeben dieser Formate mag wie bei den unterhaltungsfokussierten Club-Shows damit zusammenhängen, dass sich diese Schreibszenen an anderen Orten treffen, in Hamburg zum Beispiel im writer's room, ein Arbeitsraum für literarisch Schreibende, oder in der im Jahr 2002 initiierten Location Mathilde, Literatur \& Café, wo regelmäßig Poetry-Slams und Offene-Bühnen-Abende vonstattengehen. Das Literaturhaus lädt demgegenüber erstens vor allem arrivierte,

\footnotetext{
1258 „Eine Lesebühne ist ein festes Autorenensemble, das einen regelmäßigen Termin - manche monatlich, manche wöchentlich - in einer Kneipe, einem Club oder einem Kulturhaus hat, zu dem die Literaten ihre eigenen Texte vorlesen“, Stracke: „Passivlesen oder“.

${ }^{1259}$ Vgl. Broder und Mohr 2000. Auch Stephan Ditschke macht darauf aufmerksam, dass es schwer sei, den „Beginn der Verbreitung eventartig strukturierter Literaturveranstaltungen präzise zu datieren“, Ditschke 2009, S. 309.

${ }^{1260}$ In Hamburg beispielsweise fand sich im Jahre 2005 die bis heute aktive Lesebühne LÄNGS zusammen. In Frankfurt entwickelte sich 2001 Die Lesebühne Ibres Vertranens.
} 
zum Teil internationale Autor*innen ein, und zweitens jene, die nicht zuvorderst mündliche literarische Formen präsentieren, sondern Texte vor allem schriftlich fixieren und für die stille Lektüre vorsehen. Sie sind vornehmlich dem Böttiger zufolge ,traditionellen Literaturbetrieb` zuzurechnen.

Gegenwärtig bieten die vier Fallbeispiele in Deutschland also keine Bühne mehr für nicht-professionelle Autor*innen im Erwachsenenalter. In Oslo hingegen stehen einmal im Quartal am Freitagabend unter dem Namen Apen mikrofon [Offenes Mikrofon] Podium und Mikrofon allen Interessierten offen, um eigene Texte vorzustellen. Gerahmt werden diese maximal dreiminütigen Präsentationen mit Musik von DJ und Kulturjournalist Guttorm Andreasen (*1966), sodass eine ausgelassene Atmosphäre entsteht (erstmals OL 2008-02-27). Diese Veranstaltungen, die keinen Eintritt kosten, illustrieren, dass im norwegischen Literaturhaus neben konsekrierten Autor*innen alle, die schreiben, zumindest eine kleine Auftrittschance erhalten. Das kann als weiteres Argument dafür angeführt werden, dass Litteraturbuset im Vergleich zu den deutschen Einrichtungen niederschwelliger agiert. Es mag jedoch auch der Tatsache geschuldet sein, dass sich in Oslo der Literaturveranstaltungsbetrieb (noch) nicht so weit ausdifferenziert hat wie der deutsche, der sich auf mehrere Akteur*innen verteilt. Im Litteraturbuset kommen diese zusammen, es schaffte vor rund zehn Jahren einen wichtigen Anstoß für Live-Literaturvermittlung in Norwegen.

\section{Il 13.2.5 Zwischenfazit - Veranstaltungen mit literaturinszenierendem Anteil}

\section{Formate}

Zunehmend bilden moderierte Lesungen die hauptsächliche Art der Literaturveranstaltung in den deutschen Literaturhäusern. Die Lesung ist dabei ein Bestandteil, der in den Programmen nicht als zentral markiert, aber als etablierte Praktik fortgeführt wird. Obwohl die Veranstaltungen im Literaturhaus natürlich per se mündlich sind, lässt sich erkennen, dass sich das Literaturhaus gegenwärtig weniger als Versuchsfeld mit spracherforschenden Formaten versteht. Um die Jahrtausendwende wurden Performances abgelöst von Veranstaltungen mit Gesprächsshowcharakter. Heute werden derartige Unterhaltungsformate nicht mehr forciert als solche kommuniziert. Dennoch lassen sich seit den frühen 2000er-Jahren in den LiteraturhausProgrammen Veranstaltungen und Formulierungen entdecken, in denen diese ,lauten', poppigen Formate Nachklang finden. Im jüngeren Literarischen Zentrum Göttingen tauchen diese von Beginn an auf.

Mit der Absicht, Literatur zu vermitteln, setzen die deutschen Literaturhäuser seit den Anfängen Moderator*innen ein. Den Bedeutungsgewinn der Vermittlung bezeugt der Preis der Literaturhäuser, der seit 2001 an Autor*innen vergeben wird, „die sich für neuartige Konzepte der Vermittlung von Literatur stark machen. Dabei sind die Möglichkeiten praktisch unbegrenzt. Sie reichen von der szenischen, musikalischen oder bildnerischen Darbietung von Literatur bis zur theoretischen Erläuterung literarischer Konzepte. “1261

Die Entwicklung des Literaturhauses und seine Verstetigung als Ort des Austausches zeigt sich prononciert anhand des Transfers der Institution nach Norwegen.

1261 „Der Preis“, Netzwerk der Literaturhäuser. 
In den norwegischen Literaturhäusern in Oslo und Bergen lässt sich beobachten, dass das Erleben von Literatur auf klanglicher/sinnlicher Ebene eine untergeordnete Rolle spielt. Dass die Formate sich vor allem auf Gespräche konzentrieren, die nicht unbedingt mit einer Lesung verbunden sind, belegt, dass inhaltlichen Aspekten (der Literatur) dort eine größere Relevanz zugeschrieben wird als stilistischen Punkten und unmittelbarer Kunsterfahrung. Deutlich wird aufgrund des deutsch-skandinavischen Vergleiches, dass es zwei Schwerpunkte der Literaturhaus-Arbeit geben kann: Entweder präsentiert das Literaturhaus direkte ästhetische Erfahrungen durch Lesungen und Performances, bei denen das Bühnengeschehen selbst als Artefakt inszeniert wird, oder es vermittelt stärker zwischen existierendem Text und Publikum, indem es die Lesung als Grundlage für ein Gespräch mit dem empirischen Autor begreift.

\section{Novitäten}

Es lässt sich festhalten, dass mit der Zeit im Literaturhaus mehr Lesungen aus neu erschienenen Büchern stattfinden, die nicht so sehr den experimentellen Charakter der Einrichtung betonen, sondern stärker zur Vermittlung bereits durch Verlage ausgewählter Literatur tendieren, und dass etwa ab 1998 der Anteil und nach und nach auch die Akzentuierung von Novitäten im Programm tendenziell mehr werden. Dies stützt die These unter anderem von Richard Kämmerlings und Volker Hage, dass Ende der 1990er-Jahre das Interesse an neuer Gegenwartsliteratur gestiegen sei. ${ }^{1262}$ Befördert habe dies die sogenannte Popliteratur und das ,literarische Fräuleinwunder ${ }^{6}{ }^{1263}$ deren Vertreter*innen teilweise in den Literaturhäusern zu Gast waren. ${ }^{1264}$ In dieser Zeit kamen außerdem Anthologien wie Beste Deutsche Erzäbler heraus, die die deutsche Gegenwartsliteratur bündelnd präsentieren wollten und zu illustrieren versuchten, ,weshalb deutschschreibende Autoren international bekannte Namen von ihrer Platzhirschrolle auf den Sellerlisten und in den Feuilletons verdrängen“, wie der offensive Klappentext des ersten dieser insgesamt fünf Bände erklärt. ${ }^{1265}$ Zugleich herrschte in dieser Zeit ein Übersetzerstreit über die Honorare für Übersetzer*innen, der unter anderem dafür sorgte, dass in den ersten Jahren des 21. Jahrhunderts weniger Übersetzungen auf den Markt kamen - parallel mit der höheren Zahl an deutschsprachigen Originalausgaben. ${ }^{1266}$

\footnotetext{
1262 Vgl. z. B. Kämmerlings 2011, S. 136; Hage 2010, S. 15.

1263 Vgl. z. B. Opitz und Opitz-Wiemers 2013, S. 728-730. Die Formulierung, Fräuleinwunder ' geht zurück auf Volker Hage, der diesen Ausdruck 1999 in einem Artikel in Der Spiegel verwendete: „Das literarische Fräuleinwunder ist jedenfalls augenfällig“, Hage 1999b, S. 245. Der Ausdruck wurde schnell zum literaturbetrieblichen Schlagwort. Katrin Blumenkamp untersucht ihn in ihrer Doktorarbeit intensiv und kommt zu dem Schluss, dass es sich dabei weder um eine Autorengruppe noch ein Phänomen, noch eine Marke handele, sondern um eine literaturkritische Debatte, ein Marktwunder und eine literarische Sammelbezeichnung, vgl. Blumenkamp 2011, S. 389.

1264 Vgl. Kapitel II 14.2.3.

1265 Vgl. Auffermann (Hg.) 2000. Dem zweiten Band davon widmete das Literaturbaus Frankfurt eine Veranstaltung (FF 2001-09-28).

1266 Vgl. Bachleitner und Wolf 2010, S. 19.
} 


\section{Aufmerksamkeitsökonomie}

Diese Entwicklung geht einher mit einer stärkeren Einbeziehung aufmerksamkeitsökonomischer Aspekte des Buchmarktes in die Arbeit der Literaturvermittlungseinrichtungen. So erkennt etwa Katrin Blumenkamp eine Parallele zwischen dem „Boom“ des ,Neuen Marktes“, der ,New Economy“ und dem „Boom der deutschsprachigen Literatur" um die Jahrtausendwende, den sie anhand des ,Literarischen Fräuleinwunders ${ }^{6}$ - es ,,ist beinahe ein literarisches Wirtschaftswunder “1267 herausarbeitet. ${ }^{1268}$ Ursache und Symptom für den „Boom“ zugleich ist außerdem die Tatsache, dass 2002 der Börsenverein des Deutschen Buchbandels den Deutschen Bücherpreis ins Leben rief, aus dem 2005 zum einen der Deutsche Buchpreis für den Roman des Jahres, zum anderen der Preis der Leipziger Buchmesse erwuchs, und damit eine Auszeichnung für Novitäten initiierte, die mittels Longlist und Shortlist die Aufmerksamkeit des Publikums auf Neuerscheinungen richten sollte. ${ }^{1269}$ Der verkaufsfördernde Aspekt dieses Preises unterstreicht die ökonomischen Belange des Literaturbetriebs, zu denen sich die Literaturhäuser positionieren müssen. Mit der seit 2008 jährlichen Einladung der Autor*innen, die für die Deutscher Buchpreis-Shortlist nominiert sind, markiert etwa das Literaturhaus Frankfurt explizit seine Teilnahme am Buchmarktgeschehen. Auch Nominierte für den 2008 initiierten Schweizer Buchpreis „ziehen mit ihren Texten durch deutsche Städte und geben einen Einblick ins eidgenössische Literaturschaffen der Gegenwart" (BE 2010-10-20), die Literaturhäuser in Berlin und Hamburg waren an dieser Tour beteiligt. Das Interesse an diesen Kooperationen ist reziprok, denn die Organisator*innen der öffentlichkeitswirksamen Literaturpreise möchten die eingeführten Strukturen der Literaturhäuser nutzen, während die Literaturhäuser mehrere Autor*innen präsentieren können, die in der jeweiligen Saison in Presse und Buchhandel sichtbar sind. Die Aufmerksamkeit für diese Shortlist-Autor*innen verstärken die Literaturhäuser dadurch natürlich.

Wie bereits erwähnt, beziehen sich die norwegischen Literaturhäuser nicht so ausdrücklich auf den Literaturbetrieb. Doch direkt auf literaturbetriebliche Vorgänge und Routinen referiert die jährlich Ende Oktober im Osloer Literaturhaus abgehaltene Veranstaltung mit dem Titel Äntligen [Endlich], in deren Rahmen sich die Gäste über den neuen Literaturnobelpreisträger, der oder die Mitte Oktober bekanntgegeben wird, austauschen (z. B. OL 2012-10-30). Diese Veranstaltung vermittelt Wissen und Einordnungen, sodass die Zuhörer*innen ein eigenes Urteil zum designierten Preisträger treffen können. Ebenso stellt sich jeweils der aktuelle Träger des Forschungspreises Holberghrisen [Holberg-Preis] - „Norges svar på Nobelprisen“ [Norwegens Antwort auf den Nobelpreis] - vor (OL 2009-11-26). Eine denkbare Präsentation des jährlichen Gewinners des Nordisk Råds litteraturpris [Literaturpreis des Nordischen Rats] findet hier beispielsweise aber nicht statt, obgleich zumindest im Januar 2008 im Litteraturbuset in Oslo die norwegischen Kandidat*innen über ihre Nominierung sprachen (OL 2008-01-17). ${ }^{1270}$

\footnotetext{
1267 Blumenkamp 2011, S. 389.

1268 Vgl. ebd., S. 316.

1269 Zur Rolle des Deutschen Buchpreises im Literaturbetrieb vgl. Peers und Wolf 2014.

1270 Dieser Literaturpreis ist jedoch insgesamt weniger kommerziell ausgerichtet als beispielsweise der Deutsche Buchpreis, weshalb es nicht nur im Litteraturbuset keine Preisträgerlesungen gibt, sondern insgesamt noch darauf verzichtet wird, was auch darauf zurückzuführen ist, dass Autor*innen aus ganz Nordeuropa nominiert werden.
} 
Die These, dass die Formate im Literaturhaus sich mit der Zeit, erlebnisorientierter gestalten, lässt sich anhand der Literaturhaus-Programme so nicht bestätigen, vielmehr spiegeln sie Linien ihrer jeweiligen Zeit. Sprachexperimentelle Lektüren rufen stärker performative Formate hervor, popliterarische Einflüsse unterstützen unterhaltungsorientierte Veranstaltungskonzepte und romanfokussierte Autorenbesuche fordern konzentrierte Gespräche. In allen Jahren des Literaturhauses lassen sich vielfältige Formate verzeichnen, die in der ständigen Verschiedenartigkeit weder nach Perioden noch nach Einrichtungen sortierte klare kategoriale Einordnungen zulassen. Die Veranstaltungen lassen sich insgesamt als Indizien der Erlebnisgesellschaft deuten, da sie als Live-Erlebnis beschrieben werden können. Mit der stärkeren Betonung des Gesprächsanteils, der vor allem durch den Vergleich mit den norwegischen Einrichtungen offensichtlich wird, lässt sich erkennen, dass Literaturvermittlung einerseits Literaturerfahrung, andererseits Autorenbegegnung bedeutet und beide Aspekte untrennbar miteinander verknüpft sind. Der Austausch über Literatur wird selbst zum Erlebnis. Dies entspricht dem, was zum Beispiel Paul Atkinson und David Silverman mit ihrer Beschreibung gegenwärtiger Gesellschaften als „Interview Society“ erkannt haben. ${ }^{1271}$ Dies beweist der Blick auf die Akteur*innen im nächsten Unterkapitel ebenso wie die folgenden Ausführungen zu den Formaten, die noch ausdrücklicher auf den Austausch, die Debatte, die Diskussion abzielen, doch zunächst schließen Hinweise zu den im Literaturhaus vermittelten Gattungen und Genres an.

\section{13.2.6 Gattungen und Genres}

Kvifor er det berre romanforfattarar som får sitte i djupe stolar på scena og leggja ut om sine tema, sine forteljemåter og sine tankar om alt ikring oss?

[Warum dürfen nur Romanautor*innen in tiefen Stühlen auf der Bühne sitzen und ihre Themen ausbreiten, ihre Erzählweisen und ihre Gedanken über alles um uns herum?] (OL 2009-01-29)

Diese Einleitung für einen Lyrikabend im Osloer Literaturhaus ist symptomatisch für die Verteilung der Literaturhaus-Programmpunkte hinsichtlich der drei literarischen Großgattungen: Sie konzentrieren sich auf Epik, während sie Lyrik und Drama eher marginal behandeln. ${ }^{1272}$ Was dazu in der vorliegenden Arbeit schon anklang, wird an dieser Stelle knapp gebündelt. ${ }^{1273}$

\footnotetext{
1271 ,We ask how it is that the interview and its narrative products - in all their variety - come to occupy so central a place in contemporary sociological discourse. Our suggestion is that contemporary research methods and analytic perspectives reflect a more general Zeitgeist in which the production ofselves and lives is accorded special significance“, Atkinson und Silverman 1997, S. 313.

1272 Sicherlich auch aus diesem Grund hat sich die Literaturwerkstatt Berlin 2016 in Haus für Poesie umbenannt, um den Fokus auf Lyrik und die Abgrenzung zu den anderen funktionellen Literaturhäusern in der Stadt zu betonen.

1273 Ausführlichere Befunde zu diesem Themenkomplex bedürfte einer umfassenden Untersuchung des Materials unter diesem Gesichtspunkt. Dazu müssten alle in den Programmen vorkommenden Texte kategorisiert werden.
} 
Lyrik

Die herausgearbeitete Hinwendung zu Gesprächsformaten, die ästhetischen und thematischen Fragen nachgehen, findet einfacher anhand von Prosatexten statt, da bei ihnen in der Regel der erzählende Anteil höher ist als etwa bei Gedichten. Lyrik gilt auf dem Buchmarkt insgesamt als schwieriger vermittelbare literarische Gattung. Für Gedichtbände sind geringe Verkaufszahlen üblich, massenwirksam werden sie selten ökonomisiert, daran hat sich in den letzten Jahren wenig geändert. Gleichzeitig erkennt etwa Thomas Wohlfahrt, der Leiter des Berliner Hauses für Poesie wohlgemerkt, dass während die großen Verlagshäuser ihre Lyrikproduktionen aufgäben oder sehr einschränkten, an vielen Orten kleine, sich ausdrücklich der Lyrik verschreibende Print- und Audioverlage entstünden. ${ }^{1274}$ Weiter konstatiert er: „Das Gedicht braucht, medial betrachtet, den Doppelauftritt: als zu Lesendes und zu Hörendes. "1275 Darin sieht er einen zunehmenden Erfolg von Poesiefestivals und Lyrikveranstaltungen begründet. In der Literaturwissenschaft wurde die Performance lange nicht als basale Eigenschaft von Lyrik untersucht, obwohl Aufführung und Text in der Lyrikpraxis auf das Engste verknüpft sind. ${ }^{1276}$ Neuere Forschungsbeiträge plädieren entsprechend dafür, Sprecher*in und Stimme als literaturwissenschaftliche Basismetaphern zu interpretieren und nach dem Verhältnis von Text und Darbietung zu fragen. ${ }^{1277}$ Lyrik und ihre Inszenierung nehmen diesen Beiträgen zufolge zwar ökonomisch eine Randposition ein, sind in den kleinen Szenen aber sehr aktiv. „Fakt ist“, wie ein Text aus dem Literarischen Zentrum Göttingen schon 2001 zuspitzt, „dass in der gegenwärtigen Lyrik mehr passiert als bei den neudeutschen Storytellern. Schade nur, dass die Lyrik im Nieselregen der Avantgarde zu späteren Klassikern versauert oder wegweisende Randerscheinung bleibt“ (GT 2001-04-27). Diese behauptete Zustandsbeschreibung ruft in diesem Ankündigungstext zum Gegenentwurf auf: „Aber hier nicht!“ - die Literaturhäuser könnten der Lyrik mehr Sichtbarkeit verschaffen.

Obwohl sich festhalten lässt, dass Prosa die Hauptrolle im Literaturhaus spielt, stimmt es ebenfalls, dass über die gesamte Literaturhaus-Zeit immer auch Lyrik ins Programm eingebunden ist. Die Intensivität hängt, so ist anzunehmen, unter anderem mit den Präferenzen der Programmleitungen zusammen. Für alle Fallbeispiele lässt sich festhalten, dass Lyrikangebote oft besonders gerahmt oder gleich mehrere Autor*innen eingeladen werden. Die dazugehörigen Veranstaltungsankündigungstexte beinhalten dann häufig eine besondere Einleitung: Entweder es stehen Performancequalitäten im Fokus, was der engen Verknüpfung von Lyrik und Vortrag Rechnung trägt, oder sie heben die allgemeine Bedeutung von Dichtung im Literaturbetrieb hervor, wie das Zitat aus Göttingen nahelegt. Die Bündelung mehrerer Lyriker*innen bei einer Veranstaltung erhöht die Aufmerksamkeit für die Gattung insgesamt und schafft eine Textvielfalt. Zugleich suggeriert die gemeinsame Vorstellung mehrerer Autor*innen, dass das Werk von Lyriker*innen, im Gegensatz zu dem von Prosaautor*innen, nicht für eine abendfüllende Veranstaltung tauge. Aus

\footnotetext{
1274 Vgl. Wohlfahrt: „Blick auf“.

1275 Ebd.

1276 Vgl. z. B. Novak 2012.

1277 Dies versucht ein Sammelband von 2017 systematisch und mit historischen Fallstudien anzugehen, vgl. Bers und Trilcke (Hg.) 2017.
} 
organisationalen Gründen trifft dies bei den meist in Relation zu Prosa quantitativ weniger umfangreichen Gedichten häufig zu. Beispiele aus den Fallstudien sind die Präsentation der Gedichtbände des Jahres im Literaturhaus Berlin (z. B. BE 2005-1217/18) ${ }^{1278}$, im Litteraturbuset in Oslo der Termin Snikkikk - Poesispesial (OL 2010-0805) oder die Poesiparade in der Eröffnungswoche (OL 2007-10-07). Das Literaturhaus Frankfurt betonte mit Veranstaltungen wie Deutsche und englische Lyrik von Jetzt in Kooperation mit der Universität sein Interesse an gegenwärtiger Lyrik (FF 2014-02-11). Einen Schwerpunkt auf neu entstehende Gedichte legte das Literarische Zentrum Göttingen mit dem von einem Kuratorenteam durchgeführten Poetree Lyrikfestival Göttingen, das unter anderem dezidiert mit Vermittlungsformaten experimentiert und damit die Verbindung von Lyriktext und Darbietung sichtbar macht (erstmals GT 2015-05-30). Das von Wohlfahrt beschriebene wieder steigende Interesse an Lyrikveranstaltungen lässt sich ansatzweise in den Literaturhäusern nachzeichnen, ein „Lyrikboom“ hingegen nicht.

\section{Kurzprosa}

Reflexionen über die Gattung findet in den Ankündigungstexten häufiger bei kürzeren Prosatexten und Lyrik statt. So fasste Litteraturbuset in Oslo die Auftritte von drei Autor*innen, die neue Bände mit Kurzprosa veröffentlicht hatten, unter dem Veranstaltungstitel Korttekst [Kurztext] zusammen und stellte sie umfangreichen Romanen etwa von Lars Saabye Christensen oder Vigdis Hjorth gegenüber, die zeitgleich erschienen. Präsentiert wurden Ingrid Z. Aenestad (*1983) mit der Publikation Eg kjem med toget [Ich kam mit dem Zug], Markus Midrés (*1975) mit seinem Kurzroman Tunnel und Johan Harstad (*1979) mit den kurzen Dramatexten im Band B-sider [B-Seiten] (OL 2008-11-13). ${ }^{127}$ In den 1990er-Jahren erlebte Kurzprosa in Skandinavien einen Relevanzzuwachs, was unter anderem in Zusammenhang mit dem minimalistischen Stil von Autor*innen wie der Dänin Helle Helle (*1965) oder der Norwegerin Hanne Ørstavik (*1969) befördert wurde, ${ }^{1280}$ sodass einige Novellensammlungen auch ökonomisch erfolgreich waren, etwa Bavian [Pavian, auf Deutsch unter dem Titel Süßigkeiten erschienen] der Dänin Naja Marie Aidt (*1963). Schon seit dem Realismus hat die ,Novelle', die im skandinavischen Kontext nicht nur mit dem deutschen Terminus ,Novelle‘, sondern auch als ,Kurzgeschichte übersetzt wird, eine besondere Bedeutung, sodass zu erwarten wäre, dass kürzere Prosaformen, die sich ob ihrer Länge für Veranstaltungen sowieso gut eignen, häufig in den Literaturhäusern präsentiert werden. Doch bestimmen in den vergangenen Jahren eher quantitativ umfangreiche Publikationen den Buchmarkt und die Literaturhaus-Programme, wie der Verweis im obigen Beispiel verdeutlicht. Dies tun auch andere Texte, die Veranstaltungen zu Kurzprosa ankündigen: „Novellen stiller ofte bakerst i køen når sjangrene skal på fest i det gode selskap. Nå vil vi gjøre novellen til festens midtpunkt" [Novellen stehen oft am Ende der Reihe, wenn Gattungen zu einem Fest der guten Gesellschaft gehen. Jetzt möchten wir Novellen zum Mittelpunkt des Festes machen], wie Litteraturbuset Bergen seine auf Kurzprosa

\footnotetext{
1278 Vgl. Kapitel II 13.1.2.

${ }^{1279}$ Diese drei Titel liegen bisher nicht auf Deutsch vor.

1280 Vgl. Wischmann 2006, S. 384.
} 
fokussierte Reihe Kort og godt [Kurz und gut] einleitete (BG 2015-II, S. 7). Ein Novellefest [Novellenfest] führte gleichfalls Litteraturbuset in Oslo in Kooperation mit Deichmanske bibliotek durch, bei dem unter anderem Kjell Askildsen (*1929), einer der etabliertesten gegenwärtigen norwegischen Autoren von Erzählungen, las (OL 2008-02-20). Doch den Hauptanteil am belletristischen Programm haben Romane, die als die im Literaturhaus, übliche' literarische Form angenommen wird, da bei ihnen weniger Reflektion über die Gattung stattfindet und sie so eher als ,Normalfälle ${ }^{6}$ angekündigt werden. Dies zeigt sich ebenfalls in den untersuchten deutschen Literaturhäusern.

\section{Genreliteratur}

In Skandinavien gewannen insbesondere Kriminalromane als populäres Genre seit der Postmoderne deutlich an Aufmerksamkeit. Die „entschiedene Weiterführung der sozialrealistischen Erzählung“"1281, die sich in diesem Genre erkennen lässt, sorgte unter anderem für dessen Erfolg, auch außerhalb Skandinaviens. Aus diesem Grund lässt sich vermuten, dass auch im Litteraturbuset häufig Kriminalautor*innen zu Gast sind. Doch im vom Litteraturbuset organisierten Programm finden sich nicht auffällig viele Veranstaltungen zu diesem Genre. Und das muss nicht überraschen, denn die Institution versucht immer auch Literatur zu vermitteln, die nicht bereits hohe Publizität erfährt. In den untersuchten norwegischen Einrichtungen befassen sich Veranstaltungen zu Kriminalliteratur in der Regel auf einer Metaebene mit dem Genre. Gefragt wurde etwa, was es mit dem paskeekrim [Osterkrimi] auf sich habe (OL 2008-03-11). Ein weiteres Beispiel dafür, dass Genreliteratur in Oslo wie in anderen Literaturhäusern übergeordnet betrachtet präsentiert wird und dabei nicht nur das Eintauchen in eine spannende Geschichte als relevant erachtet wird, ist der Ankündigungstext zum Besuch der britischen Autorin von Kriminalromanen Kate Mosse (*1961), der nicht die Handlung der publizierten Romane referierte, sondern explizit einen Bezug zur Rolle von Frauen in der Literatur herstellte - was wiederum eine Brücke zum Thema Feminismus schlägt (OL 2008-06-12).

In den deutschen Literaturhäusern zeigt sich eine noch deutlichere Abgrenzung beispielsweise von Kriminalliteratur in den Programmen. Das Literaturhaus Hamburg stellt diese Autor*innen beim seit 2006 durchgeführten Hamburger Krimifestival vor, eine Kooperation an anderem Ort mit dem Hamburger Abendblatt und der Hamburger Buchhandelskette Heymann. Das Literarische Zentrum Göttingen initiierte 2013 eine eigene Reihe für dieses Genre (erstmals GT 2013-03-19). Es kommt also in den Literaturhäusern nicht zu einem kategorischen Ausschluss dieser Art von Literatur, doch deutet sich an, dass eindeutige Kriminalliteratur nicht kommentarlos ins Programm integriert wird.

Dass mindestens seit dem Genrehybridroman Froken Smillas fornemmelse for sne (Fräulein Smillas Gespür für Schnee) des dänischen Autors Peter Høeg (*1957) aus dem Jahr 1992 (deutsche Ausgabe 1994) Kriminalromane ,salonfähig' wurden, lässt sich mit Beispielen aus den Literaturhäusern belegen, denn es ist nicht so, dass gar keine Kriminalromane in den Programmen vorkommen würden. Die explizite Einbeziehung dieses Genres in Hamburg und Göttingen kann im Zuge des im Fachbe-

${ }^{1281}$ Hoff und Rühling 2017, S. 27. 
reich Kulturmanagement als ,Audience development' beschriebenen Bestrebens, das Publikum zu erweitern und zu diversifizieren, interpretiert werden. ${ }^{1282}$ Genreorientierte Literatur wird im Literaturhaus nicht grundsätzlich ausgeschlossen, obgleich sie marginal vorkommt. Fantasyromane etwa finden sich maximal im Kinder- und Jugendprogramm wieder.

Ähnlich wie mit Kriminalromanen verhält es sich mit einer anderen Darstellungsform, die als Gattung von rein textbasierten Ausdrucksformen abgegrenzt werden kann: Spätestens mit Einrichtung der Hamburger Graphic Novel Tage im Jahr 2012 wird augenscheinlich, dass auch Comics in den Literaturhäusern eine Rolle spielen. Es finden sich bereits deutlich früher Beispiele: Schon 1990 gab es im Literaturhaus Hamburg Comicveranstaltungen, etwa Durchbruch. Internationale Comic-Künstler sehen die Wende im Ostblock. Dabei war vermutlich zugleich der enge Bezug zur politischen Situation ausschlaggebend für die Veranstaltung, der durch eine Ausstellung mit Originalzeichnungen aus dem Band noch unterstrichen wurde (HH 1990-04-03). Dies spricht dafür, den Literaturhaus-Programmen ein nicht rein konservierendes Literaturverständnis zu attestieren, sondern festzuhalten, dass die Einrichtungen einen offenen, experimentellen Zugang zulassen beziehungsweise dass Comics als literarisches Genre akzeptiert sind, was sich ebenfalls in der literaturwissenschaftlichen Forschung spiegelt.

\section{13.2.7 Diskussionen und Vorträge}

Die Bedeutung von Gesprächen und Debatten im Literaturhaus zeigte sich bereits in den vorherigen Kapiteln immer wieder. Explizit wird diese Wirkungsabsicht anhand der Diskussionsformate, die den Austausch zentral stellen. Vorträge, die ebenfalls regelmäßig stattfinden, stehen diesen dialogischen Formaten hinsichtlich der Vermittlungssituation zwar oppositionell gegenüber, doch sind beide sich in ihrer Vermittlungsintention sehr ähnlich: Sie beabsichtigen, das Publikum weiterzubilden. Dabei lässt sich erstens unterscheiden, wer diskutiert: Autor*innen, Verleger*innen, Literaturwissenschaftler*innen, Literaturkritiker*innen oder andere Akteur*innen. Zweitens lassen sich die Vorträge und Diskussionen nach ihrem Thema sortieren, grob gefragt: Behandeln sie einen konkreten Text oder Autor, befragen sie Literatur beziehungsweise den Literaturbetrieb auf einer Metaebene oder befassen sie sich mit einem nicht-literarischen Sujet?

Es standen in den Literaturhäusern von Beginn an metareflexive Diskussionen auf dem Programm, die sich mit dem Literaturbetrieb, seinen Institutionen und Praktiken auseinandersetzen. Das Literaturhaus Berlin widmete sich zum Beispiel in einer Reihe der Zukunft des Verlegens und so kamen dort Verlagsakteur*innen, zum Beispiel Antje Kunstmann, Gründerin und Inhaberin des gleichnamigen Münchener Verlags, und der Journalist Holger Heimann ins Gespräch (BE 2015-01-21). Das

1282 Vgl. z. B. FN 329 und Mandel 2013, S. 13. ,Audience Development ' bezeichne die Generierung und Bindung neuen Publikums mittels einer Kombination aus Besucherforschung, Marketing und Kulturvermittlung. Es beinhaltet, ,sich um bestimmte neue Nutzergruppen explizit zu bemühen und zu vermitteln: Ihr seid herzlich eingeladen“. 
Literarische Zentrum Göttingen beabsichtigte Vergleichbares mit der Kurzreihe Literaturverteiler I-III (erstmals GT 2011-06-07). Dies ist zugleich ein weiteres Beispiel dafür, dass personeller Transfer sich in den Programmen widerspiegelt, denn die Göttinger Leiterin Anja Johannsen war vorher im Literaturhaus Zürich tätig, das eine Reihe mit dem Titel Der Literaturbetrieb unter der Lupe durchführte, die ebenfalls der „Frage nach dem Zustand des Literaturbetriebs detailliert, gut informiert, zwar kritisch, aber nicht larmoyant auf den Grund gehen" ${ }^{1283}$ wollte. Haben Literaturzeitschriften noch eine Zukunft? - Das lässt sich beispielsweise in diesem Zusammenhang fragen, wie vom Literaturhaus Frankfurt angeregt. Da unter diesem Veranstaltungstitel die 1961 gegründete Zeitschrift Sprache im technischen Zeitalter ${ }^{1284}$ vorgestellt wurde, ist diese Frage als rhetorisch zu interpretieren (FF 2006-05-22). Bereits 2003 diskutierte das Literaturhaus Frankfurt über die Aussichten der Zeitschrift Literaturen, die seit 2013 nicht mehr als eigenständiges Magazin erscheint (FF 2003-12-11). Im Litteraturbuset in Oslo fand beispielsweise eine Debatte zu E-Books statt, konkret zum Steuersatz für elektronisch publizierte Texte sowie zum pressestotte [staatlicher Zuschuss für Zeitschriften] ${ }^{1285}$ (OL 2011-02-02). Diese Beispiele zeigen, dass die Frage, wie sich der Literaturbetrieb verändert und welche Auswirkungen dies auf die Akteur*innen und Praktiken hat, die Literaturhäuser diskursiv beschäftigt.

In diesem Zusammenhang sind die immer wieder auffindbaren selbstreflexiven Veranstaltungen zu nennen. In den Anfangsjahren traten diese häufiger auf, was als Station des Institutionalisierungsprozesses zu interpretieren ist, weil die eigene Position nach Legitimation sucht. Der Erste akustische Literatur-Salon Frankfurts - eine Sendung des Hessischen Rundfunks mit „Unterhaltung rund um Literatur und literarisches Leben“" begleitet von Live-Musik, Kabarett und mit Autor*innen - enthielt einen für die Radiohörer*innen erklärenden Beitrag: „Das Literaturhaus: Was ist das?" (FF 1991-10-05). 1991 wurde kurz nach der Eröffnung des Literaturhauses Frankfurt konkret zu vermitteln versucht, worum es sich dabei handelt.

Danach setzten sich die Diskussionen vermehrt damit auseinander, ob Literaturhäuser gebraucht werden, was als fortgeführte Legitimationsstrategie zu interpretieren ist. Anlässlich der Frage Brauchen wir Literatur? 1994 in Hamburg fungierte beispielsweise in diesem Ankündigungstext die Tatsache, dass Literaturhäuser aufgebaut werden, als ein Zeichen für die Relevanz von Literatur - „ganz so, als stünde die Literatur gesellschaftlich noch auf der Tagesordnung. Aber tut sie das wirklich?“ (HH 1994-03-01). ${ }^{1286} 1998$ stand unter der Überschrift Kultur im Salon die gegenwärtige Praxis des Austausches über Kultur zur Debatte: „Ist das Bedürfnis nach kultureller Reflexion, kultivierter Geselligkeit und geistreichem Umgang miteinander aus dem gesellschaftlichen Leben verschwunden?“ - oder könnte eine Renaissance der Salonkultur denkbar sein, wie im Ankündigungstext gefragt wird. Bei den Gedanken darüber, wie diese heute aussehen könne, wurde gefragt, welche Rolle Galerien und Literaturhäuser dabei spielen können (HH 1998-06-30). Diese beiden Beispiele, die

\footnotetext{
1283 „Programmarchiv, 21“, Literaturhaus Zürich.

1284 Vgl. Kapitel I 4.2.2.

1285 Vgl. Smith-Meyer und Garvik: „Pressestøtte“.

1286 Der Journalist, Übersetzer und Autor Lothar Baier (1942-2004) las an diesem Abend aus seinem 1993 als Buch publizierten Essay W as wird Literatur? und sprach auf der Bühne mit dem Literaturkritiker Hubert Winkels (*1955). Der Essay wurde 2001 im Verlag Antje Kunstmann neuaufgelegt.
} 
provokant nach der Notwendigkeit von Literatur und Literaturhäusern fragen, lieferten - so ist anzunehmen - Argumente dafür, beide als wichtig anzusehen, und mündeten vermutlich in eine Bestätigung ihrer Daseinsberechtigung.

Zu seinem sechsten Geburtstag initiierte Litteraturbuset in Oslo mit einem Symposium eine ähnliche Reflexion über seine Anfangsjahre. Eine Diskussion folgte der Leitfrage Trenger vi Litteraturhus? [Brauchen wir Literaturhäuser] (OL 2013-10-30/1103, Extraflyer). Dies belegt auch die vom Netzwerk der Literaturbäuser beauftragte und von der Bundesregierung geförderte Studie Zum literarischen Leben in den fünf neuen Bundesländern. ${ }^{1287}$ Die Autoren der Studie Stephan Porombka und Kai Splittgerber stellten ihre Ergebnisse außerdem beispielsweise im Gespräch mit Reinhard Wittmann, bis Sommer 2016 Leiter des Literaturhauses München und bis 2010 Vorsitzender des Netzwerkes, im Literaturhaus Berlin „der interessierten Öffentlichkeit“ vor (BE 2010-02-04). Die in den letzten Jahren angestoßenen Diskussionen sind seitens der Institution als Ausdruck des Selbsterhalts und der Innovation zu werten, die mit den brancheninternen Tagungen in Lenzburg und in Frankfurt fortgeführt wurden. ${ }^{1288}$ Dies betrifft nicht nur die eigene Rolle der Literaturvermittlungsinstitution als Veranstalterin, sondern bezieht den Stand der Literatur und seiner Akteur*innen insgesamt mit ein. Wie eng die Verbindung von Programm und Metareflexion ist, veranschaulicht das erwähnte Osloer Symposium, das zum einen die direkte Frage, ob Literaturhäuser nötig seien, diskutierte und zum anderen mit Gesprächen von Gästen wie der nigerianischen Autorin Chimamanda Ngozi Adichie (*1977), der Finnin Sofi Oksanen (*1977), dem rumänischen Schriftsteller Mircea Cărtărescu (*1956) oder dem Norweger Dag Solstad (*1941) in der Anwendung konkretisierte, in welcher Form Litteraturbuset als wichtige Literaturvermittlungsinstitution zu verstehen sei.

Außerdem finden in den Literaturhäusern Veranstaltungen statt, die sich mit literarästhetischen Überlegungen befassen. 2003 beispielsweise sprachen der schwedische Autor und Literaturwissenschaftler Aris Fioretos, der deutsche Autor Thomas Hettche sowie die Literaturwissenschaftlerinnen Corina Caduff und Ulrike Vedder im Literaturhaus Berlin anlässlich des Sammelbandes Chiffre 2000 über Neue Paradigmen der Gegenwartsliteratur (BE 2005-11-21).1289 Neben derartig literaturwissenschaftlich motivierten Diskussionen standen Veranstaltungen, die Literat*innen zu poetologischen Fragen explizit zu Wort kommen ließen: Für das Literarische Zentrum Göttingen schrieben Felicitas Hoppe, Feridun Zaimoglu und Roger Willemsen unter der Überschrift Das erste Jahr - im 21. Jahrbundert jeweils einen Text, ,in dem sie ihren persönlichen Blick auf den Jahrhundertanlauf festhalten“" (GT 2001-01-20) - ein medienwirksames Projekt, denn mehrere überregionale Tageszeitungen druckten „diese literarischen Inspektionen“ nachher ab. Knapp zehn Jahre später regte Litteraturhuset in Oslo einen Rückblick auf das erste Dezennium des 21. Jahrhunderts an (OL 2011-01-26): Vier Literaturkenner*innen reflektierten dabei, ob der Kampf um die Wirklichkeit - allen voran von Karl Ove Knausgård geführt, der als Bekanntester

\footnotetext{
1287 Vgl. FN 54.

1288 Vgl. FN 63.

1289 Diese Diskussion war eine gemeinsame Veranstaltung mit dem Zentrum für Gegenwartsforschung und damit explizit eine literaturwissenschaftliche Annäherung an zeitgenössische Literatur.
} 
mit der Autofiktion das Verhältnis von Privatleben und Literatur infrage stellte -, wirklich das zentrale Moment des Jahrzehnts gewesen sei, wie die Suche nach dem politischen Roman und dem Einwandererroman abgelaufen sei, und ob die große Erzählung tatsächlich passé sei. Diese Veranstaltung „En statusoppdatering“ [Eine Statusaktualisierung] bezieht 2011 dabei in der Ankündigung selbstverständlich die sozialen Medien Facebook, Twitter und Youtube ein, da diese eindeutig Einfluss auf unsere Wirklichkeitswahrnehmung haben. Derartige Veranstaltungen kommen allerdings relativ selten vor. Das Literaturhaus könnte durch sie jedoch seine Position als Ort der Gegenwartsliteratur ausbauen.

Jenseits von Debatten, die explizit die Literatur respektive den Literaturbetrieb betreffen, finden in allen untersuchten Literaturhäusern regelmäßig allgemeine kulturpolitische Diskussionen statt. Schon 1993 fragte das Literaturhaus Hamburg zum Auftakt der Reihe Perspektiven metropolitaner Kultur nach der Legitimationskrise der Literatur: Kultur für alle? (HH 1993-09-30). Die ehemalige Programmleiterin des Literaturhauses Hamburg Christina Weiss sprach später in ihrer Rolle als Kultursenatorin Hamburgs im Literaturhaus Frankfurt über Die Kunst der Vermittlung und stellte ihre Idee von Kulturpolitik als intermediäres Konzept zwischen Staat, Publikum und Kulturszene vor (FF 1998-02-27). Im folgenden Jahr erschien ihr Buch Stadt ist Bühne - Kulturpolitik heute, das ein Kapitel mit dem Titel des Vortrag enthält. ${ }^{1290}$ Diese strukturell interessierten Beiträge finden sich in den Folgejahren in den untersuchten deutschen Literaturhäusern seltener. Es liegt die Vermutung nahe, dass dies auf die enge Zusammenarbeit respektive Abhängigkeit von öffentlichen Geldern zurückzuführen ist, sodass das Literaturhaus die jeweils gegenwärtige Kulturpolitik nicht infrage stellen will. ${ }^{1291}$ Gleichzeitig birgt die Literaturhaus-Historie Beweise dafür, dass öffentlich geäußerte Forderungen fruchten können: Schon im Februar 1995 beteiligte sich das Literaturhaus Berlin an einem Aufruf von Berliner Literaturvermittlungseinrichtungen, unter anderem von der Akademie der Künste, dass die Politik das Überleben der literarischen Einrichtungen finanziell absichern solle. ${ }^{1292}$ Kulturpolitische Zuspitzungen tauchten hingegen schon früher nur vereinzelt auf: „Da dies das vorläufig letzte Nachtcafé ist (die Kürzungen!), geht die Performance in ein ,rappiges‘ Abschiedsfest über“" (HH 1994-04).

Zeithistorische Diskussionen und Gedächtnisarbeit leisten die Literaturhäuser ebenfalls - in unterschiedlicher Ausdrücklichkeit. Zum Themenkomplex ,kulturelles Gedächtnis`s sprach in Frankfurt etwa der Autor und Übersetzer Karl Dedecius (1921-

\footnotetext{
1290 Vgl. Weiss 1999. „,Wo Politik die geistige Verankerung der Gemeinschaft und ihrer einzelnen Mitglieder in der Kultur vergißt, vernachlässigt sie das eigentlich Politische. Wenn unsere Gesellschaft ihre Verantwortung für Kultur nicht erkennt und pflegt, nimmt sie dem einzelnen die wichtigste Möglichkeit, Gemeinsinn zu entwickeln. Diesen Gedanken, diesen Wert zu vermitteln, ist mein Ziel mit diesem Buch und der Leitgedanke meiner politischen Arbeit", ebd., S. 13.

${ }^{1291}$ Dies trägt möglicherweise zur Erklärung bei, weshalb der offene Brief von Hauke Hückstädt zur Förderpolitik des örtlichen Kulturamts 2015 in Frankfurt und deutschlandweit so kontrovers aufgenommen wurde, denn Veränderungsforderungen aus der Institution heraus überraschten die beteiligten Akteur*innen, vgl. Kapitel II 3.1.2.

1292 Vgl. dazu auch „Literarisches Leben“, Universität Göttingen. Diese Internetdatenbank und Dokumentationsstelle zur deutschsprachigen Literatur 1945 bis 2000 liefert hilfreiche Eckpunkte für Recherchen zum deutschsprachigen Literaturbetrieb. Die Datenbank wurde nach 2004 nicht fortgeführt, ist jedoch weiterhin einsehbar.
} 
2016) über seine Autobiografie Ein Europäer aus Lodz. (FF 2006-05-23); Tagebuchaufzeichnungen liegen dem Buch Untergetaucht. Eine junge Frau überlebt in Berlin 1940 1945 von Marie Jalowicz Simon zugrunde, das 2014 dort vorgestellt wurde (FF 2014-04-23). Markant war diese Programmausrichtung im Literaturhaus Berlin, für das sich viele Beispiele für Erinnerungs- und Aufarbeitungsveranstaltungen nennen lassen. Es nahm etwa teil am Gedenken zum Jahrestag der Bücherverbrennung (BE 2010-05-10) oder an einer weltweiten Lesung zum Völkermord in Armenien, die während des internationalen literaturfestivals berlin stattfand (BE 2015-04-21). Texte, die sich mit der Shoa auseinandersetzen, und Erinnerungspublikationen stellte die Einrichtung ebenfalls regelmäßig vor; so las etwa die Holocaust-Überlebende Lucille Eichengreen (*1925) aus ihrem Buch Von Asche zum Leben, das 1992 erstmals und 2010 in einer Neuauflage erschien (BE 2010-06-02). Ein weiteres Beispiel ist die Beschäftigung mit dem Journalisten und Autor Thomas Gnielka (1928-1965), der bereits 1952 bei der Tagung der Gruppe 47 einen Text vorstellte, der erst 2015 erschien: Seine Tochter und eine der Herausgeberinnen Kerstin Gnielka präsentierte das posthum als Buch publizierte Romanfragment Als Kindersoldat in Ausschwitz - Die Geschichte einer Klasse, das zusätzlich eine Dokumentation journalistischer Arbeiten beinhaltet (BE 2015-01-15). Flüchtlingsgespräche befassten sich in Berlin im Jahr 2000 mit Flüchtlingen des Zweiten Weltkrieges (BE 2000-02-06). Und der Literaturwissenschaftler Hans Dieter Schäfer sprach dort über sein Buch Das gespaltene Bewußtsein. Vom Dritten Reich bis zu den langen Fünfiger Jahren (BE 2010-06-04) - um nur einige Beispiele zu nennen.

Ferner werden in den Literaturhäusern zeitgenössische Phänomene, Motive und Themen reflektiert, deren detaillierte Untersuchung für Arbeiten, die sich mit konkreten Diskurssträngen befassen, ergiebig wäre. Beispielsweise war Mitte der 1990er mehrfach die in den 1980er-Jahren aufkommende Krankheit AIDS im Literaturhaus Hamburg Thema („Prae-Aids-Ära“, HH 1994-10-25, HH 1994-11-01). Mit der Zeit seltener finden sich in den deutschen Einrichtungen direkte Reaktionen auf zeitgeschichtliche Ereignisse. Das Literaturhaus Frankfurt führte etwa im Sommer 2011 den Dokumentarfilm Unter Kontrolle des Regisseurs Volker Sattel mit anschließender Diskussion vor. Die Programmankündigung stellt einen Bezug zum Atomunfall von Fukushima im März des gleichen Jahres her (FF 2011-06-09). Insgesamt lässt sich erkennen, dass die Literaturhäuser weniger versuchen, Einzelereignisse einzuordnen, sondern vielmehr allgemeinere Fragen aufwerfen. Dies zeigt sich an dem Fukushima-Beispiel, denn das konkrete Vorkommnis der Nuklearkatastrophe wird zum Anlass genommen, ein Thema aufzugreifen, das mit dem Geschehen zwar direkt verbunden ist und durch dieses an Tagesrelevanz gewinnt, doch insgesamt für wichtig erachtet wird. Die Herangehensweise der Literaturhäuser ist in diesen Fällen eher analytisch und aufklärend als kurzfristig informierend, sodass eine gewisse zeitliche Distanz nötig ist. Darin spiegelt sich ein Verständnis von Literatur als Mittel zur Weltwahrnehmung und Denkstruktur.

Die deutschen Literaturhäuser platzieren aktuelle politische Themenbereiche relativ selten ins Programm und meist in enger Kooperation mit stärker gesellschaftspolitisch engagierten Organisationen. Als Beispiel anzuführen ist die Zusammenarbeit des Literaturbauseses Frankfurt mit dem Institut für Sozialforschung und br2 Kultur, 
die sich seit 2003 halbjährlich Zeitbrüche - Diagnosen zur Gegenwart zum Thema nimmt und bei der „Zeitdiagnosen, die sich mit dem Strukturwandel des gegenwärtigen Kapitalismus beschäftigten“, vorgestellt werden (erstmals FF 2003-06-30). Im Oktober 2011 diskutierten die Teilnehmer*innen zum Beispiel über Europas Grenzen und die Situation auf der italienischen Insel Lampedusa, die seit dem sogenannten ,Arabischen Frühling‘ im Frühjahr 2011 die europäische Öffentlichkeit intensiv beschäftigte (FF 2011-10-24). Von den untersuchten deutschen Literaturhäusern in alleiniger Eigenregie angestoßen werden vergleichbare Veranstaltungen höchstens, wenn eine Neuerscheinung das Thema nahelegt.

Litteraturbuset in Oslo agiert in dieser Hinsicht energischer, da es öfter direkt auf politische Situationen reagiert. Zwei Tage nach der US-amerikanischen Wahl 2008, die Barack Obama zum Präsidenten machte, bot es „en litterær tilstandsrapport“ [einen literarischen Zustandsbericht], bei dem in der Planungsphase der Wahlausgang noch nicht antizipiert werden konnte, dieser hatte jedoch am Veranstaltungsabend direkten Einfluss auf die Diskussion (OL 2008-11-06). ${ }^{1293}$ Dabei wirkte das Literaturhaus an der unmittelbar auf das Geschehnis folgenden Reflexion und Urteilsbildung mit. Aufgrund des Aktualitätsbezugs erinnern einige Veranstaltungen an politische Talkformate im Fernsehen, wie Debatten [die Debatte]. ${ }^{1294}$ Es fällt auf, dass die norwegischen Literaturhäuser regelmäßig bestimmte Daten oder bevorstehende Ereignisse zum Anlass für Diskussionen nehmen. Am 8. März findet in der Regel eine feministisch ausgerichtete Debatte statt. Zum 1. Mai 2008 präsentierte das Literaturhaus Oslo Litteratur for arbeidernes dag [Literatur für den Tag der Arbeit], bei dem Lotta Elstad ihr Debattenbuch En såkalt drittjobb [Ein sogenannter Drecksjob] vorstellte (OL 2008-05-01).

Die in dieser Arbeit als Quellen genutzten gedruckten Programmhefte bilden keine kurzfristigen Aktualisierungen ab. So lässt sich erst bei ergänzender Onlinerecherche herausfinden, dass zum Beispiel kurz nach dem Attentat auf das französische Satiremagazin Charlie Hebdo am 7. Januar 2015 in Paris, der in Europa zum Symbol für einen Angriff auf die Meinungs- und Pressefreiheit wurde, das Osloer Literaturhaus gemeinsam mit Fritt Ord und Norsk PEN zu einer Podiumsdiskussion einlud. ${ }^{1295}$ Obschon nicht ersichtlich ist, von welcher der drei beteiligten Organisationen die Initiative ausging, markiert die Veranstaltung einen Unterschied zu den deutschen Literaturhäusern, denn die Literaturhäuser in Deutschland reagierten gerade nicht ebenso sofort auf die Ereignisse. ${ }^{1296}$ Für das Literaturhaus Frankfurt lässt sich herausfinden, dass das Kolleg Schöne Aussicht, ein Fortbildungsformat für Lehrer*innen, sich im Mai des Jahres der Frage nach der Funktion von Satire und Pressefreiheit wid-

\footnotetext{
${ }^{1293} \mathrm{Im}$ Literaturhaus Berlin wurde diese Wahl zwar ebenfalls bei einem Podiumsgespräch diskutiert, doch war dies eine Gastveranstaltung und nicht vom Literaturbaus Berlin e. V. organisiert (BE 2008-11-05). 1294 Ähnlichkeiten mit Fernsehendungen lassen sich folglich nicht nur für die Raumgestaltung festhalten, die in Kapitel II 6.3.2, S. 187 dargestellt wurde. Dieser Vergleich mit Fernsehshows soll sich an dieser Stelle nicht auf die Themenwahl beziehen, die etwa bei Polittalkshows bereits kritisch untersucht wurde. $\mathrm{Zu}$ Inszenierungsstrategien bei Polittalkshows und deren kritischer Reflexion inklusiver Zusammenfassung zu Polittalkshow im deutschen Fernsehen vgl. Gäbler 2011.

1295 Vgl. „Attentatet i“, Norsk PEN.

1296 Zumindest ergab die Recherche keine Ergebnisse. Genutzt wurde die Suchfunktion auf den Websites der Literaturhäuser, Suchwort: ,Hebdo‘ und die Suchmaschine Google (Stand: 13.08.2018).
} 
mete. ${ }^{1297} 2017$ stellte dort Catherine Meurisse, Charlie Hebdo-Redaktionsmitglied, ihr Buch Die Leichtigkeit vor (FF 2017-03-09). Im Literaturhaus Stuttgart fand bereits im Mai 2015 eine Diskussion mit dem Titel Nach Hebdo? statt, ebenfalls als Kooperation unter anderem mit dem französischen Kulturinstitut Institut Français. ${ }^{1298}$ Dies ist zwar nur ein Beispiel, doch illustriert es gut die oben beschriebene langfristigere Planung der Literaturhäuser. Die Monate im Voraus gebuchten Termine lassen in der Regel relativ wenig Platz für kurzfristigere Eingriffe ins Programm.

\section{13.2.8 Literaturproduktion}

Es lässt sich in den Literaturhäusern ferner nach Formaten suchen, die der Domäne der Literaturproduktion zuzuordnen sind. In den Literaturhäusern gilt es zu differenzieren zwischen der Schreibaktivität von Laienautor*innen und der Ausbildung von Nachwuchsautor*innen, die planen, später Berufsschriftsteller*innen zu werden. Frappant ist nämlich, dass die untersuchten Literaturhaus-Programme keine von den Literaturhaus-Teams organisierten Schreibkurse für Erwachsene, die vornehmlich zum Freizeitvergnügen schreiben, enthalten.

Institutionalisierte Schriftstellerausbildungen ermöglichen in Deutschland unter anderem das seit 1995 aktive Deutsche Literaturinstitut Leipzig (DLL) und der seit 1999 angebotene Studiengang Kreatives Schreiben und Kulturjournalismus an der Universität in Hildesheim, sowie in der Schweiz seit 2006 das Schweizerische Literaturinstitut in Biel. Die erste Einrichtung dieser Art in den hier untersuchten Regionen gründete sich 1987 in Kopenhagen: Forfatterskolen [die Autorenschule], die, zunächst in privater Trägerschaft, seit 2004 formal und ökonomisch anderen Kunsthochschulen gleichgestellt ist. Das Fach Litterär gestaltning [Literarisches Gestalten] an Göteborgs Universitet existiert seit 1996. ${ }^{1299}$ In Norwegen entstand 2007, also im Jahr, als Litteraturhuset in Oslo eröffnete, Forfatterstudiet [das Autorenstudium] an der Kunstakademie in Tromsø. Für die Aufnahme in all diese Studiengänge ist eine Bewerbung nötig, die Eignung wird somit vorab geprüft. Gewiss unter anderem als Reaktion darauf starteten die Literaturhäuser in Hamburg und Frankfurt Workshops, die Jugendlichen das Handwerk des Schreibens vermitteln und Talente entwickeln sollen. In Hamburg arbeiten seit 2006 14- bis 21-Jährige in zwei den Altersgruppen angepassten Kursen in der Prosawerkstatt Schreiblabor und in Frankfurt öffnet sich regelmäßig unter diesem Namen seit 2007 - das Schreibrimmer, das jeweils eine Prosa- und eine Lyrikwerkstatt für 14- bis 18-Jährige anbietet. ${ }^{1300}$ Geübte Autor*innen, beispielsweise in den ersten Durchgängen in Hamburg Mareike Krügel (*1977) und Kristof Magnusson (*1976) (HH 2007-01-15) und in Frankfurt Peter Kurzeck (1943-2013) und Matthias Göritz (*1969) (FF 2007-11-17/18), begleiten die Teilnehmenden im Schreibprozess. Am Ende steht eine öffentliche Abschlusslesung. In Oslo und Ber-

\footnotetext{
1297 Vgl. „Kolleg Schöne Aussicht, 06.05.2015“, Literaturhaus Frankfurt. URL: literaturhausfrankfurt.de/kolleg-schoene-aussicht/treffen/ (Stand: 30.08.2018).

1298 Vgl. „Programmarchiv 06“, Literaturhaus Stuttgart.

1299 Vgl. Kapitel II 8.2.1, S. 215.

${ }^{1300}$ Seit 2005 gab es Vorläufer, unter anderem eine Schreibwerkstatt mit dem Titel Open Writing in Kooperation mit dem Open Mike - Internationaler Wettbewerb junger deutschsprachiger Prosa und Lyrik, angeleitet von der vorherigen Preisträgerin Zsuzsa Bánk.
} 
gen bieten die Literaturhäuser gelegentlich, nicht jedoch kontinuierlich derartige Workshops an.

Aufgrund der konstatierten Absicht von Litteraturbuset, für das ,freie Wort' einzustehen, wäre zu erwarten, dass die norwegischen Einrichtungen Bürger*innen stärker zum Selbstschreiben anregen. Im eigenen Veranstaltungsprogramm finden sich aber keine Kurse dieser Art. Allenfalls die erwähnten Formate wie Apen mikrofon oder Snikkikk weisen eine Nähe zum Handlungsbereich der Produktion auf, da sie zumindest Einblicke in Unveröffentlichtes gewähren. Dabei ist eine kritische Diskussion mit der Zuhörerschaft über den Text nicht Teil des Konzeptes, sodass der Produktionsaspekt eher indirekt relevant ist, weil nicht-professionelle Schriftsteller*innen auftreten können - und auf diese Weise eventuell motiviert sind, ihre Schreibarbeit fortzusetzen. Ähnlich einzuordnen ist Litteraturcaféen [das Literaturcafé] in Kopenhagen, bei dem - jedes Mal mehrere - etablierte und neue Autor*innen ihre aktuellen Texte vorstellen, was eine Mischung aus offener Bühne und dem Osloer Snikkikk darstellt. Wie die deutschen Organisationen laden die skandinavischen folglich nicht selbst zu Literaturschulungen für Laien ein. Damit ließe sich eigentlich zu dem Schluss kommen, dass die norwegischen Literaturhäuser, wie die deutschen, vorrangig Orte für Literaturrezipient*innen und nicht so sehr für Literaturproduzent*innen sind.

In Deutschland erklärt sich dies unter anderem aus der historischen Entwicklung der Literaturhäuser, denn Literaturhäuser sind anders als Literaturbüros als Publikumsorte entwickelt worden. Hingegen sind sowohl in Deutschland als auch in Norwegen andere Organisationen auf Creative-Writing-Kurse spezialisiert. In Norwegen warten Studienverbunde wie Folkeuniversitetet [wörtlich: die Volksuniversität], private Abendkurse wie Aschehougs forfatterskole [Aschehougs Autorenschule (Aschehong ist einer der drei größten norwegischen Publikumsverlage, Anmerkung C. L.)] oder Norsk Forfattersentrum [Norwegisches Autorenzentrum] mit Schreibwerkstätten auf. Letztgenannter Verband hat seinen Hauptsitz im Osloer und eine Dependance im Bergener Literaturhaus, wo er Schreibkurse durchführt. Das ist eine Erklärung dafür, weshalb die beiden norwegischen Litteraturbuset-Stiftungen vornehmlich im Bereich der Literaturvermittlung beziehungsweise -rezeption tätig sind. Außerdem ist zu bedenken, dass durch das Internet neue Interaktionsmöglichkeiten für Schreibende entstanden sind, sodass Kritik und Hilfestellungen im Schreibprozess über spezielle Schreibforen ausgetauscht werden. ${ }^{1301}$

Die Literaturhaus-Programme bilden also kaum Angebote zur Literaturproduktion jenseits des Kinder- und Jugendbereiches ab. Es erweist sich jedoch erneut als sinnvoll, nicht nur die Veranstaltungsprogramme zu studieren, sondern die Literaturhaus-/Litteraturbuset-Konzeption einzubeziehen. Die für Autor*innen reservierten Räume im Litteraturhuset - Skriveloftet [die Schreibetage] in Oslo und Skrivestuen [das Schreibzimmer] in Bergen - sorgen nämlich dafür, literarische Schreibarbeit selbstverständlich in die Litteraturbuset-Gesamtidee zu integrieren. In Oslo waren diese insgesamt 45 Plätze schon immer kostenlos nutzbar, jede*r mit einem literaturbezo-

${ }^{1301}$ Julian Ingelmann befasst sich in seiner Doktorarbeit mit Laienliteratur in Onlineschreibforen, vgl. Ingelmann: Wortkrieger. 
genen Schreibprojekt kann sich bewerben; in Bergen kosteten sie zunächst jeweils 200 Norwegische Kronen (circa 20 Euro) pro Woche, inzwischen sind sie ebenfalls umsonst.

Damit schaffen die Einrichtungen Raum für die Autor*innen, die in der Regel weniger geleitete Schreibwerkstätten benötigen, um mit dem eigenen Text voranzukommen, hingegen einen ruhigen, gut eingerichteten Schreibplatz und die Möglichkeit, im Arbeitsalltag Kolleg*innen zu begegnen. Die dort herrschende Kombination aus konzentrierter Arbeitsruhe und kollegialem Austausch beschreibt die amerikanische Journalistin Kerri Arsenault anschaulich in ihrem Artikel über das Literaturhaus in Oslo. ${ }^{1302}$

In Göteborg erfüllt das Angebot Ett (inte helt) enkelt rum [Ein (nicht ganz) eigenes Zimmer] ${ }^{1303}$ die Aufgabe des Osloer Skriveloftet, obgleich der schwedische offene Arbeitsraum nur an bestimmten Tagen geöffnet ist. Den Austausch unter Literat*innen schrieb das LiteraturHaus in Kopenhagen vor allem in seiner Selbstdarstellung groß. ${ }^{1304}$ Diese Funktion des Litteraturhuset ist den skandinavischen Varianten gemein und unterscheidet es vom deutschen Modell. Zugleich nähert sich die skandinavische Umsetzung auf diese Weise konzeptuell dem ersten funktionellen Literaturhaus, dem Literarischen Colloquium Berlin, an, das in erster Linie ein Haus für Stipendiat*innen und damit ein Ort literarischer Produktion ist. ${ }^{1305}$

Litteraturbuset gelingt mit diesen Schreibräumen die Synthese der beiden Extreme von Literatur - geräuschlose Vertiefung und Zurückgezogenheit auf der einen, lautstarke Debatte und Sichtbarkeit auf der anderen Seite. Es reintegriert die Texterzeugung in die Institution und verknüpft damit die literarischen Handlungsbereiche Produktion, Vermittlung, Rezeption und mit der Buchhandlung ebenso die Distribution. Indem Litteraturbuset die Arbeit der Autor*innen zunächst der Öffentlichkeit entzieht, schafft es Raum für das weiterhin hauptsächliche Schaffen der Schriftsteller*innen - das Schreiben. Obwohl über diese Tätigkeit auf der Bühne gesprochen wird, wenngleich mit professioneller Distanz, und Lesungen sowie andere Auftritte das Berufsbild des Autors erweitern, bleibt die individuelle Beschäftigung mit dem eigenen Text essenziell.

Unbestritten existiert bereits lange vor dem Literaturhaus ein öffentlicher Ort für die stille und konzentrierte Auseinandersetzung mit Texten: Die Bibliothek steht traditionell gar symbolisch für den schwellenlosen Zugang zu Büchern und hält Arbeitsplätze bereit. Die bereits erläuterten Transferprozesse zwischen Litteraturhuset und Bibliothek lassen sich mit dem gerade Dargelegten noch besser veranschaulichen. Dadurch, dass das Literaturhaus die grundsätzliche Idee der Bibliothek, ein Produktionsort zu sein, modifiziert, erfährt andersherum die Institution Bibliothek

\footnotetext{
1302 Vgl. Arsenault: „At Oslo“. Der Beitrag ist auch aufschlussreich für die Weiterentwicklung der Institution Literaturhaus, weil er im Untertitel fragt: „How can we make this kind of thing happen in America?“ 1303 Vgl. Kapitel II 8.2.3, S. 218.

1304 Vgl. Kapitel II 9.3.

1305 Dank an Florian Höllerer, mit dem ich mich über diese Verbindung ausgetauscht habe und der insbesondere auf die Nähe zum LCB hingewiesen hat, zum LCB vgl. Kapitel I 4.2.2.
} 
einen Anstoß zur Aktualisierung, wie das erneuerte Bibliotheksgesetz und die daraus resultierende nationale Bibliotheksstrategie für Norwegen beweisen. ${ }^{1306}$

Durch den Vergleich des deutschen mit dem norwegischen Literaturhaus wird noch offensichtlicher, wie sehr die deutsche Version ein Ort der Vermittlung abgeschlossener Literatur ist, während das norwegische dezidiert der Literaturproduktion Platz bereitet. Gleichzeitig verknüpft Litteraturbuset Referenzmodelle wie das LCB und andere eher autorenorientierte Einrichtungen wie die Literaturbüros mit dem ,traditionellen' Konzept des Literaturhauses. Es regt implizit eine Diskussion darüber an, ob das Literaturhaus weiterhin allein ein Ort der Literaturvermittlung sein sollte beziehungsweise ob sich Literatur überhaupt ohne die Integration des Schreibprozesses vermitteln lassen sollte. Literaturvermittlung geschieht schließlich auch über den Bereich der Produktion. Die Einbeziehung von Schreibwerkstätten für junge Erwachsene und kombinierte Formate von Produktion und Rezeption im Kinderprogramm belegen, dass möglicherweise eine Öffnung in diese Richtung ebenfalls bei den deutschen Literaturhäusern im Erwachsenenbereich ansteht. Dies unterstützen nicht zuletzt Einrichtungen wie das neugegründete Literaturbaus Freiburg, das seiner Geschichte als Verein für Autor*innen und Übersetzer*innen mit der Fortführung des Literarischen Werkstattgesprächs treu bleibt und damit gegebenenfalls für die Institution neue Akzente setzt.

Neben der konkreten Produktion von Literatur gewinnen in den deutschen Einrichtungen in letzter Zeit andere Formate der Partizipation an Gewicht: Während eine Rückkehr von Lesegemeinschaften im Internet - spätestens seit erfolgreichen Plattformen wie lovelybooks - sichtbar machte, dass es ,analoge' Lesekreise durchgängig gegeben hat, ${ }^{1307}$ initiieren die untersuchten Literaturhäuser hin und wieder ebenfalls Lesekreise oder Literaturclubs. Erst seit 2016 organisiert das Literaturhaus Hamburg eine Leserunde für seine Vereinsmitglieder. Das Literaturbaus Frankfurt testet seit 2017 Shared Reading, das sich als „literaturbasierte Intervention“ präsentiert und gemeinsames Lesen in Gruppen als Anlass zum persönlichen, tendenziell therapeutischen Gespräch nimmt. ${ }^{1308}$ Beides sind Formate, die einerseits die Lektürepraxis der Teilnehmenden weiter herausbilden und andererseits einen sozialen, psychologischen Zugang zum Text nahelegen. Sie sind als Versuche zu werten, eigene Lektüreerfahrungen stärker in den Gesamtakteur Literaturhaus einzubinden.

An dieser Stelle sind außerdem die Veranstaltungen zu nennen, die sich in Diskussionen und Vorträgen dem Schreiben widmen. Obwohl sie nicht als Praxisanleitungen für Autor*innen zu verstehen sind, setzen sie sich mit der Produktion von Literatur auseinander. Fragen zum Schriftstellerberuf spielen dabei genauso eine Rolle wie Aspekte zum Handwerk und zur Kunst des Schreibens. „Ist kreatives Schreiben lehr-/lernbar?“, fragte etwa das Literaturhaus Hamburg 1999 und ließ über das „Zauberwort ,Creative Writing““ und die Veränderungen der Schreibschulen diskutieren (HH 1999-06-03). Angeschlossen an die Ausstellung Stimulanzien oder Wie sich zum

\footnotetext{
1306 Vgl. Kapitel II 7.5.

1307 Vgl. z. B. Knipp 2017, S. 176.

1308 Vgl. „An Worten“, Shared Reading.
} 
Schreiben bringen? Vom Schreiben III, die zunächst im Schiller-Nationalmuseum Marbach lief, fanden in Berlin mehrere Veranstaltungen zu diesem Themenbereich statt (BE 1995-11-03/12-03). Im Jahr 2000 sprachen ebenfalls Autor*innen unter dem Titel Schraffur der Welt über ihre Arbeit (BE 2000-03-03) oder über Paratexte. Aus der Hand oder was mit den Büchern passiert (BE 2000-04-30).

Die Reflexion über die Arbeit von Autor*innen, die über ihr eigenes Schreiben, ihren Alltag oder etwa über Aspekte literarischer Übersetzung informieren, richtet sich an ein Publikum, das an übergeordneten literarischen Fragen interessiert ist. Das Literaturhaus markiert damit, dass nicht nur die in den Texten akzentuierten Themen als zur Literatur gehörig gerechnet werden, sondern ästhetische Auseinandersetzungen auf Fragen nach den Bedingungen des Schreibens fußen. So nähert sich das Literaturhaus deutlich gegenwärtigen literaturwissenschaftlichen Fragestellungen an. Die Besonderheit des Literaturhauses ist es, dass nicht nur beobachtende Wissenschaftler*innen über derartige Untersuchungsgegenstände sprechen, sondern die Produzent*innen selbst zu Wort kommen, was andernfalls vor allem bei Poetikvorlesungen akademisch etabliert ist. Denn „,[i]n Zeiten von Poetikdozenturen und einer immer stärkeren Betonung der Gegenwartsliteratur - auch im universitären Bereich - kommt man nicht umhin, den Autor als Wertungs- und Interpretationsinstanz seiner eigenen Texte miteinzubeziehen." ${ }^{1309}$ Auf die direkte Zusammenarbeit des Literarischen Zentrums Göttingen mit der örtlichen Universität bei der 1999 eingeführten Lichtenberg-Poetikvorlesung wurde bereits eingegangen. In Frankfurt findet jedes Jahr im Literaturhaus die Abschlusslesung der über mehrere Wochen in der Goethe-Universität Frankfurt abgehaltenen Poetikdozenturen statt (z. B. FF 199602-07).

Die Veranstaltungen in den Literaturhäusern sind grundsätzlich im gesamten Literaturkontext zu begreifen, denn auf der Bühne reflektieren die Akteur*innen mehr oder weniger ausführlich ihre Rolle als Schreibende, als Kritisierende und immer auch als Lesende. Dies geschieht dezidiert für ein Publikum, weshalb es - so gesehen - als Akt der Literaturvermittlung einzuordnen ist.

\section{13.2.9 Weitere Formate}

Unter diesem Punkt lassen sich all die Formate bündeln, die nicht einer der oben genannten Kategorien angehören. Darunter sind etwa Formate zu fassen, bei denen Literatur einem anderen Aspekt gleichgestellt erscheint, wie literarische Spaziergänge oder mit einem Menü kombinierte Lesungen. Erwähnt wurden schon die über die Jahre immer wieder stattfindenden Tanzveranstaltungen, die 1997 noch als „Rock-Feten“ (HH 1997-10-23) bezeichnet wurden und ganz ausdrücklich die Geselligkeit und zwanglose Feier zelebrieren. Es fanden bereits 1993 Kombinationen aus Lesung und Dinner statt, die zum Beispiel unter dem Titel Geschmaxache die Verknüpfung von Literatur und Gastronomie betonten, denn die dabei vorgestellte Literatur sei „den Genüssen des Geistes bekanntlich zugetan, wie denen des Gaumens" (HH 1993-12-04). Als zeitlich davon entfernt liegendes Beispiel fungiert ein Fall aus dem Osloer Haus: Zunächst luden Litteraturbuset und Kafe Oslo unter dem

\footnotetext{
1309 Schmitt 2016, S. 328.
} 
Namen Spis en forfatter [Iss einen Autor] (erstmals OL 2007-10-06), dann als Kok en bokorm [Koch einen Bücherwurm] nur noch vom Restaurant organisiert (seit OL 2008-10-25), jeweils eine Autorenperson als Gastkoch ein, die begleitend zum Kochen erzählte. Dass seit jeher die Literaturhäuser Veranstaltungen mit kulinarischem Anteil durchführen, liegt an den einfachen Kooperationsmöglichkeiten mit dem im Gebäude ansässigen Restaurant. Gleichzeitig sind diese Beispiele einzuordnen in die Beobachtungen zur Bedeutungszunahme des ,Events' im Literaturveranstaltungsbetrieb, denn wenn zur Veranstaltung Essen gereicht wird, steht die Vermittlung von Literatur nicht im Mittelpunkt, sondern an der Seite von Momenten der Geselligkeit. Zugleich konkretisiert sich die beschriebene Kopplung von Literatur und Genuss im Literaturhaus, die das Literarische Zentrum Göttingen beispielsweise mit einer Veranstaltung unter dem Titel In Sachen: Genuss unterstrich (GT 2002-01-28). Über den gesamten Untersuchungszeitraum lassen sich ohne markante An- oder Abstiege kulinarisch-kombinierte Veranstaltungen verzeichnen, sie kommen gelegentlich vor und sind mit der allgemein angenommenen Eventisierung nicht mehr geworden.

Die untersuchten Literaturhäuser lassen sich folglich im Eventdiskurs weniger aufgrund von Literaturveranstaltungen in Verbindung mit ,außerliterarischen' Momenten wie Menus oder dem Wechsel an außergewöhnliche Orte positionieren, sondern durch die dargestellte leichte Zunahme an unterhaltsamen, an Fernsehshows erinnernden und vor allem Geselligkeit und Vergnügen forcierenden Formaten. Zusätzlich zu den bisherigen Ausführungen können Literaturquiz-Angebote als Beispiele angeführt werden, die an ein Kneipen- oder Pub-Quiz erinnern, bei denen in ungezwungener Atmosphäre Fragen beantwortet und Rätsel gelöst werden müssen. Der Schwerpunkt liegt dann selbstredend auf Literatur. Littquiz ist im Literaturhaus Bergen seit Eröffnung ein beständiges, jeden ersten Dienstag im Monat durchgeführtes Format mit dem in Bergen bekannten Quizmaster Jan Arild Breistein, der zudem unter anderem seit Jahren Raterunden im Café Operan und seit 2014 die TVQuizshow Jaget moderiert sowie einen festen Platz in der Zeitung Bergens Tidende belegt (erstmals BG 2013-02-05). Littquiz im Literaturhaus in Bergen ist somit eine Modifikation des ,allgemeinen' Quiz in der Stadt, möglicherweise mitinspiriert von der Osloer Idee, wo zum Jahresende der ,Norwegen-Meister' der Literatur gesucht wird (OL 2008-12-09). Das Hamburger Literaturquiz findet seit 2014 regelmäßig statt (erstmals HH 2014-07-09).

Die norwegischen Einrichtungen setzen den Unterhaltungsaspekt von Veranstaltungen zentraler als die deutschen, zum einen durch die dargestellte Konzentration auf das Gespräch der Bühnengäste ohne Lesung, zum anderen durch Versuche, die Einzelveranstaltung mit weiterem Programm zu rahmen und sie als abendfüllendes Angebot erscheinen zu lassen, wie das Publikum es vom Fernsehen gewohnt ist: In den Anfangsjahren stand in Oslo vor der eigentlichen Veranstaltung bei den Onsdagskvelder-Terminen Singelkuttet [der Single-Schnitt], wo auf Länge einer Popmusiksingle einem Publikum „som ikke først of fremst er kommet for å høre på dikt“ [das nicht vor allem gekommen ist, um Dichtung zu hören] neuere norwegische Lyrik vorgelesen wurde (OL 2007-IV, S. 4). Diese Idee wurde, wie der Name schon sagt, aus der Popmusik übernommen, wo bei Konzerten häufig Vorbands als Ope- 
ning Act auftreten; genauso sind Vorfilme aus dem Kino bekannt, die allerdings zugunsten von (Film-)Werbung seltener werden. Neben dem Einleitungscharakter eröffnet die Gedichtlektüre den Zuschauer*innen gegebenenfalls eine Entdeckung. Warum dieses interessante Prä-Format eingestellt wurde, erschließt sich aus dem Material nicht. Vermutlich stieß das Format auf kein großes Interesse oder es wurde schwieriger, Autor*innen für das Format zu gewinnen. Auch lohnte sich möglicherweise der Aufwand aus anderen Gründen nicht mehr für das Litteraturhuset-Team. Ebenso ist denkbar, dass gerade die Konzentration auf den Hauptgast herausgestellt werden sollte. Dies spräche für eine ganz andere Ausrichtung, nämlich dafür, dass mit der Literaturhaus-Veranstaltung dem Charakter einer Show mit mehreren, kurzzeitig auftretenden Gästen entgegengewirkt werden soll und die Lyriker*innen nicht nur zur Einleitung beansprucht werden sollen, sondern eine Veranstaltung jeweils nur einer Akteurskonstellation gewidmet ist - und neue Lyrik einen eigenen Programmpunkt erhalten soll.

\section{13.2.10 Intermedialität und Interdisziplinarität}

Außerdem lässt sich festhalten, dass die Literaturhäuser mit einem über Literatur hinaus ausgedehnten Gegenstandsbereich etwa hin zur Populärkultur auftreten, der sich seit der Postmoderne insgesamt in der Literatur finden lässt. Für ein erweitertes Kulturverständnis sprechen zudem die zahlreichen intermedialen und interdisziplinären Veranstaltungen, die in allen untersuchten Literaturhäusern zu allen Zeiten zu finden sind. Im Einzelfall ist eine Differenzierung zwischen intermedialen Veranstaltungen und interdisziplinären Veranstaltungen sinnvoll, weil die Betrachtungsebenen sich unterscheiden. Das erstgenannte Attribut bezieht sich auf den behandelten Gegenstand als „eine in einem Artefakt nachweisliche Verwendung oder (referentielle) Einbeziehung wenigstens zweier Medien“1310, zum Beispiel, wenn auf der Bühne Text und Musik zusammentreffen. Das zweite wird allgemein vor allem zur Benennung einer „Praxis in der Lehre und Forschung, an der mehr als eine Disziplin beteiligt ist" ${ }^{1311}$, verwendet. Es lässt sich hier jedoch auf das Zusammentreffen unterschiedlicher Arbeitsfelder und Praxisbereiche beziehen, die nicht auf die Wissenschaft beschränkt bleiben. ,Interdisziplinär' beschreibt damit eher die Art und Weise der Betrachtung eines Gegenstandes oder Themas, etwa wenn sich Literaturkritiker*innen, Literaturwissenschaftler*innen, Politiker*innen und Sportler*innen im Gespräch begegnen.

\section{Literatur und andere Kunstsparten}

Hinsichtlich ihrer Aufführungssituationen ordnen sich die hier gemeinten Veranstaltungen gegebenenfalls auf unterschiedliche Weise in die oben aufgestellten Rubriken ein. Einige sind eher Diskussionsformate, die kunstästhetische Fragen auf einer Metaebene debattieren, und somit interdisziplinär angelegt, andere sind intermedial zu nennen, da sie etwa als Performances mit theatralem Moment konzipiert sind. Die

\footnotetext{
1310 Wolf 2008, S. 327.

1311 Schlaeger 2008, S. 324.
} 
Verbindungen von Literatur und Film als narrative Medien und von Literatur und Musik als klangfokussierte Ausdrucksformen liegen nahe und werden in den Literaturhäusern regelmäßig einbezogen, sodass sich in jedem Programm Beispiele dafür finden. Auch Verbindungen von Literatur mit bildender Kunst kommen vor. Das Literaturhaus Frankfurt kooperierte beispielsweise mit dem Städel Museum begleitend zu einer Ausstellung von Emil Nolde (FF 2014-03-27). Später entstanden gemeinsam mit dem $M M K$ - Museum für moderne Kunst Frankfurt literarische Auseinandersetzungen mit Bilder unter dem Titel Acht Betrachtungen (erstmals FF 2012-10-23). ${ }^{1312}$ Originalessays zu Bildern wurden auch vom Literaturhaus Hamburg zusammen mit der Hamburger Kunsthalle in Auftrag gegeben (erstmals HH 2009-03-02).1313 Ebenso finden sich für das Literaturhaus naheliegende Veranstaltungen zur Bühnenliteratur des Theaters, wobei noch deutlicher wird, dass die Unterscheidung von ,intermedial und ,interdisziplinär' keine kategoriale, vielmehr eine analytische ist, die die verschiedenen Untersuchungsebenen der Veranstaltungen herausstellen kann. Ursula Keller initiierte etwa eine Reihe unter dem Namen Sprache ist auch ein Theater (erstmals HH 1992-02-11) und präsentierte Stücke auf dem halben Weg ins Theater (erstmals HH 2001-05-15). Beim Autorentheater wurden im Literaturhaus Berlin neue Theatertexte vor der Uraufführung vorgelesen (BE 2005-09-18). Ebenfalls kooperierte das Literarische Zentrum Göttingen bereits in seinem ersten Jahr mit dem Deutschen Theater (DT) und mit dem Jungen Theater (JT), des Weiteren führten dort etwa der damalige JT-Intendant Thorsten Schilling, eine Regisseurin des ThOP - Theater im OP Mini von Platen und der frühere DT-Intendant Mark Zurmühle ein Gespräch über die Funktion von Theater (GT 2001-11-02). Diese Veranstaltung ist nicht nur als interdisziplinäre Auseinandersetzung zu verstehen, sondern, weil das Literarische Zentrum als neue Einrichtung den gefestigten Theatern der Stadt eine Bühne bietet, auch als kulturpolitische Strategie zu interpretieren.

Gegenwärtig konzentrieren sich Zusammenarbeiten der deutschen Literaturhäuser mit Theatern auf organisationspraktische Kooperationen, indem sie beispielsweise gemeinsam Autor*innen einladen. Eine thematische Auseinandersetzung findet seltener statt, vermutlich weil in den Theatern selbst inzwischen häufig Lesungen sowie vermittelnde Angebote stattfinden.

Im Litteraturbuset fanden Veranstaltungen zu aktuellen Inszenierungen auf den städtischen Theaterbühnen statt. In Oslo standen beispielsweise Sofokles Tragödien zur Debatte (OL 2008-01-22). In Bergen lotete die Reihe Dramatiske samtaler [Dramatische Gespräche] auf unterschiedliche Weise die Verbindungen von Theater und Literatur aus (erstmals BG 2014-05-07). Zum Auftakt setzten sich der Autor Olaug Nilssen (*1977), der Dramentexte schreibt und Romane, die zum Teil auf der Bühne umgesetzt wurden, die Autorin Vigdis Hjorth, deren Roman Leve posthornet! [Es lebe das Posthorn!] von 2012 ebenfalls für das Theater adaptiert wurde, sowie die Moderatorin Agnete Haaland, Schauspielerin und Chefin des Bergener Theaters Den

\footnotetext{
13122016 wurde eine weitere Reihe durchgeführt. Die Essays der beiden Acht Betrachtungen sind jeweils als Sammelband erschienen, vgl. Gaensheimer und Hückstädt (Hg.) 2013; Gorschlüter und Hückstädt (Hg.) 2016.

1313 Diese Essays wurden ebenfalls in einem Band publiziert, vgl. Gassner et al. (Hg.) 2013. Im Frühjahr 2018 wurde die Reihe wiederaufgenommen.
} 
Nationale Scene, mit dem Trend auseinander, dass in jüngster Zeit oft Theaterstücke gespielt werden, die auf Romanen basieren. ${ }^{1314}$

\section{Literatur und andere Disziplinen}

Neben Verbindungen zu anderen Kunstsparten lassen sich Kombinationen von Literatur und beispielsweise Politik relativ oft verzeichnen, die nicht selten innerhalb von Reihen präsentiert werden. Darunter sind sowohl motivgeschichtliche Annäherungen an Literatur zu bündeln als auch Lektüreerfahrungen von politischen Akteur*innen. Das theoretisch endlose Themenspektrum literarischer Texte grenzen die Schwerpunkte somit auf einige Sujets ein. Inhaltsfundierte Zugänge zur Literatur sind dabei eine übliche Annäherung an literarische Texte, so habe beispielsweise der Begriff des Wissens auch in der Literaturwissenschaft in den letzten Jahren „eine außerordentliche Bedeutung gewonnen" ${ }^{1315}$. Zudem lassen sich auf diese Weise möglicherweise neue Publika erschließen und Zuschauer*innen attrahieren, die sich für das interdisziplinäre Zusammentreffen aus der anderen Perspektive interessieren, da sie etwa aus dem Bereich der Politik kommen. So könnte deren Interesse für Literatur geweckt werden, denn diese Veranstaltungen propagieren schließlich indirekt die Vielfalt der Literatur, indem sie sie gleichzeitig auf spezielle Lesarten zuspitzen und Sachbücher sowieso schon einbeziehen. Es gibt ebenfalls Versuche, die Nähe von Literatur zu verschiedenen Disziplinen anhand von Einzelpersonen zu illustrieren: „Welche Bedeutung haben zeitgenössische deutschsprachige Bücher für die Haltungen und Handlungen der sogenannten Entscheider" - so lud das Literaturhaus Berlin in einer Reihe Personen aus der Wirtschaft zum Gespräch mit Autor*innen ein, deren Werke für sie wichtig waren (erstmals BE 2008-01-25). Ein vergleichbares Konzept setzte Litteraturbuset Bergen mit Bok \& Storting um.1316

Auf die intensive Auseinandersetzung mit (gesellschafts-)politischen Fragestellungen im Literaturhaus wurde an mehreren Stellen in dieser Arbeit bereits eingegangen. Direkt zur politischen Diskussion trug Litteraturhuset in Oslo beispielsweise im Wahljahr 2009 bei mit Kulturens partilederdebatt, wo analog zu der im Fernsehen gesendeten Den store partilederdebatt [Die große Debatte der Parteivorsitzenden] die kulturpolitischen Sprecher*innen der Parteien zu Fragen, die in der großen Diskussion oft nicht vorkommen, Position bezogen (OL 2009-08/10). Diese Debatte wurde im Hörfunk live ausgestrahlt und der Eintritt war frei, sodass alle Bürger*innen teilhaben konnten. Im gleichen Quartal setzten sich die Lordagsforedrag mit Wahlkampfthemen wie dem medialen Einfluss auf Wahlentscheidungen oder der Rhetorik der Politik auseinander. In kommenden Wahljahren setzten die Partilederforedrag [Parteichefvorträge] fort. Diese Reden aller Parteichefs dienen als Instrument zur Urteilsfindung für das Publikum und sind natürlich auch als Wahlkampf zu bewerten, bei dem Litteraturhuset alle Bewerber*innen zu Wort kommen lässt.

\footnotetext{
${ }^{1314}$ Dies ist eine Beobachtung, die für deutsche Theaterbühnen auch gilt, vgl. z. B. Lipinski 2014, S. 1.

1315 Geisenhanslüke 2013, S. 152.

1316 Vgl. II 13.1.6, S. 356 sowie S. 358.
} 
Einen weiteren großen Bereich stellen Literaturveranstaltungen dar, die einen Bezug zu Glaubens- und Denkrichtungen herstellen, denn: „Seit Beginn der 2000er beobachten Philosophen und Sozialwissenschaftler etwas, das sie die ,Wiederkehr der Religion(en)' nennen. Postsäkulare Gesellschaft hin oder her - die Frage nach einem Gott beschäftigt viele Leute offenbar wieder verstärkt, nicht zuletzt die Schriftsteller.“ (GT 2012-07-12) Mit diesen Worten führte das Literarische Zentrum Göttingen seine neue Reihe Der Geist webt ein, die mit dem Besuch des deutschen Autors Patrick Roth (*1953) begann. Die Literaturhäuser in Oslo und Bergen führten ähnliche Reihen durch. In den anderen Literaturhäusern finden sich genauso Belege für das Interesse an einer Auseinandersetzung mit Religion. Zugleich wird Religion immer wieder implizit bei der Lektüre thematisiert, beispielsweise bei der Lesung des französisch-belgischen Autors Éric-Emmanuel Schmitt (*1960) aus seiner Erzählung Monsieur Ibrabim und die Blumen des Koran, denn ,,so erfahren wir mehr über den muslimischen Glauben, französische Holocaust-Opfer und muslimische Einwanderer“ (FF 2003-03-16).

Andere interdisziplinäre Abende befassen sich mit Literatur und Philosophie, wie Der Autor \& sein Kritiker, wo der Wiener Autor Robert Menasse (*1954) aus Schubumkehr (1995) las und der Philosoph Konrad Paul Liessmann „den Roman kritisch kommentieren" sollte (BE 1995-03-24). Weiteres Beispiel ist das Philosophische Café in Hamburg (erstmals HH 1999-01-14). ${ }^{1317}$ Überdies ist die Kombination von Literatur und Psychologie anzuführen, die besonders Veranstaltungen unter den Überschriften Literatur und Psychoanalyse (z. B. FF 1994-11-08; HH 1999-11-23), Literatur und Unbewnßtes (z. B. FF 1994-01-27; FF 1996-02-29) oder, in der für Titel beliebten chiastischen Struktur, Psychoanalyse in der Literatur - Literatur in der Psychoanalyse (z. B. FF 2001-09-19) präsentieren, oder die Berliner Serie Der Autor und sein Seelenarzt (z. B. BE 2015-06-04).

Literatur und Sport ist ferner ein regelmäßig präsentiertes Thema: Schon Mitte der 1990er-Jahre liefen in den Literaturhäusern Veranstaltungen zum Beispiel über Fußball. „Am Wochenende finden die zeitgenössischen Dramen nicht auf den Bühnen der Stadttheater, sondern in den Fußballstadien statt. [...] Gibt es eine Ästhetik des Fußballs?" (FF 1994-06-14) wird im Programmtext zur Literarischen WMEröffnung mit Helmut Böttiger und seinem Buch Kein Mann, kein Schuß, kein Tor. Das Drama des deutschen Fußballs gefragt. Die Verbindung zur Literatur ist auch augenscheinlich beim Besuch des italienischen Autors Nanni Balestrini (1935-2019), dessen vorgestelltes Buch von Mailänder Fußballfans erzähle, aber vielmehr ein Spiel mit Sprachmaterial sei: „Ein Rückblick auf die Avantgarde und ein Ausblick auf die zeitgenössische Moderne“ (FF 1996-02-15).

Besonders während der im Sommer durchgeführten Europa- oder Weltmeisterschaften, Zeiten, in denen diese Sportart im Alltag noch präsenter ist, greifen die Literaturhäuser Fußball als kulturwissenschaftlichen Gegenstand auf. So veranstaltete das Literaturhaus Berlin bereits an seinen Eröffnungstagen „eine offene Gesprächsrunde nach dem Endspiel der Weltmeisterschaft" unter dem programmatischen Titel Fußball - Kultur - Literatur mit unter anderem dem Autor Hans Christoph Buch, der Literaturkritikerin Sibylle Cramer, dem Politiker Otto Schily unter der

${ }^{1317}$ Bereits eingeführt wurde diese Reihe in Kapitel II 13.1.6. 
Moderation von Klaus Ramm (BE 1986-06-30). Dies geschah vermutlich mitunter deshalb, weil das WM-Finale viele potenzielle Besucher*innen der LiteraturhausEröffnung attrahierte. Litteraturbuset in Oslo überträgt gelegentlich sogar Fußballspiele und rahmt die Ausstrahlung mit einer literarisch oder kulturwissenschaftlich fundierten Diskussion. Der Text zur Veranstaltung Cupfinalevorspiel - Fotball, filosofi und litteratur [Cupfinalevorspiel (Cupen, kurz für Norgesmesterskap i fotball for herrer, vergleichbar mit dem DFB-Pokal Deutschland, Anmerkung C. L.) - Fußball, Philosophie und Literatur] weist daraufhin, dass in den vergangenen zehn Jahren eine Wechselbeziehung zwischen Autor*innen und Fußball stattgefunden habe, dass etwa die Bücher von Jon Michelet (*1944), Autor und Journalist, und Dag Solstad (*1941), einer der bedeutendsten norwegischen Gegenwartsautoren, eine andere, kulturwissenschaftliche Perspektive auf Fußball voranbrachten (OL 2007-11-10). ${ }^{1318}$ Zugleich erzählten, dem Programmtext zufolge, Fußballer*innen häufiger von ihrer Lesebegeisterung und veröffentlichten teilweise selbst Bücher. Zu erwähnen ist beispielsweise die 2011 erschienene ,genredifuse“"1319 Biografie Jag är Zlatan Ibrabimovic/Ich, Zlatan Ibrabimovic des schwedischen Profifußballers, die der schwedische Autor David Lagercrantz $(* 1962)$ verfasste. Auch in den Geisteswissenschaften besteht, nicht zuletzt seit dem Bedeutungsgewinn der Cultural Studies, eine enge Verbindung zu Themen wie Fußball respektive Sport allgemein, wie zahlreiche Publikationen nahelegen. Das Literarische Zentrum Göttingen wendete sich dabei unter anderem dem insgesamt eher marginalisierten professionellen Fußball von Frauen zu, etwa mit dem Besuch des ehemaligen Fußballprofis Renate Lingor (GT 2010-0701). Radsport beispielsweise war dort ebenfalls Thema (z. B. GT 2010-07-05).

In Norwegen kommt noch der Wintersport hinzu. Während der Skiweltmeisterschaft in Oslo 2011 diskutierten jeden Abend „forfattere og gamle skihelter“ [Autor*innen und alte Skiheld*innen] über die Zusammenhänge von Skisport, Literatur und kulturellem Gedächtnis, denn Skisport sei „en del av den norske identiteten i over hundre år" [seit über hundert Jahren ein Teil der norwegischen Identität] (OL 2011-02-23/03-06). Litteraturbuset $i$ Bergen widmete dem Thema Sport eine eigene Reihe Mål og mening ${ }^{1320}$. Der Sportjournalist Davy Wathne interviewte dabei jeweils Kulturakteur*innen und Sportakteur*innen gemeinsam. Den Auftakt machten der norwegische unter anderem mit dem Bragepreis ausgezeichnete Autor und „fotballyriker" [Fußballlyriker] Frode Grytten $(* 1960)$ und der Kreativdirektor des Senders TV 2 Sporten Michael Allen (BG 2015-04-21). Daran exemplifiziert sich ebenfalls, dass im Literaturhaus ein weites Kulturverständnis vorherrscht, denn die Fragen: „Er ikke sport kultur? Og er ikke kultur ofte en ekstremsport?“ [Ist Sport nicht Kultur? Und ist Kultur nicht oft ein Extremsport?] sind als rhetorische zu deuten.

Interdisziplinarität und Intermedialität spielen für die Institution folglich eine wichtige Rolle. Dabei gilt es wieder, eine Balance zu finden zwischen der Zusammenarbeit mit anderen Bereichen und der Betonung der eigenen Alleinstellungsmerkmale, um zu legitimieren, dass das Literaturhaus einerseits relevanter kultureller und sozia-

\footnotetext{
1318 Die beiden Autoren haben zusammen fünf Bücher zu den fünf Fußballweltmeisterschaften 1982 bis 1998 im Verlag Oktober veröffentlicht.

1319 Eglinger 2016, S. 390.

1320 Buchstäbliche Übersetzung: Ziel/Tor und Sinn, referiert auf die Redewendung ,uten mål og mening“, was ,planlos` bzw. ,ohne Sinn und Verstand' bedeutet.
} 
ler Akteur ist, andererseits seine Grundidee, ein Haus für Literatur zu sein, fortführt. Über die gesamte Existenzzeit des Literaturhauses lassen sich derartige Veranstaltungen verzeichnen, was darauf hinweist, dass es sich dabei um grundsätzlich zeitlose und Literatur insgesamt eingeschriebene Themenbereiche handelt. In den Anfangsjahren der untersuchten deutschen Literaturhäuser wurden diese Fokussierungen offensiver kommuniziert, später müssen interdisziplinäre und intermediale Veranstaltungen in der Außenkommunikation nicht mehr besonders herausgestellt werden, sie finden sich selbstverständlicher ins Programm integriert.

Wie angekündigt waren die in diesem Unterkapitel deduktiv aufgestellten Rubriken Anlass, zum einen die Programme der Literaturhäuser näher zu beschreiben, zum anderen übergeordnete Fragestellungen anzugehen, um die Institution Literaturhaus in ihrer jeweiligen Zeit zu kontextualisieren. Es zeigte sich, dass das jeweilige kulturelle Umfeld Einfluss auf die Art der Literaturvermittlung nimmt. Gleichzeitig offenbarte der Vergleich, dass in den deutschen und skandinavischen Literaturhäusern sehr ähnliche und diverse Formate genutzt werden, was für die Mobilität von Praktiken spricht. ${ }^{1321}$ Wie sich ferner bewiesen hat, lassen sich die Formate kaum getrennt von inhaltlichen Aspekten betrachten, weshalb immer wieder Vor- und Rückbezüge auf andere Stellen in dieser Arbeit sinnvoll waren. Diese Vorgehensweise setzt sich im folgenden Abschnitt fort. Leitend ist dabei die Konklusion aus der Analyse der Formate, dass Literaturvermittlung im Literaturhaus einerseits reine Literaturerfahrung, andererseits stärker diskursive Auseinandersetzung bedeutet und damit die Einbeziehung der Autor*innen eng verknüpft ist.

\section{14 Programmanalyse - Autor*innen als Akteur*innen}

Grundsätzlich ist die Tatsache, dass zwischen 1995 und 2001 weitere Literaturhäuser, unter anderem in Stuttgart und Köln, und das Literarische Zentrum Göttingen eröffneten, und dass die Idee in Skandinavien aufgegriffen wurde, gleichermaßen Indiz wie Grund für die Erweiterung der Autorenrolle um den öffentlichen Auftritt. Diese Frage, ob Autor*in oder jeweiliger Text Anlass für die Einladung ins Literaturhaus ist, steht am Anfang einer Diskussion. Die hier vorgenommene Analyse von Veranstaltungsankündigungstexten zeigt unmissverständlich, dass es nicht nur um die Bedeutung eines Themas oder eines Buches geht, sondern die beteiligten Akteur*innen ebenso eine beachtliche Rolle spielen. Das zeichnet sich mit der Zeit deutlicher ab, etwa aufgrund des metonymischen Gebrauchs der Personennamen der Autor*innen für deren Texte und der Gleichsetzung etwa von ,Debütant' mit dem ,Debüt“ - gleichsam eine Verwendung als Markenlabel. „Der Autorname fungiert dabei als Markenname, der einen Stil, eine Erzählweise, eine Vorliebe für Themen, Settings und Plots, aber auch bestimmte Inszenierungspraktiken einer Künstlerpersönlichkeit in nuce markiert." ${ }^{3322}$ Außerdem erwähnen die Programmtexte

1321 Vgl. Grage 2014.

1322 Wegmann 2011, S. 12. 
biografische wie bibliografische Informationen zu den Akteur*innen. Der Biografie des Gastes wird also eine Bedeutung für die Literaturveranstaltung zugeschrieben. Anschaulich macht dies ein Wortlaut des Literaturbauses Hamburg zu einer Lesung des schwedischen Autors Lars Gustafsson (1936-2016), dass seine Bücher oft persönlich seien, er an diesem Abend jedoch ,ganz persönlich“ auftrete (HH 1991-1015). Diese Formulierung ist zwar nicht typisch für die frühen Texte des Literaturhauses Hamburg, macht aber klar, dass die persönliche Seite des Schriftstellers sowohl in dessen Werken als auch auf der Bühne keinesfalls zugunsten textästhetischer Aspekte ausgeklammert bleibt, sondern - im Gegenteil - ein wichtiger Punkt bei dem Besuch ist. Die Überlegungen aus dem ersten Kapitel zur Authentizitätsdebatte greifen an dieser Stelle. ${ }^{1323}$ Zudem bestätigt sich wieder einmal, dass die literaturtheoretische Diskussion um den sogenannten ,Tod des Autors' und seine Rückkehr als bedeutungskonstituierende Instanz des Textes für die Untersuchung der Institution Literaturhaus überhaupt keine Rolle spielt, da es hier um den empirischen Autor geht. ${ }^{1324}$ In den Literaturhäusern wird eine Mischung aus Veranstaltungen mit noch unbekannten, zu entdeckenden Autor*innen und arrivierten Literat*innen sowie Abenden zu ,Klassikern' angeboten. Veranstaltungen zu Verstorbenen finden besonders anlässlich von Jubiläen, der Publikation von Biografien, Neuübersetzungen oder Werkausgaben statt.

\section{14.1 Autor*innen im Literaturhaus - Beruf und Funktion}

Neben der ästhetischen und inhaltlichen Programmatik ist die Anwesenheit der Autor*innen von Beginn an zentral für die Literaturvermittlung im Literaturhaus. Doch wer ist mit ,Autor*in' eigentlich gemeint? Die bereits herausgestellte Einbeziehung von Sachbüchern und die Ausweitung dessen, was im Programm des Literaturhauses über ein streng literarisches Verständnis hinaus präsentiert wird, beweist, dass ,Autor*innen“ im Literaturhaus nicht nur Autor*innen in einem engeren Sinne, also Schriftsteller*innen belletristischer Literatur, sind. Neben Verfasser*innen von Publikationen, im Belletristik- und im Sachbuchsegment, werden beispielsweise Musiker*innen, Politiker*innen oder Wissenschaftler*innen in die Programme einbezogen, die ebenfalls ,Autor*in“ sein können, wenn dies als „Bezeichnung für den geistigen Urheber von Texten jeglicher Art" ${ }^{\text {"1325 }}$ definiert wird. ${ }^{1326}$

$\mathrm{Zu}$ differenzieren ist zwischen der Verwendung von ,Autor*in' als Berufsbezeichnung respektive Selbstverständnis und als Funktionsbezeichnung bei der einzelnen Veranstaltung. Letzterer benennt die Person auf der Bühne, die über ihr eigenes Schaffen spricht, beziehungsweise deren Werk Thema ist, also die Person, auf die der Fokus eingestellt ist. Der Terminus ist somit anwendbar sowohl etwa auf den

\footnotetext{
${ }^{1323}$ Vgl. Kapitel I 5.6.3.

1324 Vgl. Kapitel I 5.4.

1325 Nünning 2008, S. 41.

${ }^{1326}$ Das Register der erwähnten Autor*innen im Anhang umfasst die in dieser Arbeit erwähnten, aus den Literaturhaus-Programmen entnommenen Autorennamen. Dabei werden die Künstler*innen einbezogen, die im Fokus der Veranstaltung stehen, vgl. V 4. Dass dies nicht immer trennscharf ist, führt das vorliegende Kapitel aus.
} 
Inder Kiran Nagarkar (1942-2019), der seinen übersetzten Roman vorstellte (BE 2005-03-15), als auch auf Ralf Rothmann (*1953), der aus seinem Roman Junges Licht las (BE 2005-03-11), und auf die Übersetzerin Rosemarie Tietze (*1944), die ihre deutsche Fassung von Wiktor Wawitsch präsentierte, und den Russen Boris Schitkow (1882-1938), den Verfasser dieses Romans von 1941 (BE 2005-02-17).

Nicht alle Gäste auf den Literaturhaus-Bühnen sind als ,Fokusgäste‘ zu klassifizieren. Moderator*innen oder Diskutant*innen nehmen eine vermittelnde Position ein. Für literarische Interviews allgemein lässt sich zusammenfassen, dass zu den Aufgaben des Interviewers gehört: „to direct the talk, to create a sense of intimacy, and to extract new information while typically rendering himself as invisive as possible." ${ }^{1327}$ Bei unterschiedlichen Veranstaltungsformaten und Gästen bedarf es verschiedener Gesprächsleiter*innen, Mediator*innen oder Kontrahent*innen beziehungsweise hat die Auswahl der Moderator*innen markanten Einfluss auf die Konzeptionierung der Veranstaltung, denn es handelt sich in der Regel um dialogische Formate. ${ }^{1328}$

Die Mediation ist für das Verständnis des Literaturhauses als Literaturvermittlungsinstitution wichtig, sodass für die Analyse ebenfalls relevant ist, wer für die Gesprächsführung verantwortlich zeichnet. Dabei fällt auf, dass einige Moderator*innen wiederkehrend vorkommen. Aus organisatorischen Gründen sind oft ortsansässige Moderator*innen eingeladen, weil dann die Reise- und Übernachtungskosten geringer sind. ${ }^{1329}$ Dennoch werden nicht immer dieselben Personen engagiert und nicht alle kommen aus der jeweiligen Veranstaltungsstadt, was die Hypothese stützt, dass die Literaturhäuser abwechslungsreiche Gespräche anbieten möchten. Auch die professionelle Herkunft der Podiumsgäste ist relevant, um nachzuvollziehen, welche Disziplinen in den Einrichtungen aufeinandertreffen. Das gilt auch, obwohl, wie oben zitiert, die Moderator*innen in der Regel möglichst unsichtbar sein sollen - was die Ankündigungstexte zeigen, weil sie ihnen deutlich weniger Platz einräumen als den Hauptgästen. Und gleichzeitig sind sie für das Gelingen einer Veranstaltung maßgeblich verantwortlich.

Ebenso im Hintergrund präsentiert finden sich in den deutschen Einrichtungen die Schauspieler*innen oder Sprecher*innen, die bei ausländischen Gästen aus den Übersetzungen lesen. Namentlich erwähnt werden sie in der Regel, sodass implizit deutlich wird, dass sie erstens für die Vermittlung eine notwendige Rolle spielen und zweitens, dass es eine Lesung aus der deutschen Übersetzung überhaupt geben wird. Die Nennung von Moderator*innen und gegebenenfalls Vorleser*innen oder Dolmetscher*innen macht sie sichtbar und informiert das Publikum über die Akteur*innen und erläutert zumindest ansatzweise die Praktik der Literaturveranstaltung.

Autor*innen sind gelegentlich als Moderator*innen oder Diskutant*innen tätig. Obgleich Akteur*innen ihrem Beruf und/oder Selbstverständnis zufolge als Au-

1327 Masschelein et al. 2014, S. 20-21.

${ }^{1328}$ Dies betonen Hoffmann und Kaiser für Autoreninterviews, vgl. Hoffmann und Kaiser 2014, S. 20.

${ }^{1329}$ Die Lordagsforedrag im Litteraturbuset in Oslo etwa werden in der Regel von Referenten aus Oslo gehalten, was aber nur dadurch kommuniziert wird, weil in einem Programmtext steht, dass ein Gast dieses eine Mal nicht - wie sonst üblich - aus Oslo komme (OL 2009-12-12). 
tor*innen zu klassifizieren wären, muss dies nicht ihrer Funktion bei der einzelnen Veranstaltung entsprechen. Besonders in Norwegen ist aus den Ankündigungstexten oft nicht ersichtlich, in welcher Rolle Autor*innen eingeladen sind. Sind sie als Moderator*innen beim Besuch von anderen Schriftsteller*innen oder als gleichermaßen zentrale Gäste eingeladen? Das kollegiale Nebeneinander bringt eine andere Unterhaltung über Literatur hervor als bei vor allem professionellen Leser*innen als Gegenüber.

Anja Johannsen macht darauf aufmerksam, dass zahlreiche personelle Überschneidungen zwischen Wissenschaft und Feuilleton wahrnehmbar seien. ${ }^{1330}$ Und Berufsschriftsteller*innen sind ebenfalls professionelle Leser*innen - oft haben sie ein literaturwissenschaftliches Studium absolviert - und viele sind als Literaturkritiker*innen, Literaturexpert*innen, Moderator*innen und Kurator*innen im Einsatz.

In Oslo stellten gelegentlich zeitgenössische Autor*innen ihre Vorbilder oder von ihnen geschätzte Texte vor. So sprach Frode Grytten (*1960) über den Japaner Haruki Murakami (OL 2008-10-16), Tore Renberg (*1972) an drei Abenden über seine Lieblingsautoren (OL 2009-02-14). In ein Gespräch trat der norwegische Prosaautor Johan Harsted (*1979) an mehreren Terminen mit Autor*innen, „han har et spesielt forhold til“" (OL 2009-02-19) [zu denen er eine besondere Beziehung hat]. Die Zuschauer*innen interessieren sich offenbar dafür, wie diese in Norwegen sehr bekannten Autoren über Literatur und ihre eigenen Leseerfahrungen sprechen.

In Deutschland lud etwa die deutsche Autorin und studierte Religionswissenschaftlerin Sybille Lewitscharoff (*1954), die 1994 mit einem Prosaband debütierte und 2013 den Georg-Büchner-Preis erhielt, im Literaturbaus Berlin zur Reihe Literatur und Theologie (erstmals BE 2005-06-14). Im Literaturbaus Frankfurt sprach der Autor Thomas Hettche $(* 1964)$ an vier Abenden über Kunst und Leben mit Autor*innen wie Karl Schlögel (FF 2011-05-04) - zudem ein Beispiel für eine Veranstaltung, die Literaturproduktion und -vermittlung auf einer Metaebene betrachtete. Hettche kuratierte 2000 bereits das Symposium Buchmaschinen im Literaturbaus Frankfurt. ${ }^{1331}$ Er war und ist außerdem gelegentlich zu Diskussionsrunden zur Situation der Gegenwartsliteratur eingeladen. Daran zeigt sich ferner, dass einige Autor*innen sich für spezielle Themen qualifizieren und als passende Gesprächspartner*innen häufiger im Einsatz sind. So ist der deutsche Autor und Musiker Thomas Meinecke (*1955) oft Gesprächspartner bei Veranstaltungen, die Literatur mit (Pop-)Musik verbinden. Regelmäßige Auftritte im Literaturhaus tragen nicht nur zu ihrer Kanonisierung als Schriftsteller*innen bei, sondern schaffen außerdem eine Art „Bühnenkanon“ des Literaturhauses.

Autor*innen sind in verschiedenen Rollen und Funktionen im Literaturhaus aktiv, was auch damit zusammenhängt, dass unterschiedliche Formate das Programm der Einrichtungen bestimmen. Statt kategorisierender Untersuchungen sind qualitative und beispielhafte Analysen für dieses literarisch geprägte Forschungsobjekt zielfüh-

${ }^{1330}$ Vgl. Johannsen 2010, S. 107. Diese Annahme findet mit der vorliegenden Arbeit Bestätigung und sie betrifft die als Kritiker*innen und Mitarbeiter*innen in den Literaturhäusern Tätigen und gleichfalls die Bühnengäste. Bei diesen wird in der Regel erwähnt, wie sie ausgebildet sind oder in welchen Arbeitsbereichen sie aktiv sind/waren.

1331 Vgl. FN 1080. 
render, die dem jeweiligen Einzelfall Rechnung tragen. Die folgenden Überlegungen zu den Teilbereichen (1.) Kanonisierung, (2.) nationale beziehungsweise internationale Ausrichtung und (3.) Gender gehen von den Bühnengästen aus und beziehen übergeordnete Überlegungen mit ein. Es zeigt sich - zum Beispiel anhand der Frage nach der internationalen Ausrichtung der Literaturhäuser -, dass die einzelnen Variablen - wie die Herkunft der Gäste, politische Handlungsabsichten oder Programmschwerpunkte der Einrichtungen - sich gerade in ihrem Zusammenspiel zu entscheidenden Faktoren entwickeln.

\section{14.2 Kanonisierung}

„Die Kultur unserer Gegenwart ist eine Frontlist-Kultur. Was ,alt ${ }^{6}$ ist, was nicht mehr in Front ist, entscheidet sich ratzfatz. Nicht gerade ermutigend für Autorschaft, die naturgemäß Ewigkeit will.“"1332 Einmal angenommen, diese Ausführungen, die das Literaturhaus Frankfurt zur Beschreibung der Reihe Backlist nutzte, stimmen, so referiert der dritte Satz auf das, was fachsprachlich mit der Bezeichnung „Kanon' gefasst wird. Antithetisch dazu beschreibt dieses Zitat die Beschleunigung des Literaturbetriebs, der relativ schnell entscheide, welche Texte und Autor*innen bleiben und überdauern werden. Auf diese Kanonisierungsprozesse hat jede Veranstaltung im Literaturhaus Einfluss, da diese Einrichtungen an der Verbreitung eines Werkes beteiligt sind - auch, weil sie andere Akteur*innen nicht auswählen. Detlev Schöttker betont, dass Autorpräsenz als Voraussetzung für Kanonpräsenz gelte, denn ohne die Sichtbarkeit des Autors sei die Aufnahme in den Kanon unwahrscheinlich. ${ }^{1333}$ Die Literaturhäuser befördern diese Präsenz des Autors, ${ }^{1334}$ sie tragen somit zur Kanonisierung von Autor*in und Text bei, die ohnehin eng verbunden sind, was sich in den Veranstaltungsankündigungen widerspiegelt.

Als erster Schritt zur Kanonisierung kann schon die Einladung zu einer Buchvorstellung ins Literaturhaus überhaupt angesehen werden, denn damit attestiert diese Einrichtung den Verfasser*innen einen Status als Autor*in. Zwar müssen sie damit noch nicht weit bekannt sein, jedoch können sie als akzeptiert gelten, denn es steht außer Frage, dass die schreibenden Personen als Schöpfer*innen eines Textes vorgestellt werden. Dies trifft zumindest auf das Literaturhaus und die einzelne Veranstaltung zu, denn was danach hinsichtlich des Status passiert, entscheidet mit darüber, ob sich weiteres Potenzial zur Kanonisierung entfaltet: Werden die Akteur*innen erneut ins Literaturhaus oder von anderen Einrichtungen eingeladen? Werden die vorgestellten Bücher weiterhin von der Literaturkritik besprochen? Wie also entwickeln sich die Autorenlaufbahnen?

Um die Beziehung von Kanon und Literaturhaus zu beleuchten, soll die oftmals, auch in der vorliegenden Arbeit, selbstverständlich genutzte Begrifflichkeit um das

\footnotetext{
1332 „Programm. In steter Folge“, Literaturhaus Frankfurt. URL: literaturhaus-frankfurt.de/programm/ in-steter-folge/ (Stand: 30.08.2018).

1333 Vgl. Schöttker 2002 und FN 1123.

1334 Vgl. Johannsen 2012b, S. 183.
} 
Lexem ,Kanon' präzisiert werden. Ich schließe an die Beiträge an, die einen ,Kanon` nicht normativ setzen, sondern deskriptiv verwenden. ${ }^{1335}$ Simone Winko stellt heraus, dass ein Kanon literarischer Texte nicht als Verzeichnis vorliege, hingegen sei er rekonstruierbar über die Präsenz literarischer Texte und die Kommunikation über diese. ${ }^{1336}$,Kanon“ ist „ein diskursiver und materialer Verweisungszusammenhang [...], der Texte explizit als kanonisch markiert oder implizit ihre Zugehörigkeit zu anderen Texten herausstellt, die als kanonisch gelten. “1337 Kanon ist folglich als ,per se dynamisches, sich kontinuierlich veränderndes Phänomen“"1338 zu verstehen. Damit verbunden ist die Annahme einer „Kanonpluralität“: „Verschiedene Trägergruppen haben abweichende Selbstdarstellungs- und Legitimationsbedürfnisse und kanonisieren daher unterschiedliche Texte." "1339 Aus diesem Grund müssen die jeweilige Bezugsgruppe und der historische Kontext in die Überlegungen einbezogen werden. ${ }^{1340}$ Wenn vom dem Kanon die Rede ist, ist meist ein mit unterschiedlichen Attributen bezeichneter Kanon gemeint. Ein absoluter Kanon, ein Spitzen- oder Musterkanon „umfaßt weltliterarisch unangefochtene Werke/Autoren. [...] [S]eine Zeitresistenz scheint auf intraästhetischen Qualitäten zu beruhen, die ihn für künstlerische wie für nichtkünstlerische Diskurse in den verschiedensten Zeiten anschlußfähig machen“1341. Dieser wird von deutungsmächtigen Instanzen geprägt.

Simone Winko beschreibt die Bildung von Kanones einleuchtend als invisible handPhänomen. ${ }^{1342}$ Anja Johannsen betont in diesem Zusammenhang den Nutzen der Untersuchung des Literaturhauses, „die Chance nämlich, Kanonisierungsprozesse gewissermaßen am lebenden Beispiel zu beobachten“1343. So kann das Vorkommen bestimmter Autor*innen und Texte in den Literaturhaus-Programmen ebenfalls als ein Zeichen von Kanonisierung interpretiert werden. Sie lassen - darin Literaturgeschichten, Jubiläumsfeiern oder Gedenkorten ähnlich - „gleichsam ,empirische Rückschlüsse zu auf Gestalt und Struktur, aber auch den Grad der Normativität, Stabilität und Dynamik ,des` Kanons ,der' Gegenwart, der zwar als Ganzer analytisch unzugänglich bleibt, sich aber in konkreten Wertungshandlungen manifestiert."1344 Außerdem ist zu bedenken, dass das Literaturhaus als Literaturvermittlungsinstitution in Bezug auf Kanones sowohl unbewusst als auch absichtlich agiert.

Er [der Kanon, Anmerkung C. L.] resultiert aus zahlreichen einzelnen Handlungen (Mikroebene), die jede für sich einen anderen Zweck haben als den, einen Kanon zu bilden, und die unter Ausnutzung allgemeiner Prämissen einen Prozess in Gang gesetzt haben, der ihn (auf der Makroebene) dennoch entstehen lässt. Dem widerspricht nicht, dass es auch Instanzen gibt, die der ,Pflege' von Kanones

\footnotetext{
1335 Vgl. Winko 1996, S. 585.

1336 Vgl. ebd., S. 597.

1337 Kampmann 2011, S. 15. Kampmann entwickelt die Idee des von Renate von Heydebrand geprägten ,Deutungskanons' weiter, den diese vom ,materialen' Kanon differenziert, den sie in einen fixen ,Kernkanon' und einen ,akuten Kanon' mit geringerer Festigkeit unterteilt, vgl. Heydebrand 1993, S. 5.

1338 Herrmann 2013, S. 103.

1339 Winko 1996, S. 597.

${ }^{1340}$ Vgl. Heydebrand 1998, S. 612 sowie Blumenkamp et al.: „Kanon war“.

${ }^{1341}$ Heydebrand 1998, S. 615, mit Verweis auf die Beiträge von Alois Hahn, Jutta Osinksi und Jürgen Link im gleichen Band.

1342 Vgl. Winko 2002.

1343 Johannsen 2010, S. 108.

${ }^{1344}$ Herrmann 2013, S. 109.
} 
dienen, dass also Kanones nicht allein aus kontingenten Handlungen entstanden sind, sondern auch mit gezielten Maßnahmen gestärkt und gefördert werden. ${ }^{1345}$

Das Literaturhaus lässt sich als Instanz der bewussten Kanonpflege einordnen und zugleich als Akteur, der eher ,zufällig' die Entstehung eines Kanons auf der Makroebene unterstützt.

Da Kanonisierung mit Verzögerung eintritt, ${ }^{1346}$ ist es sinnvoll, für die Analyse von Gegenwartsliteratur Abstufungen zwischen den Extrempolen ,unbekannt ${ }^{6}$ und ,kanonisiert ${ }^{`} \mathrm{zu}$ nutzen - zumal Gegenwartsliteratur oft das noch unabgeschlossene und damit vorläufige Werk von Autor*innen umfasst. ${ }^{1347}$ Gewinnbringend für die Forschung zu heutigen Kanonisierungsprozessen ist Elisabeth Kampmanns Dissertation über den Deutschen Taschenbuch Verlag, die die „Bedeutung, die Verlagen hinsichtlich der Kanonisierung literarischer Texte und Autoren zukommt" ${ }^{\text {"1348, }}$, herausstellt. Mit ihrem darin entwickelten Beschreibungsmodell für Kanonisierungsprozesse differenziert sie die drei Status Publizität, Etabliertheit und Kanonisierung durch die Dimensionen Reichweite und Dauer, die vor allem für die Untersuchung von Gegenwartsliteratur produktiv sind. „Für die Herstellung der Publizität für einen Text oder Autor ist die Dimension der Reichweite entscheidend, für die Etabliertheit die der Dauer. Finden Texte oder Autoren über einen langen Zeitraum in der Öffentlichkeit Beachtung, lässt sich von Kanonizität sprechen. “1349 Zwischen ihnen bestehe keine lineare Abhängigkeit. Publizität und Etabliertheit weisen lediglich ein Potenzial zur Kanonizität aus, die ihrerseits dem „Paradigma der Verbindlichkeit" ${ }^{\text {"1350 }}$ unterliege und der Rezeption in institutionellen Rahmen mit hoher Reichweite bedürfe. Die breite Anerkennung verstetige sich dann in der Praxis von Universitäten, Schulen, Bibliotheken oder beispielsweise in Gesamtausgaben.

Gerade für die Analyse der Gäste im Literaturhaus sind die Vorstufen von Kanonizität nützliche Ausdrücke, da sie Nuancen ermöglichen. Die in den Programmheften angekündigten Veranstaltungen beziehen sich mehrheitlich auf in Verlagen erschienene Publikationen. ${ }^{1351}$ Passend $\mathrm{zu}$ dieser Beobachtung führt Elisabeth Kampmann aus, dass Verlage durch die Bereitstellung und das Labeling von Titeln entscheidend Teil an der Rezeptionssteuerung von Literatur und von Kanonisierungsprozessen haben. ${ }^{1352}$ Das Literaturhaus ist als ein den Verlagen nachfolgender Akteur der Rezeption und Verbreitung von Literatur zu betrachten, nach Heydebrand und Winko „der zweite Filter, den Neuerscheinungen zu passieren haben“"1353. Das Literaturhaus bestätigt entweder den Status des jeweiligen Autors, verstärkt ihn, oder es bezieht sich ex negativo darauf, indem es aus der Verlagsselektion noch unbekannte Titel auswählt und ,entdeckt‘. Der Auftritt von Autor*innen

\footnotetext{
1345 Winko 2002, S. 11.

1346 Vgl. Winko 1996, S. 585.

1347 Vgl. Beilein 2012, S. 43.

1348 Kampmann 2011, S. 407.

${ }^{1349}$ Ebd., S. 31

${ }^{1350}$ Ebd., S. 32-33.

1351 Vgl. Kapitel II 11.2.3.

1352 Vgl. Kampmann 2011, S. 7.

1353 Heydebrand und Winko 1996, S. 100.
} 
im Literaturhaus lässt sich einerseits als Indikator für den jeweiligen zuschreibbaren Status deuten, andererseits als ursächlicher Faktor beziehungsweise Beitrag dazu interpretieren.

Das Literaturhaus ist eines der „Registrationsmedien [...], die die diskursive Präsenz literarischer Texte herstellen, konstatieren oder reflektieren“1354. Dabei trägt es zu allen drei Zuständen bei, was die Annahme von Kampmann relativiert, dass die Status unterschiedlichen Registrationsmedien zugeordnet seien. ${ }^{1355}$ Das liegt hier mit daran, dass das Literaturhaus selbst Akteur innerhalb von Verweiszusammenhängen ist und entsprechend andere Registrationsmedien einbezieht, indem es Bestsellerlisten erwähnt, Buchrezensionen aus überregionalen Zeitungen zitiert, Autor*innen als Referenzen hinzuzieht oder Gedenkveranstaltungen organisiert. Dies wurde in der vorliegenden Arbeit berücksichtigt, indem den Veranstaltungsankündigungstexten unter anderem Funktionen als Zeitdokument, als feuilletonistischer Kommentar und als Speicher zugeschrieben wurden. Darüber hinaus spielt die Rezeptionslenkung eine wichtige Rolle. Vor allem die in dieser Arbeit untersuchten Programmhefte bieten mit ihren Texten teilweise eigene kleine Buchrezensionen, die zwar in der Regel lobend bis neutral sind und doch eigene Blicke auf die jeweilige Publikation offenlegen. Teilweise werden lediglich die Pressetexte der Verlage übernommen oder paraphrasiert, womit nur eine bereits vollzogene Textinterpretation wiederholt wird. Dies ist ebenfalls der Fall, wenn Kritiken zitiert werden. Das unbewusste Mitschreiben am Kanon wird auch dadurch plastisch, dass das Literaturhaus als Literaturvermittler die präsentierten Texte gar nicht vorstellen kann, ohne zu einer bestimmten Lesart anzuregen. Bei der eigentlichen Präsentation während der Veranstaltung gibt das Literaturhaus-Team die Kontrolle zwar größtenteils ab und überlässt Moderator*in und Autor*in die Bühne, doch im Vorfeld steuert die Einrichtung über die Ankündigung und gegebenenfalls im Nachgang in Berichten die Wahrnehmung von Autor*in und Text.

Das Beschreibungsmodell von Kampmann ist sehr hilfreich, ${ }^{1356}$ sofern die verwendeten Vokabeln nicht als Kategorien, sondern als Pole verstanden werden, die ein Kontinuum abstecken. Auf die Relationalität der Status Publizität, Etabliertheit und Kanonizität geht Kampmann nicht ausdrücklich ein, führt jedoch später die Fachwörter ,Kanonisierungsgrad ${ }^{6}$ und ,Kanonisierungsfortschritt‘ ein. ${ }^{1357}$ Das Modell sollte jedenfalls von einer ununterbrochenen Reihe möglicher Zwischenstatus ausgehen, denn ein Text kann nur in Beziehung zu anderen beispielsweise als etabliert gelten. So sollte etwa der Status der Etabliertheit nicht ausschließlich binär funktio-

\footnotetext{
1354 Kampmann 2011, S. 31.

1355 Vgl. ebd., S. 34.

1356 Kampmann betont, dass ihr Modell auf deutschsprachige Literatur in der Bundesrepublik Deutschland zugeschnitten und nicht unbedingt ohne Modifizierungen übertragbar sei. Die vorliegende Arbeit legt nahe, dass ihr Zugang durchaus auf die internationalen Autor*innen im Literaturhaus sowie auf den norwegischen Literaturbetrieb angewendet werden kann. Zumindest ließe sich auf diese Weise etwas über den Status des ausländischen Autors im jeweiligen Literaturhaus-Land herausfinden. Zugleich sind das Übersetztwerden und die Lesereisen im Ausland gegebenenfalls Zeichen der Etabliertheit im Erstkontext, was sich auf die Rezeption im Zweitkontext auswirkt. Gerade bei Markteinführung eines Autors spielt die mögliche Publizität oder Etabliertheit im Erstkontext als Werbemittel eine wichtige Rolle. 1357 Vgl. ebd., S. 367-368.
} 
nieren, denn Autor*innen sind nicht nur etabliert oder nicht, sie können auch etablierter oder weniger etabliert sein als Vergleichsakteur*innen.

Ebenfalls sind die Dimensionen der Dauer und der Reichweite für den Einzelfall zu operationalisieren. Hat der schweizerische Autor Peter Stamm (*1963) Kanonizitätsstatus, weil sein Roman Agnes seit einigen Jahren ,Sternchenthema' im Deutschabitur in Baden-Württemberg ist, und es entsprechend mindestens zwei als Buch publizierte Lektüreschlüssel gibt? ${ }^{1358}$ Dies legt die Vermutung nahe, dass die stärkere Beschäftigung mit Gegenwartsliteratur in Bildungs- und Forschungsinstitutionen den Aspekt der Dauer relativiert. Doch spricht das Beispiel zugleich dafür, der Dauer gerade mehr Bedeutung zuzuteilen. In kürzerer Distanz zur Publikation wird Gegenwartsliteratur beispielsweise von schulischen Curricula aufgenommen, doch Kanonizität bedarf weiterhin längerer Präsenz. Wird der Roman Agnes in zehn, zwanzig Jahren noch mit großer Reichweite rezipiert werden, also nach der Periode seiner Zeitgenossenschaft? Darüber lässt sich nur spekulieren, allerdings macht die Frage deutlich, dass zu gegenwärtigen Texten und Autor*innen nur Indizien vorliegen können, die eine Option auf Kanonizität anzeigen, und keine Belege.

Betont sei noch einmal, dass die Literaturhaus-Programme in diesem Kontext lediglich einen Teil zur Untersuchung von Einzelfällen beitragen. Kanonisierung ist ein komplexer Prozess, bei dem das Literaturhaus nur eine Komponente darstellt. ${ }^{1359}$ Die vorliegende Arbeit ist hinsichtlich ihrer Überlegungen zur Kanonforschung auf einer Mesoebene angesiedelt. Mit der Institution Literaturhaus bezieht sie die Akteursebene mit ein, legt also nicht nur eine Makroperspektive vor, die eher übergeordnet theoretisch interessiert ist. Sie fokussiert jedoch ebenso wenig auf Einzelfälle auf der Mikroebene, die in diesem Fall eine Untersuchung einzelner Autor*innen bedeuten würde. So ist die Arbeit ein Zwischenschritt, der ein Anstoß für die Erforschung des Kanonisierungsprozesses konkreter Beispiele, das heißt einzelner Autor*innen, sein kann. Dazu müssten weitere Kanonisierungsinstanzen hinzugezogen und eine Art Vergleichskorpus genutzt werden. Außerdem sollten zusätzlich zu kontextuellen Faktoren textuelle Eigenschaften einbezogen werden, um zu beantworten, warum ein bestimmter Text beziehungsweise Autor kanonisiert wird und andere nicht. ${ }^{1360}$ Außerdem sei ausdrücklich gesagt, dass „die Rekonstruktion eines Kanons immer nur bedeuten [kann], einen Ausschnitt des dynamischen, diskursiven Prozesses annäherungsweise nachzubilden“1361. Das Folgende stellt exemplarisch vor, wie die über die Literaturhaus-Programmhefte vermittelten Inhalte zur Analyse von Kanonisierungsprozessen fruchtbar sein können, wobei für ausführliche Studien die jeweilige Fragestellung beziehungsweise der betrachtete Kanon Präzisierung erfahren müssen.

\footnotetext{
1358 Vgl. Königs Erläuterungen und Materialien (2014) und Reclam Lektürescblüssel (2011).

${ }^{1359}$ Das umfassende Handbuch Kanon und Wertung berücksichtigt eine Reihe weiterer Instanzen der Wertung von Literatur, vgl. Rippl und Winko (Hg.) 2013.

${ }^{1360}$ Vgl. Rippl und Winko 2013, S. 1. Zur Notwendigkeit empirischer Belege für die Kanonforschung vgl. auch Heydebrand 1998, S. 619.

1361 Kampmann 2013, S. 407, 411. In ihrem Artikel bündelt Kampmann wichtige Aspekte hinsichtlich der Rekonstruierbarkeit von Kanones.
} 


\section{14.2.1 Publizität und Etabliertheit}

Die Publizität lässt sich etwa rekonstruieren mittels der Programmtexte, die möglicherweise auf den Bekanntheitsgrad - „weltbekannt“ - oder auf eine kurzfristige Popularität ${ }^{1362}$ - „aufsehenerregend“ - hinweisen. Ebenso spricht für die Publizität der Autor*innen, wenn bei der Lesung ein größerer Raum außerhalb des Literaturhauses gewählt wird. Die Etabliertheit von Künstler*innen innerhalb des Literaturhauses lässt sich daran ablesen, ob sie häufiger und mit unterschiedlichen Büchern zu Gast sind, oder daran, ob ihnen Aufmerksamkeit über die aktuelle Neuerscheinung hinaus zuteilwird, ob ihnen „diskursive Präsenz"1363 zugeschrieben werden kann. Werden sie beispielsweise zu Diskussionen oder zu Werkschauen eingeladen?

Autor*innen, die im gesamten Untersuchungszeitraum immer wieder in den deutschen Literaturhäusern auftreten, sind zum Beispiel Felicitas Hoppe (*1960) und Ingo Schulze (*1962). ${ }^{1364}$ Anhand dieser zwei Figuren lässt sich gut illustrieren, wie die Literaturhaus-Programme die Entwicklung der Anerkennung als Autor*in dokumentieren, denn beide sind seit ihren Debüts in den Literaturhäusern präsent. Sie debütierten in den 1990er-Jahren und waren etwa in Hamburg innerhalb der Reihe Junge deutsche Autoren zu Gast (HH 1997-10-08, Hoppe, HH 1998-03-19, Schulze). Hoppes Erzählungsband Picknick der Friseure erschien im Mai 1996. Regelmäßig und in unterschiedlichen Funktionen war Felicitas Hoppe im Anschluss in den untersuchten Literaturhäusern. In Berlin etwa stellte sie ihren Kollegen Peter Stamm vor (BE 2000-01-25), in Frankfurt las sie aus ihrem Ende Januar 2013 erschienenen Roman Paradiese, Übersee (FF 2003-02-06) und in Göttingen wurde sie 2009 mit der Einladung zur Lichtenberg-Poetikvorlesung geehrt (GT 2009-12-02). Im März 2012 erschien ihr Roman Hoppe. Da zu vermuten ist, dass auch dieser zeitnah in den Literaturhäusern vorgestellt wurde, lässt sich andersherum suchen, ob sich im März oder April Veranstaltungen mit Felicitas Hoppe in den Programmen finden. Tatsächlich besuchte die Autorin im April das Literaturhaus Frankfurt (FF 2012-0423) und das Literarische Zentrum Göttingen (GT 2012-04-20). Im Mai 2015 wurde bekanntgegeben, dass sie den Georg-Büchner-Preis erhält, eine Auszeichnung, die sich als Zeichen ihrer Publizität und ihrer Etablierung interpretieren lässt. Während sie davor eher ein „Geheimtipp“ für Literaturwissenschaftler*innen und einen kleinen Teil der literarisch interessierten Öffentlichkeit gewesen sei, sei sie danach verstärkt im „Mainstream“ sichtbar gewesen. ${ }^{1365}$ Zum ,kleinen Teil der literarisch interessierten Öffentlichkeit‘ lassen sich die untersuchten deutschen Literaturhäuser folglich zählen. Die Verleihung des Georg-Büchner-Preises ist in diesem Fall als Registrationsmedium für Publizität zu werten, und auch dann, wenn eigentlich nur ihr Name genannt werden könnte, ergänzen die Ankündigungen häufig ein Auszeichnungsattribut: „die aktuelle Büchnerpreisträgerin Felicitas Hoppe“ (GT 2013-06-02).

\footnotetext{
1362 ,Popularität‘ alltagssprachlich verstanden als ,Beliebtheit‘. Zur Verbindung von ,Kanonisierung und ,Popularisierung‘ äußert sich Kampmann ebenfalls, vgl. Kampmann 2011, S. 49-59.

1363 Ebd., S. 32.

1364 Mit einer Datenbank aller Literaturhaus-Gäste ließen sich alle Auftritte verzeichnen, hier dienen nur einige Veranstaltungen als Beispiele.

1365 Michaela Holdenried macht dies daran fest, dass Felicitas Hoppe im Cicero-Ranking, das in einem eigenen Verfahren die Referenzhäufigkeit einzelner Akteure in deutschsprachigen Zeitungen und Zeitschriften misst, von 2012 auf 2013 deutlich weiter oben platziert wurde, vgl. Holdenried 2015, S. 7.
} 
Ingo Schulzes Debüt war der Erzählband 33 Augenblicke des Glücks. Sein Buch Simple Storys. Ein Roman aus der ostdeutschen Provin₹, mit dem er bekannt wurde, ${ }^{1366}$ veröffentlichte er Ende Februar 1998. Der Autor stellte dieses im April 1998 im Literaturhaus Frankfurt vor (FF 1998-04-21). 2000 sprach er im Literaturbaus Berlin bei der Vorstellung des Buches Schraffur der Welt - Junge Schriftsteller über das ,Schreiben', für das er einen Beitrag verfasst hatte (BE 2000-03-03) - ein weiteres Beispiel für die Thematisierung von Schreibprozessen im Literaturhaus und an dieser Stelle vor allem für die zunehmende Etablierung Schulzes als Schriftsteller. Im Literaturbaus Hamburg war Ingo Schulze seit Simple Storys mit jedem seiner belletristischen Titel zu Gast. Dieses Beispiel liefert außerdem einen Beleg für den oben ausgeführten Eindruck, dass die Präsentationen von Novitäten in den großen deutschen Literaturhäusern meistens sehr nah am Erscheinungstermin liegen. ${ }^{1367}$ Dies unterstützt mindestens zwei Vermutungen: erstens, dass die Buchvorstellungen auch Marketingmaßnahmen seitens der Verlage sind, zweitens, dass die Programmleitungen gelegentlich vor Lektüre des jeweiligen Buches eine Lesung zusagen. Letzteres lässt sich wiederum als Zeichen dafür deuten, dass entweder die Ankündigung vielversprechend genug klingt oder dass der Autor ,etabliert' genug ist, um auf den neuen Text vertrauen zu können, und der Autor als Person ein umgänglicher Gast ist. Schulzes Roman Neue Leben erschien im Oktober 2005 zur Frankfurter Buchmesse (HH 2005-10-28); Handy. Dreizehn Geschichten in alter Manier, erschienen im Frühjahr 2007, stellte er Ende März des Jahres vor (HH 2007-03-26); aus dem im August 2008 publizierten Adam und Evelyn las er im September (HH 2008-09-15), über Orangen und Engel. Italienische Skizzen, das im Sommer 2010 erschien, sprach er nach der Sommerpause (HH 2010-09-02) und 2017 stellte er fünf Tage nach dessen Erscheinen den Roman Peter Holtz vor (HH 2017-09-12). Zusätzlich kam er zu einer Veranstaltung anlässlich von Arno Schmidts 100. Geburtstag (HH 2014-01-18) ${ }^{1368}$ und er sprach bei der Literatursoiree über sein Werk und seine Schreibpraxis (HH 2010-03-03). Interesse an seinen Arbeiten besteht damit zweifellos und das über seine gesamte bisherige Schaffenszeit. Das Fallbeispiel Literaturhaus Hamburg wirkt mit, Ingo Schulzes Potenzial zur Kanonizität, also die dauerhafte Rezeption seines Werkes mit großer Reichweite, zu erhöhen. Andere Hinweise darauf sind etwa Forschungsarbeiten über diesen Autor oder das Ingo-Schulze-Archiv an der Akademie der Künste Berlin. Das Literaturhaus Hamburg zitiert im Ankündigungstext zur Handy-Veranstaltung ein als Referenz akzeptiertes Medium und reproduziert auf diese Weise die Annahme, dass Ingo Schulze, der mit „seinem großen Roman ,Neue Leben', der als ,Weltliteratur (Literarische Welt) gefeiert wurde“ (HH 2007-03-26), kanonisiert werde oder werden könnte. Ist Ingo Schulze Teil eines Kanons? Zum Kanon des Literaturhauses Hamburg gehört er;

\footnotetext{
${ }^{1366}$ Es wird inzwischen ebenfalls als Schullektüre genutzt.

${ }^{1367}$ Der Monat des Erscheinens lässt sich häufig nicht mehr anhand der bibliografischen Angaben nachvollziehen, allerdings geben Buchrezensionen Hinweise auf das Veröffentlichungsdatum. In der Regel obliegen die Rezensionsexemplare einer Sperrfrist für Veröffentlichungen von Besprechungen, die meist mit dem Erscheinungstermin übereinstimmt, bzw. kurz davor liegt. Hier wurde die Übersicht, die die Website perlentaucher.de zu jedem besprochenen Titel bereitstellt, als Quelle genutzt. Dort sind die Rezensionen, die im überregionalen Feuilleton erschienen sind, zusammengefasst, ihr Erscheinungsdatum ist da ebenfalls notiert.

1368 Dabei war das Literaturhaus allerdings nur Kooperationspartner und die Veranstaltung fand nicht im Literaturhaus statt. Es kann also davon ausgegangen werden, dass das Literaturhaus kaum Einfluss auf die Konzeption hatte.
} 
das Literaturhaus ist allerdings nur eine Kanoninstanz innerhalb eines verzweigten Komplexes. Dabei ist zu bedenken, dass Schulze als Autor, der markant zur Auseinandersetzung mit der deutsch-deutschen Teilung aus Ost-Perspektive beitrug, eingeordnet wird und damit unbedingt auch unter zeithistorischen Gesichtspunkten im Literaturbetrieb kontextualisiert werden muss. In den Programmtexten genutzte Verweise auf andere Kanoninstanzen, wie Zeitungen, Formulierungen wie ,kanonisiert $^{6}$, ,Klassiker ${ }^{6}$ oder ,Weltliteratur ${ }^{6369}$ oder die zeitige Einladung mit jedem - damit als wichtig erachteten - Buch und andere Aspekte liefern umfassendes Material und Anstoß für eine Vertiefung dieser Überlegungen.

Auf eine etwas andere Weise müssen Untersuchungen zu den Kanonisierungsstatus von Autor*innen im Litteraturbuset vorgehen, schlicht aufgrund der Tatsache, dass die norwegischen Einrichtungen deutlich jünger sind als die erwähnten deutschen. So spiegeln die Besuche beispielsweise des Norwegers Dag Solstad, der bereits mehrmals im Litteraturbuset in Oslo zu Gast war - etwa mit seinem 17. Roman, dessen Erscheinen „en litterær storhending“ (OL 2009-11-12) [ein literarisches Großereignis] in Norwegen war - seinen Status, den er bereits vor Eröffnung des Literaturhauses innehatte; ein Beispiel, das vergleichbar in den deutschen Einrichtungen natürlich auch vorkommt. Das Literaturhaus begleitet in diesem Fall keine Entwicklung ab dem Debüt, sondern verstärkt die Etabliertheit. Ebenfalls beweist sich Solstads Etabliertheit daran, dass er in den Programmen zitiert wird beziehungsweise auf seine Arbeiten angespielt wird. ${ }^{1370}$ Mit der relativ hohen Reichweite des Litteraturbuset lässt sich vermuten, dass Litteraturhuset sowohl zur Etabliertheit als auch zur Publizität Solstads beiträgt. Noch entscheidender an der dauerhaften diskursiven Präsenz wirken sicherlich die Aufnahme in Literaturgeschichten mit sowie andere kanonrelevante Auszeichnungen: Solstad erhielt mehrere wichtige skandinavische Literaturpreise, 2017 den Svenska Akademiens nordiska pris [Nordischer Preis der Schwedischen Akademie], und bekommt seit 2011 Statens areslonn, ein jährliches mit 200.000 Norwegischen Kronen dotiertes steuerfreies Einkommen auf Lebenszeit, ein ,Ehren-Gehalt'. ${ }^{1371}$ Dieses erkläre ihn zu einem von Norwegens allergrößten Autor*innen, wie es bei der Verkündung geheißen habe. ${ }^{1372}$ Bekanntgegeben wurde diese Ehrerweisung von der Kultusministerin gerade im Litteraturhuset an dem Tag, an dem Solstad dort anlässlich seines 70 . Geburtstags gehuldigt wurde. ${ }^{1373}$ Kolleg*innen wie Kjartan Fløgstad, Roy Jacobsen, Jon Michelet, Vigdis Hjorth, Øyvind Rimbereid, Einar Økland, Jan Erik Vold, Ingrid Lorentzen und Ole Robert Sunde ihrerseits selbst bekannte Künstler*innen - kamen „for å feire en helt spesiell mann og et helt spesielt forfatterskap“ (OL 2011-06-17) [um einen ganz besonderen Mann und ein ganz besonderes schriftstellerisches Schaffen zu feiern]. Des Weiteren reflektierte Dag Solstad im Osloer Literaturhaus vorher - und Jahre nach Ersterscheinen - mit Kolleg*innen über die Rolle seiner sogenannten Krigstrilogi [Kriegstrilogie]

\footnotetext{
${ }^{1369}$ In enger Anlehnung an Kampmann 2011, S. 34.

1370 Dies wurde auch in dieser Arbeit bereits dargestellt, vgl. Kapitel II 13.2.10, S. 409.

${ }^{1371}$ Vgl. „Æreslønn“, Store norske leksikon. Bisher haben nur insgesamt vier Künstler diese Förderung erhalten.

1372 Vgl. Ottosen „Får 200.000“.

1373 Dies bezeugt außerdem, wie dieser Ort als der öffentliche Ort für Literatur in Norwegen wahrgenommen wird.
} 
mit den Titeln Svik. Forkrigsår [Verrat. Vorkriegsjahre] (1977), Krig. 1940 [Krieg. 1940] (1978) und Brod og våpen [Brot und Waffen] (1980) (OL 2008-11-20). Im Programm des Litteraturbuset Bergen war er allerdings im Untersuchungszeitraum nicht vertreten, was verschiedene Ursachen haben kann und zu bedenken gibt, dass sich die Etabliertheit eines Autors auch daran ablesen lassen könnte, dass er beispielsweise in kleineren Literaturhäusern nicht mehr liest, sei es aus finanziellen oder terminlichen Gründen, oder da er aufgrund seines Renommees in der Öffentlichkeit ausreichend sichtbar ist. Möglich ist es ebenso, dass in der relativ kurzen Zeit, in der das Literaturhaus in Bergen aktiv ist, nur aus organisationspraktischen Ursachen bisher noch keine Einladung Solstads zustande kam. Außerdem war der Autor 1968 einer der Gründer von Norsk Forfattersentrum, ${ }^{1374}$ deshalb besteht beispielsweise eine engere Verbindung zu dieser Organisation als zum Litteraturbuset.

Aus den Programmen des Litteraturbuset in Oslo lässt sich als weiteres Beispiel für Kanonisierungsprozesse der Autor Jan Erik Vold (*1939) anführen. Anlässlich des 40. Jubiläums seines Lyrikbandes Mor godhjertas glade versjon: ja [Die fröhliche Version von Mutter Gutherz: Ja], der ihn für seine Alltagslyrik über profane Dinge zum Publikumserfolg machte, ${ }^{1375}$ sprach der Autor, der außerdem als „brillanter Gedichtrezitator" 1376 bekannt wurde, über diese frühe Veröffentlichung (OL 2008-0515). Eine derartige Veranstaltung transferiert den älteren Text in eine andere Zeit, denn mit gegenwärtiger Perspektive auf ein früheres Werk zu blicken, beinhaltet einen Vergleich der damaligen Rezeption mit der aktuellen Wirkung. So wird implizit seine Kanontauglichkeit beziehungsweise seine Dauerhaftigkeit geprüft. Auch zu seinem 70. Geburtstag ehrte Litteraturhuset diesen norwegischen Lyriker (OL 200910-22). Eine ähnliche Feier wurde Erlend Loe (*1969) in Oslo zuteil, dessen fünfzehntes Jubiläum als Autor dort zelebriert wurde (OL 2008-03-06). Diese Veranstaltungen reflektieren wie etwa die Literatursoiree in Hamburg ein vorläufiges schriftstellerisches Gesamtwerk. Des Weiteren böten sich anhand des Osloer Litteraturbuset detaillierte Untersuchungen etwa zu Hanne Ørstavik oder Vigdis Hjorth an, die regelmäßig dort zu Gast sind. Die genannten norwegischen Autor*innen sind außerdem auf der Wandmalerei von Steffen Kverneland ,verewigt'. ${ }^{1377}$

Ebenso als im Literaturhaus etabliert geltend eingeschätzt werden können zeitgenössische Autor*innen, zu denen, obwohl sie nicht selbst anwesend sind, Veranstaltungen stattfinden. Das Literaturhaus Hamburg organisierte zum Beispiel Abende zu den späteren Nobelpreisträgerinnen Elfriede Jelinek aus Österreich (*1946, Nobelpreis für Literatur 2004, HH 2000-09-28) und Alice Munro aus Kanada (*1931, Nobelpreis für Literatur 2013, HH 2010-03-02), die beide nicht oft öffentlich auftreten. Der amerikanische Autor der Postmoderne Thomas Pynchon (*1937), der als Privatperson weitgehend unbekannt ist und dessen einziger öffentlicher Auftritt 1953 an der Oyster Bay High School in Long Island stattfand, ${ }^{1378}$ ist ein noch treffenderes Beispiel: Schon 1993 widmete sich ihm das Literaturbaus Hamburg (HH 1993-11-09) und 22 Jahre später waren seine Bücher weiterhin Veranstaltungsgegenstand, der

\footnotetext{
1374 Vgl. Rottem und Norsk Forfattersentrum: „Dag Solstad“.

1375 Vgl. Seiler 2006, S. 305. Das Buch ist nicht in deutscher Übersetzung erschienen.

1376 Ebd., S. 307.

1377 Vgl. FN 757.

1378 Vgl. „Cheers, Thomas“, Rowohlt.
} 
Autor war auch dann nicht zugegen. Seine Texte werden für so wichtig erachtet, dass zum Beispiel der Übersetzer Dirk van Gunsteren im Gespräch mit dem Autor Thomas Lehr Pynchons neues Buch Vineland vorstellte, „[s]chließlich kennt der Übersetzer das Buch in allen Einzelheiten“" (BE 2015-01-27). Diese Autor*innen sind allerdings als Ausnahmen einzuschätzen.

\section{14.2.2 Kanonizität}

Weitere Indizien für längerfristige und umfassende Auseinandersetzungen mit Autor*innen und Werken sind Symposien und Ausstellungen, die die Literaturhäuser ebenfalls gelegentlich anbieten. Diese markieren eine weitere Stufe im Kanonisierungsprozess als es einzelne Veranstaltungen tun, denn eine mehrperspektivische Auseinandersetzung mit einem schriftstellerischen Werk bedeutet für dieses Werk einen Relevanzzuwachs. Das Literaturhaus Frankfurt führte beispielsweise Uwe Johnson-Wochen zum 1984 verstorbenen Autor (1934-1984) durch (FF 2000-11-12). Wie erwähnt fanden derartige konzentrierte Symposien früher in den deutschen Literaturhäusern regelmäßiger statt.

Wie dargestellt setzen die Ausstellungen im Literaturhaus Berlin weiterhin explizite Programmschwerpunkte, die im Einzelnen untersucht werden könnten. Sie befassen sich nicht nur mit bereits verstorbenen Persönlichkeiten und so konnte die Einrichtung 2010 verkünden: „Zum ersten Mal wird Herta Müller eine Ausstellung gewidmet“ (BE 2010-09). Die aus Rumänien stammende Autorin Herta Müller (*1953) war bei Begleitveranstaltungen zur Ausstellung zugegen. Mit der Adelung durch die Ausstellung wurde ihrem Gesamtwerk eine Anerkennung zuteil, die die vom im Jahr vorher zuerkannten Literaturnobelpreis weiterführt. In dem zitierten Ankündigungstext ist außerdem die Information enthalten, dass im Literaturhaus Berlin diese erste Ausstellung stattfinde, weil es damit aktiv Herta Müllers Autorschaft umfassender behandelt wissen wolle.

Die Präsenz einer Autorenpersona wird zu Lebzeiten entscheidend von ihr selbst mitbestimmt. Dabei spielen zwischenmenschliche Faktoren immer auch eine Rolle, denn Kritik und Kränkung können nicht ausgeblendet werden, wenn die physische Anwesenheit eines Autors zum Konzept der Einrichtung gehört. Der leibhaftige Tod des Autors setzt im Falle des Literaturhauses, wo Autor*in und Werk kaum voneinander zu trennen sind, eine stärke Zäsur in der Rezeption als bei Akteur*innen, die sich stärker auf die Texte konzentrieren, wie die Literaturwissenschaft, Schule oder teilweise sogar der Buchhandel. ${ }^{1379}$ Nach dem Tod eines Autors entscheidet sich erst nach und nach, ob das Werk den Menschen überdauert, was im eingangs aufgeführten Zitat hyperbolisch mit „Ewigkeit“ gefasst wurde. Gedenkstätten, Stiftungen oder Preise im Namen der verstorbenen Künstler*innen sind Mittel, dies zu erreichen. Im Literaturhaus können Gedenkabende oder Veranstaltungen zum Werk an Autor*innen erinnern.

1379 Zum ,etablierten Metapherngebrauch von ,toter“ und ,lebendiger` Autor“" vgl. Spoerhase 2014, S. 23-24. 
Zur Feier seines zehnten Jubiläums ließ das Literarische Zentrum Göttingen eine Schauspielerin Texte von ehemaligen Gästen, die in der Zwischenzeit gestorben waren, rezitieren, darunter waren Adolf Endler (1930-2009), Robert Gernhardt (1937-2006), Walter Kempowski (1929-2007), Oskar Pastior (1927-2006) sowie W. G. Sebald (1944-2001) (GT 2010-04-12). Damit reflektierte die Einrichtung ihre eigene Geschichte, indem sie an Texte von seitens des Zentrums geschätzten verstorbenen Schriftstellern erinnerte.

Es finden sich auch Verfasser*innen, die in den Jahren vor Gründung des ersten Literaturhauses gestorben sind und ebenfalls durch Literaturveranstaltungen sichtbar bleiben. Auffallend häufig kommen etwa Veranstaltungen zu dem deutschen Autor Arno Schmidt (1914-1979) in den älteren untersuchten deutschen Literaturhäusern vor. In Hamburg etwa waren ihm die Bargfelder VorLesungen gewidmet, die sich auf die Gesamtausgabe von Schmidts Texten, die Bargfelder Ausgabe, bezogen (z. B. HH 1990-03-29). ${ }^{1380}$ Ein Arno-Schmidt-Tag fand ebenfalls im Literaturbaus Frankfurt seit Eröffnung der Einrichtung jeden Februar statt (z. B. FF 1992-02051381; FF 1993-02-05; FF 1994-02-05; FF 2003-02-05; FF 2006-02-20) Die 20. und letzte Folge ist im Jahr 2010 verzeichnet; der seit Herbst 2010 neue Leiter Hauke Hückstädt hat sich, so ist anzunehmen, gegen eine Fortsetzung entschieden (FF 2010-02-11), zum 100. Geburtstag des Autors gab es dort wieder eine Lesung zu Arno Schmidt (FF 2014-12-10). Das Literaturbaus Berlin führte eine Veranstaltung zum Erscheinen der Subrkamp-Ausgabe von Zettel's Traum durch (BE 2010-10-15). Mitverantwortlich für die meisten dieser Veranstaltungen ist die Arno Schmidt Stiftung, die nach dem Tod von Schmidt gegründet wurde und es zur Aufgabe hat, das Andenken Arno Schmidts zu pflegen, sein Werk und seine Persönlichkeit für die Nachwelt darzustellen und zu erforschen sowie die Literatur zu fördern. ${ }^{1382}$ Diese Stiftung verdeutlicht besonders gut, wie der Einsatz für ein schriftstellerisches Werk nach dem Tod des Verfassers für dessen Verstetigung und Verbreitung entscheidend ist. Daran wird das Zusammenspiel unterschiedlicher Kanoninstanzen sichtbar, denn die Literaturhaus-Veranstaltungen finden auf Initiative der Stiftung statt, die ihrerseits auf die öffentliche Wirkung des Literaturhauses angewiesen ist. Die Literaturhäuser, die diese Veranstaltungen anbieten, fördern zusätzlich die von der Stiftung angestoßene, positive Rezeption Arno Schmidts.

Alle Veranstaltungen des Literaturhauses, die sich mit einem Autor oder einem Text befassen, wirken - in unterschiedlichem Ausmaß und verschiedentlich explizit - mit an der Erweiterung, Revision und Bestätigung eines Kanons, was unter dem Aspekt der Kanonpflege zu fassen ist, die Renate von Heydebrand als „die Voraussetzung auch für kontroverse Wertreflexion in der Literatur einer Gesellschaft" ${ }^{\text {"1383 }}$ bezeich-

\footnotetext{
1380 Bargfeld in Niedersachsen war Schmidts letzter Wohnort.

1381 Das Programmheft Februar 1991 ist nicht archiviert und liegt dementsprechend nicht vor. Aus den Ankündigungen der Folgejahre lässt sich schließen, dass bereits vor 1992 diese Lesungen stattfanden. 1382 Die Stiftung wurde 1981 gegründet und wird geführt von dem Vorstand bestehend aus Susanne Fischer, Bernd Rauschenbach, Jan Philipp Reemtsma und Joachim Kersten, vgl. „Arno Schmidt“, Arno Schmidt Stiftung.

1383 Heydebrand 1993, S. 13. Aufgrund dieser möglichen Wertreflexion plädiert sie für die „Neukonzeption des materialen Kanons“, ebd., S. 14.
} 
net. Dabei trägt das Literaturhaus als Literaturvermittlungsinstitution dazu bei, zeitgenössische Autor*innen im ersten Schritt zur Etablierung zu verhelfen und nach und nach einen Autorenpool zu generieren, der als Bezugsgröße für das Literaturhaus dienen kann. Bei der Frage nach der literarischen Ausrichtung des Literaturhauses fungiert das Veranstaltungsprogramm als Maßstab, sodass sich einschätzen lässt, welche Autor*innen eher ,Literaturhaus-Autor*innen' sind als andere. Gezeigt wurde oben zum Beispiel, dass Autor*innen von Genreliteratur relativ selten eingeladen werden, was unter anderem damit zusammenhängt, dass beispielsweise für Autor*innen von Kriminalliteratur andere Bühnen, häufig mit deutlich größerem Publikum, in anderen Bereichen des Literaturbetriebes zur Verfügung stehen. Die in den Literaturhäusern rezipierten Autor*innen finden sich häufig in der Literaturwissenschaft ebenfalls behandelt, wie die Darstellung zu Hoppe und Schulze andeutete. Außerdem lassen etwa die Ankündigungstexte einen Verweiszusammenhang fasslich werden, der sich durch Zitate, Referenzen und die grundsätzliche Art der Textgestaltung analysieren lässt und der zu einem übergreifenden Diskurs gehört.

Dieser Verweiszusammenhang wird besonders dann in den Ankündigungstexten betont, wenn mit einer Veranstaltung die Absicht besteht, bisher unstrittige Annahmen und Werkinterpretationen zu einzelnen Autor*innen zu relativieren. Das Literaturhaus Frankfurt etwa lud zu einer Veranstaltung über Rolf Dieter Brinkmann (1940-1975) - „der Pionier der Underground-Literatur“ (FF 1996-02-02) - mit seinem Weggefährten Ralf-Rainer Rygulla ein, bei der ausdrücklich ein Bild entstand, „das die vor allem von ,Rom, Blicke‘ und weiteren Publikationen aus dem Nachlaß ausgehende vornehmlich düstere Brinkmann-Rezeption revidiert“ (FF 2006-0123). ${ }^{1384}$ Brinkmann ist zudem ein Beispiel dafür, dass Autor*innen, die sich eher gegen einen bestehenden Kanon richteten, später selbst zum Kanon zu zählen sind. ${ }^{1385}$ Ein weiteres Beispiel dafür ist, wenn etwa der Germanist und Literaturkritiker Michael Maar (*1960) aufgedeckt zu haben meinte, dass Vladimir Nabokovs Lolita (1955) einen bisher unbekannten Vorgänger gehabt habe und der berühmte Roman mit diesem Wissen anders eingeschätzt werden müsse (FF 2006-01-31). Ebenso lasse die Veranstaltung zum 2001 frisch erschienenen Briefwechsel von Lev Tolstoj (1828-1908) und Sofja Tolstaja (1844-1919) einen neuen Blick auf den russischen zweifellos kanonisierten Schriftsteller und seine Frau, die ebenfalls Autorin war, erwarten (FF 2001-05-24). Die Sachbücher, auf denen die beiden genannten Veranstaltungen basieren, beabsichtigten ihrerseits eine Revision des Kanons; mit der Einladung ins Literaturhaus erhalten diese Unterstützung.

Bei Abenden zu Ehren eines eher am Rande eines Spitzenkanons zu verortenden Schriftstellers liegt das Interesse in der Wiederentdeckung oder Aufwertung des Werkes. Diese Veranstaltungen offenbaren ganz besonders die Funktion des Literaturhauses als Kanonisierungsinstanz, die entweder die bestehende Aufmerksamkeit verstärkt - wenn zum Beispiel eine Neuübersetzung präsentiert wird - oder den Wert eines bisher übersehenen Werkes gerade erst herausstellt. Der Kanon soll auf diese Weise ausgeweitet werden - wenn etwa „Geheimtipps“ oder „zu Unrecht unbeachtetes“ vorgestellt werden; so etwa die Veranstaltungen zu Adolph Freiherr

1384 Rom, Blicke ist eine Textcollage, die 1972/1973 entstand und erst posthum bei Rowoblt erschien. 1385 Vgl. Jürgensen und Kaiser 2011, S. 26. 
Knigge (1752-1796) oder Oskar Loerke (1884-1941) im Literaturhaus Berlin, die Texte in den Fokus rückten, „die angesichts fortschreitender Konzentrations- und Kommerzialisierungsprozesse im Verlagswesen und einem wachsenden Rentabilitätsdruck bei der Programmplanung aus dem kulturellen Gedächtnis zu fallen drohen“ (BE 2010-03-24; BE 2010-10-26). ${ }^{1386}$

Zudem finden Veranstaltungen statt, die den Kanonizitätsstatus eines Autors bestätigen. Walter Benjamin (1892-1940) ehrend bot das Literaturbaus Berlin eine Ausstellung anlässlich des 50. Todestages, Veranstaltungen zum 60. und eine Hommage zum 70. Jahrestag an (BE 1990-10-21; BE 2000-09-08; BE 2010-09-07). „Zur Aktualität Adornos“ anlässlich des 90. Geburtstages von Theodor W. Adorno (19031969) veranstaltete das Literaturbaus Frankfurt ein Symposium (FF 1994-03-09). Natürlich widmen sich die Literaturhäuser nicht nur Kulturkritikern, sondern auch Autoren im engeren Sinne: Friedrich Hölderlin war etwa Thema an fünf Abenden in Berlin (BE 2005-01). Neben Jubiläen sind häufig Neuausgaben oder Erstausgaben beispielsweise von Tagebüchern oder anderen zu Lebzeiten unveröffentlichten Texten Anlass für eine Veranstaltung zu einem bereits verstorbenen Autor. ${ }^{1387}$

So wählte Litteraturbuset Bergen zum Auftakt des Reihenformats Dypdykk $i$ klassikerne [tiefgetaucht in die Klassiker] Olav H. Hauges Tagebücher als Thema (BG 2014-12-04). 1388 Diese Reihe stellte eine intensive und kritische Auseinandersetzung mit kanonisierten Texten dar und näherte sich ihnen aus heutiger Sicht, was als Kanonpflege auszulegen ist. Dies ist ein völlig anderer Zugang zu kanonisierten Texten als das kommentarlose, ehrfürchtige Vorlesen, das früher in den deutschen Literaturhäusern häufiger vorkam. ${ }^{1389}$ Veranstaltungen zu Texten von nicht-anwesenden, in der Regel bereits verstorbenen Autor*innen finden inzwischen in der Mehrzahl in Verbindung mit einer Auseinandersetzung zu Leben und Werk statt. Zum Beispiel belegen die regelmäßig im Literaturhaus Hamburg abgehaltenen literaturhistorischen Abende, dass diese Art der Vermittlung von literarischen ,Klassikern' oder eher unbekannteren historischen Texten und Künstler*innen keinesfalls vollständig von Veranstaltungen mit Gegenwartsautor*innen abgelöst wird, sondern offenbar ein fortwährendes Interesse daran besteht. In Anbetracht der Tatsache, dass Lesungen mit zeitgenössischen Schriftsteller*innen an anderen Orten ebenfalls stattfinden, ist diese Klassikerpräsentation als Gegengewicht und als Versuch zu beurteilen, das eigene Programm zu prägen und weniger kurzlebige, sondern sich über die Zeit bewährte Texte vorzustellen.

\footnotetext{
1386 Die beiden besprochenen Texte erschienen in einer Publikationsreihe im Wallstein Verlag.

1387 Die Beschäftigung mit Tagebüchern und Briefwechseln betont besonders das Interesse an einer bestimmten Autorenpersona seitens der Literaturvermittler*innen und der Rezipient*innen. Die Literaturhäuser in Oslo und in Bergen präsentierten zum Beispiel die umfangreiche Edition von Olav H. Hauges Tagebüchern (z. B. OL 2008-10-04). Hin und wieder waren Autor*innen eingeladen, aus ihren eigenen Tagebüchern zu lesen (z. B. HH 1992-11-15). Das Interesse an dieser ,intimen Textsorte' geht folglich wirklich nicht nur auf das Interesse an der kanonisierten Figur zurück, sondern offenbart die Neugier auf ,authentische', ,intime' Erkenntnisse über einen bestimmten Autor - oder sogar über einen relativ beliebigen Autor - als Person.

1388 Zur Bedeutung Olav H. Hauges für Litteraturbuset i Bergen vgl. Kapitel II 7.3.2.

${ }^{1389} \mathrm{Vgl}$. Kapitel II 13.2.2.
} 
Ein besonderes Format, bestimmte ältere Texte lebendig zu vermitteln, entwickelte Litteraturbuset in Oslo mit Som sagt [Wie gesagt]. In dieser Reihe rezitierten Schauspieler*innen Vorträge, die ursprünglich von Literat*innen geschrieben und in der Regel tatsächlich gehalten wurden und die ins kulturelle Gedächtnis Norwegens eingegangen sind: unter anderem Reden der Nobelpreisträgerin Sigrid Undset (1882-1949) über Krieg und Literatur aus den 1940er-Jahren, des sozialkritischen Autors Jens Bjørneboe (1920-1976) über Svikeren [der Verräter] - gehalten 1961 vor dem Studentersamfundet [Studentenvereinigung] - oder des Erweckungspredigers Ole Hallesby (1879-1961) über seine „helvetestalen“ [die Höllenrede] - vorgetragen im norwegischen Radio 1953. Den Auftakt bildeten mehrere verfasste, jedoch nie öffentlich gehaltene Verteidigungsreden des Autors Agnar Mykle (1915-1994), dessen 1956 publiziertes Buch Sangen om den rode rubin [Das Lied vom roten Rubin] aufgrund angeblich pornografischen Inhalts gerichtlich verboten wurde (OL 2015-0822). Die Texte wurden im Literaturhaus durch die gegenwärtige Live-Situation in ihrer ursprünglichen Medialisierung präsentiert und auf diese Weise aktualisiert. Diese Annäherung an verschiedenste Klassiker der Gesellschafts- und Literaturgeschichte unterstreicht die bereits anhand verschiedener Parameter herausgearbeitete Ausrichtung des Litteraturbuset als Ort der gesellschaftsbildenden Debatte. Die Aufführungssituation trug entscheidend zu diesem Veranstaltungskonzept bei, das von vornherein auf acht Termine angelegt war und mit einem gesonderten Flyer als Reihe angekündigt wurde. Diese Reihe lädt zum einen dazu ein, sich mit den kanonisierten Autor*innen auseinanderzusetzen, zum anderen werden die politisch motivierten Reden aktualisiert präsentiert. Beides ist als Teil von Kanonisierungsprozessen zu sehen.

Aufgrund der diachron vergleichenden Untersuchung der vorliegenden Arbeit lässt sich entdecken, das im Literaturbaus Hamburg bereits 1992 eine ganz ähnliche Idee realisiert wurde: Schriftsteller-Reden, die, so oder so, Furore machten waren Thema eines Abends zum Autor, A(u)ctor, Agitator, bei dem der Schauspieler Matthias Fuchs Reden von den in alphabetischer Reihenfolge genannten Gabriele D'Annunzio, Hans Magnus Enzensberger, Johann Wolfgang Goethe und Helmut Heißenbüttel vorlas, und Friedrich Dieckmann, Gaston Salvatore und Klaus Schröter unter der Moderation von Regula Venske diskutierten:

Was treibt den Schriftsteller immer wieder vom Schreibtsich (sic!) auf die Tribüne, ans Rednerpult, ans Mikrophon? Wie verhält sich die Kunst zur schönen Kunst der öffentlichen Einmischung? Welchen Gebrauch macht der sprachmächtige Autor von der öffentlichen Macht der Sprache? Gebraucht er sie als Citoyen, als Statthalter staatsbürgerlicher Tugenden, als öffentliches Gewissen, als moralische Instanz? Oder mißbraucht er sie für die fatalen Strategien der Agitation und Demagogie? Soll er aufklären, überzeugen, überreden? Oder soll er verführen, fesseln, in Bann schlagen? Warum tut er zur Zeit weder das eine noch das andere? Wenn es stimmt, daß die Hoch-Zeiten der Rede die Zeiten des Wandels, des Umbruchs sind, warum hat es unseren Schriftstellern gerade jetzt die öffentliche Sprache verschlagen? (HH 1992-04-23)

An diesem Zitat zeigt sich deutlich, dass einerseits die Frage nach gesellschaftlicher Einmischung und künstlerischer Produktion Anfang der 1990er-Jahre weiterhin Thema war; zu diskutieren sei, wie beides vereinbar sein könne, ohne eines dem anderen zu opfern. Andererseits ist mit diesen historischen Reden ein Aufruf an die 
gegenwärtigen Autor*innen verbunden, sich stärker in gesellschaftliche Diskussionen einzubringen. Implizit steckt darin, dass die Literaturhäuser Autor*innen als Intellektuelle wahrnehmen.

Veranstaltungen zu kanonisierten Autor*innen können auch als Serviceveranstaltungen für das Publikum interpretiert werden, denn in 90 Minuten werden Einblicke in ein Werk und eine Autorenbiografie vermittelt, die möglicherweise ausreichen, um ,mitreden zu können', um über den diskursiven Verweiszusammenhang, in dem der Text verortet wird, informiert zu sein, und entsprechend Teil der Trägergruppe zu sein. So ,ist Kanonwissen kein profundes Textwissen, kein Ausdruck von Deutungskompetenz, sondern das nach außen hin dokumentierbare Wissen darüber,

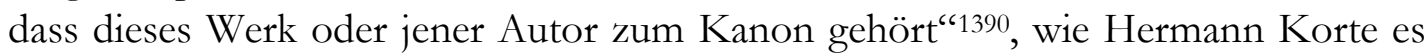
formuliert. Umso klarer dieser Verweiszusammenhang abgesteckt ist, in dem sich Veranstalter*innen, Autor*innen und Publikum bewegen, desto stärker kann die Identifikation innerhalb und die Abgrenzung nach außen sein. Je vielfältiger das Programm, desto breiter anschlussfähig ist es - bei gleichzeitigem Verlust des Gefühls der Zugehörigkeit der einzelnen Akteur*innen. Simone Winko schreibt dem Kanon drei wichtige Funktionen zu: „Selbstdarstellung und Identitätsstiftung einer Gruppe [...,] Legitimationsfunktion; sie dienen zur Rechtfertigung und Abgrenzung der Gruppe gegen andere. Und drittens liefern Kanones Handlungsorientierung“"1391. Der Begriff des Kanons kann somit auch deshalb für die Untersuchung von (Literaturvermittlungs-)Institutionen hilfreich sein, weil er das inhaltliche Programm, also die vermittelten Autor*innen und Texte, mit einer sozialen, Akteur*innen verbindenden Dimension zusammenbringen kann. „Kanon schafft nicht Kultur, sondern Kulturen, und auch die Umkehrung mag gelten: (Sub-)Kulturen schaffen sich ihre Kanones. "1392 Kampmann stellt als wichtige Funktion explizit die Schaffung von Anschlusskommunikation heraus, die in den anderen Beschreibungen nur implizit enthalten sei. ${ }^{1393}$ Die Überlegungen zum Thema Kanon kommen also nicht aus ohne den Versuch, die ,Szene' des Literaturhauses zu spezifizieren; und - reziprok - können die im Literaturhaus etablierten und kanonisierten $\mathrm{Au}$ tor*innen und Texte aufschlussreich für die Einordnung der Institution in den Literaturbetrieb sein. Dazu bedarf es jedoch einer mehrperspektivischen Annäherung und einer umfassenden Kontextualisierung der referenzierten Autor*innen und Texte, die hier angestoßen wurde. Die Platzierung des deutschen Literaturhauses in einen Deutungszusammenhang mit Literaturwissenschaft und ,Feuilleton“ findet mit den hier exemplarisch aufgeführten Figuren Bestätigung. Die norwegische Variante korrespondiert ebenso mit einem akademischen Kanon der Gegenwartsliteratur und schließt kaum an beispielsweise genrespezifische Kanones an. Im Litteraturhuset in Oslo wird dabei eine politisch motivierte Erweiterung dessen, welche Literatur in Norwegen rezipiert werden soll, aktiver angestrebt, was im Abschnitt zur Internationalität vertieft werden wird.

\footnotetext{
1390 Korte 2002, S. 34.

1391 Winko 1996, S. 597.

1392 Heydebrand 1998, S. 624.

1393 Vgl. Kampmann 2011, S. 23.
} 
Für die Analyse ist es relevant, dass ein Besuch von Autor*innen nicht nur eine apodiktische Schlussfolgerung zulässt - das sei noch einmal betont: Es ist beispielsweise keine eindeutige Absage an die Literatur eines Autors oder an die Autorenpersona, wenn diese nicht wiederholt im Literaturhaus auftritt. Und zugleich sollte das Literaturhaus-Programm nicht alleine als Quelle dienen, denn beispielsweise können Autor*innen, die in allen Literaturhäusern lesen, entweder einen weiteren Bekanntheitsgrad haben oder nur innerhalb des Literaturhaus-Kontextes etabliert sein, sie können aufgrund guter Verbindungen der Verlage zu den Einrichtungen überall lesen oder aufgrund für die Veranstalter*innen besonders verlockender Vertragskonditionen eingeladen worden sein. Bei der Programmgestaltung sind finanzielle Aspekte immer mitentscheidend, wie Vandenrath und Johannsen jeweils anschaulich darlegen. ${ }^{1394}$ Auch das persönliche Netzwerk der Akteur*innen ist bei der Veranstaltungsplanung wichtig. Des Weiteren gilt es zu berücksichtigen, dass die Einrichtungen im Sinne des Selbsterhalts und der Erneuerung eine Mischkalkulation unter anderem mit etablierten Autor*innen, die möglicherweise nicht weit bekannt sind, mit berühmten, über den Literaturhaus-Kontext hinausgehend sichtbaren Gästen und neuen Akteur*innen im Literaturbetrieb zu realisieren versuchen. Dabei spielt auch die Einbeziehung beispielsweise von Genres wie Kriminalliteratur eine Rolle. ${ }^{1395}$ Einerseits berufen sich die Einrichtungen auf erprobte und verlässliche Autor*innen, andererseits bringen sie stetig neue Akteur*innen ein, um ein vielfältigeres Bild zu präsentieren und selbst als Entdecker aufzutreten.

\section{14.2.3 Entdeckungen und Debüts}

Gast bei einer Literaturhaus-Veranstaltung zu sein, verschafft den Autor*innen gegebenenfalls einen Zuwachs an Anerkennung und Aufmerksamkeit in dem Bereich des Literaturbetriebs, in dem sich das Literaturhaus verorten lässt. Gleichzeitig nutzt es dem Renommee der Einrichtung, namhafte Autor*innen einzuladen. ${ }^{1396}$ Ebenso kann es sich positiv auf die Reputation auswirken, wenn das Literaturhaus später etablierte Autor*innen schon früh einlädt und sich als Entdecker bezeichnen kann. Damit markiert es seine Position als Wertungsinstanz, die nicht nur an bereits Akzeptiertes anschließt, sondern selbst literaturkritisch aktiv ist. Dies lässt sich jedoch erst im Nachhinein kommunizieren, denn es ist selten abzusehen, welche Debütant*innen längerfristig reüssieren werden. Für die Analyse, welchen Einfluss das Literaturhaus auf den Erfolg von Autor*innen hat, ist zu bedenken, dass viele Faktoren relevant sein können und es empirisch nur in Einzelstudien nachweisbar ist, ob die Akteur*innen im Literaturhaus tatsächlich ausschlaggebenden aktiven Anteil am Durchbruch eines Autors haben, ob sie eher "Trittbrettfahrer' waren - was jedoch durch die Verstärkung der Aufmerksamkeit ebenfalls wesentlich sein kann oder ob sie eher hinderlich oder zumindest passiv waren. Die oben genannten Fälle aus den deutschen Literaturhäusern - Hoppe und Schulze - sind jedenfalls in der Bilanz erfolgreiche Beispiele, bei denen die Literaturhäuser zu einer Steigerung der

\footnotetext{
1394 Während Vandenraths gesamte Studie auf diese Mischkalkulation ausgerichtet ist, komprimiert Johannsen diese Thematik für ihren Artikel, vgl. Vandenrath 2006 sowie Johannsen 2013b, S. 213. 1395 Vgl. Kapitel II 13.2.6.

1396 Vgl. Heydebrand und Winko 1996, S. 98.
} 
Publizität und Etabliertheit durch die Präsentation der Autor*innen beitrugen. Es finden sich selbstverständlich desgleichen Exempel, die nach dem Debüt nicht weiter in Erscheinung getreten sind oder denen keine weitere Aufmerksamkeit zuteilwurde. ${ }^{1397}$

In der Regel erfolgt die Einordnung in einen längerfristigen Rezeptionskontext erst durch rekonstruierende Ansätze, etwa durch die vorliegende Arbeit. Hin und wieder findet sich schon bei Ankündigungstexten zu Besuchen von noch nicht arrivierten Autor*innen eine direkte Thematisierung der Kanonisierung. Beispielsweise lud das Literaturbaus Frankfurt drei junge Lyrikerinnen unter dem Titel Sortierungen ein und kommentierte darin die aktuelle Kanonpraxis: „Die drei Autorinnen [...] schreiben gerade das, was Nachkommende zwar nicht mehr Kanon nennen werden, aber das wir jetzt schon als Labor unserer Sprache erkennen. " Zu Gast waren Nora Bossong (*1982), Katharina Schultens (*1980) und Judith Zander (*1980), die zu diesem Zeitpunkt zwar bereits mehr als ein Buch veröffentlicht hatten, doch noch am Beginn ihrer, dem Literaturhaus Frankfurt zufolge, verheißungsvollen literarischen Karriere standen (FF 2011-05-17). Trotz Ablehnung des normativen Kanonbegriffs wird, dem Text zufolge, weiterhin mit einer Idee von Kanon gearbeitet.

Die gesamte Literaturhaus-Zeit über werden Debütant*innen präsentiert. Literarhistorisch besteht heute weitestgehend Einigkeit darüber, dass in den 1990er-Jahren junge Autor*innen große Aufmerksamkeit erfuhren. Die unter anderem mit den Schlagworten ,Popliteratur ${ }^{6}$ und ,Literarisches Fräuleinwunder ${ }^{\varsigma 1398}$ attribuierten Autor*innen sorgten für dieses starke Interesse an unverbrauchten Texten und jungen Schriftsteller*innen, die auch im Ausland rezipiert wurden. ${ }^{1399}$ Und wenig später ernteten Debütautor*innen satte Vorschüsse für ihre Romane, sodass „Jungschriftsteller zu werden [...] ein ziemlich lukratives Karrieremodell“"1400 darstellte. Dass die damit gemeinten Autor*innen zum Teil in den Literaturhäusern zu Gast waren, lässt sich mittels Stichproben belegen. Das Literaturhaus Hamburg initiierte 1994 die bereits erwähnte Reihe Junge deutschsprachige Autoren und lud dazu unter anderem zum Auftakt Joachim Helfer (*1964) mit seinem ersten Roman Du Idiot (HH 1994-09-29) sowie Zoë Jenny (*1974) (HH 1998-01-29) und Judith Hermann (*1970) (HH 199902-10) mit ihren erfolgreichen Debüts ein. Judith Hermann kam mit ihrem zweiten Buch wieder ins Literaturhaus Hamburg (HH 2003-02-20). ${ }^{1401}$ Das Literarische Zentrum Göttingen organisierte 2001 im Zuge der Uraufführung von Tristesse Royal ${ }^{1402}$ im Jungen Theater eine Lesung mit anschließender Party - Let it Rock II, die Einbeziehung

${ }^{1397}$ Daneben gibt es internationale Autor*innen, die ein Literaturhaus bei einer Veranstaltung präsentierte, deren Texte aber nicht fortgesetzt ins Deutsche übertragen wurden. So stellte der russische Autor Jus Aleškovskij [Aleschkowski] (*1929) sein erstes, und anscheinend einziges, auf Deutsch publiziertes Buch Die Hand. Geständnisse eines Henkers im Literaturbaus Frankfurt vor (FF 1993-04-29).

1398 Vgl. z. B. Opitz und Opitz-Wiemers 2013, S. 728-730. Zum Ausdruck ,Literarisches Fräuleinwunder vgl. FN 1263.

1399 Vgl. Hage 2010, S. 15.

1400 Kämmerlings 2011, S. 136.

1401 Dass das Literaturhaus Berlin weniger an den feuilletonistisch-ökonomischen Linien orientiert war, lässt sich zum Beispiel daran ablesen, dass 1998/1999 weder Judith Hermann noch Ingo Schulze dort gelesen haben. Grund dafür muss jedoch nicht Desinteresse sein, auch finanzielle Aspekte, Terminkollisionen oder die Konkurrenzsituation in Berlin können dafür gesorgt haben.

14021999 verbrachten die Autoren drei Tage im Berliner Hotel Adlon, um über Popliteratur zu diskutieren. Ergebnis war u. a. das Buch: Bessing et al. 1999. 
der Popliteratur war Programm: Es lasen „5 Minuten, zweimal“ unter anderem Alexa Hennig von Lange (*1973), Christian Kracht (*1966), Benjamin von Stuckrad-Barre (*1975), Moritz von Uslar (*1970) und Rainald Goetz (*1954), um nur die bekanntesten deutschsprachigen Popliterat*innen zu nennen (GT 2001-01-27). Zum einen handelte es sich bei diesen Namen um viel diskutierte Autor*innen, die mit hoher Publizität rezipiert wurden, zum anderen wurden sie relativ schnell - auch von der Literaturwissenschaft - zum Beispiel für eine sich verändernden literarische Landschaft in Deutschland stilisiert.

Fakt ist, dass alle untersuchten Literaturhäuser seit den 1990er-Jahren regelmäßig Veranstaltungen anbieten, die explizit literarische Debüts beziehungsweise noch unbekannte Autor*innen vorstellen. Die Vermittlungsstrategien sind in der Regel etwas anders als bei arrivierten Autor*innen, die bereits im Literaturbetrieb sichtbar waren. Häufig sind dann mehrere Gäste zum Gespräch eingeladen. In einigen Literaturhäusern gibt es feste Formate für die Vorstellung von jungen Autor*innen. Das Literaturhaus Hamburg widmet sich diesen etwa in der Reihe Schwanenwik goes Schulterblatt, das Literaturbaus Frankfurt mit Qualitätskontrolle zu Beginn jeden Jahres (erstmals FF 2011-01-13) und andere Einrichtungen beispielsweise mit dem Format zwischen/miete - Junge Literatur in WGs. ${ }^{1403}$ Schon dem Namen nach eine Initiationsveranstaltung führt das Literarische Zentrum Göttingen seit 2014 mit dem Debütantenball regelmäßig durch (erstmals GT 2014-01-30). ${ }^{1404}$ Vorgänger dieser jeweils drei Autoren oder drei Autorinnen präsentierenden Abende waren Einzelveranstaltungen wie Fräuleinzunder mit sieben Lyrikerinnen, darunter Ulrike Almut Sandig (*1979), deren Gedichtband Zunder von 2005 für das Wortspiel des Titels maßgeblich war, Ann Cotten (*1982), Kerstin Preiwuss (*1980) und Judith Zander (*1980) (GT 2010-0206) ${ }^{1405}$ und ein Jahr später Herrengedeck mit unter anderem Daniel Falb (*1977), CarlChristian Elze (*1974) und Christoph Wenzel (*1979) (GT 2011-02-05). Bei diesen beiden Abenden stand Gegenwartslyrik im Fokus, der Debütantenball stellt Lyrik und Prosa vor. Litteraturbuset in Oslo organisiert von Beginn an De store debutantdagene [Die großen Debütantentage] jährlich Anfang Dezember (erstmals OL 2007-1205/06). Arrivierte Schriftsteller*innen stellen „fremtidenes forfattare“ [Autor*innen der Zukunft] vor, die im Literaturbetrieb neuen Autor*innen werden also von bereits konsekrierten präsentiert. Auf diese Weise wird den Debütant*innen kollegiale Anerkennung zuteil, die auch die Aufmerksamkeit des Publikums für sie steigern kann. Die Auswahl treffen in diesem Fall also nicht Literaturkritiker*innen oder Literaturhaus-Leitungen, sondern Literaturproduzent*innen. An diesem Beispiel zeigt sich die beschriebene Rollendiversifizierung der Autor*innen in der Gegenwart, die im Literaturhaus auch als Mediator*innen und als professionelle Leser*innen aktiv sind. Außerdem betont diese gebündelte Präsentation mehrerer neu-

\footnotetext{
${ }^{1403}$ Diese Beispiele kamen schon verschiedentlich in dieser Arbeit vor, z. B. Kapitel II 11.1, S. 293. 1404 Debütantenball hieß auch eine Veranstaltung im Literaturbaus Hamburg 2002 vgl. FN 1410. Da ein ,Debütantenball' ursprünglich den ersten Auftritt einer Frau in der Gesellschaft feierte, und damit eine übliche Kombination mit dem dem Wort ,Debütant` eingeht, wird hier nicht von einer Übernahme des Veranstaltungstitels ausgegangen, zumal beide Termine zeitlich weit auseinanderstehen. Auf den Ritualcharakter, dass eine Person in die ,Gesellschaft', hier in den Literaturbetrieb, eingeführt wird, wird mit dem Titel angespielt.

1405 Nicht alle Gäste waren im Veranstaltungstext angekündigt. Ein Veranstaltungsbericht im Göttinger Tageblatt schließt diese Lücke, vgl. Varela 2010.
} 
er Autor*innen, dass es Litteraturbuset vor allem auf die Vorstellung einer Vielfalt ankommt, während die nachfolgende Selektion in den Händen des Publikums liegt: Wer beziehungsweise welches Buch wird gelesen? „Hvor lovende er de lovende?“ [Wie vielversprechend sind die Vielversprechenden?]

Litteraturbuset Bergen präsentierte in seinem Eröffnungsprogramm in der Reihe Nye Stemmer [Neue Stimmen] zu entdeckende Autor*innen, die in der Regel gerade ein Buch vorgelegt hatten; in der ersten Saison traten diese Gäste auf: Zum Auftakt sprach die dänische Autorin Josefine Klougart (*1985) zwei Jahre nach ihrem in Nordeuropa gefeierten und für den Nordisk Råds litteraturpris nominierten Debütroman Stigninger og fald [Aufstiege und Fall] und kurz nach Erscheinen ihres dritten Buchs Én af os sover [Einer von uns schläft] ${ }^{1406}$ mit der norwegischen Autorin Edy Poppy (*1975) (BG 2013-02-21). Außerdem kam die Dänin und Absolventin von Kobenhavns Forfatterskole Stine Pilgaard (*1984), die mit Min mor siger [Meine Mutter sagt] debütierte (BG 2013-03-07). Über Songtexte unterhielten sich die norwegische Künstlerin Jenny Hval (*1980) und der Komponist und Autor Eivind Buene (*1973), deren literarisches Schaffen unmittelbar mit Musik und einer Gesangsstimme gekoppelt sei (BG 2013-93-14). Dies ist nebenbei ein weiteres Beispiel für die selbstverständliche Verknüpfung literarischer mit anderen künstlerischen Ausdrucksformen.

Neben den Lesungsveranstaltungen mit neuen Autor*innen finden Debütautor*innen in den Literaturhäusern in Frankfurt und Hamburg durch Preisverleihungen Beachtung. Das Literaturbaus Frankfurt initiierte im Jahr 2001 einen eigenen Literaturpreis, den Blauer Salon Literaturpreis, ${ }^{1407}$ der jedoch schon 2004 zum letzten Mal verliehen wurde. In Frankfurt wird der Literaturpreis der Jürgen-Ponto-Stiftung, der seit 1978 existiert, vergeben. In Hamburg gibt es seit 1970 den Preis für den besten deutschsprachigen Debütroman, der später nach der Stifterin in Mara-Cassens-Preis umbenannt wurde. Seit 1985 wird er von einer Leserjury bestehend aus Mitgliedern des Literaturhaus-Vereins vergeben, die Preisverleihung eröffnet seitdem traditionell das Lesungsjahr des Literaturhauses Hamburg. Dieser Einstieg mit einer feierlichen Preisverleihung an einen verheißungsvollen Debütromanautor kann als programmatisch für das Literaturhaus insgesamt interpretiert werden: Das Zelebrieren steht hier am Beginn des Programmes eines jeden Jahres. Auch der Fokus auf erzählende Literatur innerhalb der Institution ließ sich erkennen.

\section{14.3 Nationale und internationale Ausrichtung}

Literaturhäuser präsentieren nicht nur regionale Literatur, sondern verstehen sich als Vermittler internationaler Literaturen. ${ }^{1408}$ Dieser bei der Analyse der Selbstdarstellungstexte herausgearbeitete Bestandteil des Selbstbildes der Literaturhäuser steht im Folgenden auf dem Prüfstand. Auf diese Weise lässt sich zum einen sehen, ob

\footnotetext{
1406 Das Debüt ist bisher nicht auf Deutsch erschienen, Einer von uns schläft erschien 2019 auf Deutsch. ${ }_{1407}$ Diesen Preis erwähnt Sonja Vandenrath in ihrer Studie, weitere Informationen dazu finden sich heute kaum noch, vgl. Vandenrath 2006, S. 160, 225.

${ }^{1408}$ Vgl. Kapitel II 9.4.1. Dort wurde unter anderem deutlich, dass die Literaturhäuser mit der Hervorhebung ihrer Internationalität zugleich Aussagen über ihre literaturästhetische Verortung treffen: Kriterium für die Rezeption von Literatur ist statt ihrer regionalen Wirksamkeit ihre ortsunabhängige Gültigkeit.
} 
das Selbstbild der Programmrealität entspricht, zum anderen beleuchtet das Kapitel die nationale beziehungsweise internationale Ausrichtung der Institution, die auch ohne die Hervorhebung in der Selbstdarstellung von Interesse wäre. Zu fragen ist also unter anderem, ob die Internationalität besonders hervorgehoben wird und welchen Anteil ursprünglich nicht-deutschsprachige respektive nicht-norwegische Texte bilden.

Um die regionale, nationale und internationale Ausrichtung des Literaturhauses zu überprüfen, ist entscheidend, wie die Bühnenakteur*innen sich geografisch und sprachlich verorten. Der Ausdruck, national' sei hier als Synonym für ,inländisch und als Abgrenzung zu ,international' verstanden, eine politische Dimension in Richtung, nationalistisch' oder zumindest ,die Interessen des Staates betreffend' ist nicht mitgemeint. Die unter diesem Aspekt inspizierten Ankündigungstexte wurden daraufhin untersucht, ob sie Angaben zum Herkunftsland, Wohnort oder zur Sprache der Autor*innen machen. Bei einigen Akteur*innen wird als bekannt vorausgesetzt, woher sie kommen, zusätzlich können Personennamen oder Literaturpreise Hinweise auf das Land geben, aus dem der Gast angereist ist. Gibt es keine ausdrücklichen Hinweise auf die Nationalität oder sprachliche Verortung, handelt es sich in der Regel um Gäste aus Deutschland respektive aus Norwegen. Es wird in den deutschen Programmtexten nicht immer betont, wenn Autor*innen aus der deutschsprachigen Schweiz oder Österreich kommen. Wenn es sich nicht um deutsch- beziehungsweise norwegischsprachige Künstler*innen handelt oder wenn ein lokaler Bezug betont werden soll, wird meistens explizit auf die jeweilige Nation oder Stadt hingewiesen.

\section{14.3.1 Regionalität}

Wie ausgeführt weisen Literaturhäuser ortsbezogene Besonderheiten auf. Zum Teil spiegeln sich diese im Programm wider, beispielsweise über die Einladung von lokal und regional relevanten Autor*innen; in Frankfurt sind etwa Wilhelm Genazino (1943-2018) (z. B. FF 2011-05-10; Frankfurter Poetikvorlesungen FF 2006-02-08) oder Martin Mosebach (*1951) (z. B. FF 2014-02-27; FF 2014-04-01) regelmäßig zu Gast - wobei die Einladungen nicht allein auf ihre lokale Verwurzelung zurückzuführen sind, schließlich gelten sie als etablierte Autoren, denn beide wurden unter anderem mit dem Georg-Büchner-Preis ausgezeichnet und sind in den anderen Literaturhäusern ebenfalls eingeladen. ${ }^{1409}$ Lesungen mit lokalen Autor*innen, bei denen der Regionalbezug das Einladungskriterium ist, finden kaum statt. Das Literaturhaus Hamburg hob beispielsweise ausdrücklich hervor, dass es selten sei, „dass in einer Stadt, einer Stadt wie Hamburg, in einem einzigen Jahr, acht äußerst bemerkenswerte Debüts von jungen Hamburger Autoren gleichzeitig erscheinen“, und lud diese zum Debütantenball ein (HH 2002-06-03). ${ }^{1410}$ Ebenso sind Gedenkabende zu erwähnen; etwa

\footnotetext{
1409 Wilhelm Genazino z. B. (HH 1999-02-95); (FF 2003-03-11); Poetikvorlesung (GT 2003-12-10/11); Moderator bei der Lesung von Hans Joachim Schädlich (HH 1998-04-02); Bildbeschreibungen (BE 2000-03-08).

1410 Verena Carl, Andreas Münzner, Jürgen Noltensmeier, Tina Uebel, Michael Weins, Marc Wortmann und Stefanie Viereck lasen aus ihren Debüts. Durch den Abend führte der Autor Matthias Göritz. Für die Musik sorgte DJ Carla Riveros.
} 
die dem verstorbenen Literaturkritiker Walter Boehlich (1921-2006) zum 90. Geburtstag gewidmete Veranstaltung im Literaturbaus Frankfurt (FF 2011-09-16).

Themen, die sich besonders mit der jeweiligen Stadt befassen, sind auf die lokale Verwurzelung zurückzuführen; das Literaturbaus Berlin organisierte etwa eine Veranstaltung zu Das gute alte West-Berlin mit dem Wiener Autor und Künstler Günter Brus (*1938), der in den 1970er-Jahren in Berlin lebte (BE 2010-12-03). Oder das Literarische Zentrum Göttingen lud Steffen Martus anlässlich seiner Biografie Die Brüder Grimm ein (GT 2010-05-27). Außerdem schafft die Präsentation von ortsansässigen kollektiven Akteur*innen des Literaturbetriebs eine spezielle Ortsanbindung, beispielsweise Die Göttinger Verlagsnacht (GT 2007-05-09). Zum einen kann von einem Interesse des Publikums an diesen lokalen Themen ausgegangen werden. Zum anderen stellen hin und wieder ortsansässige Unternehmen, Stiftungen oder Behörden Mittel für derartig basierte Veranstaltungen zur Verfügung. Seine lokale Relevanz ist seitens des Literaturhauses unter anderem aus finanziellen Gründen zu stärken. ${ }^{1411}$ So trägt das Literaturhaus an seinem jeweiligen Platz seiner unmittelbaren Umgebung Rechnung.

\section{14.3.2 Verhältnis national - international}

Exemplarisch wurden aufwendige quantitative Untersuchungen der eingeladenen Akteur*innen der Literaturhäuser Frankfurt und Bergen durchgeführt: eine Zufallsauswahl, die für die anderen Fallstudien ebenfalls aussagekräftig ist, da es hier mehr auf eine Tendenz und nicht auf genaue Zahlen ankommen soll. Bei dieser Datenerhebung wurden aufgrund der oben dargelegten Bedenken hinsichtlich einer Kategorisierung in ,Autor*innen' und ,Nicht-Autor*innen' alle erwähnten an den Veranstaltungen Beteiligten berücksichtigt, sodass vereinigend von ,Akteur*innen“ die Rede ist.

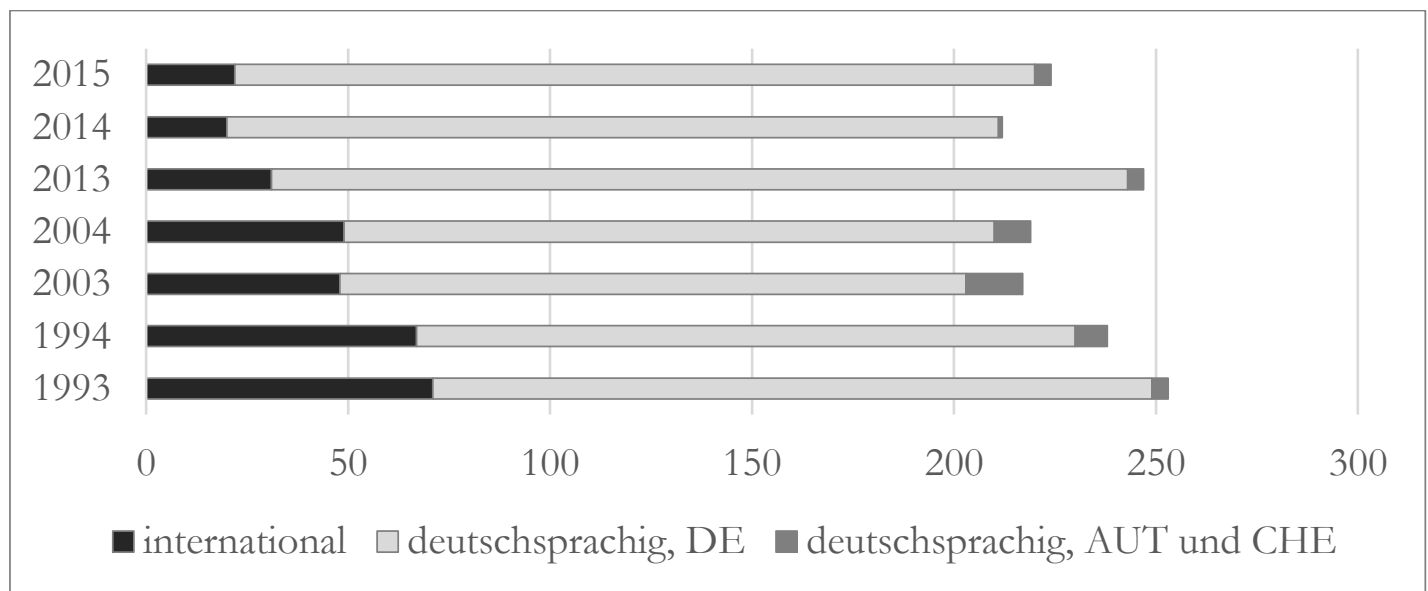

Abbildung 14: Literaturbaus Frankfurt, Gäste nach Land (1993-2015, ausgewählte Jahre), eigene Darstellung

${ }^{1411}$ Der Rückgriff auf vor Ort lebende Bühnengäste zur Moderation oder zur Lesung des deutschen Parts hat zudem deshalb praktische Gründe, weil dann keine Reisekosten anfallen. 


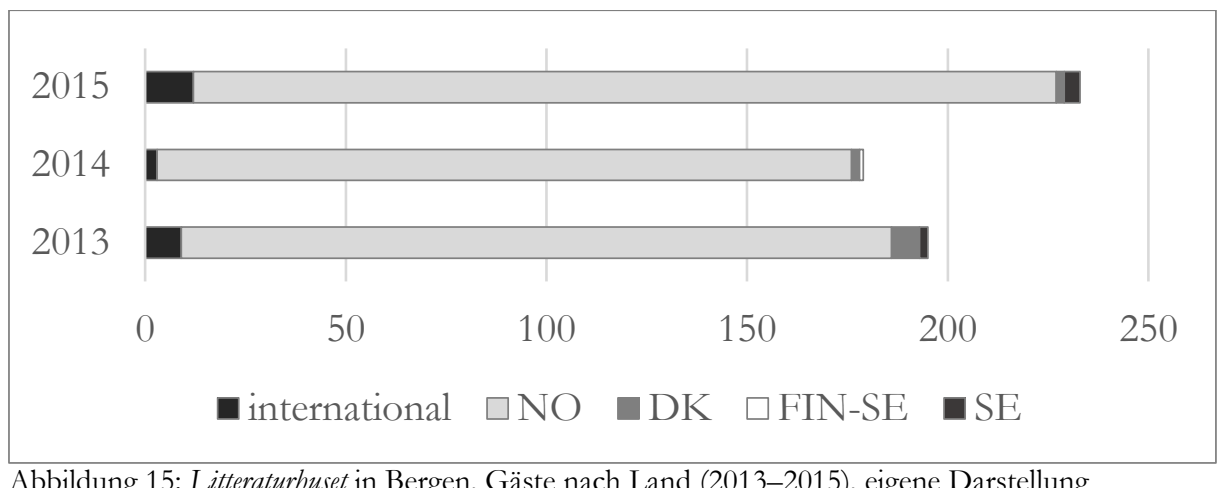

Abbildung 15: Litteraturbuset in Bergen, Gäste nach Land (2013-2015), eigene Darstellung

(1.) Es geht aus den Datenauswertungen hervor, dass nationale Akteur*innen den mit Abstand größten Anteil am Literaturhaus-Programm darstellen. Insgesamt bilden deutsche/deutschsprachige respektive norwegische Gäste rund 90 Prozent der Bühnenbesucher*innen in den Literaturhäusern. Dieser Wert blieb über die Jahre relativ konstant, sodass keine markante Änderung der Verteilung vorliegt. Es ist zu bedenken, dass bei der hier vorgenommen Datenerhebung alle genannten Akteur*innen einbezogen wurden. Dies begründet teilweise die deutliche Mehrzahl nationaler Beteiligter, da meistens inländische Moderator*innen das Gespräch mit ausländischen Autor*innen führen. Bei den deutschen Literaturhäusern kommen oft noch weitere Personen hinzu, die aus der Übersetzung vorlesen, sodass bei jedem ausländischen Gast mindestens ein nationaler auftaucht. Da die Veranstaltungen in der Regel in der Landessprache stattfinden, liegt es außerdem nahe, dass deutschbeziehungsweise norwegischsprachige Gäste in der Mehrheit sind, was es zusätzlich nachvollziehbar macht, häufig nationale Literatur vorzustellen, die im Original rezipiert werden und auf Übersetzer*innen und Dolmetscher*innen verzichten kann.

(2.) Internationale Gäste bilden seit jeher einen Bestandteil der LiteraturhausProgramme. In den Anfangsjahren lassen sich im Literaturbaus Frankfurt eher mehr internationale Gäste verzeichnen, was im Zusammenhang mit den Länderschwerpunkten zu deuten ist, auf die zurückzukommen sein wird. Beim Literaturhaus in Bergen fällt der Anteil ausländischer Gäste etwas geringer aus. Dies stützt die Vermutung, dass diese kleinere Einrichtung, nicht zuletzt aufgrund finanzieller Gründe, eher regional agiert und internationale Gäste häufiger in der Hauptstadt Oslo zu Gast sind. ${ }^{1412}$ Unterstützt wird dies vom Selbstverständnis der Bergener Einrichtung, die beispielsweise zu ihrem fünften Geburtstag zu einem Vestlandsfest einlud und nur Autor*innen der Region auftreten ließ (BG 2018-02-01).

\section{14.3.3 Internationalität}

Die lokale Komponente in ihren Programmen betonen die untersuchten Literaturhäuser weitaus zurückhaltender als ihre Offenheit der globalen Literaturszene gegenüber. Sie erwähnen in den Ankündigungstexten Informationen zur geografischkulturellen Situierung der Gäste vor allem dann, wenn verschiedene Länder und Sprachen eine Rolle spielen. Das legt die Vermutung nahe, dass ein transkultureller

${ }^{1412}$ Vgl. Kapitel II 6.2. 
Hintergrund als interessant für die Auseinandersetzung mit Literatur genauso wie für die Beschäftigung mit der Autorenpersona eingestuft wird.

\section{Übersetzungen}

Die Unterscheidung in den Ankündigungstexten von nicht-deutschsprachigen/ nicht-norwegischsprachigen und ex negativo deutschsprachigen/norwegischsprachigen Akteur*innen ist, wie gesagt, zweckmäßig, weil bei Literaturveranstaltungen die zugrunde liegende Sprache zentral ist, wenngleich in der Regel ins Deutsche respektive Norwegische gedolmetscht wird. Anfangs uneinheitlich, später regelmäßig finden sich außerdem die Übersetzer*innen der vorgestellten Publikationen in den Programmhefttexten genannt. Damit wird ihnen zwar Anerkennung zuteil, doch dadurch, dass sie selten anwesend sind, unterliegen sie insgesamt weiterhin der Einschätzung „des Übersetzens als untergeordnete Hilfstätigkeit" "1413, woran nicht einmal der Übersetzerstreit Anfang des 21. Jahrhunderts viel geändert habe. Es lassen sich aber Veranstaltungen verzeichnen, die sich dieses Themas diskursiv annehmen. ${ }^{1414}$

Obwohl die Einrichtungen gelegentlich eigene Übersetzungsprojekte durchführen, bilden in der Regel publizierte Übertragungen die Grundlage für die internationalen Literaturhaus-Veranstaltungen. ${ }^{1415}$ Sofern die Literaturhäuser keine größeren Projekte entwickeln, die eigene Übersetzungen und Expert*innen als Kurator*innen finanzieren können, sind die Programmleiter*innen stark auf die Verlagsangebote angewiesen. Dies schränkt die Selektionsmöglichkeiten hinsichtlich internationaler Literatur für die Veranstalter*innen auf die von Verlagen ausgewählten - ursprünglich fremdsprachigen, dann übersetzten - Titel ein. Die Relationen von ausländischen und inländischen Gästen in den Literaturhäusern entsprechen etwa dem Verhältnis von Originalausgaben zu Übersetzungen auf dem deutschen Buchmarkt. ${ }^{1416}$ Die Literaturhäuser sind also im Bereich der internationalen Literatur in ihrer Programmgestaltung besonders von den Erzeugnissen des Buchmarktes abhängig. Dies veranschaulicht die mächtige Gatekeeper-Position von Verlagen, die mit ihren Lizenzentscheidungen über die Vermittlung bestimmter Autor*innen und Texte richten.

1413 Bachleitner und Wolf 2010, S. 14. Sie führen aus, dass Übersetzer*innen ,zweifellos die schwächsten Glieder in der translatorischen Verarbeitungskette“ darstellen. Zur Unterstützung dieser Berufssparte gründete sich 1997 der Deutsche Übersetzerfond e. V.

1414 Norbert Bachleitner und Michaela Wolf konstatieren, dass ein soziologischer Ansatz zur Übersetzungsforschung die an ihrer Produktion, Distribution und Rezeption beteiligten Institutionen und Akteur*innen berücksichtigen müsse. Die beiden Autoren untersuchen Übersetzungen mittels der Theorie des literarischen Feldes nach Bourdieu. „Diese [Übersetzungen, Anmerkung C. L.] sind in einem vorwiegend durch Sprachgrenzen definierten Feld tätig, das seinerseits innerhalb eines globalen literarischen Feldes situiert werden muss“, ebd., S. 7. Die Begrenzung durch Sprachbarrieren gilt nicht nur für Übersetzungen, sondern für jede sprachbasierte Kunstform. Übersetzungen öffneten jedoch „,von Sprachbarrieren umgrenzte Räume“, ebd., S. 8. So leisten Übersetzungen zweifellos einen Beitrag zum Literaturtransfer. Das Literaturhaus wäre bei einem solchen Zugang unbedingt zu berücksichtigen, was aber nicht im Fokus der vorliegenden Arbeit liegt. Die Bedeutung von Übersetzung für komparatistische Arbeiten und Prozesse des Kulturtransfers ist so groß, dass ihr ein eigenes Kapitel beziehungsweise ein eigener Beitrag gewidmet werden könnte. Für einen Überblick vgl. Abel 2013.

1415 Vgl. Kapitel II 11.2.3. Gelegentlich führen die Literaturhäuser eigene Projekte durch, bei denen Schriftsteller*innen Auftragsarbeiten erfüllen. Diese meist größer angelegten Projekte sind zum einen als Beitrag zur Literaturproduktion zu verstehen und zum anderen als Autorenförderung, weil die Teilnehmenden in der Regel ein zusätzliches Honorar erhalten.

1416 Vgl. Cronau et al. 2018, S. 97. 
Zugleich bedeutet dies, dass die Literaturhäuser so keine Konkurrenzprodukte zu den bereits verfügbaren Übersetzungstiteln bereitstellen, sondern sich eher der Aufmerksamkeitsgenerierung für verfügbare Bücher anschließen. Dies kann die Vermittlungsarbeit erleichtern, weil Autor*innen und Titel eventuell beim allgemeinen Publikum bereits bekannt sind. Eine Abhängigkeit vom Markt bleibt bestehen.

Ebenso ist die Expertise der Literaturhaus-Teams einzuberechnen, denn die Fachgebiete der Programmleitungen wirken sich auf die internationalen Schwerpunktsetzungen aus. Für das Literaturhaus Berlin ließ sich bis 2018 ein starker Bezug zur rumänischen und zur Literatur des ehemaligen sogenannten, Ostblocks' ${ }^{`}$ erkennen, der unter anderem auf den Leiter Ernest Wichner zurückzuführen ist, der in Guttenbrunn, Rumänien geboren wurde, 1975 nach Deutschland ausreiste und selbst als Übersetzer aus dem Rumänischen tätig ist. So wirkte er gelegentlich als Moderator mit, wenn rumänische Autoren in anderen Literaturhäusern zu Gast waren, zum Beispiel im Literaturbaus Frankfurt Norman Manea (*1936), der Rumänien 1986 verließ und in den USA lebt (FF 2004-03-02). Ebenso moderierte die gebürtige Italienerin Maria Gazzetti mehrere Abende mit italienischen Autoren im Literaturhaus Hamburg (z. B. HH 1994-03-30). ${ }^{1417}$

In den Literaturhäusern sind, wie gesagt, von Beginn an auch internationale Autor*innen zu Gast. Es fällt dabei auf, dass die internationale Ausrichtung in den ersten Jahren durch Reihen und Festivals stärker betont wurde. In Hamburg waren dies zum Beispiel Schwerpunkte zur Literatur Österreichs oder Italiens (HH 199402), im Literaturbaus Frankfurt die Reihe Europäische Erzähler, unter anderem mit dem portugiesischen Autor José Saramago (1922-2010), der 1998 den Nobelpreis für Literatur erhielt (FF 1993-10-26). Grundsätzlich lässt sich bestätigen, dass Literatur aus Europa eine große Rolle in den Programmen spielt. Einerseits sind dafür ökonomische Argumente anzuführen, denn Lesereisen europäischer Autor*innen sind wesentlich einfacher und kostengünstiger zu organisieren als Touren von Gästen, die Interkontinentalflüge und Visumszusagen bedürfen. Andererseits schwingt dabei in den Ankündigungen inhaltlich häufig die Frage nach einer Idee von gemeinsamer europäischer Literatur und Kultur mit. Das Symposium Europa schreibt im Literaturhaus Hamburg nahm explizit an, dass ein Austausch von Autor*innen unterschiedlicher europäischer Länder - aus West-, Süd- und Nordeuropa ebenso wie aus Mittelund Osteuropa - aufschlussreich für eine Diskussion nicht nur über europäisches Schreiben, sondern generell über Europa als Kulturraum sei. Die enge Verbindung von Literatur und Gesellschaftspolitik, die auf das Literaturhaus insgesamt übertragen werden kann, zeigt sich an diesem Beispiel ausdrücklich. Europa ist der zentrale Bezugspunkt.

Besonders ist ein Interesse erkennbar an der Veränderung der europäischen Gesellschaften nach 1989 und der seit 1990 diskutierten sogenannten Osterweiterung der Europäischen Union, die 2004 realisiert wurde. Die Programme der deutschen Li-

\footnotetext{
${ }^{1417}$ Möglicherweise hat sie die Abende gar mitgeplant, sie fanden nämlich noch vor ihrem Amtsantritt in Frankfurt statt. Auch Rainer Moritz moderierte im Literaturhaus Hamburg schon 1999 mindestens eine Lesung - mit der 1959 geborenen deutschen Autorin Judith Kuckart (HH 1999-03-04). Dies zeigt, dass die Leitungen oft schon vor ihrer Stelle dort mit den Literaturhäusern zu tun hatten.
} 
teraturhäuser zeigen, dass dieses Thema sich im Kulturbetrieb widerspiegelte, denn es fällt für die 1990er-Jahre auf, dass es in den Programmen der Literaturhäuser relativ häufig um Ost- und Mitteleuropa ging beziehungsweise um den postsowjetischen Raum. In Berlin spielen derartige Sujets aufgrund des Standortes eine noch gewichtigere Rolle. Die bereits erwähnte Ausstellung zur Zensur in der Deutschen Demokratischen Republik: Geschichte, Praxis und ,Ästhetik" der Bebinderung von Literatur im Literaturhaus Berlin stellte einen bedeutenden Beitrag zur Aufarbeitung der Kulturgeschichte dar (BE 1991-03-17/05-01). Doch selbstverständlich war und ist dies kein berlinspezifisches, sondern ein deutschland- und europaweites Thema, wie Veranstaltungen in anderen Literaturhäusern zeigen. Das Literaturhaus Frankfurt stellte etwa 1991 innerhalb der Reihe Fremde Nachbarn in Vorträgen und Lesungen die ehemalige Sowjetunion vor, unter anderem mit der Kulturvermittlerin Olga Mamontowa (FF 1991-09-04), dem Historiker Karl Schlögel (FF 1991-10-21), der Beschreibung einer Polen-Reise des Schweizer Autors Reto Hänny (FF 1991-09-24), dem ungarischen Schriftsteller Péter Nádas (FF 1991-10-08) sowie dem estnischen Autor Arvo Valton (FF 1991-10-17).

Der Umbruch nach dem Fall der Mauer betraf als Thema gesellschaftspolitische Aspekte, kulturpolitische Fragen ebenso wie die Auseinandersetzung mit ästhetischen Debatten, etwa bei einer Diskussion zum Theater Ost-West (HH 1992-0503). Belege dafür, dass es kurz vor 1989 tagesaktuelle politische Debatten gegeben habe, lassen sich in den untersuchten Berliner Literaturhaus-Programmen nicht finden. Am 9. November 1989 übrigens fand - dem Monatsprogramm zufolge - im Literaturhaus Berlin keine Veranstaltung statt. Und das Literaturbaus Hamburg war da gerade erst eröffnet worden

1989 ist ein für Europa wichtiges Jahr. Dass beispielsweise in Norwegen ein anderes Verhältnis zur deutsch-deutschen Teilung und der Gegenüberstellung von Ost und West besteht, beweist der Themenschwerpunkt Murens fall [der Fall der Mauer] im Litteraturhuset in Oslo anlässlich des 20. Jubiläums des Mauerfalls (OL 2009-1204/05). Zur Auseinandersetzung mit diesem weltpolitischen Sujet kamen Literat*innen als Intellektuelle ins Litteraturbuset, um historische Gegebenheiten zu reflektieren und die Erkenntnisse zu aktualisieren. Der Frage „Men hva skjedde egentlig i Tyskland i 1989, og hva førte det til?“" [Aber was passierte eigentlich 1989 in Deutschland und wozu führte das?] näherten sich der NRK-Korrespondent Wilhelm Steinfeld, der deutsche Autor und „Øst-Tysklands kronikør“ [Ost-Deutschlands Chronist] Christoph Hein $(* 1944)$ und der russische Autor Vladimir Sorokin (*1955). Die niederschwellige Formulierung der zentralen Frage macht deutlich, dass das Literaturhaus vor allem Aufklärungsarbeit leistete und dem norwegischen Publikum Wissen über deutsche respektive europäische Geschichte vermitteln wollte. Dies belegt sowohl, dass Litteraturhuset stark als Volksbildungseinrichtung auftritt, als auch, dass es sich als europa- beziehungsweise globalorientierter Kulturvermittler versteht. Bemerkenswert ist an diesem Beispiel, dass mit dem in der DDR sozialisierten Hein und dem in Russland lebenden Sorokin allein der Blick aus dem Osten auf den Mauerfall präsentiert wird. Die Perspektive der BRD wird ausgespart. Es liegt die Vermutung nahe, dass vor allem die ,andere Seite', also das den westlich sozialisierten Norweger*innen weniger Bekannte, vermittelt werden wollte, um da- 
mit ein vollständigeres multiperspektivisches Verständnis der Zeit um 1989 anzubieten. Auch organisationspraktische Gründe für diese Gastauswahl sind möglich.

Im Literaturbaus Berlin fand am gleichen Wochenende das Symposium Der Osten liegt in der Mitte. Literarische Ost-West-Passagen als Thema der Literaturtage des ZfL statt (BE 2009-12-04/05)1418. Zu Jahres- oder Gedenktagen knüpfen LiteraturhausVeranstaltungen also weiterhin durchaus historische Bezüge. Besuche von Autor*innen aus dem postsowjetischen Raum werden hingegen inzwischen in dem Gesamtprogramm der deutschen Literaturhäuser nicht mehr explizit hervorgehoben, die Herkunft der Akteur*innen wird wie bei anderen internationalen Gästen genannt, beispielsweise bei den russischen Autoren Viktor Pelewin (*1962) (FF 2000-12-05) oder Vladimir Sorokin (GT 2015-10-22).

\section{,Weltliteratur}

Der Eindruck, dass die Betonung der globalen Ausrichtung der Programme anfangs deutlicher war, kommt zudem dadurch zustande, dass die Literaturhäuser früher häufiger Literaturen anderer nicht-europäischer Länder in den Mittelpunkt stellten. So organisierten sie Veranstaltungen zu asiatischen und afrikanischen Literaturen, die meist in Anlehnung an größere Projekte oder in direkter Kooperation mit landesspezifischen Einrichtungen wie Kulturinstituten stattfanden, beispielsweise die Teilnahme an den Asien-Parifik-Wochen Berlin 2005 mit dem Fokus Korea (BE 200509-30/10-01) oder am Nippon Connection - Japanisches Filmfest in Frankfurt (FF 200404-15). In Frankfurt wurde bereits in den Anfangsjahren Literatur der Welt präsentiert, unter anderem kam der, laut Programmtext, einflussreichste Lyriker Indonesiens Rendra (1935-2009, Willibrordus Surendra Broto Rendra, bekannt als WS Rendra) (FF 1991-09-30). Die spätere Umbenennung der Reihe in Literatur(b)aus der Welt hob das globale Interesse der Einrichtung noch stärker hervor. Unter anderem war Ismail Kadaré (*1936) zu Gast, der dem Ankündigungstext zufolge ,als der bedeutendste albanische Schriftsteller der Gegenwart" gelte (FF 1996-01-31). Beide Beispiele illustrieren, dass das Literaturhaus an einer Revision eines eurozentrischen Kanons der Weltliteratur mitwirkte. Zugleich markiert die Bezeichnung Literatur(b)aus der Welt für derartige Veranstaltungen eine Differenzierung zwischen dem europäisch und US-amerikanisch ausgerichteten Programm und den ,anderen' Literaturen, der ,Weltliteratur ${ }^{6}$ - im Sinne des nicht unproblematischen Terminus ,World Music/Weltmusik', der sich auf außereuropäische traditionelle Musik bezieht.

Innerhalb der Reihe Literatur(b)aus der Welt kooperierte das Literaturhaus Frankfurt zudem mit dem damals neuen Kulturfestival Africa Alive (FF 1996-01-26): Afrikas Frauen an der Feder - von Oratur zur Literatur mit der gabunischen Autorin Ntyugwetondo Angèle Rawiri (1954-2010) und der senegalesischen Schriftstellerin Aminata Sow-Fall (*1941). Mit Veranstaltungen trug das Literaturhaus Frankfurt schon $1992 \mathrm{zu}$ den Afrika-Wochen mit Diskussionsthemen wie Afrikanische Literatur im Prozeß der Demokratisierung (FF 1992-10-23) bei. Afrika wird dort vereinigend als ein Kulturraum verstanden und nicht als Konglomerat von Einzelstaaten mit eigenen Hintergründen.

${ }^{1418}$ Auf diese Kooperation wurde schon im entsprechenden Kapitel verwiesen, vgl. Kapitel II 11.2.2. 
Diese eurozentrische Perspektive und ein gewisser ,Exotismus' wird durch den Reihentitel Fremde Welten? noch deutlicher: 1994 fanden unter dieser Überschrift Lesungen statt, beispielsweise mit V. S. Naipaul (1932-2018), deren „eigene Biographie durch die Vielfalt der Kulturen der Welt bestimmt ist", wie es im Programmtext steht (FF 1994-02-01). Unter der Überschrift Fremde Welten? Konfrontation und Entdeckung sprach der deutsch-iranische Autor SAID (*1947) über den iranischen Autor Mohammed-Ali Dschamâlsâdeh (auch transkribiert als Mohammad Ali Dschamālzāde und Muhammad'Alī Jamālzādah, 1892-1997) - laut Programmtext „einer der wichtigsten Autoren der modernen persischen Literatur“ (FF 1994-0315). Darüber hinaus richtet das Literaturhaus Frankfurt schon seit langem die Lesung mit der jeweiligen Gewinnerin des aktuellen LiBeraturpreises aus, der seit 1988 Schriftstellerinnen aus Afrika, Asien und Lateinamerika auszeichnet. Obwohl das Literaturhaus nicht der Initiator des Preises ist, demonstriert es mit dieser Zusammenarbeit, dass es diesen Preis als wichtig einschätzt (z. B. FF 1993-10-05; FF 2011 10-11).

Im Literaturhaus Frankfurt lässt sich in den Anfangsjahren also ein besonderer Bezug zu einer vielfältigeren Literaturlandschaft erkennen, was mit dem internationalen Selbstverständnis der Stadt zusammenhängen mag. Diese Lesungen waren eingebettet in Diskussionen, wie Das Fremde und das Eigene - Gespräche über multikulturelle Gesellschaft, die im Literaturhaus schon 1992 stattfanden, zum Beispiel zum Thema Arbeitsmigration und Fundamentalismus - Eine islamische Bildungsgeschicbte (FF 1992-0116) oder Der Preis der multikulturellen Gesellschaft. Amerikanische Erfahrungen (FF 199205-21). Gesellschaftsdiagnostische Debatten angelehnt an die Präsentation noch unbekannterer Literaturen trugen die anderen Literaturhäuser ebenfalls aus. Wir und die Anderen - Die multikulturelle Gesellschaft: Lebensform oder Schlachtfeld lautete beispielsweise der Titel eines Gesprächs in Hamburg (HH 1993-02-02), was von Texten gegen Ausländerfeindlichkeit begleitet wurde (HH 1993-01-31). Und es wurde etwa Literatur aus Mexiko vorgestellt (HH 1992-02-11).

Autor*innen werden häufig als Intellektuelle sowie Kulturvermittler*innen angesehen, die über Literatur einen Eindruck, ihres' Landes transferieren. In dieser Hinsicht sind die Veranstaltungen als politische Handlungen zu deuten, was stärker an das heutige Programm des Litteraturbuset in Oslo erinnert. Bei Themenreihen und Länderschwerpunkten kommt dieses Ansinnen besonders deutlich heraus, da es sich nicht nur um für sich stehende Abende handelt, sondern diskursive Rahmungen entstehen können.

Thementage zu einzelnen Ländern führten die deutschen Literaturhäuser, wie beschrieben, in den Anfangsjahren häufiger durch. Internationale Literaturen finden sich später in der Regel ohne explizite Trennung von der landessprachlichen Literatur im Programm vorgestellt. Diese Beobachtung ist ein Argument dafür, anzunehmen, dass die Grenzen zwischen den einzelnen ,Nationalliteraturen“ zwar nicht gänzlich verwischen, und doch unbedeutender werden. ${ }^{1419}$ Damit manifestiert sich zugleich ein Fokus auf westliche Literatur. Es lässt sich nämlich sehen, dass so nicht-westlicher Literatur in den deutschen Literaturhäusern eine geringere Sichtbarkeit zuteilwird als früher. Ein Festival zu indischer Literatur im Literaturhaus Zü-

1419 Zum Verhältnis von Nationalphilologien zur Komparatistik vgl. Winkler 2013. 
rich im Frühjahr 2018 macht beispielsweise deutlich, dass Literatur aus diesem Kulturraum nicht selbstverständlich in die Literaturhaus-Programme eingebunden ist, sondern es ausdrücklicher Schwerpunktsetzungen bedarf. Erneut ist ein Zusammenhang mit den verfügbaren Übersetzungen auf dem deutschen Buchmarkt herzustellen, denn dort bilden Übersetzungen aus dem Angloamerikanischen ebenfalls die Mehrheit. ${ }^{1420}$ Hinzu kommt, dass Autor*innen, die in Deutschland noch unbekannt sind und vielleicht einen vom üblichen Publikum abweichenden kulturellen Hintergrund haben, gegebenenfalls anders präsentiert werden müssen als Autor*innen und Texte, die auf einem ähnlichen Kulturkontext beruhen. Möglicherweise versucht die Vermittlung in diesen Fällen zunächst stärker, die eventuellen kulturellen Differenzen zu überbrücken, als eine direkte kunstfokussierte Auseinandersetzung mit Text anzubieten. Sich auf unterschiedliche Kontexte einzulassen, erfordert andere kuratorische Arbeit.

\section{Schwerpunkt Frankfurter Buchmesse}

In die Überlegungen zur Integration internationaler Autor*innen in die deutschen Literaturhaus-Programme sind ferner die Gastlandauftritte der Frankfurter Buchmesse im Oktober und in geringerem Maße der Leipziger Buchmesse im März einzubeziehen, die jeweils fast ein Jahr lang die Aufmerksamkeit auf die Literatur eines Landes richten. Die seit 1976 wechselnden Schwerpunktthemen der Frankfurter Buchmesse wurden 1988 abgelöst von den Gastlandauftritten, deren Ausrichtung seitdem bei den jeweiligen Ländern liegt. Mit den Gastlandeinladungen entstand zunächst „ein neues Konzept, das sich darauf konzentrierte, traditionsreichen Nationen eine Bühne zur Darstellung ihres kulturellen und literarischen Profils zu bieten. "1421 Die Auswahl der beiden ersten Länder - Italien und Frankreich - bestätigte diese Intention. Damit wurde und wird ein kulturpolitischer Auftrag erfüllt, um das Land mittels der Literatur im Ausland zu präsentieren. Die Buchmesse beabsichtigte damit zudem, mehr Publikum und Pressevertreter*innen auf die Messe zu locken und nicht nur eine Geschäftsmesse zu bleiben. ${ }^{1422}$ Die Programme der Literaturhäuser zeigen, dass die Gastlandauftritte über die Messe hinaus wirken, denn in der Regel schließen sie sich diesen - mehr oder weniger intensiv - an, sodass sie seltener eigene, davon abweichende Länderschwerpunkte setzen. ${ }^{1423}$

In der Buchmesse-Stadt Frankfurt gab es seitens des Literaturhauses von Anfang an eine Zusammenarbeit mit dem Gastlandauftritt. So wurde 1994 in der Bockenheimer Landstraße 104, die vom Messegelände fußläufig erreichbar ist, brasilianische Literatur präsentiert. Obwohl das Programm dieser vier Tage nicht vom Literaturhaus selbst organisiert wurde, fügte sich der Werbeflyer ins Design der Einrichtung ein und so strahlten die Veranstaltungen auf das Literaturhaus ab. Die Gastlandauftritte sind nicht mehr nur im Buchmesse-Monat in den deutschen Programmen er-

\footnotetext{
${ }^{1420}$ Vgl. Cronau et al. 2018, S. 97.

1421 Rütten 1999, S. 140.

${ }^{1422} \mathrm{Zu}$ den Anfängen der Frankfurter Buchmesse in den 1950er-Jahren vgl. Füssel 1999.

1423 Ähnliche Kulturpromotionen im Ausland aus kulturpolitischen Bestrebungen betreiben zum Beispiel die Organisation NORL A für norwegische Literatur und das Goethe-Institut für deutsche Literatur, das beispielsweise mit der Plattform Litrix.de dezidiert online deutsche Publikationen, deren Übersetzung gefördert wird, vorstellen.
} 
wähnt, vielmehr finden sich über das Jahr verteilt Veranstaltungen, bei denen ein entsprechender Bezug herausgestellt wird. Eine vom Literaturhaus initiierte Konzentration auf wenige Tage ist nicht mehr nötig, denn in der Öffentlichkeit ist die Aufmerksamkeit für die Literatur des jeweiligen Landes eh relativ groß. Zugleich stellen Kulturinstitute der Länder und beteiligte Organisationen auf dieses Projekt bezogene Gelder zur Verfügung, die es für Literaturveranstalter*innen attraktiv machen, zum Gastlandjahr beizutragen. Dabei ergeben sich manchmal größere Reihen, beispielsweise bot das Netzwerk der Literaturbäuser beim Island-Auftritt $2011^{1424}$ eine gemeinsame Präsentation isländischer Lyrik an (z. B. FF 2011-09-29). Ihre eigene Position markierten die Mitglieder des Netzwerks deutlicher, als Finnland kurzerhand - angeblich aufgrund der Schließung des Nokia-Werkes in Bochum - 2011 doch nicht Gastland wurde. Gemeinsam mit FiLi (Finnish Literature Exchange), das finnische Pendant zu NORLA, organisierten sie eine Lesereise finnischer Autor*innen durch Deutschland. ${ }^{1425}$ Das Projekt von 2010 hatte einen finnischschwedisch-deutschen Namen: Kaksinkertainen/Dubbelt/Doppelt, eingeladen waren unter anderem die finnlandschwedischen Autoren Robert Åsbacka (*1961) (z. B. BE 2010-04-19) und Kjell Westö (*1961) (z. B. HH 2010-04-21) ${ }^{1426}$.

Auch jenseits der Gastlandauftritte beeinflussen die Buchmessen die deutschen Literaturhäuser: Zur Frankfurter Buchmesse Mitte Oktober sind bekannte internationale Autor*innen in Deutschland unterwegs. Das äußert sich in den Programmen der Literaturhäuser, vor allem in Frankfurt und Hamburg, die viele dieser Autor*innen einladen. Die breite Wirkung dieser Veranstaltungen zeigt sich etwa darin, dass häufiger größere Veranstaltungsorte avisiert werden. ${ }^{1427}$ Das Literaturhaus Frankfurt arbeitet dabei aus Kapazitätsgründen oft mit dem Schauspiel Frankfurt zusammen, zum Beispiel um den peruanischen Autor Mario Vargas Llosa (*1936) im Jahr nach seiner Auszeichnung mit dem Nobelpreis für Literatur (FF 2011-10-14) oder den italienischen Autor und Literaturwissenschaftler Umberto Eco (1932-2016) zu empfangen (FF 2011-10-15). Das Interesse, international erfolgreiche Schriftsteller*innen zu präsentieren, besteht schon länger: Im Oktober 1998 traten etwa im Literaturhaus Hamburg Siegfried Lenz (1926-2014) aus Hamburg, Orhan Pamuk (*1952) aus der Türkei, Ian McEwan (*1948) aus England und Louis Begley (*1933) aus den USA auf (HH 1998-10). Im folgenden Oktober las die amerikanische Literaturnobelpreisträgerin Toni Morrison (*1931) im Thalia Theater (HH 1999-10-19). Die Einladungen dieser berühmten und feuilletonistisch wie akademisch konsekrierten Autor*innen unterstreichen die Position der Literaturhäuser im Literaturbetrieb, da sie nicht nur kleine Publika bedienen, sondern gelegentlich ökonomisch erfolgreiche Literat*innen präsentieren (können).

Das Literaturhaus Berlin lud seltener bei einem großen Publikum bekannte Autor*innen ein. Dies kann auf ausrückliche Entscheidung der Leitung zurückgehen,

\footnotetext{
1424 Der Projektleiter des Island-Auftrittes Halldór Gudmundsson zeichnet seit 2017 auch für die Organisation des Norwegen-Schwerpunktes auf der Frankfurter Buchmesse 2019 verantwortlich, dieses Projekt ist bei der staatlich verankerten Einrichtung NORLA (Norwegian Literature Abroad) angesiedelt. 1425 Vgl. Johannsen 2012b, S. 191.

${ }^{1426}$ Allerdings musste Kjell Westö seine Teilnahme aufgrund der Aschewolke nach dem Ausbruch des isländischen Vulkans Eyjafjallajökull absagen.

1427 Vgl. Kapitel II 10.4.2.
} 
es muss zugleich nicht auf fehlendes Interesse zurückzuführen sein, sondern kann finanzielle Gründe haben oder auf dem persönlichen Netzwerk der Leiter basieren, sodass die anderen Einrichtungen in Berlin diese Autor*innen präsentieren. Die Beobachtung dieser Tendenz im Literaturbaus Berlin lässt sich an einem Beispiel illustrieren: Der amerikanische Autor Jonathan Franzen (*1959) tourte im Herbst 2015 anlässlich seines im September in der Übersetzung von Bettina Abarbanell und Eike Schönfeld veröffentlichten Romans Purity [Unschuld] durch Deutschland und las unter anderem auf Einladung des Literaturbauses Hamburg im Thalia Theater $(\mathrm{HH}$ 2015-01-05), auf Einladung des Literaturhauses Frankfurt im Schauspiel Frankfurt (FF 2015-10-15) sowie ohne explizite Beteiligung des Literarischen Zentrums Göttingen beim Göttinger Literaturherbst und ohne Einfluss des dortigen Literaturhauses in der Akademie der Künste in Berlin.

Oslo international und politisch

Das Osloer Literaturhaus betont seine internationale Ausrichtung ausdrücklich. Dieser Aspekt spiegelt sich im Programm darin wider, dass neben norwegischen Autor*innen immer wieder ausländische Schriftsteller*innen zu Einzelveranstaltungen eingeladen werden. Ebenso tragen Festivals wie das im November 2012 durchgeführte Latin-Amerika på Litteraturhuset [Lateinamerika im Litteraturbuset] zum internationalen Blick bei. Programmatisch wurde jedes Jahr eine Woche zu einem anderen Schwerpunktland geplant. 2008 fand die Tyske Uke [Deutsche Woche] statt, im folgenden Jahr die Afrikanske Uke [Afrikanische Woche]. Damit versuchte das Literaturhaus das Interesse des norwegischen Literaturbetriebs für ausländische, in Norwegen insgesamt oft noch marginalisierte Literaturen zu erregen.

Diese kulturell wie politisch ausgerichteten Schwerpunkttage erinnern an die oben erwähnten deutschen Projekte. Im Editorial eines der Programmhefte aus dem Jahr 2008 verweist der damalige Leiter Aslak Sira Myhre explizit auf die Recherchen in deutschen Literaturhäusern, bevor Litteraturbuset eröffnet wurde. Dabei spricht er aus, dass die Idee zu länderbezogenen Programmtagen aus Hamburg stammte, wo die Nordischen Literaturtage seit 1986 alle zwei Jahre Autor*innen aus Nordeuropa präsentierten (OL 2008-I, S. 3). An dieser Aussage sind zwei Aspekte für diese Studie besonders relevant:

(1.) Darin enthalten sind Belege für den intentionalen Transfer von Konzepten. Die Akteur*innen übertragen ganz bewusst Strukturen von einem anderen Kontext in den eigenen. Die in der vorliegenden Arbeit angesetzte theoretische Konstruktion, das Literaturhaus als Objekt und als Subjekt von Kulturtransfers zu betrachten, findet damit empirische Bestätigung.

(2.) Daraus lassen sich Rückschlüsse auf den Zweitkontext des Literaturhauses beziehungsweise des Veranstaltungskonzeptes der Länderwochen ziehen. Mit den temporär konzentrierten und inhaltlich verdichteten Tagen versucht das Literaturhaus-Team in Oslo, das Interesse an internationaler Literatur und die Rezeption von nicht-norwegischen Texten zu erhöhen. Dieses Ansinnen setzt die Annahme voraus, dass in Norwegen tendenziell wenig nicht-norwegische Literatur wahrgenommen wird, obwohl Norwegen insgesamt als ein Land gilt, in dem überproportional viel gelesen wird. Staatliche Maßnahmen wie die seit 1965 wirksame Innkjopsordning - 
ny norsk skjonnlitteratur [Einkaufsverordnung - neue norwegische Literatur] sind ein wichtiger Einflussfaktor für die Verbreitung norwegischer Literatur im Land. Diese Regelung beinhaltet, dass der Staat von jeder neuen Originalausgabe knapp 1000 Exemplare kauft, um sie in den Bibliotheken verfügbar zu machen. ${ }^{1428}$ Durch diese Förderung ist seitens der Verlage das Interesse an norwegischer Literatur erhöht, weil aufgrund der Pflichtabnahme die Auflagen entsprechend höher sein können als bei Übersetzungen. Litteraturbuset versucht, dem größere internationale Vielfalt entgegenzusetzen - obwohl es gleichzeitig in hoher Zahl norwegische Autor*innen präsentiert.

Ein Beispiel für diese Vermittlungsabsicht ist die Tyske Uke, die erstmals 2008 vom Litteraturbuset in Oslo in Kooperation mit dem Goethe-Institut Oslo und der deutschen Botschaft in Norwegen organisiert wurde. Der Ankündigungstext dazu hält explizit fest, dass in Deutschland jedes Jahr ,lassevis av skandinavisk litteratur" [massenweise skandinavische Literatur] publiziert werde und deshalb zu fragen sei, warum es nicht andersherum ebenso sei (OL 2008-02-05/08). Zu Gast waren unter anderem Daniel Kehlmann (*1975) mit der Übersetzung seines Weltbestsellers Die Vermessung der Welt und die Schweizerin Zoë Jenny, die in Deutschland mit ihrem Debüt Blütenstaubəimmer zum ,Fräuleinwunder gezählt wurde, sowie Autor*innen, die für das „flerkulturelle Tyskland“ [multikulturelle Deutschland] standen wie der in Moskau geborene Wladimir Kaminer (*1967) mit seinem Buch Russendisko oder Que Du Luu (*1973), die chinesischer Abstammung ist und mit dem Roman Totalschaden erfolgreich debütierte. Litteraturbuset betont dabei den Aspekt der sogenannten Migrationsliteratur, der in Deutschland zu der Zeit gar nicht so stark war. Ein Vortrag „om det du trenger å vite om tysk litteratur“ [über das, was du über deutsche Literatur wissen musst] von Knut Hoem führte in die Schwerpunktwoche ein (OL 2008-02-05). Die Veranstalter*innen setzten nicht voraus, dass das Publikum sich bisher mit deutschsprachiger Literatur befasst hatte, sondern dies möglicherweise der erste Kontakt mit ihr sein würde.

2012 wurden nochmals Tyske Dager [Deutsche Tage] durchgeführt (OL 2012-0209/11). Dabei lag ein Fokus mit dem Titel Berlin i våre bjerter [Berlin in unseren Herzen] auf damals aktueller Gegenwartsliteratur mit den jungen Autor*innen Jan Böttcher (*1973) und Helene Hegemann (*1992) sowie Poesi og performance mit der Lyrikerin Nora Gomringer (*1980) und ihrer Übersetzerin ins Schwedische Cecilia Hansson (*1973). Außerdem wurden Filme gezeigt. Der Kulturhistoriker Helge Jordheim $\left({ }^{*} 1971\right)$ hielt einen Vortrag zu Det tyske in det norske [das Deutsche im Norwegischen], stellte damit explizit eine Verbindung der deutschen Kultur zur norwegischen her und prüfte diese Verbindung auf ihre Aktualität. Auf diese Weise wurde die Relevanz von Tyske Dager betont und die (positiven) Einwirkungen der außernorwegischen Literatur und Kultur auf das norwegische Leben herausgearbeitet. Des Weiteren feierte der Themenschwerpunkt den Geburtstag Bertolt Brechts (1898-1956). Bereits drei Jahre zuvor organisierte Litteraturbuset ein Brecht-Fest, das „en av de mest innflytelserike og medrivende forfatterne fra det 20. århundre“ [einem der einflussreichsten und mitreißendsten Autoren des 20. Jahrhunderts] huldigte (OL 2009-04-02). Da im Osloer Literaturhaus relativ selten deutsche Autor*innen

${ }^{1428}$ Vgl. „Støtteordning“, Kulturrådet. 
zu Gast sind, ist es bezeichnend, dass dann gerade ein Abend zu Bertolt Brecht veranstaltet wurde. „Den samfunnsengasjerte poeten“ [Der sozial engagierte Poet] ist in den deutschen Literaturhäusern eher wenig präsent - Ausnahme bildet das Literaturforum im Brecht-Haus in Berlin. Der politisch links engagierte Impetus des Autors und Regisseurs fügt sich ein in die skandinavische Tradition der Arbeiterbewegung und der bereits erwähnten sozialkritischen, gesellschaftsbildenden Funktion von Literatur. Allerdings ist zu bedenken, dass Brecht unter anderem in Dänemark, Schweden und Finnland im Exil lebte und so ein direkter Bezug zur nordeuropäischen Literatur besteht.

Litteraturbuset betonte an mehreren Stellen, dass es sich als „eit vindauge mot verda“ (OL 2009-I, S. 3) [ein Fenster zur Welt] versteht, was sich anhand der Programmanalysen bestätigt. Die in Norwegen neue Literaturvermittlungseinrichtung markierte damit von Anfang an Weltoffenheit. In diesem Kontext formulierte der ehemalige Leiter, dass das Literaturhaus in Norwegen dazu beitragen solle, internationale Literatur - übersetzt und noch nicht übersetzt - bekannter zu machen und mit bestehenden Vorurteilen aufzuräumen. Bei der Ankündigung der Afrikanske Uke ist dies ausdrücklich formuliert: „Når vi nå retter blikket mot Afrika, vil vi gjøre det uten trommer, dans og ider om ,rytme i blodet" og ,nærhet til natturen“" (OL 2009IV, S. 49) [Wenn wir nun den Blick nach Afrika richten, wollen wir das ohne Trommeln, Tanz und Ideen von ,Rhythmus im Blut ${ }^{\varsigma}$ und ,Nähe zur Natur tun]. Besonders im Vergleich zu den deutschen Literaturhäusern heute fällt auf, dass im Litteraturbuset nicht nur Literatur aus Europa oder der westlichen Welt präsentiert wird und dort mit der Idee von Literaturvermittlung explizit ein politischer Anspruch verbunden ist.

Inwiefern dabei ein neuer Zugang auch zu kanonisierter norwegischer Literatur gesucht wird, verdeutlicht beispielsweise die internationale Konferenz, die das Literaturhaus Oslo 2008 organisierte: Der 200. Geburtstag von Henrik Wergeland (1808-1845), dem Patron des größten Saales im Litteraturbuset, ${ }^{1429}$ wurde zum Anlass genommen, Literatur und Politik des Mittleren Ostens vorzustellen. Auf diese Weise konnte eine andere Perspektive auf den norwegischen Nationalautor angeregt und so ein Bild eines sich verändernden Norwegens vertreten werden (OL 2008-0605/06). Es ist davon auszugehen, dass in diesem Fall von Beginn an intendiert war, Wergeland nicht zu verehren, sondern ausgehend von dessen Werk aktuelle politische Themen zu bearbeiten. Aus dieser Kooperation mit der Stiftung Fritt Ord und dem Utenriksdepartementet [Auswärtigen Amt] entstand in den Folgejahren das Projekt Saladindagene [Saladin-Tage], die von Wergeland ganz wegführten (erstmals OL 2009-03-04/07). Der Bezug auf den arabischen Heerführer Saladin, der 1187 Jerusalem eroberte und dabei Angehörige unterschiedlicher Religionen kampflos nebeneinander leben ließ, ist dabei Programm, denn die drängende Aktualität einer friedlichen Auseinandersetzung über und zwischen Menschen verschiedenen Glaubens ist mindestens seit 2001 in Europa wieder offensichtlich. Litteraturbuset in Oslo reagierte damit direkt auf Veränderungen europäischer Gesellschaften, so sprach etwa Lawrence Wright $\left({ }^{*} 1947\right)$ über sein dann auf Norwegisch erschienenes Sachbuch The Looming Tower: Al Qaeda and the Road to 9/11 (OL 2008-10-20). Die aufklärende,

${ }^{1429}$ Vgl. Kapitel II 6.3.2. 
nicht polarisierende Beschäftigung mit dem Nahen Osten und dem Islam ist dabei auffällig: „For å forstå vår egen samtid, trenger vi kunskap om Islam, uavhengig av eget religiøst ståsted“ (OL 2008-11-08) [Um unsere eigene Gegenwart zu verstehen, brauchen wir Wissen über den Islam, unabhängig vom eigenen religiösen Standpunkt].

Diese politisch motivierten Themen waren im Litteraturbuset in Oslo nicht erst seit den Attentaten vom 22. Juli 2011 virulent und sind als Reaktion auf konservative bis fremdenfeindliche Tendenzen zu sehen, die mit der Wahl einer konservativen Regierung 2013 amtlich wurden. Nach den Anschlägen in Oslo und auf der Insel Utøya erhielt das Thema in Norwegen insgesamt eine größere Brisanz. Auf diese reagierte Litteraturbuset im Herbst 2011 mit einer Vortragsserie, in der drei schwedische Autor*innen und Diskutant*innen - der Autor Ola Larsmo (*1957), die Journalistin Lisa Bjurwald (*1978) und der Politiker Ali Esbati (*1976) - eingeladen waren, „til å presentere sine tanker i kjølvannet av terrorhandlingene 22. juli“ [ihre Gedanken nach (buchstäblich: im Kielwasser von) den Terrorakten des 22. Juli zu präsentieren] (erstmals OL 2011-11-12). Auch das Literaturhaus in Bergen führte Veranstaltungen zu diesem aktuellen Themenkomplex durch. Zum Gespräch war zum Beispiel die Journalistin Mah-Rukh Ali (*1982) eingeladen, die das erste Buch über den sogenannten Islamischen Staat auf Norwegisch vorgelegt hat - Trusselen fra IS. Terror, propaganda og ideologi [Die Bedrohung durch den IS. Terror, Propaganda und Ideologie] (BG 2015-10-28). Anders als in den deutschen Literaturhäusern sticht in Norwegen eine politische Vermittlungsabsicht markant hervor.

Noch Mitte und Ende der 1990er-Jahre beschäftigten sich die untersuchten deutschen Programme ebenfalls mit dezidiert politischen Themen, etwa mit der Frage, welche Rolle die westlichen Staaten bei der Zunahme des Fundamentalismus in Algerien spielten (FF 1994-02-11) oder mit dem Sujet Islam und Moderne, wie eine 1998 im Literaturhaus Hamburg durchgeführte Reihe hieß (erstmals HH 1998-11-02/05, letztmals HH 1999-05-26/27). Doch zugespitzt formuliert: In den letzten Jahren beschränkte sich die Auseinandersetzung mit dem Islam in den deutschen Literaturhäusern auf Veranstaltungen, zu denen der etablierte Orientalist und Autor Navid Kermani (*1967) eingeladen war (z. B. FF 2006-02-01). Allerdings deutet sich an, dass politisch-diskursive wie politisch-bildende Veranstaltungen wieder mehr werden.

Diese Ausführungen verdeutlichen einmal mehr, wie sehr die Kommunikation seitens des Literaturhauses Auswirkungen auf seine Wahrnehmung hat, denn die Veranstaltungen zu Themen wie Islam bilden im Litteraturbuset in Oslo nicht den größten Anteil am Programm. Durch die Vermittlung dieser Themen zum Beispiel über Schwerpunkttage mit eigenen Werbemitteln erhalten sie in der Gesamtsicht der Einrichtung jedoch mehr Gewicht. Das Selbstverständnis ist somit maßgeblich und reziprok mit der Außenwahrnehmung gekoppelt, was besonders mittels der hier durchgeführten qualitativen exemplarischen Analysen herausgearbeitet werden konnte. Obwohl die ermittelten Daten zeigen, dass internationale Akteur*innen in den Literaturhäusern zahlenmäßig nur marginal vertreten sind, spielt die Selbstpräsentation und damit beabsichtigte Außenwahrnehmung als international orientierte 
Einrichtungen eine große Rolle. ${ }^{1430}$ Zugleich - und das spiegeln die Zahlen - vermitteln die Literaturhäuser hauptsächlich deutsche respektive norwegische Gegenwartsliteratur.

\section{Skandinavische Autor*innen in den norwegischen Literaturhäusern}

Unter dem Stichwort der Internationalität lohnt es sich, in dieser skandinavistischen Studie noch einmal zu reflektieren, wie sich neben den norwegischen andere skandinavische Autor*innen in die norwegischen Programme einfügen. Es lässt sich für die Literaturhäuser Oslo und Bergen zeigen, dass Gäste aus den weiteren skandinavischen Ländern regelmäßig eingeladen und als ,skandinaviske stemmer“ (OL 200811-27) [skandinavische Stimmen] vorgestellt werden. In der Summe sind es, wie die Zahlen aus Bergen in Abbildung 15 (S. 433) zeigen, nicht viele, weshalb vor allem der inhaltliche Umgang mit ihnen interessant ist. In den Ankündigungstexten zeichnen sich zwei Positionen zum Verhältnis norwegischer zu skandinavischer Literatur ab, die die vorliegende Arbeit ebenfalls vertritt:

(1.) Es lässt sich sehr wohl von einem gemeinsamen skandinavischen Kulturraum sprechen, der gerade im globalen Zusammenhang benutzt wird - bei Veranstaltungen etwa zu dem Thema Tredja verda sedd frå Skandinavia [Die dritte Welt von Skandinavien aus gesehen] (OL 2009-09-24). Außerdem sind einige Autor*innen zwischen den festlandskandinavischen Ländern Norwegen, Dänemark und Schweden unterwegs. Beispielsweise ist die schwedische Kulturjournalistin Åsa Linderborg regelmäßiger Gast in den norwegischen Literaturhäusern - was erklärt, warum sie in der schwedischen Litteraturhuset-Diskussion so gut über die norwegischen Einrichtungen Bescheid wusste. ${ }^{1431}$ In Bergen war sie als „en av Sveriges mest profilerte samfunnsdebattanter“" [eine von Schwedens profiliertesten Debattierer*innen gesellschaftlicher Themen] im Gespräch mit einer Politikerin zu Gast (BG 2013-02-13); in Oslo führte sie eine Unterhaltung mit dem norwegischen Autor Kjartan Fløgstad (*1944) (OL 2012-09-05), war Gesprächspartnerin der italienischen Autorin Silvia Avallone (*1984) (OL 2013-05-08), war zusammen mit ihrer Kollegin Kerstin Ekman (*1933) auf der Bühne (OL 2011-01-19) und diskutierte mit dem norwegischen Autor Roy Jacobsen (*1954) und dem damaligen Literaturhaus-Leiter Aslak Sira Myrhe über Sozialdemokratie (OL 2009-10-01). Dieses Beispiel verdeutlicht zudem, wie die Funktionen der Bühnenakteur*innen variieren können: Åsa Linderborg, die in Deutschland vor allem durch die Übersetzung ihres autobiografisch beeinflussten Romans Mig äger ingen [Ich gehöre keinem] bekannt ist, tritt in Norwegen als Romanautorin, Moderatorin und Diskutantin auf - dass sie aus Schweden kommt, spielt dabei kaum Rolle, erwähnt wird es in den Ankündigungen dennoch.

Insgesamt lässt sich feststellen, dass die ,großen', anerkannten Autor*innen aus Schweden, Dänemark oder Island ebenfalls im Osloer Literaturhaus auftreten - und sie dabei als Verfasser*innen aus Nordeuropa präsentiert werden. Die Ankündigungstexte belegen, dass diese Gäste in Norwegen ebenso etabliert sind wie in ihren

\footnotetext{
${ }^{1430}$ Die kulturpolitischen Dimensionen dieser internationalen Repräsentation wurden im Oslo-Kapitel ausführlich diskutiert, vgl. Kapitel II 6.2.

1431 Vgl. Kapitel II 8.1.
} 
Ursprungsländern. So treffen der Norweger Dag Solstad und der Schwede Per Olov Enquist (*1934) - „,blant de mest sentrale i nordisk prosa“ [unter der zentralsten in der nordeuropäischen Prosa] - zu einem „mestermøte“ [Meistertreffen] zusammen: „I 2011 [...] er det vanskelig å tenke seg noe større møte i nordisk litteratur enn mellom nettopp disse to " (OL 2011-03-02) [2011 ist es schwierig sich ein größeres Treffen in nordischer Literatur vorzustellen als gerade zwischen diesen beiden]. Innerhalb Skandinaviens besteht also ein Verständnis eines skandinavischen Kulturraums. Kulturpolitisch fixiert wird diese Gemeinsamkeit etwa durch die Zusammenarbeit von Dänemark, Finnland, Island, Norwegen, Schweden, den Färöern-Inseln, Grönland und Åland im interparlamentarischen Gremium Nordisk Råd [Nordischer Rat]. Dieser vergibt jährlich inzwischen fünf verschiedene Kulturpreise - darunter bereits seit 1962 Nordisk Rads litteraturpris [Literaturpreis des Nordischen Rats] und seit 2013 zusätzlich den Preis für Kinder- und Jugendliteratur. Diese in Nordeuropa wichtigen Würdigungen sind Zeichen der dortigen institutionalisierten Zusammenarbeit im Kulturbereich und auch außerhalb von Nordeuropa geschätzte Auszeichnungen.

$\mathrm{Zu}$ berücksichtigen ist ergänzend, dass der exemplarisch genannte P. O. Enquist nicht nur in Schweden und ganz Skandinavien als bedeutender Autor angesehen ist, sondern für die europäische Literatur insgesamt Bedeutung hat. So stellten ihn die deutschen Literaturhäuser ebenfalls als hochkarätigen Schriftsteller vor (z. B. FF 2001-03-07) und so kündigte Litteraturhuset in Oslo seinen Besuch mit folgendem Zitat an:

Ingen svensk bok utgitt i 2008 har høyere litterært innhold enn Enquists Ett annat liv. Jeg våger til og med å påstå at dette er årets store bok i Europa.

[Kein 2008 herausgegebenes schwedisches Buch ist von höherem literarischem Gehalt als Enquists Ein anderes Leben. Ich wage sogar zu behaupten, dass dies das große Buch des Jahres in Europa ist.] (OL 2009-01-22) ${ }^{1432}$

Die Verbindungen innerhalb des skandinavischen Kulturraumes schließen somit nicht aus, die Literat*innen darüber hinaus als Teil einer europäischen beziehungsweise weltweiten Literatur zu betrachten.

(2.) In den Programmen der norwegischen Literaturhäuser wird zuweilen dennoch eine Unterscheidung zwischen norwegischer und gesamtskandinavischer Literatur getroffen. Der schwedische Schriftsteller Jonas Hassen Khemiri (*1978) wird als „[e]n unik svenske“ [ein einzigartiger Schwede] vorgestellt - ein Verweis auf den Untertitel seines Romans Montecore - En unik tiger [auf Deutsch unter dem Titel Montecore, ein Tiger auf zwei Beinen erschienen] (OL 2008-02-21). Seine Arbeit wird in den norwegischen Kontext übertragen, indem aus seinem rinkebysvenska [Rinkebyschwedisch] ${ }^{1433}$ das norwegische kebabnorsk [Kebabnorwegisch] wird, ein erfundener Soziolekt, der auf Deutsch in der von Feridun Zaimoglu in seinem gleichnamigen Roman beschriebenen Kanak-Sprak ein Pendant findet. Schwedische Spezifika werden also für die norwegischen Rezipient*innen modifiziert. So sind es in der Regel norwegische Übersetzungen, die von ihren schwedischen oder dänischen Verfas-

1432 Ursprünglich stammen die Sätze von Gabi Gleichmann, erschienen in Aftenposten.

1433 Rinkeby ist ein Vorort von Stockholm, in dem vielen Migrant*innen leben. 
ser*innen vorgestellt werden, obwohl die Norweger*innen die Originaltexte aufgrund interskandinavischer Semikommunikation eigentlich verstehen könnten. ${ }^{1434}$ Dass es dabei nicht allein um die Sprachfähigkeit geht, sondern die Buchmärkte, wenngleich ein enger Austausch besteht, als voneinander unabhängig wahrgenommen werden, belegen weitere Aussagen in den Programmtexten: „Geografisk og kulturell nærhet til tross - det er ikke alltid så lett å orientere seg i samtidslitteraturen fra våre naboland" (OL 2007-11-15) [Trotz der geografischen und kulturellen Nähe ist es nicht immer so leicht, sich in der Gegenwartsliteratur unserer Nachbarländern zu orientieren]. Damit ist zusammengefasst, was es bei der Analyse kultureller Phänomene im skandinavischen Raum zu beachten gilt: Es bestehen viele Gemeinsamund Ähnlichkeiten, dennoch greift es zu kurz, keine Differenzierung zwischen Norwegen, Dänemark und Schweden vorzunehmen. Diese Reflexion findet nicht nur in der Komparatistik und Skandinavistik statt, sondern ist Teil des Selbstverständnisses der Skandinavier*innen, wie die Erwähnung in den LitteraturbusetProgrammtexten belegt.

\section{Skandinavische Autor*innen in den deutschen Literaturhäusern}

Vergleichbar mit den skandinavischen Ländern selbst bündeln die deutschen Literaturhäuser insbesondere norwegische, schwedische und dänische Autor*innen als Vertreter*innen skandinavischer Literatur und nehmen zugleich die einzelnen Länder getrennt wahr, ohne dass das Herkunftsland des Gastes die wichtigste Information ist. Literatur aus diesen Ländern wird in den deutschen Literaturhäusern regelmäßig vorgestellt. Die geografische wie kulturelle Nähe vereinfacht die Organisation von Lesereisen. Und natürlich spiegelt sich darin die relativ hohe Sichtbarkeit nordeuropäischer Literatur auf dem deutschen Buchmarkt - schon lange. ${ }^{1435}$

So galt den deutschen Literaturhäusern etwa der Norweger Jan Kjærstad (*1953) 1996 „zu Recht“ als „die literarische Entdeckung der letzten Jahre“ (HH-1996-0604), weitere Besuche folgten. Wie oben bei P. O. Enquist erwähnt, werden diese Autor*innen als international bedeutend rezipiert, sodass der Bezug zu Norwegen beziehungsweise Schweden zwar genannt wird, aber nicht unbedingt entscheidend ist. Karl Ove Knausgård (*1968), der in Deutschland erst ab 2011 mit der Übersetzung seines sechsbändigen Werkes Min kamp bekannt wurde, während er in Norwegen schon für sein Debüt Ute av verden 1998 den renommierten Kritikerprisen erhielt und mit seinem zweiten Buch En tid for alt [Alles hat seine Zeit] 2005 für den Nordisk Råds litteraturpris nominiert war (OL 2009-12-08), ist ein weiteres Beispiel, das sich für eine detaillierte vergleichende Untersuchung der Rezeptions- und Vermittlungsweisen in den norwegischen und deutschen Literaturhäusern eignen würde.

Bestes Beispiel für den Import nordeuropäischer Autor*innen nach Deutschland sind die bereits erwähnten Nordischen Literaturtage. ${ }^{1436}$ Aus Hamburger Sicht ist weni-

\footnotetext{
1434 Zur interskandinavischen Kommunikation und Mehrsprachigkeit in Skandinavien vgl. Braunmüller 1999, S. 308-315.

1435 Dass der aktuelle Boom skandinavischer Bestseller auf dem deutschen Buchmarkt sich nicht auf Kriminalliteratur beschränkt, stellt Elisabeth Böker in ihrer Doktorarbeit heraus. Sie zeigt, dass zwei Drittel aller Bestseller zu diesem Genre gezählt werden, der Boom allerdings mit anderen Titeln begonnen hat, vgl. Böker 2018, S. 316, 331.

1436 Die ersten Nordischen Literaturtage fanden 1986 anlässlich der Jahrestagung des Buchbändlerverbandes statt und wechselten erst 1990 zum Literaturhaus (HH 1990-10-03/11-01).
} 
ger die beschriebene strukturelle Übertragung des Konzeptes nach Oslo relevant, vielmehr der inhaltliche Aspekt der Literaturvermittlung. Das Literaturbaus Hamburg garantiert durch dieses Festival der nordeuropäischen Literatur Programmplätze, was in dieser Ausführlichkeit ohne die damit verbundenen Fördergelder und die erhöhte Aufmerksamkeit vermutlich kaum umsetzbar wäre. Dabei zielen die Nordischen Literaturtage, anders als die Länderschwerpunkte in Oslo, nicht darauf, nur einmalig die Literatur eines bestimmten Kulturraumes sichtbar zu machen, sondern dafür eine regelmäßige Präsentationsform zu etablieren. Dass dies von Seiten der Herkunftsländer unterstützt wird, beweist die Liste der Förderer der Nordischen Literaturtage, auf der sich etwa die nordischen Botschaften und Kulturinstitute finden. Die Untersuchung der Teilnehmer*innen und der kommunikativen Rahmung dieses Festivals liefert Material für eine eigene Arbeit zu einem deutsch-skandinavischen Kulturtransfer und über den deutschen Übersetzungsmarkt, denn wie bei den anderen internationalen Gästen orientieren sich die Einladungen an aktuellen Übertragungen ins Deutsche und damit an den national organisierten Buchmärkten. Ohne Übersetzer*innen würden Grenzen also gar nicht überschritten.

\section{14.4 Autorinnen und Autoren}

Frauen sind im Literaturveranstaltungsbetrieb unterrepräsentiert. Diese Annahme lässt sich anhand der untersuchten Literaturhaus-Programme stützen, obwohl in den Literaturhaus-Teams Männer nicht zahlenmäßig dominierend sind: Dort sind weibliche Mitarbeiter eher in der Überzahl und bei den Literaturhaus-Programmleitungen liegt inzwischen ein tendenziell ausgeglichenes Verhältnis vor - werden die beiden seit 2018 aktiven Geschäftsführerinnen des Literaturbauses Berlin einberechnet, ist die Quote aller jemals eingesetzten Programmleitungen der deutschen Fallbeispiele tatsächlich sechs zu sechs. Und während dem Litteraturbuset in Bergen eine weibliche Leitungsperson vorsteht, ist es in Oslo eine männliche - allerdings ist dort aktuell bereits der zweite Mann Geschäftsführer. Dieser wurde im Mai 2019 von einer Frau abgelöst. Bei den Bühnenakteur*innen sind männliche Akteure quantitativ hingegen überlegen, wie die vorliegende Studie bestätigt.

Schon bei einem weiteren Blick auf die untersuchten Selbstdarstellungstexte zeigt sich diese Tendenz: Insgesamt finden sich dort 46 männliche und 14 weibliche $\mathrm{Na}$ men von Gästen, die bereits im Literaturhaus aufgetreten sind - ein Verhältnis von drei zu eins also. Unter Einbeziehung aller in diesen Über-uns-Texten erwähnten Namen, also etwa die von Leitungspersonen oder Hauseigentümer*innen, relativiert sich das Ergebnis geringfügig; von insgesamt 78 Menschen müssten 21 weiblich und 57 männlich gegendert werden. Bei den 21 Frauen wird zweimal der Bezug zu ihrem Ehemann hergestellt, Männer werden kein Mal vornehmlich als Ehepartner vorgestellt. Was sich auszugsweise bereits anhand der in den Selbstdarstellungstexten erwähnten Autorinnen und Autoren belegen ließ, unterstützt die Programmanalyse. ${ }^{1437}$

\footnotetext{
${ }^{1437}$ Die Annahme einer binären Geschlechtszuordnung soll nicht ausschließen, dass es Gäste gibt, die sich nicht dem einen oder dem anderen zugehörig fühlen. Die vorliegende Studie selbst folgt dieser historisch gewachsenen Zweiteilung in ihrer Vorgehensweise hier, die Zuordnung zu männlich oder weib-
} 


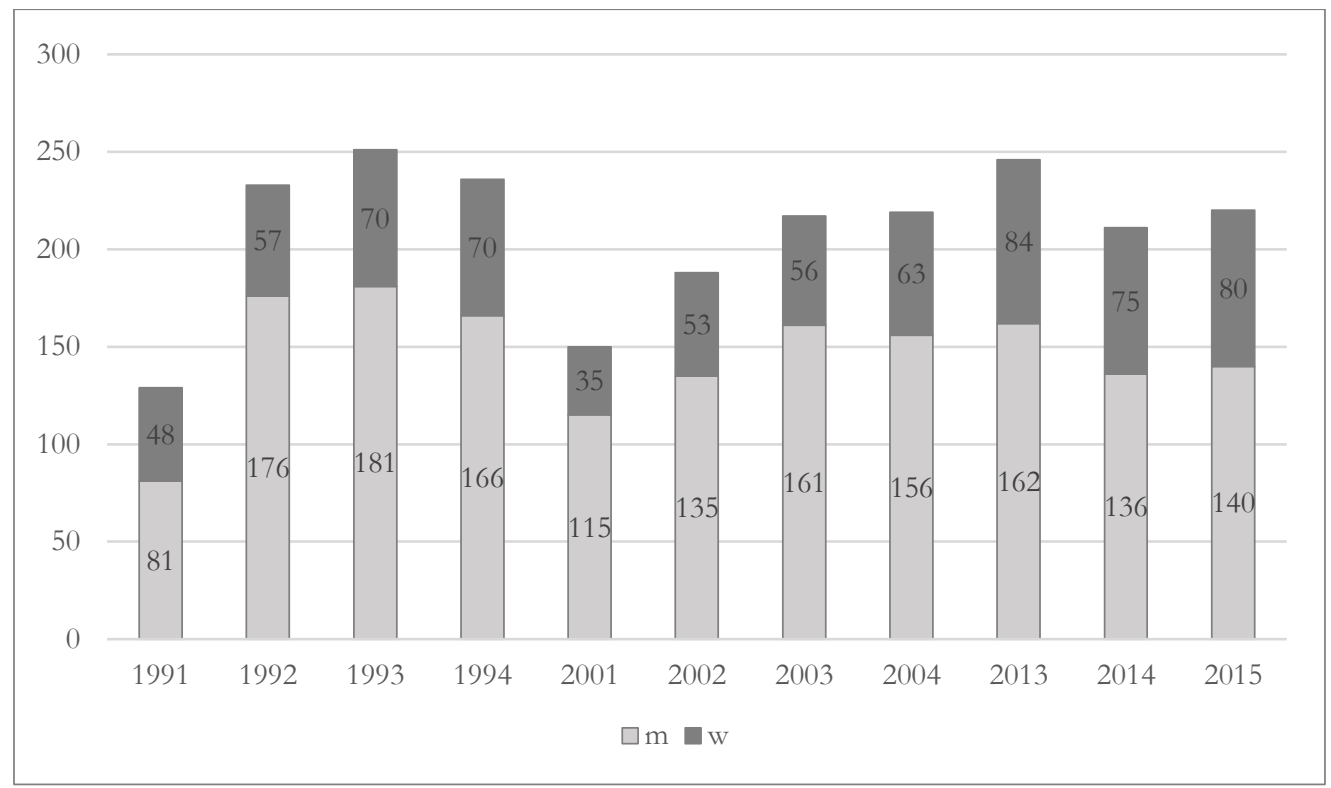

Abbildung 16: Verteilung der Gäste im Literaturbaus Frankfurt hinsichtlich des Geschlechts $\mathrm{m} / \mathrm{w}$ (eigene Darstellung)

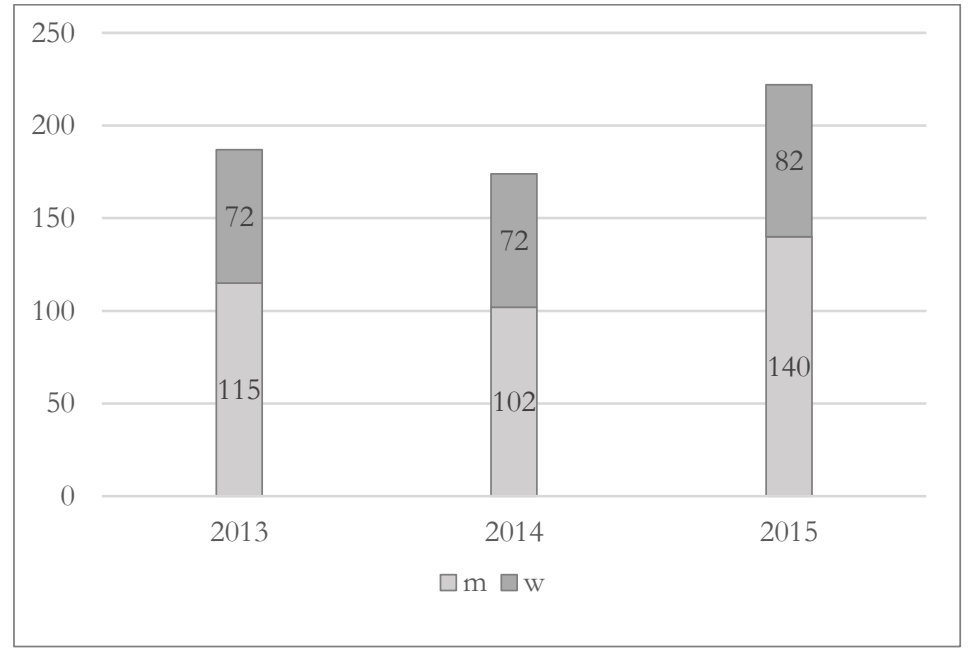

Abbildung 17: Verteilung der Gäste im Litteraturbuset in Bergen, hinsichtlich des Geschlechts m/w (eigene Darstellung)

lich daran abzulesen, ob in den Ankündigungstexten geschlechtsbezogene Personalpronomen und Namen verwendet werden. Um herauszustellen, dass Frauen, die sich in der Mehrzahl als solche verstehen, in unserer patriarchal geprägten Gesellschaft nicht gleichberechtigt zu Männern behandelt werden, bedarf es dieser binären Vereinfachung. Und obgleich in der gesamten Arbeit neben der Benutzung der *Variante gelegentlich zugunsten des Textflusses auf die Betonung der Geschlechtervielfalt verzichtet wird, meistens aber alle gemeint sind, gilt in diesem Abschnitt, dass ,Autor' männlichen und ,Autorin weiblichen Genderkonventionen zugerechnet wird, vgl. FN 2. In die hier vorgenommene Untersuchung der Programmtexte lassen sich andere Zugehörigkeiten zu bestimmten von Diskriminierung betroffenen Gruppen wie People of Colour beziehungsweise Fragen der Intersektionalität kaum einbeziehen, da dies differenzierterer Auseinandersetzungen bedürfte, weil diese Aspekte in den Programmtexten in der Regel nicht thematisiert werden. Andersherum ließe sich anhand von Einzelfallstudien herausarbeiten, wie schwarze Autor*innen in den Programmtexten und mit Fotos präsentiert werden, dies wäre jedoch eine eigene Arbeit zu einem ganz anderen Thema. Insgesamt ist mein feministisches Selbstverständnis an dieser Stelle kaum auszuklammern. Hinter der Setzung von feministischen Themen steht die Anerkennung des Problems, das nicht mein persönliches, sondern ein strukturelles ist. 


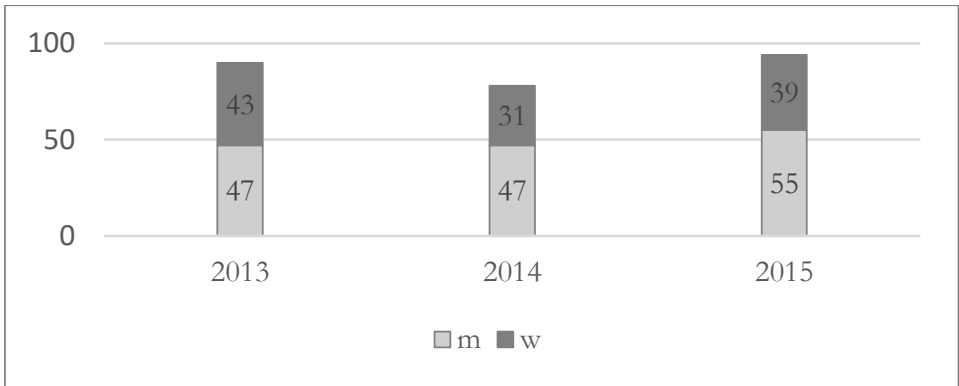

Abbildung 18: Verteilung der Gäste im Literarischen Zentrum Göttingen,

hinsichtlich des Geschlechts m/w (eigene Darstellung)

Wie die exemplarischen Untersuchungen in den Literaturhäusern in Frankfurt und Bergen offenbaren, ist in den Anfangsjahren der Institution das Verhältnis von männlichen zu weiblichen Gästen, die in den Programmtexten erwähnt werden, drei zu eins in der deutschen Einrichtung. Seit den 2010er-Jahren zeichnet sich eine Relation von zwei zu eins ab. Weiterhin sind beinahe mehr als doppelt so viele männliche Akteure wie weibliche auf den Podien sichtbar (vgl. Abbildung 16). Dies gilt für Frankfurt wie für Bergen gleichermaßen, obwohl im norwegischen Literaturhaus die Differenz ein bisschen geringer ausfällt (vgl. Abbildung 17). Selbst in Norwegen, einem der Länder, das hinsichtlich seiner Genderpolitik als vorbildlich gilt, stellen männliche Autoren den umfangreichsten Anteil am Literaturhaus-Programm dar. Auffällig sind hingegen die Zahlen, die für die Jahre 2013 bis 2015 im Literarischen Zentrum Göttingen ermittelt wurden: Dort liegt ein tendenziell ausgeglichenes Verhältnis vor, obgleich weibliche Akteure ebenfalls in keinem Jahr in der Mehrzahl sind (vgl. Abbildung 18).

Die Programmgäste werden zwar von den jeweiligen Leitungspersonen ausgewählt, die Entscheidungen gehen somit auf relativ wenige Akteur*innen zurück und sind damit individuell, doch die ermittelte Relation von Männern zu Frauen korrespondiert mit Zahlen anderer Untersuchungen. Die zahlenmäßig größere Sichtbarkeit von Autoren ist also nicht unbedingt auf die persönlichen Einschätzungen der Leiter*innen zurückzuführen, sondern symptomatisch für den gegenwärtigen Literaturbetrieb - jedenfalls in Deutschland, wie die vom Bundesministerium für Kultur und Medien initiierte Studie Frauen in Kultur und Medien aus dem Jahr 2016 belegt: Obwohl das Verhältnis der freiberuflich in der Künstlersozialkasse Versicherten der Berufsgruppe ,Wort' hinsichtlich des Geschlechts relativ ausgeglichen ist und Frauen inzwischen dort gar in der Überzahl sind, ${ }^{1438}$ verdienen sie - erstens - im Durchschnitt jährlich rund 5.500 Euro weniger, was einer Gehaltsdifferenz von 25\% entspricht, ${ }^{1439}$ und werden ihnen - zweitens - seltener Literaturpreise und Stipendien zugesprochen. Fördermaßnahmen des Deutschen Literaturfonds kommen meistens in klarer Mehrzahl Schriftstellern zugute, Ausnahmen finden sich im Kinder- und Jugendbuchbereich und bei den Übersetzerförderungen, allerdings sind dort anteilig deutlich mehr weibliche Kulturschaffende verzeichnet, sodass sich die Zahlen relativieren. Ebenfalls waren bisher auffällig mehr Autoren für den Deutschen Buchpreis nominiert. ${ }^{1440} \mathrm{Da}$ Auszeichnungen für Autor*innen sowohl eine wichtige finanzielle

\footnotetext{
1438 Vgl. Schulz 2016, S. 159.

1439 Vgl. ebd., S. 167.

${ }^{1440}$ Vgl. ebd., S. 228-232. Die Studie hält fest, dass bis 2014 sechs Autorinnen und vier Autoren den Preis gewonnen haben. Inzwischen hat sich das Verhältnis wieder geändert, denn von 2014 bis 2017
} 
Basis bilden als auch zu ihrer Anerkennung beitragen, lässt sich daraus schließen, dass Autorinnen, obwohl sie zahlenmäßig eigentlich nicht unterlegen sind, weniger Aufmerksamkeit zuteilwird. Die vorliegende Arbeit fügt diesen empirischen Belegen hinzu, dass Frauen seltener als männliche Akteure auf die Veranstaltungsbühnen treten. In keinem der untersuchten Programme werden mehr Frauen als Männer präsentiert. Dies spiegelt auch diese Arbeit selbst, denn, obwohl versucht wurde ein möglichst ausgewogenes Verhältnis von Beispielen mit Akteuren und Akteurinnen herzustellen, kommen vermutlich mehrheitlich Männer vor. Dadurch repräsentiert die hier genutzte Auswahl die tatsächlichen Verhältnisse.

Die Verteilung lässt sich ebenfalls in anderen Teilen des Literaturbetriebs beobachten, sodass der Überhang von Autoren gegenüber Autorinnen bereits bei den Produktions- und Distributionsprozessen beginnt. Für den Bereich der Literaturkritik kommt Veronika Schuchter zu dem Schluss, dass es zum einen deutlich mehr Kritiker gibt und zum anderen, dass das Geschlecht, sowohl das der kritisierenden Person als auch des kritisierten Autors und der kritisierten Autorin, den Wertungsprozess beeinflusst. ${ }^{1441}$ Ihr Forschungsprojekt zur ,Literaturkritik als GenderDiskurs' ${ }^{6}$ wird diese ersten Ergebnisse vertiefen. ${ }^{1442} \mathrm{Zu}$ Thema Sichtbarkeit von Frauen in Medien und im Literaturbetrieb ist außerdem das verbandsübergreifende 2018 angestoßene Projekt \#frauenzäblen zu nennen.

Neben der zahlenmäßigen Auseinandersetzung mit diesem Sujet lohnt es sich, in den Literaturhaus-Programmen nach Veranstaltungen zu suchen, die sich mit den Themenkomplexen um Gleichstellung, Feminismus und Gender befassen. Dabei fällt auf, dass die Beschäftigung damit in den deutschen Literaturhäusern früher häufiger ganz explizit stattfand und sie bei den Fallbeispielen heute seltener vorkommt. Das könnte bedeuten, dass die Auseinandersetzung damit obsolet geworden ist oder vielschichtiger, doch die genannten Zahlen deuten darauf hin, dass auf den Literaturhaus-Bühnen keine Gleichstellung der Geschlechter vorliegt. Es kann ebenfalls heißen, dass diese Themen für die Programmleitungen an Relevanz verloren haben beziehungsweise keine Relevanz haben, gegebenenfalls auch, weil die drei großen untersuchten Literaturhäuser seit Jahren von Männern geleitet werden. Dabei lässt sich nämlich ein Zusammenhang erkennen: Es fiel bei den Programmanalysen auf, ohne dass im Detail alle Veranstaltungen überprüft worden sind, dass sich Veranstaltungen mit einem ,Frauen'-Bezug vor allem dann finden lassen, wenn Frauen die Programmleitung innehatten - das gilt folglich für die Literaturhäuser in Hamburg und in Frankfurt, denn in Berlin waren im Untersuchungszeitraum nur Männer für das Programm verantwortlich. Die Entscheidungen sind nicht nur auf systemische Verhältnisse zurückzuführen, sondern liegen offenbar in den Händen der jeweiligen Leitungsperson, die ihrerseits vom System geprägt sind. Dabei lassen sich auch Annäherungen an den Themenbereich ausfindig machen, die interessante Fragen nach der Positionierung von Autorinnen aufwerfen. Mit der Reihe Nun breche

erhielten nur Männer den Preis, 2018 bekam ihn Inger-Maria Mahlke, 2019 Saša Stanišić, was inklusive 20182019 acht Autoren zu sieben Autorinnen ergibt.

1441 Vgl. Schuchter: „Männer werten“. In diesem Artikel finden sich auch Verweise auf frühere Arbeiten zum Thema, etwa von Renate von Heydebrand und Simone Winko.

${ }^{1442}$ Eine Publikation liegt noch nicht vor, ein Radiointerview umreißt den Ansatz und erste Ergebnisse, vgl. Schuchter und Lieske: „,Im Feuilleton“. 
ich in Stücke (HH 1998-04) präsentierte etwa das Literaturbaus Hamburg Autorinnen, die durch Suizid starben, wie Sylvia Plath (1932-1963). Ein Beispiel aus dem Literaturbaus Frankfurt belegt außerdem, dass die Literaturhaus-Programme zeithistorische Zeugnisse sind. Ein Mann, was ist das? lautete der Titel eines Vortrages in Kooperation mit dem Institut Français (FF 1994-01-17): Die französische Philosophin Elisabeth Badinter (*1944) habe „die heutige Identitätskrise des Mannes als tiefgreifenden psychisch-sozialen Wandlungsprozeß“ beschrieben und „de[n] ,versöhnte[n] Mann der Zukunft [...] als ganze[n] Mensch[en], der Partnerschaft und Väterlichkeit in sich vereint." Für die heutige Perspektive auf die weiterhin diskutierte Veränderung der Rolle des Mannes ist es - um heutige Diskursbeiträge einzuschätzen und historisch zu situieren - aufschlussreich, zu sehen, dass dies schon 1994 ein Thema war.

Es gab also in den Literaturhäusern in Hamburg und Frankfurt eine theoretische Beschäftigung mit feministischen Themen, jedoch ließ sich keine Handlungsabsicht dahingehend bemerken, mehr weibliche Akteure auf die Bühne einzuladen. Dies reflektiert möglicherweise vor allem, dass sich der gesamtgesellschaftliche Diskurs zur Positionierung von Frauen wandelt, Diskussionen um Geschlechterquoten erst in den letzten Jahren auf breiter Ebene stattfinden und sich auch realpolitisch insgesamt Bestrebungen ausmachen lassen, die Gleichstellung der Geschlechter zum zentralen Handlungsziel zu machen. Ausdruck davon ist in Deutschland etwa das am Deutschen Kulturrat angesiedelte Projektbüro Franen in Kultur \& Medien, das seit Herbst 2017 tätig ist.

Es ist anzunehmen, dass die Leiterin des Literarischen Zentrums Göttingen Anja Johannsen explizit auf ein relativ ausgeglichenes Verhältnis von Akteuren und Akteurinnen auf der dortigen Bühne achtet, was die Zahlen in Abbildung 18 (S. 450) erklären würde. Dies korrespondiert mit der Beobachtung, dass dort in der letzten Zeit zunehmend Veranstaltungen stattfinden, die sich ausdrücklich mit Feminismus und seinen gegenwärtigen Facetten befassen. So sprachen beispielsweise die Autorinnen Sarah Diehl (*1978) und Gertraud Klemm (*1971) über Mütter-Mythen (GT 2015-12-10). ${ }^{1443}$ Nach demUntersuchungszeitraum dieser Arbeit, also seit 2016 gibt es weitere Beispiele, wie die Einladung der Autorin Margarete Stokowski (*1986) mit ihrem Buch Untenrum frei (GT 2016-12-06) oder der Feminist Four der Journalistin Sonja Eismann $(* 1973)$, der englischen Journalistin und Autorin Laurie Penny (*1986), der Journalistin und Autorin Mithu Melanie Sanyal (*1971) und der Rapperin Sookee $\left({ }^{* 1983)}\right.$ (GT 2017-03-07). Ebenfalls wäre ein Abgleich dieser Vermutungen zur Entwicklung der Genderthematik einige Zeit nach dem Leitungswechsel 2018 im Literaturhaus Berlin interessant. Das Literarische Zentrum Göttingen erscheint von den untersuchten deutschen Einrichtungen hinsichtlich der Gendersensibilität dem Osloer Literaturhaus nahezustehen.

Im Litteraturbuset in Oslo wird - laut Stiftungsjahresbericht 2012 - ein ausgeglichenes Verhältnis von Frauen und Männern zumindest offiziell angestrebt und die

\footnotetext{
${ }^{1443}$ Früher lassen sich dort jedoch gleichfalls Abende wie Frauen. Naja. Schwierig mit den Lyrikern Steffen Jacobs, Hellmuth Opitz und Matthias Politycki verzeichnen (GT 2005-10-06). Der Titel stammt von den drei zusammen tourenden Lyrikern, die auch ein gleichnamiges Hörbuch herausbrachten (2004), doch klingt dabei eine nicht gerade feministische Haltung mit.
} 
Umsetzung jeweils ausgewertet. ${ }^{1444}$ Analog dazu finden sich im Programm dieses Literaturhauses viele Veranstaltungen, die das Thema Feminismus direkt aufgreifen und damit als wichtig anerkennen. Bereits in der ersten Woche stand unter anderem das Verhältnis von Gender und Literaturtheorie zur Debatte: Die Norwegerin Toril Moi (*1953), Professorin für Literaturwissenschaft in den USA mit Schwerpunkt auf feministischer Theorie, fragte in ihrem Vortrag Jeg er ikke en kvinnelig forfatter [Ich bin kein weiblicher Autor], ob es noch relevant sei, über,weibliches Schreiben' und über ,Frauen und Literatur ${ }^{6}$ zu sprechen (OL 2007-10-06). Diese Überlegungen spannten den Bogen zum Autorengespräch danach: Toril Moi sprach mit der britischen Autorin Zadie Smith (*1975), die dem Ankündigungstext zufolge oft aufgrund von ethnischer Zugehörigkeit und sozialer Klasse als „en representant for det nye, multikulturelle Storbritannia“ [ein*e Repräsentant*in für das neue, multikulturelle Großbritannien] bezeichnet werde, sich selbst aber eher in einer modernen britischen Romantradition verorte (OL 2007-01-09). Da Litteraturbuset mit einem durchgeplanten, Aufmerksamkeit erregenden Fest seine Eröffnung zelebrierte, können diese ersten Veranstaltungen als programmatisch gelten. Mit der Infragestellung einer Abgrenzung von ,weiblichem Schreiben' markiert Litteraturbuset einen seiner politischen Standpunkte. Zusammen mit den oben dargelegten Ausführungen zur Internationalität lässt sich eine Positionierung des Litteraturhuset jenseits einer allein weißen, männlichen, heterosexuellen und damit privilegierten Literatur und Gesellschaft erkennen. Weitere Beispiele aus den Programmen unterstützen diese Interpretation: So kam die britische Autorin Fay Weldon (*1931) „til samtale om forfatterskapet og 2010-tallets utfordringer for likestilling og kvinnekamp“ [zum Gespräch über Autorschaft und die Herausforderungen der 2010er-Jahre für die Gleichstellung und die Emanzipationsbewegung (die in Skandinavien als ,Frauenkampf $f^{\varsigma}$ bezeichnet wird, Anmerkung C. L.)] (OL 2009-10-21). Der bekannte Satz aus Simone de Beauvoirs Band Das andere Geschlecht „Man fødes ikke til kvinne“ [Man wird nicht als Frau geboren] war Anlass für einen Vortrag (OL 2008-03-08). Und die schwedische Autorin Sara Stridsberg (*1972) unterhielt sich ausgehend von ihrem mit dem Nordisk Råds litteraturpris ausgezeichneten Buch Drömfakulteten - tillägg till sexualteorin [auf Deutsch unter dem Titel Traumfabrik - ohne den norwegischen Untertitel ,Beitrag zur Sexualtheorie“ - erschienen], eine Mischung aus dokumentarischem Material und freier Fiktion, mit der Musikerin Jenny Hval (*1980), die das Thema Feminismus ebenfalls in ihren Kunstaktionen verarbeitet, über die verschiedenen Unterdrückungsmechanismen der Gesellschaft (OL 2008-05-08). Weiteres Beispiel ist der Besuch der Sprachwissenschaftlerin Julia Kristeva (*1941), die mit den norwegischen Autorinnen Hanne Ørstavik und Vigdis Hjorth, die beide häufig im Litteraturbuset zu Gast sind, laut Ankündigungstext schwerpunktmäßig über Frauenrollen zu sprechen aufgefordert war (OL 2009-09-26). Hanne Ørstavik ist zudem eine der Autorinnen, die zum Thema Mamma skal vere god. 2000-talets mor $i$ litteraturen [Mama soll gut sein. Die Mutter in den 2000er-Jahren in der Literatur] eingeladen wurde (OL 2009-05-07). Die in Skandinavien starke Kvinnekamp-Tradition und das

1444 Vgl. Arsberetning for Stiftelsen Litteraturbuset 2012 2013. Im Jahresbericht der Stiftung findet sich ein Absatz zur Gleichstellung sowohl von Mann und Frau als auch der zwei norwegischen Sprachen, die zumindest beide regelmäßig vorkommen sollen. Derartige prinzipielle Gleichstellungsmaßnahmen respektive -absichtsbekundungen sind mir aus den deutschen Literaturhäusern nicht bekannt. 
entwickelte Selbstverständnis der Gleichberechtigung reflektieren die LitteraturbusetProgramme. Den direkten Zusammenhang von Gesetzestexten und Normen und Werten hinsichtlich der Rolle der Frau illuminierte ein Lordagsforedrag (OL 2009-0919) und verdeutlichte einmal mehr die enge Verbindung von Gesellschaftsbildung und Litteraturbuset.

Auch dieser Themenkomplex ließe sich noch eingehender untersuchen, als es ist dieser breitangelegten Arbeit umsetzbar war. Die Reflexion über Zugehörigkeiten und Abgrenzungen ist heute schließlich sehr wichtig, und selbst im Literaturbetrieb werden die Rufe lauter, sich intensiver damit auseinanderzusetzen. ${ }^{1445}$ Die Reflexion, die das Literaturhaus bieten kann, sollte es nicht zugunsten des Präsenzaspektes aufgeben.

\footnotetext{
$1445 \mathrm{Zu}$ nennen sind etwa die Aktionen zu den Buchmessen, in Deutschland wie in Schweden, die sich gegen die dort vertretenen dezidiert rechten Verlage bildeten. Weitere Diskussionen, etwa die 2017 geführte zur Genderpolitik an den zwei deutschen Schreibschulen in Hildesheim und Leipzig, vgl. Herbing und Vöcklinghaus: „Sexismus an“, oder zum Rassismus im Literaturbetrieb im Zuge von \#metwo, vgl. Czollek et al.: „Es fängt““. In Zusammenhang damit steht auch die Entscheidung der Robert Bosch Stiftung, den Adelbert-von-Chamisso-Preis, der laut Statuten herausragende auf Deutsch schreibende Autor*innen, deren Werk von einem Kulturwechsel geprägt ist, ehrt, 2017 zum letzten Mal zu vergeben.
} 


\section{Fazit -}

\section{Individualität und Institution unter einem Dach}

Die Frage in der Einleitung dieser Arbeit, ob von ,Institution“ Literaturhaus überhaupt die Rede sein könne, war, wie die Arbeit demonstriert, natürlich eine rhetorische. Das Literaturhaus ist eine prototypische Institution, die greifbar macht, was zur gegenwärtigen Literaturvermittlung bisher vermutet oder allgemein diagnostiziert wurde. Das erste Kapitel bildete den Grundriss für die Analyse der Fallstudien im zweiten Kapitel. Dort lieferten sowohl die mitunter sehr kleinteiligen, vom Material ausgehenden als auch die stellenweise eher weitgefassten Auseinandersetzungen mit Einzelbeispielen empirische Belege dafür. Mein Praxiswissen und meine Beobachtungen der Diskurse flossen ebenfalls mit ein. Die einzelnen Abschnitte bezogen sich in unterschiedlicher Hinsicht auf die übergeordneten Analysemomente. Einige wichtige Befunde und Hauptlinien werden nun noch einmal gebüdelt. Dies folgt der anfangs aufgestellten Leithypothese, dass die Querverbindungen zwischen den einzelnen Betrachtungsebenen für die Beschäftigung mit dem Literaturhaus zentral sind. In dieser literaturwissenschaftlichen Arbeit wurden ökonomische Momente ebenso wenig ausgeblendet wie organisationale Strukturen, Kommunikationsstrategien oder Raumgestaltungen der Einrichtungen. Behandelt wurden auch die Fragen, was ein Literaturhaus überhaupt ist, wie es als Akteur tätig ist, wie es sich entwickelt und was anhand dieser Institution über die gegenwärtige Literatur und Literaturvermittlung sowie über generelle gesellschaftliche Entwicklungen anschaulich wird. Dazu musste zunächst der Gegenstand konkret erfasst werden, was hier mittels der Fallstudien geschehen ist. Von diesen Beispielen ließ sich unter Berücksichtigung von Kontextfaktoren auf das Allgemeinere schließen, vom einzelnen Literaturhaus auf die Institution Literaturhaus. So bildet diese Studie nicht nur Einzelfälle $\mathrm{ab}$, sondern stellt umfassend das Literaturhaus und seine Umgebung dar.

Die Untersuchung stellte außerdem wichtige Erkenntnisse über die Arbeitspraxis des Literaturhauses heraus, die sich an Beispielen konkretisierten. Diese Reflexionen sind hilfreich, um zu erfahren, was ein Literaturhaus eigentlich genau macht, aber auch für Literaturhaus-Beteiligte nutzbar, um ihre eigene Arbeitsweise zu überdenken und gegebenenfalls zu modifizieren. In der Übertragung auf den Einzelfall kann diese linienzeichnende Studie für die Literaturhaus-Teams brauchbar sein, denn sie ist ein Beitrag zu einer aktuellen Diskussion, die nicht ausschließlich innerhalb des universitären Kontextes geführt wird, sondern auch die Literaturhäuser beschäftigt. Dass die vorliegende Arbeit allerdings vorrangig eine wissenschaftlich-beobachtende Studie ist, daran gilt es zu erinnern.

„Es war eine Aufbruchsstimmung, als in den neunziger Jahren die Literaturhäuser gegründet wurden. Heute müssen sie gegen eine blühende Festivalitis bestehen“1446, schreibt Ina Hartwig, wie schon im ersten Teil dieser Arbeit zitiert. ,Bestehen“ und ,Aufbrechen' sind die zwei Aktionsbereiche, die für die Literaturhäuser zentral blei-

1446 Hartwig 2009, vgl. FN 259. 
ben. Dem Wesen der Institution nach sind sie aufgrund ihrer eigenen eingeschriebenen Geschichte langsamer wandlungsfähig. Doch um ein handlungsfähiger kollektiver Akteur zu bleiben, bedarf es stetiger Neuerung und einer Reaktion auf eine sich verändernde Umwelt. Das Austarieren zwischen Aktion und Reaktion, zwischen Tradition und Innovation, zwischen Individualität und Institution sind essenziell für das Literaturhaus. Einige weitere konkrete divergierende Motivationen, Positionen, Rollen und Funktionen, die sich im Verlauf der Arbeit als Spielraum des Literaturhauses erwiesen haben, bilden den Rahmen für dieses Abschlusskapitel.

\section{1 Zwischen Gesamtkonzept und Literaturveranstalter}

Sehr deutlich wurde, dass das Literaturhaus als Ort der Literaturvermittlung und als literaturvermittelnder Akteur begriffen werden kann. Beide Momente hängen jedoch voneinander $\mathrm{ab}$ und gerade dies gehört zum Gesamtkonzept des Literaturhauses. Mit dem Ausdruck ,umfassendes Literaturhaus' wurde der Raum bezeichnet, den das gesamte öffentlich zugängliche Gebäude mit der Kombination von Literaturveranstalter, meist Café und Buchhandlung und anderen Akteur*innen entstehen lässt. Dieser bildet den Rahmen für die Auseinandersetzung mit Literatur. Zur Praxis, die dort kultiviert wird, tragen das Ambiente und der soziale Aspekt entscheidend bei. In den älteren Literaturhäusern ist eine eher gehobene und exklusive Präsentation unverkennbar, denn sie erscheinen schon bautechnisch ehrwürdiger und historisch aufgeladen, wie etwa der Portikus vor dem Literaturhaus Frankfurt eindrücklich zeigt. Das wirkungsvolle Gebäude integriert das Literaturhaus Frankfurt in seine Selbstdarstellung, dies illustriert beispielsweise in den aktuellen Frankfurter Programmheften die direkte Einbindung gestalterischer Details des Hauses. Demgegenüber arbeiten die norwegischen Literaturhäuser mit grafischen Elementen in den Druckprodukten. Das Literaturhaus Hamburg fokussiert mit Autorenfotos auf dem Umschlag des Programmheftes auf die Bühnengäste. Besonders im Vergleich zu den norwegischen offenbarte sich, dass vor allem die älteren deutschen Literaturhäuser sehr auf die Wirkung des Ortes setzen, während die norwegischen Einrichtungen stärker versuchen, sich über die Raumnutzung zu profilieren. Diese betonen weniger das prächtige Ambiente, sondern die Funktion als Arena für Literatur und Debatten. In der Gestaltung der beiden norwegischen Literaturhäuser selbst wie in ihren Programmheften spiegelt sich die schlichte, funktional designte Ästhetik der protestantischen Länder wider. Dass der Auftritt aus deutscher Perspektive ,lässiger ${ }^{6}$ und durchlässiger wirkt, ist unter anderem darauf zurückzuführen, dass den deutschen Einrichtungen eine Bildungsbürgerlichkeit innewohnt, die es in Skandinavien so gar nicht gibt.

Zugleich stellte sich dar, dass in Deutschland wegen der hoheitlichen Nutzung des Gebäudes durch den Literaturhaus-Verein dieser den Raum als Literaturveranstalter stärker bestimmt. Mit seinem Namen als Marke führt er außerdem gelegentlich Veranstaltungen an anderen Orten durch, was diese Positionierung noch unterstreicht. 
Die skandinavischen Häuser bieten anderen Organisationen Räumlichkeiten und Infrastruktur an und integrieren diese eindeutig als wichtigen Bestandteil in ihr Gesamtkonzept. Dies belegte außerdem der hier identifizierte Transfer nach Göteborg mit der dortigen Litteraturbuset-Umsetzung. Obwohl in Deutschland wie in Norwegen die Literaturhäuser über Vermietungen kofinanziert werden, kommunizieren die Einrichtungen die externen Veranstaltungen auf unterschiedliche Weise. Während die norwegischen sie für ihre Präsentation als offenen, demokratischen Ort nutzen, grenzen sich die deutschen Literaturhäuser sichtbar von ihnen ab. Beide Verfahren zeigen sich von den kulturellen Kontexten geprägt und sind zudem auf die Haltungen ihrer Initiator*innen zurückzuführen. Stärker von den drei großen Volksbewegungen geprägt - Erweckungs-, Abstinenz - und Arbeiterbewegung -, hat das Prinzip der Egalität in Norwegen einen hohen Stellenwert, sodass nicht nur eine Leitungsperson oder ein Team das Programm kuratieren soll, sondern ohne inhaltlichen Filter alle Organisationen eine Bühne finden können und gleichberechtigt präsentiert werden. Entscheidend zur Ausrichtung von Litteraturbuset trugen ferner die Stiftung Fritt Ord und der Mitinitiator und erste Leiter in Oslo Aslak Sira Myhre bei.

Auch in den deutschen Literaturhäusern waren es Einzelpersonen oder Gruppen, die die Ausrichtung prägten. Anders als in Norwegen jedoch wollten diese in erster Linie $i b r$ literarisches Programm an einem definierten Ort durchführen. Es zeigte sich beim stärker vom Senat unterstützten Literaturbaus Berlin, dass dies aus kulturpolitischer Sicht so nicht unbedingt intendiert war. Die Vertreter*innen der Stadt Berlin plädierten deutlicher dafür, das Haus als Treffpunkt für die verschiedenen literarischen Akteur*innen Berlins zu konzipieren, was im Kontext der kulturpolitischen Leitlinie einer ,Kultur für alle zu sehen ist. In der Gründungsidee war das Literaturbaus Berlin den heute aktiven Umsetzungen in Skandinavien strukturell viel ähnlicher. Es waren dann die stärker auf Initiative von Bürger*innen entstandenen Einrichtungen wie das Literaturbaus Hamburg, die eine Fokussierung auf die Ideen einer Leitungsinstanz bevorzugten. So garantieren diese Literaturhäuser mit einem inhaltlich schlüssigen Programm für die Qualität des gesamten Angebots in ,ihrem` Haus.

Die jüngeren deutschen Häuser wie das Literarische Zentrum Göttingen oder das Literaturhaus Freiburg öffnen ihre Türen bisher nur zu den Veranstaltungen. Sein Selbstverständnis als markanter Literaturveranstalter trägt beispielsweise das Literaturbaus Freiburg über ein ausdrucksstarkes Programm(-heft) nach außen, denn es präsentiert sich seit seiner Neueröffnung 2017 mit einem aufwendig gestalteten Programmheft. Dies erscheint wichtiger als die Umsetzung des Umfassenden-LiteraturhausKonzeptes mit Buchhandlung und stetig geöffneter Gastronomie in gehobener Atmosphäre. Dass dies auch dem Umstand geschuldet ist, dass die Gebäude nicht allein vom Literaturhaus-Verein genutzt werden und für tagtägliche Öffnungen keine Kapazitäten - finanziell unter anderem für das notwendige Personal, räumlich, weil es keinen Platz für anlockende Tagesangebote gibt - vorhanden sind, interessiert an dieser Stelle weniger, da es vor allem eine Rolle spielt, wie die Einrichtungen tatsächlich auftreten. Dass die neueren Literaturhäuser primär als Literaturveranstalter und als Ort des Austausches bei Veranstaltungen arbeiten, hat also Auswirkun- 
gen auf die Institution und unterstreicht eine Tendenz, die sich auch in den älteren Einrichtungen sehen lässt. Das Literaturhaus in Deutschland verändert sich gesamtkonzeptuell dahingehend, dass nicht mehr unbedingt ein besonders für die bürgerliche Kultur repräsentativer Ort ausgewählt wird, sondern dass das seit jeher ebenso prägende inhaltliche Konzept sich öffnet. Gerade anhand des Literarischen Zentrums Göttingen wurde ersichtlich, dass die etwas andere Geschichte des Trägervereins, der in der Gründungsphase eher eine Abgrenzung vom ,Literaturhaus'vertrat, die heutige Konstellation miterklärt. Zugleich lässt sich nur spekulieren, wie sich dieses Literaturhaus gestaltet hätte, wenn es nicht im Dachgeschoss in der Düsteren Straße heimisch geworden wäre, sondern beispielsweise in einer feudalen historischen Villa im Göttinger Ostviertel. Es bleibt außerdem abzuwarten, wie sich das Literarische Zentrum Göttingen im in direkter Umgebung neu entstehenden, maßgeblich vom Göttinger Verleger Gerhard Steidl mit der Stadt Göttingen konzipierten und mit Bundesmitteln finanzierten Kulturquartier (Kuqua) mit seinem geplanten zentralen Kunsthaus entwickeln wird.

\section{2 Kontextfaktoren}

Für die Untersuchung der Institution hat sich die Einbeziehung von Debatten in verschiedener Hinsicht als produktiv erwiesen, denn auf diese Weise wurden die unterschiedlichen Interessen und Wirkungsabsichten deutlich. Anhand der referierten öffentlichen Diskussionen offenbarte sich unter anderem der Institutionalisierungsgrad des Literaturhauses in Deutschland und Skandinavien in den letzten Jahren. Während in Skandinavien der Nutzen von Literaturhäusern zunächst noch grundsätzlich infrage stand, fand in Deutschland in den Städten mit etablierten Literaturhäusern schon keine Diskussion mehr darüber statt, ob diese überhaupt eine Daseinsberechtigung haben. Selbst in deutschen Städten, in denen sich Neugründungen erst anbahnen, steht nicht zur Diskussion, ob Literaturhäuser überhaupt gebraucht werden, vielmehr wird gefragt, wie sie realisiert werden können. Dies hängt allerdings mit dem institutionellen Selbstverständnis der bestehenden Einrichtungen zusammen, denn die Beteiligten werden kaum die existierenden Einrichtungen abschaffen wollen und so an ihren, eigenen Stühlen sägen'.

\section{2.1 Zwischen, analog' und, digital'}

Im Ländervergleich ist ein Unterschied erkennbar, in welchen Kontext die Literaturhäuser eingeordnet werden: In Deutschland entsteht der Bezug von Literaturhäusern viel eher zu anderen Kulturbetrieben wie Konzert- und Opernhäusern oder Theatern, während in Skandinavien vor allem die öffentlichen Bibliotheken als Referenz dienen. Auch an dieser Beobachtung lässt sich die Annahme festmachen, dass die norwegischen Literaturhäuser stärker in einem von der Literatur ausgehen- 
den Bildungskontext zu verorten sind, während die deutschen Einrichtungen stärker der bildungsbürgerlich geprägten Kunstrezeption zugerechnet werden.

Interessanterweise steht aber, selbst in Skandinavien, nicht zur Diskussion, ob es überhaupt Orte zur Literaturvermittlung diesseits des Digitalen geben sollte. Es wird nicht gefragt, ob digitale Literaturvermittlungspraktiken nicht einen kollektiven Akteur wie das Literaturhaus insgesamt überflüssig machen. Vielmehr lässt sich bemerken, dass in der Stadt sichtbare Literaturvermittlungseinrichtungen in Zeiten sinkender Leserzahlen als notwendig angesehen werden und auch kleinere Städte sich mit Literaturhäusern oder vergleichbaren Einrichtungen dekorieren möchten. Litteraturhuset und Neugründungen im deutschsprachigen Raum beweisen, dass das Bestreben, begehbare Orte literarischer Öffentlichkeit zu schaffen, weiterhin existieren beziehungsweise gerade erst konstituiert wird. Die Literaturhäuser trugen und tragen dazu bei, Literatur sinnbildlich aus dem Keller in die Beletage zu holen, aber auch dazu, Literaturvermittlung aus dem Bildungsbereich in die Freizeit zu transferieren. Lektüre wird dort zum gemeinsamen Erlebnis nach Feierabend an einem mit Literatur besetzten Ort. Wie die neuen Einrichtungen in Deutschland zeigen, muss das nicht in prächtigen historischen Gebäuden stattfinden, die von vornherein ganz unabhängig vom tatsächlichen Programm - höhere Schwellen aufweisen.

Das Nebeneinander von gedruckten Programmheften und Websiteauftritten, das ausführlich anhand der Fallstudien dargelegt wurde, steht pars pro toto für die Sichtbarkeit in einer Stadt, die ein eigenes Haus der Literatur verschafft. Dass dessen Bedeutung mit zunehmender digitaler Durchdringung des Alltags nicht abnimmt, sondern sich möglicherweise gar verstärkt, benannte diese Arbeit in ihrem Verlauf mehrfach. Der feste Ort trägt dazu bei, einen Raum der Literaturvermittlung zu schaffen, der in sozialer Rahmung durch Kontinuität Wiedererkennung, Anknüpfung und Fortsetzung ermöglicht. Gerade im Zeitalter der Digitalisierung kann das Literaturhaus also eine bedeutsame Literaturplattform sein.

Die hier durchgeführte Untersuchung der Website- und Social-Media-Aktivitäten legte dar, dass die Literaturhäuser diese zwar als Instrumente im Arbeitsalltag nutzen, was von ihrer Professionalität als Veranstaltungsbetrieb zeugt, sie diese Möglichkeiten jedoch selten direkt zur Literaturvermittlung einsetzen und maximal Veranstaltungsmitschnitte online verfügbar machen. Diese Beobachtung spricht dafür, dass die einmalige Live-Veranstaltung vor Ort ihnen in Zeiten weiterhin zunehmender Digitalisierung nicht überholt erscheint, im Gegenteil: Sie kann als Alleinstellungsmerkmal des Literaturhauses stark gemacht werden - sogar noch deutlicher, als es heute der Fall ist. Dabei bleibt für die Einrichtungen zu überlegen, wie sie dies umsetzen könnten, ohne sich explizit abgrenzend auf ,das Digitale‘, ,die Digitalisierung' und ,das Internet' zu beziehen, was leicht einen ablehnenden Gestus bekommt. Dieser besteht nicht unbedingt, denn obwohl sich das Literaturhaus keiner genuin digitalen Vermittlungspraktiken bedient, koexistieren digitale und analoge Verfahren. Unmittelbares Erleben bleibt dabei sehr wichtig.

Mit Blick auf die Finanzierungsmodelle der Literaturhäuser könnten die deutschen Einrichtungen dies nachdrücklicher herausstellen. Es ist zu vermuten, dass im Zuge der insgesamt steigenden Thematisierung von Digitalisierung Projekte, die sich damit auseinandersetzen, Chancen auf Fördermittel haben. Das Literaturhaus 
könnte gerade für die analoge, direkte Begegnung argumentieren und sein Spezifikum noch prägnanter betonen. Folglich sollten die Einrichtungen weitere Konzepte entwickeln, um die digitale Gegenwart im Programm zu reflektieren. Dass dies nicht unbedingt in rein digital basierte Formate münden muss, ist in dieser Arbeit deutlich geworden.

\section{2.2 Zwischen Koalition und Konkurrenz}

Für das Literaturhaus spielen Fragen der Finanzierung eine entscheidende Rolle, sie nehmen sowohl in der Gründungsphase wie während des laufenden Betriebs eine wichtige Position ein. Auch in der Literaturwissenschaft ist inzwischen akzeptiert, dass Studien zur gegenwärtigen Literatur und Literaturvermittlung merkantile Interessen etwa seitens der Verlage sowie der Autor*innen berücksichtigen müssen. In dieser literaturwissenschaftlichen Studie standen dabei nicht die Zahlen im Vordergrund, vielmehr integrierte sie die Annahme, dass die verschiedenen Handlungsmotive des Literaturhauses zwischen öffentlicher Verantwortung, unabhängiger Programmplanung und Marktorientierung in einem Spannungsverhältnis stehen, und sie unterstützte dies in ihrem Verlauf durch konkrete Beispiele. Die finanzielle Abhängigkeit des Literaturhauses äußert sich etwa in der Zusammenarbeit mit Verlagen und in den Kooperationen mit anderen Kultureinrichtungen sowie in der Unterstützung durch private Sponsor*innen und öffentliche Stellen.

Die ökonomische Komponente kann dabei die Programmarbeit konterkarieren oder zumindest beeinflussen und das Programm wirkt sich auf Finanzierungsoptionen aus, wenn etwa Projekte auf bestimmte Ausschreibungen hin entwickelt werden. Um also programmatisch unabhängig agieren zu können, bedarf es, wie Forschungsbeiträge darstellen und woraus selbst Literaturhaus-Leiter*innen kein Geheimnis machen, verschiedener Geldquellen. ${ }^{1447}$ Die gesamte Arbeit des professionell tätigen Literaturhauses ist auf Einnahmen - obgleich nicht unbedingt auf Gewinne - angewiesen. Es bedarf Geld, um den Betrieb überhaupt aufrechterhalten zu können - und weder die Bühnengäste noch die Literaturhaus-Angestellten sind rein ehrenamtlich tätig.

\section{2.2.1 Kulturpolitik}

Wie sich vor allem in den Einzeldarstellungen und bei den Ausführungen zu kooperierenden und konkurrierenden kollektiven Akteur*innen zeigte, lässt sich das Literaturhaus exemplarisch für die Relevanz von kulturpolitischen Motiven im Literaturbetrieb untersuchen. Obwohl es sich bei Literaturhäusern nicht um kommunale Einrichtungen handelt, prägen kulturpolitische Fragestellungen ihre Arbeit. Aus Finanzierungssicht stieg mit der Zeit aus Gründen des Selbsterhalts für die Institution der Druck, sich zu öffnen und das Programm auszuweiten beziehungsweise mit einer angepassten Ansprache Hürden abzubauen, um sich damit für die öffentliche

\footnotetext{
1447 Rainer Moritz stellte dies in seinem Vortrag auf der Literaturhaus-Tagung in Lenzburg 2014 heraus,
} vgl. FN 399. 
Mitfinanzierung zu rechtfertigen. ${ }^{1448}$ Die kulturpolitische Dimension mit den Programmanalysen zusammenzubringen, erwies sich als fruchtbar sowohl für die Überlegungen zum Programm, weil so beispielsweise verständlich wurde, woher der Fokus auf Debatten in den norwegischen Einrichtungen rührt, als auch für die Kontextualisierung des Literaturhauses, weil sich zeigte, dass zum Beispiel der für die deutschen Literaturhäuser spezielle Lesungsteil auf die Intention, Literatur nicht nur gesellschaftspolitisch $\mathrm{zu}$ instrumentalisieren, sondern als für sich stehende Kunstform zu zelebrieren, zurückgeht. Die Untersuchung der Programme lieferte so Argumente dafür, dass historisch gewachsene Spannungen zwischen kulturpolitischem und kunstästhetischem Anspruch weiterhin virulent sind.

Dadurch, dass es meistens zumindest teilweise von öffentlichen Mitteln abhängig ist, trägt das Literaturhaus gesellschaftspolitische Verantwortung und kann nicht mehr nur ein elitäres Kulturverständnis vertreten. Die Äußerungen früherer Literaturhaus-Leitungen, wie Herbert Wiesner in Berlin oder Ursula Keller in Hamburg, dass die Einrichtungen gar nicht, für alle offenstehen wollten und sie überhaupt nichts anderes sein sollten, als Häuser für Literaturkenner*innen, wäre so heute kaum noch denkbar. Dass die öffentliche Legitimation mit der Zeit wichtiger wird, wird unter anderem von der Tatsache unterstützt, dass die deutschen Literaturhäuser das Angebot für Kinder und Jugendliche sukzessive erweiterten und erweitern. Diese Projekte stoßen bei öffentlichen wie privaten Förder*innen auf Resonanz. Allerdings lässt sich festhalten, dass im Untersuchungszeitraum im Erwachsenenprogramm in Deutschland selten explizit niederschwellige Projekte zu finden waren. Erst nach und nach entstehen in dieser Hinsicht Ideen: Das Literaturbaus Frankfurt initiierte etwa 2016 das Projekt Frankfurt, deine Geschichte, bei dem Autor*innen sich mit sogenannter ,leichter Sprache ${ }^{6}$ auseinandersetzten und entsprechende Texte verfassten. ${ }^{1449}$ Das Literaturhaus Berlin widmet sich seit dem Leitungswechsel 2018 stärker der breiten Bevölkerung der Stadt, indem es Migrant*innen und Berlins Vielsprachigkeit ausdrücklich ins Programm einbindet. Es ist also zu vermuten, dass das Moment der Inklusion, das im Kinder- und Jugendbereich schon wichtig ist, im Erwachsenenprogramm an Bedeutung gewinnen wird. Auch dies ist als Reaktion auf die sich verändernde Gegenwart zu interpretieren, weil etwa das Thema Migration für die deutsche wie die norwegische Gesellschaft in den letzten Jahren an Brisanz gewonnen hat. Die Veränderungen allein als Legitimationsstrategie zu beurteilen, ist aber zu einseitig gedacht. Einzuberechnen ist ebenfalls, dass die Verantwortlichen in den Einrichtungen vermutlich nicht nur aus diplomatischem Kalkül, sondern aus Überzeugung mehr Gleichberechtigung anstreben, weil das politische Selbstverständnis insgesamt im Wandel ist.

Mit der Etablierung des Literaturhauses als Ort in der jeweiligen Stadt stellt dieses nicht nur einen Akteur im Literaturbereich, sondern auch in der (Kultur-)Politik dar. Um seine Position dort auszubauen, muss es ebenfalls politisch klar Position beziehen - ohne sich dabei instrumentalisieren zu lassen. Mit diesen Überlegungen

1448 Vgl. Vandenrath 2006, S. 179.

${ }_{1449}$ Als Autor*innen wirkten Henning Ahrens, Mirko Bonné, Nora Bossong, Olga Grjasnowa, Kristof Magnusson und Alissa Walser mit. Das Literaturhaus führte dieses Projekt in Kooperation mit dem Historischen Museum Frankfurt und der Stabsstelle Inklusion Frankfurt durch, mit Förderung vom Hessischen Ministerium für Soziales und Integration, in Partnerschaft mit dem Netzwerk Inklusion Frankfurt (FF 2016-12-13). 
kann die vorliegende Arbeit ein Anlass sein, sich vertiefend mit dem Verhältnis von teilöffentlichen, und von freien Literaturvermittler*innen zur kulturpolitischen Linie in Deutschland und anderen Ländern zu befassen. Zu reflektieren ist ferner, inwiefern die Literaturhäuser zwar vom kulturellen Kontext abhängig sind, sie diesen jedoch zugleich mitprägen. Um die Institution weiterzuentwickeln, bedarf es eines soliden Budgets, das wiederum von Geldgeber*innen abhängt, die durch ihren Fokus auf Projektförderung stetig Innovation verlangen. ${ }^{1450}$ Das ist ein Dilemma, denn während das Literaturhaus den Betrieb mit seinem ganzjährigen Angebot aufrechterhalten muss und selten Reflexionspausen einlegen kann, muss es gleichzeitig weiterdenken - dafür braucht es Ressourcen. Dies begründet die nur langsame Wandlungsfähigkeit der Institution aus praktischer Sicht. Dass gerade die solide Finanzierung daran etwas ändern könnte, stellt Florian Höllerer heraus: „Feste Wurzeln verankern die Literatur in der Gesellschaft und befördern deren Zusammenhalt nachhaltig und langfristig. “

Dass die Realisierung eines Literaturhaus-Konzeptes letztlich an fehlendem Geld, nicht-professioneller Infrastruktur sowie mangelnder öffentlicher Unterstützung scheitern kann, illustriert das LiteraturHaus in Kopenhagen, das von Beginn an als privatorganisierte Unternehmung tätig war. Demgegenüber konnte Litteraturhuset in Oslo - monetär und argumentativ gleich zu Anfang entscheidend von der Stiftung Fritt Ord etabliert - sich als Erfolgsmodell und Vorbild in Norwegen und Skandinavien durchsetzen.

Die Beschäftigung mit den norwegischen Einrichtungen offenbarte, dass sich der dortige Literaturveranstaltungsbetrieb im Zuge der Literaturhaus-Eröffnungen drastisch verändert hat.

Litteraturformidling fra scene er $\mathrm{i}$ de senere år imidlertid blitt en mer utbredt aktivitet for mange forfattere, ikke bare $\mathrm{i}$ regi av festivaler. Det etableres litteraturhus stadig flere steder og bibliotekene er blitt lovpålagt å gjennomføre arrangementer som litterær møteplass og debattarena. ${ }^{1452}$

[Literaturvermittlung von der Bühne aus ist in den letzten Jahren jedoch zu einer ausgeweiteten Tätigkeit für viele Autor*innen geworden, nicht nur in Regie von Festivals. Es etablieren sich an ständig mehr Orten Literaturhäuser und den Bibliotheken wurde gesetzlich vorgeschrieben, als literarischer Treffpunkt und Debattenarena Veranstaltungen durchzuführen.]

Für Norwegen lässt sich explizit festhalten, dass es dabei zu einer Parallelentwicklung von Literaturfestivals, Literaturhäusern und Bibliotheken gekommen ist, die sich alle um ,Literaturvermittlung auf der Bühne' kümmern. Gleichzeitig nutzen beispielsweise Universitäten die Literaturhäuser, um sich weiter zu öffnen, wie die Beispiele aus Göttingen und Bergen belegen. Beim Literaturhaus handelt es sich also nicht um ein Einzelphänomen, vielmehr steht es in einem kulturpolitisch geprägten Literaturvermittlungskontext.

\footnotetext{
1450 Vgl. Johannsen 2013b, S. 214.

1451 Höllerer 2007, S. 220.

1452 Ericsson und Rykkja 2015, S. 5.
} 
Am Beispiel der norwegischen Literaturhäuser wurde außerdem an konkreten Fällen diskutiert, inwiefern der Transfer des Literaturhauses - zunächst aus Deutschland nach Norwegen, dann von Oslo nach Bergen - sich als kulturpolitische Strategie erwies, die jeweilige Stadt mittels des Literaturhauses neu zu positionieren. Das überregionale Wirken der Einrichtungen ist eng verknüpft mit einem Verständnis von Urbanität, denn während das Bergener Literaturhaus seine regionale Verwurzelung herausstellt und sich somit als ,Hauptstadt der Provinz und als Gegenspieler zu Oslo inszeniert, strebt das Osloer Haus vor allem danach, an internationale Diskurse anzuknüpfen. Allerdings versucht inzwischen auch Litthusbergen, mit mehr internationalen Autor*innen seine Relevanz im nach Überregionalität strebenden Literaturbetrieb zu erhöhen: Im Frühjahr 2019 fand dort das erste Littfestbergen statt - ein internationales Literaturfestival, ausgerichtet vom Literaturhaus.

\section{2.2.2 Literaturbetrieb}

Mit dem Aufstieg der Literatur zur Zeitgeist-Avantgarde und deren raumzeitlicher Entgrenzung verlieren die Literaturhäuser nicht nur ihre Monopolstellung, sondern drohen zu Refugien innovationsresistenter Minderheitenprogramme zu werden: Orte der guten alten Autorenlesung für das lokale Bildungsbürgertum. ${ }^{1453}$

Sonja Vandenraths Kommentar von 2002, dass seit der Eröffnung der Literaturhäuser zahlreiche andere Literaturveranstalter*innen hinzugekommen seien und die Literaturhäuser statt auf Innovationen zu setzen an ihrem Kernprodukt „der guten alten Autorenlesung“ festhielten, fokussiert auf die Vermittlungsformate. Wie die vorliegende Arbeit zeigt, lag die Ausrichtung der älteren Literaturhäuser auf das ,lokale Bürgertum' nicht so sehr in den Formaten selbst begründet, die immer schon eine Mischung aus Performance, Diskussion und klassischer Lesung boten, sondern in ihren örtlichen und kommunikativen Rahmungen. Dass die früheren Leitungen ausdrücklich ein exklusives Programm als ,Refugium' befürworteten, lässt sich nicht mit heutigen Maßstäben messen, sondern verdeutlicht den in der Zeit üblichen hochkulturellen Umgang mit Literatur. Allerdings zeigen die beschriebenen Diskussionen über die Leitungswechsel 2004 in Hamburg und 2010 in Frankfurt, dass die Vereinsvorstände bei Vertragsende der amtierenden Leitungen selbst einen programmatischen Wandel suchten, der die Öffnung zu einem breiteren Publikum beinhalten sollte, was hier als zeitgemäße Entscheidung eingeschätzt wurde. Neue Formate der Vermittlung schienen diese Öffnung zunächst zu befördern.

Die Hypothese von Anja Johannsen, die direkt an Vandenrath anschließt, dass es heute als die große Gefahr gelte, ,,in der die Literaturhäuser stehen, nicht mehr , Refugien innovationsresistenter Minderheitenprogramme' zu sein, als vielmehr die, zum verlängerten Arm der Marketingabteilungen der Verlage zu verkommen“1454, ist in diesem Kontext zu präzisieren. Damit sind nämlich eigentlich keine Veränderungen in der Veranstaltungsausrichtung beschrieben, denn der Marketingvorwurf widerspricht nicht grundsätzlich den ,innovationsresistenten Minderheitenprogrammen' für das Bildungsbürgertum: Mit dem Verlagseinfluss ist die Literaturaus-

1453 Vandenrath 2002, S. 173.

${ }^{1454}$ Johannsen 2012b, S. 187-188. Vgl. auch Johannsen 2013a, S. 65. Sie verweist dabei auf Vandenrath 2002, S. 173, vgl. FN 1453. 
wahl gemeint und Innovationsresistenz spielt auf die Veranstaltungsformate an. Johannsen zufolge steht aktuell nicht so sehr die klassische Vermittlungsform in der Kritik, denn die sei inzwischen sogar jenseits des ,lokalen Bildungsbürgertums“ etabliert. Hingegen werde kritisiert, dass die Auswahl der Literatur sich vornehmlich an den Vorgaben der Publikumsverlage orientiere und damit deren Interessen stärker auf die Programme einwirkten, als das früher der Fall gewesen sei.

Die intensive Beschäftigung mit den Literaturhaus-Programmen seit 1986 ließ erkennen, dass über die Jahre in der Tat Verlagsnovitäten expliziter eine Rolle spielten. Dies hat unter anderem damit zu tun, dass die Literaturhäuser sich als Veranstaltungsorte etabliert haben, die auch für die Verlage attraktiv sind - gerade, weil sie autonom und nicht gewinnorientiert arbeiten sowie dem Anspruch nach allein nach literarischer Qualität auswählen und deshalb für das Publikum eine glaubwürdige Instanz darstellen. Dies hängt mit dem Punkt zusammen, den Anja Johannsen anspricht, indem sie erwähnt, dass beispielsweise die Literaturkritikerin Sigrid Löffler mehrfach öffentlich gewarnt habe, ,diese Institutionen müssten achtgeben, nicht bloß zu Abspielstätten der Verlage zu mutieren“1455. Die pejorative Konnotation der Zuschreibung ,Abspielstätte` ist offensichtlich. In dem von Johannsen referenzierten Artikel Sigrid Löfflers ist zwar nicht explizit die Rede von ,Abspielstätte', sodass sich hier nicht rekonstruieren lässt, wer diesen durchaus virulenten Ausdruck zuerst verwendete, doch problematisiert Löffler dort, dass die Lebensspanne von Büchern im Buchhandel nach Erscheinen nur noch wenige Wochen beträgt und Aufmerksamkeit für die Titel in der kurzen Zeit entsprechend wichtig ist. ${ }^{1456}$ Damit erklärt sich, warum die Verlage Lesereisen von Autor*innen häufig relativ zeitnah nach dem Publikationsdatum planen und somit die Auftritte in den Literaturhäusern ebenfalls mit der von den Beteiligten erhofften allgemeinen Aufmerksamkeit zusammenfallen. Dies kann sich folglich positiv auf die Werbung für die Veranstaltungen auswirken, weil Buch und Autor*in gegebenenfalls in den Medien präsent sind. Allerdings merkt Löffler weiter kritisch an, dass sich durch die zeitliche Konzentration die Aufmerksamkeit ebenfalls extrem fokussiert, sodass einige Autor*innen sehr hohe Sichtbarkeit erhalten, während viele deutlich weniger Beachtung als früher bekommen. ${ }^{1457}$ Löffler folgend lässt sich schließen, dass die Literaturhäuser diese Tendenz befördern.

Während das Literaturhaus in den Anfangsjahren vor allem eine ,elitäre' Literaturidee vertrat, ließ sich in dieser Arbeit ferner attestieren, dass in den letzten Jahren kommerzielle Motivationen vermehrt erkennbar wurden. Die ,AbspielstättenHypothese' steht damit nicht in direktem Zusammenhang, denn nur weil die Literaturhäuser zunehmend von den Verlagsprogrammen durchdrungen sind, ist damit noch kein breitenwirksamer wirtschaftlicher Gewinn garantiert - was die Verlage, deren Programme im Literaturhaus vorkommen, mit ihren ebenfalls steigenden Kosten und sinkenden Leserzahlen nahelegen. Die ökonomische Komponente betrifft stärker die Nachfrageorientierung, weil Erfolgskriterien des Marktes auf das

\footnotetext{
1455 Johannsen 2013b, S. 213.

1456 Vgl. Löffler 2008, S. 7.

1457 Vgl. ebd., S. 8.
} 
Literaturhaus übertragen werden: Kommen genug Besucher*innen zu den Veranstaltungen?

Dies steht natürlich doch in engem Zusammenhang mit der oben genannten Aufmerksamkeitsbündelung im Literaturbetrieb, die dafür sorgen kann, dass unter strengeren finanziellen Bedingungen die Literaturhäuser ,allein dasjenige katalysatorengleich noch befördern, was ohnehin erfolgreich ist"1458 und damit die eigenen Wertungskriterien gegebenenfalls hintenanstehen. Die folgende Frage allerdings bleibt wichtig: Entsprechen die Veranstaltungen den Vorstellungen der Programmleitungen von beachtenswerter Literatur und von guter Literaturvermittlung?

Die Begriffe von ,Elitarismus ${ }^{6}$ und ,Popularität ${ }^{6}$ beziehen sich auf die öffentliche Wirkungsweise, meinen also soziale Distinktion und breite Integration. Die Diskussion darüber im Literaturhaus-Diskurs enthält zugleich die Vorstellung, dass ein breitenwirksames Programm ein abnehmendes intellektuelles Profil bedeute, ${ }^{1459}$ sodass Popularität mit Oberflächlichkeit zusammengebracht wird. Dass mit dieser Annahme eine Befürchtung verbunden ist, impliziert, dass die Literaturhäuser den Anspruch hegen, eine intellektuelle Programmatik zu vertreten. Und damit stehen sie unvermeidlich in dem Spannungsverhältnis von intellektuellem Anspruch und Elitarismus auf der einen Seite sowie leichter Unterhaltung und Popularität auf der anderen. Beide Seiten verhalten sich aber nicht grundsätzlich diametral zueinander. „Anspruchsvoll‘ ist nicht das Gegenteil von ,populär““1460, wie Florian Höllerer konstatiert. Konträr gegenüber stehen sich die „Flucht in einen Kulturdünkel“ und die „,bedenkenlose Anpassung an die ,Marktfähigkeit' von Kultur“"1461, wie es Holger Noltze in seiner Streitschrift Die Leichtigkeitslüge formuliert. Dies bezieht sich auf den Umgang mit der Prämisse, dass einige Kulturprodukte komplexer gestaltet und damit anstrengender zu rezipieren sind als andere. Noltze plädiert dabei mit durchaus treffsicheren Beobachtungen für „eine andere Kultur der positiv verstandenen Anstrengung " ${ }^{\text {"1462 }}$, wo der Vermittlung eine wichtige Position zukommt. Die von Rainer Moritz benannte Anstrengung, die eine Lesung erfordern dürfe, ${ }^{1463}$ ist mit Noltzes Ausführungen vereinbar. Die vorliegende Auseinandersetzung mit dem Literaturhaus stellte heraus, dass diese Institution sich einer Literatur verpflichtet sieht, die nicht immer nur leicht konsumierbar und dabei in einen über den Einzeltext hinausweisenden Kontext gestellt ist. Dieses Verständnis wird allerdings leicht mit einer elitären Kunstvorstellung zusammengebracht: Diese Art von Literatur kann als Nischenprodukt für eine kleine Gruppe vermittelt werden, wie die früheren Jahre der Literaturhäuser zeigten; oder es kommt, wie die jüngeren Entwicklung nahelegen, zu einem Konflikt, weil die Einrichtungen nicht von ihrem eigentlich gleichbleibenden Literaturverständnis abweichen und sich parallel einem größeren Publikum öffnen wollen. Zu verbinden sind beide Bestrebungen nur, wenn die Literaturhäuser ihre Vorstellung von Literatur ,unter die Leute bringen' und sich weder nur der breiten

\footnotetext{
1458 Johannsen 2013b, S. 213.

1459 Vgl. Johannsen 2012b, S. 187-188.

${ }^{1460}$ Höllerer 2007, S. 218. „[N] achhaltige Gunst des Publikums wird es ohne nachhaltige Forderung des

Publikums nicht geben.“

1461 Noltze 2010, S. 16.

1462 Ebd., S. 24.

1463 Vgl. Moritz 2013b, S. 294. Vgl. FN 1204.
} 
Nachfrage, noch allein einem exkludierenden Angebot hingeben. Zu bedenken ist allerdings, dass, wie Splittgerber und Porombka betonen, es sich bei Literatur in der öffentlichen Wahrnehmung und Förderung weiterhin „um eine „Peripherkultur“"1464 handelt. Die Ausweitung des Kinder- und Jugendprogramms ist in diesem Kontext sehr nachvollziehbar, denn seine gesellschaftliche Relevanz ist aus Bildungsgründen bereits anerkannter und die idealiter positiven Erfahrungen der Kinder und Jugendlichen mit Literatur könnten die Position der Literatur(häuser) insgesamt stärken. Wie dies im Erwachsenenbereich umgesetzt werden kann, wird die Literaturhäuser weiterhin beschäftigen.

In der diskursiv mit den an das Literaturhaus gerichteten ,Vorwürfen' verbundenen Kritik lässt sich vor allem eine auf den deutschen Kontext bezogene Diskussion aufdecken. Während in den deutschen Literaturhäusern die Sorge größer ist, zu populär ergo zu wenig intellektuell zu sein, betonen die norwegischen stetig ihre demokratische Funktion, alle gleichberechtigt einzubeziehen. Aufgrund der unterschiedlichen Bildungshintergründe verwundert dies nicht. In Skandinavien fußt es auf der generellen Ablehnung von Eliten, eine möglichst breite Wirkung zum Ziel zu erklären. Ihre öffentliche Relevanz betonen diese Einrichtungen zusätzlich darüber, dass sie die anderen im Literaturhaus stattfindenden Veranstaltungen ebenfalls sichtbar machen.

In der norwegischen Diskussion ist die Einflussnahme des Marktes auf das Literaturhaus-Programm nicht so offensichtlich Thema wie in Deutschland. Litteraturbuset in Oslo positioniert sich sogar tendenziell als Gegenspieler zum nationalgeprägten und monopolgesteuerten Buchmarkt. Außerdem ermöglicht die Grundstruktur des norwegischen Literaturhauses, dass die Verlage selbst im Litteraturbuset Veranstaltungen organisieren können. Sie nutzen den Rahmen - den Ort, die Kommunikationsstrukturen und das Ansehen des Literaturhauses - und ,entlasten“ so das Programm der Literaturhaus-Stiftung. ${ }^{1465}$ Diese Konzeption führt zum einen zu einem offeneren Programm des gesamten Literaturhauses, weil viele Veranstalter*innen dazu beitragen. Zum anderen lässt sie der Litteraturbuset-Stiftung programmatisch mehr Freiheit und Unabhängigkeit, da sie sich von Forderungen der Verlage besser abgrenzen kann. Zugleich verfügt das Literaturhaus-Team über die Vermietung der Räume und behält sich die Terminkoordination vor, sodass sein Programm Oberhand behält.

In den deutschen Literaturhäusern können Verlage und andere Organisationen zwar als externe Veranstalter*innen die Räume mieten, doch stehen ihnen selten die etablierten Infrastrukturen der Einrichtung zur Verfügung. Diese Lesungen behalten den Status einer Gastveranstaltung, die die Mieter*innen selbst organisieren müssen. Die Verlage haben dazu meist allerdings keine Kapazitäten, zumal der Literaturveranstaltungsbetrieb in Deutschland - allein, weil es mehr Großstädte gibt als in Norwegen - deutlich umfangreicher, der Markt also größer ist. Die Verlage haben

\footnotetext{
1464 Porombka und Splittgerber 2010, S. 118.

1465 Die Rahmung durch Litteraturbuset führt zu der Außenwahrnehmung, dass es sich auch bei den von Verlagen organisierten Veranstaltungen nicht um reine Marketingevents handelt. Dabei ist zu bedenken, dass ohnehin bei Autorenbesuchen kritische Werturteile nur marginal geäußert werden, wie die vorliegende Arbeit betonte.
} 
also definitiv Interesse an den Strukturen der Literaturhäuser. Auch diese Aufgabenverteilung hat sich über die Jahre entwickelt und bedingt so die heutige Arbeitsweise.

\section{3 Literaturvermittlungsobjekte und -praktiken}

\section{3.1 Zwischen Einzelveranstaltung und Gesamtprogramm}

Gesamtkonzeptuell stellt das Literaturhaus einen Raum und einen Akteur dar, der generell bestrebt ist, Zugewandtheit zur Literatur zu vermitteln, indem das Gebäude ihr einen Ort in der Stadt reserviert. Auf diese Weise hält das Haus Literatur - und seinem Namen ,Literaturhaus' nach gerade nicht dem Buch oder Büchern, die von Buchhandlungen und Bibliotheken repräsentiert werden - sichtbar. Selbst wenn ein Essen im dortigen Restaurant oder eine Feier im angeschlossenen Café für die Besucher*innen zunächst nichts damit zu tun haben, bleibt Literatur als Vokabel präsent. Allerdings rahmt Literatur dabei eher andere Praktiken und wird zur Marginalie. Im Zentrum steht sie im Veranstaltungsprogramm der Literaturhaus-Organisation. Der Bezug zu ihr ergibt sich darin teilweise auch nur, weil die Veranstaltung in einem Literaturhaus und nicht etwa in einem Konzertsaal, einer Bildungseinrichtung, einem Kino oder Stadion stattfindet. So bestimmt die Einrichtung mit darüber, was als Literatur verstanden wird. Alles, was in einem Literaturhaus-Programm vorkommt, steht mit Literatur in einem Zusammenhang.

In diesem Kontext lassen sich Überlegungen zu den Wertungsprozessen im Literaturhaus bündeln. Beide Betrachtungsebenen, die Simone Winko für die Untersuchung von literarischen Wertungen unterscheidet, sind zu berücksichtigen: ${ }^{1466}$ Erstens werten Literaturhäuser Literatur insgesamt, indem sie die Auseinandersetzung mit ihr als „wertvoll“ ausweisen, was ja die Grundmotivation für die Eröffnung eines Literaturhauses darstellt. Zweitens werten sie konkret einzelne literarische Texte - vor allem über ihre Selektion. Diese Auswahl basiert nur zum Teil auf ästhetischen Kriterien, denn die Programmverantwortlichen greifen vornehmlich auf die von Verlagen getroffene Vorauswahl zurück, weshalb organisatorische wie ökonomische Belange die Entscheidung mitprägen, besonders bei Einladungen internationaler Autor*innen. Selten aber werden die Punkte, die zu einer Programmauswahl geführt haben, offengelegt, sodass es so wirkt, als hätten ästhetische Kriterien - welcher Art auch immer - für die Auswahl gesorgt. In Zusammenhang mit der Rolle des Literaturhauses als Kanonisierungsinstanz ist dies bemerkenswert: Es wird anschaulich, wie sehr außerliterarische Faktoren auf den Status von Autor*innen einwirken. Empirisch lassen sich die tatsächlichen Beweggründe für den Einzelfall jedoch kaum nachweisen, da sie weder über die Programmtexte noch über Interviews in Erfahrung zu bringen sind. Untersuchbar sind hingegen die Absichts-

${ }^{1466}$ Vgl. Winko 1996, S. 589. 
bekundungen und literarisch motivierten Entscheidungen, die quellenkritisch unter Berücksichtigung ihrer Werbe- und Legitimationsfunktion behandelt werden müssen. Die vorliegende Arbeit veranschaulichte, dass organisatorische Fragen - zum Beispiel: Ist Autor*in N. N. auf Lesereise? Ist noch ein Termin frei? Kann das Literaturhaus für das Honorar aufkommen? Passt das Buch ins Gesamtprogramm? maßgeblich Einfluss auf die Programmplanung haben. Von außen sichtbar ist nur die Tatsache, dass Autor*in N. N. zu Gast im Literaturhaus war und so Aufmerksamkeit erfahren hat.

Die Literaturhäuser wählen zwar einzelne Texte aus, doch macht gerade die Summe der Einzelentscheidungen das Literaturhaus-Programm aus. Darin äußert sich eine der grundlegenden Ambivalenzen des Literaturhauses: Die einzelnen Veranstaltungen sind auf den Moment und das einmalige Erleben hin ausgerichtet, und doch ist es das Gesamtprogramm, das das Haus prägt und Kontinuität schafft. Die Programmhefte ließen sich hier entsprechend als Visitenkarte respektive pars pro toto für das komplette Literaturhaus begutachten. Die Selbstdarstellungen betonen vor allem inhaltliche Vielfalt. Dies konnte anhand der Programmanalysen bestätigt werden, denn es ergab sich bei keinem der Literaturhäuser eine eindeutige Spezialisierung. Die Einzelveranstaltungen stehen in den untersuchten Literaturhäusern in den umfassenden Monats- oder Quartalsprogrammen relativ gleichberechtigt nebeneinander. Einzelne ,Highlights' lassen sich durch die grafische Präsentation im Programmheft, das Editorial oder zusätzliche Bewerbung hervorheben. In der Regel kommunizieren die Einrichtungen ihr komplettes Programm.

Etwas anders ist dies bei Reihen, Festivals und Symposien, die durch ihre längere Laufzeit oder spezielle Bedeutung für das Programm häufig eigens angekündigt werden. Diese sind als explizite Schwerpunktsetzungen zu interpretieren, die das Profil des jeweiligen Literaturhauses besonders gut erkennen lassen, weil sie eine Sortierung des Programms anbieten. Allerdings kann es ebenfalls zum Profil eines Literaturhauses zählen, gerade auf einzelne bündelnde Fokusthemen zu verzichten, sondern die Sammlung von Einzelterminen als Leitidee zu präsentieren, die erst der Rahmen des Monatsprogramms in einen Zusammenhang stellt.

Anschließende Studien zu einzelnen Einrichtungen könnten die jeweiligen Programmprofile noch deutlicher herausarbeiten; wegen des umfangreichen Materials rückte hier der Vergleich in den Mittelpunkt. Die Literaturhäuser stehen über den Institutionskontext in einem mehr oder weniger intensiven Austauschverhältnis. Transfers vollziehen sie dabei nicht nur durch die grundlegende Modifikation des Literaturhaus-Modells, sondern ebenfalls in kleinerem Maßstab auf Programmebene. Untersuchungen zu einzelnen Autor*innen, Publikationen oder Veranstaltungsformaten könnten vertiefen und empirisch belegen, dass die Häuser sich gegenseitig befruchten, indem sie gelegentlich Ideen voneinander aufgreifen und weiterentwickeln. 


\section{3.2 Zwischen engem Literaturverständnis und Interdisziplinarität}

Während die im Literaturhaus vorgestellte belletristische Literatur für einen engeren Werkbegriff spricht, äußert sich dort gleichzeitig eine Offenheit, die andere Disziplinen selbstverständlich einbezieht. Auf der einen Seite identifizierte die Programmanalyse ein relativ klar begrenztes Literaturverständnis, denn es kommt dort wenig Genreliteratur vor und selten Publikationen, die sich vornehmlich als Unterhaltungsliteratur bezeichnen lassen. Der Schwerpunkt in den letzten Jahren lag auf erzählender Prosa mit deutlicher Überzahl an Romanen. Gleichzeitig findet sich die gesamte Literaturhaus-Zeit über Lyrik in den Programmen vertreten, was noch unterstreicht, dass der Institution eine Idee von Literatur zugrunde liegt, die die Machart als Qualitätskriterium berücksichtigt. Außerdem offenbart sich dadurch, dass die Literaturhäuser ihre Internationalität hervorheben, dass für sie ein Kennzeichen für literarischen Wert die ortsunabhängige und zeitungebundene Gültigkeit von Texten ist, nicht allein ihr regionaler Bezug. Weiter zeigte sich, dass die Literaturhäuser vor allem auf die Vorauswahl der Verlage, im deutschen Raum besonders der großen anerkannten literarischen Publikumsverlage, zurückgreifen, was ebenfalls dazu beiträgt, dass nur ein abgesteckter Bereich überhaupt zur Präsentation in Erwägung gezogen wird. Gelegentlich finden sich zwar Texte abseits dieser Sphäre des Literaturbetriebs, doch zeigte sich unter anderem, dass über inzwischen weitverbreitete Publikationsformen wie Selfpublishing veröffentliche Texte höchstens ausnahmsweise vorkommen. Die Literaturhäuser rezipieren damit ähnliche Texte wie etwa die überregionalen Feuilletons, die sich in den Programmtexten oft zitiert finden und die so in einem Verweiszusammenhang stehen.

Aufgrund der zahlreichen Neuerscheinungen werden, wie Sigrid Löffler darstellt, Literaturmoden ausgerufen, um die Titel thematisch bündeln zu können. Diese Moden wechselten sich jedoch so rasant und vollends ab, dass sie schnell wieder vergessen seien. Als Beispiele nennt Löffler die „Debütantenwelle“1467 Ende der 1990er-Jahre und die ihr folgende „Ostalgie-Welle“1468, über die im Feuilleton und inzwischen in der Literaturwissenschaft Konsens herrscht, die dort also gerade nicht vergessen, sondern dokumentiert sind. Die vorliegende Arbeit zeigt, dass neben der Medienberichterstattung die Literaturhaus-Programme als Quellenmaterial hinzugezogen werden können, um vergleichbare Moden empirisch nachzuzeichnen. Das Literaturhaus ist ein Akteur, der durch sein eigenes Programm literaturbetriebliche Tendenzen nicht nur spiegelt, sondern intensiviert und teilweise erst entstehen lässt. Was hier für die Debüts zur Jahrtausendwende nur angerissen werden konnte, ${ }^{1469}$ ließe sich in Beiträgen mit engerer Fragestellung zu einzelnen ,Literaturmoden` ausbauen und für die Gegenwartsliteraturgeschichtsschreibung nutzen. Hier wurden zunächst verschiedene Anwendungsmöglichkeiten des umfangreichen Materials durchgespielt und diese dementsprechend nicht erschöpfend behandelt.

Darüber hinaus zeichnete sich ab, dass das Literaturhaus in erster Linie die belletristischen Texte einbezieht, die in abgeschlossener Form als Buch vorliegen. Genuin

\footnotetext{
${ }^{1467}$ Löffler 2008, S. 10.

1468 Ebd.

${ }^{1469}$ Vgl. Kapitel II 14.2.3.
} 
orale Texte finden zum Beispiel bei Formaten wie offenen Bühnen Platz. Allerdings existiert aktuell nur noch im Literaturhaus Oslo Apen mikrofon. Andere Häuser wie Hamburg oder Göttingen schafften derartige Reihen wieder ab, was mitunter darauf zurückzuführen ist, dass andere Orte sich darauf spezialisierten. Das Literaturhaus verweist auf Literatur vor allem in ihrer schriftlichen Form, die Veranstaltung stellt eine Auseinandersetzung damit dar und führt zur stillen Lektüre zurück. Dies zeigt sich noch stärker in Norwegen, weil es dort nicht einmal ausführliche Leseparts gibt. Die Ablösebewegung bei der Veranstaltung vom Text als Text ist dort, den Programmtexten folgend, klarer als in den deutschen Ankündigungen. Das Gespräch macht gegebenenfalls neugierig auf die anschließende Lektüre, der literarische Text steht aber bei den Veranstaltungen nicht als vorgetragene Kunst im Mittelpunkt.

Auf der anderen Seite offenbarte sich, dass das Literaturhaus sich nicht auf einen engen Literaturbegriff begrenzt, weil Sachbücher sowie andere Kunstsparten, vor allem Musik und Film, und weitere Disziplinen von Politik bis Sport neben belletristischer Literatur einen Platz erhalten. Diese disziplinäre Ausweitung gehörte bereits zur Gründungsidee des Literarischen Colloquiums Berlin 1963 und lässt sich als typisch für Literatur und Literaturvermittlung im technischen beziehungsweise digitalisierten Zeitalter identifizieren. Bei den Fallbeispielen in Skandinavien, wo die Kulturlandschaft insgesamt egalitärer ist, ${ }^{1470}$ überraschte die deutlichere Nebeneinanderstellung unterschiedlicher Kulturgegenstände noch weniger. Dies exemplifiziert, wie philologische Verfahren nicht mehr nur auf Literatur angewendet werden, sondern auf unterschiedliche Kunst- und Alltagsbereiche. ${ }^{1471}$ Die Vorstellung des Literaturhauses als Feuilleton lässt sich so durchaus begründen, denn es ist ,gerade die Eigenart des Feuilletons, daß es sich nicht eindeutig auf einen bestimmten Inhalt bzw. eine bestimmte Form festlegen läßt." ${ }^{1472}$ Bei Ausweitung auf andere Sparten ist gleichzeitig der Blick auf Literatur selbst deutlich enger. Die Auswahl des einzelnen Kunstwerks erfolgt nach ästhetischen Qualitätskriterien, dabei beschränken sich die Einrichtungen nicht auf literarische Texte, sondern legen eine Einordnung in einen künstlerisch-kulturellen Kontext nahe.

\section{3.3 Zwischen Literatur und Literaturvermittlung}

Das Literaturhaus erweiterte die literarische Praxis, indem es den Vermittlungsaspekt als sein zentrales Moment setzte. Es fanden sich bei den Programmanalysen keine Beispiele dafür, dass die Formate im Literaturhaus sich mit der Zeit grundlegend veränderten hin zu einer stärker spektakelorientierten Eventisierung - im Gegenteil ließ sich sehen, dass in den letzten Jahren viel häufiger ,klassische‘ Lesungen und Gespräche stattfanden. Allerdings lassen sich die Veranstaltungen in ihrer sozialen Rahmung und ihrer Flüchtigkeit selbst als Ausdruck der sogenannten Eventisierung begreifen und als empirischer Beleg dafür, dass Erlebnisorientierung das

\footnotetext{
1470 Vgl. Hoff und Rühling 2017, S. 27.

${ }^{1471}$ Dies führt Thomas Steinfeld in seinem Buch Der leidenschaftliche Buchhalter aus, vgl. Steinfeld 2004.

1472 Kauffmann 2000, S. 14.
} 
Interesse an Literaturvermittlung mittels Literaturveranstaltungen überhaupt begründete. Das Literaturhaus trug zu dessen Institutionalisierung bei, weil es eine Infrastruktur ausbildete, die den Literaturveranstaltungsbetrieb professionalisierte.

Die Veranstaltungen gehen meist von einem Buch und seiner stillen Lektüre aus, sie sind aber auch ohne vorherige Kenntnis des Textes oder nachgelagerte Lektüre rezipierbar. Bei den einzelnen Veranstaltungen zeigte sich im Vergleich, dass für Deutschland die Lesung als Baustein der Literaturveranstaltung in seiner speziellen Beschaffenheit wichtig ist. Das Gespräch macht allerdings wie in Skandinavien den entscheidenden Bestandteil aus, sodass zu fragen ist, ob die Lesung als solche noch gebraucht wird beziehungsweise welchen Zweck sie erfüllt. Sie wurde für den deutschen Kontext zum einen als Relikt der Lesungstradition erkannt, zum anderen als Zeichen dafür, dass das Literaturhaus sich explizit auch in den Dienst der unvermittelten Rezeption von Literatur stellt. Sie demonstriert, dass Literatur Kontemplation und Ruhe zugleich erfordert wie ermöglicht, was in einer beschleunigten Gegenwart wichtiger wird.

Die Lesung weist also wieder zur ausführlichen wie intensiven Lektüre. Die Vorstellung des ,Literaturhaus-Erfinders' Herbert Wiesner, dass diese Institution Werbung für das „eher einsame Erlebnis des Lesens“1473 mache und Vortrag, Diskussion und Moderation das Verständnis verbesserten, spricht dafür, die Veranstaltungen als Vermittlungsakte zu begreifen, die zur Praktik des stillen Lesens zurückführen. Andere Beiträge zum Thema sind eher der Ansicht, die Thomas Wegmann so formuliert: „Literatur inszeniert sich als Literatur auch jenseits der gedruckten Worte. “1474 Wie sich vor allem für die Entwicklung der letzten Jahre zeigen ließ, referenzieren die Veranstaltungen in den Literaturhäusern in der Regel auf eine gedruckte Publikation. Dies ist ein Argument dafür, die Veranstaltungen nicht selbst als Literatur zu verstehen, sondern als Literaturvermittlung, als Beiwerk, als Epitext. Dies widerspricht nicht der Forderung, die Literaturveranstaltung als eigene Praktik ernst zu nehmen und sie als der Literatur zugehörig zu interpretieren. Eine Veranstaltung dort ist immer ein Akt der Vermittlung, reine Immersion ohne diskursive Rahmung gibt es anders als in Theatern oder Konzerten selten.

Die Vermittlung geschieht dabei zum einen über die Interpretation des vorgelesenen Textes durch Stimme und körperliche Präsenz, zum anderen über die Einordnung durch das moderierte Gespräch. Vermittlung findet im Literaturhaus auBerdem als Wissensvermittlung über Vorträge, literarhistorische Themen oder im Kinderprogramm statt. Die Vermittlung des Wertes von Literatur erzeugt die Institution über ihre professionell-seriöse wie unterhaltsam-soziale Rahmung.

\section{Publikum}

Im Kontext von Literaturvermittlung spielen die Zuschauer*innen, die Zuhörer*innen natürlich eine entscheidende Rolle. Publikumsanalysen erscheinen sowohl für die weitere wissenschaftliche Beschäftigung mit Literaturhäusern als auch für die Einrichtungen selbst vielversprechend. Kenntnisse über die Bedürfnisse und Urteile

\footnotetext{
1473 Wiesner 2000, S. 311.

1474 Wegmann 2002, S. 133.
} 
der Besucher*innen müssen selbstverständlich nicht darin münden, dass die nichtgewinnorientierten Literaturhäuser nur noch Programm für die Mehrheit machen. Sie können hingegen die diskursiven Annahmen zum Kulturpublikum empirisch präzisieren. Diese könnten die Einrichtungen nutzen, um beispielsweise zu erkennen, ob die Personen, die sich für die Programminhalte interessieren, wirklich angesprochen werden, und ob die, die angesprochen werden, sich tatsächlich für die Programminhalte interessieren. Die Forschung könnte damit die Antwort auf die Frage schärfen, wer das Literaturhaus besucht und wie es rezipiert wird. Diesem ließe sich ebenfalls über Aufführungsanalysen näherkommen, bei denen allerdings weitere Einflussfaktoren berücksichtigt werden müssten und aufwendig sind, wenn Korpora bearbeitet werden, die verallgemeinerbare Aussagen ermöglichen. Die hier exemplarisch durchgeführten Textanalysen wiesen nach, dass die Veranstaltungsankündigungen voraussetzungsreich sind und sich sprachlich an ein akademisch gebildetes Publikum wenden, was mit den Selbstdarstellungstexten übereinstimmt, die ebenfalls besonders jene Kulturrezipient*innen ansprechen, die in einem Verweiszusammenhang etwa mit dem ,klassischen Feuilleton'stehen.

Die Frage, wer Literatur an wen wie vermittelt, wird die Literaturhäuser weiterhin beschäftigen. Aktuell wenden sie sich mit ihrem Erwachsenenprogramm an Literaturinteressierte. Herausforderung für die zukünftige Arbeit bleibt - auch jenseits von schwindenden Leserzahlen und stagnierenden Budgets -, wie sie dort Interesse für Literatur generieren können, wo es zu verschwinden droht oder bisher nicht vorhanden war, und wie sie zugleich das existierende Interesse befriedigen und verstärken können.

\section{3.4 Zwischen Kunst, Debatte und Ökonomie}

Schon in den Anfangsjahren präsentierten die Literaturhaus-Programme einerseits auf stilistische Gesichtspunkte von Literatur und Sprache ausgerichtete Veranstaltungen und andererseits inhaltsfokussierte Diskussionen gesellschaftspolitischer Fragestellungen. Im Gegensatz zur politisch engagierten Literatur der 1970er-Jahre wurden die literarischen Texte kaum selbst für Inhaltsdiskussionen eingesetzt. Diese Tendenz prägt die deutschen Literaturhäuser weiterhin. In den bisherigen Forschungsbeiträgen wurde seltener als eine strukturelle Ähnlichkeit mit dem literarischen Salon eine Verbindung des Literaturhauses zu einer Avantgarde gesehen, die den Auftritt als Teil des künstlerischen Ausdrucks verstand und in den 1980erJahren sprachkritische experimentelle Texte erzeugte. Diese Traditionslinie etwa der Konkreten Poesie wird weder anhand von Konzeptbeschreibungen deutlich, noch ergibt sie sich aus den gegenwärtigen Programmen; sie offenbart sich erst bei den in der vorliegenden Arbeit erstmalig durchgeführten auch historischen Programmanalysen. In den vergangenen Jahren spielte diese Art von Literatur in den Literaturhäusern wie im Literaturbetrieb insgesamt kaum noch eine Rolle, sie ist aber für die Institution wichtig, weil das Literaturhaus sich zunächst in einer experimentelleren Nische platzierte. Die frühen deutschen Literaturhäuser entstammen also einer kunstfokussierten Tradition der avantgardistisch-modernistischen Literatur, die sich 
von der politisch-agitatorischen Literaturproduktion der 1970er- und frühen 1980erJahre abgrenzte und den Text als erlebbares Kunstwerk revitalisierte.

Zugleich zeigen die Ankündigungstexte zu den einzelnen Veranstaltungen, dass die Literaturhäuser Argumente für den Topos von Literatur als Gesellschaftsseismograf vertreten. Literatur wird eine gesellschaftsbildende Funktion zugeschrieben. In den ersten Jahren noch stärker war diese selbst explizit Anlass zum Gespräch und beispielsweise zum Auftakt der Reihe Kunst und Moral die „Frage nach der Moral in der Literaturdebatte wieder da“ (HH 1992-03-13). Allerdings wurden im deutschen Kontext gesellschaftspolitische Fragstellungen nicht direkt mittels literarischer Texte thematisiert, sondern in Diskussionsformaten und Vorträgen behandelt. In den norwegischen Einrichtungen scheinen politisch relevante Wertungskriterien ästhetische zu überragen, es geht stärker um das Wort generell als um die Literatur als Kunstästhetik.

Grob gefasst: Die deutschen Literaturhäuser schaffen einen Zugang zur Literatur, der zunächst darauf achtet, dass es sich um einen literarischen Text, der für sich selbst steht, handelt, dem in einem nächsten Schritt auch Gesellschaftsrelevanz zugeschrieben wird. In Norwegen steht die Frage, wie der Text über sich hinaus auf dieses und jenes Thema weist, am Anfang. In den norwegischen Literaturhäusern ist Literatur demnach bisher weniger ihrer selbst willen Gegenstand, sondern Anlass für die Verhandlung von inhaltlichen Fragestellungen. Das sichtbarere politische Handeln von Litteraturbuset, vor allem in Oslo, ist ein Beleg für die Hypothese, dass die norwegischen Literaturhäuser stärker als die deutschen in gesamtgesellschaftliche Sujets involviert sind. Dies liegt unter anderem daran, dass die Stiftung Fritt Ord das Osloer Haus maßgeblich und das Bergener Haus unterstützend finanziert und damit Meinungs- und Ausdrucksfreiheit als zentrale Werte vermittelt werden. Zudem sind sie damit symptomatisch für das dortige Literaturverständnis, das seit den Veröffentlichungen des sogenannten Modernen Durchbruchs, aber auch des fortgesetzten sozialrealistischen Schreibens der 1970er- und 1980er-Jahre in enger Verbindung mit gesellschaftsbildenden Ansprüchen steht. Hanna Eglinger sieht das in den letzten Jahren gar verstärkt und spricht von einer Tendenz der Politisierung der Literatur in Skandinavien, denn seit der 2000er-Wende finde eine differenzierte Auseinandersetzung mit dem eigenen politischen System und den Lebensbedingungen des Wohlfahrtsstaates statt. ${ }^{1475}$ So sei von einer „Vermischung von literarischer, politischer, populärer und massenkultureller Öffentlichkeit" ${ }^{\text {"1476 }}$ auszugehen. Britt Dahlström hält für Schweden fest, dass Literarische Gesellschaften - „,vår tids folkrörelser"1477 [die Volksbewegungen unserer Zeit] - die Rolle der Volksbewegungen übernehmen; Litteraturhuset ist definitiv vergleichbar zu kontextualisieren. Der folgende Satz im Schlusskapitel von Trond Andreassens literatursoziologischer Studie über den Buchmarkt Norwegens demonstriert das Selbstverständnis, das Literatur in Norwegen sehr stark mit gesellschaftspolitischen Intentionen verbunden wird,

\footnotetext{
1475 Vgl. Eglinger 2016, S. 402.

1476 Ebd., S. 391.

1477 Dahlström 1996, S. 12.
} 
obwohl die Beeinflussung der Produktion von Kunst durch ökonomische Belange nicht ausgeblendet wird. Die Literatur

vil da lettere bli offer for krefter som tenker mer i økonomiske termer enn ti fordel for bokens rolle som bærer av norsk skriftkultur og som et redskap for utviklingen av demokratiet. ${ }^{1478}$

[wird da leichter Kräften zum Opfer fallen, die mehr in ökonomischen Begriffen denken als zugunsten der Rolle des Buches als Träger norwegischer Schriftkultur und als ein Instrument für die Weiterentwicklung der Demokratie.]

Die Diskussionen vor Eröffnung des Literaturhauses in Bergen offenbarten zudem, dass sich die sich wiederholende Debatte über Schönliteratur versus Demokratisierung und Politisierung anhand des Literaturhauses aufgreifen lässt. Die Divergenz zwischen künstlerischen Interessen der Autor*innen und kulturpolitischen Absichten spitzt Skaftnesmo mit der Beschreibung des Literaturhauses mit den Schlagworten ,Salong' [Salon] und ,Samfunnshus' [Gesellschaftshaus] zu. ${ }^{1479}$ Während eine Fraktion für eine kunstorientierte salonähnliche Ausgestaltung des Literaturhauses plädiere, die dem LiteraturHaus in Kopenhagen oder der Ursprungsvariante in Berlin ähnelt, spreche sich ein anderes Lager für ein Gesellschaftshaus aus, das Literatur und genereller das Wort mit politischer Debatte verknüpft sieht, wie es das Litteraturbuset in Oslo umsetzt. Beide Positionen finden sich in unterschiedlichem Ausmaß in jedem Literaturhaus wieder. Im Literaturhaus zeigt sich weiterhin eine Spannung zwischen ,Ästhetik ${ }^{6}$ und ,Debatte', die bereits für die Anfangsjahre der Institution herausgearbeitet werden konnte und literarische Diskussionen immer wieder beschäftigt.

Die Auseinandersetzung mit den deutschen und skandinavischen Literaturhäusern lässt prognostizieren, dass gesellschaftliche Diskussionen zunehmend in die Programme der Institution integriert werden - gleichzeitig bleibt die ästhetische Beschäftigung mit Literatur zentral. Interessant ist, wie ich in Gesprächen erfahren habe und wie es bei den Programmanalysen anklang, dass einige deutsche Literaturhäuser sich aktuell damit befassen, wie sie sich stärker politisch engagieren können, während sich die norwegischen Literaturhäuser fragen, wie die ästhetische Seite von Literatur mehr zur Wirkung gebracht werden könne. Zu diesen Überlegungen kann die vorliegende Arbeit beitragen, weil sie die traditionelle Verwurzelung der Häuser klar macht und so Anschlüsse bietet, inwiefern etwa Transfers einzelner Programmideen im Zweitkontext fruchten könnten.

Am Beispiel des Literaturhauses lassen sich also grundlegende Fragen von Literaturvermittlung diskutieren: Wird Literatur als Anstoß zur Debatte benutzt oder als Kunstwerk rezipiert? Die Frage lässt sich aufsplittern in weitere anscheinende Gegensatzpaare von Kunst als Anstrengung und Kunst als Unterhaltung; von Literatur, die zur Debatte instrumentalisiert wird, und Texten, die selbst Themen explizit setzen. Diese Überlegungen führen zurück zur Institution und zur Frage, was ein Literaturhaus ist und sein will: Das Literaturhaus als experimenteller Salon? Als konsumbasierte Verkaufsbörse? Als debattenorientierte Arena? Als bildungsfokussiertes Gemeinschaftshaus? Als unterhaltungsbetontes Freizeitprogramm? Als Raum sozia-

1478 Andreassen 2006, S. 552.

1479 Vgl. Skaftnesmo 2014, S. 121 sowie Skaftnesmo 2016, S. 39-40. 
ler Distinktion? Als Raum gesellschaftlicher Inklusion? Die vorliegende Arbeit legt nahe, dass dabei keine dichotome Entscheidung gefällt werden muss, dass aber etwa die offensive Selbstdarstellung des Litteraturbuset in Oslo als Debattenarena, die in Über-uns-Texten, in Interviews, in der Programmgestaltung wie in den Veranstaltungstexten konsequent auftaucht, dazu beiträgt, dass eine klare Positionierung des Literaturhauses erkennbar wird. Und nur was erkennbar ist, lässt sich von außen vom Publikum, von Geldgeber*innen oder, wie hier gezeigt, von der Wissenschaft auch wahrnehmen und aufgreifen.

\section{3.5 Zwischen Text und Autor*in}

Anfangs stand außerdem die Frage, die bei den Überlegungen zur Funktion des Literaturhauses nicht aus dem Blick verloren werden sollte, ob dort literarische Texte oder Autor*innen in den Mittelpunkt rücken. Nach den Fallstudien lässt sich die Vermutung unterstützen, dass im Literaturhaus-Programm sowohl Autor*innen als auch Texte Literaturvermittlungsobjekte darstellen und es nicht zu einer Trennung von Autor*in und Werk kommt. Dass dies keine grundsätzlich überraschende Beobachtung ist, zeigte die hier durchgeführte exemplarische Betrachtung der geografischen Verortung der vorgestellten Texte und Autor*innen, denn gerade bei der Frage nach der internationalen Ausrichtung ist zentral, woher die Verfasser*innen kommen und in welcher Sprache sie schreiben. Der empirische Autor fungiert als Moment zur Einordnung der Literatur. Darüber hinaus ist anzumerken, dass das Interesse an Autor*innen nicht grundsätzlich neu ist, wie das folgende Zitat Wilfried Webers aus dem Jahr 1992 belegt. Allerdings beleben die Literaturhäuser nach den politisch-engagierten 1970ern und den kunstbezogenen 1980ern Anfang der 1990erJahre das Interesse wieder, Autor*innen als Autor*innen zu begegnen.

Desweiteren sollte man nicht vergessen, daß das Interesse an öffentlicher Literaturvermittlung starken modischen Schwankungen ausgeliefert ist. In den 60er Jahren waren Podiumsdiskussionen und Signierstunden der Renner auf diesem Gebiet. Diese Veranstaltungsformen zeigten dann starke Verschleißerscheinungen, und erst heute [1992, Anmerkung C. L.] belebt sich wieder - bei der nächsten Generation die Neugier auf die lebendigen, zeitgenössischen Autoren, auf die Begegnung mit ihnen. ${ }^{1480}$

Diese Neugier auf Gegenwartsautor*innen lässt sich mehr als 25 Jahre später nach wie vor festhalten - in den letzten Jahren gar verstärkt, was hier in Zusammenhang mit den Entwicklungen im Zeitalter der Digitalisierung gesetzt wurde. Die Erwähnung biografischer Informationen und die eingesetzten fotografischen Porträts in den Programmheften unterstreichen, dass die Autor*innen als Personen eine zentrale Rolle im Prozess der Literaturvermittlung einnehmen. Die Weiterführung der von Michel Foucault benannten Autorfunktion im literaturwissenschaftlichen Diskurs und die Analyse der Selbstinszenierung von Autor*innen als Paratexte beziehungsweise Epitexte haben, Christine Künzel zufolge, „den Effekt, den Aspekt der Körperlichkeit zu verdrängen“"1481. Dabei solle nicht vergessen werden, dass es

\footnotetext{
1480 Weber 1992, S. 422.

1481 Künzel 2007, S. 10-11.
} 
sich bei Schriftsteller*innen um ,leibhaftige' Personen handele. Darauf, dass der physischen Anwesenheit Bedeutung zukommt, lässt sich bei den untersuchten Literaturhäusern weniger aufgrund der Veranstaltungsankündigungen schließen, sondern ist vielmehr an den ebenfalls analysierten Selbstdarstellungstexten ablesbar, die die im Literaturhaus mögliche Begegnung deutlicher betonen, und an der Konzeption vieler Literaturhäuser als Kombination aus Veranstaltungsort und Gastronomiebetrieb erkennbar. Besonders die Rahmung durch das umfassende Literaturhaus hebt diesen Aspekt hervor.

Das Interesse an den Autor*innen als Personen im Sinne eines Starkults zeigte sich nicht so klar wie vermutet. Das untersuchte Material stellt hingegen eine Begegnung auf Augenhöhe zwischen Leser*innen und Autor*innen in Aussicht. Die verschiedenen Bühnenarrangements verdeutlichten unterschiedlich eindeutig, dass die Akteur*innen auf dem Podium statt unerreichbar erhöht oder theatral distanziert als authentische Gesprächspartner*innen wirken sollen. Weiterhin wird aber eine klare Trennung zwischen Autor*innen und Leser*innen aufrechterhalten. Eine Art Ehrfurcht seitens des Publikums den Künstler*innen gegenüber, die gekoppelt ist mit einer Neugier auf die Personen ,hinter den Texten', die sich beim Signieren nach Veranstaltungen und bei Fragen aus dem Publikum äußert, lässt sich stärker bei den Veranstaltungen selbst entdecken. Aus dem vom Literaturhaus veröffentlichten Material ist dieser Aspekt nicht herauszulesen, weshalb es wichtig ist, mehrere Untersuchungsdimensionen in die Betrachtung einzubeziehen und mit Praxiswissen die aus dem Material gezogenen Schlüsse abzusichern, um ein vollständigeres Bild zu erhalten.

Das Literaturhaus insgesamt ist als Beispiel dafür anzusehen, dass der Aspekt der Mündlichkeit und vor allem die auditive Rezeption von Literatur in den letzten Jahrzehnten wieder an Bedeutung gewonnen haben. Allerdings offenbart die hier herausgearbeitete Entwicklung der Veranstaltungsformate, dass es dabei auf das klangliche Kunsterlebnis nur noch untergeordnet ankommt. Treffender erscheint es hier aufgrund der Anwesenheit der Autor*innen beim Gespräch, von einer ,Renaissance der Authentizität ${ }^{6} 1482$ auszugehen. Diese ist im Zusammenhang mit dem ,Tod des Autors' und seiner Wiederkehr ebenfalls zum feuilletonistischen wie literaturwissenschaftlichen Schlagwort der letzten Jahre geworden. ${ }^{1483}$ „Teilt Authentizität somit das Schicksal jener Begriffe, die zwar auf theoretischer Ebene ,dekonstruiert werden, deren Relevanz davon allerdings nicht beeinträchtigt wird?“"1484 Hier lautet die Antwort: Ja, denn wie sich bei den Analysen der Formate gezeigt hat, nimmt die für sich stehende Präsentation von Literatur als Kunst, die in den Anfangsjahren im Literaturhaus noch wichtiger war, ab zugunsten des ,Kennenlernens ${ }^{6}$ der Autor*innen. Die Betonung liegt auf dem Gespräch, in dem die Autor*innen mit Aussagen und Urteilen ebenfalls jenseits ihrer literarischen Texte erlebbar sind. Allerdings bleibt der literarische Text relevant und ist in der Regel Anlass für einen Besuch. Dass Literatur weiterhin die zentrale Rolle spielt, markiert ferner die Tatsa-

\footnotetext{
1482 So lautet auch der Titel eines Sammelbandes, vgl. Rössner und Uhl (Hg.) 2012.

1483 Vgl. Knaller und Müller 2006, S. 7. Sie rekapitulieren in ihrer Einleitung außerdem die Begriffsgeschichte und stellen die Verbindung zum Terminus, Originalität ${ }^{\star}$ heraus, vgl. ebd., S. 13.

1484 Rössner und Uhl 2012, S. 10.
} 
che, dass nicht nur Autor*innen, sondern auch Literaturkritiker*innen oder andere mit Literatur professionell Tätige auf den Literaturhaus-Podien zu Wort kommen.

Die Anwesenheit der Autor*innen hat weitreichende Konsequenzen für die Funktion des Literaturhauses als Ort der Literaturkritik, denn sie kann, wie die Überlegungen zu literaturkritischen Veranstaltungsreihen vorführten, dem Gespräch auf der Bühne die kritische Auseinandersetzung mit dem Buch entziehen. Umso wichtiger ist es für die Literaturhäuser, die als Veranstaltungsgegenstand geplanten Publikationen vorab kritisch zu prüfen. Allerdings ist aufgrund der erwähnten zunehmend langfristigeren Planung und der zeitlichen Nähe von Erscheinungstermin und Veranstaltungsdatum anzunehmen, dass Novitäten von bekannten Autor*innen gelegentlich ,blind' gebucht werden. Durch die Entwicklung des Literaturbetriebs dahin, möglichst zeitnah nach Veröffentlichung die Veranstaltungen durchzuführen, was sich vor allem auf aufmerksamkeitsökonomische Gründe zurückführen lässt, wird die hohe Bedeutung des Autorennamens als Marke sehr klar. Weil die vorherigen Titel der Autor*innen geschätzt wurden, entweder nur von der LiteraturhausLeitung oder auch von einer größeren Gruppe, und damit im Vertrauen darauf, dass auch die neue Publikation Erfolg verdient, erhalten die Schriftsteller*innen wieder eine Einladung und ihre Bücher damit Aufmerksamkeit, womit die Rolle des Literaturhauses in Kanonisierungsprozessen aufscheint.

Literaturkritik auf das Podium bringen explizit darauf ausgerichtete Diskussionsformate, bei denen professionelle Leser*innen über mehrere Titel sprechen, disputieren, streiten. Diese ermöglichen es, das Gespräch über Literatur losgelöst von den Autor*innen zu führen und damit die enge Verbindung von Autor*in und Werk, die im Literaturhaus besonders betont wird, etwas zu lockern. Dass vergleichbare Formate in letzter Zeit eher mehr als weniger werden, weist darauf hin, dass Interesse daran besteht, dass im Literaturhaus auch eine dezidiert kritische Auseinandersetzung mit Literatur stattfindet. Diese Formate vermitteln implizit Praktiken des Wertens, durch die das Publikum Literatur zu beurteilen und zu schätzen lernt - eine wichtige Voraussetzung für die Teilhabe an der literarischen Praxis, für die das Literaturhaus prototypisch steht. Und zugleich kann es unterhaltsam sein, einer lebhaften Diskussion beizuwohnen.

\section{4 Zwischen Einzelfall und Institution}

Schon bei der Vorstellung der ausgewählten Literaturhäuser bestätigte sich die Ausgangsannahme, dass die Einrichtungen vereinigend als ,Institution Literaturhaus beschrieben werden können. Hilfreich war es in diesem Fall, dass sich der Ursprung der Institution auf eine einzelne Einrichtung zurückführen ließ. Es hat sich erwiesen, dass die Institution seit der Gründung des Literaturbauses Berlin 1986 ihre Grundidee über die Jahre gefestigt und ihre Position im Literaturbetrieb konsolidiert hat. Zugleich lassen sich insbesondere im letzten Jahrzehnt, angefangen mit dem Transfer nach Skandinavien, diverse Ausprägungen des Literaturhauses verzeichnen. ,Literaturhaus' hat sich dabei als Funktionsbegriff etabliert. Mit der Wahl, einen 
neuen Ort der Literaturvermittlung mit dieser Bezeichnung zu benennen, schreibt sich diese Einrichtung in den Institutionskontext ein. Dieser bietet keine klare Definition davon, was ein Literaturhaus ist oder zu sein hat, im Gegenteil ist er als Aushandlungsraum zu verstehen, der mit seinen unterschiedlichen konkreten Realisierungen absteckt, was ein Literaturhaus im Einzelnen sein kann. Die verschiedenen Programmatiken weisen jedoch die entscheidende Gemeinsamkeit auf, dass es vorrangig um die Vermittlung von Gegenwartsliteratur mittels Veranstaltungen an ein Publikum geht. Der analog erreichbare Ort stellt dabei eine entscheidende Komponente dar. An dieser Basis hat sich seit 1986 wenig geändert.

Die jeweils spezifischen Ausprägungen der einzelnen Literaturhäuser sind im Verlauf ebenso herausgekommen wie die grundsätzlichen Gemeinsamkeiten. Bei allen untersuchten Literaturhäusern ließ sich ein eigenes Profil erkennen, das in enger Verbindung mit den örtlichen Gegebenheiten, der finanziellen Ausstattung, der Interaktion mit lokalen Akteur*innen und der kulturellen Umwelt sowie den jeweils wirkenden Personen steht. Die individuellen Eigenarten lassen sich in anschließenden Studien noch genauer herausarbeiten. Die vergleichende Perspektive konzentrierte sich vor allem darauf, verallgemeinernde Aussagen zum Literaturhaus zu treffen. Die Darstellung als ,Institution Literaturhaus' bot einen geeigneten Rahmen, weil einerseits die Einzeleinrichtungen zueinander in Relation gestellt werden konnten und andererseits die Institution Literaturhaus mit anderen Akteur*innen des Kulturbetriebs zusammengebracht werden konnte. Diese Strukturierung ist nicht nur auf das Literaturhaus anwendbar und bietet mit ihrem Fokus auf die Mesoebene Anschlussmöglichkeiten für andere Forschungsgegenstände.

Die Einzeleinrichtung ebenso wie die Institution führt einen Balanceakt zwischen Alleinstellungsmerkmalen und Gruppen- beziehungsweise Kulturbetriebszugehörigkeit aus. Zugleich stehen die einzelnen Häuser zueinander in einem Verhältnis aus Konkurrenz und Koalition. Dabei ist es für sie von Vorteil, dass sie vor allem für ein lokales Publikum Programm machen. Sie stehen also miteinander in keinem direkten Wettbewerb um Besucher*innen, rivalisieren jedoch um überregionale Anerkennung und zum Teil um beliebte Autor*innen und ihre begrenzten Auftrittstermine. Zusammen arbeiten einige von ihnen konkret im Netzwerk der Literaturbäuser, das gemeinsame Projekte realisiert und Austauschmöglichkeiten bietet. Auf einer theoretischen Ebene interagieren Literaturhäuser über das Konstrukt der Institution. Der Bezug zum übergeordneten Konzept verschafft ihnen Legitimation, weil sie nicht nur als ,Einzelkämpfer' zu betrachten sind. Dies wurde am Osloer Beispiel und dessen Verweis auf das, deutsche Literaturhaus' deutlich, ebenso wie dadurch, dass die Bergener Einrichtung explizit auf Oslo referenziert oder dadurch, dass das Literarische Zentrum Göttingen seine Mitgliedschaft im Netzwerk der Literaturhäuser hervorhebt.

Die Entstehung und Weiterentwicklung des Literaturhauses gründen auf Veränderungen im Literaturbetrieb und prägen diese zugleich mit. In Norwegen deckten die Literaturhäuser einen Mangel bei den öffentlichen Bibliotheken auf, indem sie mit einem aus einem anderen Kulturraum inspirierten Vermittlungskonzept auf die Relevanz und Chancen von Literaturveranstaltungen hinwiesen und ein Bedürfnis be- 
friedigten, dass die existierenden Institutionen noch nicht erfüllten. Die Entstehung der Literaturhäuser stellte dann auch die Funktion der Bibliotheken zur Diskussion und trug somit zu einem Wandel einerseits der transnationalen Institution Literaturhaus, andererseits der norwegischen Bibliotheken bei. Litteraturbuset, die norwegische Variante des Literaturhauses, entstand Ende der Nullerjahre, nahm sich die deutschen Häuser zum Vorbild und modifizierte die Konzepte für den norwegischen Kontext und ihre Gegenwart. Es entwickelte die Vorgänger also direkt weiter. Die deutschen Einrichtungen hingegen sind stärker von ihren eigenen Traditionen geprägt, sodass sie auf den ersten Blick behäbiger wirken. Die diachrone Perspektive dieser Arbeit legte aber offen, dass sie dabei sind, ihre Grundkonzeption für die Jetztzeit zu aktualisieren. Auch in Deutschland entstehen weitere Literaturhäuser, wechseln mit Leitungspersonen die Profile, entwickeln die Verantwortlichen die Programmatiken weiter. Es lohnt sich folglich, die Institution Literaturhaus als Ausdruck gegenwärtiger Literaturvermittlung weiterhin zu beobachten.

In Bewegung bleibt die Institution, indem sie die potenziellen Positionierungen, eventuell divergierenden Handlungsoptionen und Spannungsverhältnisse gar als ihren Antrieb anerkennt und sich nicht für eine Seite klar und ein für alle Mal entscheidet, sondern ständig abwägt zwischen Tradition und Innovation, Konkurrenz und Koalition, Ästhetik und Debatte, Gefallen und Protest und somit multiperspektivisch bleibt - wie die Literatur selbst. ,Literaturhaus' ist keine geschützte Bezeichnung und dennoch, wie diese Arbeit zeigen konnte, ein nützliches Konzept, eine Marke. Eine Dachmarke für Literatur. 



\section{Literaturverzeichnis}

Alphabetische Sortierung nach erstem Autorennamen beziehungsweise nach Titel, dann nach Jahr. Skandinavische Buchstaben werden wie deutsche Umlaute eingeordnet. Elektronische Quellen sind die Dokumente, die (vermutlich) nicht gedruckt erschienen sind. Sofern gedruckte Publikationen online verfügbar sind, ist dies mit angegeben.

\section{1 Gedruckte Publikationen}

Abel, Julia: „Übersetzung““. In: Zymner, Rüdiger und Hölter, Achim (Hg.): Handbuch Komparatistik. Theorien, Arbeitsfelder, Wissenspraxis. Stuttgart, Weimar: Metzler 2013, S. 134-138.

Adloff, Frank: „Kollektives Handeln und kollektive Akteure“. In: Jaeger, Friedrich und Straub, Jürgen (Hg.): Handbuch der Kulturwissenschaften. Band 2. Paradigmen und Disziplinen. Stuttgart, Weimar: Metzler 2004, S. 308-326.

Allwörden, Hubertus von: Die Geschichte der Stadtbibliothek in Frankfurt am Main. Frankfurt am Main: Literaturhaus Frankfurt e. V. 2006.

Almbjerg, Sarah-Iben: „Kunstnerisk ledelse forlader litteraturhus“. In: Berlingske 20.11.2017. Online verfügbar, URL: www.b.dk/kultur/kunstnerisk-ledelse-forladerlitteraturhus (Stand: 30.08.2018).

Amt für Statistik Berlin-Brandenburg: „Einwohnerwachstum in Berlin setzt sich auch 2017 fort", Pressemitteilung 23.08.2017. Online verfügbar, URL: www.statistikberlin-brandenburg.de/pms/2017/17-08-23.pdf (Stand: 30.08.2018).

Andersen, Carsten: „Litteraturhus i København“. In: Politiken 02.11.2000.

Andersen, Carsten: „Litterær appetitvækker“. In: Politiken 07.05.2001a.

Andersen, Carsten: „Litteraturhus deler vandene“. In: Politiken 08.05.2001b.

Andersen, Patrick Lie und Ljunggren, Jørn: „Gylne ghettoer. Inntektselitens bostedssegregering i Oslo, 1980-2005“. In: Korsnes, Olav et al. (Hg.): Elite og klasse i et egalitart samfunn. Oslo: Universitetsforlaget 2014, S. 126-143.

Andre, Thomas: „Kultur: Das literarische Hamburg streitet“. In: Hamburger Abendblatt 22.09.2015.

Andreassen, Trond: Bok-Norge. En litteratursosiologisk oversikt. 3. Auflage. Oslo: Universitetsforlaget 2006.

Arnold, Heinz Ludwig: Die Gruppe 47. Ein kritischer Grundriss. 2., gründlich überarbeitete und erweiterte Auflage. München: Edition Text + Kritik 1987.

Arsberetning for Stiftelsen Litteraturbuset 2012. Hg. von Stiftelsen Litteraturhusets styre. Oslo: Litteraturhuset 2013.

Atkinson, Paul und Silverman, David: „Kundera's Immortality. The Interview Society and the Invention of the Self“. In: Qualitative Inquiry (1997), Nr. 3, S. 304-325.

Aubert, Marie G.: „35 forfattere skal pryde Litteraturhuset“. In: Aftenposten 05.10.2007. 
Audunson, Ragnar: „Biblioteket er noe mer enn litteraturhus“. In: Bok og Bibliotek (2014), Nr. 1, S. 22-23.

Auffermann, Verena (Hg.): Beste deutsche Erzähler 2000. Eine Anthologie. Stuttgart: Deutsche Verlags-Anstalt 2000.

Autsch, Sabiene; Grisko, Michael und Seibert, Peter (Hg.): Atelier und Dichterzimmer in neuen Medienwelten. Zur aktuellen Situation von Künstler- und Literaturbäusern. Bielefeld: Transcript 2005.

Bachleitner, Norbert und Wolf, Michaela: „Einleitung. Zur soziologischen Erforschung der literarischen Übersetzung im deutschsprachigen Raum“. In: Bachleitner, Norbert und Wolf, Michaela (Hg.): Streifzüge im translatorischen Feld. Zur Soziologie der literarischen Übersetzung im deutschsprachigen Raum. Wien, Münster: Lit 2010, S. 7-29.

Bachmann-Medick, Doris: „Iconic turn“. In: Nünning, Ansgar (Hg.): Metzler Lexikon Literatur- und Kulturtheorie. Ansätze - Personen - Grundbegriffe. 4., aktualisierte und erweiterte Auflage. Stuttgart, Weimar: Metzler 2008, S. 300-301.

Bachmann-Medick, Doris: Cultural turns. Neuorientierungen in den Kulturwissenschaften. 3., neu bearbeitete Auflage. Reinbek bei Hamburg: Rowohlt Taschenbuch 2009.

Bähr, Julia: „Und der Schwertfisch, der hat Zähne. Mach nie die Rechnung ohne den Wirt: Die deutschen Literaturhäsuer und ihre Gastronomie“. In: Frankfurter Allgemeine Zeitung 01.11.2006.

Balke, Florian: „Lauter weiße Programmblätter“. In: Frankfurter Allgemeine Zeitung 11.05.2010.

Balke, Florian: „Böse Menschen haben keine Bücher“. In: Frankfurter Allgemeine Zeitung 24.03.2015.

Barke, Jörn: „Jenseits der Event-Kultur. Literarisches Zentrum. Start mit einer Lesung im Deutschen Theater“. In: Göttinger Tageblatt 03.05.2000.

Barner, Wilfried: „Einführung“. In: Barner, Wilfried (Hg.): Literaturkritik. Anspruch und Wirklichkeit. Stuttgart, Weimar: Metzler 1990, S. 1-7.

Barth, Bertram; Flaig, Berthold Bodo; Schäuble, Norbert und Tautscher, Manfred (Hg.): Praxis der Sinus-Milieus ${ }^{\circledR}$. Gegenwart und Zukunft eines modernen Gesellschafts- und Zielgruppenmodells. Wiesbaden: Springer VS 2018.

Barthes, Roland: Die Lust am Text. Aus dem Französischen von Traugott König. Frankfurt am Main: Suhrkamp 1974.

Barthes, Roland: „Der Tod des Autors“. Aus dem Französischen von Matias Martinez. In: Jannidis, Fotis et al. (Hg.): Texte zur Theorie der Autorschaft. Stuttgart: Reclam 2000, S. 185-193.

Bartmann, Christoph: „Dicht am Dichter. Die Lesung als Ritual und Routine“. In: HillZenk, Anja und Sousa, Karin (Hg.): To read or not to read. Von Leseerlebnissen und Leseerfahrungen, Leseförderung und Lesemarketing, Leselust und Lesefrust. München: Iudicium 2004, S. 120-129.

Basse, Michael und Pfeifer, Eckard: Literaturwerkstätten und Literaturbüros in der Bundesrepublik. Ein Handbuch der Literaturförderung und der literarischen Einrichtungen der Bundesländer. Lebach: J. Hempel 1988. 
Baumann, Stefanie: Literaturförderung im kulturpolitischen Kontext. Die Arbeit der Literaturbüros in Deutschland. Hg. von Otfried Hoppe und Markus Pohlmann. Lüneburg: Universität Lüneburg, Fachbereich Kulturwissenschaften 1995 (=Kulturarbeit und Kulturmanagement 7).

Baur, Joachim: „Was ist ein Museum? Vier Umkreisungen eines widerspenstigen Gegenstands". In: Baur, Joachim (Hg.): Museumsanalyse. Methoden und Konturen eines neuen Forschungsfeldes. Bielefeld: Transcript 2010, S. 15-48.

Bausch, Mechthild und Briegleb, Till: „,Chance auf ein anregendes Gespräch‘. Ursula Keller, zukünftige Programmchefin im Literaturhaus setzt auf Qualität, Kontroverse und vor allem auf sich selbst“. In: taz 31.10.1991.

Beilein, Matthias: „Sehr interessant. Über einige spezifische Problem der Beschäftigung mit und Bewertung von Gegenwartsliteratur"“. In: Bierwirth, Maik et al. (Hg.): Doing contemporary literature. Praktiken, Wertungen, Automatismen. München: Wilhelm Fink 2012, S. 41-51.

Beilein, Matthias; Stockinger, Claudia und Winko, Simone (Hg.): Kanon, Wertung und Vermittlung. Literatur in der Wissensgesellschaft. Berlin, Boston: De Gruyter 2012.

Beilein, Matthias; Stockinger, Claudia und Winko, Simone: „Einleitung. Kanonbildung und Literaturvermittlung in der Wissensgesellschaft". In: Beilein, Matthias et al. (Hg.): Kanon, Wertung und Vermittlung. Literatur in der Wissensgesellschaft. Berlin, Boston: De Gruyter 2012, S. 1-15.

Beilein, Matthias: „Der Literaturbetrieb“. In: Beutin, Wolfgang et al. (Hg.): Deutsche Literaturgeschichte. Von den Anfängen bis zur Gegenwart. 8., aktualisierte und erweiterte Auflage. Stuttgart, Weimar: Metzler 2013, S. 585-598.

Beilein, Matthias und Stockinger, Claudia: „Literatur und Digitalisierung. Editorial“. In: Zeitschrift für Germanistik (2017), Nr. 2, S. 233-238.

Benzinger, Fredrik: Die Tagung der, Gruppe 47`in Schweden 1964 und ibre Folgen. Ein Kapitel deutsch-schwedischer Kultur- und Literaturberiehungen. Stockholm: Germanistisches Institut, Universität Stockholm 1983.

Berbig, Roland und Brandes, Vanessa: „„Ich begrüsse Ilse Aichinger und Günther Eich' - Höllerers Hörsaal-Lesereihe 1959/60. Ein Beitrag zur Typologie von Dichterlesungen“. In: Geisenhanslüke, Achim und Hehl, Michael Peter (Hg.): Poetik im technischen Zeitalter. Walter Höllerer und die Entstehung des modernen Literaturbetriebs. Bielefeld: Transcript 2013, S. 65-96.

Berg, Antje vom: „Die Gruppe 47 und die Institution Kritik“. In: Gendolla, Peter und Leinecke, Rita (Hg.): Die Gruppe 47 und die Medien. (=Massenmedien und Kommunikation: MuK 114/115). Siegen: Fachbereich 3, Sprach- und Literaturwissenschaften, Universität-Gesamthochschule Siegen 1997, S. 87-101.

Bernhofer, Edith; Friedmann, Thomas und Huez, Robert (Hg.): Zwischen Schreiben und Lesen. Über Situation, Herausforderungen und Möglichkeiten von Literatur und Literaturvermittlung in Österreich. Wien: Klever 2016.

Berrenberg, Christian: ,Es ist deine Pflicht zu benutzen, was du weißt!!. Literatur und literarische Praktiken in der norwegischen Arbeiterbewegung 1900-1931. Würzburg: Ergon 2014.

Bers, Anna und Trilcke, Peer (Hg.): Phänomene des Performativen in der Lyrik. Systematische Entwürfe und historische Fallbeispiele. Göttingen: Wallstein 2017. 
Bessing, Joachim; Kracht, Christian; Nickel, Eckhart; Schönburg, Alexander von und Stuckrad-Barre, Benjamin von: Tristesse royale. Das popkulturelle Quintett. Berlin: Ullstein 1999.

Bibliotekutvikling.no. Nasjonal bibliotekstrategi 2015-2018. Oslo: Nasjonalbiblioteket 2014. Online verfügbar, URL: bibliotekutvikling.no/sekretariat-for-bibliotekutvikling/ nasjonal-bibliotekstrategi/ (Stand: 30.08.2018).

Bickenbach, Matthias: Das Autorenfoto in der Medienevolution. Anachronie einer Norm. München: Wilhelm Fink 2010.

Bierwirth, Maik; Johannsen, Anja und Zeman, Mirna (Hg.): Doing contemporary literature. Praktiken, Wertungen, Automatismen. München: Wilhelm Fink 2012.

Birnstiel, Klaus: „Interview, Präsenz, Paratext. Versuch einer vorläufigen Feldbestimmung“. In: Hoffmann, Torsten und Kaiser, Gerhard (Hg.): Echt inszeniert. Interviews in Literatur und Literaturbetrieb. Paderborn: Wilhelm Fink 2014, S. 63-80.

Bischoff, Matthias: „Im Mangel nach den fetten Jahren. Viel Villa, wenig Geld: Das Frankfurter Literaturhaus“. In: Frankfurter Allgemeine Zeitung 27.12.1993.

Bjørkås, Svein: „Fra enhetskultur til kulturell pluralisme?“. In: Frønes, Ivar und Kjølsrød, Lise (Hg.): Det norske samfunn. Oslo: Gyldendal akademisk 2003, S. 432-456.

Björkman, Margareta: „Läsning för nytta och nöje. Något om gamla och nya läsvanor““. In: Historiska och litteraturbistoriska studier (2002), Nr. 77, S. 105-132.

Bjørnstad, Ketil: „Hva er det med Bergen? To av Bergens store forfattere prøver å stikke kjepper i hjulene for etablering av litteraturhus i byen. Er Bergen seg selv nok? Så til de grader?“. In: Aftenposten 02.03.2011.

Blumenkamp, Katrin und Hückstädt, Hauke (Hg.): Das begebbare Fenilleton. Gespräche und Berichte aus dem Kulturbetrieb. Göttingen: Blumenkamp 2007.

Blumenkamp, Katrin: „Interview mit Heinz Ludwig Arnold“. In: Blumenkamp, Katrin und Hückstädt, Hauke (Hg.): Das begehbare Feuilleton. Gespräche und Berichte aus dem Kulturbetrieb. Göttingen: Blumenkamp 2007, S. 201-205.

Blumenkamp, Katrin: Das ,Literarische Fräuleinwunder. Die Funktionsweise eines Etiketts im literarischen Feld der Jahrtausendwende. Münster: Lit 2011.

Böck, Sebastian; Ingelmann, Julian; Matuszkiewicz, Kai und Schruhl, Friederike: „Lesen in der digitalen Gegenwart. Eine Einleitung““. In: Böck, Sebastian et al. (Hg.): Lesen X.0. Rezeptionsprozesse in der digitalen Gegenwart. Göttingen: V \& R Unipress 2017, S. 7-23.

Böhm, Thomas (Hg.): Auf kurze Distan\%: Die Autorenlesung: O-Töne, Geschichten, Ideen. Köln: Tropen 2003.

Böhm, Thomas: „Für ein literarisches Verständnis von Lesungen“. In: Böhm, Thomas (Hg.): Auf kurze Distanz: Die Autorenlesung: O-Töne, Geschichten, Ideen. Köln: Tropen 2003, S. 170-185.

Böhm, Thomas: „Lesung“. In: Schütz, Erhard (Hg.): Das BucbMarktBuch. Der Literaturbetrieb in Grundbegriffen. Reinbek bei Hamburg: Rowohlt 2005a, S. 203-206.

Böhm, Thomas: „Literaturhaus“. In: Schütz, Erhard (Hg.): Das BuchMarktBuch. Der Literaturbetrieb in Grundbegriffen. Reinbek bei Hamburg: Rowohlt 2005b, S. 228-230.

Böhm, Thomas (Hg.): Weltempfang. Panorama internationaler Autorenlesungen. Berlin: Tropen 2006. 
Bohnenkamp, Anne und Vandenrath, Sonja (Hg.): Wort-Räume, Zeichen-Wechsel, AugenPoesie. Zur Theorie und Praxis von Literaturausstellungen. Göttingen: Wallstein 2011.

Böker, Elisabeth: Skandinavische Bestseller auf dem deutschen Buchmarkt. Analyse des gegenwärtigen Literaturbooms. Würzburg: Königshausen \& Neumann 2018.

Bollow, Uta und Kruse, Sören: „,Ich glaube nicht an Kultur-für-Alle‘. Ursula Keller, die neue Programmchefin des Literaturhauses will solide Elite neu präsentieren“. In: Hamburger Rundschau (1991), Nr. 46, S. 1, 10.

Bösch, Frank und Büschel, Hubertus: „Transnational and Global Perspectives as Travelling Concepts in the Study of Culture". In: Neumann, Birgit und Nünning, Ansgar in Zusammenarbeit mit Horn, Mirjam (Hg.): Travelling concepts for the study of culture. Berlin, Boston: De Gruyter 2012, S. 371-388.

Böttiger, Helmut: „Das langsame Abwürgen. Was wird aus der Literatur(haupt)stadt Berlin? Ein Streifzug durch die Metropole“. In: Frankfurter Rundschau 10.11.1995.

Böttiger, Helmut: Elefantenrunden. Walter Höllerer und die Erfindung des Literaturbetriebs. Ausstellungsbuch. Berlin: Literaturhaus Berlin 2005.

Böttiger, Helmut: „Vorwort“. In: Blumenkamp, Katrin und Hückstädt, Hauke (Hg.): Das begehbare Feuilleton. Gespräche und Berichte aus dem Kulturbetrieb. Göttingen: Blumenkamp 2007, S. 7-16.

Böttiger, Helmut: Die Gruppe 47. Als die deutsche Literatur Geschichte schrieb. München: Deutsche Verlags-Anstalt 2012.

Bourdieu, Pierre: Die feinen Unterschiede. Kritik der gesellschaftlichen Urteilskraft. Aus dem Französischen von Bernd Schwibs und Achim Russer. Frankfurt am Main: Suhrkamp 1982.

Bourdieu, Pierre: Die Regeln der Kunst. Genese und Struktur des literarischen Feldes. Aus dem Französischen von Bernd Schwibs und Achim Russer. Frankfurt am Main: Suhrkamp 2001.

Brandt, Thomas Balslvev: „Hvad mener du, Paul Opstrup?“. In: Politiken 25.11.2017a.

Brandt, Thomas Balslvev: „Hvad mener I, Ariane og Henny?“. In: Politiken 02.12.2017b.

Braunmüller, Kurt: Die skandinavischen Sprachen im Überblick. 2., vollständig überarbeitete Auflage. Tübingen, Basel: Francke 1999.

Brenner-Wilczek, Sabine und Singh, Sikander (Hg.): , . . das hohe Geistergespräch؛ Über Literatur im musealen und digitalen Raum. Bielefeld: Aisthesis 2008.

Briegleb, Till: „,Weniger Lesereisen. Prosteste gegen Leitungswechsel des Hamburger Literaturhauses“. In: Süddeutsche Zeitung 22.11.2003.

Broder, Henryk M. und Mohr, Reinhard: „Der Aufstand der Surfpoeten“. In: Der Spiegel (2000), Nr. 6, S. 110-113.

Bundegaard, Anita Bay: „Poesiens hus bor vi alle sammen i“. In: Politiken 18.12.2011.

Bunz, Mercedes: Vom Speicher zum Verteiler. Die Geschichte des Internet. 2. Auflage. Berlin: Kadmos 2009.

Caduff, Corina und Vedder, Ulrike (Hg.): Chiffre 2000. Nene Paradigmen der Gegenwartsliteratur. München: Wilhelm Fink 2005.

Cammann, Alexander: „Was für ein Bass! Harry Rowohlt erzählt sein Leben“. In: Die Zeit (2017), Nr. 20. 
Christ, Tobias: „Formen literaturbezogener Autor-Rezipient-Kommunikation vor der ,digitalen Revolution‘. Ein sozialgeschichtlicher Überblick“. In: Böck, Sebastian et al. (Hg.): Lesen X.0. Rezeptionsprozesse in der digitalen Gegenwart. Göttingen: V \& R Unipress 2017, S. 253-280.

Clausson, Malin: „Göteborg kan få litteraturhus“. In: Göteborgs-Posten 16.09.2011.

Cronau, Sabine; Lippmann, Jana und Bechler, Nora: Buch und Buchhandel in Zablen 2018. Zablen, Fakten und Analysen zur wirtschaftlichen Entwicklung. Frankfurt am Main: Börsenverein des Deutschen Buchhandels e. V. 2018.

Dahlström, Britt: Litterära sällskap i Sverige. Stockholm: Bokförlaget Cordia 1996.

Dalager, Stig: „Mere mod - flere ambitioner“. In: Politiken 18.05.2012.

Dander, Valentin; Gründhammer, Veronika; Ortner, Heike; Pfurtscheller, Daniel und Rizzolli, Michaela: „Medienräume. Materialität und Regionalität“. In: Dander, Valentin et al. (Hg.): Medienräume. Materialität und Regionalität. Innsbruck: Innsbruck University Press 2013, S. 7-21.

Dederichs, Andrea Maria und Florian, Michael: „Felder, Organisationen und Akteure. Eine organisationssoziolgische Skizze“. In: Ebrecht, Jörg (Hg.): Bourdieus Theorie der Praxis. Erklärungskraft, Anwendung, Perspektiven. 2., durchgesehene Auflage Wiesbaden: VS Verlag für Sozialwissenschaften 2004, S. 69-96.

des. (Kürzel): „Ärger über die schlechte Akustik“. In: Frankfurter Allgemeine Zeitung 14.11.2005.

Detering, Heinrich (Hg.): Grenægänge. Skandinavisch-deutsche Nachbarschaften. Göttingen: Wallstein 1996.

Detering, Heinrich; Gerecke, Anne-Bitt und Mylius, Johan de (Hg.): Dänisch-deutsche Doppelgänger. Transnationale und bikulturelle Literatur zwischen Barock und Moderne. Göttingen: Wallstein 2001.

Detering, Heinrich (Hg.): Autorschaft. Positionen und Revisionen. DFG-Symposium 2001. Stuttgart, Weimar: Metzler 2002.

Detering, Heinrich: „Vorbemerkung“. In: Detering, Heinrich (Hg.): Autorschaft. Positionen und Revisionen. Stuttgart, Weimar: Metzler 2002, S. 9-16.

Dircks, Lena: Gelingende Literaturvermittlung. Qualität und Potenzial literarischer Lesungen im Horizont einer Ästhetik des Performativen. Masterarbeit. Berlin: epubli 2016.

Directmedia Publishing (Hg.): Das Literarische Quartett. Gesamtausgabe aller 77 Sendungen von 1988 bis 2001. Vollständige Transkription, CD-Rom. Berlin: Directmedia Publishing 2005.

Ditschke, Stephan: „,Das Publikum hat getobt!‘. Literarische Events“. In: Arnold, Heinz Ludwig und Beilein, Matthias (Hg.): Literaturbetrieb in Deutschland. 3. Auflage Neufassung. München: Edition Text + Kritik 2009, S. 307-321.

Dotzauer, Gregor: „Belletristik“. In: Schütz, Erhard (Hg.): Das BucbMarktBuch. Der Literaturbetrieb in Grundbegriffen. Reinbek bei Hamburg: Rowohlt Taschenbuch 2005, S. 42-45.

dpa: „Wir Kellerkinder. Neues Literaturzentrum in Göttingen“. In: Frankfurter Allgemeine Zeitung 15.01.2001.

Dücker, Burckhard: „Ritual““. In: Nünning, Ansgar (Hg.): Metzler Lexikon Literatur- und Kulturtheorie. Ansätze - Personen - Grundbegriffe. 4., aktualisierte und erweiterte Auflage. Stuttgart, Weimar: Metzler 2008, S. 629-631. 
Dücker, Julia und Müllerburg, Marcel: „Bilanz eines Aufbruchs“. In: Borgolte, Michael et al. (Hg.): Integration und Desintegration der Kulturen im europäischen Mittelalter. Berlin: Akademie Verlag 2011, S. 561-586.

Düffel, John von: „Die nichtideale Lesung“. In: Siblewski, Klaus und Ortheil, HannsJosef (Hg.): Die ideale Lesung. Mainz: Dieterich'sche Verlagsbuchhandlung 2017, S. 28-35.

Dumitriu, Petru: Die nenen Medien. Heidelberg: V. Decker; Müller 1985.

Dürr, Claudia: SchriftstellerInnen bei der Arbeit. Herausforderungen einer empirischen Untersuchung des literarischen Schreibprozesses. Klagenfurt: Alpen-Adria-Universität Klagenfurt 2009 (=Beiträge zur Qualitativen Inhaltsanalyse des Instituts für Psychologie der AlpenAdria-Universität Klagenfurt 16). Online verfügbar, URL: hdl.handle.net/20.500.11780/3417 (Stand: 30.08.2018).

Dürr, Claudia: „,Das Gegenwärtige ist immer flüchtig‘. Zur Erfassung des literarischen Schaffensprozesses“. In: Bierwirth, Maik; Johannsen, Anja und Zeman, Mirna (Hg.): Doing contemporary literature. Praktiken, Wertungen, Automatismen. München: Wilhelm Fink 2012, S. 91-104.

Eglinger, Hanna: „Entwicklungen seit 2000“. In: Glauser, Jürg (Hg.): Skandinavische Literaturgeschichte. 2. aktualisierte und erweiterte Auflage. Stuttgart, Weimar: Metzler 2016, S. 389-407.

Eke, Norbert Otto: „Beobachtungen beobachten. Beiläufiges aus germanistischer Sicht zum Umgang mit einer Literatur der Gegenwärtigkeit“". In: Bierwirth, Maik; Johannsen, Anja und Zeman, Mirna (Hg.): Doing contemporary literature. Praktiken, Wertungen, Automatismen. München: Wilhelm Fink 2012, S. 23-40.

Elam, Ingrid: Litteraturens hus: plats för författare, rum för läsare. Litteraturbusutredningen. Göteborg: Göteborgs Stad Kultur 2011. Online verfügbar, URL:

www5.goteborg.se/prod/intraservice/ namndhandlingar/namndhandlingararkiv/samrumportalarkiv.nsf/0/ 48f54435a77ca815c12579c200454ae4/\$file/9_litteraturhusutredningen.pdf (Stand: 30.08.2018).

Engberg, Kathrine Læsøe: „Litteraturens by - Berlin“. In: Kristeligt Dagblad 07.03.2007.

Ericsson, Birgitta und Rykkja, Anders: Litteraturformidling fra scene. Undersokelse av litteraturfestivaler. Lillehammer: Østlandsforskning 2015.

Ernst, Jutta: „Institutionen, literarische“. In: Nünning, Ansgar (Hg.): Metəler Lexikon Literatur- und Kulturtheorie. Ansätze - Personen - Grundbegriffe. 4., aktualisierte und erweiterte Auflage. Stuttgart, Weimar: Metzler 2008, S. 320-321.

Ernst, Jutta und Freitag, Florian: „Einleitung. Transkulturelle Dynamiken - Entwicklungen und Perspektiven eines Konzepts“. In: Ernst, Jutta und Freitag, Florian (Hg.): Transkulturelle Dynamiken. Aktanten - Prozesse - Theorien. Bielefeld: Transcript 2015, S. 7-30.

Esmann, Susan: „Die Autorenlesung - eine Form der Literaturvermittlung. In Annäherung an den Paratext". In: Kritische Ausgabe (2007a), Nr. 15, 89-92 (1-6 artikelinterne Zählung).

Esmann, Susan: „Leidenschaft - der Motor für eine erfolgreiche Literaturvermittlung. Interview mit Roger Willemsen“. In: Kritische Ausgabe (2007b), Nr. 15, S. 93-96. 
Espagne, Michel und Werner, Michael: „Deutsch-französischer Kulturtransfer als Forschungsgegenstand. Eine Problemskizze“. In: Espagne, Michel und Werner, Michael (Hg.): Transferts. Les rélations interculturelles dans l'espace franco-allemand (XVIIIe et XIXe siècle). Paris: Éditions Recherche sur les Civilisations 1988, S. 7-34.

Espagne, Michel: „Der Begriff Kulturtransfer“. In: Hoff, Karin; Schöning, Udo und Weinmann, Frédéric (Hg.): Internationale Netzinerke. Literarische und ästhetische Transfers im Dreieck Deutschland, Frankreich und Skandinavien zwischen 1870 und 1945. Würzburg: Königshausen \& Neumann 2016, S. 45-55.

Espedal, Tomas: „Litteraturhus for litteraturen. Hvorfor har styret for Litteraturhuset i Bergen ansatt en leder som ikke kjenner de litterære miljøene i Bergen?". In: Bergens Tidende 26.02.2011.

European Literature House Meeting. The transformative power of words. Flyer zur Veranstaltung 04.-06.06.2014. London: Free Word Centre 2014. Online verfügbar, URL: cdn.freewordcentre.com/uploads/2016/06/ELH_Meeting_Programme.pdf (Stand: 30.08.2018).

Ewers, Hans-Heino: Literatur für Kinder und Jugendliche. Eine Einführung in grundlegende Aspekte des Handlungs- und Symbolsystems Kinder-und Jugendliteratur. Mit einer Auswahlbibliographie Kinder- und Jugendliteraturwissenschaft. München: Wilhelm Fink 2000.

Fauth, Søren R.; Magnússon, Gislí und Wolgast, Karin (Hg.): INFLUX. Der deutschskandinavische Kulturaustausch um 1900. Würzburg: Königshausen \& Neumann 2014.

„Fehlende Unterscheidungskraft einer Vereinsbezeichnung - Literaturhaus“, Bundesgerichtshof 16.12.2004. In: Neue Juristische Wochenschrift 58 (2004), S. 1503-1505.

Fetzer, Günther: „Literaturvermittlung“. In: Rautenberg, Ursula (Hg.): Reclams Sacblexikon des Buches. Von der Handschrift zum E-Book. 3., vollständig überarbeitete und aktualisierte Auflage. Stuttgart: Reclam 2015, S. 267-268.

Fiell, Charlotte und Fiell, Peter: Scandinavian design. Skandinavisches Design. Köln: Taschen 2015.

Florida, Richard: Cities and the creative class. New York, London: Routledge 2005.

Forslid, Torbjörn und Ohlsson, Anders: „Författare som celebriteter. Om litteraturvetenskap och celebrity studies“. In: Bergman, Kerstin (Hg.): Det universella och det individuella. Festskrift till Eva Hattner Aurelius. Stockholm: Makadam 2013, S. 223-233.

Franck, Georg: Ökonomie der Aufmerksamkeit. Ein Entwurf. München, Wien: Hanser 1998.

Franck, Georg: ,,Jenseits von Geld und Information. Zur Ökonomie der Aufmerksamkeit". In: Piwinger, Manfred und Zerfaß, Ansgar (Hg.): Handbuch Unternehmenskommunikation. Wiesbaden: Springer Gabler 2007, S. 159-168.

Frank, Simon A.: „Kulturmarketing im Internet“. In: Klein, Armin (Hg.): Kompendium Kulturmanagement. Handbuch für Studium und Praxis. 3., überarbeitete Auflage. München: Franz Vahlen 2011, S. 559-586.

Friedl, Armin: „Florian Höllerer verabschiedet sich. ,Unser Verein ist eine Bürgerbewegung““. In: Stuttgarter Nachrichten 17.12.2013.

Führer, Karl Christian: Die Stadt, das Geld und der Mark.t. Immobilienspekulation in der Bundesrepublik 1960-1985. Berlin, Boston: De Gruyter Oldenbourg 2016.

Funk, Holger und Wittmann, Reinhard G. (Hg.): Literatur-Hauptstadt. Schriftsteller in Berlin beute. Berlin: Berlin-Verlag 1983. 
Funk, Holger und Wittmann, Reinhard G.: „Schlußbemerkung“. In: Funk, Holger und Wittmann, Reinhard G. (Hg.): Literatur-Hauptstadt. Schriftsteller in Berlin heute. Berlin: Berlin-Verlag 1983, S. 586-597.

Fure, Odd-Bjørn: „Nationale Habitusentwicklung in Norwegen und Deutschland. Konstallationen und Grunderfahrungen“. In: Uecker, Heiko (Hg.): DeutschNorwegische Kontraste. Spiegelungen europäischer Mentalitätsgeschichte. Baden-Baden: Nomos 2001, S. 23-35.

Füssel, Stephan: „Frankfurter Phoenix. Die Anfänge der Frankfurter Messe und ihre frühe Internationalisierung“". In: Füssel, Stephan (Hg.): 50 Jahre Frankfurter Buchmesse. 1949-1999. Frankfurt am Main: Suhrkamp 1999, S. 12-25.

Gäbler, Bernd: ,... und unseren täglichen Talk gibt uns heute؛ Inszenierungsstrategien, redaktionelle Dramaturgien und Rolle der TV-Polit-Talkeshows. Eine Studie der Otto-BrennerStiftung. Frankfurt am Main: Otto-Brenner-Stiftung 2011 (=OBS-Arbeitsheft 68).

Gaensheimer, Susanne und Hückstädt, Hauke (Hg.): Acht Betrachtungen. 8 Autoren, 8 Kunstwerke. Frankfurt am Main: Henrich Editionen 2013.

Gaiser, Gottlieb: Literaturgeschichte und literarische Institutionen. Zu einer Pragmatik der Literatur. Meitingen: Verlag Literatur und Wissenschaft 1993.

Gassner, Hubertus; Koep, Daniel und Moritz, Rainer (Hg.): Erstaunliche Einsichten. Schriftsteller über Bilder in der Hamburger Kunsthalle. Neumünster: Wachholtz Verlag 2013.

Gebhardt, Winfried; Hitzler, Ronald und Pfadenhauer, Michaela: „Einleitung“. In: Gebhardt, Winfried et al. (Hg.): Events. Soziologie des Außergewöhnlichen. Opladen: Leske + Budrich 2000, S. 9-13.

Gebhardt, Winfried: „Feste, Feiern und Events. Zur Soziologie des Außergewöhnlichen“. In: Gebhardt, Winfried et al. (Hg.): Events. Soziologie des Außergewöhnlichen. Opladen: Leske + Budrich 2000, S. 17-31.

Gehlen, Dirk von: Eine neue Version ist verfügbar - Update. Wie die Digitalisierung Kunst und Kultur verändert. Berlin: Metrolit 2013.

Geisenhanslüke, Achim: Einführung in die Literaturtheorie. Von der Hermeneutik zu den Kulturwissenschaften. 6., erweiterte Auflage. Darmstadt: Wissenschaftliche Buchgesellschaft 2013.

Geisenhanslüke, Achim und Hehl, Michael Peter: „Walter Höllerer und die Entstehung des modernen Literaturbetriebs. Einleitung“". In: Geisenhanslüke, Achim und Hehl, Michael Peter (Hg.): Poetik im technischen Zeitalter. Walter Höllerer und die Entstehung des modernen Literaturbetriebs. Bielefeld: Transcript 2013, S. 7-13.

Gendolla, Peter: „Vorwort“. In: Gendolla, Peter und Leinecke, Rita (Hg.): Die Gruppe 47 und die Medien. (=Massenmedien und Kommunikation: MuK 114/115). Siegen:

Fachbereich 3, Sprach- und Literaturwissenschaften, Universität-Gesamthochschule Siegen 1997, S. 3-4.

Genette, Gérard: Paratexte. Das Buch vom Beinverk des Buches. Aus dem Französischen von Dieter Hornig. Frankfurt am Main: Campus 1989.

Gerogiorgakis, Stamatios; Scheel, Roland und Schorkowitz, Dittmar: „Kulturtransfer vergleichend betrachtet“. In: Borgolte, Michael et al. (Hg.): Integration und Desintegration der Kulturen im europä̈schen Mittelalter. Berlin: Akademie Verlag 2011, S. 385-466. 
Giacomuzzi, Renate: „Autorenlesungen im Internet“. In: Rühr, Sandra (Hg.): Geschichten am Lagerfeuer. Ereignischarakter und Dispositve von Literaturveranstaltungen im digitalen Zeitalter. (=Alles Buch. Studien der Erlanger Buchwissenschaft 52). Erlangen: Universität Erlangen-Nürnberg, Buchwissenschaft 2014, S. 23-37.

Gieseke, Wiltrud (Hg.): Institutionelle Innensichten der Weiterbildung. Bielefeld: W. Bertelsmann 2003.

Gimmler, Antje: Institution und Individuum. Die implizite Institutionentheorie von Max Weber und Jürgen Habermas. Bamberg: Otto-Friedrich-Universität, Fakultät Pädagogik, Philososphie, Psychologie. Dissertation 1996.

Gjelsvik, Erling: „Tid for en time-out? Erling Gjelsvik heller litt malurt i litteraturhusbegeret ...“. In: Bergens Avisen 26.02.2011.

Glogner-Pilz, Patrick und Föhl, Patrick S. (Hg.): Das Kulturpublikum. Fragestellungen und Befunde der empirischen Forschung. 2., erweiterte Auflage. Wiesbaden: VS Verlag für Sozialwissenschaften 2011.

Glogner-Pilz, Patrick und Föhl, Patrick S.: „Zur Relevanz empirischer Kulturpublikumsforschung. Eine Einführung in das Handbuch“. In: Glogner-Pilz, Patrick und Föhl, Patrick S. (Hg.): Handbuch Kulturpublikum. Forschungsfragen und-befunde. Wiesbaden: Springer VS 2016, S. 19-33.

Göhler, Gerhard: „Politische Institutionen und ihr Kontext. Begriffliche und konzeptionelle Überlegungen zur Theorie politischer Institutionen“. In: Göhler, Gerhard (Hg.): Die Eigenart der Institutionen. Zum Profil politischer Institutionentheorie. Baden-Baden: Nomos 1994, S. 19-46.

Gollhardt, Heinz: „Studien zum Klappentext“. In: Börsenblatt für den Deutschen Buchbandel (1966), Nr. 78, S. 2101-2215.

Gorschlüter, Peter und Hückstädt, Hauke (Hg.): Acht Betrachtungen II. 8 Autoren, 8 Kunstwerke. Frankfurt am Main: Henrich Editionen 2016.

Grage, Joachim und Schröder, Stephan Michael: „Performativität und literarische Praktiken. Zum Erkenntnispotential einer Verschränkung von Performativitätsforschung und Praxistheorie“. In: Grage, Joachim und Schröder, Stephan Michael (Hg.): Literarische Praktiken in Skandinavien um 1900. Fallstudien. Würzburg: Ergon 2012, S. 7-35.

Grage, Joachim: „Zur Mobilität literarischer Praktiken“. In: Wischmann, Antje (Hg.): Mobiler Norden. Mobilität aus skandinavistischer Perspektive. Freiburg im Breisgau u. a.: Rombach 2014, S. 103-116.

Gräsberg, Sofia und Ljusberg, Tora: Verksambetsberättelse 2015. Göteborg: Göteborgs Litteraturhus 2016. Online verfügbar, URL: goteborgslitteraturhus.se/wpcontent/uploads/2016/03/GLH_verksamhetsber\%C3\%A4ttelse_2015.pdf (Stand: 30.08.2018).

Gregersen, Magnus Heie: Litteraturbuset som det nye Folkets Hus? En kultursosiologisk undersokelse av litteraturhus $i$ Norge. Oslo: Universitetet i Oslo, Institutt for sosiologi og samfunnsgeografi. Masterarbeit 2014. Online verfügbar, URL: www.duo.uio.no/bitstream/handle/10852/41387/Litteraturhuset-som-detnye-Folkets-Hus.pdf? sequence $=1$ (Stand: 30.08.2018).

Greiner, Ulrich: „Champagner, Schafskäse. Das Behagen in der Kultur oder: Kulturpolitiker ohne Konzept"،. In: Die Zeit (1989), Nr. 30.

Greiner, Ulrich: „Hamburger Freiheit. Personelle Querelen um das Literaturhaus“. In: Die Zeit (2003), Nr. 49. 
Grimm, Gunter E. und Schärf, Christian (Hg.): Schriftsteller-Inszenierungen. Bielefeld: Aisthesis 2008.

Grimm, Gunter E. und Schärf, Christian: „Einleitung“. In: Grimm, Gunter E. und Schärf, Christian (Hg.): Schriftsteller-Inszenierungen. Bielefeld: Aisthesis 2008, S. 7-11.

Grimm, Gunter E.: „,Nichts ist widerlicher als eine sogenannte Dichterlesung. Deutsche Autorenlesung zwischen Marketing und Selbstpräsentation“. In: Grimm, Gunter E. und Schärf, Christian (Hg.): Schriftsteller-Inszenierungen. Bielefeld: Aisthesis 2008, S. 141-168.

Grund, Stefan: „,Wir wollen auch Jugendliche erreichen“. Der neue Literaturhauschef Rainer Moritz setzt auf junge Autoren, junge Leser und die Literaturgeschichte“. In: Die Welt 08.12.2004.

Gumbrecht, Hans Ulrich: Diesseits der Hermenentik. Die Produktion von Präsenz. Frankfurt am Main: Suhrkamp 2004.

Gumbrecht, Hans Ulrich: „Wahrnehmung versus Erfahrung oder die schnellen Bilder und ihre Interpretationsresistenz“. In: Gumbrecht, Hans Ulrich: Präsenæ. Hg. von Jürgen Klein. Berlin: Suhrkamp 2012, S. 240-260.

Haag, Klaus: Lesung \& Vortrag. Zur Theorie und Praxis der öffentlichen Leseveranstaltung: ein Lesebuch mit Ratschlägen für Autoren, Referenten und Veranstalter, mit 50 Auftrittskonzepten. Speyer: Marsilius 2001.

Hadenius, Stig und Weibull, Lennart: Massmedier. En bok om press, radio \& TV. 8., überarbeitete Auflage. Stockholm: Albert Bonnier 2003.

Hage, Volker: „Die Enkel kommen“. In: Der Spiegel (1999a), Nr. 41, S. 244-254.

Hage, Volker: „Ganz schön abgedreht“. In: Der Spiegel (1999b), Nr. 12, S. 244-246.

Hage, Volker: Letzte Tänz̨e, erste Schritte. Deutsche Literatur der Gegenwart. München: Bbt 2010.

Hartling, Florian: „Literarische Autorschaft“. In: Grond-Rigler, Christine und Straub, Wolfgang (Hg.): Literatur und Digitalisierung. Berlin: De Gruyter 2013, S. 69-94.

Hartwig, Ina: „Frankfurt verliert seine beste Italienerin“. In: Frankfurter Rundschau 27.04.2009.

Haselbach, Dieter; Klein, Armin; Knüsel, Pius und Opitz, Stephan: Der Kulturinfarkt. Von allem zu viel und überall das Gleiche. Eine Polemike über Kulturpolitik, Kulturstaat, Kultursubvention. 3. Auflage. München: Knaus 2012a.

Haselbach, Dieter; Klein, Armin; Knüsel, Pius und Opitz, Stephan: „Die Hälfte? Warum die Subventionskultur, wie wir sie kennen, ein Ende finden muss“. In: Der Spiegel (2012b), Nr. 11, S. 136-141.

Hehl, Michael Peter: „Berliner Netzwerke. Walter Höllerer, die Gruppe 47 und die Gründung des Literarischen Colloquiums Berlin“. In: Geisenhanslüke, Achim und Hehl, Michael Peter (Hg.): Poetik im technischen Zeitalter. Walter Höllerer und die Entstebung des modernen Literaturbetriebs. Bielefeld: Transcript 2013, S. 155-189.

Heinrichs, Werner: „Kulturbetrieb“. In: Lewinski-Reuter, Verena und Lüddemann, Stefan (Hg.): Glossar Kulturmanagement. Wiesbaden: VS Verlag für Sozialwissenschaften 2011, S. 131-137.

Heißenbüttel, Helmut: „Konkrete Poesie als Alternative? Ein Kolloquium an der Universität Bielefeld“. In: Die Zeit (1978), Nr. 9. 
Heitmann, Annegret: „Die Moderne im Durchbruch (1870-1910““. In: Glauser, Jürg (Hg.): Skandinavische Literaturgeschichte. Stuttgart, Weimar: Metzler 2006, S. 183-229.

Hejl, Peter M.: „Kultur“. In: Nünning, Ansgar (Hg.): Metzler Lexikon Literatur- und Kulturtheorie. Ansätze - Personen - Grundbegriffe. 4., aktualisierte und erweiterte Auflage. Stuttgart, Weimar: Metzler 2008, S. 391-393.

Helling, Reinhard: „,Das kann auch mal in der Nähe eines Skandals sein‘. Die neue Literaturhaus-Chefin Ursula Keller über ihr Programm". In: Hamburger Morgenpost 12.11.1991.

Henningsen, Bernd: „Mentalität, Identität, Nationalität. Die Skandinavier auf der Suche nach dem, was sie sind“. In: Schottmann, Hans (Hg.): Arbeiten qur Skandinavistik. Dokumentation der 11. Arbeitstagung der deutschsprachigen Skandinavistik, 8.-14.8.1993 in Sigtuna. Münster: Kleinheinrich 1994, S. 400-416.

Henze, Valeska: Der schwedische Woblfahrtsstaat. Zur Struktur und Funktion eines politischen Ordnungsmodells. Berlin, Florenz 1999. Online verfügbar, URL: www.valeskahenze.de/Daten/Das\%20schwedische\%20Volksheim.pdf (30.08.2018).

Herrmann, Leonhard: „Kanondynamik“. In: Rippl, Gabriele und Winko, Simone (Hg.): Handbuch Kanon und Wertung. Theorien, Instanzen, Geschichte. Stuttgart, Weimar: Metzler 2013, S. 103-110.

Heydebrand, Renate von: „Probleme des ,Kanons“ - Probleme der Kultur- und Bildungspolitik“. In: Janota, Johannes (Hg.): Germanistik, Deutschunterricht und Kulturpolitik. Vorträge des Augsburger Germanistentags 1991. Tübingen: Niemeyer 1993, S. 3-22.

Heydebrand, Renate von und Winko, Simone: Einführung in die Wertung von Literatur. Systematik - Geschichte - Legitimation. Paderborn: Schöningh 1996.

Heydebrand, Renate von: „Kanon Macht Kultur. Versuch einer Zusammenfassung“. In: Heydebrand, Renate von (Hg.): Kanon Macht Kultur. Theoretische, historische und soziale Aspekte ästhetischer Kanonbildungen. Stuttgart, Weimar: Metzler 1998, S. 612-625.

Heyden-Rynsch, Verena von der: Europäische Salons. Höhepunkte einer versunkenen weiblichen Kultur. Reinbek bei Hamburg: Rowohlt 1995.

Hickethier, Knut: Einführung in die Medienwissenschaft. Stuttgart, Weimar: Metzler 2003.

Hieber, Lutz: „Grafikdesign im gesellschaftlichen Strukturwandel“. In: Prinz, Sophia und Moebius, Stephan (Hg.): Das Design der Gesellschaft. Zur Kultursoziologie des Designs. Bielefeld: Transcript 2012, S. 359-385.

Hillebrandt, Frank: Soziologische Praxistheorien. Eine Einfübrung. Wiesbaden: Springer VS 2014.

Hintermeier, Hannes: „Er will doch nur der Platzhirsch sein. Frankfurter Literaturstreit“". In: Frankfurter Allgemeine Zeitung 13.02.2015.

Hitzler, Ronald: „„Ein bißchen Spaß muß sein!‘. Zur Konstruktion kultureller Erlebniswelten“. In: Gebhardt, Winfried et al. (Hg.): Events. Soziologie des Außergewöhnlichen. Opladen: Leske + Budrich 2000, S. 401-412.

Hitzler, Ronald: Eventisierung. Drei Fallstudien zum marketingstrategischen Massenspaß. Wiesbaden: VS Verlag für Sozialwissenschaften 2011.

Hoff, Karin; Sandberg, Anna und Schöning, Udo (Hg.): Literarische Transnationalität. Die kulturellen Dreiecksberiebungen zwischen Skandinavien-Deutschland-Frankreich im 19. Jahrbundert. Würzburg: Königshausen \& Neumann 2014. 
Hoff, Karin und Rühling, Lutz: „Die skandinavischen Literaturen des 19. Jahrhunderts“. In: Hoff, Karin und Rühling, Lutz (Hg.): Kindler kompakt skandinavische Literatur 19. Jahrbundert. Stuttgart, Weimar: Metzler 2016, S. 9-25.

Hoff, Karin und Rühling, Lutz: „Die skandinavischen Literaturen des 20. Jahrhunderts". In: Hoff, Karin und Rühling, Lutz (Hg.): Kindler kompakt skandinavische Literatur 20. Jabrhundert. Stuttgart, Weimar: Metzler 2017, S. 11-28.

Hoffmann, Hilmar: Kultur für alle. Perspektiven und Modelle. Erweiterte und aktualisierte Auflage. Frankfurt am Main: Fischer 1981.

Hoffmann, Hilmar: Kultur als Lebensform. Frankfurt am Main: Fischer 1990.

Hoffmann, Torsten und Kaiser, Gerhard: „Echt inszeniert. Schriftstellerinterviews als Forschungsgegenstand“. In: Hoffmann, Torsten und Kaiser, Gerhard (Hg.): Echt inszeniert. Interviews in Literatur und Literaturbetrieb. Paderborn: Wilhelm Fink 2014, S. 9-25.

Hohendahl, Peter Uwe: Literarische Kultur im Zeitalter des Liberalismus 1830-1870. München: C. H. Beck 1985.

Holdenried, Michaela: „Einleitung“. In: Holdenried, Michaela und Hermes, Stefan (Hg.): Felicitas Hoppe. Das Werk. Berlin: Erich Schmidt 2015, S. 7-10.

Höllerer, Florian: „Ein (Literatur-)Haus für Europa“. In: Körber, Sebastian; Roth, Jenni und Serwotka, Kornelia (Hg.): Kulturreport: Fortschritt Europa. Stuttgart: Institut für Auslandsbeziehungen, Robert Bosch Stiftung 2007, S. 215-220. Online verfügbar, URL: www.ifa.de/fileadmin/pdf/kulturreport/kr2007_Fortschritt-Europa_de.pdf (Stand: 30.08.2018).

Hortman, Kari: „A house of literature“. In: Scandinavian public library quarterly (2013), Nr. 3. Online verfügbar, URL: slq.nu/?article=volume-46-no-3-2013-2 (Stand: 30.08.2018).

Hückstädt, Hauke: „Begehbare Feuilletons oder die Metropole im Kopf“. In: Böhm, Thomas (Hg.): Auf kurze Distan₹. Die Autorenlesung: O-Töne, Geschichten, Ideen. Köln: Tropen 2003, S. 93-105.

Hückstädt, Hauke: „Konkurrenz und aktive Behinderung. Offener Brief an den Frankfurter Kulturdezernenten Felix Semmelroth“. In: Frankfurter Allgemeine Zeitung RheinMain-Zeitung 10.02.2015. Online verfügbar, URL: literaturhaus-

frankfurt.de/fileadmin/user_upload/download/F.A.Z._10.2.15_Offener_Brief.pdf (Stand: 30.08.2018).

Hückstädt, Hauke: „Literatur vollplastisch. Das Buchgeschäft kriselt, die Lesungen aber boomen: Die Blickachse zwischen Autor und Publikum ist die beste Verkaufsförderung“. In: Frankfurter Allgemeine Zeitung 03.03.2018.

Hügel, Hans-Otto: „Der Ausstellungsort als populärer Ort““. In: Roesner, David et al. (Hg.): Szenische Orte - mediale Räume. Hildesheim: Olms 2005, S. 221-238.

Hühn, Melanie; Lerp, Dörte; Petzold, Knut und Stock, Miriam (Hg.): Transkulturalität, Transnationalität, Transstaatlichkeit, Translokalität. Theoretische und empirische Begriffsbestimmungen. Münster u. a.: Lit 2010.

Hühn, Melanie; Lerp, Dörte; Petzold, Knut und Stock, Miriam: „In neuen Dimensionen denken? Einführende Überlegungen zu Transkulturalität, Transnationalität, Transstaatlichkeit und Translokalität"،. In: Hühn, Melanie et al. (Hg.): Transkulturalität, Transnationalität, Transstaatlichkeit, Translokalität. Theoretische und empirische Begriffsbestimmungen. Münster u. a.: Lit 2010, S. 11-46. 
Huse, Ulrich: „Buchmarketing“. In: Rautenberg, Ursula (Hg.): Reclams Sachlexikon des Buches. Von der Handschrift zum E-Book. 3., vollständig überarbeitete und aktualisierte Auflage. Stuttgart: Reclam 2015, S. 92.

Huttenlocher, Armin: „Unterm Fallbeil. Die Krise der Literaturhäuser in Berlin“. In: Süddeutsche Zeitung 05.08.1996.

Jaeggi, Rahel: Kritik von Lebensformen. Berlin: Suhrkamp 2014.

Jandl, Ernst: „Hinweise für eine Veranstaltung mit Ernst Jandl““. In: Siblewski, Klaus und Ortheil, Hanns-Josef (Hg.): Die ideale Lesung. Mainz: Dieterich'sche Verlagsbuchhandlung 2017, S. 10-13.

Jannidis, Fotis; Lauer, Gerhard; Martínez, Matías und Winko, Simone (Hg.): Rückkehr des Autors. Zur Erneuerung eines umstrittenen Begriffs. Tübingen: Niemeyer, De Gruyter 1999.

Jannidis, Fotis; Lauer, Gerhard; Martínez, Matías und Winko, Simone: „Einleitung. Rede über den Autor an die Gebildeten unter seinen Verächtern. Historische Modelle und systematische Perspektiven“. In: Jannidis, Fotis et al. (Hg.): Rückkehr des Autors. Zur Erneuerung eines umstrittenen Begriffs. Tübingen: Niemeyer, De Gruyter 1999, S. 3-35.

Jannidis, Fotis; Lauer, Gerhard; Martínez, Matías und Winko, Simone (Hg.): Texte zur Theorie der Autorschaft. Stuttgart: Reclam 2000.

Jannidis, Fotis; Lauer, Gerhard; Martínez, Matías und Winko, Simone: „Einleitung““ In: Jannidis, Fotis et al. (Hg.): Texte zur Theorie der Autorschaft. Stuttgart: Reclam 2000a, S. 7-29.

Jannidis, Fotis; Lauer, Gerhard; Martínez, Matías und Winko, Simone: „Einleitung zu Barthes“. In: Jannidis, Fotis et al. (Hg.): Texte zur Theorie der Autorschaft. Stuttgart: Reclam 2000b, S. 181-184.

Jenkins, Henry: Convergence culture. Where old and new media collide. New York: New York University Press 2006a.

Jenkins, Henry: Fans, bloggers, and gamers. Exploring participatory culture. New York: New York University Press 2006b.

Jensen, Eline Mørch: „LiteraturHaus - et år efter“. In: BogMarkedet (2006), Nr. 12, S. $14-16$.

Joachimsthaler, Jürgen: „Die totale Gegenwart. Aktuelle Kultur als methodologisches Problem“. In: Joachimsthaler, Jürgen (Hg.): Gegenwartskultur als methodologische Herausforderung der Kulturwissenschaft(en). Frankfurt am Main: Peter Lang 2016, S. 267-304.

Johannsen, Anja: „,In einem Anfall von Literaturbetriebswiderwillen‘. Die Romane Thomas Glavinics im Geflecht des Literaturbetriebs“. In: Brodowsky, Paul und Klupp, Thomas (Hg.): Wie über Gegenwart sprechen? Überlegungen zu den Methoden einer Gegenwartsliteraturwissenschaft. Frankfurt am Main u. a.: Peter Lang 2010, S. 105-118.

Johannsen, Anja: „,Zuviel zielwütige Kräfte?‘ Der Literaturveranstaltungsbetrieb unter der Lupe“. In: Bierwirth, Maik et al. (Hg.): Doing contemporary literature. Praktiken, Wertungen, Automatismen. München: Wilhelm Fink 2012a, S. 263-281.

Johannsen, Anja: „(Un)sichtbare Handschriften. Zur problematischen Funktion von Literaturhäusern in Kanonisierungsprozessen“". In: Beilein, Matthias et al. (Hg.): Kanon, Wertung und Vermittlung. Literatur in der Wissensgesellschaft. Berlin, Boston: De Gruyter 2012b, S. 179-192. 
Johannsen, Anja: „Stroh zu Gold oder Gold zu Stroh? Zur Ambivalenz öffentlicher Autorenlesungen“. In: Theisohn, Philipp und Weder, Christine (Hg.): Literaturbetrieb. Zur Poetik einer Produktionsgemeinschaft. München: Wilhelm Fink 2013a, S. 63-75.

Johannsen, Anja: „Literaturhäuser“. In: Rippl, Gabriele und Winko, Simone (Hg.): Handbuch Kanon und Wertung. Theorien, Instanzen, Geschichte. Stuttgart, Weimar: Metzler 2013b, S. 211-215.

John-Wenndorf, Carolin: Der öffentliche Autor. Über die Selbstinszenierung von Schriftstellern. Bielefeld: Transcript 2014.

Juchem, Kerstin: Literaturbäuser, Literaturbüros und Literaturzentren im deutschsprachigen Raum. Eine Bestandsaufnahme. Berlin: Nicolai 2013.

Jürgensen, Christoph und Kaiser, Gerhard (Hg.): Schriftstellerische Inszenierungspraktiken. Typologie und Geschichte. Heidelberg: Universitätsverlag Winter 2011.

Jürgensen, Christoph und Kaiser, Gerhard: „Schriftstellerische Inszenierungspraktiken. Heuristische Typologie und Genese“. In: Jürgensen, Christoph und Kaiser, Gerhard (Hg.): Schriftstellerische Inszenierungspraktiken. Typologie und Geschichte. Heidelberg: Universitätsverlag Winter 2011, S. 9-30.

Jurt, Joseph: „Das Konzept des literarischen Feldes und die Internationalisierung der Literatur". In: Turk, Horst et al. (Hg.): Kulturelle Grenzziehungen im Spiegel der Literaturen. Nationalismus, Regionalismus, Fundamentalismus. Göttingen: Wallstein 1998, S. 84-103.

Kaelble, Hartmut: „Die Debatte über Vergleich und Transfer und was jetzt?“. In: Connections. A Journal for Historians and Area Specialists (2005). Online verfügbar, URL: www.connections.clio-online.net/debate/id/diskussionen-574 (Stand: 30.08.2015).

Kahl, Paul: „Kulturgeschichte des Dichterhauses. Das Dichterhaus als historisches Phänomen“. In: Jahrbuch der Deutschen Schillergesellschaft (2017), S. 325-345.

Kajetzke, Laura und Schroer, Markus: „Sozialer Raum. Verräumlichung“. In: Günzel, Stephan (Hg.): Raum. Ein interdis₹iplinäres Handbuch. Stuttgart, Weimar: Metzler 2010, S. 192-203.

Kämmerlings, Richard: Das kurze Glück der Gegenwart. Deutschsprachige Literatur seit'89. Stuttgart: Klett-Cotta 2011.

Kampmann, Elisabeth: Kanon und Verlag. Zur Kanonisierungspraxis des Deutschen Taschenbuch Verlags. Berlin: Akademie Verlag 2011.

Kampmann, Elisabeth: „Wie lässt sich ein Kanon rekonstruieren?“. In: Rippl, Gabriele und Winko, Simone (Hg.): Handbuch Kanon und Wertung. Theorien, Instanzen, Geschichte. Stuttgart, Weimar: Metzler 2013, S. 407-412.

Kappes, Christoph: „Papierbücher werden so schnell nicht verschwinden“. In: Upload Magazin (2013), Nr. 11, S. 37-39. Online verfügbar, URL: de.scribd.com/document/ 305005280/Neun-Stimmen-zur-Zukunft-der-Buchbranche (Stand: 30.08.2018).

Kauffmann, Kai: „Zur derzeitigen Situation der Feuilleton-Forschung“. In: Kauffmann, Kai und Schütz, Erhard (Hg.): Die lange Geschichte der Kleinen Form. Beiträge zur Fevilletonforschung. Berlin: Weidler 2000, S. 10-24.

Keller, Thomas: „Kulturtransferforschung. Grenzgänge zwischen den Kulturen“. In: Moebius, Stephan und Quadflieg, Dirk (Hg.): Kultur. Theorien der Gegenwart. 2., erweiterte und aktualisierte Auflage. Wiesbaden: VS Verlag für Sozialwissenschaften 2011, S. 106-119. 
Keller, Ursula (Hg.): Perspektiven metropolitaner Kultur. Frankfurt am Main: Suhrkamp 2000.

Kelleter, Frank: „Populäre Serialität. Eine Einführung“. In: Kelleter, Frank (Hg.): Populäre Serialität: Narration - Evolution - Distinktion. Zum seriellen Erzäblen seit dem 19. Jahrbundert. Bielefeld: Transcript 2012, S. 11-46.

Kemper, Peter: „Event“. In: Schütz, Erhard (Hg.): Das BuchMarketBuch. Der Literaturbetrieb in Grundbegriffen. Reinbek bei Hamburg: Rowohlt 2005, S. 119-120.

Kirchner, Petra: Literatur-Shows. Die Präsentation von Literatur im Fernsehen. Wiesbaden: Deutscher Universitätsverlag 1994.

Klein, Armin: Besucherbindung im Kulturbetrieb. Ein Handbuch. Wiesbaden: Westdeutscher Verlag 2003.

Klein, Armin (Hg.): Kompendium Kulturmanagement. Handbuch für Studium und Praxis. 3., überarbeitete Auflage. München: Franz Vahlen 2011.

Klein, Armin: „Kompendium Kulturmanagement. Eine Einführung“. In: Klein, Armin (Hg.): Kompendium Kulturmanagement. Handbuch für Studium und Praxis. 3., überarbeitete Auflage. München: Franz Vahlen 2011a, S. 1-8.

Klein, Armin: „Kulturmarketing“. In: Klein, Armin (Hg.): Kompendium Kulturmanagement. Handbuch für Studium und Praxis. 3., überarbeitete Auflage. München: Franz Vahlen 2011b, S. 539-558.

Klein, Armin: „Kulturpolitik (allgemein)“. In: Klein, Armin (Hg.): Kompendium Kulturmanagement. Handbuch für Studium und Praxis. 3., überarbeitete Auflage. München: Franz Vahlen 2011c, S. 91-99.

Klettenhammer, Sieglinde und Wiesmüller, Wolfgang: „Literaturpreise als Institutionen der Literaturvermittlung. Der Darmstädter Leonce-und-Lena-Preis und der Lyrikpreis Meran im Vergleich“. In: Neuhaus, Stefan und Ruf, Oliver (Hg.): Perspektiven der Literaturvermittlung. Innsbruck: Studienverlag 2011, S. 115-132.

Klinggräff, Fritz von: „Vorschlag. Vorlesen, zuhören, sich fetzen: Lesung(en) im Café Clara“. In: taz 05.09.1995.

Knaller, Susanne und Müller, Harro: „Einleitung“. In: Knaller, Susanne und Müller, Harro (Hg.): Authentizität. Diskussion eines ästhetischen Begriffs. München: Wilhelm Fink 2006, S. 7-16.

Knaller, Susanne: „Genealogie des ästhetischen Authentizitätsbegriffs“. In: Knaller, Susanne und Müller, Harro (Hg.): Authentizität. Diskussion eines ästhetischen Begriffs. München: Wilhelm Fink 2006, S. 17-35.

Knipp, Raphaela: „Gemeinsam lesen. Zur Kollektivität des Lesens in analogen und digitalen Kontexten (LovelyBooks)“. In: Böck, Sebastian et al. (Hg.): Lesen X.0. Rezeptionsprozesse in der digitalen Gegenwart. Göttingen: V \& R Unipress 2017, S. 171-190.

Knoblauch, Hubert: „Das strategische Ritual der kollektiven Einsamkeit. Zur Begrifflichkeit und Theorie des Events“. In: Gebhardt, Winfried et al. (Hg.): Events. Soziologie des Außergewöhnlichen. Opladen: Leske + Budrich 2000, S. 33-50.

Köhler, Andrea und Moritz, Rainer (Hg.): Maulhelden und Königskinder. Zur Debatte über die deutschsprachige Gegenwartsliteratur. Leipzig: Reclam 1998.

Kolbe, Jürgen: „Ein Literaturhaus ohne Literatur?“. In: Der Tagesspiegel 27.06.1997.

Korsnes, Olav: „Innledning““. In: Korsnes, Olav; Hansen et al. (Hg.): Elite og klasse $i$ et egalitert samfunn. Oslo: Universitetsforlaget 2014, S. 11-24. 
Korsvold, Kaja: „Går så det suser, men sliter med økonomien. De tre norske litteraturhusene har vært en enestående suksess. Men alle sliter med å få budsjettet til å gå opp“. In: Aftenposten 16.11.2013.

Korte, Hermann: „K wie Kanon und Kultur. Kleines Kanonglossar in 25 Stichworten“. In: Arnold, Heinz Ludwig und Korte, Hermann (Hg.): Literarische Kanonbildung. München: Edition Text + Kritik 2002, S. 25-38.

Kortländer, Bernd: „Begrenzung - Entgrenzung. Kultur- und Wissenstransfer in Europa“. In: Jordan, Lothar und Kortländer, Bernd (Hg.): Nationale Grenzen und internationaler Austausch. Studien zum Kultur- und Wissenschaftstransfer in Europa. Tübingen:

Niemeyer 1995, S. 1-19.

Kovač, Lena: ,Häuser sind ideale Sujets für Erääblungen؛ Zur Geschicbte der Stadthausvilla am Schwanenwik 38. Hamburg: Literaturhaus e. V. 2009. Online verfügbar, URL: literaturhaus-hamburg.de/sites/default/files/web/pdf/LH-Geschichte-Schwanenwik38.pdf (Stand: 30.08.2018).

Krämer, Sybille: „Zum Paradoxen von Zeugenschaft im Spannungsfeld von Personalität und Depersonalisierung. Ein Kommentar über Authentizität in fünf Thesen“. In: Rössner, Michael und Uhl, Heidemarie (Hg.): Renaissance der Authentizität? Über die neue Sehnsucht nach dem Ursprünglichen. Bielefeld: Transcript 2012, S. 15-26.

Krause, Tilman: „Vom Souterrain in die Bel Etage. Unverzichtbarer Bestandteil der Hauptstadtkultur: Das Berliner Literaturhaus feiert heute und morgen sein zehnjähriges Bestehen“. In: Der Tagesspiegel 28.06.1996.

Krause, Tilman: „Wo die Bücher und Bürger zusammenkommen. Literaturhaus Berlin“. In: Die Welt 02.07.2016.

Krause, Tilman: „Der Mann, der das Literaturhaus erfand“. In: Die Welt 19.03.2017.

Kroucheva, Katerina und Schaff, Barbara (Hg.): Kafkas Gabel. Überlegungen zum Ausstellen von Literatur. Bielefeld: Transcript 2013.

Krüger-Lenz, Peter: „,Furchtbar, wenn wir konkurrieren würden‘. Das Literarische Zentrum wird beim Göttinger Literaturherbst nicht mitmachen“. In: Göttinger Tageblatt 25.08.2001.

Krüger-Lenz, Peter: „,Nicht alle waren am Haus, die hätten hier sein müssen‘. Interview mit Hauke Hückstädt"،. In: Göttinger Tageblatt 22.04.2010.

Krüger-Lenz, Peter: ,Johannes-Peter Herberhold übernimmt den Göttinger Literaturherbst. ,Ein wenig renovieren““. In: Göttinger Tageblatt 11.04.2014.

Kulturstrategi för Göteborgs Stad. Göteborg: Göteborgs Stad Kultur 2012. Online verfügbar, URL: www5.goteborg.se/prod/Intraservice/Namndhandlingar/NamndhandlingarArkiv/S amrumPortalArkiv.nsf/419AFA885FFF4760C1257A0F003FC985/\$File/7_ Kulturstrategi.pdf?OpenElement (Stand: 30.08.2018).

Künzel, Christine und Schönert, Jörg (Hg.): Autorinsz̧enierungen. Autorschaft und literarisches Werk im Kontext der Medien. Würzburg: Königshausen \& Neumann 2007.

Künzel, Christine: „Einleitung“. In: Künzel, Christine und Schönert, Jörg (Hg.): Autorinszenierungen. Autorschaft und literarisches Werk im Kontext der Medien. Würzburg: Königshausen \& Neumann 2007, S. 9-23.

Kurzal, Andreas: ,Auch Literatur braucht eine Adresse ... 'Literaturbäuser in Deutschland und Österreich. Bamberg: Otto-Friedrich-Universität, Germanistik. Diplomarbeit 1997. 
Küveler, Jan: „Die Saison wird ein Gedicht. Hauke Hückstädt berichtet über den Herbst am Literaturhaus“. In: Die Welt 27.08.2010.

Kobenhavns Biblioteker. Scenarier for den fremtidige kerneopgave: Kultur- og Fritidsforvaltningen 2018. Online verfügbar, URL: bibliotek.kk.dk/sites/koebenhavn.ddbcms.dk/files/ files/page/scenarier_for_den_fremtidige_kerneopgave_-_koebenhavns_ biblioteker.pdf (Stand: 30.08.2018).

Lange, Wolfgang: „Stille Selbstauflösung“. In: Neue Zürcher Zeitung 06.05.2002.

Latsch, Heike: „Der Verfall der Gruppe“. In: Gendolla, Peter und Leinecke, Rita (Hg.): Die Gruppe 47 und die Medien. (=Massenmedien und Kommunikation: MuK 114/115). Siegen: Fachbereich 3, Sprach- und Literaturwissenschaften, UniversitätGesamthochschule Siegen 1997, S. 115-129.

Leira, Arnlaug: „Familier og velferdsstat. Familieendring og politisk reform i 1990-åra“. In: Frønes, Ivar und Kjølsrød, Lise (Hg.): Det norske samfunn. Oslo: Gyldendal akademisk 2003, S. 261-282.

Lesen in Deutschland 2008. Lesestudie Kuraform. Hg. von Stiftung Lesen in Zusammenarbeit mit dem Bundesministerium für Bildung und Forschung. Mainz: Stiftung Lesen 2008. Online verfügbar, URL: www.stiftunglesen.de/download.php?type $=$ documentpdf\&id=11 (Stand: 30.08.2018).

Leseverbalten in Deutschland im neuen Jahrtausend. Ausgewählte Ergebnisse. Dokumentation zum Forschungsprojekt der Stiftung Lesen. Hg. von Stiftung Lesen in Zusammenarbeit mit Börsenverein des Deutschen Buchhandels, Bundesministerium für Bildung und Forschung, Spiegel-Verlag, Stiftung Presse-Grosso und Zeitungs Marketing Gesellschaft. Mainz: Stiftung Lesen 2000. Online verfügbar, URL: www.stiftunglesen.de/download.php?type=documentpdf\&id=1831 (Stand: 30.08.2018).

Lilienthal, Volker: „Marketing, Mobilität und Mündlichkeit“. In: Füssel, Stephan (Hg.): Gutenberg-Jahrbuch 2003. Mainz: Gutenberg-Gesellschaft 2003, S. 251-258.

Linderborg, Åsa: „Norge har allt som vi i Sverige saknar. En procent av den oljestinna BNP:n går till kulturen“. In: Aftonbladet 10.09.2012. Online verfügbar, URL: www.aftonbladet.se/kultur/kronikorer/linderborg/article15410661.ab (Stand: 30.08.2018).

Lipinski, Birte: Romane auf der Bühne. Form und Funktion von Dramatisierungen im deutschsprachigen Gegenwartstheater. Tübingen: Narr 2014.

Literaturhaus Hamburg: „Kurzbeschreibung Literaturhaus“. O. J. [vermutlich 1997], Archiv: Literaturhaus Hamburg.

Ljunggren, Jørn: „Finnes det en norsk kulturelite?“. In: Korsnes, Olav et al. (Hg.): Elite og klasse $i$ et egalitart samfunn. Oslo: Universitetsforlaget 2014, S. 193-210.

Löffler, Sigrid: „First Lady des Literaturhauses. Geburtstag“. In: Hamburger Abendblatt 12.02.2002.

Löffler, Sigrid: „Im Sog der Stromlinie. Der deutsche Literaturmarkt zwischen Moden und Trends“. In: Literaturen (2008), Nr. 1/2, S. 6-13.

Löfgren, Henrik (Hg.): De första trettio åren. Kulturbuset 1974-2004. Stockholm: Kulturhuset 2004 .

Lovenberg, Felicitas von: „Haus ohne Hüterin“. In: Frankefurter Allgemeine Zeitung 28.04.2009. 
Luft, Sabine: ,Visitenkarten eines Verlags'- Aufbau, Funktion und Entwicklung der Verlagsvorschau seit der 2. Hälfte des 20. Jahrbunderts. Mit einer Studie zu den Vorschauen des C. H. Beck-Verlags. Erlangen: Universität Erlangen-Nürnberg, Buchwissenschaft. Magisterarbeit 2004.

Lülfing, Hans: „Zur Entwicklung der deutschen Bibliotheksgeschichtsschreibung“. In: Archiv für Kulturgeschichte (1943), Nr. 31, S. 173-197.

Lüsebrink, Hans-Jürgen: Interkulturelle Kommunikation. Interaktion, Fremdwabrnehmung, Kulturtransfer. 3., aktualisierte und erweiterte Auflage. Stuttgart, Weimar: Metzler 2012.

Lüsebrink, Hans-Jürgen; Schmeling, Manfred und Solte-Gresser, Christiane: „Einführung. Zwischen Transfer und Vergleich“. In: Solte-Gresser, Christiane et al. (Hg.): Zwischen Transfer und Vergleich. Theorien und Methoden der Literatur- und Kulturbeziehungen aus deutsch-franæösischer Perspektive. Stuttgart: Steiner 2013, S. 9-19.

Lykkeberg, Rune: „Mellem værksted og verden. Bred tilslutning til ideen om et litteraturhus i København. Hvis Magdeburg kan, kan vi også“". In: Dagbladet Information 08.05.2001.

Mandel, Birgit (Hg.): Kulturvermittlung - zwischen kultureller Bildung und Kulturmarketing. Eine Profession mit Zukunft. Bielefeld: Transcript 2005.

Mandel, Birgit: „Event“. In: Lewinski-Reuter, Verena und Lüddemann, Stefan (Hg.): Glossar Kulturmanagement. Wiesbaden: VS Verlag für Sozialwissenschaften 2011, S. 49-55.

Mandel, Birgit (Hg.): Interkulturelles Audience Development. Zukunftsstrategien für öffentlich geförderte Kultureinrichtungen. Bielefeld: Transcript 2013.

Mandel, Birgit: „Interkulturelles Audience Development als Marketingstrategie und Veränderungsprozess öffentlich geförderter Kulturinstitutionen. Begrifflichkeiten und Ziele“. In: Mandel, Birgit (Hg.): Interkulturelles Audience Development. Zukunftsstrategien für öffentlich geförderte Kultureinrichtungen. Bielefeld: Transcript 2013, S. 11-18.

Manganelli, Giorgio: „Die Literatur als Lüge“. Aus dem Italienischen von Alice Vollenweider. In: Wagenbach, Klaus (Hg.): Giorgio Manganellis Lügenbuch. Berlin: Wagenbach 1987, S. 135-142.

Manganelli, Giorgio: „Literatur als Lüge (Auszug)“. In: Literaturhaus e. V. (Hg.): Broschüre zur Eröffnung des Literaturbauses Hamburg. Hamburg: Literaturhaus e. V. 1989, S. 12.

Mangset, Per: En armlengdes avstand eller statens forlengede arm? Om armlengdesprinsippet $i$ norsk og internasjonal kulturpolitike. Bø: Telemarksforsking, Kulturdepartementet 2003.

Martens, Eva: Literatur als öffentliches Ereignis. Eine Fallstudie qum Hamburger Literaturhaus. Köln: Universität zu Köln, Germanistik. Magisterarbeit 2005.

Martus, Steffen: „,In der Hölle soll sie braten‘. Zur Literatur der Literaturwissenschaft mit einem Seitenblick auf Matthias Polityckis, Weiberroman' und die Computerphilologie“. In: Zeitschrift für Germanistik (2007a), Nr. 1, S. 8-27.

Martus, Steffen: Werkpolitik. Zur Literaturgeschichte kritischer Kommunikation vom 17. bis ins 20. Jahrbundert. Mit Studien zu Klopstock, Tieck, Goethe und George. Berlin: De Gruyter 2007b.

Masschelein, Anneleen; Meuree, Christophe; Martens, David und Vanasten, Stéphanie: „The Literary Interview. Toward a Poetics of a Hybrid Genre“. In: Poetics Today (2014), Nr. 1/2, S. 1-49. 
Meyer, Claus Heinrich: „Kulturhauskultur. Briefe aus der Hauptstadt (9)“. In: Süddentsche Zeitung 15.03.2003.

Meyer, Petra Maria: „Vorwort“. In: Meyer, Petra Maria (Hg.): Acoustic turn. München: Wilhelm Fink 2008, S. 11-32.

Meyer, Sonja: Die Gruppe 47 und der Buchmarkt der frühen Bundesrepublik. Mit umfangreichen Korpora auf CD-ROM. Wiesbaden: Harrassowitz 2013.

Meyer-Kahrweg, Dorothee: „Hörbücher drängen aus der Nische“. In: Füssel, Stephan (Hg.): Gutenberg-Jahrbuch 2003. Mainz: Gutenberg-Gesellschaft 2003, S. 241-244.

Meyer-Kalkus, Reinhart: Stimme und Sprechkünste im 20. Jabrhundert. Berlin: Akademie Verlag 2001.

Michaelis, Rolf: „Wartesaal der Poesie. Das Literaturhaus Berlin wird eröffnet“. In: Die Zeit (1986), Nr. 27.

Modig, Jonas und Nasiell, Malin: „Stockholm Literature tar paus - utvärderar under 2018“, Pressemitteilung 08.02.2018. Online verfügbar, URL: docs.wixstatic.com/ ugd/bdfe7b_9bda3710a0904f3c8f9757f7acb742b1.pdf (Stand: 30.08.2018).

Moldenhauer, Friederike und Bitter, Joachim: Literatur veranstalten: Lesung, Vortrag, Event. Ein Ratgeber ₹u Konzept, Organisation und Durchführung. München: Meidenbauer 2005.

Moritz, Rainer: „Literaturhäuser. Ein Forum für die Literatur“. In: Arnold, Heinz Ludwig und Beilein, Matthias (Hg.): Literaturbetrieb in Deutscbland. 3. Auflage Neufassung. München: Edition Text + Kritik 2009, S. 123-129.

Moritz, Rainer: „Kontrollierte Offenheit. Literaturhaus statt ,event location““. In: Flender, Reinhard David (Hg.): Offene Räume für Kunst \& Kultur. Innovatives Kulturmanagement aus Hamburg. Berlin u. a.: Lit 2013a, S. 131-139.

Moritz, Rainer: „Der präsentierte Schriftsteller. Zur notwendigen Langeweile von Autorenlesungen". In: Kroucheva, Katerina und Schaff, Barbara (Hg.): Kafkas Gabel. Überlegungen zum Ausstellen von Literatur. Bielefeld: Transcript 2013b, S. 289-295.

Müller, Katharina: Autorenlesungen in Skandinavien um 1900. Knut Hamsun, Herman Bang, Selma Lagerlöf. Baden-Baden: Ergon 2018.

Müller-Jentsch, Walther: „Der Verein - ein blinder Fleck der Organisationssoziologie“. In: Berliner Journal für Soziologie (2008), Nr. 3, S. 476-502.

Myrhe, Aslak Sira: „Direktøren for Nasjonalbibliotekets innledning“. In: Nasjonalbiblioteket (Hg.): Bibliotekutvikling.no. Nasjonal bibliotekstrategi 2015-2018. Oslo: Nasjonalbiblioteket 2014, S. 5-6.

Nestvold, Ruth: „Der neue Autor. Die elektronische Gemeinschaft und das Ende des einsamen Schriftstellers“. In: Griem, Julika (Hg.): Bildschirmfiktionen. Interferenzen zwischen Literatur und neuen Medien. Tübingen: Narr 1998, S. 205-221.

Netzwerk der Literaturhäuser e. V.: „Das Netzwerk der Literaturhäuser gewinnt einen neuen vertrauten Partner“", Pressemitteilung 16.01.2018. Online verfügbar, URL: literaturhaus-frankfurt.de/fileadmin/user_upload/News/PM_Neues_Mitglied_im_ Netzwerk_der_Literaturhaeuser_16.1.18.pdf (Stand: 30.08.2018).

Neuhaus, Stefan: Literaturvermittlung. Konstanz: UVK 2009.

Neuhaus, Stefan und Ruf, Oliver: „Was ist Literaturvermittlung?“. In: Neuhaus, Stefan und Ruf, Oliver (Hg.): Perspektiven der Literaturvermittlung. Innsbruck: Studienverlag 2011, S. 9-23. 
Neutzling, Ulli: Typo und Layout im Web. Reinbek bei Hamburg: Rowohlt 2002.

Nielsen, Mikkel Thulstrup: „LiteraturHaus: Et kunstnerisk laboratorium“. In: Politiken 17.03.2017.

Nielsen, Susanne: „Nytt hjemsted for litterater“. In: Politiken 30.03.2005.

Nipen, Kjersti: „Dagbladet-kommentator blir ny sjef på Litteraturhuset. Styret ved Litteraturhuset har ansatt Andreas Wiese som ny daglig leder“". In: Aftenposten 26.09.2014.

Nizon, Paul: „Metropole im Kopf. Die Weltstadt - ein Laboratorium der Zukunft“. In: Frankfurter Rundschau 07.01.2000.

Nolda, Sigrid: „Paradoxa von Programmanalysen“. In: Gieseke, Wiltrud (Hg.): Institutionelle Innensichten der Weiterbildung. Bielefeld: W. Bertelsmann 2003, S. 212-227.

Noltze, Holger: Die Leichtigkeitslïge. Über Musik, Medien und Komplexität. Hamburg: Edition Körber-Stiftung 2010.

Norrmann, Ingrid: „Äntligen lade Göteborg ner sina litteraturpriser“. In: Göteborgs-Posten 16.12.2016.

Novak, Julia: „Performing the Poet, Reading (to) the Audience. Some Thoughts on Live Poetry as Literary Communication“. In: Journal of Literary Theory (2012), Nr. 2, S. 358-382. Online verfügbar, URL: www.degruyter.com/view/j/jlt.2012.6.issue-2/jlt2012-0003/jlt-2012-0003.xml (Stand: 30.08.2018).

Nünning, Ansgar: „Autor, historischer“. In: Nünning, Ansgar (Hg.): Metəler Lexikon Literatur- und Kulturtheorie. Ansätze - Personen - Grundbegriffe. 4., aktualisierte und erweiterte Auflage. Stuttgart, Weimar: Metzler 2008, S. 41-42.

Nünning, Vera und Nünning, Ansgar: „Kulturwissenschaften. Eine multiperspektivische Einführung in einen interdisziplinären Diskussionszusammenhang“". In: Nünning, Ansgar und Nünning, Vera (Hg.): Konzepte der Kulturwissenschaften. Theoretische Grundlagen - Ansätze - Perspektiven. Stuttgart, Weimar: Metzler 2003, S. 1-18.

Ohnesorg, Franz-Xaver: „Kulturbetriebe“. In: Wittmann, Waldemar et al. (Hg.): Handwörterbuch der Betriebswirtschaft. Band 2. I-Q. 5., völlig neu gestaltete Auflage. Stuttgart: Schäffer-Poeschel 1993, S. 2465-2476.

Opitz, Michael und Opitz-Wiemers, Carola: „Tendenzen in der deutschsprachigen Gegenwartsliteratur seit 1989“. In: Beutin, Wolfgang et al. (Hg.): Deutsche Literaturgeschichte. Von den Anfängen bis zur Gegenwart. 8., aktualisierte und erweiterte Auflage. Stuttgart, Weimar: Metzler 2013, S. 669-756.

Ort, Claus-Michael: „Kulturbegriffe und Kulturtheorien“. In: Nünning, Ansgar und Nünning, Vera (Hg.): Konzepte der Kulturwissenschaften. Theoretische Grundlagen - Ansätze - Perspektiven. Stuttgart, Weimar: Metzler 2003, S. 19-38.

Ortheil, Hanns-Josef: Das große Fest der Schrift. Aufzeichnungen zum Literaturfestival „Prosanova". Hildesheim: Glück und Schiller 2005.

Oster, Sandra: Das Autorenfoto in Buch und Buchwerbung. Autorinszenierung und Kanonisierung mit Bildern. Berlin: De Gruyter 2014.

Passig, Kathrin und Scholz, Aleks: „Schlamm und Brei und Bits. Warum es die Digitalisierung nicht gibt"“. In: Merkur (2015), Nr. 798, S. 75-81. 
Paulsen, Kerstin: „Von Amazon bis Weblog. Inszenierung von Autoren und Autorschaft im Internet". In: Künzel, Christine und Schönert, Jörg (Hg.): Autorinszenierungen. Autorschaft und literarisches Werk im Kontext der Medien. Würzburg: Königshausen \& Neumann 2007, S. 257-269.

Peers, Katharina und Wolf, Heinrich: „Frische Ware fürs Feld. Der Deutsche Buchpreis als Akteur im Literaturbetrieb“. In: Irsigler, Ingo und Lembke, Gerrit (Hg.): Spiel, Satz. und Sieg. 10 Jahre Deutscher Buchpreis. Berlin: Berlin University Press 2014, S. 31-42.

Pettersson, Magnus: „Litteraturhusen allt fler - men inte i Sverige“. In: Göteborgs-Posten 20.02.2008.

Plachta, Bodo: „Das Dichterhaus. Ein Ort für ,abgelebte“ Dinge“. In: Neuhaus, Stefan und Ruf, Oliver (Hg.): Perspektiven der Literaturvermittlung. Innsbruck: Studienverlag 2011, S. 380-392.

Plath, Jörg: „Ein Herr aus Gründerzeiten. Kommen und Gehen: Direktorenwechsel im Literaturhaus“. In: Der Tagesspiegel 28.02.2003.

Plinke, Manfred: „Autorenverband/-vereinigung“. In: Schütz, Erhard (Hg.): Das BuchMarktBuch. Der Literaturbetrieb in Grundbegriffen. Reinbek bei Hamburg: Rowohlt 2005, S. 34-38.

Porombka, Stephan: „Vom Event zum Non-Event und zurück. Über den notwendigen Zusammenhang von Literatur und Marketing“. In: Böhm, Thomas (Hg.): Aufkurze Distan₹: Die Autorenlesung: O-Töne, Geschichten, Ideen. Köln: Tropen 2003, S. 125-139.

Porombka, Stephan: „,Der Autor schaut direkt in die Kamera (und damit dem Zuschauer in die Augen)'. Über alte und neue Formen der Literaturvermittlung“. In: Mandel, Birgit (Hg.): Kulturvermittlung - zwischen kultureller Bildung und Kulturmarketing. Eine Profession mit Zukunft. Bielefeld: Transcript 2005, S. 205-216.

Porombka, Stephan: „Literaturbetriebskunde. Zur ,genetischen Kritik` kollektiver Kreativität“". In: Porombka, Stephan et al. (Hg.): Kollektive Kreativität. Tübingen: Francke 2006, S. 72-87.

Porombka, Stephan und Splittgerber, Kai: Studie zur Literaturvermittlung in den fünf neuen Bundesländern zu Beginn des 21. Jahrbunderts. 3., um ein Nachwort und kritische Stellungnahmen erweiterte Fassung. Hildesheim u. a.: Netzwerk der Literaturhäuser e. V. 2010. Online verfügbar, URL: literaturhaus.webteam.de/lithausData/dateien/ pdf/originals/studie_4d.pdf (Stand: 30.08.2018).

Posner, Roland: „Kultursemiotik“. In: Nünning, Ansgar und Nünning, Vera (Hg.): Konzepte der Kulturwissenschaften. Theoretische Grundlagen - Ansätze - Perspektiven. Stuttgart, Weimar: Metzler 2003, S. 39-72.

Präauer, Teresa: „Lesungen, wozu?““. In: Bernhofer, Edith et al. (Hg.): Zwischen Schreiben und Lesen. Über Situation, Herausforderungen und Möglichkeiten von Literatur und Literaturvermittlung in Österreich. Wien: Klever 2016, S. 57-64.

Pröhl, Stefan: „Interdisziplinär mit prägendem Ambiente. Das Literaturhaus wird zehn - sein Verhältnis zur hiesigen Autorenszene ist längst entkrampft“. In: taz, hamburg 11.09.1999.

Prop. 135 L (2012-2013) Proposisjon til Stortinget (forslag til lovvedtak). Endringer i lov om folkebibliotek. Hg. von Det kongelige kulturdepartement. Oslo: Det kongelige kulturdepartement 2013. Online verfügbar, URL: www.regjeringen.no/contentassets/9942dc16bdb3427982c7e68cb717 5b00/no/pdfs/prp201220130135000dddpdfs.pdf (Stand: 30.08.2018). 
Prytz, Øyvind: Litteratur i digitale omgivelser. En forstudie. Oslo: Kulturrådet 2013.

Raddatz, Fritz J.: „Die Auflösung des kausalen Denkens durch die Häppchen-Kultur““ In: Hoffmann, Hilmar (Hg.): ,Kultur-Zerstörung?؛ 10. Römerberggespräche in Frankfurt am Main. Königstein im Taunus: Athenäum 1983, S. 130-135.

Rautenberg, Ursula: „Buch“. In: Rautenberg, Ursula (Hg.): Reclams Sacblexikon des Buches. Von der Handschrift zum E-Book. 3., vollständig überarbeitete und aktualisierte Auflage. Stuttgart: Reclam 2015, S. 65-68.

Rautenberg, Ursula und Kuhn, Axel: „Lesen“. In: Rautenberg, Ursula (Hg.): Reclams Sachlexikon des Buches. Von der Handschrift zum E-Book. 3., vollständig überarbeitete und aktualisierte Auflage. Stuttgart: Reclam 2015, S. 257-260.

Reckwitz, Andreas: Die Gesellschaft der Singularitäten. Zum Strukturwandel der Moderne. Berlin: Suhrkamp 2017.

Reich-Ranicki, Marcel: „Hüben und drüber. Unbehagen“. In: Die Zeit (1962), Nr. 8.

Reichwein, Marc: „Diesseits und jenseits des Skandals. Literaturvermittlung als zunehmende Inszenierung von Paratexten“. In: Neuhaus, Stefan und Holzer, Stefan (Hg.): Literatur als Skandal. Fälle - Funktionen - Folgen. Göttingen: Vandenhoeck \& Ruprecht 2007, S. 89-99.

Reifsteck, Peter: Handbuch Lesungen und Literaturveranstaltungen. Konzeption, Organisation, Öffentlichkeitsarbeit. 3., aktualisierte, überarbeitete und erweiterte Auflage. Reutlingen: Reifsteck 2005.

Renz, Peter (Hg.): Dichterlesung. Der Kampf des Autors mit dem Publikum. Friedrichshafen: Gessler 1988.

Renz, Thomas: Nicht-Besucherforschung. Die Förderung kultureller Teilhabe durch Audience Development. Bielefeld: Transcript 2016.

Reuter, Susanne: Literaturbäuser in deutschen Großstädten. Eine vergleichende Studie über inhaltliche, organisatorische und marketingstrategische Konzeptionen. Hamburg: Hochschule für $\mathrm{Mu}-$ sik und Theater, Kultur- und Medienmanagement. Diplomarbeit 2000.

Riebsamen, Hans: „Beckermann hört auf. Der Leiter des Literaturhauses hat nach fünf Jahren gekündigt“". In: Frankfurter Allgemeine Zeitung 01.03.1995.

Rinck, Monika: „Oft geht es eine Treppe hinab, seltener auch eine Treppe herauf“. In: Böhm, Thomas (Hg.): Auf kurze Distan₹. Die Autorenlesung: O-Töne, Gescbichten, Ideen. Köln: Tropen 2003, S. 78-92.

Rippl, Gabriele und Winko, Simone (Hg.): Handbuch Kanon und Wertung. Theorien, Instanzen, Geschichte. Stuttgart, Weimar: Metzler 2013.

Rippl, Gabriele und Winko, Simone: „Einleitung“. In: Rippl, Gabriele und Winko, Simone (Hg.): Handbuch Kanon und Wertung. Theorien, Instanzen, Geschichte. Stuttgart, Weimar: Metzler 2013, S. 1-5.

Rosengren, Anna und Ulin, Jonna: Förslag till fördelning av verksambetsstöd andra halvåret 2015 till Göteborgs Litteraturbus. Hg. von Göteborgs Stad Kultur. Göteborg: Göteborgs Stad Kultur 2015. Online verfügbar, URL: www4.goteborg.se/prod/ Intraservice/Namndhandlingar/SamrumPortal.nsf/ 9C0A44023960C34BC1257EE00034612B/\$File/Nr_11_Verksamhetsstod_ Goteborgs_Litteraturhus_andra_halvaret_2015.pdf?OpenElement (Stand: 30.08.2018). 
Rössner, Michael und Uhl, Heidemarie (Hg.): Renaissance der Authentizität? Über die neue Sehnsucht nach dem Ursprünglichen. Bielefeld: Transcript 2012.

Rössner, Michael und Uhl, Heidemarie: „Vorwort“. In: Rössner, Michael und Uhl, Heidemarie (Hg.): Renaissance der Authentizität? Über die neue Sehnsucht nach dem Ursprünglichen. Bielefeld: Transcript 2012, S. 9-12.

Rothholz, Walter: „Norwegen und die EG“. In: Schottmann, Hans (Hg.): Arbeiten zur Skandinavistik. Dokumentation der 11. Arbeitstagung der deutschsprachigen Skandinavistik, 8.-14.8.1993 in Sigtuna. Münster: Kleinheinrich 1994, S. 436-446.

Rott, Wilfried: Die Insel. Eine Geschichte West-Berlins 1948-1990. München: C. H. Beck 2009.

Rushkoff, Douglas: Present Shock. Wenn alles jetzt passiert. Aus dem Englischen von Gesine Schröder und Andy Hahnemann. Freiburg: Orange Press 2014.

Rütten, Marion: „Die Länderschwerpunkte ab 1988. Fallbeispiele Italien und Frankreich“. In: Füssel, Stephan (Hg.): 50 Jabre Frankfurter Buchmesse. 1949-1999. Frankfurt am Main: Suhrkamp 1999, S. 139-149.

Sanders, Hans: Institution Literatur und Roman. Zur Rekonstruktion der Literatursoziologie. Frankfurt am Main: Suhrkamp 1981.

Sandmark, Björn und Frizell, Kristina: Litteraturens hus - ett steg vidare. Göteborg: Göteborgs Stad Kultur 2012. Online verfügbar, URL: www4.goteborg.se/prod/Intraservice/Namndhandlingar/SamrumPortal. nsf/CCA360B3D0928E99C1257A7C004B58CB/\$File/8_Litteraturens_hus.pdf?Op enElement (Stand: 30.01.2017).

Sandmark, Björn und Frizell, Kristina: Förslag till hantering och utformning av två litterära pris: Göteborgs Stads litteraturpris. Göteborg: Göteborgs Stad Kultur 2013a. Online verfügbar, URL: www5.goteborg.se/prod/intraservice/namndhandlingar/ namndhandlingararkiv/samrumportalarkiv.nsf/0/2626d989e52ee76fc125 7b2e002d0099/\$file/12_tu_tva_litterara_pris.pdf (Stand: 30.08.2018).

Sandmark, Björn und Frizell, Kristina: Förslag till hantering och organisation av Litteraturens bus/Rum för litteratur. Göteborg: Göteborgs Stad Kultur 2013b. Online verfügbar, URL: www5.goteborg.se/prod/intraservice/namndhandlingar/ namndhandlingararkiv/samrumportalarkiv.nsf/0/e24c77b8b6c2db3ec1257b2 e002e697d/\$file/18_tu_organisation_litteraturens_hus.pdf (Stand: 30.08.2018).

Sandmark, Björn und Magnusson, Eva: Förslag om framtida drift av Litteraturbuset. Göteborg: Göteborgs Stad Kultur 2014. Online verfügbar, URL: www5.goteborg.se /prod/intraservice/namndhandlingar/namndhandlingararkiv/samrumportalarkiv.ns f/0/7342ac5bde140d84c1257ce6004b0113/\$file/14_tu_forslag_om_framtida_drift_ av_litteraturhuset.pdf (Stand: 30.08.2018).

Sandmark, Björn: „Så lyckas man med ett litteraturhus“. In: Dala-Demokraten 16.01.2016.

Sarkowicz, Hans: „Hörbuch und Rundfunk“. In: Füssel, Stephan (Hg.): GutenbergJabrbuch 2003. Mainz: Gutenberg-Gesellschaft 2003, S. 245-250.

„Satzung Literaturhaus Berlin e. V.“ O. J., Archiv: Literaturhaus Berlin.

sb. (Kürzel): „Treffpunkt für Literaten. Diskussion zum Thema ,Frankfurt - Literaturstadt?"“. In: Frankfurter Allgemeine Zeitung Rhein-Main-Zeitung 10.10.1989. 
Schaff, Barbara: „Literaturfestivals. Überlegungen zur Eventisierung von Literatur“. In: Kroucheva, Katerina und Schaff, Barbara (Hg.): Kafkas Gabel. Überlegungen zum Ausstellen von Literatur. Bielefeld: Transcript 2013, S. 271-288.

Schaffrick, Matthias und Willand, Marcus: „Auswahlbibliographie. Autorschaftsforschung zwischen 2000 und 2014“. In: Schaffrick, Matthias und Willand, Marcus (Hg.): Theorien und Praktiken der Autorschaft. Berlin: De Gruyter 2014, S. 615-655.

Schalansky, Judith (Hg.): S-Bahn nach Arkadien. Das literarische Colloquium Berlin in Wort und Bild. 50 Jahre Literarisches Colloquium Berlin. Berlin: Matthes \& Seitz 2013.

Schellen, Petra: „Buch macht froh. Der neue Literaturhaus-Leiter Rainer Moritz jovialt mit Denis Scheck“. In: taz am Wochenende 11.12.2004.

Schenk, Günter und Krause, Andrej: „Vergleich“. In: Ritter, Joachim et al. (Hg.): Historisches Wörterbuch der Philosophie. Band 11. U-V. Darmstadt: Wissenschaftliche Buchgesellschaft 2001, S. 676-680.

Schenkel, Hubertus: „Buchpreisbindung“. In: Schütz, Erhard (Hg.): Das BuchMarktBuch. Der Literaturbetrieb in Grundbegriffen. Reinbek bei Hamburg: Rowohlt 2005, S. 88-91.

Schimank, Uwe: „Handeln in Institutionen und handelnde Institutionen“. In: Jaeger, Friedrich und Straub, Jürgen (Hg.): Handbuch der Kulturwissenschaften. Band

2. Paradigmen und Disziplinen. Stuttgart, Weimar: Metzler 2004, S. 293-307.

Schimank, Uwe: „Hochschule als Institution: Gussform, Arena und Akteur“. In: Zimmermann, Karin et al. (Hg.): Perspektiven der Hochschulforschung. Wiesbaden: VS Verlag für Sozialwissenschaften 2008, S. 157-163.

Schlaeger, Jürgen: „Interdisziplinarität“. In: Nünning, Ansgar (Hg.): Metəller Lexikon Literatur- und Kulturtheorie. Ansätze - Personen - Grundbegriffe. 4., aktualisierte und erweiterte Auflage. Stuttgart, Weimar: Metzler 2008, S. 324-325.

Schlaffer, Heinz: „Der Umgang mit Literatur. Diesseits und jenseits der Lektüre“. In: Poetica. Zeitschrift für Sprach- und Literaturwissenschaft (1999), Nr. 31, S. 1-25.

Schmidt, Hans-Christian: „Hörfunk in Nöten? Liebeserklärung in kritischsympathischer Dankbarkeit an öffentlich-rechtliche Musikredakteure“. In: Die Zeit (1991), Nr. 33.

Schmidt, Robert: „,Von der Performativität zu den Praktiken. Anregungen für eine Praxeografie des Textuellen“. In: Grage, Joachim und Schröder, Stephan Michael (Hg.): Milieus, Akteure, Medien. Zur Vielfalt literarischer Praktiken um 1900. Würzburg: Ergon 2013, S. 11-25.

Schmidt, Siegfried J.: Grundriß der Empirischen Literaturwissenschaft. Teilband 1. Der gesellschaftliche Handlungsbereich Literatur. Braunschweig, Wiesbaden: Friedrich Vieweg \& Sohn 1980.

Schmidt, Ulrich und Vogt, Michael (Hg.): aussicht, absicht, einsicht. 25 Jabre Bielefelder Colloquium Neue Poesie. Bielefeld: Aisthesis 2002, CD.

Schmitt, Susann Sophie: Nachwuchs für die Literatur. Kinder-und Jugendprogramme ausgewählter Literaturhäuser Deutschlands, Österreichs und der Schweiæ. Frankfurt am Main: Peter Lang 2016.

Schneider, Jost: Sozialgeschichte des Lesens. Zur historischen Entwicklung und sozialen Differenzierung der literarischen Kommunikation in Deutschland. Berlin: De Gruyter 2004.

Schneider, Wolfgang (Hg.): Kulturelle Bildung braucht Kulturpolitik. Hilmar Hoffmanns Kultur für alle reloaded. Hildesheim: Universitätsverlag 2010. 
Schneider-Kempf, Barbara; Saur, Klaus G. und Schuster, Peter-Klaus (Hg.): Wissenschaft und Kultur in Bibliotheken, Museen und Archiven. Klaus-Dieter Lehmann zum 65. Geburtstag. München: Saur 2005.

Schnell, Nicola: „Corporate Identity“. In: Schütz, Erhard (Hg.): Das BuchMarktBuch. Der Literaturbetrieb in Grundbegriffen. Reinbek bei Hamburg: Rowohlt 2005, S. 95-97.

Schnell, Ralf: „Die Literatur der Bundesrepublik“. In: Beutin, Wolfgang et al. (Hg.): Deutsche Literaturgeschichte. Von den Anfängen bis zur Gegenwart. 8., aktualisierte und erweiterte Auflage. Stuttgart, Weimar: Metzler 2013, S. 598-668.

Schöne, Veronika: „Spiegelschrift. Seit zehn Jahren: Ursula Keller leitet das Literaturhaus Hamburg“". In: Süddeutsche Zeitung 14.02.2002.

Schöning, Udo und Pohl, Burkhard: „Einleitung“. In: Engelbert, Manfred et al. (Hg.): Märkte, Medien, Vermittler. Fallstudien zur interkulturellen Vernetzung von Literatur und Film. Göttingen: Wallstein 2001, S. 9-31.

Schoon, Andi: „Hamburgs Literaturszene boomt. Nobles an der Außenalster, frischer Wind aus dem Off“. In: Hosfeld, Rolf (Hg.): Hamburg Kultur-ver-führer. 4., aktualisierte Auflage. Hamburg: Metz 2005, S. 194-196.

Schöttker, Detlev: „Der literarische Souverän. Autorpräsenz als Voraussetzung für Kanonpräsenz“. In: Arnold, Heinz Ludwig und Korte, Hermann (Hg.): Literarische Kanonbildung. München: Edition Text + Kritik 2002, S. 277-290.

Schröder, Christoph: „Frankfurter Wechselfälle. Literaturhaus und Literaturforum“. In: Frankfurter Rundschau 01.02.2010.

Schruhl, Friederike: Formationen der Praxis. Studien zu Darstellungsformen von Digital Humanities und Literaturwissenschaft. Göttingen: V \& R Unipress 2020 (im Druck).

Schulz, Gabriele: „Zahlen - Daten - Fakten. Geschlechterverhältnisse im Kultur- und Medienbetrieb“. In: Schulz, Gabriele et al. (Hg.): Frauen in Kultur und Medien: Ein Überblick über aktuelle Tendenzen, Entwicklungen und Lösungsvorschläge. Berlin: Deutscher Kulturrat e. V. 2016, S. 27-361.

Schulze, Gerhard: Die Erlebnisgesellschaft. Kultursoziologie der Gegenwart. 4. Auflage. Frankfurt am Main, New York: Campus 1993.

Schulze, Gerhard: „Die Zukunft der Erlebnisgesellschaft“. In: Nickel, Oliver (Hg.): Eventmarketing. Grundlagen und Erfolgsbeispiele. 2., vollständig überarbeitete Auflage. München: Vahlen 2007, S. 309-320.

Seegers, Armgard: „Sprache ist auch Theater. Ursula Kellers neue Konzepte“. In: Hamburger Abendblatt 29.10.1991.

Seegers, Armgard: „Ursula Keller und die Büchse der Pandora. Literaturhaus: Matthias Wegner über den Führungs-Streit am Schwanenwik“. In: Hamburger Abendblatt 05.02.2004.

Segeberg, Harro: „Menschsein heißt, medial sein wollen. Autorinszenierung im Medienzeitalter". In: Künzel, Christine und Schönert, Jörg (Hg.): Autorinszenierungen. Autorschaft und literarisches Werk im Kontext der Medien. Würzburg: Königshausen \& Neumann 2007, S. 245-256.

Seiler, Thomas: „Modernismus (1940-1980)“. In: Glauser, Jürg (Hg.): Skandinavische Literaturgeschichte. Stuttgart, Weimar: Metzler 2006, S. 271-331.

Senat von Berlin - Kultur: „Beschluss Literaturhaus“. Protokoll Haupttauschuss 11.05.1983, Archiv: Literaturhaus Berlin. 
Siblewski, Klaus und Ortheil, Hanns-Josef (Hg.): Die ideale Lesung. Mainz: Dieterich'sche Verlagsbuchhandlung 2017.

Simanowski, Roberto: „Einleitung. Zum Problem kultureller Grenzziehung“. In: Turk, Horst et al. (Hg.): Kulturelle Grenzriebungen im Spiegel der Literaturen. Nationalismus, Regionalismus, Fundamentalismus. Göttingen: Wallstein 1998, S. 8-60.

Simanowski, Roberto: „Einleitung. Der Salon als dreifache Vermittlungsinstanz“. In: Simanowski, Roberto et al. (Hg.): Europa - ein Salon? Beiträge zur Internationalität des literarischen Salons. Göttingen: Wallstein 1999, S. 8-39.

Skaftnesmo, Hilde Kari: Litteraturbuset forfatterne ikke ville ha? En diskursanalyse av debatten om Litteraturbuset i Bergen. Telemark: Høgskolen i Telemark, Kultur- und Geisteswissenschaften. Masterarbeit 2014. Online verfügbar, URL: teora.hit.no/bitstream/ handle/2282/2321/LitteraturhusdebattMasteroppgaveHildeKari.pdf?sequence $=1$ (Stand: 30.08.2018).

Skaftnesmo, Hilde Kari: „Hvorfor litteraturhus? Debatten om Litteraturhuset i Bergen“. In: Samtiden (2016), Nr. 2, S. 30-44.

Söderling, Fredrik: „Stockholm får hus för litteratur“. In: Dagens Nyheter 29.08.2012.

Soltau, Heide: „Ursula Keller - seit 10 Jahren Chefin des Hamburger Literaturhauses“. Transkription des Beitrags von NDR 4 Info 12.02.2002, Archiv: Literaturhaus Hamburg.

Solte-Gresser, Christiane: „Potenziale und Grenzen des Vergleichs. Versuch einer literatur- und kulturwissenschaftlichen Systematik“. In: Solte-Gresser et al. (Hg.): Zwischen Transfer und Vergleich. Theorien und Methoden der Literatur- und Kulturbeziebungen aus deutsch-französischer Perspektive. Stuttgart: Steiner 2013, S. 23-35.

Spoerhase, Carlos und Martus, Steffen: „Praxeologie der Literaturwissenschaft“. In: Gescbicbte der Germanistik (2009), Nr. 35/36, S. 89-96.

Spoerhase, Carlos: „Literaturwissenschaft und Gegenwartsliteratur“. In: Merkur (2014), Nr. 776, S. 15-24.

Stach, Reiner: 100 Jahre S.-Fischer-Verlag. 1886-1986. 3. Auflage. Frankfurt am Main: Fischer 2003.

Starre, Alexander: Metamedia. American book fictions and literary print culture after digitization. Iowa City: University of Iowa Press 2015.

Statistisches Amt für Hamburg und Schleswig-Holstein: Hamburger Stadtteil-Profile 2015. Hg. von Statistisches Amt für Hamburg und Schleswig. Hamburg 2015 (=NORD.regional 17). Online verfügbar, URL: www.statistik-nord.de/fileadmin/ Dokumente/NORD.regional/NR17_Statistik-Profile_HH_2015.pdf (Stand: 30.08.2018).

Statistisches Amt für Hamburg und Schleswig-Holstein: „Bevölkerung in Hamburg 2015. Bevölkerungszahl weiter gestiegen“, Pressemitteilung 24.08.2016. Online verfügbar, URL: www.statistik-nord.de/fileadmin/Dokumente/Presseinformationen/ SI16_131.pdf (Stand: 30.08.2018).

Steinfeld, Thomas: „Dichter Tourismus. Der Schriftsteller und die literarische Dienstreise“. In: Merkur (1988), Nr. 477, S. 978-987.

Steinfeld, Thomas: Der leidenschaftliche Buchbalter. Philologie als Lebensform. München: Hanser 2004. 
Steinmetz, Hanna: „Urbanes Design von Atmosphären. Ästhetische und sinnengeleitete Praktiken mit Gebäuden“. In: Prinz, Sophia und Moebius, Stephan (Hg.): Das Design der Gesellschaft. Zur Kultursoziologie des Designs. Bielefeld: Transcript 2012, S. 337-358.

Stenseth, Bodil: Wergelandsveien. Fra Grotten til Litteraturhuset. Oslo: Press 2013.

Streisand, Marianne: Intimität. Begriffsgeschichte und Entdeckung der ,Intimität' auf dem Theater um 1900. München: Wilhelm Fink 2001.

Tgahrt, Reinhard (Hg.): Dichter lesen. Band 1. Von Gellert bis Liliencron. Marbach am Neckar: Deutsche Schillergesellschaft 1984.

Tgahrt, Reinhard (Hg.): Dichter lesen. Band 2. Jahrbundertwende. Marbach am Neckar: Deutsche Schillergesellschaft 1989.

Tgahrt, Reinhard (Hg.): Dichter lesen. Band 3. Vom Expressionismus in die Weimarer Republik. Marbach am Neckar: Deutsche Schillergesellschaft 1995.

Theisohn, Philipp und Weder, Christine: „Literatur als/statt Betrieb. Einleitung“. In: Theisohn, Philipp und Weder, Christine (Hg.): Literaturbetrieb. Zur Poetik einer Produktionsgemeinschaft. München: Wilhelm Fink 2013, S. 7-16.

Thiele, Wolfgang: „Text“. In: Nünning, Ansgar (Hg.): Metəler Lexikon Literatur- und Kulturtheorie. Ansätz̧e - Personen - Grundbegriffe. 4., aktualisierte und erweiterte Auflage. Stuttgart, Weimar: Metzler 2008, S. 706.

Thomsen, Thomas Bo und Starup, Marie: „LiteraturHaus - litteraturens hjemmebane?". In: Dagbladet Information 12.04.2006.

Tielebier-Langenscheidt, Florian: Werbung für deutsche Gegenwartsliteratur. Ein Beitrag zur Theorie und Praxis der Literaturvermittlung. Frankfurt am Main: BuchhändlerVereinigung 1983.

Tschopp, Silvia Serena: „Überlegungen zu einer historischen Leseforschung der Gegenwart. Im Gespräch mit Friederike Schruhl und Matthias Beilein“. In: Böck, Sebastian et al. (Hg.): Lesen X.0. Rezeptionsprozesse in der digitalen Gegenwart. Göttingen: V \& R Unipress 2017, S. 281-298.

Tuschling, Jeanine: Autorschaft in der digitalen Literatur. Bremen: Universität Bremen 2006 (=Materialien und Ergebnisse aus Forschungsprojekten des Institutes/Institut für Kulturwissenschaftliche Deutschlandstudien an der Universität Bremen, Fachbereich 10 19).

Twickel, Christoph: „Keine Häppchen. Interview mit Rainer Moritz“. In: Die Zeit (2014), Nr. 37.

Uschtrin, Sandra und Hinrichs, Heribert (Hg.): Handbuch für Autorinnen und Autoren. 8., völlig überarbeitete und erweiterte Auflage. Inning am Ammersee: Uschtrin 2015.

Uschtrin, Sandra: „Lesungen. Mehr als ein Zubrot“. In: Uschtrin, Sandra und Hinrichs, Heribert (Hg.): Handbuch für Autorinnen und Autoren. 8., völlig überarbeitete und erweiterte Auflage. Inning am Ammersee: Uschtrin 2015, S. 540-547.

Ustorf, Anne-Ev: „,Ende mit Schrecken‘. Dr. Ursula Keller zu ihrem Abschied vom Literaturhaus 2005“. In: Szene Hamburg (2004), Nr. 1, S. 59.

Vaihinger, Dirk: „Backlist“. In: Schütz, Erhard (Hg.): Das BuchMarktBuch. Der Literaturbetrieb in Grundbegriffen. Reinbek bei Hamburg: Rowohlt 2005, S. 39-41.

Vandenrath, Sonja: „Zwischen LitClubbing und Roundtable. Strategien von Literaturhäusern". In: Schütz, Erhard und Wegmann, Thomas (Hg.): literatur.com. Tendenzen im Literaturmarketing. Berlin: Weidler 2002, S. 172-188. 
Vandenrath, Sonja: Private Förderung zeitgenössischer Literatur. Eine Bestandsaufnahme. Bielefeld: Transcript 2006.

Vandenrath, Sonja: „Das Gespenst des Events. Zum Relaunch der Wasserglaslesung“. In: Dittberner, Hugo et al. (Hg.): Zukunft der Literatur. München: Edition Text + Kritik 2013, S. 122-131.

Varela, Marie: „Junge Gegenwartsdichterinnen zu Gast in Göttingen“. In: Göttinger Tageblatt 08.02.2010.

Verksambetsberättelse 2017. Göteborg: Göteborgs Litteraturhus 2018. Online verfügbar, URL: goteborgslitteraturhus.se/wp-content/uploads/2018/02/Verksamhetsbera \%CC\%88ttelse-2017.pdf (Stand: 30.08.2018).

Vassenden, Eirik: Den store overflaten. Tekster om samtidslitteraturen. Oslo: Damm 2004.

Vogel, Anke: Der Buchmarkt als Kommunikationsraum. Eine kritische Analyse aus medienwissenschaftlicher Perspektive. Wiesbaden: VS Verlag für Sozialwissenschaften 2011.

Vogel, Sabine: „Tagebuch. Ein Wohlfühlfest für die Leser“. In: Berliner Zeitung 17.09.2005.

„Vorläufige Konzeption für das Literaturhaus Wintergarten“. Konzeptpapier o. J. [vermutlich Frühjahr 1983], Archiv: Literaturhaus Berlin.

Wagner, Hans-Ulrich: „Über den ,Sitzplatz eines Autors‘. Inszenierung von Autorschaft und Werk als Medienereignis bei Siegfried Lenz“. In: Künzel, Christine und Schönert, Jörg (Hg.): Autorinszenierungen. Autorschaft und literarisches Werk im Kontext der Medien. Würzburg: Königshausen \& Neumann 2007, S. 111-128.

Waldenfels, Bernhard: Pbänomenologie der Aufmerksamkeit. Frankfurt am Main: Suhrkamp 2004.

Weber, Wilfried: „Literaturhaus contra Buchhandel. Die subventionierte Konkurrenz?“. In: Abel, Jürgen et al. (Hg.): Hamburger Ziegel. Jahrbuch für Literatur. Hamburg: Dölling und Galitz 1992, S. 421-424.

Wegmann, Thomas: „Zwischen Gottesdienst und Rummelplatz. Das Literaturfestival als Teil der Eventkultur“. In: Schütz, Erhard und Wegmann, Thomas (Hg.): literatur.com. Tendenzen im Literaturmarketing. Berlin: Weidler 2002, S. 121-136.

Wegmann, Thomas: „Autor“. In: Schütz, Erhard (Hg.): Das BuchMarktBuch. Der Literaturbetrieb in Grundbegriffen. Reinbek bei Hamburg: Rowohlt Taschenbuch 2005a, S. 25-31.

Wegmann, Thomas: „Literaturfestival“. In: Schütz, Erhard (Hg.): Das BuchMarktBuch. Der Literaturbetrieb in Grundbegriffen. Reinbek bei Hamburg: Rowohlt Taschenbuch 2005b, S. 223-226.

Wegmann, Thomas: Dichtung und Warenzeichen. Reklame im literarischen Feld 1850-2000. Göttingen: Wallstein 2011.

Wegmann, Thomas: „Das Haus. Prolegomena zur Literaturgeschichte einer affektiven Immobilie“. In: Zeitschrift für Germanistik (2016), Nr. 1, S. 40-60.

Weichhart, Peter: „Das ,Trans-Syndrom‘. Wenn die Welt durch das Netz unserer Begriffe fällt". In: Hühn, Melanie et al. (Hg.): Transkulturalität, Transnationalität, Transstaatlichkeit, Translokalität. Theoretische und empirische Begriffshestimmungen. Münster u. a.: Lit 2010, S. 47-70.

Weiss, Christina: Seh-Texte. Zur Erweiterung des Textbegriffes in konkreten und nach-konkreten visuellen Texten. Zirndorf: Verlag für Moderne Kunst 1984. 
Weiss, Christina: „Konzept“. In: Literaturhaus e. V. (Hg.): Broschüre zur Eröffnung des Literaturbanses Hamburg. Hamburg: Literaturhaus e. V. 1989, S. 10.

Weiss, Christina: Stadt ist Bühne. Kulturpolitik heute. Hamburg: Europäische Verlagsanstalt 1999.

wend. (Kürzel): „Literaturhaus: Diesmal war alles ganz anders“. In: Hamburger Abendblatt 13.02.2002.

Wendland, Anna Veronika: „Cultural Transfer“. In: Neumann, Birgit und Nünning, Ansgar in Zusammenarbeit mit Horn, Mirjam (Hg.): Travelling concepts for the study of culture. Berlin, Boston: De Gruyter 2012, S. 45-66.

Werber, Niels: „Im gleichen Rhythmus schwingen. Der Literaturwissenschaftler Hans Ulrich Gumbrecht erlebt die ,Dinge dieser Welt““. In: Frankfurter Rundschau 07.10.2004.

Werner, Michael und Zimmermann, Bénédicte: „Vergleich, Transfer, Verflechtung. Der Ansatz der Histoire croisée und die Herausforderung des Transnationalen“. In: Geschichte und Gesellschaft (2002), Nr. 4, S. 607-636.

Wetzel, Michael: „Artefaktualitäten. Zum Verhältnis von Authentizität und Autorschaft"“. In: Knaller, Susanne und Müller, Harro (Hg.): Authentizität. Diskussion eines ästhetischen Begriffs. München: Wilhelm Fink 2006, S. 36-54.

Wiesner, Herbert: „Leserbrief an Berkholz. Betreff: Tucholsky Gedenken“. Brief 27.12.1995, Archiv: Literaturhaus Berlin.

Wiesner, Herbert: „Man möge lesen! Literaturhäuser und ihre Funktion - Eine Entgegnung auf Jürgen Kolbe“. In: Der Tagesspiegel 02.07.1997.

Wiesner, Herbert: „Literaturhäuser“. In: Schnell, Ralf (Hg.): Metəler Lexikon Kultur der Gegenwart. Themen und Theorien, Formen und Institutionen seit 1945. Stuttgart: Metzler 2000, S. 311-312.

Wiesner, Herbert: „Markenzeichen für Vermittlung. Vom Werden der Literaturhäuser in Berlin“. In: Kölner Stadt-Anzeiger 34 10.02.2004.

Wilkens, André: Analog ist das neue Bio. Ein Plädoyer für eine menschliche digitale Welt. Bonn: Bundeszentrale für Politische Bildung 2015.

Winkler, Markus: „Nationalphilologien und Komparatistik“. In: Zymner, Rüdiger und Hölter, Achim (Hg.): Handbuch Komparatistik. Theorien, Arbeitsfelder, Wissenspraxis. Stuttgart, Weimar: Metzler 2013, S. 190-193.

Winko, Simone: „Literarische Wertung und Kanonbildung“. In: Arnold, Heinz Ludwig und Detering, Heinrich (Hg.): Grundzüge der Literaturwissenschaft. 3. Auflage. München: Deutscher Taschenbuch Verlag 1996, S. 585-600.

Winko, Simone: „Literatur-Kanon als invisible hand-Phänomen“. In: Arnold, Heinz Ludwig und Korte, Hermann (Hg.): Literarische Kanonbildung. München: Edition Text + Kritik 2002, S. 9-25.

Wischmann, Antje: „Gegenwart (1980-2000““. In: Glauser, Jürg (Hg.): Skandinavische Literaturgeschichte. Stuttgart, Weimar: Metzler 2006, S. 332-389.

Wittmann, Reinhard G.: „Die Schriftsteller und das literarische Kräftefeld“. In: Funk, Holger und Wittmann, Reinhard G. (Hg.): Literatur-Hauptstadt. Schriftsteller in Berlin heute. Berlin: Berlin-Verlag 1983, S. 31-368. 
Wolf, Werner: „Intermedialität“. In: Nünning, Ansgar (Hg.): Metəler Lexikon Literaturund Kulturtheorie. Ansätze - Personen - Grundbegriffe. 4., aktualisierte und erweiterte Auflage. Stuttgart, Weimar: Metzler 2008, S. 327-328.

Wolff, Stephan: „Wege ins Feld und ihre Varianten“. In: Flick, Uwe et al. (Hg.): Qualitative Forschung. Ein Handbuch. 10. Auflage. Reinbek bei Hamburg: Rowohlt 2013, S. 334-349.

Wrobel, Dieter: „Lesekultur und literarisches Leben. Literaturunterricht als Ort und Institution der Literaturvermittlung“. In: Neuhaus, Stefan und Ruf, Oliver (Hg.): Perspektiven der Literaturvermittlung. Innsbruck: Studienverlag 2011, S. 315-326.

Zahner, Nina Tessa: Die neuen Regeln der Kunst. Andy Warbol und der Umbau des Kunstbetriebs im 20. Jahrbundert. Frankfurt, New York: Campus 2006.

Zelle, Carsten: „Vergleich“. In: Zymner, Rüdiger und Hölter, Achim (Hg.): Handbuch Komparatistik. Theorien, Arbeitsfelder, Wissenspraxis. Stuttgart, Weimar: Metzler 2013, S. 129-134.

Zemanek, Evi: „Was ist Komparatistik?“. In: Zemanek, Evi und Nebrig, Alexander (Hg.): Komparatistik. Berlin: Akademie Verlag 2012, S. 7-20.

Zembylas, Tasos: Kulturbetriebslebre. Grundlagen einer Inter-Disæiplin. Wiesbaden: VS Verlag für Sozialwissenschaften 2004.

Zirlewagen, Marc: Bockenheimer Landstraße 102 in Frankfurt am Main. Von der Großbürgervilla zur Kulturinstitution. Frankfurt am Main: Henrich Editionen 2014.

Zwoll, Elisabeth van: „,Es ist schwer, das Publikum im Osten zu erreichen‘. Viel Konkurrenz, wenig Geld: Gespräch mit Herbert Wiesner, Leiter des Literaturhauses in der Fasanenstraße“. In: Die Welt-Berlin 24.04.1995.

25. Göttinger Literaturherbst. Das Programm. Göttingen: Göttinger Literaturherbst 2016. Online verfügbar, URL: www.literaturherbst.com/files/literaturherbst/dokumente/ Literaturherbst_2016_lowres.pdf (Stand: 30.08.2018).

\section{2 Elektronische Quellen}

In den Fußnoten sind bei Internetquellen Autor*in und Kurztitel (IV 2.1) oder Kurztitel und Institution bzw. Veröffentlichungsplattform (IV 2.2) genannt, das Abrufdatum steht hier im Literaturverzeichnis. Ist in den Fußnoten eine Jahreszahl angegeben, handelt es sich um gedruckte Publikationen (IV 1).

\section{2.1 Mit Autor*innen}

Andersen, Stina Ørregaard: „Hun vil få folk til at mødes om litteraturen“, Kristeligt Dagblad Online 08.08.2017. URL: www.kristeligt-dagblad.dk/mennesker/hun-vilfaa-folk-til-moedes-om-litteraturen (Stand: 30.08.2018).

Arsenault, Kerri: „At Oslo’s House of Literature, a free space for ideas (and writers). How can we make this kind of thing happen in America?", Literary Hub 20.10.2017. URL: lithub.com/at-oslos-house-of-literature-a-free-space-for-ideas-and-writers/ (Stand: 30.08.2018). 
Bangsgaard, Jeppe: „Boghandel, restaurant og café: Nyt litteraturhus på vej til København“, Berlingske 21.03.2017. URL: www.b.dk/kultur/boghandel-restaurant-ogcafe-nyt-litteraturhus-paa-vej-til-koebenhavn (Stand: 30.08.2018).

Blumenkamp, Katrin; Buck, Sabine und Kessel, Markus: „Kanon war gestern? Beiträge zur literaturhistorischen und gegenwartsdiagnostischen Aussagekraft der Wertungsanalyse". Tagungsbericht: Wertung, Kanon und die Vermittlung von Literatur in der Wissensgesellschaft. Tagung des Promotionskollegs Wertung und Kanon, 05.07.02.2010, Göttingen, JLTonline 29.04.2010. URL: www.jltonline.de/index.php/conferences/article/view/175/548 (Stand: 30.08.2018).

Cepl-Kaufmann, Gertrude: „Vom Einblatt zum Programmheft - Theaterzettel“. Bericht, H-Soz-u-Kult, H-Net reviews 2007. URL: www.hnet.org/reviews/showrev.php?id=28791 (Stand: 30.08.2018).

Czollek, Max; Dündar, Özlem Özgül; Gugić, Sandra; Moradpour, Mehdi und Othmann, Ronya: „Es fängt hier nicht an, es hört hier nicht auf“, Zeit Online 08.08.2018. URL: www.zeit.de/kultur/literatur/2018-08/rassismus-literaturbetriebmetwo-diskriminierung-autoren-integration/komplettansicht?print (Stand: 20.08.2018).

Fitzek, Sebastian: „Meine Biographie (in ausführlicher Länge)“. URL: www.sebastianfitzek.de/autor/biografie/ (Stand: 30.08.2018).

Gonsholt Ighanian, Catherine: „Derfor er ikke flere med på forfatterveggen“, Verdens Gang 29.10.2007. URL: www.vg.no/rampelys/bok/i/Gza2B/derfor-er-ikke-fleremed-paa-forfatterveggen (Stand: 30.08.2018).

Hegenscheidt, Susanne: „An Regeln halten müssen Kinder sich überall. Norwegen: Kinder dürfen mitentscheiden“, Zeit Online 15.05.2017.

URL: www.zeit.de/gesellschaft/familie/2017-05/kinder-familie-stillenkinderfreundlichkeit (Stand: 30.08.2018).

Herbing, Alina und Vöcklinghaus, Lena: „Sexismus an Hochschulen. 8 - und Schluss“, Merkur Online 28.08.2018. URL: www.merkur-zeitschrift.de/2017/08/28/sexismus -an-hochschulen-8-und-schluss/ (Stand: 30.08.2018).

Hevrøy, Stein Arnold: „Kulturmiljøet Vågsbunnen“, Bergen Kommune 19.07.2013.

URL: www.bergen.kommune.no/omkommunen/avdelinger/byantikvaren/ 9791/article-107636 (Stand: 30.08.2018).

Hirschbiegel, Thomas: „Vijay Sapre (50). Das ist der neue Chef vom LiteraturhausCafé", Hamburger Morgenpost 02.08.2013. URL: www.mopo.de/hamburg/vijaysapre--50--das-ist-der-neue-chef-vom-literaturhaus-caf\%C3\%A9-4732066 (30.08.2018).

Ingelmann, Julian: Die Wortkrieger des Web 2.0. Laienliterarische Praktiken im Mikrofeld digitaler Schreibforen, elektronische Dissertation, Göttingen 2019. URL: http://hdl.handle.net/21.11130/00-1735-0000-0005-12DB-0 (02.01.2020).

Jäger, Georg: „Der Schriftsteller als Intellektueller. Ein Problemaufriß“, IASL Diskussionsforum 1999. URL: www.iasl.uni-muenchen.de/discuss/lisforen/intel1.htm (Stand: 30.08.2018).

Lekvall, Lotta: „Transformation: From Warehouse to Cultural Center“, Social and cultural entrepreneur 27.05.2009. URL: www.culturalentrepreneur.se/2009/05/27/ transformation-from-warehouse-to-cultural-center/ (Stand: 30.08.2018). 
Loge, Julia: „Domus Bibliotheca kan bli UiOs nye ,Litteraturhus““, Uniforum Nettavis for Universitetet i Oslo 08.06.2017. URL: www.uniforum.uio.no/nyheter/2017/ 06/domus-bibliotheca-kan-bli-uios-nye- $\% \mathrm{C} 2 \%$ ABlitteraturhus $\% \mathrm{C} 2 \% \mathrm{BB} \cdot \mathrm{html}$ (Stand: 30.08.2018).

Lovink, Geert: „Portrait of the virtual intellectual. On the design of the public cybersphere. Lecture at 100 days program of Documenta X Kassel, July 13, 1997“ 1997. URL: www.thing.desk.nl/bilwet/Geert/100.LEX (Stand: 30.08.2018).

Metcalf, Stephen: „Sweden Unzipped“, New York Times Online 23.09.2007. URL: www.nytimes.com/2007/09/23/travel/tmagazine/10well-goteborg-t.html (Stand: 30.08.2018).

Moritz, Rainer: „Die Verteidigung des Wasserglases“, Buchreport 07.04.2010. URL: www.buchreport.de/2010/04/07/die-verteidigung-des-wasserglases/ (Stand: 30.08.2018).

Nielsen, Atle: „Stor litteraturfestival planlegges“, Bok365 13.09.2017. URL: bok365.no/artikkel/stor-litteraturfestival-planlegges/ (Stand: 30.08.2018).

Nielsen, Mikkel Thulstrup und Wittrock, Sebastian: „Nyt litteraturhus i København vil forene mad og gode bøger", Politiken 22.03.2017. URL: politiken.dk/ibyen/byliv/art5881200/Nyt-litteraturhus-i-K\%C3\%B8benhavn-vil-forenemad-og-gode-b\%C3\%B8ger (Stand: 30.08.2018).

Økland, Einar: „Zinken Hopp“, Norsk biografisk leksikon 2009. URL: nbl.snl.no/Zinken_Hopp (Stand: 30.08.2018).

Ottosen, Peder: „Får 200.000 i året - resten av livet“, Dagbladet Online 17.06.2011. URL: www.dagbladet.no/kultur/far-200000-i-aret---resten-av-livet/63710278 (Stand: 30.08.2018).

Porombka, Stephan: „Hat die Lesung ausgedient, Herr Porombka?“, Buchreport 07.03.2010. URL: www.buchreport.de/2010/03/07/hat-die-lesung-ausgedient-herrporombka/ (Stand: 30.08.2018).

Porombka, Stephan: „Sturm aufs Wasserglas“, Buchreport 12.04.2010. URL: www.buchreport.de/2010/04/12/sturm-aufs-wasserglas/ (Stand: 30.08.2018).

Rottem, Øystein und Norsk Forfattersentrum: „Dag Solstad“, Store norske leksikon 2018. URL: snl.no/Dag_Solstad (Stand: 30.08.2018).

Rottem, Øystein: „Jon Fosse“, Norsk biografisk leksikon 2013. URL: nbl.snl.no/Jon_Fosse (Stand: 30.08.2018).

Sandell, Malin: „Litteraturhuset våren 2014“, Stadsbiblioteket Göteborg 16.01.2014. URL: www.stadsbiblioteket.nu/litteraturhuset-varen-2014/ (Stand: 30.08.2018).

Sauerland, Dirk: „Institution“, Gabler Wirtschaftslexikon o. J. URL: wirtschaftslexikon.gabler.de/definition/institution-37388/version-181217 (Stand: 30.08.2018).

Schuchter, Veronika: „Männer werten anders. Frauen auch. Die Literaturkritik als Gender-Diskurs“, Innsbrucker Zeitungsarchiv 29.02.2012.

URL: www.uibk.ac.at/literaturkritik/zeitschrift/1020031.html (Stand: 30.08.2018).

Schuchter, Veronika und Lieske, Tanya: „,Im Feuilleton dominieren männliche Kritiker'. Gender in der Literaturkritik“, Deutschlandfunk 22.05.2018. URL: www.deutschlandfunk.de/gender-in-der-literaturkritik-im-feuilletondominieren.700.de.html?dram:article_id=418465 (Stand: 30.08.2018). 
Schuldt, Wiebke: „Irritationsmanagement. Interview mit Anja Johannsen“, Litlog. Göttinger eMagazin für Literatur - Kultur - Wissenschaft 25.09.2010. URL: www.litlog.de/literarisches-leben/irritationsmanagement/ (Stand: 30.08.2018).

Smith-Meyer, Trond und Garvik, Olav: „Pressestøtte“, Store norske leksikon 2017. URL: snl.no/pressest\%CC3\%B8tte (Stand: 30.08.2018).

Steenberg, Nora: „København får litteraturhus“, Bok365 26.04.2017. URL: bok365.no/artikkel/kobenhavn-far-litteraturhus/ (Stand: 30.08.2018).

Stegane, Idar: „Olav H. Hauge“, Norsk biografisk leksikon 2009. URL: nbl.snl.no/Olav_H_Hauge (Stand: 30.08.2018).

Stracke, Anika: „Passivlesen oder Was ist eigentlich eine Lesebühne?“, Literaturcafe 11.03.2008. URL: www.literaturcafe.de/was-ist-eigentlich-eine-lesebuehne/ (Stand: 30.08.2018).

Veiergang, Ariane: „Om vores fratrædelse som kunstneriske ledere af Literaturhaus“, Posting via Facebook 26.11.2017.

URL: www.facebook.com/ariane.veiergang/posts/10155828701219477 ?_tn__=K-R (Stand: 30.08.2018, Screenshot gespeichert C. L.).

Weerth, Carsten und Mecke, Ingo: „Kooperation“, Gabler Wirtschaftslexikon o. J. URL: wirtschaftslexikon.gabler.de/Archiv/7992/kooperation-v12.html (Stand: 30.08.2018).

Wehus, Walter: „Litteraturhuset i Bergen vinner Christieprisen 2016“, Universitetet 1 Bergen 18.04.2016. URL: www.uib.no/aktuelt/97335/litteraturhuset-i-bergenvinner-christieprisen-2016 (Stand: 30.08.2018).

Weiss, Hermann: „,Die Leute wollen heute Autoren zum Anfassen‘. Interview mit Tanja Graf“, Die Welt online 01.08.2016. URL: www.welt.de/regionales/bayern/article156910530/Die-Leute-wollen-heuteAutoren-zum-Anfassen.html (Stand: 30.08.2018).

Westh, Asger: „Husets leder fjernet fra jobbet“, Jyllands Posten 17.03.2003. URL: jyllands-posten.dk/indland/kbh/ECE3434600/Husets-leder-fjernet-fra-jobbet/ (Stand: 30.08.2018).

Wohlfahrt, Thomas: „Blick auf die deutschsprachige Literaturszene. Lyrik boomt!“, Goethe-Institut 2012. URL: www.goethe.de/kue/lit/prj/lit/ess/de9994879.htm (Stand: 30.08.2018).

\section{2.2 Ohne Autor*innen}

„Åbningen af LiteraturHaus“, LiteraturHaus via Wayback Machine. URL: web.archive.org/web/20160617114652/http://www.literaturhaus.dk:80/\%C3\%85b ningen-af-LiteraturHaus.17.aspx (Stand: 30.08.2018).

„About Free Word“, Free Word Centre. URL: www.freewordcentre.com/about (Stand: 30.08.2018).

„Æreslønn“, Store norske leksikon 2014. URL: snl.no/\%C3\%A6resl\%C3\%B8nn (Stand: 30.08.2018).

„An Worten wachsen“, Shared Reading. URL: shared-reading.de/ (Stand: 30.08.2018).

„Arno Schmidt Stiftung“", Arno Schmidt Stiftung. URL: www.arno-schmidtstiftung.de/Stiftung/ArnoSchmidtStiftung.html (Stand: 30.08.2018). 
„Attentatet i Paris. Debatt på Litteraturhuset lørdag 10. januar kl. 16“, Norsk PEN. URL: norskpen.no/nb_NO/tag/charlie-hebdo/ (Stand: 30.08.2018).

„Bokbad“, Det Norske Akademis ordbok. URL: www.naob.no/ordbok/bokbad (Stand: 30.08.2018).

„Bokdagar i Dalsland. Ett nordiskt centrum för litteräre upplevelser“, Bokdagar i Dalsland. URL: www.bokdagaridalsland.se/ (Stand: 30.08.2018).

„Buchkäufer: Entwicklung und Chancen. Der Buchmarkt in Deutschland 2017“. Wirtschafts-Pressekonferenz, Börsenverein des Deutschen Buchhandels 07.06.2018.

URL: www.boersenverein.de/sixcms/media.php/1117/

Wirtschaftspressekonferenz_2018.pdf (Stand: 30.08.2018).

„Cheers, Thomas Pynchon! Glückwunsch zum 80. Geburtstag des ,großen Verschwinders"“, Rowohlt 08.05.2017. URL: www.rowohlt.de/news/cheers-thomas-pynchonder-grosse-verschwinder-wird-80.html (Stand: 30.08.2018).

„Chronik für das Jahr 1990“, Stadtarchiv Göttingen. URL: stadtarchiv.goettingen.de/chronik/1990_05.htm (Stand: 30.08.2018).

„Das Lit“, Literaturzentrum Hamburg. URL: www.lit-hamburg.de/?q=node/4 (Stand: 30.08.2018).

„Das Netzwerk der Literaturhäuser“, Netzwerk der Literaturhäuser. URL: www.literaturhaus.net/netzwerk (Stand: 30.08.2018).

„Das Projekt“, Deutsches Romantik-Museum. URL: deutsches-romantikmuseum.de/das-projekt (Stand: 30.08.2018).

„Das Social-Reading-Experiment mit Tilman Rammstedt“, Lovely Books 29.09.2016. URL: www.lovelybooks.de/lesung/tilman-rammstedt/ (Stand: 30.08.2018).

„Der Preis der Literaturhäuser“, Netzwerk der Literaturhäuser. URL: www.literaturhaus.net/projekte/der-preis-der-literaturhaeuser (Stand: 30.08.2018).

„Desktop-Publishing“, Wikipedia 28.07.2018. URL: de.wikipedia.org/w/index.php?title=Desktop-Publishing\&oldid $=179515151$ (Stand: 30.08.2018).

„Deutsches Theater Göttingen Facebook-Seite“, Deutsches Theater Göttingen via Facebook. URL: www.facebook.com/deutschestheateringoettingen/ (Stand: 27.07.2017, Screenshot gespeichert C. L.).

„Die Hausgötter des Literaturhauses München“, Literaturhaus München. URL: www.literaturhaus-muenchen.de/Hausgoetter.html (Stand: 30.08.2018).

„Domain-Registrierung“, Wikipedia 07.04.2018. URL: de.wikipedia.org/wiki/DomainRegistrierung (Stand: 30.08.2018).

„Einwohnerinnen und Einwohner in Frankfurt am Main am 30. Juni 2016“, Stadt Frankfurt, Bürgeramt, Statistik und Wahlen 2016.

URL: www.frankfurt.de/sixcms/media.php/678/17_Bev\%C3\%B6lkerung_ Halbjahr2016.pdf (Stand: 30.08.2018).

„Folkemengde og befolkningsendringar“, Statistisk sentralbyrå 2017. URL: www.ssb.no/befolkning/statistikker/folkemengde/aar-berekna (Stand: 30.08.2018).

„Fornyelsen af LiteraturHaus“, LiteraturHaus via Wayback Machine. URL: web.archive.org/web/20170605215325/https://www.literaturhaus.dk/ (Stand: 30.08.2018). 
„Frankfurter Buchmesse Facebook-Seite“, Frankfurter Buchmesse via Facebook. URL: facebook.com/frankfurterbuchmesse/ (Stand: 27.07.2017, Screenshot gespeichert C. L.).

„Fylkesbiblioteket. Weiterleitung von http://www.litteraturhus-nt.no/“, Trøndelag fylkeskommune. URL: ntfyb.no/?a=12576 (Stand: 30.08.2018).

„Geschichte“, Göttinger Literaturherbst.

URL:www.literaturherbst.com/geschichte.html (Stand: 30.08.2018).

„Geschichte“, Romanfabrik. URL: www.romanfabrik.de/romanfabrik/geschichte/ (Stand: 30.08.2018).

„Göteborgsbladet 2015. Områdesfakta“, Samhällsanalys och Statistik, Göteborgs stadsledningskontor 2015. URL: statistik.goteborg.se/Global/Faktablad/ G\%c3\%b6teborgsblad/GbgBlad2015/G\%c3\%b6teborg_SDN\%202015.pdf (Stand: 30.08.2018).

„Heftig debatt om Litteraturhuset i Bergen“, Den norske Foratterforening 01.03.2011. URL: www.forfatterforeningen.no/artikkel/heftig-debatt-om-litteraturhuset-i-bergen (Stand: 30.08.2018).

„Huset. Litteraturhus Lillehammer“, Litteraturhus Lillehammer. URL: litteraturhuslillehammer.no/blogg/?page_id=645 (Stand: 30.08.2018).

„Huset og vi som holder til her“, Litteraturhuset Fredrikstad. URL: litthusfred.no/sliker-bygget-og-vi-organisert/ (Stand: 30.08.2018).

„Husets Historia“, Kulturhuset Stadsteatern. URL: kulturhusetstadsteatern.se/OmKulturhuset-Stadsteatern/Husets-historia/ (Stand: 30.08.2018).

„Informationen zum Buchmarkt in Schweden“, Frankfurter Buchmesse. URL: www.buchmesse.de/images/fbm/dokumente-ua-pdfs/2015/details _buchmarkt_schweden_stand_2015.pdf_53266.pdf (Stand: 31.01.2017).

„Institution“, Duden online. URL: www.duden.de/rechtschreibung/Institution (Stand: 30.08.2018).

„Københavns livlige og farverige bydel“, Visit Copenhagen. URL: www.visitcopenhagen.dk/da/kobenhavn/kultur/multikulturelle-norrebro (Stand: 30.08.2018).

„Kommuner i siffror. Göteborg - Stockholm“, Statistiska centralbyrån 2017. URL: www.scb.se/hitta-statistik/sverige-i-siffror/kommuner-i-siffror/ (Stand: 30.08.2018).

„Kulturvermittlung online“, Institut für Kulturpolitik der Universität Hildesheim. URL: www.kulturvermittlung-online.de/ (Stand: 30.08.2018).

„Langtidsprosjekter. Free Word Centre“, Fritt Ord. URL: www.frittord.no/langtidsprosjekter/free-word-centre (Stand: 30.08.2018).

„Literarisches Leben. Jahreschroniken 1995“, Universität Göttingen 2004. URL: www.literarischesleben.uni-goettingen.de/frame_chronik.html (Stand: 30.08.2018).

„Literaturförderung“, Kulturamt Frankfurt am Main. URL: www.kulturfrankfurt.de/portal/de/Literatur/Literaturfoerderung/1281/0/0/0/6.aspx (Stand: 30.08.2018). 
„Literaturhäuser“, Senatsverwaltung für Kultur und Europa. URL: www.berlin.de/sen/kultur/kultureinrichtungen/literaturhaeuser/artikel.32417.php (Stand: 30.08.2018).

„LitHouse podcast“, Litteraturhuset via Liberated Syndication. URL: lithouse.libsyn.com/ (Stand: 30.08.2018).

„Litteraturhus 2017. Folkebibliotek som litteraturhus“, Troms fylkeskommune. URL: bibliotek.tromsfylke.no/index.php/prosjekter/avsluttede-prosjekter/folkebiblioteksom-litteraturhus/ (Stand: 30.08.2018).

„Litteraturhuset Trampolin“, Sandvikens Kommun. URL: sandviken.se/kulturfritid/ kulturcentrum/litteraturhusettrampolin.4.1a4512da14276e94fbc139d.html (30.08.2018).

„Litteraturhusets podkast“, Litteraturhuset via iTunes. URL: itunes.apple.com/no/podcast/litteraturhusets-podkast/id1172303725?1=nb\&mt=2 (Stand: 30.08.2018).

„LittPod“, Litteraturhuset i Bergen via iTunes. URL: itunes.apple.com/no/podcast/littpod/id1012407910?mt=2 (Stand: 30.08.2018).

„Louisiana Historie“, Louisiana Museum of Modern Art. URL: www.louisiana.dk/louisianas-historie (Stand: 30.08.2018).

„Lyse Nætter 2018. About“, Ark Books; Møllegades Boghandel; LiteraturHaus. URL: lysenaetter.dk/about-3/ (Stand: 30.08.2018).

„Malmö Litteraturfestival 2017“, Malmö Litteraturfestival. URL: malmolitteraturfestival.se/ (Stand: 30.08.2018).

„Nasjonal bibliotekstrategi 2015-2018. Statens oppgaver og ansvar for utvikling av folkebibliotekene“, Kulturdepartementet 12.08.2015. URL: bibliotekutvikling.no/content/uploads/2016/09/nasjonal_bibliotekstrategi_2015-2018.pdf (Stand: 30.08.2018).

„Om biblioteket“, Deichman Hovedbiblioteket. URL: blogg.deichman.no/nyedeichman/om-biblioteket/ (Stand: 30.08.2018).

„Om Det fria ordets hus“, Växjö Kommun. URL: vaxjo.se/sidor/se-och-gora/kulturoch-noje/det-fria-ordets-hus/om-det-fria-ordet-hus.html (Stand: 30.08.2018).

„Om Fritt Ord. Stiftelsens Formål“, Fritt Ord. URL: www.frittord.no/om-frittord/stiftelsens-formal (Stand: 30.08.2018).

„Om Huset. Historien bag Poesiens Hus“, Poesiens Hus. URL: poesienshus.dk/huset (Stand: 30.08.2018).

„Om Huset. Hvad er Huset-KBH?““, Huset-KBH. URL: huset-kbh.dk/om-huset/ (Stand: 30.08.2018).

„Om International Forfatterscene i Diamanten“, Det Kgl. Bibliotek. URL: www.kb.dk/da/dia/kalender/ord/forfatterscene/om.html (Stand: 30.08.2018).

„Om Kbh Læser“, Kbh Læser, Københavns Biblioteker. URL: www.kbhlaeser.dk/omfestivalen/ (Stand: 30.08.2018).

„Om LiS“, Litteraturhuset i Skien. URL: www.litteraturhusetiskien.no/om-lis.html (Stand: 30.08.2018).

„Om oss“, Foreningen !les. URL: foreningenles.no/om-oss (Stand: 25.07.2018).

„Om oss“, Leser søker bok. URL: lesersokerbok.no/om-oss/ (Stand: 30.08.2018). 
„Om oss“, Litteraturhuset i Trondheim. URL: litteraturhusetitrondheim.no/om-oss/ (Stand: 30.08.2018).

„Podcasts“, Literaturhaus Zürich. URL: www.literaturhaus.ch/literaturhaus/podcasts (Stand: 30.08.2018).

„Presseomtale. Kronik om LiteraturHaus 2006“, LiteraturHaus via Wayback Machine 02.04.2016. URL: web.archive.org/web/20160402073031/http://literaturhaus.dk/ Presse.3.aspx (Stand: 30.08.2018).

„Programmarchiv 06.05.2015. Nach Charlie?““, Literaturhaus Stuttgart. URL: www.literaturhaus-stuttgart.de/event/3130-1-nach-charlie/ (Stand: 30.08.2018).

„Programmarchiv, 21.04.2009. Unter der Lupe I: Lektorat - Textarbeit oder Produktmanagement?", Literaturhaus Zürich. URL: www.literaturhaus.ch/literaturhaus/ veranstaltungen/unter-der-lupe-i-lektorat-textarbeit-oder-produktmanagement (Stand: 30.08.2018).

„Publications“, Litteraturhuset via Issuu. URL: issuu.com/litteraturhuset/docs (Stand: 30.08.2018).

„Scheitern. Ein Festival des Misserfolgs“, Literaturhaus Stuttgart 2015. URL: www.literaturhaus-stuttgart.de/event/3099-1-scheitern-ein-festival-des-misserfolgs / (Stand: 30.08.2018).

„Serie“, Duden online. URL: www.duden.de/rechtschreibung/Serie (Stand: 30.08.2018).

„Søndagsskoler, borgerlige“", Store norske leksikon 2017. URL: snl.no/s\%C3\%B8ndagsskoler_-_borgerlige (Stand: 30.08.2018).

„Statistikbanken. Folketal 1. Janar efter byområder, landdistrikter, alter und køn“, Danmarks Statistik. URL: www.statistikbanken.dk/BY1 (Stand: 30.08.2018).

„Støtteordning. Innkjøpsordning - ny norsk skjønnlitteratur“, Kulturrådet. URL: www.kulturradet.no/stotteordning/-/vis/innkjopsordning-ny-norskskjonnlitteratur (Stand: 30.08.2018).

„Über das Portal“, dichterlesen.net, Literarisches Colloquium Berlin. URL: www.dichterlesen.net/ueber-das-portal/ (Stand: 20.08.2018).

„Übersichtstabelle Studenten und Bevölkerung“, Göttinger Statistisches Informationssystem. URL: www.goesis.goettingen.de/pdf/055_01.pdf (Stand: 30.08.2018).

„Ungdomsskole“, Store norske leksikon 2013. URL: snl.no/ungdomsskole (Stand: 30.08.2018).

„Villa Bockenheimer Landstraße 102“, KfW. URL: www.kfw.de/villa102/index.html (Stand: 30.08.2018).

„Was bedeutet es, wenn ich jemanden oder eine Seite abonniere?“, Facebook. URL: de-de.facebook.com/help/279614732052951?helpref=about_content (Stand: 30.08.2018).

„Wir“, Unabhängige Lesereihen. URL: www.lesereihen.org/ (Stand: 30.08.2018) 


\section{Anhang}

\section{1 Selbstdarstellungstexte}

\section{1.1 Text aus dem Folder zur Eröffnung des Literaturhauses Berlin}

Ein Haus für die Literatur

Palmenhäuser, Gewächshäuser, Freudenhäuser und Vogelhäuser sind Pflanz-, Brut- oder Heimstätten für das, was sie im Namen und im Schilde führen. Das Literaturhaus führt die Literatur im Schilde: Es ist ein Haus für die Literatur, für Autoren und ihre Leser, ein Haus aber auch für diejenigen, die glauben, auf die Phantasie der Dichtung, auf deren Entwürfe und Strukturen erinnerter Zukunft verzichten zu können. „Kunst“, sagt Karl Mickel, „,ist Kunst und nicht das Leben; ohne Kunst sähen wir nur 1/10 des Wirklichen." Die anderen 9/10 sind beileibe nicht immer das Wahre, Schöne, Gute; sie können auch die Wirklichkeit der Lüge, des Bösen und Häßlichen sein, Falsifikate einer Wahrheit, die niemand ungeteilt besitzt, und deshalb Artefakte der Wirklichkeit. „So eine Sau“, schreibt Elfriede Jelinek, ,ist die Kunst. Lügt wie ein menschl. Wesen. Sie liebt niemanden ... so eine ist das." Für so eine wirbt dieses Haus, für so eine will es Leser gewinnen, wenn es sein muß, auch mit den Mitteln der Visualisierung. Literarische Ausstellungen, Hörspielvorführungen, Filme von und über Autoren, Gesang, Performance und improvisiertes Theaterspiel sollen in diesem Haus ebenso ihren Platz haben wie die klassische Dichterlesung oder der Disput über literarische und literaturpolitische Gegenstände. Das Programm des Literaturhauses wird sich nicht an der Wirklichkeit vorbeidrücken, aber es wird mit Nachdruck den Fälschungen des Wirklichen die Wirklichkeit des Falschen zur richtigen Zeit entgegensetzen, und es wird zur falschen Zeit den richtigen Gegenentwurf riskieren. Ein Club für Literaten wird das Literaturhaus nicht sein. Autoren können hier übernachten, können sich im Café oder in der Buchhandlung treffen, auch ein Arbeitsraum steht ihnen zur Verfügung, aber Literaturförderung besteht nicht in der Schaffung von Reservaten. Literatur ist eine öffentliche Angelegenheit, ein Bestandteil auch der politischen Kultur, unserer Schriftlichkeit, unserer Mündlichkeit und unserer Mündigkeit. Literatur in diesem Haus ist Berliner Literatur und Literatur für Berlin, aber vor allem eben Literatur- also überregional und international. Die politische und ästhetische Unabhängigkeit des Hauses ist garantiert. Dieses Haus ist ein Freiraum, der vom Berliner Senat zwar finanziert wird, ihm ober nicht unterstellt ist. Ein literarischer Trägerverein ermöglicht dem Leiter des Hauses, ein Konzept zu entwickeln, in das sich die Programmvorstellungen externer Anbieter wie der Mitgliedervereine einfügen lassen. Das aus dem Etat des Literaturhauses finanzierte Programm wird versuchen, literarische Maßstäbe zu finden. Wer dieses Haus „bespielen“ und nutzen will, kann sich ihrer bedienen oder sich an ihnen reiben. (Herbert Wiesner) 


\section{1.2 Selbstdarstellungstexte auf den Websites}

Die folgenden Texte bilden die Grundlage für die in Kapitel II 9 durchgeführten Textanalysen. URL und Abrufdatum sind unter dem jeweiligen Text angeben. Die Absätze wurden beibehalten, weitere Auszeichnungen sind nicht übernommen worden, der Umbruch und die Anführungszeichen wurden dieser Arbeit angepasst.

\section{Literaturhaus Berlin}

$>$ Geschichte

Das LiteraturHaus Berlin ist als Stätte vielfältiger öffentlicher literarischer Veranstaltungen, Symposien und Ausstellungen Ende Juni 1986 eröffnet worden. Damals galt der Name des Hauses als erklärungsbedürftig, inzwischen ist er zum Begriff geworden. Gegründet wurde das Literaturhaus Berlin noch als die zentral [in nächster Nähe zum Kurfürstendamm] gelegene literarische Einrichtung WestBerlins zur Verbreitung, kritischen Rezeption und Förderung der Gegenwartsliteratur. Spätestens 1991 hat es sich im Rahmen einer Ausstellung über die literarische Zensur in der DDR den Besuchern aus den östlichen Teilen der Stadt mit Erfolg als ein Ort der Diskussion über ästhetische und literaturpolitische Probleme angeboten.

Heute wendet es sich ganz selbstverständlich an alle Bewohner und Gäste Berlins, die an der gegenwärtigen deutschsprachigen und internationalen Literatur interessiert sind, wie auch an der Geschichte der literarischen Moderne und ihren Konflikten mit der Politik. Das »Projekt der Moderne«, dessen Brüche und Neuanfänge, verdient unsere grenzüberschreitende Aufmerksamkeit, schon weil wir wissen wollen, wie sich Literatur kontinuierlich oder sprunghaft weiter entwickelt. Unsere Neugier gilt gleichermaßen Gedichten, poetischen Texten, erzählender Prosa und Romanen, die nicht in ihren Inhalten ertrinken, Essays, Notaten, Tagebüchern und Briefen, Sachbüchern und wissenschaftlichen Untersuchungen, vornehmlich zu ästhetischen, literarischen, zeitgeschichtlichen, gelegentlich auch kulturgeschichtlichen, soziologischen und sogar naturwissenschaftlichen Themen. Solche Texte stellen wir in Autorenlesungen, Vorträgen, szenischen Lesungen und Diskussionen vor. Übersetzer, Schauspieler und Sprecher, Wissenschaftler und Kritiker, selten auch Musiker und bildende Künstler sind neben den Schriftstellern unsere Mittler - auch unsere Gesprächspartner. Neben den jährlich 80 bis 90 zumeist abendlichen Veranstaltungen des Hauptprogramms finden zahlreiche, in einem eigenen Programmteil angekündigte Gastveranstaltungen statt.

Produktion ziehen wir gelegentlich der Reproduktion [Vorstellung vorhandener Bücher] vor. Eine Vielzahl literarischer Texte und Vorträge sind auf Anregung des Literaturhauses geschrieben, hier vorgetragen und zum Teil auch in der von Herbert Wiesner herausgegebenen Buchreihe „Texte aus dem Literaturhaus Berlin“ publiziert worden. Dazu zählen 18 kurze Theaterstücke, die in den ersten Jahren hier uraufgeführt und gedruckt wurden, und die reich illustrierten Katalogbücher zu unseren Ausstellungen.

Literaturausstellungen in überschaubarem Umfang und thematischer Zuspitzung, Eigenproduktionen wie Übernahmen, die - wenn eben möglich - die auratische Wirkung der Originale vermitteln, sind Forschungsausstellungen, die literarische Zusammenhänge sinnlich anschaubar machen. Mit den im Hause erarbeiteten Ausstellungen über den Neuen Berliner Westen, über Walter Serner, die Literatur aus Czernowitz/Bukowina, die Prager deutsche Literatur, den Flaneur Franz Hessel, das Jahr 1929, über Walter Höllerer, Samuel Beckett, Hannah Arendt, über die deutsche Literatur der Nachkriegszeit („Doppelleben“), über die Nobelpreisträgerin 2009 Herta Müller und zuletzt über Ernst Jandl hat das Literaturhaus weit über Berlin hinaus gewirkt. 
Das Haus gehört der Stadt Berlin; es wurde dem Trägerverein Berlin e. V. zur Nutzung überlassen. Zuvor hätte es wie auch andere Häuser in der Fasanenstraße zugunsten einer abenteuerlichen Stadtplanung abgerissen werden sollen. Dies hat eine Bürgerinitiative verhindert. Heute steht das Haus unter Denkmalschutz. Die Decken im Hochparterre und Wandmalereien im Eingangsbereich wurden restauriert. Erbaut wurde die Villa 1889/1890 für den zum Korvettenkapitän ernannten Teilnehmer der ersten und zweiten deutschen Nordpolfahrt, den späteren Charlottenburger Abgeordneten Richard Hildebrandt und seine Frau Louise geb. Gruson. Sie führten ein gastliches Haus, in dem Forscher und Schauspieler verkehrten. Max Bruch hat hier musiziert. Später wurde das Haus ein Etablissement mit häufig wechselnden Zweckbestimmungen: Reservelazarett im Ersten Weltkrieg, dann Volksküche, am Ende der zwanziger Jahre ein Haus der Alexander von Humboldt-Gesellschaft für ausländische Studierende [Pierre Bertaux zählte zu ihnen], Café, Bordell, Diskothek etc. Heute ist das Literaturhaus zusammen mit der Buchhandlung und dem Café - Restaurant ein lebendiges, urbanes Zentrum literarischen Lebens.

URL: www.literaturhaus-berlin.de/haus.html (Stand: 11.01.2016), (Sigel in Kapitel II 9: BE)

\section{Literaturhaus Hamburg}

$>$ Haus

Das Literaturhaus Hamburg: Seit 1989 ist die weiße Villa am Schwanenwik auf der Uhlenhorst Heimat für Nobelpreisträger und Nachwuchsautoren, für Künstler und Theaterleute, für Philosophen und Diskutierfreudige. Nicht nur Autoren und Autorinnen der ganzen Welt, sondern auch das Publikum liebt die gastfreundliche Atmosphäre, das anregende Klima und das anspruchsvolle literarische Programm im wunderbar restaurierten spätklassizistischen Haus an der Außenalster.

Erdacht im Jahre 1985 von literaturbegeisterten Hanseaten, hat sich das Literaturhaus zum Mittelpunkt des literarischen Lebens der Hansestadt entwickelt und sorgt mit seinem Renommee für Aufmerksamkeit über die Grenzen Hamburgs hinaus. Etwa 150 Lesungen, Podiumsdiskussionen, Gesprächsrunden oder literarische Abende organisiert das Team des Literaturhauses pro Jahr. Regelmäßig finden Reihen statt, z. B. das „Philosophische Cafe““, „März \& Moritz \& 1 Gast“, „Irgendwie komisch“ oder das „Gemischte Doppel“. Es gibt Literaturentertainment mit der „Team\&Struppi-Show" sowie mehrtägige Festivals wie die „Nordischen Literaturtage“ oder die „Hamburger Graphic Novel Tage“.

Um Nachwuchsleser kümmert sich das Junge Literaturhaus: mit der monatlichen Reihe „Spaß mit Büchern“, dem „STA*-Club“, in dem schon prominente Schriftsteller wie Peter Rühmkorf oder Siegfried Lenz Rede und Antwort standen, die Rap-Poeten Timo Brunke und Bas Böttcher ihre Lyrik performten oder junge Autoren aus ihren Debüts lasen. Oder mit dem „Schreiblabor“ für die jungen Menschen, in deren Schreibtischschublade ein Romananfang schlummert und die davon träumen, Schriftsteller zu werden. Mit dem von Schülerinnen und Schülern verfassten „Schulhausroman“. Mit den „Gedankenfliegern“, wo Kinder über Lebensfragen philosophieren.

Mit seinem prächtigen Festsaal und der Beletage, mit dem einladenden gastronomischen Angebot, dem gemütlichen Lesecafé, der Bar und der hervorragend sortierten Buchhandlung Samtleben ist das Literaturhaus eine kulturelle Oase, wo es leicht fällt, sich wohlzufühlen.

URL: www.literaturhaus-hamburg.de/haus (Stand: 11.01.2016), (Sigel in Kapitel II 9: $\mathrm{HH})$ 


\section{Literaturhaus Frankfurt}

$>$ Haus > Pro Domo

Inmitten Deutschlands / Inmitten Frankfurts am Main / Ein Haus mit vielen Räumen für Literatur

Wer Bücher liebt, weiß, dass alles an ihnen interessant ist: Der materielle Prozess ihrer Entstehung, ihre Vermittlung, ihre Verbreitung, ihr Preis, die Kreise von Menschen, die sich um ihretwillen allein bilden, ihre Aufnahme, das Auf und Ab ihrer Geltung, ihre Verdrängung, ihr Verschwinden, aber auch das Rätsel ihres Bestandes. So definierte es der Schriftsteller und Aphoristiker Elias Canetti. Und Canetti sprach damit gültig aus, worum es nach wie vor geht. Das Literaturhaus Frankfurt liebt gute Bücher. Hier, in der wiedererrichteten Alten Stadtbibliothek dreht sich alles darum, dem Publikum Autoren, Bücher und Ideen auf unterhaltsame, inspirierende Weise in bester Atmosphäre vorzustellen. Bücher von guten Bekannten wie guten Unbekannten. Dafür finden sich im Programm wie am Haus viele Formen, Formate, Reihen, Schwerpunkte und Interessengruppen. Es gibt Lesungen, Diskussionen, Tagungen, Partys und Performances. Wer still liest, folgt einem Autor. Wer ins Literaturhaus geht, trifft ihn auch. Das Publikum des Literaturhauses ist dabei wie die Bücher selbst: vielschichtig und vielseitig.

URL: www.literaturhaus-frankfurt.de/haus/pro-domo/ (Stand: 11.01.2016), (Sigel in Kapitel II 9: FF1)

$>$ Verein > Historie

Eine kurze Geschichte des Literaturhaus Frankfurt am Main e. V. / Bekenntnis zur Metropole

Ein Literaturhaus in der Main-Metropole zu errichten - das war für eine Gruppe engagierter Frankfurter Bürger 1989 ein Projekt mit Zukunft. Gemeinsam mit dem damaligen Kulturdezernenten Hilmar Hoffmann ging es zunächst um Grundsätzliches: Ein Ort musste gefunden werden, das Vereinsrecht studiert und die Institution finanziell abgesichert werden. 1991 fand man mit der Villa Hoffmann im Frankfurter Westend ein repräsentatives Ambiente; eine Villa, die fast 15 Jahre dem Literaturhaus eine Heimat bot. Im Oktober 2005 zog das Literaturhaus dann in die neue, wiedererrichtete Alte Stadtbibliothek Frankfurts, die neben der guten Lage, direkt am Mainufer und im Zentrum zwischen der angrenzenden Innenstadt, Sachsenhausen-Nord, Bornheim und dem sich täglich aufschließenden Ostend vor allem auch vielfältigere und größere Veranstaltungsräume bot. Das Literaturhaus in der Rekonstruktion der Stadtbibliothek von 1825 ist eines der prächtigsten Gebäude für die lebendige Vermittlung der Literatur in Europa.

Seit seinem Beginn schaut das Literaturhaus auf eine lange Reihe von literarischen Veranstaltungen und Ausstellungen mit international bekannten Gästen zurück. Wechselnde ehrenamtliche Vorstände und zwei Leiter haben die Institution vor Hauke Hückstädt geprägt: Dr. Thomas Beckermann für die ersten fünf Jahre bis 1996 und dann bis Mitte 2010 Dr. Maria Gazzetti. Eine schwer überschaubare Zahl bedeutender Schriftsteller und Künstler waren und sind im Literaturhaus immer wieder zu Gast, darunter Elfriede Jelinek, Adam Zagajewski, António Lobo Antunes, Robert Gernhardt, Wilhelm Genazino, Peter Handke, Josef Bierbichler, Imre Kertész, Alexander Kluge, Mario Vargas Llosa, Javier Marías, Friederike Mayröcker, Jonathan Frantzen [sic], Jeffrey Eugenides, Umberto Eco, Margriet de Moor, Martin Mosebach, Les Murray, Cees Nooteboom, Herlinde Koelbl, Tom Tykwer, Franz Josef Czernin, Christian Kracht, Marcel ReichRanicki, Jorge Semprún, Bodo Kirchhoff, Karl Schlögel, Peter Kurzeck, Herta Müller und viele andere. 
Das Literaturhaus Frankfurt ist der Ort für die Begegnung und Auseinandersetzung mit den Literaturen, Künsten, Medien und Wissenschaften unserer Gegenwart. Neben der Autorenlesung und Diskussion veranstaltet das Literaturhaus aber auch Lesungskonzerte (etwa mit Jacques Palminger, Christiane Rösinger oder Knarf Rellöm) und große Partys. So jährlich der Tanz in den Mai und zur Frankfurter Buchmesse die Open Party sowie seit 2012 auch die HotlistPreisverleihung und Party der unabhängigen Verlage. Neben den traditionsreichen Diskussionsveranstaltungen in Zusammenarbeit mit dem Hessischen Rundfunk wie Streitfall oder Schöne Aussichten werden aber auch immer wieder neue Formate probiert. Das Literaturhaus betreibt mit Kopf \& Hörer seit 2012 das bundesweit einzige kritische Diskussionspodium zum Hörbuch und kooperiert auch hier mit hr2-kultur. Mit Zur Sache! Das Frankfurter Sachbuchquartett ist ein kritisch begleitendes Organ für all jene Bücher ins Leben gerufen worden, die auf unterhaltsame Weise Wissen transportieren, hinterfragen oder vertiefen. Es gibt außerdem Lesungen in Privatwohnungen und Abende zu vergessenen Büchern und Autoren. Alljährlich im September sind zur einzigen gemeinsamen Lesung die sechs Autoren der Shortlist des Deutschen Buchpreises zu Gast. Im Rahmen der Zusammenarbeit mit der Johann Wolfgang Goethe-Universität Frankfurt liest der jeweilige Inhaber der Stiftungsgastdozentur Poetik zum Abschluss im Literaturhaus aus seinen Werken.

Außerdem veranstaltet das Literaturhaus Frankfurt Symposien und Tagungen und kooperiert dafür ebenso mit den Universitäten Göttingens, Siegens und Frankfurts wie mit litprom Gesellschaft zur Förderung der Literatur aus Afrika, Asien und Lateinamerika e.V.

Das Literaturhaus Frankfurt zeigte in der Vergangenheit Ausstellungen zu literarischen Themen. Etwa zu Robert Walser, Ernst Jandl, Hannah Arendt und Robert Gernhardt sowie Ausstellungen, die den Bogen von der Literatur zur bildenden Kunst schlagen, wie die Fotographien von Péter Nádas und Barbara Klemm, Fotomalereien von Rebecca Horn zu einem Manuskript von Martin Mosebach oder die Fotografie- und Wortinstallationen zu Heiner Müller von seiner Witwe Brigitte Maria Mayer.

Auch für Kinder und Jugendliche macht das Literaturhaus Frankfurt Programm: neben den Kinderbuch-Sonntagen und Schülerveranstaltungen gibt es Schreibwerkstätten für Jugendliche unter Anleitung profilierter Autoren wie Harriet Köhler, Matthias Göritz, Jamal Tuschick, Arne Rautenberg und Antje Wagner. Seit 2010 findet das Kinder- und Jugendprogramm unter der Marke Junges Literaturhaus statt.

Das KOLLEG SCHÖNE AUSSICHT ist das Literaturhaus Frankfurt für Lehrerinnen und Lehrer aller Fächer und Stufen aus Frankfurt und Umgebung und bietet seit 2011 Austausch auf Augenhöhe, es vernetzt Kultur und Schule und setzt in der schulübergreifenden Gemeinschaft des KOLLEGs kreative Impulse.

2005 erhielt das Literaturhaus Frankfurt den „Binding-Kulturpreis“ für seine Aktivitäten und seine Bedeutung für das kulturelle Leben in der Stadt Frankfurt.

Der Literaturhaus-Verein zählt mittlerweile ca. 700 Mitglieder.

URL: www.literaturhaus-frankfurt.de/verein/historie/ (Stand: 11.01.2016), (Sigel in Kapitel II 9: FF2) 


\section{Literarisches Zentrum Göttingen}

$>$ Marginale Startseite

Literatur braucht Orte!

Seit April 2000 ist das Literarische Zentrum der Ort in Göttingen für alle Literaturinteressierten, an dem öffentliche Diskussionen über Literatur stattfinden, immer eingebettet in größere kulturelle, soziale und politische Zusammenhänge. Ein Ort, der das Bedürfnis nach Austausch, nach Anregungen zum Nachdenken ebenso erfüllen will wie jenes nach einem unterhaltsamen, an der Bar ausklingenden Abend. Ein Ort, der Lesende und Schreibende, aber auch Lesende und Lesende zusammenführt, ins Gespräch bringt und dort hält.

Vieles hat sich seit der Gründung verändert, aber in vielem ist sich das Haus auch treu geblieben: Charakteristikum des Literarischen Zentrums bleibt es, ein „begehbares Feuilleton“ sein zu wollen. Darum trifft die Literatur hier immer wieder auf andere Künste, auf die Medien und Wissenschaften, auf Sachbücher, auf Songs, Comicstrips und Performances. Über unser Profil geben am besten unsre Veranstaltungsreihen Auskunft.

2008 begann das Zentrum, auch den lesebegeisterten Nachwuchs zu fördern: Unser mittlerweile großes Kinder- und Jugendprogramm „Literatur macht Schule“ stellt sich hier vor.

Seit 2014 ist das Literarische Zentrum außerdem maßgeblich an der Programmplanung für den Göttinger Literaturherbst beteiligt - und seit 2015 Mitglied im Netzwerk der Literaturhäuser.

Seien Sie unsre Gäste - wir freuen uns auf Sie!

URL: www.literarisches-zentrum-goettingen.de/ (Stand 08.01.2016), (Sigel in Kapitel II 9: GT1)

\section{$>$ Literarisches Zentrum}

Im Jahr 2000 wurde das Literarische Zentrum Göttingen e. V. gegründet, um die beachtlichen literarischen Kräfte der Stadt zu bündeln und mit dem Zentrum eine Schnittstelle und einen Treffpunkt für Verlage, die Universität, Buchhandlungen und - vor allem - alle Literaturinteressierten zu schaffen. Das Zentrum will Literatur in ihren vielfältigen Erscheinungsformen vorstellen und zur Diskussion stellen. Das Zentrum vernetzt, kooperiert, schließt Lücken, öffnet Türen, baut Fenster und schafft Öffentlichkeit: für Literatur.

Von 2000 bis zum Frühjahr 2010 war Hauke Hückstädt Geschäfts- und Programmleiter des Literarischen Zentrums Göttingen und hat dem Zentrum in diesen Jahren zu seinem unverwechselbaren Profil verholfen. Seit Mai 2010 setzt Anja Johannsen diese Arbeit fort. Hauke Hückstädt leitet seit Juli das Literaturhaus Frankfurt.

Kernarbeit des Literarischen Zentrums war und ist die Planung und Realisierung zweier Veranstaltungsprogramme für Erwachsene pro Jahr mit mittlerweile ca. 40 Veranstaltungen zur professionellen Vermittlung der zeitgenössischen deutschsprachigen, europäischen und internationalen Literatur auf hohem künstlerischem Niveau bei gleichermaßen hohem Unterhaltungswert. Das programmatische Profil des Literarischen Zentrums zeichnet sich aber auch dadurch aus, dass die Literatur immer wieder mit anderen, die Literatur mit bedingenden Künsten, den Medien und den Wissenschaften in ein gemeinsames kulturelles Gelände gestellt wird: ein „begehbares Feuilleton“ will das Literarische Zentrum sein. Neben Autoren und Philologinnen sind deshalb häufig auch Filmemacherinnen, Musiker, Wissenschaftlerinnen technischer Fächer sowie Medienköpfe oder bildende Künstler zu Gast. 
Im Rahmen unseres umfassenden Bildungprogramms „Literatur macht Schule“, das ebenfalls mindestens 20 Veranstaltungen pro Halbjahr - öffentlich und schulintern - anbietet, bringen wir Schülerinnen und Schüler mit Kulturschaffenden in Kontakt.

Seit 2014 ist das Literarische Zentrum außerdem maßgeblich an der Programmplanung für den „Göttinger Literaturherbst“ beteiligt.

URL: www.literarisches-zentrum-goettingen.de/zentrum/ (Stand: 08.01.2016), (Sigel in Kapitel II 9: GT2)

\section{LiteraturHaus in Kopenhagen}

$>$ Startseite

LiteraturHaus er Danmarks eneste litteraturhus. I en nedlagt kirke på Nørrebro i København finder du litteraturens tiltrængte hjemsted - et samlingspunkt for forfattere, kritikere, litterater, studerende og i det hele taget alle, der holder af at beskæftige sig med litteratur. Kom tæt på litteraturen og oplev også musik, film og kunst etc. i litteraturens eget hus.

LiteraturHaus byder velkommen til en lang række arrangementer, festivaler, debatog læseklubber, koncerter, litteraturcaféer, litterære selskaber, foredrag og filmaftener. God fornøjelse!

URL: www.literaturhaus.dk/ (Stand: 08.01.2016), (Sigel in Kapitel II 9: KH1)

$>$ Huset $>$ om LiteraturHaus

Om LiteraturHaus: LiteraturHaus er det første litteraturhus i Danmark. Huset har siden april 2005 været et aktivt, litterært mødested for etablerede og spirende forfattere, kunstnere og litterært interesserede. LiteraturHaus lægger hus til tværkunstneriske arrangementer med litteratur, musik, film, billed- og videokunst. Her kan danske og udenlandske kunstnere møde et deltagende publikum, og enhver har mulighed for at komme med sit indspark, når litteraturen sættes til debat.

Idéen med LiteraturHaus er at bringe litteraturen i spil og skabe rammerne for et åbent forum for alle litteraturinteresserede. Her kan du få skæve oplevelser og gå $\mathrm{i}$ dialog med litteraturen og de udøvende kunstnere. Litteraturhusidéen har rødder i Tyskland, hvor man i dag har godt 20 veletablerede litteraturhuse.

LiteraturHaus ligger i en tidligere metodistkirke, Bethania, bygget i 1892 i Møllegade 7 på Nørrebro. De fysiske rammer med den højloftede sal i kirkerummet og den intime café i kælderen er med til at skabe en god og anderledes atmosfære til husets mange arrangementer.

Initiativtageren og ejeren af LiteraturHaus Paul Opstrup har allieret sig med en litterær tænketank og en række frivillige, der er med til at udvikle og gennemføre husets aktiviteter. Går du rundt med en god idé til et arrangement, eller har du lyst til at give en hånd med, er du velkommen til at kontakte os. Paul Opstrup paul@literaturhaus.dk

URL: www.literaturhaus.dk/Huset.4.aspx (Stand: 08.01.2016), (Sigel in Kapitel II 9: $\mathrm{KH} 2$ ) 


\section{Litteraturhuset in Oslo}

$>$ Marginale Startseite

Et sted for alle litteraturinteresserte

Landets første litteraturhus åpnet dørene høsten 2007 i Oslos gamle lærerskole. Fra kjeller til loft vies nå huset i Wergelandsveien 29 til litteratur i ordets videste forstand.

Litteraturhuset drives av Stiftelsen Litteraturhuset, som ble opprettet av Institusjonen Fritt Ord i 2006. Les mer.

URL: www.litteraturhuset.no/ (Stand: 08.01.2016), (Sigel in Kapitel II 9: OL1)

$>$ Huset > Om Litteraturhuset

Noregs fyrste litteraturhus opna hausten 2007. Huset er vigt litteratur i den romslegaste tydinga av ordet, og årleg vitjar meir enn 250.000 huset.

Wergelandsveien 29 er Europas største litteraturhus og har rom for mange typar aktivitetar. Det passar både for dei som vil lese avisa over ein kopp kaffi, dei som vil ha mat for tanken på eit av arrangementa våre, og dei som vil halde sitt eige møte.

I fyrste etasje ligg bokhandel, kafé og hovudscena vår, Wergeland. Vidare opp i etasjane har vi fem scener og rom for samtale, debatt og formidling. Ei eiga avdeling er sett av til arbeid med barn og ungdom. Loftet er reservert for forfattarar og skribentar som treng ein arbeidsplass og ein møtestad i Oslo sentrum. Huset har òg ei eiga forfattarleilegheit for utanlandske forfattarar og intellektuelle.

Litteraturhuset er drive av Stiftelsen Litteraturhuset, som vart skipa av Institusjonen Fritt Ord i 2006. Huset er inspirert av ein tysk tradisjon for frie litteraturhus. Stiftelsen Litteraturhuset er uavhengig og ikkjekommersiell og har til føremål å formidle og vekkje interesse for litteratur og lesing.

Information in English

URL: www.litteraturhuset.no/huset (Stand: 08.01.2016), (Sigel in Kapitel II 9: OL2)

\section{Litteraturhuset Bergen}

$>$ facebook $>$ Info

En arena for litteratur, debatt og kulturopplevelser. Meld deg opp på nyhetsbrev eller vår facebookgruppe for oppdateringer om arrangementer.

Litteraturhuset leier også ut lokaler til åpnede og lukkede arrangementer. Se http://www.litthusbergen.no/utleie/ Kontakt booking@litthusbergen.no for informasjon og bestilling. Billetter for arrangementer kan bestilles på vår nettside litthusbergen.no eller i husets bokhandel.

URL: www.facebook.com/litthusbergen/info/?tab=page_info (Stand: 08.01.2016), (Sigel in Kapitel II 9: BG)

Kontakt $>$ Om oss

Litteraturhuset i Bergen er en ikke-kommersiell stiftelse og har som formål å formidle og vekke interesse for litteratur og lesning, samt stimulere til debatt om samfunnsaktuelle spørsmål. Huset åpnet dørene 31. januar 2013 og består av fem rom viet arrangementer og litteraturformidling, bokhandel, kontorlokaler, kafé og brasseri. Vi leirer også ut skriveplass til forfattere og skribenter i Skrivestua.

URL: www.litthusbergen.no/kontakt (Stand 15.07.2018) (In Kapitel II. 9 nicht mit Sigel verzeichnet, weil der Text erst später auf der Website war.) 


\section{Göteborgs Litteraturhus}

$>$ Om oss

Den ideella föreningen Göteborgs Litteraturhus har som syfte att, som det heter i stadgarna, "verka för litterär bildning i Göteborg". Föreningens programförklaring och stadgar finns att läsa här.

Göteborgs Litteraturhus ligger i Lagerhuset, nära Järntorget i Göteborg, med ungdomskulturhuset Frilagret med kafé som närmaste granne. På markplan ligger även restaurang Lagerhuset med tillhörande stor uteservering. På våning tre och fyra i samma hus har en mängd tidskrifter, förlag, översättare, journalister och andra viktiga kulturaktörer sina kontor.

Göteborgs Litteraturhus samarbetar med Folkuniversitetet och Litterär gestaltning på Akademin Valand, Göteborgs universitet.

Föreningens medlemmar består av trettiotalet litterära organisationer och föreningen har två anställda; en verksamhetsledare och en konstnärlig ledare på vardera $50 \%$.

\section{Historik}

Lagerhuset i Göteborg har sedan 90-talet varit en arbetsplats för förlag, tidskriftsredaktioner, frilansande journalister, översättare och kulturarbetare. Idén om ett litteraturhus har vuxit fram under lång tid och 2013 sammanföll flera faktorer som gjorde det möjligt att göra idén till verklighet. En rymlig och vacker lokal på bottenplan av Lagerhuset blev ledig, Göteborgs Stadsbibliotek var i behov av en extern scen på grund av ombyggnationer och aktörerna i Lagerhuset hade arbetat fram ett konkret förslag på hur ett litteraturhus kunde drivas. Lösningen blev att Göteborgs stadsbibliotek startade upp sin tillfälliga verksamhet "Litteraturhuset Göteborg" i väntan på ombyggt bibliotek. När det nya stadsbiblioteket var klart, sommaren 2014, flyttade Göteborgs stadsbibliotek ut och den ideella föreningen Göteborgs Litteraturhus bildades och flyttade in.

Styrelsen för Göteborgs Litteraturhus består av:

Helena Rignér, ordförande, Lotta Lekvall, vice ordförande, Tomas Lindelöw, kassör, Margareta Lundberg-Rodin, sekreterare, Lina Ekdahl, ledamot, Suppleant: Nils-Aage Larsson.

\section{Medlemskap}

Medlem kan en organisation eller annan juridisk person bli som delar föreningens målsättning. Beslut om medlemskap fattas av föreningens medlemsmöte som hålls i september och mars. Avgiften är $1000 \mathrm{kr}$ per år och ger rätt att använda lokalen för litterära evenemang utan kostnad. Sista datum att skicka ansökningar för medlemskap 2015 är 18 september. Kommande medlemsmöte sker den 6 oktober, kl. 17.30. Medlemsavgiften gäller helår (dvs mars- mars eller sept - sept).

Ansökan om medlemskap i föreningen sker genom att de tre frågor nedan besvaras kort i mejl till oss: Vilken huvudsaklig verksamhet bedriver ni idag? På vilket sätt skulle ni vilja bidra till att förverkliga föreningens programförklaring? Har ni konkreta programidéer som ni skulle vilja genomföra?

\section{Hyra Litteraturhuset?}

Göteborgs litteraturhus kan hyras av privatpersoner, föreningar, organisationer, företag för en kostnad av 750 kronor. I första hand gäller detta bokningar för kulturella arrangemang, konferenser, årsmöten, kurser m.m och som har litterär anknytning eller som kan relateras till föreningens plattform och stadgar. Lokalen rymmer 120 personer men passar precis lika bra för sällskap mellan 10-80 personer. Scen, projektor, enkelt PA finns, liksom stort konferensbord, toaletter och pentry med kaffekokare och kylskåp. Lokalen är tillgänglig för personer som 
använder rullstol eller permobil. För frågor kontakta info@goteborgslitteraturhus.se.

Våra medlemmar: ANTAL Redaktion, Arena Idé, Autor, Bengt Anderbergsällskapet, Bo Ejeby förlag, Daidalos, Dixikon, Dockhaveri förlag, Förlagshuset, Författarcentrum, Fanzinet T E X T, Egenutgivarna, Glänta, Göteborgs förening för psykoanalys och filosofi, Göteborgs poesifestival, Hammarkullen 365, Kabusa, Korpen, KulturUngdom, Kvinnofolkhögskolans elevrepresentantgrupp, Lindelöws förlag, Lublin press, Makedoniska riksförbundet, Merci Poesi, NUKQA, Nätverkstan, Offside press AB, Ord\&Bild, Poesiwerken, Seriöst förlag, Svenska PEN, Textival, Tidskriftsverkstaden i Väst, Tvillingskapet, Wikimedia Sverige, Winter Word Festival, Västra Frilansklubben

URL: www.goteborgslitteraturhus.se/om/ (Stand: 02.02.2016) (Sigel in Kapitel II 9: GB) 


\section{2 Abbildungen der Programmhefte (Auswahl)}

Die fotografierten Programme sollen einen Eindruck des verwendeten Materials vermitteln.

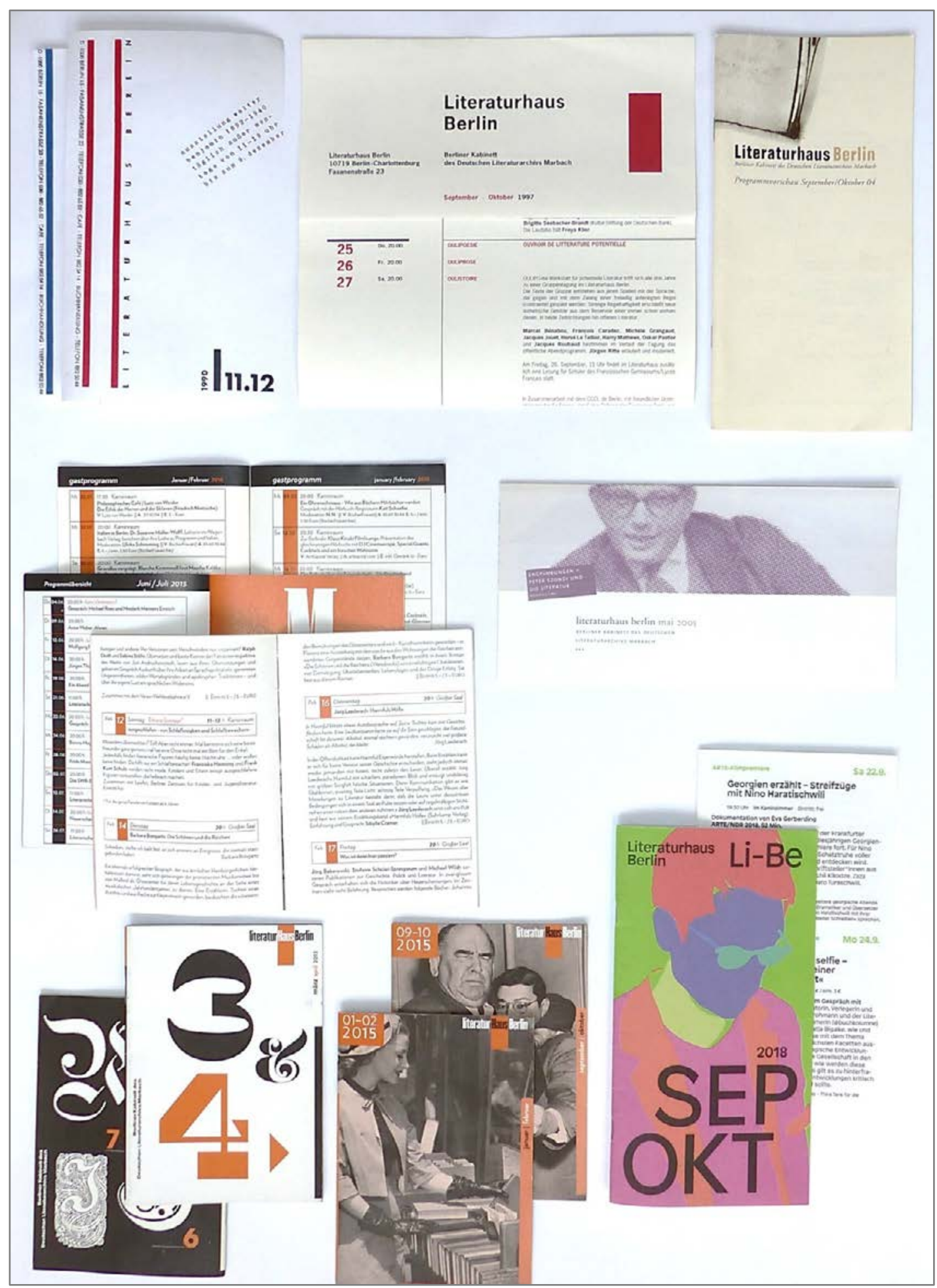

Abbildung 19: Literaturbaus Berlin (eigenes Foto) 


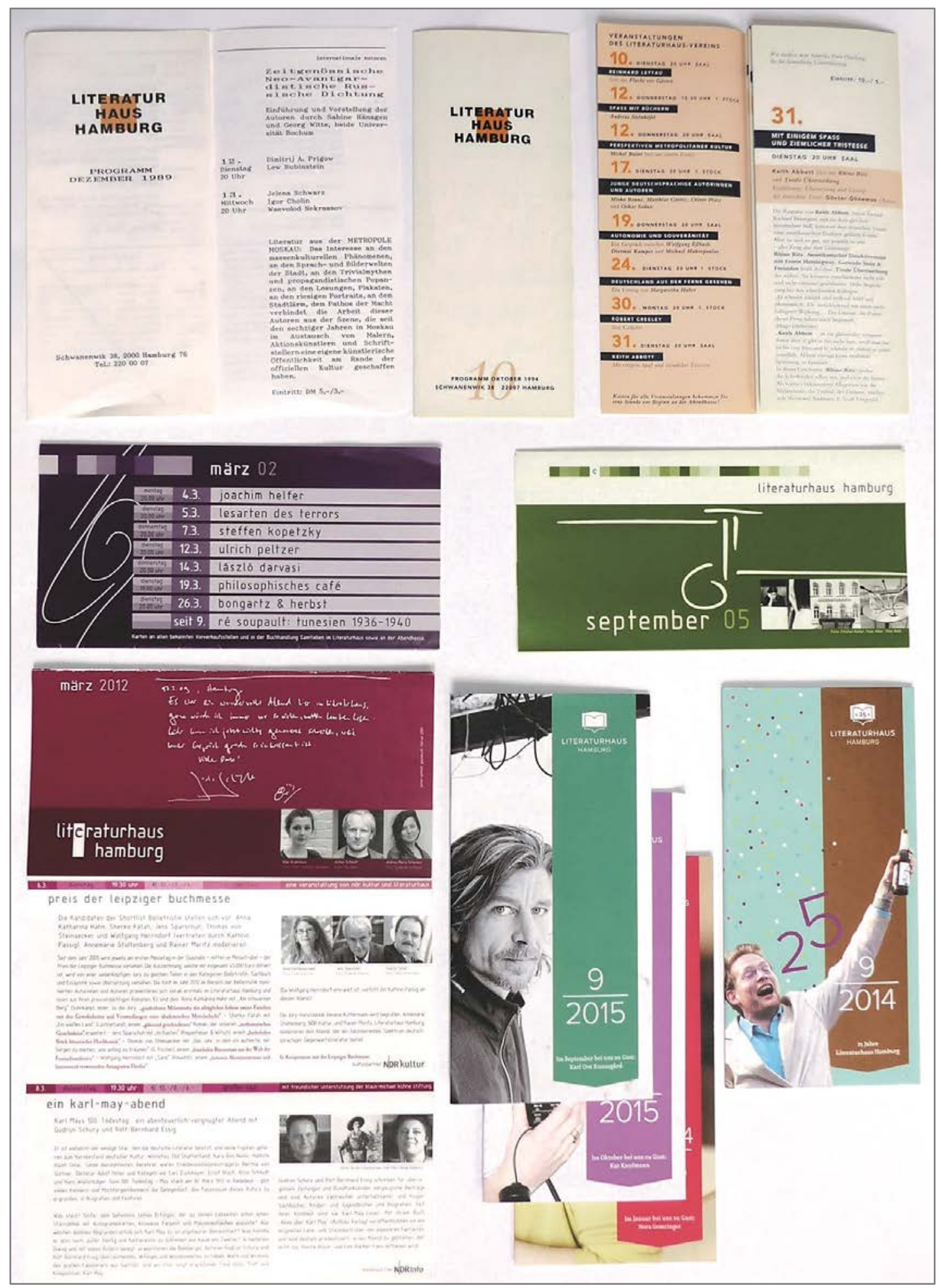

Abbildung 20: Literaturbaus Hamburg (eigenes Foto) 


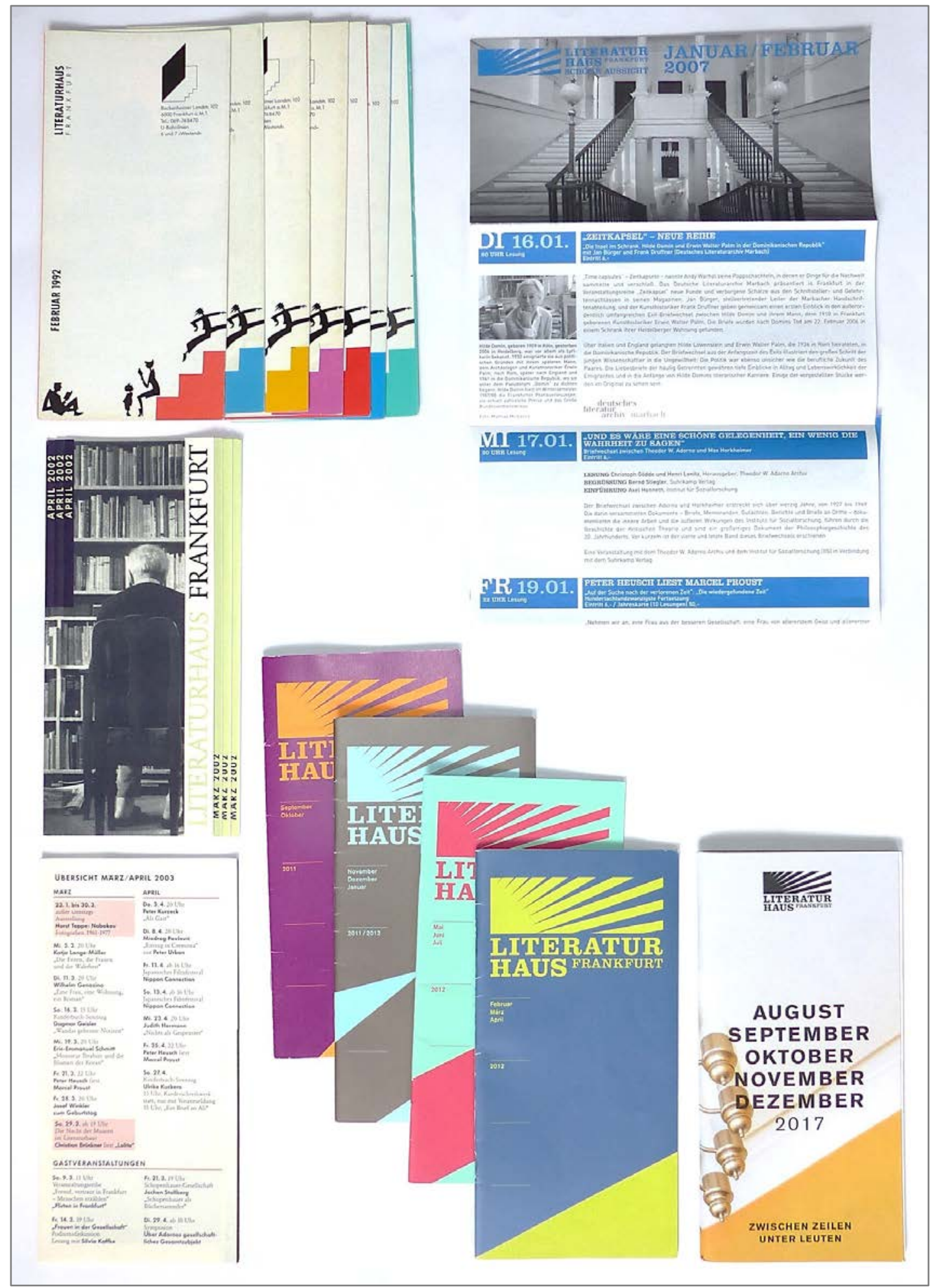

Abbildung 21: Literaturbaus Frankfurt (eigenes Foto) 


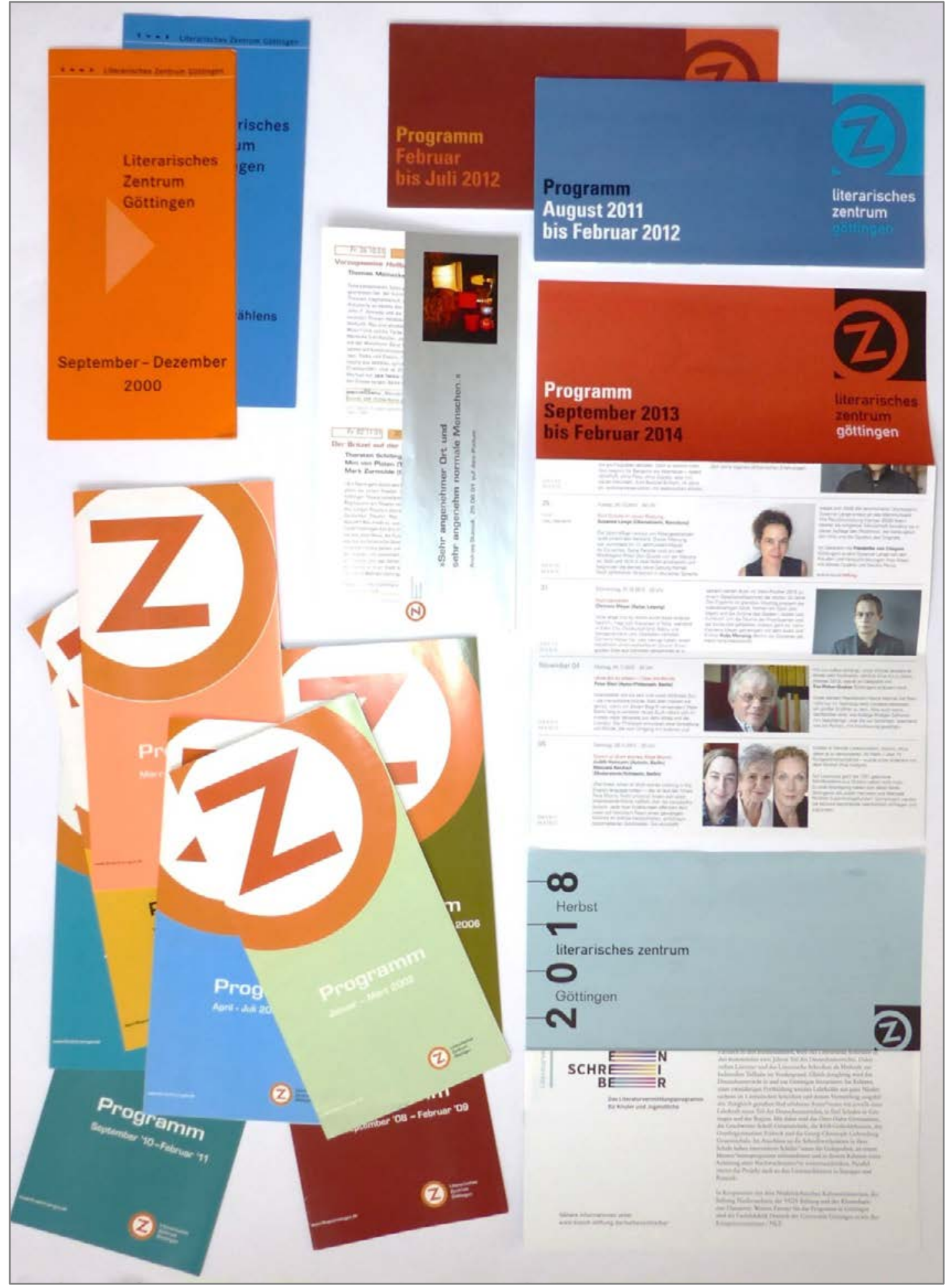

Abbildung 22: Literarisches Zentrum Göttingen (eigenes Foto) 


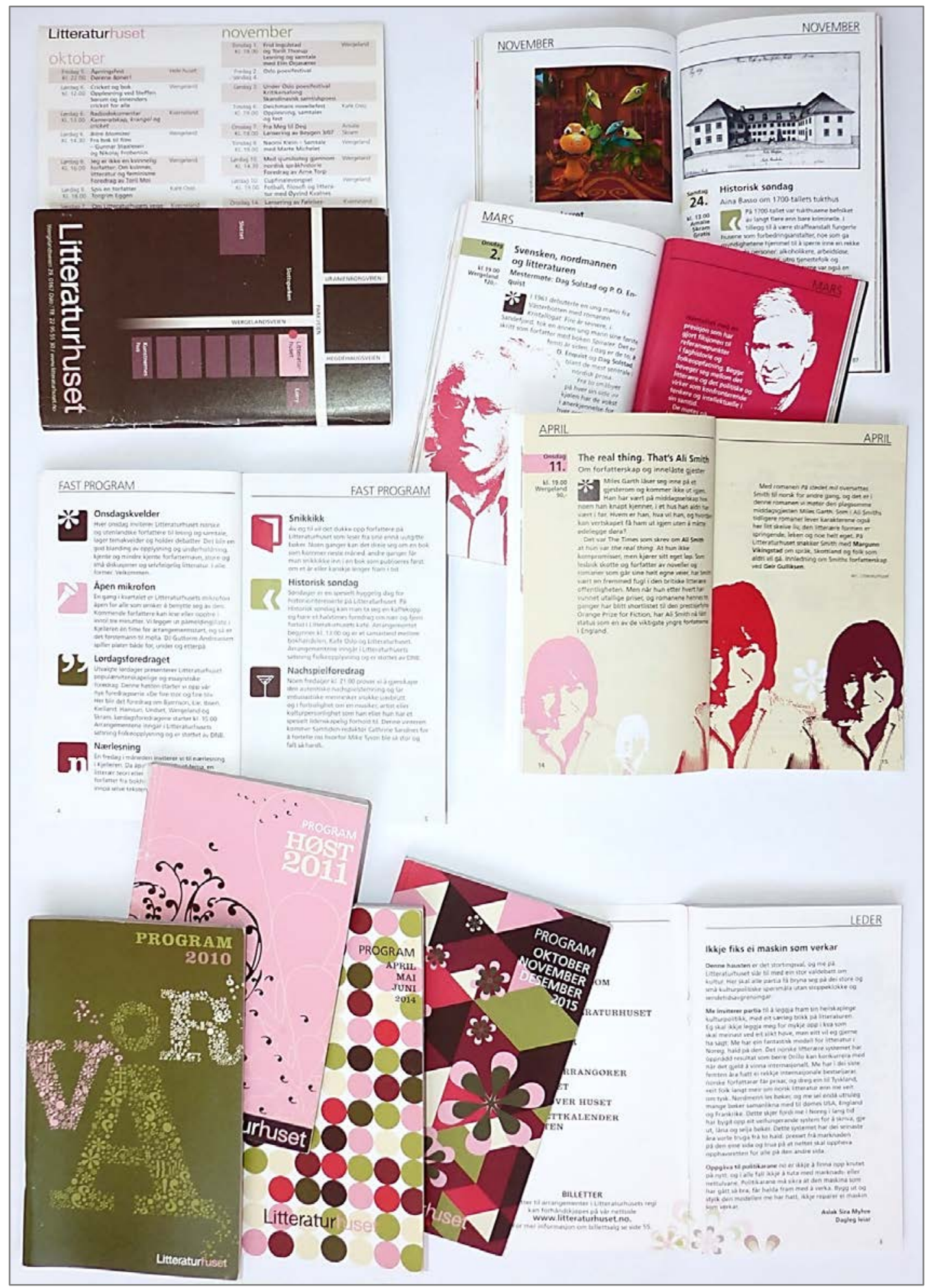

Abbildung 23: Litteraturbuset in Oslo (eigenes Foto) 


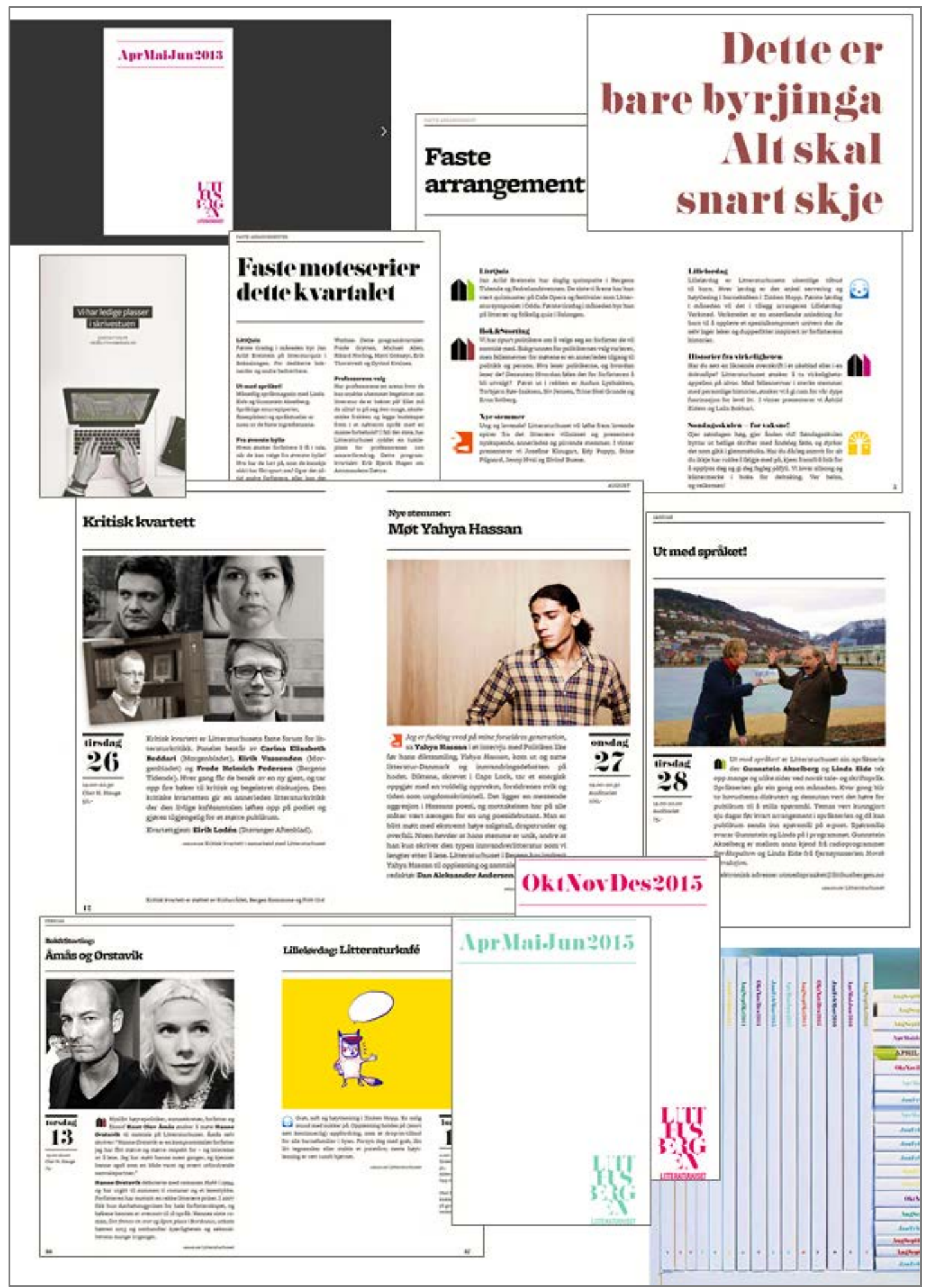

Abbildung 24: Litteraturbuset in Bergen (eigene Darstellung mit Bilder aus den PDFs der Programmhefte), Quelle des Fotos unten rechts: Litthusbergen via Instagram 08.08.2016, URL: www.instagram.com/p/BI2bMCZDYt1/?takenby=litthusbergen (Stand: 30.08.2018), Bild oben rechts: Litthusebergen via Issuu 18.04.2013, URL: issuu.com/tormartinboe/docs/o_litthus_0213_test (Stand: 30.08.2018). 


\section{3 Websites und Social Media}

\section{3.1 Internetauftritte der untersuchten Literaturhäuser}

\section{Literaturbaus Berlin}

literaturhaus-berlin.de facebook.com/literaturHausBerlin twitter.com/LiteraturhausB instagram.com/jungesliteraturhausberlin/

\section{Literaturhaus Hamburg}

literaturhaus-hamburg.de facebook.com/literaturhaus.hamburg instagram.com/literaturhaushamburg

\section{Literaturhaus Frankfurt}

literaturhaus-frankfurt.de facebook.com/literaturhaus.ffm instagram.com/literaturhausfrankfurt

\section{Literarisches Zentrum Göttingen}

literarisches-zentrum-goettingen.de facebook.com/LiterarischesZentrumGottingen twitter.com/LitZentrumGoe instagram.com/litzentrumgoe/

\section{LiteraturHaus in Kopenhagen}

literaturhaus.dk facebook.com/literaturhauskbh twitter.com/literaturhausdk instagram.com/literaturhauskbh

Litteraturbuset ved V andkunsten

Keine eigene Website facebook.com/litteraturhusetkbh/ instagram.com/litteraturhusetcph/

Litteraturbuset in Oslo

litteraturhuset.no

facebook.com/litteraturhuset twitter.com/litteraturhuset

Litteraturbuset i Bergen

litthusbergen.no

facebook.com/litthusbergen twitter.com/LitthusBergen instagram.com/litthusbergen

Göteborgs Litteraturbus

goteborgslitteraturhus.se facebook.com/gbglitteraturhus 
1

\section{LITERATURHAUS BERLIN}

Fasanenstraße 23 Berlin-Charlottenburg

2

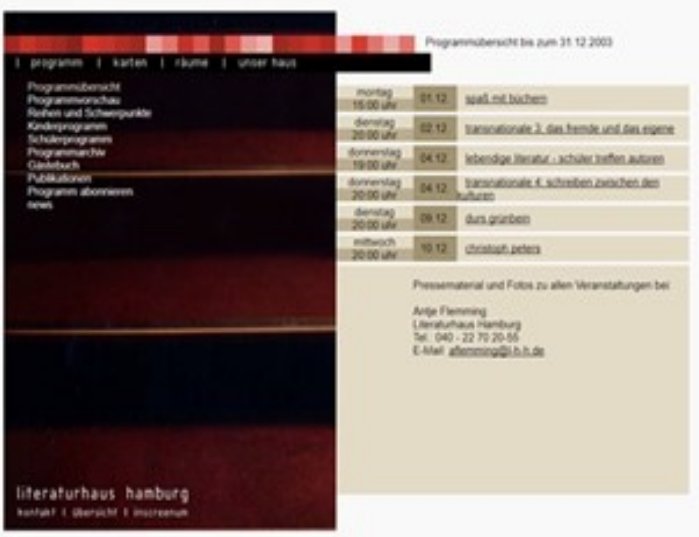

3

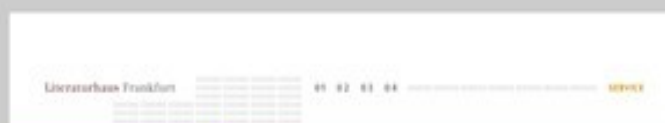

R

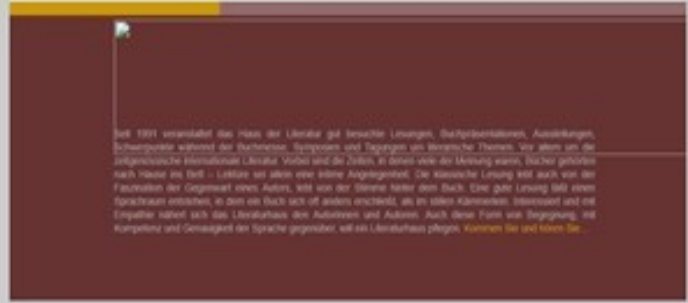

Abbildung 25: Startseiten der älteren Websites (2003-10): 1 Literaturhaus Berlin, 2 Literaturbaus Hamburg, 3 Literaturbaus Frankfurt 
V 3.2 Facebook-Seiten der untersuchten Literaturhäuser

(Stand: 26.07.2017)

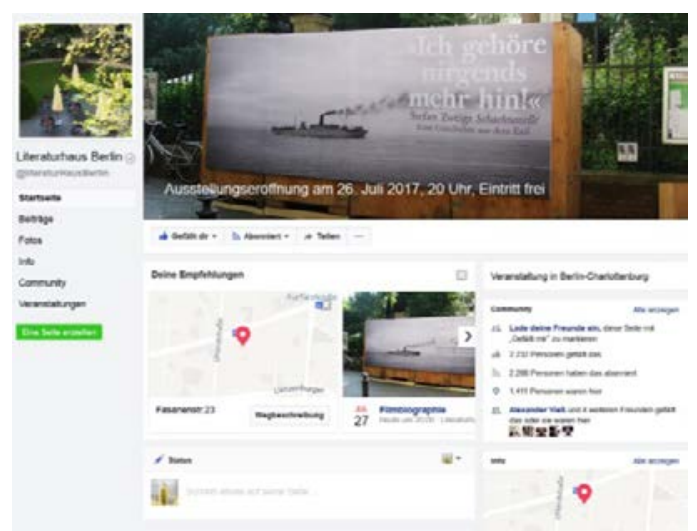

Literaturbaus Berlin

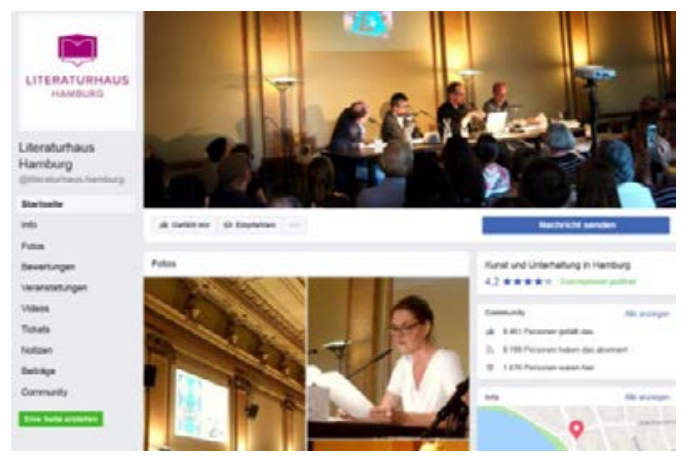

Literaturhaus Hamburg

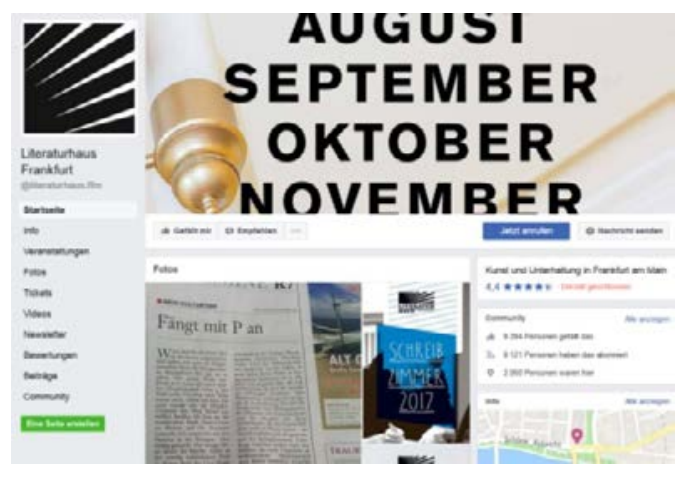

Literaturbaus Frankfurt

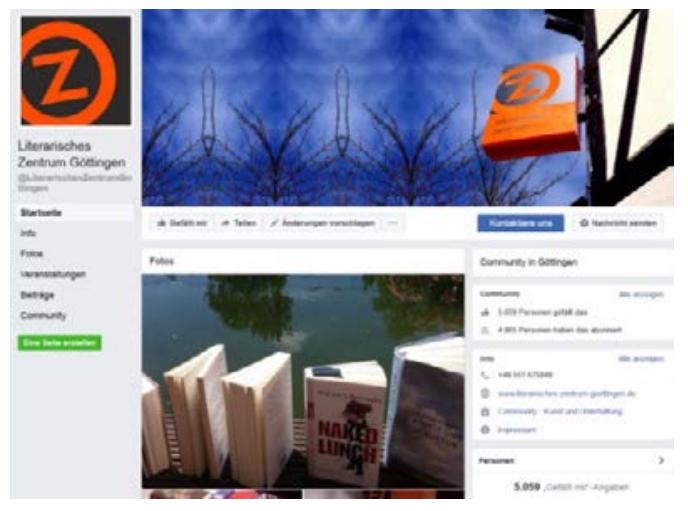

Literarisches Zentrum Göttingen

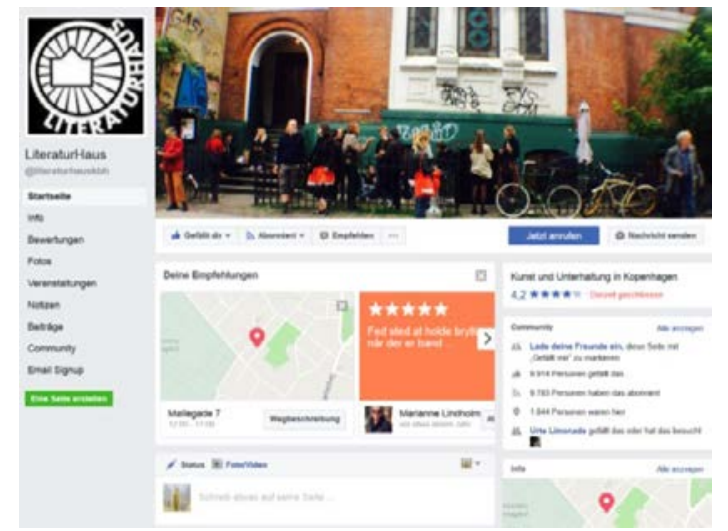

LiteraturHaus

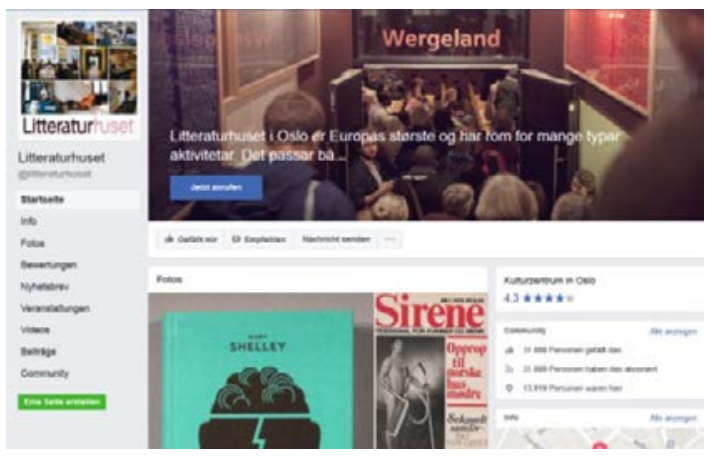

Litteraturbuset in Oslo

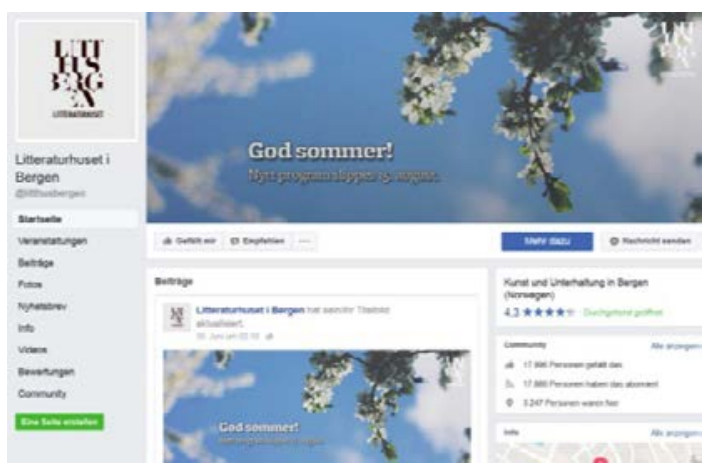

Litteraturbuset in Bergen

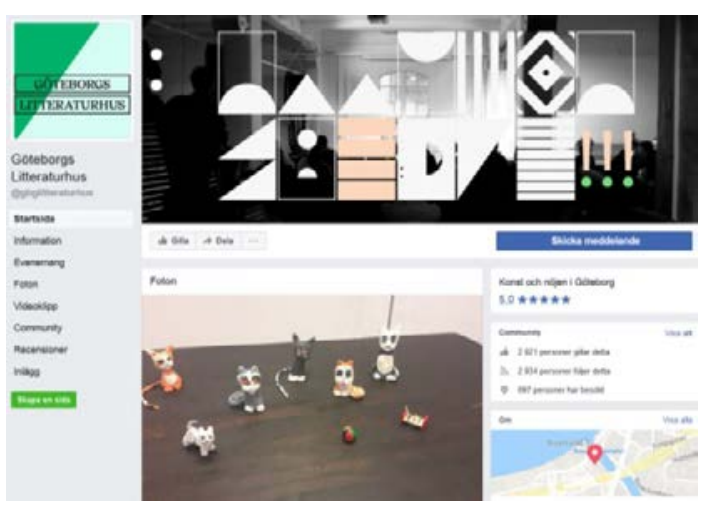

Göteborgs Litteraturbus 


\section{4 Register der erwähnten Autor*innen}

Das Register umfasst in dieser Arbeit erwähnte, den Literaturhaus-Programmen entnommene Autorennamen. Dabei werden die Künstler*innen einbezogen, die im Fokus der jeweiligen Veranstaltung stehen. Die Seitenzahl bezieht sich auf eine Nennung in direkter Verbindung zu einem Literaturhaus-Programm. Die in Klammern angegebenen Lebensdaten der Autor*innen erlauben eine zeitliche Einordnung der Autorenpersona.

Abouet, Marguerite (*1971) S. 266

Adichie, Chimamanda Ngozi (*1977) S. 393

Adorno, Theodor W. (1903-1969) S. 350, 424

Aenestad, Ingrid Z. (*1983) S. 389

Ahrens, Henning (*1964) S. 461

Aleškovskij [Aleschkowski], Jus (*1929) S. 428

Ali, Mah-Rukh (*1982) S. 444

al-Kubaisi, Walid (1958-2018) S. 187

Ambjørnsen, Ingvar (*1956) S. 187, 290

Amtsberg, Sven (*1972) S. 433

Andreassen, Kyrre (*1971) S. 187

Antunes, António Lobo (*1942) S. 522

Arendt, Hannah (1906-1975) S. 520, 523

Arias-Misson, Alain (*1936) S. 375

Åsbacka, Robert (*1961) S. 440

Askildsen, Kjell (*1929) S. 187, 390

Augé, Marc (*1935) S. 348

Austen, Jane (1775-1817) S. 264

Auster, Paul (*1947) S. 168

Avallone, Silvia (*1984) S. 445

Badinter, Elisabeth (*1944) S. 452

Baier, Lothar (1942-2004) S. 392

Balestrini, Nanni (1935-2019) S. 406

Bang, Herman (1857-1912) S. 52

Bánk, Zsuzsa (*1965) S. 397

Barthes, Roland (1912-1980) S. 72, 378

Baudrillard, Jean (1929-2007) S. 261, 349

Beckett, Samuel (1906-1989) S. 520

Begley, Louis (*1933) S. 440

Beltz, Matthias (1945-2002) S. 136

Benjamin, Walter (1892-1940) S. 424

Bierbichler, Josef $(* 1948)$ S. 522

Bierce, Ambrose (1842-1914) S. 371

Bing, Jon (1944-2014) S. 187

Bjørneboe, Jens (1920-1976) S. 425

Bjørnstad, Ketil (*1952) S. 190-192

Bjurwald, Lisa (*1978) S. 444

Boehlich, Walter (1921-2006) S. 432

Bomann-Larsen, Tor (*1951) S. 187

Bonné, Mirko (*1965) S. 461

Bossong, Nora (*1982) S. 428, 461

Böttcher, Bas (*1974) S. 521

Böttcher, Jan $(* 1973)$ S. 442

Böttiger, Helmut (*1956) S. 57, 346, 406

Brecht, Bertolt (1898-1956) S. 442-443

Brillowska, Mariola (*1961) S. 257, 382

Bringsværd, Tor Åge (*1939) S. 187

Brinkmann, Rolf Dieter (1940-1975) S. 423

Brunke, Timo (*1972) S. 521
Brus, Günter (*1938) S. 258, 432

Buch, Hans Christoph (*1944) S. 406

Buene, Eivind (*1973) S. 430

Canetti, Elias (1905-1994) S. 230, 232, 522

Carl, Verena (*1969) S. 431

Cărtărescu, Mircea (*1956) S. 393

Christensen, Inger (1935-2009) S. 355, 357

Christensen, Lars Saabye (*1953) S. 187, 389

Collodis, Carlo (1826-1890) S. 286

Cotten, Ann (*1982) S. 429

Czernin, Franz Josef (*1952) S. 522

D'Annunzio, Gabriele (1863-1938) S. 425

Dahle, Gro (*1962) S. 187

Danielewski, Mark Z. (*1966) S. 263, 332

Darvasi, László (*1962) S. 260

De Carlo, Andrea (*1952) S. 300

Dedecius, Karl (1921-2016) S. 394

DeLillo, Don (*1936) S. 71

Delius, Friedrich Christian (*1943) S. 300

Demski, Eva (*1944) S. 129

Diehl, Sarah (*1978) S. 452

Dschamâlsâdeh, Mohammed-Ali (1892-1997)

S. 438

Eco, Umberto (1932-2016) S. 440, 522

Eichengreen, Lucille (*1925) S. 395

Eismann, Sonja (*1973) S. 452

Ekman, Kerstin (*1933) S. 445

Elstad, Lotta (*1982) S. 396

Elze, Carl-Christian (*1974) S. 429

Endler, Adolf (1930-2009) S. 422

Enquist, Per Olov (*1934) S. 168, 446-447

Enzensberger, Hans Magnus (*1929) S. 425

Erb, Elke $(* 1938)$ S. 377

Eriksen, Thomas Hylland (*1962) S. 187

Esbati, Ali (*1976) S. 444

Espedal, Tomas $(* 1961)$ S. 192

Eugenides, Jeffrey $(* 1960)$ S. 522

Falb, Daniel (*1977) S. 429

Fitzek, Sebastian $(* 1971)$ S. 76, 84

Fløgstad, Kjartan (*1944) S. 187, 419, 445

Foer, Jonathan Safran (*1977) S. 168, 332

Fosse, Jon (*1959) S. 187, 195-199

Fossum, Karin $(* 1954)$ S. 266

Franck, Georg (*1946) S. 349

Franck, Julia (*1970) S. 301

Franzen, Jonathan (*1959) S. 441, 522

Gaarder, Jostein (*1952) S. 187, 290

Geerken, Hartmut (*1939) S. 376 
Genazino, Wilhelm (1943-2018) S. 129, 278, 342, 431, 522

Gernhardt, Robert (1937-2006) S. 371, 422, 522, 523

Giordamo, Paolo (*1982) S. 297

Gjelsvik, Erling (*1949) S. 190

Glissant, Édouard (1928-2011) S. 142, 298

Glück, Anselm (*1950) S. 417

Gnielka, Thomas (1928-1965) S. 395

Goethe, Johann Wolfgang von (1749-1832) S. 425

Goetz, Rainald (*1954) S. 328, 350, 429

Gomringer, Nora (*1980) S. 442

Göritz, Matthias (*1969) S. 397, 431, 522

Graf, Oskar Maria (1894-1967) S. 199

Grass, Günter (1927-2015) S. 64, 109, 163, 288, 339

Grjasnowa, Olga (*1984) S. 461

Grytten, Frode (*1960) S. 407, 411

Gunsteren, Dirk van $(* 1953)$ S. 421

Gustafsson, Lars (1936-2016) S. 409

Hahn, Anna Katharina (*1970) S. 254

Hallesby, Ole (1879-1961) S. 425

Handke, Peter (*1942) S. 522

Hänny, Reto $(* 1947)$ S. 436

Hansson, Cecilia (*1973) S. 442

Harstad, Johan (*1979) S. 389

Hauge, Olav H. (1909-1994) S. 192, 196-199, 424

Hegemann, Helene (*1992) S. 442

Hein, Christoph (*1944) S. 436

Heißenbüttel, Helmut (1921-1996) S. 376, 425

Helfer, Joachim (*1964) S. 259, 428

Helle, Helle $(* 1965)$ S. 171, 389

Hennig von Lange, Alexa (*1973) S. 429

Hermann, Judith $(* 1970)$ S. 428

Hessel, Franz (1880-1941) S. 520

Hettche, Thomas (*1964) S. 328, 393, 411

Hjorth, Vigdis (*1959) S. 187, 290, 389, 404, 419-420, 453

Hødnebø, Tone (*1962) S. 187

Höllerer, Walter (1922-2003) S. 57, 346, 520

Hopp, Zinken (1905-1987) S. 196-199

Hoppe, Felicitas (*1960) S. 263, 393, 417, 423, 427

Hovland, Ragnar $(* 1952)$ S. 187

Hustvedt, Siri $(* 1955)$ S. 168

Hval, Jenny (*1980) S. 430, 453

Itkonen, Juha (*1975) S. 268

Jacobs, Steffen $(* 1968)$ S. 452

Jacobsen, Roy $(* 1954)$ S. 419, 445

Jandl, Ernst (1925-2000) S. 75, 346, 376, 520, 523

Jelinek, Elfriede (*1946) S. 420, 519, 522

Jenny, Zoë (*1974) S. 428, 442

Jerofejew, Wenedikt (1938-1990) S. 371

Johnson, Uwe (1934-1984) S. 421

Jordheim, Helge (*1971) S. 442

Joyce, James (1882-1941) S. 371

Kadaré, Ismail (*1936) S. 437

Kaminer, Wladimir (*1967) S. 442

Kant, Immanuel (1724-1804) S. 265

Kapielski, Thomas (*1951) S. 85

Kehlmann, Daniel (*1975) S. 442

Kempowski, Walter (1929-2007) S. 422

Kermani, Navid (*1967) S. 444

Kertész, Imre (1929-2016) S. 522
Khemiri, Jonas Hassen (*1978) S. 446

Kirchhoff, Bodo (*1948) S. 522

Kittler, Friedrich (1943-2011) S. 328

Kjærstad, Jan (*1953) S. 187, 447

Klemm, Barbara (*1939) S. 523

Klemm, Gertraud (*1971) S. 452

Klougart, Josefine $(* 1985)$ S. 430

Kluge, Alexander (*1932) S. 343, 522

Knarf, Rellöm (*1962) S. 523

Knausgård, Karl Ove (*1968) S. 86, 187, 393, 447

Knigge, Adolf Freiherr (1752-1796) S. 424

Koelbl, Herlinde $(* 1939)$ S. 522

Köhler, Harriet (*1977) S. 523

Kopetzky, Steffen (*1971) S. 259

Koziol, Alexander (*1957) S. 257

Kracht, Christian (*1966) S. 64, 429, 522

Kristeva, Julia $(* 1941)$ S. 453

Krügel, Mareike (*1977) S. 397

Krüll, Marianne (*1936) S. 256

Kuckart, Judith (*1959) S. 435

Kurzeck, Peter (1943-2013) S. 397, 522

Kverneland, Steffen $(* 1963)$ S. 186, 420

Lagerlöf, Selma (1858-1940) S. 52, 289

Lanoye, Tom (*1958) S. 375

Larsmo, Ola $(* 1957)$ S. 444

Larsson, Stig (*1955) S. 371

Leine, Kim $(* 1961)$ S. 171

Lentz, Michael (*1964) S. 374

Lenz, Siegfried (1926-2014) S. 440, 521

Lewitscharoff, Sybille (*1954) S. 411

Lindell, Unni (*1957) S. 187

Linderborg, Åsa (*1968) S. 206-210, 445

Lingor, Renate $(* 1975)$ S. 407

Linke, Detlef B. (1945-2005) S. 328

Llosa, Mario Vargas (*1936) S. 273, 440, 522

Loe, Erlend (*1969) S. 187, 420

Loerke, Oskar (1884-1941) S. 424

Lorentzen, Ingrid $(* 1972)$ S. 419

Lund, Thure Erik (*1959) S. 187

Lunden, Eldrid $(* 1940)$ S. 187

Luu, Que Du (*1973) S. 442

Lyotard, Jean-François (1924-1998) S. 349

Mabanckou, Alain (*1966) S. 266, 268

Magnusson, Kristof (*1976) S. 397, 461

Maier, Andreas (*1967) S. 129

Manea, Norman (*1936) S. 435

Manganelli, Giorgio (1922-1990) S. 378

Mann, Thomas (1875-1955) S. 200

Marías, Javier (*1951) S. 522

Marquardt, Odo (1928-2015) S. 355

Marstein, Trude (*1973) S. 187

Martenstein, Harald (*1953) S. 264

Martus, Steffen $(* 1968)$ S. 432

May, Karl (1842-1912) S. 264

Mayer, Brigitte Maria (*1965) S. 523

Mayröcker, Friederike $(* 1924)$ S. 522

McEwan, Ian (*1948) S. 440

Mehren, Stein (1935-2017) S. 187

Meinecke, Thomas (*1955) S. 271, 411

Melville, Herman (1819-1891) S. 355, 371

Menasse, Robert $(* 1954)$ S. 406

Meurisse, Catherine $(* 1980)$ S. 397

Michelet, Jon (*1944) S. 407, 419 
Mickel, Karl (1935-2000) S. 519

Moi, Toril (*1953) S. 453

Mon, Franz $(* 1926)$ S. 376

Moor, Margriet de (*1941) S. 375, 522

Morrison, Jim (*1943-1971) S. 381

Morrison, Toni (*1931) S. 440

Mosebach, Martin (*1951) S. 254, 431, 522, 523

Mosse, Kate (*1961) S. 390

Müller, Heiner (1929-1995) S. 263, 523

Müller, Herta (*1953) S. 421, 520, 522

Munro, Alice (*1931) S. 420

Münzner, Andreas (*1967) S. 431

Murakami, Haruki (*1949) S. 411

Murray, Les (*1938) S. 368, 522

Mykle, Agnar (1915-1994) S. 42

Nabokov, Vladimir (1899-1977) S. 298, 346, 423

Nádas, Péter $(* 1942)$ S. 436, 523

Nagarkar, Kiran (1942-2019) S. 410

Naipaul, V. S. (1932-2018) S. 438

Nesbø, Jo (*1960) S. 187, 290

Nietzsche, Friedrich (1844-1900) S. 261

Nilssen, Olaug (*1977) S. 187, 404

Nødtvedt, Erlend (*1984) S. 355

Nolde, Emil (1867-1956) S. 404

Noltensmeier, Jürgen (*1967) S. 431

Nooteboom, Cees (*1933) S. 522

Nors, Dorthe $(* 1970)$ S. 171

Økland, Einar (*1940) S. 419

Oksanen, Sofi $(* 1977)$ S. 393

Opitz, Hellmuth $(* 1959)$ S. 452

Oppenheim, Meret (1913-1985) S. 371

Ørstavik, Hanne (*1969) S. 187, 389, 420, 453

Palminger, Jacques (*1964) S. 523

Pamuk, Orhan (*1952) S. 440

Pastior, Oskar (1927-2006) S. 376-377, 422

Pelewin, Viktor (*1962) S. 437

Peltzer, Ulrich (*1956) S. 259

Penny, Laurie $(* 1986)$ S. 452

Petterson, Per $(* 1952)$ S. 187

Pilátová, Markéta $(* 1973)$ S. 264

Pilgaard, Stine $(* 1984)$ S. 430

Plath, Sylvia (1932-1963) S. 452

Politycki, Matthias $(* 1955)$ S. 452

Poppy, Edy (*1975) S. 430

Posch, Alexander $(* 1968)$ S. 382

Präauer, Teresa $(* 1979)$ S. 80

Preiwuss, Kerstin $(* 1980)$ S. 429

Proust, Marcel (1871-1922) S. 258, 345, 372

Puganigg, Ingrid (*1974) S. 257

Pynchon, Thomas $(* 1937)$ S. 420

Ragde, Anne B. (*1957) S. 187

Ramm, Klaus (*1939) S. 376-377, 407

Rammstedt, Tilman (*1975) S. 327

Rancière, Jacques (*1940) S. 265

Rautenberg, Arne (*1967) S. 523

Rawiri, Angèle (1954-2010) S. 437

Reich-Ranicki, Marcel (1920-2013) S. 522

Renberg, Tore (*1972) S. 411

Rendra, Willibrordus S. (1935-2009) S. 437

Rimbereid, Øyvind (*1966) S. 419

Rösinger, Christiane $(* 1961)$ S. 523

Roth, Patrick (*1953) S. 406

Rothmann, Ralf (*1953) S. 410
Rowohlt, Harry (1945-2015) S. 368, 371

Rühmkorf, Peter (1929-2008) S. 521

Sahl, Hans (1902-1993) S. 257

SAID (*1947) S. 438

Sandemo, Margit (1924-2018) S. 187

Sandig, Ulrike Almut (*1979) S. 429

Sanyal, Mithu Melanie (*1971) S. 452

Saramago, José (1922-2010) S. 435

Saramonowicz, Malgorzata (*1964) S. 261

Savinio, Alberto (1891-1952) S. 371

Schäfer, Hans Dieter (*1939) S. 395

Schami, Rafik (*1946) S. 368

Schätzing, Frank (*1957) S. 84

Schitkow, Boris (1882-1938) S. 410

Schlögel, Karl (*1948) S. 411, 436, 522

Schmidt, Arno (1914-1979) S. 418, 422

Schmidt, Jochen $(* 1970)$ S. 264

Schmidt, Siegfried J. (*1940) S. 342

Schmitt, Éric-Emmanuel (*1960) S. 406

Schuldt (*1941) S. 377

Schultens, Katharina (*1980) S. 428

Schulze, Ingo (*1962) S. 417-419, 423, 427,

Sebald, W. G (1944-2001) S. 422

Seierstad, Åsne (*1970) S. 187, 366

Semprún, Jorge (1923-2011) S. 522

Sennett, Richard (*1943) S. 349

Serner, Walter (1889-1942) S. 347, 520

Shakespeare, William (1564-1616) S. 355

Simon, Marie Jalowicz (1922-1998) S. 395

Skram, Amalie (1846-1905) S. 186, 196-200

Sloterdijk, Peter $(* 1947)$ S. 328

Smith, Zadie (*1975) S. 453

Solstad, Dag (*1941) S. 187, 393, 407, 419-420,

446

Sontag, Susan (1933-2004) S. 258

Sookee (*1983) S. 452

Sorokin, Vladimir $(* 1955)$ S. 436

Sow-Fall, Aminata (*1941) S. 437

Spohn, Jürgen (1934-1992) S. 285

Stamm, Peter $(* 1963)$ S. 416-417

Steen, Thorvald (*1954) S. 187

Stokowski, Margarete (*1986) S. 452

Stridsberg, Sara (*1972) S. 453

Strindberg, August (1849-1912) S. 52

Strømsted, Anja Høvik (*1986) S. 355

Strunk, Heinz (*1962) S. 382

Stuckrad-Barre, Benjamin von $(* 1975)$ S. 429

Sunde, Ole Robert (*1952) S. 371, 419

Tabucchi, Antonio (1943-2012) S. 71

Tafdrup, Pia $(* 1952)$ S. 161,

Theorin, Johan (*1963) S. 266

Tietze, Rosemarie (*1944) S. 346, 410

Tolstaja, Sofja (1844-1919) S. 423

Tolstoj, Lev (1828-1908) S. 423

Tucholsky, Kurt (1890-1935) S. 102, 107-108, 199

Tuschick, Jamal (*1961) S. 523

Tykwer, Tom $(* 1965)$ S. 522

Uebel, Tina $(* 1969)$ S. 431

Uhly, Steven (*1964) S. 263

Ulitzkaja, Ljudmila (*1943) S. 254

Undset, Sigrid (1882-1949) S. 425

Uslar, Moritz von $(* 1970)$ S. 429

Valton, Arvo (*1935) S. 436 
Vestly, Anne-Cath. (1920-2008) S. 187

Viereck, Stefanie $(* 1955)$ S. 431

Vigan, Delphine de (*1966) S. 168

Villanger, Aina (*1979) S. 355

Vold, Jan Erik (*1939) S. 187, 419-420

Wagner, Antje (*1974) S. 523

Walser, Alissa (*1961) S. 461

Walser, Robert (1878-1956) S. 523

Wassmo, Herbjørg (*1942) S. 187

Weins, Michael (*1971) S. 382, 431

Weldon, Fay (*1931) S. 453

Welzer, Harald $(* 1958)$ S. 301

Wenzel, Christoph (*1979) S. 429

Wergeland, Henrik (1808-1845) S. 186, 443

Westö, Kjell (*1961) S. 440

Willemsen, Roger (1955-2016) S. 81, 393

Winkler, Eugen Gottlob (1912-1936) S. 371

Wittgenstein, Ludwig (1889-1951) S. 378

Wortmann, Marc (*1966) S. 431

Wright, Lawrence $(* 1947)$ S. 443

Zagajewski, Adam (*1945) S. 522

Zaimoglu, Feridun (*1964) S. 393, 446

Zander, Judith (*1980) S. 428-429

Zeh, Juli (*1974) S. 168

Zieger, Ulrich (1961-2015) S. 257

Ziegler, Ulf Erdmann (*1959) S. 373

Zmeškal, Tomás (*1966) S. 264 
ffnete in Berlin das erste rhaus, weitere Gründungen - ab 2005 auch in SlkandiDer Transfer ist Anlass für mparative Arbeit, die zuhe der ersten umfassenden hungen des Literaturt. An acht Fallstudien aus and und Slrandinavien die Einrichtungen in ihren n dar und trifft Auser die abstralkte Variante: ution Literaturhaus. r Materialbasis analysiert namische Institution, falls Geschichte ist, und Literatur(-vermittlung) wart in den Blick. 